\title{
A
}

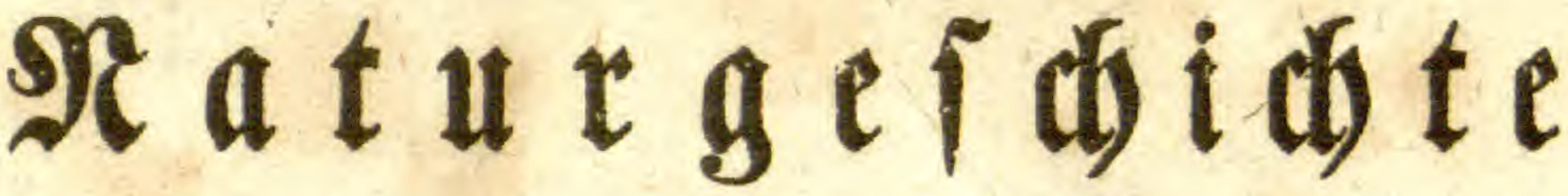

fitr

\section{alle Stánde,}

ขอก

\section{profertor (1)ken.}

Jumb X. Iftis

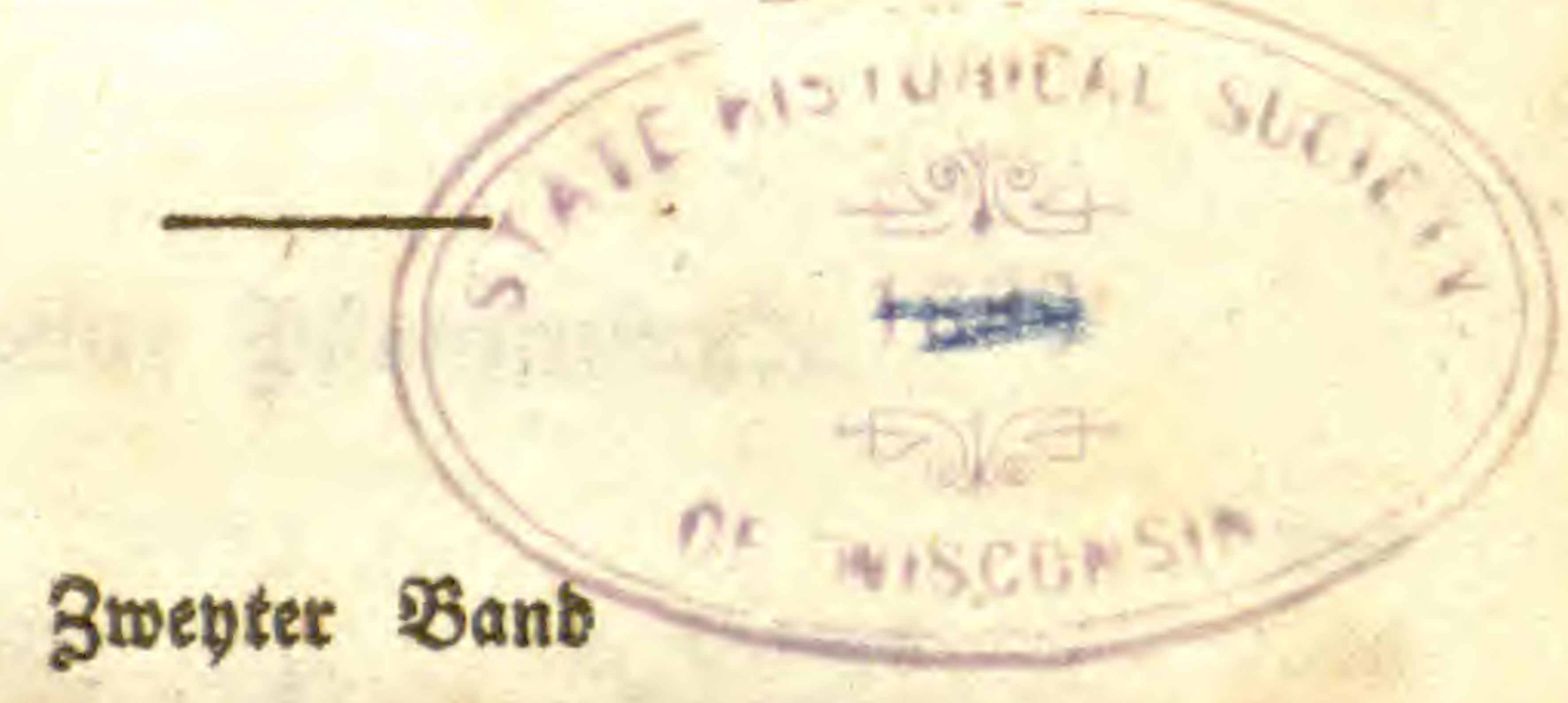

ober

Botant erfer $\mathfrak{B a n d .}$

\section{Stuttgart,}

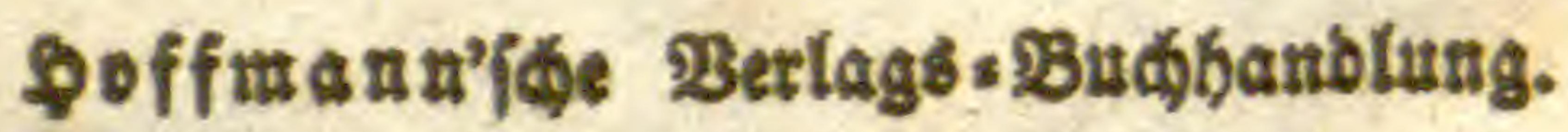


Heberid t

Der

\section{0 a $t$ i (band I.)}

\section{Artgemeine}

Segriff Det Wfiatze. 3

1. 2Inatomie ber Pflanze - 12

1. Sierobe,., 12

a. Bellen , . . 13

b. 2ubern . . . 15

c. Epiralgefäße . . 17

2. Hnatomif́pe Spfteme . 19
a. Kinbe . . . 20
b. Baft . . . 21
c. Şolz $\cdots, \ldots, 22$

3. Drgane .... 23

A. Mfianzenftod . . 23

a. 23urgel , , , 24
Geite

b. Etengel : * 25 Sinofipe. . . 29

c. Blätter $\quad: 32$

B. Strau,$\ldots 38$

1. Blütbe *. 46

a. Bluft . . 47

1. Reld, . 47

2. Blume . 60 Sarben . 61

b. Brŏps . , 71

c. Samen . . 79

2. Irudt . . 89

Siteratur . . . 94 
I. PFlanzen=EGemie • 97

1. Pfanzenfroffe • . 97

A. Unorganíde • 99

a. Urifofie . . 101

b. Elemente. . . 101

1. Feuer ob. Iether 101

2. Euft, 101

3. פ⿹alfer . . 102

4. Erde, 103

c. Mineratien $\quad 103$

B. Drganifhe Pflanzens ftoffe . . . . . 111

1. Einfade , . 112

a. Drganifide Elemente.

1. Uetberartige . 112

2. Euftartige . 112

3. Walierartige , 115

b. Drganifdes Mines ralien

4. Erbartige Pflan= zenftoffe. . 118

5. Salzartige . 120

6. Brenzartige .127

7. Erjartige . 128

2. Bufammengefeste . 130

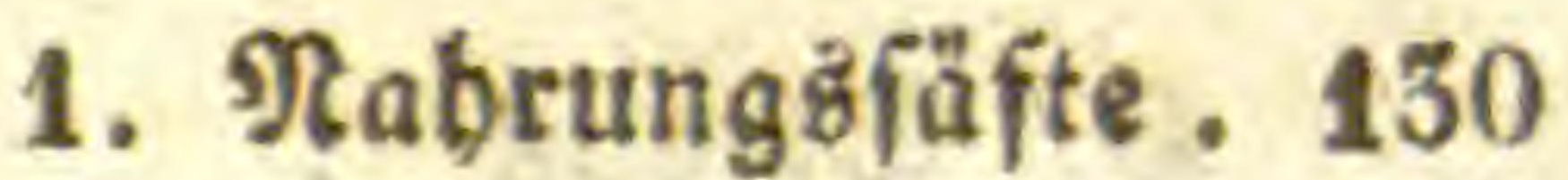

2. 26ionderungs:s fäfte. . . 131

Pfanzengerủdbe . 135

Pfanzengef (umăcte 138

3. Ebemíde Procelfe 139

ß3ăb̧rung, ŢäuIniß . 139

III. Prlanzen=PGyfit . 144

A. Einwirlung ber Ele: a. 2letber . . 145

1. Sdwere, Rid= tung. .145

2. Iid)t . 151 Pflanzeníblaf . 157

3. Wärme . . 163

b. I vft . . 169

c. Waffer . • . 170

d. Erbe . . 172

B. Einnirfung Der $\mathfrak{M} i$ neratien . . 172

IV. Pfanzen=\$gyfiotogie . $\mathbf{1 7 5}$

A. W3adbitbum 177

a. Alfgemeine Berrid)= tungen . . 177

b. Befondere . 183

1. Derobuung oder Einfaugung .183

2. 2 tbmung und $\mathfrak{4}$ Dünftung . . 190

3. Snftlnuf oder Er= näbrung . . 200 2rbfteigen bez ఠaf: tez... . 205

4. Erideinungen 211

a. 2lbionoscungen 212

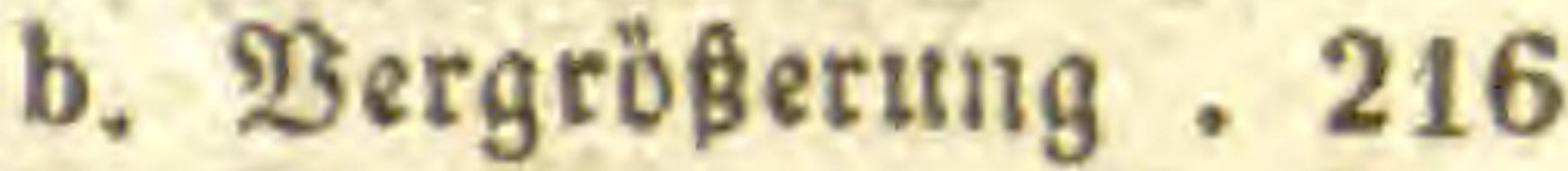

c. Zbeilung .. . 219

d. Wermebrung . 22 t

e. Reproduction . 226

B. fortpflanzung . 227 Befäubung .233 Reifung . . 239

Roimen . . . . 247 
(5)attung. .9 .253$

\section{Bejondere \$̧ศlanzenfunde,}

ธ. 285.

\begin{abstract}
Pflanzenfuftem: zulest.

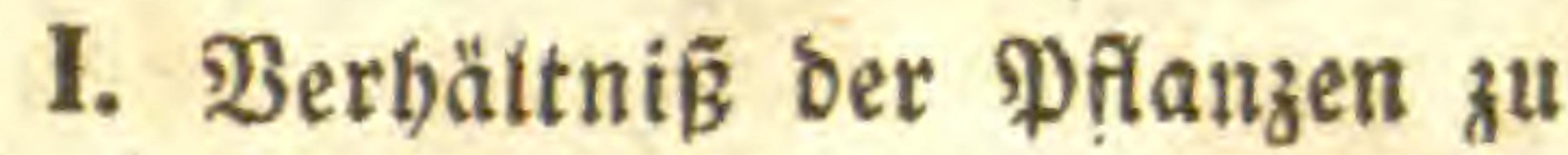
Den Elementen.
\end{abstract}

Pflanzen= S5eograpbie 288

A. Berbältniß der Pfanzen

Berbreitung zur Sonne.

B. Berbältniß zum Planeten: Stanbort . . . . 380

a. Einfus Der \&uft: Şb̈he . . . 300

b. Einfluß des ferz 307

c. Einfus ber Erben 309

II. Berbältnī̄ Det \$Flamzen untereinander.

Pftanzen=Pbyfiogno=

mie... . 310

Bisflligfeit . . . 311

Şeipe Sone . . . 315

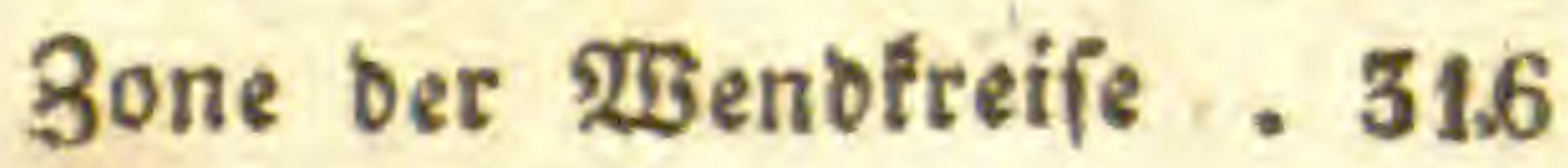
Semäfigte 3onen - 318 Ralte fonen . . 319

III. Serbåltnī̄ sum Thier= reicí)

Eulturpflanzen. 320 (S)etraide

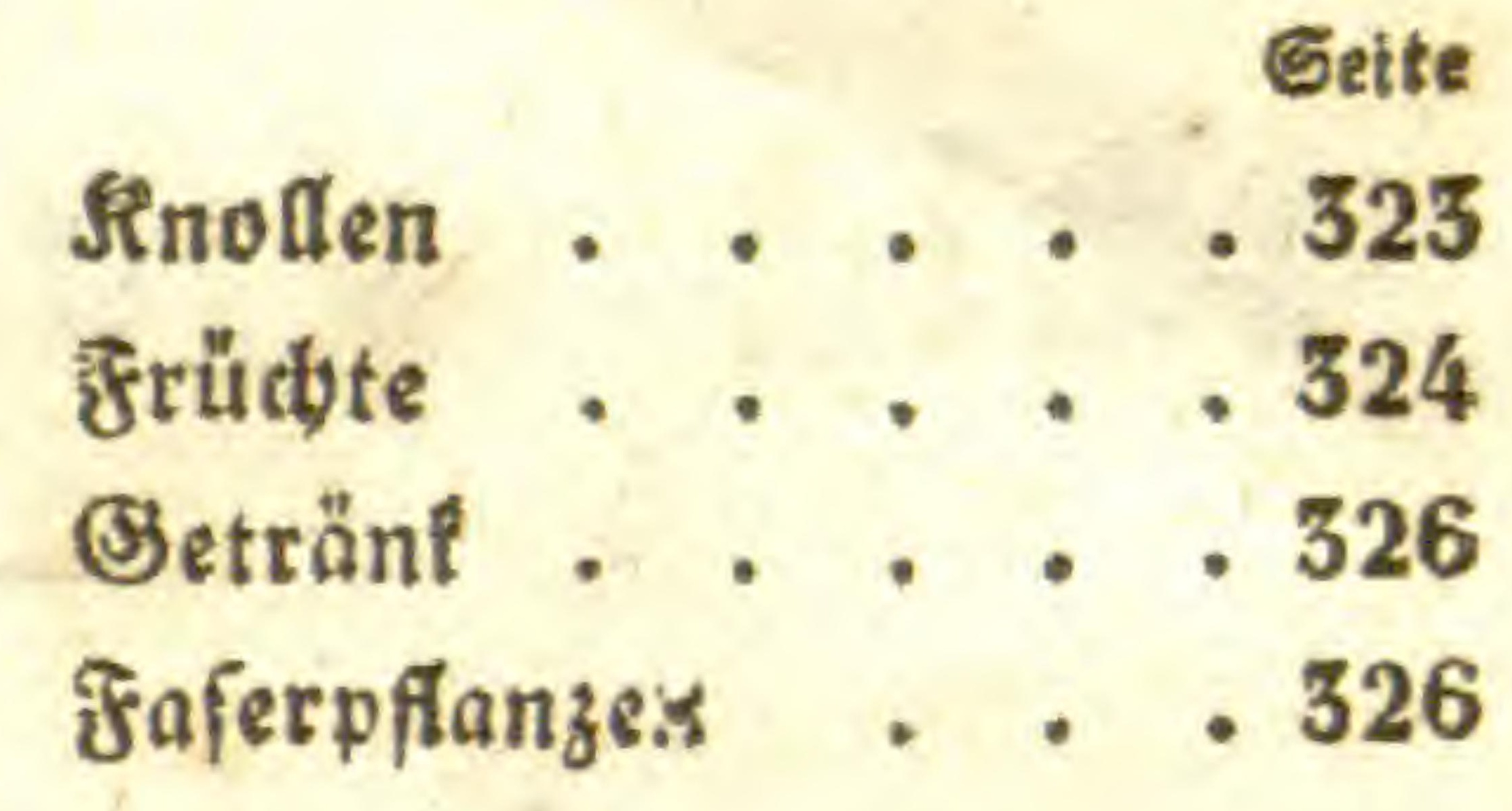

\section{Angewanote Botaute.}

I. Deconomifae $\mathfrak{B D}=$ tanif. . . 329

A. Rabrungšpfianzen . : 330 1. Dbft . . . 330 In İmerica . . . 331 Su Snoien . . 339

2. ङ5emüje . . . 340

3. Meblpflanzen . 343

4. (Senürzpflanzen . 346

5. Sjetränf́pflanzen . 350

B. Futterpflanzen . . 353

C. Forfiptlanzen *. 355 Ђุötzer in 24merica. .358 5ุöger in Subien, \&uftras

lien unb Sübafrica . 360

D. Unfrătiter . . . 361

E. Ebiftpflanzen . . 362

F. Bierpflanzen . . 562 Btumen in Imerica . 364 Blumen in Shloafrica 365 Bitumen in Snoien . 366

II. Ted)nifde $\mathfrak{f}(\mathfrak{a} n=$ z $\mathrm{en} \cdot 366$ A. SBerătbłflanzen. 


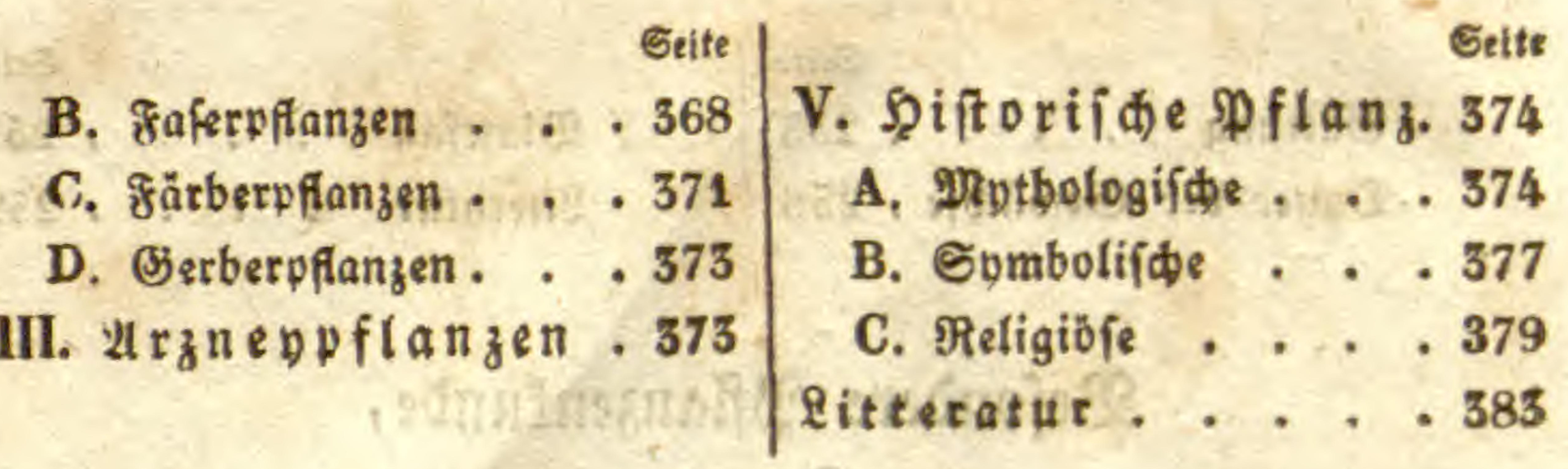

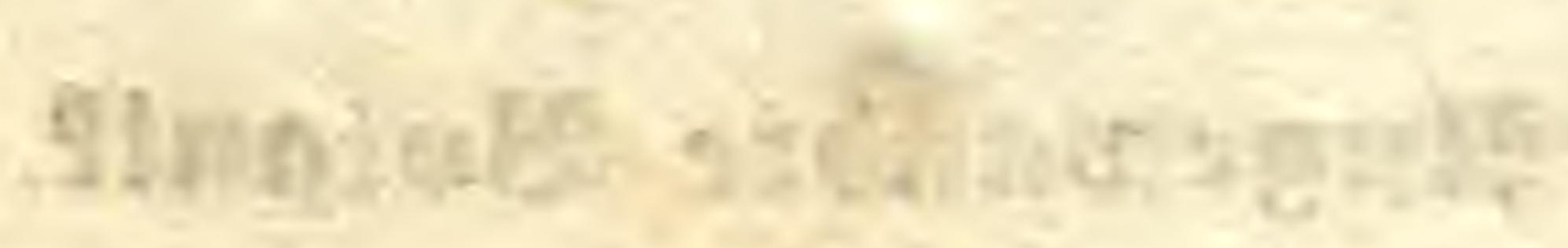




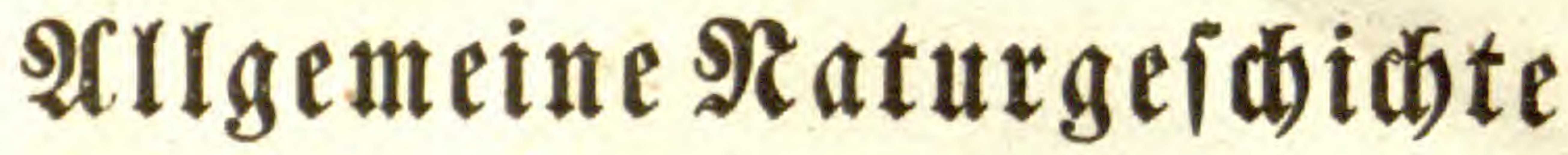

\author{
für \\ $a \mathfrak{l} \mathfrak{e} \mathfrak{G} \mathfrak{a} \mathfrak{n} \mathfrak{d}$.
}

3weyter $\mathfrak{B a n b}$.

(PSfanzenteid 1. 20atb.) 


\section{Raturgefdictste}

\section{ber \\ T) f 1 a}

Die Reicte der Jatur find nidts anderes als bie Berbin= oungen ber brey beneglicten Elemente mit Dem unbewegliden oder gefitalteten Eroelement. EB Eann baber nur fo viele Reide geben, als Berbindungen oder Combinationen oiejer 2trt mög= (ic) find.

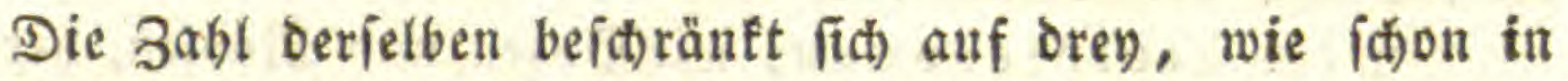

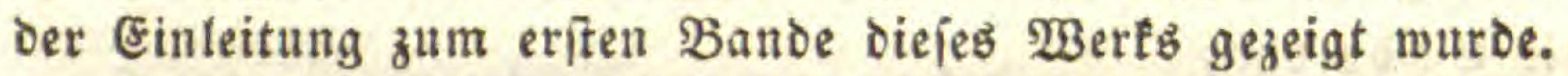

I. 2tus Der binären Berbinbung ber Elemente entítebt Das Mineralreid).

II. 24us Der ternären Berbinoung, nebmlid aus Eroe,

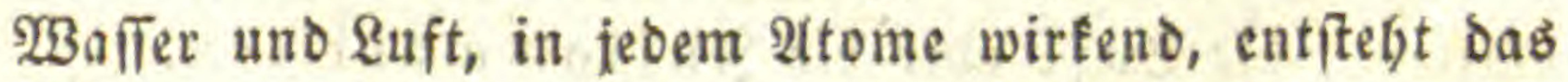
Pflanzenreid). EB vereinigt mitbin in fid) nur die Elemente des Ploneten.

III. शนв Der quaternären Berbinoung, nebmlid) aus Erbe, Waffer, Ruft uno Feuer entifebt das Ibierreid. Eళ vereinigt mitbin in (fid) alle Elemente ber $\mathfrak{W B}_{\text {elt. }}$

Mebr Berbinoungen fub nicht möglid, uno Daber auゅ nid)t mebr Reide. Es gibt tein $\mathfrak{B}$ a fierrei (f) für die Ratur:

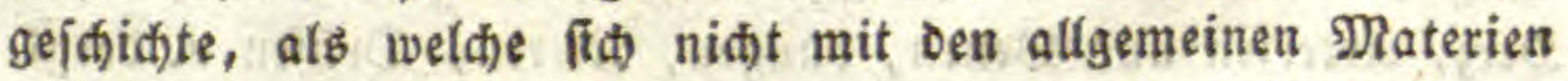




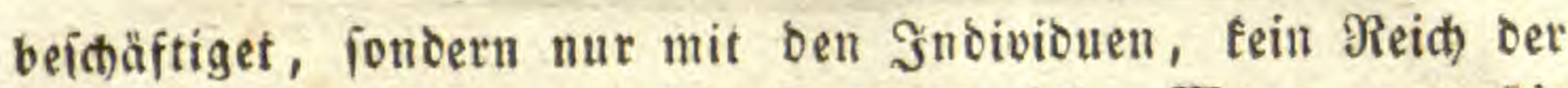
It tmoiphărilien uno fein Feuerreid). SWenn man die Erricheinungen deร $\mathfrak{B a f f e r s , ~ D e r ~ \& u f t ~ u n o ~ D e s ~ F e u e r s ~ m i t ~ b e m ~}$

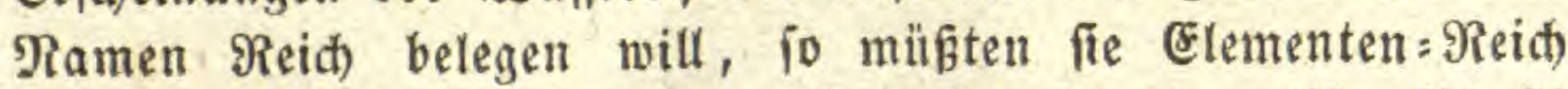
beiß̄en, welches aber ein (Siegenftano der Matbematif, Phyfite uno Ebemie ift.

1. Das Erroelement fïr fith bildet die Dronung der Eroen;

Surc) Das Waffer veråndert oder Damit verbunden, Die ber $\mathcal{E a l}_{z}$;

ourd) uno mit ber Ruft bie ber $\Im n f l a m m a b i l i e n$ oder B renze;

Ourct) Ridt), Waarme tuno (Sravitation bie E $\mathrm{r}_{z} \mathrm{e}$, welche

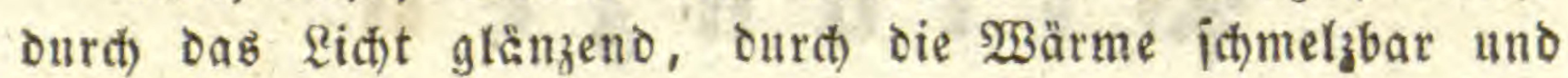
ourd bie (jravitation all gezeict) net fitwer find.

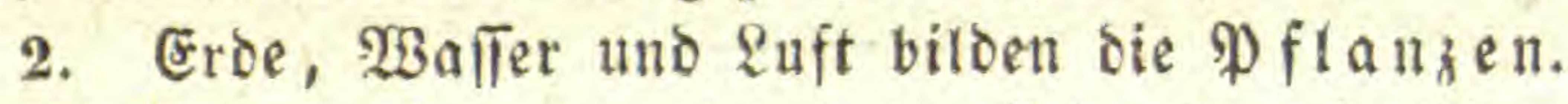

Die Pflanze befommt Durt) die Eros den Ërnährungspros

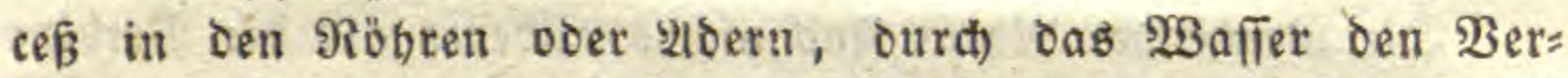
baunngsproce in Den 3ellen, burd) Die Ruft ben 2lthemprocé in oen Spiralgefäßzеn.

Selbit die Bertbeilung oer Pflanzen in oren Scaufen rid)= tet fich nad) ben Elementen.

In ben 2 cotylebonen, wie Milzen und Modien, herridt Die Er De vor;

in ben Monocotyledonen oder Pflanzen mit Streifen=

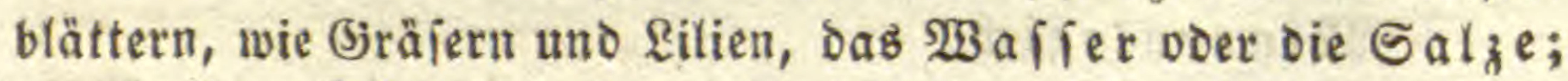

in ben Dicotgledonen oder ben Pflanzen mit Regs: blättern, die $\&$ uft ooer bie $\mathfrak{s}$ flammabilien.

3. Eroe, $\mathfrak{W a f f e r}$, Luft uno Fetter biloen bie $\mathfrak{T} b i$ ere.

Bey den Thieren fommen zu ben orey Prlanzenproceffen, nefynlich Ernäbrung, Seroaunng uno 2tthmung, noc) bie Proceffe unb Srgane bes Ridits in oen Nerven, ber Wärme poer ber Bewegung in ben Mruafeln, ber Sthwere in Den șnoden, von Denen in ben Pflanzen nid)ts 2lefnlid,es vortommt, aud) Eeine Eingeweide, welđher 2rt fie fenn mögen, Magen, Darm, Leber,

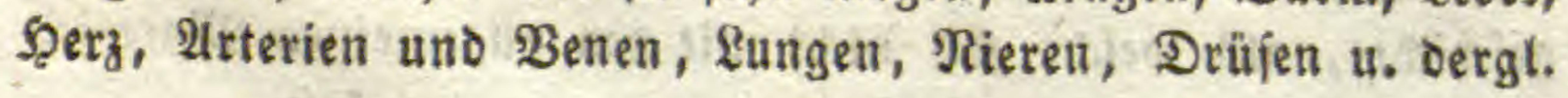


Die Mineralien find Erolement = Sndiviouen.

Die Pflanzen fino Planeten= Jnoiviouen.

Die Ibiere fino Welt = Snoiviouen.

Die Ibiere zerfallen baber in vier Scaufen.

Der Erde entiprecten bie Eorallen oder Gjallertthiere. Roblenjaurer sialt.

Dem Waffer die Sdhalthiere oder die Muideln uno Sdnecten. 2(bjonderung von Salleim.

Der Rlft bie $\Re$ ingeltbiere oder bie Würmer und Jn= fecten. Zeib meifít trocfen, Derb, hornig.

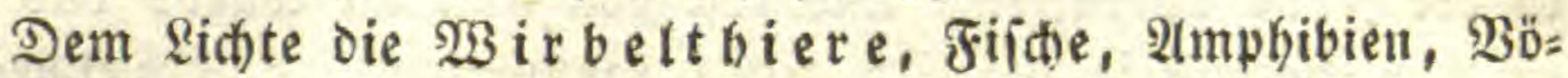
get uno Sängthiere.

Bielleidft fann man bie Wirbeltbiere Den Mineral=હlaflen gegenitber ftellen:

Den Erden die Fiíche. Erites $2(u f t r e t e n$ des snodenín= ftems mit \$gosphoriäure.

Den Salzen die $21 m p$ bibien. Sdjnelle WBirtung des Speidiel uno Magenfafts.

Den Snflammabilien die $\mathfrak{B} \not ̈ g e l$. Bebettung mit blatt= artigen Federn.

Den Metallen die Säugthiere. Bedecfung mit orabts artigen ફ̧aaren.

\section{\$planzenreidh.}

Die Raturgeididite Der Pflanzen ift ein Eigentbun ber neuern Zeit. Die (jriect)en baben niat mebr als 2 Werfe itber bie Pflanzen bervorgebract); I Teophraft, ein Sctiullet Des 2 rift o teles, eine (jeidsidte der $\$$ flanzen, uno Diofcoris

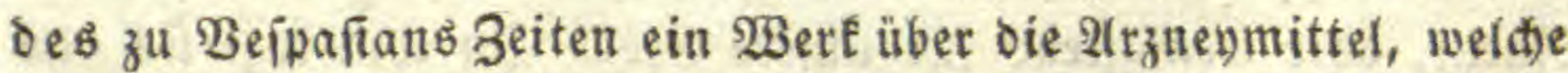
beibe mit äbnliden WBerken unferer Zeit faft nidbt mebr vers glicten werben fönner. Die Rümer baben in biejer 2 rt gar

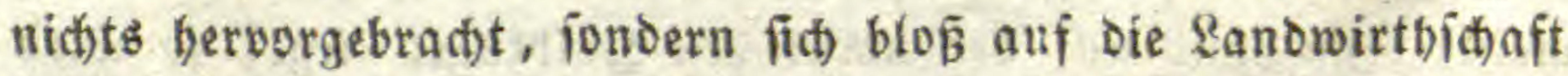
beict)räntt. (Erit nad) Der (Erfindung Der Budobrucferen) wendete man fich aud bem Pflanzenreich zu. Btterft jammelte man 
Pfanzen und fudte fie auf allerley 2 trt zut oromen, was aber erit bem $\&$ inne vor 100 Jabren gelang, nadbem man bie Theile ber $\mathfrak{B l i t t h e n}$ genauer fennen gelernt hatte. Erft vor 50 Jabren fam das eríte fogenannte natirliche Snftem der Pflanzen von $\Im$ uficut heraub. Es fitmmerte fith aber nies

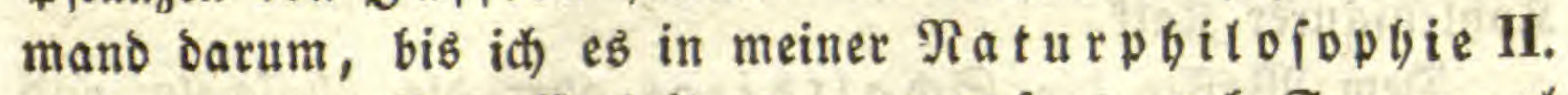
1810 aus ber Bergeffenbeit zog, worauf es aud Sprengel in ber zwenten 2 tuflage feiner 21 nleit ung, 1816, amuahm.

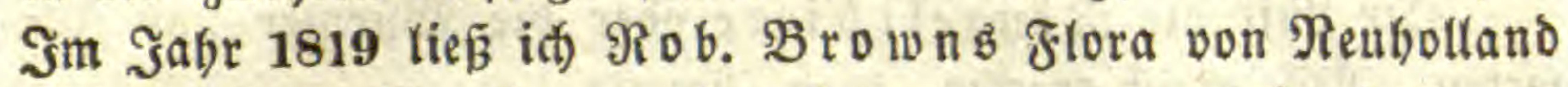
in ber Sfi tilrlide Syitem in bie Sd)ulen anfgenommen, aub welden eв feit faum einem Duksend von Jabren in bas öffentlicte Reben ilbergetreten ift.

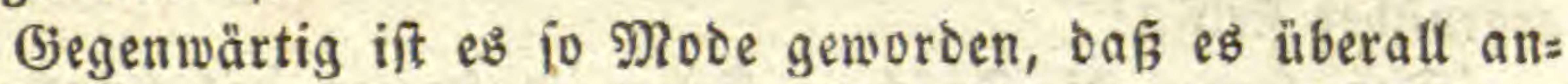

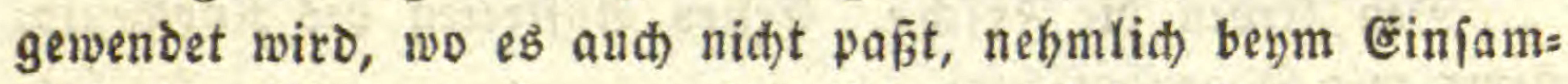
meln der Pflanzen, wo nur das \&inne if d)e oder fogenannte tünftlidge Syftem gute Dienfte leiftet.

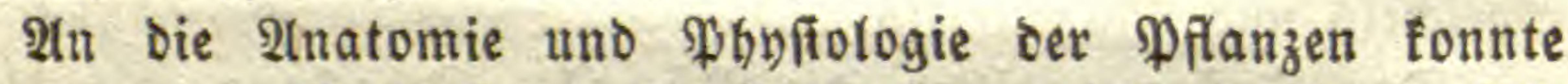
man vor ber Entbectung bes Microjcops nicht benEen. Die Werfe von Dem Staliäner Malpighi uñ Dem Engtänber R. (J) rew warett baber vor etwa 160 Sabren bie eriten, welde über bieje Dinge handeln. Sie rindten aber wäbrend eitres ganzen Jabrgunderts nicht weit vor, und haben erfít feit Dem 2nfange biejes Sabrhunderts eine mebr wiffenifhaftliche

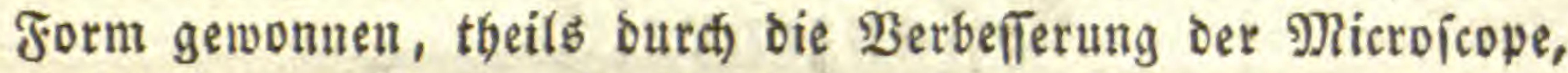
theils burd) Die Fortichritte ber andern Raturwifienid)aften,

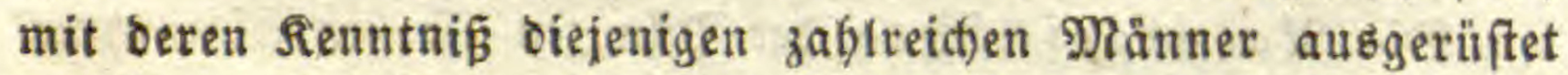
waren, weldhe fich aufs nete mit ber 2tnatomie uno Phyfiolos gie der Pflanzen beictäftigten.

Daz Pflanzenreich) ift von grofer 23 ichtig teit für bie Ratur, oder wentigitens für uniere Erde. In ibm regt fich bas erfte Seben, und es ift nidbt bló ber (jrumb nub Boden, fon= Dern auch oas einzige $\Re a b r u n g s m i t t e l$ Der $\mathfrak{T}$ biere. Da bas meifte veite $\mathfrak{L} a$ and auf ber nördlicten Şalbfuget liegt; fo wiro faît bie ganze Eroe wåbreno bes Sommers grün uno belebt,

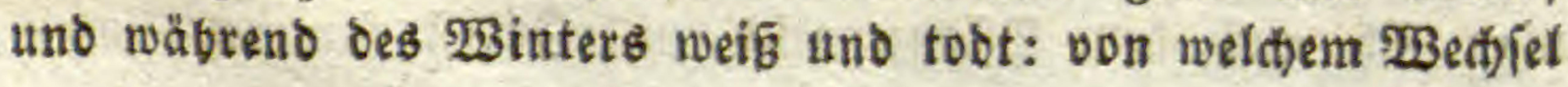


obne 3weifel eine Menge Berbältniffe abbången, weldhe wir nod) gar nidit Eennen, ja an bie wir noch nidjt einmal gedadit baben. Der 3uftand ber Buft, bes Waffers und ber Erbe, felbit

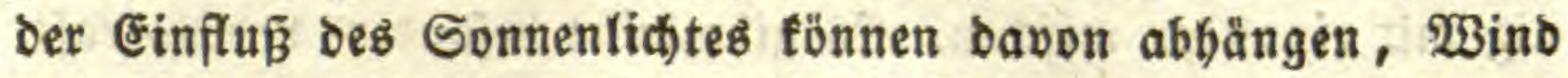
und Piegen, Feudtigleit und aroctenbeit, bie Gefundøeit Der Ifbiere und Menichen. Cine Menge Jniecten und viele andere Ibiere leben bloz von Pflanzen, uno die Fleíidfreffenden von den Pflanzenfreffenden. So beftebt das Fleif́) nur aus ver= wandelten \$flanzenitoffen. W3ir ernäbren unjer $\mathfrak{B}$ ieb mit ben Pflanzen, madten baraus unjere Maj́dinen, Şäujer, Rleider und bie sornebmiten und allgemeinften Rabrungs: ino $2 \mathfrak{r}_{z}$ neys mittel; wir erfreuen uns an ibrem (jrün, bewundern ibre fleirs beit, ibre (5röbe uno ifge Alter, ftubieren bie mandfaltigen (5)e: ftalten ifrer $\mathfrak{B l u m e n , ~ b e t r a d t e n ~ i b r e ~ F a r b e n ~ u n d ~ z i e b e n ~ i b r e n ~}$

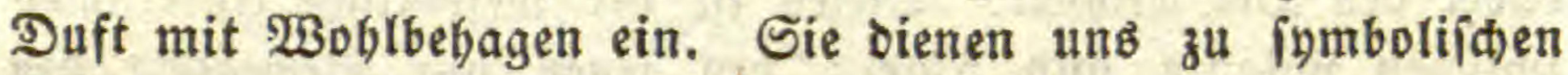
Spielen, zur Be(t)åftigung uno Unterbaltung in (Järten uno Simmern, uno enolid fönneแ wir nur an ifgren einfachen $\mathcal{Q}_{e s}$ bensverridtungen bie entipredtenden im thierif(ten Reibe ftubies ren, uno baraus Sdliffe auf unjer Reben uno auf unfere

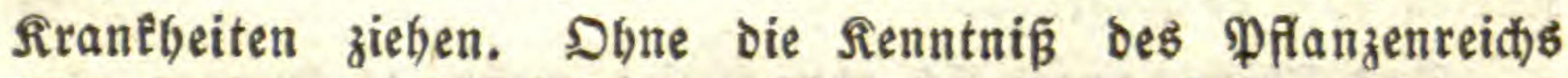
bätten wir nur eine jebr anyollfommene vom Thierreid, unb fo viel wie gar feine beillennft. Diejer geiftige Bortbeil ift eben fo gró als ber materielle, weldten uns bie Pflanzen vers id)affen; von bem unithulbigen Stubieren ber Pflanzen, von ber Beidäftigung uno ber Uebung Des Beobadtungstalentes bey Spaziergängen unb jelbfí auf Reijen, worauf Biele von Eangeweile geplagt werben, nidt zut reden.

Die Pfanzen fino als innige Bereinigung von Crbe oder Roblemftoff, von $\mathfrak{B}_{\text {affer und }}$ \&uft, worinn alle orey ibre eigentbümlide Thätig feit bebalten, ein galvanif

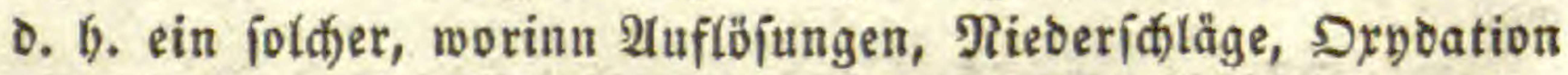
uno Serję̧ung felbittitänoig fitattfinben uno fich) wiederbolen; oder

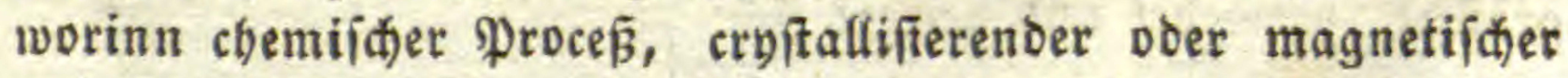
und electrif(d)er fith wedfielfeitig antegen und erbalten. Ein Sörper aber, in weld)em ber chemifhe Procé felbititändig vor

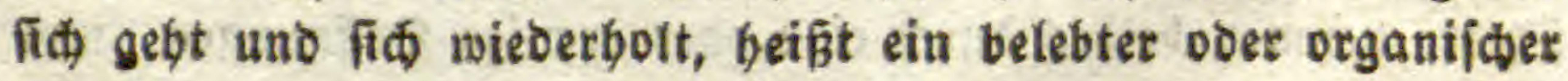


Sïrper. Die Pflanzen fino oaber bie eriten organijđen fïrs per, uno der Doganismus mur überall ba entíteben, wo bie

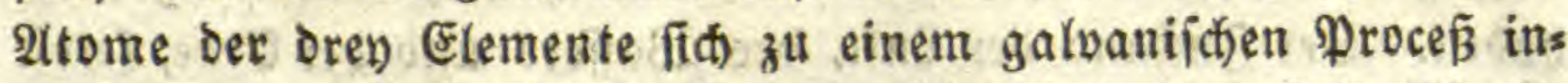
nig mit einander miidsen. Eg gibt feine bejondere Qebensfraft.

2(ud) muß bas $\mathfrak{T}$ (bier Diejelben procefle und beren Drgane

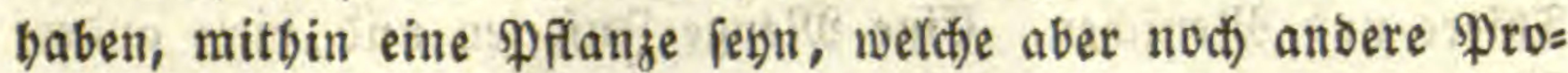
celle oder Drgane betommt.

Da bie Pflanze bloź auz dem galvanificten Procéz beftegt; fo founen fid) in ibr nutr bie flitffigteiten bewegen, aber nidit Die veften Ibeile. Es bewegen fid baber nur bie Säfte, aber

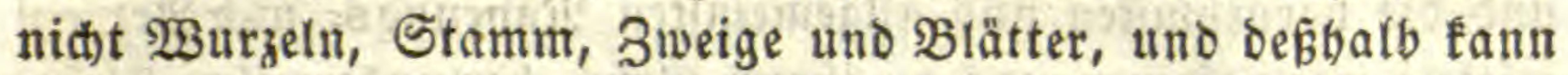
fie igren Drt nidft wedtieln. Das Thier ift einer Pflanze zut vergleidten, bey weldier aud Der vefte Reib fidt) bewegt, uno baber oen Drt wedfielt. Diejes ift oer wejentlicte unteridtied zwiften Pflanze uno Ibter; bey jener nur Bewegung Der Säfte, bey Diefem Bemegung der Säfte uno ber Drgane. Es gibt zwar now viele Unteridtiede, welche aber nut Folgen bes Şauptunterichieds, uno Band IV. S. 15 Dargef́tellt find. Im Surzen find $e \mathfrak{B}$ folgende:

Das Iffier bewegt fith obne Yieiz: wenn es Şunger ober Durit bat, fo fucht eร Plabrung uno Gieträné. Da bie Pflanze ibre veften Drgane nid)t bemegen fann, io muf fie warten, bis Nabrung und $\mathfrak{B a f l e r}$ zh the fommt, D. h., Das Thier bewegt jeinen Leib willeürlich, die Pflanze gar nid)t. W̉enn einige

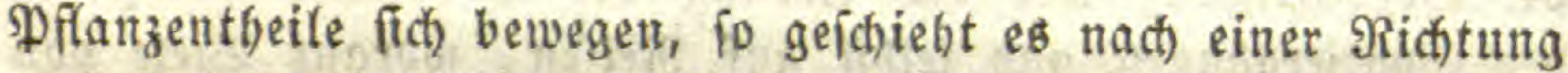

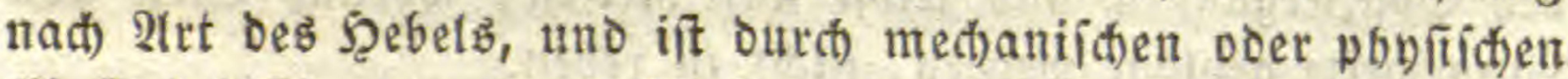
EinfluE beftimmt, ourd $\mathfrak{B a f f e r}$ oder $\& i d t$. Bewegungen mi=

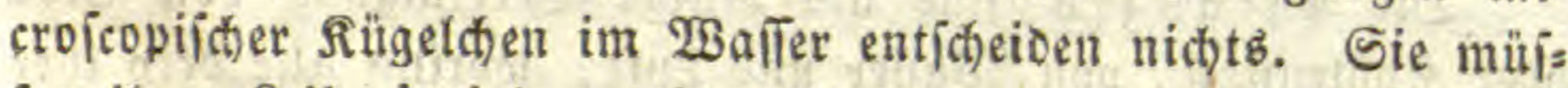
fen ibren feib einzieben uno aubbebnen, wenn fie Thiere fenn wollen,

Die PFlanze vergröfert und vermegrt fit); Dag Thier ver: gröfert, vermegrt und benegt fich.

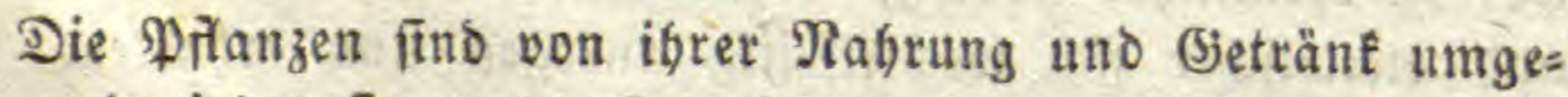
ben, und zieben fie von aufen ein ourd) viele Deffnungen; die Thiere nebmen beibeb ourd) eine ober wenige Deffungen, uno 
ziteben es von Snnen ein, ebenfalls burch viele Deffnungen, négmlich aus Dem Magen oder den Därmen.

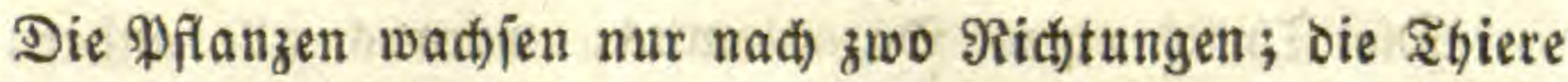
aud), aber nod nad) andern.

Die Pflanzen fteben nur in einer Ridftung auf bem $\mathfrak{P l a}=$ neten, uno zwar gegen feitren Mittelpunct; die Thiere fteben abivect)jelno in allen Richtungen.

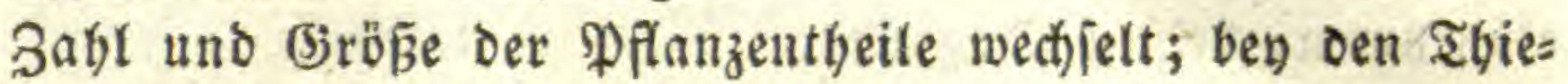
ren ift alles beftimmt.

Die Iabile der Pflanzen find freisförmig geftellt, ben ben Thieven paarig und zweyjertig, felbit bey Den logenannten ftern= förmigen: faum mit einer gültigen 2 (us̆ahme.

Die ganze Pflanze beftebt aus nidht als boblen, faum er= fennbaren Theilen; bas $\mathfrak{s}$ bier beftebt aus boblen und vollen Theilen, weldhe feine Flüriftgteiten füthren, wie Rerven, Museetn uno Rnod)en, benen nichts ähnliches in ben \$flanzen vorÉommt, weder Dem Stoffe, nod) Der (jeftalt, nod) Der Rage, nod Der Berrid)tung nad).

Die Pflanzen befteken grögtentbeils auz soglentorf; die tobiere aus Sticfitoff.

Die Pflanzen geben bey der Defitillation $\mathfrak{B a}$ aller uno Del, oie Thiere $\mathfrak{B a f f e r}_{\text {und }}$ immoniaf.

Die getroctneten Pflanzen brennen, die SGiere nict)t.

Man hat atci) einen Unterífied barinn finden wollen, bá Die Blitthen ibre Befruthtung nuv eitmal ausïbten, oie ents fprectenden $\mathfrak{I}$ geile bey ben $\mathfrak{T}$ bieren mebrmals: allein ben bẹt

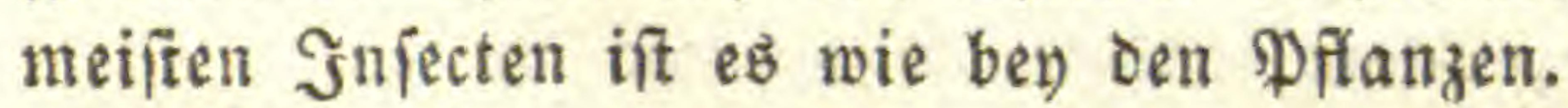

Eine vollfommene Pflanze zerfält zunäbit in Sto of uno Stratt追 oder $\mathfrak{B}$ tîtbe, oder in Erthaltungs= uno Fortpflan= zungsorgane, wowon oie lektern nach iffer $\mathfrak{B e r t i d}$ ) ung ab/ferben.

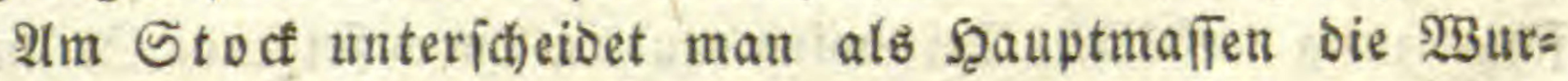
zer, Den Stengel uno das Laub.

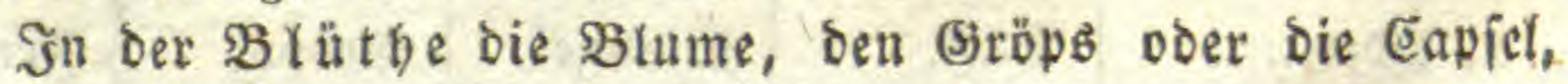
ben Gamen und bie Frud)t.

Illle dieje genannten Theile befteben aub Zellen, Röbren voer 2 been uno Epiralgefăben voer Ruftröbren. 
2(m Stoct fann man nod) beutlid unterífeiden Rinbe, Baft und Selz.

Die Theile eines Drganismus, woraus alle andern jus fammenge febst find, nennt man (j) e webe.

Diejenigen, weld)e abgejondert burd) ben ganzen Leib lau= fen, beifen a natomiide Sy fiteme.

Diejenigen, welde nur einen f́leineren und bejondern Drt einnebmen, beisen $\searrow \mathrm{rgane.}$

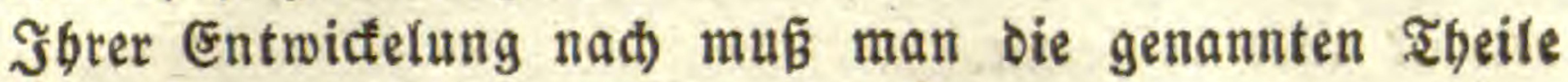
auf folgende 2irt orbmen:

A. (3) ewebe.

1. Bellen; Berbauungzorgane, Baffer.

2. R̈̈hren oder 2 bern; Ernäbrungsorgane, Erde.

3. Spiralgefä ze oder Droffeln; 2lthemorgane, \&uft.

B. 2natomifde Syfteme.
4. Rinde, Bellipitem.
5. $\mathfrak{B} \mathfrak{a} \mathfrak{i t}, 21$ erinftem.

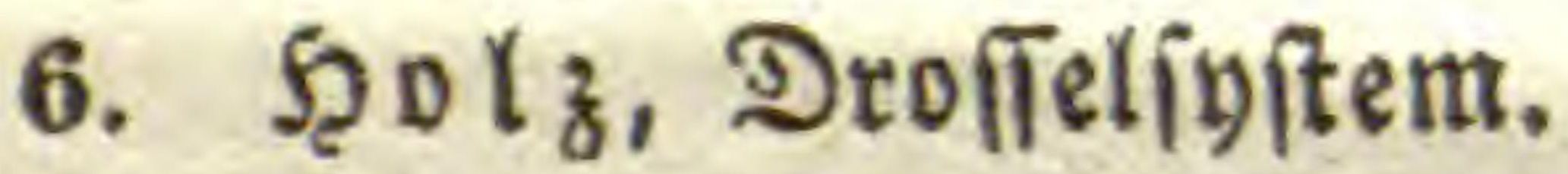

C. Drgane.
a. DeB Stoctis.

7. $\mathfrak{Z}$ u rzel, Zellen, ober Rindenorgan.

8. Stengel, 2loer = doer Baftorgan.

9. Blat $t$, Droffel = oder 5̧olzorgan.

b. Der Blüthe.

10. Sa men, פ̧urzel.

11. (3) $x \ddot{p}$ \&, Stengel.

12. Bla $\mathrm{m} e$, Blatt.

13. $₹ r u$ d) $t$, Stocf.

Man fann und muß alle Syfteme und Drgane als.2Bieders Golungen ber (semebe betracten, uno bie Frudtht als eine ßers fidmelzung berílben. Das wiro beutlich burd) folgende Etellung:

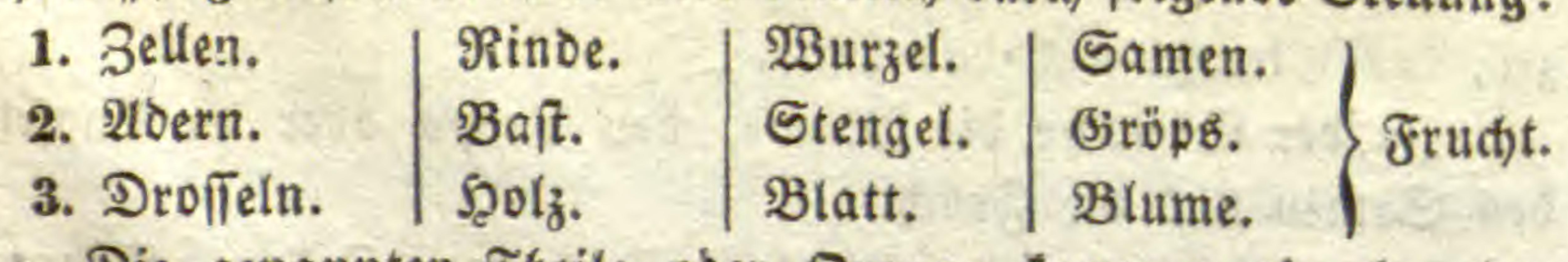

Die genanten Theile ober Drgane fonmen einzeln ober auf mandfaltige 21rt uno in veridiedener Menge verbunden 
vor, und billen baburd) veridiedene Pflanzen, welde zu= fammen bas Pflanzenreich) ausmađien. Die einzelnen Pflanzen find Daber nidts anderes als Darítellungen ber Pflanzenor: gane, einzeln ober mit einanber verbunden.

Diefe Pflanzen ånbern manđffaltig ab nach) ibren (joburtš orten, nach) Trodenkeit uno Feudtigfeit, Boden t. I. m.

Sie fteben endlich in eigentbĭmlidben Berbältnif̣en zu Den Sbieren, und befonders Dem Meníden.

Man theilt Darnach die Raturgeifid)te ber Pflanzen ein in reitre und angemanbte.

A. Die reine beichäftigt fid entweder

a. mit ber Pflanze ïberbaupt - allgemeine Botanif, uno zwat

1. mit ben TGeilen Der Pflanze - Pflanzenanatomie,

2. mit Den Stoffen Derfelben - Pflanzenchemie,

3. mit Den Berridtungen berfelben - Pflanzenphyfif ober Phyffologie; oder

b. mit Den einzelnen Pflanzen - bejondere Botanif, uno zwar

1. mit Der senntnís berielben - PFlanzeninitem,

2. mit Den Standorten Derielben - Pflanzenöconomie,

3. mit Den $\mathfrak{B}$ obnorten Derielben - Planzengeographie.

B. Die angewandte Raturge faict) ber Pflanzen theilt fid

1. in bis medicinifiche,

2. in bie Forit $=$, uno

3. in Die öconomifict)e Botanif.

Die 2tnwenoung Der Pflanzen in Der Mebicin, Der \&and=

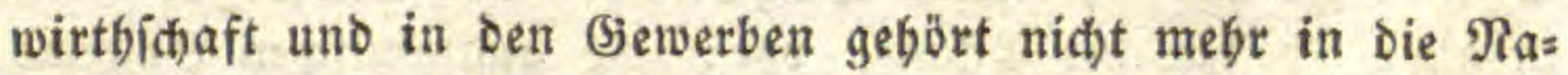
turgeichidt) ber Pflanzen.

Indeflen wirb biefe Sheidung bier niht befolgt, fonoern das berreffende gebörigen Drts eingefügt. 


\section{Aflgemeine \$flauzenfunde.}

\section{Inatomie bex Pflanzen.}

Die Gründer der Pflanzenanatomie find: Nebemias (5) rew, Secretär ber philojophijhen Bejellichaft zu Lonoon, Marcelr Malpigbi, Profefír zu Bologna, uno \&eeunen= boef, Privatmann zu Delft in Şolfand, weld)e zu gleither Beit microjcopij(t)e Beobactungen ïber Das (jewebe ber Pflanzen an= ftellten. Der erfte machte fie 1670, der zweyte 1671, Der britte

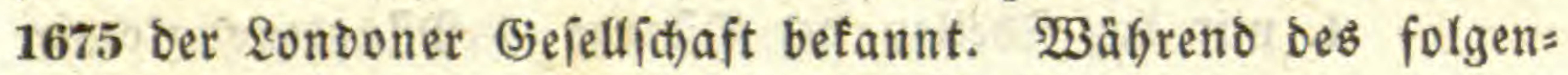
Den Safrhunderts gejthah jefre wenig, uno es famen nur ein= zelne Beobadtungen zum Borfdein, bis Э. Scebwig fith wies Der ernftlider mit microfcopificten $\mathfrak{B} e$ obad)tungen, bejonders ber Nooie, in ben adtziger Jahten bej̧äftigte. Die 2tnatomie ber Pflanzen wurbe aber erft vollftändig und initematifít) bear= beitet won $\Re$ irbel 1800, R. Eprengel 1802, Қ. Linf 1805, 8. Treviranus 1806, 2. Rubblphi 1807, Э. Molden=

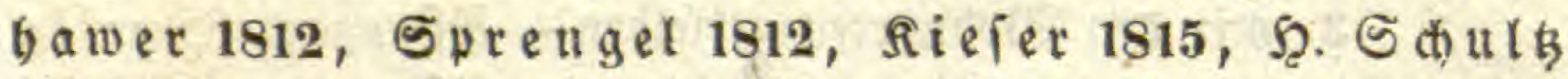
1823, De Eanoolle 1827 , Meyen 1830, 1835, Ђ. Linf 1837. Die Sitel igrer Werke werden am S(blulfe angezeigt werden.

Die Pflanze befteht alio aus (3) eweben, anatomijaen Syftemen uno bejondern Drganen. Die Semebe founmen in allen SGeilen ber Pflanze por; Die anatomifhen Snfteme zieben fich abgeiondert butrch die ganze Pflanze bindurct); bie Drgane fino ganz von einander getrennt, uno fto Ben nur mit iğren Gränzen an einander.

\section{Genebe (Tela).}

Die Gewebe fino $3 e l l e n$, doern uno 8 uftröbren ober Drofieln. 


\section{a. Belten (Cellulae).}

Man bat frïber gemennt, Die Sirunomafie Des Drganifhen iey ein unförmlicher Brey, Den man Brenftoff nannte. Sक

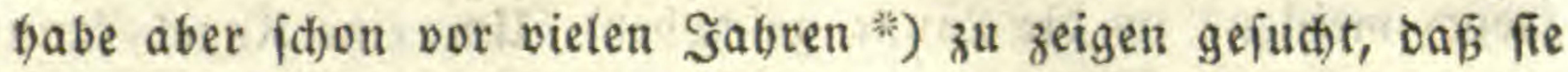
aแ lanter Sđ)leimbläschen beftebe, uno mitbin fdion bey ibrem eriten 2 uftreten geftaltet jey. 2 (n Diejem : Berbalten zweifelt

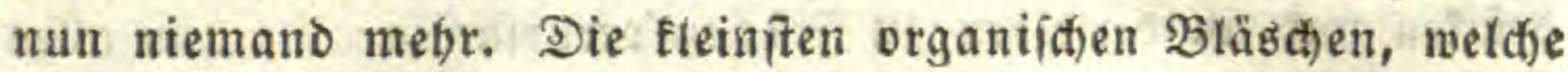
man Durch oas Microicop als jelbitftänoig erfennen fann, find oie Infuiorien, uno baber fann man die organijase (Sirunomaffe eine infujoriale, mithin lebendige Mafle nennen, worats Die Seiber ber Pflanzen uno Itiere zujammengejęt fino: nid) als

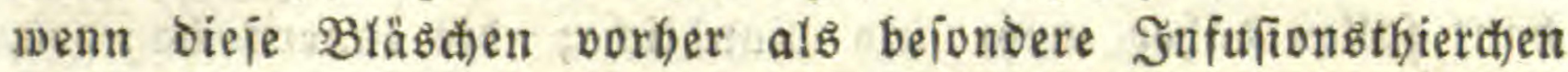
berumgeftwonmen wären, uno fid) fooann in einen Stoff voer

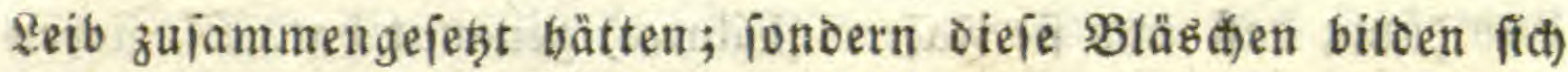
erit, uno verbinoen fith in bem 9 tugenblict, wo ibre chemifichen

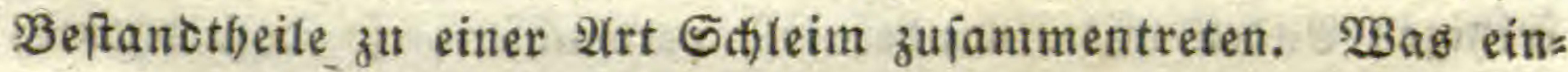
mal zu einer bejondern Pflanzen = oder Ibiergattung fict) ver= bunben bat, ănoert fid nidht mebr in eine anbere um, wofern fit) Die Stoffe nidft wieder auflöien und nad) andern Berwand: (i)aften und Ridtungen fich verbinden.

Man tann Den Anfang Der organifotien Sirunomaffe als weiđhe \$utcte oder Rügelden betrađten, weld)e allmåbliđ bohl werden, indem fich Durch Drybation der Umfang verdichtet unb Das $\mathfrak{2}$ affer fith in Der Mitte fammelt.

Betrachtet man nun burd ein Microicop einett binnen 2(bidnitt von irgend einem \$planzentbeil, jey es Rinde, Baft

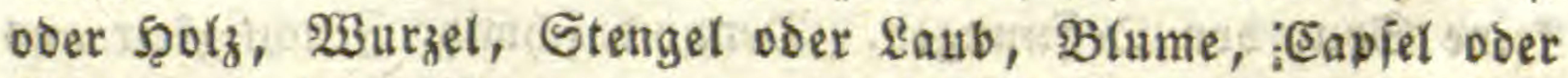
Samen, io bemertt man eine zabtloje menge fleiner Bläs̆tien, wovon mefrere Sundert faum eine Sinie lang, balo rund, balo ecfig, bald walzig voer fadenförmig ftto, uno oicht an einanber liegen. IRan nennt fie Bellen, uno das (5)anze zujammen Beflgenebe (Tela cellulosa).

Ju Den niebern uno weiden Pflanzen, bejonders in ben: jenigen, welche im 23 afler leben, zeigen fie fich meiftens runds.

7s *) Sn meiner Sфrift über bif 3eugung. 1805. 
lid); in ben böbern aber und mebr trocfenen ectig. Siefer

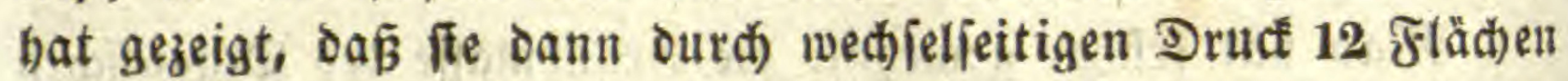
bef́ommen oder die (Sieftalt eines Rauten=Dodecaëders annehmen, jeovh meiftens in Die Ränge geí()oben. Um eine fingel tann man nebmlich nicht mebrlals 6 andere gleid) groß̧e legen, Dar: über uno Darunter nurg3; jo Daß̧ alio 12 Rugeltn Die mittlere orïcfen uno an berílben 12 Fläh)en verurjactien. Da nun alles Zellgewebe in Der Pflanze oidht an einander liegt, fo müffen alle Zellen diefe (Sieitalt betommen; veritebt fich) mit vielen 2 lbände: rungen, weil ber Druct verífieden ift nno das Streben der Prlanze in oie Şöhe gebt. Die äußjeriten Zellen in ber Dber: baut fallen baher mebr ins Rundlide; bie innern bagegen, welche längs ber Suftröhren oder im Şolze liegen, find fo lang

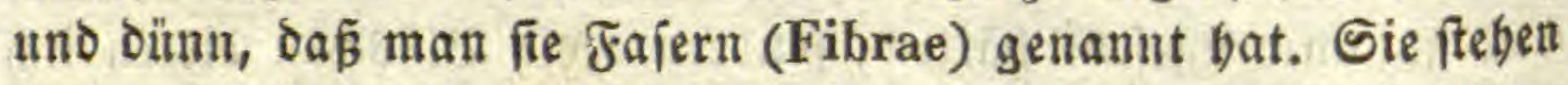
immer bündelweife und bidit beyiammen, uno fino mit ibren ipiz̧igen Enden mit einander veft verwad)ien, fo baß̧ badurch lange Fäben entiteben mit Sdeiowänden, wie im Şanf. Dir iogenannten Solzfajern fino Daber nid)ts anderes, als fehr lang geftrectte uno Düne Bellen. Sie zeigen fit) auf Dem Duerínitt bohl wie die anbern, aber mit Dicferer $\mathfrak{B a n d , ~ e n t h a l t e n ~ e b e n = ~}$

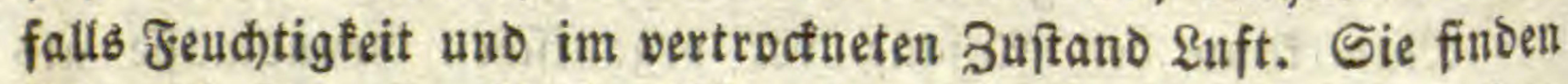
fi() aud) (đ)on im Bait. Man bat fie mit ben Mubfelfajern verglidien: allein fie fönnen fich weder verfittzen nod biegen. Sie find offenbar nid)tb als Durch das $23 a d j e n$ nach oben febt verlängerte Sellen, und baben aud) fein anderes (jeja)äft.

Die Saut Der Bellen ift burdifichtig, gleichartig uno zeigt teiue Spur von Deffnungen. Dennod) idwist Feudtigteit aub uno ein: Denn fie entbalten einen ourhfichtigen, farbloien Saft, uno vertieren Denjelben ourch Iroctnen.

Inn Dem Safte jebod, fiebt man gewöbnlid) einige Dukeno fleine sügeldinen fowimmen, welde fid mit ber 3 eit an bis Wände fę̧en; wab bann ausfebt, als wenn. 20̈djer bajelbit

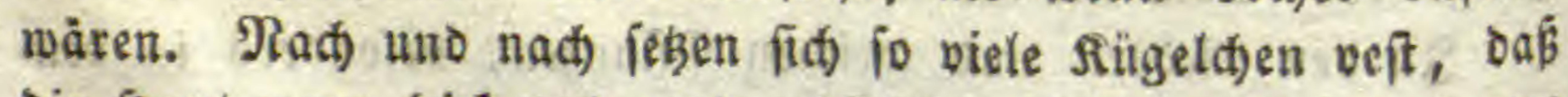
die Şaut ganz Did uno unourd)fiditig wirb, und Der innere

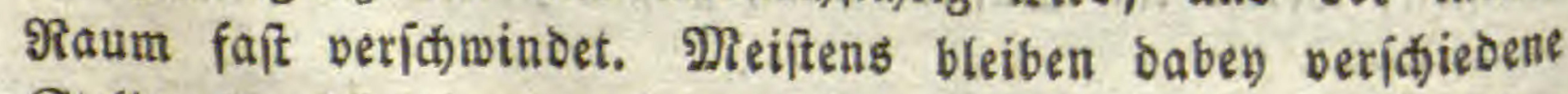

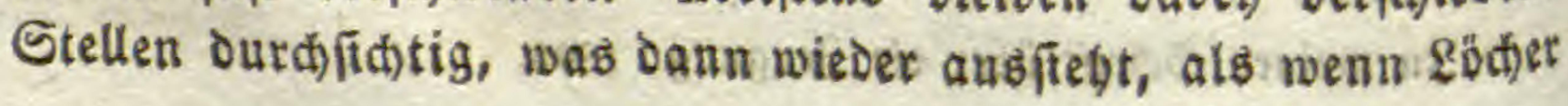


porbanben wären. Man weiß nidbt recht, wober biefe outchs fid)tigen Stellen rübren. Bisweilen tegen fich bie Sörner aud) linienförmig an einander, uno bilden Spiralen ober Sweige in ben Zellen. Mandimal betommen bie Bellen allerley 2usfactun gen, uno feben dann fternförmig aus. 2lltes biefes änoert aber nidts an ber Ratur ber $3 e l l e n:$ uno ffe mögen baber eine Wand oder eine Beftalt baben, wie fie wollen; fo mus man bens nod) annebmen, baß fie überall ein und bafielbe (Bejhäft baben.

Die fïbrner in ben Bellen fino eine 2(rt Stàrfemegt, weil

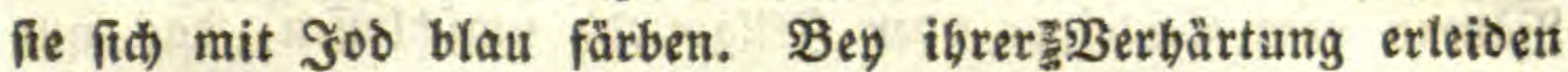

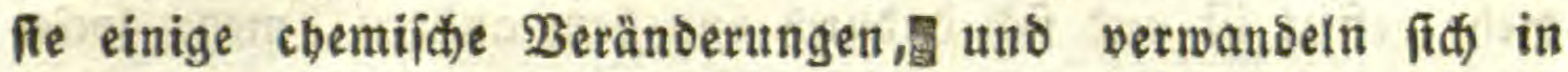
Solziubitanz.

Эn ben Zellen, unmittelbar unter ber Dberbaut, baben Diefe Siörner eine barzartige Ratur angenommen uno ftno grŭn geworben. Man nennt fie Blattgrün (Chlorophyllum).

Die Zellen Der Dberbaut uno Des Marfs fino leer, ober

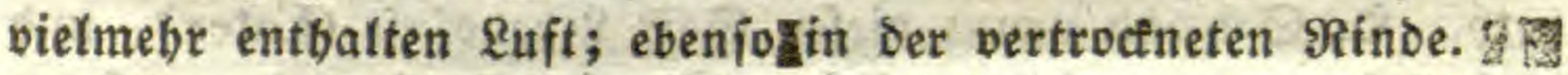

Bey vielen PFlanzen, bejonders faftreidten uno ben Mono=

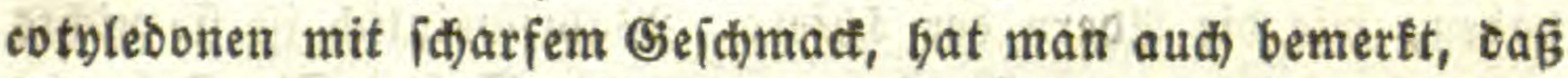
fid) meift ipiesige eryftatle in mandien Bellen abjetsen, bejon= Ders mann bie gabeile alt werben uno ibre Giejoäfte vollenbet baben. Sie liegen oft bündelartig beyjammen, uno befteben gröstentbeils aus zucferjaurem (fauerfleefaurem) salf. Diefes fino obne Sweifel 2(usfdeioungen, welde nid)ts mebr mit bem Zeben zu fdaffen baben.

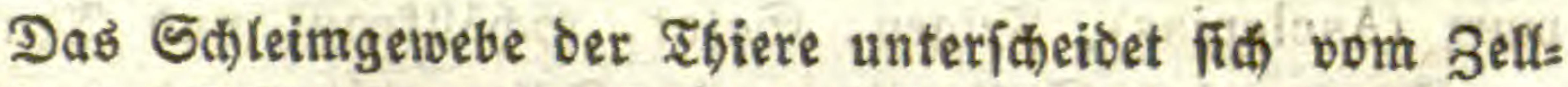

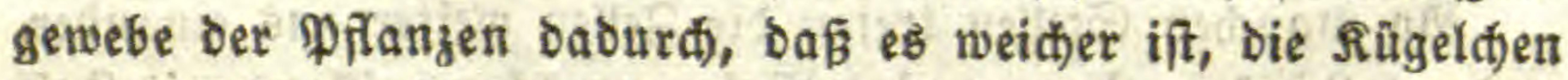

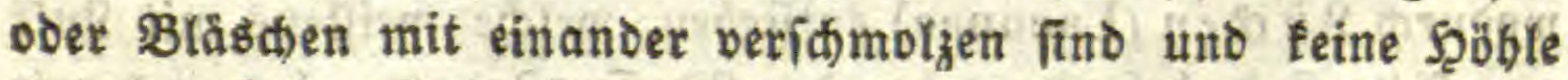
baben. Dennod ziegt eछ Såfte ein uno läbt fie ourd.

\section{b. A bern (Venae).}

Ueberall, wo brey Bellen zujammenftofen, bleiben orenectige 3wifđentäume, weldhe burd bie ganze Pflanze fowohl nach ber

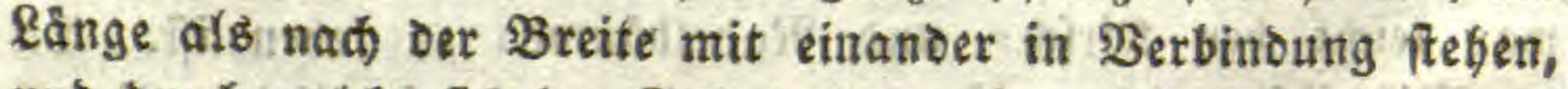
und ourd weldie fich ber Saft bewegen fann. \&. I revir an us

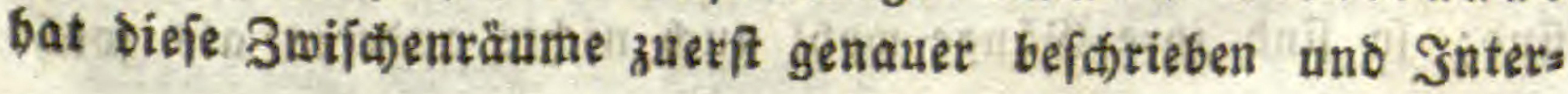


cellular=ङ̋ånge (Ductus intercellulares) genannt. Sie entbalten ben eigentlichen Pflanzenfaft, weldher burchfichtig ift, aber aud) Rörner entbălt, Solleim, Zutcter uno einige Salze. W̉enn man einen Baum anbofrt oder einen 3 weig abidneibet, fo

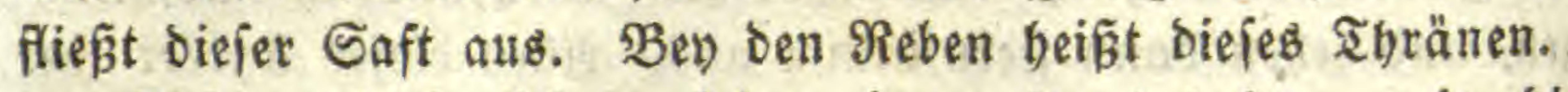

Dbichon dieje (sänge feine eigene Şaut baben, wie bie 21bern ber shiere, fondern nur won ben anföß̈enden Bellen ein=

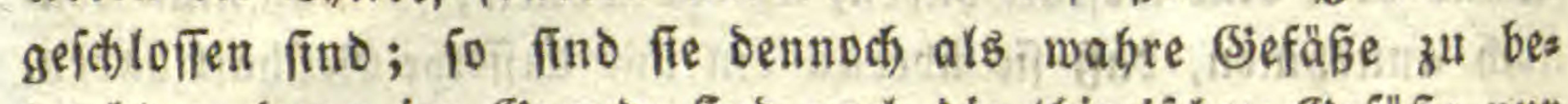
trachten; benn im (j)unde fino autch die thieriftsen (Siefäse nut Räume vom Sd)leim = ober Bellgewebe umichlofien, bab nut mehr gefilzt if und fict) oadurd) von bem anbern, mehr loctes ren abgeiondert bat.

(5s gibt aud) weite Intercellalur=(5änge, jogenannte eige ne

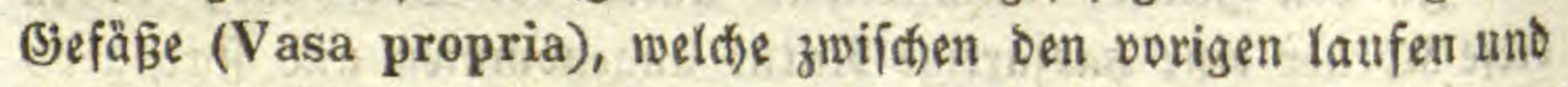
einen gefärbten Saft enthalten, bict wie Mild) uno meiftens

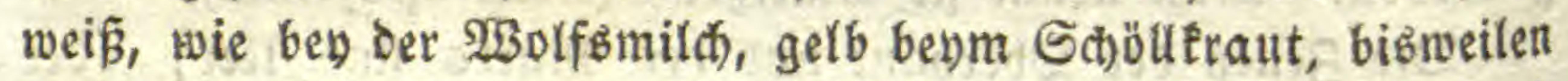

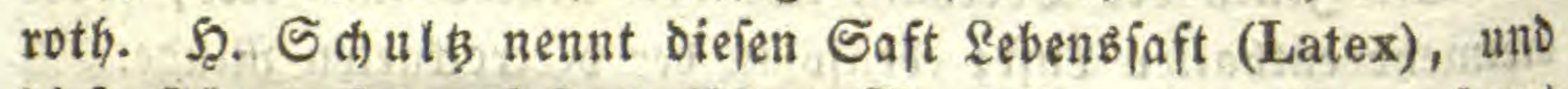

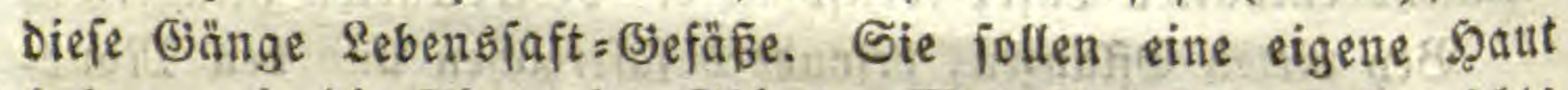

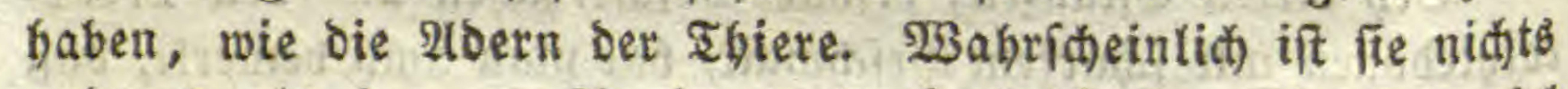
anderes als ber am Fande vertrocfnete Saft. Sie find viel weniger zahlreid) als die bes äd)ten Pflanzenjaftes, eigentlión nur zwifhen benjelben zerftreut, fteben aber aud bisweilen jeits wårts mit einander in Berbinoung, to dá̧ ibr Saft nach, allen Seiten ausfliešen Eann, wenn er Enft befommt. Sie finoen

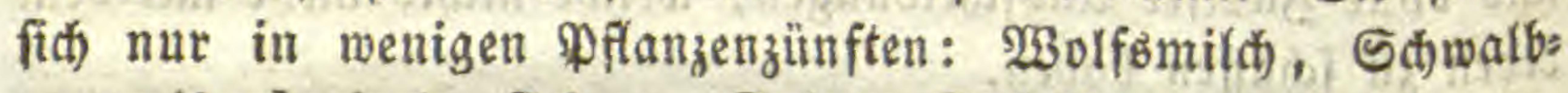
wurz (Asclepias), Feigen, Salat, Schölltraut unঠ Santen.

2u manchen Stellen treten bie Bellen weiter aub einander, woourd) \& ü of en (Lacunae) entifteben, welde meiftens mit \&uft

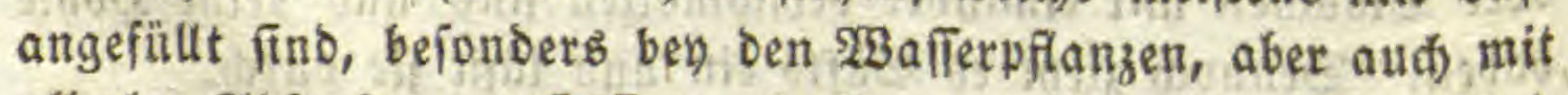

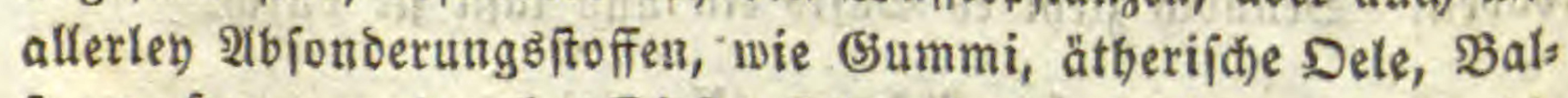
fame, Sarze n. Dergl. Diefes fino alfo 2(nsfideioungen wie bie Eryitalle, uno baben ebenfalls nidfts mebr mit dem Leben zu (क)affen, wie benn aud bieie Stoffe oft fren nach) $2(u$ Ben tweten,

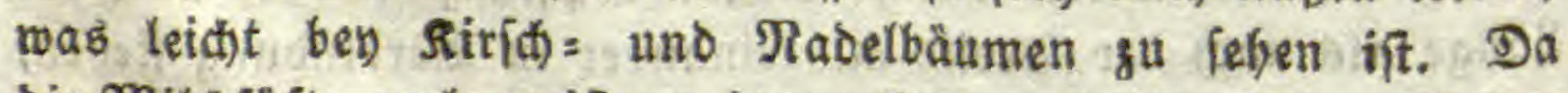
bie Mildiafte au(b) meiftens Garzartiger uno oft giftiger (atur

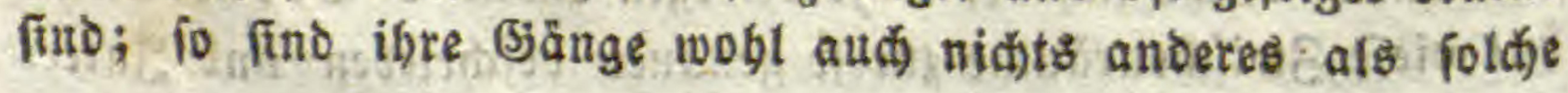


lăngere, ourd) Seitengänge mit einander in Berbindung fitefende Qücten.

c. Droffern ober SpiralgefäBa

(Tracheae, Vasa spiralia).

Berreist man irgend ein dünes $\mathfrak{B l a t t ,} ;$. B. ein Rolens blatt, vorfichtig uno langiam entzwen, inoem man etwa oie 2trme an bie Seiten Der Bruft legt; io bleiben beive Stitce alt einander băngen, und zwar ourd) fpiralförmig gewundene fäben, nod) Düner als Spinnmeben, merthe aus ben Shattrippen ber: vorfommen. Diejes fino aufgezogene Spiralgefäze.

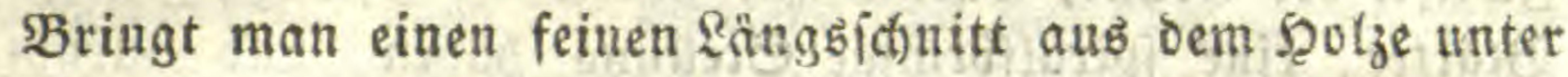
oas Microicop, fo bemert man mefrere neben einander liegende

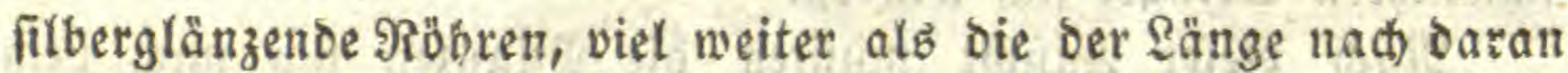
riegenden Fajerzeflen, aus einem febr bünnen uno fteifen Faben befteheno, welcher gewunden if wie oer Drabt in einem Sobiens tråger. Sie gleidten auffalleno ben suftröbren ber Snfecten. Die 2 Bindungen liegen meiftens bidit an einanter, unb fino oft mit einander verwactien, fo oaßs, anf fithtbare 23 eife menigitens, nid)ts burdjoringen fann. Bibmeilen beribren fie jeboth einan=

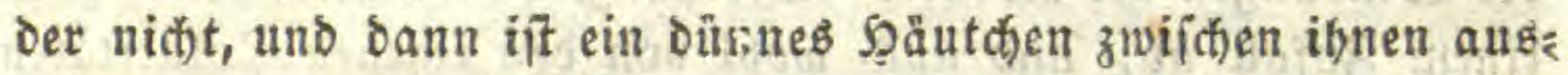
geipannt, weldes die $23 a n \delta$ ber Röhre mitbilden bilfs. Es fommt auth vor, Daß bie Spiralfajer fid ipaltet in zwey uno mebrere 2lefte, welche ebenfalls ipiralförmig laufen uno ber

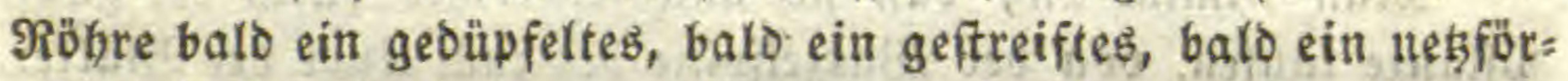
miges 2triehen geben, - geouipfelte, gefítreifte, neşförmige Spi= ralgefäßse. Dieie Unterídiede iđeinen vom Atter abzubängen. Bisweilen liegen aud) mehrere Jajern banofërmig uno ungetbeilt neben einanoer. 2(ut) verwadjien fie mand)mal ringförmig mit einander - Ringgefäße. Sieine 2trt von Epiralgefäßen bat

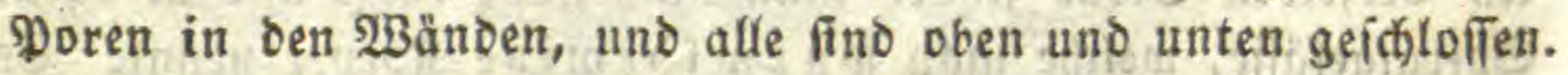
Uebrigens ftreitet man fich nod, ob oie Spitalfajer inter= ober auferfalb ber Scautröbre liege. Da diele Biefäвe als ver: längerte Zellen betradtet werden mürien, und bie Faiern als gebiloet von Sïrnern; io mú man annebmen, bas fe Oarinn entfeben, aber fpäter io bamit verwachien, wie bie Bellifubitanz Dlens allg. Raturg. II. Sotanif I. 


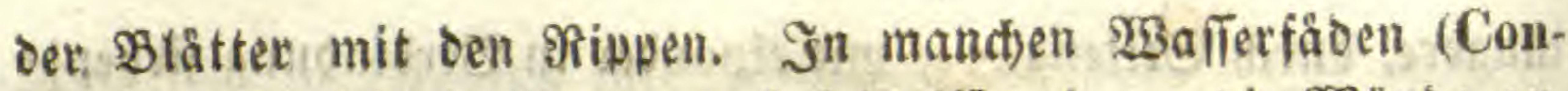
ferva) legen fich Die Rörner aud ipiralförmig an die $\mathfrak{B a ̈ n d e ~ a n . ~}$ Det (Girund oer Spiralform liegt wabrideinlid) im Unlauf

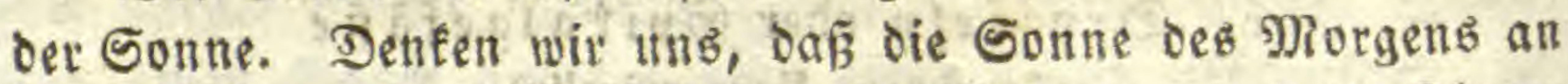

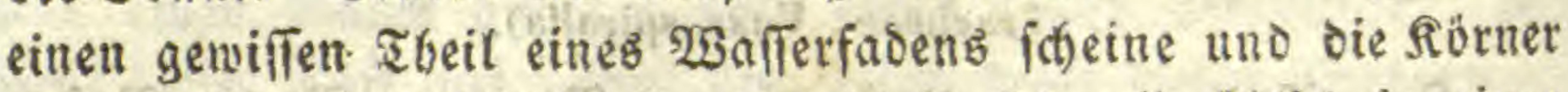
an bie 23 and ziebe; fo werden dieje fta altmäblich in einer Spirale an einatioer reiken, fo wie die Sonne nach) Jittag

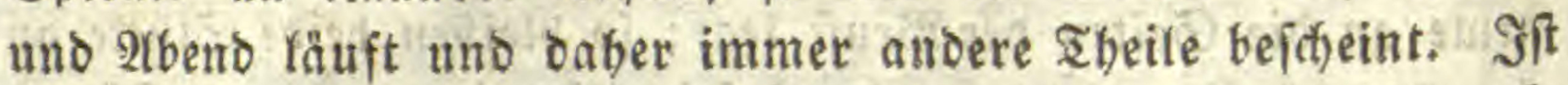
aber efinmal nur Den erften förnern bie Ridjtung gegeben, io muह fie fich obne शlenderung fortjegen. Darinn liegt auch ofne 3weifel ber Giruno, warum alle IGeile ber Pflanze, Zweige uno Blätter, eine fuiralfürmige Stellung baben, uno warum die fifwäbern Stengel fict) minden.

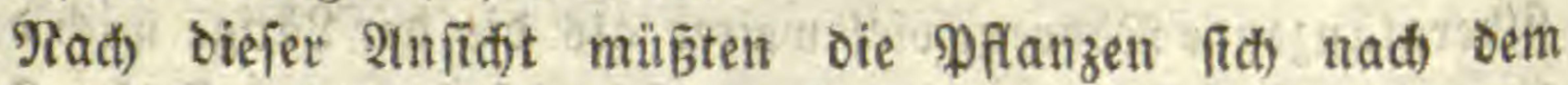
Raufe ber Gonne winben, auf ber nörblid)en (Erobălfte von oer

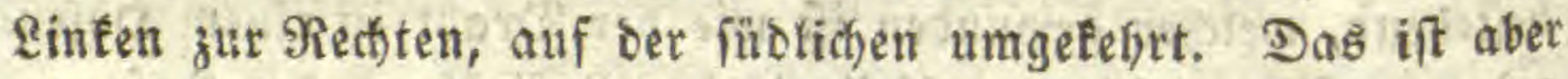
nicht ber Fall, uno auth die Gpiralgefäge minden fich bald nath rectits, balo nach linfs in derfelben Pflanze, uno oft in oems felbet $\mathfrak{B}$ iundet; in mandjen $\mathfrak{W a f f e r f a ̈ b e n ~ o u t a f r e u z e n ~ f t a ~ f o g a t ~}$

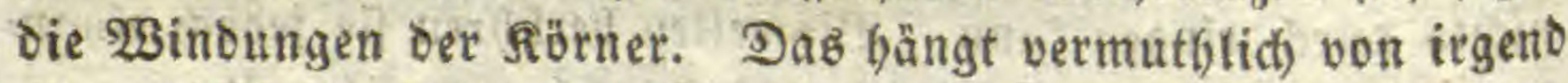
eitten Sufall ab, uno auch wobl von ben eigenten polaritäten in oer Yflanze, weldbe jebod immer ourch oas Qid)t beftimmt werden mögen.

Man nimmt an, das fie ununterbroben ourch bie ganj? Pflanze laufen, von ber Wurzelpipe bis zum Ende ber Brätter. Sie berzweigen fid) nirgends, fondern liegen gerad und einfach an einanber, wie bie Fäben in einem Rerbenbundel. In ben Fnoten jeobd ber Gräfer uno anberer finotenpflanzen pflegen bie untern zu endigen und nach oben wieder nette zu entifeben. थn Derietben Stelle finoet man aud) ganz furze uno gebogene Spiralgefäbe, welđ)e man wurmförmige sörper nennt. Es fino wabridbeinlid) junge Droffeln, welde aber wegen oer Ber: bidtung Des finotens verfummern.

Die Drolleti manen einen f̧auptbeftanotheil Des Şolzeg aub, uno billoen faif ganz die Rippen ber Blątter.

Gie feblen in bet פinde und im Sapt, in den pilzen, 
Sangen, Flectiten uno Moofen, uno beginnen zuerft in ben Far:

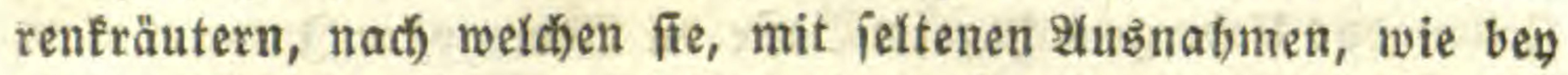

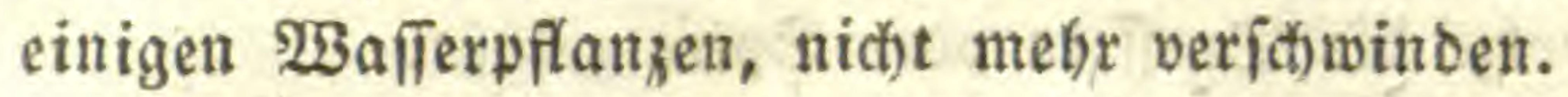

In Den Farrenfräutern bilden fte ein eitzziges Bün bel mitten im Stengel, weldese fich) jobann im Raube mandiffaltig vertheilt.

Bey ben jogenanten Monocotyledonen oder ben Pflanzen, welche mit eitnem einzigen fpibigen Lappen feimen, fteken fie in melgreren burd) Belfgewebe getrennten Bitndetn im Rreile, uno laufen in bie Blätter alB gerabe Streifen auts, welche fith fer: ten veräfteln, ober wenigitens nicht nekgartig mit igren Spiķen

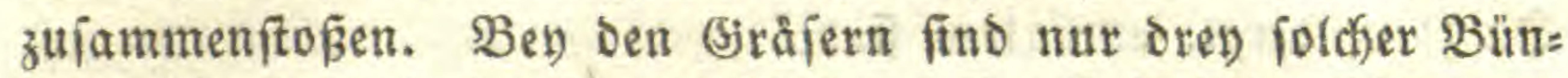
bef vorbanden; baber fommt die brenectige (jeftalt Des Gtengets.

Bey Den Dicotyledonen, welde mit zween ftumpfen Samens lappen feimen, wie Die Sobnen uno bas Raubfolz, ftelen fie in melyreren Bündeln bald Durd) viel Zellgewebe getrennt, balb ganz Dict)t an einanber, meift in mebreren Rreifen, uno veräfteln fid)

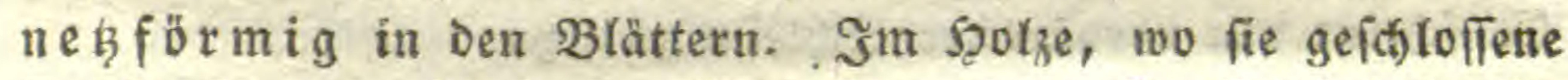
Rreife bilben, wiro das zwifhen oen viełen Droffelbändełn lies

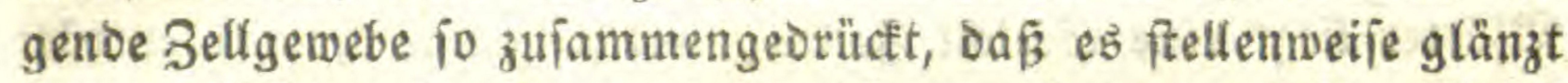

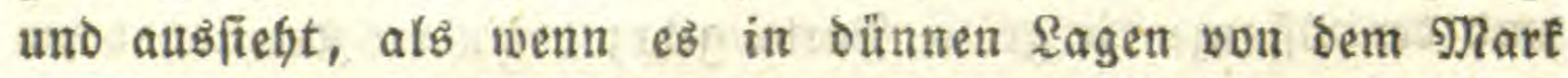
aub gegen bie Rinde liefe. Man nent fie Spiegelfafern.

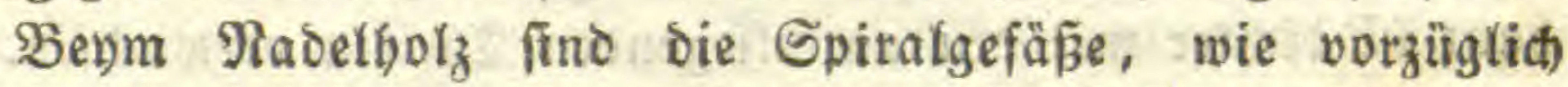
fiiefer gezeigt hat, zu jogenannten poröjen Beffen vertümmert, mit unbeutlicten $\mathfrak{B}^{3}$ indungen. Ueberhanpt fideinen bier bie Fas ferzeflen bas Uebergewidt)t zu baben.

\section{2uatomifle Softeme \\ (Systemata anatomica).}

Die anatomifichen Snfteme fino von einatior getrennte (jes webe, weldie ourch Die ganze PFlanze faufen.

Schreibet man einen Stamm voer Smeig quer burdh, io

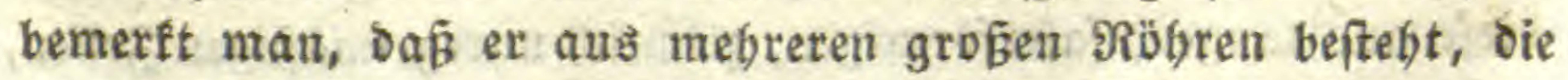
wie Sd)ad̆tefn in eimander fterten. Die änşere if̂t trocten, meiftens braun uno beist Rinde; dann folgt eitre ounne, faft= reid)e S(f)idt, Der bait; Darauf eine jebr bicte, faferige, Das

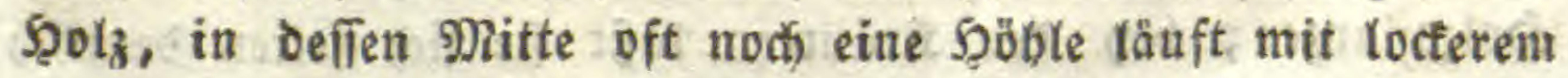


Zellgewebe ausgefillt, Dem 9arf. In ber Rinde haben Die כellen bas Uebergewid)t; im Bafte bie 2(bern oder Intercellulars Gảnge; in Şotze bie Droffeln ober Epiralgefäfae.

\section{a. Rinbe (Cortex).}

Die Rinde beftebt ดuв bren Theilen, bem innern bicteren, bem åuÉern doer ber Dberbaut (Epidermis), uno dem mitt= teren oder ber grit nen 5 a a t. 2(fle befteben btó aus Bellen mit Intercellular: (3ängen, ohne alle SpiralgefăBe, jeboch) nicht ferten mit Rücfen, worinn allerlen Stoffe, wie ätberifice Sele, F̧arze u. Dergl. entbalten fint.

Die Sberbaut befteht nur aus einer einzigen Rage von Bels

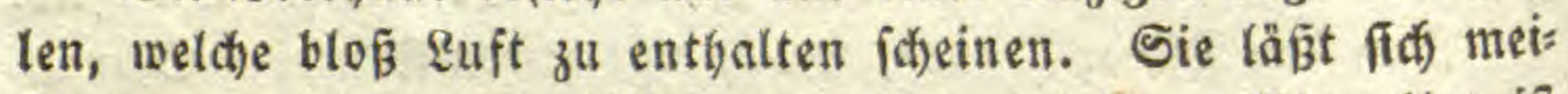
ftens nur bes jungen splanzen reidft abziefen. Sisweilen ift fie noch mit einem bünnen, einfachen Şăuttchen (Cuticula) übers zogen, welches fich ourd) Maceration ablöst, wie berm sobl. (E) (d)eint nur verbärteter Sd)leim zu jenn.

Unter Der Dberbaut des Stengets ber 3weige und bet

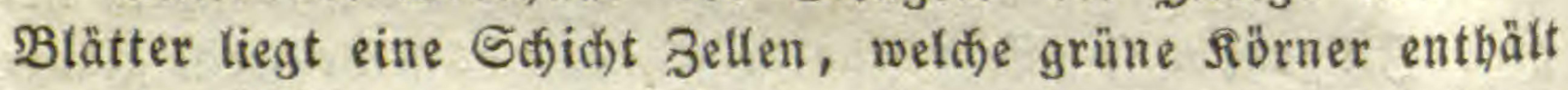
und Der Pflanze Die grime Farbe gibt; bejonoers oeutlich benm Şolunder. In ber 23 urzel fehlt bie grime Farbe, unb bie Dber baut ift bidter mit ben unterliegenden Iheilen verwadten.

Die Sberbaut ift an ben gritnen Sbeilen mit längliden Eöd)ern Durchbobrt, meldie Gpaltmindungen (Stomata) beisen, meifí megrere Dukeno, aber aud byunderte in einer Quabrattinie. Sie werden gebildet von zwo Belfen, welthe nidft Didft an einander ftoß̧en, uno fie füfren in bie Intercellular: Gänge, niđ)t in bie Spiralgeiäge. 2tn allen Theilen, welthe

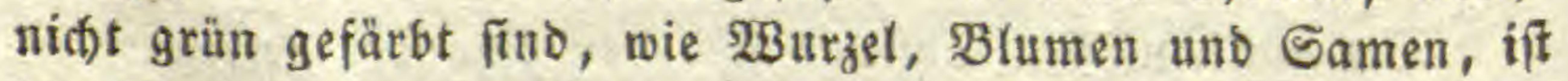
Die Dberbaut undurchlödert.

Die eigentliche Rinde befteht aus blätterigen $\mathfrak{a g e n}$ uno bieje aus langen, fajerförmigen, ziemlid) unregelmägigen Zellen, welche größstentfeil's vertrocfnet fino. Daber löst fie fid) meifteng leidt $a b$, bejonders im Frübjabr zur ßeit bes Safttriebs.

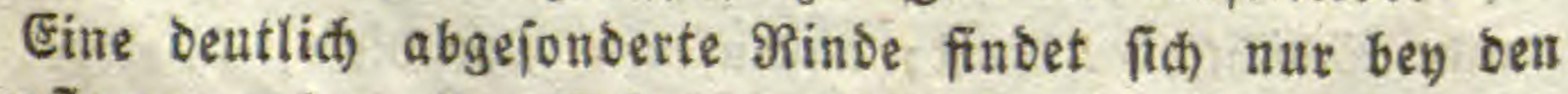
Şotzpflanzen; bey ben siräutern lägt fie fich) felten beutlich 
unterfheiben; bey ben Monocotylebotren gebt fie unmittelbar in סab oarunter liegende Bellgewebe über, bat jeboch eine beuts liche Sberbaut mit Epaltmünoungen. Bey ben Pflanzen ofne Epiralgefäze, wie bey Moofen, Flect)ten, rangen uno pilzen, gibt es weder eine unterict)eibbare Rinde nod) Dberbaut, indem fie ganz aus ziemlich gleichförmigem Sellgewebe beftehen.

\section{b. B aft (Liber).}

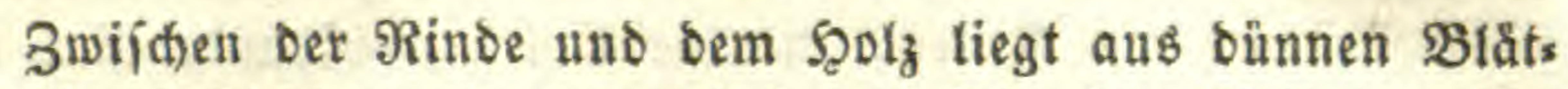
tern eine Sdjidft von langen und furzen faftreiden Bellen, welde

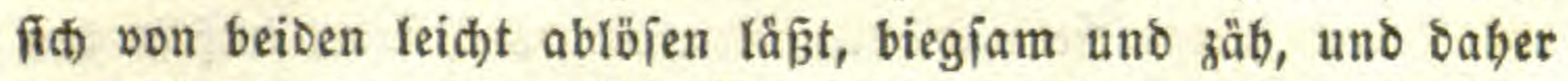
zum Binden braudbar ift. Sie beiß̧t $\mathfrak{B} a$ ft, uno entbălt teine Spiralgefäze. Die gewöbnliden Zellen liegen nah̆ $2(u$ ien, bie fajerförmigen nad) Inten. (Es fommen barinn aud) Rücten vor, weldie allerley Stoffe enthalten, wie (5) mmi uno Bjerbftoff, aber teine Ruft.

Bey Pflanzen mit einem ganz geidloffenen 5̧olzzing bilbet ciejer $\mathfrak{B a f t}$ ebenfalls einen geidhlofienen $\Re$ ing; bey Den Pflanzen

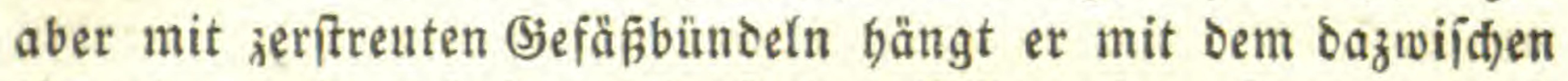
liegenden und nach innen laufenden Bellgemebe zufammen, und

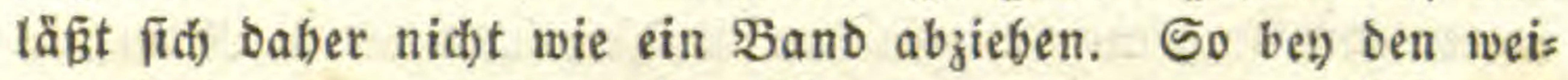
den Rräutern uno bey allen Monocotyleoonen oder Pflanzen mit graoftreifigen $\mathfrak{B l a ̆ t t e r n . ~}$

2(ed)ten Baft haben nur die Şol

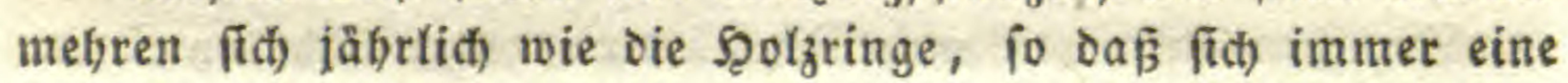
Lage nach) $2(u$ sen und eite nach) Эnnen bildet.

Die Pflanzen obne alle Epiralgefäze, wie die Pilze uno Mooje, befteben eigentlid) ganz ans Baft, weldfer mit der Rinde zujammen flię̧t.

3ur 3eit Des Saftriebes bemerft man unter dem Bafte einen bräunlidgen Saft, von Dem man glaubt, baß fich Daraus bas junge Fel $_{z}$ bildet. Man nennt ibn baber $\mathfrak{B}$ illoungs: iaft (Cambium). Er if jebr reid) an gerinnbarer Subs

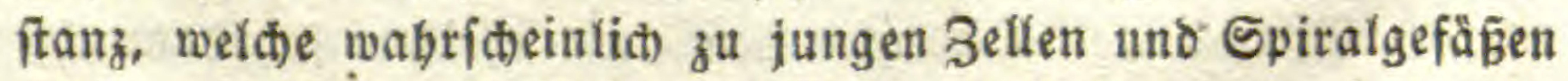

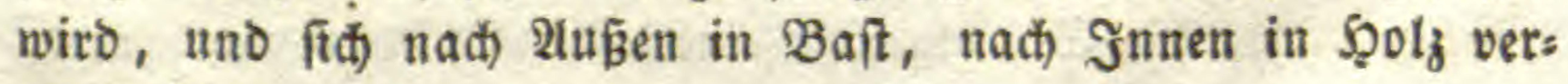
wattoelt. 


\section{c. 万ृ० ₹ (Lignum).}

Das Solz liegt nach Şmen uno befteht aus bartgewor: benen, langen, Dünnen tno an ígren Ënden mit einander ver= wadjienen Fajerzellen nebit Epiralgefäßen, alles burd) gewöbn= li(d)es Bellgewebe untermifat oder verbunden.

Die Epiralgefä̧e liegen bündelartig benjammen, uno find iuberail von geftrecten Bellen eingebüllt. Eigentlid) beffeht die ganze Pflanze aแร Zellen, uno die Spiralgefä̧̧вbindel fino unt gleid Sctintren ober Stäben Gineingefoboben.

Buerit treten fie nur alb ein einzigeb $\mathfrak{B u ̈ n o e l}$ auf in Den

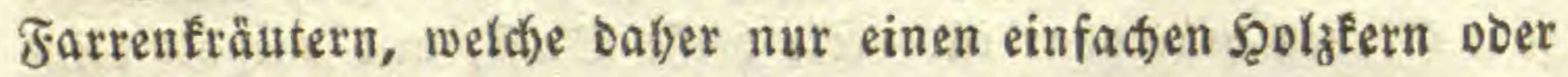
Enlinder baben.

Bey Den Monocotyledonen treten mehrere auf, wowon aber feines in ber Mitte fteht, jondern alle wie Säulen in einem oder mebreren Sreijen, io oafi Das Bellgewebe ilberall frey bas zuifichen Durchlaufen fant. Daber fino bieje Pflanzen gröfräten= theits weid), martig uno jaftreic), nno baben feine Epiegels fajern.

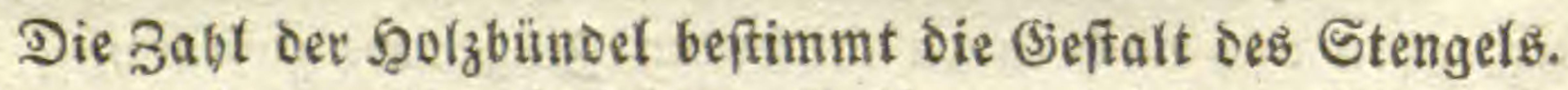
Treten nur orey auf, wie in ben Gräjern uno vielen Rilien, io fteben fie im Drebet, mo Der Stengel felbit wiro orenectig. Sommen fie in gröferer $3 \mathfrak{a b l}$ vor, wie beh Den Paradiesfeigen uno \$almen, Dann wiro der Stengel rund.

Bey Den STäntern und गeß̧blättern zeigen fict) bey einem vierectigen Stengel, wie bey den Rippenblumen, vier Şolzbündel; bey den fïnfectigen, wie ben ben Stürbjen, fünf. Şänfig ftehen

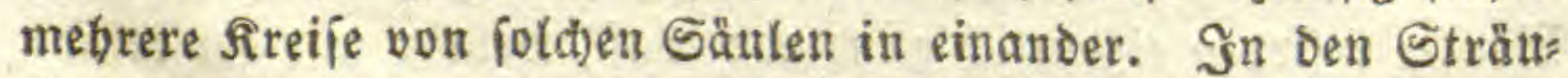

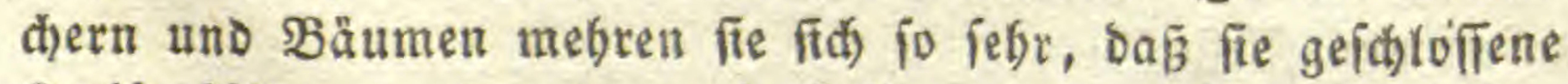
Freife bilden, uno nur wenig Sellgewebe zwiīhen fich laffen, die Epiegelfaiern. In Dieiem Falle nimmt Das Şolz bey weitem ben gröften Theil Des Stammes ein, uno ift leid)t won

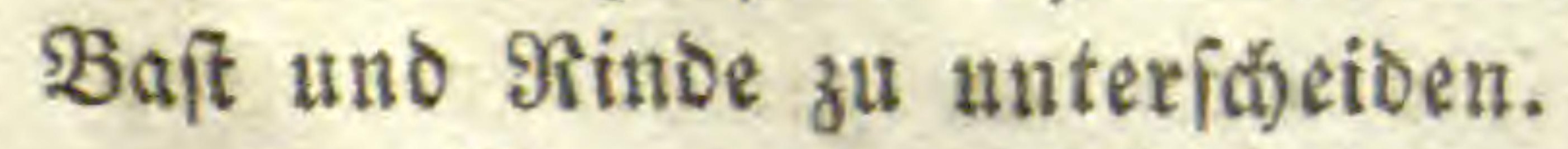

Die Miono = uno Dicotrlebonen unterid)eioen fid) baburd,

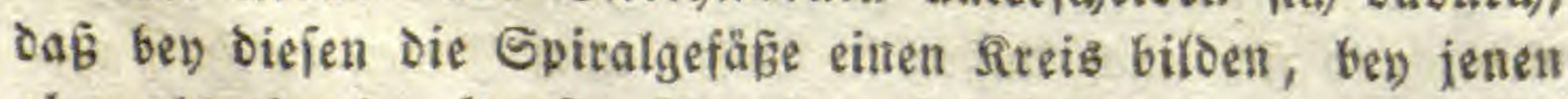
aber als einzelne Szaufen überall zerftreut fteben. 


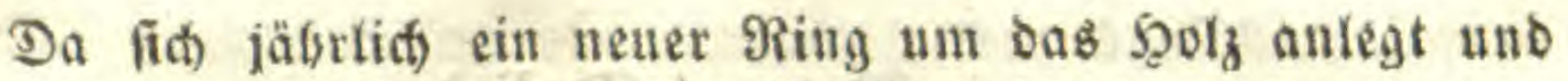
Der jüngere beller ift, fo unteridfeidet man ifn burd ben Pamen Splint (Alburnum), oer mitbin fein bejonderes allatoinifacs Syftem ift, uno Den Monocotyledonen feblt.

Die ફ̧olzlagen fino felten ringsum gleid) Dict. Man bat

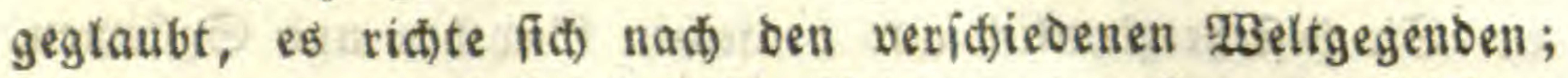
alleín es fommt fait ofne 3 meifel vou der Lage ber bictern

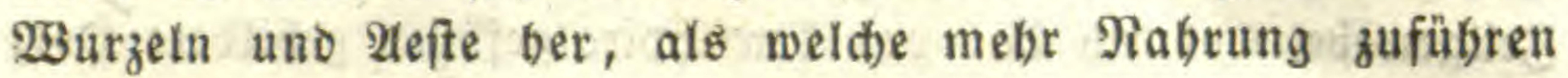
und megr anzieben.

Das Ma r $\mathfrak{k}$ (Medulla) ift nidfts alloeres alz bas in Det Mitte zurüctgebfiebene Bellgewebe, welches vertroctnet uno fich mit atmoiphärif(d)er \&uft füllt, weil ibm burd) bas veroid)tete Zellgewebe in ben Spiegelfajern fein Saft mefir zugefübrt wer: Den tann. שs bat baber nidsts mebr za bebenten, uno mú als ein abgeftorbener Ibeil betractet merben. Daber feblt $e \mathfrak{b}$ auth) bey vielen Pflanzen, entweder weil eร ganz verífyindet uno eine Şöble an feine Stelle tritt ober auth \$olz. 2tm be: fanteiten if es bey den Binien und dem Solumber, wo es fic) ourd) jeine weise Tarbe auszeid̆net. Die Siruatuter baben

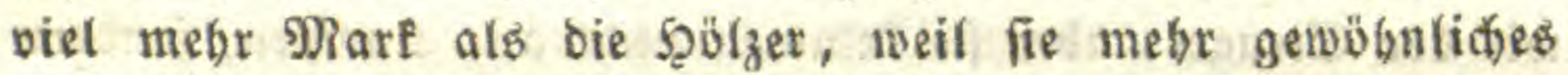
Zellgewebe uno oagegen meniger Faiern uno Spirafgefäвe gaben.

\section{Drgatie.}

Drgane fino zujammengefęte (jenvebe, weld)e abgejonderte Theile des ganzen Förvers aumachen. 2tud in then bat wieber irgend ein Sewebe oder ein anatomijates Snftem dav Uebergewidit itber bie andern.

Soldie Srgane bilden ben Storf nno den Straus poer die Blütbe.

\section{A. Pflanzenftoct (Stirps).}

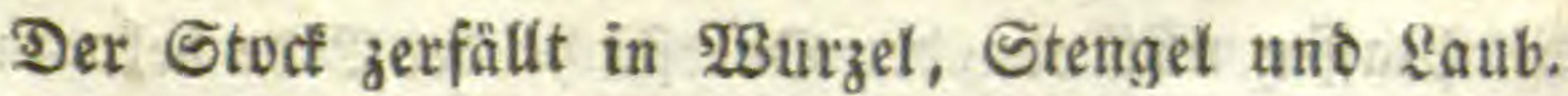

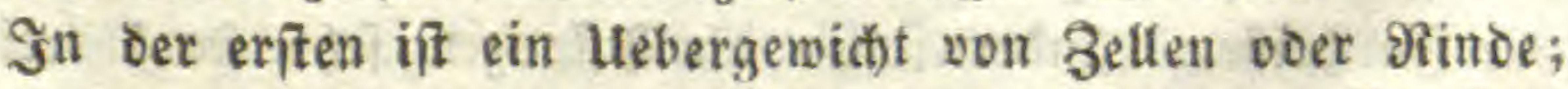
in zwenten von 2loern ooer $B$ aif; in oritten von Droffeln Doer 5 gelz. 


\section{- a. $\mathfrak{B} \Perp \mathrm{rzel}$ (Radix).}

Die 13 urzel if ber mitere Ifyeil an ber Pflanze, melher,

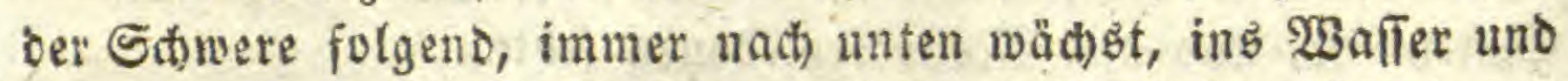
in bie Eroe, uno die Rahrung mit Dem (jetränt einjaugt.

Sie befteft ziemlid aus benfelben Sieweben unb Syitemen, wie oer Etengel, tat aber ein fuftreideres uno mebr locteres Zellgewebe, wodurch bas von Den Epiralgefäвen gebildete Şolz

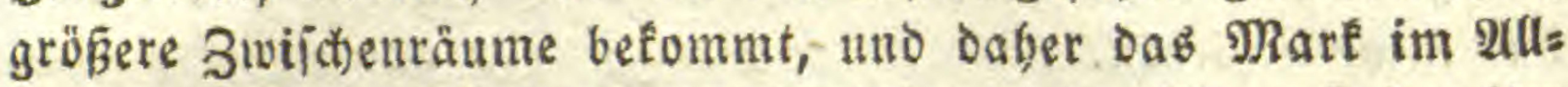

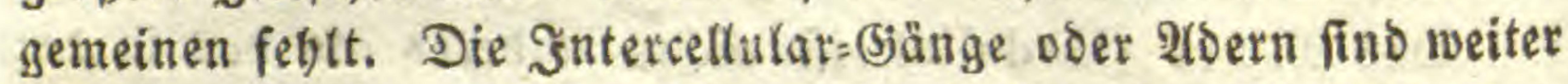

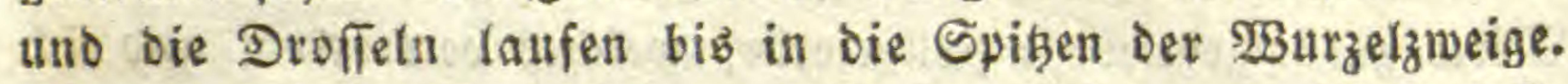

Die Rinde if weniger vom $\mathfrak{B}$ afte geithieben, weil bie fafts reide Maffe überbaupt gleicbförmiger ift.

Der Sberfaut feblen die Spaltmitnoungen, und es fineen fid) auti) teine grimen (it)i(t)t.

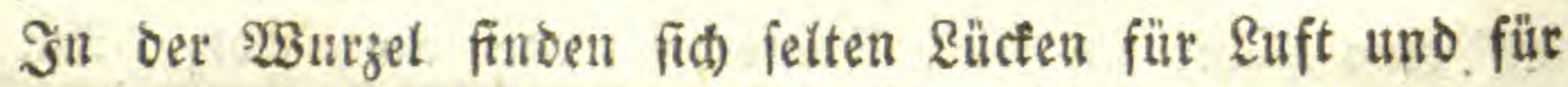

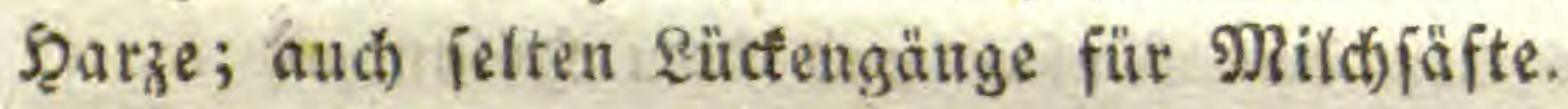

Die $\$ 3$ urzel theilt fich gewöbnlid in 2lefte und 3weige, wie ber Stengel; aber fie fommen nidit ats snojpen, fonbern

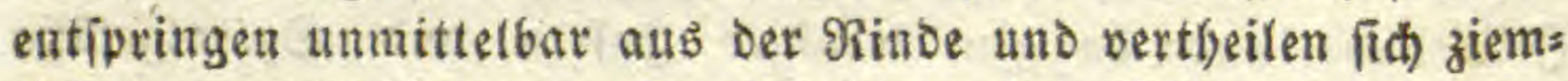

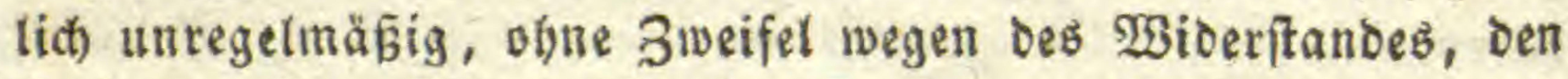
fie in ber Eroe finden. 21n ben 3 weigen entifteben wieder viele

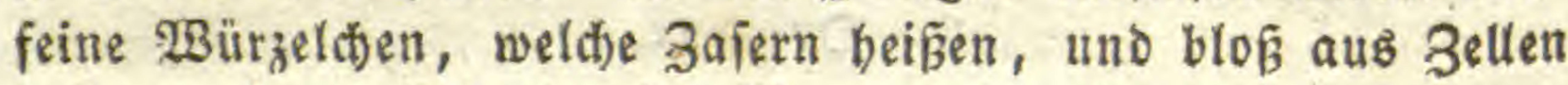
beffeben, beren Enbe in eine $\mathfrak{B a r z e}$ anjhmillt, weldie einfaugt. Die glatte Dberfähe ber 23 urzel fideint wenig oder gar nidbt einzufaugen.

Sn ber Reget wird die erite oder mittlere $\mathfrak{B}$ urzel am Dicfitelt, unb fteigt gerao binunter - Pfabl wurzel. Die

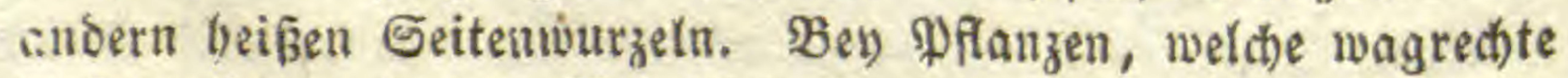
2lefte baben, wie bas शabelfolz, breiten fidh and bie 23 urzeln

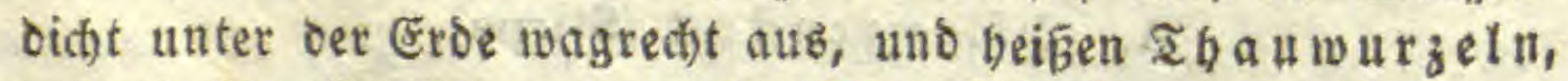
weil fie ibr $\mathfrak{Z a} a f$ er nur von ber Dberfädje ber Erbe befommen. In beipen Eänbern, no bie Pflanzen fehr ftarêt treiben, wathien aud bisweilen bünne 25 แrzeln aแb Dem Stamm, uno fenfen fid) in bie Erbe. Sie beisen suftwurzeln. 
Die meifen Sơmarogerpflanzen treiben åbnlidje Ruftwur: zeln aus oem Stengel, weldi)e aber jefr, furz bleiben, uno fint) mit ibren warzenförmigen Enden an bie Rinbe anderer Pflans zen beften. Die meiften verlieren jobann ibre ächten Wauzzeln, wie bie Flachsfeide; mandhe bebalten fie feodh, wie oas Ephen. (E) baben eigentlich) alle Pflanzen $\mathfrak{B}_{3}$ trzeln, wenn man etwa

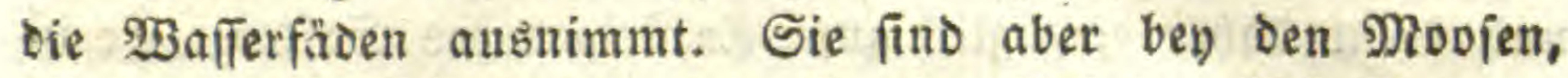
Flechten uno Pilzen nur haarförmige 3ajern. Indefien ent: fiteben aud) bie Eleinen $\mathfrak{3 a f f e r p f l a n z e n ~ n i d ) t ~ i n ~ b e r ~ M i t t e ~ b e s ~}$ \$3affers jelbit, jondern auf bem Boben.

a. Nan fann bie 13 urzeln nach ben (5eweben eintbeilen in Sellenwurzeln, wie bey Den \$ilzen; in 2 doerw urzeln, wie bey ben Moofen, und in Droffelwaraeln, wie bey ben böberen Pflanzen.

b. Rad) Den Syftemen in Rinbenwa rzeln, wie bie $3 a=$ fern; in $\mathfrak{B} \mathfrak{a}$ ftwarzel $\mathfrak{n}$, wie bie fnollen uno Rüben, uno in

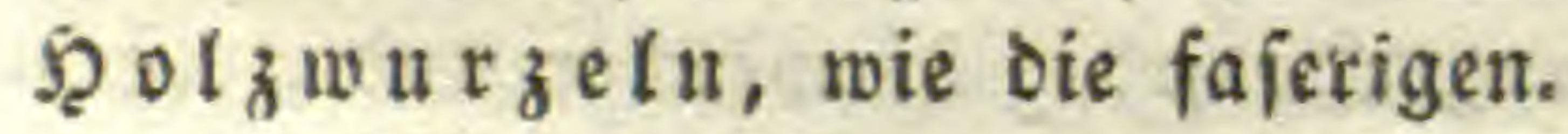

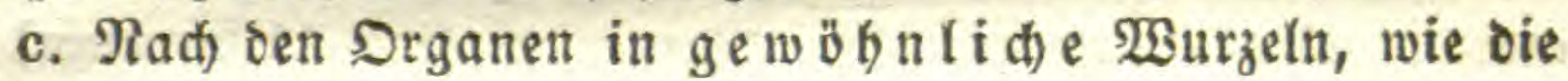
Seitemutrzeln; in Stengelwurzeln, wie die Pfahlwurzeln, uno in $\mathfrak{Q} a$ ub w $r$ zel $n$, wie die 2 ufwurzeln.

\section{b. Stengel (Caulis).}

Der Stengel ift Der unmittelbar auf ber 23 urzel fenfredt nac) oben ip bie \&uft uno bas \&idjt wadjiende Iheil ber Pflanze, weldyer ben शatbrungsjaft fortfübrt uno in andere Säfte ver: wandelt.

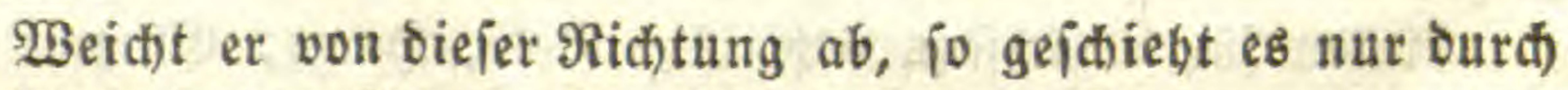
Den Einflus des Ridtts oder feiner eigenen Sd)were, wenn er zu weich) ober zu Dīnn ift, um fich) gerab zu balten.

Er bejtegt aus allen Beweben, mit bem Uebergewidgte ber

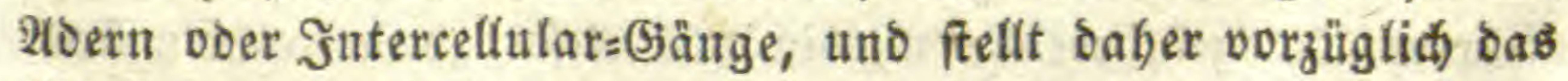
2loerinitem ber Pflanze Dar.

Er zerfällt ben ben vollfommenen शftanzen deutlid in bie

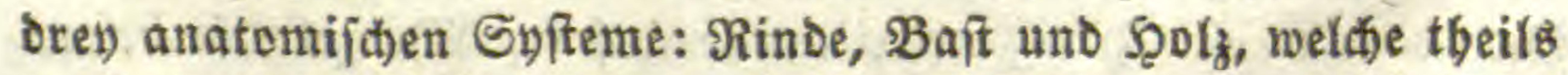

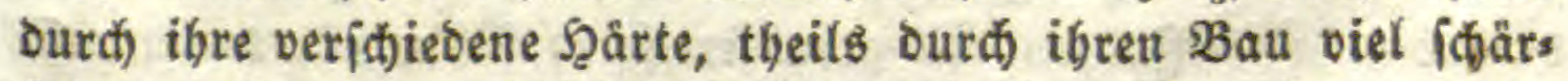

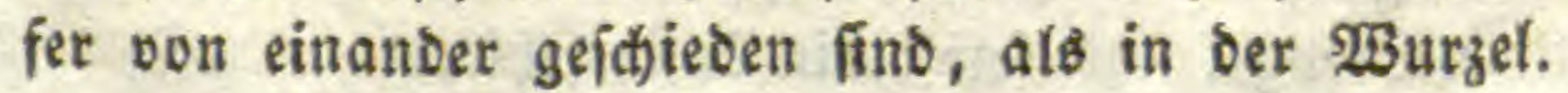


Die Rinde ift mit einer abtosbaren Sberbaut bedectt, uno ben) jüngeren Pflanzen wenigitens grün.

Die Sberbaut bat Spaltminoungen, uno barunter liegt eine Sellenídidft mit grünen Sörnern, weldhe iedod) an alten Rinden vertrocfnet uno ftă) verfärbt.

Der Baft ift viel weidher uno zäber alb die andern Ibeile, und bient baber vorzügliç zum Aufíteigen bes Saftes. Er ift Das Şallptorgan im Stengel.

Die meiften Stengel fund rund; eb gibt jeodch aud) fünfs ectige, vierectige, ores)= uno zwenectige ober zwevifineioige.

Bey Den Pflanzen mit Rekzblättern beîteht Dab Şolz alls

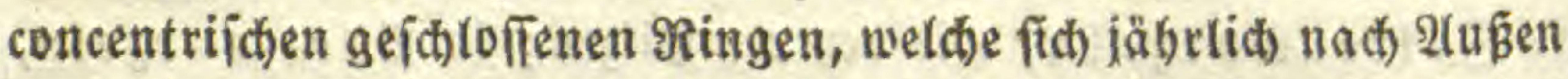
vermebren. Der neue Folzring entiftebt baher innerbalb bes Bajtes, in bem fiø), wie man glaubt, aus den Ritgelden bes Biloungsfaftes (Cambium), welder shne 3weifel in Den Inter= cellular = ङången des Baftę bereitet wird, lange Zellen uno Epiralgefäfe biloen. Der junge Şolgring ift weidber uno weiser als bie alten, und bat ben Ramen Splint (Alburnum) bes tommen.

Da bey ben Mionocotyledonen die Droffelbünol nidt io gebrängt fteben, fo ziebt fíd) Der $\mathfrak{B a f t}$ mebr zwifhen ifhnen bin=

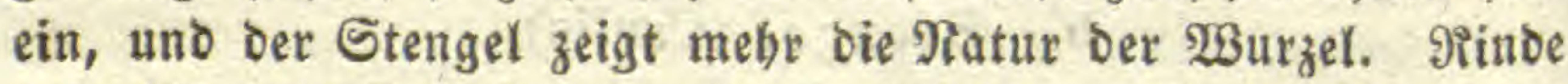
nebmlid uno SBaft fino weniger geiddieden; aber die Sberbaut verbålt fịc) wie bey ben antern.

Der Etengel ber broffellofen Pflanzen, wie ber Mopie uno Pilze, beftebt eigentlici) ganz aus $\mathfrak{B a f t}$.

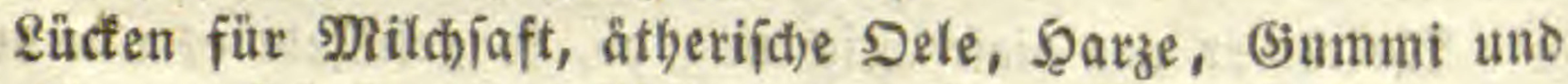
Suft fönnen fich) in allen Theilen des Stengels finden.

Das Maré if̂t zufällig uno feghlt Daber febr băufig.

2(uB mandjen 23 urzeln fommen mandfmal zu gleidter Beit mebrere Stengel, welche mithin ats 2leite zu betraditen fitno, benen ber Stengel feblt.

Ein Stengel, ber fich nicht theilt, beifst Edaft. Er ift im Grunde nur ein 3 weig unmittelbar auf Der 23 urzer: fo befons ders bey den Pflanzen mit getadftreifigen $\mathfrak{B}$ lättern, derten aljo Det eigentlithe Stengel unt felbit bie 2lefte feblen. 


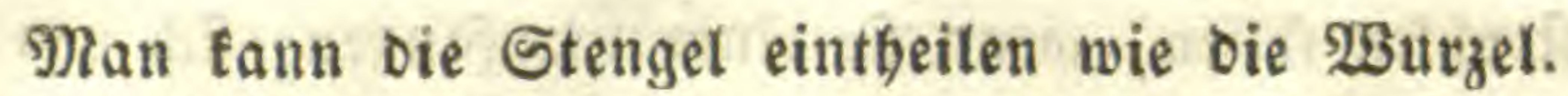

a, Ëg gibt Bellenftengel, wie ber Strunt (Stipes) ben Den Pilzen; 2 beriftengel (Surculus), wie bey den Moofen uno Iangen; Droifelitengel, wie ber $\mathfrak{B e d e l}$ (Frons) ber Farrenträuter.

b. Ës gibt ferner Rindenitengel, wie Der f̧alm (Culmus) bev ben Sräjern; $\mathfrak{B}$ aftiftengel, wie ber Sđaft (Scapus) bey Den lilienartigen (Gewächien; Şol zaftenger, wie bey Den Palmen.

c. Ferner $\mathfrak{B}$ urzelftengel; wie die 3 wiebeln und $\mathfrak{B u r}$ zelfitocte (Rhizoma) bey oen Zwiebelgewäđjen, Farren u. a.; volffommene Stengel, wie ber Stamm (Truncus) ber Bäume, uno Raubftengel, wie etwa die oer Rräuter.

Pflanzen, welthe jäbrlid) oder nach) Dem Blithen abfterben, heisen $\mathfrak{R} \mathbf{r} a$ uter (Herba); Deren $\mathscr{B}$ urzel allein aubdauert, Stauben (Suffrutex); weldie mebrere Şolzftenger auf oer Wुurzel baben, Sträucher (Frutex).

Dieje Stenget werden manchfaltig gebrautht; viele in ber Medicin tno Färbereb, andere als Futter und Strob, andere

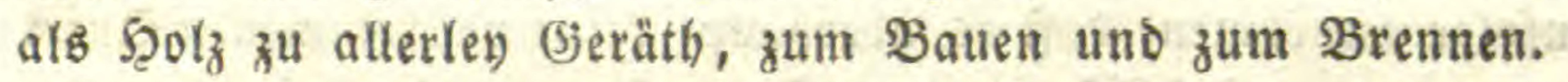

\section{Aeite (Rami).}

Die meiften Stengel theilen fith in 2lefte.

હૈs lătift ein Şof bildet Dajelbit eine אnoipe, wetche anfbrid)t uno das Bündet

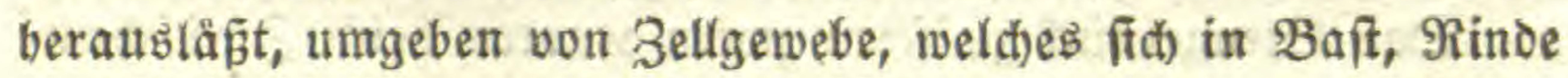
uno Şolz fitheibet, ganz wie am Stenget.

Die Rnoipe befteht aus Blattblajen, welde an ber Spize aufipringen uno ben 3 weig heraus lafien. Die ăunere Blaje umfafit immer ben Stengel wie eine Sdeibe, Dentlich am (Sirabs: blatt. Daker fteht jeber 3 weig in bem $23 i n f e f$ eines $B$ latteb̆, und wird am Grunde bavon bedecft. Es heist St üblat t.

Wenn fid) an irgend einer Seite eine Sinvipe entwictelt, io geben aud gemöhnlich ringsum andere 5̧olzbilnoet $a b$, uno oie 2efte itellen fid) quirlförmig um ben Stenget. Es ît nebmlich fein Grund vorbanben, warum nibf nach allen Seiten Sgolzbün= 
Del ausftrablen follen, wenn fie einmal anfangen, fich von ber Mitte bes Gtengels zu entfernen. Die Uriache bavon ift obne 3weifet das Ridyt uno die \&uft, weldhe bie Theile zum 2 adjfen uno zur Irennung von einander anregen. Die Zahl ber 2lefte Gängt obne zweifel von ber Menge Der Şolzbündel $a b$, und ebenfo die W̉ieberbolung ber Quirl. Zwenjidneidige Stengel treiben genæobnlid) zween 2(efte gegenüber, oreyectige 3, vierectige 4, fünfectige 5, runde in größerer 2 (nzabl.

(Es tönnen jeod d) Die Quirl=2Aefte nie vollfemmen neben einander oder auf gleider Şöbe ftehen, weil ein jeber in einer beionbern Stengelíbeibe fieft, und alle Stengelífeiden in ein: ander, fo baß̃ fie aud) nur nach) einander plaken und bie 2tefte beraublafien fönnen.

Bon biefer 2tnorbnung weidjen baber bie 2efte bäuftg ab. sommt einer etwas fpäter als ber andere bervor, fo verwandelt fid) Der Duirl in eine Epiralftellung; uno biefe ift ziemliö bie bäufigfte unter den Pflanzen mit Reķblättern. Nach) uno nach treten fie noch) unregelmäfiger bervor und fteben zeritrent, wie bey) unfern $\mathfrak{B a l d}_{\text {a }}$ und Dbftbåumen. Man fann Dem obigen z̆lfolge annet)men, Daßs es überhaupt feine vollémmenen Quirl gebe, und baß jelbit bey den Sternpflanzen die Ref́te nur ein: geidobene Epiralen ienen.

Da wo fth eine Blatticheide öffnet, oder wo 2leite entiprins gen, verbicft fitib ber Stengel in einen $\Omega \cap$ ot en (Nodus). Es

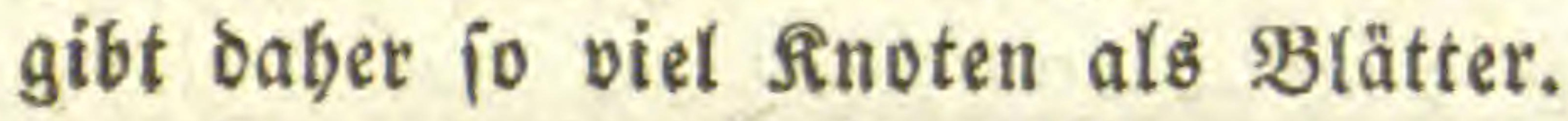

Das Stengelfitud zwifhen zween Snoten beißst 3 wifden: ft î of (Internodium), weldees bemma de felgr lang uno jehr furz fenn tann.

Sollten im Quirl nur zween 2lefte gegenibberiteben, io wers

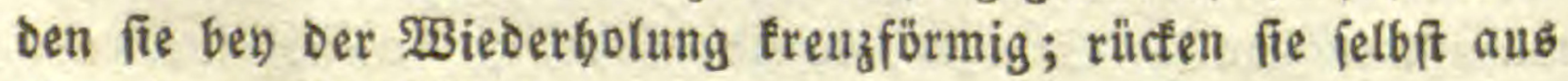
einander, abwedjelno.

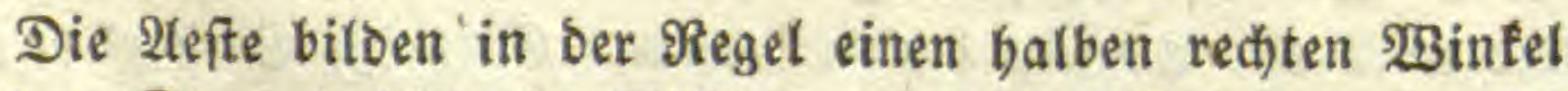

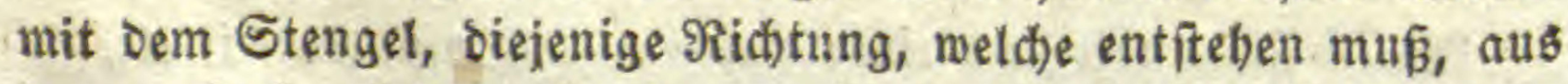
bem uriprïugliaben Streben nach oben uno bem Fallen nad) unten burd) bie eigene S(f)were. Bey ben Pappeln mad)en fie

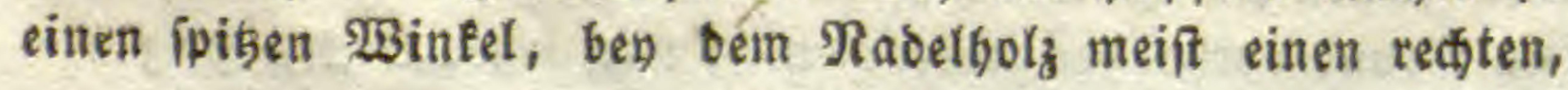


bey Der Şäng=2Aeíhe einen ftumpfen. Bey Trauerweioen uno Birfen bängen fie ïber.

(jewöhntid befommen bie 2lefte wieder 2lejte, welde man 3łweige nennt, uno bie Theilung Der leķteren 3weiglein. Die fungen 2lefte ober 3 weige beisen Sprofien (Turiones).

Man fann bie 3 weige auch eintbeilen in:

a. (5) ip fel z we ige, die jâhrlidłe Berlängerung des Stengels,

b. Stengelzweige, bie Seitenzweige, uno

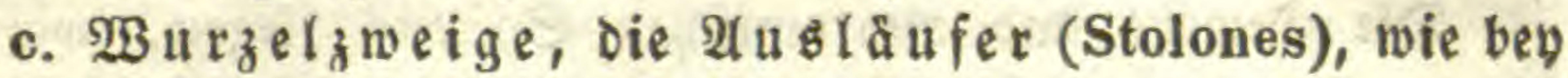
Den Erobeeren und vielen anderen PFlanzen.

\section{Sin of pe (Gemma)}

ift ber burd bie Rinde gebrod)ene, aber nod in feinten

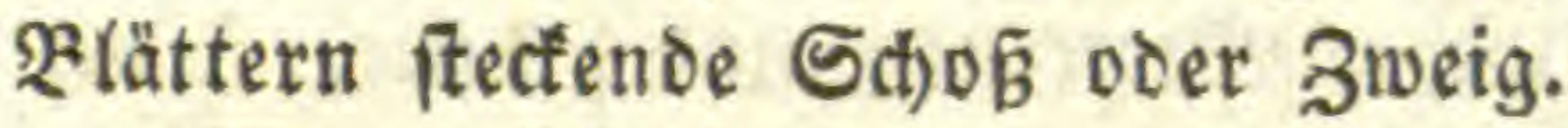

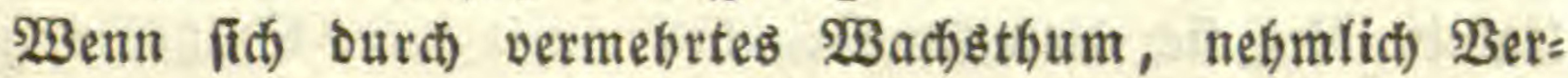
mebrung ber (jewebe, uno ourd Den $\Re i_{z}$ von Ridit uno Iuft Die Şolźbitndel von einander trennen und fid) einzeln verlän= gern; fo Durdfbrect)en fie an irgens einer Stelle, entweder feits wät's ober oben am Stengel, die Rinde uno bleiben bajelbit, da biejes gewöbnlich erît im Spätjabr eintritt, ftecten, obne fitch wåbreno des Şinters weiter zt entwicteln. Die Entwidf:

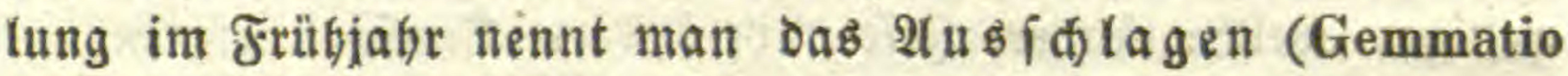
s, Vernatio).

Jedes joldees Droffelbintel beftebt jelbft wieder aus allen Sierveben, und ift mithin in Stande, wieder eine ganze Pflanze

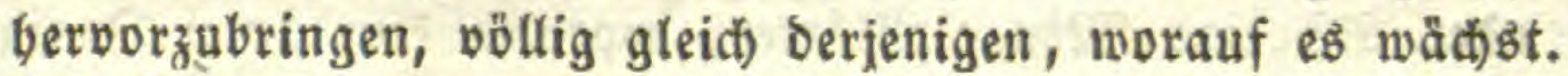

Sd)neibet man einen foldsen 3 weig ab und fectt $i$ bn zu gegöriger Beit in ben Boben, jo treibt er $\mathfrak{W u r z e t n}$, neue Zweige uno Bläthen. 2luf bieje 2 trt fann jede Pflanze, welde aus= bauternoe Sweige hat, ing Unendidie vermebrt werben, uno man fann in biejer Şinfid)t [agen, baß́ ein äftiger Stenget aus einer Menge \$flanzen zufammengejeß̧t jey, ganz auf biejelbe Weife, wie ein \$olypenftamm atb vielen Ibieren befteht.

जn ber Regel löjen fich) die einzelnen Polnpen von bem muitterlicien \$olypen $a b$, fobalo fie felbft freffen fönnen; bey

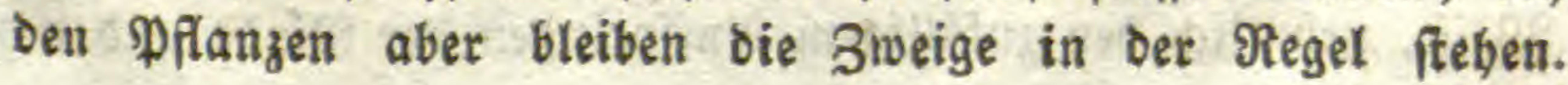


Sinbefien gibt es ood) aud), welde $\mathfrak{W u r z e l n}$ treiben und fid eno: lid) vom Stengel abịondern, wie bie 2ubläufer.

Die 3weige fino nicht bloß Serlängerungen ber Stengel: gemebe, fondern fie befommen aud neue Drofieln uno Bellen,

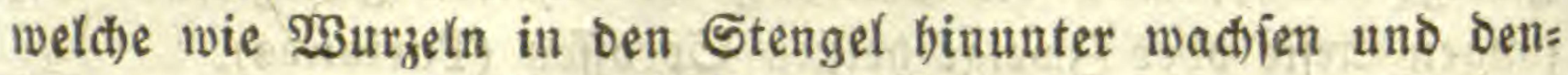
jelben auf eine gewiffe Strecte verbicten. Sie find bem Stengel gewiffermasen eingeimuft, wie ein Pfropfreis, uno wadfen baber in inm, wie er felbit in ber Erbe.

Die Gewebe und anatomifiden Syfteme liegen, wie am ganzen Stengel, ebenfalls blajen = ober ídeibenfürmig ttm eins anber, uno zerfallen in Blätter, welche ben fitnftigen S(t)ó wäh= reno des Winters bict)t ungeben uno Denjelben gegen ben Ein=

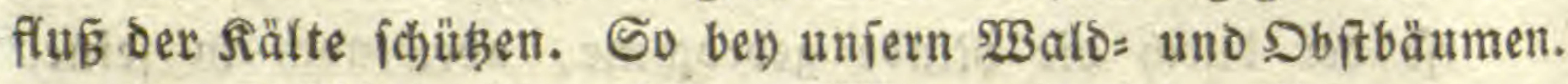

Im Frïhjabr bey miloerer $23 i t t e r u n g$ uno gröberer Fpuct= tigeeit röfen ftch diefe snoipenblätter mit ibren Spizen von ein=

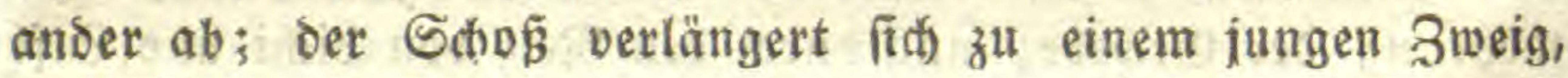

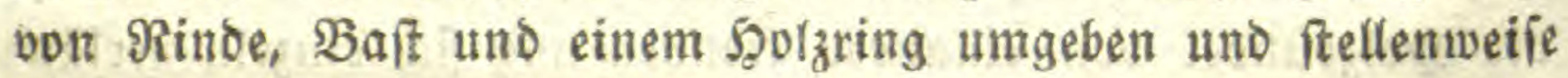
mit den 3 lättern bedect, weld)e er aub Der Rnoipe mitgenom:

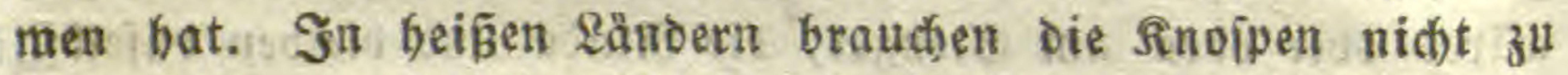
äberwintern, und oaber fallagen fe fogleid aus, fodalo fie ent: ftanden find. Ës gibt baber Daielbft feine Bäume, voer äuẼerft wenige, weldhe längere Beit unveränoerte Rnoipen zeigten.

Dbiction fich indeffen in jeber Blattad)iel eine Rnofpe bitbet, io fommt bod) nidft jebe zu ihrer Entwictelung, fondern ver: Eummert uno fitbt ab. Daker freht man fait an jedem Sten= gel oder 2lît eine - Menge Slåtter, woraus kein neter 3 weig fommt. Das fino aljo leere Blätter.

In ber Regel fteht in einem $\mathfrak{B l a t t}$ auch nur eine 3 weig= tnofpe; bismeilen jebod) nod ein und die andere neben ber Sauptfnoipe, wie bey Solunder, Şartriegel, ben 21pricoien.

Soin und wieber fommen aud Sweige obue Stitbblatt yor, welche mithin in teiner 2l(d)iel ftehen, Soldte bementt man an ben Steffen, wo ber Baum verwundet und gleidjiam ourd) Sumft

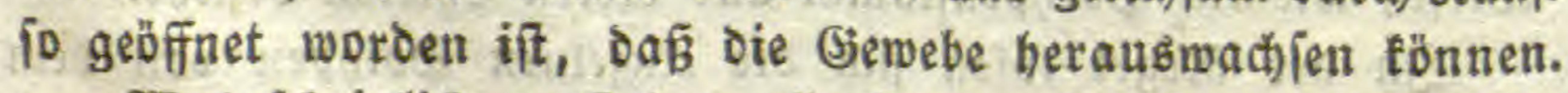

I3abridseinlid entifehen alle Bweige ber 2 rt auf oiefelbe

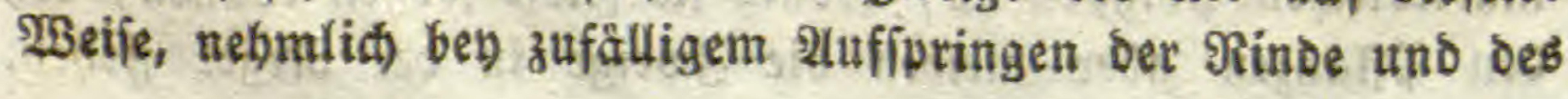


Bậtes ; wenigitens zeigen fie fid) am bäufigiten ben alten fnor= rigen Säumen.

Die untern fnofpen treiben gewöbnlid bló Sweige, uno baber nent man fie Şorzfnoipen; bie obern treiben Sthlitthen, uno baber nennt man fie Frudténofpen. Diejenigen, worinn zufältig ber Zweig verfümmert uno nur bie Slåtter fteben blei= ben, hei

Dem Stande nad) muß man bie Fnoipen aud eintheilen

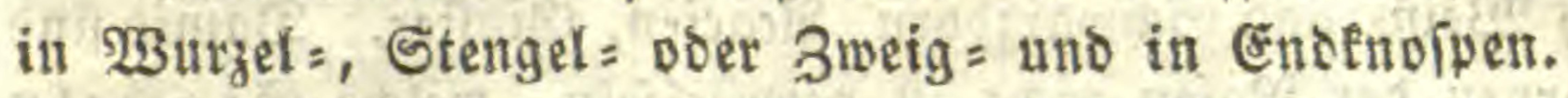

a. 3แ Den 23 ur zelf no pipen gebỏren die 3 wiebeln (Bulbus). Ben ibnen ift ber Stengel verfiummert, uno bilbet nut eine Scheibe, auf Deren untern Jlåd)e bie Würzelden entifteben, auf Deren obern aber bie Sdalen, weldes verfimmmerte Sheiben= blätter fino. In manchen biejer $\mathfrak{B l a ̈ t t e r}$ oder Sdileiden bildoen fich Snoipen ober iunge Zwiebeln, die fogenannten Zeben beym Snoblauch a. bergl. 2lus jeber joldhen Snofipe ober Swiebel ichießst ein Stengel auf, weldher meiftens mit größ̈ern Sheidene blättern umgeben ift uno in Blittben endigt. Dergleid)en Zwies betn finten fid) auter ben gemeinen (Allium) aud ben Silien.

Bey mandben Zwiebeln fino die Blätter io bidnt mit ein=

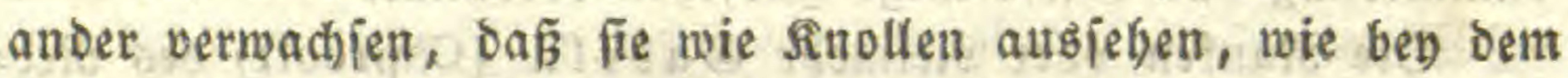
Safran und Schwerdel. 2febnliche Swiebelchen find die söruer an ber Wurzel eines Steinbrect) (Saxifraga granulata).

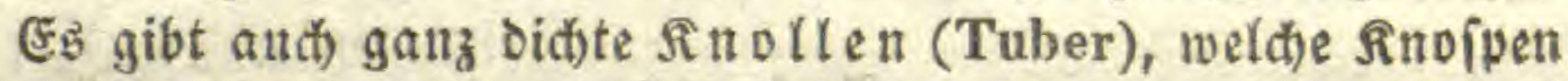
treiben, wie bie Erøäpfel uno Eroeidfeln (Spiraea filipendula). (EB fitio eigentlic) vergeilte no veroicte Stengel unter ber

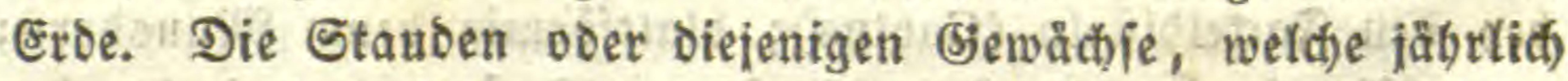
Den Stenget verlieren aber bie $\mathfrak{B u r z e l}$ behalten, treiben néte Rnoipen unter ber Erde, wie die Steorginen, Selferie u. Dergl.

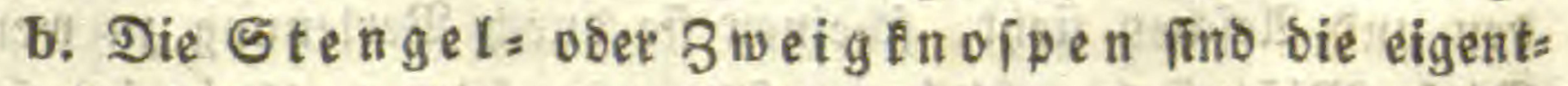
lichen finopen, woraus, wie gefagt, ein neuer 3 weig, ober Blits then, oder nur Blätter fommen. Es gibt aber oajelbit in ben

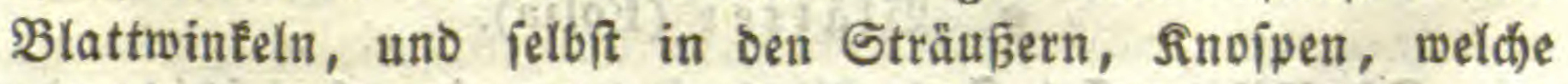
verbictt und fleifinig find, nie 3 wiebeln. Sie fallen $a b$ und entwicteln fid) in bet Erbe. Man nennt fie 3wiebeldsen (Bulbilli). So bey gewifien Silien, \&auden uno bem Sabntraut. 


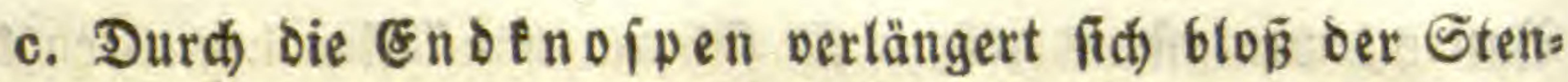
gel oder $\mathfrak{a}$ (fí, und vermegrt fid) im (Sirunbe nicht; am beutlichs ften beym Radelfolz.

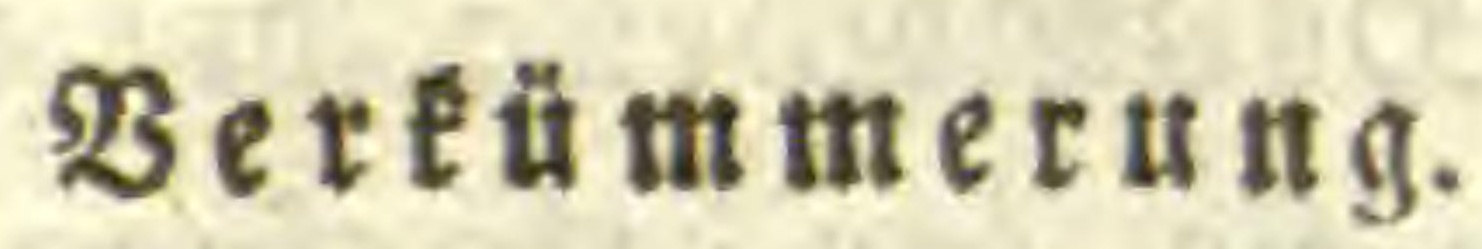

Die 3meige verfummern auf mandbe 2 rt und befomment unfenntliche (sieftalten.

Die gewöbnlide ift die Berfurzung zum D orn (Spina), wie bey $\mathfrak{B}_{\text {ei }}=$ und Schwarzoorn, 2lcacien, Sinfiter. Daunit fino die Dornen Der Rojen nidht zu verwedfeln, welche St a di)eln

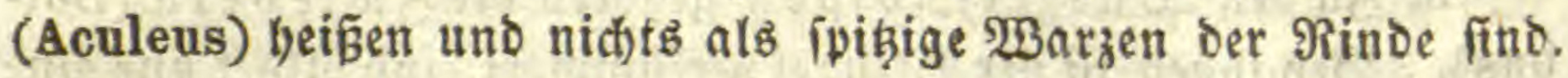

Seem mungen.

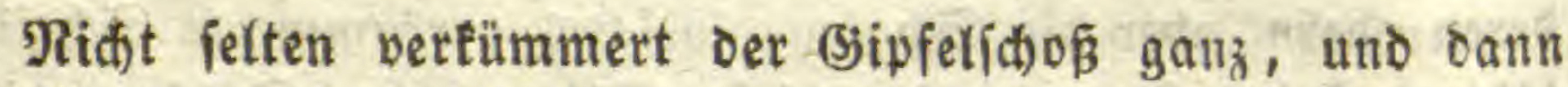
wachien die Seitenäfte allein aus, Dấ ber Stenget gabelig er= (đ)eint, wie bey ber Miftel und Dem Flieber. Doer Der (Jipfel wird zum Strauf, und Dann fann ein Seitenzweig fid fo ver:

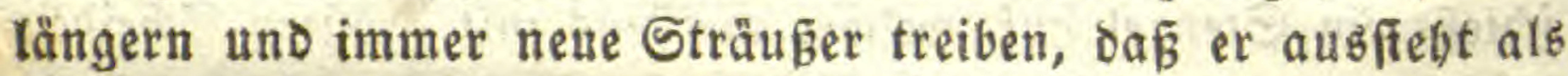
wenn er die Fortieşung bes Stengelв felbit twåre, wie benm Rebitocf, Der von diejer fonderbaren, fict) wiederbolenden $\mathfrak{B e t}$ fümmerung Das fnieförmige 2usfehen betommt.

Die Ranfen Doer vielmebr (5jabeln (Capreoli) Des Reb: frocts uno ber fitrbien fino auth nid)ts anderes als verfü: merte Gipfel.

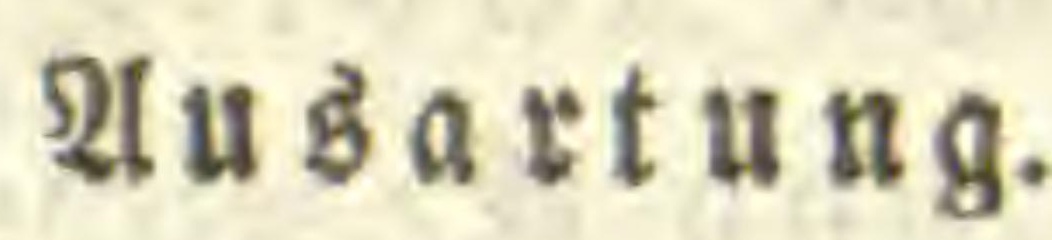

Die 2 leite werben flumpig, gefurdt, breit und ideibenförmig bey ben Factelbijteln (Cactus); blattförmig beym Mausoorn;

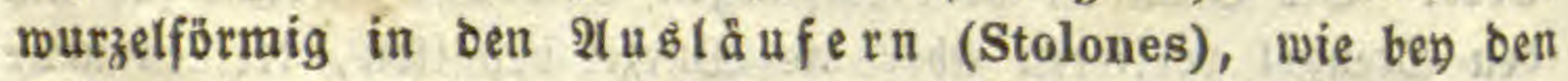
Erobeeren. Breit ober georüdt, wie man fie bisweilen bey Wrei= den und 2lejwen fieht, (A)einen fie ourc) Berlebung zu werben. Diefe gígeftalt erbt beym Şabnen fam m (Celosia) fort.

\section{c. Blăt ter (Folia).}

Die Blätter find fladje Fusbreitungen einer Solzididit oder von Droffelbündeln, weldie Durd) Bellgewebe nur feitwärţ ver: bunden bleiben. 
Das Btatt hat oben und unten eine Dberbaut, mit vieten Spaltmünoungen. 3wijđen beiben liegt locteres Zellgewebe,

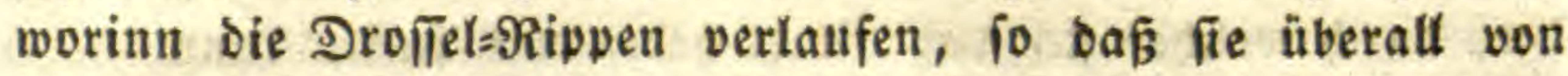
ber Dberhaut bebect finb. Die obere ober der uripringliden Sage nach innere fläd)e ifî meiften glatt, Die untere oder åıßere bagegen băufig mit $\mathfrak{B a r z e n ~ v o e r ~ S ̧ a a r e n ~ b e b e d t , ~ b e : ~}$ fonder's längs ber Rippen. Sie beiteben bloǵ aus Zellgewebe obne Spiralgefäßze.

Die Slätter entítelyen aus Snoipen an ber Seite unb am Ende bes Stengelz oder ber 2lefte. Die Blatténoipe ift eigent: lich eine ïber bas Ende bes hervoriproflenden 3 weiges geipannte Blaje, welde auf veridiedene 2(trt zerreiß̧t und ben Zweig hers

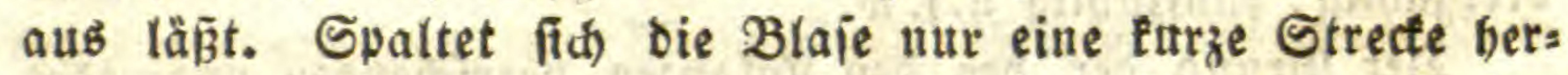
unter, fo befält sas Blatt die Beifalt einer $\Re$ öbre, weldhe ben Stengel umgibt, uno beíst Scheidenblatt, wie ben ben (Stå̆fern.

Die Sdheibenblätter baben, mit feltenen 2lusnabmen, ge= rade uno unverzweigte Rippen, fino baber meitens lang uno ganz, bišweilen zeríg)lifien, aber nid)t in förmlictse sappen zertheilt.

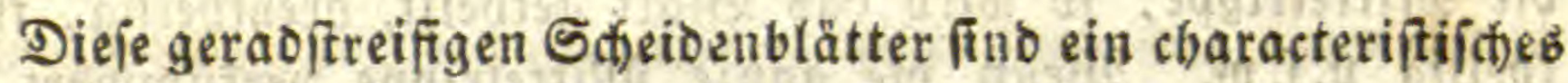
Drgan ber Monocotylebonen oder ber Pflanzen mit einem Samenlappen. Man fann fie baber Sheiden= poer Strei= fenpflanzen nenuen.

Spaltet fith bie sinoipenblaie aber von oben nash unten biz auf den Grunb, io geht bie Sheibe verloren. Solde Blät= ter gleiden 2lbijhnitten einer boblen Rugel ober Blais, uno baben bie Geftalt einer Ellipie, jeDod mit jebr períciedenen Durd)meffern, woburch fie einerjeits lanzetförmig, uno endid ganz fidmal ober linien= uno nabelförmig werben, anberieits breit, runolid, Getzförmig u. bergl.

In biejer 21 rt von Blättern Laufen die Droffelbündel aus einander, verziveigen und verbinden fï) wieder, wodurd neķ= förmige Rippen entftehen. Diefe Ręblätter finb ein characs teriftíftes Drgan der Dicotyleoonen oder der Pflanzen mit zween Samentappen. Sie fino bas eigentlitie $\mathbb{a} a \mathrm{ub}$.

Diens alfg. Raturg. II. Botanit. I. 
Sie fino gemöhntich geftielt, uno ber Stiel (Petiolus) bat am Girunte einen snoten, weldher nidist jelten ein Bjelent bil= bet, Durd) weldtes fith bas Blatt bebeu und ienten fann.

\section{Theilung.}

In oer Regel hat jeoes Blatt eine Mitteltippe von Spi= ralgefäßen, vou welchen Seitenrippen gegenüber abgeben. Soft ziebt fict) Die Zellfubitanz zwif(t)en 2 Rippen zurict, uno bann wiro bas Blatt lappig. Die geringite Sabl ber $\mathfrak{L a p p e n}$ if Daber orey.

Die regetmäßagige 3 abl ber Blattlappen if́ baber bie uns gerabe. Die Streifenblätter fint einzăhlig, die నę̧blätter orebzäblig, fïnfzählig u.f.m.

Der (jrund Der bey den Pflanzen herrídenden ungeraben

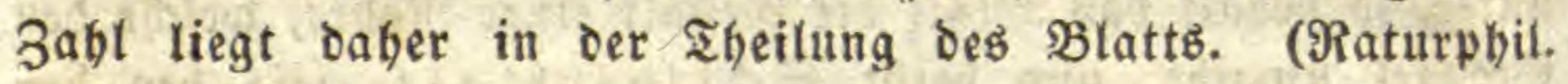
1810. S. S3.)

Die gerabe 3abl ber $\mathfrak{D}$ beitung entiftebt nur Durch Berfüm: merung ber Mittelrippe oder des Mittellappens, uno ift baber für die Prlanże zufällig.

Berínwinbet bie Belliubitanz oder trennt fie fict) bis auf bie Mittelrippe, io wiro cas $B$ latt getheilt, orentheilig, fünfs theilig u.f.m. Wenn die ganze Mittelrippe verfümmert, io wiro oas Blatt zweycheilig.

Bíswailen verlängert fịt) die Rippe Der Lappen in einen

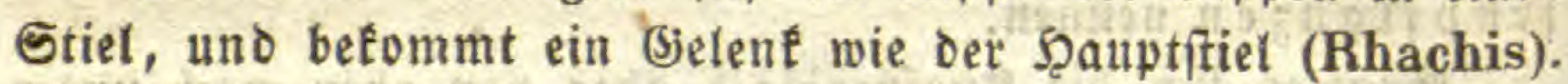
Solche Blätter beisen julammengejegte voer gefie berte (F. pinnata), und find aut) gerad uno ungerad, ie nachbem ber Endlappen oder bas Endblättchen verfümmert oder nicht. Erbs fen, Bobnen, 2teiden, Solunber u. bergl.

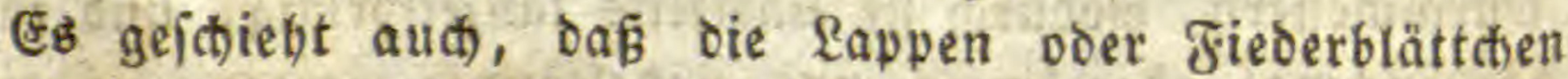
(Pinnae) wieber fich) in felbitifänoige glätțen theilen, uno bann heift oas Blatt ooppelt geftedert, (Es fann nod) weiter jufammengejegt merben, wie ben ten Mimojen.

\section{Stellung.}

2ulle bieje Blätter ftellen fid) unt einen 3 weig auf biefelbe Rtt, wie bie 2lefte um ben Stengel, quirlförmig, fpiral, zeriftent, 
gegenüber, freujförmig uno abwectjelno. Farl Sdimper bat fich) vorzüglich mit ben Gejekgen ber Blattitellung be:

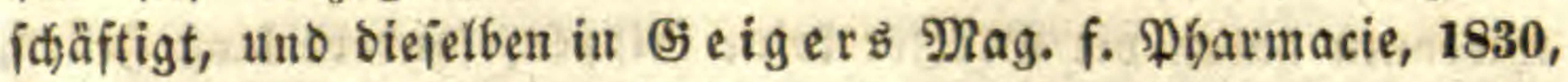
uno in Der botanijhen Beitung von Regensburg Dargeitellt. 2. $\mathfrak{B} \mathfrak{r}$ un bat fie auf bie Stellung Der 3 apfeniduppen ange= wendet. (Reopoldinilate Berbandungen XV. 1831.)

Da fie alle nid)ts anderes als aufgerifiene Sdeiben fino, wie furz auch diefe übrig bleiben mag; fo veriteht es fich, Daßs fie aut(t) alte eingeict)act)telt waren und fict) mitbin nur nact) einander öffnen fonnten. Sie bilden daher eben fo wenig einen vollfommenen Quirl alb bie 2tefte. Ein folder Duirl fitheint im ganzen \$flanzenteid) nicht vorzufommen, é mūste benn bey

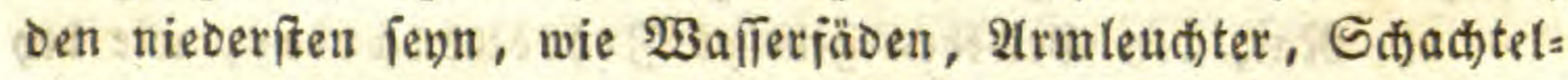
falm, wo eigentlid) sie Ruopen feblen.

Die büíhelförmigen Blätter bey Dem Sparget uno ben Rabelhölzern entipringen nid)t aแs ein em Puncte bes Sten, gelb, iondern ftégen an jegr vertümmerten 3weigen; ebenio beym Saueract) auf einem Dorn.

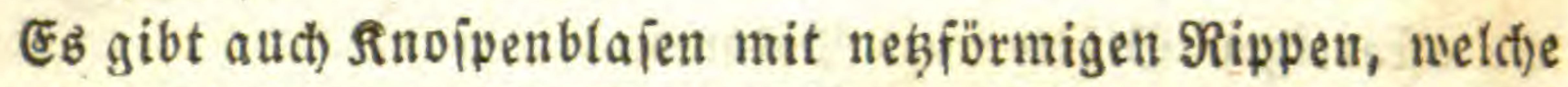
fid) nidft wie die gerabiftreifigen Sd)eidenblätter von oben nach unten fpalten; jondern die Blaje reiß̧t quer auf einer Seite

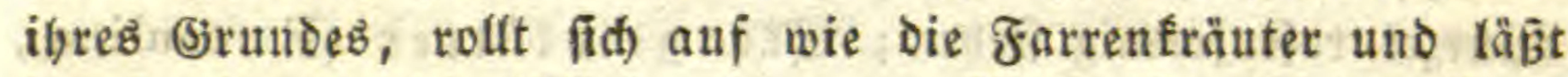
ben 3 weig oder bie Blutthen heraus. Sn bey ben Dordenpflan= zen. Diefes fub unvollfommene voer unäd)te Sd)eidenblätter mit Stielfideioen (Phyllodium). Sie theilen fid meiftens in Lappen oder Fiederb(ättchen, jedod) mit unvolifommenen Stielen und Gielenken.

Das folgente Sdheibenblatt offnet fidh in ber Fiegel tem untern gegentitber, io ba B ber ganta Stengel eine Reife von Sđciben ift, weldee oben balo lints balo rechts aufreisen, wie bey ben Gräjern. Streng genummen beftebt aud ber Stengel Der Rę̧pflamzen mur aus Blattitteiden in einander geidachtelt. Der 2(ugenjat)ein veridwindet aber, weil bie slätter Stiele be= fommen, wågrend Der S(heibentheil diḑt mit Dem Stengel ver, wadien Eleibt, uno fid nidt abiontert wie bey ben Streifen: prifanzen. 
Qreteu.

Bey Den Pflanzen mit Samen obne Lappen, oder den $21 c 0$

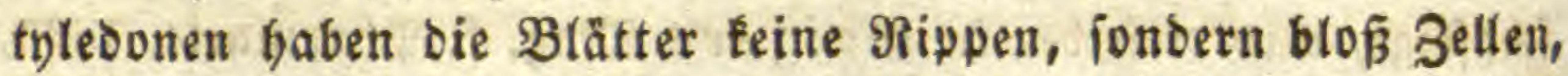
wie bey ben Moojen. Bey ben Flect)ten nno Iangen bleiben bie Blätter mit bem Stengel verwahjen, obne als Snojpen aufzuplazen. Die ganze Pflanze ifit nur ein Şaufen von nidt geöfrueten finojpen, unb bat baber aud) ibre Frudttbeile in ber Subitanz jelbit verborgen. Bey ben Pilzen find oie Blätter fo wenig entwirfelt unb Der ïbrigen Subitanz fo äbnlid) geblieben, dấ fie nicht einmal die grüne Farbe zeigen.

Man fann bie Blätter nach) Denielben Entwictlungsftuffen eintbeilen, wie Stenget uno $\mathfrak{3}$ urzel.

a. शach) Den (5emeben gibt es Sellenblätter, wie ben den Sentpilzen; 2loerblätter oder Sauppen, wie bey ben Moojen; Droffelblätter, wie bey ben Farren.

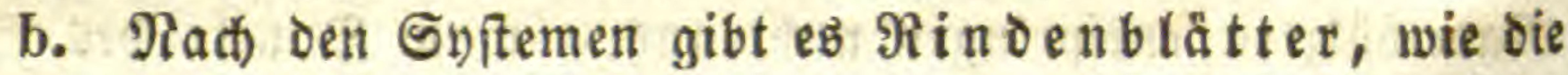
Sa)eidenblätter Der (jiräjer uno ber anbern Streifenpflanzen;

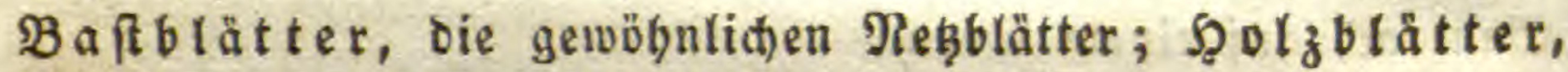
Die aftartigen $\mathfrak{B l a ̈ t t e r ~ D e r ~ P a l m e n . ~}$

c. Rach ben Drganen gibt eB 23 urzel blät ter (F. radicalia), wie bey Den meiften Rräutern, wo fte oid)t Hber oet פुurzel rofenförmig fteben; Stengelblät ter (F. caulina), die einfaden all ben Bweigen; volltommene Blătter find bie ztiammengejegten oder geglieberten (F. articulata), wie die bano = und fufförmigen und bie geftederten.

Die $\mathfrak{R}$ nofpenlage (Vernatio)

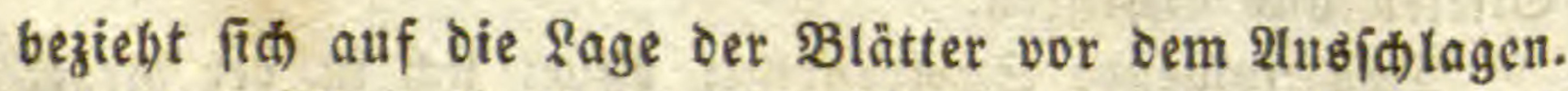
Das eingelne Blatt liegt' entweder $f(a d)$, oder ber Långe nađ z gen. Es if ferner eingerollt, a usgerollt, zugerollt, gefaltet. Mebrere Blätter umfafien und becten fid auf vers fdiebene Weife.

$\mathfrak{B}$ er eft mer ung.

Bey vielen Blåttern, bejonders den gefièerten, verlängert fid Der allgemeine Blattítiel ftatt in ein Endblåttc)en, in eite 
$\Re$ a $n f e$ (Cirrus), welde fít) un Stangen mindet. Daher ges bören aud) bie Seitenranten ber Fürbjen. Solde Fäben fom= men aber auch ben Sträunern vor, wie bey den Reben.

Beym Iragantb verbärtet das Ende bes Stiels in einen Dorn; bey ber Stedpalnte, ben Difteln, ber פiannstreu uno dem Sauterad) geft febe গippe in einen Dorn über.

Bey manten 2tcacien aus Reubolland geben alfe Fieder= blättch)en verloren, uno es bleibt blof ber allgemeine Stiel übrig. Bey vielen $\mathfrak{W a f i e r p f l a n z e n , ~ b e j o n d e r s ~ b e m ~ S ̧ a b n e n f u ß ~}$ und Wafferid)laud, geidjieht baffelbe.

\section{Berbilong.}

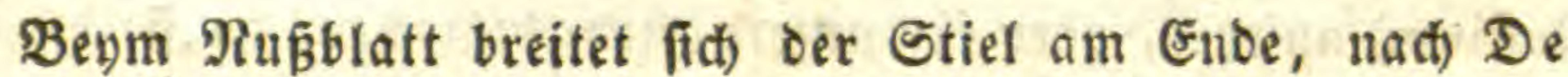
Ea noolles Bemeréung, in einen Lappen aus.

Mandmal trennen fich bie Ränoer Der Sđeibenblätter nidt, fonbern bleiben verwadjen, woburd fie febr idneidend werben, wie bey ben Sdiwerditien; baffelbe f(t)eint aud ben Den boblen aber runden Blăttern oer Zwiebeln ber Fall zu fenn.

Bey bem fonderbaren indijaen fannenfraut (Nepenthes) erweitert fich ber Stiel gegen Då Ende in eine grofe anfredte

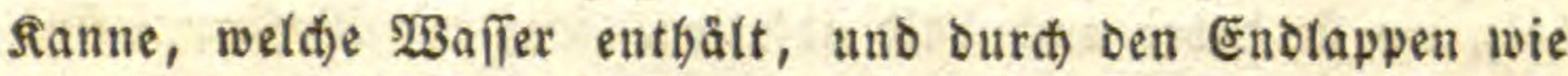
mit einem Dectel verid)lofien wiro.

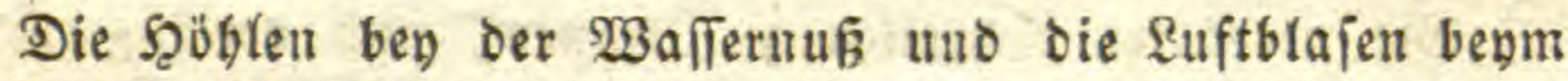
Wafferí)laud) (Utricularia) find Rücten im Zellgewebe, wie bey Den Seeroín.

Die Blätter, oder jelbft der ganze Stoct ber 2 cotylevonen, enthalten teine bejonderen Stoffe, ober Göhftens Jarbenitoffe; Die ber झonocotnledonen genöbnlich fïßse oder ficharfe Stoffe; bie ber Dicothledonen bagegen fino jebr reich an allen 21rten von Stoffen, bejonders jauren uno wohlriect)enten, wie ätherifice Dele unb Searze, auth an verificbenen Farbenftoffen. Sie fino balb in Den \&itcfen, balo jelbit in Den Bellen entbalten.

Die Blätter wedjeln im Şerbit ibre Farbe uno werten gewoubntid) gelb, alío wie bie \$̧urzel; viele rotb, braun uno [đ)warz, felten blau uno weís. Ës fommt von ber veränoerten Drvodation ber grünen Rö̈rner. 


\section{Die Rebenblätter (Stipulae)}

find iđdeinbar unbedentenbe, aber nod) feines̉wegg ganz ent=

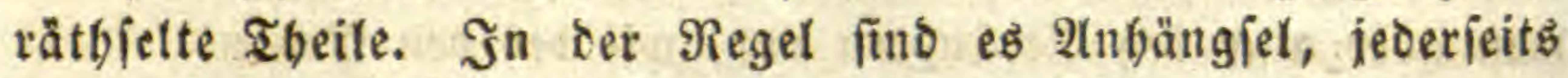
am (jintude Des $\Re$ lattítiels, wie Flüger deflelben. Sie fommen aber aud bavon ganz getrennt vor, uno balo mit ígren innern,

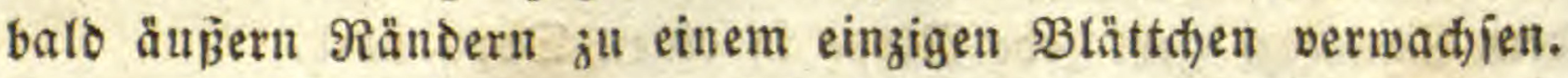
In erften Fall fiteben fie neben Dem Stiel, im zwenten dem Blatt gegenüber nuo umgeben Den Stengel, im leß̧ten fteben fie in cer Blattadiel.

Da fie allen Streifenpflanzen feblen unb aud) ben Ress= pflangen mit einem facibenartigen $B$ lattifiel, fo fann man fie

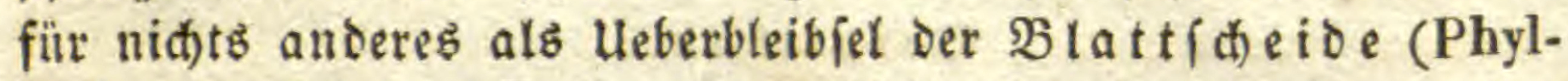
lodium) aufeben, ooer für untere Fiederblättchen, oa fie bey ven Seüljenpflanzen bejonders auggebildet nno mandf faltig vorfom= men. 2(uc) finden fie fith bey ben roienartigen Pflanzen, den Malven, Dem Raubbolz, wäbreno fie Den Relten uno bejonoers

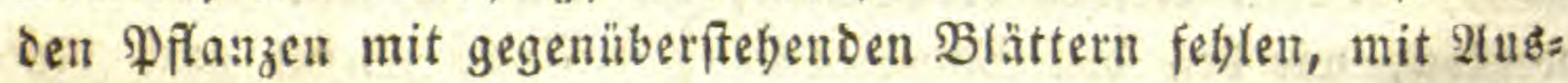
nahme jedod) ber Sterupflamien.

Sie find in ber Regel viel teiner uno fummerlidber alb Die Blätter, oft nur wie Papierínnikel, bejonders beym \&aub= bolz, wo fie baber aud bald abfallen. Bey Der 2 Bnflermus fino fie unter bem $\mathfrak{B a f f e r}$ fabenförmig, über Demielben breit.

Sie verbärten bisweilen zแ Dornen, und verlängern fidi) bey ben Rutrbien in Ranfen.

\section{B. Straun (Thyrsus) \\ ober}

Drgane ber Fortpflanzung.

Bisher baben wir blō̄ diejenigen abeile betract)tet, weldte zur Entwictlung und Erhaltung ver indiviouellen PFlanze Dienen. Es gibt aber aud Drgane, wodurt) bie Bermelyrung oder Jortpflanzung ber Gjattung, D. h. Die W3ieberbolung des Snoi= vidums, bewirt wiro, und diejes find oie Drgane der

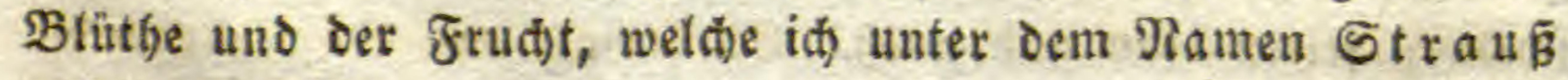

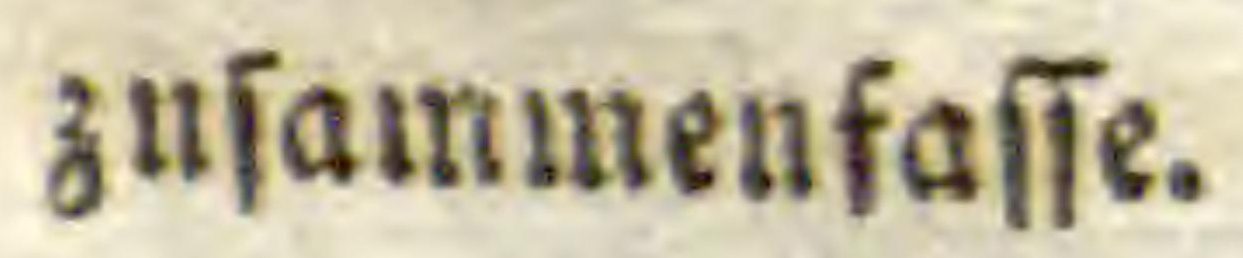


Wenn biejer 3wed erreid)t merben foll, fo milifen fid) alle Theile des Pflanzenftoct's in Etrauß̧e wieberbolen, und zwar zu= nåd)ît die unmittelbar vorber gegangenen: Denn eines entwicfelt (i்) aแt bem andern, uno eb fann feinen Sprung bażwifhen geben, weil jonf̂t Rücten entiftänben, Dur(h) welche der Sufam: menbang, und mithin bie Eimwirtung aufgeboben witroe.

Die zunähit vorbergebenden Drgane find aber $\mathfrak{W B u}_{3}$ Stengel und \&aub, weldee nod) organifi) mit einander zuiam: menbången, uno gleidfiam ein Stüct, einen unuterbrodjenen Seib bilben.

24les $\mathfrak{W a}$ atthum ber Pflanzen berubt aber auf bem $B_{e}=$ ftreben, die Gienebe, Snfteme uno Drgane von einander zu trennen, uno felbit fändig zu maden. Dieje rennung wiro in bem Stocte felbit nicht erreidst, aufer theilweife ben ben Blättern, injofern fie abfallen, aber nicht bey Stengel und Wurzel, uno gar nidst bey Den Siemeben. Sobalo fie bey allen gelingt, nebmlid) ben 23 urzel, Stengel uno Blatt; fo entiteben die Drgane, weldye wir Blätbe nenten. Sie bildet baher wies ber einen ganzen Stoct für fick, weldher fith nidit blós von Dem Sauptitoct abjonoert; iondern worinn aud bie Drgane Der Blithe felbit fich won einander trenten.

Der Straus oder die Drgane Der Fortpflanzung zerfallen in $B$ lütbe uno $\mathfrak{F}$ rad t.

1. Die felbititänbig geworbene und fia) abjonbernde $934 r z e t$ ift ber Samen.

2. Der Stengel in ber Blütbe wiederbolt ift bie Eapiel voer Der (5) röps.

3. Dag Blatt in ber $\mathfrak{B l u ̈ t}$ le ift bie $\mathfrak{B}$ rume, ober genauer das $\mathfrak{B l}$ uft.

Der Gamen ift ein abgeglieberter uno für fich beftehender Ibeil; bie Eapiel ift ebenfalls ein abgeionderter Theil, uno ebenjo bie Blume mit ífren Staubfäben, indem alle fich ablöen und aus einander fallen.

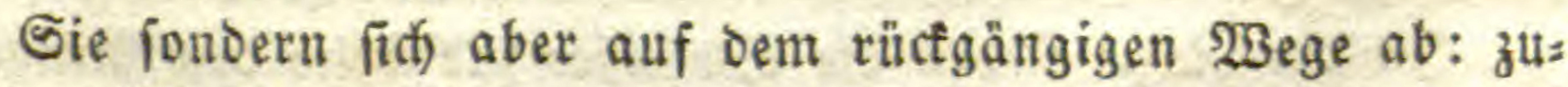
erît bas Blatt als Blume; jodann ber Stengel als Srtöps, uno

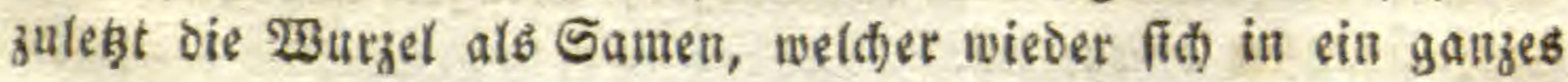


Inbivibum verwanbelt, wie aแร ber $\mathfrak{B u r z e l ~ e i n ~ g a u z e r ~} \mathfrak{P f l a n s}$ zenftoct entiftert.

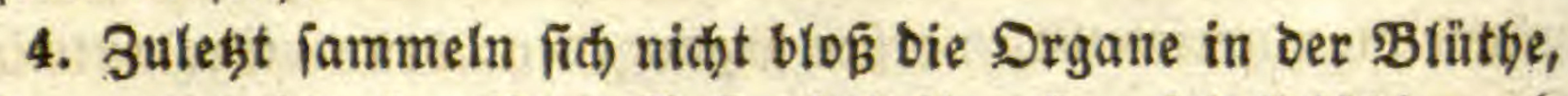
jonbern aud bie chemifhen Beftanotbeile; fre wiro fleifhig uno beißgt Frudt, weldbe mitbin als Darftellung bes ganzen Pflanzenftocts in Miniatur betrabtet werben muß.

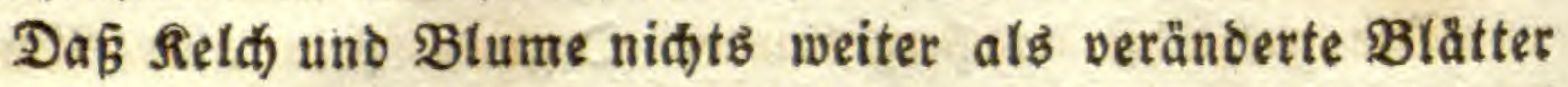
finb, fann auch Der Slinbe mit Şänben greifen, uno es beonrf feines Sdjarfínn eines Sebenten, um fohthes zu erfenten. Die Şauptiathe aber ift bie Bedeutung biefer Igeile, unb biefe

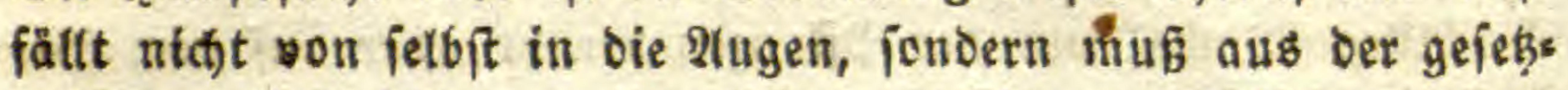
mäbigen Entwictlung aller. Pflanzentbeile geíd)lofien werben. Rur wenn man erfennt, daß afle Pfanzenorgane nichts anderes als bie wieberholten und abgejonderten (jewebe fino; fo ertennt

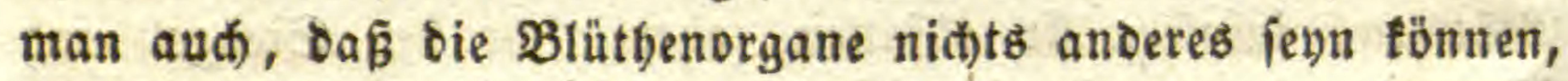
als bie \$ieberbolung oer zunäthit vorangegangenen Drgane,

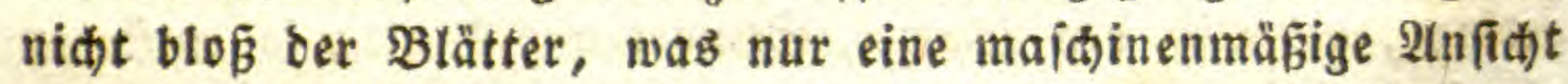
wåre, fonbern aud bes Stengels uno Der $\mathfrak{B u r}_{\text {zel. }}$ Rur $D a=$

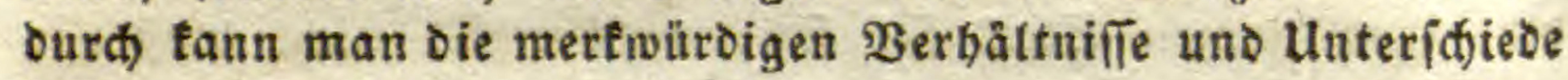
erelaren, weld)e bey ben Blüthen vorfommen.

Die Blüthen, nehmlid) bie Bereinigung Der Btume, beร (jröpies uno bes Samens, itehen wieber auf 3weigen oder Stielen, von Blättern umgeben wie bie 2tefte. 2tud) befolgen Die Blätbenftiele in ibrem Stano, in Der Theilung, Derlängerung ganz bie Bjeję̧e ber 2lefte, und fitllen wieber ein 2litwert im sleinen vor. Diejes diftwert heişt

\section{Błü the nftand (Inflorescentia).}

Der Blïthenftand oder Strauß in engeren Sinn ents

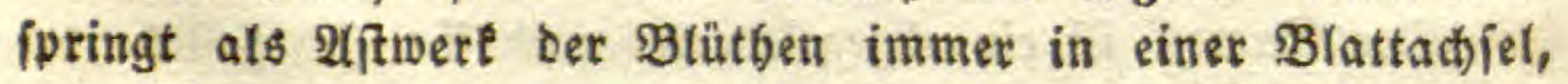
unb if auswenbig von einem Blatt bebectt, weldes balb einem 3̂tweig = ober Stühblatt vollig gleidst, bald aber in (5es ftalt uno Farbe abweidjt uno bann Dectblatt (Bractea) beiśt.

In ber Regel fiteben bie Sträußer jur Seite bes Stengels; indeffen fann man fie ocd) in \$urzets, Stengels uno Ent: ober (3ipfelftrăußer eintbeilen. 
a) 13 urzef ftră gewädjen. Sie beißen aud Sdjaft (Seapus). Ferner bey Şajelwurz (Asarum), Sauerflee, $\mathfrak{B}$ intergrün (Pyrola), Eros fibeibe (Cyclamen), $\mathfrak{W} a$ ffernabel (Hydrocotyle).

b) Stengel = oder 3 weigit $r a ̈ u \tilde{B} e r$, übergaupt Seitens fträußer, ftef̧en faít alle einzeln bey Eapucinerblume (Tropaeolum), Miere (Alsine), Raben (Agrostemma), Şeibelbeere, Pfennigfraut (Lysimachia), (jaudb)eil (Anagallis), $\mathfrak{B i n d e , ~} \mathfrak{B} e l=$ laoouna, Sinngrün; megrere bey Seibelbaft, Sjeiß̧blatt. Dann jeben fie oft aus, als wenn fie in Quirlen ftänden, wie ben Den meiften Sippenblumen. İt åd) ten Quirfen, netgmlic) rings um Den Stengel, fommen fie äußerfít felten vor, wie z. B. benm Iannenvedel (Hippuris).

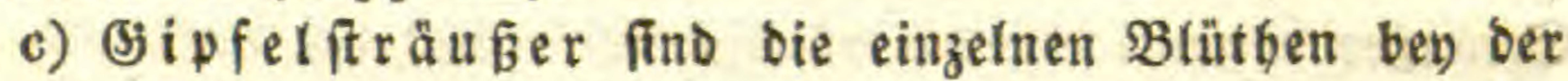
Einbeere (Paris), Dem Sd)irmfrairt, Einblatt (Parnassia); fer= ner bie zablreichern bev Seifentraut, Natterfopf, Taujenogit:

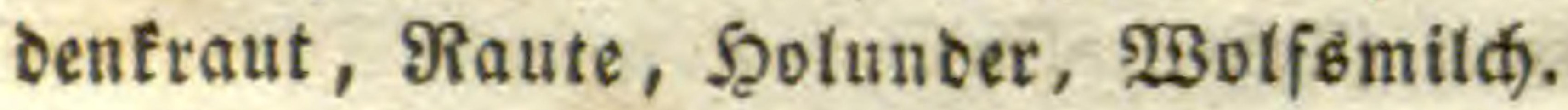

Der Strauß beftebt zunächif auş Blättern uno Stielen.

$2 B a$ jeine $\mathfrak{B l a ̈ t}$ ter betrift, fo mur man zuerít alle, weldye zal ber Blattblitthe gelören, eintheilen in 23 urgel=, Sten: gel $=$ und Bipfel $=$ ober eigentliche Blätter. Die Wüżelblätter werben zu Dectblättern an Den Stielen, Die Stengelblätter zu Sield), Die Sipfelblätter zur Blume.

Die Dectblätter fino alío allein wabre Strauß̧blätter, uno es gibt beren wieder brenerley.

Steben mehrere wirtelförmig um Den Stiel, fo beifen fie ஒૃälle (Involucrum).

Einzelne ober att) gebrängte, aber fełpr veränderte, meift verfümmerte Blättçen befalten ben Ramen $D$ e ct bla $t$ (Bractea); ein ablveict)eno geftaltetes und meift verfürbtes

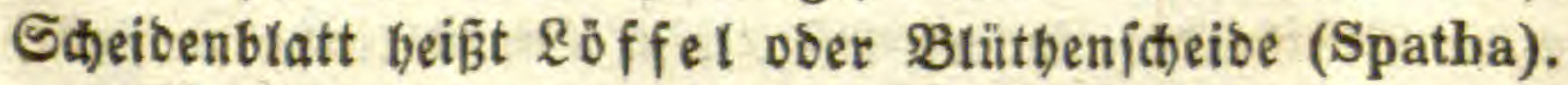

Stehen bie Dectblätter jebr Elein unter georångten Blüthen auf einem Boben, wie bey den Siopfblüthen, Diffeln; fo heifen fie Spreublätthen (Palea).

Die Stiele oder die 3weige bes Stranges find entweber einfad) oder zufa mmengefents. Steben fie in einem Stübs: 
blatt, io ridgten fie fict) gäuzlich nad) Dem Stande ber 3 weigs

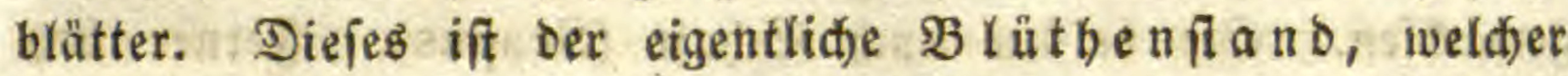
fich auf bie Sertbeifung ber Blittben an ber ganzen Pflanze beziebt.

Die Bläthen fönnen alfo ftehen: gegenüber, quirlförmig,

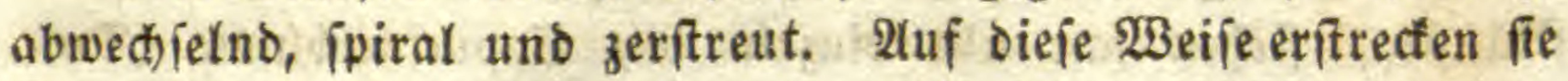
fich tiber bie ganze Pflanze, wie 3 . $\mathfrak{B}$. bey den Rippenblumen,

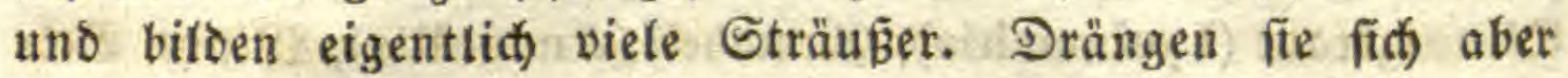
nab zujammen, jo betractet man fie aud) als einen Straur, obitton ein vollfommener Strauß eigentlich ein joldier ift, wel= ()er burch) ein (Gelent fid) vom Stengel oder 3 weig abjonoert uno oft für fid) abfällt.

a. Bey ben (jipfelblüthen fommen veridiedene Stränßer vor.

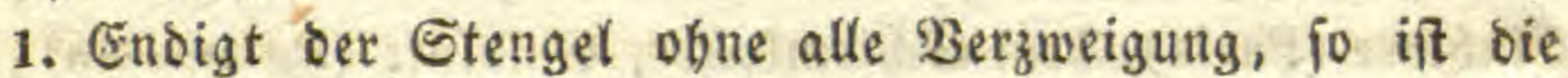
Släthe einzeln, wie bey Der Einbeere (Paris), Dem Esinblatt (Parnassia), Stfirmfraut (Trientalis).

2. Stehen neben Der Enoblintbe 2lefte gegenibber, ebenfalls mit einer Enoblitbe; io ift es ein Dreyzaft (Trichotomia), wie bey bem Seifenfraut, ફ̧ornfrant (Cerastinm), Spergel (Spergula), Gattotraut (Arenaria), Gternftaut (Stellaria), Saujenogüloentraut, Raute.

3. Wien in biejen Falle Der Mittelitiel vertümmert; io entifebt der (jabelft $r$ a falat, ber Miftet.

4. Berfilmmern bie 2tệte einer Seite, dá̧ nur bie ber an= Dern uno Der Mittelifiel eine Sthithe tragen; io ift es bie Şa $16 \operatorname{tra}$ u be, wie bey dem Leimfrant (Silene).

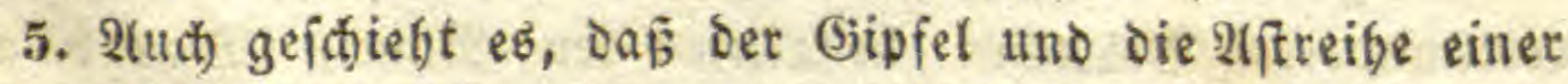
Seite verfümmert, bie anbere aber allmählid bervorwäd) b̆t, fo Dẩ je die Blüthe des innern 2lites ein Bipfelblüthe vorifellt, und jeber folgende git poer Stiel nach außen und unten ge= f(foten wiro, wodurd) fich Der Straus mad unten rollt, wie bey der Sonnenwende (Heliotropium), dem Rattert́pf (Eehium). Diejer Blitthemitano beiß̧t ber 23 icfel, auch Georpionídıuan (Inflorescentia scorpioides). 
(Enolid) feģen fich oiefe Bipfelblitthen mebr zufammen.

6. Sinb Die (jabel= oder Dreyzactzweige ungleid) lang; io ift es eit $\mathfrak{B}$ üf

7. Werben fie alle gleich) hod), io bas bie Blüthen in einer Ebene ftehen; fo ifit es oie 2lfterooloe (iCyma), wie ben Şolunber, Sd)lingbaum (Viburnum lantana), Spierítaube, ફ̧art= riegel (Cornus).

8. Steben verfinzte 2 fterdolden in SBlattadyjeln gegenibber,

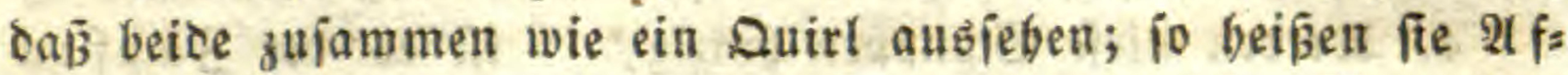
terquirl (Pseudoverticillus), wie bey ben meiften Sinpenbln=

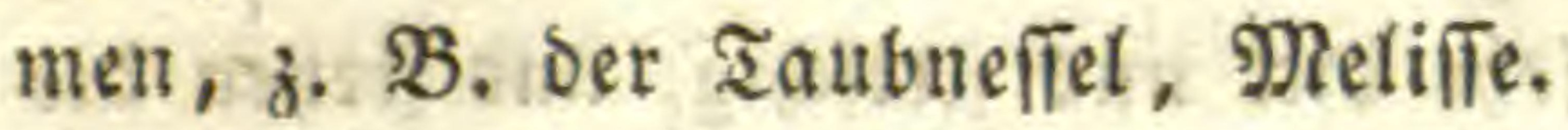

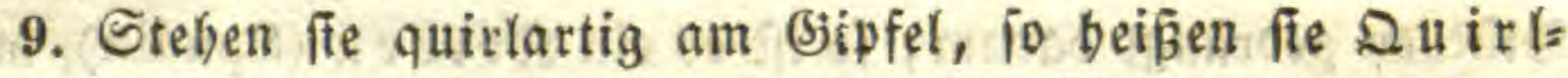
bof oen (Cyma verticillata), wie bey ben 1301 fmmildarten.

10. Sino die Stiele der 2 fterdoloen jefr furr, fo beipen fie Rnä uel (Glomerulus), wie bẹ Den Meldeu, 2tmaranten, (ङansfüßen (Chenopodium).

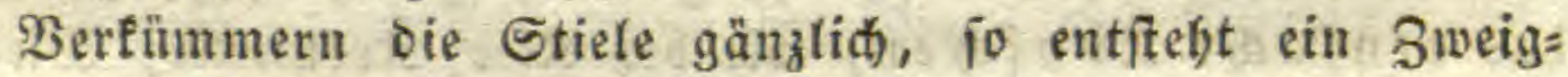

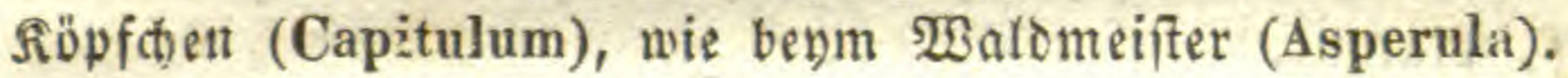

b. Die Seitenblüben find viel zablreider.

Unverzlueigte.

Benn eine Menge Blütffen lăng einem 3weige georängt Fteben; io beißit Der 3 weig oder Etengel Spindel (Rhachis) uno der Blitthenifano Spindelítraufi.

1. Bececten ftiellofe Btütgen die Spindel, fo ift der Strauß eine 2f ebre (Spica). (Jewvöbnlich) ftehen Die Blüthen in Beilen: einzeilig (Sp. secunda), zwenzeilig (Sp. disticha) \#. f.f.

Davon veroient die for ä hre bey den (jrăjern bejonders attggezei(t)net zt werben, weil bie Spindel niकt mit idheiben= förmigen Blitthen bedectt iff, fondern mit idfeibenförmigen oder jogenannten Spelzen, uno zwar vorzïglid zellenförmig. Man

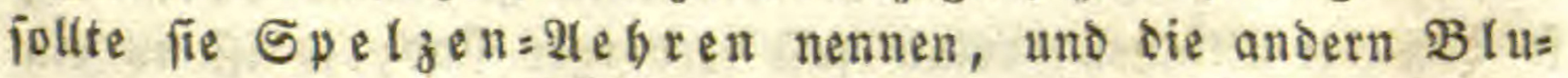

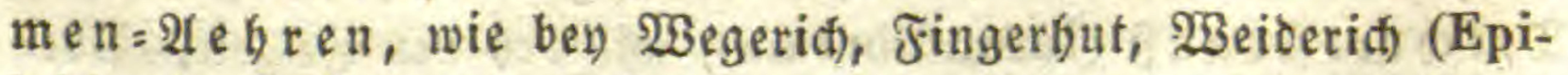
lobium), Jlöbtraut (Polygonum persicaria), ভゅarfadjbeere (Phytolacca), Melde.

Einfeitig oder einzeilig ift fie bey fingerbut, f̧eite, Son= nentbau (Drosera), Mabblümd)en. 
2. Scaben bie Blüthen um bie Spindel einfacte Stiele, fo ift es eine Stiet =2l e bre, welde gewöbntich) aud Sraube ge: nannt wiro. Go bey ber \$impernuß, Johannisbeere, Sautad) (Berberis).

3. Iit die Spindet abgegliebert, io daß fie gatzo abfällt, unb ftatt Spelzen ober Blumen blof mit frautartigen Sdappent:

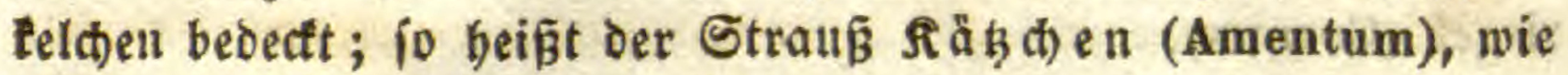
ben den Sạeln, Pappeln, Weiben, Eichen, Nuģbäumen.

4. Werden biefe Sduppen holzig, io ift eह ber 3 apfen (Strobilus), benm Rabelbolz.

5. Wiro bie Spindel fefr bicf und fleiffig, und fteben bie

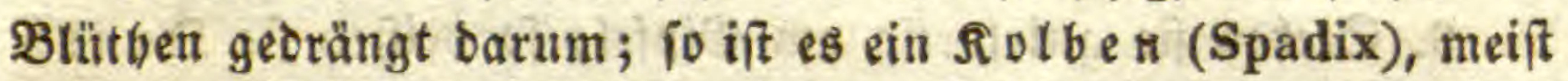
von einer Blüthenífeibe umgeben, wie beym Solbenrobr, Cals

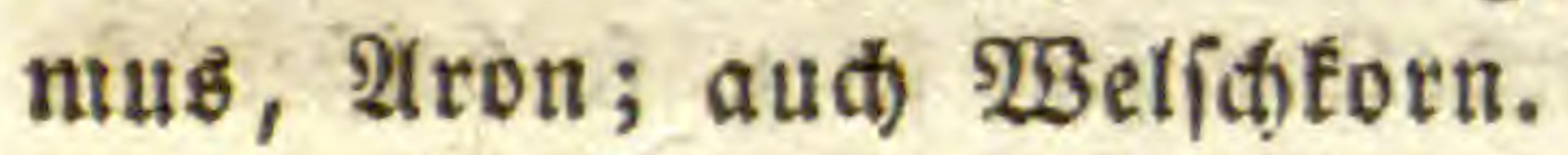

6. Entipringen bie Stiele febr didt benjammen um bas Ende ber Spindel, uno find fie ziemlide gleid) lang; io if es

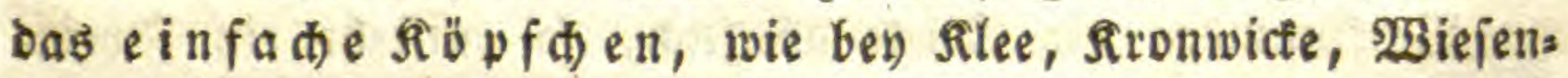
Enopf, Ptatane.

7. Steben bie Stiele auf bem Sipfel eines Stengelo von einer Şülle umgeben, uno die äuß̧ern länger, fo daß̧ die Blï: then in einer Ebene liegen; fo if es eine Dolbe (Umbella), wie ben ben fogenannten Dolbengewädjen, Möbren, Rtïm: mel u.j. w.

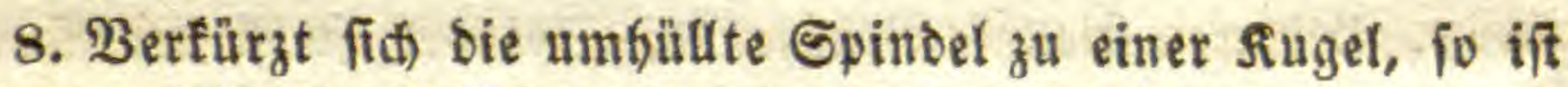

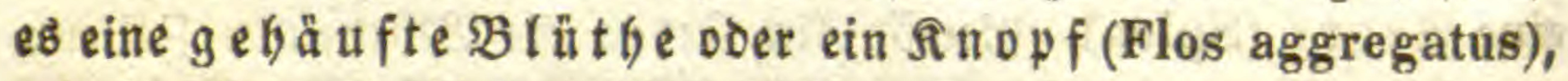
wic bey ben Scabiojen, W3eberdifteln.

9. $\mathfrak{B}$ irb Der stopf flach wie ein Feller, fo ift es eine z fammengeiebte SBlutbe oder Ropfblïtbe (Flos compositus), wie bey ben Salatpflamzen, Difteln, Sonnenblume.

10. Bertieft fith Diejer Blitthenboben zu einem $\mathfrak{I}$ rid)ter, fo daf bie slüthen barinn faft verborgen fino; fo ift es ein Iri d) terît $r a$ в (Infundibulum), wie bey ben Jeigen, Dor: ftenien.

Die verzweigten Stråuber

ober mit verźweigten Rebenfielen gefen ben vorigen ziems liđ parallel. 
1. Die Spelzenähre fommt verzweigt vor (Spica ramosa) bey dem Bartgrab (Andropogon ischaemum), Dem Wunbers weizen.

2. Beräftetn auth die zweyten 2(ebren, fo entffeft eine $\Re$ i ipe (Panicula), wie bey bem Şaber uno den meiften Gräiern. Man

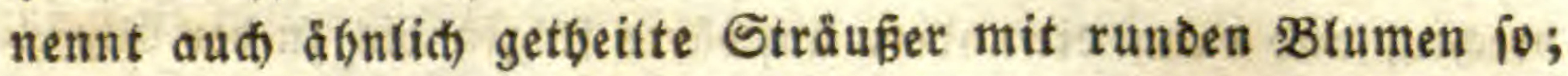
allein es wăre befier, fie unter bie zujammengeję̧ten Trauben zu rect)nen.

İt die Rijpe febr gebrängt, weil bie Bweige Eurz fino, io

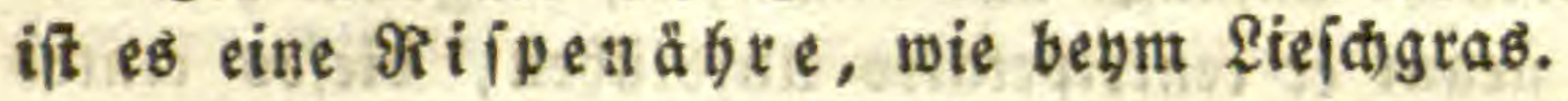

3. Eine verźmeigte Stielähre iît eine $\mathfrak{x} \mathfrak{x} a b e$ (Racemus), wie bey ber $\mathfrak{B}$ eintraube.

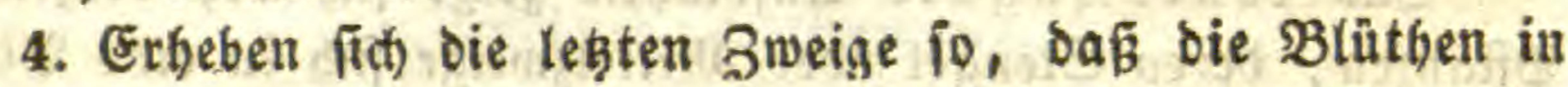
eine Ebene zu fitehen Fommen, io entitegt Die Dolbentraube (Corymbus), wie bey vielen siretzblumen, ben Birnen, Der Sogetmil(t) (Ornithogalum umbellatum).

5. (jeht bie Berzweigung ins Drey = unb $\mathfrak{B i e r f a d e , ~ u n d ~}$ find bie Zweige febr lang, fo if es eine Ri ipentra ube, wie benm Frojdilbffel (Alisma).

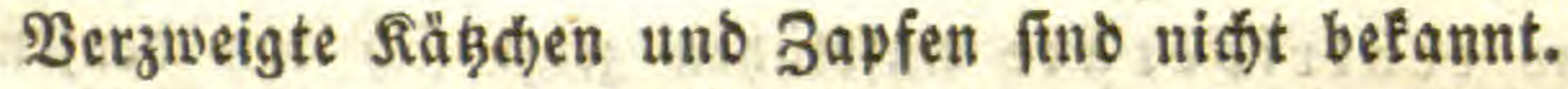

6. 2lber verzmeigte Solben fommen bey vielen \$almen vor. Эัd) neune fie $\mathfrak{B}$ efen oder Bejenftrauß (Spadix).

7. Dolden, welthe fith wieder in Döltden (Umbellula) theis len, beisen zujammengefezte Dolben, wie ben den meis ften Doloengewådjen.

c. Enolid) gibt es Sträußer, welde aus mehweren $B$ lü= thenftänoen zufammengeiegt fino.

Dorben in einer $\Re$ Ripe bey ber Beeren = 21ngelica (Aralia).

Ifterbolben in einer Rippe bey ber Rainweibe uns bem Flieder.

Sopfoluthen in Afterooloen bey vielen zufammengejebsten Blütben, S(t)afgarbe u. f.w.

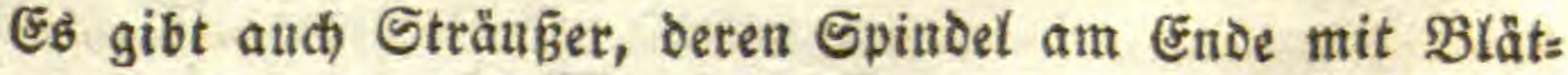
tern obne Blüthen umgeben ift, dem Sd)opf (Coma) G do p fittäufer, wie bey der 2manas (Bromelia), Sthopf= Vilie (Eucomis), Es find unfrud)tbare Dectblatter. 


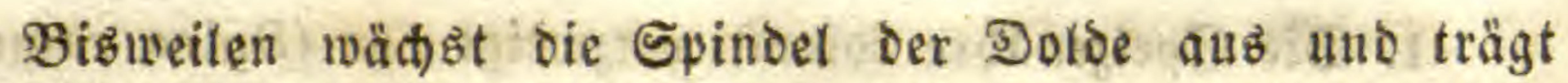
im nächiten Эabr wieder eine Dolde, wie bey ber \$orcellan= blume (Asclepias carnosa).

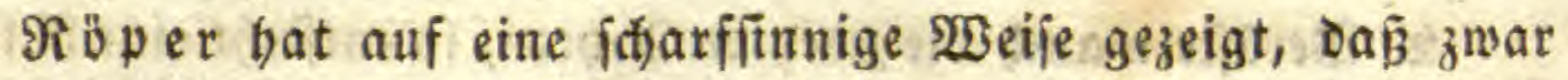
bey Den meiffen $\mathfrak{B}$ lüttgenfänoen bie untern Blütben zuerît auf: brecten, und dann bie andern aufwärts folgen bis zu ber (5ipfel= blitthe, was ber natürliche (jang ift, ba bie untern 3weige bie älteren fino; Daß́ es aber aud) Fälle gebe, wo bas 2(ufbrect)en mit ber (sipfelblüthe anfängt uno allmählid) ringsum berunter fteigt. Senes nent et centripetales 2uffiluben, diejes centri= fugales.

Das centrifugale 2ufblüben zeigt fid) bey benjenigen Pflanzen, Deren Stengel ober Mittelzweige fith it eine Blittbe endigen uno Daber furz bleiben, wälreno die Seitenitiele weiter wadjent uno auf älntid)e 2(rt enoigen, alio überbaupt bey ben Sipfelblittber, wie bey ber Trugovlbe, Dem Büjthet, Snäuel, SBicfel n.f.w. Dergleitten Blïthenftände finden fich vorzüglid bey ben Enzianen, Siloctenblumen, SBalbrianen, Nelfen, Şaf)= nenfǖen, Roienartigen.

Das centrivet a fe 2ufbfitben zeigt ftd bey benjenigen Pflanzen, Deren (jipfel nicht ourch eine Blitthe geendigt mird, jondern immer fortwädbe tho an ben Seiten Blittben treibt, alfo bey den feitlichen Blitbenfänden: fo bey 2tegren, Säbd)en, Zapfen, Folben, Röpfcten, Dolden, Irauben und Doldentrauben. Dergleid)en Blïthenftände finden fid) bey Den (jräjern, Drct)i= Den, 2tron=2trten, Salatpflanzen, Scabioien, Doldengewäct)ien, Sreuzblumen, $\mathfrak{L} a u b=$ uud Radelfolz, Şitlienpflanzen, Seif̧blatt: Atten, Sinben.

130 mebrere 93lihthenftände in einem Strause vereinigh fint, ba zeigen fich) auth) beioe 2rten von 2ufblithen. (Roeper, Inflorescentiarum natura, in $\mathfrak{l}$ in $\mathrm{a}$ \& a $I$. 1826. 433.)

Das Ende des Strauges ift die Blithe oder die Fruct)t.

$$
\text { 1. Blithe (Flos). }
$$

Die Blüthe bejteht aus $\mathfrak{B}$ tuift, Eapiel oder (5röps (Pistillum, Germen s. Pericarpium) unb Gamen (Semen). 
Эc) babe es zuerfit in meiner Raturpbitojopbie (1810.

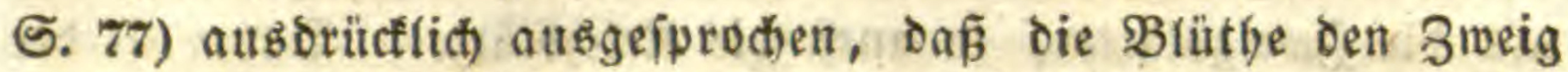

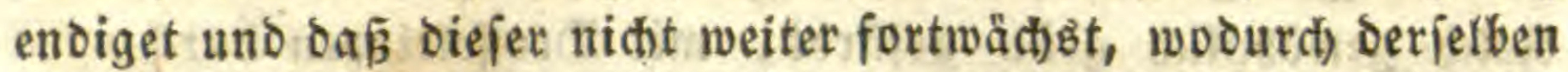
ifr beftimmter Drt angewieien wir D. Daraus folgt, da eine Blütbe nie andersెwo ftehen fann, als am ende eines Zweiges, nno das biefer feinen Rebenglauf vollendet hat, fobald er $\mathfrak{B l t}=$ then trägt. So ftirbt nid)t bloß ber Sdaft ber 3 wiebel $a b$, fonbern aud) Der groß̧e Stamm ber 2lgave ober fogenannten 2lloe, uno felbit der Pijange no Palmen. Soll ein Baum neue Blütben treiben, io mub er aut wieder neue 3 meige entwicfeln. (Es verftegt fit(), daßs ber Straus aut') ein 3weig ift.

\section{a. $B \mathfrak{l}$ if (Anthemon).}

Das SBluft iff bas $\mathfrak{B l a t t w e r f ~ b e s ~ S t o c t s ~ i n ~ o e n ~ F o r t : ~}$ pflanzungsorganen wiederbolt. Yllfes,, was daz̧ gebört, wirb fich) auf den Bau uno die Bethåltniffe Der Blătter allein bezieben.

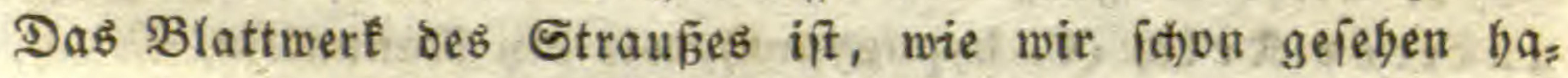
ben, eine orenfache Blattfnoipe, f̧ülle, Relch uno Blume, wo= von jene als bie Wieberbolung der $\mathfrak{3}$ urzel = voer Sduppen= blätter, Der Relth als wiederbulte Stengel= oder Sheibenblät= ter, uno bie Bhume fammt ifren Staubfäben als wieberbolte Sweig= oder Fiederblätter alzujeben fino. Die Şülle liegt ba= ber notbwendig aub wendig, bie Blume innwendig uno ber Feld) zowifien beioen.

Fielth) und $B$ hume bilden zween bidit an eitnander liegende

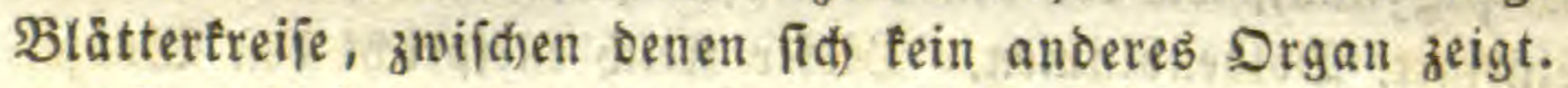

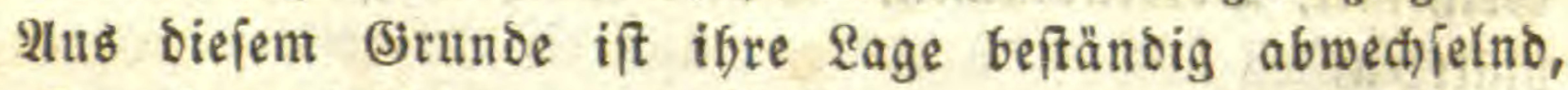
uno fie wären leicht ă unterífeiden, wenn aud bie Blume niaft gefärbt und zarter wäre. Uebrigens verifebt man unter Bluft feden blattartigen Igeil um bie Frudt, welder biefelbe unmittelbar umgibt, er mag grün oder gefärbt, aljo field oder Blume allein fenn. So die Rähben Der Şajelitanden uno die abfälligen Blätbentbeile der Sbif́bäume.

\section{Reld) (Calyx).}

Der Reld) ift Das in ber Blitthe wiederbolte Stengel= oder Stheidenblatt, weldies unmittelbar unter ber Blunte liegt. 
WBie die Sd)eioenblätter bicter und weniger getbeilt fino als bie Zweigblätter, fo auth Die Reldbblätter. Daher ift oer Rel(d) gewöbnlid) grün gefärbt, mit Drofielrippen ourd)zogen Itno Spaltöffnungen bedectt, wie bie Blätter; meift röbrens ober fđuppenförmig, mit weniger Cisid)nitten als bey ber Blume, oft mur brenfpaltig, wenn biefe fünfipaltig ift, ober nur gezäbnt, wenn bieje ganz getbeilt ift.

Bald ift er regefmäbig oder rund; bald unregelmåăig voer zufammengeoriuct uno zweslipwig; balo ganz getheilt voer viels blätterig; balo ganz oder röbrenfürmig; balo ftellt er nur ein Rlättd)en oder eine S(b) uppe vor.

Seine Theile wedffeln immer mit ben Blumentbeilen ab. Sat eine Rippenblume oben zween Rappen, fo hat ber Rippen= telch) bajelbit nur einen.

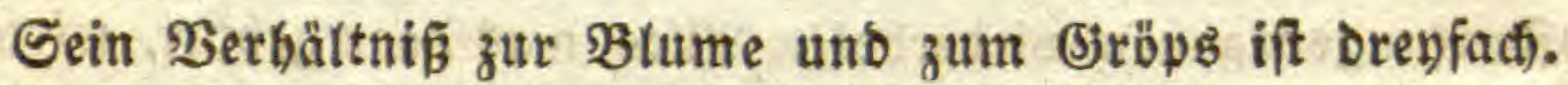

1. Stebt er ganz von ber Blume getrennt, io beifst er u n ter e r I efd (C. hypogynus), wie bey Ranuneln, Mohn, Sreuzblumen, Eitronen, Itauben. Diejer freve Seld) entipridht Den 3weigblăttern.

2. Steben die Blumenblätter und Staubfäben darauf, io heist er mittlerer field) (C. perigynus), wie bey den Illpenroien, Seiben, Giloctenblumen. Diejer Reld) entipridi)t ben Stengetblàttern.

3. Sit er mit Dem Gröpie verwachien, jo heipit ex o berer (C. epigynns), wie ben den Satatpflamzen, Difteln, Labfrättern, (Seiß̧blatt, Dolbenblumen. Diejer Rel() entiprid)t ben Wurzel= blättern.

In biejem Fall verwäd)bt et bisweilen fo bid)t mit Capiel und Samen, bás er bamit abfällt und ausfiebt, als went er bie Samenjiale felbit wäte; io ben Rümmel, Rerber. Seine Eappen werben bey den Salatpflanzen boriten= uno baarformig, uno beifen jobani felatetrone (Pappus).

1. Es gibt $S$ d) nppentelde, worauf oder wotinn bie

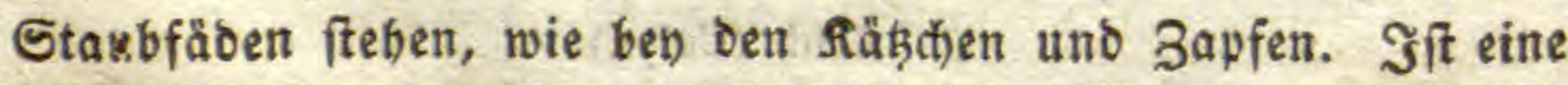
jolthe Satuppe ber Räinge nach) zujammengetlappt, fo beifit fie

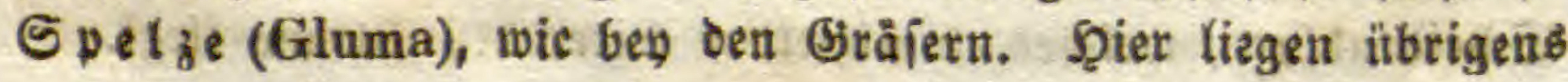


zwo ïheibenartige Spelzen gegenüber, wovon bie innere aus zwey verwadifenen Blättern befteht, und oer Rel(d) baber oren: blätterig ift.

2. E⿺ gibt Sd)eidenfelde: Die röbrenförmigen ober fo: genannten einblätterigen (Calyx monophyllus), bey vielen Pflan:

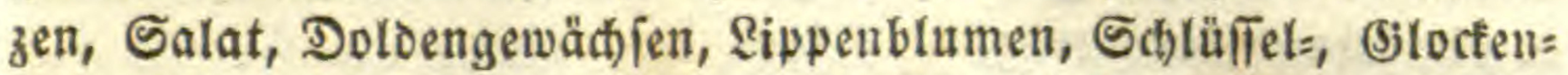
uno Windenblumen, Ënzianen, Relfẹ, Rojen u. f. w.

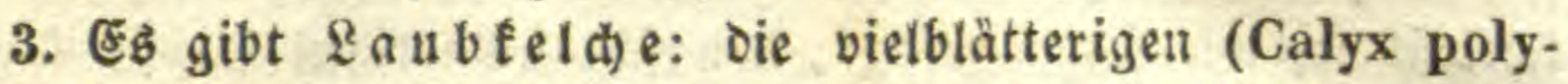
phyllus), wie bey ben Raunteln, Sirezblumen, Mobn u. f.w. Diefe fallen leidt)t $a b$.

Nidi)t felten find Sielobblätter zart und gefärbt, und felyen

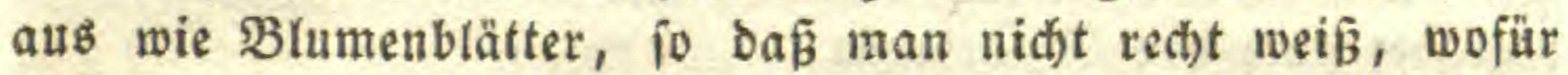
man fie balten foll. $23 e c h i e l n$ bie Stanbfäben bamit $a \mathfrak{b}$, fo nimme mant fie für $B$ lumenblätter; ftetgen fie aber barauf, fo nimmt man fie für Reldhblätter, wie ben den Rilien uno Sd)werd: litien. Es wäre aber itberbaupt beffer, wenn man aud bier Die åı Éeren Blätter Sielch), uno Die inneren Blımen nännte.

Man if jeşt gleidfam äbereingefommen, bie Blitthe ber Streifenpflanzen alı Ret(h) zu betrachten, aljo aud bey Silien und Tulper. Man nennt fie $\mathfrak{B} \mathfrak{l}$ uft (Perigonium), un leichten

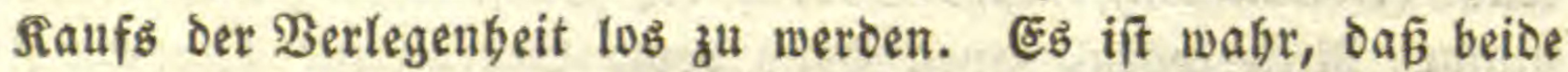
Sreife Diejer Blüthe meif̂ten auf Der äuß̧eren fläche Spalt: minoungen haben, dap oft beide mit Dem (jröps verwatien ftno, was jonit die Blume nicht thut, dán bie Staubäben ge= wöbnlid) an ben Blütbenblättern fteben, wie benm ä(b)ten Reld): allein es̉ gibt aud) viele abwedjelnde, viele ganz freve Blätter, uno endlic) welche, wo bie äแsern ganz grün fino uno bie in= nera gefärbt uno zart, wie bey ben Eommelinen uno Trabeican:

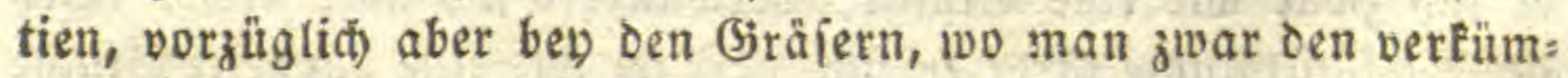
merten Błumenblättđon aud einen andern Namen (Lodiculae) gegeben, jebod) Damit ibre Ratur nicht geändert hat. Meift ift nur eines oder zwey oorhanben, aber bren bey Bambus.

\section{Berfüm merungen.}

Wenn man Die Rippenbiloung Des Relch ह eine Bertümmerung nennen will, fo foumt diejer 3 uifallo oft por. Sonft if er Dtens allg. Naturg. II. Botanif. I. 
fetren ben Zunften, beren-Blütben volffonmen ju jevn pflegen.

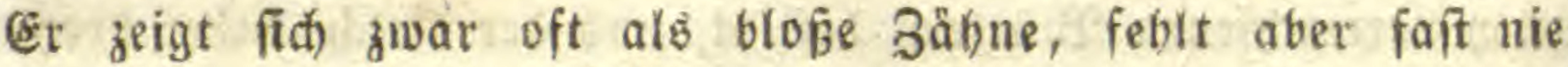
gånzlid).

Dagegen gibt es ganze Zünfte, wo er natïrtider Weife einen fïmmerlichen Buftand angenommen bat, bejonders oa, wo er die Staubfäben trägt.

Bey ben Ropfblüthen, wie Salat, Dijteln, \&öwenzabn, um=

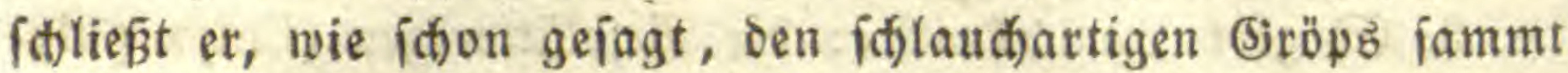
bem Samen, verwächst nicht blof́ bamit, fonbern audi) feine fünf Eappen verwachjen mit einander oft zu einem langen Stiel,

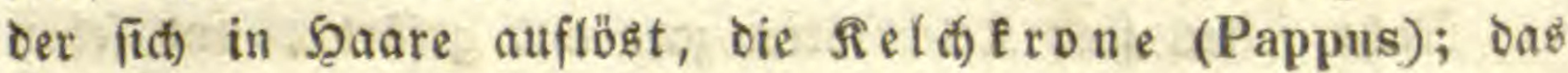
begeghet aut) den $\mathfrak{B a l}$ arianen.

Bey den Drdiden vermathien oft zwey Blätter, io Daß̧ bey Dem ebenfalls abweict)enden $\mathfrak{B}$ aut der $B$ lumenblätter die Zäblung und Deutung ber Theile oft id)wierig wirb.

\section{Berbiloungen}

bes fiel(t)s fommen nicht hăufig vor. (Er bläst fid) auf ben Der Jutenfixíthe, befommt unten Rappen bey Den Seiltiten, Såcte ben Den (Siloctenblumen, einen an ber Seite benm Sd)ilo: Eraut (Seutularia), lange Sporen bey Balfaminen, Eapuciner: blume, Ritterjporn, einen Şelm bebm Sturmbut. - Randimal vermadien feine sappen uno fpringen quer $a b$, wie bey ber Dectel= Pyrte (Eucalyptus); aut) beym Shilofraut und dem Stechapfel. Bey der $\mathfrak{B}$ affermuß wird er bart, und jeine \&ap= pen bornförmig.

\section{It u}

fino febr felten. SBey Der Scafelmurz, Der Diterlucen färbt er fid) zwar wie eine Blume, verwandelt fíd) aber nidt. Ben

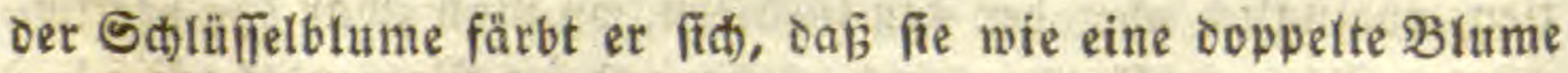
ausftebt. Ebenjo fiebt er blumenartig aus bey Sturmbut, Ritteriporn, J̋ungfer in Şaaren, 2(feleb), Trollblume, 2(nemonen, Imaranten, Fud)fien, Pimpernuf́, Seioelbaît.

\section{Btume (Corolla).}

गan prlegt bie Slume allgemein $B$ (umenfrone zu nennen, obne andern (5itund, als meil bas lateinifde $\mathfrak{W}_{\text {Bort }}$ firone 
bedentet. Pllein unter bem beutichen $\mathscr{B}$ ort $B$ hume verifebt man ganz סaffelbe, was unter Corolla; daber babe iđ es eingefïbrt uno boffe, dag man nid)ts bagegen einzuwenden baben wiro.

Die Blume ift bas Rebs= oder wollfommene Blatt, alfo oas Fieberblatt in Der Blittbe.

Sie if ein zarter uno verfärbter $\mathfrak{B}$ lattwirtel unmittelbar um die Staubfäben, weldbe eigentlid) baza gebören.

Ueber menig Drgane find jeit einigen Эabren fo vielerleb Menmungen zum Borihein gefommen, wie über die Blume.

Man bält fte allgemein für einen Blattwirtel, mitbin für ielbitifändige Sabidenblätter, welche uriprünglid) in einer oder swo Spiralen ftanden uno mur zujammengerüt wären. Beb die= fer 2 tnnabme ift man gezwungen, wenigitens bie abwedielnoen Staubfäcen auch fütr einen Wirtel von Blättern anzujeben, wenn man aut) die an oen $\mathfrak{B}$ (umenblättern liegenden fïr blofe $2(n=$ bängiel beriefben wollte gelten lafien. (Sewöbnlid) bålt man jedo(b) auth) dieje für einen bejonberen Blattwirtel, jo dak aljo eine vollitånoige Blume aus orey in einander liegenden $\mathfrak{S}_{\text {Sirteln }}$ befänoe. Da es aber Blumen mit mebreren Saundert Staub: fäden in vielen fireifen gibt, fo muß man bie Zabl der Blumen= wirtel ins Unbeftimmte geben lafien: eine Ylnnabme, weldbe

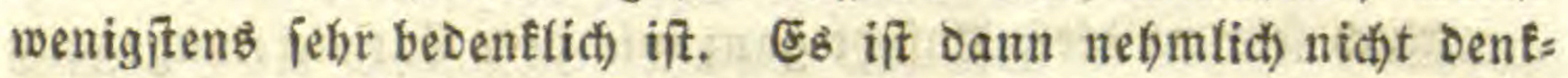
bar, dấ ein Blumenblatt dem andern vỏllig gleich fenn fönue; weil die zu ber obern Spirale gebörenden fleiner fenn witroen. Sie fönnten au(b) nich)t natb der Reibe fleiner werben, fonbern nur fiprungweife; weil die fid) einfdiebenden ans ber oberen Spirale zwifhen die der unteren fielen, uno zwar balo eitn, balb

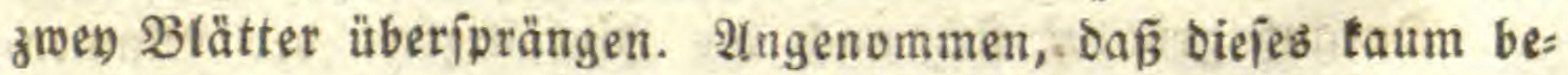

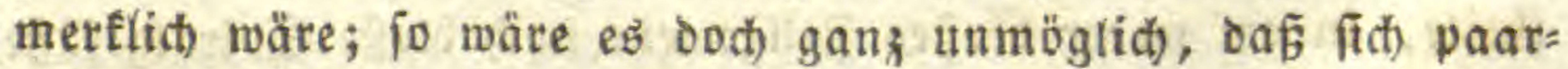
weife gleidhe $B$ lumenblätter gegenüber ftellten, wie bie Flügels und Rielblätthen ber Sametterlingablumen, Weber biefe noch) die zwo folgenten Mennungen find im Stanbe die herridiende Dren= uno Funfzabl oer Bratbentbeile begreiflich zu madten.

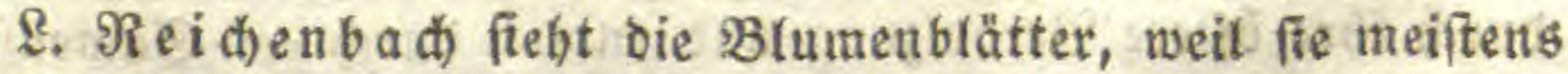
mit den Štaubfäben abwed) feln, füt Tebenblätter an, wovon alfo immer 2 uno 2 verwad) fen fenn minften, uno zwar die gepaarten 
bey Blumen=Staubfäben, die von zwey verifhiedenen Paaren bey field): Staubfäben.

A garob enolich betractet die Staubfäben als Bweige in Blattwinfeln, uno mitbin die Blumenblåtter als Stüb̧blärter. Dann gäbe es aber ben vielfäbigen Shlumen eime Menge Rreife von 3weigen obne alle Stübblätter, nebmlith alle abwect)ietnoen Staubfäben, fo wie diejenigen, weld)e in oen innern fireifen fteben.

2ule bieje Annabmen Gaben ibre groß̧en S(f)wierigfeiten, weldhe fid wenigitens vermindern nad meiner 2 (nftat, die id) faton in meiner Raturphilofophie (II. 1510. S. 89) vorgelegt babe, daß mebmliá Staubfäden uno $\mathfrak{B l u m e n b l a ̈ t t e r ~ z u ~ e i n ~ u n o ~}$ Demielben fireife gebören, uno jene nidts anderes ftno, als die völig frey geworbenen uno abgelösten Blattrippen, wodurd erfit eine völlige Irennung oer (jewebe erreid)t wirb. Damit allein lägt fid) die zweyleitige Stellung ber Sametterlings: blume, die grof̧e 3 abl der Staubfäben uno ibre verítiedene Stellung gegen die Blumenblätter begreifen, wie nicht minder

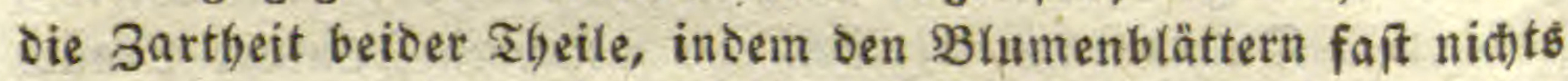
als 3ellgewebe, Den Staubfäben faît nichts als Spiralgefäbe geblieben find.

2(uc) ftimmt Dieje $2(n f$ fid)t ganz mit bem Entwicfelungघgang

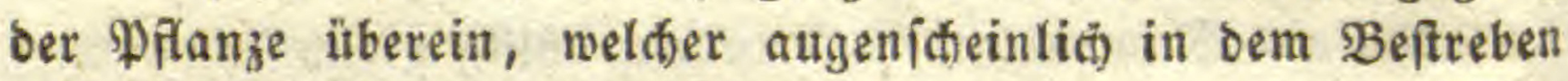
beftebt, ein (5ienebe vom andern za trenmen, und ebenfo die anatomijhen Syiteme wie die Drgane, z. $\mathfrak{B}$. das Solz von ber Rinde, ठаร Blatt vom Stengel, die Blattlappen von einander uno die Rippen von ber Blattfubf́tan.

Darauf grünoet fi(đ) aud) Die Sinfällgéteit Der Blumen=

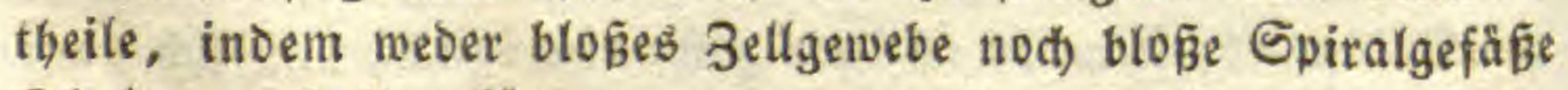
(iid) lang erbalten fönnen.

Enolich) bleibt fodann nur ein Sireis für ote 3 weigbilonng in Der $\mathfrak{B l u ̈ t b e}$ ïbrig, nebmlid) die fruthtbälge, welche innerbalb oer Blumenblätter fiteben uno fith theils Durd) ibre Rage, theil: Durd) ibre öftere Berbolzung uno enolid) Durd) Den Samenitand

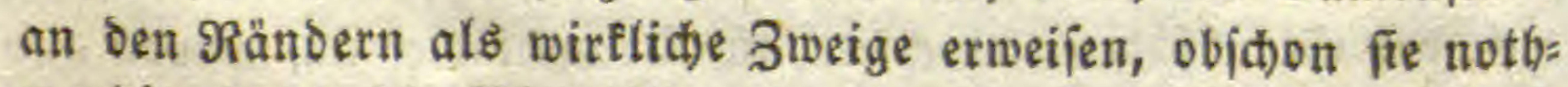
wendig ourd) bie Blattbiloung geben, weil bieje fpäter ift alb 
oie Stengelbiloung. Sey ben Malven biloen fie einen reiden

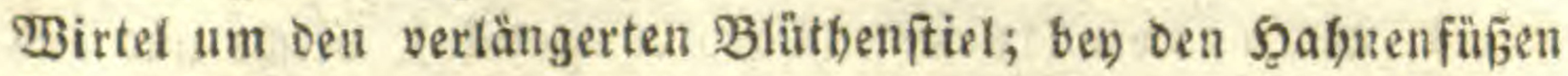
fiteben fie fogar zerftreut über einander.

Die Blume beitebt aus jebr zartem Bellgewebe und ebent joldben Epiralgefä̧en. Dieje bilben aber feíten eine Mittel= rippe, fondern trennen fid) fison unten uno vertbeilen fich in Das Blatt. Ueberbaupt zeigt fitc) überall bas Beftreben biejer (3efäze, fich fowohl unter einander als vom Zelfgewebe zu iondern.

Wenn aud oie Blumenblätter von einander getrent fino uno leid)t abfalfen, io fino ood) alle eine Fortiekung einer zarten F̧aut, weld)e ben field ausfüttert, und alio im $\mathfrak{B o b e n}$

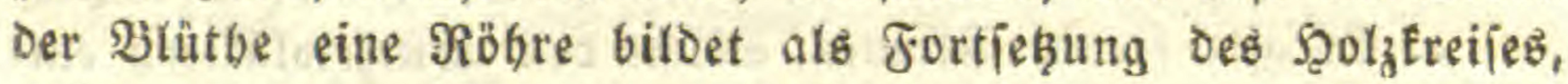
welder aus dem Stiel berauf fteigt, um fich als entfalten. Эit Diefe Unterlage Der Blume bicf uno bentlid), fo thennt man fie Sateibe voer Bett (Disens, Torus), bejon= Ders beutlich) beym sireuzoorn. Unmittelbar itebt oaber nie ein Blumenblatt auf Dem Stiel oder Reld), fo nebmlid), nls wenn

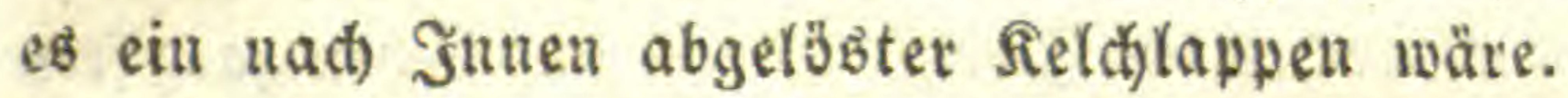

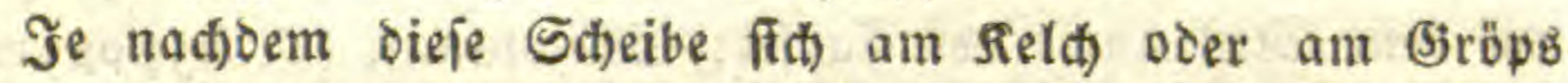
weit berauf ziebt, ehe fie fid) in Blumenblätter theilt, änoert fidh auth Der Stand Der Yekgtern: auf Dem Booen, in Der Mitte Des Reldis oder am Rande Defferben.

Die S(t)eibe theilt fid aud mandimal in S(t)uppen uno

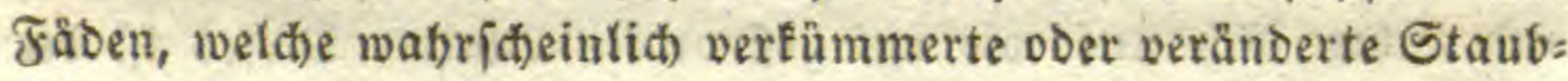

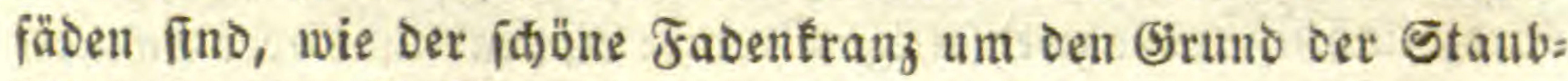
fäden bey der Paifionsblume.

Ben ber 2lfelen gibt fie innerbalb der Staubfäben zely

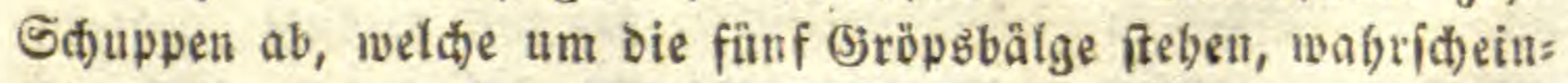
lidi) verfitmmerte Staubfäden.

Ben ber Seeroje wadien foldse S(t)uppen febr-boh um Die Eapiel berauf, uno tragen die Staubfäen. Benm Mobn umgibt bie Sabeibe die ganze Eapiel, uno baber flafft fie nur ourd) Rö(t)er unter Der Rarbe. Ben ben Eitronen ift die gelbe

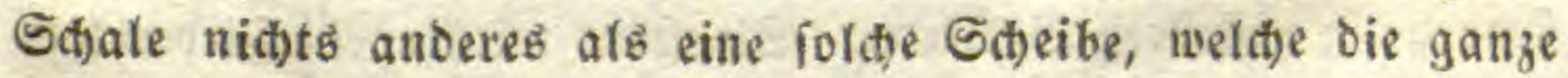
Fruact ibberziebt. 
(Eี gibt, wie bey ben Blättern oder Relchen:

1. S d) u ppen b (umen (Corolla apetala), weld)e nur aus einem und bem andern verfímmerten Blättchen beifehen, mie

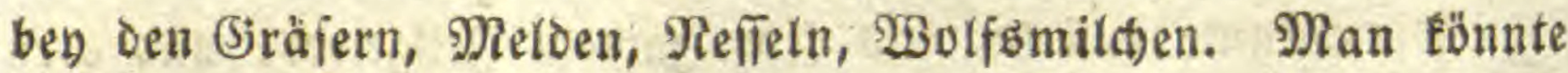

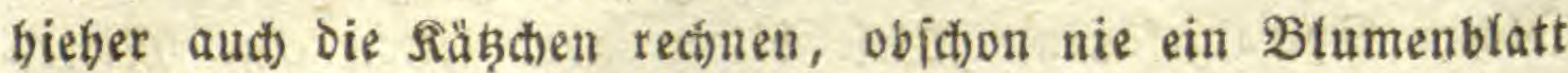
vorbanden ift.

2. Sc) eideublumeu: oie röbrenförmigen oder einblätteri= gen (Corolla monopetala), wie ben den Gchlüfielblumen, (S)locten: blumen, WinDen, Raubblätterigen, Rippenblumen.

3. Es gibt $\mathfrak{Q} a \mathfrak{b} b$ lumen, welche ganz getrennt find: Die vielblätterigen (C. polypetala), wie bet) Den Relfen, Ranunfelt, Rauten, Freuzblumen, Maloen, Dolben, Roien, 2lepfetn u.f.w.

1. Ė gibt ferner Blumen, weld)e den $\mathfrak{W}$ urzelblättern ent: iprechen. Es ftno Diejenigen, welche auf Dem mit Der Eapiel verwadjenen field)e ftebẹn (Corolla epigyna). Sie tönnten (j)röpsblumen beifen.

2. Snoere entipreden ben Stengelblättern uno fteben anf oem freyen fiel(t): field)blumen (C. perigyna).

3. 2(nDere entipreç)en Den Zweigblättern, uno fitehen ganz frey auf Dem Stiel unter Der Eapiel: Stielblumen (C, hypogyna).

Man fanu amthmen, tấ die Blumentuojpe fích auf zwenerley 21rt fpalte, wie die Slattenvipe: entweder vom Sipfel gegen ben (jirund, woourd) Die regelmäfige voer runde Blume entitebt; oder fie ipaltet fitf) quer auf einer Seite des (Sirundes, und ridjtet fid) auf wie ein gefiebertes Blatt. Diejes if die

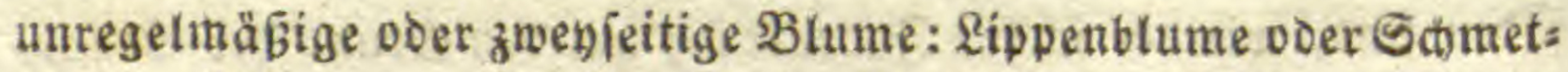
terlingsblume, je nachbem die $B$ lätter verwadjien ober ge= trent funo.

Ba th or $B$ It me.

Sie Ratur oer Blumenbiloung lägt fid am beften aus ber jwegieitigen barifellen,

Sie befteht aus einem ungeraden Blättdben uno aus zweb ober vier geraden, uno ift Daber orey= ober fünflätterig mit fiederartig geftélten Blättert. Sie ftellt mitbin ein Fieberblatt vor, und faun fiederblume beísen. 
Die regelmä̧ige $3 a b l$ oer Blumenbläter if oaber die un=

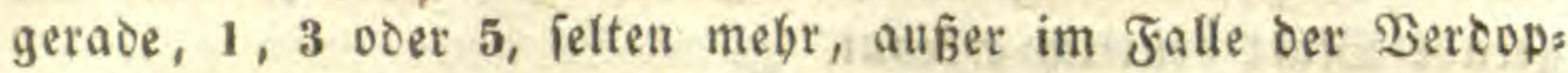

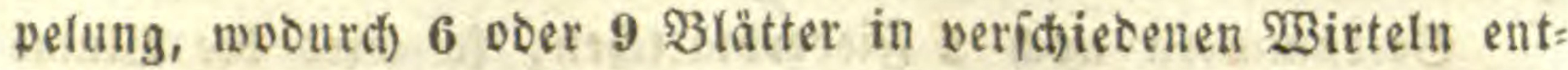
fiteben, voer aus Der fünfzäbligen Blume eine zebnzäblige wiro.

Das ungetade Btättot)en fteht natürlicher $\mathfrak{W} e i f e$ immer oben; Das nächfte Paar feitwårt geridftet in Der शitte; Das lekgte Paar unten.

Drenblätterige Fiederblumen fincen fitch beh Den Drăiden oder den Rnabmurzen; fünfblätterige ben den Beilden, Errbien uno Bohnen. Eह fino die eigentlichen Sळmetterliugb̆blumen.

Das ungerade Blatt ift oas gröbte uno beī̄t $F a b$ ue (Vexillum); Das nähfte Paar Fl ügel (Alae); Das unterife Sthiffchen oder Riele (Carina), weil es gewöhnliđ) verfüm: mert uno verwäc)st.

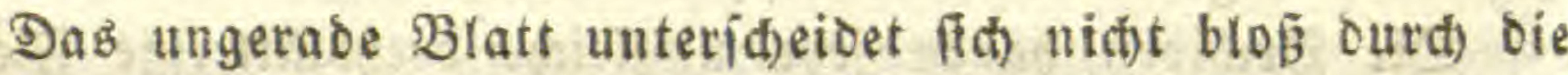
abgejonverte Stellung und die (Sirößze, jondern auch) meiftens ourch) eitle grö̧̧ere $\widehat{Z a b l}$ von Blattrippen uno eine andere Fărs

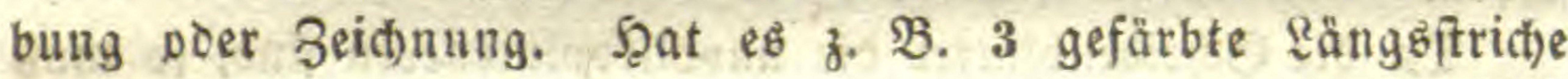
oder Pfeile, fo Gaben die Flügel nur 2, die Blättchen des Shif: कens nur einen oxer gar feinetr. Die Fabne bat oft in ber Mitte eimen Flecten, weldoer Den anbern feblt 4. f.m.

Siac) Diefer meiner 2 (nficht beftebt eine Shume mit einer eimzigen Blätterreibe nur aub einem Blatt, weld)e in mebr voer weniger Fieverblätt(b)en getbeilt iit.

Die Blume ift oaber nur eithe einfadje finoipe, uno nidt ein Sirtet von mefreren in einer Spirale ifber einander fteben= Der Rnoipen.

Sino aber die Blumenblätter niđdt felbititändige Blatt: fdeiden, fondern nur ein getbeilteg Blatt; io milifen wir aud)

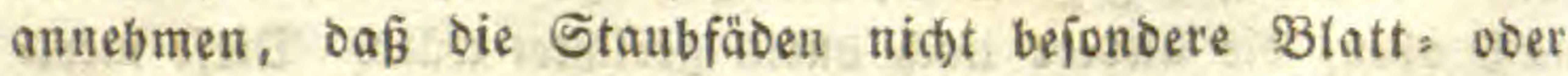
8neigmirtet find, fondern nur abgelöste $B$ lattrippen.

Bemert man beg einer Blume die gerade $3 a b l$, vier oder

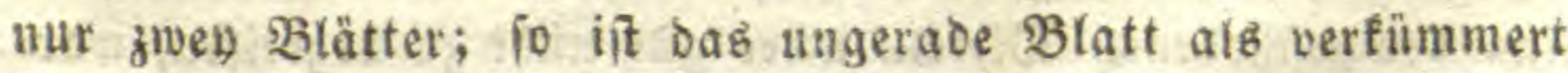
all betrachten.

Die Fabne ift befänoig verfimmert ben oen Rreuzblumen, wie beym Robl, den Reptojen. Dann fteben bie vier Blumens 
blätter io zufammengerüct, daई man bie stute für bas uns gerade Slatt bentlitit) erfennt.

Bertïmmern noct) 2 Fiederblätt(đen, fo wiro bie Blume 3)wenblätterig, wie benm Şerenfraut (Cireaea).

Sebr felten bleibt Das ungercoe Blatt allein fteben, io זa (Amorpha), Solá) ein einzelnes Blumenblatt fummt aud) ben) einer Pflame in (5muana vor, mit Ramen (5uale (Qualea), ben einheimifichen mict)t.

Mit ber Berfümmerung voa Błumenblättern verfümmetn

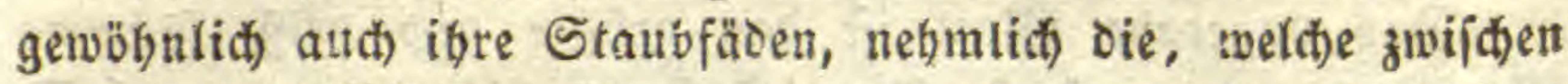
ben fleinen Blättern liegen, uno oagegen werben biejenigen grö̈ßer, welche den größern Blättern entiprecten. So bey ben Sd)metterling blumen uno sippenblumen.

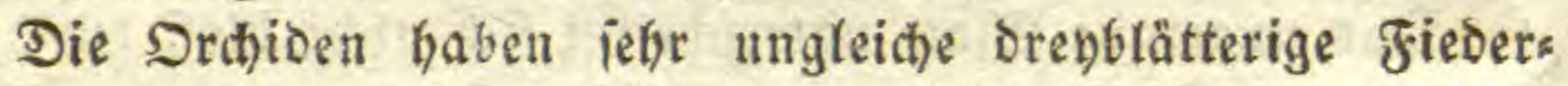
blunen, weldhe aud gegen sen brenblätterigen Reld) verḱebrt fiteben.

Da bie Sकeibenblätter bie unvollfommeneren find, fo nuв man auch bie unregetmäßigen $B$ tumen für unvolfeommen hal: ten, uno mitfin für biejenigen, aus welden fid die regels måjigen entwicteln.

In $\mathfrak{B}_{\mathfrak{e} \text { ug }}$ auf ben Fieldh iff Die Fiederblume zu betract)ten als bie zwente oder innere, mithin entgegenftebende Blatticheide. Daber verbalten fith Fiederfelth) uno Fieberblume immer um= gefebrt zu einander, Doer ibre Iappen fteben verfebrt, ber un= gerabe Rebllappen nebmlí, immer Der Fafne gegentiber, ober unten weln bieje oben ift, nebmlích zmijhen ben Sielen; bie geipaltene Relthlippe liegt Dagegen auf Dem Rücten Der Fabne. Beide fteben fich) gegenïber, wie zwo Şände, wovon bie eine nach oben, bie antere nach unten geriabtet wäre. Dieje merts würbige Stellung (pricht auch) febr für bieje 2(nfid)t; wenigftens

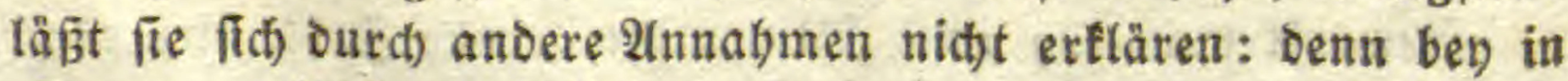
einander gef(hobenen Wirtel'n wäre gar nicht ju begreifen, wars um Selch) แno Bltume paarweife Eleinere Blättçen bätten, uno

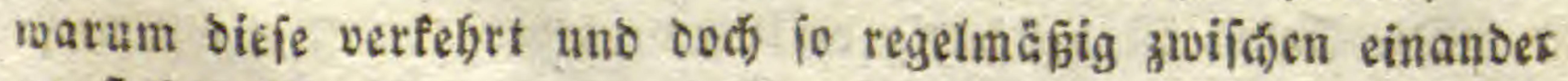
خ̀ ftêren fảmen. 
Regelmä́fige Blumen.

fian man etwa zweyerley unterideiben: $S_{d}$ rauben= uno $\mathfrak{a i r l b l u m e n .}$

Stellen fid) Die $B$ tảtter etwas fpiralig über einanber, fo if eb bie eriftere.

Rücten Die itber einander ftebenden Fiederblättđ)en in einen รireis zujammeñ, fo entîteht die ganz regelmäbige Duirl = ober Sternblume, in weld)er nebmlich die Blätter in gleidber Söbe entipringen und einen vollfommenen freis billoen.

Die regelmåjige $\mathfrak{B l u m e}$ ift oaber aud) ungerab, orebs ober fünfzăhlig.

Die erftere findet fich bey Den Monocotyledonen oder Shei= Denpflanzen; Die fünfzăblige bey Den meiften Dicotyledonen oder Meşpflanzen.

Dẩ Die regelmäßigen SBlumen aus den unregelmåfigen entifeben, fann man bey ben meif́ten nod) beutlich nadimeifen, theils ourd) etwas verídiebene (5iröbe, fdiefe Stellung und ver: iđhiedene Färbung Der Blätter.

Iuch) ben Den regetmäbigiten Blumen fteht ein Blatt febr oft ein wenig abgeionoert, oder es ift etwas gröber, oder ein wenig anders geftaltet, ober anders gefärbt uno gezeidnet. 2uf alle dieje Dinge mus man genau $2(a) t$ geben, wenn man die

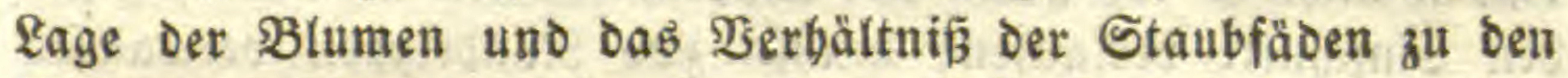
Blättern bejtimmen will. In diejem Fall ifî es faît unmỏglich), die grofie §abl ber Staubfäoen anders zu erflären, als ourch) eine völlige Zerfallung ber Spiralgefäß̈bindel.

\section{Röbrenblumen.}

Die Röbren = oder Sheibenblumen find zu betrachten als folde, bey denen oie Blätter verwachien ftno ober fich nid)t ge: trennt baben. Sie verbalten fid oaber ibrer Geitalt und $3 a b l$ nad) auf biejelbe 2 Beife.

Die regelmäßigen Röhrenblumen fno entweber orenipaltig voer fünfipaltig.

2(uc) bey diefen bleibt Der field) oft lippenförmig, weil er eitte niedere Billoung if?. 
Bleiben die Fieoerblättchen verwadjen, fo entiftebt bie \&ippens blume. Эbe Stand if gegen bie Sd)metterlingsblume verbrebt. f̧ier it nehmliä) biejenige sippe, welde aus bem ungeraden Blättchen uno den zawen obern Fiederb(ättd)en beiteft, bie untere; Die zwenzăblige oder geipaltene uno gewöbntid) Eleinere Rippe oagegen if oie obere.

Şier verfümmert in Der Regel Der Staubfaden, welder all Der Dberlippe liegt. So ben dem \&öwenmaul, ber Braunwur u. f. w. Der vertummerte Staubfaden if́t bier wie aud anders wärts nid)t felten ourah einen beiondern Farbenflecfen an ber Blume angedentet.

Bè allen unregetmäfigen Biumen ift es auth ber Feldh.

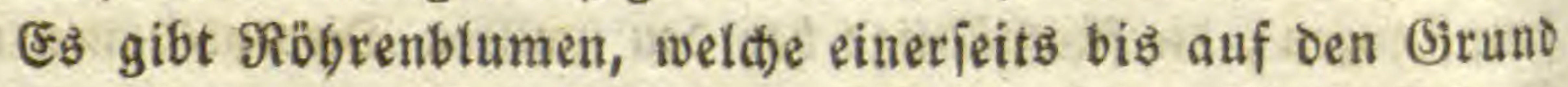
geipalten find, uno Dadurd) z $\mathrm{u} n g e n f o ̈ r m i g$ (Corolla lingulata) werben, wie benm Salat. Dennod) zeigen fie am Rante 5 Säbne. (Eigentlid) ift bier bie Dberlippe ganz geipalten.

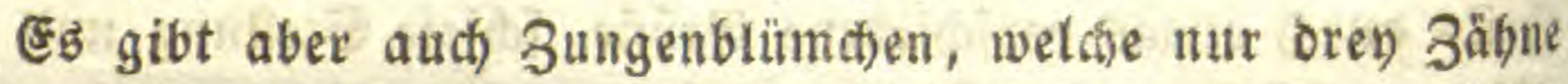
baben, wie z. 2B. in Strabl vieler Supfblïtbeti. Dann fellit oie Dbertippe ganz, oder fie sticheint nur afв Spur am Grunde, wie bey ber sonnenblume.

Die Ropfblütben yaben nod) das હigene, Daß die Droffel: rippen nict)t in Der Mitte Der Rappen, fondern am Ranoe gegen Den Einfduitt verlaufen, mithin zwo Randrippen verwadjien find. $D \mathfrak{a}$ aud bie Staubfäden bafetbit, nebmtid abivedjelno, fteben; fo fönnte biejes auch Darauf beuten, Daß fie zwo- bers wahliene uno abgetöste Ranorippen wären.

\section{Rnofpenlage (Aestivatio, Praefloratio).}

Bor bem 2tufbläben Gaben die Blumenbfätter eigentbüm: lide Ragen in ber Fnoipe, wie das Raub. Da biejes ben der Beftimmung ber Bünfte berilcfifdtigt wiro, fo muß es erwäbnt werben. Wie die Stelfung der. Błumenblätter auf orenertey 2lrt vorfommt, fo audh ibre surofipenlage. Dedft ein Blättchen Die anbern, wie bie Fahne in ben Sthnetterlingsblumen, fo ift es eine Fieberfage (Aest. imbricata), wié bey den Eippen= blumen; bectt ein Seiterirand dell andern; Sd) raubenlage 
(Ae. contorta), wie bey oem Sinngrün (Vinea); frogenen bie Blättđoen nur an einander, Duirllage (Ae, valvacea).

Berf th merungen.

Fein Theil oer PRanze it fo fehr den Berfummerungen unterworfen, wiè bie Blume nebft oen Staubfäden. Die Blät= ter verfleinern fïh nicht nur febr båufig, jondern verídwindent

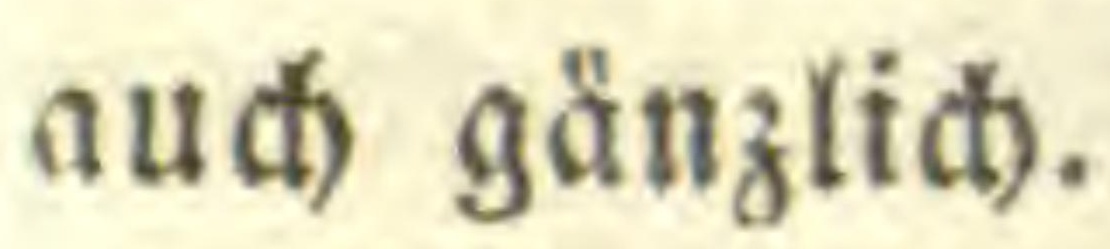

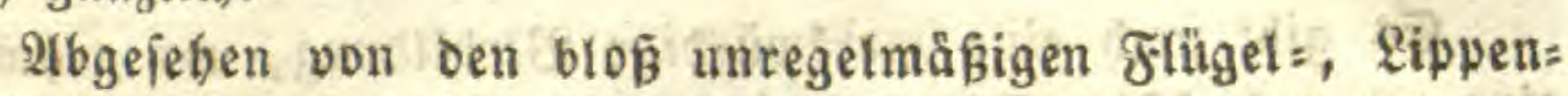
und Zungenblumen, gibt es eine Menge, wo ein uno Der atibere Eappen ober Blatt fletiner wiro, wab jeood meiftens fía auf

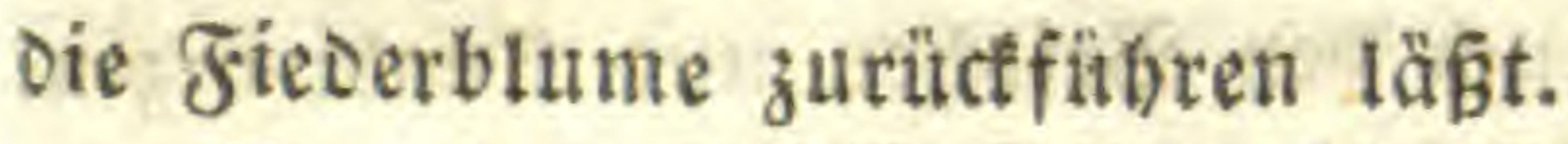

Bey oen Gräiern fino oie Blumenblätter immer ungleid) grofi, es feblt immer eines, zwey tulo wohl alle oren.

Beh Den Meloen, 2tmaranten, Nefieln zeigt fich felten ein. Blumenblatt, obidon ber seld ziemlid vollfommen ift unt \$lą̧ dafür bat. Man nenut fie daber blumentoie (Flos ape-. talus). Fnoeflen if mandimal bie Blume nod) ourd) S(buppen angedeutet.

Bon ben Rreuzblumen, benen ein $\mathfrak{B l a t t}$ feblt, ift fion ge= ipro(t)en. 2(ber aud) bey pielen Ranunculaceen feblen Blumen: bfätter. So hat ber Ritteriporn nur vier, Der Sturmbut nur zonen.

Bisweilen feblen bie Blumenblåtter ben Sattungen, wäb= reno fie ibre (Gefit)wifter baben, wie ben dem Malttraut (Sagina apetala), 2(born, 2teid)en, $\mathfrak{B}$ eil(t)en.

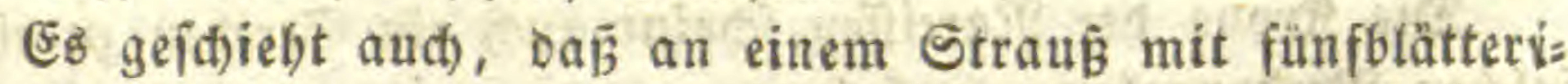
gen Blumen eine und die andere beftändig nur vier Blätter bat, wie bey Faute, (5oldomilz, Bifamfraut.

\section{Berbilougen}

fitno ben den Blumen febr Gäufig. Sie werben bejonbers gern unten fact= tho ipornförmig (Calcar), wie ben Nitteriporn, Ilfeley.

Doer fie befommen oben eine 2trt 5eetm, wie begm Sturmbur. 2ud) meroen bie Blumenbratter röbrenförmig, oap polde 
Blume aแsfiebt, atร เweแn fie z̆ ben zufammengefęten gebörte; fo bey ber Niešutrz, wo gewöfnlitit) auti) einige Staubfäben

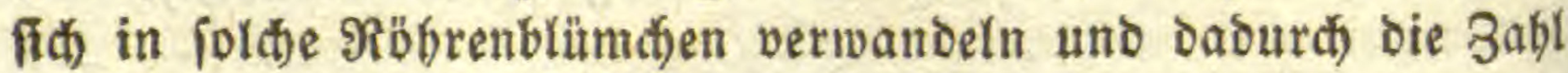
vermebren. Nur diejenigen find bier äd)te Blumenblätter, weldhe mit ben fünf Sieldblättern abwect)ieln.

Die Röbrenblümben ber 3ujammengeiesten ipalten fith manch)mal in 3ungenblümd)en. Man nennt fie mit Unrecht: gefültrt.

(Es gibt nođ) eine merf́nüroige \$erbiloung, wo nebmliđ

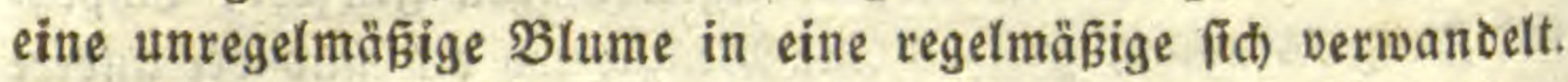
Dab fommt nidst felten vor bey den Rippenblumen, bejonder beym Reinfraut (Linaria), aud) bey Beilden uno finabwurzen. Dergleiden Bfumen heifen befegrte (Peloria).

\section{Berooppelung.}

Doppelte Blumen nennt man diejenigen, weldie aus zween

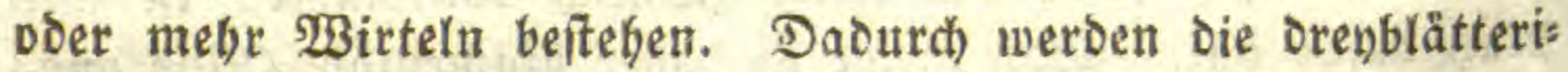
gen fech)bblätterig u.f. w., bie fünfblätterigen zeb̆nblätterig u. f. w. Die innern iff îbrigens ein natïrlicher 3 uftano, und findet fich auggezeid): net bey Blumenbinie (Butomus), Pfeilfraut, Seerofe, Factel: diftel, Faierblume.

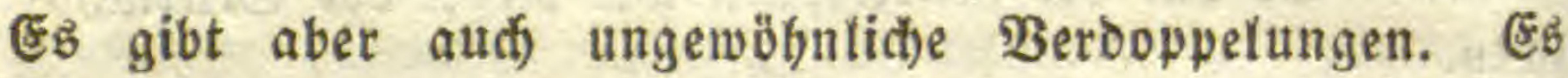
ftecten Dann zwo Blumen in einander, wie beym Sted)apfel (Datura fastuosa), bey (Jlocten= uno mandien Rippenblumen, aut)

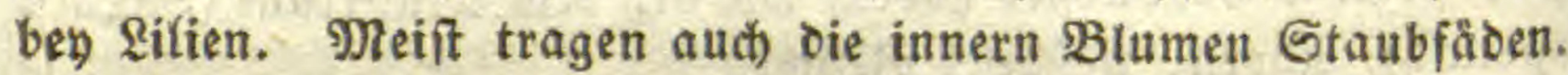
Die frone ber Rarciffen idseint auch ein Streben zu eituer folden Berooppelung zu fenn.

Bey den Relfen fommt Diefe Berboppelung oft vor.

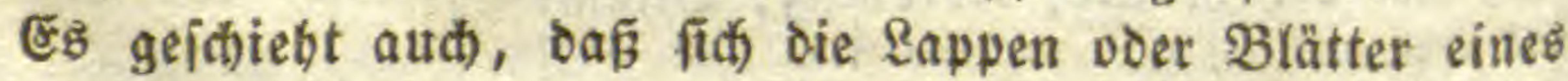
Wirtels uttr vermekren, wie bey Zeitlofe, Flieder.

\section{Die 8 uีll ung}

entfteht burd Serwanotung anderer Theile in Błumen blåtter, namentliđ) Der Staubfäden uno Bälge. So ebenfallø

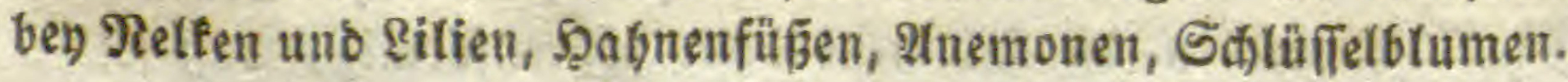


2)

ber Blumenblätter tommen' felten vor.

2(m bäufigiten in Reldblätter veråndert ben ber Radbtviole

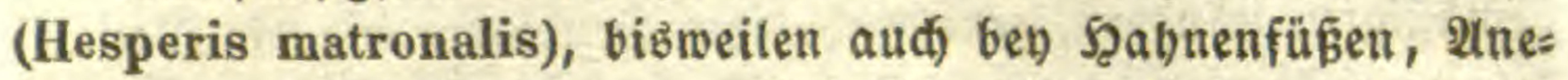
monen uno Gjlocfenblumen. In Staubfäben verwandelt bat

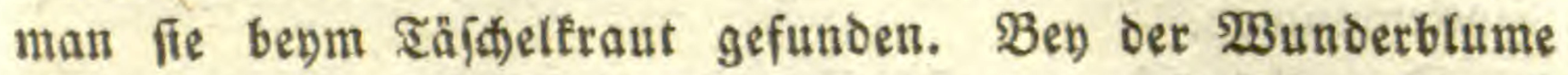
bilbet ibr unterer Igeil eine 2 rt $\Re$ ณ oer obere abipringt.

Farben.

Эđ) babe in meiner Naturpbilof́ppbie (II. 1810, 88) zu zeis

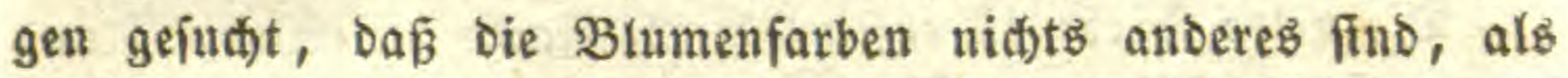
Zerfallung bes Gritnen im Stoct. Dieje Anfid)t ideint nun allgemein angenommen zu jeyn. Sie wiro aber nur begriffen, wenn man es fid) gebörig beutlid) mad)t, Dấ die Blittbe felbit nid)ts anderes î́, als ber zerfallene Stoct.

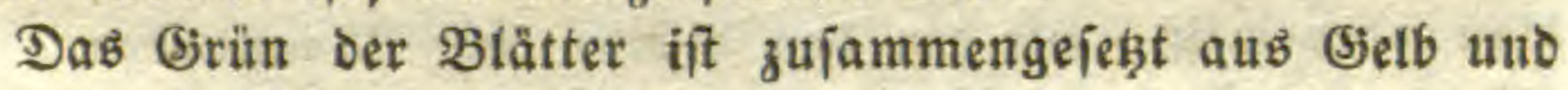
Blau, uno dieje zwo Jarben werden bey ber Entmictelung Der Blume geidieden, wahrideinlid) Durd) mebr oder weniger $\mathfrak{B e r}$ binoung bes Sauerftoffs mit ben grünen Rỏrnern. Durd Său= ren werden fie blau uno rotb, ourd) Alcalien gelb.

Das (jelbe gebört den unbeleud)teten Theilen an, bem In:

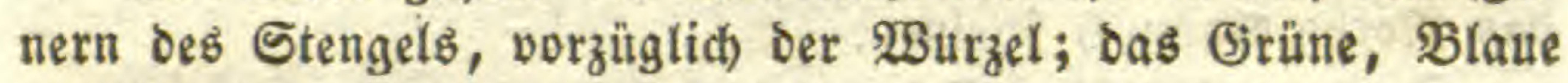
uno Fothe ben beleudteten Iheilen.

Bey mandhen Pflanzen fateiben und vertheilen fid) bie $\mathfrak{B} e=$ ftandtheile bes Grünen auffallend in Stocf uno Blütbe. So

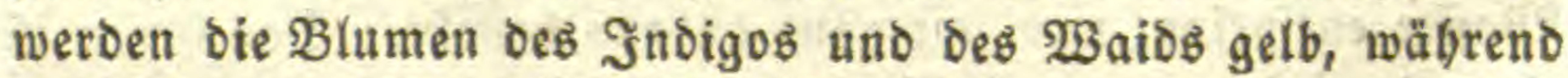

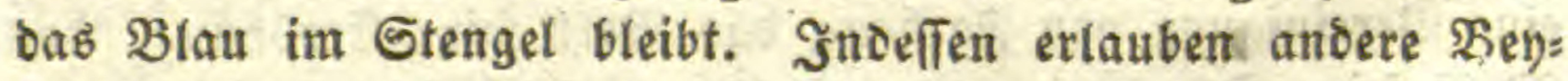
fpiele nidht, aub ben Farben ber Blumen auf bie bes Stengels oder der

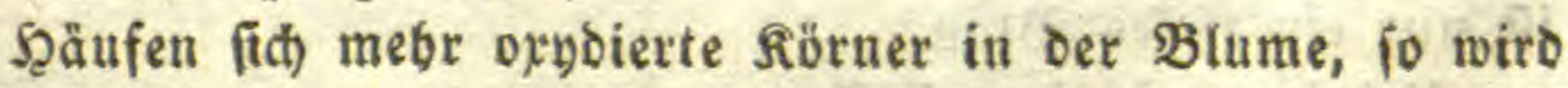
fie roth; vermindern fith bagegen bie Rörner, ober werben bie Zellen ganz leer, io wiro fte weif.

Die weisen Blumen fino Daber meiftens jefr zart uno verwelfen balb. Sie finben fid) am Gäufigiten in ben falten Siegenten, im 23 inter, Früb) = und Spätiabr. 
Die rotben Blumen fino am bäufigiten in Den beiß̧en \&än: Dern; bey uns im Sommer.

Die gelben uno blauten Blumen finto am bäufigiten in ben gemäß̈gten \&änbern, jene mebr ibm Jrïbjabr, wie bie Ranun: feln uno Rreuzblumen, diefe im Spätiabr, nie bie Enzziane uno (3)loctenblumen.

Das Gelb ift ofne 3weifel die niederite Farbe. Es geht ourd) Serfärfung in Roth über, biefes Durch Schwächung in Biolett und Blau, und Diejes enolid) Durd) Mangel an गabrung

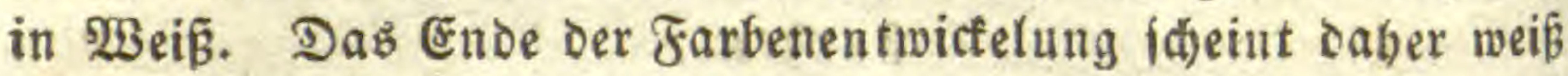
子u ienn.

Die gelbe Farbe if eigentlict Die Farbe ber Wurzel, und baher ift bie Mitte ber Slume, welche ber Wurzel entipridt und zulest ans \&idit fommt, faif immer gelb, wenigitenz cie Staubbentel. Ben zujammengejesten Blüthen fino febr häufig Die innern voer bie Der Sd)eibe gelb, bie äugern voer ber Strabl blau voer weís, wie bey Den Mftern uno Maálieben. Der Gruno ber Blumen if oft getb, wäbreno oer Saum blau ift.

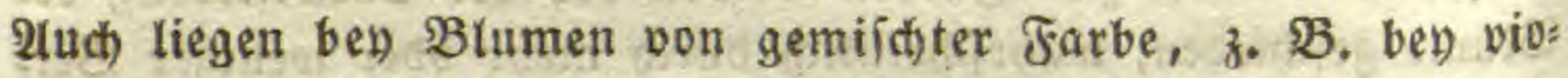
letten ober rötglithblauen, bey rotbgelben it. Dergl., bie blauen Rörner in ber äufern Sellenictidit uno bie rothen barunter; bie gelben nefmen immer bie tiefite Lage ein, io Dấ fie ourt) bas Rothe bindurch ideinen.

Da das Gelb oer Eroe, das Girün dem $\mathfrak{3 a f f e r , ~ d a s ~ B l a u ~}$ ber \&uft und Das Roth bem Fener entiprict)t; io ift bie gamze Pflanze vielleicht beģbalb grün, weil fie vorzüglich) aus bein WBaffer entipringt uno faif ganz Daraus beftebt. Das (Grin if eine Bereinigung von Farben; Das Roth feine Erböbung; bab Weiß feine Schwåchung; Das (5elb uno Blau feine Zerfallungetr.

WBirtlid)es S(f)warz fommt bey ben Blumen nidtt vor. ¿'s if nur ein tiefes Blau.

Uebrigens ideint bie Slumenfarbe nidit bloß von Rörnern Gerzutommen, fonbern auch von farbigem Saft, worinn man Eleine Sïtner bemerft. Man follte glauben, Daß̧ die Berwande lung des (Grünen in andere Farben baourch geídähe, da Be feine

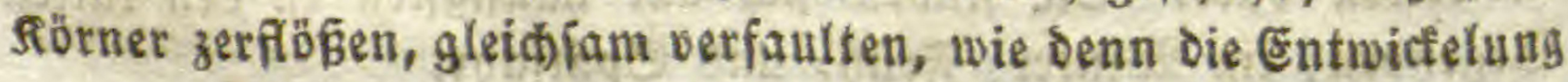


Der Blunten offenbar ourd die 2Abjonderung oer Staubfäbent oder Epiralgefäßze ein 2lbiterben der Slätter if́, uno ibnen gleidfam gefund oas begegnet, was ben Blättern am Ende des Sherbites, wo fie vor bem 2 (bfallen wieber bie Farbe ber $\mathscr{B}_{\text {Burzel }}$ annebmen, nebmlfa') gelb, bratn ober rotb werden, uno endidi \{đ)warz. Reeres, lebendiges Bellgewebe if mein, volles roth, todtes ifwarz. 2luf jeben Fall if ber Farbenwed)iel ein Ueber= gang in bas Reid) ber Mineralien, tnd zwar ber Metalle, als weldhe bie einzigen Rörper fino, Die bas Ridit zurïcfwerfen uno ourd Sxyoation alle Farben annebmen, ourd) idwadie meiftens (千)warz, bann blau, grïn, ourd ftärfere gelb uno roth werben.

Die Uriad)e des Farbenwediels ben ben Pflanzen ift ofme

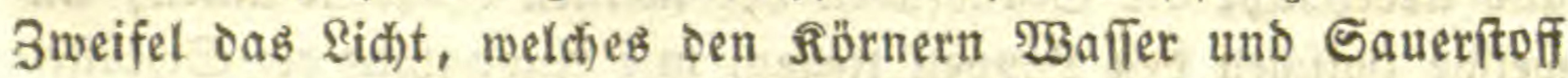

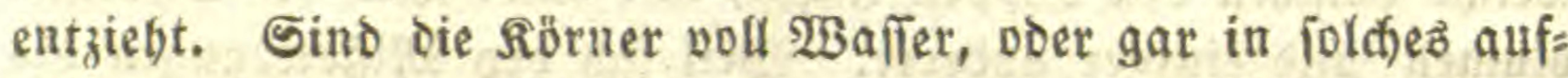

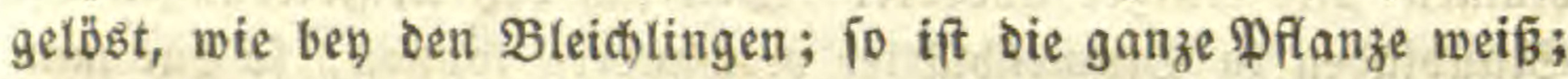
Deģgleidten die meiften Blätter uno Blumen in Der snofipe. Sobalo das \&idit barauf fällt, werden fie grün, zerfallen Dann in Gielb und Blau, aus beren jedem ftch Roth entwicteln fann, je nachdent Såure ober Rauge barauf wirft.

\section{Stau ufäden (Stamina).}

Die Staubfäden fino abgelöste Blumenrippen mit zwen ge= (A)loffenen Fiederblättden am Ende.

Eg finb verfärbte utto fitelförmige Theile, welde innerbalb Der Blume, oder wenn biefe feblt, innerbalb bes Reldfes ftehen. In Sienebe uno Bau gleidten fie vollemmen ber $\mathfrak{B l u m e}$. Im Zellgemebe läuft ein einz̧iges Droffelfbünoel. Die Spaltmün= oungen ferlen.

Sie entípringen auth), wie oie Blumenblätter, aus einer gemeini(h)aftlidfen, febr zarten Röbre ober hautartigen 2usbrei= tung, welde unten ben Stiel oder aud ben Sield ïberzieht, nebmlich) ber $S$ d) eib e ober bem bett (Disens s. Torus).

Bald fteben fie am (Grunde der Blumenblätter, Dder, wie man eg nennt, denfelben gegenủber (Stamina opposita), uno bann feken fie völlig aus, wie bie nach innen abgelöste Mittel= rippe; bald aber fteben fie abwedifielno mit oen Blumenblättern, 
D. b. im Einjichnitte Derielben (St. alterna), und Dann ieben fie

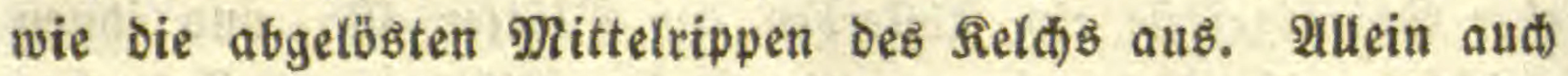
biefer Faben erhebt fich aus bem SBlumenboden oder ber Scheibe, welche Den field ïberziebt, uno gebört Daber Der Blume an, obichon Dem Uriprung Des Staubfabens aus Dem fielde felbit nid)tb entgegen fteht, wie eb bie Rilien, Shwerbel und faít alle Sڤlibenpflanzen zeigen.

Sold) ein Wedfielfaden fann aud) betradtet werden alb

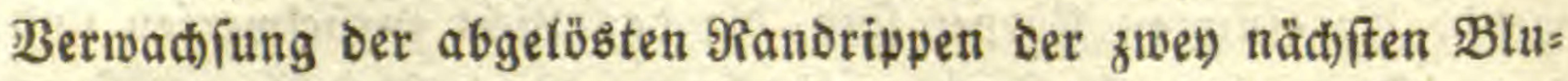
menblätter, wofür bejonders die Rippen Der Röbrenblümchen bey Den Ropfblüthen fprectien, weld)e zu ben Einjanitten laufen; uno überbaupt bie Staubfäben oer meiften Röbrenblumen, als

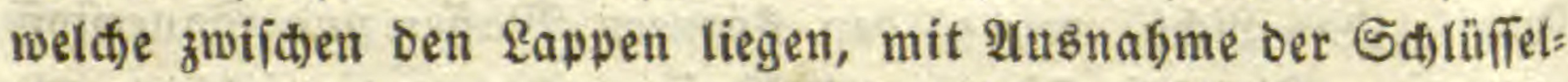
blumen und einiger anderer. Meil fich beb Mif́biloungen bie Staubfäden in Blumenblätter verwandeln tönnen, fo bat man

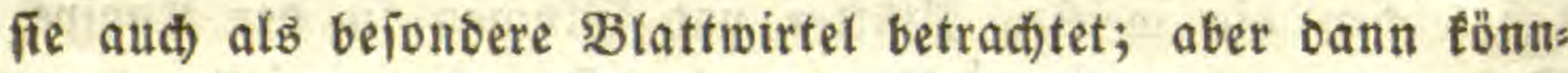
ten die Staubfäben niđ)t den $B$ lumenblättern gegenüber fteben uno mit ihnen verwachien jenn. Betrad)tet man fie als 3 meigs wirtel, io mübten alle in ben $B$ tumenblättern alb ibren Stübs: blättern ftehen und feine daneben.

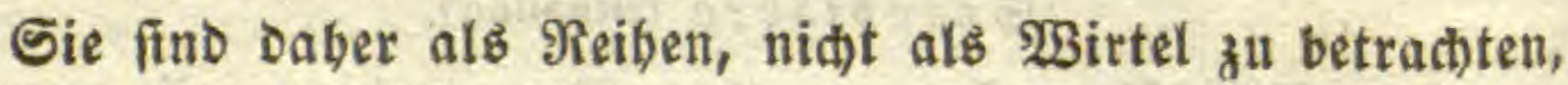
auBser in Den ooppelten Blumen.

Die abmechielnden Gtaubfäben fommen am băufigiten im Pflanzenrei

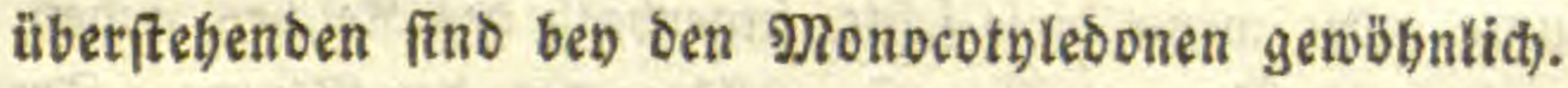

\section{$3 a \mathfrak{l}$ l.}

Die regelmåpige $3 a b l$ ber Staubfäben riđtet fid immer ttađ) Der $3 a b l$ oer Slumenblätter, fund mitfin orey= oder fünf= zăblig.

(jewöbnlich îtebt nur einer vor oder zwifđi)en ben Blättern, und Dann find es ibrer 3 voer 5 . Sind beibe Reiben vorban= Den, fo find es 6 oder 10.

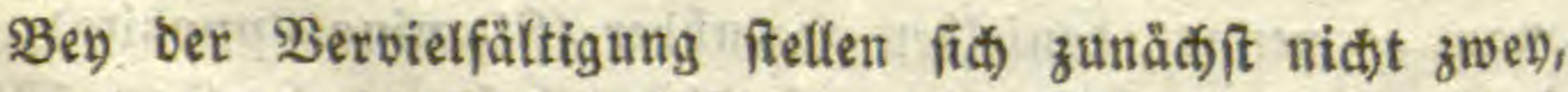
fonbern oren vor die $B$ lumenblätter, meiftens nur bey ben fünf= blätterigen. Dann find eร $5 \times 3$ oder 15. 


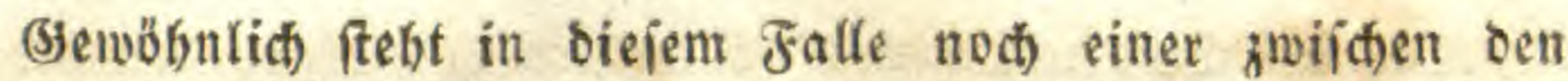
Blättern, unb bann find eE $\mathbf{1 5}$ unb 5 oder $\mathbf{2 0}$, wie bey $2(e p f e r n$, 3ogelbeeren, Miipeln, Weif̧́oorn.

Dft fteken auth 5 vor jecem Blumenblatt, aljo 25 uno 5 ober 30, wie bev Den Traubenfirict)en.

Bisweilen zeigen fid) viele Sireife ber 2 Int in einander, und baun find es $5 \times 30$ oder 150 , atti wobl noch einmal fo viel oder 300, wie bey mandien Facteldifteln (Cactus).

Ein einziger Staubfaden fommt faft gar nicht vor; beym Tantenwedel burch augenideinlidte Berfitmmerung.

હbenio zeigen alle gradzăbligen fäten bie Berfümmerung von anderen.

Berwad) f

Sn ber $\Re$ Regel find bie Staubfäben von einanber getrennt; bisweilent verwad̆fen fie aber atth) röbrenförmig mit einander, wie bey ben Malven. Man nennt fie ei nbritberige (Stamina monadelpha).

Eöst fíl) ein Staubfaden von der Röbre ab, wie bey ben

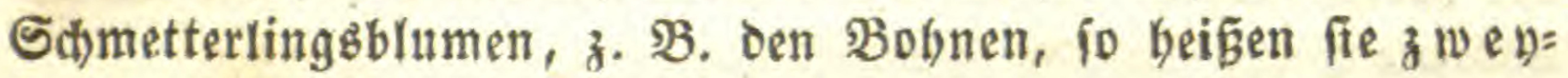
brïberig (Stamina diadelpha).

Trennen fie fith in mebrere Bändel, fo beifen fie viel= br it berig (Stamina polyadelpha), wie beym ฐobannistraut.

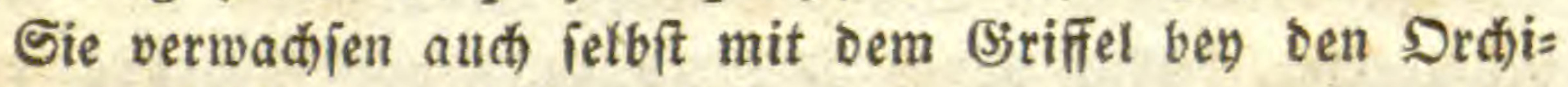
ben oder Rnabivurzen (Gynandria).

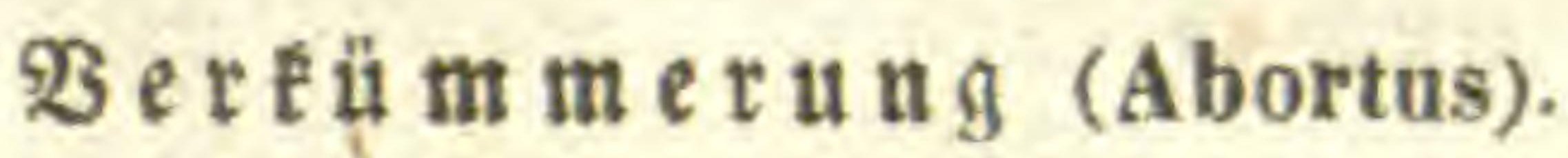

Die Berfämmerung oer Staubfäben hat igre Grade. $3 \mathfrak{u}=$ erit feblt nur ber Beutel, bann zeigt er fich balb verfürzat, end=

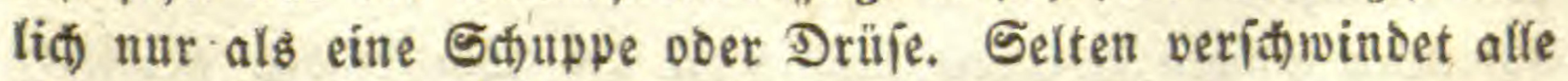
Spur. Dft ift er nod) burd) einen gefärbten Flecten angebentet.

Bey Den regelmäpigen Blumen fino oie Staubfäben mei= fitens gleid) lang; ben Den unregelmäbigen aber ungletid. Die: ienigen, welche an oder neben Dem groß̧en ober ungraden Blatt fteben, fino länger; bie andern Dagegen fürzer uno mand)mal ofne Beutel. So bey ben Sdmetterlingsblumen.

Dfen s allg. গaturg. II. Sotanif I. 
Bet) den Sippenblumen vertummert berjenige, welder in oem Spalt ber fleinern oder obern sippe fteht. Dft fieft man jeboh) noch eine Sput Davon, wie bey Der Brannwar.

2u(t) Die vier übrig gebliebenen Staubfäben werben paar=

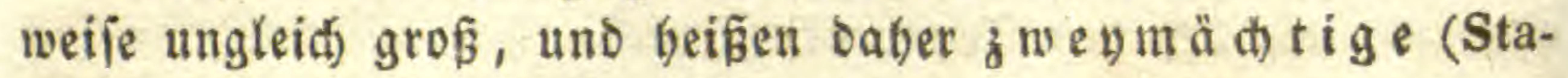
mina didynama), wie bey allen äd)ten Sippenblumen.

Feblt bey ben vielblätterigen Blumen ein Blumenblatt, io gent auct) gewöbntid) ber Staubfaden vertoren, uno es bleiben nur io viet übrig, alb Blumenblatter fino, vier ooer zwey, ober die Mebrzabt oavon.

Bey Den vierblätterigen Sirełzblumen, wie bev Den Revfojen, jollten 8 Staubfäben ienn, weil fie gegeniiber uno abwect)ielno fteben. Es fino aber zween oavon fo vertrïppelt, סaß́ fie nutr wie $\mathfrak{B a r z e n ~ o b e r ~ D r u ̈ j e n ~ e r i ́ d e i n e n ; ~ u n o ~ a u c t ) ~ v o n ~ D e n ~ f e c t ) ~}$ itbrig gebliebenten fino noch zween fürzer als bie andern. Man nennt fie baher viermå di tige (Stamina tetradynama). Diefe Blumen follten eigentliç) 5 B(ätter und 10 Staubfäden baben. 2u(t) findet man bey ben meiffen nod) 4 Drïien am (jorunde ber Staubfäben, wełd)e offenbar die 4 feblenden Staubfäben andeuten.

Erennun ber Staubfáden und Gröpie.

In Den meiften Blüthen ftehen Staubfäben uno (sröps bebjammen. Man nennt fie einbettig oder 3 witter (Flos monoclinus s. hermaphrodytus).

Ë gibt aber aud) Blütben; weldhe alle Staubfäden, ober wenigftens bie Beutel, verlieren und nur den Bröps bebalten.

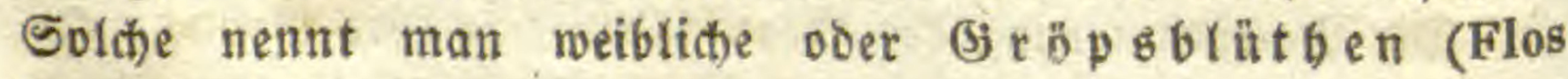
femineus).

Bey andern dagegen find blof die Staubfäden geblieben

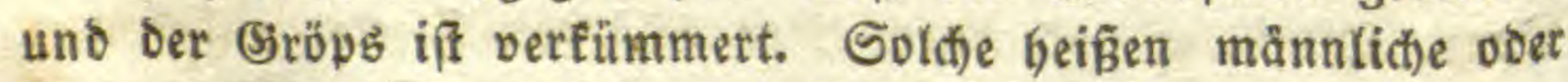
$\mathfrak{B}$ e u telblü t b en (Flos maseulinus).

Soldhe getrente Blütben entiteben nidht jelten bey Giat: turtigen eines (jeid)ledites, weldes fonft 3 witter bat: io bel einer Ridt)tnelfe (Lychnis dioica), einer शeffet (Urtica dioica), Spietifaute (Spiraea aruncus), bey vielen Ropfblumen u.f.w. 
Soldhe Irennung findet fid bey mandien Bünften ourd =

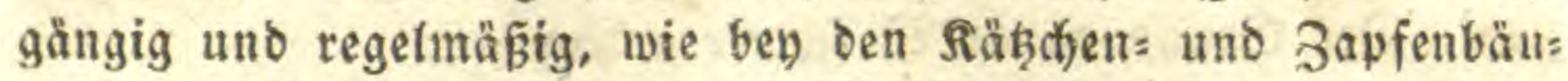
men; aud ben ben Reffeln und 230 ffsmildarten. Dergleiäen Pflanzen beisen ïberbaupt ba lbblütig voer zwebbettig (Plantae diclines).

Steben fie auf einer uno Derjerben \$flanze, fo beisen fie einbă ůig (Planta monoica). So bey Dem $\mathfrak{L} a \mathfrak{b}=$ und $\mathfrak{R} a=$

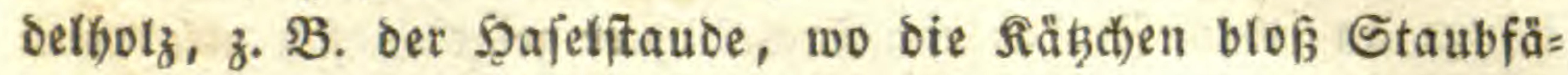
Den haben oder männlid) fint, die (sröpie bagegen, ober bie weiblichen $\mathfrak{B l u ̈ t h e n ~ i n ~ a b g e j o n d e r t e n ~ R n o i p e n ~ f t e b e n . ~}$

Es gibt aud) Pflanzen, wowon ber eine Stodf blof Statbs fäben trägt, ber andere bloß Früdte, wie ber Şanf. Sie beisen $\mathfrak{s} \mathfrak{w} \mathfrak{y} \mathfrak{y} \mathfrak{b} \mathfrak{a} \mathfrak{u} i \mathfrak{i g}$ (Planta dioica).

Endid) gibt $\mathfrak{e \xi}$ Pflamzen, worauf 3 witterblitthen fteben uno zugleich) andere unit getrennten Blüthen, ober auch wo ein Stocf lauter 3witter bat, ein anderer Yauter Staubfäben uno ein oritter lauter siröpie. In biejem Falf heiß̄en fie viel: b̆ ă ufig (Planta polygama), wie 2tborn, Teiche.

Berbiloungen

Der Staubfäben fommen fo håufig vor, baf ę zu Eleinlid wïrơ, wenn man Benipiele auffübren wollte. Berlängernn= gen, Berfủržzungen, Betbicfungen, Berf́tummungen u. f.w.

\section{2 นร a tน ngen}

fino auth etwas Gewöhnlides, bejonders ihre Beränoerung in Blumenbrätter, woourch die meiften gefüllten $\mathfrak{B l u m e n}$ ent= feben.

\section{Staubeutel (Anthera).}

Der Staubbentel ift eine boppelte $\mathfrak{B l a j e}$ voll Staub am Ende Des Fabens.

Dieje slajen fiteben einander gegenüber an ber Spibe bes Fadens, wie zwen Fiederblättchen, weldhe fich rur fẹtr wenig Uffnen. Das ungrabe Blättctien, welches an ber Epike ftehen follte, ift verfümmert. Sie fino nad) Innen, gegen Den (Siröps getid)tet, wie fieberblått(t)en, oie nod) eingeí)lagen find; febr 


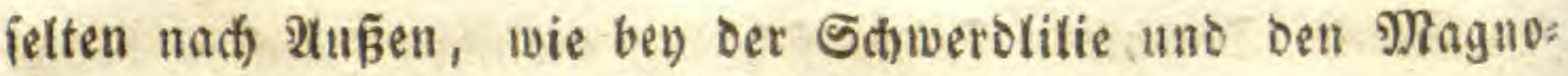
lien. Der (5irund davon ift fower anzugeben.

(5ewb̈bulict) liegen beide Beutel oder geíthloflene Blättchen oidit an einander, uno oaber zäblt man fie nur fïr eimen Beus= tel mit zwey Fäd)en. Mand)mal bängen fie jeood) nur ourd) ein Querbano (Connectivum) zujammen. Bey ber Blume: Rübr mid) nicht an (Impatiens) inaltet fth Der Faben, uno eb băngt an jebem Binfen ein Fach). Şier zeigt es fich arjo beuts

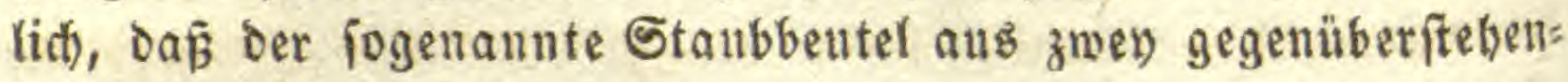
ben Slättçen beifebt.

Biछweilen wad)ien auch bie Beutel benad)barter Fäben an einander, dẩ fie wie ein Beutel mit vier Fächern ausjeben, wie bey einer $3 e i d e$ (Salix monandra). Bey Den fiorbblittben wathien die Bentel aller fünf Fäden an einander, uno biloen einen gejchlofienen fireib um Den (Sriffel. Daber nennt man

- Diefe Blumen aud): 3 ufammenftäubende voer Syngenefiften.

In feltenen Fällen verfïmmert aud) ber Beutel oder bas Fach) einer Seite, bejonders wo das Band febr lang ift, wie bey der Salbey.

(E) gibt auth folche balbe oder einfäđ)erige Bentel, weld he ganz auf ber Spike Des Fabens fteben, wie bey Den 2(maran= ten. Man follte glauben, eछ bätte fich) bier dab ungrade Blätt: den in einen Bentel vermandelt.

Die Fä(ber fpringen gewöbnlid) vorn, o. h. nact) innen, it einem \&ängsipalt auf; biछweilen jeood and) nur mit einem Lo(h) nach) oben, wie bey ben Eroäpfeln. Es verftebt fich, oa in jebem Beutel zwo Deffnungen entfteben. Die einfädjerigen

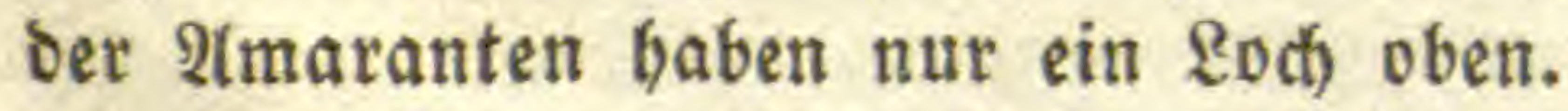

Bey Sauerad) uno Sorbeer löst fith vorn eine filappe ab von unten nad) oben, D. G., Dab Blatt fpaltet fid nidft an feinem Rande, fondern beibe Şälften trennen fich entweder von Der Mittelrippe, oder bas Slatt iff von ber Spike ber zuge: rollt wie Die Farren.

Sie beftehen bloż aub Belfgewebe, weldies, wie bey ben Blåttern, żmo Lagen, eine äuñere uno eine innere bilbet, fo

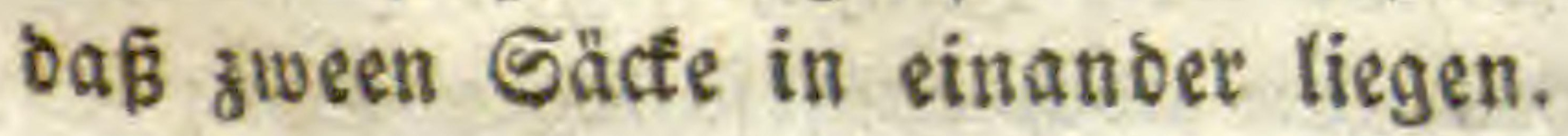


SI tน the nita ub (Pollen).

Die Şöhle oes innern if̂t mit fugelförmigem, ganz lofem, meift gelbem Staub auggefillt, meldber bey troctenem 3 etter beraubfliegt.

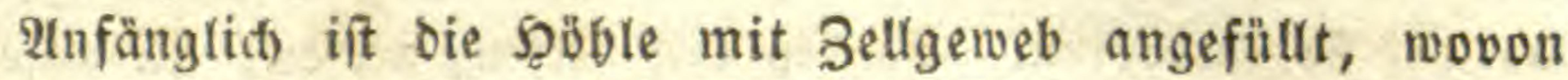
jede Belle 4 Staublörner einfogliefit. Dieje Bellen löfen fid) ipäter auf, uno lafien oie fiörner frev.

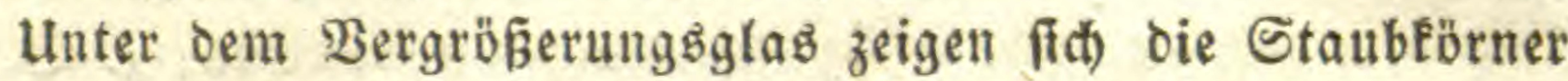
balo glatt, bald vielectig, balo fachelig, balo mit verfichiebenen Furthen bezeidnet. Sie baben eine auffallende 2lebnlid)ét mit Den Reimförnern Der Mooie, uno werden obne Zweifel blok

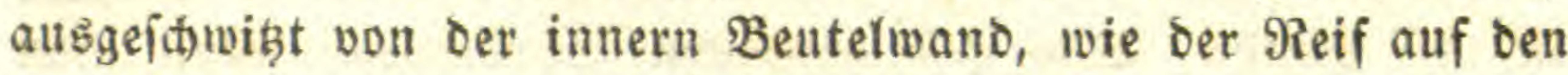
3wetichen.

Bey Den Drchiden uno Sobualbwurzen (Asclepias) Eleben fie zufammen wie $\mathfrak{W a c h}$.

Sie hefteben ebenfalls aus einer ooppelten Şaut, movon Die äunere Falten hat, oie innere aber weich if uno eine gal= lertartige Flüffigeit mit noct) feinerem Staub nno mit Del= tröpfớen entbält, weld)e man Duft (Fovilla) nennt. Wenn

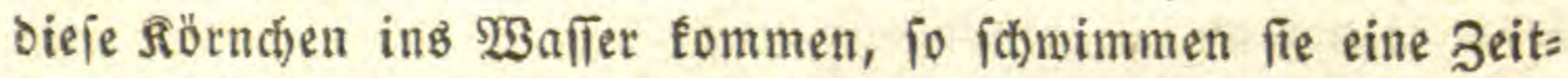
lang umber, wie Infuprien; allein fie fönnen fich niकt erwei= tern und verengern, find mitbin feine Sbiere.

Sobald Die Staubtörner auf Die Rarben fommen, fidmellen fie burch Deren Fendtigfeit an; Die äußere Şant befommt ein Ro(b), ourd) weldes die innere wie ein Sact bervororingt, enolid)

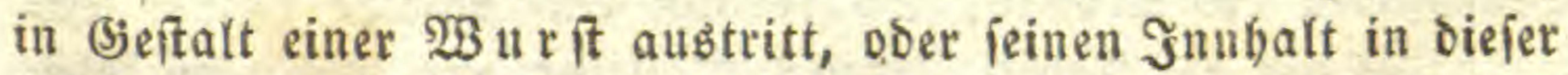

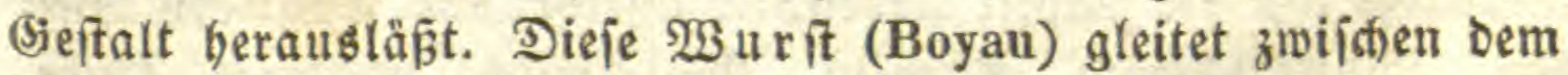
Belfgewebe deв Griffels binunter in Den (Siöps und fallüft enolid) Durd) Das Samenlod) (Micropyle) in Den Samen. Diejen Dorgang nennt man $B$ efrutht $\mathrm{ng}_{\mathrm{g}}$ (Foecundatio). Einige glauben, bajelbit oringe Der Duft aus uno errege ben Samen zur Entwicfelung Deß Feimb; andere Dagegen, die 23 urft ver= wandle fich felbit in ben fieim. (Siewöhnlich) friechen zu gleid)er 3eit eine Menge झ̈itrfte ourd) ben (Siriffel, uno baber foll es fommen, oaß bisweilen mebrere fieime in eiuem Samen gefunden 
werben, wie bey Den Pomeranzen und den firchpalmen (Cycas revoluta) gewöhnlic), bey mebreren anderu pflanzen bib: weilen, aljo zufälig.

Beb Der Befructutung biegen fich Die Staubfäben oer meiften Blumen auf bie Narbe, uno geben Dann langiam wiever zurüct, woranf fie veroorren. So bey Den Rilien, Rofen, all nnjerem Dbif, Den Rauten, Nelten, Dem Eiublatt (Parnassia). Sie bieget fit) nicht alle auf einmal auf oie Narbe, fondern entweder einer mach bem antern, voer oie gleichnamigen zuammen, z. B. bie 5 an Der Mittelrippe bes 3 lattes, Dann etwa bie 5 abwedieln= Den u.f. w. In Derielben Dronung entfernen fte fich audi) mieber.

Ben manchen $\mathfrak{B}$ tumen fthellen die Staubfäden pröglid auf Die Rarbe. Das geichiebt beym Sattetoorn, wenn man Den Girmo der Staubfàden mit etwas berübrt. Eв ift als wenn eine geipannte Feoer plökllich losgelafien mitroe.

Berbiloungen.

Ben Den Beuteln etwas fo gewöbnliçes, das man eв

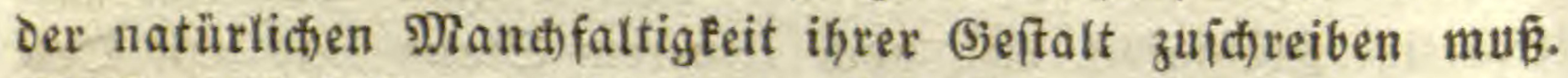
Meiftens find fte runolich; es gibt aber aud lange, gerabe, frumme U. f. w.

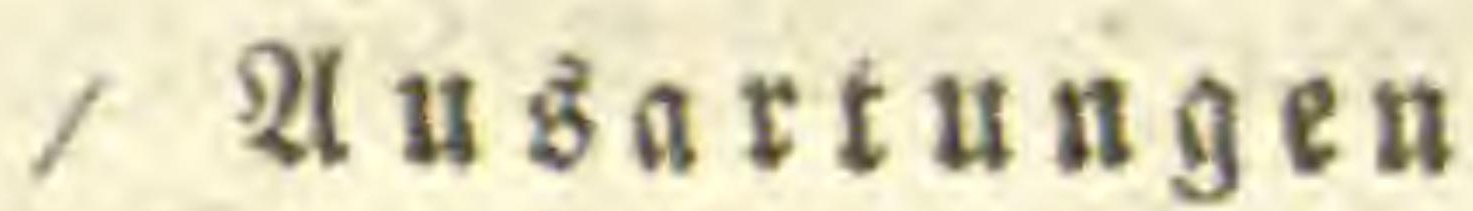

Dagegen fino felten. Sie verwanbeln fich in Suten bey ber

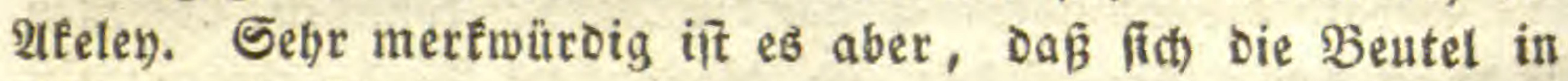
Bälge mit Samen verwandeln, nidht gan jelten bey ben Staubfäden des Mobns, wo fodann eine Minge fleiner Sa=

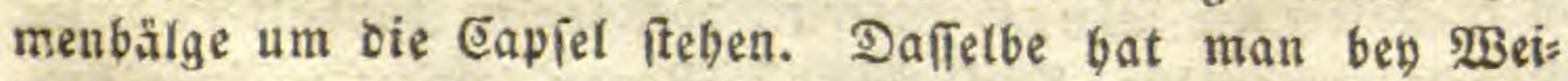

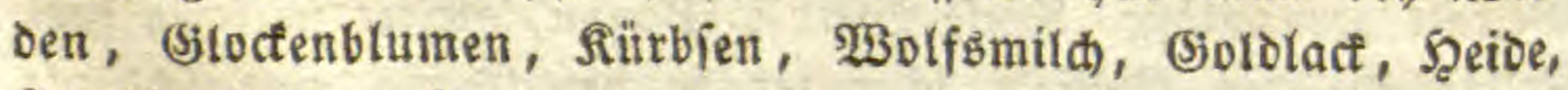
Şaนรlaud bemerft.

5o nigorgane (Nectaria)

find orïfenartige sheile in Der Slitthe, weldye einen füfen Saft abjondern, aber immer verfummerte Iheile veríhiebenen Uriprungs fino.

Sie liegen gewöhnlia auf bem Blumenboden, wie bey ber Raijertrone, wo wirflit) ganze Iropfen abgejondert werden. 
Da fie fit) am (jirunde oer Blumenblätter befinden, fo fino eb wob̆ verË̈mmerte Staubfäden. Sicherer find bey oen firengblumen uno bem Einblatt, wo fie fünf ver= zweigte Bündel an Den Blättern bildoen, abwed) felno mit Den Staubfäben. Sie jondern übrigeng feinen Şonig ab. Mit nod) mebr Unred)t rechnet man die Säcte uno Sporen bieber, obichon ibre innere Dberflät)e füjen Saft abjonoert, was ïbri= genb aut) manche Blätter thun.

Man bat ebemals geglaubt, fie bätten die bejonbere $21 b=$ fid)t, oie Bienen anzuzieben, Damit dieje gelegentlich Den Blü= thenftaub auf die Rarbe fd)afften, was bey vielen $\mathfrak{B l u m e n}$ obne ibre פilfe nicht geịcheben fönne. Das gebört in bie Zeiten, wo alles blö́ um des Rukens willen erít)affen worden. Run glauben wir, Daß̧ (jott blof́ zu jeinem Bergnügen eriđ)affen, uno nid)ts io jämmerlich auf balben WBegen babe liegen laflen,

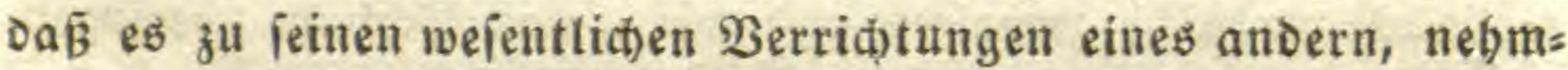
fit) ibm fremben, bedirfte. Eon rad Sprengef bat ibrigens ein jebr interefịntes $\mathfrak{B} u$ (t) über die Beftäubung Der Blumen our(h) Die Injecten geidrieben, 1793.

\section{3. (5) rö \& (Pistillum).}

Der (5j) $\mathrm{r} \not \mathfrak{p}$ ift die Wiederbolung Des Stengets in ber Blütbe, aber unter oer Form Des Blatts.

Da Die Wurzel feine finofpen ober Slätter treibt, fo fann Der (5iröps als Das lekgte Blattwirtel Der Blütbe, unb zugleiđ Der ganzen Pflanze, betractet werben, welches die Samen oder Das $\mathfrak{B}$ urzelartige in Der $\mathfrak{B l i t t b e}$ trägt.

Er befteft aub einem voer mebteren zurammengeidlagenen Blättern, welche mit ibren Seitenrändern, aljo nach innen oder

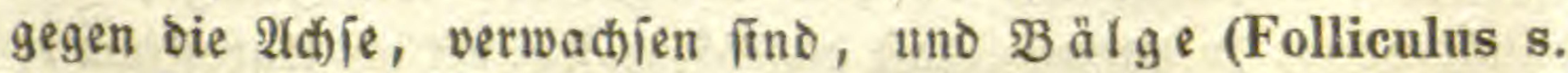
Carpellum) beifien.

So lang fie frifot) fino, fino fie grün; färben fich aber benm sroctnen auf mandfaltige $23 e i j e$.

2uch) trennen fitf) ibre Blattränder erít, nadbem fie abge= ftorben oder vertrocfnet fino. 


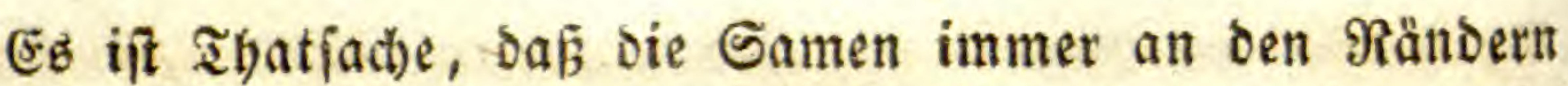
bängen, alio am Ende ber verzweigten Blattrippen, wie manthe Blätter an ifrem Ranoe Schölife treiben, z. $\mathfrak{B}$. Bryophyllum. Die 2tubeftungsrippe der Samen beiß̧t Gamenträger (Placenta s. Spermophorum).

In Der Regel feblt ignen die Mittelrippe; Dagegen fino bie Ranbrippen febr ftarf uno vertängern fich gewöbnlict) über Dell $\mathfrak{B a l g}$ Ginaus.

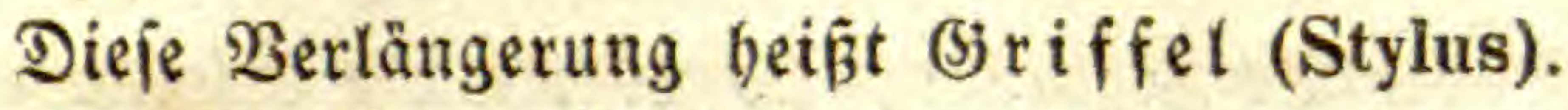

Der Griffer beftebt baher immer aus zween abeilen, welche oft am Ende geipalten fino. Er ift übrigens aub Zell= gewebe gebiloet mit groß̧en Intercellular=(ङängen, burd) welthe Der logenannte Duft bes Blüthenf́taubs bis zu den Samen wandert.

Das Ende Des Briffels heist $\mathfrak{R} a \mathrm{rbe}$ (Stigma), ift ge= wöbnlith veroict, geipalten uno mit etwas Saleim itberzogen.

Wejentlich) gibt es immer fo viele Griffel, als oer Gröps Bälge hat. Diejer ift ein $=$, zweh) =, orengriffelig u.f.w. (Flos monogynus, digynus, trigynus etc.)

Indeffen verwadjen die (jiriffel fehr bäufig in eitnen ein= zigen. Man fann aber oie Zabl teidt finden, entweder an ben Einidnitten Der Rarbe, wie beym Mobn, ober an ber 3 abl Der Fächer.

Es tann ber Fall eintreten, wo man ziweifelhaft wird, ob man einen (3röps ober einen Samen vor fid) bat. Dann braud)t man nur nad) Der 3 abl ber Griffel zal feben. So find bie saitrbienferne feine Bälge, weil ber Ritrbs nidjt fo viele (Siriffel hat als Samen. Dagegen fino bie logenannten Rofen= ferne Bälge, weil jeder einen Griffel bat.

2lles biejes mahnt an ben Stengel oder die 3weige, uno oamit bängt zuโammen, oaßs bie sälge fiă) oft ins Unbeftimmte vermefren uno fid zerftrent an bie verlängerte Slitthenjpindel

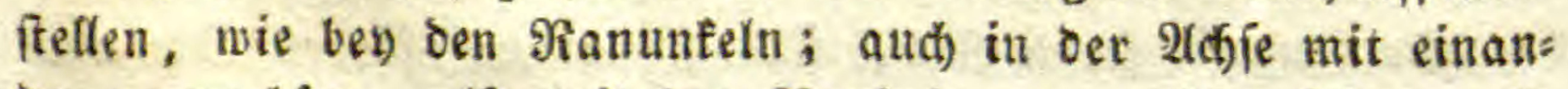
Der vermadjen, alio mit ben randrippen, weldfe jobann ein

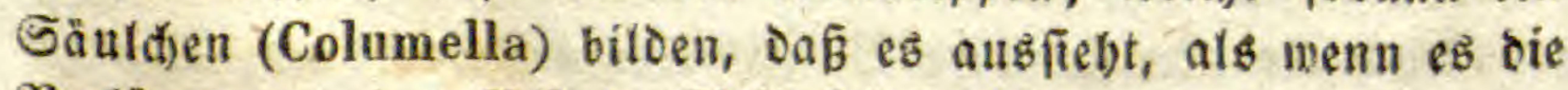
Serlängerung bes Blütbenftiels felbị wäre. 
Eintbeilung.

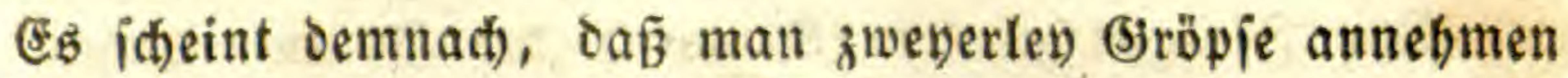
müfle, joldhe, weld)e aus der Theilung eines Blattes, uno jold)e, welche aus vielen $\mathfrak{B l a ̈ t t e r n}$ befteben, alio ei nfache uno vielfache. Su ienen würden diejenigen gebören, welde in Stellung und Bahl mit oer Blume ilbereinftimmten; zu biejen biejenigen, welde fiä) nicht barnach richteten, aljo vor= züglich) Die vielbälgigen (S̈röpje uno Diejenigen, Deren getrennte Bålge zerf́trent ftänden, wie bey Den Ranunfeln, Magnolien,

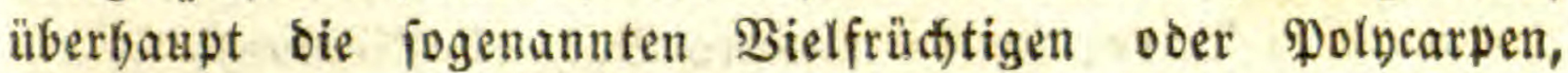
welche um eine Rittelfäule als verlängerten Stiel gereibet fino.

Die einfacisn (Gröpie find entweder rein ober vom Relti) umgeben.

1. Reine (5iröpie.

Mach) Der Stuffenfolge Der Brätter gibt eg aud) brewerley (5) röpfe: St)uppen $=$, Sheiben = uno Raubgröple.

1. S क uppengröpie find $B a ̈ l g e$, weldte didt an bem einzigen Samen wie eine Şaut anliegen mo nidt anfipringen, wie die Sant um das Weizenforn.

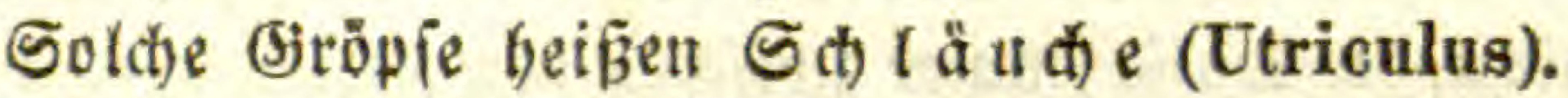

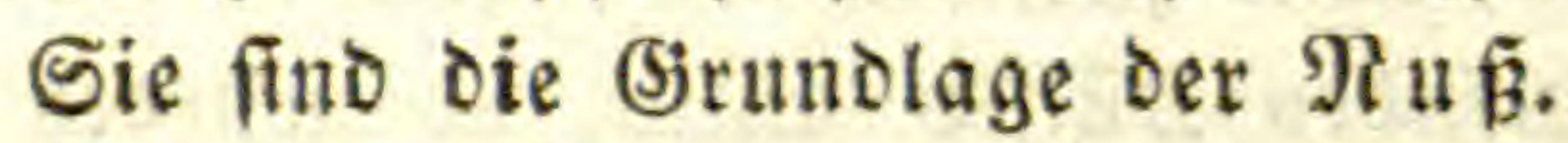

Man bat ibnen aber, je nad) Der 2(rt igres filafens, ver=

- idiedene Ramen gegeben.

a. Der Rornid $(\mathfrak{a} \|$ h) (Caryopsis)

bilbet eine ganz bünne, über bem einzelnen Samen veft verwathiene Şaut, weldie erit benm fieimen plabt, wie benm Sietraibe.

b. Die $\mathfrak{B}$ ü $\pitchfork$ i fe (Pyxidium)

iff ein um ben Samen lofe liegender Salauch, weldier meiftens quer aufipringt, wie bey शmaranten, Begeria).

Der R lappenidlaud), welder fich an ber Spike offnet, wie bey 2mpfer, Meloen, if faum bavon zu unter= id)eiden.

c. Ein Fl ügelfid) $($ a u d) findet fid beb ben Rüftern.

Bielleidt tann man Die Frindte Der Tannzapfen bieber 
fitellen. Sie werben aber jeß̧t meiften als bloß̈e Samen ange: feben, zu welctien die Dectjđuppe als $\mathfrak{B a l g}$ gebören foll.

Die Flägelfrucht (Samara) ber Plborne beitebt alls zueen verwad) fenen Sđ̆läud)en.

2. Die Scheidengröpfe

befteben aus einem einzigen Slatt, weld)es in ber Siegel mebrere Samen entbält uno an ber innern oder Ranonabt

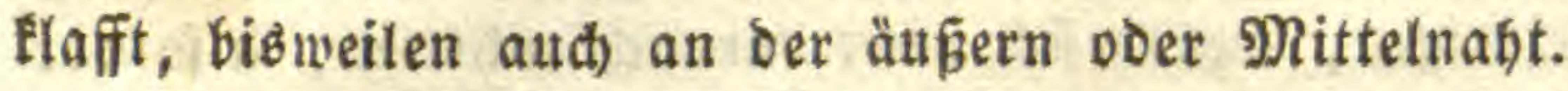

Sie fino die (Sirundlage Der $\$ f l$ a u me oder Steinfru(t)t. Mau untericheidet Darnach)

a. Die হute, jonft beionoers $\mathfrak{B a f g}$ (Folliculus),

wenn er ziemlid) walzig ít, uno nur an ber inn ern Nabt

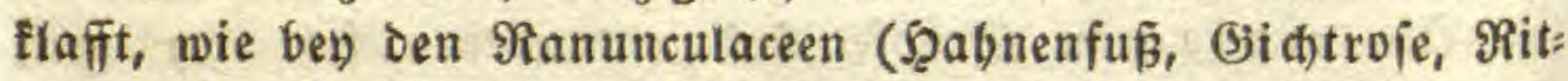
terfporn), Drebblumen (Sinngrïn), Sđumalkwurzen, Ënianen, Storchichnäbeln, Malven.

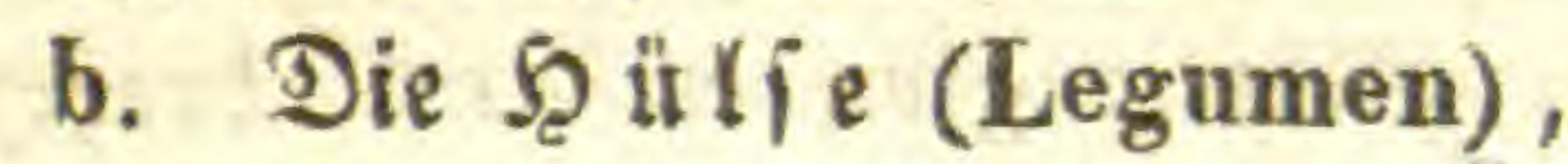

wenn ber $\mathfrak{B a l g}$ zujammengeorüct ift uno an betoen Năbten flafft, ober weientlich, wenn ber $\mathfrak{B a l g}$ bas ungerabe $\mathfrak{B l a t t}$ eines Fiedergröpjes ifit, wie bey ben Sd)metterlingsblumen oder ben

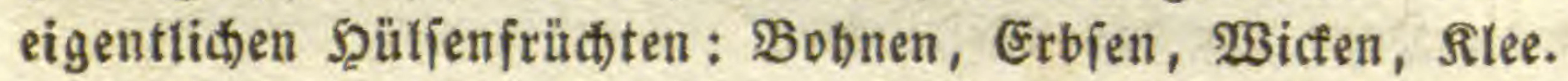

Daber liegt bie Şülie immer zwifhen ben fielen Der Błlume. Denten wir die vier feglenden Spülien binzu, fo würden die zwo neben Der Fabne liegenden die fleiniten jenn, uno aljo der (5) röpв ein Fieberblatt vorffellen, vertebrt gegen bie Blume ge: ridtet, wie Dieje gegen ben Fielch. Die Berfümmerung nimmt von bem felch an 3 . Ben biejem find alle 5 sappen faft gleid) ftarḱ, bey der $\mathfrak{B}$ (ume fino oie Siele fitmmerlid), manchmal veridumuden; bey Den (Gröps alle geraben voer paarigen Sgitlien.

3. Der $\mathfrak{R} \mathfrak{a} \mathfrak{u g r o ̈ p s}$

beftebt aub mebrern bidft mit einander vermachjenen $\mathfrak{B a ̈ l =}$ gen, welche mithin Sc) eio no ån oe (Septa, Dissepimenta) meift mit vielen Samen baben, uno c apiel (Capsula) beißen.

Die Eapieln theilen fith, wie die Blumen, in zowenfeis tige ober fiederartige, uno vielfeitige ober runoe.

1. Die zweyleitigen befteben aub zmeen gegen einander gebrüctten Bälgen, wovon der eite an ber Fabne liegt, der 
andere an Dem Sd)ifflein. Sie gleid)en baber einem Satrant voer Raften.

Bey den Fiebercapieln verfümmert der innere Rand Der Bälge oder die Saheiomano oer Eapiel, indem die famentras gende Rippe nicht wirflid) am Ende Des Randes liegt, fondern in Der Einfafiung oder $\mathfrak{B a n}_{0}$ Der Eapiel, oder auf oem $\mathfrak{B D}=$ Den Derielben. Sie beîteben eigentlia) nur aus Şalbbälgen und find bie Sirundage ier $\mathfrak{B} e$ ere.

Sie finden fith bloz ben Fiederblumen, Den Rippen $=$, Ras

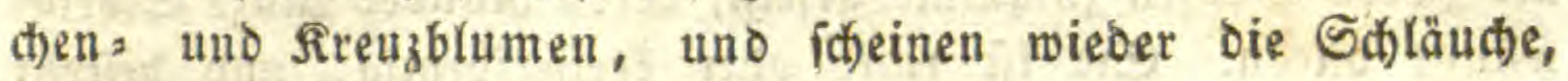
Tuten uno Sullien zu wiederbolen.

a. Bey bell Rippenblumen, wie Taubneflel, Salbey,

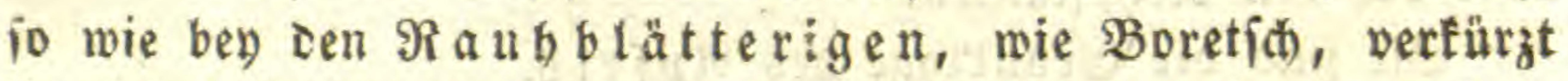
fich jeder $B a l g$ uno zieft fich in oer Mittelrippe fo ein, Daß́ er zwey förner ober Nülile vorítellt, je mit einem Samen. Es idheinen baher vier $\mathfrak{B a ̈ l g e ~ v o r b a n d e n ~ z u ~ j e n n , ~ w o v o n ~ f e d e r ~ e i m e n ~}$

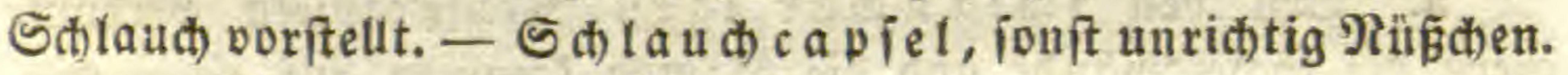

b. Ben Den Rachenblumen, wie \&üwenmaul, Fingerhut, fo wie bey Den Betäubenten, nie Eroåpfel, Tabact, Bilfenfraut, verifowindet ber obere Theil oer Sdeibwand und ber untere verwächst zu einer 2 rt fiegel oder $\mathfrak{R}$ uden (Placenta), nor= auf bie Gamen liegen. - Tutencapiel.

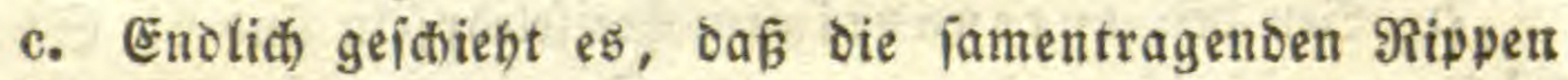
Der Bälge nidht am Ranbe felbft liegen, fonbern zwijhen oie= iem Rano uno ber Mittelrippe, mitbin Seitenrippen biloen, äber meldbe hinaus ber blof́ häutige Blattrano ober nur bie: innere Şautfläche der Bälge die Schetowano biloet, welche da: ber febr dunn ift uno oft ganz veridnninbet. - Şülfencapfer.

Wenn nur zween $\mathfrak{B a ̈ l g e ~ m i t ~ e i n a n b e r ~ v e r m a t j e n ~ f t u b , ~ f o ~}$ bat fie den Ramen S d) ote (Siliqua) betommen, wie bey den eigentlid) jogenannten Sdotenpflanzen: Fobl, Senf, Täfhelfraut.

Diefe Gdjoten fino gewöbnlich flach gebritct, o. 6. mit Der Sheiowand parallel, uno fpringen auf eine eigentbümlide $21 \cdot t$

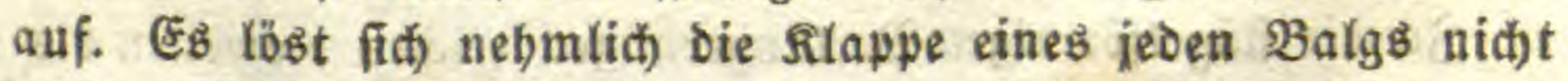
in Der Mitte oer Sd)eibmand, fondern an Den Seitenrippen $a b$,

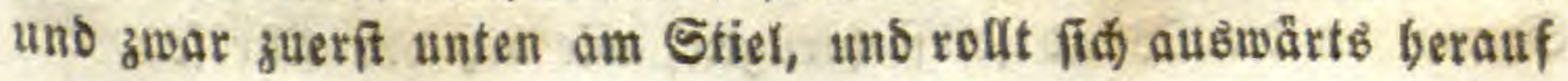


bis zum Griffel. Die Rippen bleiben fodann mit ibren Sas men und oer dinnen Stheidwand fteben, wie eit aufgeipannter Rabmen. Die Schote beftebt alio nur atth zween Şalbbälgen.

Es gibt aber zuiammengerebte Sd) oten, welde nebmlich aus vielen Şalbbälgen verwactjen fino, uno bie Sa:

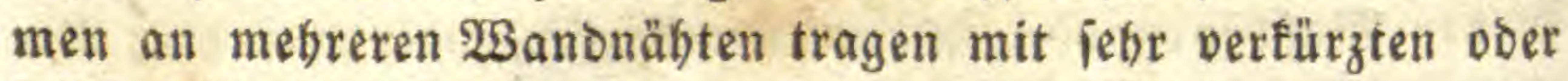
felbit fehlenden Sd)eiomånden, wie bey ber Mobncapjer.

2. Endidid entifteht bie voll fommene Eapiel aus mebr als zween Bålgen zujammengeję̧t, beren ränder ganze Scheib= wände bilden. Sie ift runo voer freifelförmig, uno beitegt meiftens aus oren oder fünf Bälgen, fene bey Den Streifen:, Dieje bey den Rekzpllanzen.

Sie find die Gruntlage des $21 p$ fels.

2udc) bier fommen wieder bren Unteríthiede vor. Eह gibt nebmlid) idflaud)artige, tuten= uno idfotenartige.

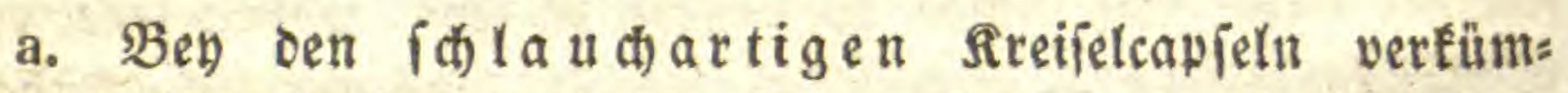
mern bie Sđeibmånde uno bie Samen fommen auf einen $\mathbb{R} u=$ () en z"l liegen; wie bey den Rachenblumen. Die Capfel b̈fnet fich nur oben in fo viele Spizen als fie slappen hat, biswei= ten in boppelt fo viel. So bey Saltiffelblumen, Nelfen. Mande ipringen fogar bildjienartig auf, wie bey (jaudheil.

b. Bey ben tutenartigen Rieifelcapieln fino bie Sheib= wände vollftändig und tragen bie Samen an Den $\Re$ änbern in Der 2ldje, wie bey den Rilien, Iulpen u.f.w. Diefes ift oas gewöfnlichfte Borfommen.

c. Die Rreifelcapiet wiro aber aud fid) otenartig, ins bem die Samen an ber $\mathfrak{B a n d}$ zu liegen fdeinet, objijon in Folge eines andern Battes, als bey Den Sdioten.

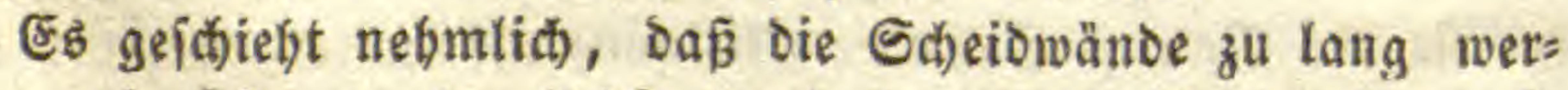
ben, uno fid) von ber $2($ d) fe ber in bas Fach bineinrollen, fo

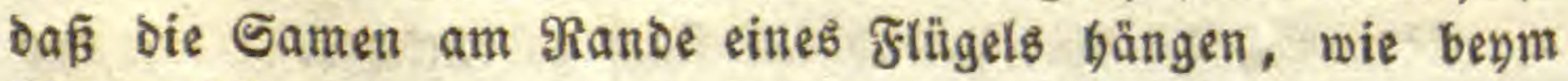
Stec)apfel.

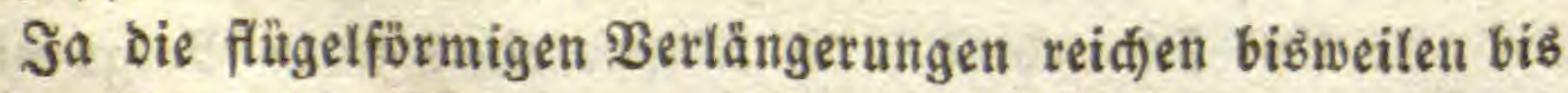
an ben Rano ber Rlappen, und bann fifeint es, als wenn bie Gamen an oer waand felbft biengen, wie bey den siurbien. 
Bey einer ganz vollétmmenten Eapjel hängen bie Samen

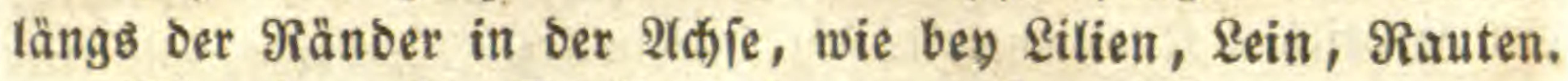

Man fann die S(t)eiowänoe am beiten zăblen, wenn man eine Eapiel vor ber Feife quer ourdifidneibet. Dann frebt man, dấ jebe Sdjetowand aus ben zween mit einander vers wadffenen Stücten ber an einander liegenden Bälge beftebt.

2ubwendig ift jede Sheiowano burd) eine $\Re$ abt (Sutura) bezeich)net.

Das Stït ber Eapjel zwiíthen zwo Rähten beiśt Rl a p pe (Valva). Es gibt bafer fo viel făd)er (Loculamenta), als es Rlappen gibt. Man nennt barnad) bie Eapiel zwen=, brey= fächerig u. f. w. (Capsula bi-tri-locularis etc.) Drey Fåder zeigt bie WBinde, finnf bie Jungfer in Şaaren (Nigella).

Die innern Ränder der Båtge oder Sđfeiomände frofen bald ofne bejondere Berdicfung an einander, wie im (jröpie Des 2tpfels; bald find fte aber verdict und mit einanber zu

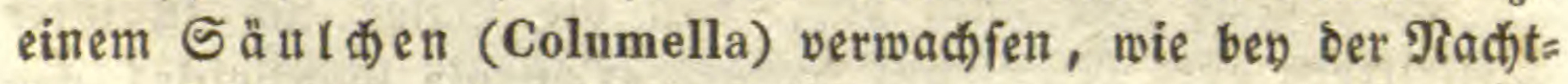

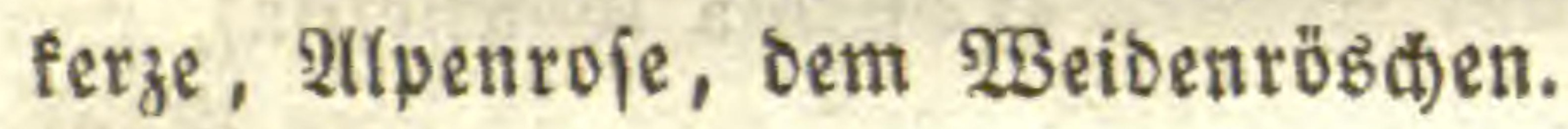

\section{Die Relat)gräpie}

find bidt) von bem bamit verwadienen field) umgeben.

Ës gibt ifflaut)artige, tutenartige uno caplelartige.

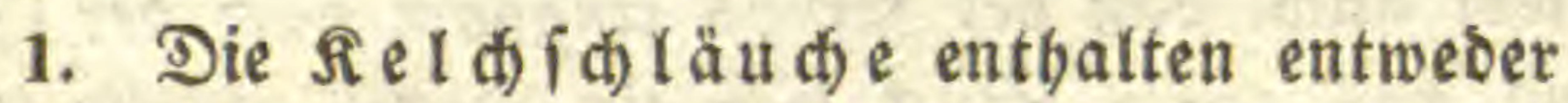

a. nur einen Samen - Futterale (Achaenium),

wie bey Den Ropfblïthen: Salat, Difteln, Sonnenblumen; Den Rnopfblüthen: Scabiojen, $\mathfrak{B}_{\text {eberdifteln; }}$

b. voer zween rundlide und aufrecthte Gamen neben ein= ander - Zwiefd)laud) (Polachaenium),

wie bay den Sternpflanzen: Labéraut, $\mathfrak{B a l b m e i f t e r , ~ F a ̈ r = ~}$ berrötbe;

c. oder zween längliche uno verf̌ebrte Samen, berabbän=

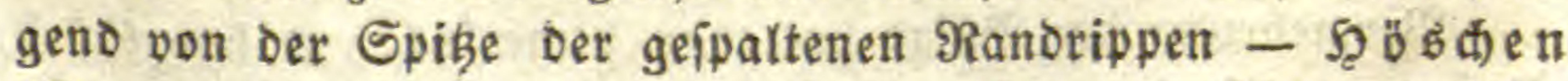
(Cremocarpium), wie bey Den Doldenpflanzen: Sïmmel, Fiet: bel, Fenchel, Möbren.

2. Die $\mathbb{R e l d} t$ tute mit zween vielamigen Bälgen bey Den Steinbrect)en, Der Ebina. 
3. Die seldicapfel finbet fít) bey Den Rarciffen,

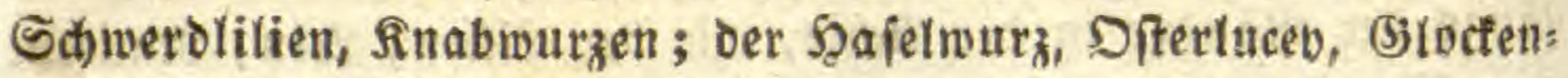
blume; Dem Weidenröвct)en.

$$
\text { Slaffen (Dehiscentia). }
$$

Oer Gröps foringt auf verihtedene शrt auf. Zuerit trens nen fich bie Bälge an ben Seiten, mit benen fie all einander gemadtien fino, D. b. in oer Stheiowano (Capsula septicida).

Dann trennen fie fich in ber 2(d)ie, woben niat) felten fid) bie innern Rippen ablöjen uno als ein freyes Säuld)en fitehen bleiben.

Dann trennen fích) die innern Ränder jedes Balgs von einanoer, uno die Bălge öffnen fích ganz nach) 2 rt ber Blätter, indem oie innere Seite nach) auß̉en fommt.

Bey andern trennen fich die Slappen in den Räbten $a b$, uno die Sd)eibwäno bleiben an Säul(hen hängen wie flïget.

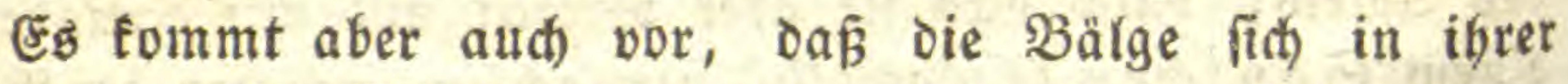
Mitteltippe ober Mittelnabt frennen (Capsula loculicida), wo: ourd) Das Blatt in 2 Şålften zerfällt, uno jede an bem Săul= d)en bången bleibt.

Mandie Bälge befommen nur oben einen Spalt, wie ben Den Şahnenfüsen; mebrere \&ödher bey Der Mohncapiel.

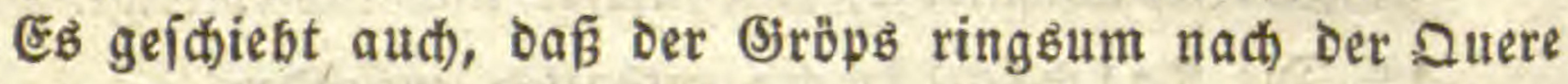
aufipringt uno bas obere Stüct wie ein Dectel abfällt (Capsula circumscissa).

Mande (jröpfe ipringen aud) gar nid)t auf, fonbern ver= faulen ober öffnen fid) erft, wann fie in bie Erbe oder in bie Jeuchtigfeit fommen, wie bie Eicheln, Şaielnitfle u. Dergl.

\section{Berbildungen.}

Berbilbungen fommen bey ben (jröpien gerabe nidbt băufig vor; bod) gibt eb mandie fonderbare.

Bermebrung oer Bälge bat man bemerft ben Şabnenfüben, Roien und Enzianen.

\section{भน เ artungen}

find noch feltener. Die (Sriffel merben bey gefültten Blumen oft blumenblattartig, wie beg den Şabnenfüben unb 2tnemonen. 
Ben Der Schwerditie ift oas Ënde Des Briffels natürlider IBeije blattförmig.

$$
\text { c. Samen (Semen). }
$$$$
\text { = corpel/pirtil }
$$

Die Samen fino geid)loffene Blatténoipen im (jröps, weldhe (id)on ben ganzen \$flanzenitoct im Rileinen entbalten, und ben= ielben erft nach) Der 2lbjoinderung vom Pflanzenleib in Der Erde entwicfeln.

Dadurd unterideicen fie fid von andern snoipen und Den \&uftzwiebeln, als weldhe nid)t in einem Gröpie vorfom= men, feine $\mathfrak{B u r z e l}$ baben und fich jelbit auf ihrem Standort entwicfeln fönnen.

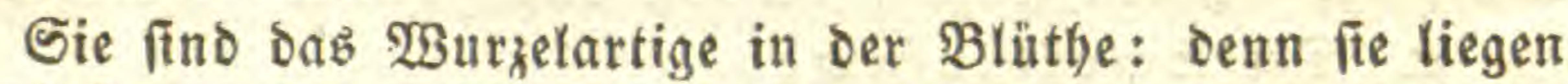
im Finftern nie bie $\mathfrak{B u r z e l , ~ f i n o ~ v o m ~} \mathfrak{W a}^{2}$ er umgeben, befte= ben meift aus Sdleim oder Miehl wie bie $\mathfrak{B u r z e l n , ~ u n o ~ t r e i = ~}$ ben endlich) Stengel, Blätter uno Blïtben.

Shre Gieftalt făllt ins Rundliche; ibre Confiftenz ift berb; ibre Subftanz meblig.

Sie baben alle mögliden Farben, auth die fdwarze, weldje bey andern Pflanzentbeilen nidt vorfommt, auser etwa benm

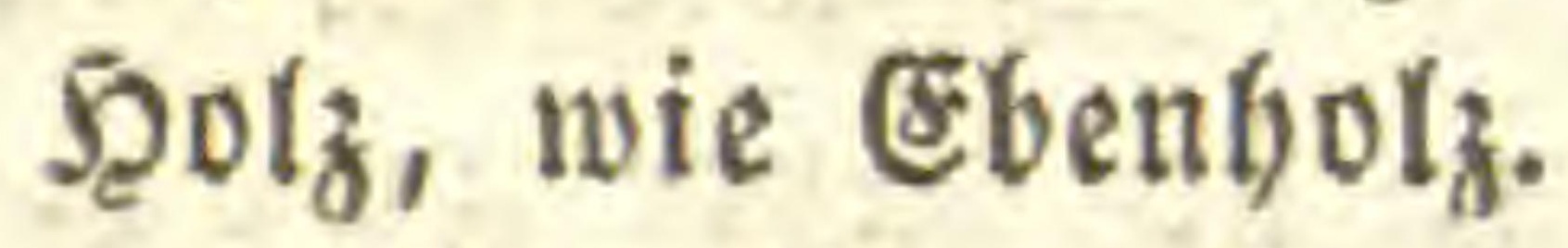

Es gibt weife, gelbe, rothe, braune, blaue, aud grüne Samen; Dod) find bie lekten feltener.

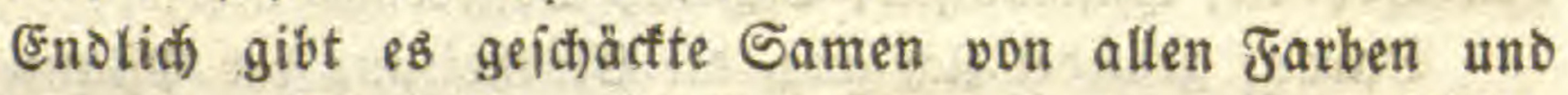
3eichnungen. Die legtern fitheinen fidi) nad) oem Serlauf ber Spiralgefäpe zu richten.

Da bie Samenifhale, wie eร fid zeigen wirb, nid)tร an= Deres als ein abgeftorbenes Blatt ift, io mun ibr Farbenwed): fel mit ben Şerbitblättern verglidien werben. Bey biejen fommt auch) oie fow warze Farbe vor.

Die Samen bängen nirgends anders alb am Rande ber Gröpsblätter. Da jedes Blatt zween $\Re$ änder bat, fo müffen in jeoem $\mathfrak{B a l g}$ wenigitens zween Samen fenn. Finbet fich nur einer, fo ift ber andere verfümmert.

Deffnet man eitten Balg oder eine Şülie, fo băngen bie

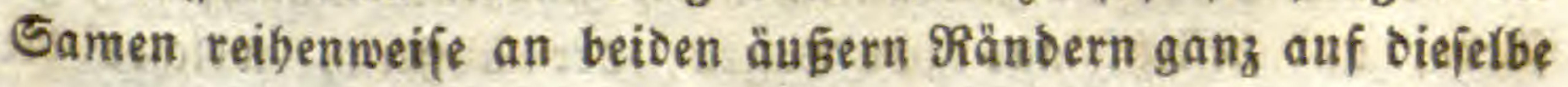


Art, wie oie Fieberblättchen am gemeinichaftlict)en Blattîtiel. WBenn fich die Gamen nod) in der Şülfe jelbit offneten, io wåren fie wirfliç fièerblättchen.

Da die Samen mur veríd)loffene Blätter fino, fo gibt es auch) nur orenerley Gamenarten, nie eg nur oren 3 lattarten gibt, nebmlid) Sduppeniamen, Sdheibenfamen uno $\Omega_{a} b=$ ober Reķamen.

\section{Die Schupenfamen}

befteben aus einer einfachen SBlattblaje, worinn unmittels bar Meblf̈brner liegen uno feine anderen $\mathfrak{B l a ̈ t t e r ~ m e b r . ~ M a n ~}$ nent fie daber Samen obne \&appen (Semina acotyledo. nea), wie bẹn ben פilzen, Moojen uno Farren.

2. Die Sdiciteniamen

befteben aus einer ooppelten $\mathfrak{B l a j e}$, wovon man die innere Samentappe (Cotyledon) nennt. ¿ேః fino mithin Samen mit einem einzigen Samenlappen, ber fheibenfürmig ift wie bie Blătter - einlappige Samen (S. monocotyledonea), wie bey den (jräjern, Rilien uno palmen.

3. Die $\& a$ ub iamen

befteben ebenfalls aus zwo Brajen, wovon fich aber bie it: nere in zween Sappen trennt. Man nennt fie baker zwey) lappige Samen (S. dicotyledonea); bejonders beutlici) ben Den Bobnen, Şafelnutfen, Eicheln, Sbfternen u.f.w.

Darauf grindet fich auci bie Eintbeilung ber Pflanzen in oren grofe Feaufen, nebmlid, in lappenlofe (2(cotyleoonen), in einlappige (פlonocotyledonen) uno in zweylappige (Dicotyledonen).

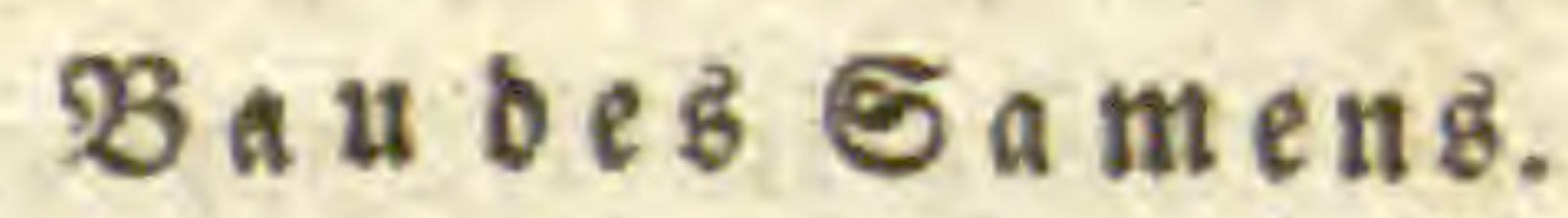

1. $2(\mathfrak{m}$ beften if Der $\mathfrak{B a u}$ bes Samens zu erfennen bey ben 3 weylappigen, namentlid) ben ber Bobne.

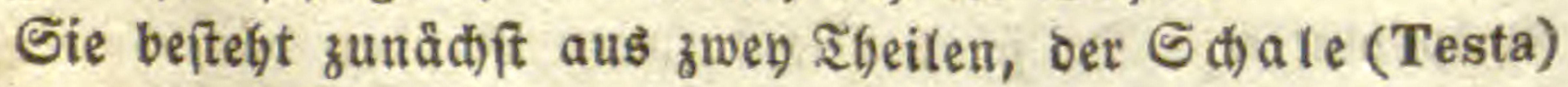
uno dem fiern (Nucleus), weld)er das biđ)t zujammengebrängte Inebl entbălt.

Die S() a le ift gewöbnliđ) bart, glänzeno, mandfaltig ge= färbt, uno beíteht aus zwo Ragen, Der ăusern, weldes bie 
eigentlidje Sd)ale iff, und ber innern, weld)e mtr ein idjwadies braunes Scäutdien vorftellt, bier felbit zweifelbaft. Bwifhen beiden laufen die Spiralgefäje bald getrennt, bald Durch) Bells gewebe verbunden, weld)es eine ordentlidbe Spaut bilbet, mie es Gier ber Fall ift. Die Beftandtbeile find mitbin wie bey jebem Blatt, eine ăuß̄ere und eine innere $\mathfrak{Z a n d , ~ u n o ~ Z e l l g e w e b e ~ m i t ~}$

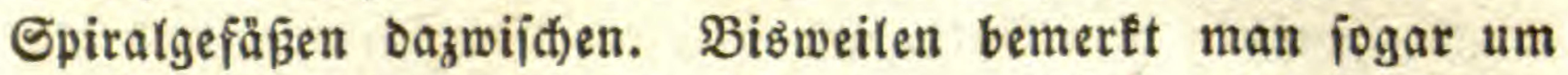
Die Sdale nod) ein dümnes Şäutden, welthes aljo ber Dber: baut entipridit.

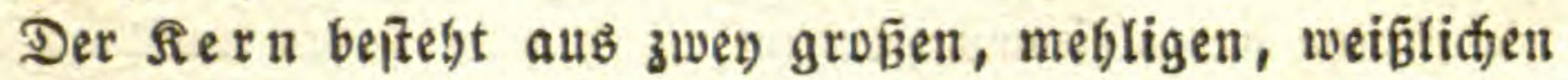
Lappen (Eotyledonen), weldje die ganze Shale einnebmen. Sie fteben einander gegenüber und find burd) febr furze Stiele mit einander verwadjen.

श(แb Der Mitte ber verwadienen Stiele gebt nad) unten

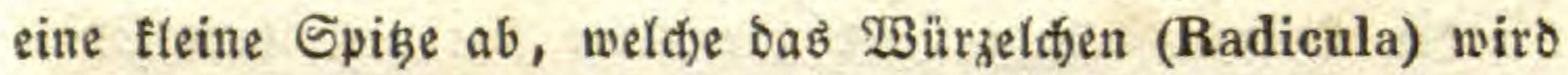

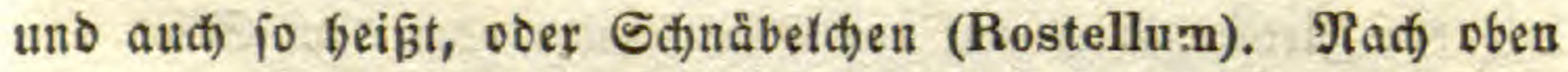
gebt ein anderer Stiel $a b$, weld)er fid fogleid) in tren zarte Blättden theilt, die Reimblätter oder bas Blattfeberden (Plumula).

Dieje Blätter treten benm Reimen zuerî aus Dem Samen und Der Erde bervor, tnd find die erîten Blätter bes Stengelb̉, Der ftđ) aus ibrer Mitte verlängert uno neue oreyzäblige Blätter treibt fort und fort. Der Rern ift baber ber eigentliche Seim (Embryo), weldfer befitebt aus einer 23 urzel, zmey dicfen Blät:

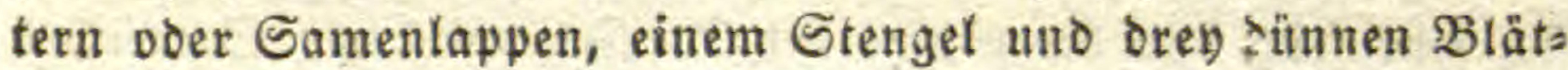
tern, mitbin fajon eine ganze Botnenpfanze ift in Miniatur.

Daber braudt man fith nid)t zut wubern, das aus einem Samen wieber eine Pflanze erwädst, welche oer Mutterpflange ganz gleich ifít vielmehr mithte man fid) wunbern, wenn es niđ)t fo wäre. Die Pflanze ifît nur ein ausgebebnter Samen.

Breitet man ben fieim mit feinen $\mathfrak{B l a ̈ t t e r n ~ a u b , ~ f o ~ f t e l l t ~}$ er ein gefiedertes $\mathfrak{B l a t t}$ mit 5 Slätt(t)en vor: unten bie zween Samenlappen, oben zwey Sieimblätter mit dem ungeraben am Enbe.

Betradtet man nun bie nierenförmige Bobne an igrem

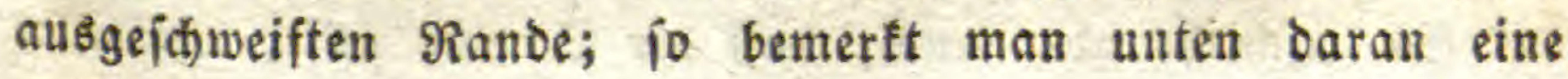
Dlens allg. Raturg. II. Botanit 1. 
längliđ̆e (Grube, ben ? a bel (Umbilicus), woran ber Sa men ft iel

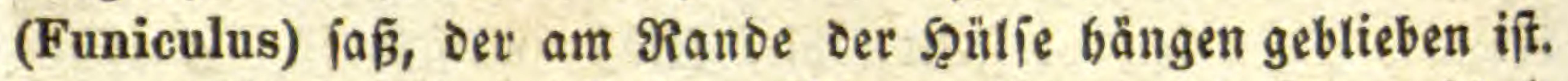
Er entbält ein Bündel Spiralgefäßąe, weldhes in die Sameniđhale übergeht, fid nad) unten biegt, auf bem Rücten ber $\mathfrak{B o b n e}$ ber: auf läuft, fid unterwegs verzweigt, oben herum geht uno fíd) vorn bis gegen ben Nabel verlängert, wo er endigt. 2tn biejer Stelle, zwifinen bem Enoe, nebmlia) Der Droffelrippe, und bem Nabel liegt ein febr fleines 20 d) wie mit einer Rabelipize ges madbt: es beifst Samenlod) (Micropyle). 2(uf biejes Lod) ftößt bie Spize bes Reimwintzeld)ens, und war baker wohl anfängs lid) eine Fortiesung ber Droffetrippe, mithin ber Sdale.

Dentt man fid) man, baź bas Samenloch) bie Stelle ifit, wo die S(j)ale ber Duere nad) aufreifit, gleich bem Farren = ober Fieberblatt; io ftellt fie eine eingerollte Blattideibe vor wie ben) Den Dolbenpflanzen, uno Der Feim fight auf igrer Spige wie bie Fieberblätter auf ber Blattífeibe ober bem Stiel.

Die ganze Bofne ift Daber ein eingerolltes Fieberblatt, wie bas Slatt eines Fartenfrauts, wovon bie Gatale ben untern, breitern oder fitheidenartigen Ifeil (Phyllodium) bilbet, in wel= dem jeine Spize mit ben gefiederten Blättern oder ber Reim nod) einmal eingerollt iff.

Entwictelt fid) ber Samen, fo jonbert bie innere fläd)e ber Sd)ale nabrbafte Flizifigteit $a b$, welde ber Reim nach uno nach einjaugt, wodurd) er fid) vergröbert. Das Wärzelden gliebert fich febr frith won Der Spike oer Droffelrippe benm Samenlod $a b$, wie bas Eitronenblatt vom Stiel, löst fic) enolid) ganz, bleibt aber an ber Sđalenwand fleben, und entfernt fith vom Samenloch, io wie die Sdjale wäd)bt. Sanneibet man eine unreife Bohne voer (Erbje ourd), fo findet man fie mit Saft angefïllt uno ben Reim ganz frey am Rücten ber Bobne lies getr. Er (đ)wimmt nidjt $b a=$ und bortbin, fondern bebält feine beftimmte Riditung uno Rage.

Mandi)mal faugt er alle flüfíigteit ein und wito fo grof́, Daßs er bie ganze Sabale ausfüllt, wie bey ben Şitllenfrüdten, Sđjotengewådîen, Rojaceen uno vielen anbern.

(Ë gejकiebt aber aud), daßs ber Samen reift, ebe aller 
Saft aufgeiogen und ber Seim fo gró ift, Daß er bie ફ̧öble ausfüllen Eönnte. Dann vertroctnet Der Saft ju Mebl uno umgibt ben Samen bald ganz, bald wie eine Rappe, balb nur wie ein Shild u.j.w. Man uennt diejen 2tbją̧ Eywei (Albumen, Perispermum). So ift es ebenfalls bey vieten Pflas= zen, namentlid) bey Budweizen, Şahnenfüben, Sđ)werdrilien.

Das Enweiś ift mitbin tein organifaer Theil bes Samens, unb bängt weder mit Der Sdale nod) mit bem Reime zufammen.

WBie die Samen in ibrer Geftalt, Giröße und Beftigfeit fehr von einander verídieben find; io ift es aud) ihre 2 nbeftung,

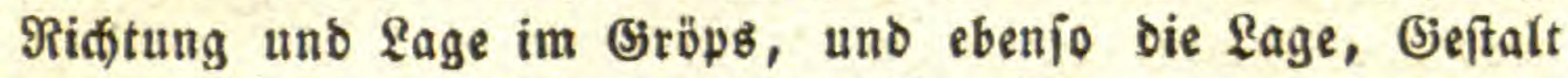

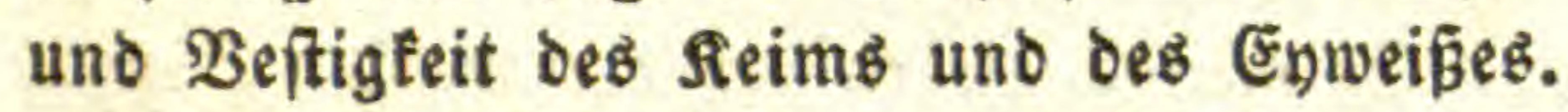

Jit Der Samenftiel furz, fo fann fict) ter Samen nur oreben, und fteht daher bald aufrectit, balo verlebrt, bald quer. Sit ber Samenftiel lang, io läuft er balo nac) oben, uno ber Samen bångt vom Giebel bes Gröpié Gerunter; bald nad) unten, bald feitwärts, bald zum $\mathfrak{T h e i l}$ um den Samen berum

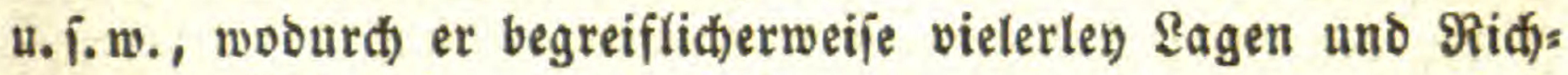
tungen erbält.

Daffelbe gilt vom Reim uno bem Enyeißs. Sit er von Demfelben eingeílolofen, io beift er central, wenn er gan in Der Mitte liegt: excentrifi), went er neben ber Mitte liegt. Jif menig Enweis vorbanden, fo tann er fith aud wohl um baffelbe herumbiegen, und dann heigt er peripherifd, wie ben bem Spinat uno Der Relfe. Er felbit ift gexab, trumm, ipirals förmig t.f. w.

2uch feiner Rid)tung nad in ber Sthale fann er, wie fition

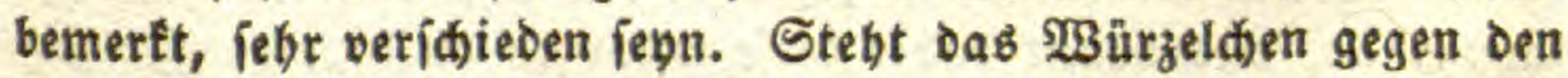
Nabel, fo ift er aufrect) ; ftebt es von ibm ab, fo if er um= getebrt. In beiben Fällen beift er gera owendig (homotropus). Es geidiebt aber aud, wie bey Der Bobne, סás bas İurzelden fammt eer Epiţe ber Gamenlappen oder ber Reims blättden gegen Den Rabel gebogen find, uno bann heißst er z $4=$ wendig (amphitropus); Doer es fino beide Spizen vom Rabel abgewendet, und bann beist et a bwend ig (heterotropus). 
Die Geftalt tnd Rage ber Gamenlappen ift felgr verfothicben; gerad, frumm, gefaltet, gewictelt u. f.w. Sie entbalten inber= baupt Mesl, wie ben ben Şülfenfrüthten, aber auth Del ben ben sreuzblumen, Sd) (eim ben den Mandeln.

Sie zeigen, fo bald fie grün werben, Spaltöfnungen wie Die Blätter.

Bey manden Pflanzen fommen fie aus ber Erbe Gervor, wie bey ben 30 hnen; bey vielen andern aber bleiben fie bar=

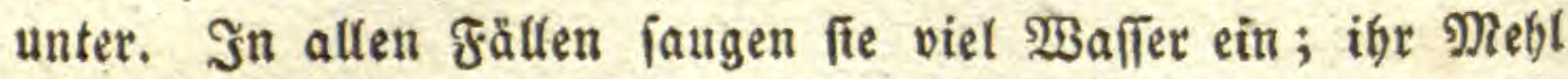
wito flififitg uno gebt in ben Reim über. Daburch merben fie rumzelig, vertrocfnen uno fallen meiłtens ab. 2(uf gleid)e 2trt wiro bas 태weiß eingeíogen.

Dả Rabel= und Samenlod) liegen bey ben meiften Samen neben einander, alio am (srunde bes Gameng. So nidjt blos bey ben Şüllenfrüd)ten, fondern aud bey Den Relfen uno Rreutz= blumen. 2tnoere weidjen ein wentig ab, nefmlid) barinn, bas Die Rabelitelle ber inmern Samenhaut etwas von ber åıßern ab= gerüctt ift, wäbrend bey ben vorigen beibe auf einander liegen: fo bey ben Rilienartigen uno şabnenfubartigen.

Es gibt aber aud Samen, bey welthen bloz ber Rabel am (jrunde liegt, das Samenlod) aber gegeniber am (Sipfel.

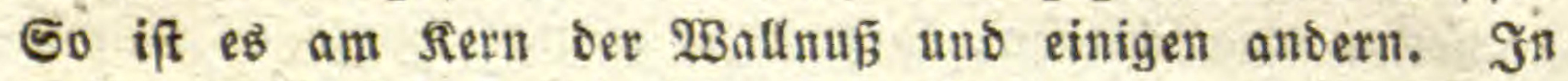
biejem Falle bildet alio bie Samenidjale eine Rnoipenblaie, weldfe nidt quer anten am Rande, fondern oben am Sipfel anfreist.

Bey Den Tadelbölzern fino die Eotylebonen, meines Erad)tens, mit einander verwadien, uno bleiben nie eine Rappe auf Den Reimblåttern fiłen. Man fiegt dieje für Samen= lsppen an, und nennt daber biefe Pflanzen vierlappige (Polnco: thleopnen).

2. Bey ben Sticibenpfianzen oder Monocotyledonen,

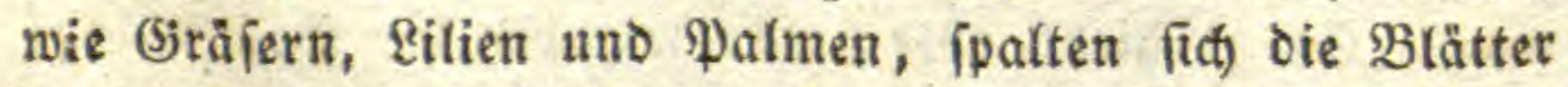
nidjt ganz, fonbern umfaffen mit ihrem unfern Theile ben Sten= gel ganz frey. Diejer Stengel ift aber felbit nur eine Stheibe, in weicher wieber eine Sd)eibe ftect u. f. f. Da nun ber- Sament nid)t sanderes als eine verťleinerte Pflanze ift; foftellt er aud 
fier nithts anderes als eine Sd)eice oor, welde aber gefiblollen bleibt uno nod) eite Sacibe entbält, nebmlid) ben Reim.

Diejer fann mitbin feine Seitenblätter baben, nno beis̄t oaber cinlappig, uno die Pflanzen nad) ibm Monocoty= ledonen.

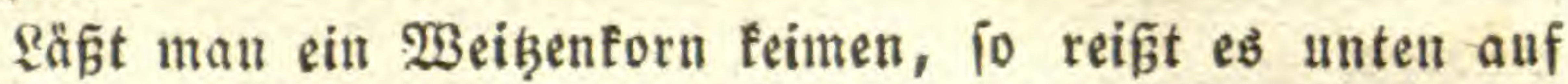

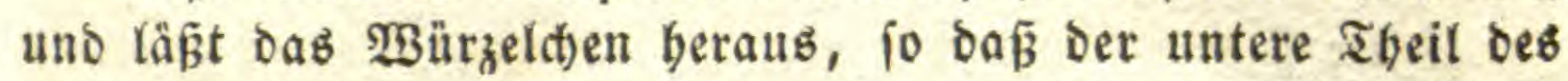
Rorns einen Ring Darum bilbet, weld)er Die eigentlide $B$ latt= ideibe vorfteflt.

(Stleid) über Dem Ring öffnet fi() Dab forn an ber Seite uno lăb̆t ein fpibiges Blatt heraus, weldes das fieimblatt ift.

Der Ring ftellt mithin die febr furze Scheibe des Blattes vor, uno Der labrige gröpere Theil des fiorns das Blatt felbit

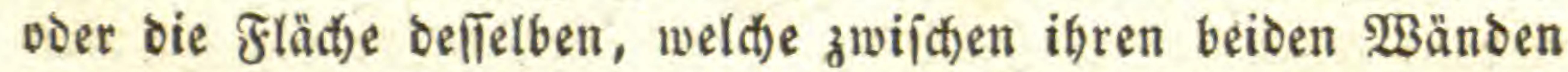
daв Mebl entbålt, und mitbin Der eigentliche Samenlappen ift,

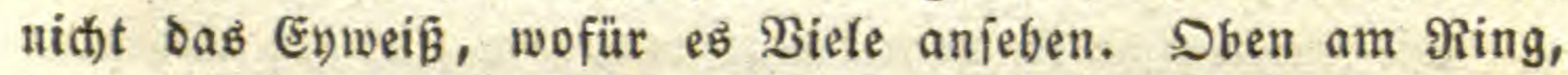
bem forn gegenuber, aljo Da, wo das fieimblatt beraus fommt, ftebt eine Eleine Spize oder S̈đuppe, melde man Dotter (Vitellus) nemur, iniem man glaubte, Der Pflanzenfamen wäre gleich Dem thierifaen (E), und entbielte aud) alle Deflen Ibeile.

Daв Reimblatt entbålt oder entwictelt wieder andere Sd) $i=$ ben in fia), weldie nach und nath beraustreten, fo wie fie fith

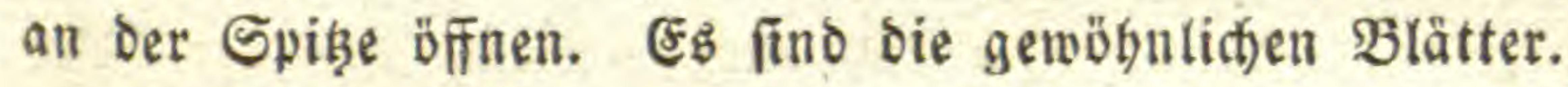

\section{3. $23 a s$ die jogenannte Blüthe ober Frudt}

Der blumenlofen Pflanzen oder Acotyledonen

betrift, fo bin id) in ibrer Deutung ganz non ber allges meinen Mennung abgewiđen, uno babe gezeigt, da反 es daielbit eben fo menig eigentlidae Fritht) ober (jröple gebe, als Blumen voer Staubfäden, doer daß̧ menigitens das, was man Fruct)t

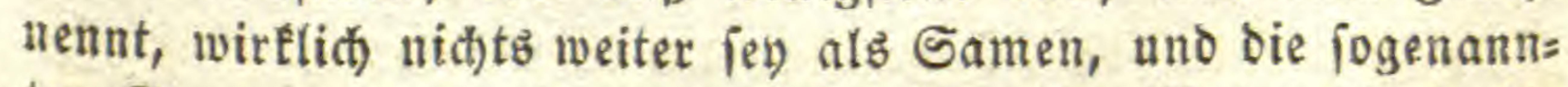
ten Samen nichts anderes als Enweifmehl. (Naturphilofophie 1810. ङ. 141. Rebrbud ber నaturgej(t). II. Botanif. 1825. ธ. 9.)

Bev diejen Pflanzen, wo es feine felbfiftåndigen Blätter gibt, beftegen die Samen blob ans einer Saut oder bes Shale 
obne Samenblätter; fino aber ausgefüllt mit Debltörnern, welde mitbin bem Ey wei B entiprechen.

Dieje Samen beftehen baber eigentlid, bloв аแв ber Sđale, obne Blatter, uno es feglt ifnen nictit bloßs bas, was man Samenlappen (Eotylebonen) nennt, fondern aud) ber ganze Embryo.

Dieje Enweiĝtörner hat man mit Unred)t Samen genannt, ipäter befier setmpulver (Sporae).

Die Shale un bieje sörner nannte man Eapiel, ebenfalls

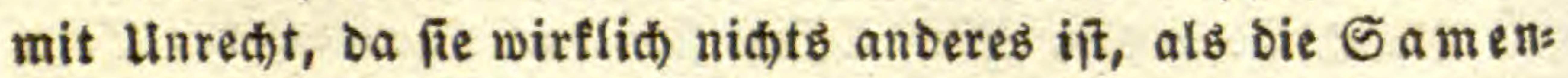
(i) ale voer bie Shale bes STeimpulvers (Sporangium).

a. Bey den Farrenf́r ä utern

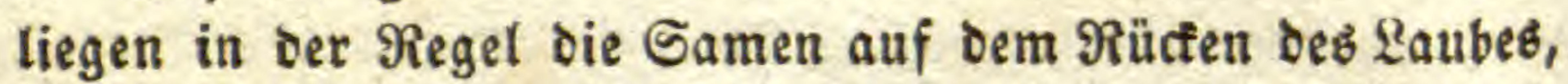
worans folgt, gewordener Stengel.

Die Samenidhalen ober bie jogenannten Eapieln liegen in Şa ufen (Sorus) beyjammen, unb find von bem jogenannten

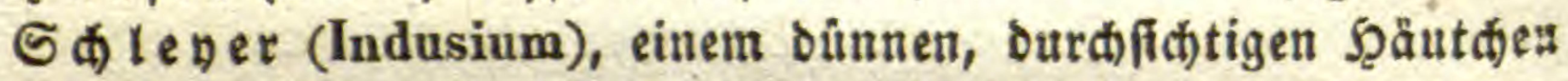
bedectt, weldes aljo bie Stelle ber Eapiel ober bes Balgs vers tritt. Es reiß̄t balo in einem Spalt, balo ausgezacti auf, und läst bie Samen oder Eapieln berausfallen.

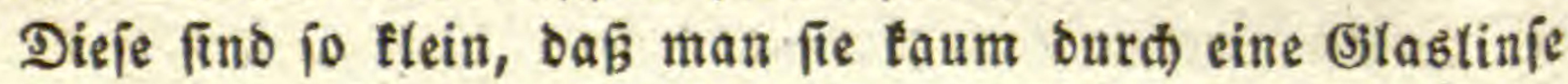
Deutlid) erfenten fann. Sie fino furz geftielt, uno ber Etiel

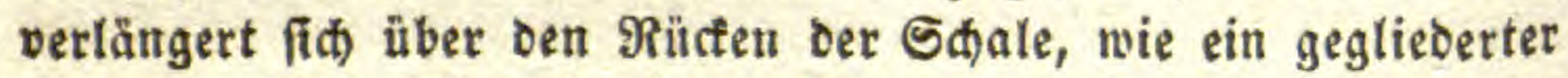

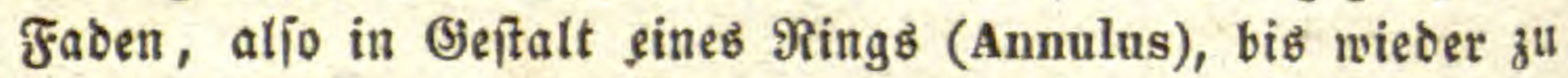

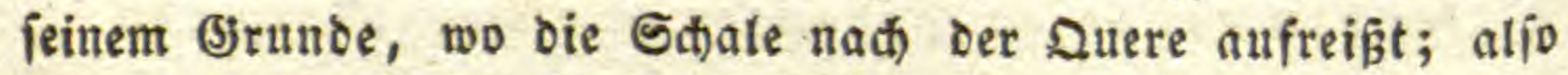
ganz wie bie Bohne in ibrem Samenlod, ober wie eine eins gerollte Blattídeibe an ibrem Grunbe. Das \&aub, ober viel: mebr ber $\mathfrak{B}_{\text {edel }}$ ber Farrenträuter ît auf ähnlide 2(rt einges

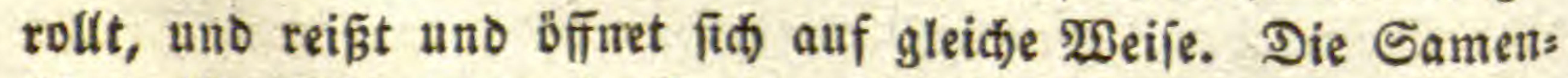
ithate if mithin nur ein Farrenwedet in Miniatur.

Das Reimpulver ober bie Eyweiftörner fallen auf ben Boben, ifwellen an, werben breit, jerreißen, uno ber Jnngalt verlängert fic) unmittelbar in bas \&aub oder ben

b. Bey den Moofen

entifteben oben am Stengel, in einem sireife von $\mathfrak{B}$ (ăttç)en, 
mebrere jogenannte Frihthe, movon aber nur eine auf einem langen Stiel ober Borfte (Seta) ausıäd)st, inbem bie andern verfummert. Sie fino noh) mit dünnen, Durd)fit)tigen fäben (Paraphysae) umgeben, weld)e man für Staubfäben angeielien bat, obiaon fich feine Spur von Staubbeiteln zeigt.

Die Frudft ift viel größjer als ben Den Farrenfräutern, oft fo grof wie eine Erbie, uno theilt fid) quer über ser Mitte, fo Daß̧ ber obere Theil wie ein Dectel abipringt. Man nennt fie Daber $\mathfrak{B}$ ŭ le $^{\mathrm{e}}$ (Theca s. Pyxidium).

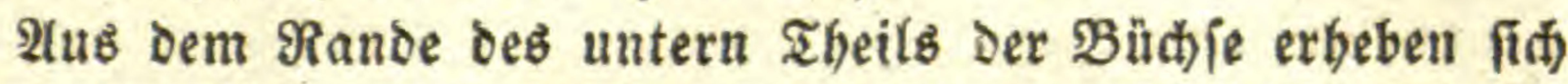
augwendig כähne, innwendig zarte, Fäben aus Zellen beftehend, welche fegr leid)t feudt uno trocten werben, uno beṕbalb fid) bin und ber trummen. Man nent fie $\mathfrak{B}_{\text {impern (Cilia). }}$ Sie riditen fich nach ber $3 a \mathfrak{b l} 4$, find aber meiftens ibrer 16 ober 32.

Mitten in ber $B$ hithje ftebt ein hohles $S$ äuld) en, weld)es balb ganz ourchgeht, balo verfitrzt ift.

Um die Büthje berum liegt ein feines Şäuta)en, weld)es

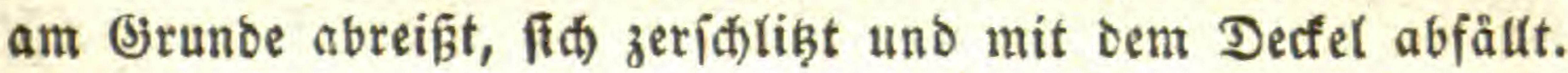

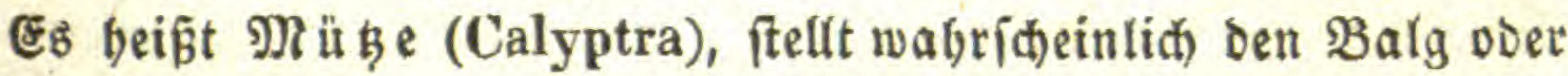
die Eapjel vor, und entiprid)t mitbin bem Shleyer ber Farren.

Die Büđ)fe und das Säulden find mit jebr feinem Staub angefillt, Dem Reimpulver, ogme alle Anbeftung. Es if mit= bin nur abgeiondert oder ausgeidivizht.

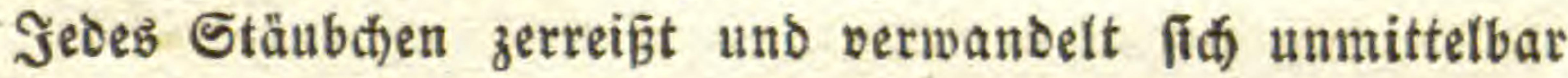
in 3 urzel uno Stengel, obne alle Samenlappen.

c. Bey den Fle d) te $n$ (Lichenes)

find bie (Gröple niđts anderes als biđ)t an einander lie= gende Röhren ober Saläude, theils auf, theils in Dem Stoct (Thallus), melde unmittelbar das seimpulver einíd)lieşen. श(1n) findet man zeritreut überall im Stocte Sörner wie fieim= pulver, von benen man aber niabt weif, ob fie ebenfalls teimen, was indeffen febr wabrídeinlich ift.

d. Bey den Iangen (Fuci)

liegen bie Gröpfe ganz im Stoct verborgen, unb befteben meiftens aus einer $W_{B}$ ano von langen uno gefärbten Bellen, 
innerbalb weldter $\mathfrak{B a n d}_{\text {bas }}$ Reimpulver liegt. Mandmal

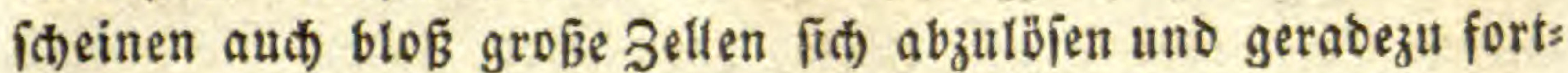
zuwadien.

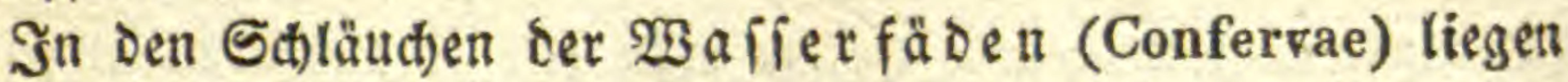
unmittelbar Sörner, meld)e beraubtreten und fortwachjen.

\section{e. Bey ben $\mathfrak{P} i l_{z} \in \mathfrak{n}$ (Fungi)}

ftectt bas Reinapulver ebenfalls in langen, bidit an eins ander liegenden Saläud)en, welde bey den $B$ lätterpilzen $B$ lät= ter unter bem seute bilden. Ben ben Morcheln liegen fie aubs wentig auf bem Sout.

Der Sđimmel (Mucedo) trägt Bläвぬen mit seimpulver. 2ud finbet man zeriftent, wie bey ben Flechten, einzelne Sïr= ner in ber Subftanz oder neben ben Sdimmelfäben. Sb es auci) Reimpulver ifí, weís man nicht.

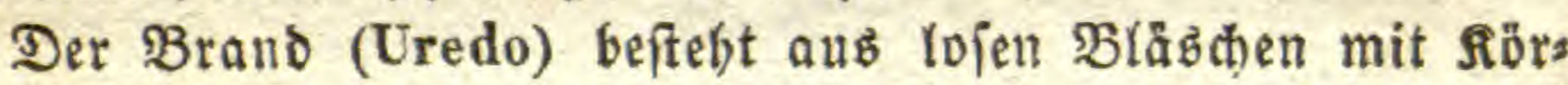

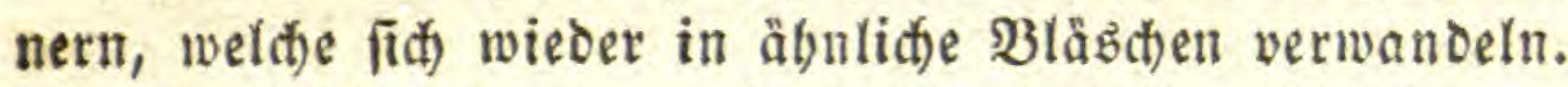

Bergleid)t man nut bieje Fruttttbeile mit einander uno benen oer Blumenpflanzen; jo ergibt es fid), bafi die fogenann= ten Eapieln ber Farren uno Mlodie eigentlid) die Samen felbit fino, Die aber ffatt eines Reims nur Ënweif̈törner abjondern, welde im Stande find, bie Gattung fortzupflanzen.

Daß nur bie Farren uno Moofe eine Spur von Eapje! baben im (⿹)lener und in ber Müke.

Bey ben Flectiten uno Tangen vertritt oas Zellgewebe bes Stocts die Stelle ber Eapfel.

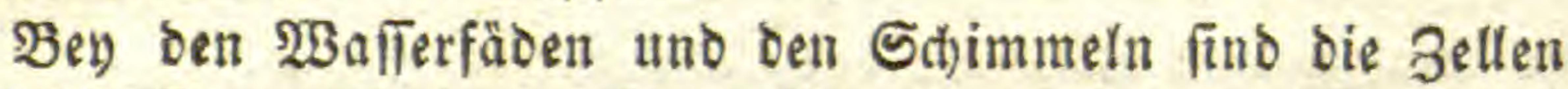
felbit bie Samenimale, welde nidht einmal von andern Bellen ober einer 2 tndeutung von Eapiel umgeben ift.

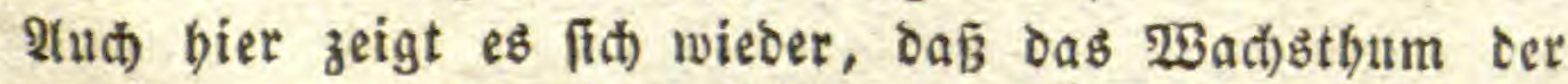
PFlanje in einer beftändigen Sonderung Der (jewebe, Snfteme uno Drgane beftebt. Suerit ift fie nidhts anderes als eine Zelle mit Sïrnern, unb bieje Belle ift zugleid) Samenichale, und die Rörner fino Reimpulver, wie bey dem Brano und ben $23 a f f e r=$ fäben. Weber 2 lätter, nod) Stengel, nod) $\$$ utzel find abge: fondert vorbanden.

Dann fondern fid gewifie Bellen ab als Samen mit 
Reimpulver, und bie anbern bilben ben Stoct zur Ernäbrung, wie bey ben Pilzen.

Man fann bier einen Stengel untericheiben mit idwachen

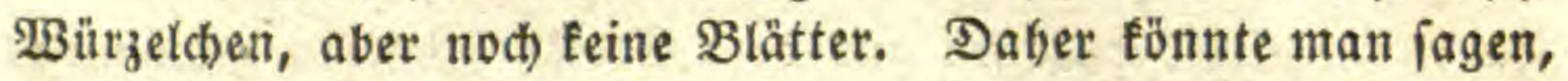
fie beftänoen blof aแв vielen Samen in einer noต) nidit indi= vioualifierten Eapiel, negmlid) Dem Stocf.

Bey ben Tangen fondern fith wenigftens bie Samen in einzelne Şaufen, uno der ziemlid) wurzelloje Stoct fängt an ourd) Feitle grüne Farbe zur $B$ lattantur fich) Ginzuneigen.

Bey ben Flect)ten ift die Sonderung nod) bentlicher, weil

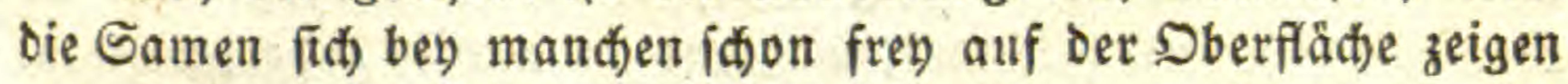
uno eine andere Farbe baben. 2(nd) fängt ber Stoct an, fíd in Stengel uno $\mathfrak{B u r}_{\mathfrak{3}} \mathrm{el}$ zu trennen, uno ourd) feine oft grüne Farbe an bie Blätter zu erinnern. Uebrigens fann man ben Stoct ber Flewten uno ber Iange, gleid' wie bey Den Pilzen, nod) als eine gemeinid)aftlidbe Eayjel betradten.

Bey ben Moofen und Farren bat fich Samen uno Eapiel ausgejtieden und fid ferbifftändig vom Stocfe getrennt. Mit Diejer Trennung baben aud bie Blätter angefangen, fid vom Stocfe abzhioncern, woburd) zuerft ein wabrer Stengel mit Wurzetn entifanden ift. Da fith bier eine Eapfel findet, fo fönnte man ben Stoct als Bhume und seld(b) betracten.

Die niebern Pflamen ftellen bemnach in gewiffer şinficht

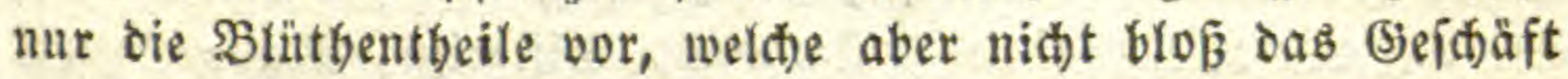
Der Fortpflanzung iiber fid) Gaben, fondern aud) Das Der Ers

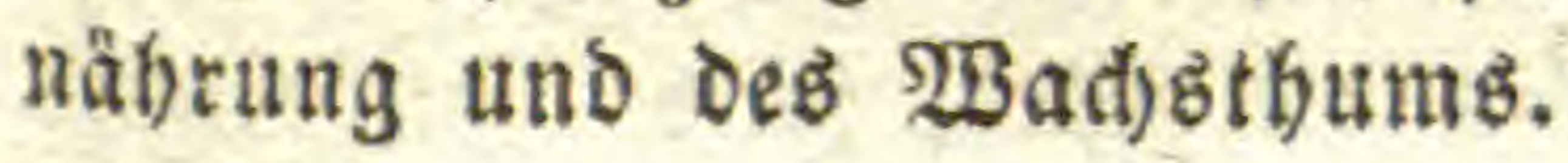

\section{Frut.}

Die Frudbt ift bie Serímelzung ber Btitthentheile, wovon einer fleifidig geworben iff.

In ber Fruckt concentrient fich bie ganze firaft Der PFlanze, und es fammeln fid) barinn alle chemifaden Stoffe, welde vorber

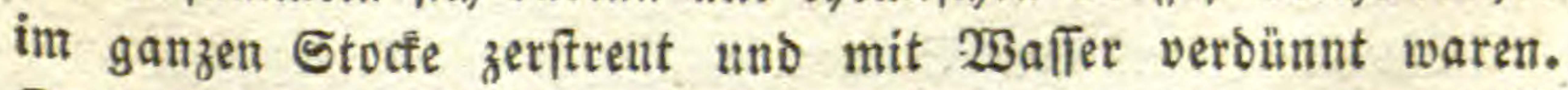

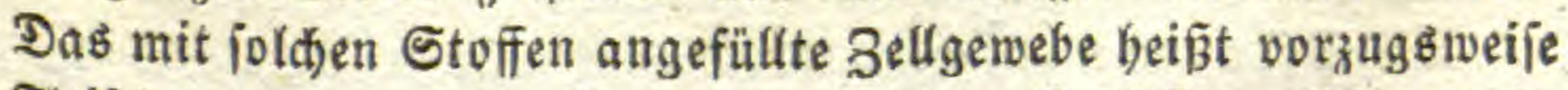
Fleijit), uno bat jeine Beftimmung über bie Pflanze binaus in

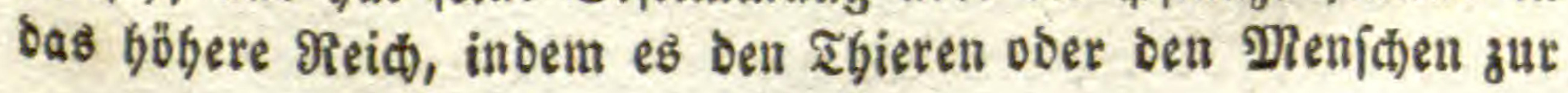


Rabrung bient, unb fich alio in wirfliches Fleifh verwandelt. Die Frühte fönnen meiftens roh verzegrt werben, und find bas ber gleidjfam fibon von ber Ratur zubereitet. Die andern Rabrungsmittel bagegen aus bem Stocte bebürfen gewöbnlich

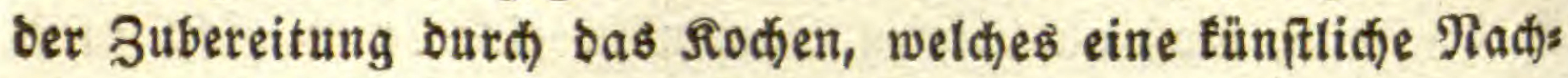
abmung Des Reifens ber Frütate ift.

Da bie Blïthe nur aub bren Şaupttheilen beftebt, nebmlia bem Gamen, bem (5röps uno ber Blume, fo fann es aud) zu= nădfit nur brenerley Jrüthte geben, ie nachoem ein ober ber ancere biejer Theile fleifhig wirb, b. h. ein Uebergewicht an chemiīten Stoffen befommt, wäbrend bie andern mager bleiben.

Es tann aber auth eine (jejammtfrubt) geben, wenn nefm= (id) alfe Theile ber Blïthe, fammt bem Rel(t)e, mit einander vereinigt bleiben.

2uf Diefe Weife befämen wir 4 2rten von Früđten.

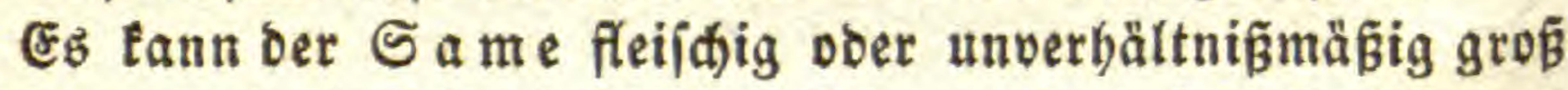

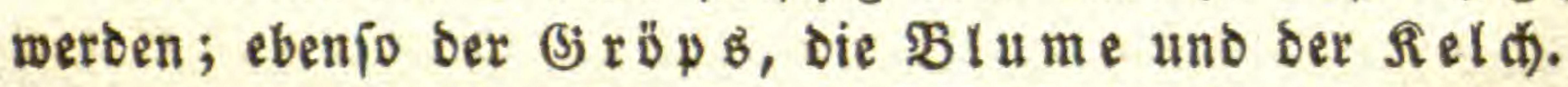

1. Die $\mathcal{S} a m e n f r u d t$ witb diejenige jenn, worinn ber Samen febr groß vertümmern voer vertroctnen, wie bey ber Şafiefnußs, Eicthel, Eaftanie n. \{. w.

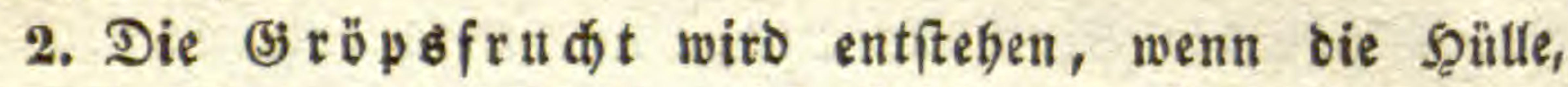

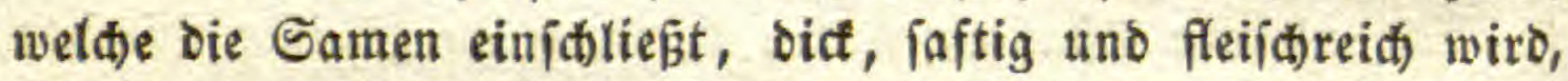
wie bey Den Ririthen uno Pflaumen, Piftacien, Mangoftanen.

3. Blumenfrat will id diejenige nemen, welde in allen ibren Theilen zart und fleif̧roth wird, fowohl auserbalb als innerlalb bes Giröpies, io bas man fie gauz veríflucten tann, wie bey den Beeren.

4. Wirb enolid fetbit ber Reld fleifidig, fo entftebt eine Giejammtfrudst, wie benm 2(epfel.

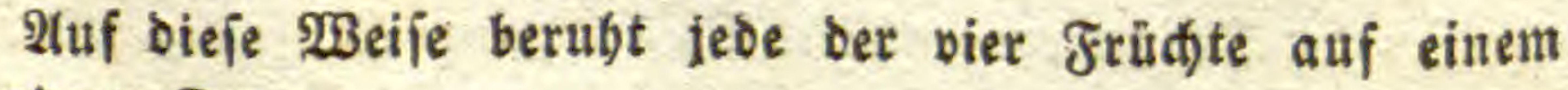
bejonbern Srgan.

Die $\Re$ ú auf bem Samen.

Die P fla ume auf Dem Gröps.

Die Beere auf ber Blume.

Der Al p fel auf bem sield). 


\section{a. Samenfruकt ober गน ह (Nux).}

Die शū if ein einfamiger, vertroctneter ober verbolzter (Sröps.

Wie frilber gezeigt, baben alle $\mathfrak{B a ̊ l g e ~ w e n i g i t e n s ~ z w e e n ~}$ Gamen, nebmlid) einen an jedem Rande. Es geífiebt aber beb vielen PFlanzen, dás einer ber Samen bie Sberband befommt, fehr grof und meglig wirb und ben ober bie anderen verbrücti, wie es beutlich bey Der Ropcaftanie zu feben ift.

Er füllt bann für fid) allein ben ganzen (jröps aus, uno

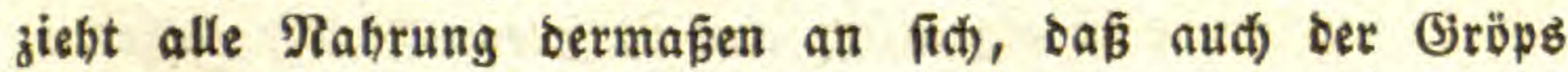
ganz verfitmmert uno haut $=$ ober bolzartig wirb.

Man fann bieker orey Stuffen unteridgeiden.

limíliefit ber Gröps den Samen wie eine ફ̧aut, welde digt bamit verwadien iff, wie bey ben Gräjern pber dem Beikentorn, fo nent man dieje Frudt Rorn.

Wiro aber ber (jröps hart und löst fich) vom Samen doer Sorn ab, wie es benm Sauterampfer, Spinat, Şanf, den Reffetn u. Dergl., auch beym Balbrian uno Wegerid) ber Fall ift; fo

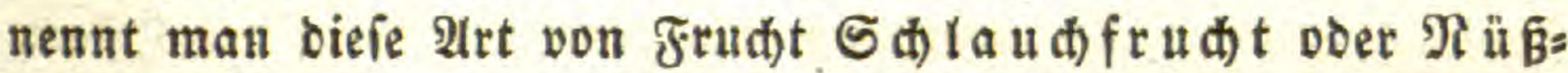
lein. Man fann ben Sdlaudi) doer bas Rorn als bie Grund= form Der $\Re u \in$ betractiten.

Endlic) umgibt niđt blof ber Gröps ben Samen, fondern aud Der Reld), io bas beibe bitft mit einander verwadien und holzartig werben, wie bey ber Eidfel, Buhe, Eaftanie uno Der

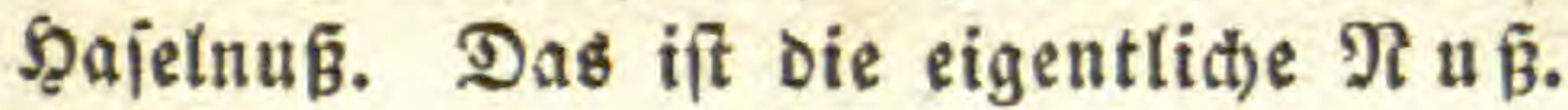

Daber theilen fid wabrideinlid bic Ritre ab je nad ben

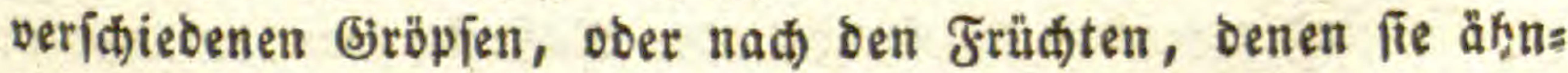
lic) werben.

Die Sd)landnuß wäre die mit einem bloß vertroctneten, einfäh)erigen (jröps, wie Der fogenannte Samen bes Gauer: ampfers, der Refieln, bes Şanfs.

Die Şüllen: voer Pflaumennus wåz̧e biejenige, weld)e einen jweyflappigen Gröps hat.

Die Capjels ober Beerennu, weldie mebrfäd)erig wäre, wie

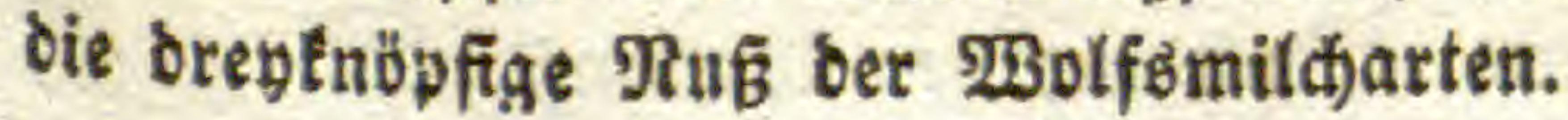


Endlich Die Rieldt) ober 2 pfelnus, weldhe vom vertroctneten Sielch) bedectt wäre, wie die şafelnus uno die Caftanie.

Benm Reimen biejer Früthte vermodert bie bäntige Schale

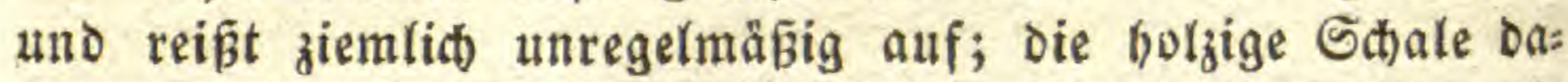
gegen fpaltet fid meiftens am Bjipfel, uno bie Reimblätter fo

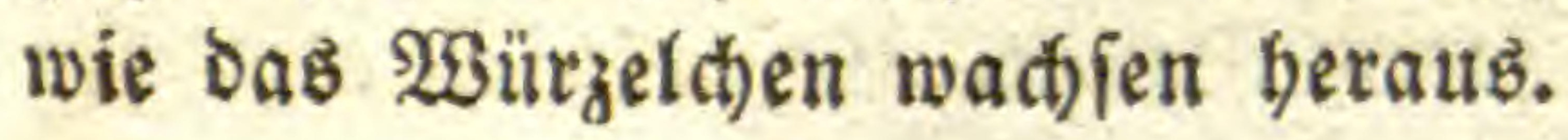

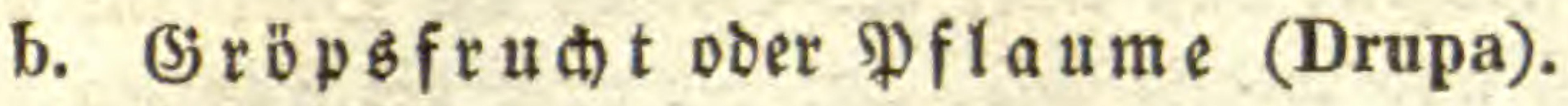

Die Pflaume if ein wenigjamiger (jröps mit verbolzter innerer $\mathfrak{W}$ and und fleifdigem 3 ellgewebe.

Die Pflaume ift eigentlict) eine $\Re$ us von gleî́) umgeben, unb hat meiftens ben Bau ber Şülie, wetche nur einen uno den andern Gamen eillifliest.

Die innere Rage oder Şaut ber Şülie wird biet allein hol zs voer fteinartig; bie äusere oagegen verwandelt fíd in ein zat=

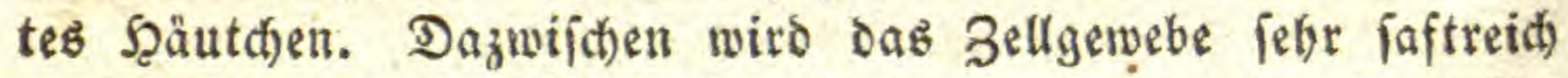
uno entfernt beibe $\mathfrak{B a ̈ n d e ~ d e r ~ S ̧ i l l f e ~ w e i t ~ v o n ~ e i n a n d e r . ~ 2 t a ~}$ Der åubern Şaut einer Zwetidie fann man jehr bentlia) bie zwey Räbte unterícheioen, wie bey ber Sohnenbülíe. Man

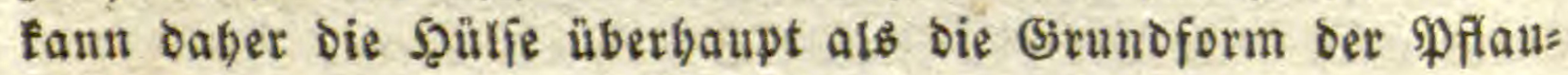
men anjeben.

Bey Der $\mathfrak{N u}$ ift ber Samen in ber Regel nur einzelu; bey ber Pflaume fängt er ífon an fï) zu vermegren, über= fteigt aber felten bie 3abl 2. In beiben Früchten gebören mits bin bie Samen zu ben grofen; bey ben folgenden find fie nuei= ftenz zaflteich) uno oaber flein.

Die Pflaumen theilen fid) wobl aud ein wie bie Nilfie.

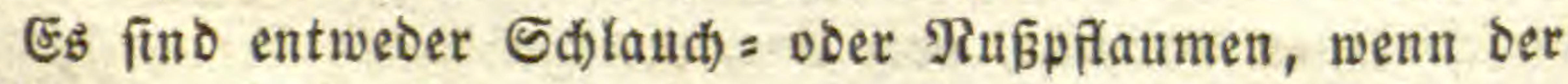
einfäntherige Stein fich) nidgt in zwey Rlappen fpaltet, wie bey Der Brombeere.

Şülfen= oder eigentlidie \$flaumen, wenn biefes ber Fall ift, wie bey Den Riríten.

Eapfel= ober Beerenpflaumen, wenn ber Stein mebrfäd)erig ift, wie bey ser Cornelfiridie.

Selch $=$ oder 2lpfelpflaumen, wenn ber Stein mit einem

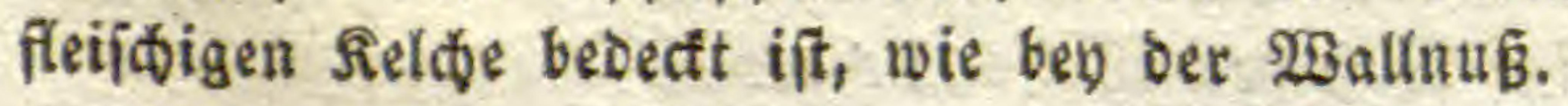




\section{o. Blumenfrudf t ober Beere (Bacea).}

Die 2 eere if ein vielfamiger, burđans weidier (5iröps,

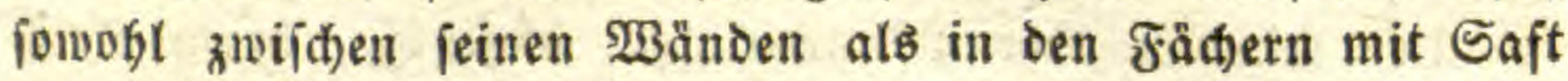
angefïllt.

Da fie meift vielfäd)erig ift, ober alb foldhe betractet wers Den fanı, uno alle Şäute oünn uno weich fino; fo fann man die Eapiel mit verfimmerten Sd)eibmänden, alio die Sd)ote, als ibre Girunoform betractiten.

Es ifi niđt immer leidt, bie Beere von ber Pflaume und

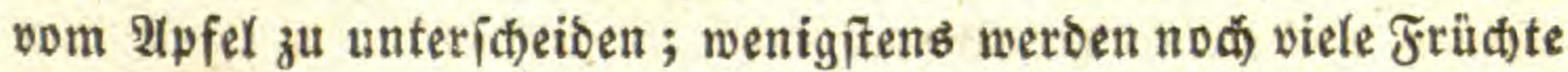
als Beeren aufgefübrt, weldhe zu jenen gebören, namentlich bie: jentgen zu ben 2 (epfeln, weld)e mit bem field)e bedectt fino. Sie lafien fich Daber noch nicht gebörig oronen. Ueberbaupt bin ith

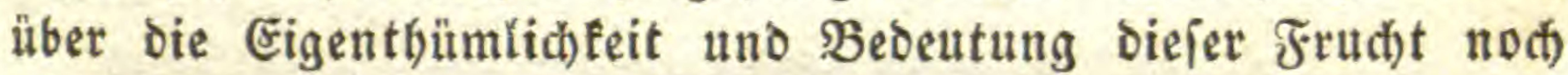

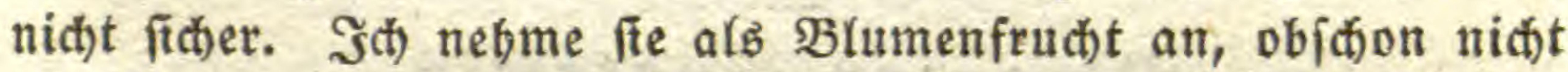
jeoe Beere mit einem Bluftbeil bebectt iff, uno vielleidht bie Fieldfrucht biejen Titel baben follte. Die Elaffen bez Pflanzen= fyftems f(t)einen jeod die srennung Der Beere und Des Apfels zu verlangen. Die Butunft wird Darüber entíheiben.

Bielleidht lafien fich bie Beeren auch in 4 abtbeilungen bringen.

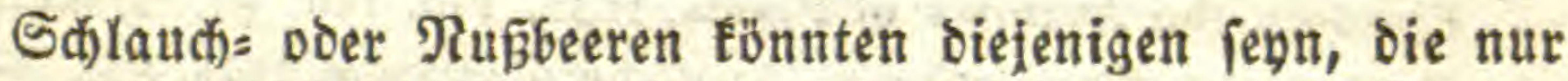
einen Gamen entbalten, wie etwa die Miftel.

Şullien= ober Pflaumenbeeren biejenigen, welde einige Sa= men entbalten, wie benm fireuzoorn uno Sumad).

Satjoten $=$ oder eigentlide Beeren die ganz weidjen, mit vielen Samen vier megreren Făhern, wie die Weinbeeren, Eitronen.

2(pfelbeeren enbli die vieljamigen, mit einem Sield) über= zogenen, wie die Myrten, Siranatäpfel.

\section{d. Reld) frud)t ober 2 ip fel (Pomum).}

Sino Eapieln mit vollfommenen Sheiowänden vom fleijđi= gen sield) bebectt.

Die vier gpfelftuffen wären etwa: 
Der Sd)laud) oder शusapfel biejenige Frudt, welde nur ein unb das anbere forn einíliefst, wie bey ben Dolbens pflanzen.

Der Şülfen = ober Pflaumenapfel biejenige, beren Relch

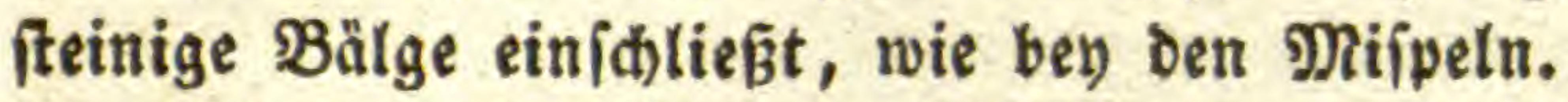

St)oten= ober Beerenapfel biejenige, bey welder bie Stheib: wänbe weidh bleiben uno viele Samen tragen, wie ben ben Stürbien.

Der Capiel = ober eigentlide 2tpfel biejenige, welde volls tommene Sdheiomånbe mit 2ldjenjamen hat, wie bey bem ges meinen Apfel und ber Birne.

\section{S d) $x$ iften \\ นีbeร \\ \$flanzen = $\mathbb{A}$ atomie.}

Nehemias Grew, the Anatomy of Vegetables. London. 1671. 12. (Miscell. nat. cur. Dec. I. Ann. 8.)

Ejusdem, An, Idea of a phytological History of roots, 1673. 8. (Miscell, nat, cur. Dec. I. Ann. $9 \&$ 10.)

Ejusdem, the Anatomy of Trunks. 1675. 8.

Ejusdem, the Anatomy of Plants. 1682. Fol. tab. 83. Şatlptwerf.

Marcellus Malpighius, Anatome plantarum. 1675. 801. tab. 39 \& 54.

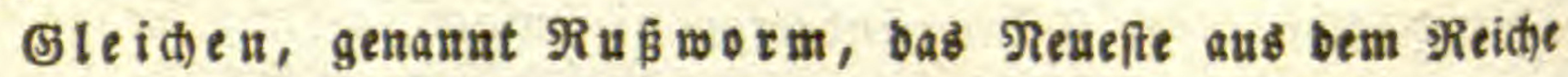
Der Pflanzen. 1764. Fol.

Hill, the Construction of Timber. 1730. 8 .

Joh. Hedwig, Fundamentum Historiae muscorum. 1782. 4.

Ejusdem, de fibrae vegetabilis et animalis ortu. 1789. 4 .

J. Gaertner, de Fructibus et Seminibus Plantarum, 1788, I. II. 4. Fig.

C. Ga ert ner, Suppl. carpologica. 1805. 4. Fig.

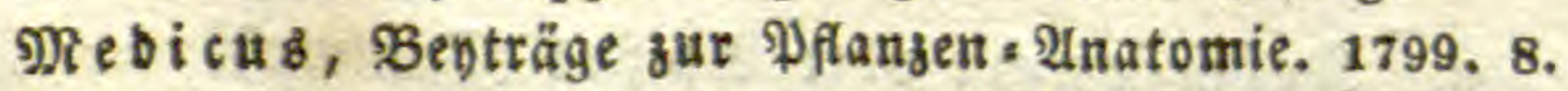

Mirbel, Essay sur l'Anatomie des Végétaux. 1800. 4.

Ejusdem, Traité d'Anatomie et de Physiologie végétale. 1802. 8.

Bernhar bi, Beobadtungen über 叉fanzengefä̧e. 1805, 8.

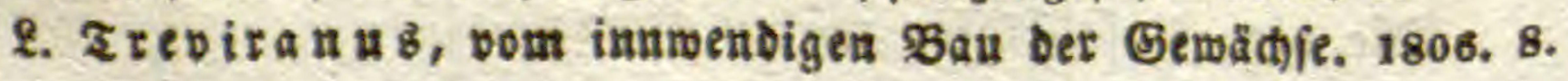


厄. $\Re$ ubolv hi, 2natomie ber Pflangen. 1807. 8.

S. Lin 3en. 1807. 8 .

A. du Petit-Thouars Essay sur l'Organisation des Plantes. 1807. 8.

Mirbel, Exposition et Défense de ma Théorie de l'Organlsation végétale. 1808.8 .

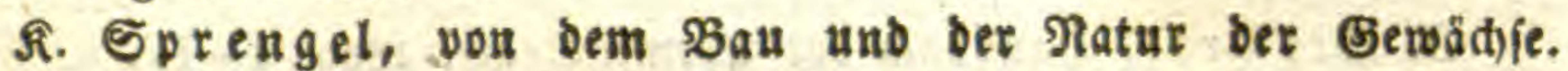
1812. 8 .

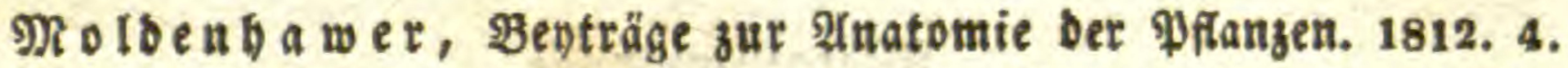

K i e s er, Mémoire sur l'Organisation des Plantes. Haarlem. 1818. 4. Fig.

Deffelben Phytotomie. 1815. 8.

Petit-Thouars, Histoire d'un morceau de bois. 1815. 8.

Dutrochet, Recherches anatomiques sur la structure des Végétaux. 1829. 8.

(3. $:$ if off, bie cruptogamifden (E)

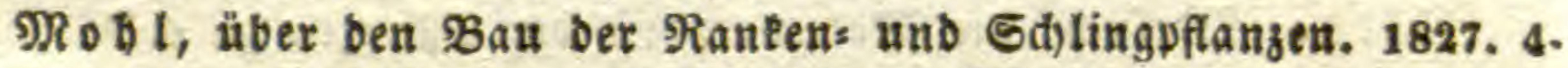
Derfelbe, über bie Poren Des Pflanzen=Dellgewebes. 1828. 4.

Ejusdem, de palmarum structura (in Martii opere).

Me ye n, ஒhytotomie. 1830.8 .

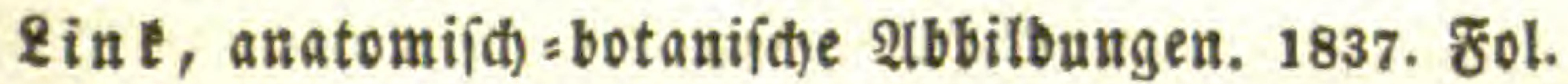

\section{IOIgemeine Sdyriftem}

นี่อย

\section{o e a fla}

Linna eus, Fundamenta botanica. 1736. 12.

Ejusdem Philosophia botanica. 1751. 8.

Rouf́cau, Botanif für grauenzimmer. 1781. 8.

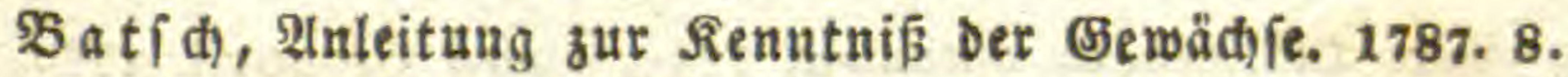

Batih, Botanif für Frauenzimmer. 1795. 8.

İillben \&int. 1821.8 .

Sayne, botanifice Runitiprad)e. 1799. 4. Fig.

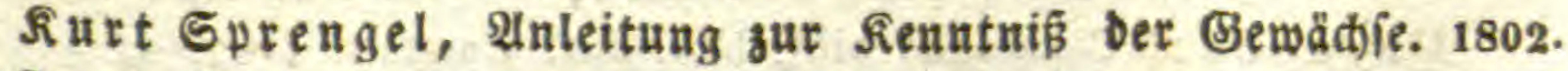

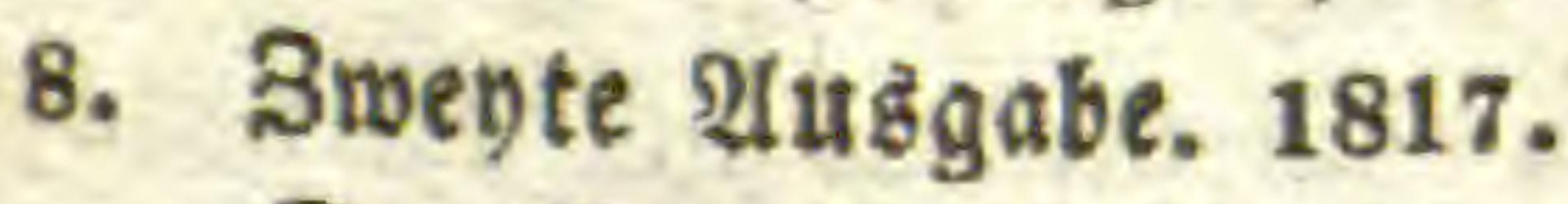

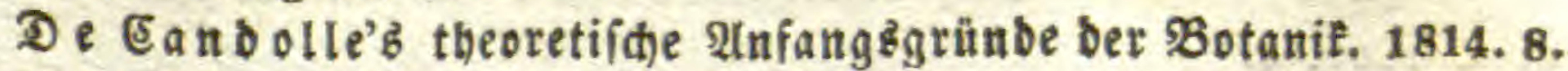

Mirbel, Elémens de Physiologie végétale et de Botanique. 1815. 8. Fig.

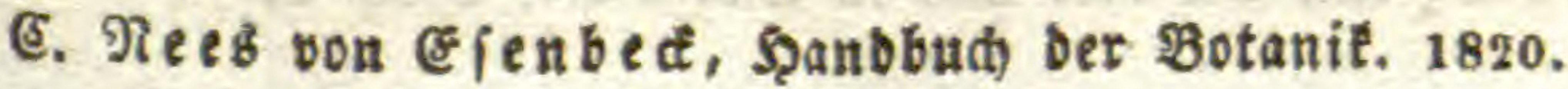


T uspin, Iconographie des Végétaux. 1820.

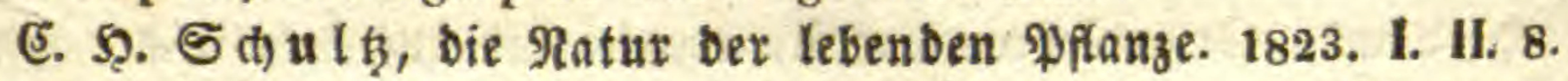

Link, Elementa philosophiae hotanicae. 1824. 2. 8. Ed. 1837.

De C a nd oll e, Organographie végétale. 1827. 8. Ueberieł̧t vou Reib̈ner.

Agarbh, \&ebrbud) ber Sotanit. 1329. 8. (Uleberfeht aus bem Scjuebifiten.)

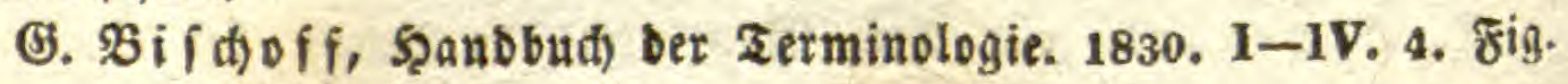

\section{Metamorphofe \\ นี้อย \\ \$ f $\mathfrak{r} \mathfrak{a}$ it $z$ t.}

Linnaeus, Metamorphosis plantarum. 1755. (Amoenit, acad. IV.)

- Prolepsis plantarum. 1760. ibid. VI.

Fr. Wolff, Theoria generationis, 1759. ed. II. 1774. 8 .

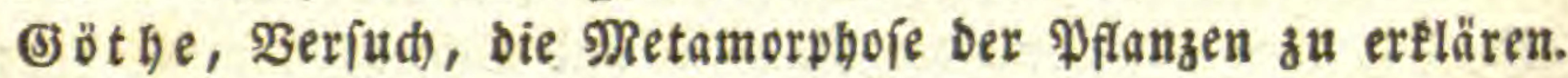
1790. 8.

Déen, Ratutphiloiophie. 1810. II. 8.

\section{(S)effictite.}

Surt Sprengel, (Eefdid)te Der Sotanik. 1807 u. 1817. 1. 11. 8. S(h) ulte s, Grunbrif einer (Gejd)idte Der Sotanik. 1817, 8. Frau (s) enliz, Sotanik Der (Sejdid)te. I. II. 1813. 8. Dierbach, Flora mythologica. 1833. 8. Defîen Flora apiciana 1831. 8.

\section{Siteratux.}

Seguier, Bibliotheca botanica, 1740, opera Gronovii. 1760. 4.

A. Haller, Bibliotheca botanica. 1771. I. II. 4.

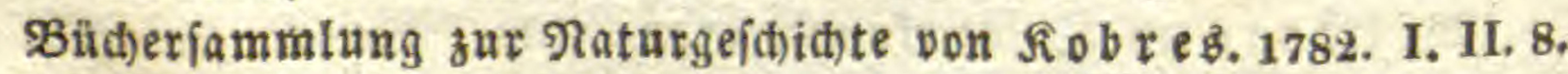
Brünnich, Lit. danica scient. nat. 1783. 8.

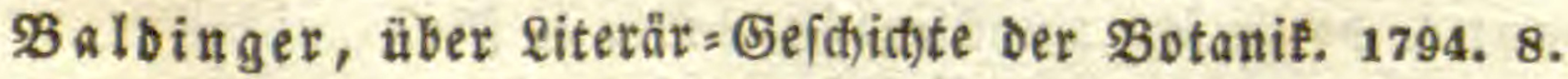

Dry ander, Catalogus bibl, hist. nat. Banksii. 1797. 8.

Reuss, Repertorium commentationum a societatibus etc. II. botanica. 1802. 4 .

(E) $\{$ (), Eiteratur Der গlaturfunde. 1828. 8.

Winther, Lit. Sc. rer. nat. in Dania etc. 1820. 8. 


\section{Die Pflanzen= Shemie}

banbelt won ben Stoffen ber PFanzen und ibren wedfel= feitigen Berbinoungen oder Procefien. Eg faun bier nur eine georängte Dariftellung oavon gegeben werden.

\section{Pflanzenitoffe.}

Эn ben Pflamen fommen fiton viele eigenthïmliche Etoffe vor, welche fict im Mineral : Reich no(t) nicht fincen, uno zwar meiftens foldie, welche atrs mehr als zween einfachen Stoffen

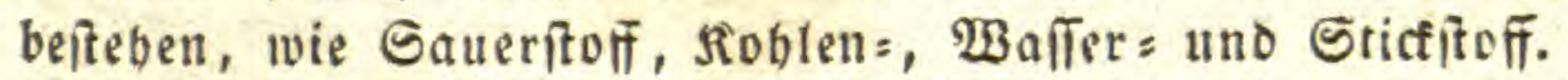

De Eandolle uno 2 . Treviranus baben in igrent

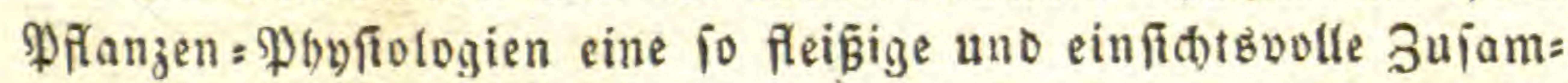
menitellung Der Stoffe gegeben, Daj id) Diefelbe als (5runolage benuken, jecod) nach meiner 21 rt oronen werbe. Bey Den $\mathfrak{B} e=$ fanctbeilen uno Den chemiitien procellen forge id $\mathbb{I} \ddot{b} w i g$ Ehemie ber organifhen Berbincungen. 1839. I.

Die Groffe verbinden fith immer in befimmten Mengen mit einander. So beftebt dem (jienictete nach

\begin{tabular}{|c|c|c|c|c|c|}
\hline פBaाাer & $\begin{array}{ll}\text { a } & 1\end{array}$ & Theil & Wallerftof & $\| 110$ & 3 Sauerítof \\
\hline Siobleniäure & - & - & sioblenitorf & -16 & - \\
\hline Enlpeterfäure & -14 & - & Srictitoff & -40 & - \\
\hline St) wefeliäure & -16 & - & Gawefel & -24 & - \\
\hline
\end{tabular}

Wenn mely ooer meniger Sanerî̃of an einen ancern (Srund= ftoff tritt, fo geidiebt es nict)t in gleidgültiger Menge; foncern

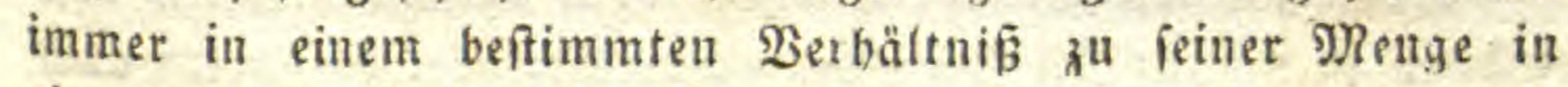
einer ancern, ja in allen Berbinoungen, alio nicht is fortlaus= fenden, fondern in Stuffenznglen. So treten z. B. nn pine gleidbleibende Menge Etictitoff nid)t 1, 2, 3, 4 Theile Sauers ftoff, ioncern etwa zweymal, oreymal fo viel, als in oer itswäd) ften Berbinoung vorfommt. Es entbält

Sticfitoff: Drnoul 14 Eticfitoff uno 8 Saueritofi,
Stictitoff Drno
14
$-16$
alio 2 mal s,
Salpeterichte Säure 14
Salpeterige Eäıre
Ofens allg. Naturg. II, Botanil I,

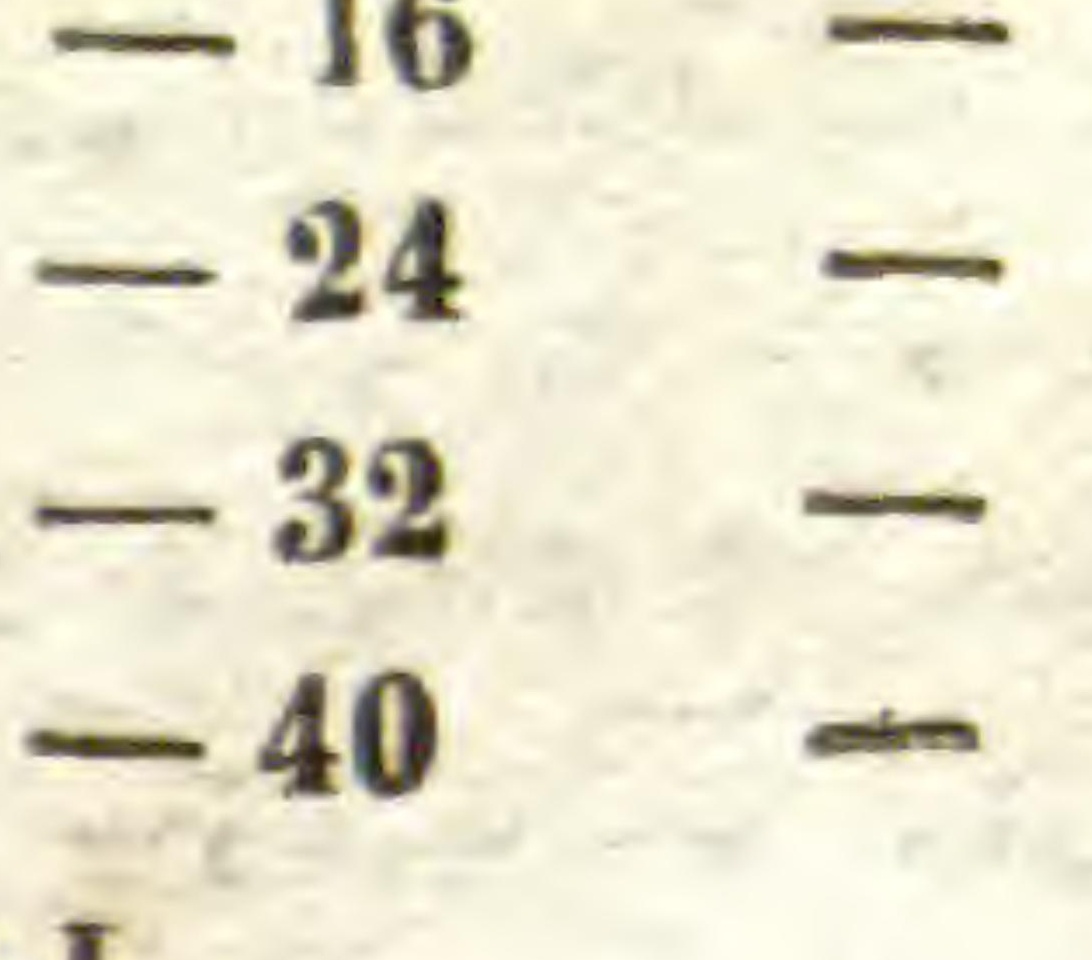
- 3mar 8 ,
- 4 mal 8 ,
- 5mar s, 
Jebe höhere Serbinoung betommt bemnach smal mebt

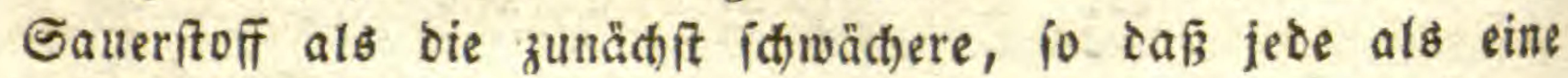

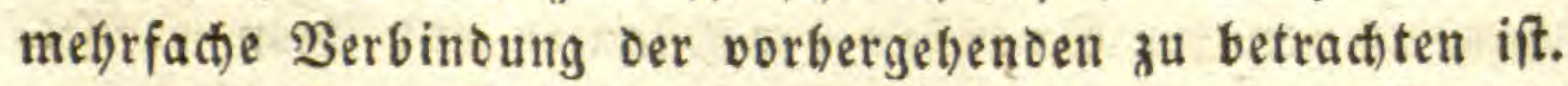

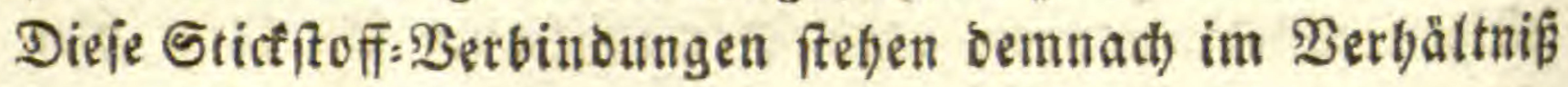
wie $1,2,3,4,5$.

Ebenio entbält

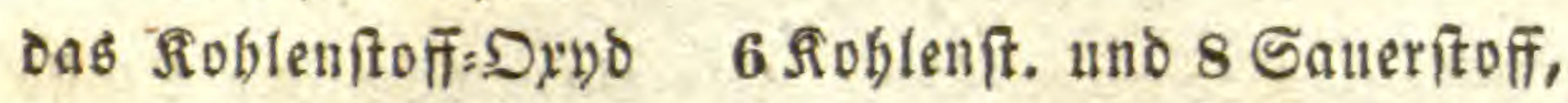
bie sioblen=Säure $6-\quad-16$ Sauerít., alio 2 mal 8 , bie fdwefelid)te Săure 16 Sdywefel - 8 Die f́twefelige Säure $16-016-$ aljo $2 \mathrm{mal}$, die S(t)wefel:Săure $16-24-3$ mals.

In allen biejen 2 berbindungen find alfo $s$ Theile Eauerfoff

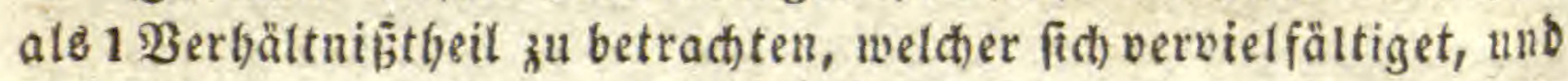
Daher faun man fagen: daz 2 a fler befteht alls 1 Derbältnips:

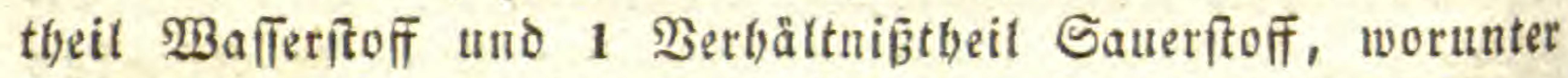
man bort nur 1 (jewiditstbeil, bier 8 verfteht. Benm Roblens

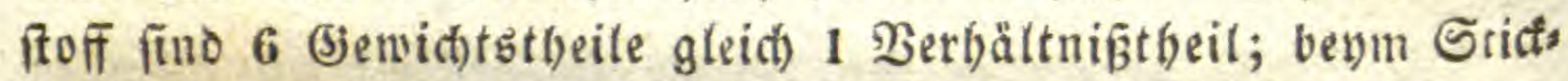
ftoff machen 14 (jetvidtstbeile 1 Berbältnistbeil, benm Sablus fet 16 น. f.w.

So befteft

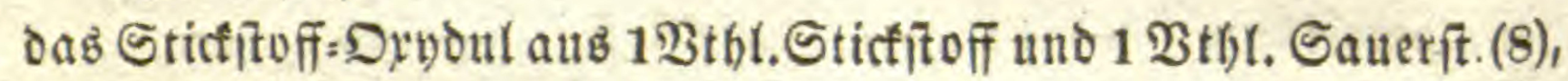
Das Sticfitoff:Drno - $1--2-2-(16)$, Die Salpeter:Säure - $1--5-5-(40)$.

WSenn fict) bie Stoffe in beftimmten (Sjewidtstätheilen ver: binben, fo mülfen fich) wenigitens bie \&uft= ober (jasarten aud) in beftimmten Maßen oder Raumtheilen verbinben.

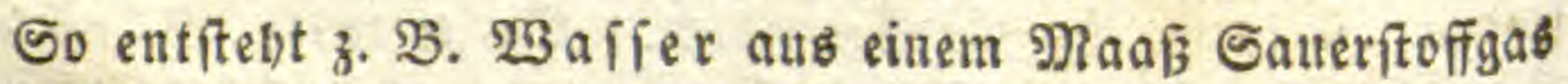
uno 2 Maá $\mathfrak{B}$ afferîtoffgas ;

2t m on aแs 1 Maaß Gtictgas unb 3 פBalferftoffgaz;

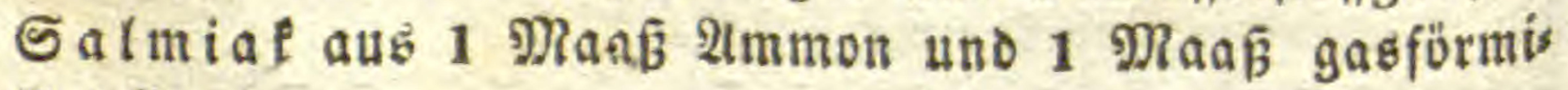
ger Salăäure;

fowefelige Sảure aus 1 Maás Sauerftoffgas uno 1 Sđ)mefeldämpfen;

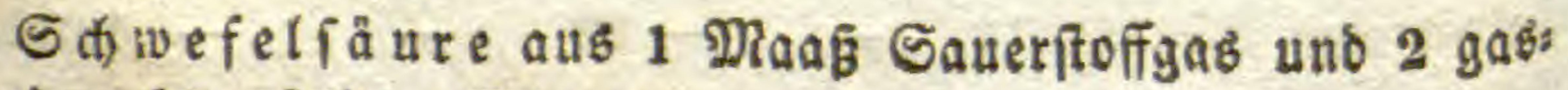
förmiger idwefeliger Săure; 
geid) wefeltes 23 a fierit offgas (St)wefelleber) aแb 1 Waî̄erfitoffyaв uno 1 Sa)befetoämpfen.

WBenn man Das (jewidt) ber Quft iekst auf 1000 , io wiegt das Gauerîtuffgas ...1111, Dab Eticfiga ..... 972, das $13 a f$ eritoffiaz.. 69.

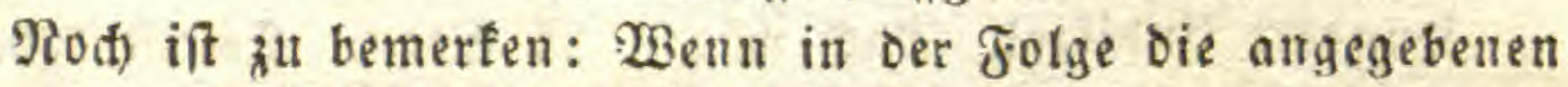
Procente nid)t ganz mit oen Serbăltniştheilen diberemintimmen;

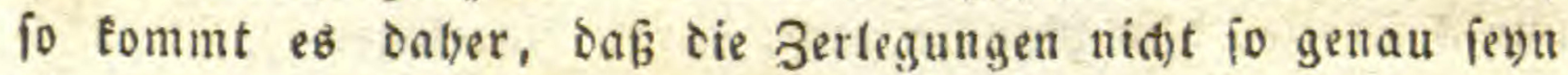
founen, wie bie Berectunngen. Die tekteren fino baber oie ridtigen.

Die in ben Pflanzen vortommenoen Stoffe theilen fid in organif(t) uno unorganifice.

\section{A. Unorganifibe Pflanzenitoffe.}

Dieje theilen fith wieder

in Uriftoffe,

in Elemente und

in Mineralien.

\section{a. Uritoffe.}

Ës gibt nut vier Stoffe, weldhe in ber ganzen Ratur ver: breitet fino, uno aus denen alle Materien zuiammengeję̧ zu fern idheinen: Soblen it off, Sauer it off, $\mathfrak{B}$ a fier it off und St tisfift off, wenn ber lekgtere nicht eine Zujammenjekzung von Sauer: uno פBatierifoff ift, wie man zu glauben Uriache bat.

Die faauptmaffe ber pllanze beftebt aแz soblenitoff, baber fie gänzhlict) verbrennt uno fich in soblenfäure verwandelt, wenn fie getroctuet worden iff. Der Rand ift nimts anderes als unverbrantite Fioble.

Der Roblenftofi ift ber einzige allgemeine Stoff Der $\Re$ atur, welcher fich beitändig im veiten Suftande befinbet. Int Diamant foll er gan rein fenn, in ber \&uft ift er mit 3 Theilen Gauter= ftoff zu Roblenfaure verbunden, und dieje beträgt etwa $1 / 100$ Der Ruft. 
Der zwente Stoff Der Menle nati if ber Sa uerit off, immer mit ben atndern vertunden, woburdh bie logenannten näbern Beftanotheile entiftehen, wie Sd)leim, Bucfer n. f.n. Er

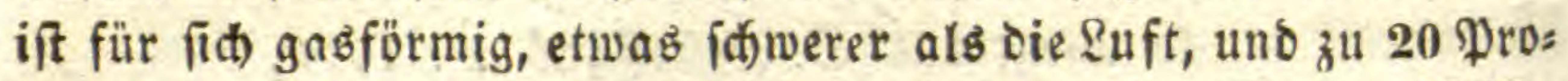
cent, dem Rautme nach, Darinn enthalten; im SMafler flüifits, und zu 8 Theilen, bem (jewidte nad), mit Wafferftoff verbu. ben.

Şundert Eltbifall (jas wägen 34 (3)an. Es ift $700 \mathrm{mal}$

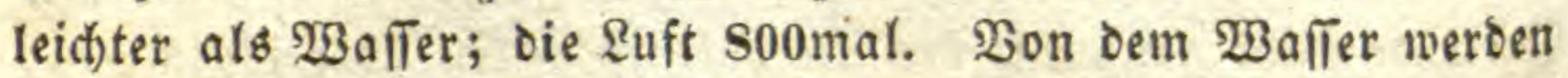
nur 4 ibeile, bem Raume nad), bavon eingeiogen *).

(Es ift auch) viel $\mathfrak{B}$ a fifer ft off in der Pflanze, welder fid beym Berbrennen mit bem Saueriftoff zu Waffer verbindet, bas als Daunf Davon geht.

Er ift für fich) immer gaéförmig und 100 Eubifiłoll wägen nur 2 Gran, ift mitbin $16 \mathrm{mal}$ leichter als Sauteritofigas. 100 Theile $\mathfrak{B a}$ fier faugen nur $1 \frac{1}{2}$ bavon eit.

St icf it off iit nur in febr wenigen Prlangentheilen, meift nutr in abgeionderten Stoffen, wie im sleber แno Е)weis. Die pilze fint bie einzigen, wo er aud) im Stocfe felbif vor:

*) (ङз müffen bier einige Stoffe erwähnt werben, weldjen mant in ber

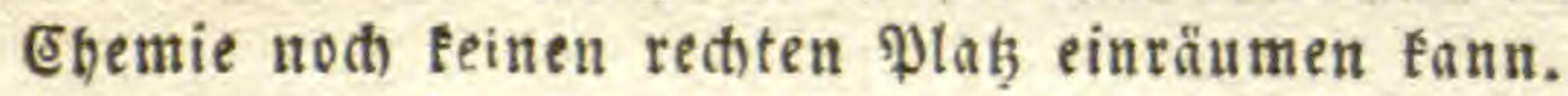

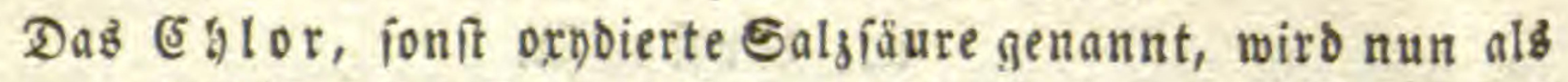
ein unzerfeşbarer Stoff betraditet, welther mit etważ $\mathfrak{B a}$ afierifoff

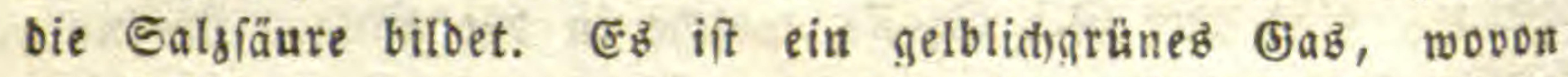
100 Eubiezolt 76 Gran wägen, weldieg febr erfitctend und äjento wirkt, fithell zufammengebrïctt Sunber anzindet, uno in bem bas Sid)t fortbrennt: allez (sineníd)aften, weldhe mit bem Eauerftoffinas

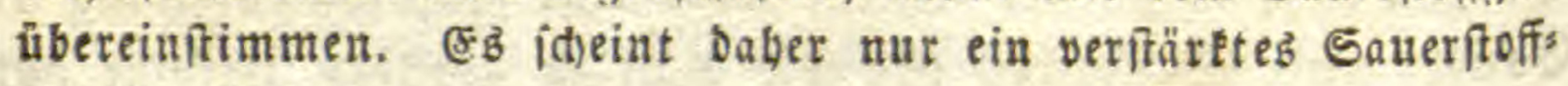
gas zu feyn.

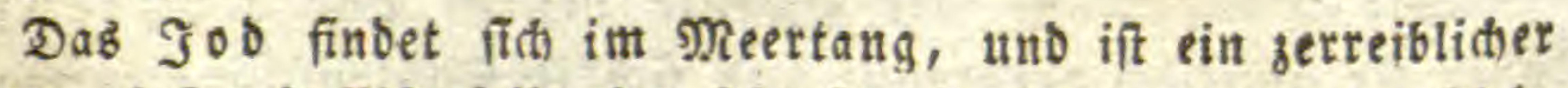
sörver, faft wie Eifenfeile, Der febr äßgend wirft und ben ber Eiebs

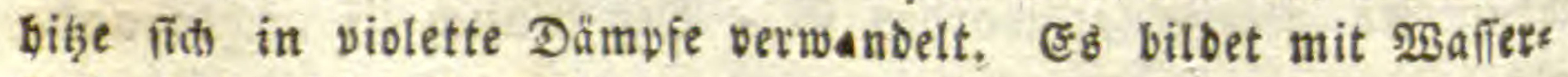
ftoffgaz ebenfallz eine Säure.

$\mathcal{D a b} \mathfrak{B}$ rom finbet fith ebenda, if eine rötblictse, gleidsfalls äbende und ftark riedjente glüfïgkeit, weldje fidh in eine Säure verwandeln läst.

Ebenio bat bie sorax = unb รlufipatbjäure cine (J)unblage, weldi) Bor und stuor beisen. 
fommt, uno raber pflegen fie mit Bieftant zu verfaulen, faft

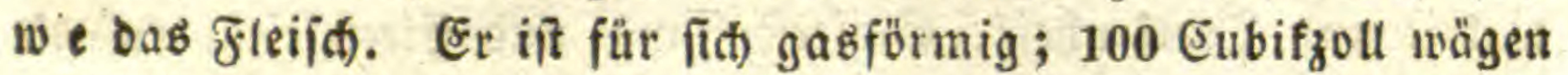
$20 \frac{1}{2}$ (jrall, ift Daber $900 \mathrm{mal}$ leidfter als $\mathfrak{W a f f e r}$. Ez find

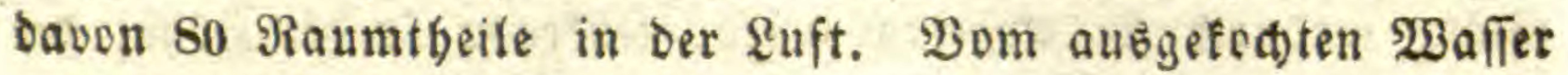
weroin nat $1 \frac{1}{2}$ Procent eingerogen.

\section{b. Elemente.}

3u ben Elemanten gegören ber 2lether voer bas Fener, bie

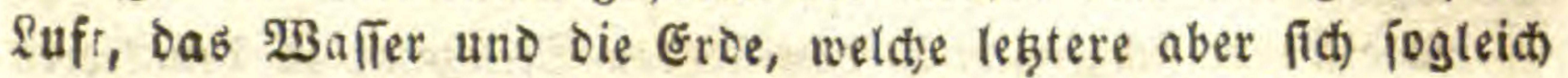
zu Mineralien indivioualifiert.

\section{2ether ober geuer.}

Der 2letber ober bas fetter erifteint in bren WBirfungs= arten, als (3ravitation ofer Materie überhaupt, als Sidft ober Polarität, und al: $\mathfrak{B a ̊ r m e ~ o d e r ~ B e w e g u n g ~ d e r ~} 21$ tome.

a. Sulofern Der Prlanze Giravitation zufommt, riditet (iic) Die 23 urzel nach Dem Mittelpunft ber Eroe.

Die Sthwere der Planzen ift gewölnntich etwab geringer

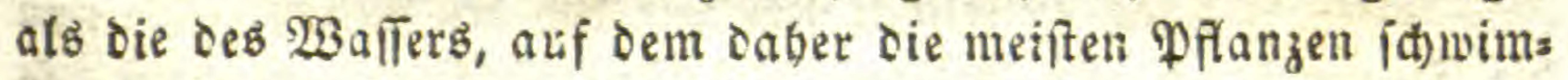
ment. Sgaben fie fith aber vollgejogen, fo finfen fie unter.

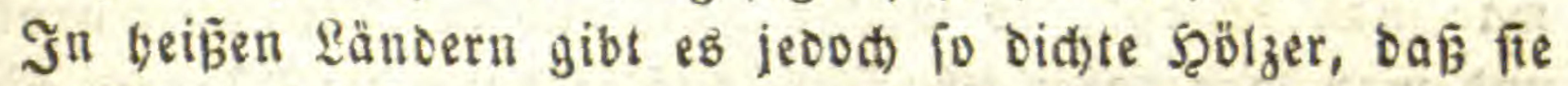
von felbit unterinfen, wie das deśbalb logenannte Eijenbolz.

b. Das $\mathfrak{L} i$ d) $t$ bewirtt in Der Planze eine allgemeine Polarität uno Zerjeģung, wodurch fie oie アRid)tung zur Gonne erbält.

2tüerbem erbält fie von thm bie grine Farbe unb bie an= Dern Farben ber Blumen. Die Farbenîtofe fitheinen veränbers tes Stärkemehl zu feyı.

c. Die $\mathfrak{B} a \mathfrak{r}$ me befördert bie 2 tusbünftung, uno baburd) ben Gaftrieb.

Die eigentbuimlide $\mathfrak{B a ̊ m e ~ b e r ~ P f l a n z e ~ i d e i n t ~ w e n i g ~ v o n ~}$ ber \&uftemperatur veríbieden zu fenn.

\section{2. \&uft.}

Die Suft befteht aus 2 Maá Sautertoffgas, 8 Maá̉ Stictgas und etwa 1 Sioblenfäure; dem (jemidhte nath wie 8 zu

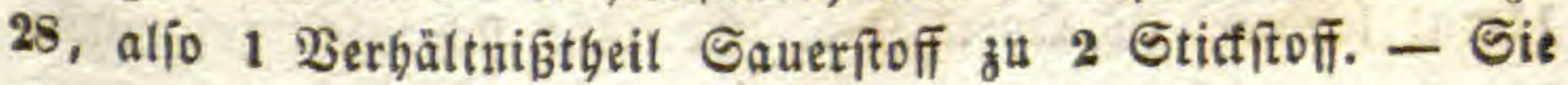




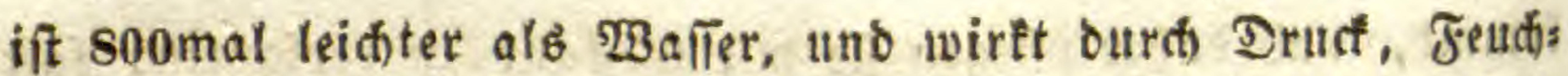
tigfeit uno Troctenbeit, Sauterftoffung uno Electriçitât auf die PFlanze. Durth bie legtere ertheilt fie ifgr bie allgemeine Polas rität, woourd) fie angeregt nird, fenfretit in die Söbe, bet

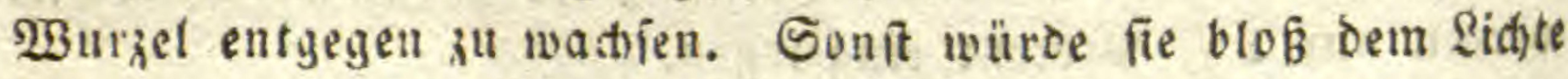
folgen, tho bald Diefe, balo jene Rititung annebmen.

Sie gebt burd) die Epiralgefäze zu allen Theilen bet Pilanze.

Sie findet fict) ferner in ben hoblen Stengetn, in ben teeren Beffen Des Marfs uno jelbit in senen oer Dberbaut.

Enolich fammelt fie fith in bejondern \&iisfen des Zellgenebes, keion bers bey Wallerpflanzen, wocurch Stengel oder Blätret

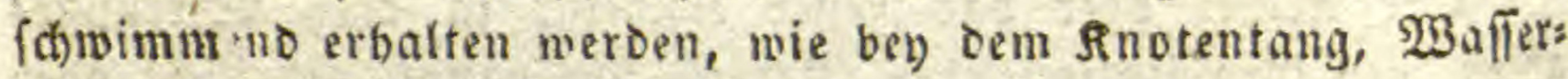
(id) auth (Utricularia), ber Geprope.

Im Eonnentict baudien die Pranjen, nit 2(ünabme bet

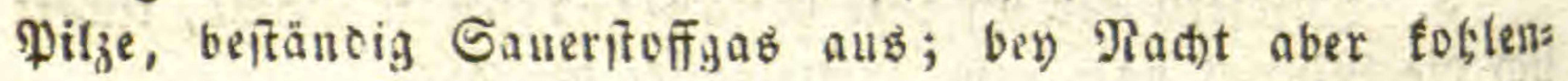
falter ßjas.

צBaflerftoff3ns entwictelt fid) nur bey ben Pilzen. Da num

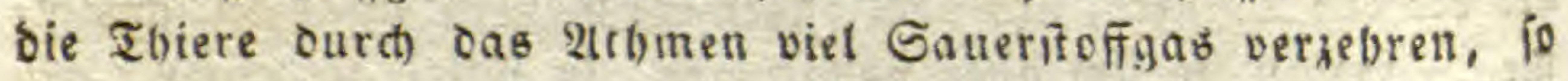
war man beiorgt, es mödte gam aub der \&uft veríhwinoen; und man war caber lel)r frob, Daß es ourd die Pranzen wieder eriest werde. Illein oie Phanzen atbmen ebenfalts, die meifie

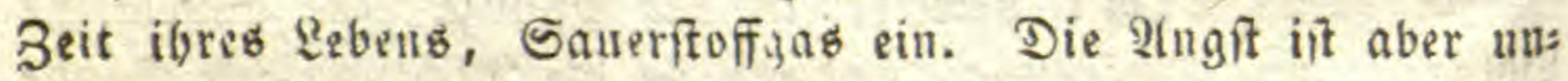

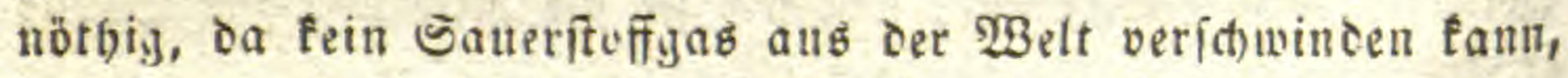

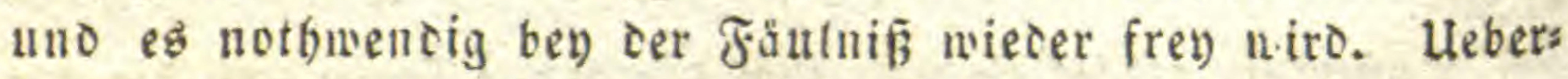

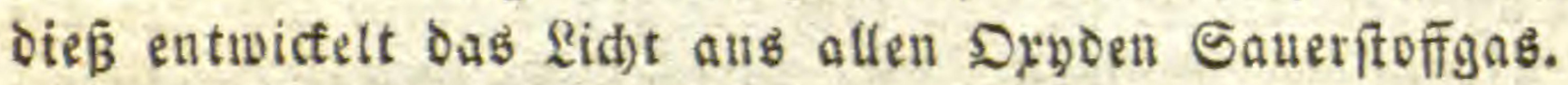

\section{3. $\mathfrak{x a f i e r . ~}$}

Das 2 Baffer iff Der eigentlicte Boden der Pflanzen, uno

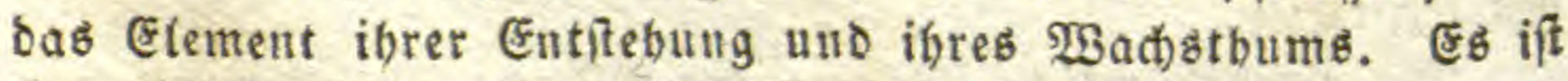

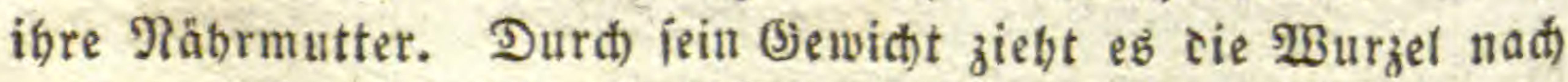
unten, und ourd feine Jusifferen; bitcet es ben (jegenjak mit

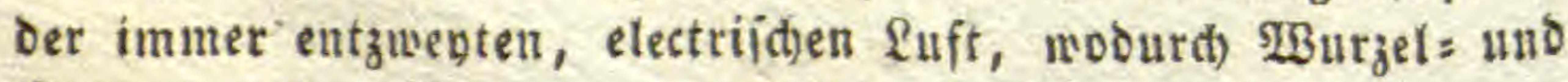
Stammwert genötbigt werben, aus einander zu treten.

Е' wiro als Einlyeit des (jewidhtes angenommen. Es ift

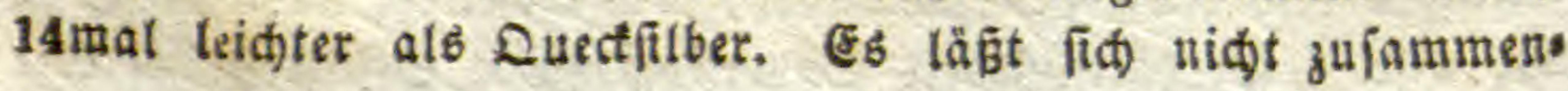


oriften. Bey Rullgrab bes reaumurif(t)en abermometers vers wandelt es fid) plöglid) in (Eiz, bey $80^{\circ}$ in Dampf. Es beftegt aus 8 Sauerftoff und 1 Wafferftoff, oder 1 uno 2 Maá.

100 Eubitzoll jaugen ein:

$$
\begin{aligned}
& \text { 23afieritoffgas ... 1,56, } \\
& \text { Stictitoffgas .... 1,56, } \\
& \text { Sauerfirfigas ... 3, 30, } \\
& \text { soblenfäure . . 100,00. }
\end{aligned}
$$

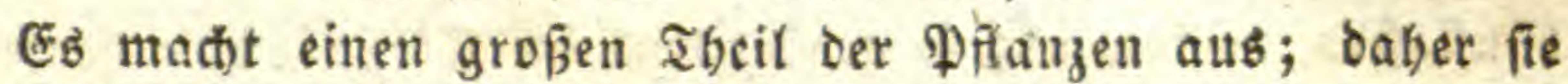
ausgetroctnet viel leidter fino als vorfer.

(F) ift aber niđt rein bariun, fondern entbält gewöbnlid

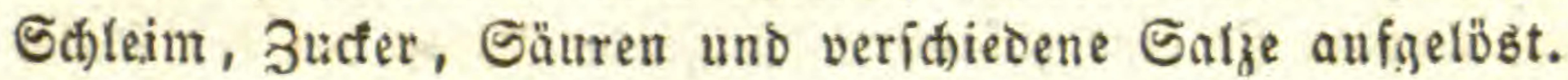

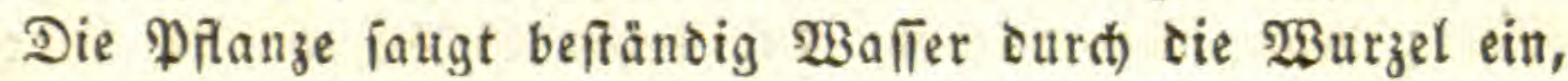
und bünitet beftänoig ourdh die Ṡätter aus.

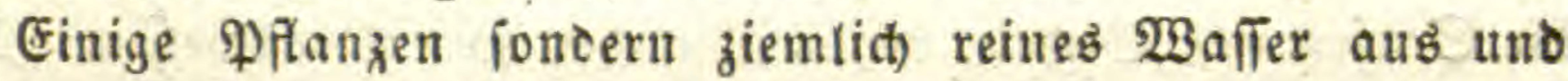

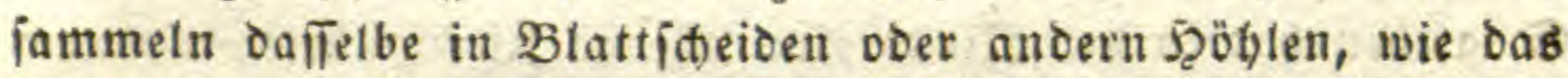
Sannenfraut (Nepenthes).

Bey mand)en ift diefes $\mathfrak{2}$ affer füflid); bey andern fâuertid, wie bay ben Rider=Erbien.

\section{4. ङroe.}

Die Erbe als Element gewábrt Der Pflanze nur einen veften Stanopunct uno vertbeitt zu Der $\mathfrak{B u r z e l}$ bringen fann, ofne welthe feine Berjegung vor fiti) get)t.

3um gebörigen Giebeiben ber Pflanze fheinen alle Ertoarten nöthig zu peyn.

In ber Pfanze felbit aber ift bie Erbe als verifhiebene Mineralien enthalten.

\section{c. Mineralien.}

Befteben aus Erben, Salzen, Inflammabifien ober Brent= zen, uno Erzen. Die PFlanje enthätt theils in ił̧ren Säften, theils aud) in ben veften Ibeilen, Stoffe aus allen Minerals 厄lafien. 


\section{Eroen.}

a. Die Rieielerbe befteht aus 52 Saueritoff uno 48 Thei= len einer foblenartigen, fthwarjen Subitanz, ziemlich nie Reiß̈: bley, welthe die Electricität nid)t leitet, nno taber fein פgetall

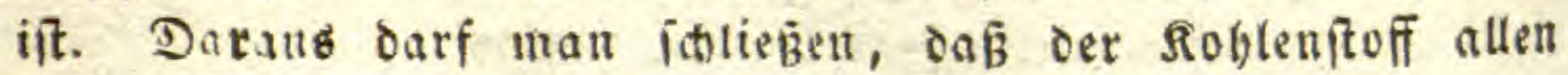
veften Subitanzen zur Sirunolage diene.

Dufton oie salferde in allen Whanzen, mo zwar am băufisfen, vorfommt; io gebört bod die Riefele roe oenielben clialacterifitit) an: indemi fte wirflit) eimen beftandtbeil von ge: wifien Drganen altsmact), vorzüglich Der Sberbaut Der (Srabs=

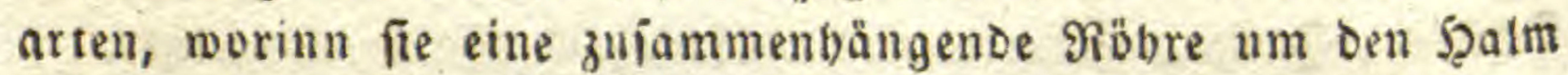
biloet; begm $\mathfrak{B a m b u b r o b r ~ 7 0 , ~ b e y i n ~ S c h i f f r o b r ~} 50$ Procent, benm Roggenbatm 6; uno Diefes ift die Hriadse, warmm fid) bie S:njen uno Sidueln beym 2lbmäben fo balo abmeken. Das S vaftbeu bat in Der Rinde eine Menge Riefelpuncte, woourd es zum Stheuren tauglict) miro. Die Dberbaut bes Mottangs joll io viel Riejeterde entbalten, oaß zwen an einander geriebene

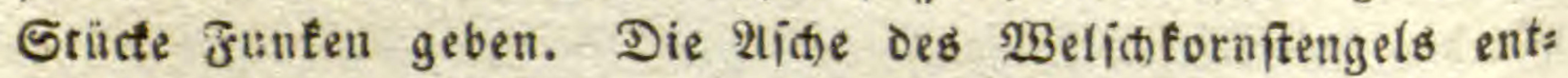

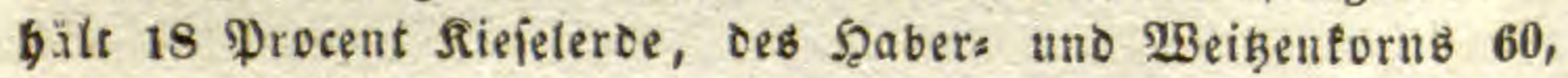
Des Beritenforns 35, Der Eittblätter 14, Der Şajel= uno \$ap: pelthiter 11, Der Rinde Des Maulbeerbaums 15.

In Den Qücten Des Bambusrobrs findet man gewöbnlid ganze Stïcfe von abgejonderter Fiejelerbe, welthe man $T a b$ as

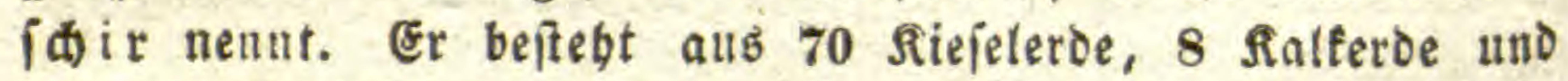
etwa 20 Pottaít)e.

Dieje Riejelerde fann nidht wohl anders in bie Pflanzen

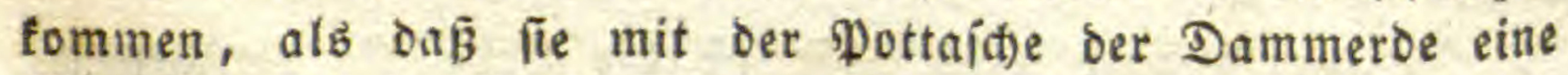

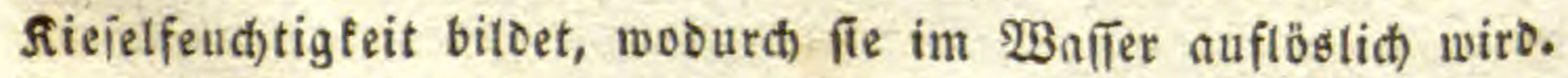
Эil ber Mijte Des Şaberbalms findet man an 60 Procent fies felerde anf 20 pottaíd)e, alio im Berbältuiß̄ wie $3: 1$, völlig wie im Silas. Man fönte baber jagen: Die Riefelerde fey in ben Prlanzen als fluífiges (jtas entbalten.

Diefes Uebermaai von Riefelerde findet fich jedo(t) nur bey) Den Gheidenuflanzen, uno ift bey den गekpflanzen in geringer Menge oder gar nidt votbanden. Steffens bat in jeinet 
St)rift: Beyträge zur innern Raturgeiatidte ber Erbe, 1801. S., febr fitharfitunis gezeigt, wie fich bie \$flanzen an bie Riejelreibe, bie sbiere an bie Ralfreibe anichlię̧en.

b. Die Ibonerbe beftert auв 10 metalt uno s Sauer= fitef, oder 1 uno 1. Man bar von ibr in ten Pflanzen faum Spuren gefuncen, obition fie fait fämmtlict im Thonboden watien. Es fincet fith aber oajelbit fein Eteff, ourd) weldten fie aufgelöst werden fönnte, was̆ nur ourch eine ftarfe Gäure möglic) wäre. Etwag weniges hat man bemert in Roggen= ftrob, im Roggens, SBeizen=, (jerften= uno Saberforn; aut)

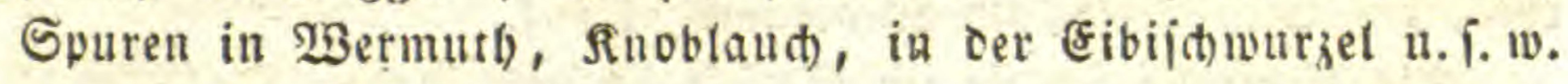

c. Talferde beftebt aus 12 Metall uno $s$ Sanerfitof, Doer 1 uno 1. Sie findet fich in febr wenigen Pflanzen, faft nur in foldtell, weldte auf Galzbooen voer im Meere wachien, in ber Sodapflange uno in Tangen. Sie ift aber barinn nitht frey, fondern mit Säuren verbuncen. Rein frb fie in Der Sork= rinoe, foblenjauer in ben Gjetraibeförnern; in ber Sooa oon Salsola soda 18; itwefeliatuer in ziemlither Menge in Tang (Fucus vesiculosus); phospgorianer in Der Zaunribe, Dem

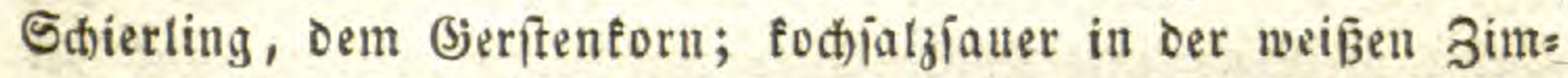
metrinbe und in Der $\mathfrak{B u r}_{j}$ el Des Benedictenfrauts (Geum).

d. Salferde fommt in allen Pflanzent vor, tho zwat gewöbulic) mit \$bog̈phor verbunden, in größerer Menge als irgend eine andere Erbe, uno in alten Pflanzentbetlen zerftreut.

Man gewiunt fie gewöbnlidi burd Einäidderung. Sie bes trägt jelten mebr al: 1 bï 2 Procent.

Im Şaberforn findet man 3 Procent Erde, uno darunter 6 Theile Riejelerde uno 4 phosphorfauren Rale. Wenn oaber bie Şübner siörner freflen, fo befommen fie binlänglich salf: erde, um baralls bie Eyeriकtalen zu bilben.

Sie beftebt aus 20 salemetall uno $s$ Sauerifoff ober 1 und 1.

Mit Soblenjäure billot fie fogat einen weínen Heberzug benm 2trmleudter (Chara), ftect itbrigens in biefem 3uitande

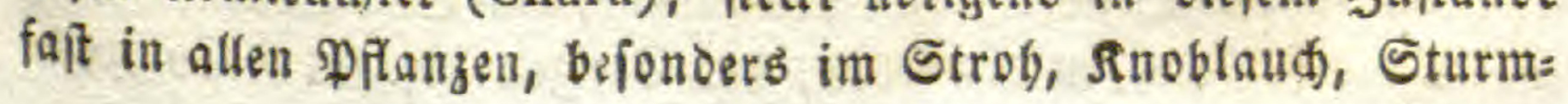


but, Boretíf). 2t(s ganze sörner ftectt fie in ben logenanntent Walierictwanz (Hydrurus).

Mit Salpeteriäure ift fie in Boretict), Reffel unb Sonnens bltume.

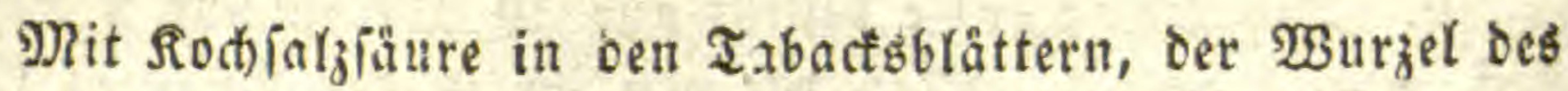
Sturmbutb, Der Eurcuma, in oen Blumen ber Rarciflen.

Mit Stomefeliäure fommt fie vor in ber Birfent = und SBeidenrinde, im Blafentang, in Der 13 urjel der Rhabarber, Des Sturmbuts, Der Zaunrübe, im Senfiamen, Dpium.

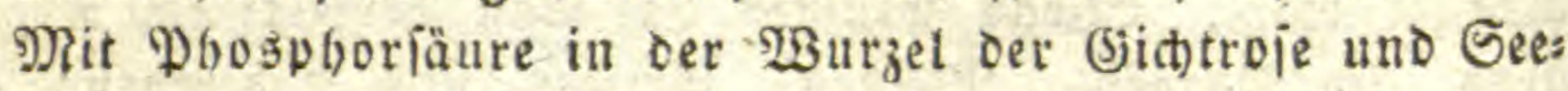
roje, des Sinisbolzes, in Sunblaud, Senf.

शl' Ernftalle fen fie in Gatifrobr und in den Drdjiden.

\section{2. $\mathrm{Sal}_{\mathrm{z}}$.}

Die Salze fommen itton viel bäufiger uno zablreidter in allen \$flanzen vor, uno zwar fowngl bie Raugen als die Säu: ren tmo ibre Bertinoungen.

\section{a. Unter ben Laugen ift}

1. Die Pottafthe oder bas fali bie gewöbnlicte, und

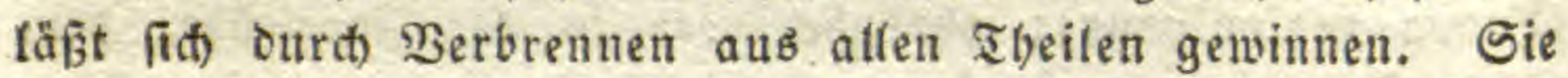
foteint meiftens mit Roblenjätre verbunden zu jeyn, und bes ftebt alls 40 sati= Metall uno $s$ Saueritofi, oder Berbältni theile 1 und 1.

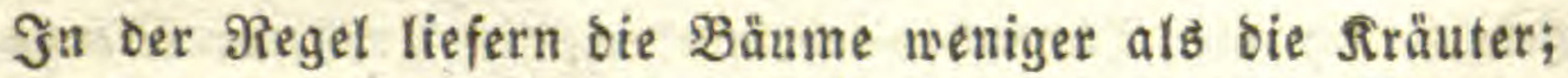
am meiften $\mathfrak{B e r m u t b}$ tno Erorautd).

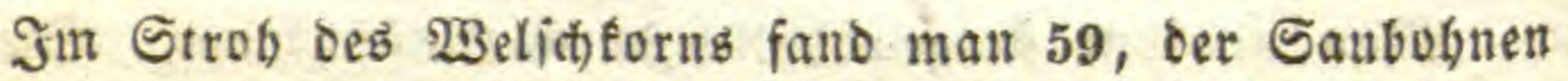
57, Der Gerite 16, Des Weikenb 12.

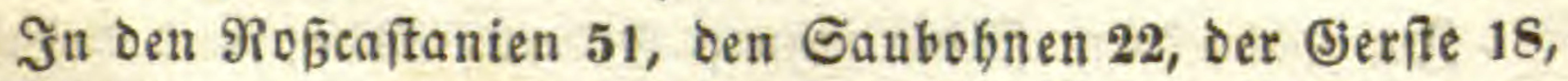
bem Weiķen 15, Dem Weljoftorn 14.

Salpeteríauer fey es in Den 2 Burzeln ber Eromandeln (Cyperus), bes Jngwers, beb Benedictenfrauts, der Sellerie, int

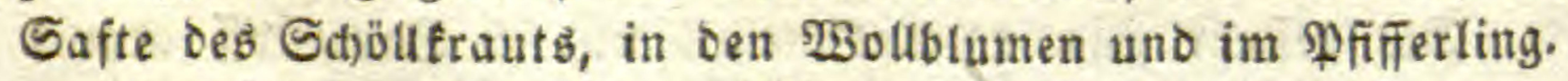

sochjalziauer in vielen Pflanzen, bejonbers ben Tangen,

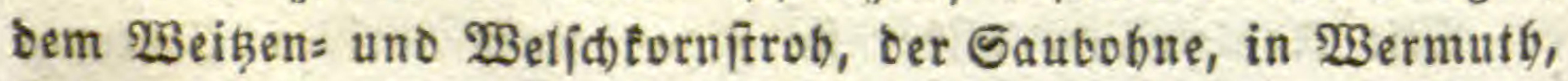
Eabact, in ber Sellerie, ben Seinjamen, im Edjülutrantíaft.

Sकwefelfauer in ber Soda, ben Tanjen 19, im siraute ber 
Salipflanzen, Saubohnen, im Snoblatch, WBeikenftroh, in ber Wurzel Der (jict)trofe.

Phosphoriater in ber 2 lifie bes 2 Beliaterns 47 , ber Galls

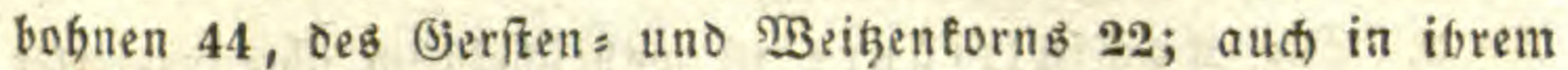
Strob; in den Ercäpfeln, Roßjcaftanien, Seinjamen, im હalmus, Pfifferling (Agaricus piperatus).

Mit Joo verbunden ill ber Gode, welde man all bem Blafentang gewinnt.

2. Sode oder $\mathfrak{R} a \operatorname{trum}$ findet fidi) nur in ben Pfanzen auf Salzboden ooer in Jeer; in Der gemeinen Sviapflanze (Salsola soda) etwa 2 Procent. Man befommr fie ourct) Bers brenuning mit sebleniăure verbunden, glaubt aber, ons fie in Der P)lanze zucter= oder fauerfleefauer f́y. Die Phanzen, worinn fie vorfommt, gebören z" oen (jeid)le(b)tern Salsola, Salicornia, Mesembryanthemum, Chenopodium uno Fucus, Sie beftegt aแs 24 Sode: Metall uno 8 Satteritoff, oder $1,1$.

3. $2(\mathrm{~m}$ mon ooer flïhtiges \&augenfarz erbält man zwar

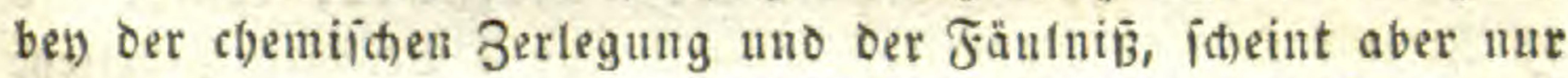

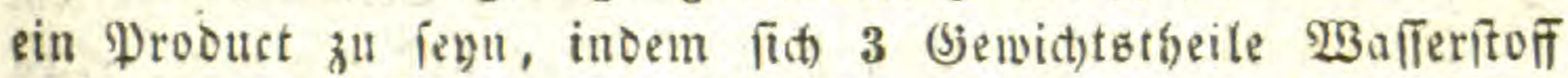
uno 14 Sticfiturf, voer 3 uno 1 Berbälnis̈tbetle mit eimancer verbinden. - Es foll jeood) freb vorfommen im $13 a i d$, in oer Rinde des Zabnuebbaumb (Xanthoxylum) uno dem blaientang; mit andern Stoffen verbunden in Der $9 B$ urzel Der Seervien, Der

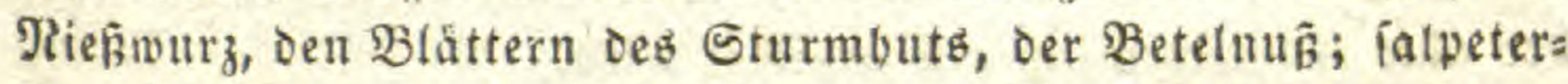
fauer in Extracte des Biljenfrauts, im sattic) (Lactuca).

b. Säuren fommen febr bäufig in allen Planzen vor, uno zwar fowohl tein als mit Raugen, Eroen uno Metallen vers bunden.

Sie theilen fith in Elementens uno Mineralfäuten.

1. Man fant die fiobleniäure, weil fte burḑ ben ganzen Suftraum verbreitet uno felbit luftförmig iit, als Die Säure des 2letbers oder Der গMaterie überbaupt beeradten, in= bem alle Materie nut verämberter soblenftoff zu jeyn fheint, wenigitens die Metalle, uno mitbin aud) die Eroen. Sie bes

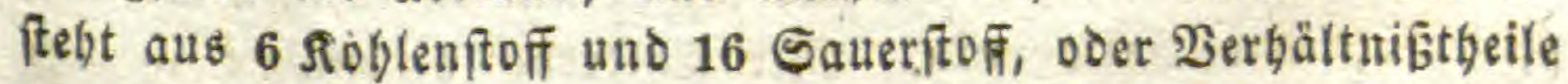
1 und 2. 
2. Die Sarpeterfä ure if überornoierter Stictitof, mits bin bie \&ufträure; beftebt ans 14 Eticfifoff uno 40 Sauterfoff, oder 1 uno, 5 Berbättniß̄tbeilen.

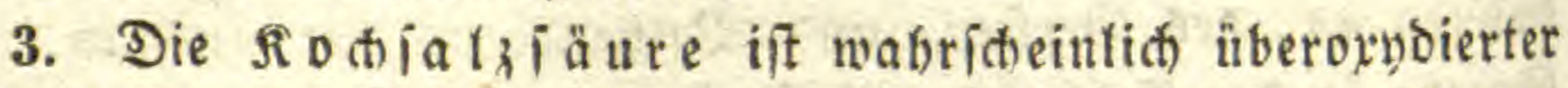

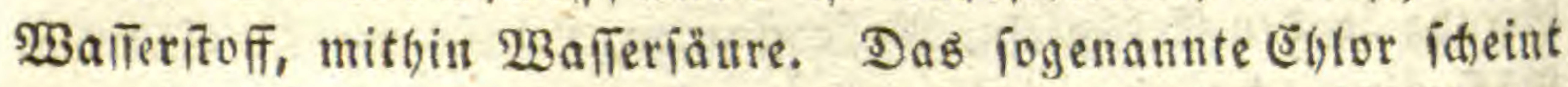
nur ein beionoerer 3uftano ber fiodfalafătre zu fenn. Sie bes

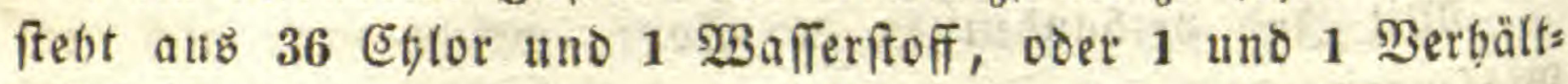
niptheiten.

Mineralià uren fann man nenmen bie aus Eroftoffen entiftancenen Gäuren.

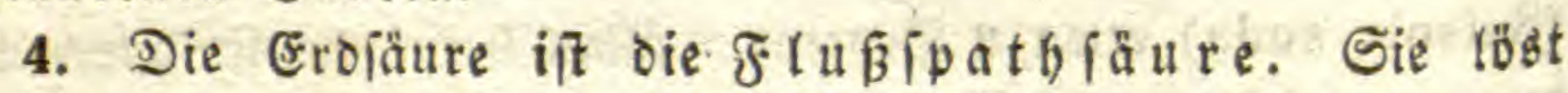
alle ñ siefelerde allf.

5. Die Gaziäure if bie Boraxfäure; beftebt aus 8 Borapitoff uno 16 Ganerifofi, ober 1 uno 2 Berbältnifstbeilen.

6. Die Brenjäure ift die S t) we felfäure; befteht aub

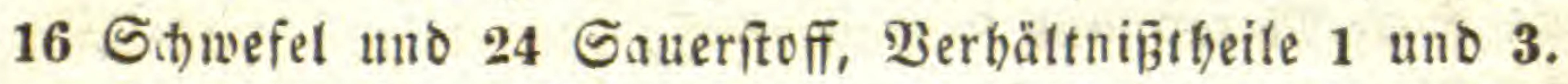

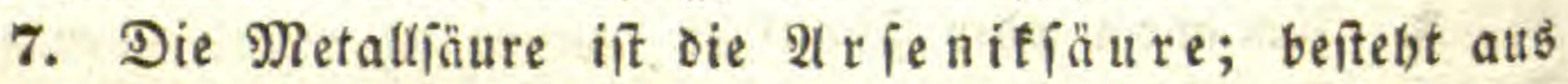
35 2trienif uno 24 Gauerftoff, oder 1 uno 3 Berbåltniß̈tbeilent.

Die unorganifiden Säuren fino felten uno nie rein, etwa mit 2ubnabme der Roblenfäure, weld)e fich in Menge in PNanzenjaft findet, uno in ber Finfterniß jogar von felbit her: vortritt.

Binm Derbrennen befommt man aud fohlenjauten salf ber aber wabricteintic) erit gebiloet wird.

Salpeterfaure Pottaftie voer Gafpeter biltet fith ben

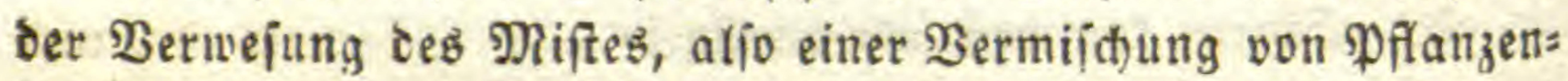
unb Ibierftofen. Er fomm aber fiton fertig vor in einigen, jedod) wenigen Pflanzen, 3. B. im Boretich, Earoobenedictens fraut uno Pifaing.

Rod) fal $\mathfrak{l}_{3}$ fäure mit Sode alb fioctialz in den meiften Pflanzen; in grögerer Menge aber in ben Meerpflanzen.

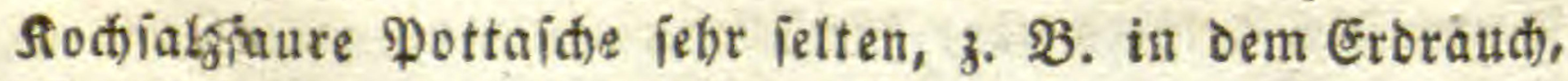
ben W3aioblättern, Der winterifhen Rinbe.

Siochialifaurer Rale faft gar nid)t; t:ur in einigen Strands pflanzen, wie Salicornia. Mit Talferbe verbunden in ber weiß̄en 3̧immetrinbe. 
Sob) wefeliaure Pottaiffe und foldie Ralferbe oder (5nps befoumt man bisweilen beym Berbrennen.

Die Pbosphorfäure beftebt ans 12 Pbosplor uno 16 Saueritofi, oder 1 uno 2 Berbältniştbeilen; foll frey vor= fommen in Den Zwiebeln, Dem Mutterforn, Der Wurzel ber (jid)troie, den $\mathfrak{3}$ ollblumen.

Dagegen ift faît aller Rale mit Pbosphoriä ure ver= bunden, namentlio im Söblletraut, bem fowarzen Senf und in oer Senega=23urzel. Şill uno wiecer gibt es aud) phošphorjau= res Eijen, bäufiger pbosphorjaures Rali.

Diefe Salze befommt man aber nidht ourd) die Berlegung auf naffen Bege, fondern mur aub ber 2 lidie.

\section{Inflammabilien oder $\mathfrak{B}$ renge.}

a. Son ben unorganifichen Stoffen bieier 21t fintet man in den Pranzen $\Omega \circ b l e, G(t)$ wel uno Phosplor.

Die Sauptmaffe ber Planze beftebt aus Roble. Wenn burc) 2(t)

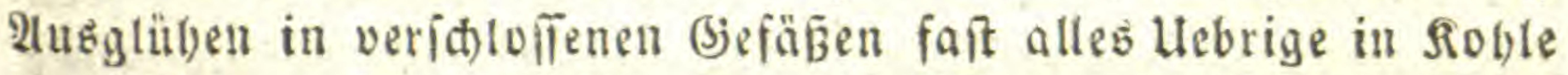
vermandelt, Sie entbält etwa $1 /$ so Erben uno Salze, meld)e beym Derbrennen in ver 2lithe zuruableiben. Die Spolzoble ift eite it)marje, lö(t)erige uno jerreiblid)e, unauf(öslid)e uno feuer= beitänoige Malle, welch)e die Electricität ziemlid) gut, Die झ३ärme aber folect) leitet. Sie verichluct alle Fluifigfeiten uno (s $a 5=$

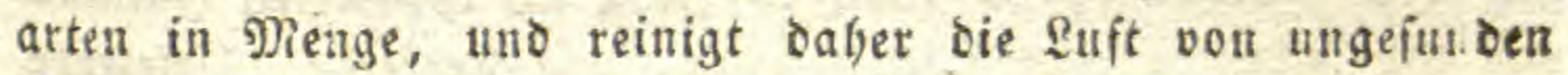
Dumften; Flüfigfeitex von ftinfencen uno färbenden Grofien.

2us diefer Roble entíteben Durch) Berbindung mit Saurs= แno $\mathfrak{B a f f e r i f o f f , ~ u n o ~ b i s w e i l e n ~ m i t ~ e t w a s ~ S t i c f i t o f , ~ a l l e ~ u ̈ b r i = ~}$ gen Stoffe der Pflanzen.

b. $S_{\text {(t) wefel finoet fid }}$ nut it geringer Menge in foldien Pflanzen, weld)e Eyweis entbalten, womit er immer verbunten su fenn foeint. Man fano ibn in Reigmebl, Senf, in den

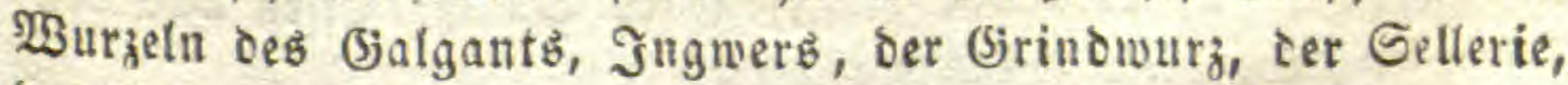
den \$omeranzenbiumen uno ben gelben förnern ces Scopfenb,

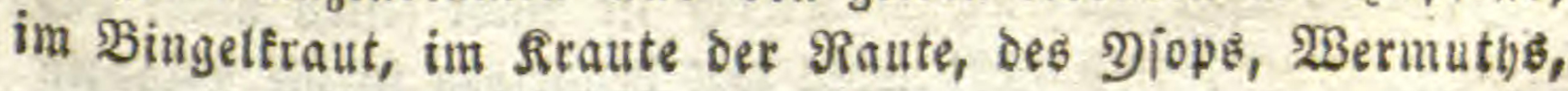


in ben Blumen bes Şolunbers, ber Sinde, im siummel, Fendiel u. f.w.

Er ift ein gelber, fpröber Sörper, 2 mal fo fómer als bas Waffer, weldher die Electricität niđt) leitet, negatio electrifon wiro, in ber Siebbize jthmilzt, unauflözlict) in $\mathfrak{B a f f e r ~ i f t , ~ a b e r ~}$ auf(öslich) in Terpentin= Det uno $\mathfrak{B}_{\text {eingeift. }}$

Biefleid)t entiftebt die Gdwefeliäure erît begm $\mathfrak{B} e r b r e n n e n$.

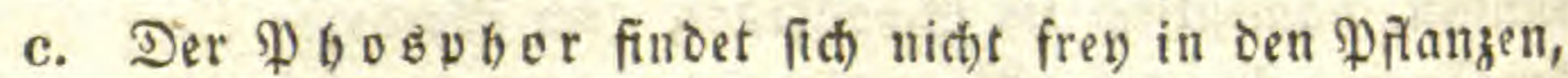
fondern nur ats Phogptorjäure, meift mit Ralferbe verbunden. $2(m$ bäufigîten ift er jeood) als Phosphoriänre in Den Rnod)en uno Dem Şarn. Er ift eine weişliche, weict)e Maffe, faft wie Waats, wetche bey geringer Temperatur verbrennt.

Dab $\mathfrak{B}$ or ocer $\mathfrak{B}$ or on it ein fthefetartiger, entzind: licter Rärper, Der nur im Mineralreiđ) atร Boraxiäure vors formint.

\section{E. roc.}

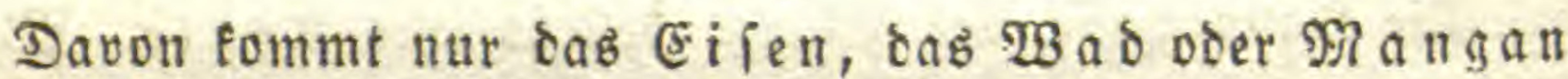

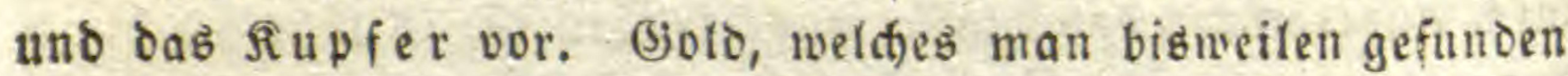
baben will, ift nur zufällig. Man ideint jelbft Injecten=ęyer fiir Golotörner angefeben za haben.

Dns Eifen wiro als Ralth in ber glifie ber meiften Pflamzen gewonnen, jedod) nur in febr geringer Menge.

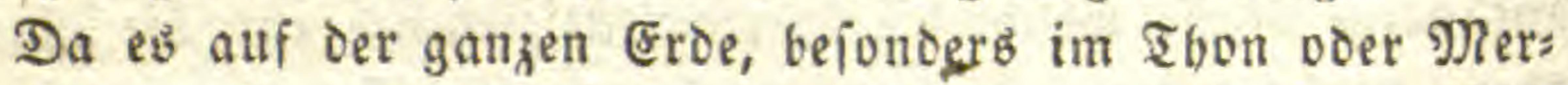
getboden vorfomrt; fo fann es leidit im oxubierten 3 uftano von den Pfanzen eingeígen werben, wie Ralferde, Riejelerde

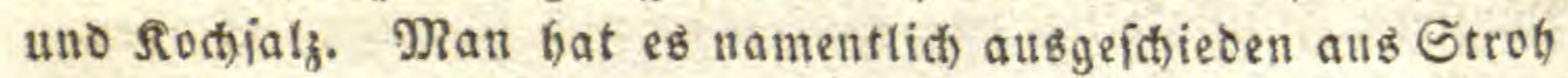

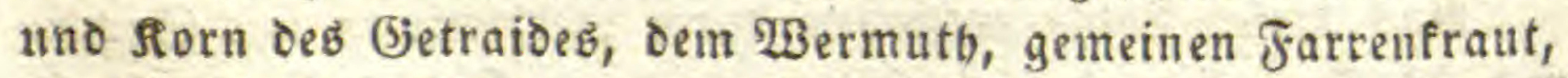
Rnoblaut), Dem Delbaum, Der Zaunrübe, Eromandel, Dem Epar: gel, Der Eatechu= Frudt, ben Blumen Der Eififgroie, Dem ฐeufels:

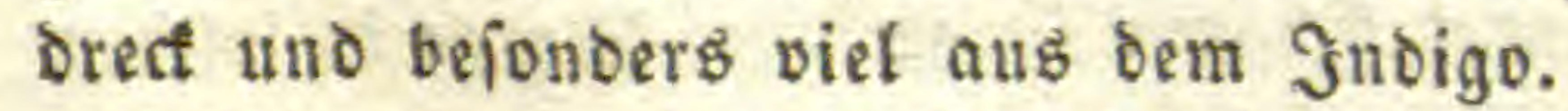

Im Ginadenfraut (Gratiola) foll es mit Phosphorfāure verbunten fenn, vielleitht eingelogenes Sumpf = Eilen aus ben Sümpfen, wo diefe Pflanze wähst.

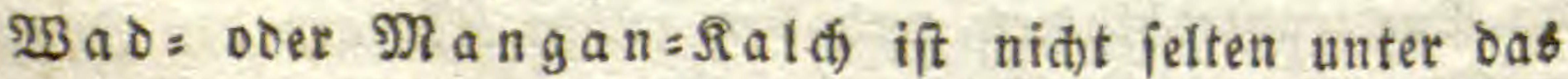
Eijen gemengt, uno gebt wohl mit demjelben in oie Pitanzen 
iber. Man hat es gefunden in ber 2iade bes Strobes uno Des Rorns, Des Weinftocts, Jeigenbaums, Der Föbre uno Der Ringelblume.

Rupfer, wabricteinlid in phozphoriaurem Buftande, fat man in ziemlid, viel Pfanzen gefuncen, aber nur zu פillion:

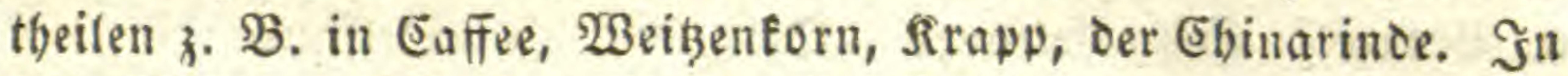
$1 \%$ Millionen Eentner Eaffe, oer in Europa verfauft wird, jollen llber 10 Eentner Rupfer ftecten; in Dem Weiken, Der in Franfreid) gebaut wird, hber 600 Eentmer.

\section{B. Drganifbe Pflangenft offe.}

Sino nidts anderes als bie unorganijenen, ourch ben $2 e=$ benzproces auf eine jo eigenthämliche 21rt mit einander verbunden, wis fie nie in bem unorganif(t)en Reid)e vorfommen. Jnoeflen erfennt man no() immer ibre $2(e b n l i d)$ feit mit ben undrganif(ben Stoffen, uno man muß fie oaber auf oiefelbe Art oronen.

Sie beíteben, mit wenigen 2 tusnabmen, minoeftens a orey Uritoffen, nebmlich Saueritof, Roblen = uno Wălerifoff, oft aud) no(t) aus Sticfitoff, wäbrend die unorganijden Stoffe gewöbnlia) nur aแs zween Uritoffen beftegen, Dem Gaueritoff und einem andern.

Dieje Stoffe find entweber $\mathfrak{B}$ iederbolungen ber Ëlemente oder ber Mineralien. S(t) veriud)e fie auf folgende 2trt neben einander zu ftellen:

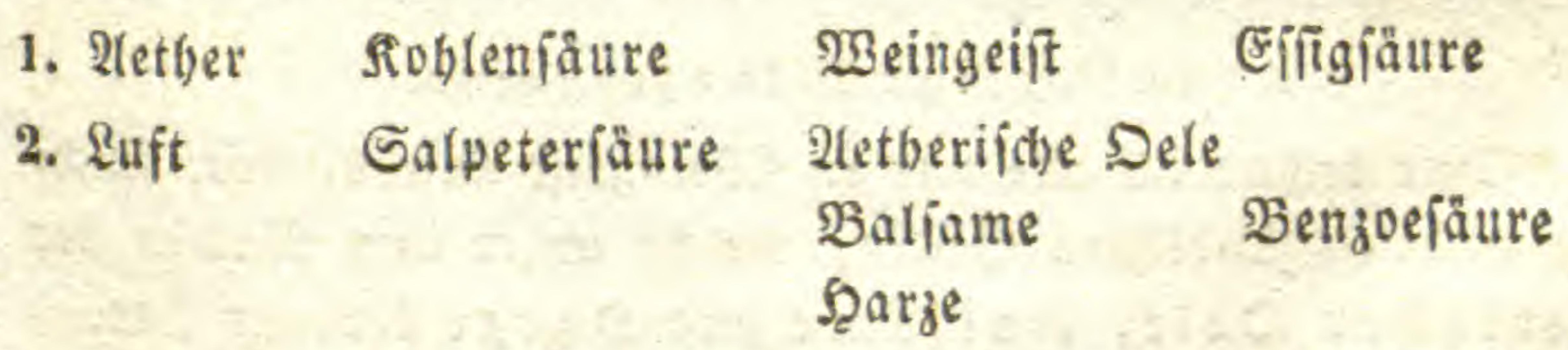

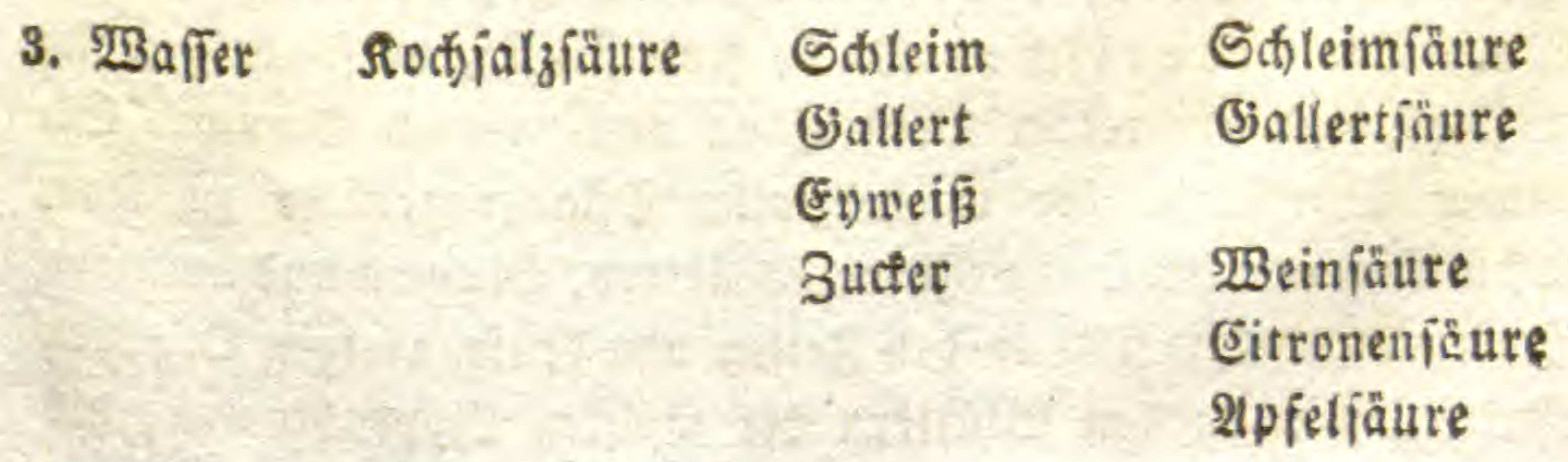


4. Eroen Flufipatbiäure Şolz

Moderitoff
Rieber
Stärfe

5. Salze Borapiäure Gerbitoff

6. Brenje

7. Erze
Sit) wefelfättre

Arjenifiäure
Del

Farbenitoff
Sauterleefäure

(j)erbiäure

Deliäure

Baiojäure.

1. Einfade Pfranzenftoffe.

a Drganifhe Elemente.

1. 2letherartige Pflanzenftofie.

Der edelfte, leidgtefte und entzünditifte Pflanzenftoff tritt

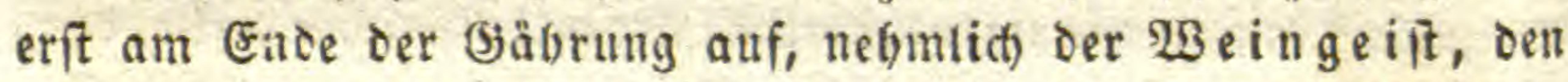
man im eigentliden Sinne ben (Geift voer dab Fener ber \$Flanze nennen fann.

Err ift viel leidter als Waffer, und beftegt ans $\mathbf{5 2}$ foblens ftoff, 13 Walferftoff unc 35 Sauerifof, oder S Berbäftnif̧tbeilen Soblemitoff, 12 'Bafferftoff uno 4 Saueritoff.

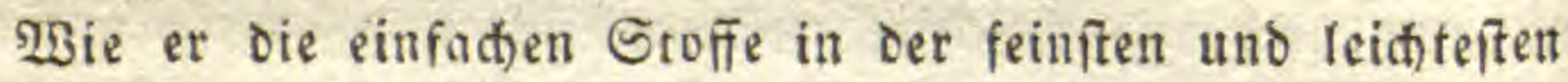
Malfe entbält; io fino im 2 Bein, deflen wirfender $\mathfrak{x}$ heil er ift, auf ähnliche $21 \mathrm{rt}$ fait alle näberen $B$ eitanotheile oer Pflanze verbunden: Sdteim, Zuder, Säuren, Salze, Farbenifof, Ercen uno eifen. Dieier ift, fo zu fagen, Die cbemiidhe 2llubeit oer Pflanje, uno daher das vollfommente und evelfite Gistränt.

\section{Quftartige Pflanzenit offe.}

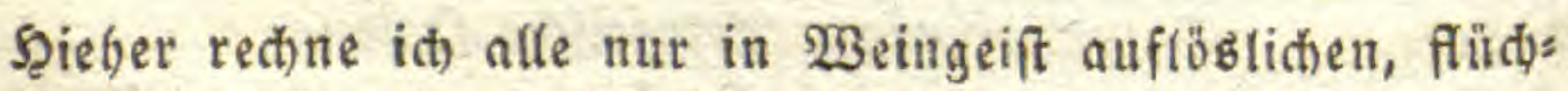
figen uno entzünolichen Gtoffe, welche unter bem Tamen ber àtberifden Dele, Bafiame uno barze befant fino.

a. Die ätberifthen Dele fino flitifis, verfüthtigen fint) von jelbit uno verbreiten meilt einen angenebmen (Serud). Sie folinen überbattpt oer (jorno aller Pflanzengeritche zu fenn, uno dünften von felbfit aus Rinoe, Blättern, Blumen uno mandten Frïthten aแb. Sie ftud in ben Zetten von orüjenartigen Drgatten enthalten, wie an ben Blätern ber meiften Sippenblumen, als 
Mitnze, Meliffe, Rosmarin; an ben Blättern ber Mnrten,

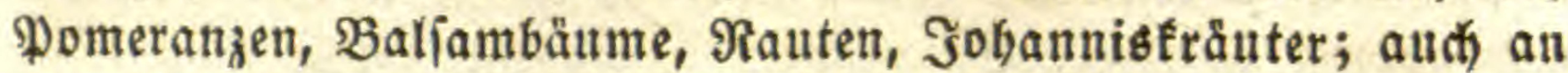
Den Fielcblättern ber lektern, an ben Blumenblättern ber Pome: ranzen, an ber Fruchtidjale ber Rauten uno Eitronen. Bey Den Shirmpflanzen ftect Das Del in Gängen unter den Rippen ber Frutht. In Samen fommt eg febr felten vor, feooct) bey

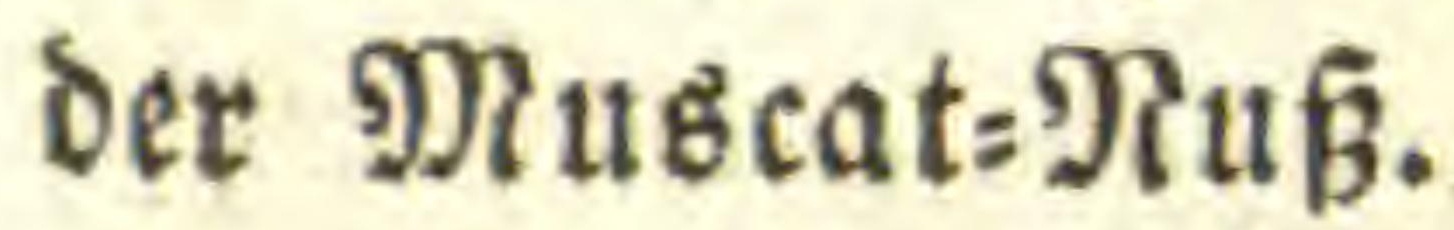

Die betannteften Dele Der Irt fino: Das Terpentit=, Ci: tronen=, Roien=, Pomeranzens, Ravendels, Spif=, Rosmarins,

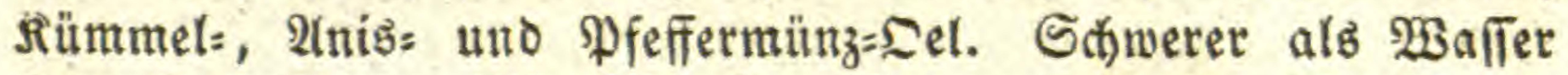

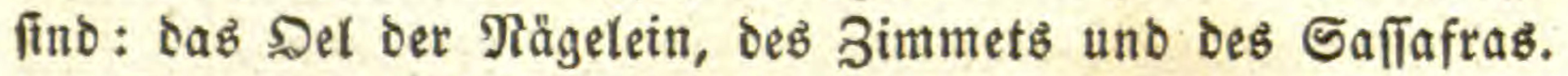

Das Terpentin=Del beiftebt aus Berbältniştbeilen $\mathfrak{x}$. 10, 23. 8.

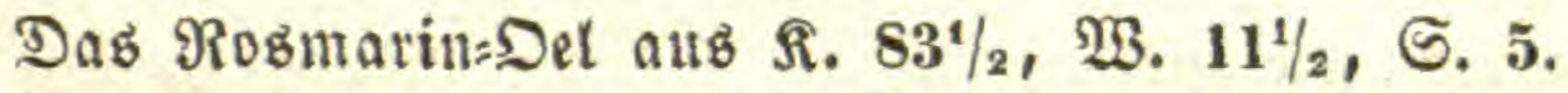

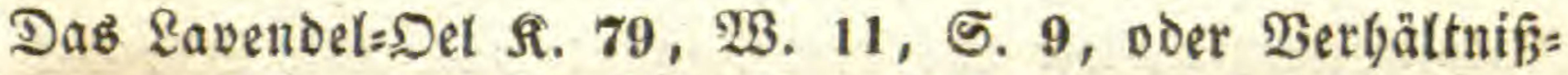
theile $15,14,2$.

b. Die $\mathfrak{B a l f a m e}$ fino etwas verdidftete, meifít oicf flüi: fige ätberif̧) Sele, werthe gemöhntid( Benzoe:Säure entbalten, ober wenigitens in Der Şike jolthe lieferm. Sie löjen fid) baber nicht blop in $\mathfrak{B} e$ ingeifi, fonoern aud in Wafler auf, uno fictern gewöhnlic) aนb Der. Rinde Der Rorbeerbäume, Der Terebintbaceen und ber Şullenpflanzell aub; manche gewinnt man jedod aud) erif Durd) fiochen, wie Den Ierpentin, wenn man ibn bieber rect)nen will. Er if eine Berbinoung von Şarz und Terpen= tin= Del.

3u den fluifigen Balfamen gebört der pertuianijđe Baljam,

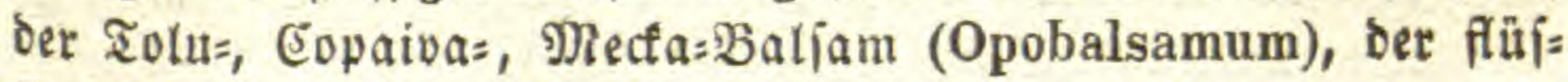
fige Storax uno ber Ierpentin.

3u den veiten Baljamen bie Benzoe, Der veite S̈torax uno Das Dradenblut.

c. Die eigentlidgen Şarze fino die lebte Deroidtung Der åtberifat)en Dele, uno zwar meiftens des Ierpentins, einer Irt Balfam, weldher aus dem Rabelfolz gewonnen wiro. Sie fino fpröb, meift gelb oder roth, verbrennen von felbft mit viel

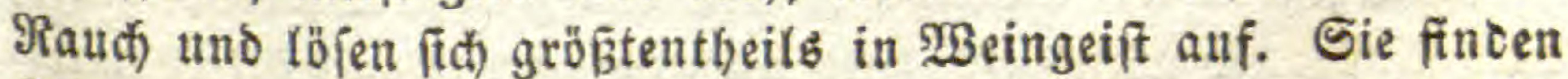

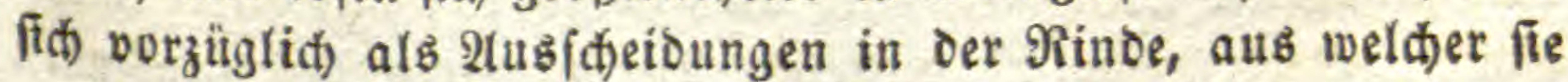

Dfeng allg. Raturg. II. Botanif $I$. 


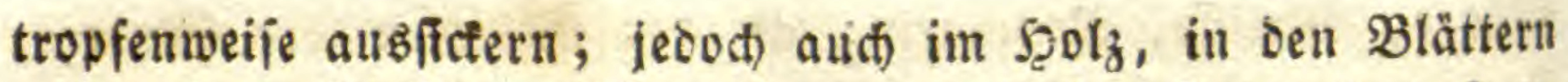
unb anbern Igeilen. Es gebören vorzüglich bieber bas loges nannte weise Şarz atı ben Tannen uno Der Eopal.

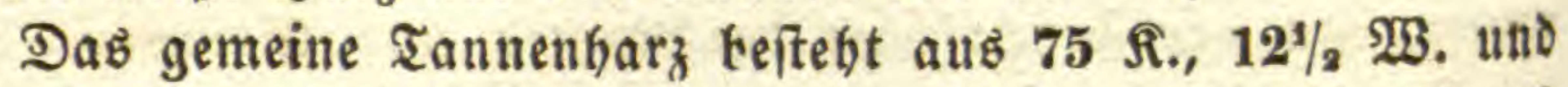
121/s S. Der Bernftein gebört auth bieber, gibt aber butt) Deitillation Berniteinfäure.

Der Eampher if ein weíses, ourdidteinendes und fart riechendes ફ̧arz, weldes als Rörner unter der Rince uno in Rücten bes Şolzes von veriftiebenen Sorbeerarten vorfommt, obne 3weifel als (jerinnungen des ätherifłken Dels. 2(ut) burd) Beroünftung ber ätherif̧t)en Dele ber Rippenpflanzen fann man Eampher geminnen, z. B. Rosmarin, Majoran, Salbey,

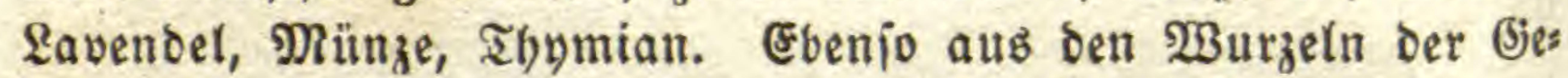
witrzpflanzen, wie Zitwer, Ingwer u.f.w.; Deg̈gleichen aus ben Doldenpflanzen, wie atts bem Fenthel= uno 2tnis:Del, uno now aub vielen anbern, felbit einigen Gräien. Er bejteht aub

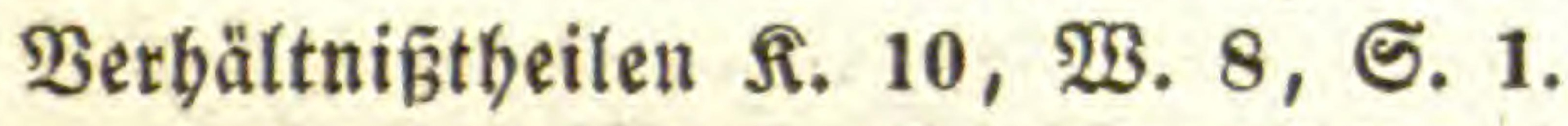

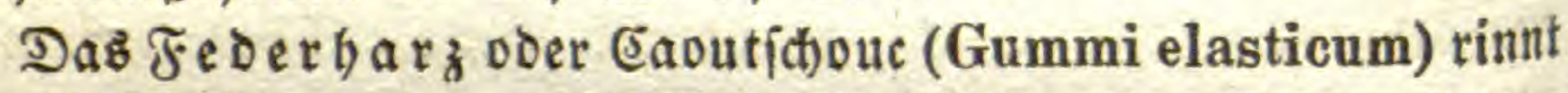

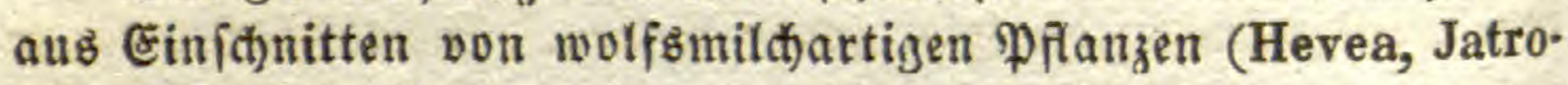
pha, Ficus indica), uno befteft aus 90 爪., 9 $\mathfrak{B}, 1$ S.

Der $\mathfrak{B}$ ogelleim wiro vorzüglich aus ben Miftelbeeren uno bem Bafte ber Stechpalmen burd) 2(btod)en gemonnen. (Fr

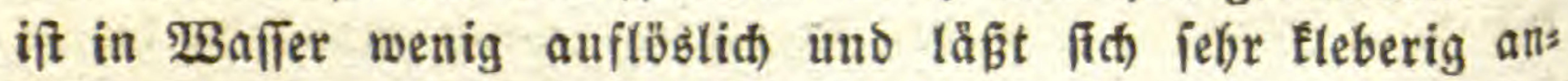
füblen. Soldt) fomierige Maffe findet fich audi) ben vielent Rnoipen, befonbers ber St)warzpappel, ber Ropicaftanie, an ben 3weigen ber Robinien, am Şornfraut (Cerastium). Er hat grofe 2(ebnlid)eit mit dem Federbarz.

Man faun aud) etwas Federbarz gewinnen auts bem Safte

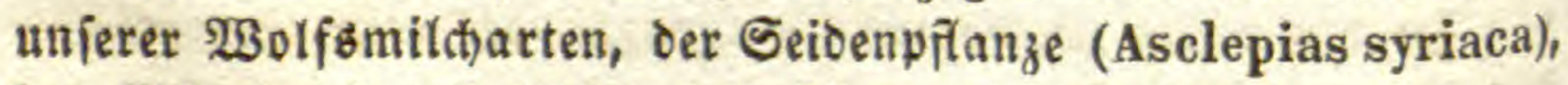

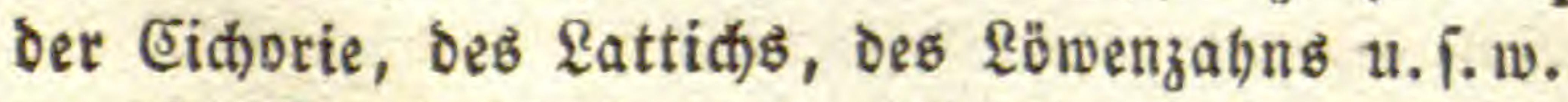

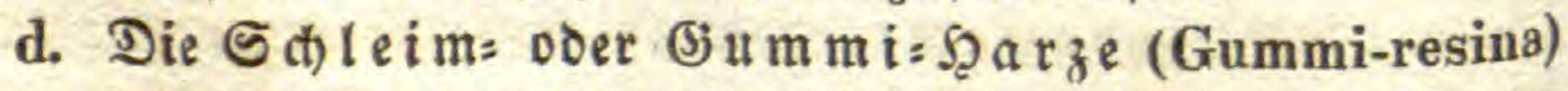

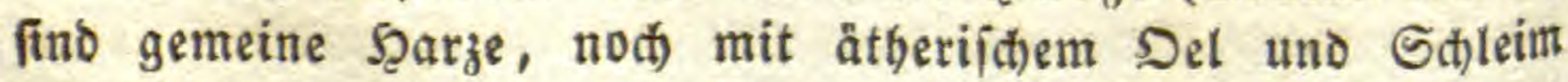

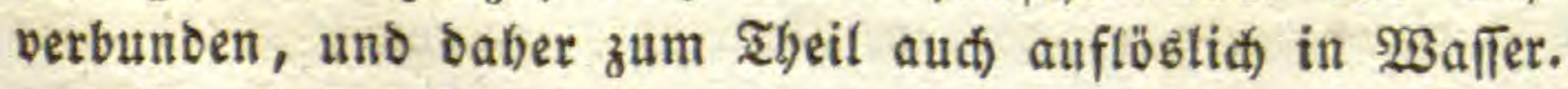

Sie finden fid meiftens in Der $\mathfrak{B}$ urzel ber Doldenpflanzen, balo fluifitg wie Mildajaft, bald auch geronnen; uno biejes unter"s

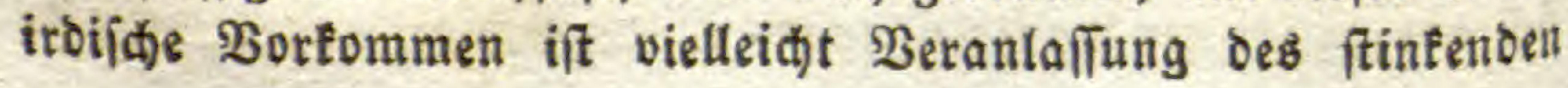


(jerudbs, weldien fie von fidi) geben, wie bejonders ber foge= nannte Teufelsorect (Assa foetida), den man in Эnoien aus Der Dolbenpflanze mit Ramen Stectentraut (Ferula) geminnt. Şieher gehören noch die Mntrbe, 2tloe, bas (jummigutt, 2(mmoniaflgarz u. v. a.

\section{Bafferartige goflangenfoffe.}

Эđ) recthe bieber bie auflöglithen, neutralen Stoffe, alfo

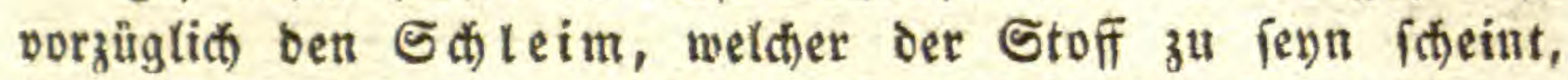
woralls fich bie andern näbern Beftandtheile ber Pflanzen ent= wicteln.

Der allgemeine Pflanzenjaft in ben 21 oetn voer Ÿntercel=

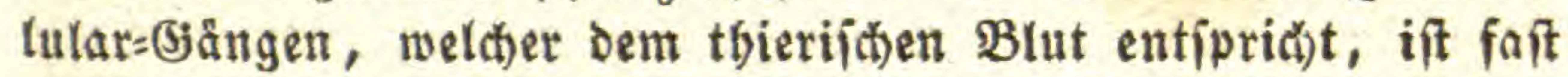

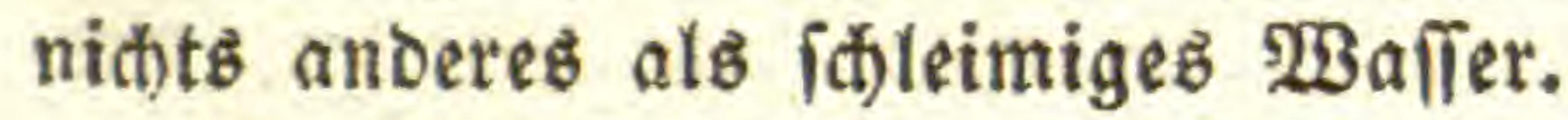

\section{a. Der Sthleim (Mucilago),}

weldien man aus vielen \$flanzentheilen, bejonbers 283 uzzeln uno Samen, austoden fann, wie aub ben 23 urzeln bes Şufs

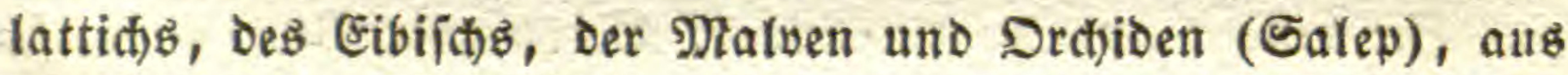

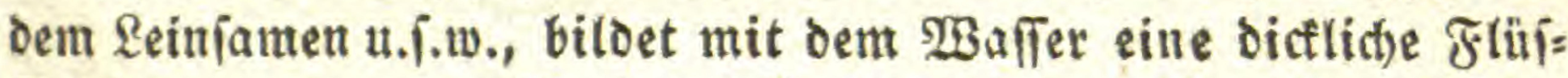
figfeit, woraus man ibn burch $\mathfrak{B}$ erbampfung beft erbalten fann. Err ift unauflöglid in S్Seingeift uno Delen, verwandert fict) burd) Salpeterfäure in Sauterlee= uno Mitchutucter= oder Sd)leim: Săure; - rägt fich aud) burch verifiebene Bebandlung in Sucter, Stärfe und Şolziftof verwandeln. - Solth ein Schleim findet fic) aud) um oie Quttren= Samen.

Er ffefert fehr bäufig aus der Rinde verídiesener Bäume aus, vertroctnet in Gejtalt von Tropfen uno heiß̧t bann (jummi,

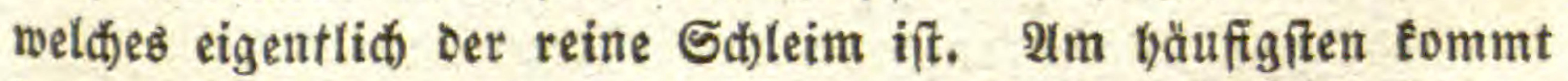

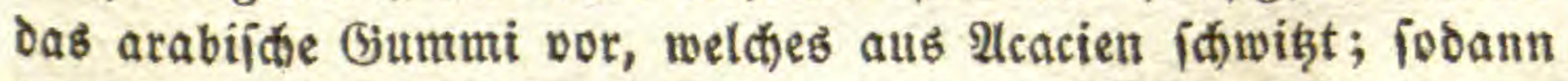
Der Iragantbfoleim, alfo beioe von Seutlenpflanzen. Es zeigt fid) aud̆ băuftg bei ben benadbarten Jamilien, nebmlich Den Terebintbaceen, wie dem Eajđubaum (Anacardium) uno uniern Steinobftbäumen, bejonbers Ririden, 3wetichen uno

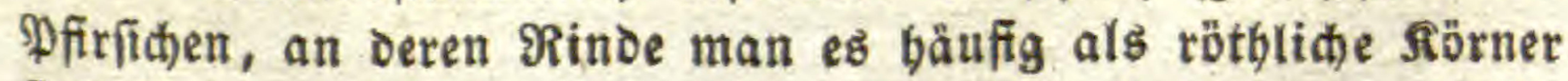
findet.

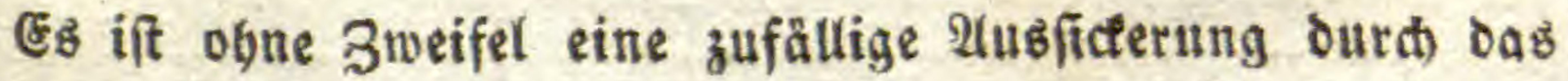
8 *ै 


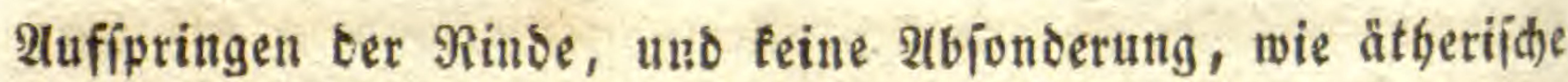

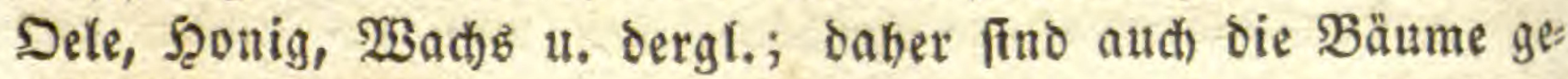

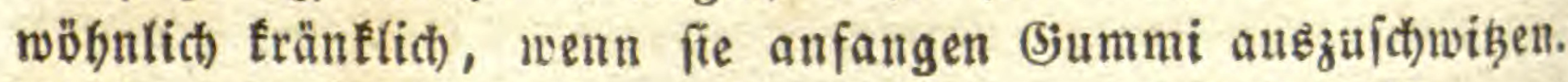
2luf ben Tragantfpplanzen zeigt es fich) vorzäilici) bes Morgens nac) Rebe(n, woourd) Das Şolz anid)willt uno es Gerausbritct.

Der reine Pflanzeniáleim oder bas arabijide Gummi be

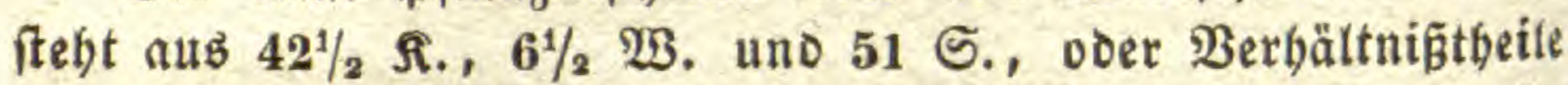

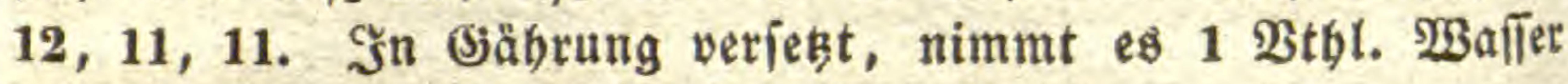
auf uno verwandelt, fich in Traubenzucter.

b. Sieher gebört aud) Die Pflanzengarlert,

welche than alls ben meiften Fritchten burch heipes $\mathfrak{W a f f e r}$ zieben fann, bejonbers aub ben Sobannisbeeren, Şimbeeren und

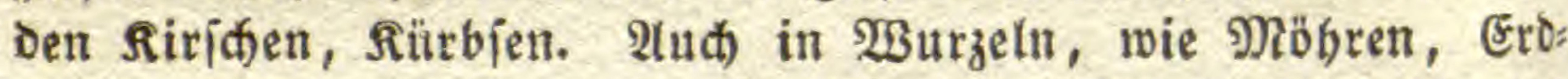
birnen, Giditroien t. f. w. Es ift eine weide, zitterabe und ourdfidtige Malle, welche fid), wie bie thierifde (ballert, in faltem $\mathfrak{B a f f e r}$ nur wenig aufiöst.

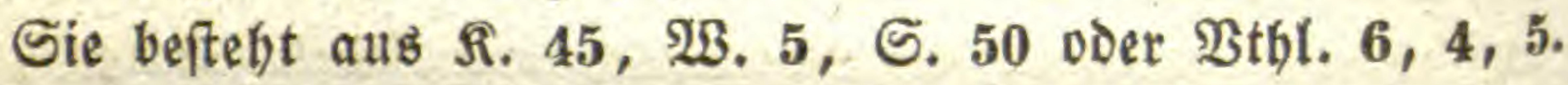

c. Das En weif (Albumen, Glutine) ift vom thierifhen etwas veríchieden, farblos, gerinnt bei $60^{\circ}$ গBärme, uno ift bant

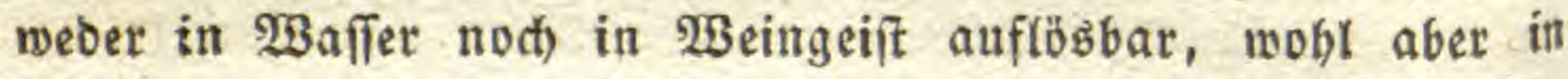
2tcalien, wodurch eb zeriegt wirb. E⿺s findet fids) nut in ges ringer Menge in febr vielen Pflanzen, bejonders im Mebl dé (Setraides, der Şüllienfrüd)te, Der Erdäpfel, der fünen Mandeln

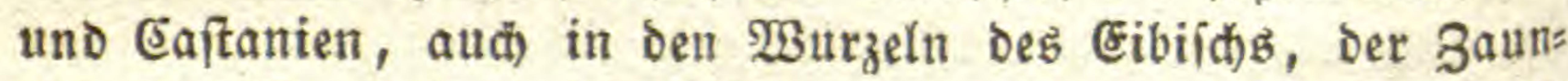

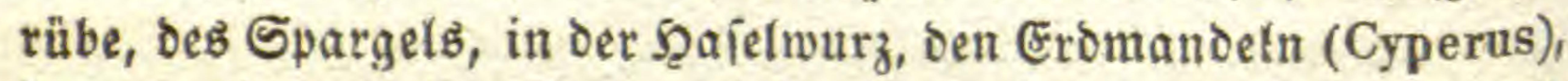
Dem Rnoblauth), Der Zimmetrinde, in veríffiedenen Blåttern uno slumen, dem Blajentang uno den Blätterpilzen.

d. Der 3 ucter iteht, gleidjam als Reutraljalz zwifdien Den Säuren uno laugenartigen oder fitarfen Stoffen, in oet

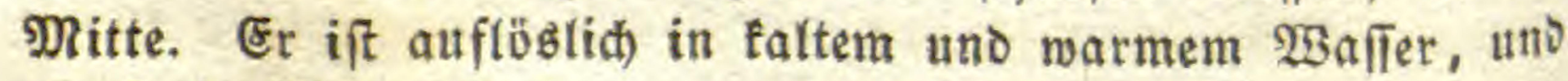

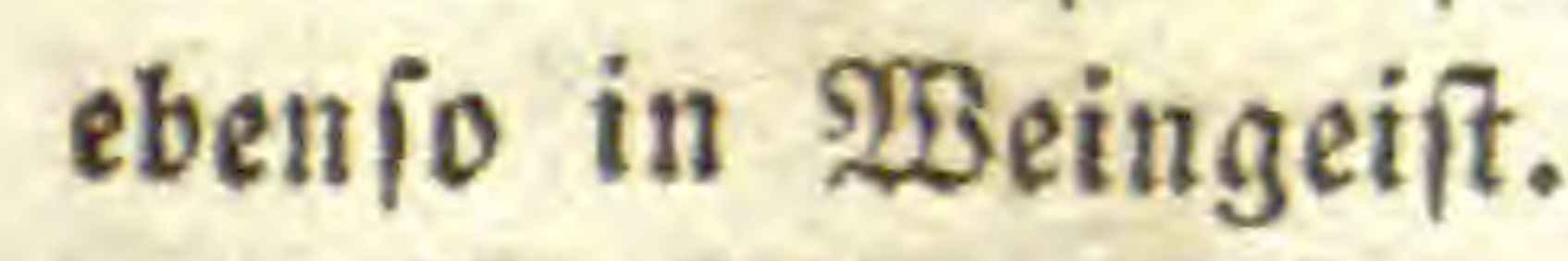

Er fommt vorzüglid) im Pflanzenjaft vor, unt ift gejams melt in ben meiften Frühten. 2(ud) bilbet er fich benm fieimen der Samen, uno baber in bem Malze zum Sier.

Man untericheidet ben Robrzucfer, weldier aus bent 


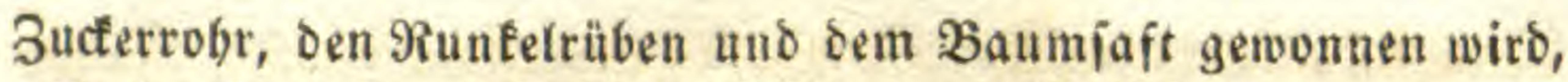
uno in vier = voer fect)bfeitigen Săulen cryftaltifiert;

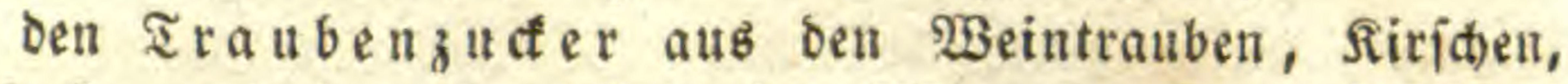
Ipricofen uno dem \$̨oniglafte ber Slumen. Er cryftallifiert nur in Rabeln, uno ift weniger auflöslic). Man fann ibn auch) Durch) S(twefeliäure aub bem Stårfemekll bereiten;

Den fluffitgen Bucfer oder Den Syrup, welder mit ben vorigen Bucferarten vorfommt uno nad) ifgrer Eryftallifation

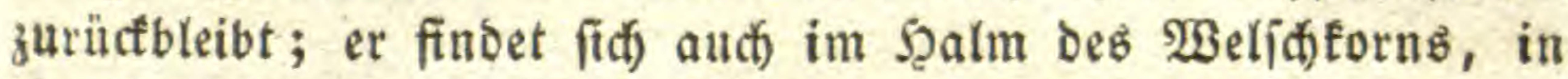
Den 2 epfeln uno Dutten, ift aber mit Sĭleim uno 2hpelfäure verumreinigt, uno gährt baher für fid) felbft, obme 3ujał von Stefe, was ber reine Sucter nidft thut.

Der Robrzucfer beftebt aus 43 R., $6 \mathfrak{B}$. und 51 S., voer Btble. 6, 5, 5. Err ift auflöglidi) in $\mathfrak{B a f f e r}$ uno $\mathfrak{B e i n g e i f t , ~}$ bo (t) bier (d)wieriger.

Der Traubenzucter beftegt auв $37 \mathfrak{K}, 7 \mathfrak{B}, 56$ S., oder Sitble. 6, 6, 6.

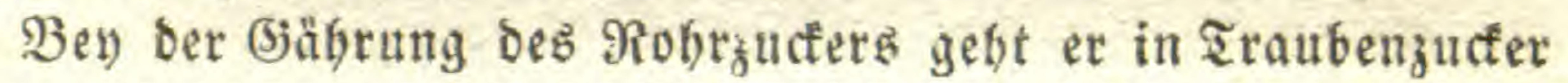
über, uno biejer zerfällt in $\mathfrak{B e i n g e i f t ~ u n o ~ F o b l e n f a ̈ u r e ; ~ o u r c h ~}$ Salpeterjäure verwandelt er fith in Zucfer: und Samerkleejäure; burd) vercinnte Säuren in Traubenzucter, uno enolid) in Damm= erve voer Moderitoff. (Er verbindet fit) mit Rangen uno Reg $=$ Ealf zu einer weidyen Mafie, ogne fich zu zeriegen.

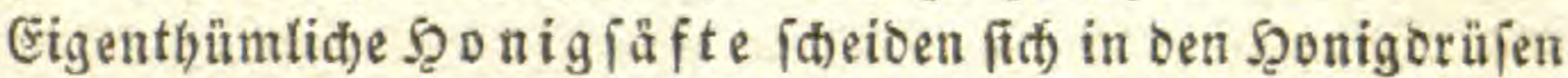
Der $\mathfrak{B l u m e n}$ aus; bejonbers reidlid) in ben Sippenblumen uno ferte gut im Ravendel uno Rogmarin, wo ifn die Bienen fam= meln uno als f̧onig wieder won fich geben. Ë gibt itroffen aud) giftigen Şonig, wie Der, welcter aus bem Sturmbut uno Der pontifiten Alpenroje gejammelt wiro.

Süke Säfte finden fich aud in bem Marfe ber Şillie bes Jobannisbroobaums (Ceratonia), der Röbrencaifte, in ben Frücten ber paiftonäblumen.

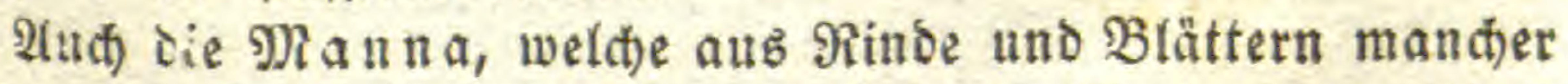

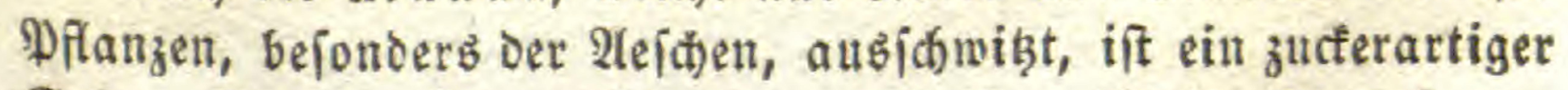

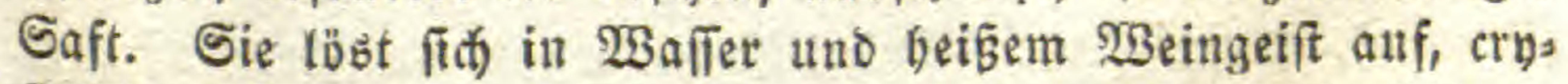
ftallifiert in Nabeln, gägrt nid)t, uno verwandelt fich nid)t in 


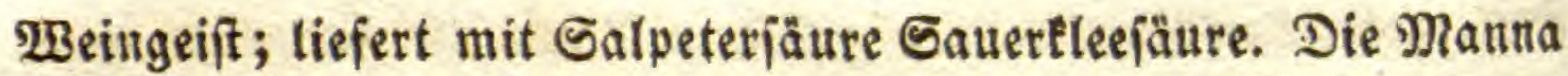

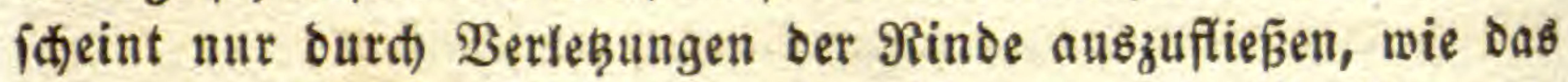
(S) madt, theils burt) Stiche der Eicaben. Sie zeigt fith ubrigens aud) auf andern Pflanzen, namentli() auf Tamarizfen in ber Revante, auf Dem 2ulfagi=Strauth (Hedysarum), ben Sprofien bes \&ärdenbaums; enolid) liefert auch) eine Fledte (Parmelia esculenta) in Perfien eine 2(rt Manna in forder Menge, Daß fie von ben sirgifen gejammelt und gegefien wirb. Sie fann

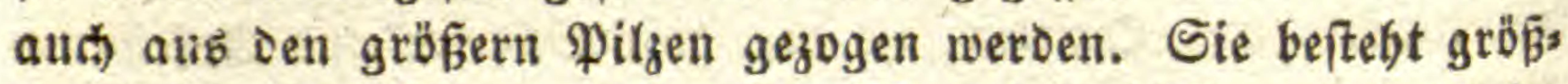
tentbeils aus Mannazucter oder Mannit, nebit etwas Robr: zurter und einem laxierenden Stoff. Die Beftanotheile bes Mannits fino: 爪. 40, W3. S, ভ. 52, ober $\mathfrak{B}$ thle. $6,7,6$.

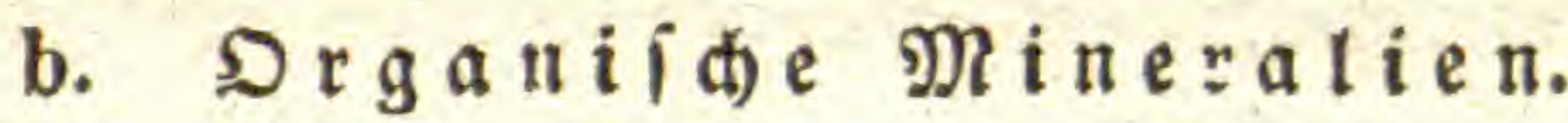

4. Eroenartige gyfanzentioffe.

Es gibt in ben Pflanzen Stoffe, weldhe barinn 2 tehnliduet

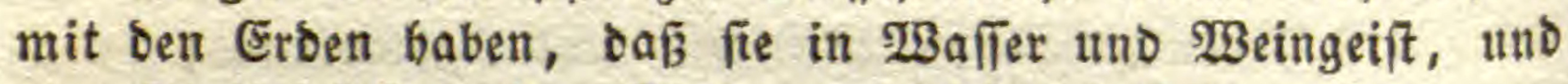
żum sheil felbft in ben Säuren unanflöstich) fino.

a. Dabin gebört vorzüglid) Die ŞO 5ृolz ft off (Qignin), Deffen (jrunblage das Stärfemehl zu fenn icheint. Um ibn zu gewinnen, ziebt man bie barzigen Theile

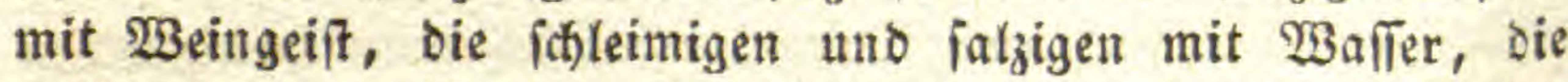

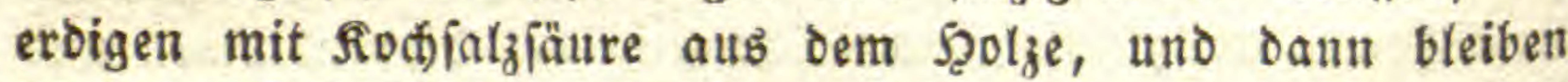
96 Procent Şolzitoff übrig, ber veft ift, fit)mubig weis, unaufs

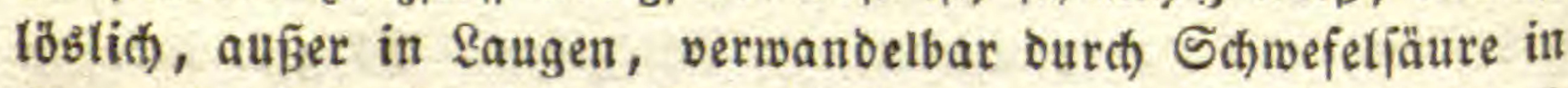
Ğummi uno 3ucter, ourd Salpeteriäure in Sauertleejäure, ourch Eauge in Dammerde (Humus). Er befteht ziemlich) aus 52 fioflen= itoff, 6 Wafferitoff uno 42 Saneritoff, ober $\mathfrak{B}$ tgl. $8,6,6$.

Der Sorfítoff, Marfitoff, Baumwollenftoff idteinen nur

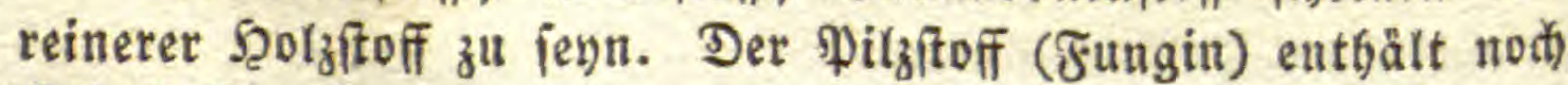
Stictitoff.

b. Der Extractiv= ober Moberit off ber Dammerbe (Humus), Şumusfättre (Ulmin) ift faum von dem (jerbftoff oder

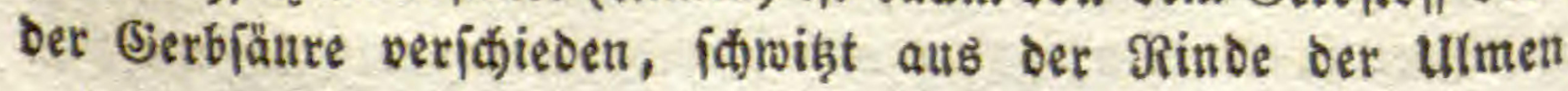


oder Rüftern uno einigen andern $B$ ăumen aแs, entîtebt aber vorzüglich) Durd) Bermoderung Deb Şolzes, und mad)t Daber ben Sauptbeftandtbeil Der. Dammerde aus uno bes Iorfb. Er fieht faft aus wie Roble, löst fidh in Weingeift auf, aber menig im SBafler, uno gebört baber faum unter die Săuren, obiaton er mit 2llcalien verbunben in $\mathfrak{B a f j e r ~ a u f l o ̈ s l i d ) ~ w i r b . ~ M a n ~ b a ̆ l t ~}$ ibn jekst für die eigentlide Pabrung der Pflanzen, weld)e fie

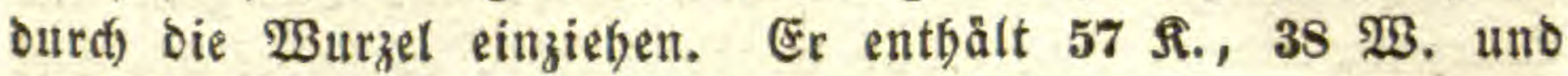

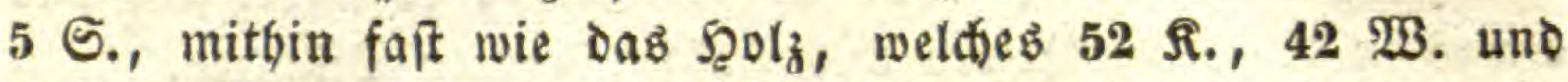
6 S. enthält, bou bem er fí) aljo nur ourch) etwas mebr WBafler unterideibet.

\section{c. Der Rleber (Gluten)}

findet fich reid)(id) im Mebl, aus welthem er burd $\mathfrak{W a}$ ajden uno Rneten gewounen wirb. Er if eine yraulidie, geid)mactloie, meide uno fidmierige Maffe, welde nad bem Berlufte des खallers fpröo wird; wenig auflöbbar in $\mathfrak{B a f f e r , ~ m e b r ~ i n ~ E i f t g = ~}$ fäure, aแв welcher er our丸) (5alläpfelaufguß gefällt wiro. Er gebt von felbit in Sährung über, und entwictelt anfangs fioblen: fäure und : $3 a$ fieritoffgas, Dann Eifig= und Pbogpboriäure nebft

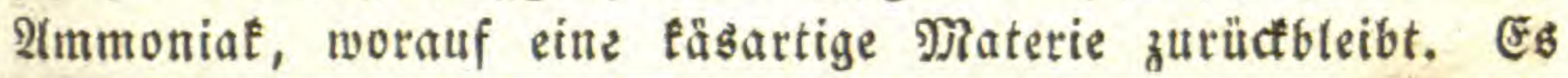

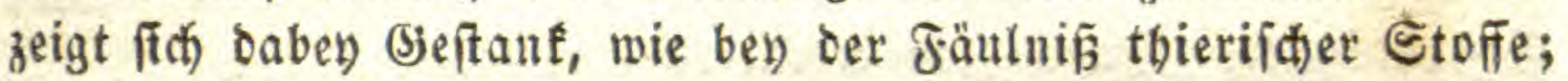
aud) enthält er offenbar Sticfítoff. Er billoet eigentlia) die ફ̧efe, bringt Den Ieig in (3äbrung, und Durch Die Entwictelung feiner Iuftarten entiteben die Qöher in Brod. Seine Beitanotbeile fitio R. $46, \mathfrak{3}, 3^{1} \frac{2}{2}$, Stictítoff $20 \frac{1}{2}$, S. 30.

Err bildoet mit Der Stärfe und etwas Enweí̄ das Mebl. Sn Weizenmebl find 68 Stärke und 24 sileber entbalten. Эm Dinfel 74 und 22.

Эim Roggen 61 uno 5.

Эิก der (j)erfite 87 uno $\mathbf{3}$.

Im Şaber 59 und 6 , oder ftatt deffelben Enweif.

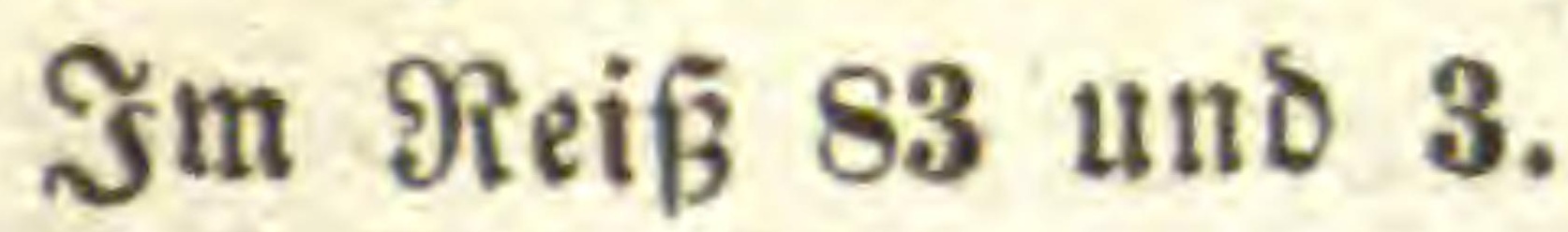

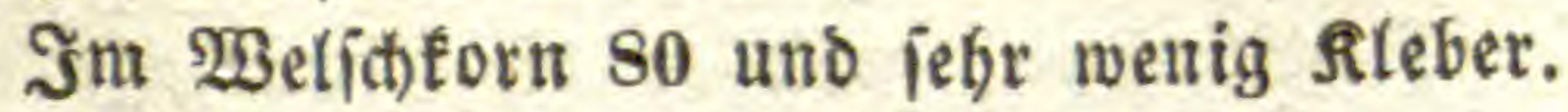

Yn Den Bobnen 46 und 22.

In ben Saubobnen 34 uno 11.

Sn ben \&inien 32 uno 36. 
In Den Erbjen 53 uno 14.

$\Im m$ Buchueiken 52 und 10.

Uebrigens wedjeln bie beiden Subitanzen bedeutend, ie na屯) Dem veridiedenen Dinger. Durdh Das Reimen verídwins Det Der Sileber.

Der fileber feflt in Den meiften Gamen, weldse nidft vom Sietraibe Gertommen, uno in bem Mehl aus Stengeln uno Wurzeln, wie in Sago= uno Eroäpfelmegl; es findet fich aber etwas in den Fohlblättern uno einigen anbern Pflanzen.

d. Das Stärfemehl fommt zwar als förner in allen Pflanzen äften, in Den Beflen uno 2(bern, vor, und f(t)eint fith in bie Sellen uno Şolzfaiern zul verwandelit.

In Maffe gefammelt ift es in allen Samen, befonders im

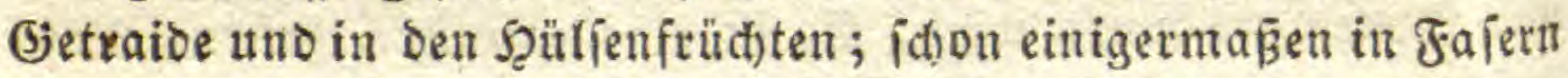
vermandelt in Den Eroäpfelt. Rein bargeftellt beiF́t es Puber.

(Es if unauflöstid) in $\mathfrak{B e i n g e i f t ~ u n o ~ f a l t e m ~} \mathfrak{W a f f e r}$, nur

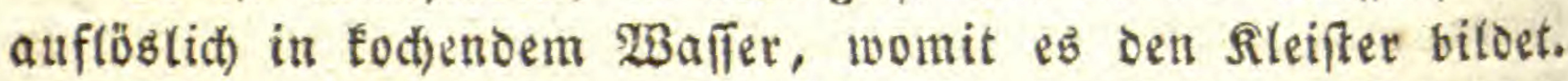
Einmal vertroctnet (b̈st eb fid) nid)t wieber auf. Durd) Sd) wefels fätre wiro es in 3ucfer verwandelt, ofue daf ihm die Säure Sauerftoff abträte, alio bloß ourd) inmere Berändernng feiter Beftandtbeile. Durd) Jod erfält es eine blaue Farbe.

Er befteht aus 45 roblemftoff, 6 'S. und 49 S., oder Berbăltnişţeile $6,5,5$.

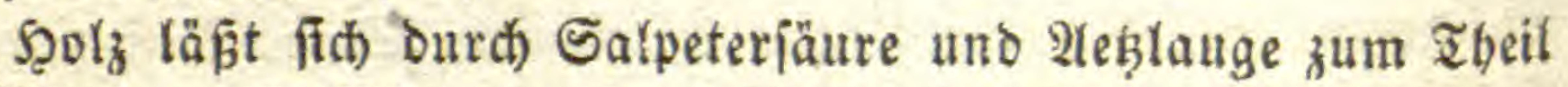

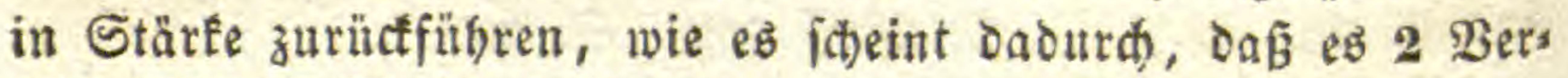
Găltniştheile Waller betommt.

\section{Salzartige grflangenftoffe.}

Sino bie organifichen Stoffe, weldte fich) im $23 a f i e r$ auflöjen uno einen ftarten (jeid)mact erregen.

Sie theilen fith in mebr indifferente, faute uno laugenartige.

a. 2lis indifferentes Salz fann man

ben (jerb ft off betracteten, weil er bie Grundlage einer Säure ift. Er folmedt indelien zujammenziebend, uno biloet mit Oallert eine unauflöslicje febnen= ober Yeberartige Malle.

(Er findet fich) vorzüglid concentriert in Den Gaalläpfeln ber 


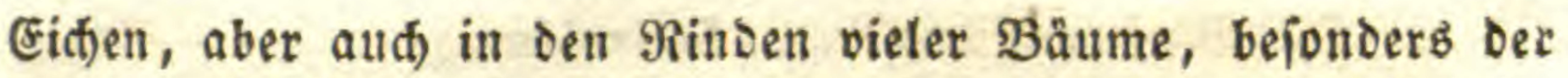
Eichen und Weidell, Der $\Re$ ojaceen, Des Sumads, im Eatedu (Mimosa), in Den Şüllẹ Der 2lcacien, Der Reifel ber Wallnuß̈; felten bey den Streifenpflanzen, in ber Betelnußs; auth im ge= meinen Farrentraut, aber nid)t bey brofleftojen Pflanzen, wie Moofen uno pilzen. Sein eigentlicher. Sik theint ber Baft zu fenn, uno er findet fid nidit in ben Samen, und faum in bes täubenden (jewåd)

Err bilbet rein Dargeftellt eine weise Mafle, uno beftebt aus 51 R., 4 W. uno 45 S., voer $\mathfrak{B}$ thle. 9, 4, 6.

b. Die Pflanzeniäuren

fommen jebr bänfig vor, bejonders ben den Rekpplanzen, fowohl frey als mit andern Stoffen verbunden, meiftens im Safte Dez Stengetb, Der Rinde, Der Blätter uno der Frucht. Die frenen Säuren untericteidet man leidtt burd) Den (sejd)mact. Sie fino oxboierte, organifite Stoffe, weldhe ben unorganif(t)en Säuren parallel geben, etwa auf bie oben angegebene 2trt.

2un Eerdem fommen in ben Pflanzen nod) geborgte Thier= fäuren vor, wie die Phosplorfäure uno Blut= ober Blaufäure.

1. Die Ëfigiăure if die allgemeine Pfanzeniăure,

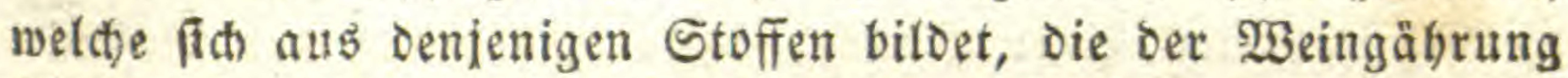
fäbig fino, alio aus oem 3ucfer uno zunäđ it dem Weingeift.

Sie ift übrigenz fityon gebildet in bem Pflanzenfaft vor= banden, aber nid)t rein, fonbern mit pottajite verbunien, uno nur in zeringer Menge. Man glaubt, Daß́ fie fith) erít biloe, wann ber Saft ausgefloflen ift, weil er Racmus=\$apier erit rinthet, nadtoem er einige Stumben an ber \&uft gewejen; jo

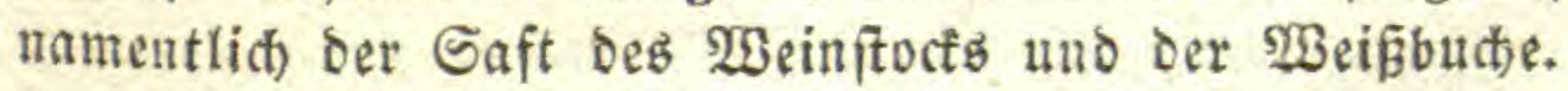

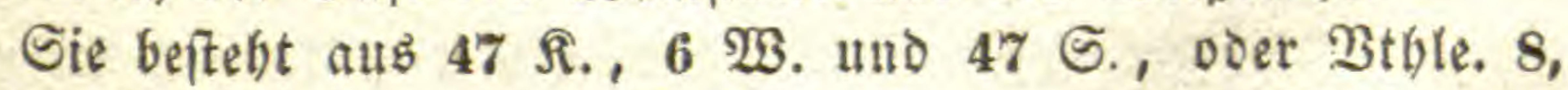
6,6 , ift aber im natürlichen 3uftand immer mit $\mathfrak{W a f f e r}$ ver= bunden, fluififg, flühtig uno jelbit entzünolid), cryitallifiert feooch) auth) unvollfommen. Ein $\mathfrak{B}$ thl. WBeingeift bilbet mit 4 Sauter=

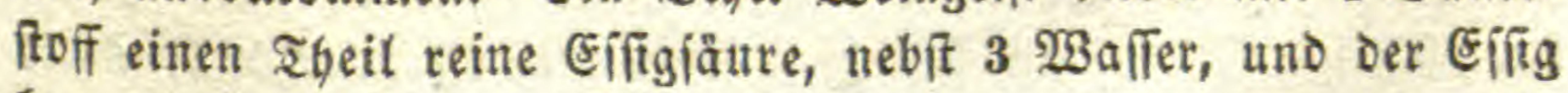
taun baher orydierter $\mathfrak{W e i n g e i f t ~ g e n a n n t ~ w e r b e n . ~}$

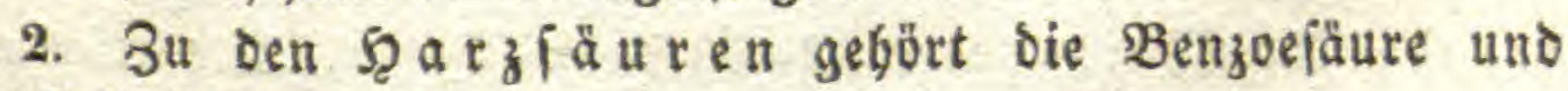
Bernfteinfăure. 
a. Die SBe nzoefäure (A. benzoicum)

bilbet fin Durch Drvoation Des Bittermandel=sels, und findet fith it Dem Benzoebarz, aus bem fie bey ber Deftillation als Flocten getrieben wito, weld)e Benzoeblumen beifen. -

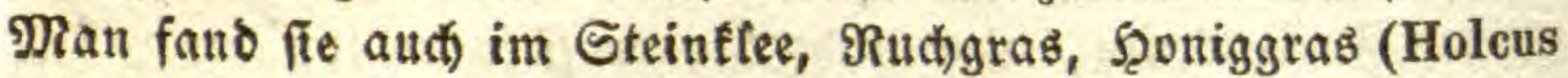
odoratus), chineftíben Jirniß̧ uno in den Ionfabobnen. $\mathfrak{B}_{e=}$ fanntlid) ift fie aud băufig im Şarn ber grasfreflenden Ibiere.

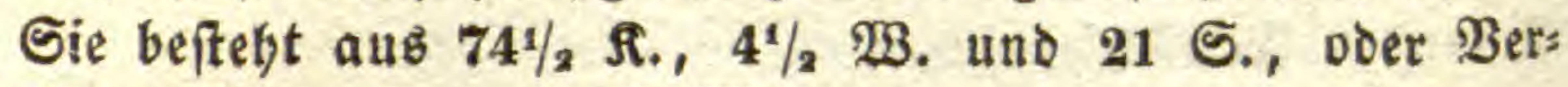

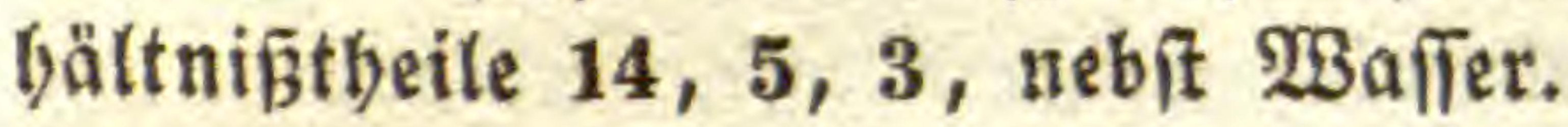

b. Die Bernfteiniäure (A. succinicum)

findet fi(h) gebildet im Bernitein, uno entifebt aud ben Der Deftillation Des Ietpentins. Sie cryftallifiert nno entbålt $48^{1} / 2$ I., 4 Wु. und $47^{1 / 2}$ S., ober $4,2,3$, nebfit $\mathfrak{W a f f e r . ~}$

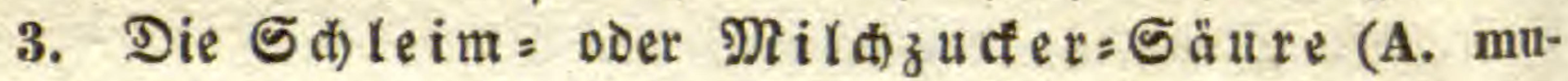
cicum)

fommt niat fertig vor, fondern entifeht aus (5)ummi, (5al= lert uno Mild)zucter, ourd) Ëinwirtung Der Salpeterjäure, uno

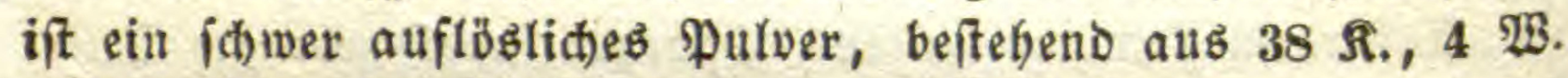
uno 58 S., poer $\mathfrak{S t b l e . ~ 6 , ~ 4 , ~ 7 , ~ n e b f i ́ ~} 23$ affer.

b. Die (J)allert befommt ourt) Die Cinwirfung ber \&augen Die Eigenfiaften einer Săure, vhne 2tenderung Der Beftant: theile. Die (5)allertiäure (A. pecticum) findet fict) mit falle

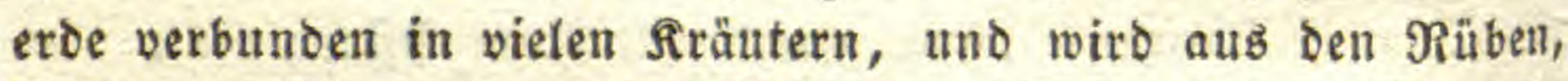
Möbren, Scorzoneren, Den Erbbirnen (Helianthus), Wurzeln Der (jeorginen, uno aud) aus Dem Bafte Der Băume gemounet. Mit Waffer bildet fie eine 21rt (3allert, weld)e das Lacmub:

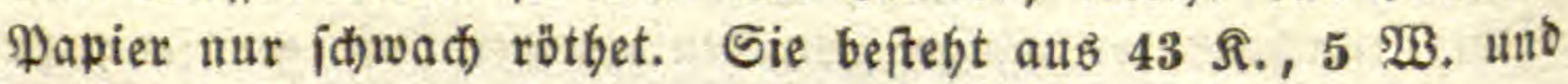
52 ऽ.

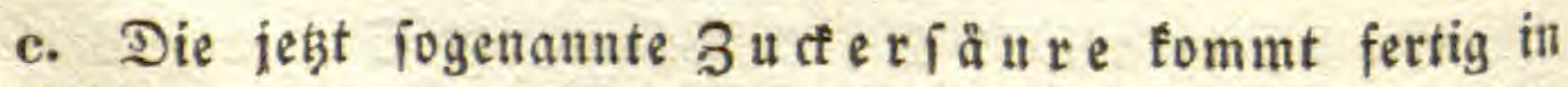
Den Pflanzen nidbt vor; fonbern entifebt exft burch) Einmirfung ber verbünten Galpeteriäure auf 3 ucfer oder Stărfe, mobeh (ith) auch) zugleich Sauertelefäure bildet. Sie ift eine fpröbe,

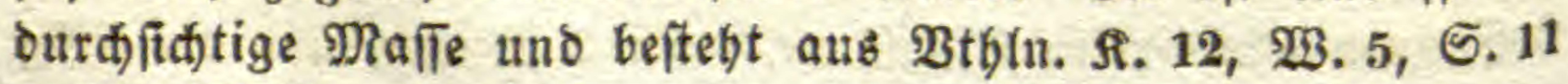
uno 5 Waffer.

d. Die $\mathfrak{B}_{\text {ein }}$ ober $\mathfrak{Z}$ einfíteinfăure (A. tartaricum)

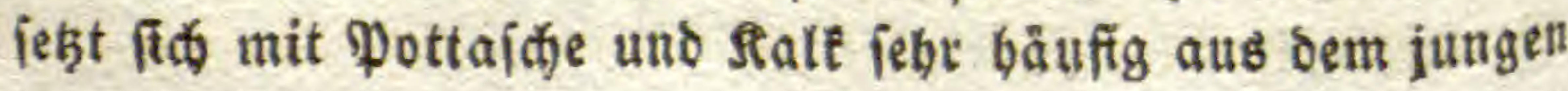




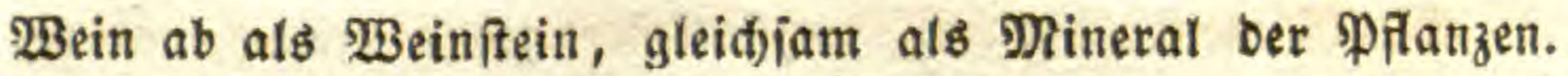
So foimmt fie attd) im išläntijhen Moos vor.

Rein findet fie fich in Den meiften fauren Frücten, in ben unreifen Irauben, Dem Iamarinbenmarf uno in Den $B$ eeren beß Gierber:Sumadts. Sie cryitaílifiert uno beiteht aus 37 Roblen= ftoff, 3 พBafferf́toff uno 60 Sauterftoff, oder 2 thln. $6,3,7 \frac{1}{2}$, nebît $\mathfrak{B a}$ afer.

\section{e. Die Citroneniäure (A. citricum)}

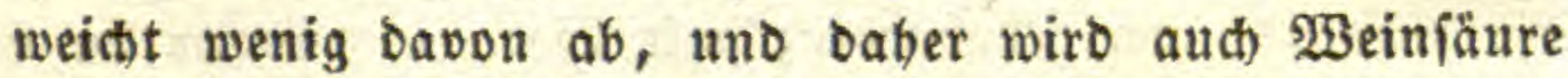
unter Dem Ramen $\mathfrak{B e i n f t e i n a b m ~ ( C r e m o r ~ t a r t a r i ) ~ z u ~ P u n i t ) ~}$ genommen; fie wirtt fedoc) lapierend.

Die Eitronenfäure findet fich) fren in dem Safte ber Eitronen,

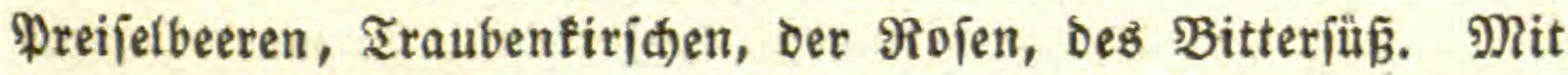
Thpelfäure in Den šobannisbeeren, Şeidel =, Brom = uno Erro= beeren; mit Salf im Safte Des Robls, Der 3 wiebeln uno bes Waidz; mit Talferde in Den Swiebeln.

Sie idjmectt jebr jauter, cryftalliffert, entbält aber viet Ernjtalliations=Wafier. Sie beftebt aus 42 R., 31/2 13 . und

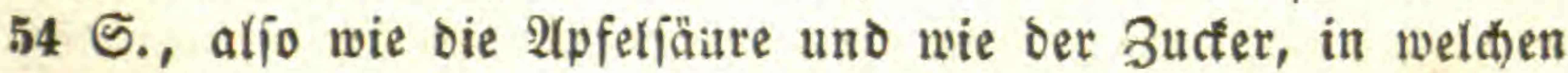
fit) beibe benm Reifen ber Früd) zu verwandeln ítheinen.

f. Die 2 prefi

findet fid) frey in ben meiften Früd)ten, namentlid) ben fau= ren $\mathfrak{A} e p f e l n$, Birnen und vielen Beeren, und gibt Denjelben ben angenefimen (5)efthmact. Sie if auth in ziemlither Menge vor= Ganben in Den Bogelbeeren, Trauben, Sallehen, Ririden, Şeidel=,

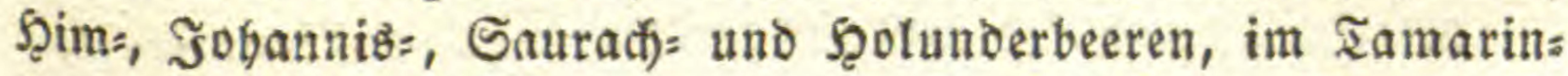
Denmarê, jelbit in ben Stengeln uno $\mathfrak{B}$ urzeln einer Menge von Prlanzen, uno jogar im Blitthenftaub oer Dattelpalme. Sie ift genöbnlich mit Saleim= uno anbern Săuren vermengt, mit falt verbunben im Mauerpfeffer. Sie ift reid)licher in ben Früd)ten vor ber Reife, uno verliert fith, wann fie fün werben; wabrideinlid inbem fie fid in Sucter verwandelt. Ben oen Pflanzen obne Gpiralgefäbe, wie Moofen uno \$ilien, fommt fie nidit vor. In bem Safte ber Gauradbeeren ift fie jo häu=

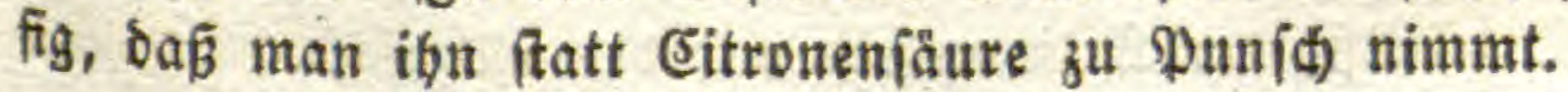


Sie ift meift iffmierig, cryftallifiert ferod) etwas, uno bes

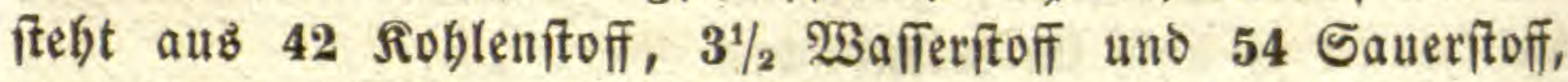
oder Bthle, S, 4, 8, nebjt $\mathfrak{3 a f i e r . ~ S i e ~ p e r b i n d e t ~ f i d i ) ~ g e r n ~ m i t ~}$ Eifen zu einer foumierigen Mafie.

\section{Die Sauerf́leẹăure (A. oxalicum)}

findet fid) felten frey, wie an Den Şaaren Der sid)ererbfen mit ber 2łpfelfäure; fonît aber häuftg mit Pottaịthe verbunden in ben fauren Säften des Sauterflees uno des Sauerampfers, des Pifangz, ber Rhabarber; mit Soda verbunden im Salz: fraut (Salsola).

Sie hat grofe Berwandifiaft zur Ralferde, welche Bets bindung nidft felten vorfommt, namentlich in Der 13 urzel bef Seifenfrautż, Diptamb, Fendels, Balorians, Tormentills, Det

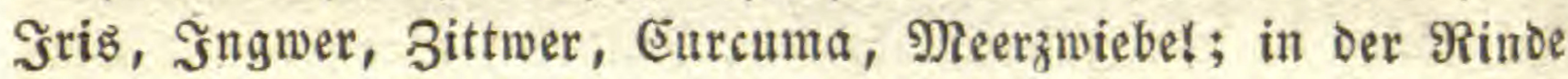
Des Şolunders, Bimmets, der Eascarille.

Sie iít veft uno erifteint in vierieitigen Ervitallen, ionmedt

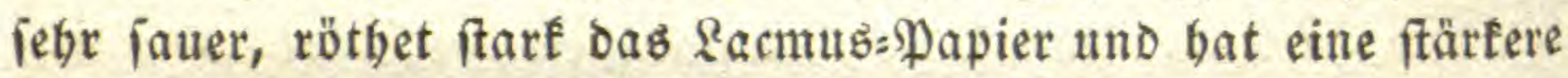
Berwandtiđaft zut Ralferde alb irgend eine anbere Säure, ent= bält auch) mehr Saueritoff als andere Pflanzeniăuren, nebmlich

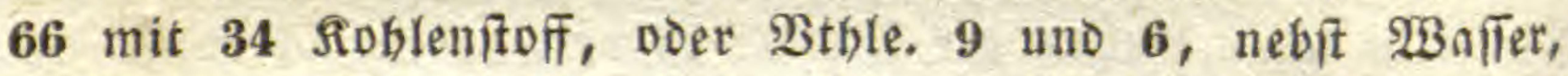
verbunden. Sie ift die einzige Pflanzenfäure von Bedeutung, welde nur aus soblenftoff uno Sauterftoff beitebt, uno Daber, fo wie felbft in inrer Menge, oer fioblenjätre nabe ftebt, won ber fie fith aber auffalleno ourch ibre veite form unters itheibet.

\section{Die (3) er $b=$ ober (5) $\mathfrak{l}$ แ}

findet fich) nicht fertig in ben Pflangen, fondern wiro erif ourd) Drybation Des Berbitoffes gebildet.

Sie bilbet vorzhitlict) mit Eifen die Dinte, indem fie bie

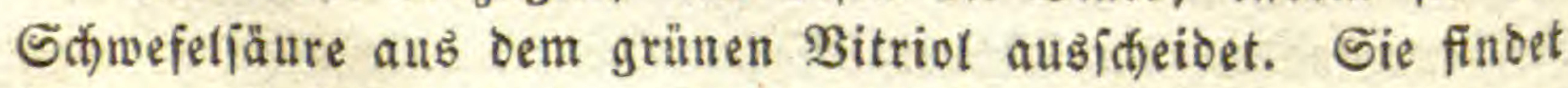

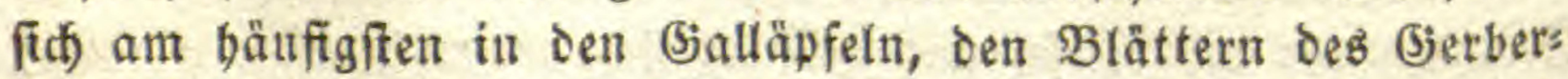

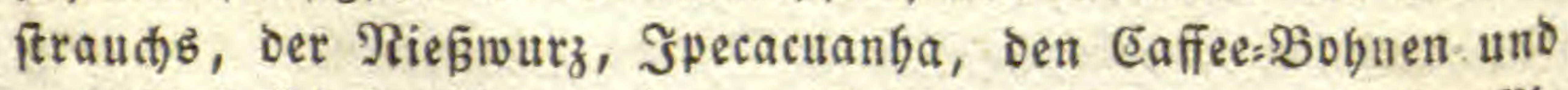
wabrideinlidy in allen zujammenziehenden Rinben, wie ber Ci: den uno $23 e i d e n$. Sebr jelten in Den Etreifenpflanzen, z. $\mathfrak{B}$. in ber Betelnus, ben Eromandeln und bem 2lloejaft. 
Sie cryftallifiert in Rabeln un befteht aus 50 R., $3^{1 / 2} \mathfrak{2}$. und $46^{1 / 2}$ S., voer $\mathfrak{B}$ thle. $7,3,5$, nebfit $23 a$ iाer.

6. Die Delfă ure (A. oleosum)

ift eit Beftandtheil ber Dele, freft alth aub wie Del, cry=

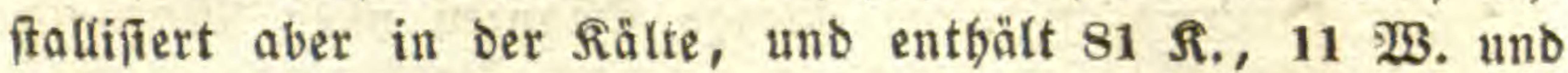
8 S., oder 14, 12, 1 thle.

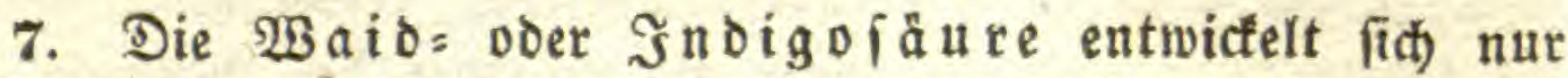

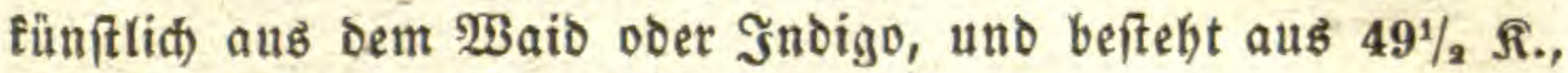
$7 \frac{1}{2}$. Stictitoff uno 43 S.

8. Unter benen aub Dem Ibierreid) geborgten Säuren fommt

die Phosphoriåtre ziemlich in allen Pflanzen vor, aber nid)t rein, jondern mit falf verbunden wie im Iobierreidf.

Sie fiebt aus wie weise Flocten, weldhe aber fogleid) Waffer anzieben uno zerfliefen. Sie beftebt aus 12 phosphor uno 16 Sauterftoff, oder Btble. 1 uno 2.

Bisweilen findet fith auti) ein wenig phosphoriaures Eifen, uno nach jeltener phosphorjaures $\mathfrak{Y Z a d . ~}$

Man gewinnt diefe falzartigen Berbindungen mur aus ber 2(iक).

9. Die $\mathfrak{B} \mathfrak{l} u t=$ doer $\mathfrak{B} \mathfrak{l} a \mathfrak{l} \mathfrak{i} \mathfrak{u} u$ re

findet fith in wenig Planzen, faft nur in ber Bunft unjerer Steinfrütote, uno zwar ganz frey, wie in ben Brättern uno

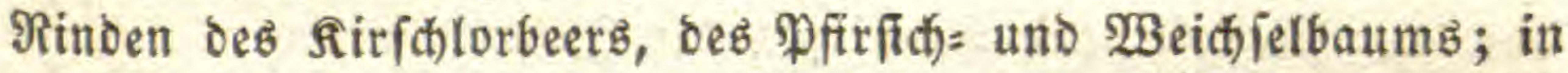
Den Rernen ber bittern Manbeln, fitwarzen Ririden, Pfirfict)e, 2pricoien, in ben Pfirfidbblütgen. Sie gibt Dem Riridjenwalfer

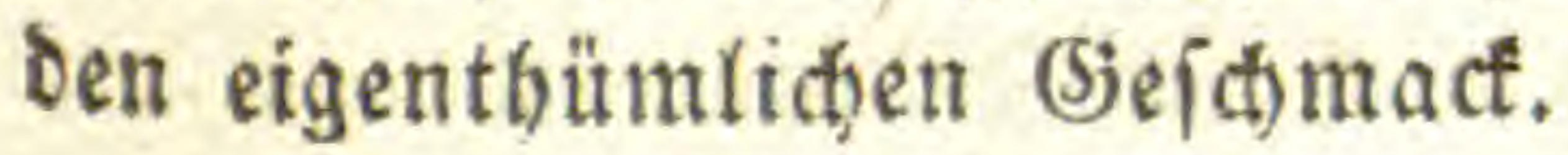

Sie befteht aus 44 Robienftoff, 4 Safferfitoff uno 52 Sticts ftoff, oder $\mathfrak{B}$ thle. 2, 1, 1.

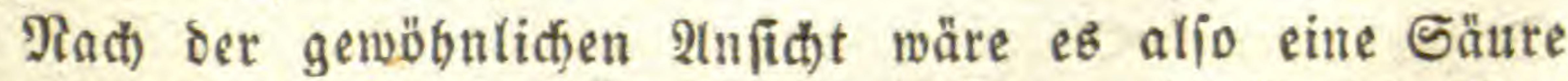
obne Saneritoff: aber biefes ift ein (jrund mebr fitr bie Ser= mutbung, das ber Sticfitoff felbit ein Drno fer.

Sie if befanntlid) eines oer gefäbrlichiten (Bifte, weiches unmittelbar auf bas Rerveninftem wirtt, und bafielbe fait au= genblictlich töbtet. 
c. 3u ben Pflanzenlaugen

gebören die fđarfen Stoffe ber 3wiebeln, bes Meerrettigs, Röfeltrauts, 2trons u.f.m.; ferner die bittern Stoffe in ben iogenannten Extracten Der 2lpotbefen.

Sie fommen in einer Menge Pflanzen vor: Wermuth, Enzian, Fieberf̂lee, Quaíta u.f.w., größstentbeils in ben Wur= zeln, fedo(t) autb) in ben anbern Ibeilen. Ueberbaupt (d)einen

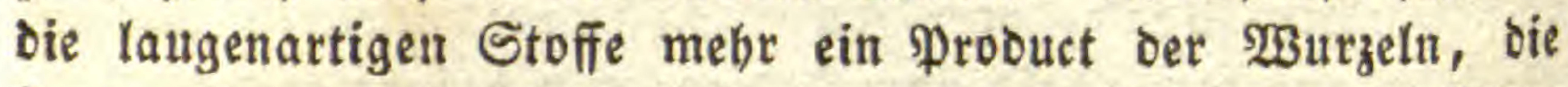
fauren aber ber Frühte z" fenn, wäbreno bie Sarze in Sten: geln, die ätberijhen Dele in Blättern, die fetten Dele in Ga: men vorfommen.

§u ben $B$ itterff offen gebören das Eoffeit, (J)entianil, 2loin, \&upulin aus bem Şopfen, Salicin aus $\mathfrak{B}_{\text {eidenrinde, }}$

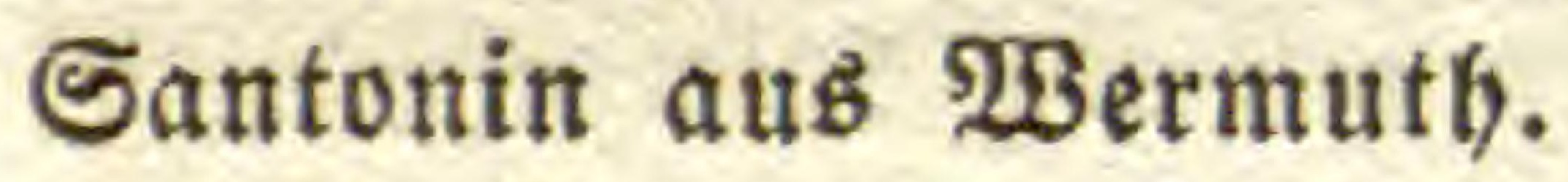

In Der nettern Beit bat man eine Menge Stoffe unter: ihteden, welthe in diefe Reibe gebören, uno fie meiftens mit ber Endinlbe in bezeidnet, wie Ebinin, 2lconitin, Beratrin 4.f.m. Sie entbalten 4-9 procent Stictitoff, ftno meiftens cryifalli: fterbar und fommen bald rein, balo mit 2tpfel= ober (5jerb: fäure verbunben, in aflen Pflanzentbeilen vor, mit $\mathscr{2}$ (usnabme Des Şolzer.

Es find febr nirtfame, meiftens betả ubende Stoffe,

wie bas 2tconitin aus bem Sturmbut; Picrotorin aแs den Socfelsförnern; Morphin im Spium poer Mobniaft, Strydnin

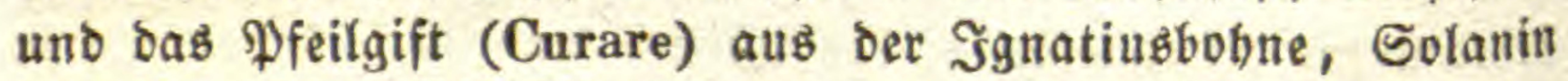
aนร bem Bitter Bella donna, Daturin aus bem Stechapfel, Beratrin aus bem Samen des Sababills, Siermers und ber Beitlofe.

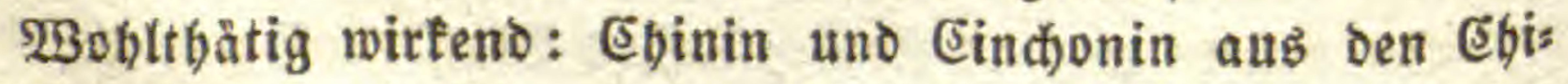
narinden, Rbabarbarin aus Der Rbabarber, Smilacin aus ber Saflaparillmurzel.

Seifenartige Stoffe finden ft(h) in Der $y_{3}$ urzel Des Seifens trautb, den Samen des 2 bocatobaums (Laurus persca). 
6. Inflammabiliens oder brenzartige Pflanzenft offe.

Sind meiffens flitifitge oder ímierige Stoffe, welde ver= brenten, ofhe Durd) $\mathfrak{B a ̈ r m e}$ flithtig ju werben.

a. Şieher gehören vorzüglici) bie fetten Dele, beren es eine grofe Menge völlig gebildet in Den Samen ber meiften Planzen gibt, bejonbers ber jogenannten Delgewäctie mit Sतt)o= ten, wie ben Den Rreuzblumen und bem Mobn; jeboch aud) bey andern, wie bey Lein uno Şanf, bey ben Sufammengefek̆ten, 3. B. Sonnenblumen; aud bey ben Rüfen, namentlid) ber 23allnuß, in ben Samen ber Şajeln, Buthen, Eict)en, Mandeln, Trauben uno ber meiften Rofaceen. Sie finben fids felten in Der S(t)ale ber Früthte, wie bey ben Dliven, woraus man mit bem aus Den Rernen 32 procent Del zieben fann. (Siewöbntlid) fiectent fie in ben Bellen ber Samen, aus benen man fie burd) bloß̧es prefien erbält.

Die vorzitglidfifen find:

a. Trodnende:

Seinöl.

Mohnör.

Şanför.

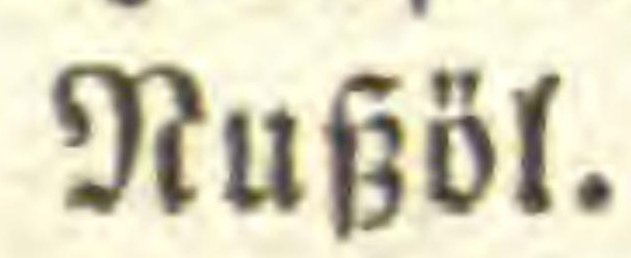

アicinuböl. b. S(i)mierige:

Räpgäl. Baumöl. Mandelöl. Bu(t)enöl.

Das Baumöl beftebt aus 77 א., 131/2 $\mathfrak{B} ., 9^{1 / 2}$ S. Das Reinöl aus 77 א., 10 $\mathfrak{3}$., 121/2 ธ.

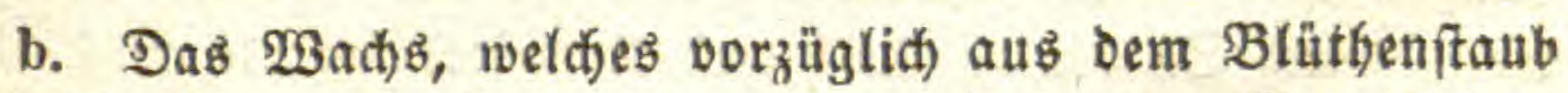
burd) Die Bienen bereitet wird, ift eine Art von veftem Del.

(Es finbet fith (eboct) aud) idton völlig gebilbet in veridjie= denen PFlanzen, wie auf ben Blättern ber $\mathfrak{B a d j e ̨ p a l m e ~ ( C e r o - ~}$ xylon), Dę (jagelı (Myrica), im Safte des fübbaumb (Galacto-

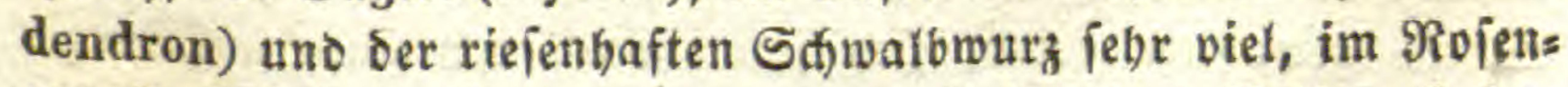
und Ravendeföl. Man redinet aud) bieber ben Reif auf ben Frủchten, bejonders ber 3 wetíden, auf ben Foblblättern. Das Bienenwacks bejtebt aus 82 א., $12 \frac{1}{2} \mathfrak{3}$. und $5^{1 / 2}$ S., pder 


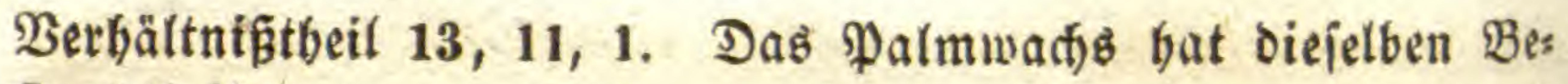
ftandtheile.

c. 2(ud) talgartige Subftanzen fommen in ben Samen ber Pflamen vor, Die Eacav=Butter, હосовиn $=$ Butter.

\section{Erzartige Pflanzenttoffe.}

2lle Farben bes Mineralreids fommen von Metalleals Gen ber, und man mus bemnad) annebmen, baß die Jarben= ftoffe ber Mflanzen in ber Bebeutung ber Metalle fitehen. Der

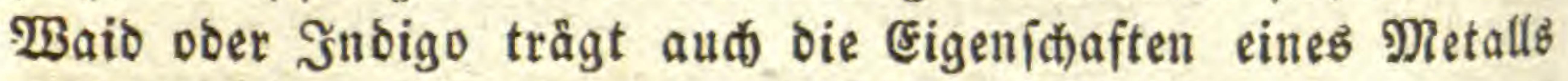
auffalleno an ftat). Farbe uno ઉ̧lanz lafien ihn faum vom supfer untericheiben.

Die Farbenftoffe finden fid in allen Theilen ber Pflanze, jebod) am reiablyaltigiten in Stengeln und $\mathfrak{W u r z e l n , ~ o b j o b o n ~ f i e ~}$ aud) in ben Blumen unb Früt)ten nid)t feblen, aber wegen ber Rleinbeit Diejer Iheile in geringerer Menge vorfommen, uno

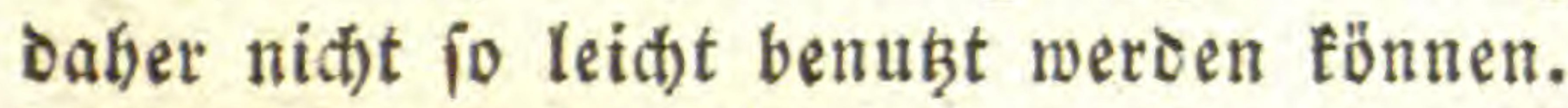

a. Der allgemeine Farbenitoff ber Pflanzen if bas joge

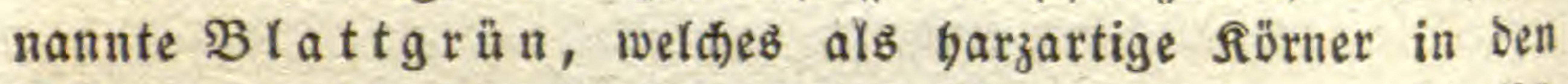
Bellen unter ber Dberbaut enthalten ift, fid) aber gewöbntich erft grün färbt, wann bie Pflanje ans Tagélid)t tommt. (5) ift unauflöblic) im $2 \mathfrak{B a f f e r}$ aber auflöвtich) in Weingeift, ätbe: rijhen uno fetten Selen, \&augen uno Säuren, uno beftegt aub viel Soblentoff, 'Bafleritoff uno etwas Saueritoff. Es ift offen: bar fehr veränderlid), indem die gelbe uno rothe farbe ber Blätter im Scerbit, fo wie der Früchte, davon berrübrt. MRit Qaugen verwandeln fid) biefe Farben nieber in (3ritn, fo wie

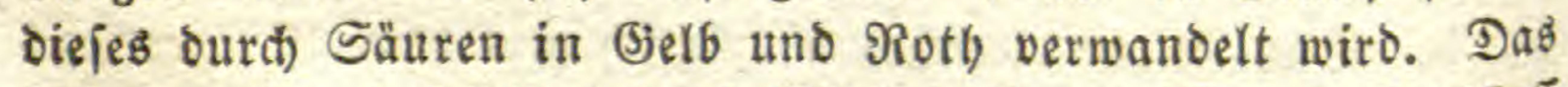

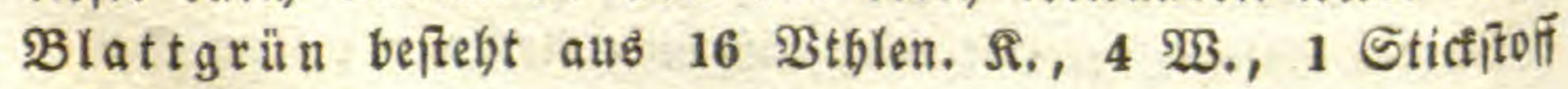
uno 2 S.

b. Die vollfommenfte Farbe ift Der $\mathfrak{B}_{3}$ io oder Inoigo, welcher aus Stengeln uno Blättern ber JnoigD-\$Flanzen uno beg Waibs gewonnen wird, fich jedod) autd bey andern Pflanzen finbet, $\mathfrak{z}$. B. bey einem Dleanber (Nerium tinctorium), einer Sd)walbwura, einem Snöterid) und mehreren Sdimetterlings: pflanzen. Mlan gewinnt am meiften zur Beit ber Blütbe, unto 


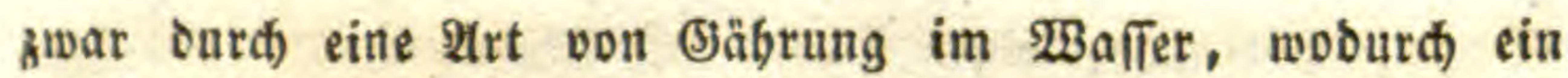
Teig entifeft, in bem 45 Procent $\mathfrak{3 a i o}$ entbalten finb. Er ift ein bunfelblaues ins purpurrotbe iffimmernbes \$ulver, un=

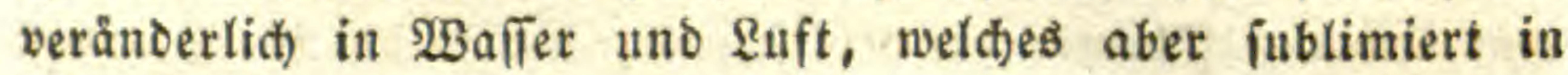
nadelförmigen Eryjtallen anjodiefst.

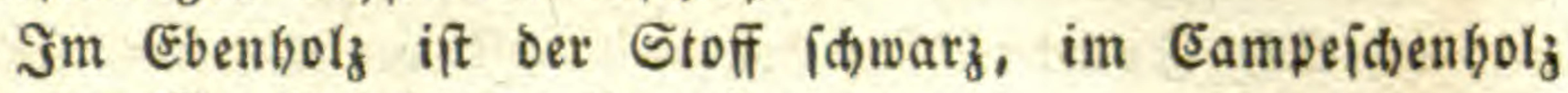
rotb, im Maulbeerbolz gelb u. f.w.

Das rothe Seämatin tommt aus bem Campeithens ober Blaubolz (Haematoxylon).

Das Braftin aus bem Fernambuc= und Brafilten = (Caesalpinia).

Dab Santalin aus bem rothen Santeltgolz (Pterocarpus).

Das gelbe Morin aus bem Ëelbbolz (Morus tinctoria).

Då̉ Bifetyola von einem Sumad) (Rhus cotinus).

In ben Rinden finden fid viel megr Farbenftoffe, als in $\mathrm{SgOl}_{2}$.

Das Duercitrin fommt von ber Quercitron=Eid)e (Quercus tinctoria) uno ift gelb.

Bey Den Streifenpflanzen fommen wenig Farbenitoffe vor. Das rothe Dradenblut im Seolze bes Dradenbaums (Dracaena), Der Rotange (Calamus draco), aber aud aub siner शrt Santelfolz (Pterocarpus).

c. Das Drcanetin if bunfelroth, uno fommt aus ber $\mathscr{2}$ urzelri n be ber unåđten 2 lleanna (Anchusa tinctoria).

Das Srapprotb ober Allizarin tommt aus ber $\mathfrak{B}_{3}$ żelrinbe Der Färberröthe (Rubia).

Die gelbe Eurcuma aus ber Eurcumanuzzel.

d. 2(uc) aus ben $\mathfrak{B} \mathfrak{1}$ men werden Farbenftoffe gewonnen. Der rothe Safflor oder Das Earthamin aus ber Blume uno den Staubfäden des Safflors (Carthamus tinctorius). 1000 Theile geben 244 Farbenftoff, unauflöslic) in $23 a$ fifer, aber auflöళlid' in $\mathfrak{B}$ eingeift, übrigens wenig Galtbar.

Der gelbe Saffran oder bas Polyd)roit wird aus ben Rarben bes Saffranz (Crocus) aub̆gezogen, etwa 60 Procent, auflöglith

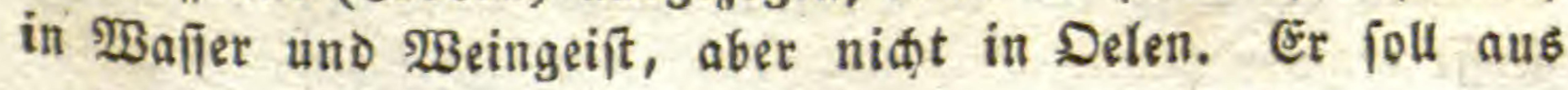

Diens allg. Naturg. II. Sotanif I. 


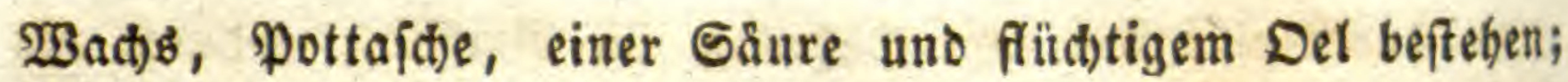
idmectt bitter uno ried)t angenelym.

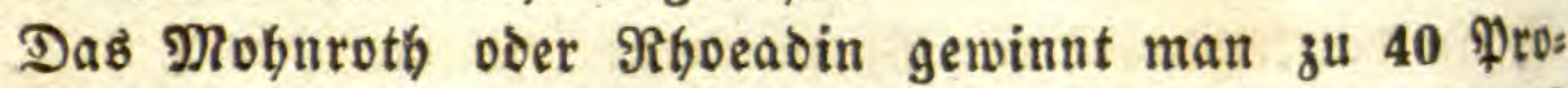

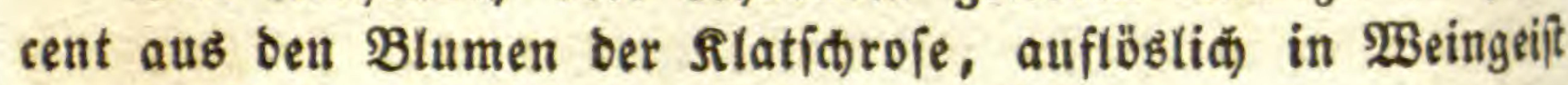
uno Sătren, wiro aber burdi Laugen fatwarz.

e. Die Frudtiäte fommen mit veridiebenen Farbent vor, weldie aber nidit baltbar fino, uno baber in ber Färbe rey wenig gebraucbt werben. Den $\mathfrak{B}$ ein färbt man betanntlif mit Şeibelbeeren u. cergl.

Das fogenannte Saftgrün forme alts ben Frillftent eines Rreuzoorns (Rhamnus infectorius), weldee unter bett Namen 2 toignon = Sörner befannt fino.

Die Rermesbeeten (Phytolacca) geben eine idtöne rotbe Farbe.

f. Bey ben blumenlofen Pflanzen fommen jebr wentis Farbenftoffe vor, mit 2tusnabme ber Fledten, welde bie rotbe Orseille liefern, wie man glaubt Durch Einmirfung Der Euft uno Laugen auf eine harzartige Gubitanz. Der eigentlide Farbenftoff beifst Drcin. Er ift farblos, auflöslid), wiro burd) Salpeterjäure roth, an ber atmoiphärifiten \&uft uno burd

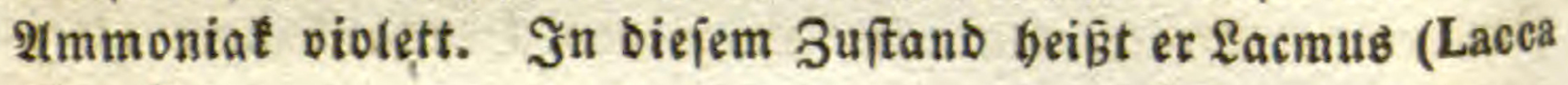
musci).

E્s witb aus verifiledenen Flecten gewonnen, bejonbert Roccella.

2. Bufammengefegte Dflanzenft offe.

Diefe Stoffe tbeilen fid) in allgemeine uno bejondere.

Die allgemeinen find in ber ganzen Pflanze oder wenigitent in ganzen anatomifon Syitemen entbalten; bie bejonbern in

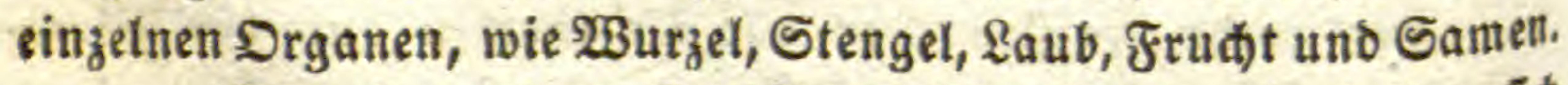

a. Die allgemeinen fino fämmtlic) Sảfte uno theilen fith in Rabrungs = uno 2ibjonberungs[äfte.

1. Die Rabrung

fino entweder in ben 2(bern enthalten ober in ben 3 ellen,

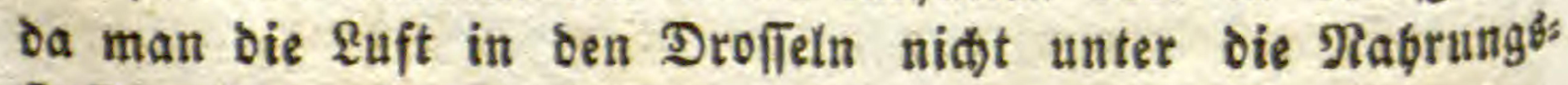
ftoffe redinen tann. 
Der Saft in ben 2roern ober Intercelfufar = (3ången ift ber

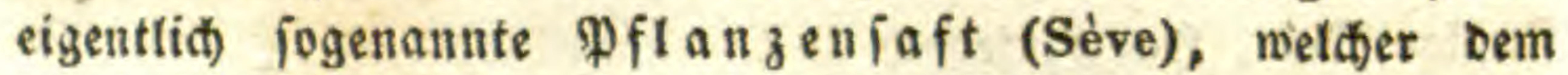
Blute Der Thiere ober vielmebr ibrem Mildfaft in ben Inmph= gefäben entipridt. Er ift in Der ganzen Pflange entbalten, weil es überall Intercellular = Bänge gibt, uno ift berienige Saft, welder außftiest, wenn bie Bảume angebohrt werben.

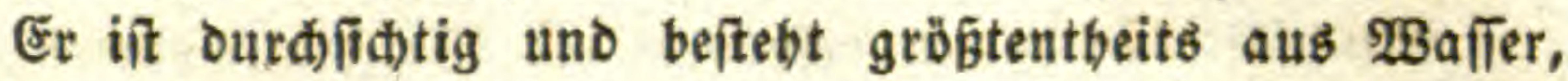
weldem allgemein Sdbleim bengemengt ift, gewöbnlid aud Stårfe, Bucfer, Săuren uno Salze.

In Diejem $\mathfrak{W a f f e r}$ muß man ben Sdjleim als ben eigents liden Nabrungsftoff betradten, noraus alle andern Stoffe nad) und nad) gebildet werben.

Eäpt man ben Saft ftehen, jo geht er wegen peines Sucfer= gebalts in Weingäbrung, balo barauf in Eifitggäbrung äber.

Unten im Stanm ift der Saft leid)ter uno mithin wäfịe riger als höber oben, ohne 3weifel, weil fi் ihm allmäblid Die ourch bie Berbaung in ben Bellen entifandenen Stoffe benmijtent, aber woh! nidht bie an genifien Stellen, nebmlich in Riucten, abgelagerten, alio aus oem Lebengprocelie ausges idiedenen Stoffe.

Unterwegs wirb er aus ben Spiralgefä̧en oppoiert; in ben Blättern zerieg̨t oder auछgedünitet, woourd) oie näberen $\mathfrak{B}_{e=}$ ftandtbeile immer zunegmen, uno fich enolid) in ber Frudt und im Samen fo angäufen, daß̧ fie veft eríteinen, wie in Mebl.

Den Zelleniaft fann man von bem allgemeinen Rabrungs= laft wobl nur in fo fern unteritheiden, als in ibm bie eigent=

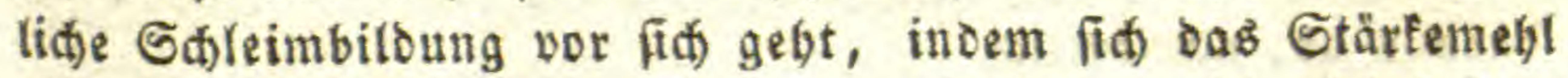
bilbet uno zum $\mathfrak{T}$ geil als Rörner ausjdeibet, weldhe fid fpäter

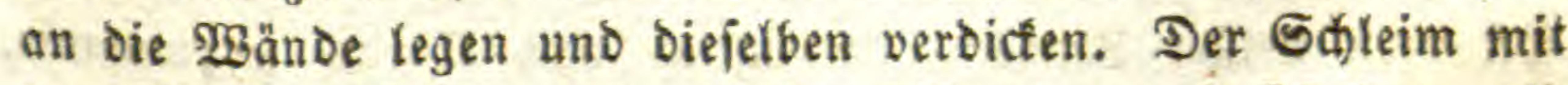

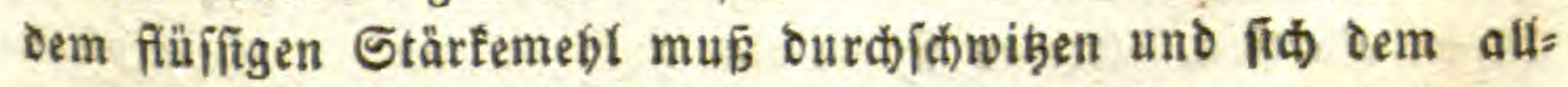
gemeinen Safte beymijahen.

2. Die 2 bionoerungsiäfte

fino bie jogenannten eigentbümliden Safte, welde in ă jammenbängenden, Durch bie ganze Pflanze taufenden Rücten enthalten fint.

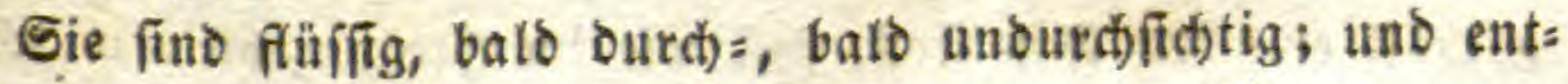


balten viełe nåbere, gewöbnlid) bešorubierte Beftanttbeile, wie fliffitge Dele, Sarze, jedoch aut) (5ummi.

Die Mildfiäfte find gefärbt uno zwar meiftens weiß,

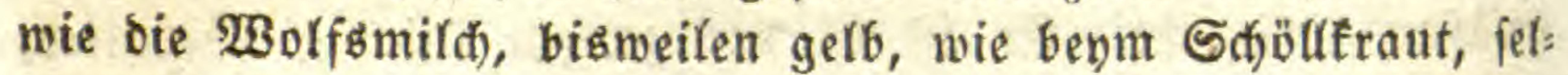
ten roth, wenn man nicht etwa bie Jarbenftoffe als vertroffs nete Mil(t)jäfte betrad)ten will.

Milchjäfte enthalten bejonders bie $\mathfrak{B o l f z m i l ( \hbar z a r t e n , ~ d i e ~}$ Galatpflanzen, Bloctenblumen, Schwalbwurze, Mobne, Jeigens und 2iron=2(rten. Sie find jelten bey den Satheibenpflanzen, uno fommen bey ben blüthenlojen Pflanzen gar nidst vor, went man die Milch Der \$ilze nidht Dabin red)net. Sie fließsen nidt von felbit aus, uno man gewinnt fie baber outch Einfounitte in die Rinbe. Indeffen bedarf es bey ben Satticharten nur eines Streidbelns ntit eituem Şaar ober einer darïber lanfenden Ilmeife, um Tröpfden aus ber sberbaut iprizen zu ieben.

Der Milctjaft fommt auth in ben $\mathfrak{B u r z e l n}$ vor. Bey verbleiditen Pflanzen verminbert er fid).

Sm Ganzen fann man biejen Mildsjaft betrad)ten als ein Gemenge von Waffer uno Gummibarz oder fludjtigem Dol. Sie find eine 2(rt Mandelmild), uno erbalten bie fremben Stoffe in unförmlitien Rlümp(t)en uno $\Re a d e l n$, mitbin in uns organiffen Formen. Das ätherifthe Del ober bas Gummi unt Şarz fociben fith gewöbnlich won felbit aus.

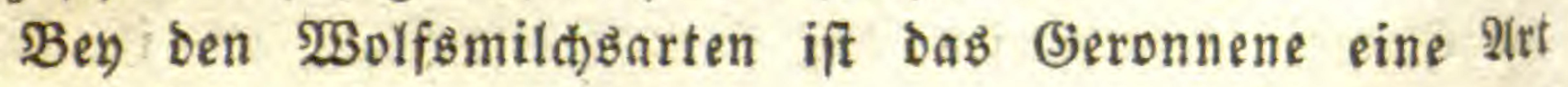
(j)ummi $=$ ફ̧arz.

Ez jegen fict) aber auch andere, ganz eigentbitmlide Stofit baraub $a b$, namentfict)

Feberbatz (Gummi elasticum) atts fehr verfófiedenen Pflanzen heiß̨er sänoer, vorzüglici) aus Hevea guyanensis, Ficus elastica. (Etwas findet fich aud) in unjern Salatpflan

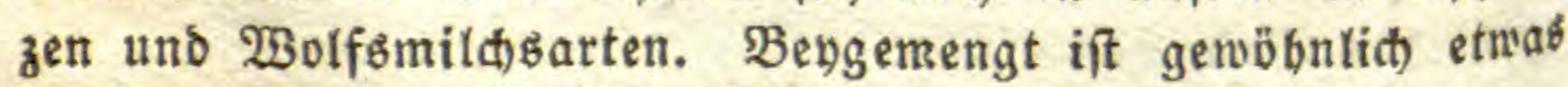

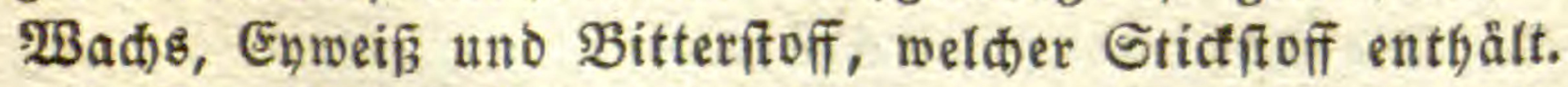

Der Mrobniaft enthålt Dpium, wovon auch etwas in Eas latpflanzen vorťommt.

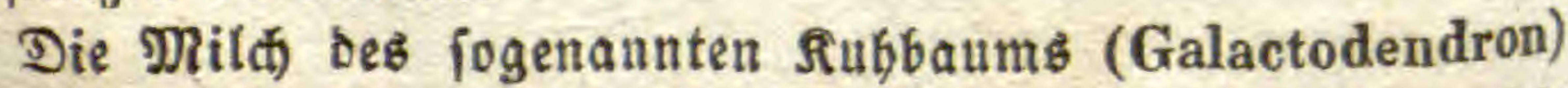

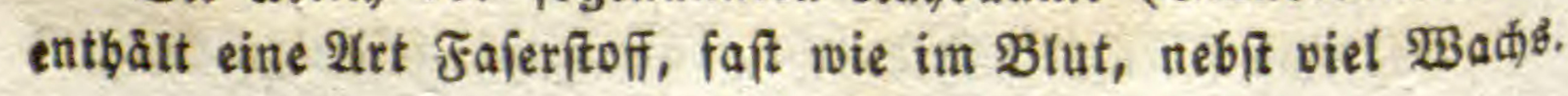


Das Sdjölleraut hat gelben Saft, eine pflanje in Roro= america (Sanguinaria) rothen.

b. Die befondernzuiammengefezten Stoffe

fino jämmtlich nabrbaft, uno theilen fich in flüiffige uno vefte.

1. Die flüfigen finden fich) vorzügliक) in Den Frü̈bten, unb beisen Fleifh, wenn fie in ber Bellenmaffe enthalten find, wie bey ben 2lepfeln, Pflaumen, Erbbeeren n.f.w.; Marf

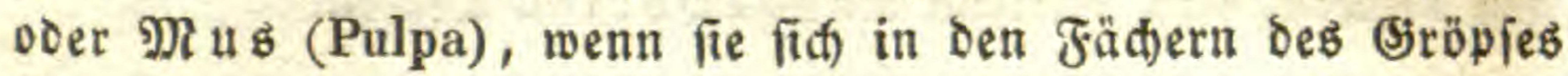

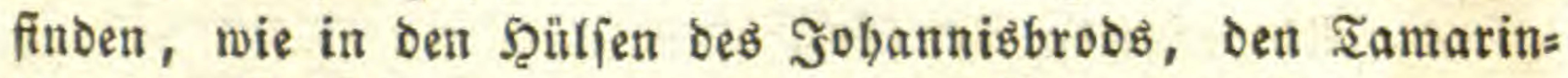
oen, Den Eapfetn ber Quitten, Paifionsblumen u. f. w.

Das Fleifh) beftegt gewöhntich aus viel Saldeim, Bucter uno Sătren, entíält aud) oft (Gallert uno etwas Enweis; böchit felten giftige Stoffe, weld)e bäufiger im Stengel uno im Samen ftecten bleiben.

2. Die veften Rabrungsiftoffe find faft ourdgängig Mebl, welches fich balo in ben $23 u r_{j}$ eln fammelt, wie in ben Fnollen ber Eroäpfel, Erobirnen, Eroeicheln, Der Manioca, mander 2tronarten; bald im Stengel, wie daz Sagomehl ber Palmen; bald im Samen, nebmlid) Dả logenannte Eyweí,

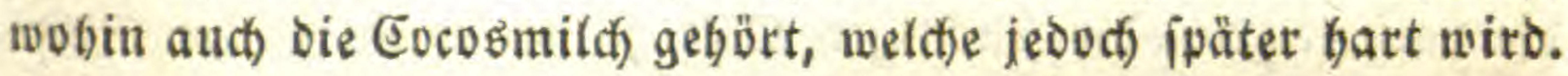

\section{Brattibarteit ber Stoffe.}

Man Eam bie Stoffe aud betrad)ten binfiditlid ibres Rukens für die Pflanze. Die einen werben zur Entwistelung Der ganzen Pflanze voer bejonderer Tabeile, wie bes Samens, verwendet, bie anderen bagegen aubgejdieden und nicht wieber jeriezt. Die eríteren find:

\section{a. $B$ raudbare Stoffe.}

Dabin gehört ber allgemeine Pflanzenfaft uno mithin Sdleim,

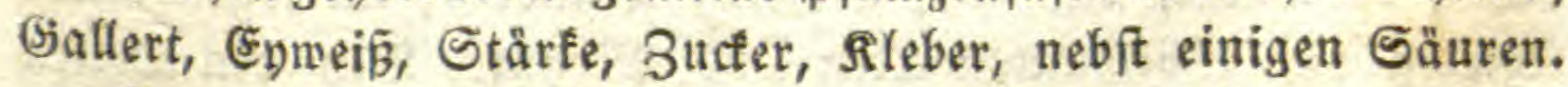

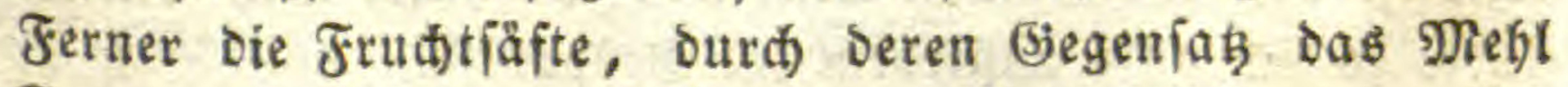
ber Samen gebilbet wirb. Endidi bas Megl jelbit, wo es fíd finten mag.

(Es gibt aud fold)e Shle im=21 n fa mmlungen, wie in ben veroicten 23 urzeln oer Rüben, פühren, Sdwarzwurzeln, 
Des Sellerie u. Dgl.; in ben finollen ber finabwurzen atz Sas lep, in ben Stengeln bes אiohls, Der Spargeln, in ben Blit: thenif)uppen ber $2(r t i j$ thocten.

Ënolid) gibt eb viele íleinige Samen.

\section{b. Unbraudbare Stoffe.}

Dabin gebören alle wabrbaft ausgeíliedenen Stoffe, welde balo bloz a bgeje $5 t$ werden, uno baher in oer Pflanze lies gen bleiben, bald wirflid) a u geworfen werben.

\section{Abgeiente Stoffe.}

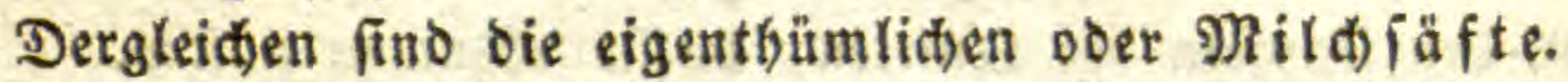

Gerner bas ätherif de Del in ben Rippenpflanzen, Mint= ten unb vielen anberen.

Die 5̧arze im Rabelbolz, wo eb bey Rillen ober Eitt: (千)nitten ausfictert und vertroctnet.

Der Balfam in den Baljambäumen, welder aus ફ̧arz unb Benzoe = Säure beftebt.

Sn ben Reben, Rinden und AfGornarten findet fid vorzügs: (id) Osummi.

2Ule dieje Safte fommen in bem gauzen Pflanzenftodf vor; bie barzartigen ober flüdtigen Dele jeood) mebr in ber Rinbe

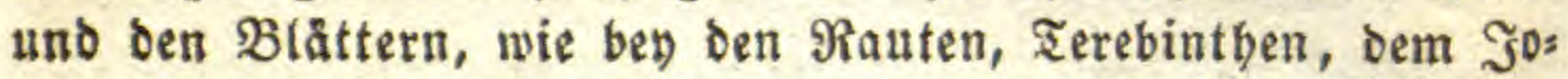
bannisftaut; in bem Rethe bey ben Doldenpflanzen; in ber Frudtíf)ale bey Den Eitronen; felten in ben Blumen, wie ben

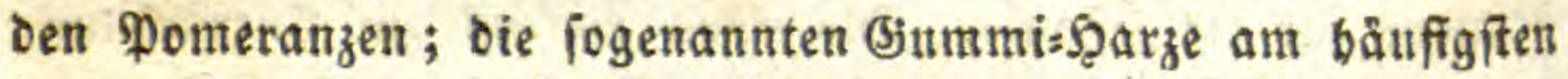

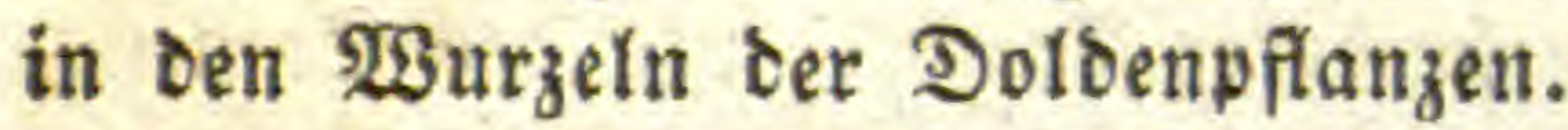

3u ben befonderen 2(usfheidungsiftoffen Eann man rectnen bie fetten Dele, welde faft nut im Jnnern ber Samen vors Commen, bejonders in ben Samenlappen ber Sreuzblumen, bes

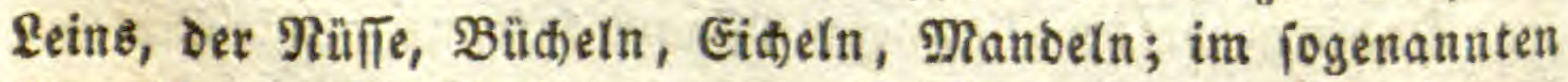

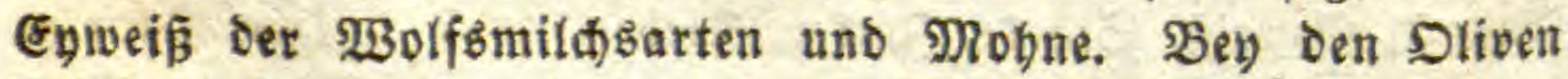

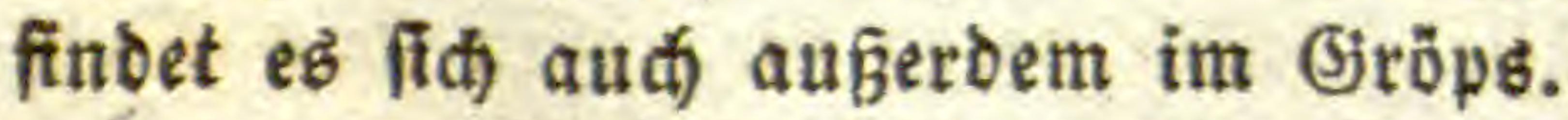

(Ein feifenartiger Stoff fintet fid in ber $\mathfrak{B}_{3}$ urzel Des Seis fenfrautb, und in ben Samen bes 2 vosato= Baums (Laurus persea).

Der Gerbft off findet fid in Der Rinbe vieter Bäume, 
bejonders ber Nekspflanzen; fehr jelten bey ben Sheibenpflan= zen und ben Farren.

Die Farben ft offe feß̧en fich) größtentheils im Snnern,

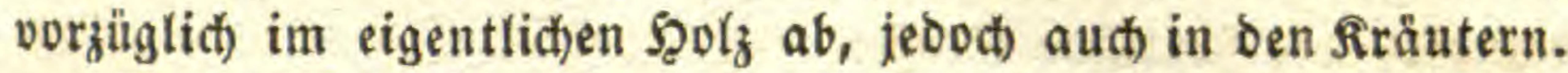

Das Mark ober Mus im Snnern ber Eapjeln; ber $\mathfrak{B} 0$ gelleim in ben Beeren der Mijtel.

F̧ierber gebören ferner bie biftîtoffe, bejonders die betäu= benden, wie im Bilfentraut, Iolleraut, Stedjapfel, Iabact.

Mande Săuren uno igre Salze, wie Sauerteejalz.

Endlid Die laugenartigen Stoffe in ben Zwiebeln u. f.w.

2. 3 u Den $\mathfrak{A}$ us w $\mathrm{r} f \boldsymbol{s}$ ti offen

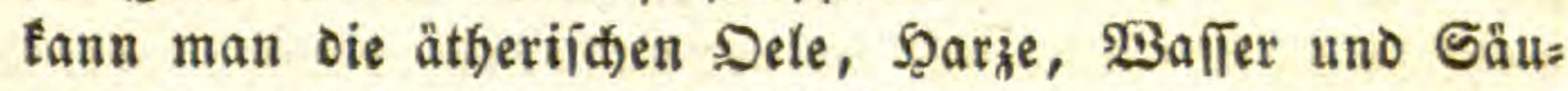
ren, etwa aนd) ঠав (5) rechnen. Die meiften dünften oder iđtwiken von jelbit aus ber Dberfäche, wo fie bavon geben oder verbärten.

Sie theilen fith in luftige oder flüfítge.

a. 3u ben ausbünftenden Stoffen gebören vorzüglich die Riedjtoffe ber Blätter und Blumen; benn bas augbünitende IBaffer und bie Rohlenfäure fann man nicht wohl zu abgejon= Derten Stoffen redinen. Der Diptan dünitet fo viel ätherifdes Del aus, dấ man es an warmen 2lbenden anzünden fann.

Der ftinfende Gjansfun (Chenopodium vulvaria) dünftet foblenfaures $2(m m o n$ aus; ber Efifigbaum 2tpfeliäure; bie EFs figrofe eine nod) nidft betannte Säure.

Pflanzengerübe.

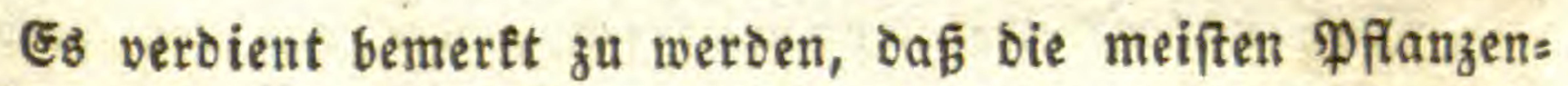
gerithe angenebm, bie abiergerüthe bagegen unakgenebm find, Bifam, 3ibeth uno 2 mber faum auggenommen. Es fommt wabrideinlid baher, baß̄ bie Thicrabjonberungen unter bie

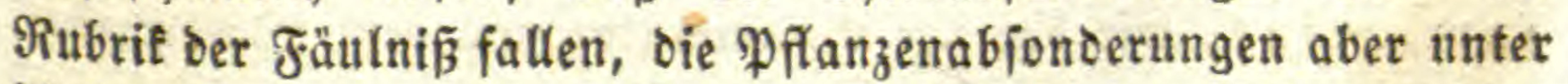
bie ber Säbrung; jene aljo dem $\mathfrak{W a f f e r}$ in ber Eroe ober ber

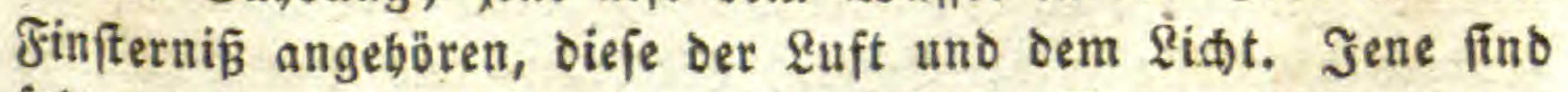
fefr zujammengejegter uno meift alcalijher Ratur, bieje bagegen einfacher Matur: Såuren oder \$̧arze, aljo cigentlich zerjeşte Stoffe, wäbreno fle bey ben Thieren ungeidieden bleiben, uno baber 
Eeinen beftimmten Gharacter Gaben. Die wenigen fintenten Stoffe ber \$flanzen, wie die Summi = Scarze, find ebenfalls ein (5emeng, weldes fich in ber Wurzel abjeght uno bajerbft vers bumpft, wie faulende Stoffe.

Eine wejentlide (Eigenidtaft Der SRied)ftoffe ift obne 3weifel, Das fie in Der \&uft auflöslid), aljo flübtig find, uno einen entidiebenen electrijden હbarafter haben; benn indifferente Dinge, wie \&uft uno $W_{B}$ fifer, wirken nicht auf bie Raje. Sie follten bafer wobl nach ibren electrifhen Eigeníf aften eingetbeilt weta Den. Da man aber biejelben nod) nicht fennt, fo mus man fid) mit ibren chemificen aubbelfen, und barnach tan man fie woht in opydierte und in reoucierte, barzige voer ätbes rijiche eintheilen; die opboierten in faure und langentafte. Diefes wären einfache (serüh)e, welche ben mäßjiger cinmirs fung angenebm find. Ess gibt aber audi unangenebme ibrer

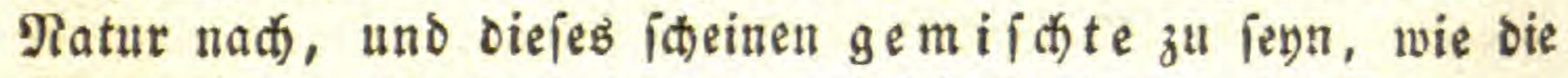
(3ummibarze, bie betäubenden uno die faulenden Stoffe.

1. Die reducierten Geritde theilen fid) wobl am beften in barzige uno weingeiftartige.

Die reztern fino nidt zablreid und entftehen wohl erft ourd) die (jäbrung. Man hat zwar wobl befauptet, es fänoe

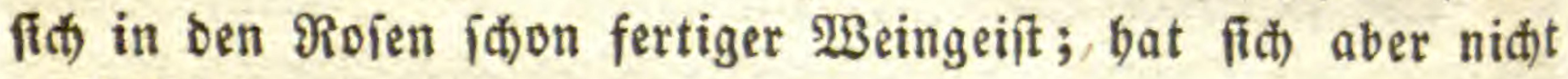
beftätigt.

Die barzigen fommen wohl fämmtlich) von åtherifothen De= len ber, und find burdygångig angenebm.

Man unterídeidet aromatifit)e, wie bey ben Rorbeer=

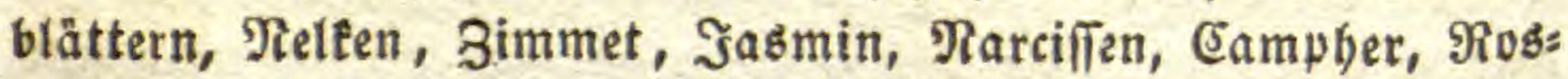
marin uno ben Rippenblumen überbaupt; ourdoringende bey den Rinbenblüthen und Tuberofen; $\mathfrak{a} \mathfrak{m b}$ rofifthe oder $b i$ fa martige, wie bey Der Bifammalve und dem $23 a l d m e i f t e r$.

2. Su den fauren Gierüden gehören alle Såuren, bes

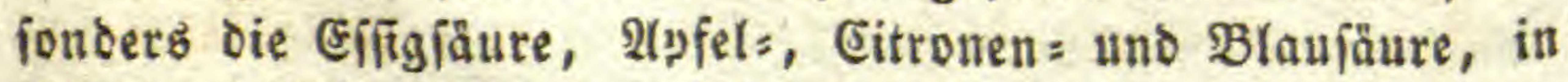
Blumen, $\mathfrak{B l a ̈ t t e r n ~ u n d ~ F r u ̈ d ) t e n . ~}$

Bielleidst aud bie balfamifden, welde ätherifo und jauer zugleidy find, wie Benzoe. 
3. Zu ben alcalifdien gebören Swiebeln, Fnoblaud, Meerrettig, Senf u. f.w.

4. Su ben gemifaten fann man alle unangenebmen ftellen, bie betäubenden verichiebener sräuter, bie fintinenben Dilze, und aud gewiffe Şblzer, wopon man ben (jrunb noch nicht fennt - Stintholz.

\section{b. Flitifige.}

Ës gibt aud eine wirklliche 2 fbjonderung von $\mathfrak{W}$ affer, welches aber immer einige Beftandtbeile entbält, wie Sdleim, 3ucter oder Säure. Das tommt tedod nur bey einzelnen Pflanzen, und an bejondern $\mathfrak{T}$ beilen vor, wie das $\mathfrak{Y a}$ affer im Raunenfraut, die Sauerfleefäure an ben Şaaren Der Rithererb= fen mit 2 lpfel = uno Eifigfäure.

Die Reffeln jondern an ibren Şaaren einen äß̧enden Saft aนเร.

Aleberige und fdmierige Stoffe werben ausgefondert von Dem Şornfraut, einigen Sathlilfelblumen, 2tcacien, Den Snofpen ber Pappeln, Rof́caftanien und vieler anderer, Der Rinde

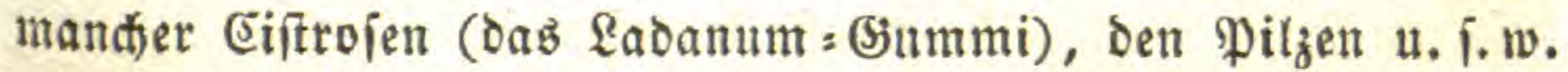

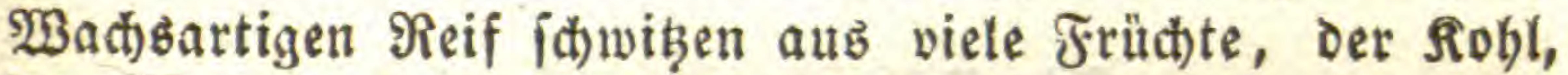
die Melden, Pappeln; $\mathfrak{B a d b}$ felbit mebrere Palmen auf Stamm uno Blättern, ber Gagel auf Den Früc(b)en.

Mit Saleim fint cie meiften $\mathfrak{B a f f e r p f l a n z e n ~ b e d e c t . ~}$

2uf ben Stranopflanzen zeigt fid oft ein Bejhlag von Salz; auf ben 2(échen won Manna.

5̧onigiafte werben endlid) in Menge von ben fogenann= ten Şonigorïlen abgejonoert.

Man bat aud) eime allgemreine $2(u s$ fonderung an ber $\mathfrak{W}$ ut $\mathrm{t}=$ zel aller Pflanzen angenommen, weldte-ungefäbr ber J̦arnab= fonderung Der Thiere entipräche. Dieje Ausjonderung foll

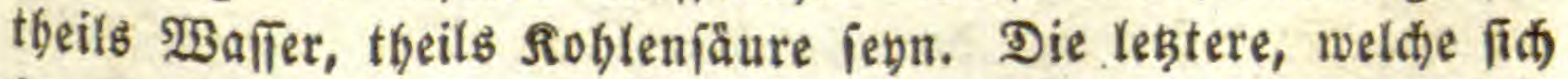

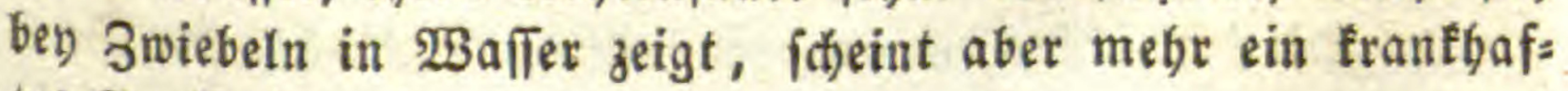
teछ \$roduct zu jenn.

Sieht man 13 urzeln, bejonderz vom (jetraibe, aus bem $\mathfrak{B}_{0}=$ Den, fo bleiben Erdeförner an ben వajern hăngen. Allein daß 
Faftreidge Drgane aud) auf ibrer Dberfäd) feutht find, ift nas tïrlich), uno fann unmöglich einem bejondern Procefie zuges (d)rieben werben.

Endlid) bat man bemertt, baß mandi)e Pflamzen nid)t ne: ben einander gebeiben, und biejes ebenfalls auf einen ithoblis

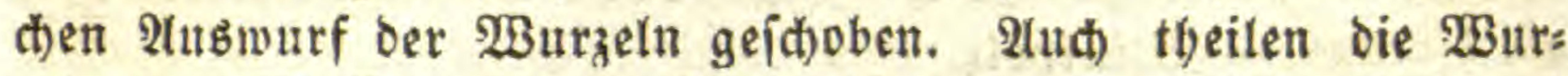
zeln bem $\mathfrak{W a f f e r}$, worinn fie wadjen, etwas von ibrem (jernd uno (5)eidimact mit.

Da iber ber Erbe allerley Stoffe aubifinwiben, fo ift nidgt

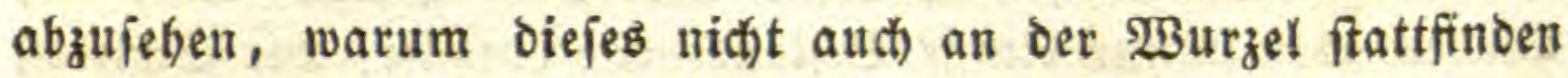
foll, bejonders ba ber Saft burd feine Sdwere nad) unten ftrebt. Da aber bie \$urzel, als ein Drgan im Finftern uno

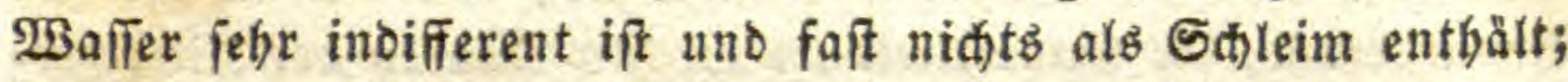
fo ift $e^{B}$ begreiflict), baß̧ fie nur wenig ausicheidet uno nur

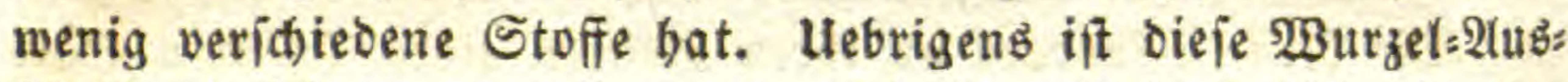
fiheioung Éeineşwegs allgemein, unb fann baher nict)t als eine wefentliche Rebenzverridjtung der Pflanzen betractitet werden, wie bie Sarnabjonderung ber Ifiere. Selbit bie Ilbjonderungen in ben Drganen an ber \&uft gefören niat zum Rebensprocé, injofern fie blós einzelne Stoffe betreffen.

\section{Die $\mathfrak{P f l a n z e n g e f d ~ m a ̊ ~ c t e ~}$}

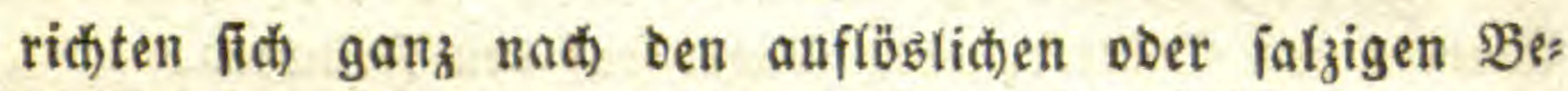
ftanbtbeilen ber Pflanzen, weil Das Samecten felbit nidbts ans Deres ift, als Ëmpfinoung Der chemi chen Einnirfung, welde Durd) bie 2 uff(b̈glid) êeit ber Stoffe beoingt ift.

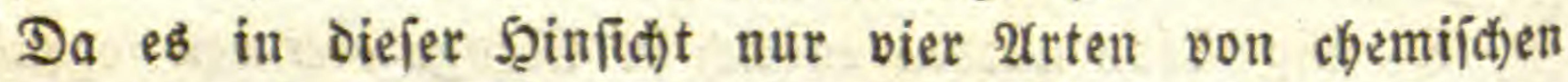
Stoffen geben fann: faure, laugenbafte, farzige und indifferente,

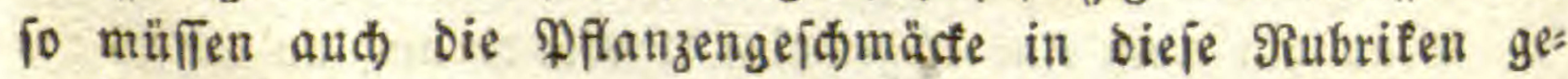
theilt werden.

Die inbifferenten (5ejđmäcte gebören ben eigentliden Epeis fen an, bie differenten ben Giewitrzen.

1. Die indifferenten oder milben Seichmäcte der Speis

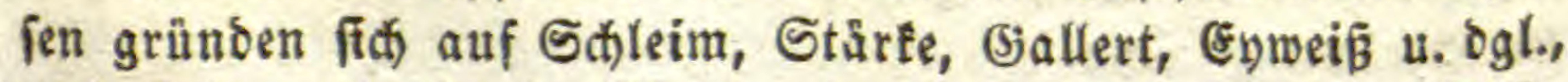
uno find vorzäglid im Miegl mit einanter verbunben. Diffe rente (5eidmäcte fudit man ourd) Berbleiden indifferent $z^{u}$ 


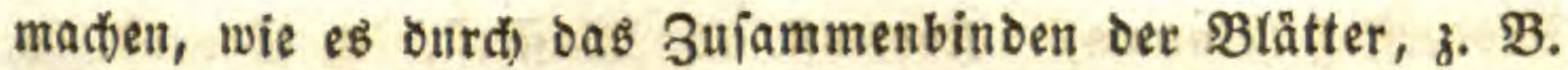

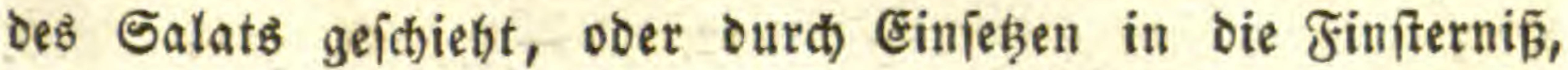

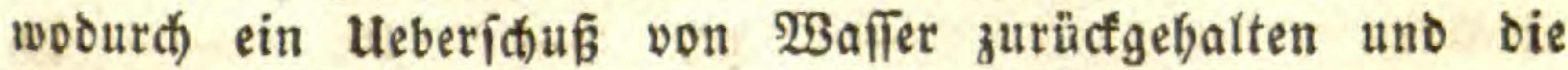
Trennung ber Stoffe verbindert wird. Man bebect mandi)e

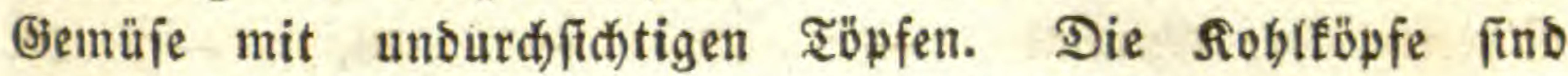
gleichjam von felbit zugebunden, uno bleiben baber weis. Die biden $\mathfrak{B u r z e l n}$ und Snollen find Durd) Die Frbe por Der Fin=

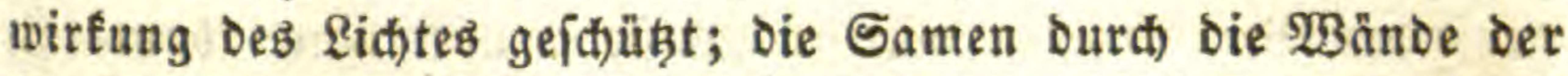
Eapiel oder Den Reld). Mand)e Pflanzen bleiben aud) Durd)

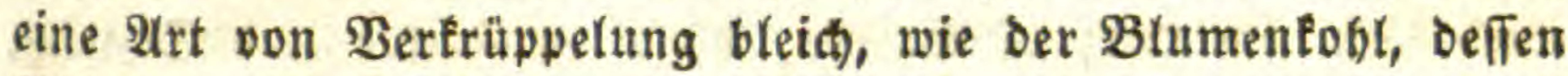
Blithenzweige anid)wellen.

Siele Pflanzen werben jung gegefien, weil fie bleich aus oer Erde fommen, wie Spargel, Şopfen, Salat u.f.m.

Pflanzentbeile mit Differenten Stoffen bienen grögtentbeils

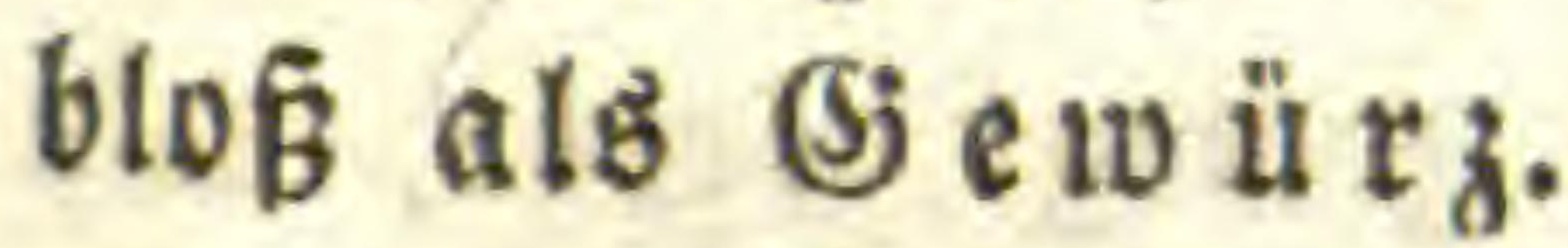

2. Sauer if vieles Dbft, wie Aepfel, Jobannißbeeren, Eitronen, Sauerbonig $u$. ogl.

3. $\mathfrak{l} a \mathfrak{u g}$ nbaft oder itharf ftud bie eigentlid fogenann= ten (jemürze, wie Rümmel, Pfeffer, Эngwer, Bimmet uno viele

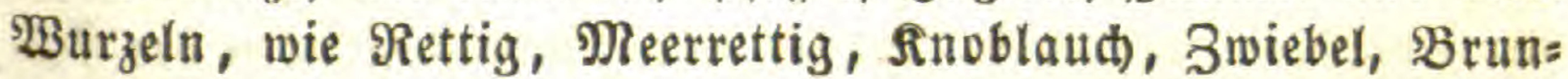
nentrefie.

4. Zu ben falzigen ober neutralen Giejatmäcfen muf man die füben voer zudferbaltigen Früchte fteflen, wie die Birnen, Ririđen, Simbeeren, Erobeeren, Melonen, Irauben, \$̧onig u.f.w.

\section{Ebemifde Proceffe.}

Es bandelt fid) bier nur son benjenigen Procefien, welde zwijhen ben allgemeinen Pfíanzenitoffen, wie Şolz, Stärf̂e, Bucter, Summi oder reinem Pflanzenjableim uno Iraubenzucter

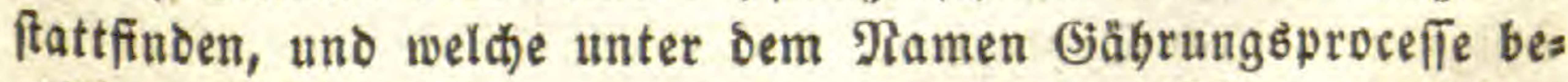
griffen werben. Man untericheibet zunächit geiftige, bie efifigs

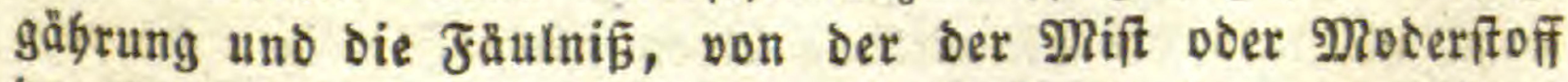
Das Ende iff. \&o wig itellt in feiner Ebemie ber organifiden Berbindungen 1839 diefe $\mathfrak{B}$ orgănge auf folgende 2lrt Dar.

Die verbältnißmäbigen Beftanbtheile der genannten Stoffe find folgende: 
Moderitoff (Humus) Soblemít. 12, פ3afferit. 6, Sauerit. 6. Şolz

Stärf̂e

Robr $=3$ ucter

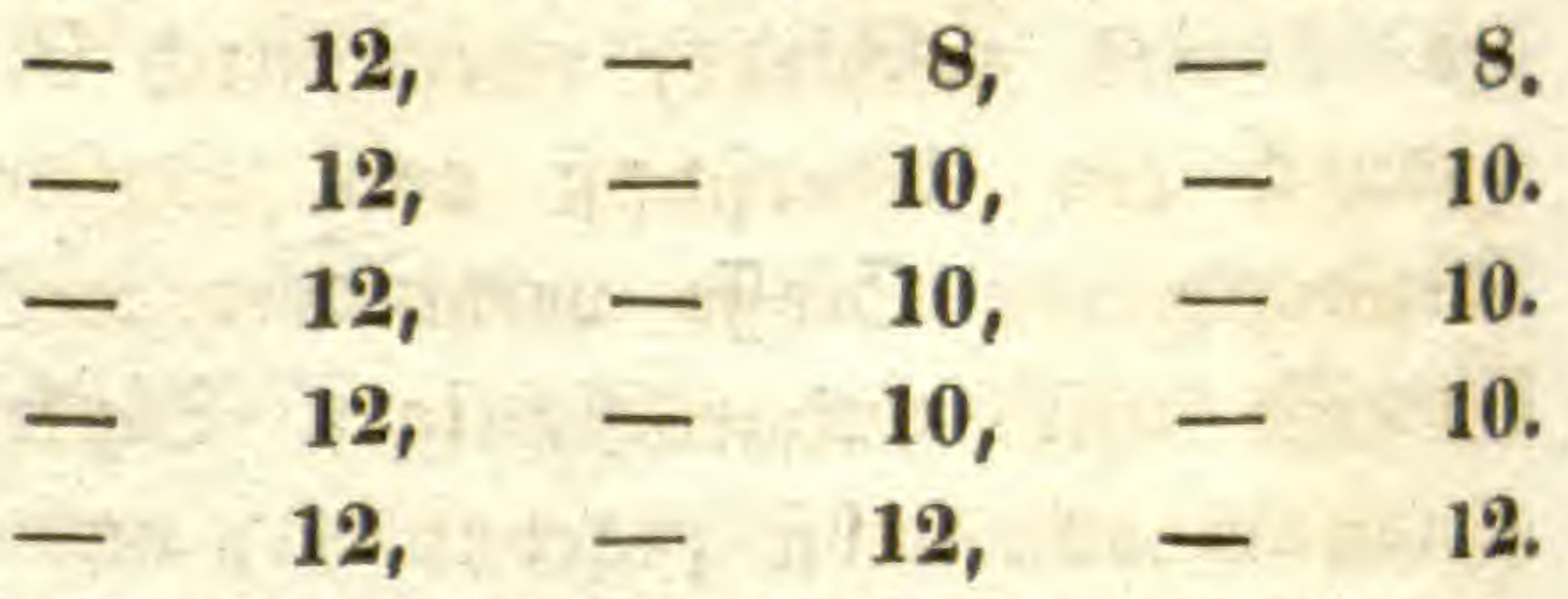

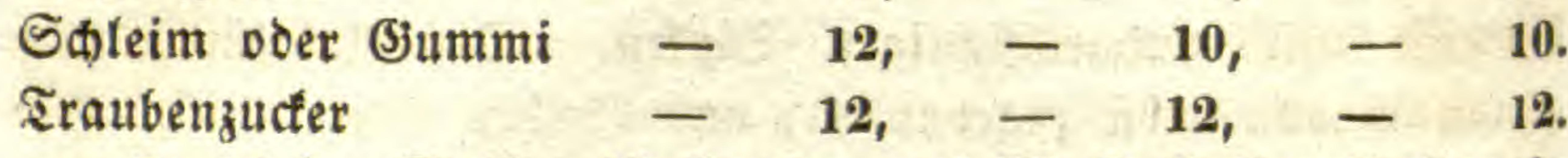

In bieien Stoffen if Sauer = und $23 a f f e r f t o f f$ enthalten in Denfelben Berbältniffen mie im $\mathfrak{B a f f e r , ~ u n o ~ m a n ~ f o ̈ n n t e ~ f i e ~}$ bafer für $\mathfrak{B e r b i n d u n g e n ~ v o n ~ R o b l e n f t o f f ~ u n o ~} 23 a f f e r$ anfehen;

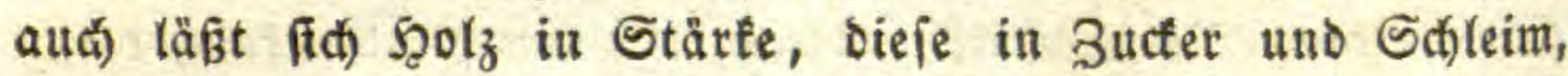
uno biejer in Iraubenzucfer verwandeln, wie es fifeint blö Durd) Den Bentritt von 2 Berbältni $=$ Theilen $\mathfrak{W a}$ alfer. 2(llein

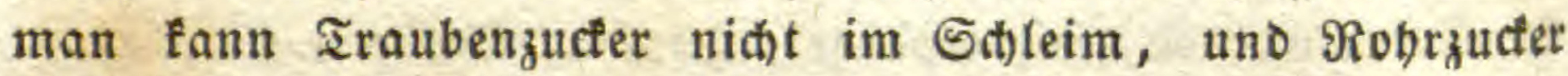
nidit in Stärfe ourd Entziehung von Wafier zuriicfiuhren; uno

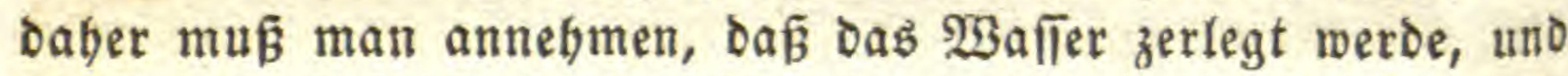
Die Beftandtheile beffelben, fowohl von dem Rohlentoff als bem \$3a

Eine Göbere Berbindung als Der Traubenzucter fdheint nidt) voržfummen: Denn bey der Einwirfung von veroünnten Găus

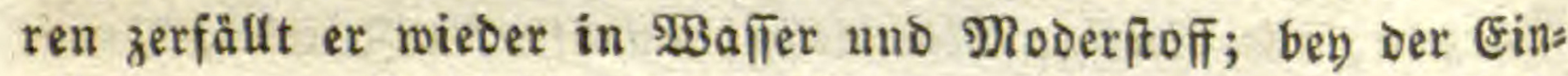
wirfung von fticfitoffbaltigen Rörpern, wie Rleber ober ફ̨efe,

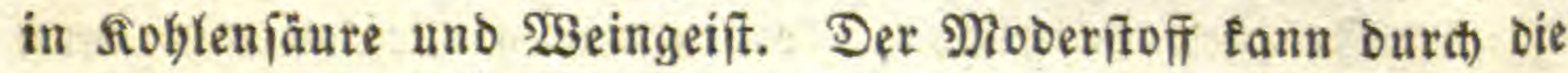
Berfę̧ung feines $\mathfrak{W a f f e r s}$ in alle anderen $\mathfrak{B e r b i n d u n g e n ~ u ̈ b e r : ~}$ geben bis zum Iraubenzucter, weld)er wieder in Moderftoff zet= fält. Daber iđeint biejer vorzinglid) zum eigentliden Ernäbs: rungsitoff der Pflanzen geeignet.

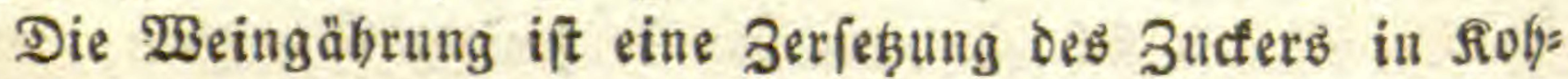
leniäure uno

Die Effitggäbrung eine Berwandlung Deछ $\mathfrak{B}^{2}$ eingeifts in Ếf

Die Fåulní eine völlige 2uflöfung Der organijđ)en Stoffe, wozu meiftens bie Einwirk̂ng eines fticfifoffhaltigen Rörpers erfordertidi ift. 


\section{a. $\mathfrak{B}$ e ingå $\mathrm{r}$ ung.}

Soll fie aub blofem 3uteer erfolgen, fo muß er minbeftens

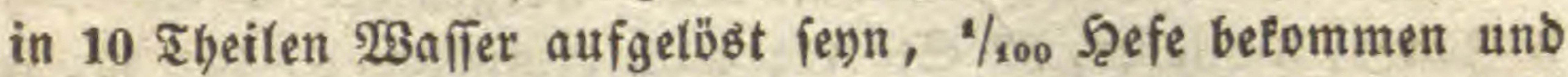
die gebörige Temperatur haben. In Diefem Falle wiro alle Şefe verzebrt uno es biloet ftd) teine nette. In den natürlidien Pflanzeniaften ift bie Sefe voer Der fileber ífon vorbanden. Die andern Stoffe, wie Såuren, Farbenftoff $\mathfrak{u}$. ogl. ftuo glei ()$=$ gitltig. Dlne 3utritt von Sauterítoffgas findet feine Jäbrung ftatt. Er leitet jeooch Diefelbe nur ein, und ift feineswegs nöthig zur Fortoauer und zur Serwandlung Des Slebers in Sefe. Rur ein Bläzd)en Sauerftoffigas veranlaß̧t bie Irit= bung des Saftes, uno bann geht Die WBeingährung vorwärts, welche auch erfolgt, wenn nidfts als soblenfäure vorbanden ift.

Die Irtibung entfteht ourd) Die Bewegung ber Slebertheil= den, weldbe von ber fid) entwictelnden Roblenfäure in bie Şöbe geriffen werben, uno bautert unter Entwictelung von W3ärme fo lange als Bucter vorbanden ift. Dann fesen ftás bie unauflöglichen Theile zu Boben, und an bie Stelle bes Sucters ift fioblenfåure, weldhe bavon gebt, uno Wreingeift ge: treten, ber mit ben auflöslidien Stoffen verbunben bleibt. Der sodenfas befteht theils aus Şefe, theils mie benm Traubenfaft aแร 2 einfteik.

श(ut) bilbet fith wabridheinlid) aus bem sleber etwas Fth felöl uno 2lmmoniat.

\section{b. Biergåbrung.}

Die Biergåbrung ift atth eine Weingåbrung, welde burd)

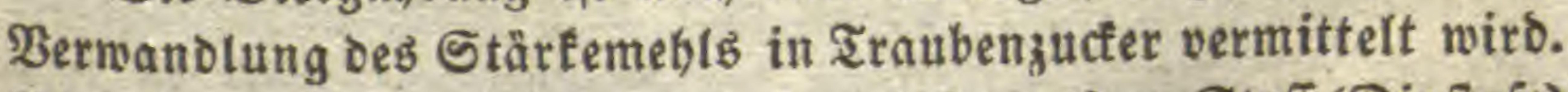
Dieje $\mathfrak{B e r w a n d l u n g ~ w i r b ~ b u r d ~ e i n e n ~ b e f e n a r t i g e n ~ S t o f f ~ ( D i a f t a j e ) ~}$ veranlast, welcher beym Reimen bes forns gebildet wirb.

Man weid)t baber bie Serfte ein, Damit fie Baffer einjaugt

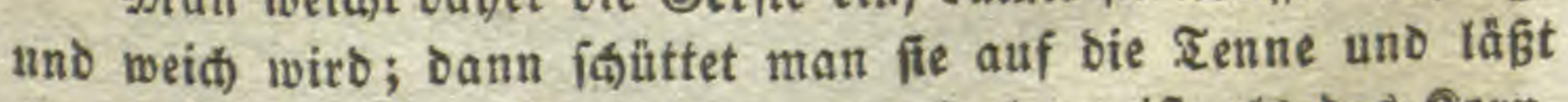
fte teimen, bis bas 2 itrzeldien etwa io lang ift als bas forn, worauf oie Mafle ober oas Malz getroctnet wirb. Währeno bes feimens verwandelt fich ber meifte fleber in Diaftaje, und 
Die Şälfte des Stårfemebls in Tranbenzucfer uno Salleim. Wä̆breno Des Dörrens fallen bie $\mathfrak{B}$ ürzeł

Bor bem Reimen enthält bas Gierftentorn 4 Sdtleim, 5 Zucter, 3 fileber, 87 Stärḱe; nad) Demielben 1, 15, 15, 1, 68, woraus man fiebt, um wie viel fid) Der Rleber und bie Stårfe vermindert, Der Sdleim Dagegen uno ber 3ucter fith vermebrt baben.

Uebrigens fann audi bie Stärfe für ftch in Iraubenzucter ïbergeben, uno zwar zur Șälfte ibres Gemidts, wenn man fie fod)t unb bann aboampft oder zum Iroctnen fteben läßjt. $3^{u=}$ gleich) bilbet fid baben Sd)leim. Das geidiebt aud) obne $3^{u=}$ tritt ber \&uft.

Dann wirb bas Malz auf einer Mithle geidroten und in

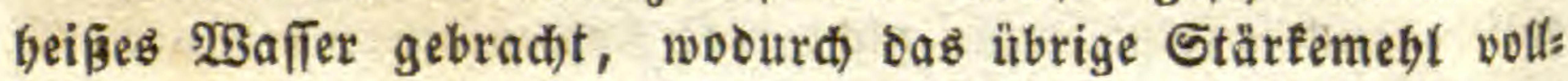
ends in Salleim und 3ucfer verwandelt wird. Dann fommt

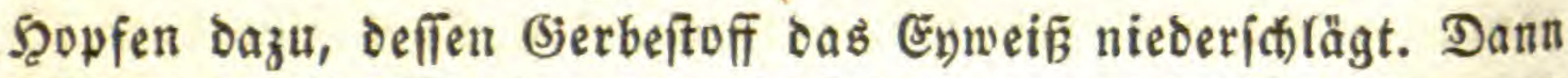

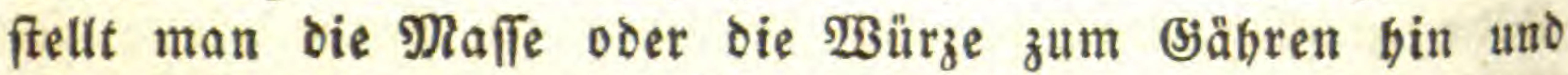
thut Şeje bazu, worauf fid Roblenfäure entmicfelt uno bie 5efe wie einen S(haum in bie Şöhe ziegt. WBähreno ber Beit billot fich) Der Weingeift.

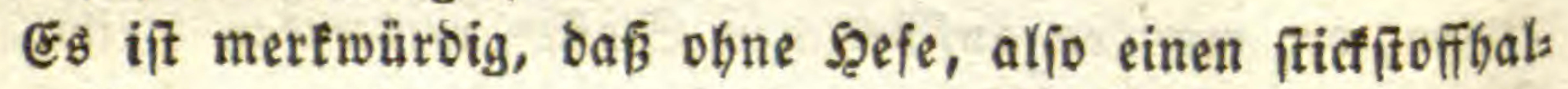
tigen Rörper, welder an bie thierifhen Stoffe erinnert, feine (jäbrung vor fid) gebt. 2(ud) bat man unter bem Microicop

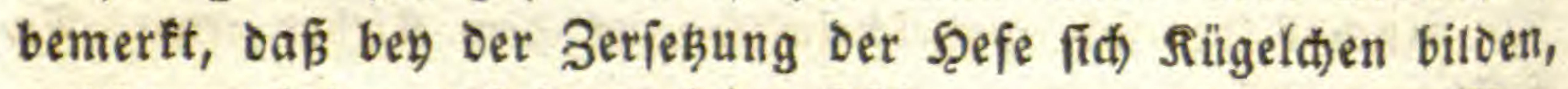
welche zerplahen uno dann feine (jäbrung mebr bewirfen. JRan

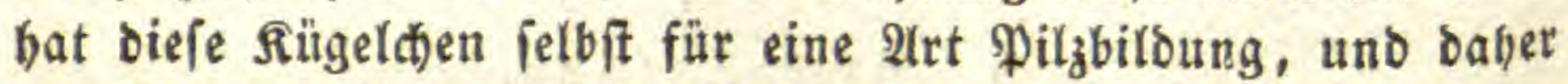
oie (jäbrung für einen lebendigen Proces, gleidjfam für eine Begetation angejehen. (Es ift aber bod wobl nidts anderes, als bie allgemeine Berfallung ber organijकen Mafle in ibren

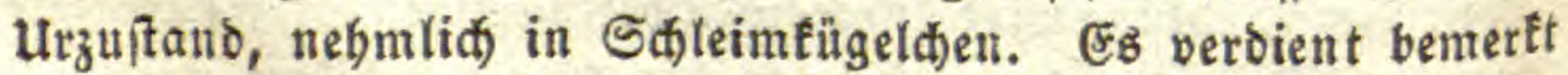

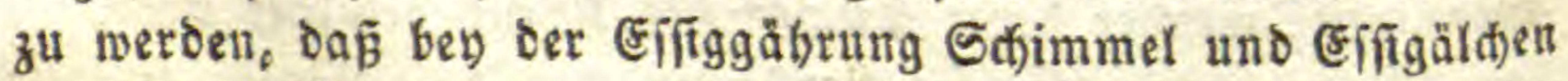
entiftehen. Sie fängt an, in bas Thierreich) iiberzuitreifen, wäb= reno bie $\mathfrak{B}$ eingäbrung im Pfanzenraidje bleibt.

Die Şefe fheint ben (jäbrungsproceß baరurd) einzuleiten, Daß̧ fie von felbft in gäulniß übergeht. Die Stärke verwandelt

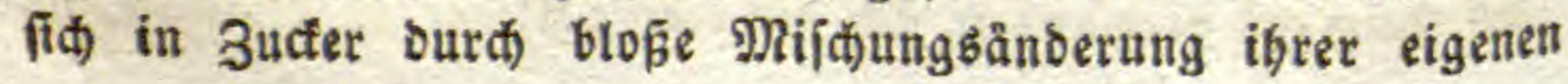


Beftandtbeile, ohne Sauerftoff anzuzieben: Denn fie geht Durch Sđ)weferfäure in 3ucter über, obne alle Berję̧ung ber Säure.

\section{c. Elfiggåd $\mathfrak{r} u \mathfrak{n g}$}

ift eine Berwandung Des Weingeiftes burd) Drubation in

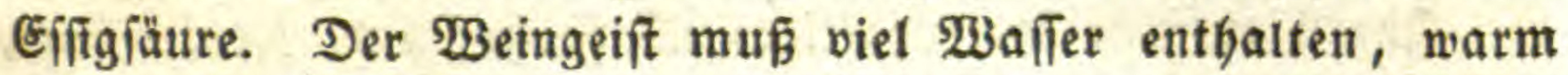
und an frever $\mathfrak{R}_{\mathrm{uft}}$ fteben, uno Şefe befommen, wodurd bie

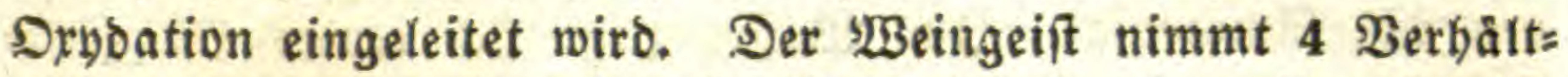
nißstbeile Sauerftoff auf uno bildet bamit einen Derbältniß̧s:

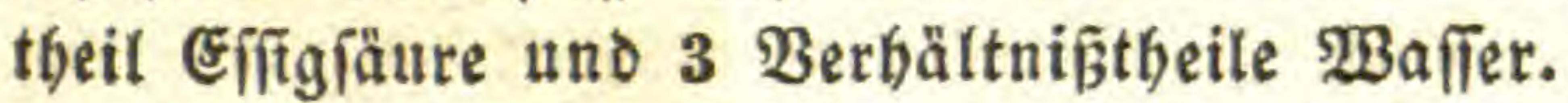

2uch Das Brod if zam Iheil ein Probuct ber (jäbrung.

Durd) Den Sauerteig, welcher bie Stelle ber Şefe vertritt, uno burd) Den Rleber bes Megls wire das Stärfemehl zum Theil in Sdileim uno in Iraubenzucter inberführt, uno ber leķtere in Weingågrung verję̧t. Die Jäăbrung wiro aber

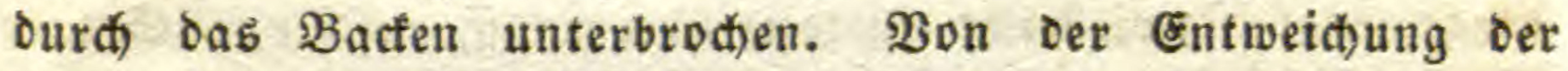

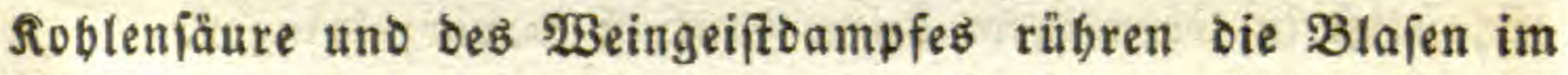
Brode ber. In neuerer Beit wurben Bactöfen gebaut, in (5ie= fitalt einer Branntweinblaie, um Den $\mathfrak{X}$ eingeif́t zll gewinnen.

Der פRift ift bas Product einer weiter gediebenen Fäul=

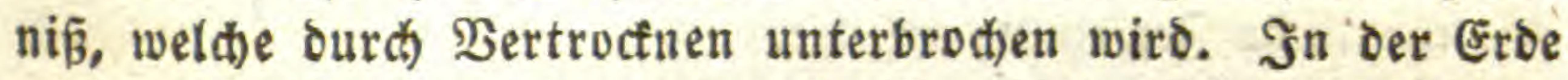
wirb er ourd Einwirtung Des $\mathfrak{B a f f e r s ~ a l l m a ̈ b l i c t ~ i n ~ M o d e r = ~}$ ftoff verwandelt.

Das Reimen Eann, wie es fich oben gezeigt bat, als eine 2lrt (sährung betractet werden, wodurd ber Rleber von ber Stärke geidaieden, uno die lekgtere in Sd)leim uno Bucter ver= wandelt wird. Der Unterífied if nur ber, daś es nidjt zur Weingäbrung formmt.

\section{d. $\mathfrak{F} \mathfrak{a} u \mathfrak{l} \mathfrak{n} \mathfrak{i}$.}

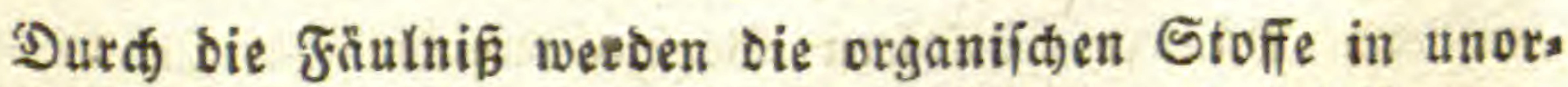
ganiid)e zerjeşt, uno zwar in vefte, fliififge uno luftförmige.

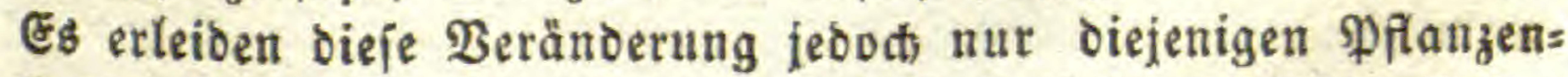

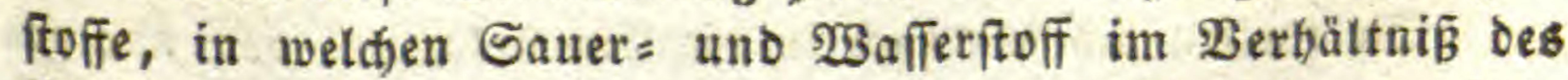
Waffers vorbanden fino; uno am leid)teften biejenigen, weldte Stictitofi entbalten, wie fileber. 
Die Dele, Şarze, ber 'Beingeif́t uno die Säuren, worinn

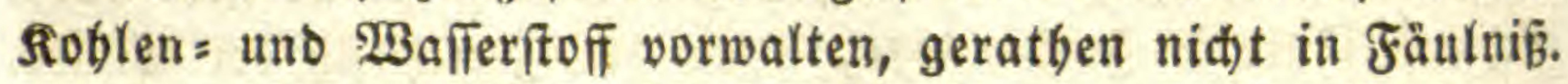

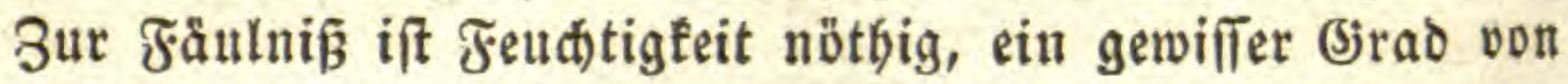

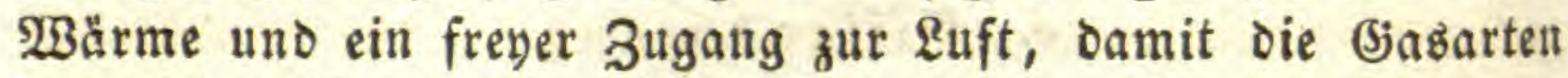
entweid)en fümen.

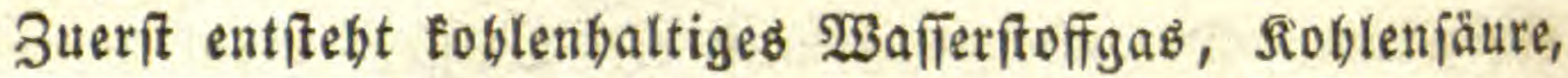
bišweilen reines $\mathfrak{B a f f e r f t o f f g a b , ~ u n o ~ w e n n ~ S t i c f i t o f ~ v o r b a n : ~}$

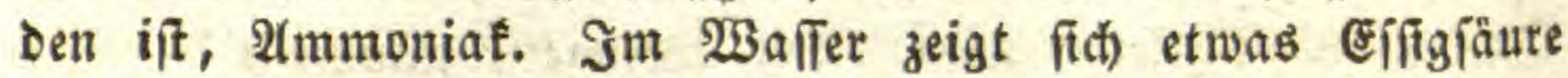
und Del. Die zurüctbleibenden veften Theile find Eroen und Salze.

Das Şauptprobuct ift fohlenhaltiges $23 a$ fiferftoffgas, wels des fid) im Sommer uno Şerbft in bem 200 an ftehender $23 a ̈$ F fer entwictelt. Stößst man mit einem Stoct binein, jo fteigen bie Blajen in bie Sëble. Die fäbliche Sumpfluft ift wahts id)einlid) bas nämliche (jas, bem aber noch eine andere Subftanz bengemengt ift; vielleidst ein thierifher Stoff, weldier im Stanoe ift, jelbif in lebenoigem Leibe Făulniß̄ hervorzubringen.

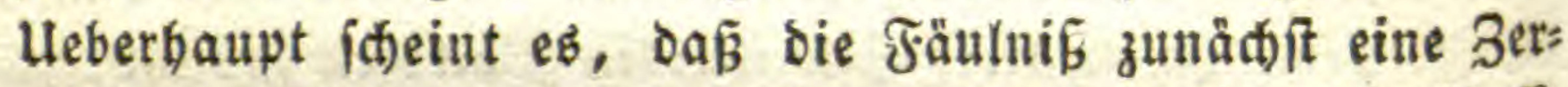
fallung bes großsen organifichen Rörpers ift in infujoriale Mafle

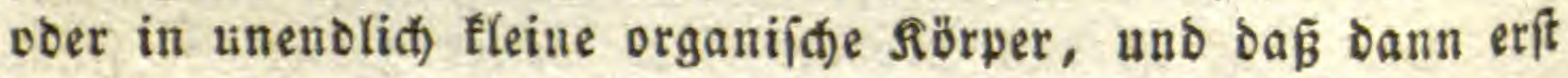
bie chemijhe Berieksung erfolgt.

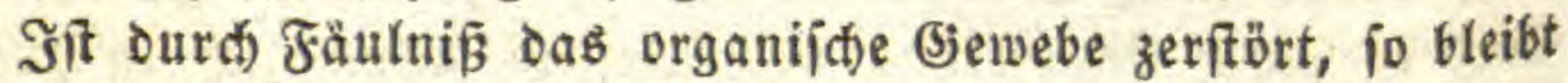
bie tohlenartige, putverige Sibbitanz zurild, weldte Dammerbe,

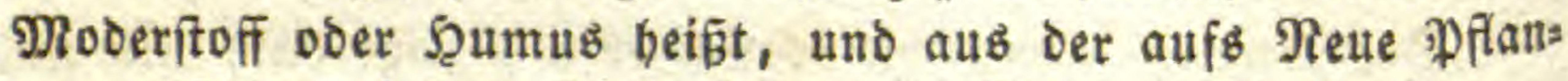
zen entifteben, indem fie benifelben als Jabrung bient.

\section{Pflanzen $=$ Phy fif.}

Эक) betradite unter biejem Titel alle åußern Einwirfungen auf bie Planze, injofern Beränoerungen barinn hervorge= bracht werden, alio foivobl materielle als immateriefle ooer oys namijache.

Sie theilen ftă) Demmad) in bie Einwirţungen ber unorga:

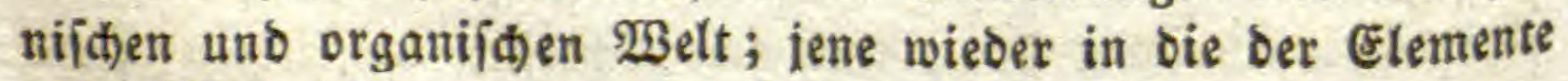
und Mineralien. 


\section{A. Einwirtung Oer Elemente.}

\section{a. 2 (etber.}

Die Thåtigteit bes Metbers åugert fịch auf brewerley Weife ats Sd)were, Riđt uno $\mathfrak{B a ̊ r m e . ~}$

\section{Die $S$ d) were oder (53ravitation}

beftimmt die Ridtung Der $\mathfrak{T f l a n z e n . ~}$

Jufofern fte allein wirft, bejiebt fie fid) blof auf oie zel; Dieje aber, einmal beftimmt, wirtt zurüt auf ben Stengel, went er aud) gleid) burch andere Siräfte, als die Sđ)were, zur Berlängerung getrieben miro.

Ri(t)tung Der $\mathfrak{2 B}$ urzel.

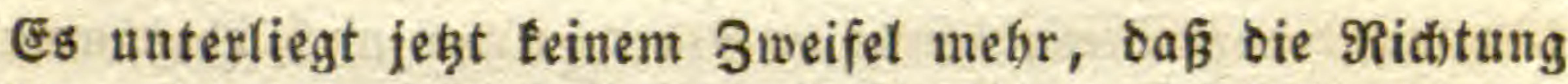
ber $\mathfrak{B}$ urzel ourd) nidfts anberes als Die Sdwere beftimmt nirb, und Dafi fte baber überall, wo fie tein Şindernif findet, gegen ben Mittelpunct ber Erbe finft. Die natürliafite Punabme fideint zu fenn, Daßj fie Der Feudtigfeit folge uno etwa ber Finfternis: alleitl die finnreichiften Deriud)e baben bas (jegen: theil bewiejen.

Läß̈t man einen Samen, z. B. eine Bobne, feimen, fo mag man fte legen, wie man will, das 23 itrzelcthen wentet fich immer nach unten, und Daв Stengel(t)en oder Blattfeberchen nach oben. Эift Der Rabel ber $\mathfrak{B o b n e}$ nact) oben geriđ(tet, fo verlängert fid() Das 2 Bürzeld)en zmat anfangs aufwärtb, trümmt fid) aber balo

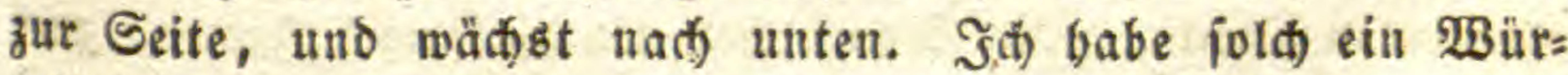
zeldien an einen Faben gebutioen uno fanmt ber Bobne aufge: bångt. Da es fich) nun nid)t umwenden fonnte, fo bilbeten fid)

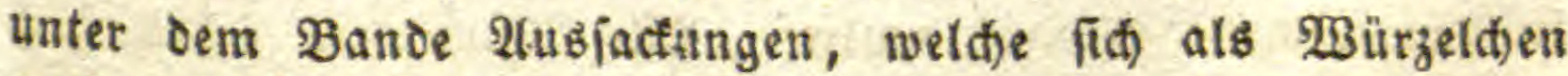
nad) unten verlängerten. (E war aljo bier offenbar bas (5)e=

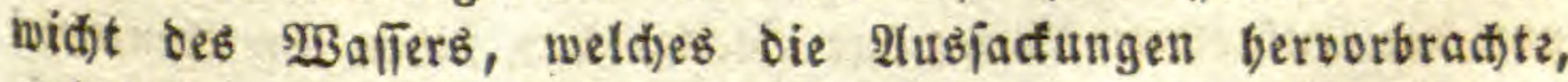

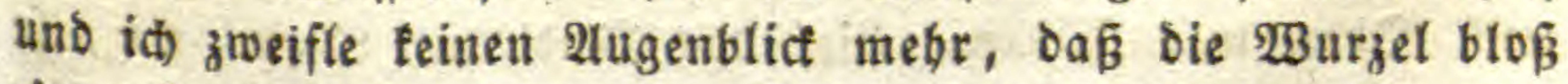
einer fogenannten tooten Sraft folgt, nebmlia) ber Shwere, objion id früber aud) mennte, fie wadhie blog Dabin, wo

Dlens allg. Raturg. II. Botanil I. 
Fendtigfeit fey. Es gibt allerdings Pfanzen, welche blop wagredte Wurzeln baben, wie die Nabelb̈̈lzer; allein in Diejem Falle

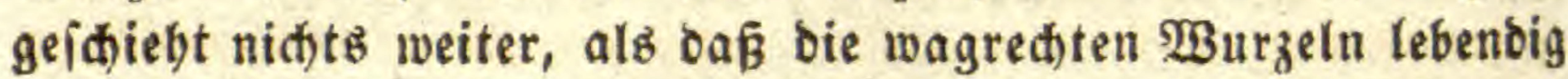
bleiben, weil fie Feutitigfeit finden, uno baß bagegen bie nah unten wadjenden abiterben, fo wie fie in ben troctenen Boben

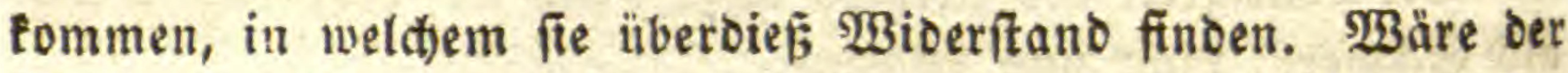
Boden dajelbit ganz locter, fo müroen fie fo lange fortwadjien, als fie Saft von ben Seitenwurzeln betåmen, wie fíth biefé bey Den unterbäblten PFlanzen, z. B. an Scoblwegen, zeigt. Reidten Dieie Şöblen bis zum Mittelpunct ber Erde, fo würs Den dis 23 urzeln bis babin fallen.

Man bat Samen in (Slazröhren geftect, uno benfelben cben feuchte (Eroe, unten troctene gegeben: bennod) wud) ba

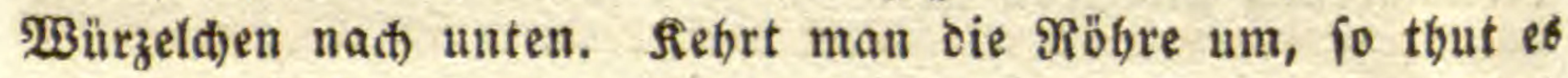
aud) bas Bürzelden, uno bas fo oft als man umfebrt. Daf lelbe thut bas Stengeldien; es febrt immer nach oben um, bas lidft mag einfallen, wо ев will.

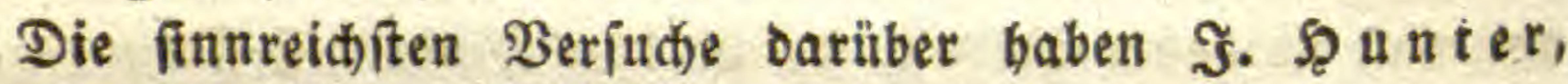
Snight und Dutrochet angeitellt.

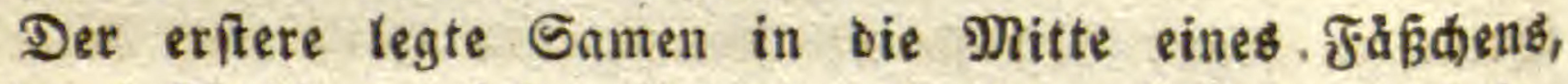
weld)es beftänoig umlief. W3urzet uno Stengel liefen nad ber Ridtutng ber Drebungbadie aubeinanber.

Snight (Phil. Transact. XI. 1806. 1. 99. Fig.) beveftigte Bobnen in allen Ridtungen bes Rabels an ber Felge eines

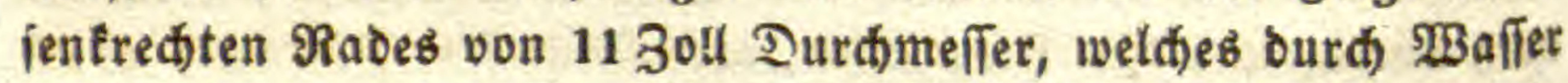

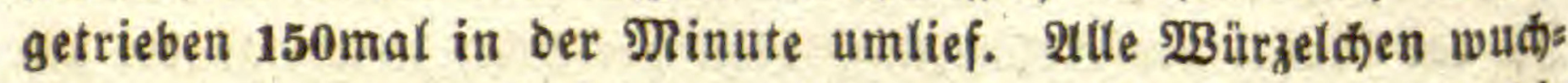
(en nad) 2 usen, uno folgten mitbin ber Salleuberf́traft als bie idwereren Theile. Die Stengelden wudifen nad S̃nnen, zum Ibeil wohl, weil fie anfangs viel leid)ter finb, als bie \$Bürzelden. Dann beveftigre er Bobnen an ein wagrectites Rab, weldes

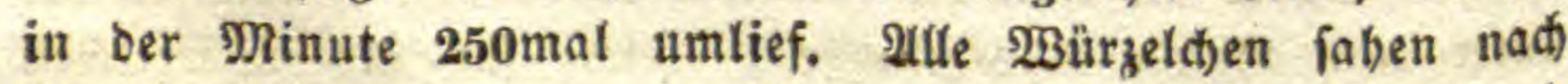
Unten uno nach 2 (ußen, und zmar um 80 (jrab abiveidfend ron ber fentrecten \&inie; bie Stengeldjen faben um ebenfodiel

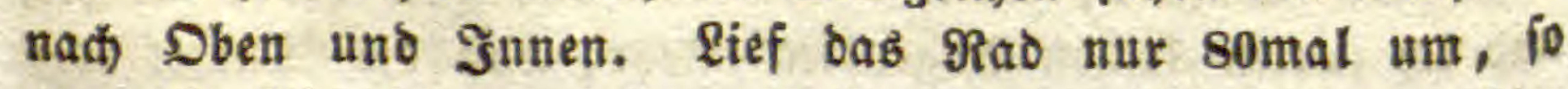
war bie Albweidung beiber 45 Grab ober ein halber redter

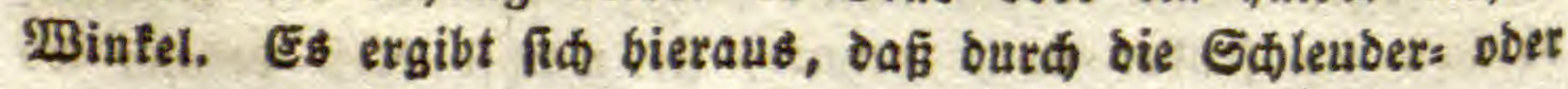




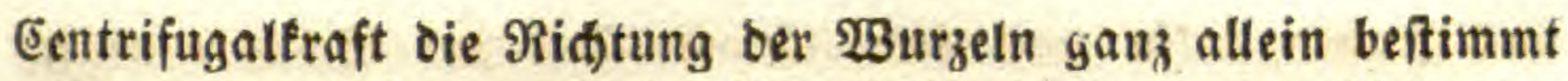

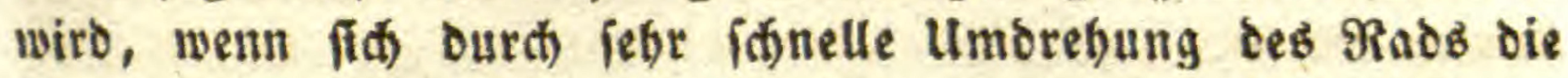

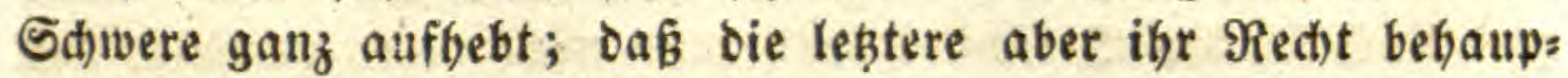
tet bey oer langiamen Umorebung.

Dutrodet bat bieje Berít(d)e vervielfältigt. (Mémoires des Végétaux. 1837. II. 38. tab. 17.)

Bicten in ber 21 dife eines fenfredten $\Re a b s$, oas 40 Um=

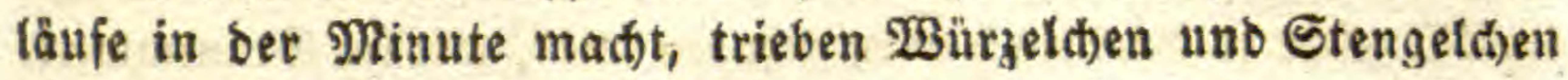
genau in ber wagrect)ten $\mathscr{A}(t) i e$, und zwar in entgegengeiegter

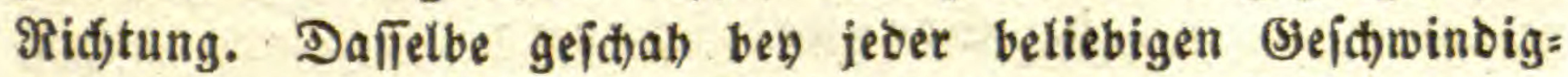

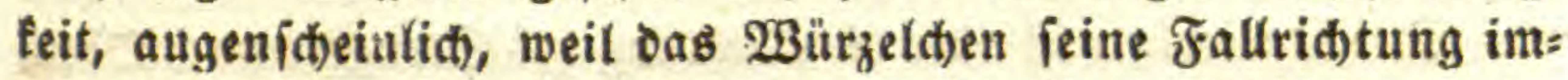
mer wedjelte. 2lls Das $\Re$ Ro um $1 \frac{1}{2}$ Grao Sitooft geneigt

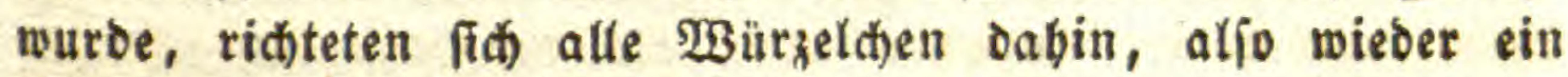
Bemeis von ber Birkung ber Sawere.

Erbien uno $3 i c t e n$ an ber Felge eines 3 Sd)ub hoben,

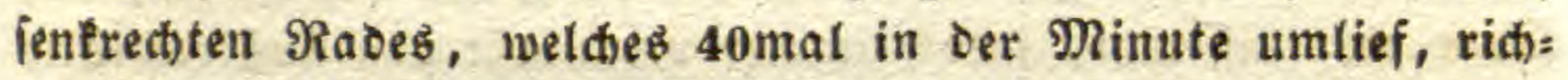

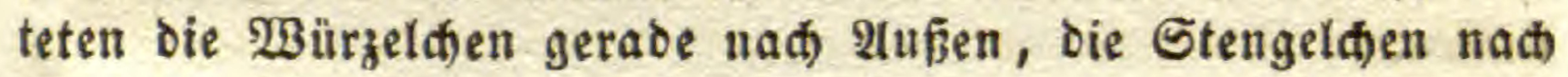
Эnnen. Bey einem wagrect)en $\Re$ ad von ungefäbr 15 Soll Durctimefier, bas 120mal umlief, zeigte fich ganz bafielbe; nebmlia bie Stengelden ftanden gerab nach Jnnen, bie 23 ür= zelden gerab nad) 2 (n Ben obne alle Reigung, obne 3weifel, weil fte viel reidster finc, als Bobnenwitrzeldfen. Bon 2 Bicten, weldhe in eine Reibe nact) bem Durctimeffer auf bas Brett ge:

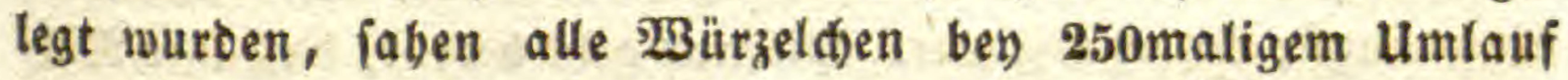

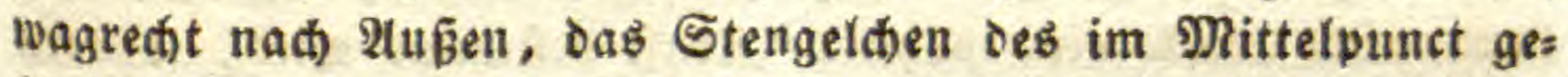
legenen હamens gerab nad Dben, bie anbern unter einem ver= fibiebenen nung; biefenigen wagrecht nach Innen, weldee 8 3oll vom Mit: telpunet lagen. Suleģt trafen fie in ber Mitte in ein $\mathfrak{B u ̈ n b e l}$ gus fammen, weldes fentred)t wud)s. Bey 54 umlăufen ftanden bie

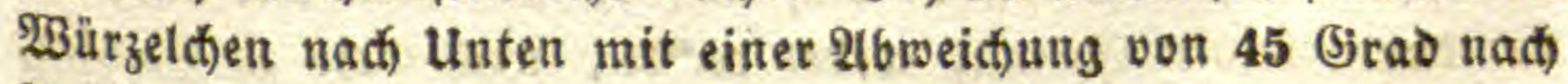
2ußsen; ebenjo bie Stengeld)en nad) Dben uno Jnnen.

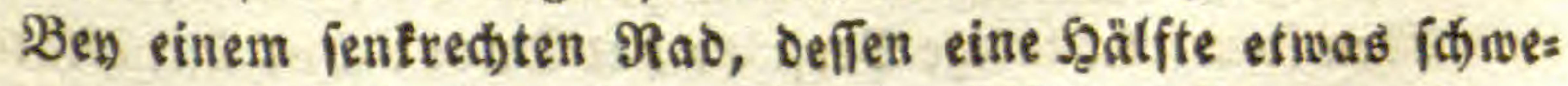
ret war, und baber langiamer ftieg, riditeten fid) bey lang:

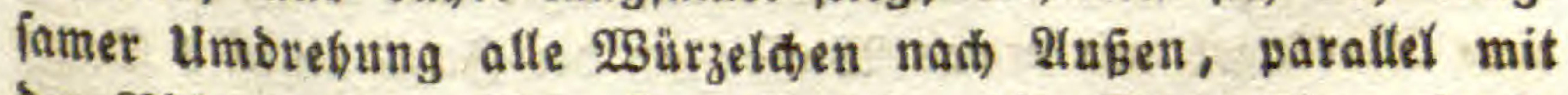

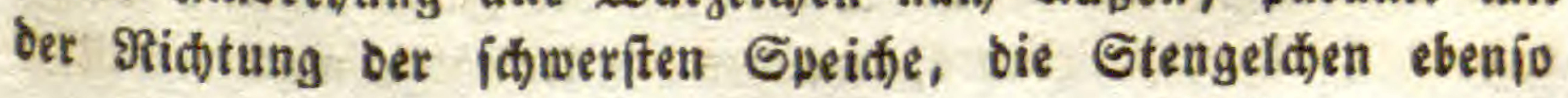


nach Innen; atio weil jene längere Beit ber Sobnere unters worfen waren.

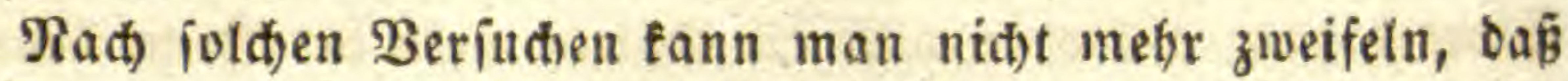
bie Sd)were allein es ift, melche die Ridtung ber 23 urzeln be: ftimmt. Sie verlängern fith befanntlid, bloßz mit ber Spike, meil biefe meicher iff, uno bieje ift neidjer, weil fict) oer Saft Dabin jenft, uno diefer fenft fith dabin, weil er burd) die Po: larität nicht jo farê nach oben gezogen wird, wie im Stammmert.

\section{b. Stengefridtung.}

Biel iđbnieriger ift aber bie Riđtung Des Stengels nah) Dben, aljo Der Sđjwere entgegen zu erflären. Dabey reicht (đ)led)ter: bings feine andere 2(nnabme aus, als ber (5egenjas zwíd)en ஐ3urzel und Stammwerf, ohne వweifel gegrünoet auf oie Ber: fajiebenbeit ber Gtoffe, bort mebr falleimig oder indifferent, bier

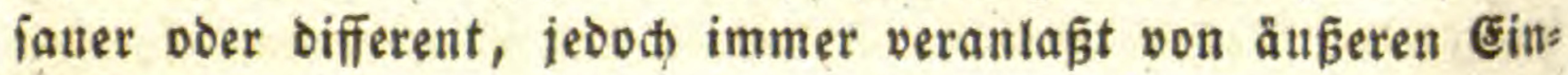
flitifen.

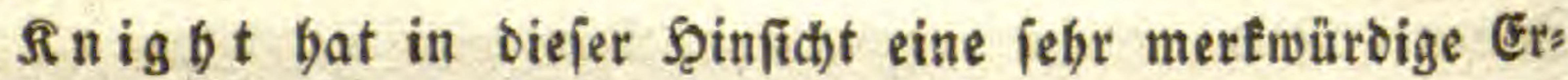
fdeinung beobachtet, Er band die von ber Felge eines fent:

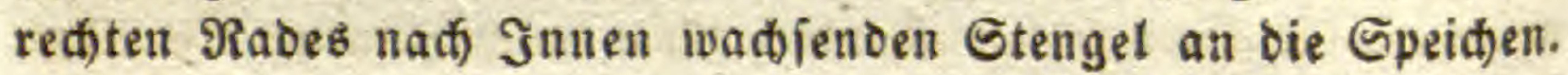

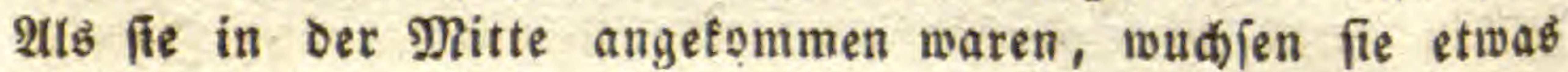
Dariber binaus, febrten aber jooann $\mathrm{um}$, und fud)ten wieber in ben \$ittelpunct ber umbrebung zu fommen, alfo babin, wo Die geringîte Bewegung war. Seieraus geht bervor, baß ibre Rid): tung nicht burd) eine phyfifbe sraft beftimmt wirb, fonbern ourch eine organifhe, nefmlia) Das rubige $\mathfrak{B}_{3}$ adjen felbit, wel= bes nact) allen Seiten Des Stengels in völligem (5leid)genid)t vor fidb gebt. Stebt ein Stengel rubig ïber Der Erbe, fo wird er überall pon gleid) viel $\mathfrak{R}$ uft umgeben, und er jiebt baber rings: um gleiđbiel Sauerítoffgas ein, uno ounftet gleidbiel aus. Er bat baher teinen (jirund, weber redits, nod) lintz: zu madien, voraubgefest, daß̧ fein Sonnenftrahl darauf fällt.

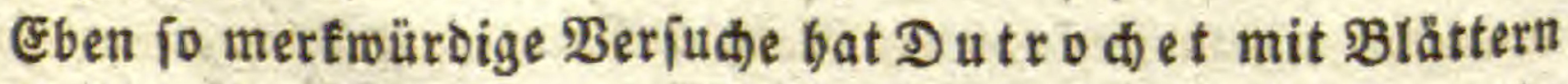

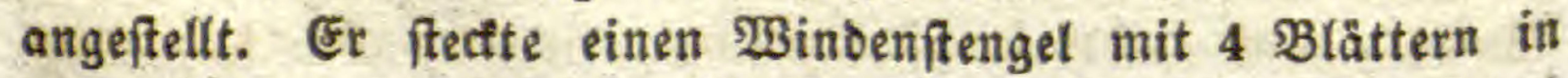

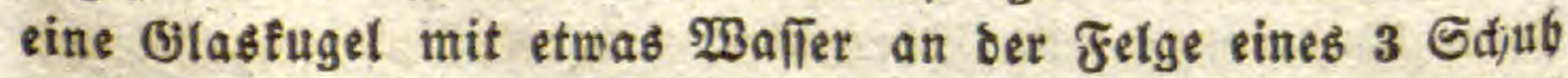

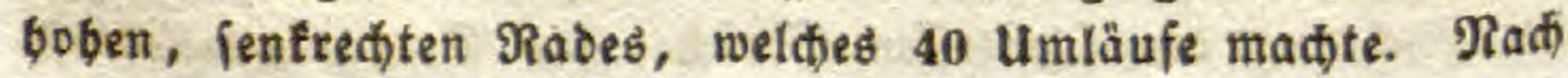


18 Stunden war Durd Frümmung Des Stiels die obere gräđe aller $B$ lätter gezen oen Mittelpunct gerid)tet. Dalielbe geíd)ab bey Beildten uno (Erbbeeren. Feier bat fic) alio bie untere voer

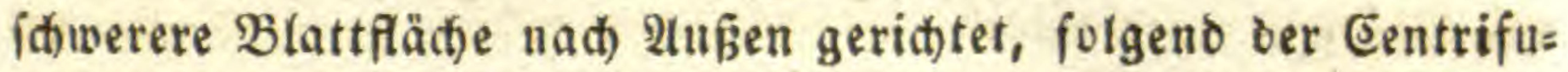
galêtraft, wie die Wärzelchen. Die Blătter verbalten fíh mits bin ganz wie bas Blattfeocrchen.

\section{c. Binben oes Stengels.}

Sd)lingpflanzen nennt man alle biejenigen Pflanzen, weldie wegen ifres dünnen uno idwad)en Stengets einer Stüke be: oürfen, um empor zu wactien. Dieje Stühe befteft meiftens in Felfen uno Bäumen, bisweilen bloß in Şecten.

Das 2(nbalten geidiegt entweder ourct) den Stengel felbit,

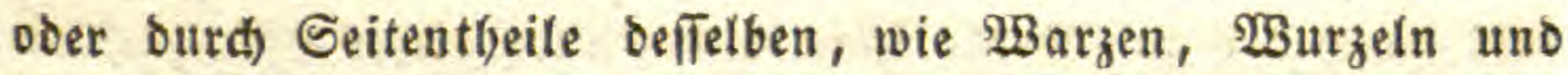

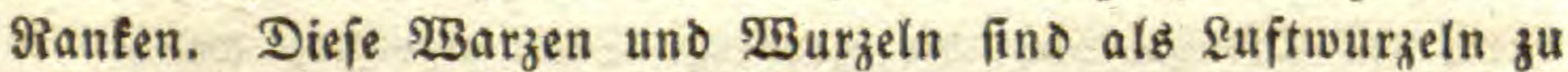
betract)ten oder als Zweige, welde fith in $\mathfrak{1 3 u r z e l n}$ verwandeln; bie Ranfen meiffens als verfümmerte Blätter voer Sträuß̧er. Beibe 2 trten von $\mathfrak{P f l a n z e n ~ G e i f e n ~ f l e t t e r n d e ~ ( P l . ~ s c a n d e n t e s ) ; ~}$ bie andern, weldte fith mit Dem Stengel emporhelfen, mindende (Pl. volubiles). Pa lm und $\mathfrak{M}$ o hl haben die meiften $\mathfrak{B e o b a d})=$ tungen Darüber angeftellt : ïber bas $\mathfrak{B i n d e n}_{\text {Der }}$ Planzen, 1827. 8., uno über ben Bau uno dab Binden ber Ranfen uno Sdjlings pflanzen, 1827. 4.

Ës gibt ungefäbr 800 Sct)lingpflanzen, worunter gegen 200 bolzige, etwas weniger ftaubenartige, uno etwa 100 firäuter (iid) befinoen. Rad) $\mathfrak{N}$ obl finc aus 2 (merica 463 (jattungen

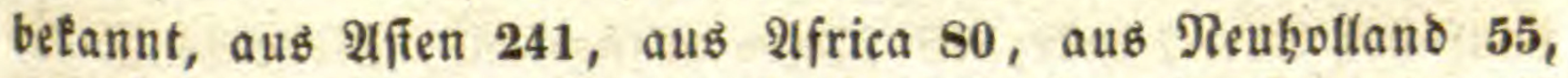
aub Europa nur 27. Die grofese 3 ahl in 2 tmerica fommt woht הaber, daß man Sỉd

Bon den windenden Stengeln fino ungefäbr 30 genauer beobadtet. Davon minden fict) etwa 20 lints, o. h. aufwärts von ber recteten zur linfen ફ̧and oder auf unjerer Erbbälfte ber Sonne entgegen; etwa 10 winben fid rechts ober nach bem Rauf ber Sonne. Unter ben eriteren finden fid) fait lauter Neģs

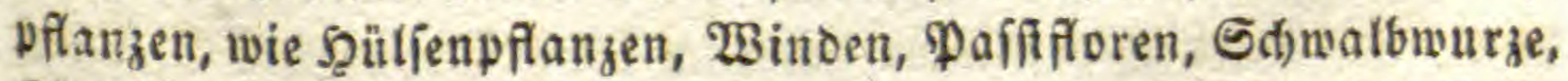
Rïrbien uno 20 olfemilde; unter ben jwenten findet fith (5)eif: 
blatt, Sđmeerwurz, finöteriđ), Şopfen und aud Stheiben: pflauzen, wie Diofcoreen und Smilaceen; jelbit Farren, wie Dzmunoa. Unter ben Pflanzen obne Spiralgefä̧e gibt ez feine windenden.

Die $2 B i n b u n g e n$ erbalten immer biejelbe Fidtung, uno lafien fith ourd) fein Mittel nach ber entgegengefesten Geite bes ftimmen; Die Ranfen Dagegen winden fíh balo redts, balo lints, je nadbem fie ben Giegenitand treffen.

Alle windenden Stengel find io iđwad), baż fie auf ben Boden fallen, wenn fie Eeinen Biegenftand finden. Dann rit): tet fid) ber Gipfel in bie Şöbe uno wät)est fo lange, bis er

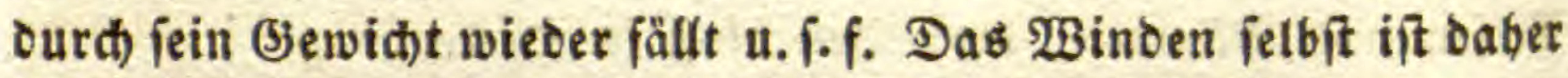
nid)t sanberes, als ein beftänoiges Fallen uno 2ufiteben, verans

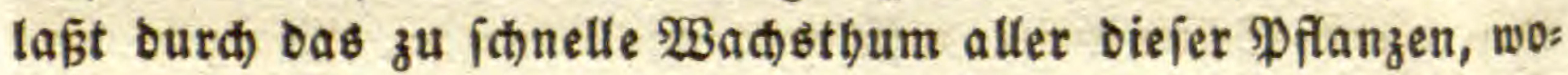
ourd) Ser Stengel nidft oie gebörige Dicte erreid)t, welde no: thig wäre, um das (jemid)t ber \&änge zu tragen.

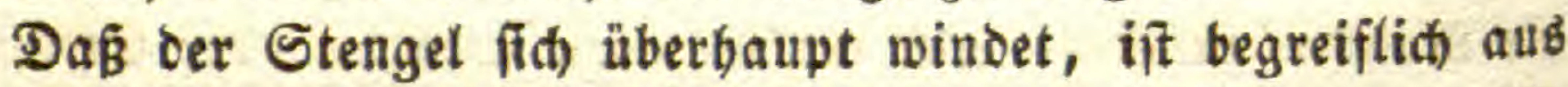
Der faft allgemein vortommenden Drebung bes Stengels, welthe fid) in ber fpiralförmigen Stellung Der 2tefte uno ber Blättet verräth, und jelbît in Den gebrebten santen vieler Stengel. Dentt man fid) Diefe zum Steben zu fitwad), fo müfien fie fich notbwendig winden.

Woher biefe Drebung überbaupt tommt, läß̧t fich freblich

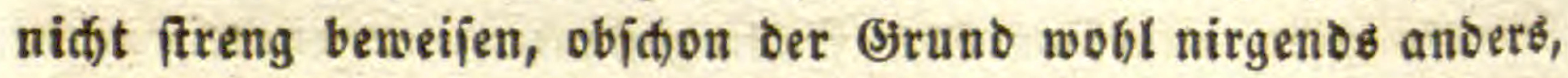
als im Einflus Der Sonne, mithin in ibrem Umlaufe liegen fann. Warun aber bas \$inben bald nad), balo wiber ben Eauf ber Sonne gebt, ift idwer anzugeben. Bielleid)t if ber eine Theil Diejer Pflanzen uriprünglid) auf ber andern Ero: bălfte entiftanben, uno fie baben jobann ihren $\mathfrak{B a u}$ bey ber 2tubwanderung benbebalten. Es fommen feood) in beiden 24 bs theilungen Pflanzen aus ber beißen Zone vor. Uebrigens fins bet man nid)t felten entgegenftehende Blätter unb Blätben autch entgegengejęt geridtet. Bielleidst betommt bey Den veridiebes nen Pflanzen balb bie eine, balb die andere शitatung bie Dbers bano, uno baburd) beitimmt fid) alld bie शRidtung bes Steingels. bey bem \$inden. 
Man bat früher geglaubt, Die Stïţen ober Stangen übten eine 2 trt 2 nziebung auf bie Gipfel ber Stengel oder bie Ran=

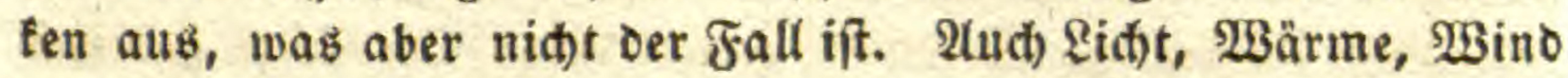
uno Feu(b)tigfeit wirken nicht Darauf; ebenjowenig tünitlich ans geweridete Electricität oder Gălvanismus. Bisweilen bleibt je= ood) oer binfel eitle Beit lang rubig fteben, uno windet fid

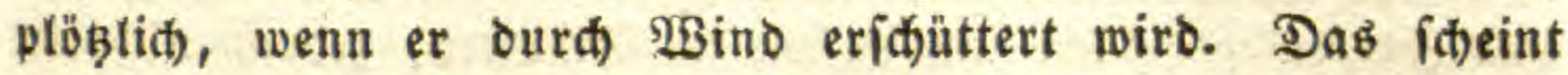
von eiter gewiffen Epannung herzutommen, welde bie Sdwere, aljo ber Druat auf das Pflanzengewebe verur ourd) einen Stó von $2(u$ Ben geboben, io ftrecten uno füllen fidi) bie Bellen, uno bie $23 i n$ oung geht vorwärts.

Der Giipfel oder bie Ranfe legt fich erft um die Stange, wann er fie berübrt, fudt fie aber nicht aus ber Ferne auf. Daḱ biejer Bewegung entgegengejektes (Einfallen Des Ridites bie Windung eine Zeit lang abbalten tann, if eine begreiflide Sad)e, bat aber felbft mit Dem Winben, wenigitens unmittelbar, nichts zu idaffen. Das Winden gebt aud bes Nadts vor fid.

Sm Reim Eann man nod) nid)t erfennen, ob die Pflanze fich winden werbe; aud wadtien fie von 2 nfang alle gerao in bie Şöhe, ein Bemeis, Dás nur ibre eigene Sdjwere fie nieder: orüct.

Die Saugwarzen, z. B. am Epheu, entwicteln fith erit an ben Stellen, welde bie Stühe berïbren, bieílbe mag toot oder lebenoig penn.

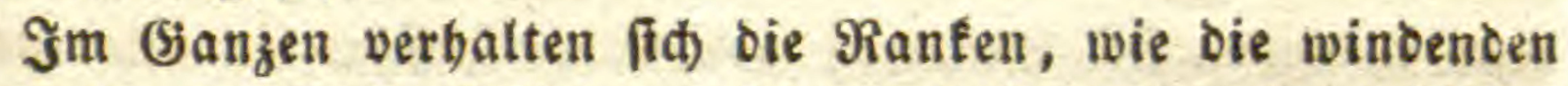

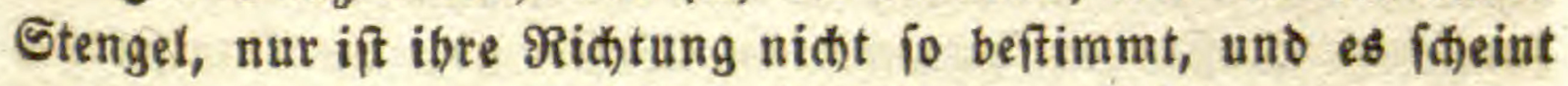
mebr bie \$ertrocfung babey eine Rolle zu fieten.

\section{Ridi)t.}

Wie bas lidtt fowogl ourd feine polarifterende ober jer= leksende alв burch) feine närmeerregende Eigenifhaft Das ganze Weltall belebt, fo aud) bie organifide $23 e t$ uno bejonders bie Pranzen. Man Eann wobl lagen, dás alle Pflanzen bes \&idtes beoürfen, vielleidft faum einige Sdimmel ausgenommen. Bey der Innäberung oer Sonne erwacht bie Pranjenwelt, uno febrt

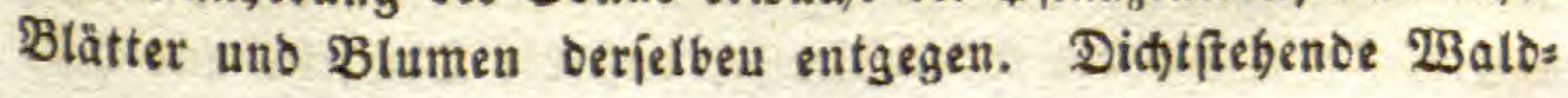


băume, in Sertiefungen wabjenbe Stauben verlångern mebr ibre Stengel, un aub bem Sthatten an bas Ridht zu fommen.

Das Beoürfnizis ift jedod veríbieden. Die pilze gedeifen am beften im S(t)atten uno jelbit in Şöhlen, wobin nie ein \&iđtfitrabl fällt uno baher nur bie Suft bie polarifterende Riaft

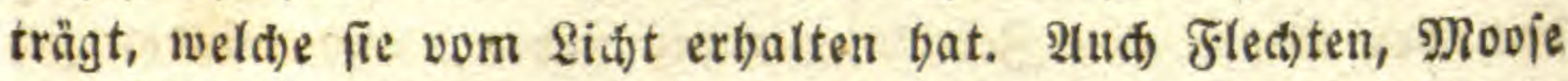
uno Farren gebeihen am beiten im Sathen, feood nidt in

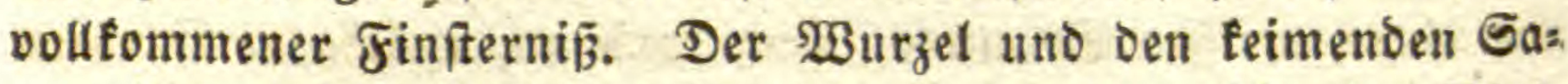
men ift oas sid)t idäblid), fo wie aud) oer Unterjeite bes slats tes, beföroert aber vorzüglid bas Deffnen ber Blumen und ibre Befäubung. Der Saft frömt babin, wo bas Ridt)t einfält;

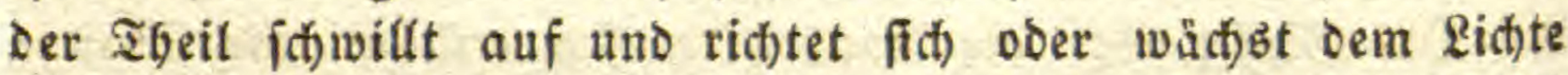
entgegen. Die 2tusbünftung wirb beförbert uno vielleidit felbft

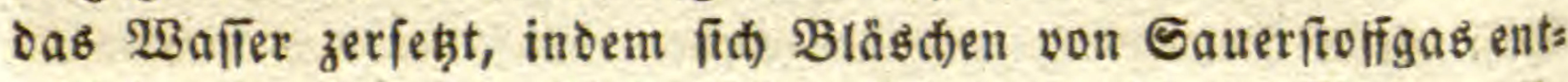
wicfeln; an ber Sberfläthe bilden fíd) Desorndierte Stoffe, wie flüdtiges ried)endes Del und Şar mebr Rublenftoff ab. Das Stärfemebl an Der Dberfädbe der Pflanzen wirb grün, in ben Bltumen uno früdten anders ge= färbt, uno bie Jarben ber $\mathfrak{B}$ tumen in ben Sändern unter bem 2lequator viel brennender als anoerwärts.

Man fann es ourd bie Berfude, befonders von $\Re$ u m for 0 (Eleine Sđ)riften IV. 1799), als entịieden anielon, baß̧ bie

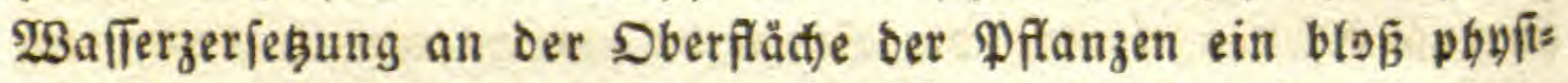

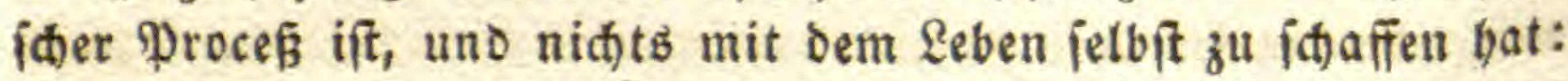
denn es feken fich Bläвd)en von Sautertoffgas an aflen unors

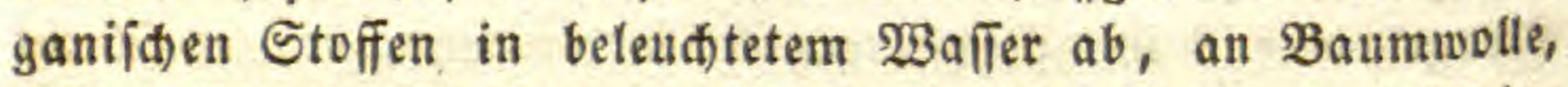

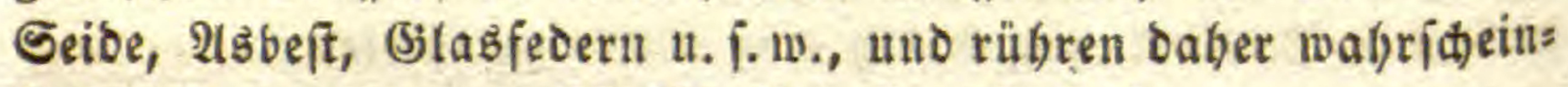
lid) bló̧ von ber am $\mathfrak{B a f f e r}$ flebenden $\mathfrak{R}$ fift ber.

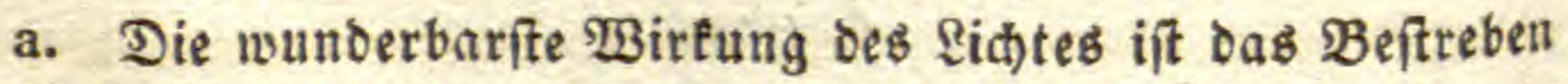
ber $\mathfrak{B}$ lå tter, ibre Sberfläct)e fenfredt)t auf oie einfallenden Strabs

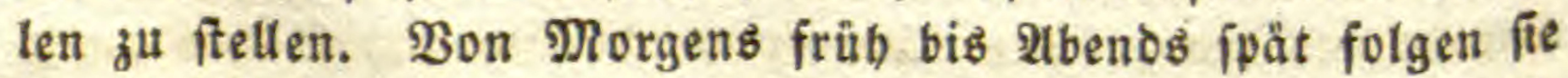

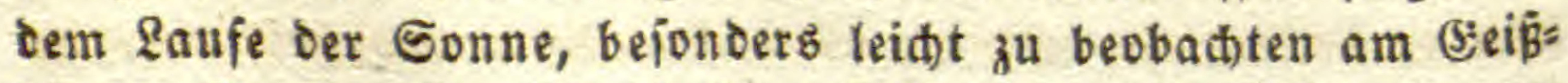
blatt. In ben (jemäd)b̆äulern fiebt man alle Blätter gegen

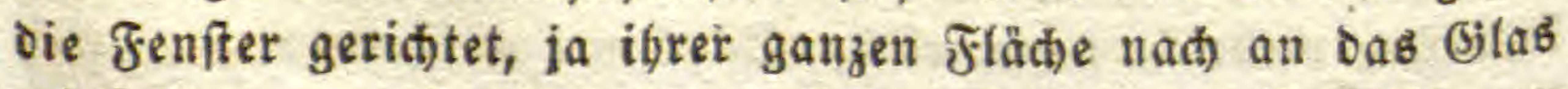
georiact, wenn fie naly genug fino. Sehrt man bie Pftanzen sm, fo Drebt fich ber Blattifiel io, bas oie Dberieite ans Sint 
fommt, uno bas gef(t)ieht mit foldher Sd)nelligteit, oas man bie Wenoungen bemerfen faun. Şält man bas Blatt veft, io biegen fich felbft die einzelnen Lappen um. Die Dberfläde ber

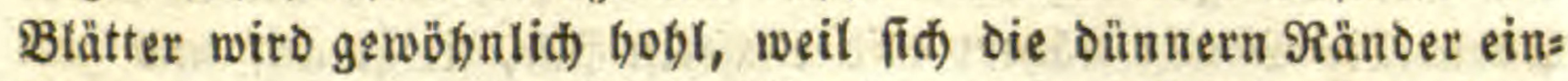
biegen, tuno die zarten Fieberblättchen rid)ten fich felbft auf.

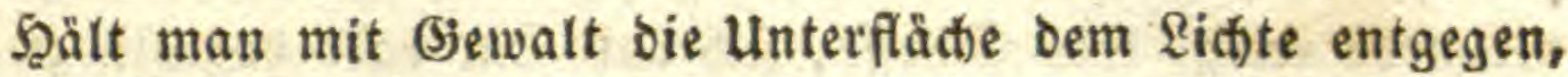
fo wirb fie braun, endlid fđwarz, und oab Blatt ftirbt $a b$, mand)mal ber ganze 3weig. Da man nid)t obne (jruno an:

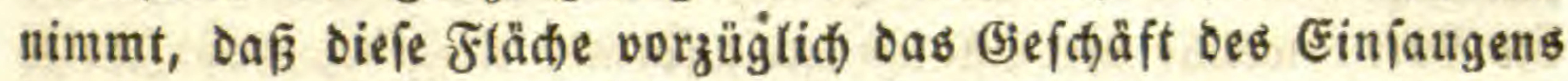
ber Fendtigfeit itber fith hat, bie obere Fläche bagegen bie bes 2lusbünftens uno wabrifieintid) bes 2ltbmens, io mag biejer Unteríbieo zu ber abweidenten Erídeinung bentragen.

So begreiflid) es ift, daßz Die Pflanze burd) die Einwirfung bes Ridhtes bemielken entgegen wäd)\&t, fo wenig ift bod ber phyfithe Srtuno von ber nirtliden Bewegung ber Blätter er= foriftit.

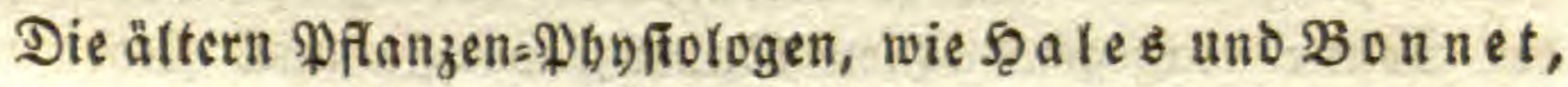

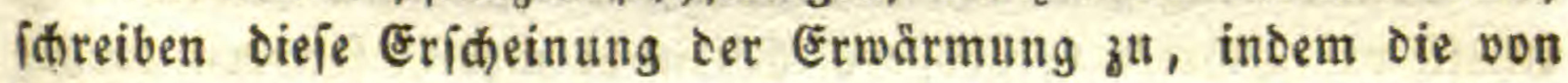

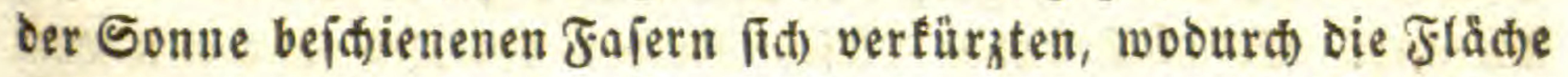
bobl werde, wie etwa ein Bogen Papier, ben man auf ben Dfen legt. De Eandolle mennt, eह jekge fid auf ber bejoienenen Geite mehr Roblenjtoff aแb ber Roblenjäure $a b$, woburd) biejer

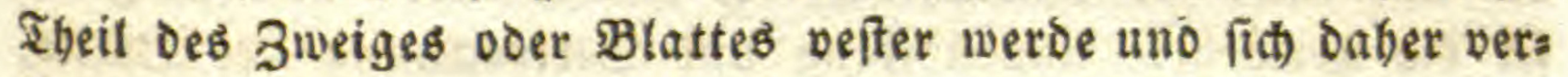
fürze. Bey beioen 2 (nnabmen ift zwar allenfalls bie Biegung bes 3 weiges oder das fouhlwerden des $\mathfrak{B l a t t e s}$ erflätt, aber feiness wegs oie Drebung Deffelben. Ueberbieß itände es folimm um Die Pflanze, wenn iłre Ernäbrung von eituem io zufälligen uno einjeitigen Beideinen ber Sonne abbienge. S. Ireviranub ithreibt baher bie Sache einer blofen $2(n z$ ziehung zwijhen bem Eidit uno ber obern Blattieite zu, womit aber ber phyfilithe Bruno ber Bewegung, welder in Der pflanze felbit liegen muf, nidt) angegeben ift. Man fann bod) unmöglid, fagen, Daß Das

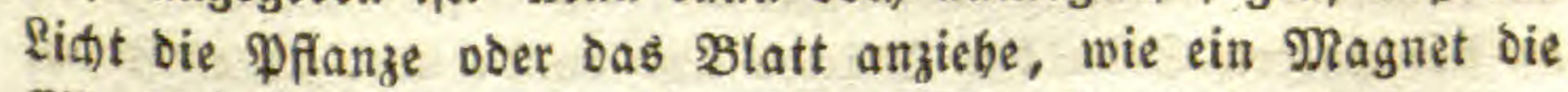
Eifenfeile, oder eine electrifłe platte bie papierínniz̧el.

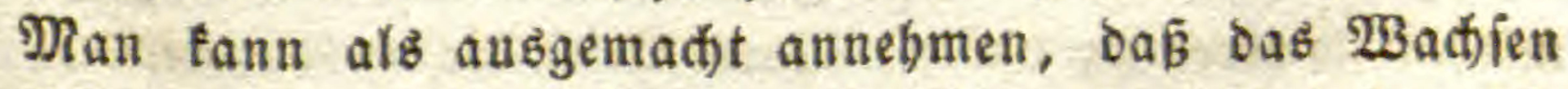
ber Pilanzen zum Sidgt einerlev phyfíden Gruno babe, wie 
Das Drehen Der Bätter. WBăroe bas Ridbt unaufbörlid) auf bie Pflanze iheinen, und wärde die Sonne fteben bleiben; fo wüt: Den alle Stengel allf unierer Erbbälfte íbief nach Süben ieben. 2tlteitt bie Sonne näbert uno entfernt fid,, fteigt auf unb geft unter, uno ziebt oaber oie PFlanze bald da= balo oortbin, oder vielmebr erregt ibre Sdjüfle, fith balb ba, bald oortí)in zu ver= längern. Da aber bie Sonne bey झुeitem bie meifte Zeit nid)t fajeint, unb baker bas sid)t von allen Seiten einfällt, aud

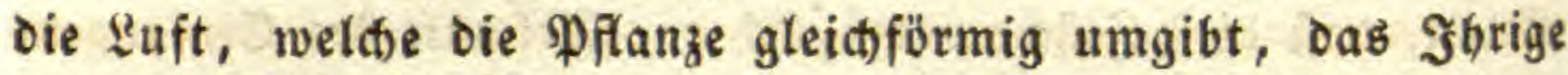
zum Eproffen benträgt, von ber geraben polarität bes Stens

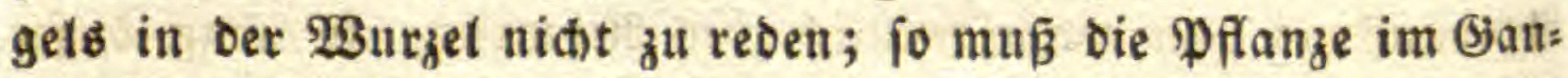

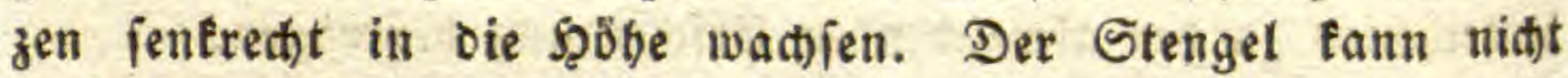
nad) bem Stande Der Sonne, und nad) ibrem 2ufs uno Unters gang fid bewegen, weil er zu fteif iff.

2tnoers verbält es fịt) mit ben Blăttern. Sie finb als immer jung uno weid) zu betradtende Stengel, weldie baher ber Sonne entgegenwadifen tönnen, wo fie aud fteben mag. 2(Uein bie Blätter vergrößern fïh) nioht mebr, fonbern breben f(d) nur. Es muß baber biefes Dreben einerley fenn mit bem

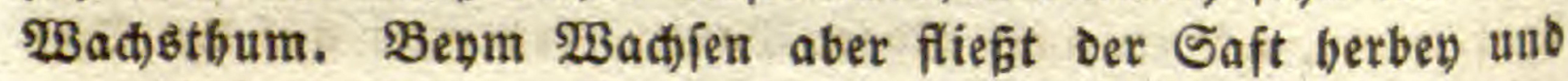
vermebrt die Bellen. Beym Blatt fann nur bas erftere geithes ben uno nidt das lektere; und ber S5runb davon ift ohne 3weis fel die vermebrte 2tuBbönftung und Bertroctnung bes Blatts,

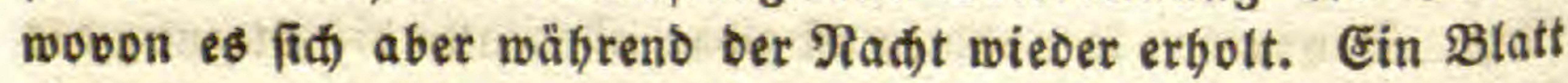

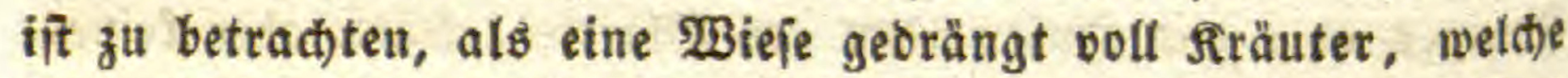
fich alle ber Sonne zumenden und fich Daber idbief ftellen. Das würbe ber Boden ber Wiefe felbit thun, wenn er in Ingeln bewegliă) wäre, und zwar bloß burd) das Uebergewicht ber nur nach) einer Seite bängenden frräuter.

Betraditen wir nun ben Bau bes Blattes, fo finb bie $3^{\text {els }}$ len auf feiner obern Flädje febr lang und fteben jentrect)t, bidjt an einanber, wie bie brasftenget auf einer 2 Bieje. Die zellen an ber untern Seite des Blattes fino rund, une fie entipridst

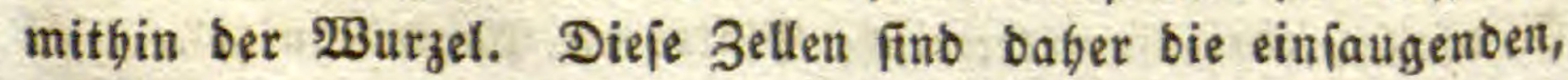
mithin fdwereren; bie ber obern Seite die ausbünfenden, und mitbin leidteren, und das $B$ latt legt fid) bemnad) wagred)t mit ber 


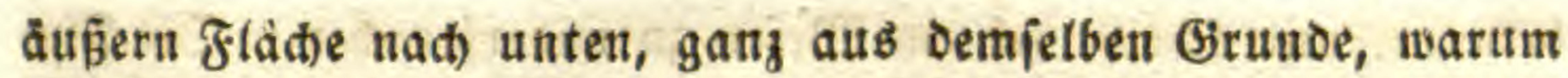

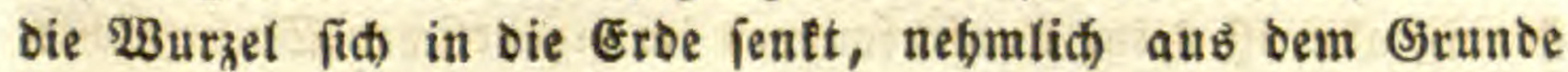
Der Sdwere.

गun if menn das Ridt auf feine untere Seite foeint. Der Wurzel be=

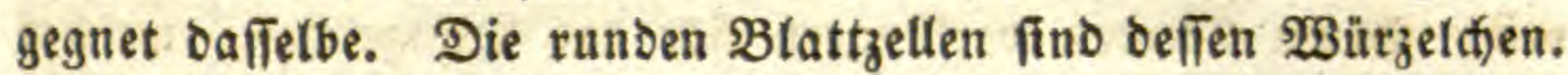

Fällt nun tein \&idbt auf Das $B$ latt, fo liegt es wagrect)t,

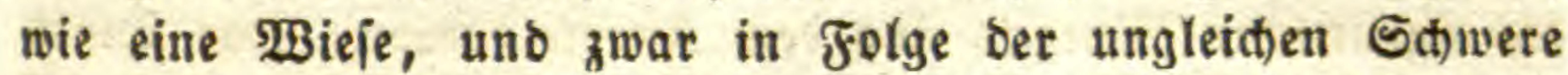
feiner Fläđen. Fäut Riđt jenfreht barauf, fo bleibt es in leiner Rage, weil bie langen Beflen fth) in Der Rid)tung befinden,

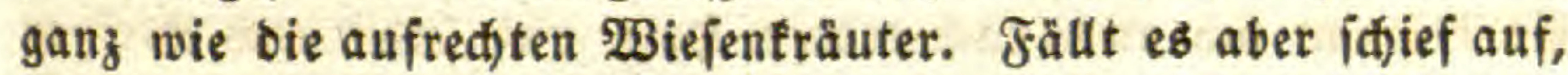
po rid)ten fich die Taujende von Zellen eben fo notbwendig bahin, wie die siăuter. Sie thun Das aber niđt aus einer 21rt von Inftinct, womit niđ)ts ertlärt wiro; jondern weil fid) ber Saft in ben Bellen nun nid)t gerabe nach Dben, fonoern nach einer Seite brăngt, uno mitbin auch) die Bellenwånte dahin treibt. Sie müften fĭ baber frümmen wie Die Rräuter. Da fie oie: ies aber wegen ifres didten Standes nidht tönnen; fo orebt oder wendet fth) Das ganze Blatt. Es ift Daber nitht die Sthwere, welde bey biejer Bewegung des Blattes wirtt, mie ben ber \$3urzel, fonbern ber 3 ug ber Säfte; turz die Erídeinung ift ein Stengelproce巨, niđ)t ein 23 urzelproce巨.

A b weidu $\mathfrak{g}$.

Ben ber Miftel fommt die fonderbare Erífeinung vor,

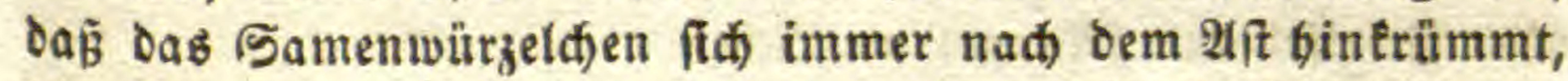
ber Same mag auf, unter ober an ber Seite befielben liegen. Die $\$$ ghnfologen verzweifeln an ber Erflärung oiefer fonber:

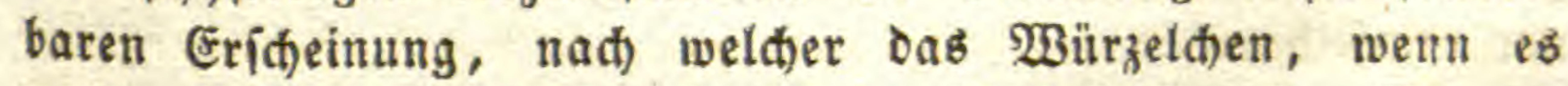
unter einem wagrehten 2 (ifte liegt, fid) offenbar oer S(t)were entgegenfrümmt. Dutrod) et hat viele Berfudie darüber ange= ftellt und glaubt, fie laffe fid) nid)t anders erflăren, als ourd)

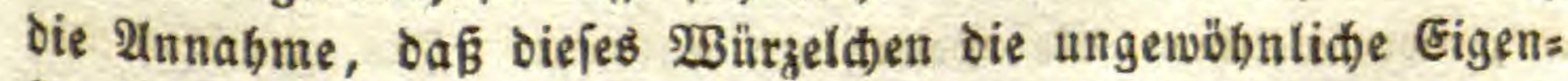
idjaft babe, bas Ridit zu flieben uno aljo oie Finfternifisu fuchen. Bon einer $\mathfrak{W}$ irfung aber bes \&id)tes, Daj es irgend einen sörper von fid) entfernte, ift in ber ganzen Ratur nichts 


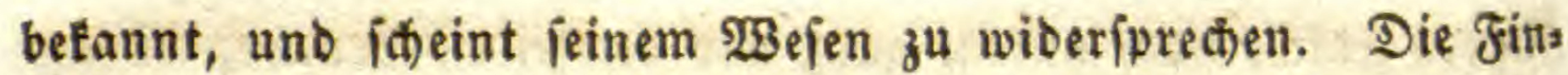
fterni $\bar{\beta}$ aber ift feine Sraft, fonoern im eigentlidsen Sinme nidts, und Eann baher nid)t anziehen. Im Srunde ift nur bie Mitte Der Eroe finfter, uno bamit fällt bie Sd)were zujammen.

Der Miftelfamen bängt burch) peine Rleberigkeit am 2ifte veft. Beym Seimen verlängert fï) bas WBürzelchen, weldes am Ende einen Snopf hat gegen ben 2 lit, uno Dann treten erft

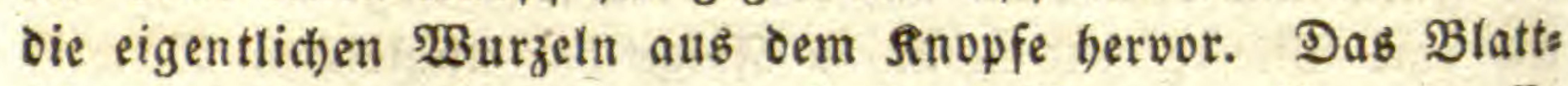

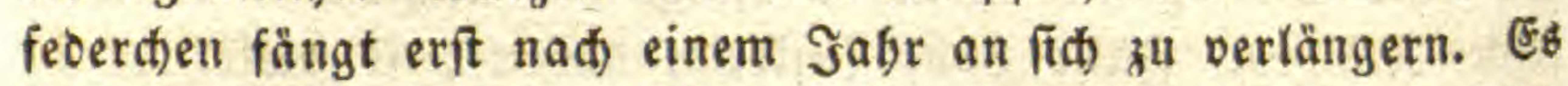

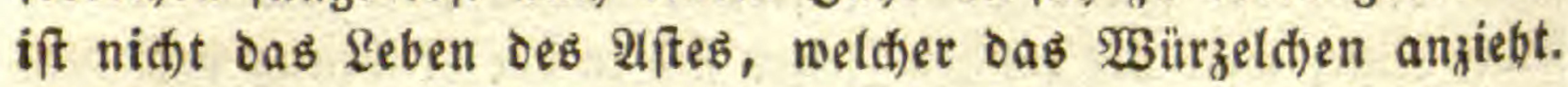

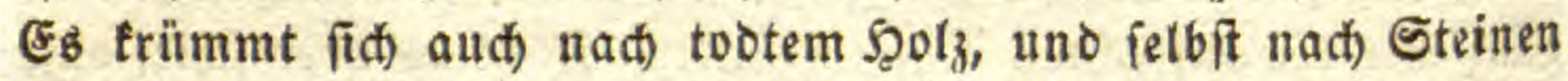
uno (jilas. Samen an eine Eiienfugel geflebt, treiben ibre

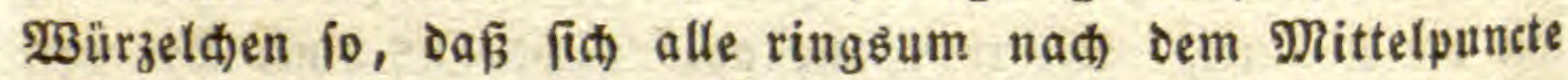
frümmen. Samen atswendig an ein Fenfter geflebt, treiben bas Würzelden nah) bem (Slafe; innwendig Daran getlebt, bas gegen vom (jlas $a b$, binten nad) Dem Simmer, aljo immer nadh Der bunfleren Seite. Samen in einer hölzernen $\Re$ öbre, welde

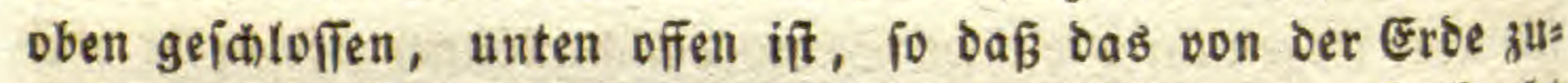

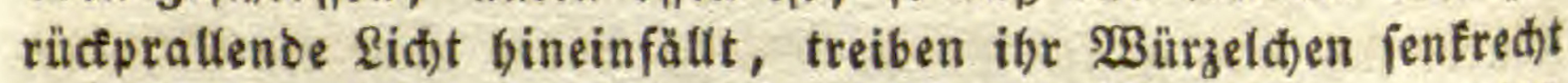

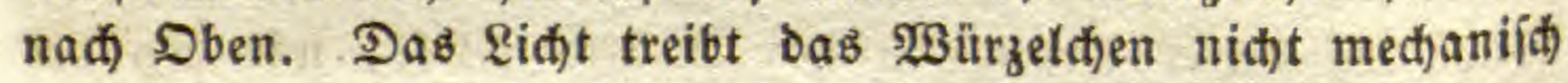
zurïct : Denn ftectt man einen Samen an eine Rabel uno bängt fie wagred)t anf, unter ein Fenfter; fo frümmt fid) bas $\mathfrak{B u ̈ h}^{2}$ jel(hen nach bem bunfleren Bimmer, ohne baßs fich bie Rabel

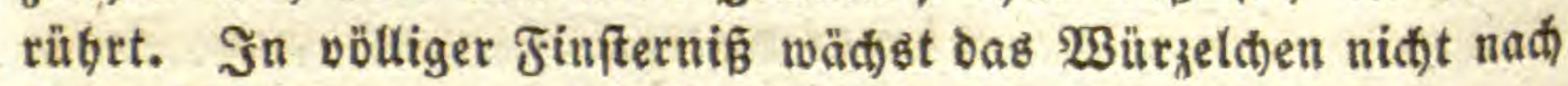
Dem Sörper, moran Der Same flebt, fondern ftirbt bald ab; obne Bweifel aus Mangel an Sidft.

Dieje Eridheinung icheint mir ertaläbar zu ienn, uno zwar ganz aus bem Beftreben nad) Dem Ridfte, nidjt aus ber F(ut) vor bemielben.

Mathematifí(h) ober medianifich genommen, ift es ganz cinets ley, ob fid) ber obere Theil bes Stengel: zum siäte wenbet, Doer ber untere bavon ab. EB Fommt nur auf ben Rubpunct all, von welchem bie Bewegung ausgebt. Эm gewöbntichen Fall if ber Stengel oben freg und unten beveftigt: baber inus fid) ber obere Ibeil nad) bem sidite frümmen. Bey ber $\mathfrak{\text { Nififel }}$ aber ift ber obere Ibeil, nebmlic) die Gamenlappen, bevefigt. 


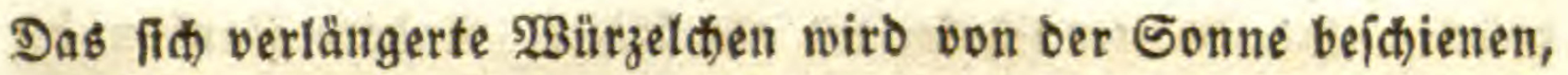
unb if baber als Stenget zu betraditen, weldier feinen oberen Ibeil jur Eonne wenden will. Da er bas nid)t fann, fo wito notgnendig fein unterer $\mathfrak{T}$ beil in berielben Richtung geftrümmt, uno Der Rnopf wäct)êt aufwärts an bie untere Seite Des 2lites.

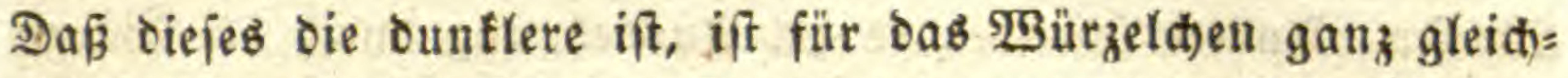
gültig. Dent man fict) Den Snopf unten an einem 2lite bängen, und bie Samenlappen fren; fo wärbe fta bas Woürzelden als

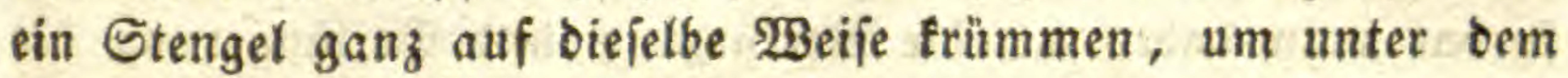
2hit bervor zum sidte zu fommen.

\section{Pflanzenfdiaf.}

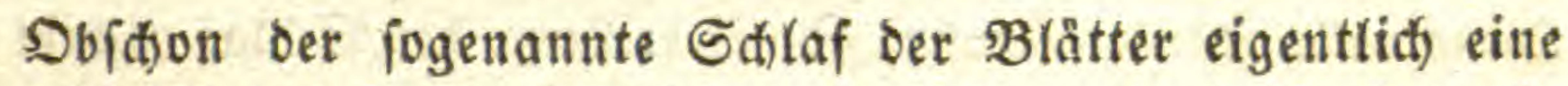
\&etenb=eridheinung ift, fo wiro er bod) bier am beiten betrad)= tet: Denn er findet ftatt ben Der arbweienbeit Deb Iidtes.

Es ift eine befannte Erfabrung, Daß ben Den meiften Pflan: zen fich) bie Blätter bes Rachts an den 3weig legen oder fith anjaliefen, wie in ber Snofpe; fo bas bie untere Geite nad, 2ußsen, bie obere nac) Innen fommt. Dieje Ericheinung zeigt fíd) jeovd häuffiger bey zarten $B$ lättern als bey bicfen, tno ift baher am beutlidiften bey den Fiederblättern, als welde fích

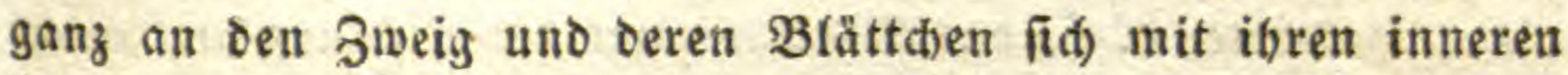
Flächen didbt an einander legen, währeno fidh bie einfact)en

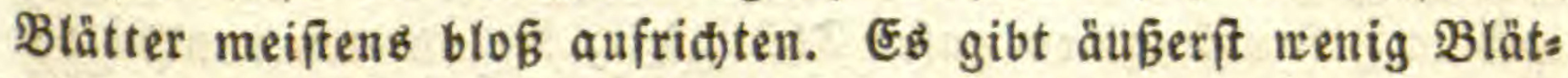
ter, weld)e fï) zurüctí(t)lagen, jo Das fie berabbängen uno bie innere Geite nad) 2 (ußsen febren, wie ben bem Springfraut (Impatiens), ber unåđten 2teacie (Robinia), bem Sauterf́lee uno ben Eaffien. Ђ̧ier muß ein abweidender Baum im Zell= gewebe frattinion.

Man Gat bieie Erideinung auf veridiebene 2(rt erflärt. Dutch Eríllaffung, wie bey Den Ihieren, indem wegen ber

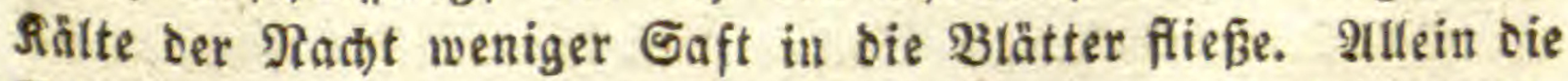
Blätter fino währeno des Sd)lafs feinebrwegs id)laff, wie bie MusEefn; fonbern nod) fteifer als ben Tage, uno idnellen fid fogleid) in ibre vorige \&age zurüct, wenn mant fie abgezogen bat: fie froben baher mebr als bey Iage, und jüngere Pflanzen 
orïțen ibre $\mathfrak{B l a ̆ t t e r ~ f t a ̈ r f e r ~ a n ~ a t ̉ ~ d ̊ l t e r e . ~ 2 n b e r e ~ g l a u b e n , ~ b i e ~}$

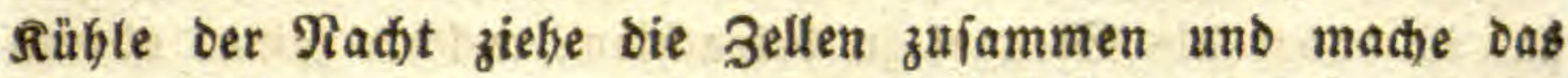
$\mathfrak{B l a t t}$ fteif; andere, $e^{\mathfrak{B}}$ ziehe aub ber $\mathbb{Q u f t}$ Feudtigfeit auf eine

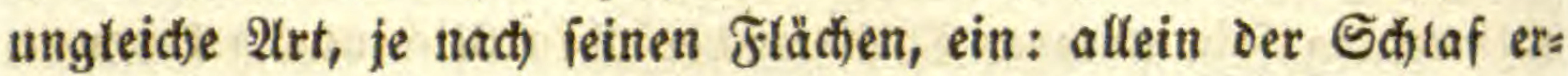
folgt bey troctener, wie bey feudter \&uft, und felbit unter Waffer. 2nbere fatreiben es ber 2(usbefnung buth bie Wärme 3u: allein ber Sd)laf finbet fatt bey allen Iemperaturen. Da bie Stelle der Bewegung eigentlid) im Bjelente bes Stiels liegt, fo hat man babey an bie Berfürzung uno Berlängerung oer

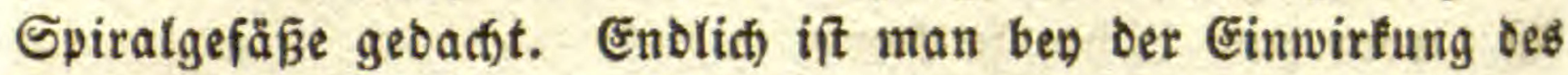
Sidtes ftehen geblieben, hat aber aud) ber $\Re$ Reizbarteit und ber

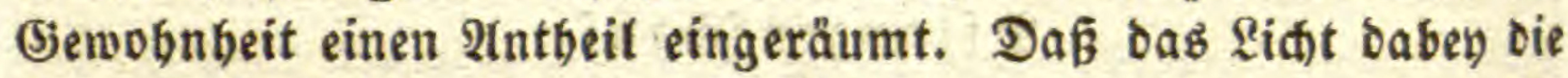
Şauptrolle fiett, ift ofne 3meifel: benn ber Sd)laf ridhtet fidh

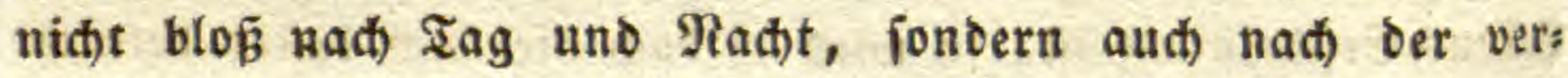
ífiedenen Sgelligfeit, und fogar nach gewiffen Stunden bes

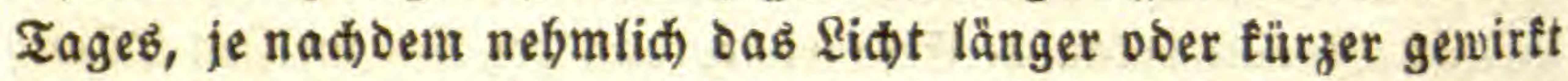
bat. De Eanoolle bradte es Durd) bas Ridt von fects

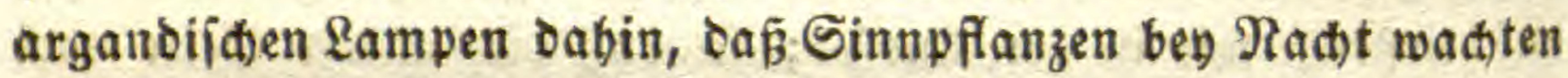
unib bey Iag fidtiefen. Enolid gleict)t bie Bewegung zum Sa)lafe fo febr bem Dreben ber Blätter nad) bem Ridite, oaß unmöglid) bie Uriache ungleid) fenn fann : nur ift bie Erideeinung

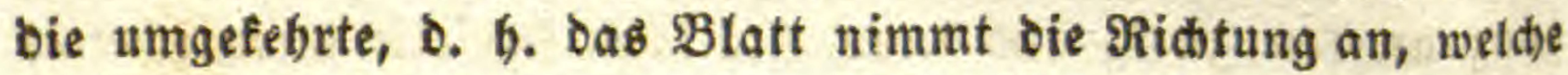
es baben witrde, wenn eв tein Sidjt gäbe. Die oberen fent:

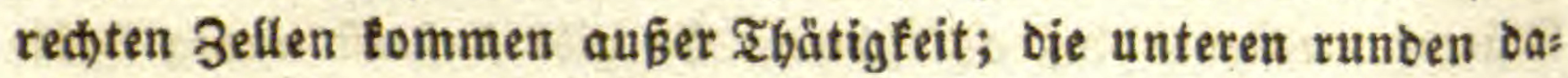
gegen fofwellen an und biegen ben Stiel nadi Innen.

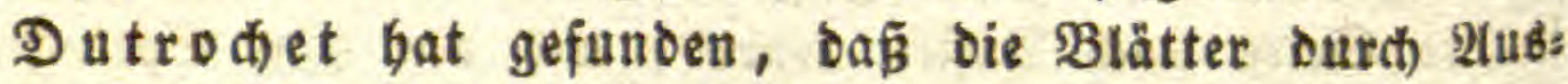
pumpen ber $\mathbb{E} u f t$ in ibren Bemegungen gleidjam geläbmt wer: ben. Das ift natürlid). Die Pflanzen mūffen gejuno fenn uno ungebindert atfmen fönnen.

\section{Blüthenidlaf.}

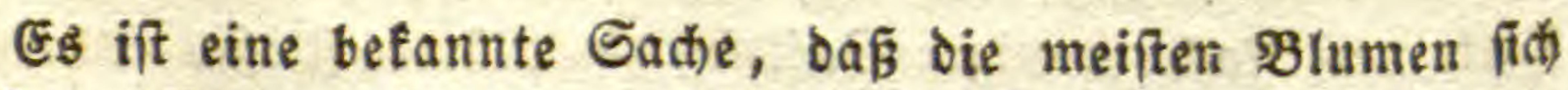
bey $\mathfrak{T a g}$ D̈fnen, uno zwar zu beitimmten Stunoen; mande aber

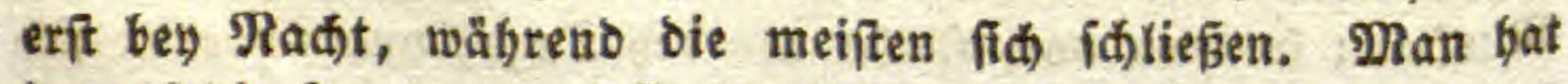
Darauf die fogenannte $P$ flanzen $=$ ubr gegrïndet.

Die meiften öfinen fic) bes Morgens früb, fobalo bie Sonnt 
erfdeint. Es gibt aber aud, bie fid) erft offnen, wann bie Sonne

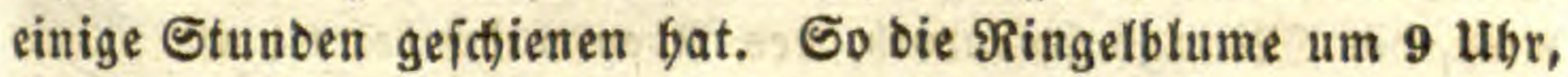
oer Portulaf und bie $\mathfrak{B o g e l m i l d}$ erfít um 11 ubr; die meiften Zajerblumen (Mesembryanthemum) um Mittag, bie $\mathfrak{R a d t f e r z e , ~}$

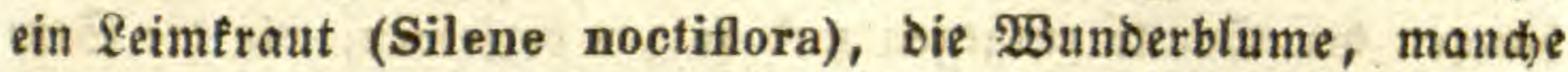
Cactus 2lbends um 6 uno 8 ubr, Die purpurrotbe Binde erft um 10 uhr. Dieje braud)t mitbin die längite Einwirtung oẹr Sonne. Die Erflärung fann feine andere fenn, als bey bem Benden der Blătter.

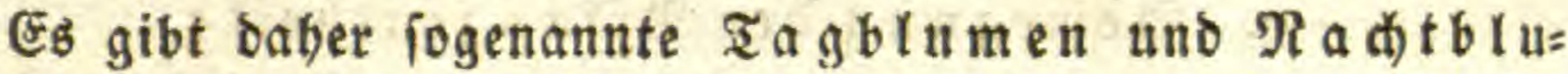
men. $\mathfrak{D b}$ bie leghteren fich erít in Folge ber langen Einwir= fung bes Ridhtes öfnen, ober wegen ber säble uno Feudtigteit

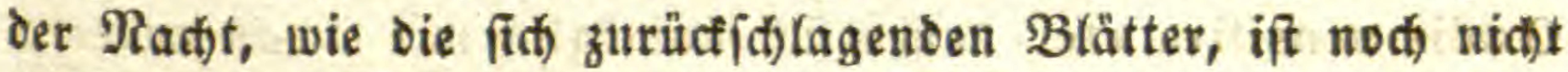
ausgematit. Daš Zellgewebe müste bann einen anderen Bau baben.

Es gibt ferner eintăgige Blumen (Flores ephemeri), welde fid bes Morgens bffnen, uno bes 2tbenos ober fiton bes

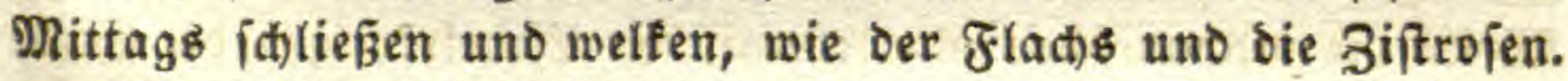

Ei nă ătige Blumen, wie ber grof́blumige Eactus.

Mehrtägige Blumen (Flores aequinoctiales) b̈fnen und iकließsen fith zu einer beftimmten Stunde, bald Des Morgens, balo शtbends, blitben aber mehrere Iage binter einander.

Endlic) gibt eb meteorif de Blumen (Flores meteorici):

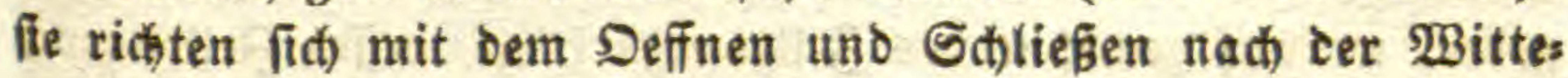
tung. Benn eb regnen will, fo b̈fnen fid bie Blumen man= der Salatpflanzen nid)t.

Iropifde B(umen offnen fid täglid bes गorgens unb fáliefen fich Des Itbends, aber zแ veridiedenen Stunden nad) Der \&änge Des Tages.

Die Borgånge haben ftatt im Treibbaub, wie in Der freyen \&uft, felbft unter $\mathfrak{B a f f e r}$, und find mitbin unabbängig von

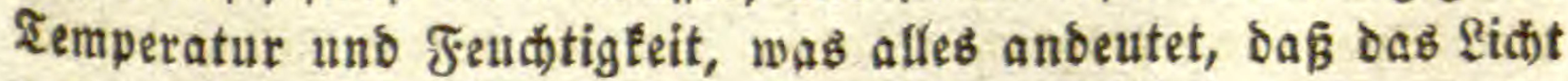
uno aud) wohl bie Dauter ber Ernäbrung bie Uriache bavon ift.

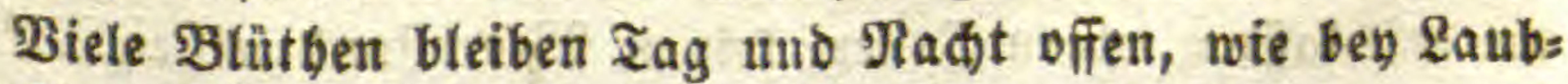
und Nabelbolz, ben Doldenpflanzen uno Den Dbffbäumen.

Die jogenannten Stundenblumen änbern unter Tags 
ibre Farbe, wie der veränderlide Hibiscus, weldjer des Morgens

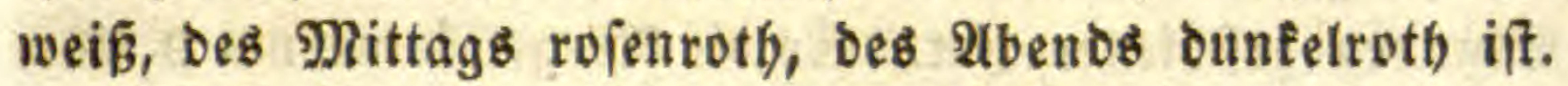

Biele Blumen bängen bes Rad)ts, weil fie ibre Stiele frümmen, wabrideintict) wegen Ërid)laffung berielben. Mande bängen ber Gonte entgegen uno folgen Derielben, wie die Son: nenblume. Das mus ebenfalls von dem beíndern Bau des Zellgewebes im slätbenftiel abhängen, und zugleid) von bem veränderten 3uge des Safteb.

\section{c. Bewegung oer Pflanzentbeile.}

Die auffallenten uno idnellen Bewegungen ber gefiederten Blătter der Ginn= $\mathfrak{A l a n z e n ~ ( M i m o s a ~ p u d i c a , ~ A v e r r h o a ~ b i l i m b i , ~}$ Oxalis sensitiva etc.) faffen fich) unmöglid) mit etwag anberem pergleidten, als mit bem Pflanzenid)laf; obition fie ourch Ers foütterungen ooer chemifide Einmirtungen veranlajt werden. Sie fönnen nidgts anderes lenn, als ein fidneller 2 Bectiel von S(t)lafen und $\mathfrak{B a d t e n . ~ E B ~ f r a ̈ g t ~ f i d ~ D a k e r ~ n u r , ~ a u f ~ m e l c h e ~}$ Weife die med)anifjen ober chemifđen Einwirtungen bie Stelle Des عid)ts oder vielmebr der Finfternis vertreten: beun bie Blätter legen fid) in Der Finfternís zufammen.

Die Bewegung geifiebt in ben (jelenfen, fowoht ber eits

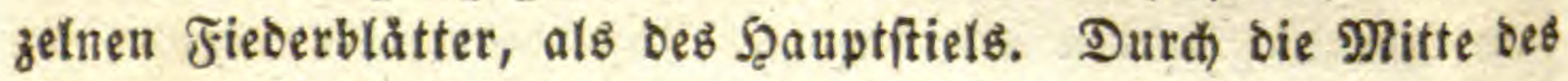
Stiel läuft ein Bündel Spiralgefäß̨e von geftrecten Zellen uns geben, worauf gewölnnlides Bellgewebe folgt, beffen Bellen nact

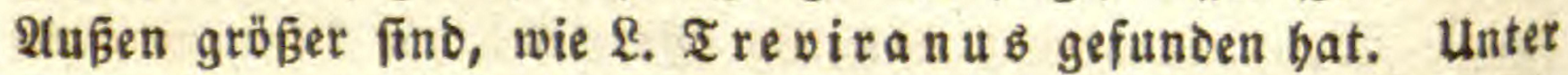

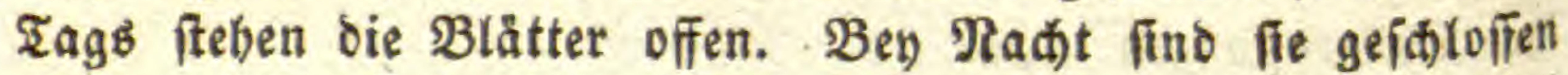
ober an eimander gelegt. Das legte erfolgt aud bey ber (E) (ifütterung, aber nicht bey fanfter Berübrung. Die Eriditterung muß ftärfer. Nun find aber im sidste alle oberen Bellen gerao ges ridftet, uno mithin in Spannung. Durd die Erídütterung wiro bieje Spannung plöb̧lich geboben, uno bie untern Bellen befom: men das Uebergewidft, woourd) das (selent fich biegt, weil bie eridlafften obern Bellen feinen গBiberiftand leiften. Es ift im Grunde Diefelbe Eriffeinung, wie bey Den fanellenden Eaps feln bes Springtrauts, welche auch erft eintritt, wann bas 
Şindernif; geboben ift. 2tu eille Reizbsrfeit Der veften Theile unb an eine 3 ufammenziebung berielben, wie bey ten Musfern, oarf man baber aud) bier nidht benfen.

\section{BIattid)wingungen.}

Jit bieje Erflärung die riabtige, fo fant man aud ben ben Bewegungen des Şabnentepfs (Hedysarum gyrans) feine andere veriudien: obidjon fie anbalteno uno jelbit bey Radt

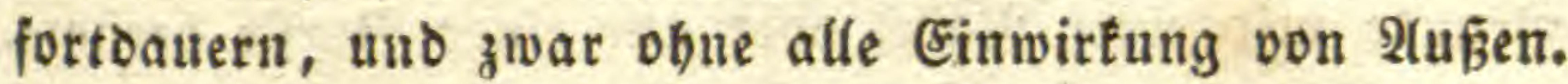

Das Blatt beftel)t atts oreb Blättchen, novon oas unge= rade fid unaufbörlid rechts und linfs brebt, als wenn es bas sidit fuctite, $\mathfrak{B o n}$ ben Seitenblätt(t)en erbebt fich bas eine rud: weife, etwa 50 (5rab hod), oft in einer Minute, uno wåhreno ber Beit fentt fíc) bas andere. Dann febrt bie Bewegung um; das erifte fällt uno oas zwente freigt.

Die Erifheinung ift alfo wie gefagt cin beftänbiges Suchen

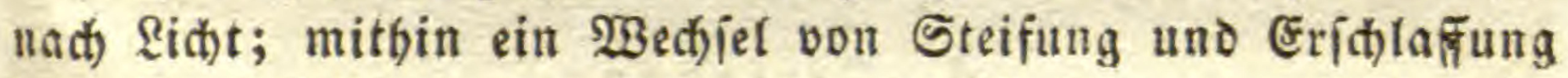
Der oberen Zellen, was vom ructweifen Ëinftrömen und Berb!n: ften ठes Saftes berfommen mu;. Man fönnte freylich fragen, warum hier ber Saft rucfweife zuftrömt: allein es fommen ïberall Extreme vor. Bey vielen Planzen iđlafen bie Blätter taum oder gar nidt, uno ber Saft fließst mithin gleid)mäßjig ein; die meiften follafen bes 2 lbends, uno fino mitbin für ben

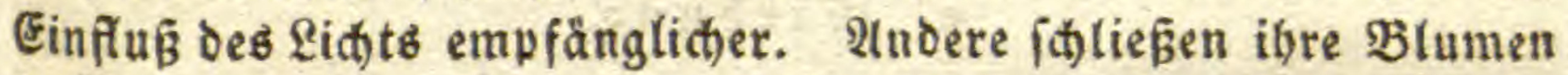
ithon bey rage, uno werben daber früher vom Sidft eridiöpft, oder an ibrer Dberfädue ítalaf. Bey den Sinnpflanzen geidiebt biejes nun fait augenblicflid).

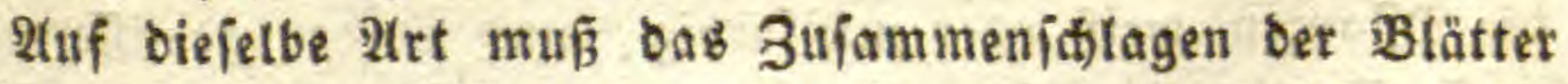
ertlärt weroen, wenn Injecten oarauf berumlaufen, wie ben ber fogenaunten Fliegenfalle (Dionaea) unb benm Gonnenthau. Das

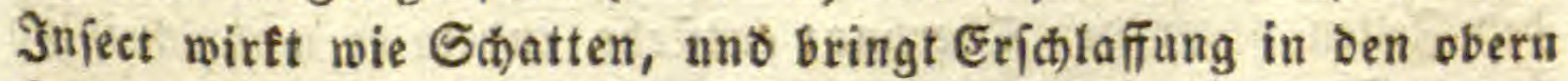
Sellen bervor, woburt) fit() bas glatt zum Ed)lafe legt.

Die $\mathfrak{B}$ ewegungen Det Staubfäben

gegen die Rarbe tönten auth nidfts anderem jugeidgrieben werden, als ber Spannung der an ber innern Seite liegenden

Dtens allg. शaturg. II. Botanit I. 
Zellen uno ibrer allmäblidten Erríd)laffung. Die meiften Staub= fäben nähern fich zur Beitäubung Der Rarbe, am Deutlidfifen bey unjerem Dbft, bey den Rauten, Relfen, Stordidnåbeln, Steinbrecten, bem Einblatt, Iabad, ben Rilien u. f. w., uno zwar meiftens abwectielno, juerit bie seld)= Staubfäben, uno Dann die Brumen= Staubfäden.

Bey bem Sauerad) bringt man bieje Bewegung plöb̨lid und fđdnellend bervor, wenn man bie Staubfäden innwendig an ifrem (3runde mit einer $\mathfrak{R a d e l}$ voer nur einer Borite beriffrt. Es brautht babey nur eine Zelle aus ibrer Spannung gebracht zu herben, io folgen bie andern nach und bie Rüctenzellen be: fommen oas Uebergenid)t.

2tebnlide Bewegungen ber Griffel find ielten; ood) fidnelit Derielbe plöb̧lid) ab bey einer neuholländijden Pflanze, Stylidium, wenn er mit einer Rabel unten berübrt wiro. Die Rarben von

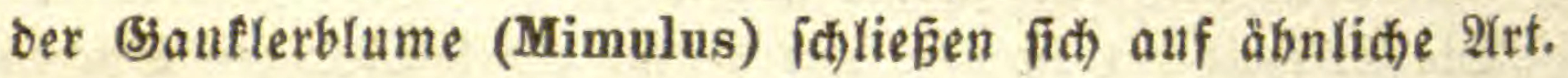

\section{d. Beriebung.}

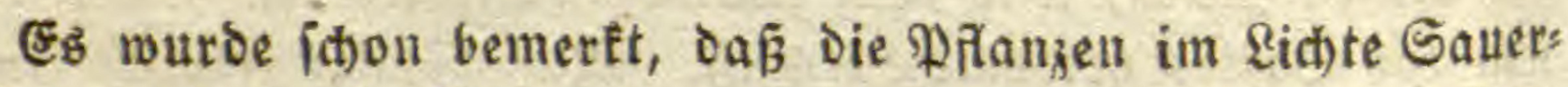
ftoffgab uno sublenfäure entwicfeln, jenes vielleid)t bur(b) 3ets

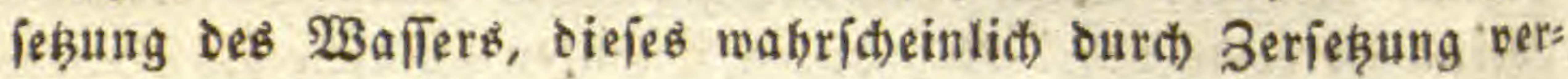
idiedener Stoffe.

\section{e. $F \mathfrak{a} \mathbf{r} b \mathfrak{t} \mathfrak{g}$.}

Eine Şauptwirfung bes Ridtes ift die Fårbung der Pflans zentbeile.

2tn bunflen Drten, wie in fiellern oder (Sebuiliden, bleiben

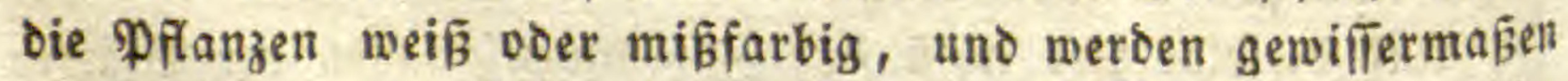

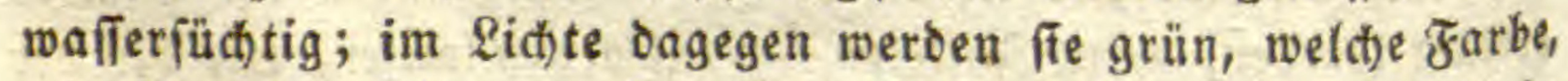

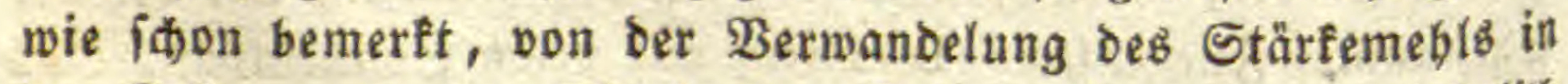
ben Bellen unter ber Sberbaut entitebt, indem es wabridbeinlid, burch) Desorybation harzartige Eigeníchaften belommt.

Es gibt feodd) auth bin und mieber innere Theile, welite grün find, wie mandie Samen und felbft ibre $2 B$ ürzeldhen.

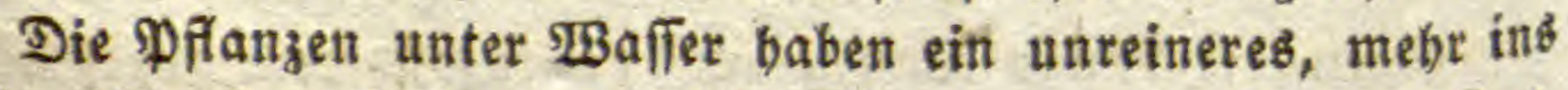
(B)elbe fallenbes Birün, wabridheinlid) wegen geringerer Dess 
orybation. Sie befinden fich zum Theil in ben Umfänden ber פsurzel.

Die Blätter verfärben fíd) vor dem $2(b f a l l e n$, weil Das Siđ)t nid)t mehr fo fräftig wirft, uno oaber weniger besornoiert.

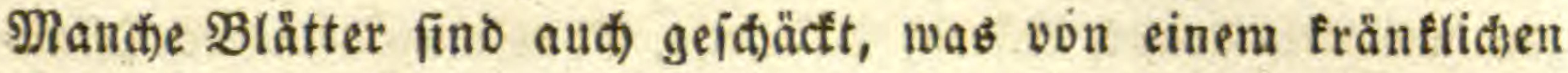
3uftande berzufommen itheint. Dieje Eigenid)aft pflangt, fith jebod) fort.

f. Eigenes $\&$ idt $t$.

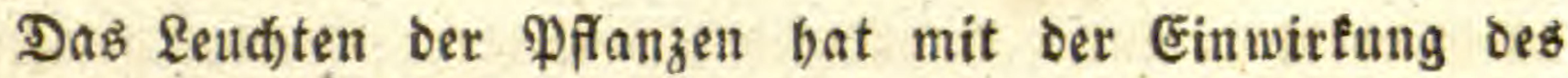

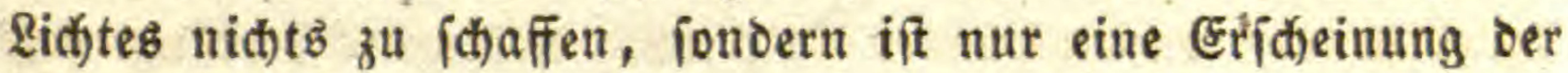
beginmenden Fäulnis. Daber entiftebt bas Reuthtbolz nur, wenn es im Safte gefällt worben ifi, uno bas Renthten zeigt fitch vor= zäglich im Baifte, wo fich am meiften Saft findet.

(E⿱ gibt auth Pilze (Rhizomorpha), welthe in Bergwerten

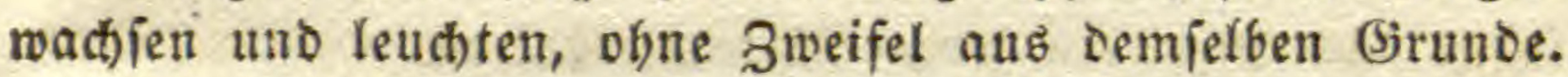

2(uct) will man ein bliz̧artiges Reu(t) ten an gelben Blumen,

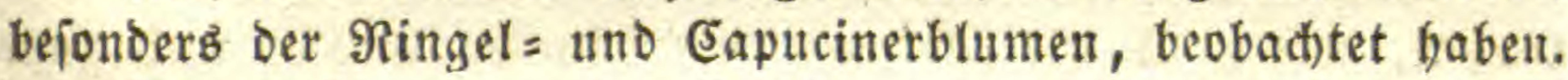

Die meiften thierifiten Subfanzen, bejonders Fiift), leuts:

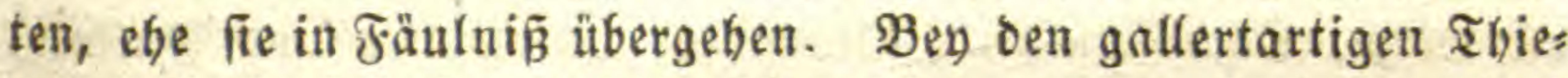
ren, wie Snfuiorien uno Quallen, fann man annebmen, baß ber Sdhleim ibrer Dberfläche in bejtänoigem Zerję̧ungèproceffe begriffen ift. Daffelbe gilt von Muideln, Sirebs(t)en uno Seut(f)t= tảfern.

Wab man von ber entzünolidien 2t moiphăre bes Diptams

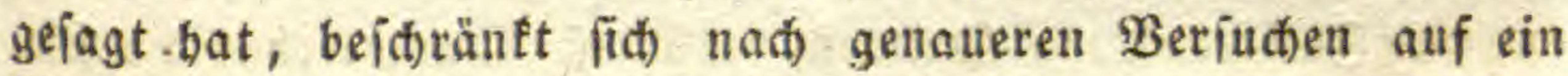

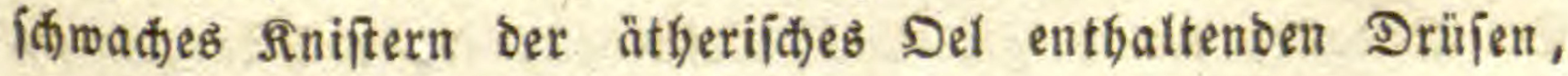
wenn man ein Riḍt baran Gält.

\section{3. $\mathfrak{B} \mathfrak{a} \mathfrak{r} \mathfrak{m e}$.}

a. 2eusete $2 \mathfrak{B}$ å $\mathrm{rme}$.

(Fs ift eine betannte Sade, baß bie Pflanzen nur bey einem

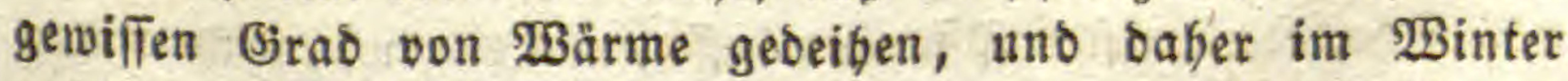

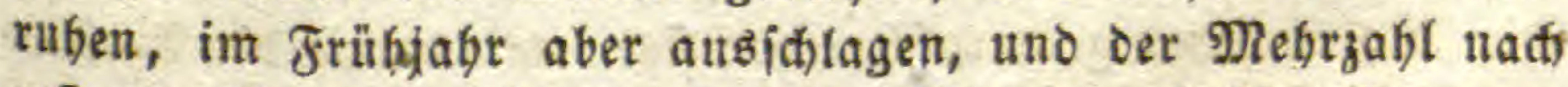

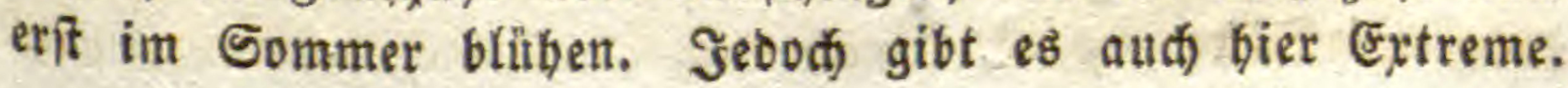




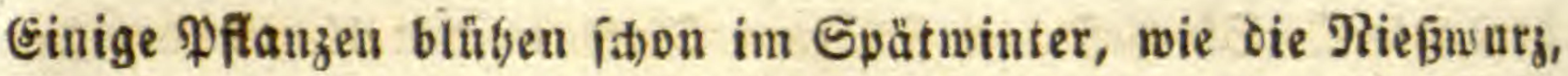

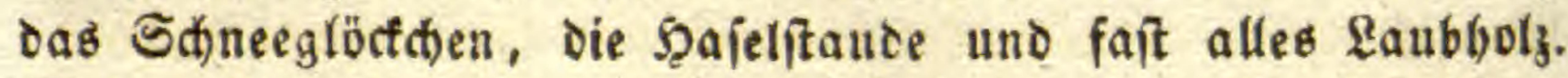
Einige gibt es auct), weldhe felbit in warmen Quellen leben, und zwar nidbt blö $\mathfrak{B a f f e r f a ̈ b e n , ~ f o n d e r n ~ v o l l f o m m e n e ~ P F l a n s ~}$ zen, wie Eijenfraut, 2(itern, Brunelle. Ebenjo wadjien nod) Pflans

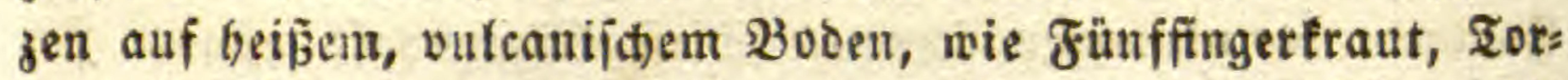

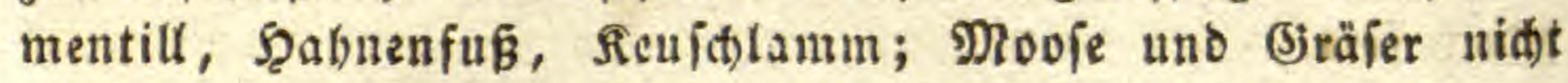
minber. Das fino aber Seltenbeiten, uno in ber $\Re$ egel gedeiben Pflanzen nur einige (jrabe liber Dem (5efrierpunct, bis etwa ju 20 Grad Reaumur. 2nhbaltend böbere Grade werden felbft bent Pflanzen Der heisen \&änber ídüdlic). Uebrigens verlangt faft jede Pflanze ibre eigentlide Temperatur, uno gedeibt baber nur in einem beftimmten Elima. Die Rabelfölzer extragent bie

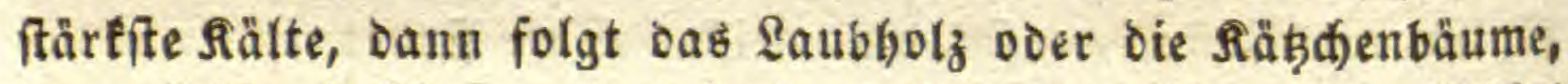
barauf bie (Sräjer, uno bejonders bas Bietraibe. Die Miftet foll jogar das biefrieren ibrer Săfte aushalten.

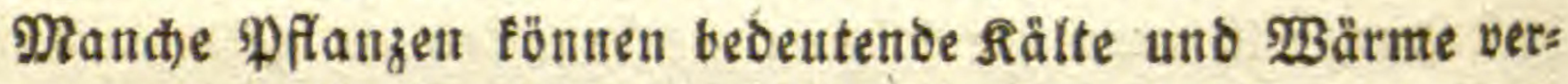
tragen, wie z. B. Die Flechten, Die Mooje, (jräjer unb zum

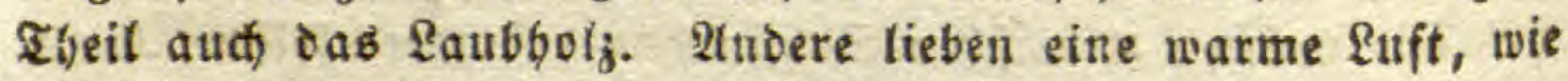
oie Pilze, Săblüfielblume, Sleander, Silienarten uno Palmen.

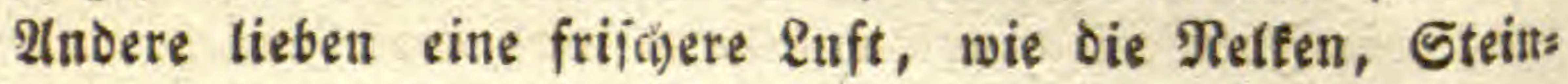

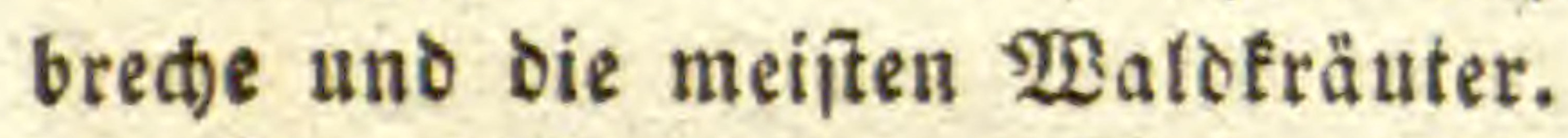

Die vollemmenern Pflanzen fino fedod) an eine beftimmte Temperatur gebunden, und es gebeiben weder bie nörolid)en in Geißen Ländern, wie unfer Dbft, noch) oie fübliden in falten,

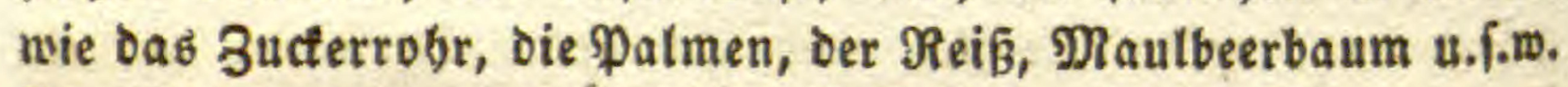
Es ift baher ein vergeblides $\mathfrak{B}$ eftreben, folthe Pflanzen an unjer Elima gewöbnen zu wollen." Jebem gebört bas Seine, und wir Gaben genug nitblid)e Pflanzen, um bie andern ent: bebren zu fönnen.

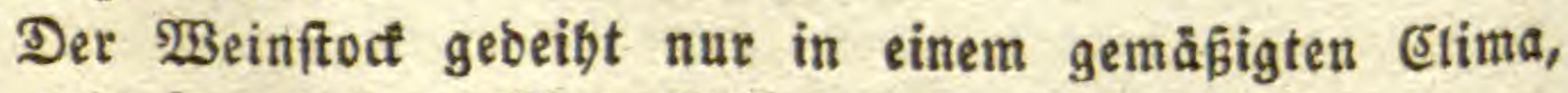
und gebt fowohl im heiß̧en als talten za Brunde.

Uebrigens betommt eine etwas höbere $\mathfrak{3 a ̊ r m e , ~ a l s ~ b i e ~ g e s ~}$ möbnliđe, ben meiften Pflanzen befier, als ungewöbnlid)e fälte. Die 2lubbunftung gebt ra[der vor fid,), und bamit die Einjauts gung ber Gafte und dis Ernảbrung. 
Die Stheibenpflanzen erfrieren leithter als bie Rezpplanzen, obne 3 weifel weil fie faftreider find uno feine Rinoe baben.

Uebrigens wirft ber Froft aud veridjieden auf veridfiedene Ibeile; Inebr auf Die zarteren Rnoipen, 3weige und Blätben, bejonters der Staubbeutel, als auf $\mathfrak{B u r z e l}$ uno Stamm. Die Samen fönnen die grögte såtte ertragen, uno ebento eine Şize, welcte felbit ten Sübgrao überifteigt, wenn fie nebmlid) trocten Derielben ausgeję̧t werben, vorăghlid) bas forn.

Mlan bat bemerft, Daß̧ ber Saft in bem Stamme fteigt uno fällt, fe năh ber Beränderung ber sälte. Ueberbaupt er: frieren bie 3weige eher als ber Stamm, und zwar vom Bjipfel

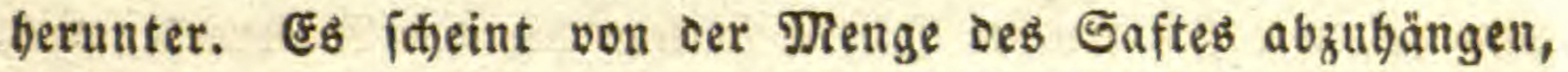
obiđon uniere Fettpflanjen uno Roblarten ber Raalte febr wiber: ftehen, vielleidtt, weil bie Rälte nidht zu ben inneren Ifeilen

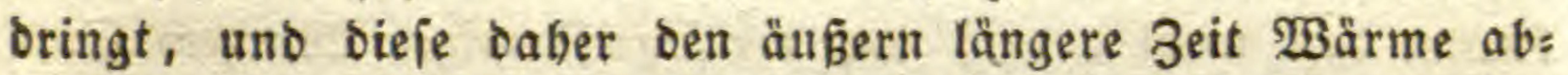
treten. 2(uB verídiedenen Beobad)tungen glaubt man id)tiȩ́en

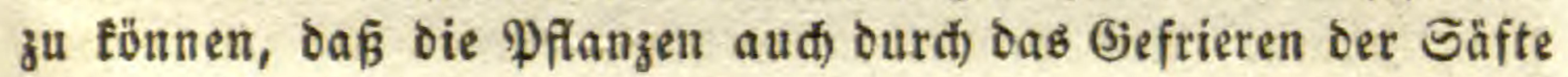
niđjt getöbtet würden. Dft findet man હißnnabeln in ben Stäm: men ber Băume und ber Fräuter, und bennod) bleiben fie ges fund; aud gefrorene 2 (epfel waren nat) bem 2 tufthauen nod gut.

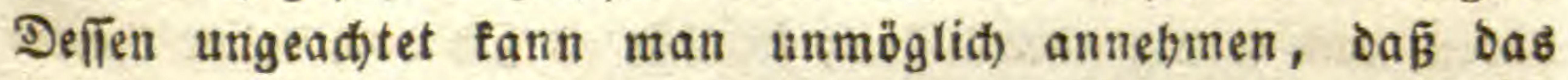
Gefrieren ber Gäfte ben Pflanzen nidte töottich ien. Es ift

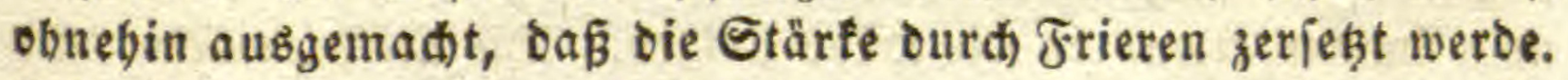
$\mathfrak{B i e}_{\text {if }}$ aber in Diejem Falle bie Fortbaner, ober vielmebr bie Wieberberftellung bes Rebens benfbar? 2(ud) wiberipridft ber allgemeine Erfolg Des (jefrierens Diejen einzelnen Beobactungen.

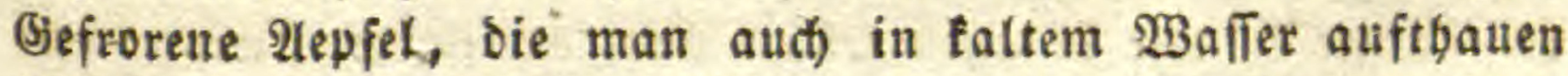
låkt, fino gejómact= uno fraftlos uno werben balo braun. Dai= felbe begegnet den Eroäpfeln. Blätter bängen wie geiotten bers unter, wenn nur ein Froft barïber geht. Swar erbolen fíth mand)e wieder, wenn man fie nur langiam aufthauen läb̆t, indem man fie mit $\mathfrak{B}_{a}$ ffer begiefst ober mit Schnee bedect. Db fie aber in Diejem Falle ganz ourd)gefroren waren, weiß man nid)t.

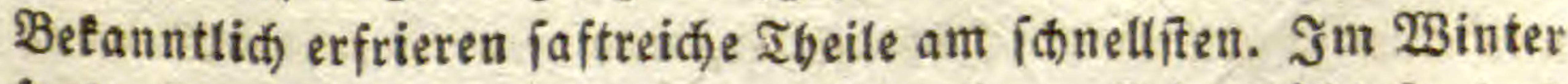

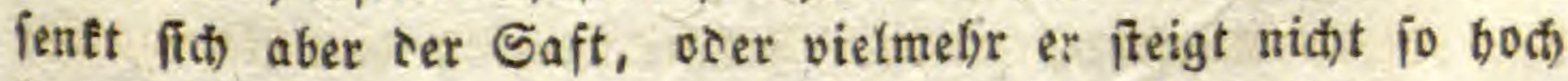
berauf, uno baber barf man mit ziemlider Sidterbeit anneb= 
men, Daß̧ nur einzelne Bellen oder Stellen in ben 21Dern uno Eücten gefrieren, was dem (Janzen nicht ichadet. Einzelne Stels lett aber zeigen fich Dod) gewöbnlic braun, fnorrig u. f.w. Bielleicht ift felbit der Nulm ber Bäume theilweife die Folge ชeอื Froftes.

In falten Wintern ift Rince uno jelbjt oas $590 l z$ ber Băume mit einem Rnall, aljo

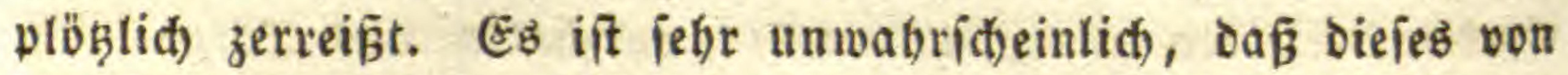
Der 2(usdehnung tes Eifes herfommt, Da effenbar die Bäume um Dieje Zeit faftleer find, fo daßs nidft wohl etwas anderes, als

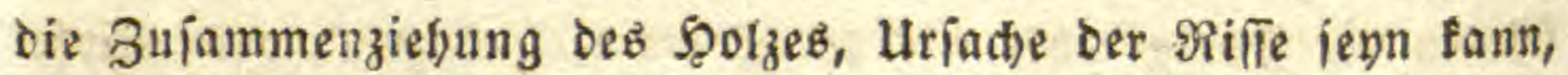
ganz fo, wie fin feutite Dielen ipalten bey ber 2htstroctnung.

Das 2tusfrieren Des (jetraibes uno anderer Pflanzen, wos bey fie nebmlidf beym 2nftbauen aus ber Eroe geboben werben, fommt ooch wohl oaher, daßs bie fegelförmiger. 23 urzeln Eaft einjaugen, und Daber in bem gefrorenen Unterboden nid)t mekr Plaķ, Gaben. 2tü demielben Jinunde werden die zugeipighten गummerbölzer uno Pfäble aus der Eroe geboben.

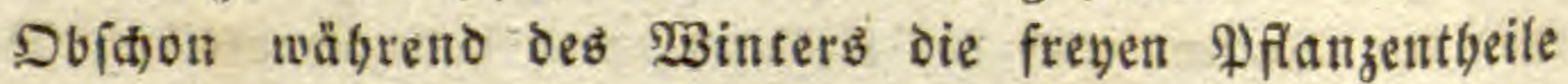
wegen Der Rälte unt des Mangets Der B!ătter wentig \&eben baben, uno wenig ausbünften; fo läftes fich ood) leitht bewei=

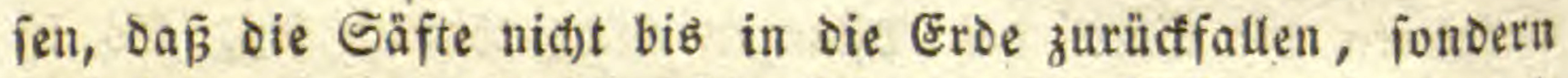
nod) immer etwas in Die Şöbe fteigen. Die Mifítel wädst uno blübt im 2 Binter; $P$ fropfreifer von immergrïmen Bäumen auf alloert erbalten fitc); im Winter abgeidnittene Sweige werten leid)ter; Rnoipen beịt)nittener Bäunte Dicfer; vor Dem $\mathfrak{W}$ Binter verpflanzte Bäume iđ)lagen früber aแร, als ins Gpätwinter ver: pflanzte. Die grüne Şaut unter Der Sberbaut bleibt grün, wiro aber braun, fobalo oer Baum wirflid, erfriert; grün bleibente Pflanzen mit uno obne Blätter wadjen fort.

Sobalo fich im Frübjabr bie 28 ärme erbebt, fatlagen die

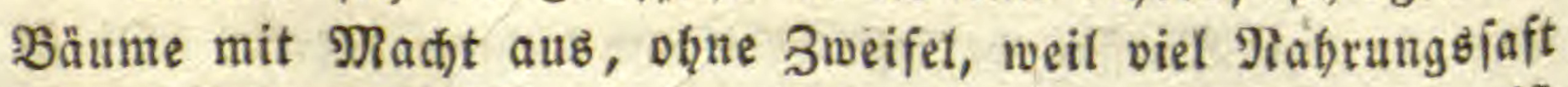
in ben Bellen ber $\mathfrak{B}$ urzel angefammelt, verarbeitet worben ift

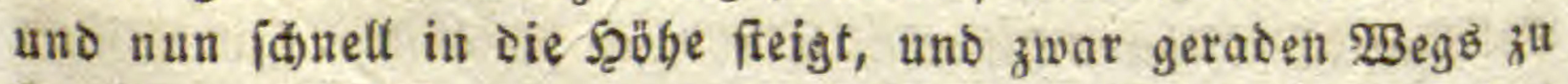

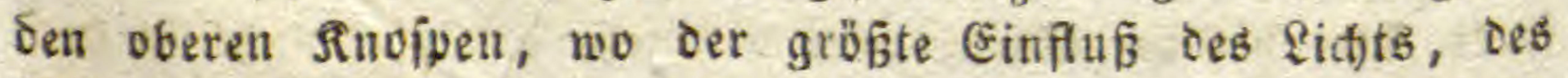
mुince, des Gaueriftoffgajes uno ber Electricität ift. Sie trei= 
ben im Frubjabr felbit bey eiter nieberern aemperatur beffer

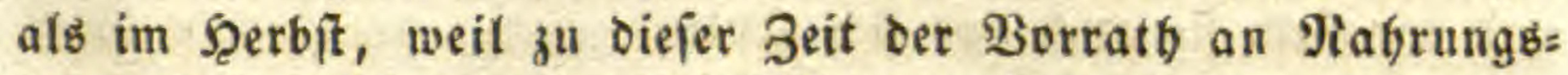
laft eríb̈̈pft ift. In oer Regel íd)lagen fie aub, weun bie mitt= lere Temperatur einige Tage lang ungefäbr 6 Grad betrifft. Das unmittelbare Riđ)t idheint babey weniger zul wirfen, als bie Feudtigfeit oer \&uft, wabrideinlid) weil bann weniger Saft verounitet.

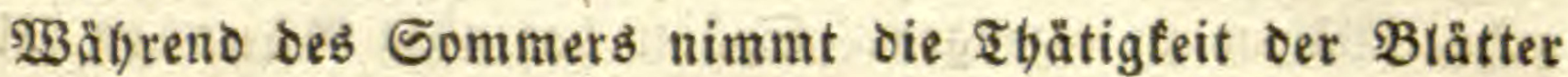
allmåblich ab, theils weil ber Saft verbrautht wird, theil(s weil fie vertroctnen, wobl aud, weil oie Bellenwände butch ben 2 b:

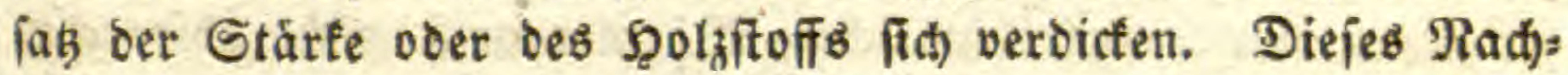
lafien ber Thätigfeit in ben $\mathfrak{B l a ̈ t t e r n ~ i f t ~ a i t d ) ~ w o b l ~ b i e ~ U r j a d e ~}$ bes netten Triebs im 2tuguft. (Es jammelt fị) nebmlid) allmäbs lich ber Saft wieder an, gerabe wie bey ben Maulbeerbäumen' die man wåbreno des Sommers entlaubt.

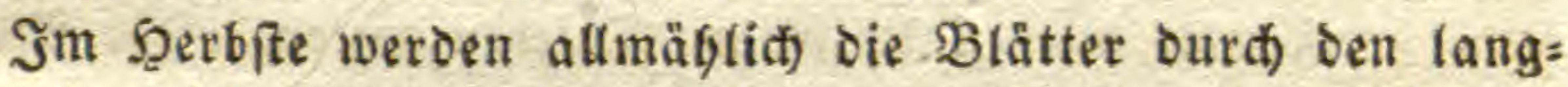

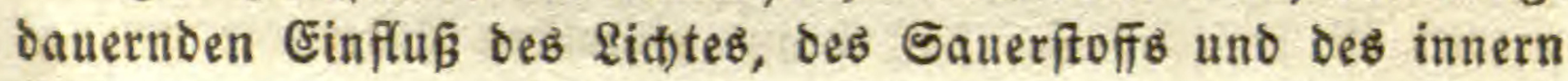
2ubjakes trocten, verfärben fïd, fallen ab und oaburch) fommt

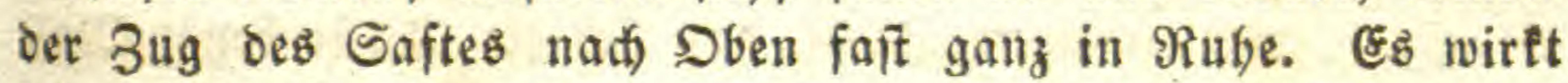
jekzt nidts mehr barauf, als bie zarte Rinde ber 3weige, welde einigermaß̧en bie "Stelle Der Blätter vertritt.

\section{b. Snuere ober eigene $\mathfrak{B a ̈ r m e . ~}$}

Eine andere Frage ift es, ob bie Pflanzen im Stande fins,

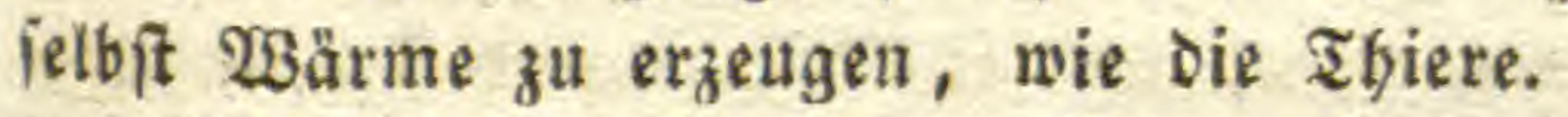

Man wollte beobadtet baben, ban ber Sance um bie Baumftåmme früher fodmelze, ałs anberwärts. Das foll jebođí) un Päble eben fo geícheben. Man ftectte Ihermometer in bie Bäume, uno fano fie etwas wärmer alł oie \&uft. Später bat man aber gefunden, Daß̃ bie Pflanzen im Sommer etwas fälter, im $2 B$ inter etwas wärmer als bie 2 uft fint, uno biefes wohl

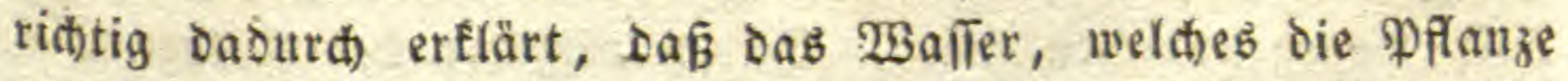

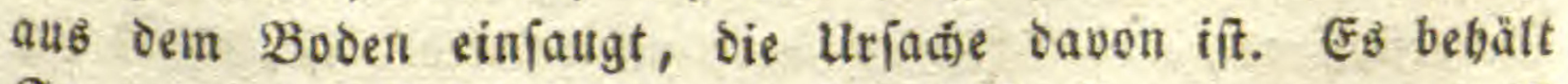

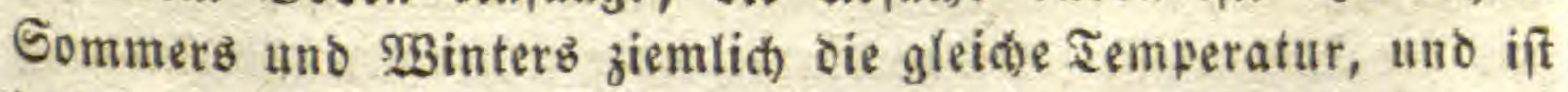
Daber bort fåtter, bier wärmer alb bie Suft.

Deflen ungeact)tet Darf Der Ernäbrungb $=$, 21tbmunge = uno 


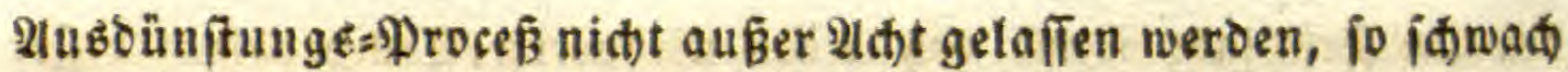
und langiam fie auth vor fich geben.

Sd) ilbler (Temperatur der Begetabilien. 1826, uno Tem:

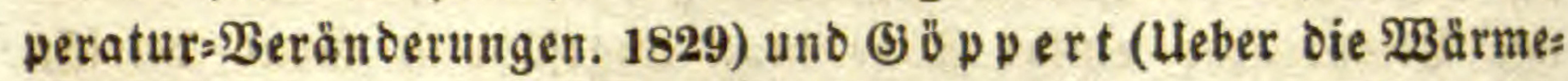
Entwicfelung in tell Pflanjen. Breslau. 1830. 8. 272) baben Die grïmblichifen $B$ cobachtungen Darilber angeftellt, uno fino zu Dem Sđlufle gefommen, daß̧ ben Planzen bas Bermögen abs gebe, গ⿰氵 Wärme=Entwictelung. WBien. 1832. 8, 25) Durd) Zufammens ftellung veridfiebener Lebensacte ood) gefunden, Dak man ben Pilanzen einen eigentbümlichen Ditrfe. Diejer zeigt fíc) am fïärfîten währeno des Reimens, bes fonders wenn viele Samen benjammen liegen, arjo ganz wie bey Den Injecten, benen man ebenfalts bie eigentbüntiche Wårme abipredten müßste, wenn es feine Bienenfïbcte gäbe. Dais felbe muß von allen faltblütigen Ihieren gelten. Shr 2ltbems proces ift io iđwad, daß̧ benm einzelnen Thier oie geringe Wärme nieder veridnuindet, wäbreno fie entifegt.

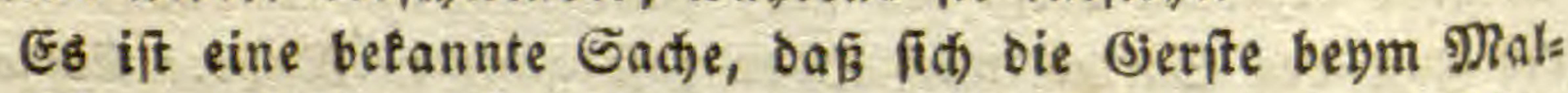

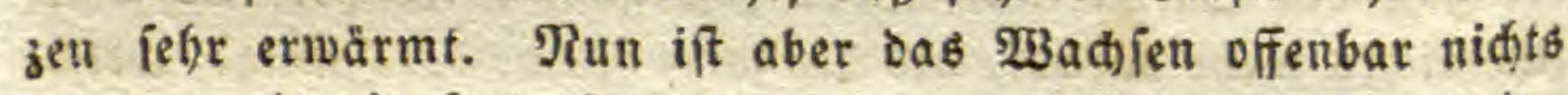

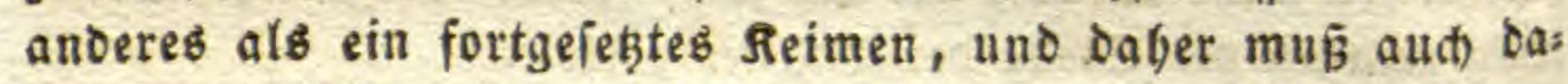
bey immar $\mathfrak{B a r m e}$ entwictelt werben. Bey erwachienen Pflats zell beträgt fie freylí, nur 1 bis 2 (5rad aus begreifliden

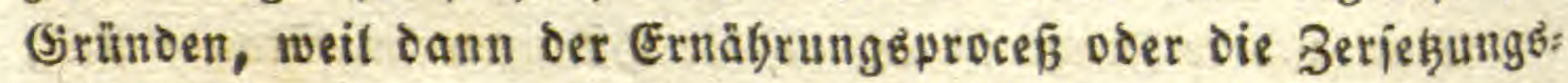
proceffe im Stoct natblaffen, uno in Blüthe uno Frndt übers gehen. Diefe finb aber binwieber in ber Regel fo tleit, Dak ibre Wärme nur mentig bemertlid) fenn fann. (5) gibt jeood)

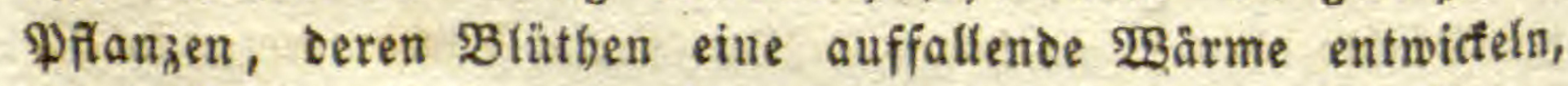
wenn fie bidt)t benfammen ftehen, uno bas fino bie 2tron=2(rten, bey welchen in ber Rähe der Staubfäden, furz vor ber Beftäu= bung, eine freve $\mathfrak{W a ̈ r m e ~ r o n ~ m e b r ~ a l s ~} 10$ Grab füber als bie Suft wabrgenommen witc. Dabey עerzebrt ber Solben viel Saueritoffgas, wobey freylich nod) unentíchieden ifi, ob es fict) mit ber Säftemaffe jelbit verbinbet, ober mit einer 2tusbünftung

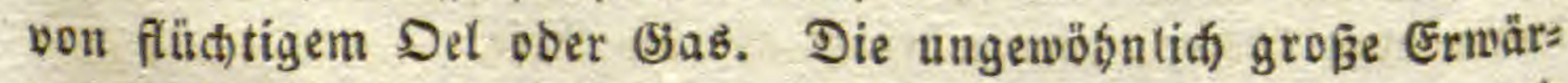
mung (prib)t fürt bas Reķtere. 2Ullein aud benm fieinten, uno 
benm 2ttbem überbaupt, bildet fíd) STohlenjăure mit bem Sauers

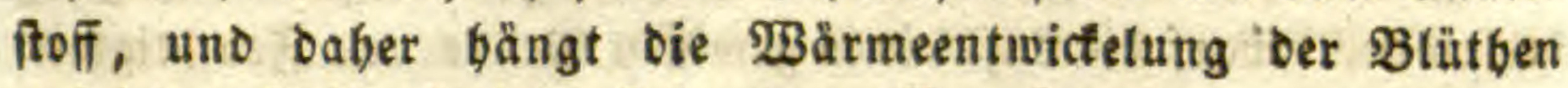
auf jeben Fall mit bem Lebengproceffe zufammen.

$$
\text { b. Inft. }
$$

Die Ruft wirtt in phyfifher Şinfidt auf bie Pflanze ourch

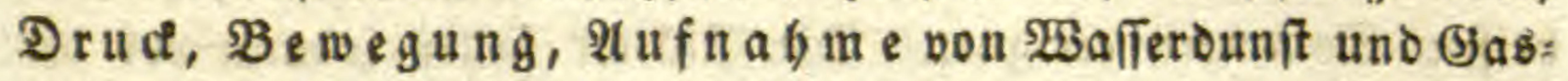
arten, uno burd) ibre Electricităt.

Dhne 3weifel wirft ber $\&$ uftor $\mathrm{r}$ a d auf bie Pflanzen wie

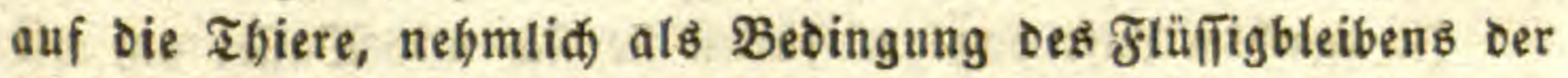
Safte; indeffen balten fie länger aus im Luftleeren Raume, uno lafien Saft uno \&uft nur austreten, wenn fie verlebst fino. Ë fino beionders die faftreidhen Pflanzen, weldhe am längiten im luftleeren $\Re$ aume ausbalten; inbeffen gehen auch fie allmäb= liđ) z̆ (jrunde, aแ begreiflicten Urjacten. Dhne Snuterftoffgas tönnen fie nidjt leben, von bem gewaltianten Suftande, in ben fie geratben, nidit zu reben.

Die Bewegung ber \&uft ift bem Jiebeiben der Pflanzen vortheilbaft. 2Utle Erfabrungen zeigen, $\delta a \mathfrak{B}$ die Säfte idneller fteigen uno bie Ernährung raịther vor fich gebt, wenn bie \$flans jen durd einen mäßigen $\mathfrak{W i n d}$ bin uno ber bewegt werden.

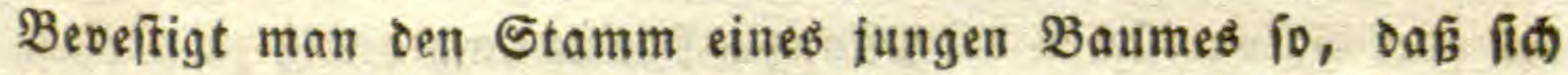
feine untere Şälfte nictht benegen fann, fo werbictt fich biejer Theil viel weniger als be robere und bie 2tefte. Beveftiget man ibn fo, oás er nur in einer $\Re$ Ridfung bin uno ber fowanten

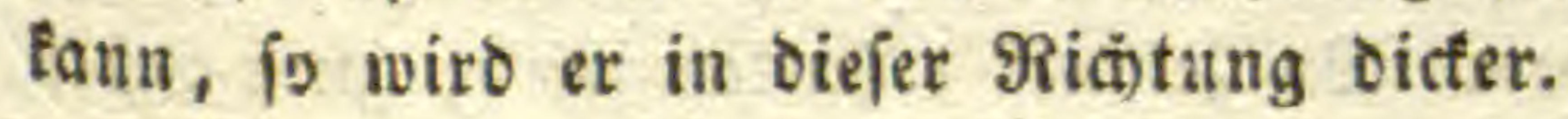

Pifanzen, welche beftändig winden ausgeję̧t fino, wie auf mäßgigen Bergen, gebeiben nicht in einem rubigen $\Re a u m$, wie die Allpenrofen 11. Dergl. Sind bagegen die Winde zu heftig, fo wähst Der Stamm nur in bie Dicte uno nidit in bie Şöbe.

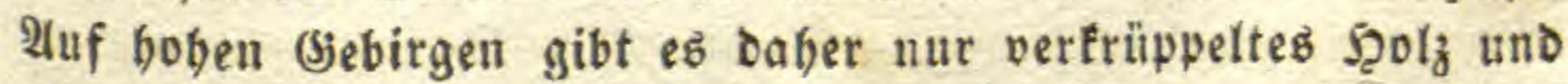
niedrige Stränber, weil die andern nitht fortfommen.

Der Wind ift endlich vorzäglich zum Beftäuben von ge= trennten $B$ tüthen nötbig, um sen Staub auf Die Rarbe ber entfernten Frudttheile zu bringen, befonbers bey unferm \&aub= und Rabelbolz. 


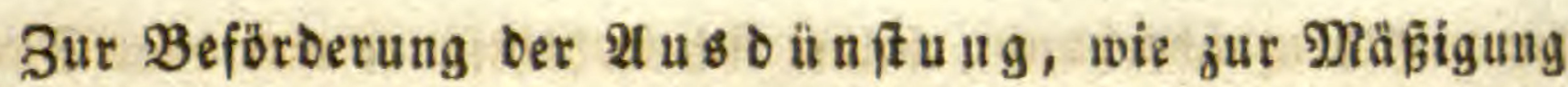
Derjelben, bedarf Die Ruft eines gemiffen Grads von Feudtigfeit.

3u heise ober troctene Suft, bejonoers wenn fie ourd ben Bind immer erneuert wirb, wie in fandreicten $\mathfrak{B e l t t}_{\text {theilen, }}$ 7. B. 2lfrica, entziebt Den Pflanzen zu viel $\mathfrak{B a f i e r , ~ j o ~ d a ß ̧ ~ f i e ~}$ leidst welfen uno fêlbît vertroctnen, was fid) auch bey uns in beişen Sommern ereignet. Die Blätter fallen fodaun vor oet

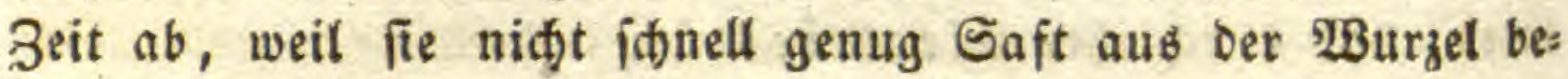
lommen.

In fend)ter Suft bagegen füllen fie fich mit $\mathfrak{Z a f f e r}$ an, wie in sen Siellern, voer wie es bey Den \$ilzen natirlich ber fall ift; ja fie verwandeln fidh jelbit zum $\mathfrak{T}$ beil in $\mathfrak{P i l}_{z}$, indem fie fófimmelig werben. Dft fino jojar bicfe Rebel bem (jetraibe und bem Weinftoct ídäb(id), wenn fie aud) nid)t lang anbautern.

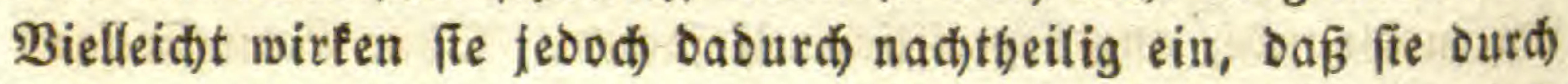
2tbję̧ung eines Stọfes, etwa von Raud), auf bie Blätter, bas 2tthmen uno oas 2(ubdüniten bemmen.

Die geiftige voer onnamijhe Einwirtung ber \&uft auf bie PFlanzen geíthieht aber burdb bie électricitåt, weld)e bejons

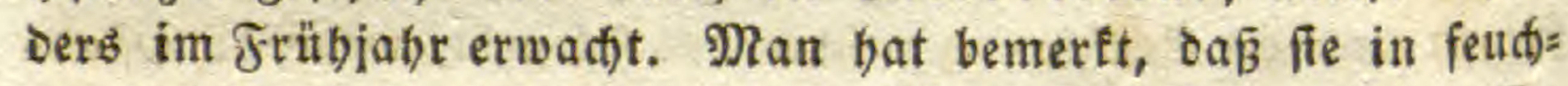
ter (s)ewitterluft am ithnelliten wadhien. Rüniftid)es Electrifies ren oder Galvanifieren ber \$flanzen foeint nad)tbeilig zu wirten, wenn es nidft ganz iffwach angewendet wirb. Starke Sithläge wirken fogar töbtfich. Shane 3weifel ift blow die beftändig ein wirfende iकwad)e \&uftelectricität, woourch ber (jegenfak bę Stammwerf́s mit Dem Wुurzelwert erbalten wiro, zum Reben Der Pflanzen nothwendig. Rünftlides Durd)leiten muß̧ bie Säfte zerieben. Uebrigens find no(b) nicht genug Beobact)tungen vorbanden, um über Dieje \$Birfung etwas Entítheidenoes jagen zu fönnen.

\section{c. Das $\mathfrak{B}$ affer}

wirtft auf Die Pflanzen, in phyficalijher Seinfitht, ourh Druct, Bedectung, Menge, Femperatur uno Benmiídung.

Der Druct ift no(t) nid)t gebörig unteriud)t, uno (d)eint

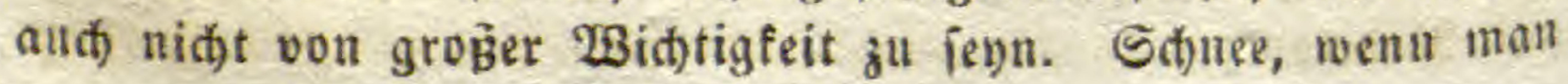


ifn bieber rect)nen will, mad)t ourd feinen Druct bie Bätune fritppelig, bejonoers das Rabelfolz, worauf er in פaffe liegen bleibt; ourch leine Bebectung fäitht er fte jeboch vor Rälte. Die WBirfungen des Sagagels fino befannt.

Die Be bectung mit Waffer if allen Theilen über ber Eroe inäblid, mit 2tusnabme bes Samens, welher jeovd) fei: nen Serridtungen nach alB $\mathfrak{B}$ urzel betradtet werben fann.

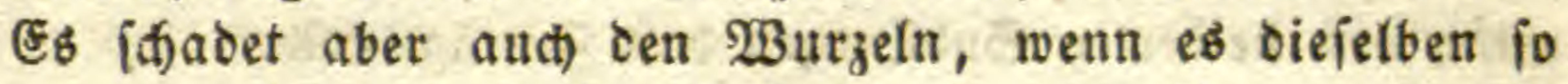
bedect, daßs feine \&uft 3utritt hat, oder bie Dammerde fid) nidht zerieken fann, wie bey Ueberíd)wemmungen ober im Thon=

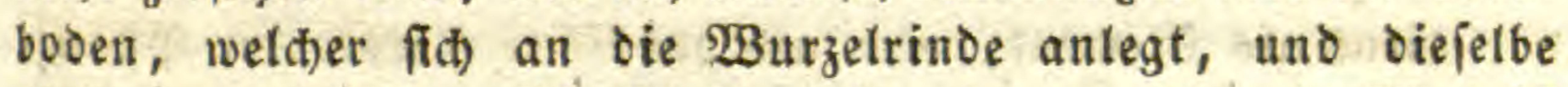
gleithjam verfflebt. Die Theile geben jooann leidt) in Făulniß

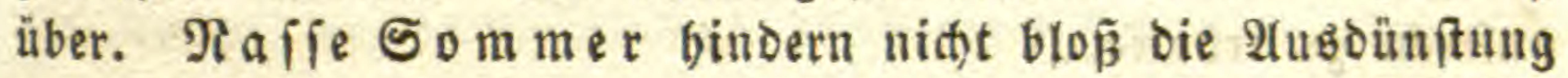

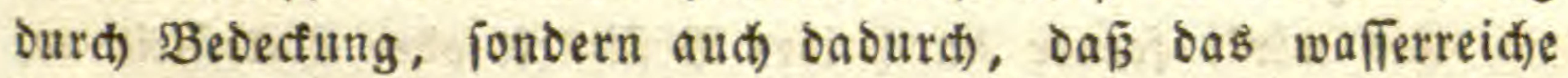

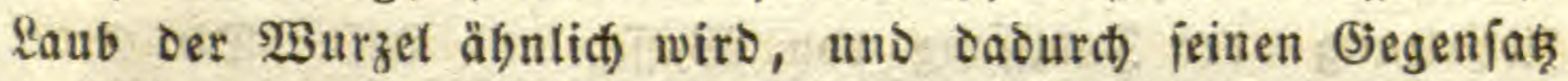
zur 23 urzel vertiert.

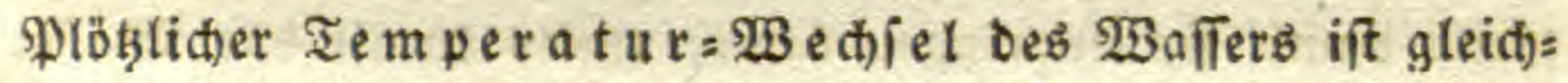

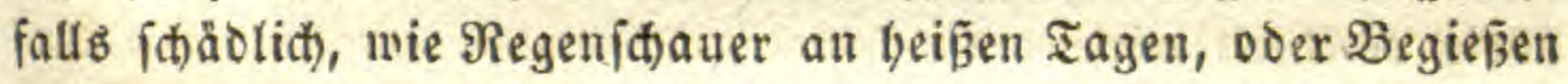
Der Pflanzen mit Quellwafler. Daber fammelt man zum $\mathfrak{B}_{e}$

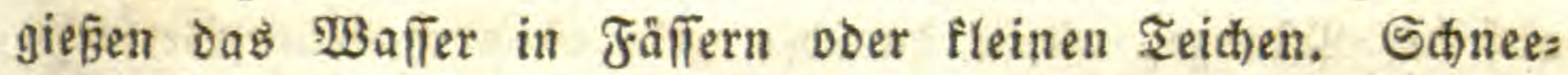

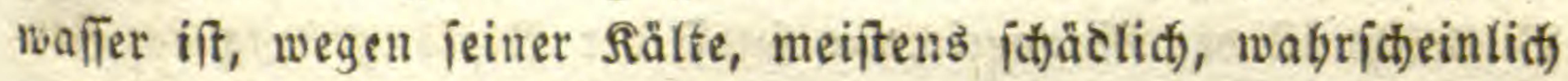
aud, weil es feine \&uft entbålt.

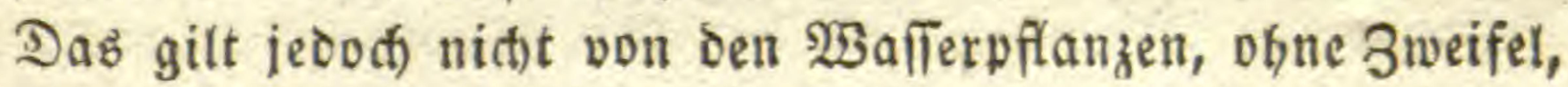
weil ifren Blättern die Dberbaut fehlt, uno fie baher, nẳ 2loolpi) Brong niart B Bemerfung, gleidfiam ourd Riemen atfmen, D. b. im Stande fino, das bem $2 \mathfrak{B a f t e r}$ antlebende Snuerifoffgas ourct ibr nactes Zellgewebe anzuiegen. Damit if eine verminoerte 2(uboünftung verbunden, wodurch bie \&uft in grof́en \&ücteli zurücfgebalten uno oas Sthweben Der Pfanze möglid) gema(t)t wiro.

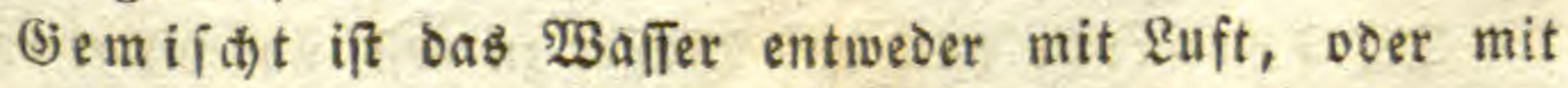
veîten Ibeilen.

Die erifte Mifdung ift wobithåtig uno notbwenoig, uno

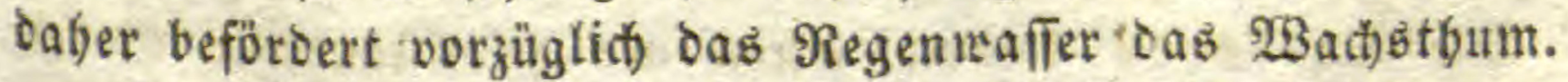

Die veften Ibeile find fo mandfaltig, oas am beften unter

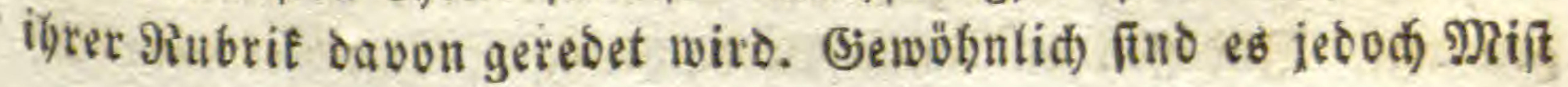


und Salze. Beibe fhaben, wenn fie in zu grofer Menge tarinu entbalten find; ber Mift bejonders baburd, baß er fidc) nidt

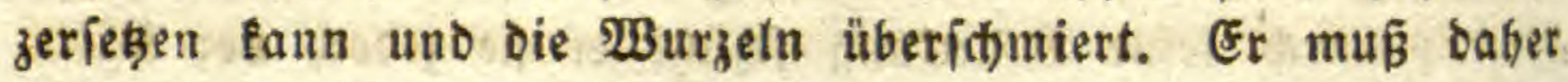
3u Derjenigen 3 eit angewendet werben, wann er im 3erję̧ung: proceffe begriffen ift, uno wann bie $\mathfrak{p}$ flanze in ber Zeit ibres Einfaugens ftebt. Da thierifache Beftandtbeile fidt) leidter jets feksen, uno bie Prlanzentbeile dazu veranlafien; io ift ein (Sie, milith von beiberlen Subftanzen bas 3uträglichite.

\section{d. Die Eroe}

bient als Element, ober als phyfifther sörper ber pflanze als Şaltpunct, woourd ber Stengel in Stand geję̧s wiro, fi由) aufrecht zu erbalten.

Sie wirft fermer burch ibre Beftigfeit ober \&octerbeit auf 2tbbaltung oder Zulafiung von $W_{\text {affer uno }}$ suft. Die Erbe, welde bie $\mathfrak{B}$ urzel unmittelbar umgibt, muß baber locter fenn, theils bamit fie einoringen fann, theils bamit bas Waffer ge: börig vertbeilt wirb.

Wabrideintid) wirft fie aud ourd) ibren Magnetismub auf bie Pflanze, allein bariber gibt es nod) feine Beriute. Bielleid)t ift Der Magnetismus felbit ber Berlängerung oer $3^{\text {els }}$ len in Befäpe uno ber Winoung ber Spiralfajer nid)t fremo.

B. Einwirtung Der Nineralien.

\section{a. Die Eroen.}

EF if teine einzelne Eroe im Stande, ben Pflanzen als ges Deiblidjer $\mathfrak{B}$ oden zu bienen.

Die Riefelerbe als Sano if zul locter, uno gibt ber Pflanze weder Şalt nod) $\mathfrak{B a f f e r . ~}$

Die Tbonerbe bålt bas खaffer zu veft, uno bilbet bamit einen Teig, welder bie $\mathfrak{B}$ urzel iiberímmiert, ben ber $\mathfrak{B}$ ertrocts nung fich zit febr zujammenziebt und die 3 ajern abreift.

Die Talferde foinmt felten alb felbiftändiger Boben vor, uno if nur ge:vőhnlid) als (stimmer bent Sanditein bets gemengt. Jnbeffen bat man Beobadtungen, baßs Sietraibe auf 
einem Boden, worinn viel toblenfaure Falterbe oder Dolomit ift, vertümmert.

Die falferbe ift zwar allgemein verbreitet, bălt febod) meiften $\mathfrak{x}$ bon im jogenannten Mergel.

3u einem den Pflanzen pafienden Boben gebört ein (S)e menge bou allen Erten, Sant, Thon uno Rale, woourd ber Boden feine gebörige Locferbeit befommt und zugleid Das nötbige Waffer balten fann. 2(ud) bier zeigt es fíd wieber, baf teine einzelne Materie für bie Drganijation binteidt. Die Pflanje bebarf des ganzen veften Planeten z" ihrem Bjebeiben.

Das ift die Urjache von ber Nub̧barfeit des fogenannten Mergelns, ober vielmegr ber Mif́lung.

Da oer meifte Boden aus Igonerbe beftebt, jo wiro ifm gewöhnlid) Ralferde bengemengt. Sand auf Ibonboben mact Denfelben erfít vollfommen locfer.

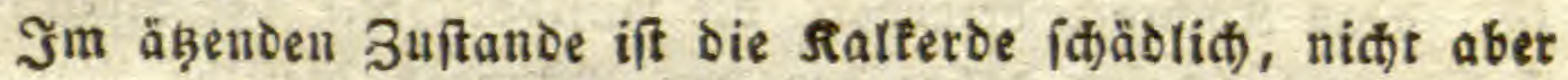
auf faurem Boden, wie Sumpf= und Torfboden, weil fie bem. felben bie Säure entzieft uno bie Pflanjentbeile auflöslid)er mad)t.

Befanntlich) beftreut man junge Pflamen, bejonders slee,

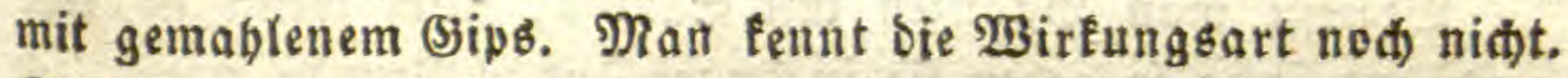

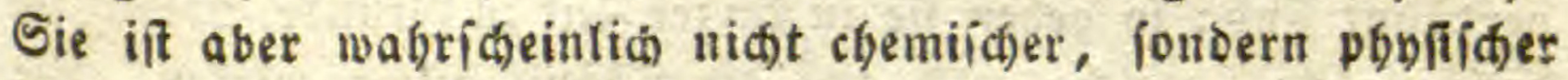
2(trt, indem er bie Feudtigfeit aแb Der \&uft anzieft und veffbält.

Durd) i)re Şårte wirfen die Erden, ober vietmehr Steine, immer nad)theilig auf bie Pflanzen. Die $\mathfrak{B u r z}_{\text {eln }}$ werben bas burd) frumm uno fuorrig, indem fie gedrüctt uno burd f(c)arfe Eaden felbit verieht werden.

Şieber gebören alle medanif́chen Berlebungen ourd Sted)ell, Sdueiten, Benagen u.f.f. WBirb ber Bulammenbang bes Bells gewebes aufgehoben, fo flieft eine Seit lang ber Saft aus, bis

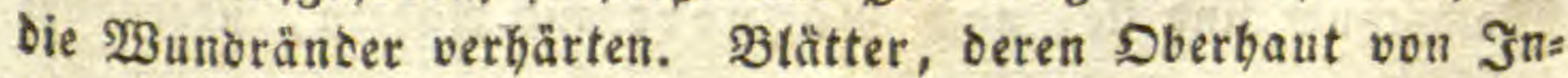
lecten abgenagt worden, vertrocfnen. Werben nur einzelne 3ellen bon Jinfectenftidfen fortbauerno verleşt, fo wenbet fich ber Safts

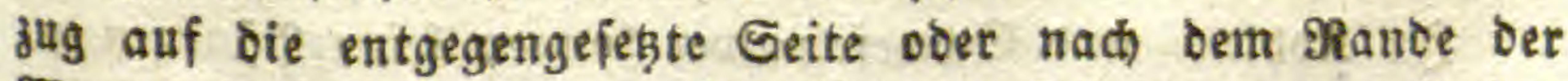
Wunde, mo bas Blatt anidnillt uno fid) gegen bas Inject zufammenrolit, woburch Blaien entiteben, welde entid bas 


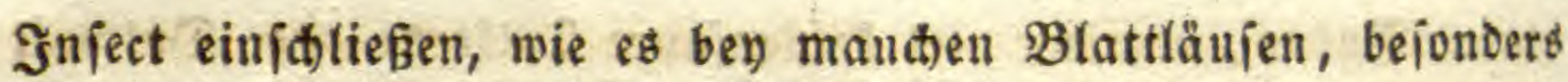
aber bey oen (Jall= Snifecten geidiebt. Die S(d)laf: hno (jalls

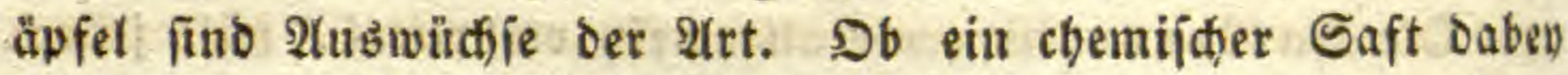
thătig if̂t, weis man nod) niđat.

\section{b. Salze.}

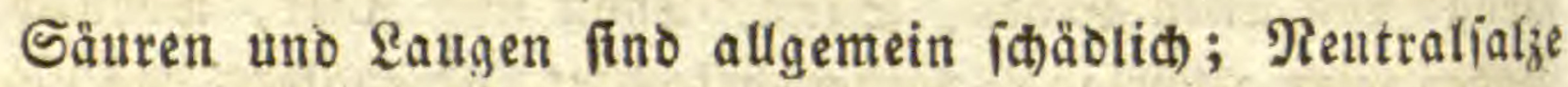

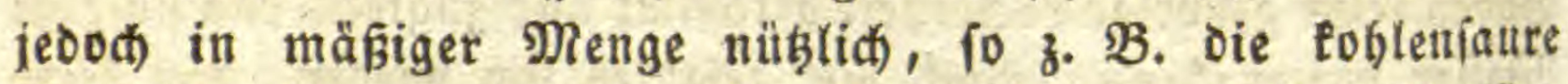
Pottaíd)e oder Şolzaid)e, weldhe ourd) Berbrenten bes (Sjeniftes auf ben Feldern entiftebt.

Rodjalzreicher Boden verbindert oas $\mathfrak{B a d b}$ thum der

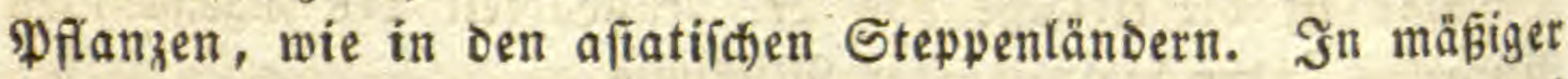

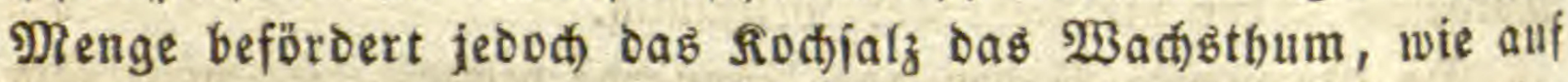
Dem gewonnenen Meeresboden, wenn er einige Jahre lang eins gedåmmt gelegen bat uno vom ఇegenwafier atigefübt worben

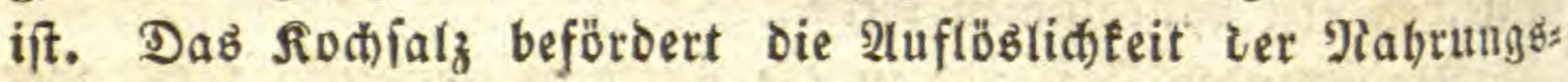
ftoffe, und itheint baber bey den Pflanzen biejelbe Rolle zu ipielen, wie in Den Speifen ber Thiere. Salpeter uno faly faurer Falt jófeinen ebenio zu wirfen; 2tlaun Dagegen uno 2(nt: moniaf find immer ídäblich.

Begief̧t man Pflanzen mit Säuren, auch) wenn fie febr verbunnt find; fo geben fie in furzer 3eit zu Grunde, vorzitgli burch) foldte, welche aud) auf bie Iotere giftig wirken, wie Blaul= uno Sauerfleefãute.

Das Reimen bes Samens wiro burd) Säuren beförbert, uno burd) Einmirfung bes (હ)lors hat man felbft hundertjăbrige Samen nod) zum Reimen gebracht. J゙ndefien müffen aud) hier bieje Stoffe febr mit $W_{3} a f i e r$ verdünnt angewendet werden.

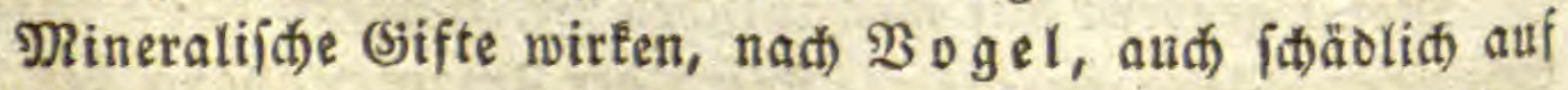

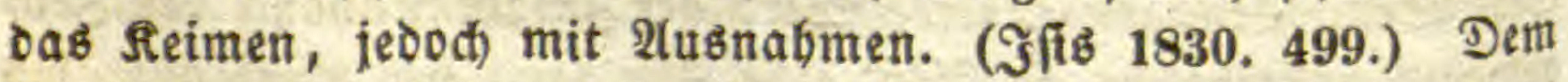
Wadtbthum find fie, nah) (5) B̈ppert uno 2ndern, ibberbaupt iđăbliđ).

c. Inflammabilien oder Brenze.

In Roblen = und Sct)wefelvulver fönnen teine Pflanzen ges beiben; fie feimen indefien barinn, wie in Sand, weil bieie Stọfe teine chemiíd) 23 irfung ausı̈ben. 
2lle fetten Subftanzen fino fadablid, weil fie bie Dber= fläden ber Pflanzen überít)mieren unb Einjaugung uno 2tus:

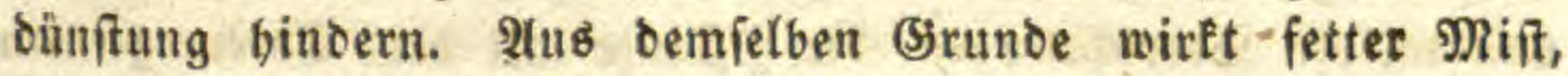
cer nod) nidst in ber Zerieksung begriffen ift, nadtheilig. In Delen feimt fein Samen.

Ëbeníp, und nod idlimmer, wirfen flitdige Dele uno WBeingeift, aud wenn er verbünnt ift.

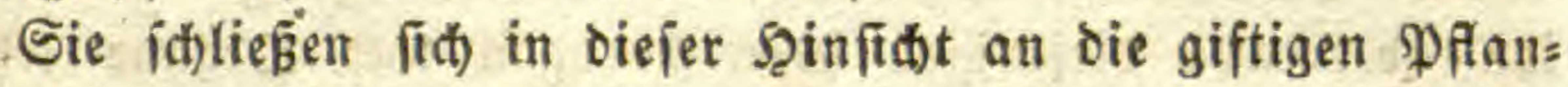
zenftuffe an, bejonders bie narcotifichen, wie Spium, Ririch)=?or= beerwaffer, Sthierling $u$. Dergl, welche eingeiogen faft eben io fothell töoten, als im sbierreid).

Die Tübtung rüct fidtlid) won unten nad) oben fort, wie

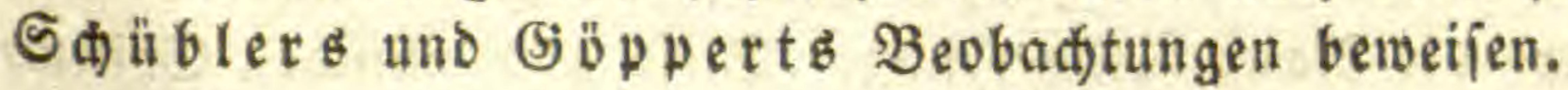

\section{d. Nietalle.}

Rein Metalleald() ift ben Pranzen zuträgliđ), felbif niđit Das Eijen, wenn es reidblith im Iobonboden enthalten ift. Die

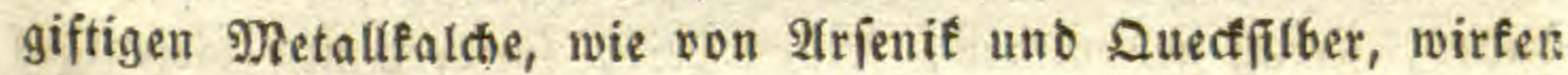
bier ebenfalls giftig, uno das thut jelbit oer Dunft oes leben= bigen Quectilitber's.

\section{Pflanzen = \$hyftologie}

odes

Biologie.

Die \$buffologie befdaftigt fid mit ben $\mathfrak{B} e r+i$ d $t u n g e n$ der Pflanzen.

So einfach Der innere Ban ber PFlanzen uno io gering die Babl ibrer bewebe ift, uno obgleid ibnen jogar alle eigentliden Eingeweide fehlen; io ift es Dod) anserorbentlich ithwer, bie Berrid)tungen, fowohl bes ganzen Pfanzenftod's als feiner ein= zelnen Theile, anzugeben.

Der Brunb bavon liegt theils in ber ungemeinen Rleinbeit

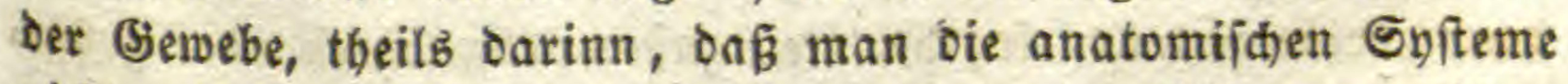
niकht mit bem gehörigen Ernft mit Denen Der Igtere verglidhen 
bat. Das ficherfte Mittel, zum Zwecte zu gelangen, ift aber bieje Bergleidfung. Man muß vor 2lllem juden, welde Theile, uno mitbin Berridtungen, oie Pflanze mit bem Ibiere gemein bat, uno weldhe ibr feblen.

2 (Is organifđer Rörper muß fie notbmendig bie wejentliden Rebensverridtungen, und mitbin beren Drgane baben, alío mins Deftens Berbauung, 2tthmung und Saftbewegung. Fo werben ibr aber alle biejenigen Berribtungen uno Drgane feblen, welche oas Ibier nejentlid) characterifteren, nebmlid): Rerven= thätigleit ober Empfinoung, Mubfeltbätigfeit oder Bewegung ber veften Theile, uno enblid) bie Rnodentbätigleit ober bie bes liebige Berfebung bes ganzen Leibeb an einen andern Drt,

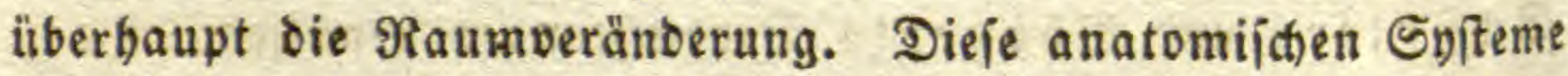
bilden aber ben eigentlidten \&eib ober bas Fleipith bes Thieres, weldes die jogenannten vegetativen Drgane ober bie Eingeweide'

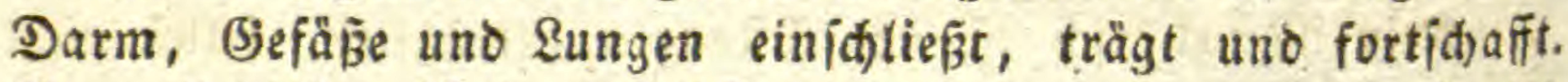
Bon all biefem ift in ber. Pflanze nidts zull finden, und fie bat baber, ftreng getrommen, feinen Leib, fonbern nur biejenigen anatomifichen Syfteme, weldhe unfern Eingeweiden entiprectien. Sie ift nur eine Eingeweiomaffe, weldhe nactent sa liegt, obne alle Umbällung. Man fönnte fagen, fie fẹ ein fleif $d=$ ober teiblojes Ibier.

Itber aud ibre Eingeweibe find nidft von ben Beweben geichieden. Sie bat feinen befondern Darm, fein befonderes Gefäbinftem uno teine bejonbere \&unge, Deren Bau nebmlich von bem ber Bjenebe veridieden wäre. Sie ift baher nur eill Eeib von (jeweben, weld)e zugleid) bie (jeid)äfte ber anatomiínen Snfteme über fid baben.

Da ibr bie abgefonberten ober jelbftfändigen anatomijhen Syfteme feblen; fo tann fie auth nidst bie Nebenorgane beriels ben baben, wie ben Munb, die Epeithelorïjen, die Mil und ¿eber, welthe bem Darin angehören, oas Spér, bie Sthiloorife, die Bröje (Thymus) uno bie Rieren, weld)e zum (jefäßípitem gebören, ben steblfopf ber Rungen u. f.w. Sie hat baber übets baupt teine 2(rt von jogenannten zujammengejegten ober gröbe ren Drüfén. 
Da ibr oer Fleifhleib feblt, io mûtîen auch biejenigen vegetativen Theile feglen, welde zu biefem \&eibe geben und ben= felben erbalten, wie bie 2lrterien uno Senen, und mitbin Das 5̧erz.

ЭGre eingeweidartigen Drgane fino baber nur bie Siewebe, welde bem Darm entiprechen, Den Rungen und den beide ver:

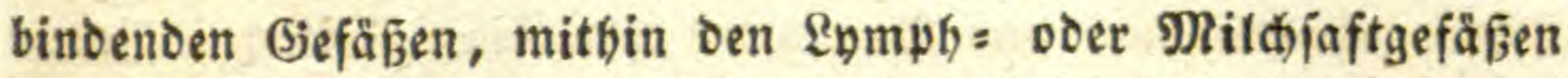

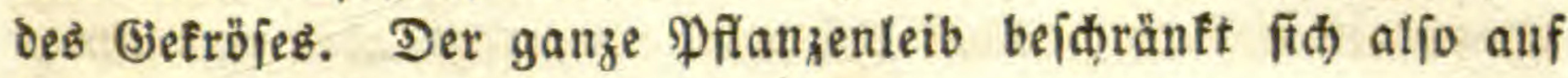
Darm, Sief̂röje uno \&unge.

24nerbem fino bie Fortpflanzungsorgane vorbanden, welde ibre eigenthümlidgen Berridgtungen baben, jebod) oiejelben (5ie: webe.

Die Pflanzenverrifftungen theilen fich Demnad zunädit in

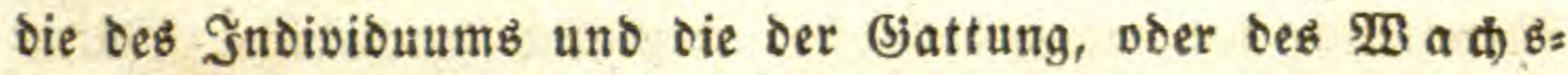
th umb uno ber Fort $\mathfrak{p}$ flanzung.

\section{A. $\mathfrak{3} a$ a) เ th $4 \mathrm{~m}$.}

Das $\mathfrak{B a d j s t h u m ~ b e z ̧ i e h t ~ f i t h ~ z ̇ w a r ~ a u f ~ d i e ~ g a n z e ~ P f l a n z ̇ e , ~}$ Die Fortplanzungsorgane mit eingefdlofien: inbefien fimmt es aud bier mit ben procefien bes Stod's ïberein, und wir brau= d)en baber nur biefe za betracijten.

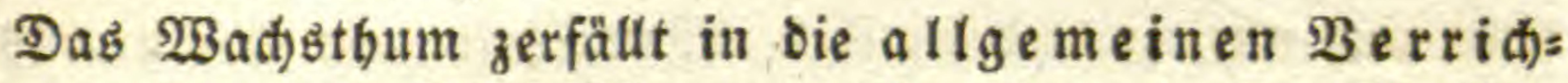
t un gen ber organifकen Rörper ïberhaupt, wie Empfänglid)=

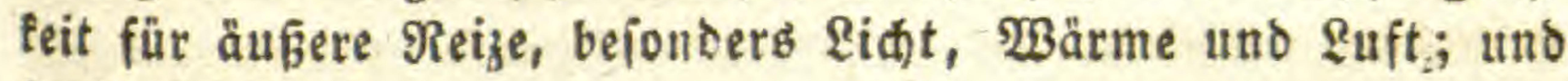
in bie beionderen.

\section{a. 2ulgemeine Berridtungen.}

Die allgemeinen Derribtungen des Lebens fint teine ein= fachen, wie etwa bie des \&idte, Der Wärme uno ber Sdwere,

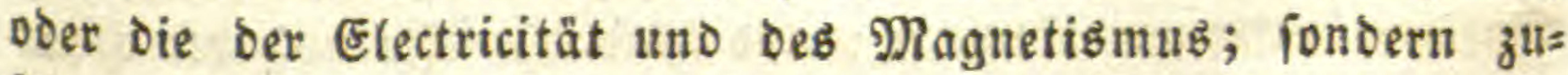
jammengejeţte, welde aus ben einzelnen Berridtungen ent: furingen, alio aub bem Berbauen, 2lthmen unb Saftlauf, ober Der Ermäbrung.

Tun ift aber bas Derbauten ber Baffer ober cbemifde

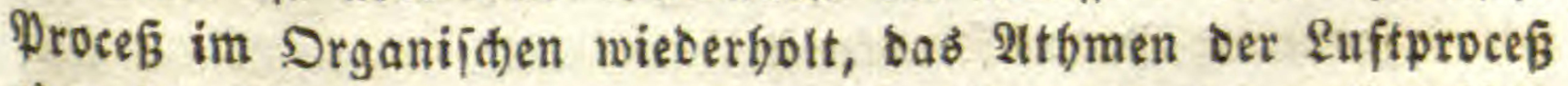
Oder Der Berbrennungbs unb der Damit verbundene electrifhe

Diens allg. Naturg. II. Botanil 1. 


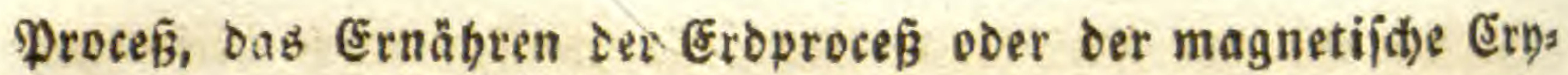

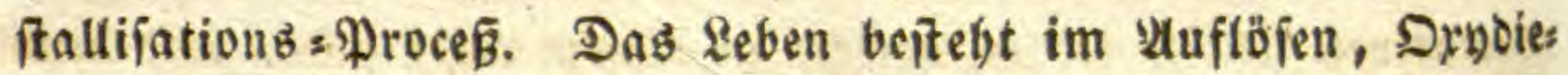

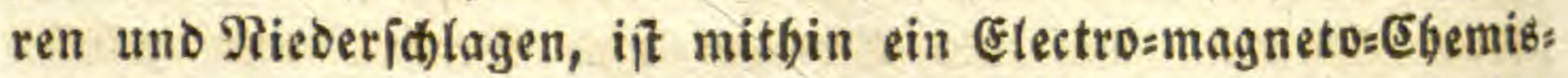
muв, ober mit einem $\mathfrak{B o r t e}$ (s) a Errdjeinung blok in ber Bewegung der Flüfïigleiten, lei= nesuregs aber in ber Bewegung der ve ft en Iheile beftebt. Sum Seben gehört oaber nur Bewegung oer flutifigteiten in jebem Itom eines individuellen Rörpers, angeregt aber uno unter: balten von onnamifitben ober polaren Fräften.

Durd) den galvanifden oder ben Lebenzproces tommt bas ber eine gemeinidjaftlide ooer allgemeine Polarität in ben Dr: ganismus, weld)e Die Einheit Des \&ebens begründet.

Diefe Polarität wiro angeregt und unterbalten ourdi) bie

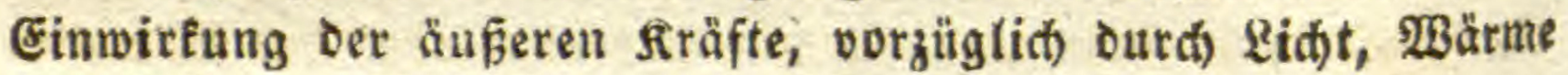

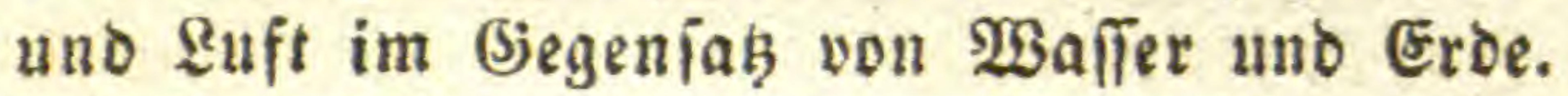

Die Pflanze, ber es an einem eigenen Sdwerpunct, nefm: (ic) Dem fortichaffenoen Eeibe fehlt, hat nothwendig ibren Sd)werpunct in ber Eroe, uno inren 2(nregungs = ober Bewe: gungepunct in ber Sonne, uno idwebt baher zwiid)en beiben unverånderliđ), gleiđ) einer Magnetnabel. Dadurd) werben ifre Safte nur nad) zwo Ridtungen aus einander getrieben, nach oben uno unten; uno oa igre veften Iheile nur 21bäßze aus ben flüifigen finb, io mülfen fie fid) in benielben Ridtungen ablas gern ober wadfen.

Die Pflanzenjäfte tönnen Daber nur zweberley Riatungen baben, aber in berielben Sinie, nebmlid) gegen bie Sonne unb gegen ben Mittelpunct ber Erde. Die Wurzel wädbet Daber immer nad) unten, fo wie ber Stamm nad) Dben.

Man bat fich felfr viele Mähe gegeben, den (5rund bet Saftbewegung zu erforiden; und balo bie Wirtung der Şats

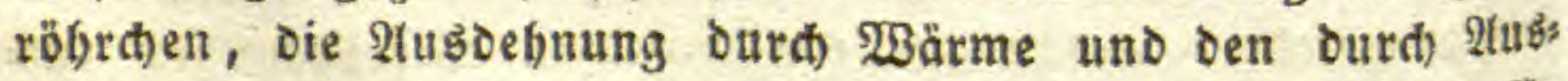
Dünftung entiftehenden leeren $\Re a u m$, mithin ben Ruftornd bafutr angenommen, balo bie 3tianmenziefung ber Bellen ober ber (Sefäße, bald endliđ) ein felbifttåndiges Laufvermögen ber Gäfte, bie fogenaunte Propulfionstraft.

Giegen alle biefe Sermuthungen wurben aber widtige 


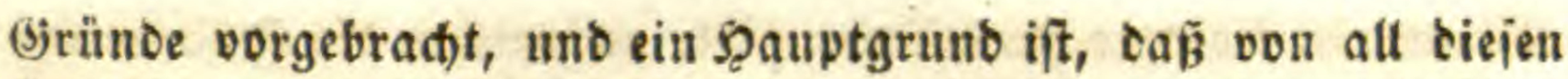
Erricheinungen nod) feine einzige beobact)tet wurbe, mit 24us: nabme ber einfachen şbatiacte, nebmlich ber Saftbenegung jelbit.

WaB bie Propulfionsfraft betrifft, fo fann man fid) nidst einmal einen Begrif bavon biloen. Das $\mathfrak{B a f f e r}$ felbit müste,

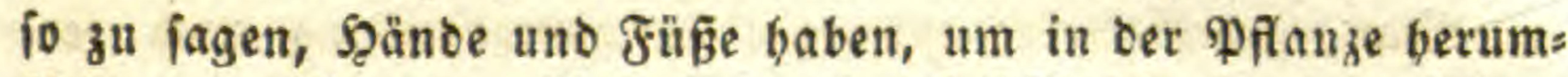

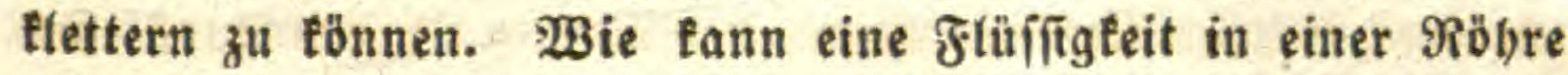

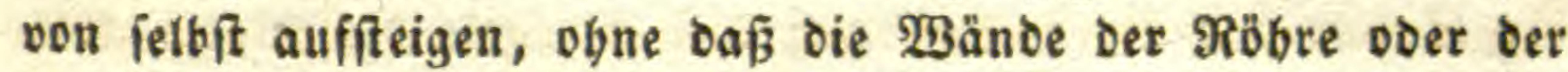
Euftoruct barauf wirtte. Dieje Soee bat baber aud) weiter Eeinen 2inflang gefunden.

Mebr hat bie Rebre von Der Şaarröbrchen = 2n żiel)ung für

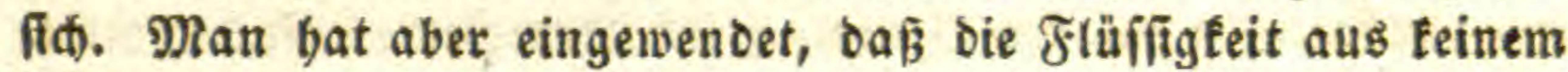

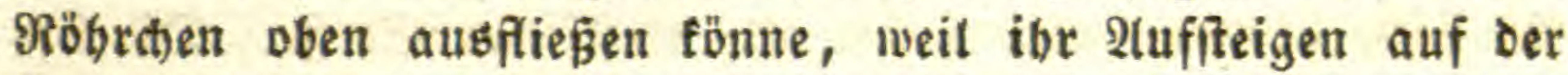

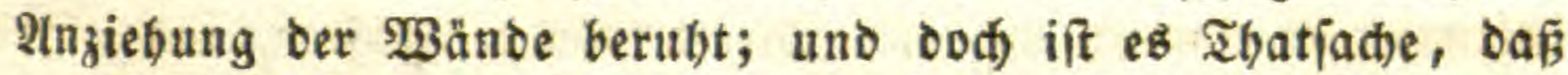
ber $\mathfrak{B}_{e}$ einfțof thränt, fo wie eigentlid) alle Pflanzen. Inbeffen

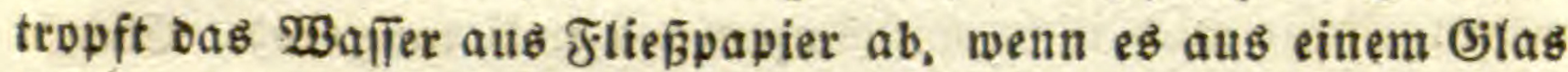

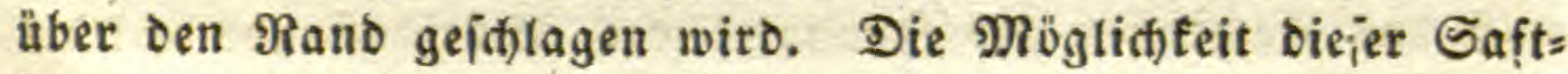
bewegung atth) angenommen, io wäre es tod) eine blof pbuft:

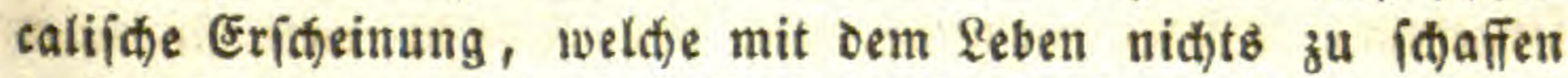
bat, uno überdief fteigt Der Saft in abgeftorbenen Pflanzen nid)t in oie f̧öh oder fliest wenigitens niat über; in feinem Falle aber wirb die Pflanje Darurd) mieder tebendig.

Nod) melgr gat für fid) oie Errwärmug, uno oie baburd

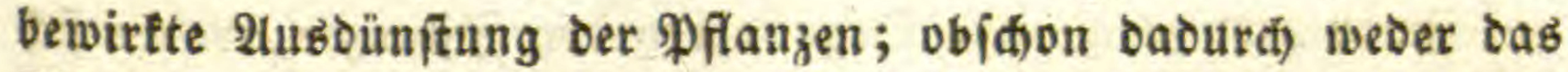
Ifyränen, nod) viel weniger das Reben begreiflich wirb.

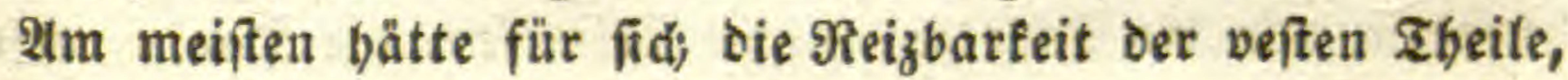
woburd) bie 3ellen oder bie (jefäflwälde in einen abwedfelnden Buftano von 3ufammenziefung uno 2 us begnung getietben, etwa wie bas ફ̧erz Der Thiere ober wie Die wurmfürmige Bewegung Der Därme: allein bie ftärfîten Bergröberungen baben nod) nie, auch niabt ben geübteften Beobac(f)tern, nur bie geringite Epur von einer abwed)ielncen Berengerung und Erweiterung einer Befle gezeigt, felbfit währeno man ganz beutlich Die freiss förmige Bewegung Der Saftërner in Der Zelle wabrnimmt. Daran fann bie fileinbeit ber zellen teineswegs urjache fenn, theils weil oer Bewegunggraum Der Saftërner fleiner ift, und 
weit es viet fleinere Infujorien gibt, an welden bie 3ujammen= ziehungen bentliob zu bemerfen find. Man fann es mitbin als eine veititebende Ihatjache annebmen, daß die (jewebe ber PFlan: zen Pethe 3 ufammenjiebunggltraft baben uno mitbin nidt im Stande find, die Säfte baburd weiter zu förbern.

Man bat für eine lebendige 3ujammenziebung nod ver=

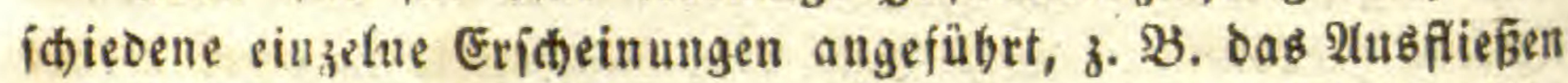

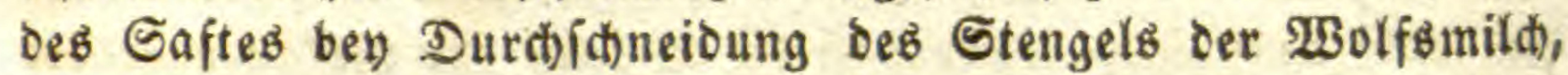
Doer bey ber blof̧en Bertigrung oes Stengels des \&attid)s: allein bieje Eríd)einung erêlärt fid) binlängliă) Durd bie Epannung Der Pflanzentbeile wäbreno fie von Saft ftrozen, und ourt) ikgre phyficalifole 3 ufammenjiel)ung, fobalo berielbe \&uft betommt. Phyjifhe Eontractilität baben alle elaftificten Stoffe. Die Er: íteinung ift einerley mit oem $\mathfrak{B}$ ertroctnen ber Fajern, unb zeigt (id) auffalleno bey vielen Capieln, namentlich bey ber Balias mine: $\Re u ̈ b r$ mid) niđf all (Impatiens noli tangere). Ebenio

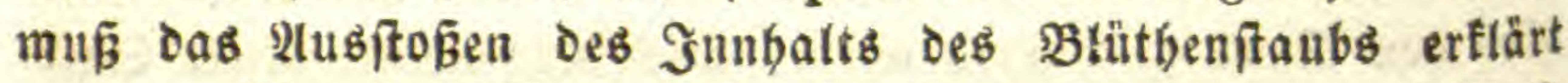
werden. Mande Blätter mit ätherijđem Del frofien, auf $\mathfrak{B a}$; jergelegt, oaffelbe rucfmeife aus, obne 3 weifel weil fie ourd Einfaugung des Baffers ftrokeno werden, woburd bie Bellen zerplaken. Eampher, auf $\mathfrak{B a f f e r}$ gelegt, gerătb in ructweife

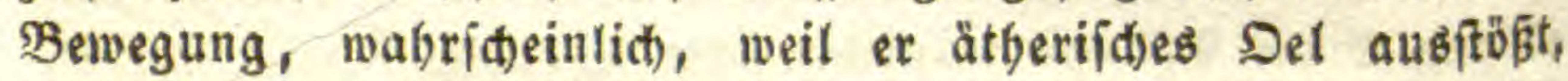
wenn nicht electrifhe Ibätigfeit babey im Spiel ift.

3 war gibt es gewiffe Drgate ben ben Pflanzen, welde fich theils von felbit, theils auf ithwathe Einwirknng von Reizen benegen, wie die Blätter einiger Mimojen, die Şaare verídjies bener Pflanzen und viele Gtaubfäden. 2lle diefe Bewegungen formen in jo fleinen Srganen uno bey fo wentig Pflanzen vor, oás fie füt das Dafenn von Sujammenjiefsungen im gangen Pflanzengewebe ober im ganzen Pflanzenreiche nid)t bas Gjeringite beweifen, uno man vielmebr baburd) gejmungen wirb, fith nat) einer andern Erêlärung umzujehen, ober, weil diefe nid)t mügs (id) ift, bie Gathe vor ber Şand auf fid) beruhen zu rafien. 2uf Eeinen Fall beweist fie etwas für bie $\mathfrak{B e w e g u n g}$ ber Säfte.

Bey vielen Pflanzentheilen if es gewí, daß̧ ibre Bewes gungen nur bom Troctnen uno Fetritwerben abbängen, $\mathfrak{z}$. $\mathfrak{B}$. 


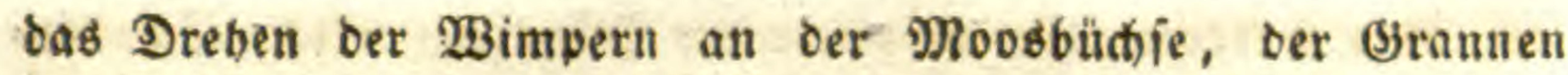
Der Grä̧er, Der ફ̧aare der Samentronen bey ben jalatartigen Pflanzen u. f. w. 2(ud) begegnet biejes vielen Trudtcapieln voer Bälgen. Die Bewegung mandher Blätter oagegen, fo wie ber

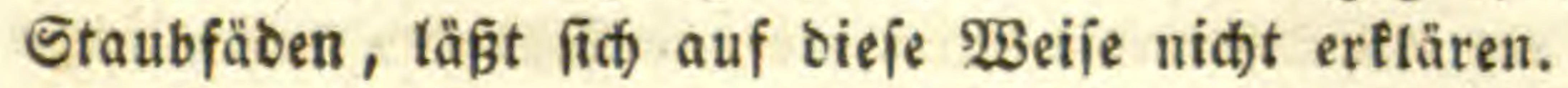

Dagegen ift es ausgemad)t, Daß̧ ber Saft der \$flanjen nur aufiteigt wäbreno bes lebendigen 3uftandes ber Sjewebe, uno baßs alle pranzentbeile bem Riate folgen, mitbin ourd) feinen Reiz ober feine Einwirfung in Bewegung gejeb̧t werden. Man bat diejes Sermögen ber Prlanzen, einer fremben Einvirtung empfängli(i) zu jenn uno berílben entgegen zu wirken oder ihr ju folgen, Erregbarfeit genannt; unb es hat bamit aud

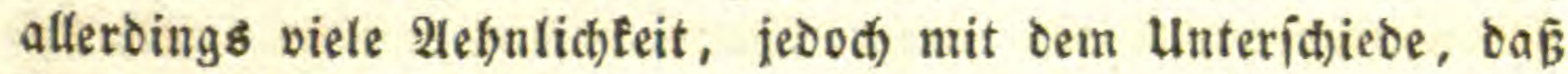
fie im Thierreide fowohl auf Der immateriellen Bewegnng oer veften Ibeile, als aud auf bem 3 uflus ber säfte berubt, weld) lez̧tere bey ben Pflanzen allein vorzufommen fheint.

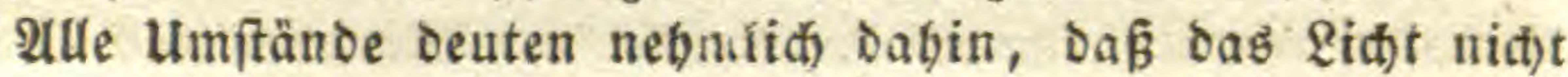
bie veften ageile der Pflanze polarifiert, iontern bloz die flit:

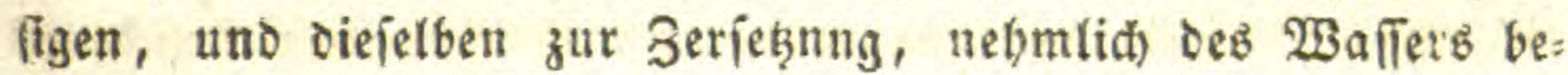
ftimmt. Ben Den bewegungen ber Pflanzen ift oaber immer ein materieller Proces in Tăätigfeit, wotur(h) Frtitffitges ver: idwindet unb anderes nad) fid) ziefgt.

W3o irgend ein Pflanzentheil dem Rid)te auggefeģt wird, Da entwiffelt fid) auf feiner Dberfläd)e Gaueritoffgas, wäbrend er

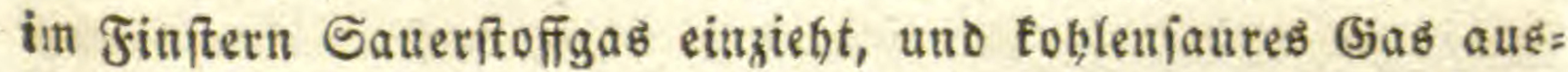
baudit. Daourd treten bie beleuditeten Theile obne 3 weifel in einen polaren Giegenjabs mit ben finftern, aljo mit ben innern Theilen uno mit ber $\mathfrak{W}$ urjel, woourd) bie Säfte beftimmt mer:

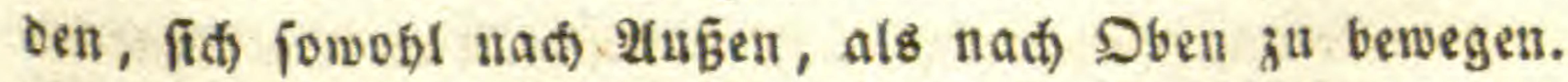

Die Pflanzen = Polarität if eaber ourd einen chemíthen

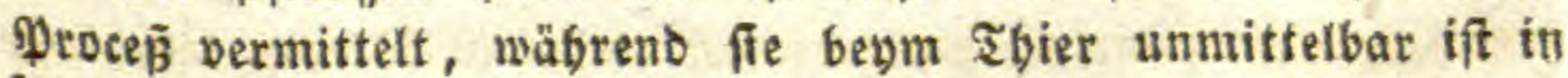
feinen rein thierífhen Theilen, uno mittelbar nur in feinen vege, tativen.

Dab Seben ber Pflanzen ocer feine Erregbarfeit berulgt ba= bet nur anf einer materieflen, uid)t auf einer geiftigen $\mathfrak{B}_{\text {eräns }}$ Derlidfeit ifjer sheile. 


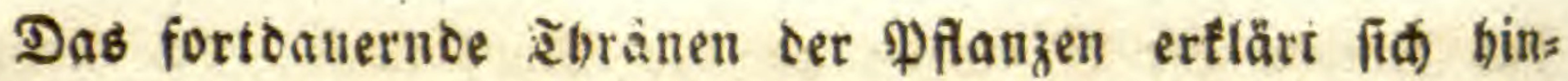
längli() aus Dem bểänoigen Racboringen Des Saftes, angeregt Durch) bie allgemeine Polarität oder bie Einmirtung oes Sidts uno Der Dryoation Der Enft.

Don einer Genfibilität fann bey den Pflanzen baber ilber: baupt Eeine Rede jeyn, obihon einige Ëríbeinungen vorfommen, welthe Daran erinnern, wie Das WBinden Der Ranfen um Stan= gen, Der Satlaf Der Blätter uno Blumen, das Deffnen Derílben bey Tag uno ifre Bewegung naih ber Sonne, uno enolith be: fonbers die Bewegungen der $\mathfrak{B l a ̈ t t e r}$ Der jogenannten Sinn: Mi: mofe uno bes Sinnhabnen=fopfs (Hedysarum gyrans). 2tllein Dieje Errideinungen beiđgränten fith nur auf einzelne Tbeile, uno haben mitbin mit ber ganzen Pflanze nidthts zu thun; aud) lajs fen fich die meiften, wentgitens ber Salaf und das 13 chen, Doer bas Folgen ber Sonne aus bem ungleichen Zutrang ber Săfte srêlären. Da nun bie Bewegungen oer Sinnpflanzen im

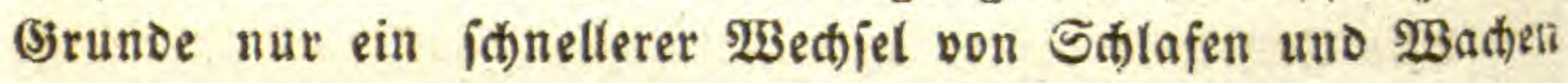
find, io milfen fie in diejalbe $\Re$ abrif geftellt weroen.

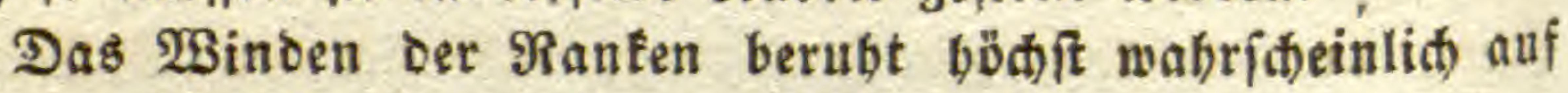
einem theilweifen Sertroctnen cerielben.

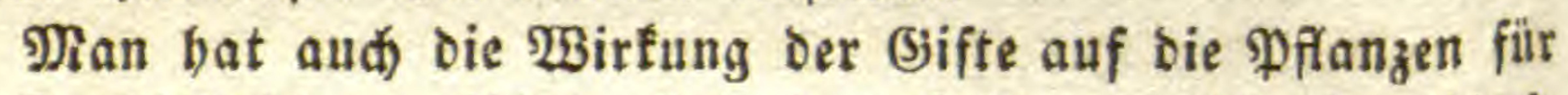
bie Genfitbilität angefütbrt, bejonders folder, welde im thieri:

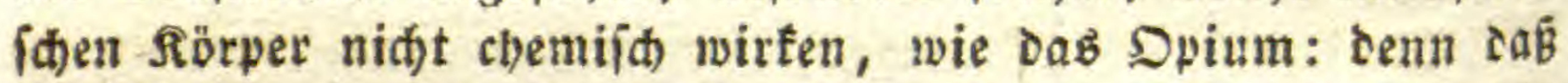
eingeiogene äzende Stoffe die Pfanze töbten, ift wobl niwt

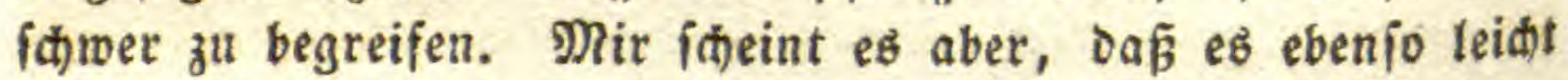
zu begreifen iit, warum eingeiogenes Dpium töbtet: Denn jeber Saft in ben Pflanzen, ber fein Pflanzenjaft ifz, mus töbten.

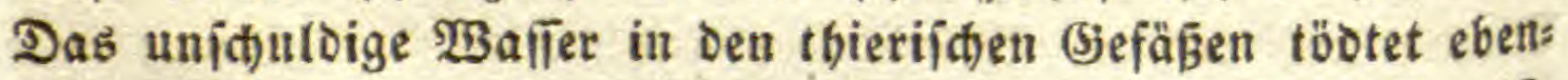

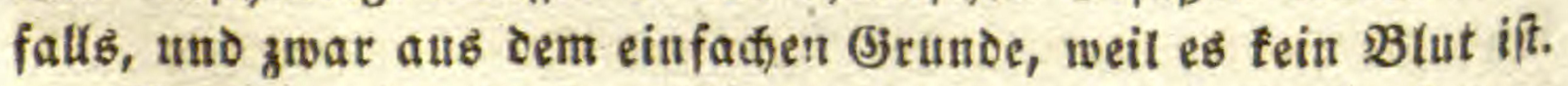

Rerven wiro in ben \$flanzen niemano im (Ernfte fuden. Э゙) vergleid)e zwar bie Spiralgefäße mit ben Rerven, aber nur

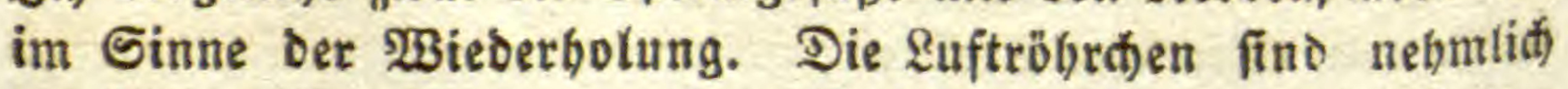
im Thiere für bie vegetativen Gyfteme $\delta a b$, was bie Rerven für bie autimaten find, Das polarifierende ober belebende Princip. Der 2tthem=\$roceß bringt bie Bewegung im Blute bervor, ber Senfibilitäts= procę̧ in oen Mustełn. 
b. Beiondere Berridtungen.

Da es in oer Pflanze nur orey anatomiiabe Snfteme gibt,

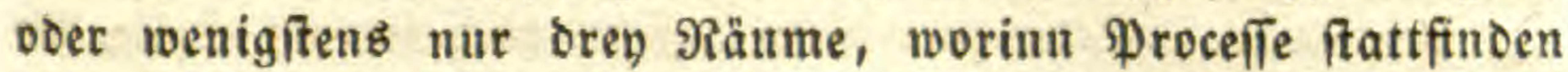
tönnen; fo fann es auth nur oreberley Berrichtungetl geben: Die

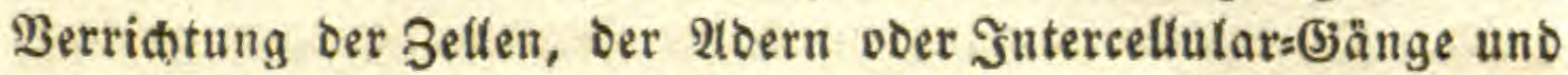
Det Spiralgefäße oder Droffeln.

\section{Beroaung ooer Einfaugung.}

Es Cann Eeinem 3weifel unterliegen, Daß̧ die Einjaugung

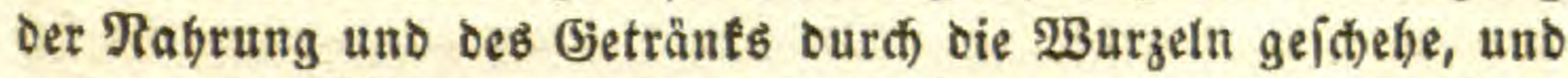
Daß̧ bey der Pflanze das (Sjeträne die Sauptiache, uno der गah= rungsftoff bemielben nur bengemijat ift. Benm Thiere umge: febrt: es nimmt bie शabrung zuerí auf und trinft bann nach Bedürfniâ, ie nadbem nehmlid) die Rabrungsftoffe mebr oder meniger Fliffitgleit zu ilfrer 2uflöfung bedurfen. Daber bat Das. Thier in Der Regel nur eine groß̧e Deffnung, Den Mumo, wäbrend die Pflanze mit tnentlid) viel phyfija)en \$oren beiect if, welde nad) phyfifhen (5̈ejeken einjaugen, wie die Sgarröbr: d)en uno aljo wie alle poröjen sörper uno felbit tobte Pflanjen. Dazu tommt aber die allgemeine Rebenspolarität, fübrt cas Sietränfe weiter uno facibet bie Rabrungsfoffe caraus ab. Die Einjaugung bey Den Pflanzen gleid)t Daber der Einiaugung un=

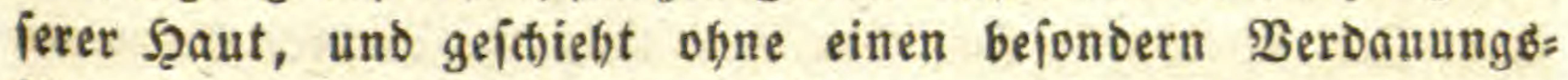

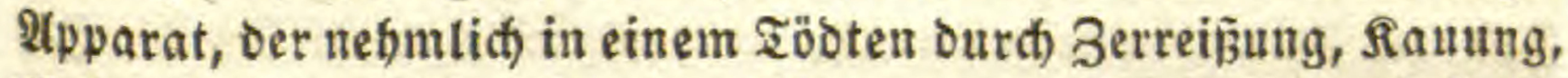
Beipeid)eln, 2tuflöfen in einem Magen unD Scheiden ourd) (bialle befteht. Die Berbauung ber \$flanzen fängt fo zu fagen erît mit Dem Einfaugen Des నabrungsfaftes (Chylus) im Dünn:

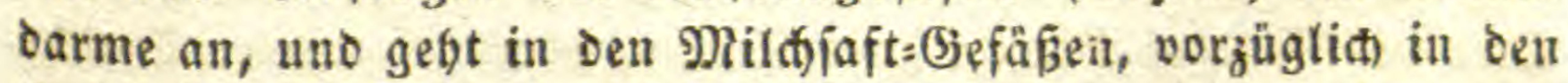
(S)etrösbrüfen, benen etwa die Bellen entiprecten, vor fid.

Eв faugt deşbalb die ganze Dberfähe oer Pflanze ein, wie unjere Saant. So wie aber bie Sgaut nidft im Stande ift, fort=

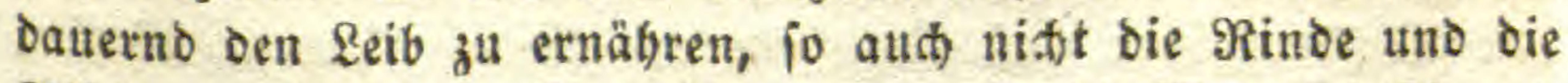

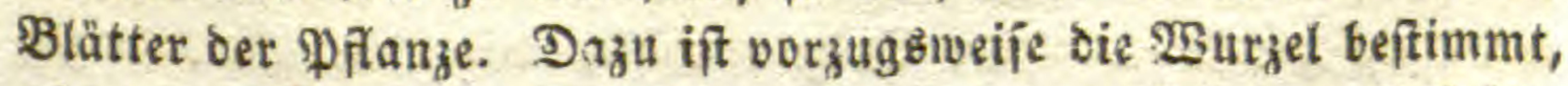
wie benm sibiere ber Dimntarm oter eigentlio bab Sjefröje. Für bie \$flange ift sie Dammetoe ber Dinnoarm mit Dem 
Nabrungsfaft, uno Die $\mathfrak{B u r z e l}$ vertritt bie Stelle Der Mildiaft: gefäß̧е, worans bie Flinifigfeit in bie 3ellen oringt, um bie ges ringe Berbaumg zu erleiten, Deren die शflanze bedarf.

Eegt man blätter mit ibrer äußern oder innern Seite, wo viele Epaltmünoungen fino, auf $\mathfrak{W a f l e r ; ~ f o ~ b l e i b e n ~ f i e ~ l a ̈ n g e r ~}$ grủn. Db dic Einjaugung ourch vie Epaltmündungen geidieht ober ob bieje zur 2 tusbituftung beitimmt fino, weis man freblich nidit: oa aber bey oer thierifhen Şaut offenbar beioes geftielft, fo faun man es auch von ben Dberfäatten bes $\mathfrak{B}$ lattes annel)=

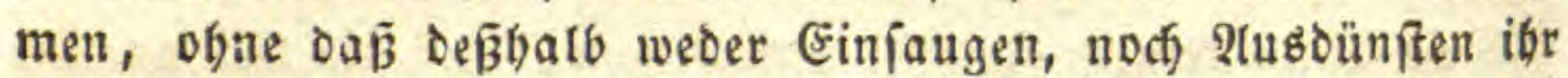
wejentlides (jeid)ät ift. Die Şaut jautgt ein, wann fie fich unter $\mathfrak{W a f f e r}$ befindet; fie Dünftet aus in bor $\mathbb{L}$ fut. Da num bie Fläđen ber Pflanzen fïh gewöbnlich in ber Ruft befinden, io fann ibr Szauptgeichäft fein anberes als $2(u g$ dünftung fenn. Dem ftelgt nidgt entgegen, daß bie Fettpflanzen ifre Feuțtigfeit vorzüglid) aus ber \&uft einjaugen. Extreme mus es in jebem Reithe geben. Daffelbe gilt von Den Sdimarogerpflanzen, welithe itbrigens burd) ihre $\mathfrak{3 a r z e n ~ i m m e : ~ F e n t i t i g f e i t ~ g e n u g ~ a n ~ o o e r ~}$ in andern Pflanzen finden.

Uebrigens baben Berjudje gezeigt, Daß̧ bie Rinde Der $\mathfrak{B}$ แt: zet nur wenig einfaugt, uno daj bie zelligen $3 a j e r n ~ c i g e n t l i d$ ) Diejes (jej巾äft bejorgen.

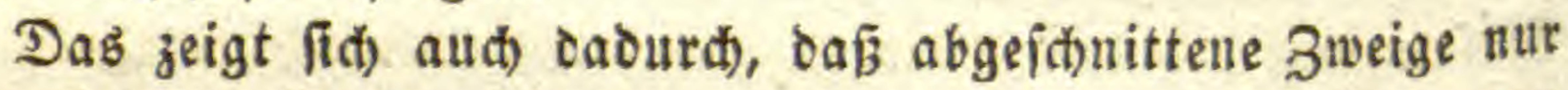
Furze Zeit in জুaffer fortleben, uno man ibr unteres Ende von

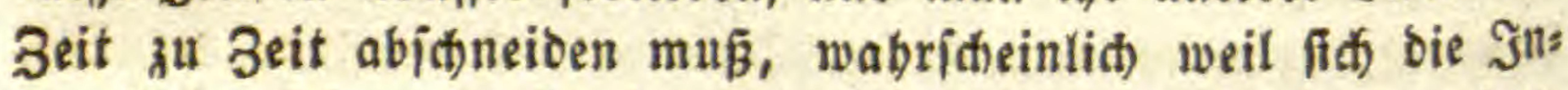
tercellular=(Sänge veriftopfen oder tie Zellen überid)miert werben. J̧aben fie Laub, fo faugen fie melyr uno länger ein, befonber wenn fie in Der Sonne ftehen, obne 3weifel wegen des polaren Berbăltniffes ber B̉lătter z̆um Stamm oder ben untern $\mathfrak{x}$ beilen Der \$flanze. Beríbmiert man bie abgeidhnittene Fläche, fo fört faft bie Einjaugung ganz auf, ein Beweis, baß̧ bie $\Re$ inbe felbjt

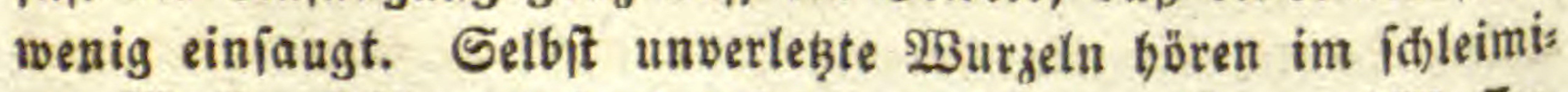

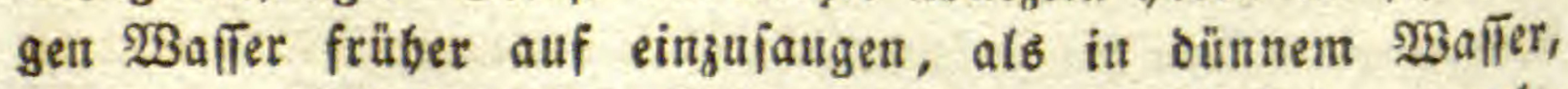

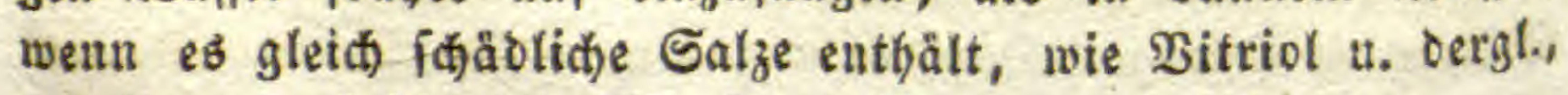
wie benn auth die thierif the Spaut 2 redinittel einfangt.

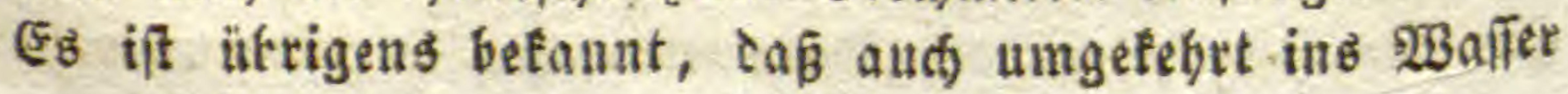


geftellte Ziveige einjaugen, uแb jelbft $2 B$ urzetn uno Blătter treiben: ein Bemeis für bie (jleichförmigteit Der Şewebe, uno fïr Das Umiallagen oer Polarität, je nad)bem ein Theil im Wnffer ooer in oer $\mathfrak{R}_{\mathrm{f} f \mathrm{ft}}$ fid befindet.

(Es wurde íton gejagt, weldhe Rräfte man annimmt, um

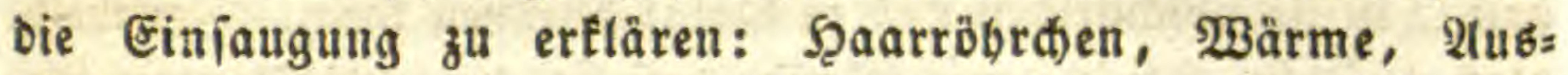
oünitung, leeren Raum uno Zu[ammenziefyung ber Bellen in ben Wurzelzajern. Es wirft obne 3 weifel alles zujammen: allein bie Fortoaner ber Einjaugung fann nur auf ber Zeriekzung Der Stoffe, mithin auf Dem galvanifđien Procép oder ber \&es benspolaritảt beruben.

Es ift febr fabwer zul beftimmen, weldes eigentlich) bie Rabrung oder Epeife Der Pflanzen ift; ia man ftreitet fidt) fogar baribber, ob fie als organijhen voer inorganifden Stof: fen beftebt, io wie, ob fie im lektern Falle aus ber Erbe oder aus ber \&uft eingejogen werbe. Ungeadtet zabllojer Weriuche

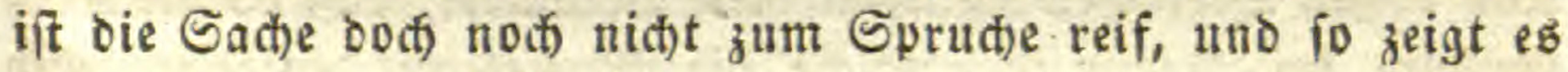

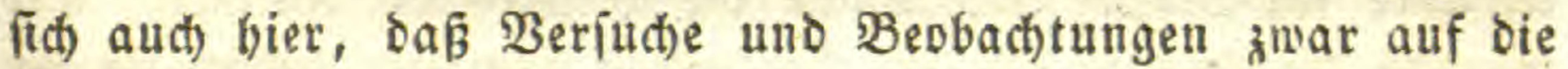
Ertfärung Doer bie Iheorie fübren, aber fie nidft jelbit bervor: bringen fönnen. Nur bie Bergleidung Der Einjaugungöorgane beiber Reide fann Die Entitheioung geben.

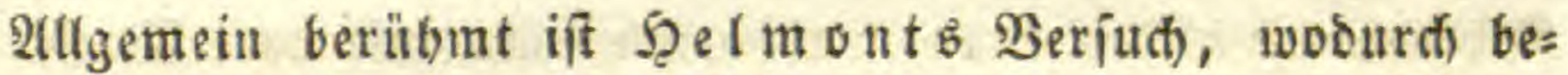
swiejen werben jollte, oná die Pflamze bloź von reinem lebe. Er that 200 Pfund im Dfen getroctnete Erbe in einen

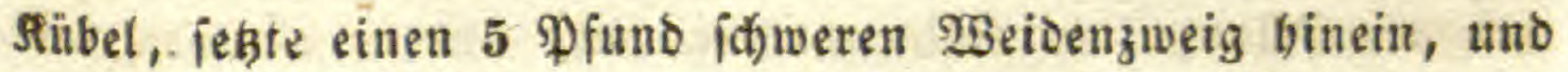

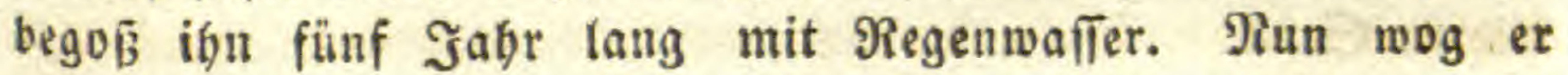
169 Pfund, uno Die Eroe nar nur um 2 Unzen leidfter. Es

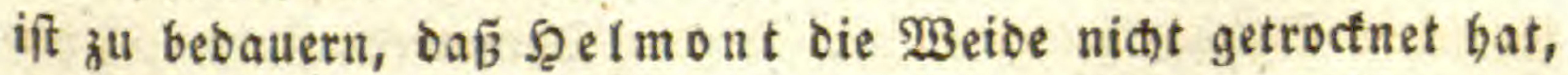
un die Menge bes in ibr entbaltenen $23 a f$ ers at beftimmen: tenn Bohnen und 3 wiebeln treiben Sath lange Stengel mit

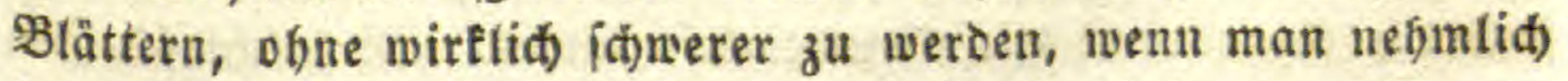
bas eingejogene $\mathfrak{B a f f e r ~ a b z i e f t . ~ D a s ~}$ Mebl in bem Samen veer ber 3 wiebel wiro aufgelöst uno in Bellen verwandelt, wo= Durd) bie Pflanze eine bebeutende (5röpe erreidht, ogne an veften

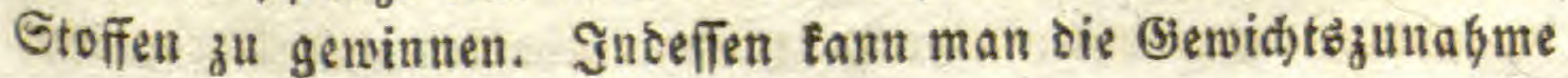




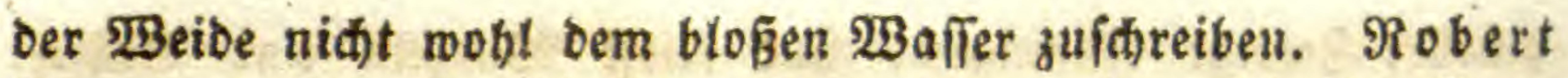
Boy le befam ben äbnlider Bebandlung einer sürbienpflange

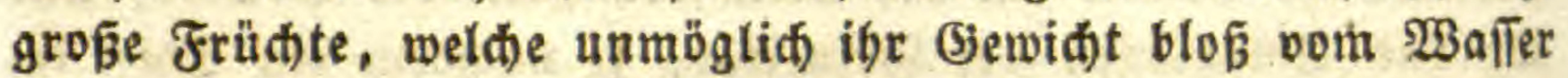

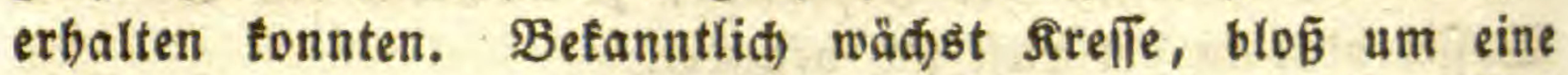

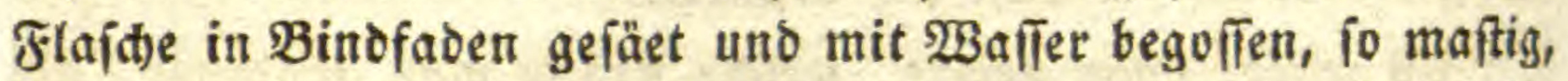
Daß̧ man fie abianeiden und zu Salat benuken fann. Zwiebeln,

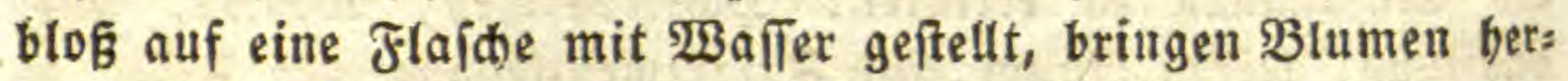
vor. Pflanzen oagegen mit vefilliertem $\mathfrak{W}_{3}$ filer begoifen, ent= widfeln fid) nur febr wenig, uno wenn fie aud) zur Blitbe gelangen, fo bringen fte es $\partial 0(t)$ nicht zu reifen Samen; aud entbalten fie, wie mebrere Beríuche, beionoers von (5) b̈ppert, bemeifen, nidit mebr Soblenftoff, als vorber in Den Samen oder Zwiebeln gewejen, obne Sweifel weil das $\mathfrak{B a f f e r}$ feine Robleniåure entbielt, welde dagegen im Regenwaffer vortommt.

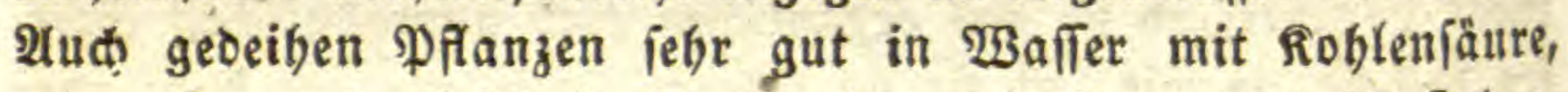
wenn fe and) gleid) in Sano oder geftofienem (Jilaje ftehen.

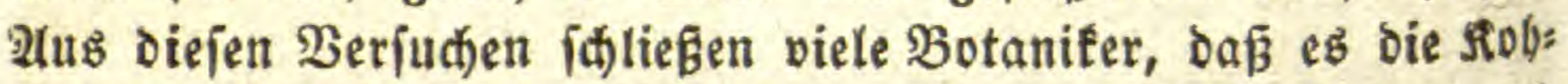

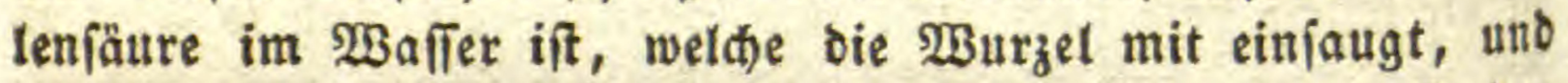
woraus bie Pflanze fich ben Roblenftoff aneignet, inbem fie den Sauerftoff fabren läß̧t. Daber geceiben aud̆ die Pflanzen nid)t in blofem खुaffer, fondern nur in Der Erbe, wo ber Sauerftoff Der \&uft 3utritt bat, uno mit Dem foblenftoff ber Dammerbe Rob)lenfäure bilden fann, we(d)e fid) leid)t mit bem 23 affer ver: bindet, was die sioble nid)t thut. शua) baben Beriudie bewie:

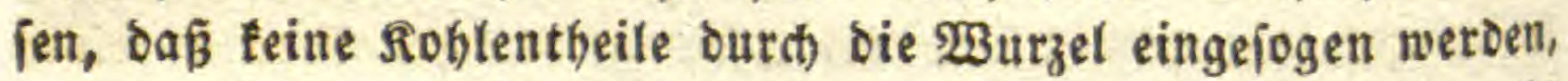
und die Pflanzen in Roblenpulver nidht anders wathien, als wie in Sand.

शufer bem Eobleniauren $\mathfrak{B a f f e r}$ faugt bie $\mathfrak{B}$ urzel bie auf: löslidien Salje ein, welthe fich in Der Dammerde findell, fenen es Mentral=, Ero= ober Metalljalze, felbit Riejelerbe, mas obne

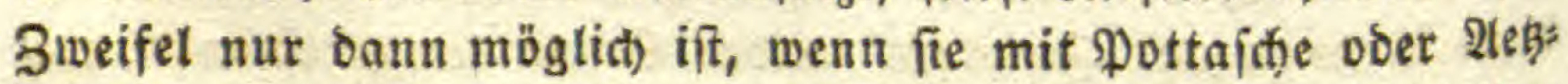
Eale bie fogenannte Riejelfeud)tigkeit biloet. Bielleicht foeiben fid) Dieje laugenartigen Gtoffe erit in Det PFlange tavon $a b$, menn fie mit Roblenjäure gefättigt werben. Die Pflanzen auf Salzboden entbalten fiochfalz oder falzfaure Sooe, wäbreno die andern nur foblenfaute ゆottaiane entbalten. Sialferbe fann 
nur eingeiogen werben, wenn fie tibertoglenfauer ift. Eifenoryo if befanntlid) in vielen Stablwaffern aufgelöst.

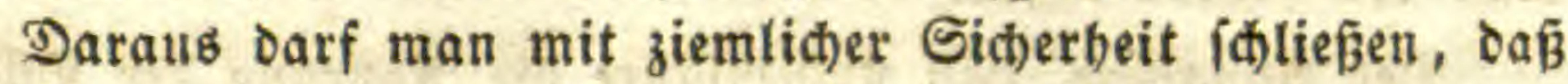
Die 23 urzel teine veften Theile, 3 . 2 . Den Mift felbit einjauge,

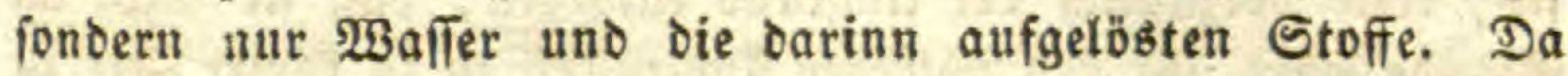
nun alle Stoffe ber Pflanzen Soblenitoff enthalten, und inre veften Theile gröstentbeils Daraus befteben; fo mus fie denfel= ben mit bem $\mathfrak{B a f f e r}$ befommen, went man nebmlich von bem= jenigen abfieft, weldien fie aus bev Roblenjäure ber $\&$ uft $a b=$ iqueiden fönnte.

Es frägt fich Daber nur, ob fie biejen Soblenitoff aus ber sebleniäure bes $\mathfrak{B a f f e r s ~ b e f ́ o m m t , ~ o b e r ~ a u s ~ a u f l o ̈ s l i d i e n ~ o r : ~}$ ganifhen Theilen Deffelben, wie Ed)leim voer Extractivitoff Der

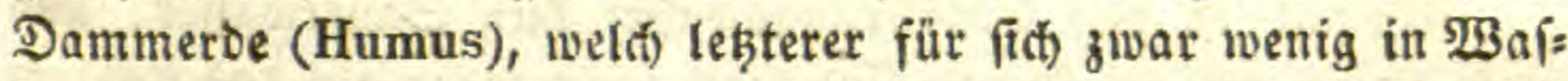
iet auflöstich) ift, mel)r aber mit 2 (mmoniấ verbunden, bas fid) ben Der Fäulnif́ bes Mifites biloet. Man hat zwar auch baben

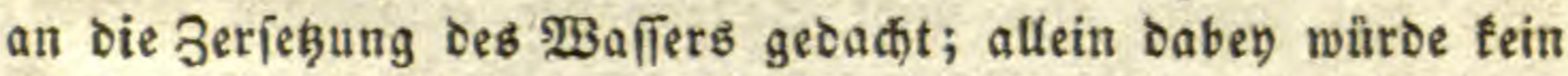

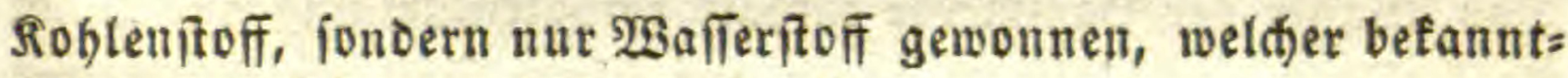
(id) in ber Pflanze nid)t bäuftg if́.

Man findet zwar Foblenjäure in Pflanzenjaft, uno nament=

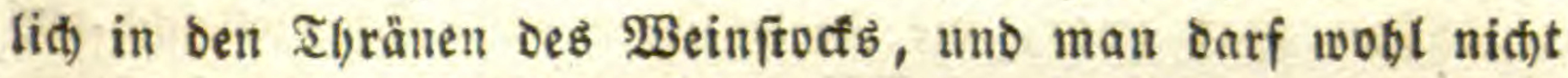
zweifeln, daßs Suhlenfäure in Der Dammeroe gebilbet werbe, fo weit nebmlid) bie Suft in bie Erbe bringt. Dak bas aber aud in größerer Tiefe geithebe, ift nidft wabrideeinlid).

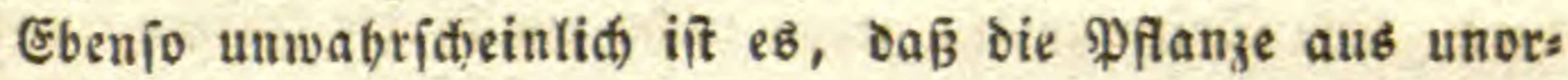
ganiijhen Stoffen fid) ibre Rabrung bereiten tönne, obíthon es niđot gerndę̆u geläugnet werben Eann, wenigitens für biejenigen

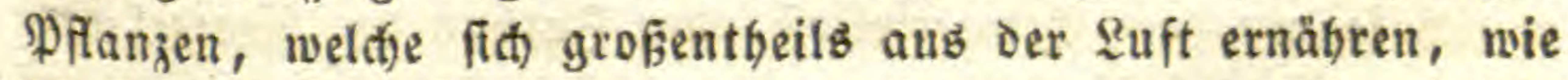

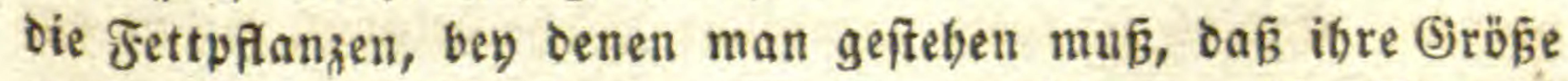

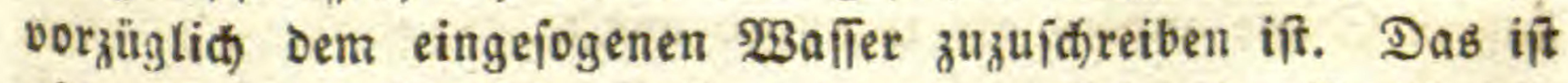
aber ein ungewöbnlicher Fall, uno man muß bey Der Ernäbrung überbaupt alif bie $\mathfrak{B u r z e l ~ f e h e n ; ~ u ̈ b e r d i e ß ~ z i e b e n ~ b i e ~ P f l a n z e n ~}$ nur währeno des Iags אobleniăure ein, indem fie Sauerîtofi entwiateln. Swar wäre ę ein guter Unteriftieb von Pflanzen uno Iljieren, wenn jene aus unorgani(t)en, tieje aus organij(t)en Stoffen fich ernäbrten. WBenn aber weder Ihatiactien nod) phby: 


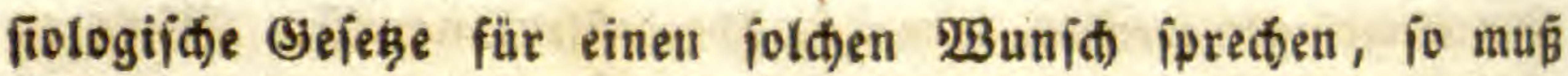
man ibn fabren lafien.

Der 2(nnabme, Dá̧ SToblenjäure die Rabrung ber Plallze

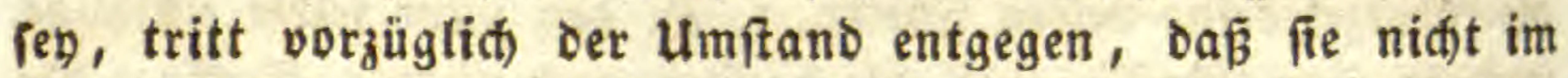
Stande wäre, igr ben nötbigen Foblenftoff in fo furzer Seit ju tiefern. 2tlerbings jaugt die Pflanze viel mebr $\mathfrak{W}$ affer ein als fie braudst, was die ftarfe 9 (usdünftung beweist; uno man barf

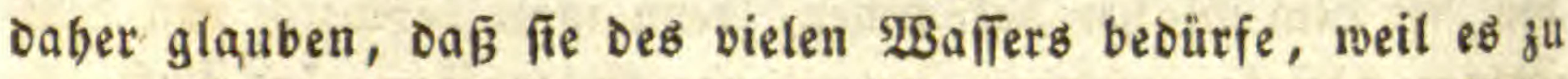
wenig నabrungsftoffe enthalte. SBäre aber nur sobleniäure barinn, io ífeint bieje ood) nidgt genug sioble zu enthalten,

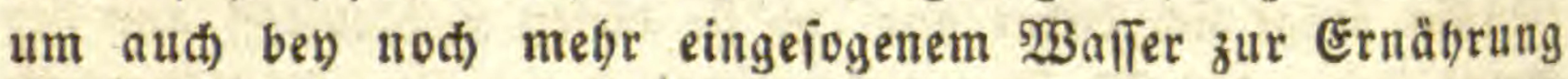
binzureitien.

Einmal ift das Ernährungswaffer fein Sauerwafier, uno auch) Diefés entbält in 100 Eubifzoll nicht mebr als 100 Roblens fäure, uno 100 zoll von diejer nur $12 \frac{1}{2}$ Gran Roblenitoff. Wie viel müBte alio nid)t Gauerwaffer eingejogen werben!

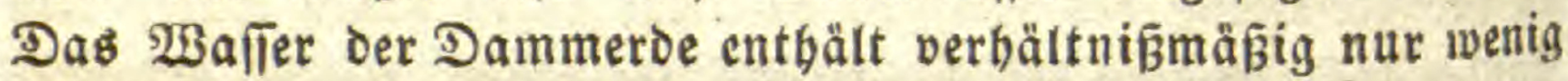
soblenjäure, uno fönnte baher auf feinen Tall bie Ernäbrung bejorgen.

Man fagt zwar, bie fioblenfăure bilde fith vielfeidt aus

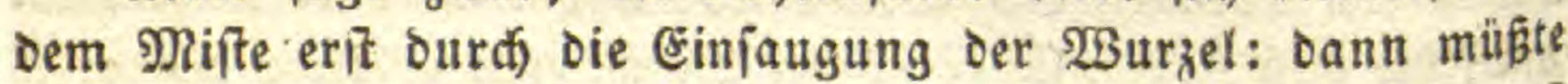

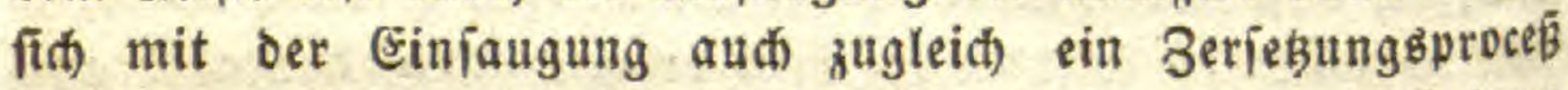
perbinden. 2(ber wo befommt bie 23 urzel ben Sauerftoff daju her? Die Spiralgefäßze gehen nidjt bis in bie Zajern, uno es

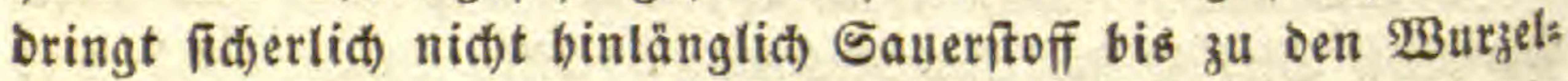

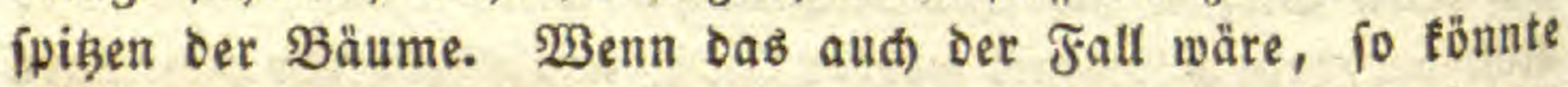
er fich) ja mit bem Extractivftoff ohne Buthun oer $\mathfrak{B}_{3}$ urzel vers binden. Enolid) ift feille organifidge Jlädte befannt, weld)e aulf äuBere Stoffe anders als treuneno wirfte.

Man muß baber bey bem Extractivitoff ober bem Şumus

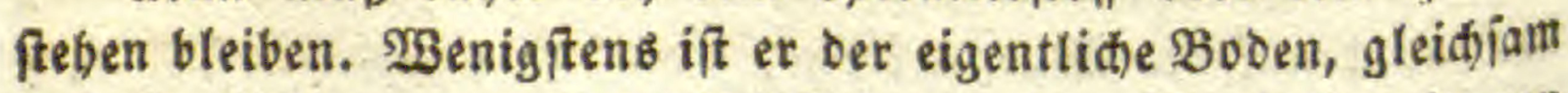
Der Epeifenbren, worinn die Pflanje fteht. Die 3ellen faugen

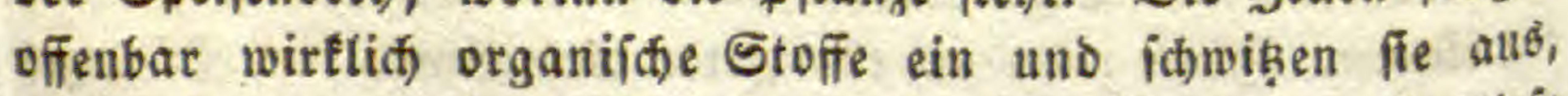
wie Gdfleim, Bucter, Gäuren 1t. dergl. 2llio baben fie tiefe

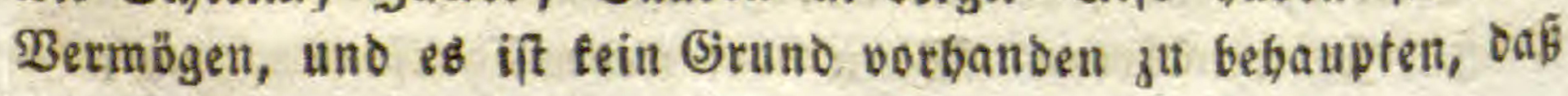


fie nur ben Roblenftof in \&uftform mit bem $\mathfrak{B a f f e r ~ e i n z u j a u g e n ~}$

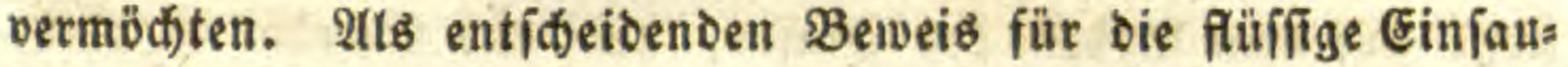

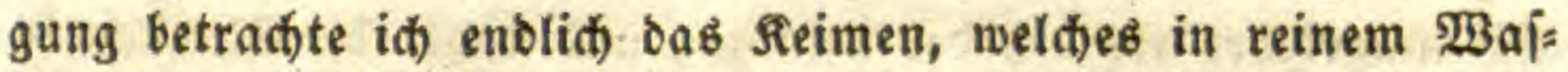
fer uno jelbit in Sâuren vor fith) gebt, wo aljo von Einjaugung voer Biloung ber Roblenjäure teine Rèe fenn fann. Dieje Einfaugung bient offenbar zu nidts anberem als zum Erweiden, Berfilifigen und Seriegen bes Mebls in ben Samenlappen

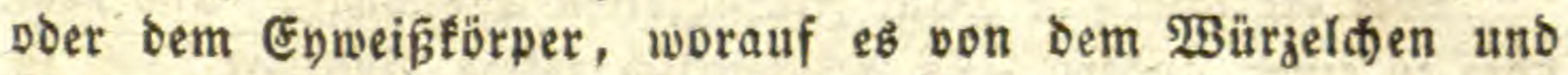
Stengelden eingejogen wirb. Das beiṕt alio genau genommen: oab Mebl wirs beym Reimen in Mift oser Ertractivftoff ber Dammerde verwandelt, uno fodaun unmittelbar von ben Pfin= zenzellen eingeiogen. Tun ift aber $\mathfrak{W a d j}$ (en nid)ts anberes als fortbauerndes Reimen, wobey an bie Stelle ber Samenlappen oder bes Meblz ber Mifít tritt, ober vielmebr fein wåferiger शैuszug, ber fogenannte Extractivitoff oder Sumus, weld)er liberbaupt von Dem falleimigen Extractivitoffe, Den man unmit= telbar aus ben Pflanzen geminnt, wenig verifbicben ift.

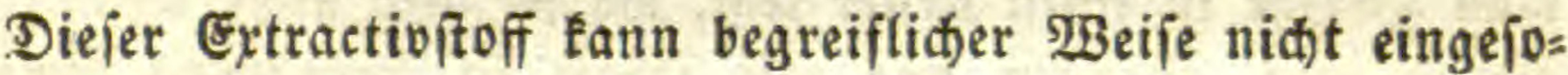
gen werben, io lang er alb tleine Feken im $\mathfrak{B a}$ afer, z. $\mathfrak{B}$.

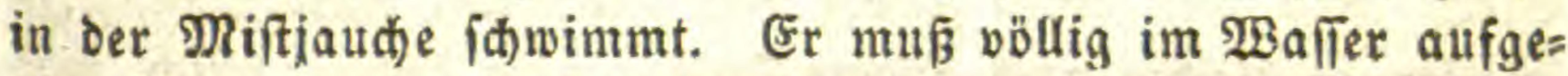
löbt fenn, etwa wie Sdbleim ober Bucfer; uno bas wiro er Durch Die Salze, bejonders die Pottaidhe, welde er in Det Erbe findet. Daß Salze uno felbft Erben von ber $\mathfrak{B}_{3}$ urzel eingejogen werben, ift eine auggemadte Sache. Man finbet fie nidit blok in ben Pflauzen, fondern aut) im Boden: und zwar werben fie in veridhiebener Menge eingejogen, ie nachoem Der Boben ver=

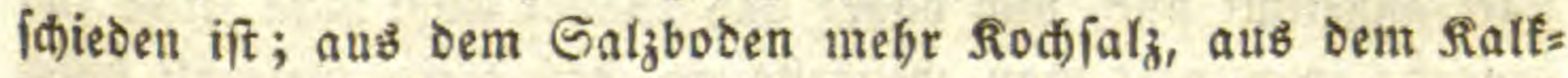
boden mebr Ralk, aus bem Sanbboben mebr Riejelerde, und aus reid)lict)er Dammerbe mebr Pottaiche. Su einer vollfom= menen Ernährung fineinen baber alle dieje Stoffe zu gebören.

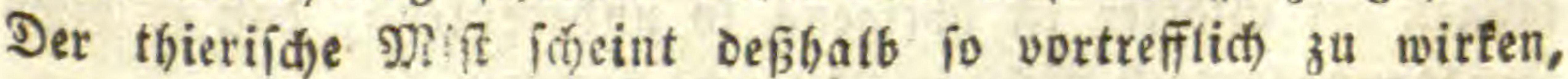
weil et 2(mmoniaf entwicfelt, woourd) ber Extractioftoff am (đ)nelliten auflöbliti) wiro.

Meiner Meyuung nad) faugen bie Burzeln in ber Tiefe

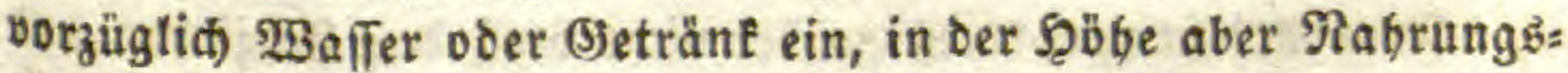
ftoff. Bey den Berjucten iff es baber nid)t gleidgültig, weld)en 
Sheit man in die Ftinffigfeit bringt. Şier liegen bie Rabrungs: ftoffe auf bem Boden bes SIlajes, uno bas (s)etränt ift oben, alio umgetebrt als bey ber Pflanze; uno baber die Serfutide fo abweidbeno uno unfid)er.

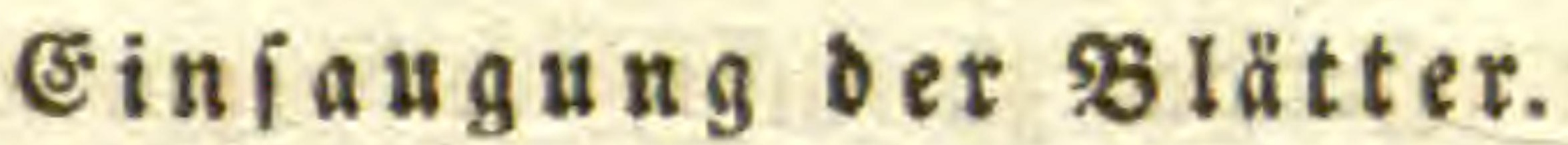

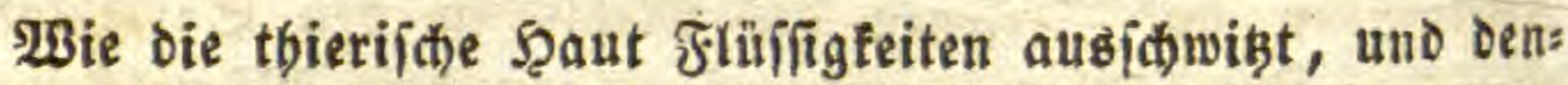
no() zu einer andern Beit gelegentlid) joldhe einjaugt, wie in einem $\mathfrak{B a b}$ oder beym Einreiten von $2(r$ zneymitteln, io alth bie Blätter. Das thun jelbit bie getroctueten Moofe, obition fie nid)t wieber lebendig werben. Begiegt man fie nethmlid mit WBaffer, fo füllen fie fid an uno werben faft augenblictlich grün. Fät ein Regen auf eine Pflanje, deren Iopf fo bedectt ift, Das fein $\mathfrak{W a}$ (Ter binein fommen fann, fo wiro fie bennod) in furzer

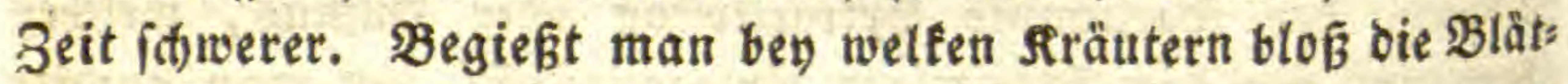
ter, fo riditen fie fich jogleid) auf. Dafferbe gejoielst, wenn man 3 weige in einen Seller legt, wo fie alfo nid)t unmittelbar mit $\mathfrak{W a}$ iाer, fondern nur mit Dunft in Berübrung commen. Stectt man tur einen 3 weig oder ein $B$ latt einer Pflanze in

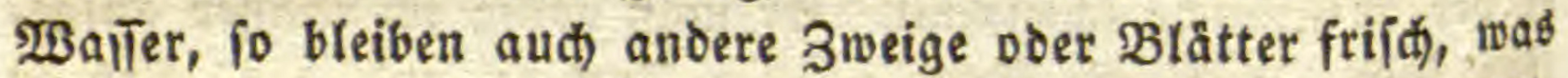
nict)t anders als burd Einjaugung erflärt werben fann. Fetts pflanzen tann man Jabre lang an eine Wano aufbängen, uno Denno() treiben fie Blütben und Früd)te, woz̆l frenlich aud) ihre id)wache 2(uboünftung, wegen ber geringen 3 abl ber Epaits mïnoungen, vieles bentrågt. Da bie Bellen ber Dberhaut mit

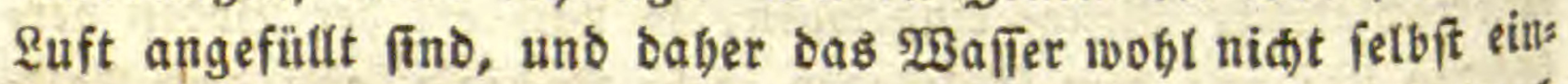

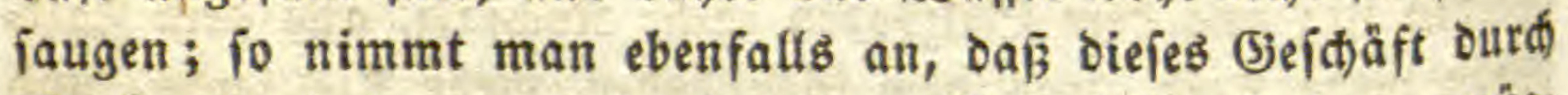
oie Spaltmünoungen bejorgt wirb. Sie müsten baber vorzĭhs (id) bey Nacht einjaugen, uno bey Tag ausbinften. Das Ein' faugen Der Blätter ift übrigens fo unbedeutend, Da $\tilde{\beta}$ es bentm Crnäbrungsproceß niđ)t in Betractit fommen Eann.

\section{2. $2 \mathfrak{t} \mathfrak{b} \mathfrak{m} \mathfrak{u} \mathfrak{g}$.}

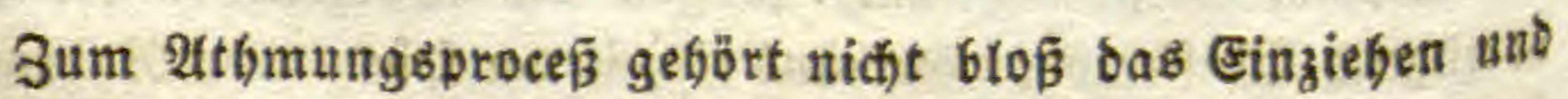
2uहftogen von Ruft, fondern aud von $23 a f i e r$. 


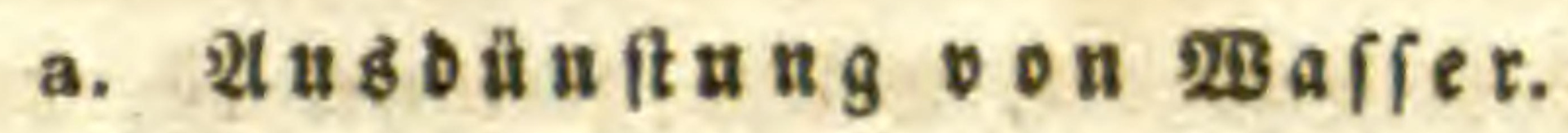

Es iff eine befannte Sadje, daß̧ die Pflarzen vertrodnen, wenn fie fein 930 ITer befommen, bejonders fónell bie Blätter; Daß̧ Die Frtichte leid)ter werden und einforumpfen, wenn fie längcre 3eit liegen. Berjuche mit \$flanzen in einem నopfe, ben

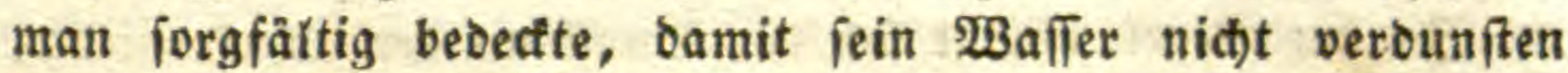
lonnte, zeigten, Daß̧ die \$flanze felbft unaufbörlid) viel $\mathfrak{B}_{\text {affer }}$ verfor: eite 3 Sdub bobe Sonnenblume täglid) 20 unzen, Fiohl 19, פBelidjforn 7, Şeliotrop 24, aljo ïberbaupt viel mebt als ber menidlide Rörper. WBafferpflanzen, ins Troctene ges bradit, verbuniten f(d)neller, weil fie feine ăd)te Dberbaut baben; Mooie und Flechten bagegen verbuniten febr langiam. Blätter mit vielen Spaltmünoungen binften mebr $\mathfrak{B}_{\mathfrak{B} a \| f r}$ aus, als wenn fte, wie die Fettpflanzen, weniger haben; die untere Seite aus demfelben (Srunde mebr als die obere, wie Berfud)e mit Beinblättern แ. a. lebrten. Beftreid)t man die Blätter mit einer Materie, weld)e die 2 (ub düntung binbert; fo werben fie braun oder fterben $a b$, felbit wenn die פRaterie ganz uniduldig ift, wie fettes Del. Das Beftreiden Der obern Seite fodabet in ber Regel weniger, als das ber untern. Ueberbaupt ftebt bie Menge Der Mutoünitung mit Der Menge ber Spattmün=

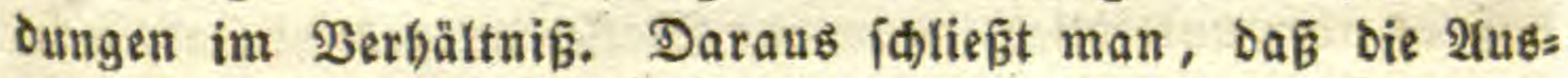
Dünftung vorzüglich Durch bie Gpaltmünoungen gejót)be, bejon=

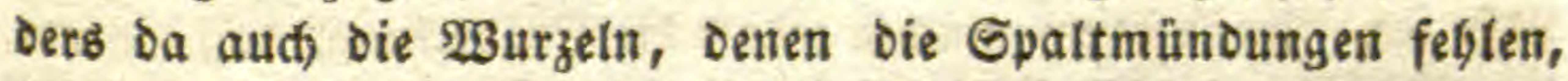

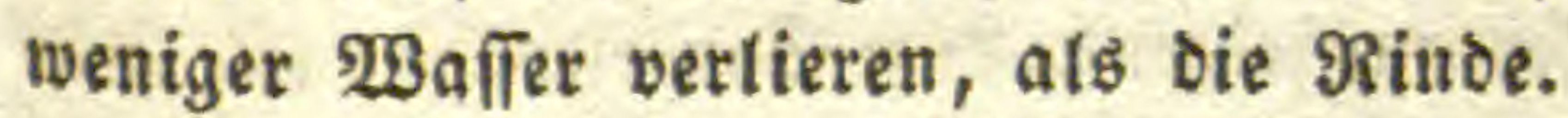

Die Berounfung ift ftärfer bey troctener \&uft, bey böberer Semperatur, bey Sage, vorzüglich aber, wenn bas Sonnen(id)t unmittelbar auf bie Blätter fideint. Es wirfen baher alle bren

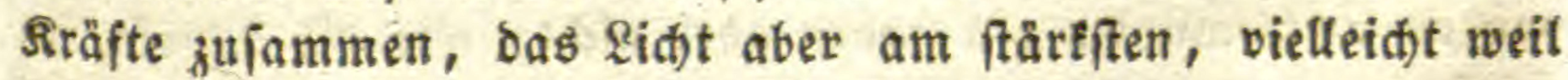
es zugleich) zeriegento auf bas 2 affer wirtt.

Das ausgedinftete Baाler ift fait ganz rein, und hat nur

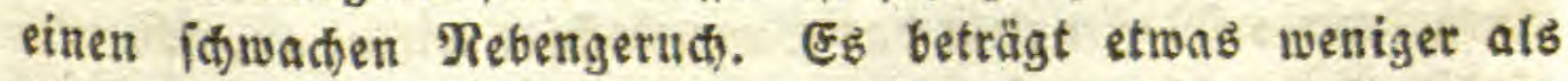
Die Einjaugung.

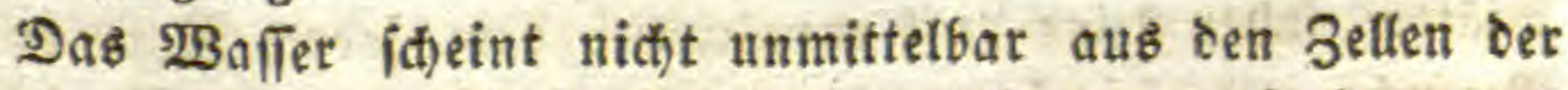
Dberhaut, als welde suft entbalten, zu fommen; fondern aus 
Den Sntercellular:९äumen unter ben Spaltmünoungen, worinn

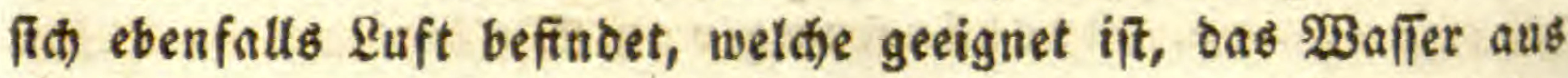
ber innern Subitanz des Blattes aufaunebmen. Man bat bes obactitet, daßs die Spaltmitnoungen des Morgens bey Sonnens fhein, wo bie meifte 2lusbünftung ftatthat, offen ftehen, forfit aber geíctolien fint.

In ber Regel fid)lägt fid ber Dunit an ber Bjlocte nieber, womit man bie Pflanze bebecft. Bismeilen zeigt er fidh aber aud) als Iropfen felbit auf ben Blättern, bejonders wenn biefe

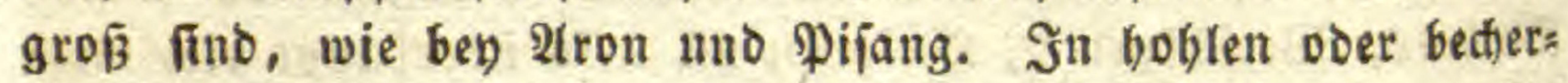
förmigen Blattern fammelt fí() fogar Dag $\mathfrak{B a f f e r ~ i n ~ g r o f ́ e r ~}$ Menge an, wie ben dem Rannenfraut (Nepenthes).

\section{b. 2thmung von \&uft.}

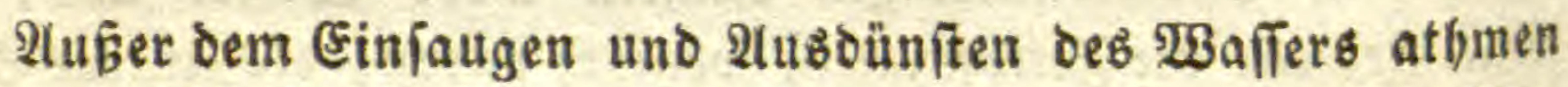

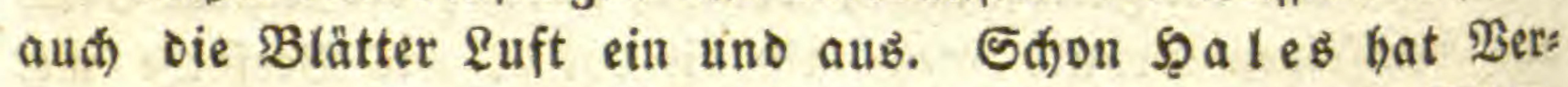
fuche Dariber angeftellt uno bered)net, Daßz eine bedectte Münzs pflanze viel Ruft verzetitt uno zum fernern (5iedeihen unbraud): bar gemadt bat. Indefien baben erft $\mathfrak{B}$ onnet, $\mathfrak{p r i e f t}$ (en, Jngenboub, Senebier, $\mathfrak{b}$. Sauffure, (5rifdow uno Andere ben Borgang grünolicher erforidst. Bonnet bementte,

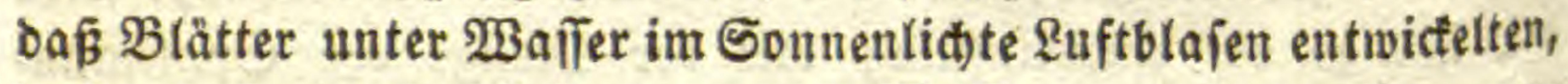

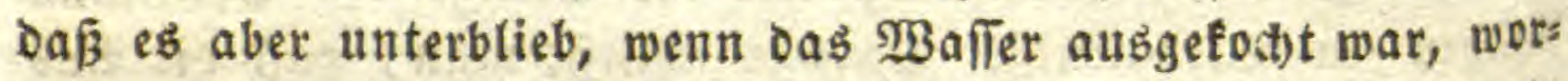

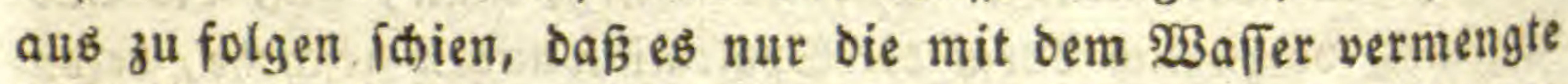
Euft (en. Prieftley madite jeodd die Entbectung, Dafi bie von ben $\mathfrak{B}$ lättern im $\mathfrak{B}$ affer auffíteigende 2 uft Sauteritoffgas ift. Das zeigt fid) jedod) nur bey grünen Pflanzentbeilen, uno feireb: wegb ben gefärbten, wie Blumen, $\mathfrak{B u r}_{\text {zeln, }}$ Pilzen u. Dergl.

Die Blätter liefern bas Saueritoffgas im Sonnenlidte, fie mögen Spaltmünoungen haben ober nicht, wie die Mooie, ia felbft wenn man oie Dberbaut abziebt, woraus man follief́n Darf, Daß̧ fie aus ben grünen Theilen Der PFlanze felbft fommt.

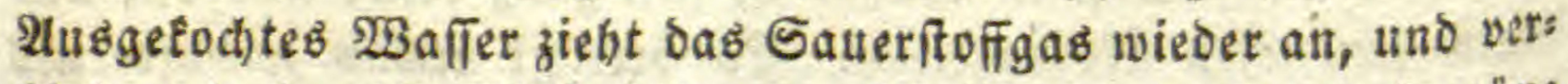
binbert Daber bie Blajenbiloung. 2lbgeftorbene, aber nod) gritne Blätter follett feine \&uft entwicteln, bem jebod) $\Re$ u m ford Beriude wiberiprechen, als weldier auch Sauterftoffblaien an 


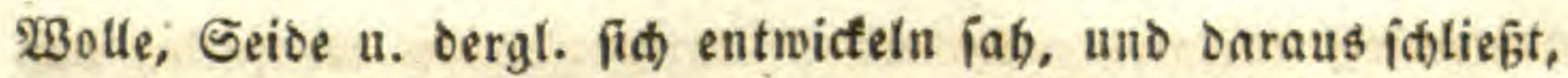

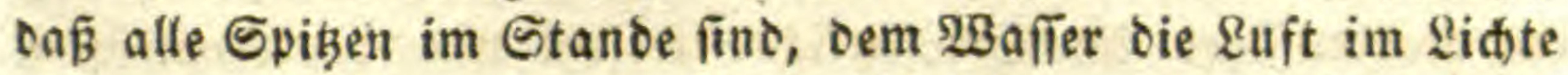
zu entziegen (Я um foros fleine Sd)riften. 1783). 2(ut) zeige

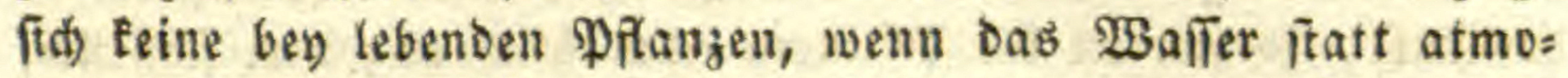
iphärifher Ruft Sticfgas, WBafferftoffgas voer jelbft Santerfitf= gas entbält, wogl aber wenn Robleniäure barinn ift, woraus

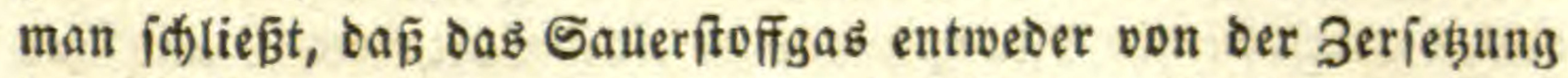

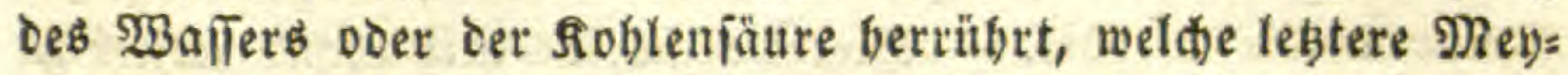
nung bejonders $\mathcal{S}_{\mathrm{c}}$ ebier unb Saufure vertbeidigen. Die

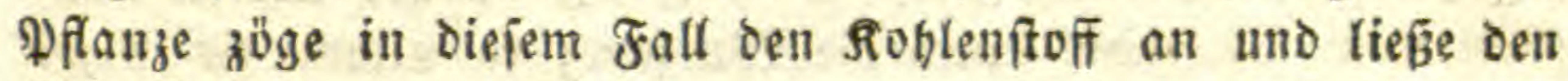
Gaueritoff fren.

Bey Radt, und felbit ben $\mathfrak{a} a g$, weun bas Sonnenlidet nid)t unmittelbar auf bie \$flanze făllt, verzebrt fie Sauerf́toffgą uno entwidfelt soblenjäure: nach Senebiers, Saufifures und De Eandolles Menung, indem der Sauerftoff fíd) mit

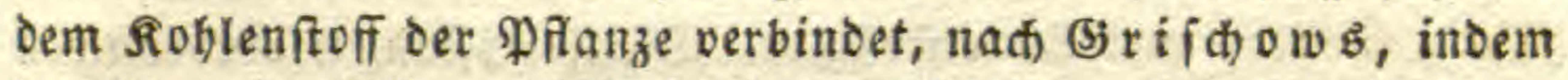
bie f(j) im Pflangenjaft fertige Roblenfäure davon geht.

Эn $\mathfrak{W a f f e r}$ mit Roblenfăure liefert Die ftoffgas, alb ohne baflelbe.

Epert man 3 affer mit fohlenfautem (J)as, fo gedeigt fie vollfommen, währeno bie Roblenäure veríd) windet uno Sauer= ftoffgas zurücf bleift; in Deftilliertem $2 B a f f e r$ aber, mit atmo= (phäriī̧)er \&uft, gebt fie allmäbliđ) zu (srunce, uno es entwictelt (iid) Pein Gauerítoffgas.

Die Pflanzpn verzebren auch Roblenjäure in Ser Sonne, wenn fie nidft unter $\mathfrak{B} a$ fler getaud)t find, und zeigen bey ber

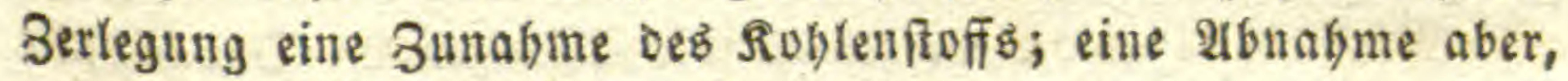
wenn fie mit Suft obne fobleniäure geipert werben, uno Dabey in Deftilliertem Waffer fteben. Sauffure ließ 6 Iage lang Sinngrün mit ben $W_{3}$ urzeln in beftilliertem $\mathfrak{W a f f e r}$ an ber Sonne wadien, in einer Ruft mit 7 procent Roblenfäure. Die lę̧tere verít)wand uno zafür zeigten fich) 3 Procent Eaueritoff:

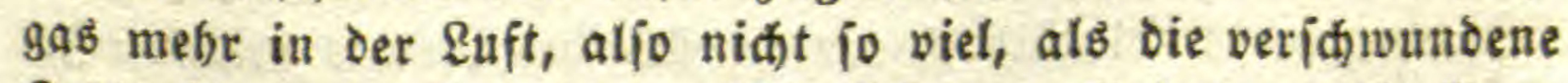
soblenjäure jelbit entbielt. Die Pflanzen lieferten $2 \%$ Gran soblenftoff mebr als vor sem $\mathfrak{B e r j u d}$. 2noere auf biejelbe TBeife in \&uft obne Roblenjäure gewadien, batten etwas Dfen s allg. Raturg. II. Botanit I. 
Stohlenitoff verloren. Andere Pflanzen zeigten ebenfalls, baß́

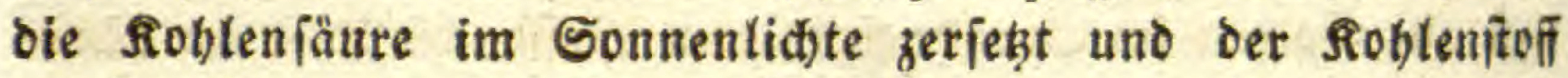
zur Ernäbrung verwendet wirb. Jift gar feine soblenfäure in ber Luft, io fterben bie Pflanżen allmåblic ab; viel ianteller, wenn aller Sauerftoffigas feblt, uno fie blof mit Stictgab, $\mathfrak{W a f}$ ferftoffgas uno jelbit toblenfaurem Gias gejpert find. Uleber: haupt gedeiben bie Pfianzen nur in einer Euft, welde alle ibre Beffandtbeile entbått. - Şieraus iđ)eint mír nichts weiter z̧u folgen, als Daß̧ bie PFlanze ibren Şunger ftillt, wie fie Eann. Gibt man inr nidts burch bie $\mathfrak{B u r z e l n}$; io nimmt fie es mit Stenget uno $\mathfrak{a} a b$, gerabe io, wie ber Menich ourd) Die Şaut

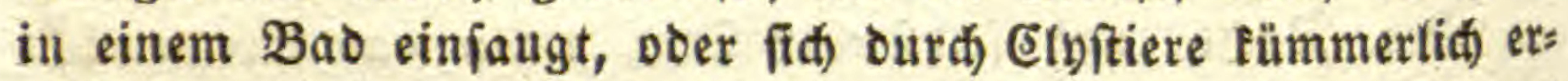
nährt, wenn er nidbts ourd) ben Magen ober feine $\mathfrak{B u r z}^{2}$ betomint.

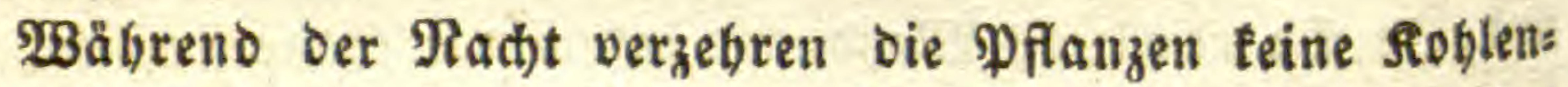
jäure, jonbern viel Saueriftoffgaz. Die Fettpflanzen verbrauhen weniger Saueritoffgas uno liefern aud weniger soblenfäure. 2(m trāftigiten gegen biefe Proceffe vor fïb) benm eigentliđen

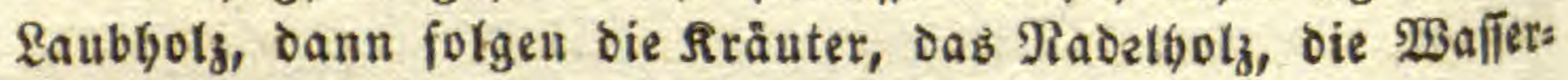
pflanzen uno enolid) oie Fettpflanzen.

Эัn Sa แโ pflanzen in Der Finfternif, wäbrend 24 Stmnden, $6 / 10$ ifrę

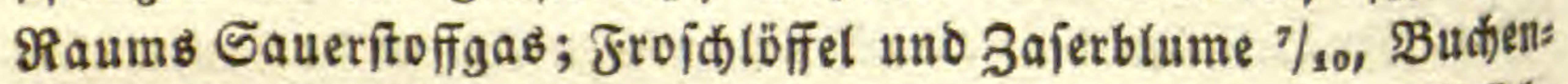
unb 2(pricoien=Blätter das 2(d)tfad)e, Pappel= uno Pfirfiths Blätter ‘as ভechвfad)e. Ueberbaupt verzebren junge Blätter mebr als alte.

Rat) (5) rifdow verzebren bie Pflanzen im Durdjitnitt $4 / 3$ i )res Raums Gaueritoffgab unb entwicfeln $3 / 4$ fogleniäure;

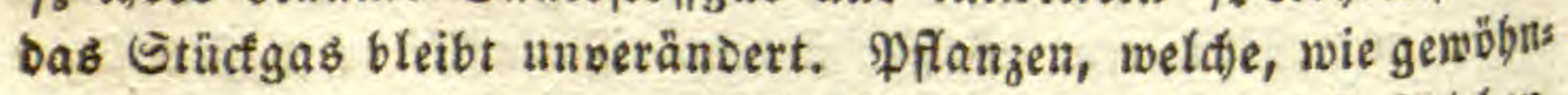
lid), abwedfielno bey Tag und ben Nacht in geiperrter \&uft leben, ändern biejelbe nidt, weil fie das Gaueritoffgas, weldhes if bey Radt verzebren, bey Tag wieber von fth geben; bafielbe gilt von ber Roblenfäture, welde fith des Rachts bildet. Stm

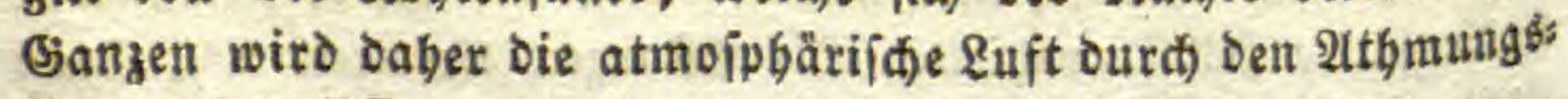
Proces ber Pflanzen weder verbeffert nod) verborben.

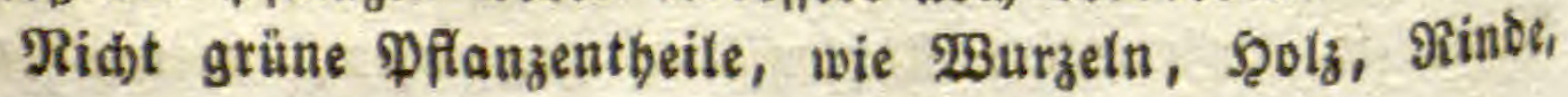


Blumenblätter, Früc)te, Sumen unઠ gefärbte ફ̧erbfitblätter ver= it)luten bey Iag uno Radt Gauerftoffgas, und entwicteln sioblenfäure.

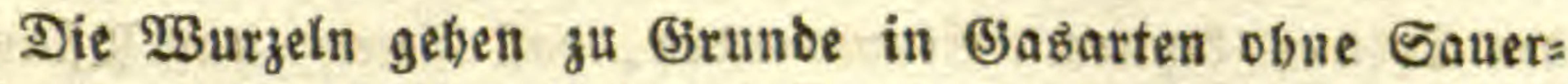
ftoffgaz, uno gedeiben baher beffer in locterer Eroe. Man

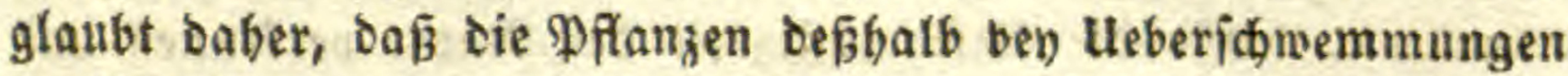
zu Grunbe geben, weil bas $\mathfrak{W a f f e r}$ den 3utritt ber \&uft vers

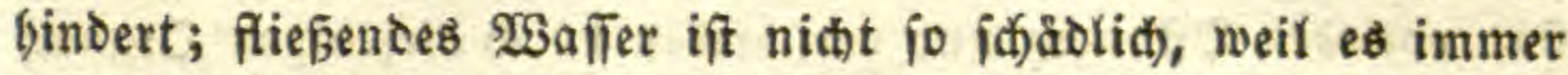

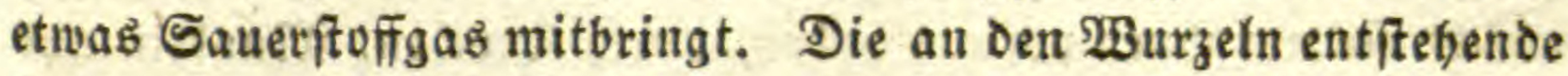
Toblenfäure foll von benjelben eingejogen werden. Ilbgejäălte 3 weige verfalten fid) auf diejelbe 2(rt. Das todte ફ̧olz verzebrt ebenfalls Saueritofigas, mithin ourd) einen blok chemifhen Procę. Eingeiperte Błumen verzebren zu jeber Zeit Sauer= ftoffgas, bilben Johlenjäure uno ftof̧en aud) etwas Stictgas aub.

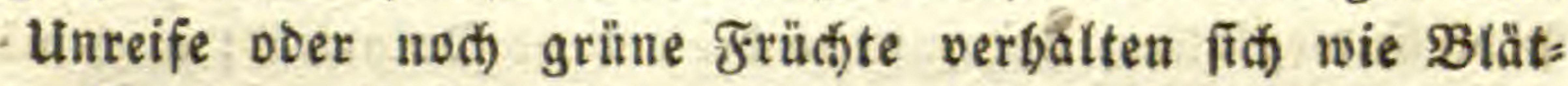
ter, reife aber wie $\mathfrak{B u r z}_{\text {eln }}$.

Benm feimen Der Samen bilDet ihr Rohlenftoff mit bein Saueritoff der \&uft fioblenjäure.

Pitze verzebren viel Sauterfoffgas, bilden damit soblens fäure uno entwicfelu aud bald Sticfigas, balo Wafierftoffgas. Die grïnen Mooje bagegen uno Bafferfäben entwicfeln im Rididte viél Sauerftoffgaz.

Nach) Bergheid)ung aller biejer Beobaditungen fann tein

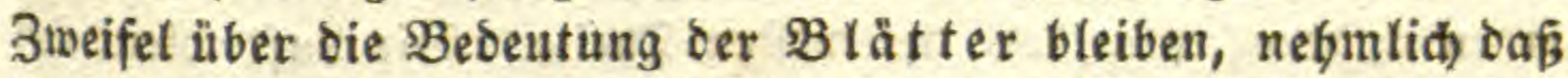

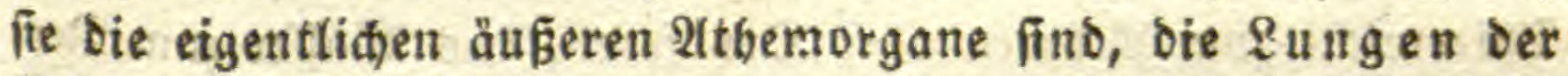
Pflanzen in Form von Siemenblåttern; baß ferner auch bie

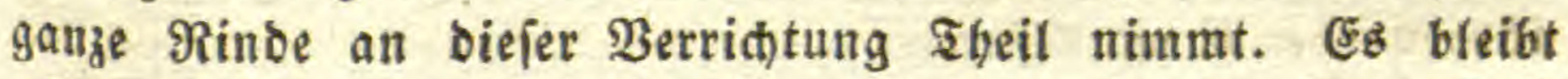
aber biebey immer nod bie Frage übrig, woher bas Saueritoff= gas im Sonnenlidjte fomme, unb bie Rohlenjäure bey Nadit. Das Saueritoffgas Eann nebmlid fonon im Pflamenjafte fren vorbanden feyn, wie im $\mathfrak{W}_{\text {affer; }}$ oder es fann bur() Zerfeģung des Waffers oder ber Roblenjätre entiftehen, in welchem Falle

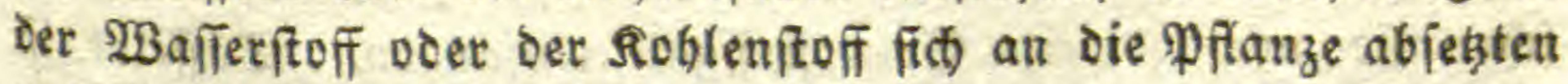
und ibr (sewidid vermelyrten.

Mand) glauben baher, die Siohlenfäure fè ber eigentlidfe Rahrungsftoff der Pflanzen, welder fowobt aus ber Ruft als 
aus bem $\mathfrak{W} a$ ffer eingejogen würde. $\mathfrak{T}$ biejem Falf wäre aber 2tbmen uno Ernäbren, oder vielmebr Berdaten, einerley, was Der $\mathfrak{P h y f i o l o g i e}$ offenbar wiberipriat, wenigitens wie wir fie ben Den Thieren fenten. Einztuwenden, daß̧ Thiere uno Rflanzen ganz verífieden feven und baher feinen Shlun auf einander

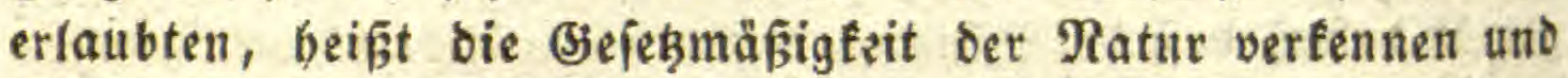
ielbit ben meientlidiften unterídied zwifthen beiden. Die Thiere futo vou Den Pflanzen nur veriffieden burd) biejenigen Drgane,

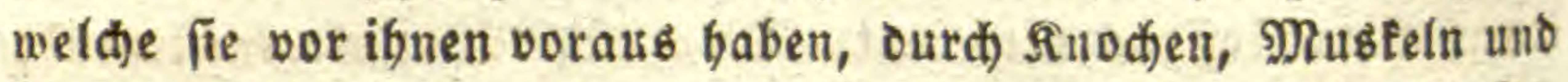
Nerven, feineswegg aber Durd) die Drgane, oder vielmelyr Sy= fteme, welche bem organifichen Reben überbaupt zutommen, nebm: lid) Serballungs =, 21thmungs s, uno Errnährungs = Syftem.

Wäre ben den Pflanzen Einfaugungs = ober Berbauntus:

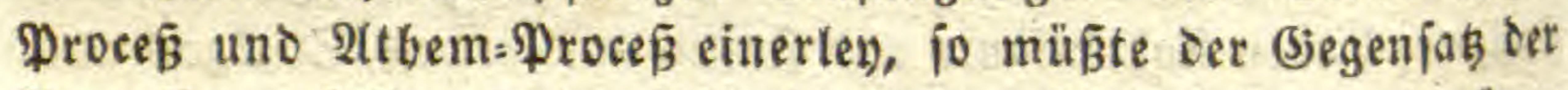
Proceffe wegfallen, uno mitbin oie Qebens: Polatität; aud wären bie verithiedenen Siemebe, Syiteme uno Drgane ganz unnibs.

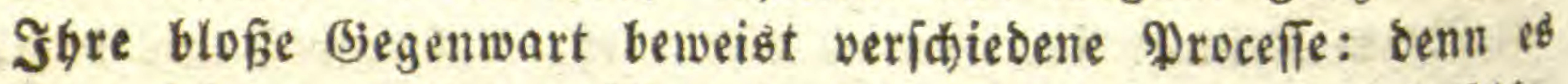
tann teine veríthiedene Materie fid abjeken, obne eine veridies oene Thätigfeit, da fie ja nur oie probucte von Ibätigfeiten fino. Wo wir baber ein anderes Drgan jeben, milfien wir aud cine andere Berridtung annebmen.

Das Einfaugen voer Zeríezen ber suft mus baher einet

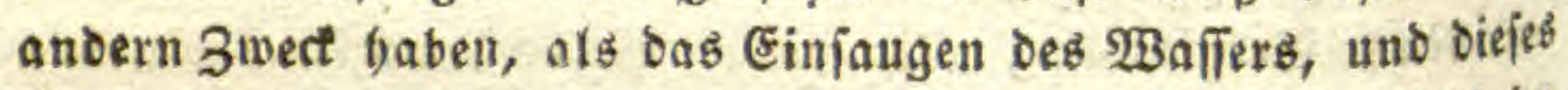
einen andern, als bas ber veften Theile. Die \&uft bient int

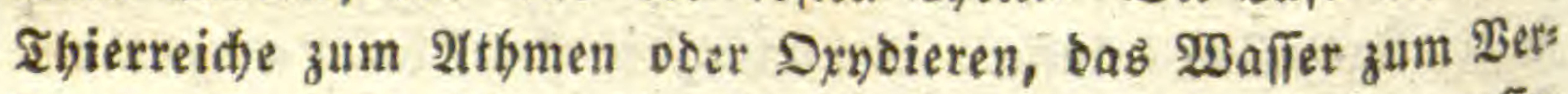
dauen oder Ebemifieren, die Epeife als das Erbartige zum Et: näbren ober Eryftallifieren.

Benm beginnenden Thier im En jaugt bie f̧aut Rabrunt ein, uno biejer Procé bauert aud wäbrend bes Rebens einiger maşen fort, obfchon die Şaupteinjangung ourch bie Dätml geidhiebt. Die f̧aut aber wirs nun vorzinglidi) ein 2 tusbinnitung

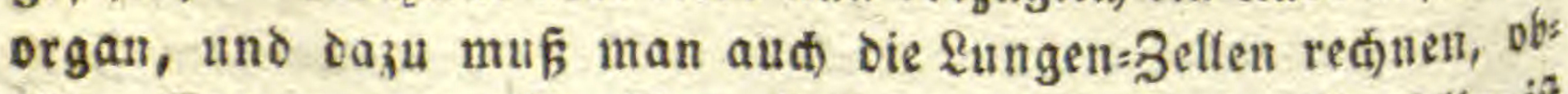
fdion fie vorzugsweife Sauerftoffgas einjaugen. Daffelbe ift ofne 3weifel bey ben Pflanzen ber Fall; nur Dás die Einjaugung auf ber gamen Dberfläche, das ganje Reben bindurd), in einett

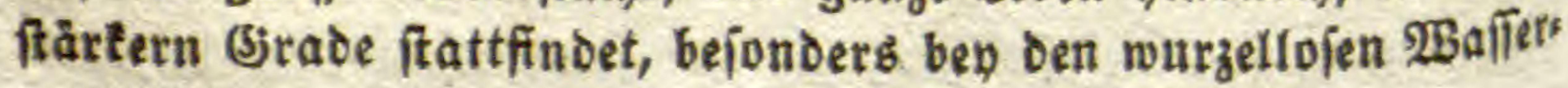


pflangen, wie Ballerfäben und Tangen, uno bey ben wurzel= armen Mopien uno Pilzen, wel(he bafer aud) nur in fenditer und fitattiger Euft geteiben. Sobald aber fid) bie 23 urzel volls ftänoig entwictelt; io übernimmt oieje bie Einfaugung bes $\mathfrak{B a}_{a}$ :

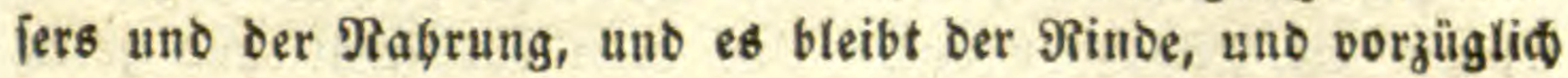
sen Slättern, nur bie Einfaugung ber Ruft übrig, wodurd) erft ber volle Ejegenfaz zwi vortritt.

Da nun bas 2tthmen blos ein Berbåltnís zur $\mathfrak{E} u f t$ ift, uno bas sidft nidts bamit zul idaffen bat; io tönnen wir ben 2(tbemprocés nur im Sđatten oder wäbreno ber $\mathfrak{R a d}$ ) in feinem reinen 3uftande finden: uno ba zeigt er fid völtig wie im Shier: reid, nefymlid) es wiro Sauterftoffgas verzehrt uno soblenfäure entwicfelt, ganz wie in unjern Rungen uno aud) no() in (d)was dem Sirabe auf ber Şaut. Diejer Zuftand if bey 23 eitem ber längite, worinn fich bie \$̣lanzen wäbrend ibres \&ebens befinben. Befanntlich gibt es wenige Tage im Sabr mit bellem Sonnen=

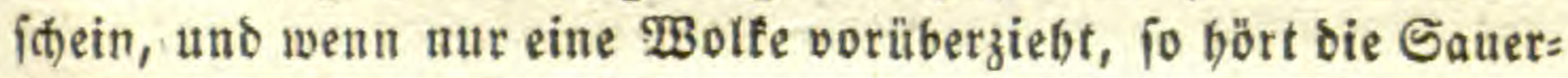
ftoff = Entwictelung oer Pflanze augenblictlid) auf. Man tann

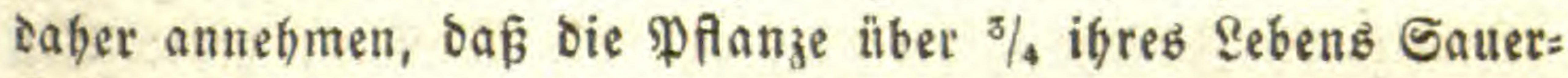
ftoffiga eintiebt oder atbmet.

Der Eiuflus des Eonnenlidts leiftet Daber ber Pflanje obne Zweifel Eeinen andern Dienft, als bem Thiere, nebmlid, nut einen zeriegenden an ber Dberflåcte, wodurch fie ibre grüne sarbe erbält.

Wie bringt aber bab Sidtt bieie Wirtung berwor?

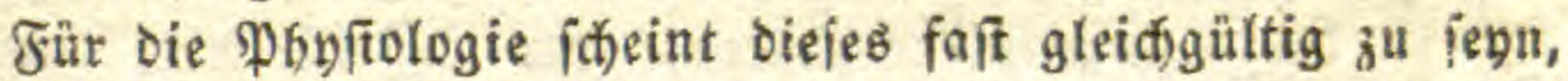

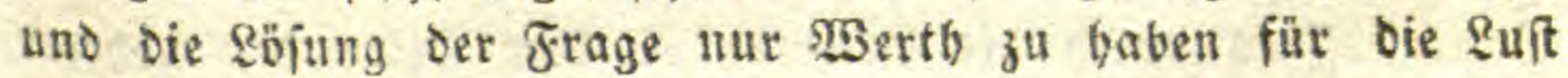
uach Erforfatung Der $\mathfrak{W a b r b e i t . ~}$

Betradten wir die phyifife Wirfung bes Riđtes, io zeigt

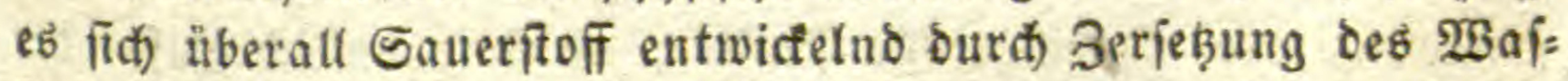
fers, ber Säuren uno ber Metalléthe. Dab ift aud wabt:

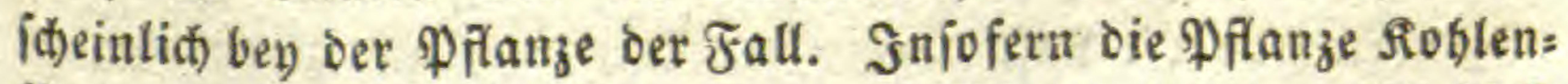
fätre anziegt, um fid) ibren foblenftoff anzueignen, wirb bieje Durd) ben phyfijhen Einflus bes sidtes zeriegt. Dafielbe wiro audi) geidjeben ber soblenfäure in bem Gafte, wenn er ber 
Dberfläde nabe tommt. Die Erwärmung ourd) ठab Rid)t mirt auth ben Saueritoff entwicfetn aub anbern Stoffen, ober atl bem Safte, weln er frey barinn ift.

Die Şauptwirtung wirb aber immer auf Das $\mathfrak{W a f f e r}$ geben, wobon die Pflanze ftrok̨t. Das sidht entwictelt aus jebemt Waffer Saueritoff, wenn es barinn einen $\mathfrak{B i b e r}_{\text {tand }}$ fintet, bes jonbers wenn es anf Spiz̧en trift. Ben ber Pflanze orängt

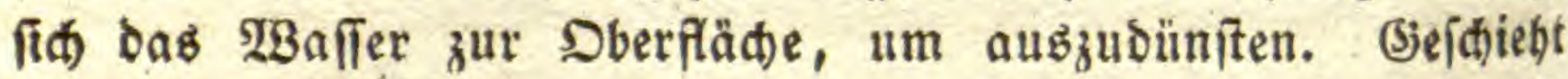
Diejes im Rict)te, fo wiro es zeriekt, im Eajatten oagegen als Iropfen niebergeidlagen. Fs tommt auf beide 2trten aus ber Pflanze. Das Ridt)t wirft aber aud outch bie burt)fititige Dbet: baut auf bas Stärfemehl in ben Weflen, nimmt ihm ben Sauts fitoff uno mad)t es grin. Das alles bat mit bem 2(thmen niकts

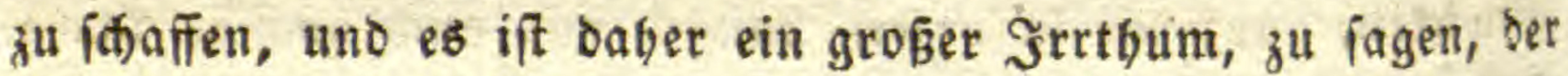

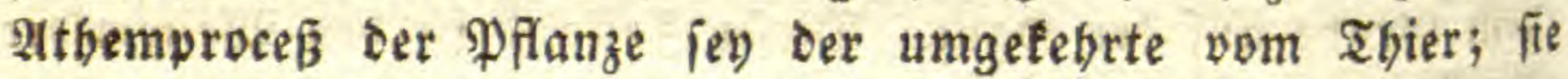
entwictle Dabey Gaueritoff, wåhrenb er hier verínluct werob.

\section{Quft im Snuer}

Die bisker betrachteten $\mathfrak{W i r f u n g e n ~ b e s ~} 2$ them $=$ proceffes,

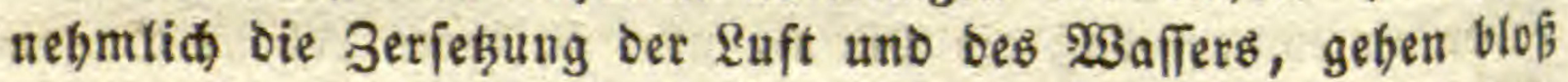
an ber Dberfäche ber \$flanze vor, uno, wie wir gejeben baben, vorzuggweife in ben Blättern; Daber aud bie \$Flanze băufig j"

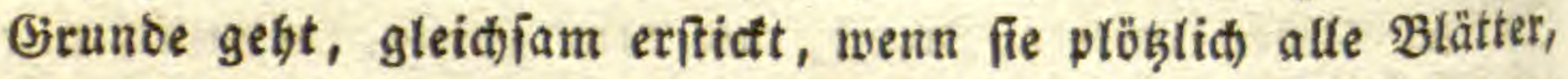

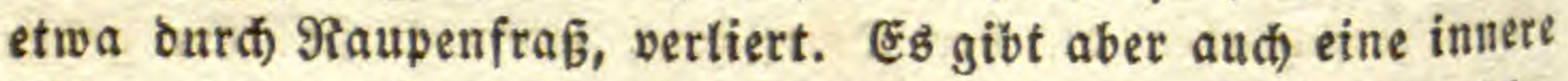
2tthmung, vermittelt Durd) die Epiralgefä́ce oder Droffeln, welde, wie bey ben Injecten, oie Ruft burd) ben ganzen Pflanzenleib

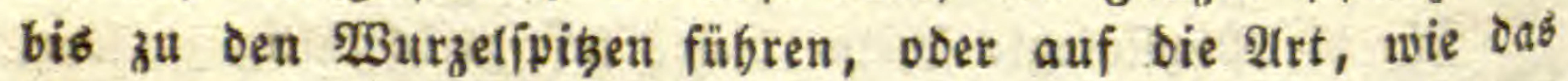
Gaueritoffgas Durd) bie 2(rterien in Dem Seibe ber böherett Thiere verbreitet wirt.

Dbithon man fich) nod) gegenmärtig liber bie eigentlithe $\mathfrak{B}$ es

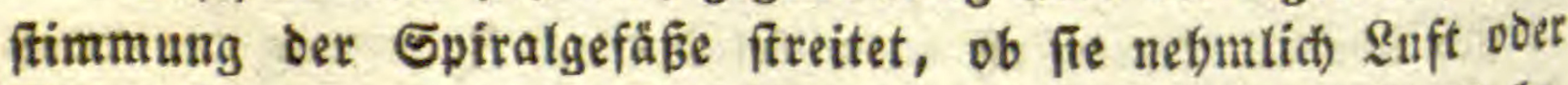
Säfte fübrend fino; jo ift es bod) eine ausgemadjte Thatjathe, ১aß́, man lehr oft \&uft barinn gefunden bat, uno zwar von betr \&lteften 3eiten ber PFlanze日=21natomie an bis auf bie unierige. Dutchidneidet man Stengel mit weiten, bem blosen $\mathscr{2}($ uge fift) baren Spiralgefägen, wie bey ben Rattrbien; fo wirb man igte 
Münoungen trocten, bie Stellen um biefelben feutht finoen.

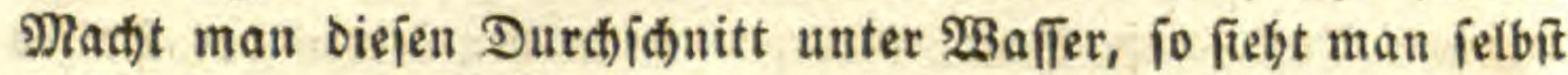

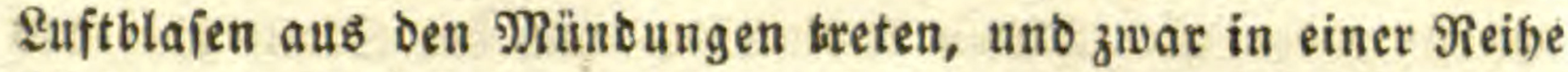
Ginter einanber, bejonbers wenn man ben Stengel brïct. Regt man Rängsfdnitte unter das Microfcop, fo bemerțt man in ben unverlę̧ten (jefäßen ebenfalls \&uftblafen, weld)e allmäbliđ fleiner

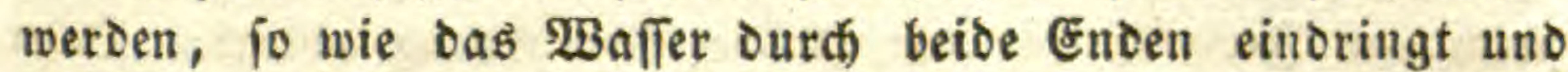
Diefelben verid)luctt. Ueber bie Ratur ber \&uft bat $\mathfrak{I} \mathfrak{h}$. $\mathfrak{B}$ i i d) off Seriutche angeftellt, und gefunden, Daß fie 28 Procent Sauer: ftoff enthält, alijo 8 procent mebr als die atmoiphärijahe, woraus bervorgebt, oaß̧ bie Spiralgefǟe mebr Sauerftoffgas einzieben als Stictgas; obue Sweifel wegen ber Berwanbtidhaft Der Pflanzenftoffe zu Demielben. W3. Focte gat-Dagegen in ber Rad)t viel Foblenfäure uno tein Sauerítoffgas gefunden, wor=

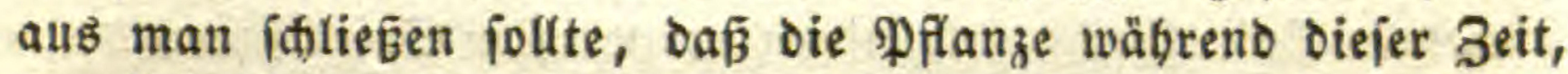
wo fie bas Sauerfifoffgas einziebt, auch am meiften bavon verzebrt.

Wie bie Ruft in bie Spiralgefä̧e tommt, weißs man niđjt, oa biefe nirgends 2 b̈her haben, und jelbit an igren Enden ge= fdilofien find. Man glaubt, fie oringe burd bie Epaltmünoungen ber grünen $\mathfrak{a}$ beile zwifhen bas Zelfgewebe, uno werbe von ba burdh die Spiralgefäge eingeiogen. Wabricheinlider oringt die

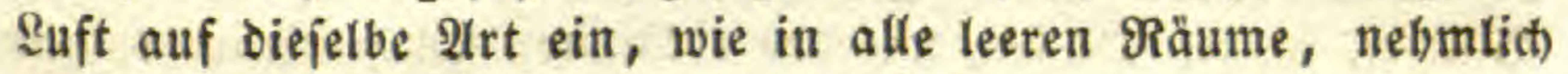
ourd) ihre eigenes (sewid)t. Es frägt fïd) oaher nur, wie ber leere Raum in Den Giefäß̄en entiteht.

2lbgejeben pon ben fünftlichen Einjaugungsveriuten ber

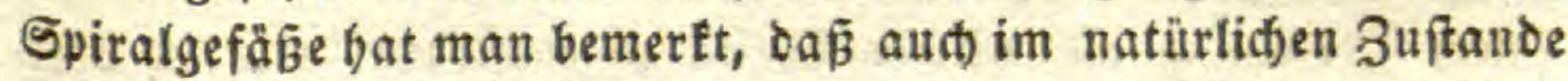
Saft aub bet Spiralgefäßen, weldye bem Saft am näditen

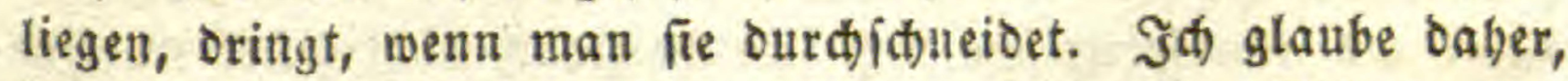
Daßs wir die Sade betradten müfien, wie bey ben $\mathfrak{T}$ bieren, wo auch) bie \&uftröhren vor Der Periode bes 2ttbmens mit Saft angefüllt fino. Die jungen Spiralgefäbe fino Zellen, uno tönnen nid)t allbers entíteben, als wie bie andern Bellen, misifen baber mit Saft angefüllt jenn. Bey ibrer Berlängerung faugen fie

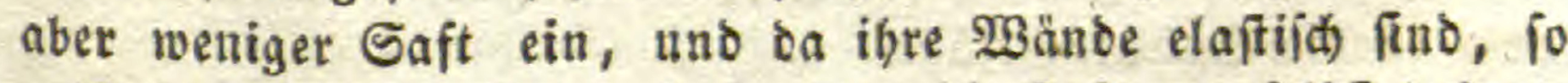
entffebt eill leeter פaum, in welden bie Suft von felbit oringt. 
Deß̧̧alb finbet man in oen jüngern Spiralgefäpen an bem fafts reidien $\mathfrak{B a f t e ~ n o c h ) ~ S a f t , ~ w a ̊ h r e n d ~ e r ~ i n ~ b e n ~ a ̈ l t e r n ~ b e s ~ S ̧ o l j e ̨ ~}$ verid)munden if. Damit fitheint fidt) aud ber Streit ilber bas

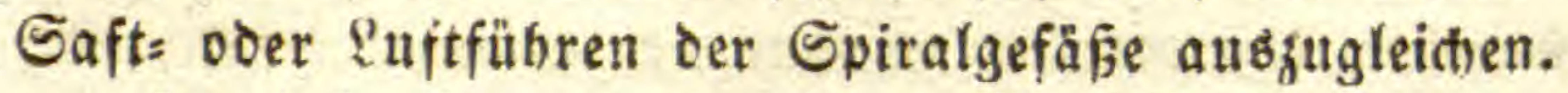

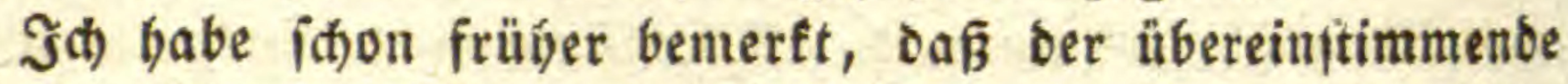
Bau ber Spiralgefäpe mit ben Enftröbren ber Jnjecten auth ein widt)tiges Zeugní

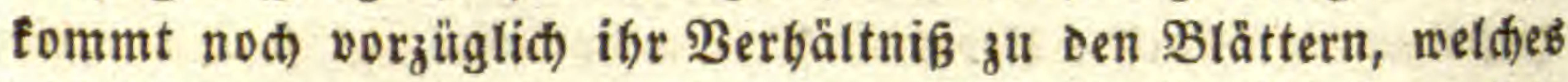

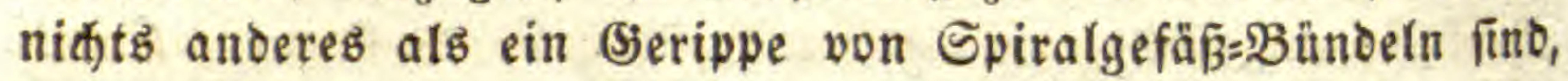
eine Befrenung berielben vom Zellgemebe, wodurd) fie bem Eins flü ber \&uft blofggelegt werden, gerabe wie bie 2trterien in ben Riemenblättern ber Mujiteln uno mander Rrebie, ober wie in

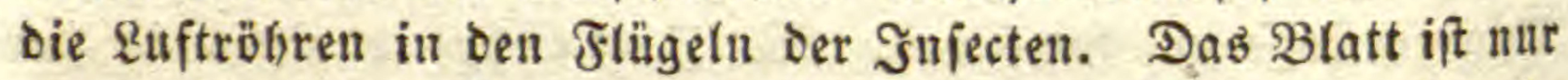
ein aufgerolltes Epiralgefä $=$ Bändel, und Denft man fich ein einzelnes Spiralgefäßz mit jeinen verzweigten Spiralfäben unges

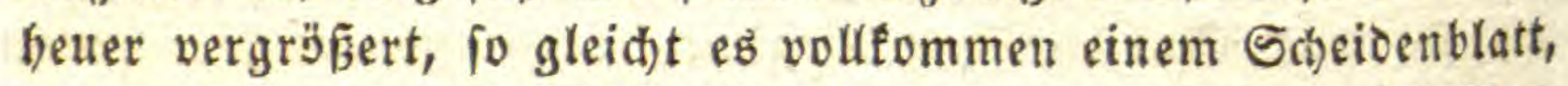

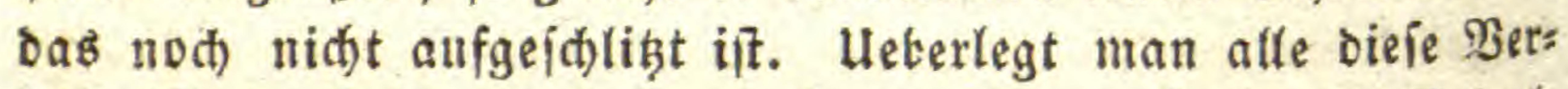
Gältniffe im Strammenţang, fo fann man unnöglich) Die Epirals gefäße für etwas anderes als die 2ithemorgane ber Pflanzen baltels.

Uebrigens findet fich aud) \&uft in ben Şöhlen bes Bell:

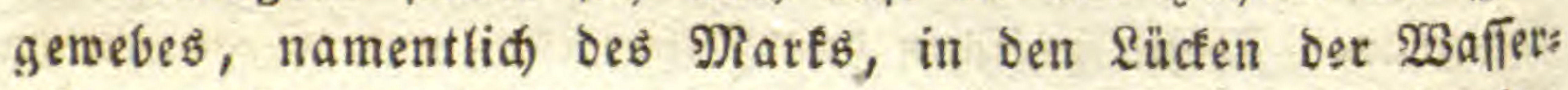
pflanjen, im bohlen Stengel ber (jräjer, in aflerley SBlajen ber Biătter; in ben Şülfien, wie Des befannten Blajenftraud), uno in ठen 3wifhenräumen mandher Eapfeln, wie ben Der Jungfer in Scaaren (Nigella), entict) in den meiften troctenen Capiefn.

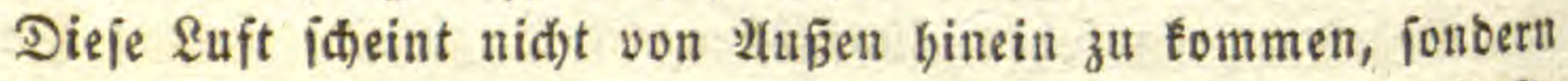
ourd Seriegung organiíd)er Theile zu entîtehen, wie in \&uft:

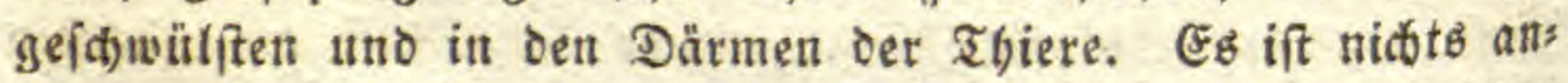

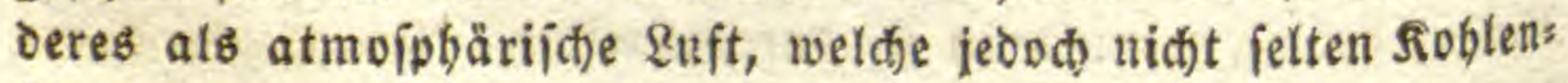
fäure enţălt.

\section{Saftlauf oder Ernäbrung.}

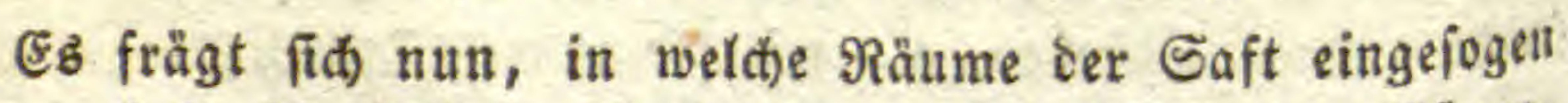
wirb, ob in bie 3eflen, die 2toern ober Intercellular = (5)änge, oder in bie Spiral= Sefäßse.

Şieriber fpreden bie Berjude fo abueidfend, uno find 
Daber bie Mevnungen io neridjieden, baß man bie Sadje völlig müfte anf fich beruben lafien, wenn man nid)t ben Bau ber Drgane uno bie \$orgånge im Ibiere, io mie bie Theorie bes Rebenछ̋roceffes überbaupt zu Şilfe rufen tönnte.

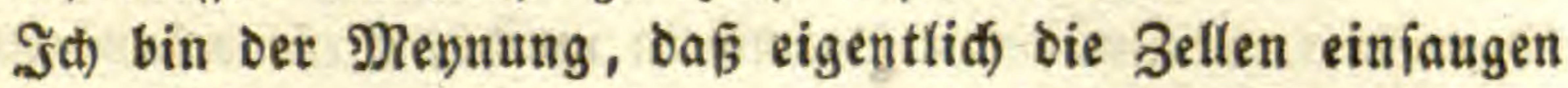
uno ben Saft verarbeiten ober verbauen; daß fie ibn aber von Den Intercellular= ङången zugefübrt erbalten, unb Den verarbeis teten wieber Dabin zurüctgeben; Dás Dagegen bie Spiralgefäßze Ruft fübren, uno baber wirkflid) Ruftröbren ober Droffełn finb. Itl biejes ergibt fid) jedod nur aus bem ganzen 3 ujammenbang ber Beobachtungen, und nidht aus ben $\mathfrak{B e r j u d f e n ~ m i t ~ e i n z e r n e n ~}$ Geweben.

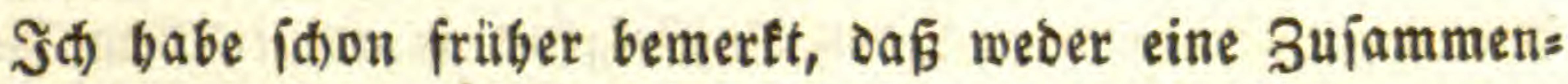
ziebung Der Bellen, mitbin eine Erweiterung uno \$erengerung

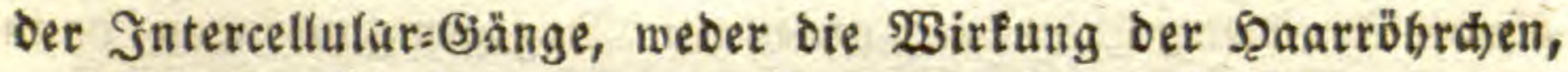

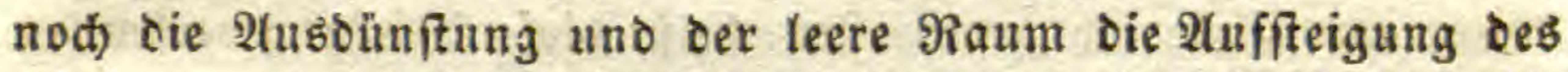
Saftes, unb mithin bie Einfaugung, weld)e bamit einerlen iff,

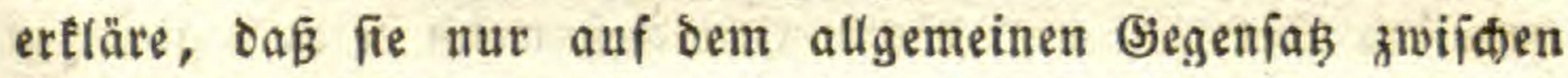
Wurzel und Stammwere, mithin auf Dem Lebensprocé und Den Damit gegebenen Berieķungen bernbe.

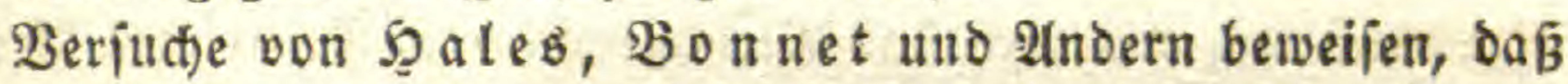
oab eingejogene $\mathfrak{W a f f e r}$ in $\mathfrak{W}$ urzeln oder 3 weigen fidon in wes uigen Minuten mebrere 30 ll hod) fteigt. Das fann offenbar

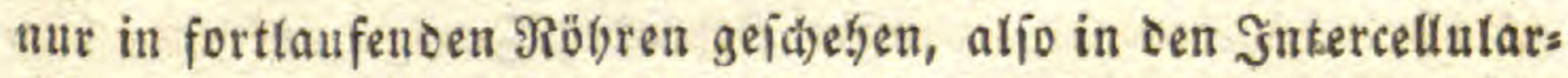
Bängen ooer ben Epiralgefä̧en: Denn wie wäre eine folde Sđ)nelligkeit möglid), wenn Dab Zellen eingeiogen, auggeid)wikt unb wieber eingeiogen werben follte. Sgales band um eine abgeidnittene Rebe eine (3lak̉röbre uno ftecte andere Darauf. Der Saft ftieg barinn 21 S(b) bod). Ein andermal fperte er eine (j) lastöbre mit Quectiflber

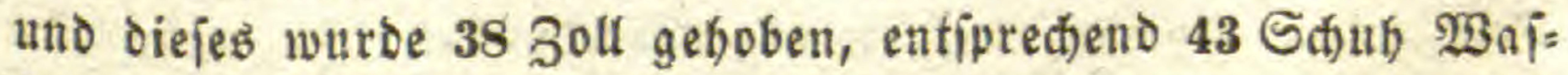
ferböbe, aljo mit einer Sraft, welde Eriftannen erregen muß̈,

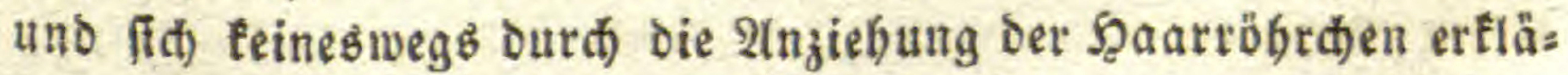

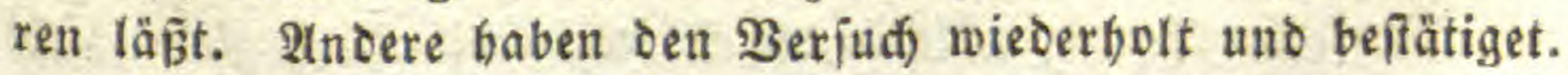

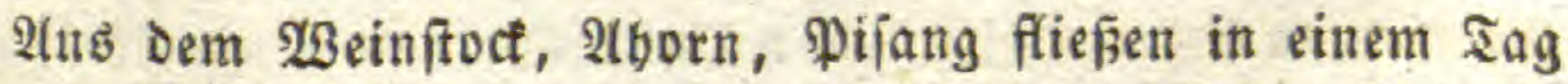
mebrere Maßs $\mathfrak{B a f f e r}$ aus; aus angebobrten Birfen flięt in 
14 Tagett fo viel, als fie felbft fthwer fitto, was eit Begriff

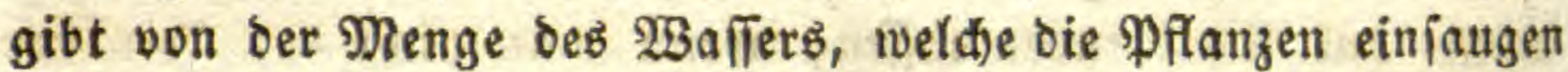
mûfien, um ben nötbigen Rabrungsitoff zu erbalten, ber aljo nur in febr verdunntem 3 uffande darinn aufgelöst fenn fann. Der Saft, woraus man \$almwein mact), fliefft befanntlid in Menge aub ben böd)ften (jipfeln bes Baumes, nebmlid) aแt ben $B$ lüthenfolben.

2tus all biefem folgt ein ungemein fonelles 2tufiteigen bes Saftes in fortlaufenden Säbren, und Durd eine Sraft, weldhe feine unorganifide jegn fann. Wenn fid Senebier wunbert,

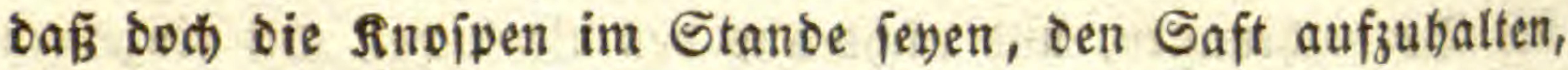
fo hat er nicht bedact)t, oder vielmegr damals noch nidst wilien

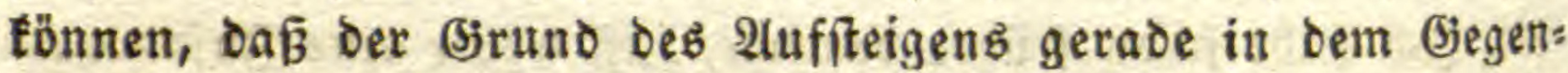
fake ber obern Theile zu ben untern berubt, und teineswegs in einem Druct oder Triebe von unten her. Dagegen einwenden: bann

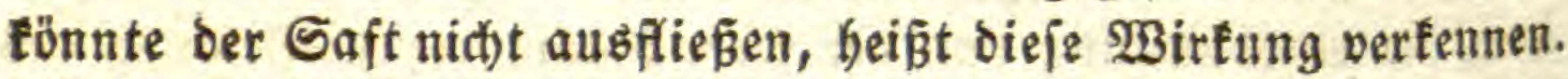
Alle obern $\mathfrak{T}$ heile, mithin viele Millionen Zellen, zieben ja ein zeln ben Saft an, uno bören nidt auf, wenn er aud) gleid) ju einer verlebten Stelle binausflefst. Sleiben fie aber unverlebt, fo verarbeiten fie ben Saft zu netten Bellen, und beförbert die

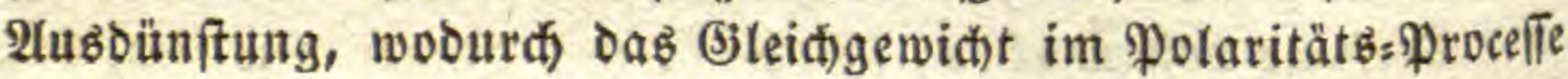
Gergeftellt wirb. Das ift aud) ber (Srund, warum eit des Minters in Die Stube gezogener Juveig eines Rebitoct: alls: iđlägt, wäbreno die braußren ftebenden 3weige unthätig bleis ben. Die Stubenwärme veranlaßst bie 2 tuboünftung uno erregt Dadurc) Die polarität Des Stoct́s.

Dafielbe thut bas \&idt, indem fid ourch feinen Einfǘ

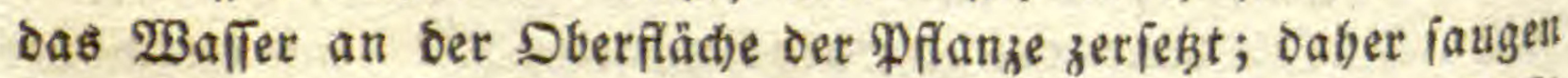

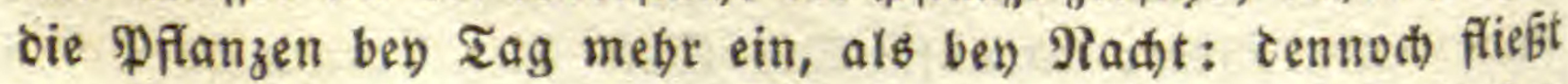

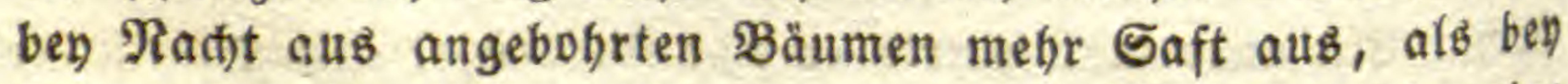
Iag, obne 3weifel, weik weniger verounftet. Se mebr eine Pflanze $\mathfrak{B l a t t e r ~ h a t , ~ d e f t o ~ m e h r ~ w i r b ~ a u s g e b u ̈ n f t e t , ~ a u s ~ b e g r e i f s ~}$ lidben Grilnden.

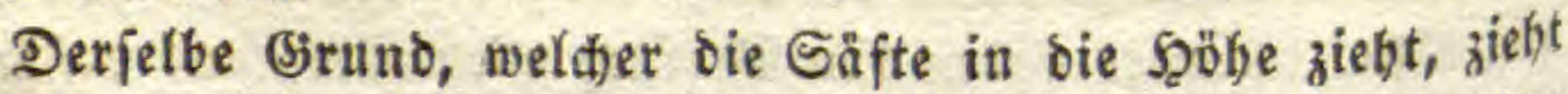
fie aud nad ben Geiten, unb ibberbaupt nach) allen Igeilen ber Pflanze, objaton bie Polarität nad) Sben und Unten bie bers: 
ihende ift. Jete Zelle wiro gegen bie andere polar, nid)t blok

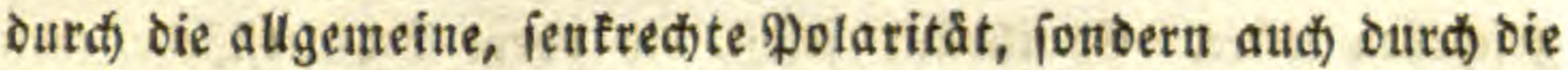
quere und in Folge ibrer eigenen Thätigleit, wodurd bie Ser= feşung uno Biloung neter Stoffe betwirft wiro. \$äbrento Oaher ber eingeígene Saft aufiteigt, wiro von allen Bellen auf: gefogen, und nac) Der $\mathfrak{B}$ erarbeitung wieder etwas zurücfgegeben,

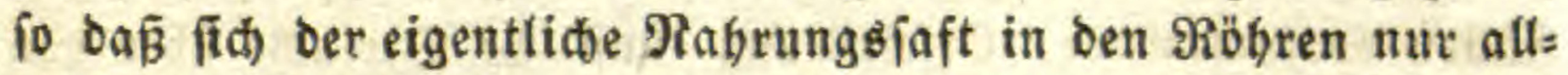

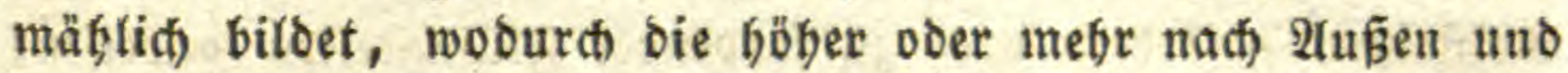
Jnnen liegenden Bellen immer andern Rabrungsjaft befommen, und Daber aud andere Stoffe bereiten, wie Bucter, G3ummi, Säuren, ätherifole Dele u. f.w.

Frägt man nun nach bem anatomija)en Syftem, worinn fid bie Safte vorzugsweife bewegen, fo mennt ber eine im Bait, Der andere im \$olz, Der britte felfif in Der Rinde. Dhne 3weiz fel bewegt er ftat) in allen lebenoigen Theilen. Man braudt)t aber nur wäbrenb bes Saftriebs einen 3 weig zu burdididneiben, um iogleid) z"l beinerfen, daf ber Baft ben weitem am meiften Saft entbätt. Die Erfabrung tefrt, ठaß̄ Bäume ganz bohl geworden, und bló burch bie Rinde fortgelebt haben, und um= getefrt andere, Denen man die Rinde genommen hat. Diejeg Seben ift aber immer iftwach uno bört vor Der gebörigen Zeit

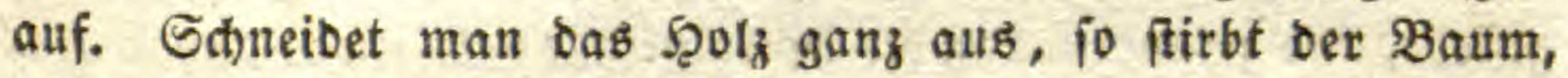
obne 3weifel, weil oer Baft baburch zu (Srunce gebt. Sieft man bie Rinde io ab, daß̧ Der Baft vertrocfnet; fo fann bens noc) immer im şolze, bejonderz in bem jüngern ober bem Splint, Saft ausfteigen uno die PFlanze einigermaß̣en ernäb= ren. Stellt man Baumzweige in gefärbtes $\mathfrak{B a}$ affer, fo wiro nur ber Baft uno oer äußerite Şolzring gefärbt, Éeineswegs aber Das ältere Şolz und die Rinde.

S(j)on bieraus ergibt ę fich) jattjam, daß̧ die Spiralgefäpe niabt Die Srgane bes Saftlaufs fenn tönnen, weil fie Dem Bafte feblen. Es gibt aber einen id)lagenten Beweis, burd) ben alte

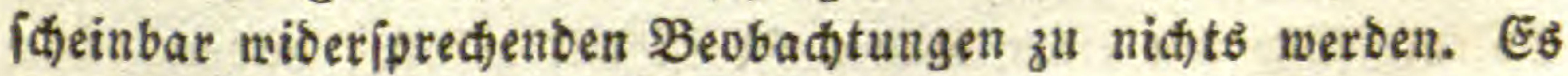
ftno bie befannten übergreifenden Sđ)nitte an einem 3weige, wo: von jeder bis itber bie Mitte reidt, fo daj alle Spiralgefäвe unterbrochen werben. Denno bautert, wie jeberman weí, bas 
2tubialagen und Blutben bes 3weiges fort, als wenn nidts

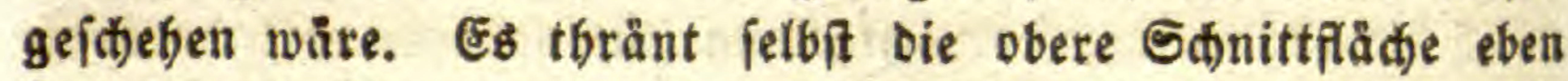
fo gut wie bie untere. Der Saft fteigt mitbin aud) über bie Sthnitte binauf, unb zwar ourd Sictzactwege, welthe fich nur in ben Sntercellular $=$ ङsången finden.

Was Eönnen nun gegen fold eine entídiedene, uno in allen Fällen vorfommenbe, Eridheinung fünftlicte Berfucte über bas 2tufiteigen gefärbter ober zu färbender Flïifigfeiten beweifen! 3war wirb aud) ber ganze Baft ourdifinitten, uno baburd bas gerabe 2lufíteigen gebindert. Allein bie Intercellular=(jänge im Baft bängen fa ringsım zufammen, unb ber Saft brauht nur ein wenig zur Seite zu zieben, um zu bem unverleģten Stürt z" gelangen und feinen gewöbnliden $\mathfrak{B e g}$ zu finben. Dod bie

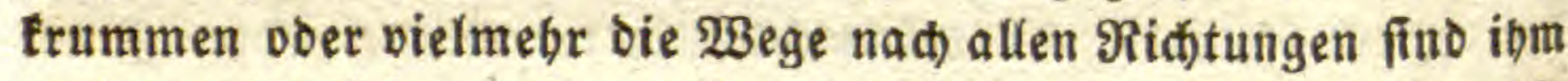
aud) gewöbnlid, weil es überall Rinde uno Blätter gibt, bie ibn anzieben. Zwar fteigt er in Flecteten und Moojen, Die man

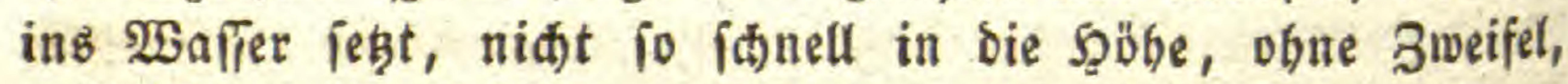

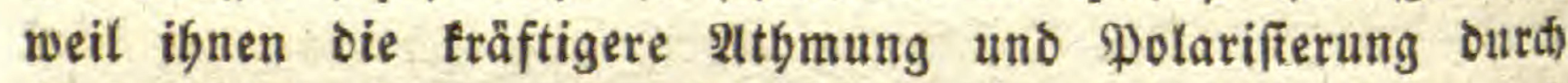
Spiralgefäße feblt. WBer tann aber läugnen, daß er bennod) in bie Şb̈be fteigt, da ffe ja leben uno wadifen?

Man hat abgeidnittene 3 weige in gefärbte Ftitifigteiten

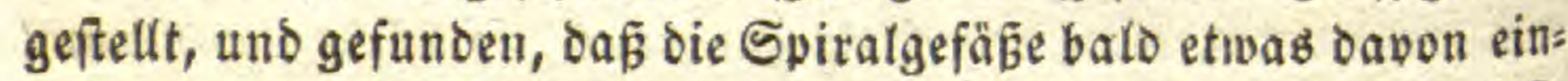

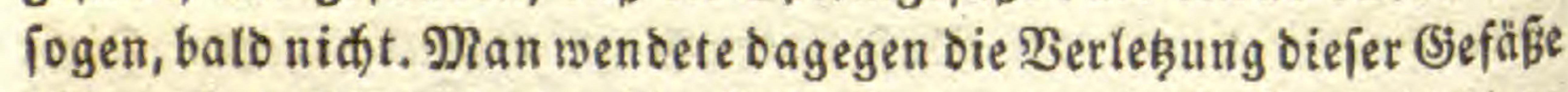
ein, und erf́lärte baher bie Eríheinung ourd) bie Şaarröbrd)en.

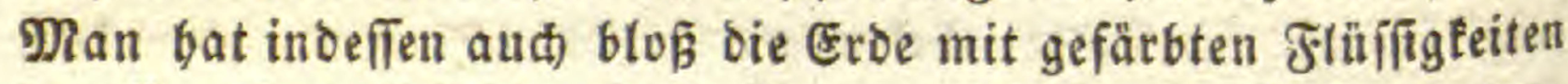

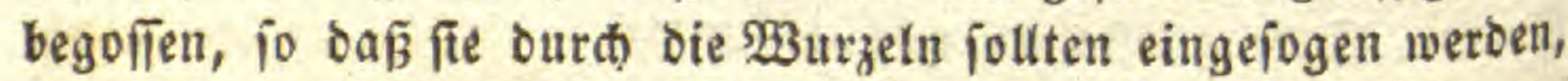
was jebod) nidft geidhah. Man half fid) mit ber Entidjuldigung,

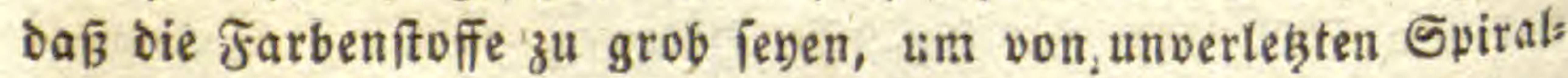

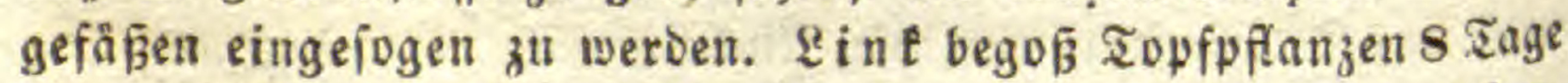
lang mit Berlinet=Blan ober blaufaurem Eifenfali. Sie befalls ben fid) wogl. Dann begó er fie einen Tag lang mit Eifens Bitriol nno fand nun mand() mal, mand)mal aud) niđbt, einzelne Spiralgefäße mit einer blauen Fliifígteit gefüllt, andere banes ben nid)t, unb bas Zellgewebe auct) nidft. Sieralls will man

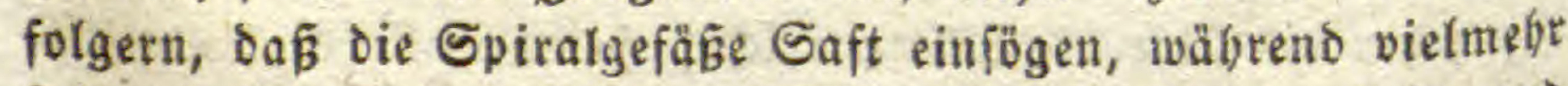
folgt, ठав ев nut jufällig geídiegt, obne 3weifel, weil ba uno 
Dort eine Stefle Der 23 urzef verleḩt war: Denn wảe Das Ein: faugen ibre natürliche Eigenichaft, fo bätten fie alle, und in allen fällen blau werben müfifen.

马̧ zweiges verfebrt in $\mathfrak{B a f f e r : ~ D e n n o d ) ~ g r u ̈ n t e ~ d e r ~ a n d e r e ~ B i n f e n ~ i n ~}$

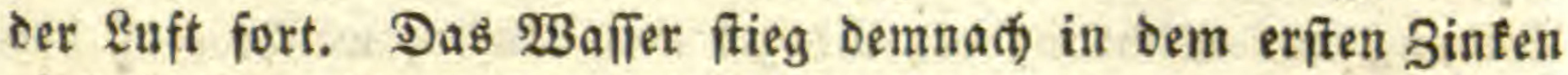
rücfwärts in oie Şöhe, uno im zwenten berunter, was nur in Den Intercellular = Jängen geidjeben fonnte, uno niat in ben Spiralgefäpen, weil Die ber beiden Binfen niät mit einander in Serbinbung fteben. Todte 3 meige faugen nidbt ein, wenigitens nid) böber, als fie im Waffer fteben.

\section{2bfteigen bes Saftes.}

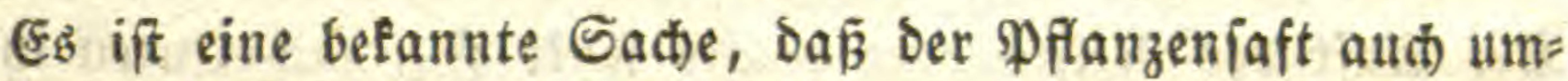
gefebrt länft, nebmlich) in Dem 3 weig in bie Şöbe fteigt, wenn

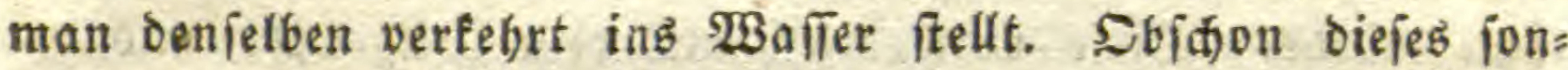
Derbar ausfitebt, fo ift ood) ber (sirund febr einfach). Der 3weig fann $\mathfrak{W a}$ fer nur ba einjaugen, wo er bat. Die Serarbeitung ber Säfte gebt in jedem Theile der Pflanze vor fic), und fie

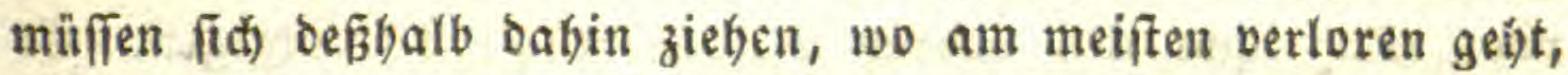
alio nac) dem troctenen Ende, eg mag fich oben oder unten be= finden. 2nders ftellt fith bie Frage: ob ber Saft überbaupt

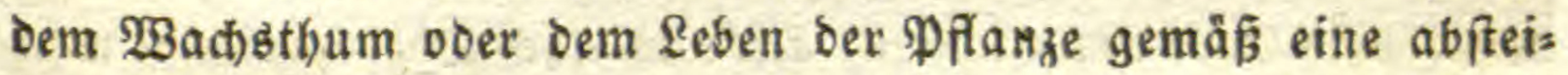
gende Bewegung bat, und in weldiem Syitem oder Giemebe Diefes ftattfindet.

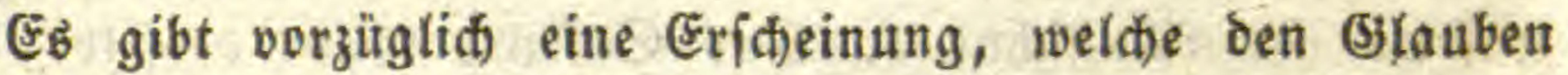
an Das naturgemäв́ 2lbfteigen des Saftes veranlaß̧t bat, und zwar in ber Rinde. Bey Dem befannten Ringidnitt ber Sweige

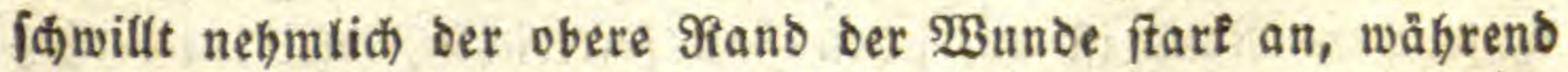
Der untere unverändert bleibt. 2and treibt ber obere Ibeil des ఫmeiges mebr Btüthen und Frühte, unb Daber wendet man

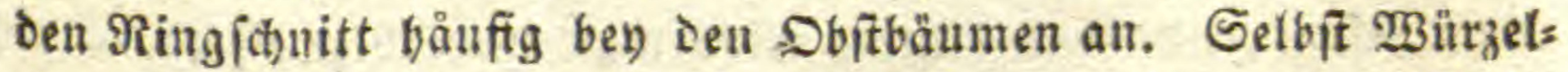
den entifeben am obern Ranbe, bejonters wenn man ben Sanitt mit Erde umgibt; leineswegs aber am unteren.

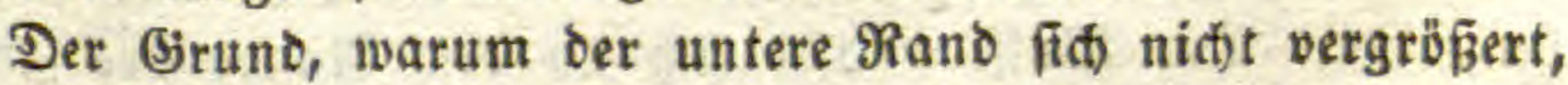
fonbern vielntegr vertroctnet, liegt einfach barinn, daßs er von 
Dem Lebensproces bes Zweig= Enbes nidht mefr vou Dben hee angeregt wirb; jondern bie Polarität ft(d) nad) S̃nnen oder gegen bas $S_{2} 0 l z$ wendet, uno baker ber untere Saft aud bafin ftrömt. Die Billung bes $\mathfrak{B u l f t e s}$ am obern Rande ift, abgejeben von Der gröferen Saftfülle im 3 weig= Ënbe, ganz einerlen mit ber Bildung uno Richtung ber 23 urzel nach Unten, weldse blof ber Sd)were bes in ibr entbaltenen $\mathfrak{B a f f e r}$ folgt. Der Saft im

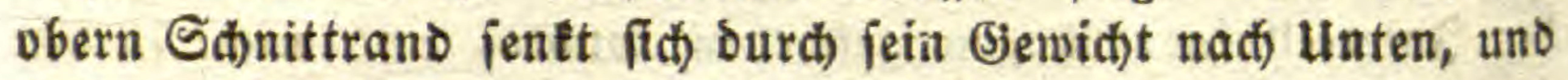

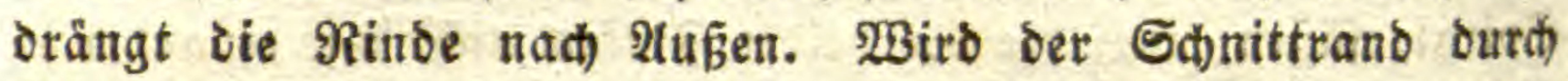

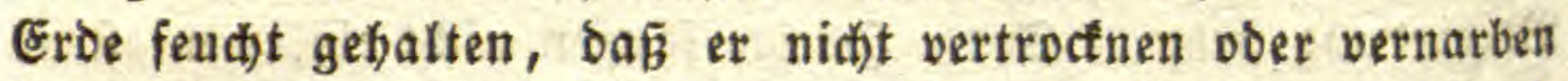
tann, io bilben fich Dajelbit neue Zellen, welcte fich) zu Wirtzel: (t)en verlängern oder als folde nach) Unten finten.

Das 3weigen und 2letgeln berubt auf bemielben Brante. Der Saft bes Reifes voer Ruges fentt fich nach Unten in ben

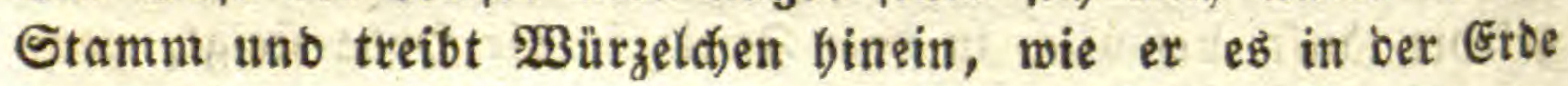
thun nitroe. Dieje verwadfen mit bem Zellgewebe no er: näbren fích nun wie ein anoerer 3 weig.

Der oben gegebenen Uriacje, ber Berbictung bes oberen

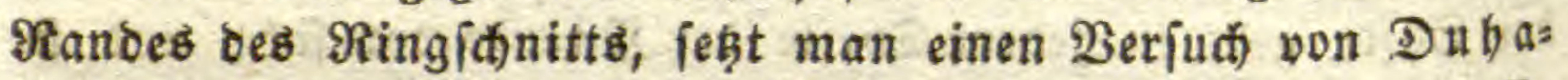
mel (Physique des arbres. II. 108. taq. 14.) entgegen. Er bog nebmliab 3 weige von Riiftern nach Unten uno ringette bie felben. Demod) billote fith Der 23 ulfit an bem SRente, weldser bem 3weig: Ënde am näaften, alio nun nach Dben gerid)tet war.

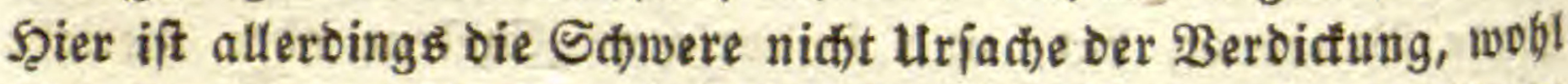

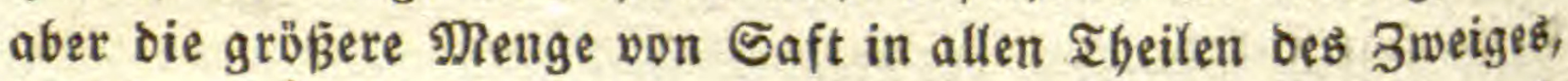
jenjeitz des গRingidnitts. Der Gaftzug bleibt berielbe, uno Der uriprünglid) untere oder ber bem Stamm näbere $\Re a n \delta$ muß mitbin vertrocfnen, wie bey bem aufrechtiftehenden 3 weig. Der entferntere Rand ift auf jeden Falf faftreider, bleibt lebentig uno mus bicter als ber andere fenn. $D \hat{b}$ er aber fo bict wirt, wie im gemögnlidfen Fall, und ob er gar $\mathfrak{B}$ urzeln treibt, if nidbt gelagt, uno oas leķtere wiro man wohl bezlweifeln.

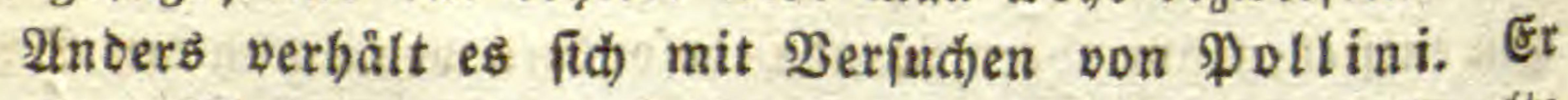
bog einen Platanenzweig, frectte ibn in bie Eroe uno ringelte

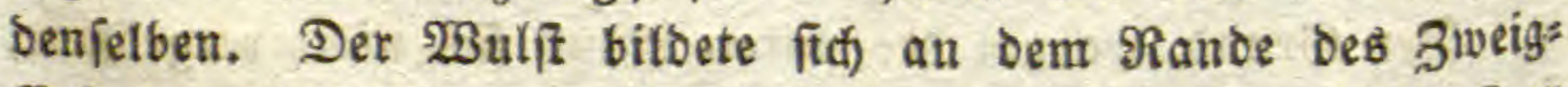

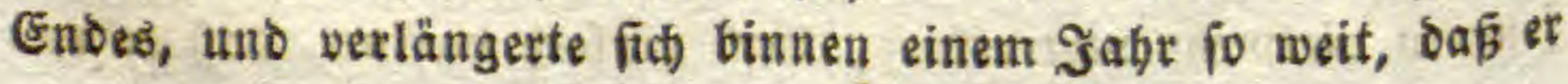




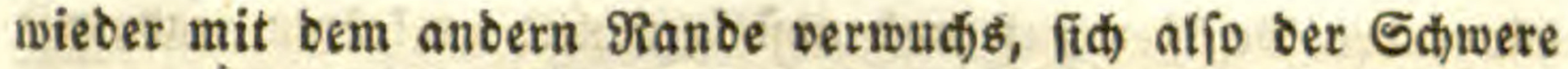
entgegen aubbegnte. Bis bieber ift ber Fall bem vorigen gleich. 2tl aber bie 3weigipize nach) 2 Jabren 23 urzel geít)lagen batte, idinitt er denjelben ab, ringelte ibn wieder, uno ber $\$ 3$ ulfit bil= bete fid) am untern Rande Des Sdunitteb. Sold einen einzel= nen Fall, weldher ber allgemeinen Erfabrung wiberiprid)t, bat

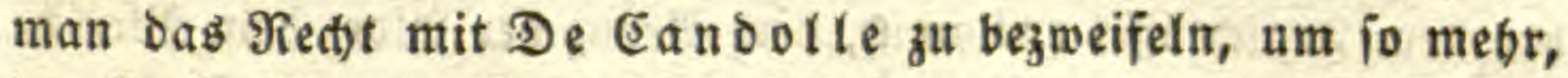

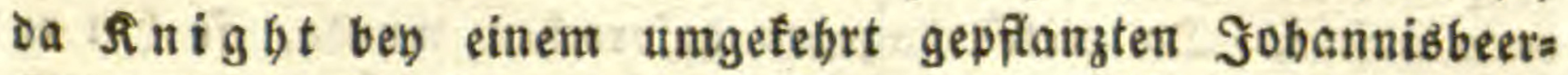
Straud) Den $\mathfrak{B u}_{\text {ult }}$ am obern Sdinittrano entifeben jab.

Für ein gewöbullides 2lbfteigen bes Safteb, aljo für eine 2trt von sreislauf, fübrt man aud) bas jogenannte Fallen bef= felben im Şerbft ober nad) bem Laubfall an. Das beweist aber getade, Daf der Saft währeno des vollen Lebens ber Pflanze

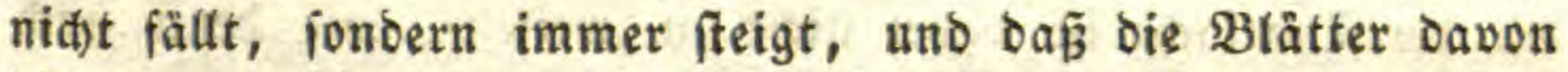
die Şaupturiade find, was aud) die Beriathe beweifen. Ein abgeínittener uno entlaubter 3 weig faugt viel langiamer ein als ein anberer. Die Früd)te reifen befler, wenn fíd über bens ferben noch) Blätter am 3weige befinoen. Ben fümmerliden 3weigen und Früd)ten, weldie abzufallen orohen, verbindet man Daber oberbalb berferben Den 3 weig bur(h) 2 bjaugen mit einem ftark belaubten Rebenzweig, woourd) bie Säfte in bie ફ̧b̆he ge= zogen werben. Das wir’ benvirtt Duectb bie vermebrte Polarität, uno es fann baber bier von feinem 2tbiteigen bes Saftes aus

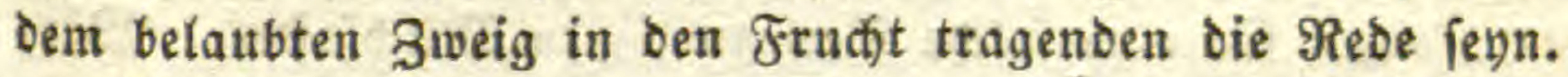

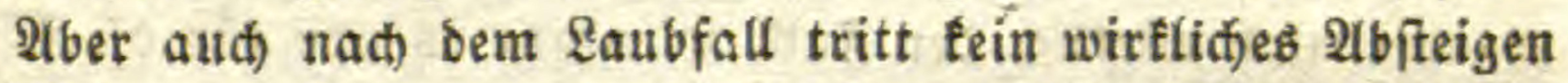
Der Săfte ein, jonbern nur ein langiameres 2ufíteigen aus be: greiflichen (3rïnoen. 2(ud) im $23 i n t e r$ fino bie 3weige nidbt faftlog, ia fie verlängern fidh jogar, obidon, natïrlidjer Weife, in geringerem Grabe als bey warmer $\mathfrak{W}$ itterung. Dabey mun

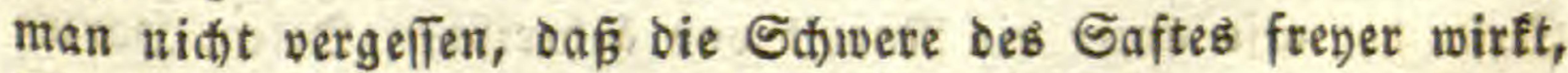
fobalo bie polarität burd bie Blătter aufbỏrt unb nur ourd)

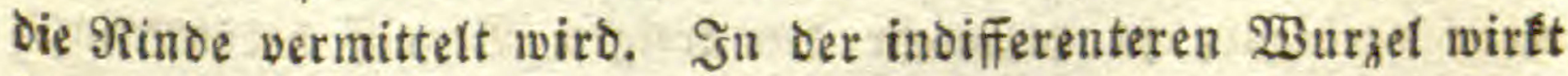
bie Sd)were färter als im Stenget. Bon einem Rreislauf ber Säfte fann baber bey Den Pflanzen feine Rede fenn.

Man ipridt aber von einem anbern fireislanf, ber wirflitit) ein jolder jenn joll, ๖. ६., worinn Safte in eigenen zujammens 
băngenden (3)efäß̧en aufs uno abfteigen uno umfebren, ganj wie in 2rterien uno Benen.

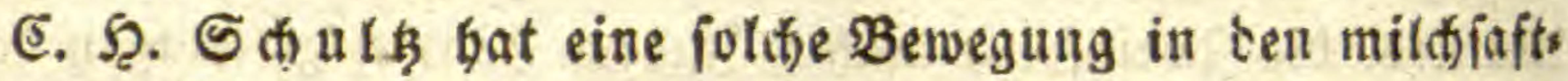
fübrenden $\mathfrak{P}$ flanzen, 1822, entbect, uno biejelbe Encloje genannt. Diefe Bewegung wurde beobact)tet im Stjölftraut, 2lborn, Sus mad), Jeigenbaum, bey ben (3loctenblumen, ben $\mathfrak{3 i n d e n , ~ a u d ~}$

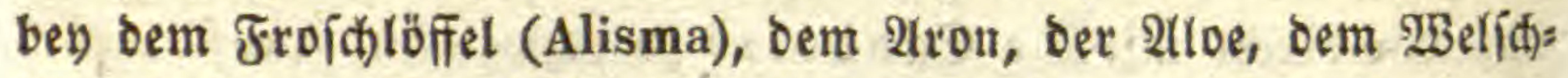
forn u.f.w. Da vieles bagegen geiproden wutre, fo hat et bey Der Berjammlung Der Raturforider zu Mündben, 1827,

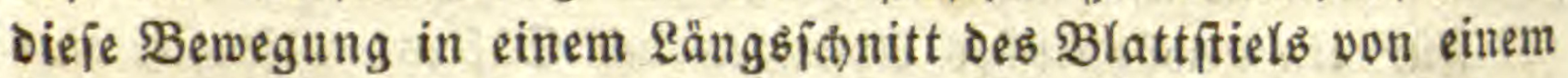
Feigenbaum gezeigt, uno id habe fie felbft mit vielen 2troern gefeben. Der Saft lief aus zmo neben einanoer liegenden $\Re$ Rb̆ten, mit ziemlidber Sd)nelligkeit, mehrere Secunden lang aus. 2In ber Thatiache ift baber niकt zu zweifeln, wie benn all't an ber Saftbewegung itberbaupt nie jemano gezweifelt hat. Ez handelt fich) blof um bie Ereflärung: ob nefmlid') ber Saft fíd)

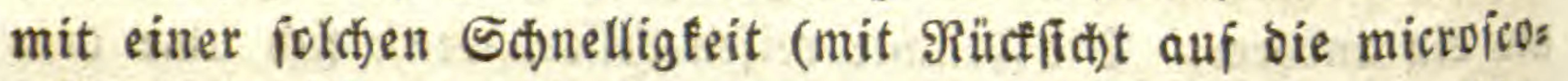
piife Bergrößerung) in der unverleşten Pflanze auf= uno abbes wegt, oder ob jowohl biefe Sdnelligkeit, alb atti) bie verifiles

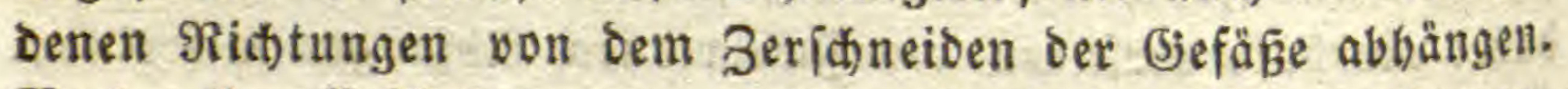
Ras) allen Erid)einungen, welde wir in ber PFlanze tennen, muß man bas leģtere annegmen. Es gibt überbaupt feinell Grunb zum 2lbfteigen des Saftes in oer Pflanze, uno baber

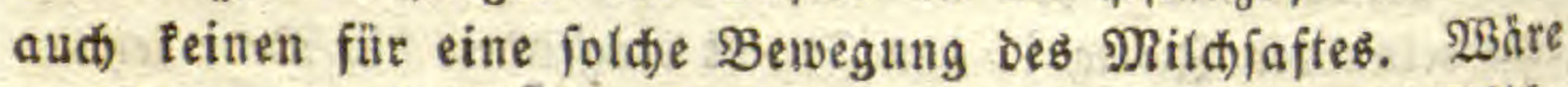
es aber aut) wirflidf ber Fall, fo wïrde es nur für bie Milds: pflanzen gelten, alio nidjt für das Pflanzenreid, uno fie gätte mit ber Bewegung des Rahrungsiaftes, Der bem thieriften

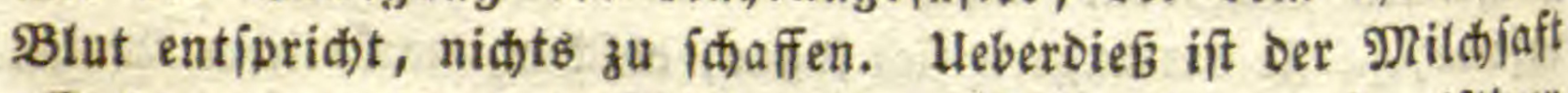
offenbar nur ein ausgeidfiebener, meift harziger, oft giftiger

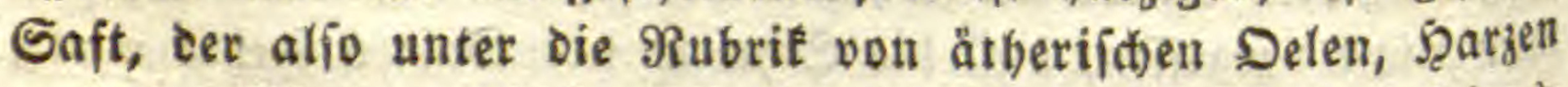
u. bgl. gebört, uno baber ben Namen Rebensiaft (Latex) feittegs wegg veroient; ia vielmebr ben irrigen Begriff hervorbringt, als wenn ex zur Ernäbrung ber NFlanze biente. Endich fino bie Mildiaftgefäge fo zerftreut in ber Pflanze, und laffen eine

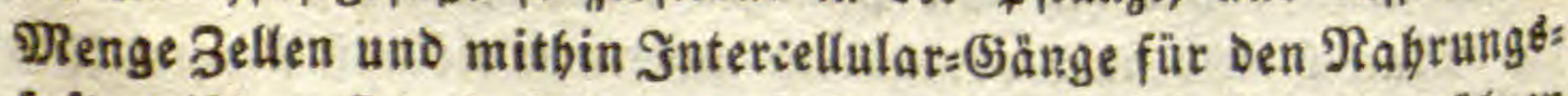

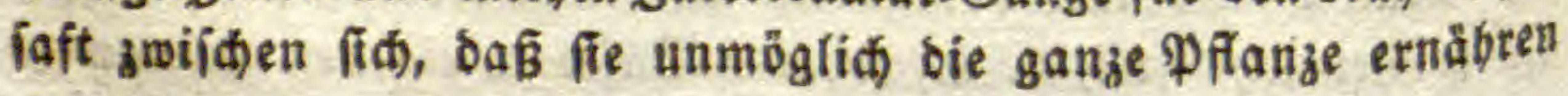


fönnten. Sie müffen Daber als zujammenbängende Qürtengänge betradtet werben, weld)e bin uno wieber aud burd Quergänge verbunden fino. Der Mildjaft felbft fteigt obne 3meifel nidt iajneller in bie Şöbe, als oie Berbunftung jeines geftattet; baber ift bie Bewegung aud) (d)neller bey warmer

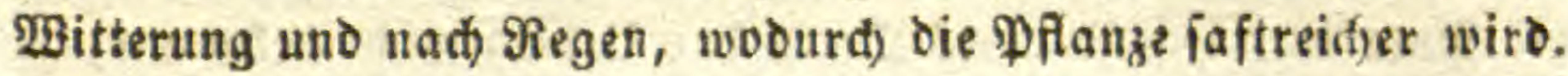

\section{Ueberblid.}

Der ganze Ernăhrungs: Proceß, injofern er auf Berănberung Der Sroffe uno 2tbjak Derielben berubt, läß̈t fid zwar nid)t Stuffe für Etuffe verfolgen, febod im 2llgemeinen angeben.

Die Bewegung ber Säfte ilberbaupt wiro beftimmt ourd) Die allgemeine Polarität in ber Pflanze, weldi)e, injofern fie als Rugel betradtet wird, zwifthen Eentrum und Peripberie beitest, vorberridend aber ift von Dben nad) Unten, injofern fid bie Pflanze walzenförmig biloet. Dieier (5jegenfaģ wiro uriprünglid, burch) bas Rid)t bervorgerufen, und if mitbin ein (jegentab vou

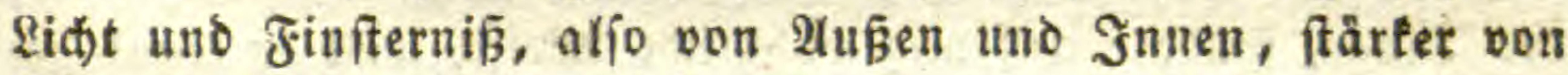
Dben und unten. 2n biejen Urgegenjah, welder alles Leben

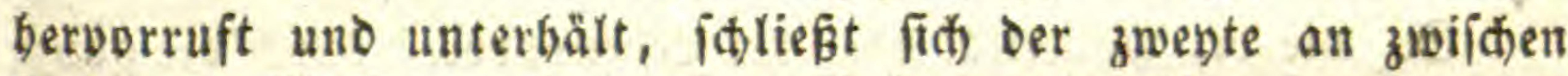
Euft und $\mathfrak{B a f f e r , ~ a l i p ~ n o c h ~ e n t i d i e d e n e r ~ z w i f h e n ~ D b e n ~ u n b ~}$ Unten, wo er ourch bas Stamm: un` $W_{3}$ tirzelwert befitimmt wirb. Das $\mathfrak{B a f f e r , ~ a l \xi ~ o a s ~ i n d i f f e r e n t e ~ o d e r ~ p o l a r i t a ̈ t z l o j e ~ E l e m e n t , ~}$ wirft' vorzüglic) ourd) feine S(j)were, und ziebt daher bie Pflanze in Regelform hernnter gegen Den Mittelpuntt ber Eroe, woburd bie 23 urzel beftimmt nird, alle ibre Theile in eine Spize wa vereinigen, uno mitbin ber Deffunng oder bem 2tufplatgen in Rnoipen z̆ widerftreben. Die \&uft Dagegen, als bas sifferente oder immer polare Element, fudt tie oberen Theile ber Pflamze zu trennen, bie Blajen als sinojpen zu bffnen uno in electrijoe Tafehn ober Blatter auzzubreiten. Die Pflanze ift caber ein umgeftürz̧ter Siegel, aut einer Menge Sdalen zufammengeiebt, meldie fich alle an bem nach Dben geriditeten Bocen bifnen. Die innerften Sdjalen, ais bie fleinften uno zarteften, werben zur Slinthe.

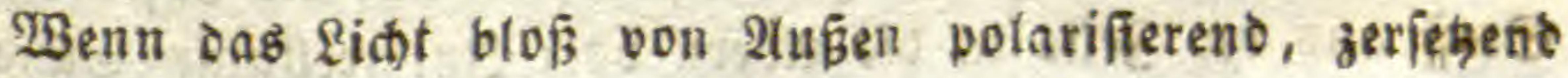
Dfens allg. Raturg. II. Botanil I. 


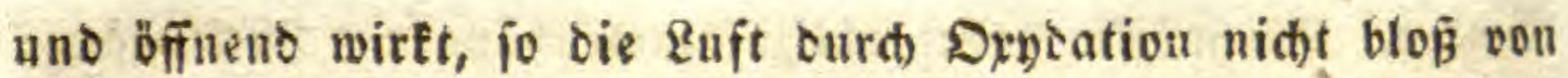
2uBen, fonoern aud vor Immen ourd Einoringen in die Drof feln ober Spiralgefäße. Daburd) wirb eine allifitige 2nziebung

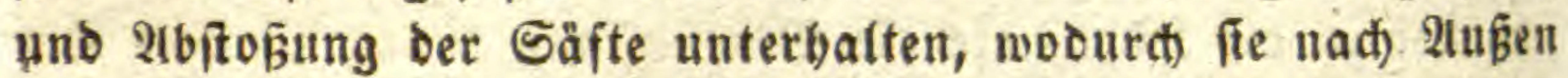

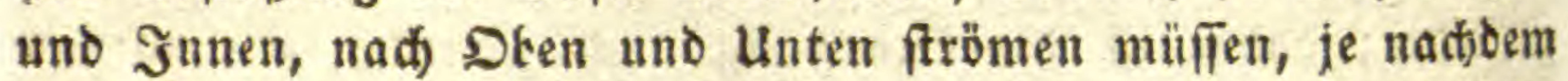
Die Polarität irgend eines Drtes das Uebergewidt befommt; im Sommer aljo, uno bey mäß̈igen WBinden, mebr nad Dben uno

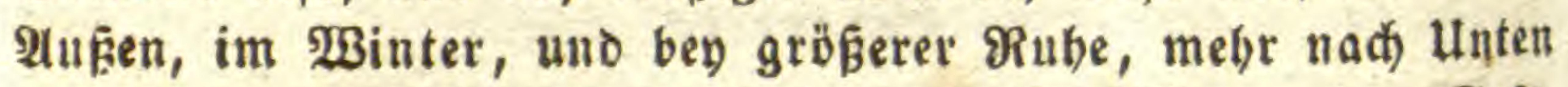
uno Jnnen. Es gibt Daber allerbing in ber Pfanze einen Safts lauf nad) allen Seiten, wie im Ibier, aber bennod) feinen fireislauf wie im Ibier, nebmliá) jo, Daß̧ Der Saft in gewiffen Suftemen in Die Sëbe friege, wie $\mathfrak{B}$ aft uno Sell, uno in andern berab= ftiege, wie in Der Rinde. Entblättert man einen 3 weig, fo jieht er nicht mebr io frart an, wie Der Rebenjweig. Diefer jiebt baber cen Saft in Die Şöbe ans jeden weniger polarifterten Theil, uno mitbin aud atb Dem entblätterten 3 weig, in wel: chem er alio berunterfiteigt, nicht nad) bem gewöbnliden Lauf Der Dinge, fondern auf ungewöbnlidbe 2 geife, weil er frant ges morben iff.

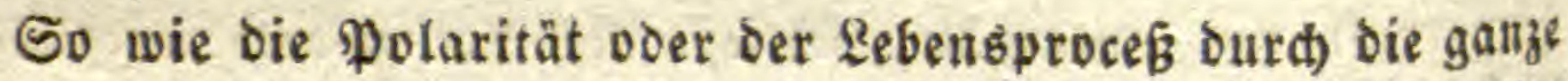
Pflange wirft; fo auch notbmendig won Belle zu Zelle, uno wies ber von ber Dberfläd)e voer der Şaut einer jeden zu ibrem Eentrum. Die innern Bellen!agen zieben baber mebr an, weil fie Den Droffeln näber liegen, wie im $\mathfrak{B a f t}$, uno babin werden fie vorzinglich die gebaltreidjern Eäfte zieben, weil ibre Stoff? Berwanbtíbaft zum Sauerfitoff baben; auth die äubern Bellens lagen jieben an, aber obne ઉweifel mehr wäfierige Gåfte, weil fie von iem Saueritoff der Drofleln ábgeftoben werben, weil fie ausbuinften, fith am Rid)te zeriesen, uno oaber meiftens rebuciette Gtofie, wie ätberijo Dele uno Şarze, zurüctaflen.

Zuerit ibeint mun ver robe oder von Der 93 urzel eingefogeti Saft in Die Beflen zu fommen, wo fich ber Gelteini ourd) bas

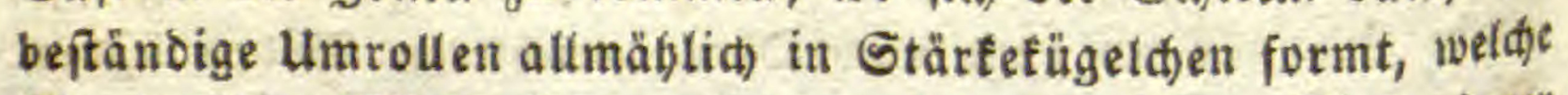

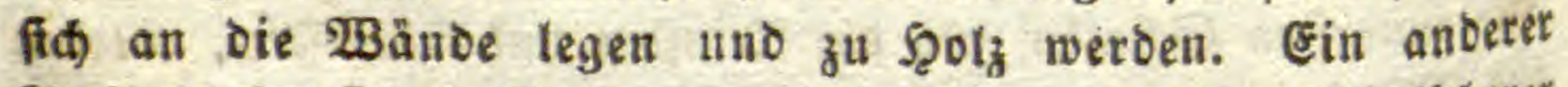
Theil idjeint fid) in 3ucfer zu verwandetn, uno als anflostideter

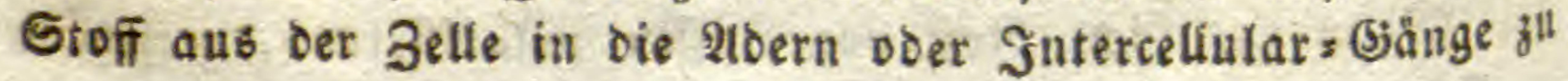


ithwižn, no er jodann aufiteigt, uno fid) unterwegs in Salure, bejonder Esfifgiåure, vermandelt, weldie fith mit Raugen uno Erben z" Salzen verbinden. So fteigt endici) ber zucterige Saft in bie ફ̧öbe, verliert in ben Blättern fein $\mathfrak{B a f f e r , ~ u n t ~ b e r ~}$ gehaltreidiere Theil begibt fith zu ben Shtitthen, wo er fith auss wendig in Bfumen uno Staubbeuteln in ätherifice Dile und

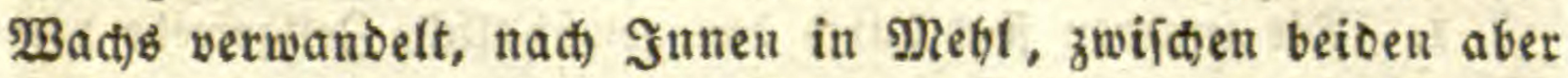
in Sd)leim uno verífhiedene Säuren, nebmlid) in ber Frud)t. Die Blutthe ift eine totale Darifellung aller Pfanzenftoffe in igrer gänzlidten Berarbeitung oder Trennung. In ber Blume

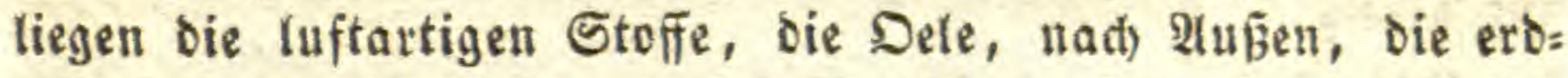
artigen, das Megl, nađ Jnnen, die wafferartigen oder bie

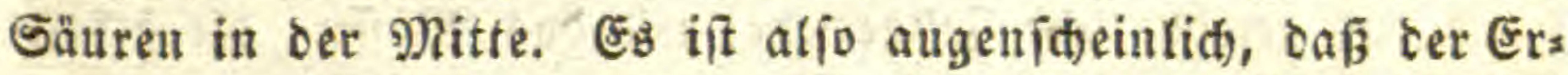

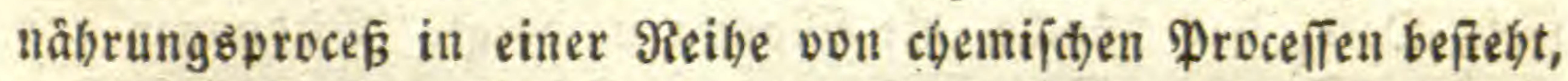
vom eingeígenen Saleim an biв z̆ ben getrennten Stoffen in Der Blütbe. Diefe Stoffe felbit weroen fifon im Stenget uno im Slatt vorbereitet: benu fid)on oa entwicteln fict) nac) 2 usen

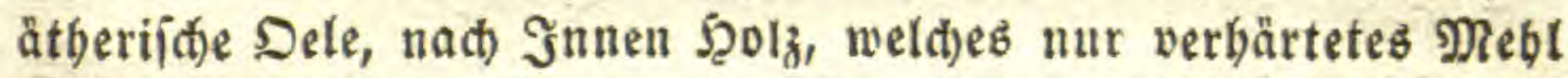

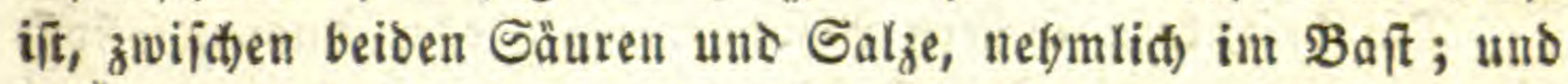
fo gebt es fort, bis endida bieje Stoffe ganz geidieden find, woburd) jeder weitere chemi (he procé, mithin oie Degetation, nothwendig aufbören umแร. Unter ben gebörigen umitänoen tritt

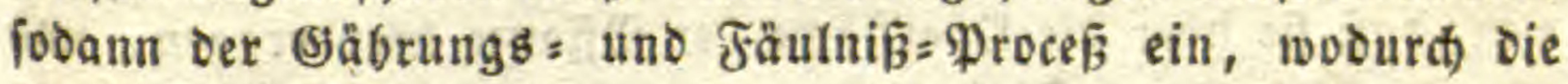
Stoffe in unorganifichere uno enolid in gan einfade jerlegt werden, womit erît der völlige Tod eintritt.

In der Pflanze werden baber feine Stoffe erzengt, weldee aus ben vegetativen Syjtemen auggeidie den, zu neuen Syftemen werden mit einem eigentbümliden biefdäft, wie es im Thier= reidibe ber Fall ift, wo aus den Blutgefäßen Rerven=, Musfel= uno Sinodhenmaffe aubgeidieben wiro, weldje neue Sniteme bars fitllen mit ganz andern (jejääten alb Berbauen, 2ttbmen und Erităbren.

\section{Erideinungen.}

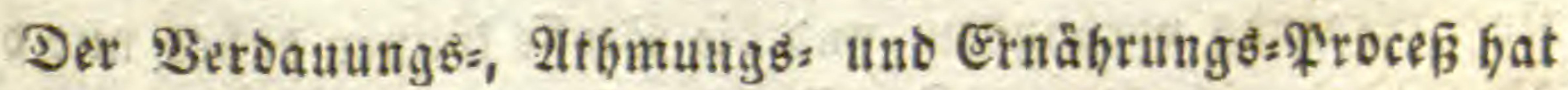
feine natürliden Folgen fowobl in ben flififigen als veiten 
Theilen. Tene erfoeinen als $21 b=$ uno 2tugjonderungen; Dieje

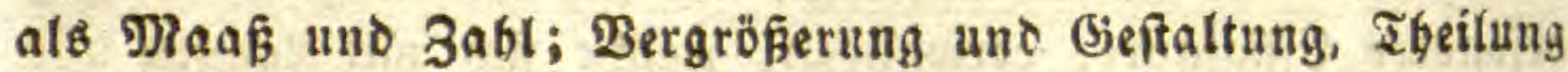
unb Bermebrung.

a. Die 2 bionderungen

fint entweber innere oder ăufere, uno in beiben fällen allgemeine poer befinbere.

1. Die inneren find ourd Das gewöbnlide Rellgewebe vers mittelt, uno bie Stoffe bleiben entweber in ben Bellen jelbit, wie Dele unb Farbenftoffe, oder fie fd)wizen aus in Sücten, wie bie Sparze, ober in zulammengängende Rüdengånge, wie bie Miløjâfte.

Die allgemeinen äußern 2lbionderungen geíchehen ebenfallı burch das gewöbntid) Zellgewebe, wie bas 23 nffer, bie àtberi-

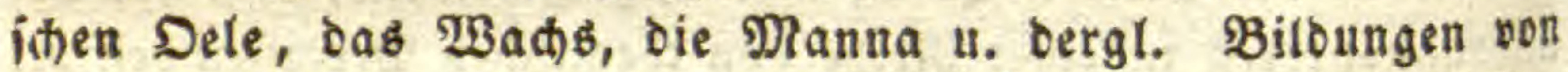
3uter, Sd)leim, Säuren fann man nidit wobl zu ben 2bjon:

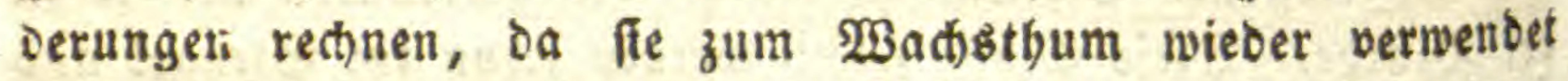
werben uno nur vorübergehenbe Eriłeinungen im \&ebenspros ceffe fino.

Die bejondern äufern 2tbjonberungs = ober 2tuswurfifteffe Fommen aus jogenannten Driiten uno Şaaren, welde aber aud aus blofeem Zellgewebe befteben, und baber wejentlid teine ei: gentbümlicben Drgane fino; fonbern fich nur badurd aubjeids: nen, Dá́ fie über bie Dberfläd) ber Pflanze Gervorragen, uno àwar nur an ben Theilen über ber Erbe, am bäufigiten atm Rande ber $\mathfrak{B l a ̈ t t e r}$ uno an den $\mathfrak{B l u m e n b l a ̆ t t e r n . ~}$

Die Drifien find ein zarteg, in eine $\mathfrak{B a r z e}_{\text {zujammenge }}$ srảngtes ßellgewebe, meiftens ourdjfít)tig ober gefärbt, an ben Jettpflanzen gewöhnlid) weiß̄ wie \$erlen, an Den 2lloe=2(nten braut. Sie fins entweder auffizend oder gefitielt, D. \%), ath Ende eines Scaars, wie an den Rojentelden, am Stengel Det Doldenpflanzen, am Gonnentyau u.j.m. Stiellos fino fie aut Jobannigfraut, an Den Rauten, Myrten. SBentn fie Durtifititig fino, fo fiebt oas Blatt wie Durdftoden aus, wie beym Jobans

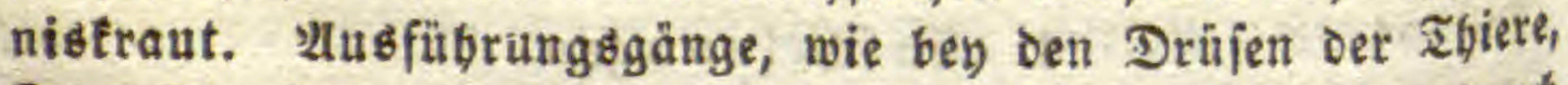
fino nirgends vorbanden, und die Stoffe fönnen baber nur bur

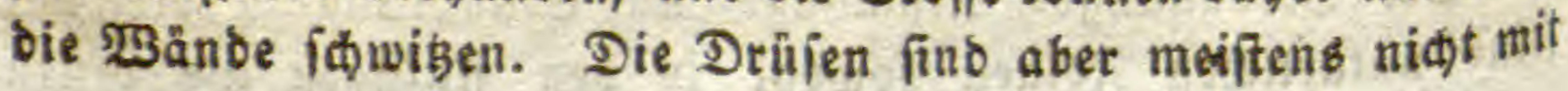


Der Dberbaut îberzogen, uno bather frene Şervorragungen Des barunter liegenden Zellgewebes.

Dbianon die 2lbionderungen einen innern (3runo babell, fo wirfen Dod) $\mathfrak{B a ̈ r m e ~ u n o ~ s i d ) t ~ m a ̊ t i g ~ D a r a u f ; ~ F e n t h t i g t e i t ~ b a : ~}$ gegen itheint fie zu bemmen; in oer Jugetro geben fie aud raidter vor fich als im 2 flter, wo ain meiften 5̧arze uno Farbens fitoffe erícheinen.

Der Grund ber verídiedencn 2tbjonderungen liegt obne 3 weifel im Jiegenfak ber Stoffe, und diefer mieder im Biegens fą̧ Der äuß̧ern Dberfläd)e zu ben innern (jeweben, und ber Spiralgefä́se zum Zellgewebe, was im (jrunde daffelbe ift, inbem

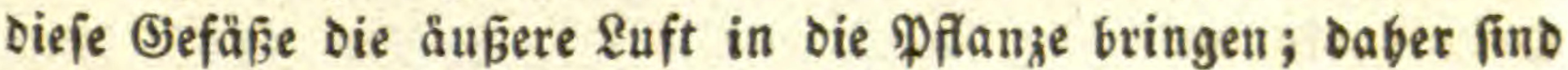
auक bie 2rbionderungen meift rebucierter Natur, wie Dele, Şarze, ફ̧onig, wäbreno bie im Snnern bleibenden Stoffe fít) zur Säure neigen; aus bemielben (sirunde feblen fie aud) faft

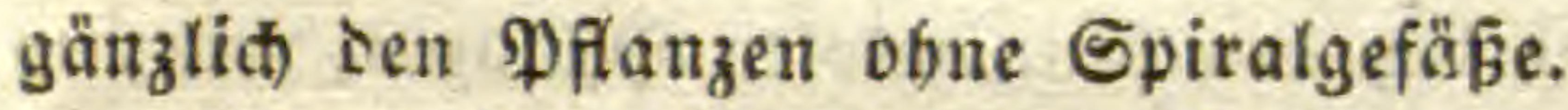

Sक)mierige 2tbionberungen finben fid) an ben Stengeln von Sidthelên, Gromandeln, Sd)lüffelblumen, an ben Relden ber

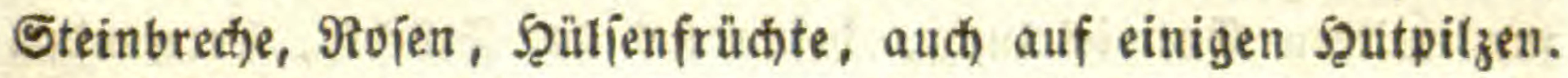

Sajleim wiro abgefondert von vielen Samen, wie von Lein, SBegerich, Salbey, Quitten.

Bertroctneter Salleim oder (Summi von Ririct)= unt 3 wet= ¡đhenbätumen, Terebinthen, Mimujen, Traganth.

Mauna auf ben 2teiđen, Dem 2llbagi=Straud, ben Tamas risten, mandien Alpenroien.

Wads an \$almen uno bem (5agel; als Reif auf veríbie:

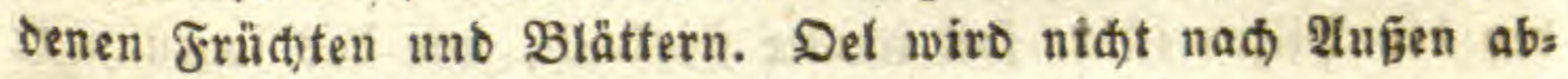
geiondert, auth nid)t it ben Blättern, fondern meiffens nur in Den Samen uno im Blütbenftaub, jelten in oer Frudtbitlle, wie

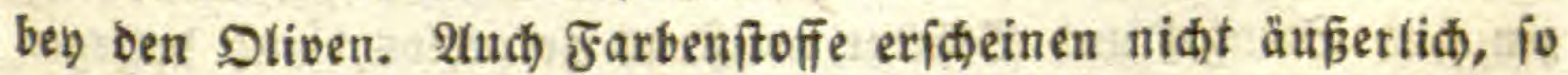
wenig als Gierbeftoff, und biejer faft nur in ter Rinbe, aber nidjt son jäfrigen PFlanzen. 2(nd) Die Milhfäfte blieben im Эnnern, fo wie bie Säuren, mit wenigen 2 (uถ๋abmen.

Die ätberifhen Dele dünften zum Theil aus bejonberen Drilien, welde als dutnfle Puncte an ber Dberfläd)e ericheinen, wie bey ben meiften \&ippenblumen, Den Mlyrten, \&orbeerbåumen 
und Eitronen, ber welden leztern aud die Fruhtichale voll bas

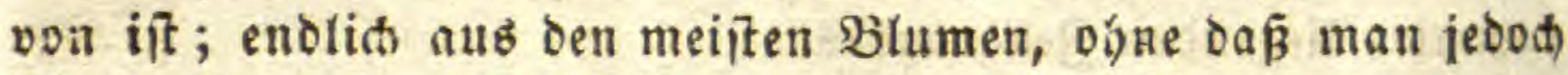
Drilien bemerte. Ė gebört Dazn warme Witterung voer war: mes Elima.

Ein anderer Theil vertroctnet im Эnnern; ben ben Sdhei= cenpflanzen fait nur in oer $\mathfrak{B}$ urzel, wie bey Ealmur, bem 2tron uno ben eigentlitgen (Siewitrzpflanzen; bey biejen jedots auth in ber Frud)t, wie श(momen unb Banille. Bey ben Stauden ber Respflanzen balo in Der Wurzel, wie bey Den Doloenuflanzen, Baldrian; bey den $\mathfrak{B a ̆ u m e n ~ m e i f t e n s ~ i n ~ b e r ~ \Re i n d e , ~ w i e ~ b e n ~}$ ben Mnrten uno Rorbeeren, wo jedod) Der (Eampher ant im Şolze vortomnt.

Die Sqarze bleiben in De: Regel im Stamme Der Jabels bölzer, Terebintben, mand)er Şülfenpflangen, uno fictern nur

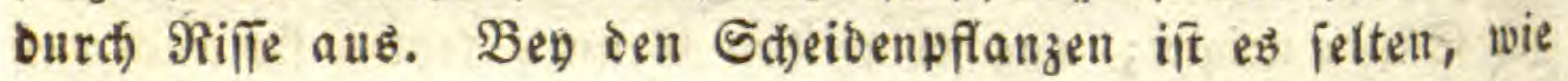
bey Iloe, nod) feltener bey den blumenlofen Pflanzen, wie bey einigen baumartigen Farren.

Die Säuren bleiben in ber Regel in S̈mnern, uno werom ăr weitern Entwictelung, befonders ber Jrüd)te, verwentet.

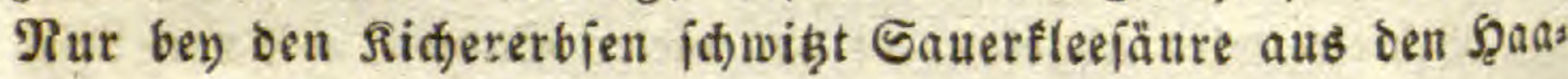
ren an Felds uno Së̈lje aus.

2. Die $2 u$ b Riechftoffe zeigen am meiften Mand)faltigfeit, weld)e fowobl

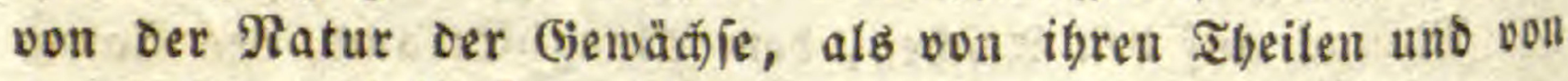

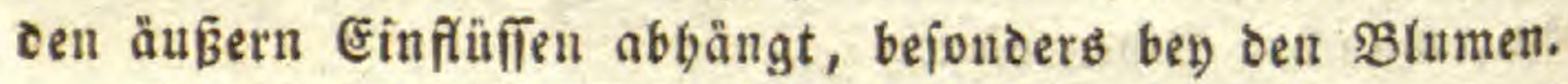

Die blumenlojen Pflanjen baben jelten einen (jierth), und bey ben פilzen iff or fait immer ftinfend; nur bas fogenannte Beild)ennods (Byssus iolithus) riect)t angenefm, fo wie einige Eaubmooje, Rebermovie und Farren. Bey Den Sateibenpflats jen fino Stengel uno Blätter meiftens geruth)los, uno bagegen

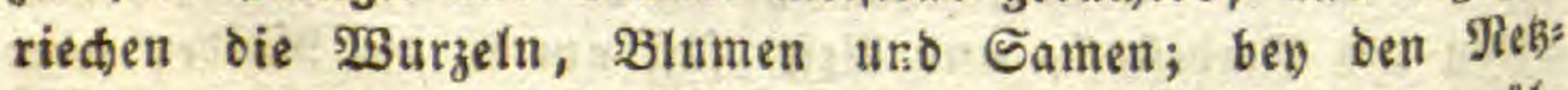

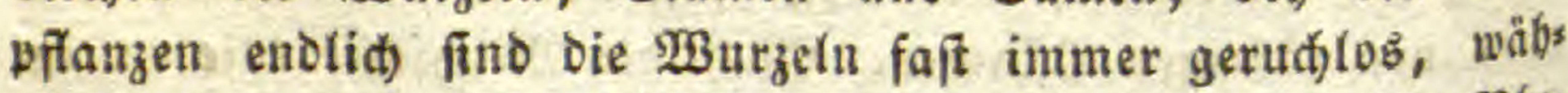
rento alle anbern Theile (5)eruth verbreiten fönnen, die $\mathfrak{B}$ (t) men am nteiften, wo zwar gewöbnlid einen angenebmett, Die Blätter nù Stengel Dagegen nițt felten dinen unange nébmen. 
Wurzel, Stengel unb Blatt rieđen gewöbnlich aud, nad)=

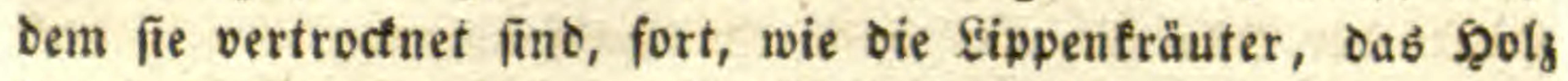
Der Evpreffen uno Eedern, bas Rofenbolz (Convolvulus scopa-

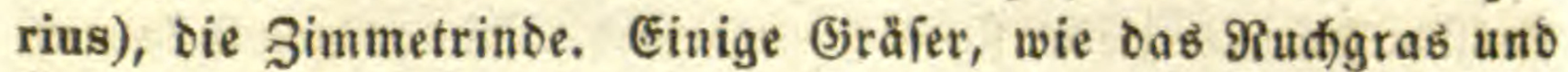
5̧oniggraz, fangen erft an ju ried)en, wann fie Şen geworben

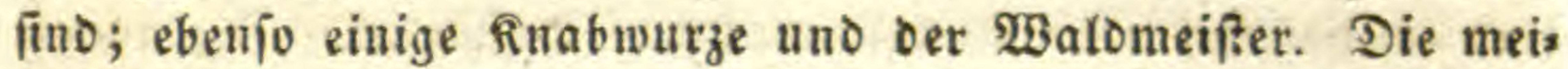
ften $B$ lumen verlieren ifren (jeruch nact) bem Iroctnen, wie die Relfen; die Rojen bebalten ibn jeood jefr lang.

Die meiften Blumen rict)en ununterbroden fort, fo lang fie leben; es gibt aber auth augieģende, welde nur bey Racht riechen, nie die Radttviole uno ïberbaupt bie Blumen, welde unter Tags geftoffien uno bey Rad)t geöfinet fino. Davon läß̈t fict) ber (Grund idtuer angeben, oa itberbaupt die meiften

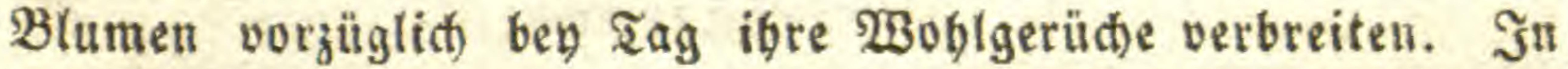

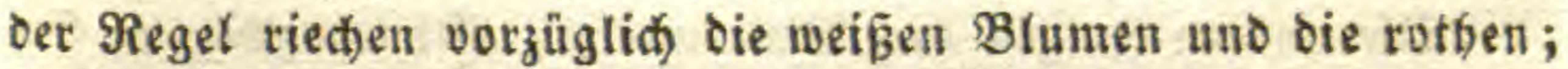
ielten bie btanen.

ङ8 gibt wenig Blumen, weld)e îtinfen, wie bie ber Stapes lien uno bes Salangenarons, uno zwar wie faules Fleijh, io

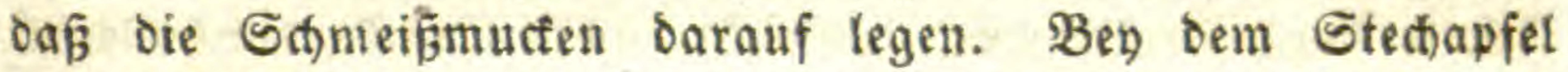
uno ben Bolfamerien riecten bie Blumen gut, wäbreno bie Blätter ftinfen, wenn man fie reibt.

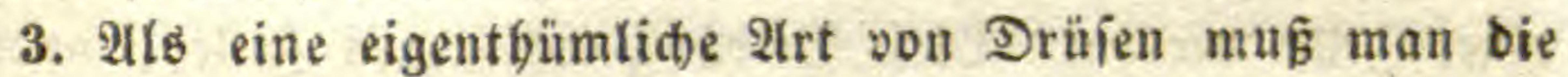
5onigorülen in ben Blumen anjeben, weil fie gröstentheils verfïmmerte Drgane fino, uno zwar meiftenz Staubfäden, welde ftatt Bläthenftaub ફ̧onig abiondern. Diejer ફ̧onig iđheint auts Bucfer und Gothleim ju befteben, bem mand)mal átherifichez Del over ein betåubeuder Stoff frembartige હigen: (đ)aften ertheilt, wie Jarbe, (5eruक, (5ejđ)mact, moblthätige oder fitjablithe Eigenithaften.

Itm meiften liefert jolden Saft Die Raijerfrone uno bie fogenannte porighflume (Melianthus). Ben iener fommt ber

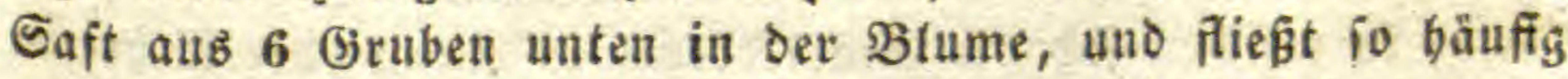

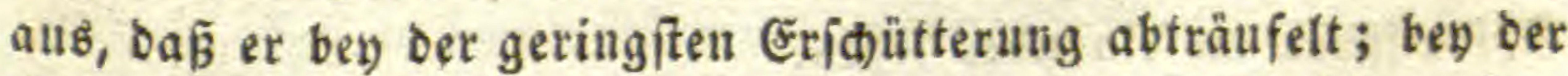

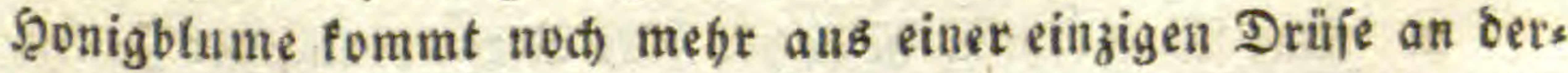
felber Stelle, weldie wobl als verfümmerter Staubfaden be= tractet werben mú, ba nur ibrer vier in ber fünfzăgligen 
Bhume vorbanden find. Uebrigens findet fich faum bey ber Szäffte ber Pflanzen eine joldte ફ̧onigabionoerung.

Diefe Säte idgmerten in Der Regel angenebm, io wie bie meiften Jrüthte, wenn fie nidth herb find. Die andern Pflanzens theile bagegen erregen faft Durdigängig einen unangenebmen uno efelbaften, voer menigitens faden (jejichmadt. Die ausges

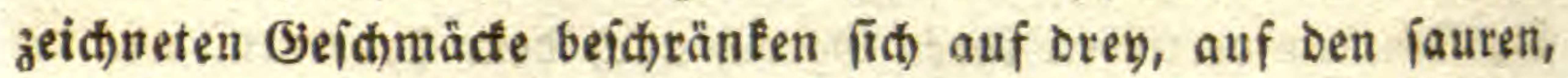
bittern uno fitarfen, uno man fann im 2 Ulgemeinen fagen, oer

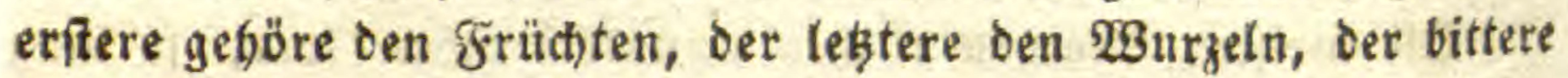
Dem straut an. Er feflt jeboch ben blumenlofen und Etheibents

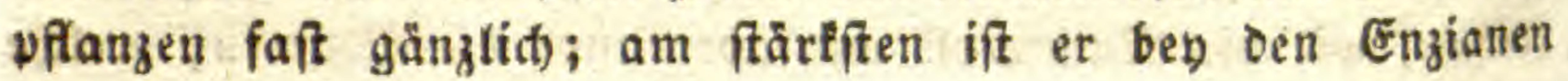
unb Rauten.

\section{b. Bergröferung.}

Die andern Folgen Des Berbaunngs", 2tthmungs: uno Er:

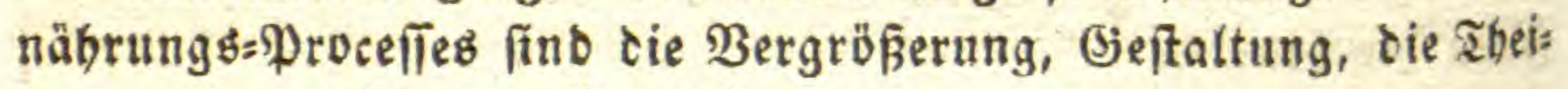
lung uno endlict) die Bermebrung.

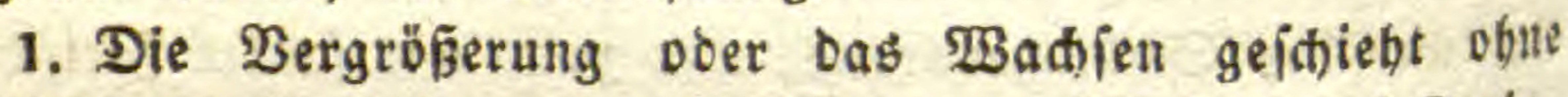
3weifel ourd Beränderung des Sd)leims in Stärke, burd (Serit: nung berielben zu Sïrnern, weldfe burd) Drybation eine bifis tere Dberfläct)e ober ફ̧aut befommen, unb auf bieje 2trt ju einer Zelle werben. Dieje Billoung von metten Bellen, woburch bie Pflanze wirtlic) wädst, faun aber nur ausertjalb ber frilbes ren Belfen vor fid) geben, alio in Den 3wijhenräumen voer \$nt:

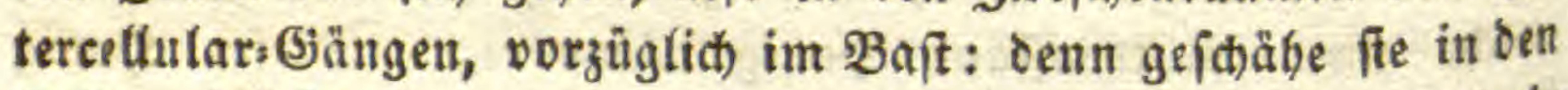
Bellen ferbit, io müsten bieje notbwendig zerreipen und in

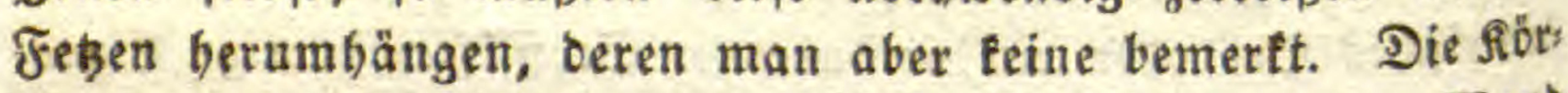
ner innerbalb ber Bellen hängen fith vielmelgr an beren WBand uno verdicten biejelbe, woourd bas eigentliche $500 t_{z}$ entifeets.

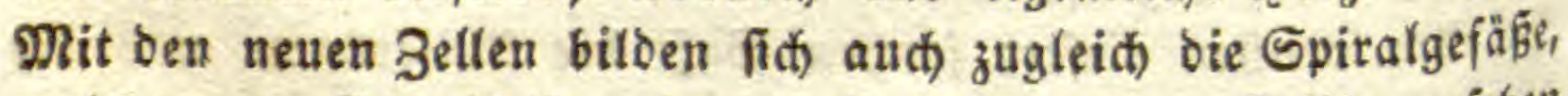
welde man für nidhts anderes als langgezogene Bellen anjelent Pann, in welden fid) die Stärfetöruer in einem oder mebreren Spiralfäben an einanber legen.

2. Das $\mathfrak{B a C b s t b u m ~ i f t ~ b a b e r ~ e i n e ~ B e r m e b r u n g ~ b e r ~ B e l l e n , ~}$

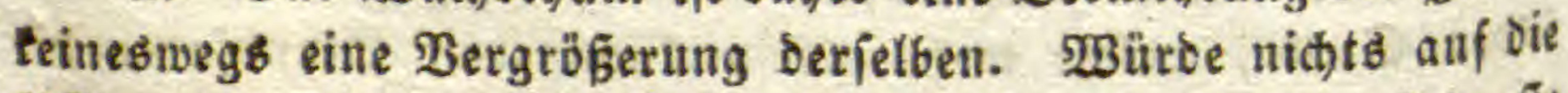
Pflanze wirten, als bet blof̧e Ernäbrungsprocé, ; fo mürbe fil 
fiti) obne 3 weifel g leidfo $\mathrm{rmig}$ nad allen Seiten ober lugels förmig ausbebnen, uno bie neuen Bellen würben in ber b̧öble Der alten eine grö́e Blafe oder Şaut bilben, unter weld)er immer neue Blajen entfänden. Sold) eine pflanze wäbre mits bin eine Einjhact)telung vou zablreiđen boblen Sugeln voer Sdalen, wie eine Swiebel doer ein $\mathfrak{P i l}_{3}$. Das ift im Grunte

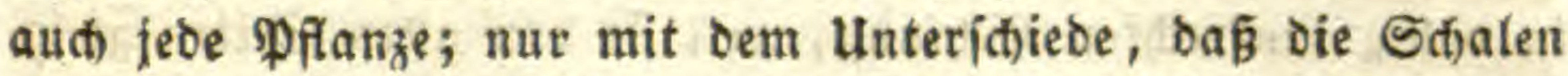
ober Rinden in bie Şöbe gezogen find und Walzen bilben.

Mithin muß ein Grunb ber $\mathfrak{B}$ erläugerung Der Pflan= jen vorfanden jegn, und zwar ein folder, weldher augerbalb liegt; fonif würoen alle zu Rugeln werden, wie bie Balgpilze.

Der Grunb fann nid)t in einent Triebe von unten liegen; benn biejer wirfte nur auf $\mathfrak{W a f f e r , ~ w e l d t e s ~ f i ́ d ~ e b e r ~ f e i t w a ̈ r t s ~}$ als nac) oben orängen, uno mitgin nur fuđhenförmige Pflanzen veranlaffen wïrbe. Er fann aud nidt) in ber 2 ärme liegen: benn bieje würbe nur Stugetn bervorbringen, voran\&gejekst, baß fie gleidfförmig einwirtte.

Es bleibt baher nur Satwere, Ruft uno Ridht ïbrig, welde nod) auf bie Pflanze wirten. Die Shwere allein würde das Zellgemebe zu einem umgefebrten segel formen, nefmlid) zur

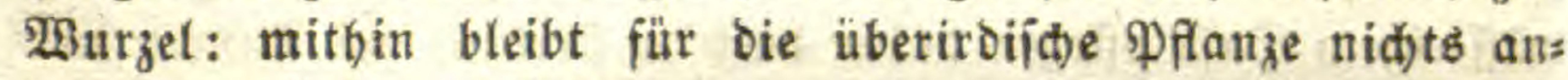
beres als \&uft uno \&icht übrig. 2(ber aud) Die \&uft wirft von allen Eeiten gleidförmig ein, uno fie mag beber burd Drybation

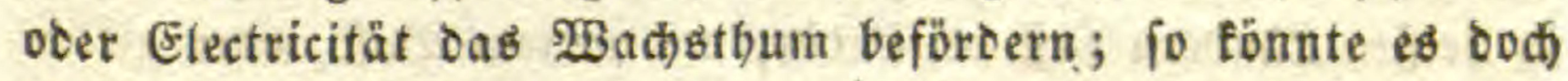
immer nur auf bie ફ̧ervorbringung einer fugel geben, wie wir benn aud) fehen, baj bie Pflanjen im Dunfeln bict uno weid werden.

Es bleibt mithin nid)ts anderes als bie Einwirtung Des

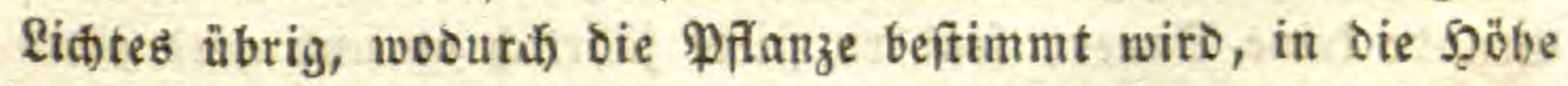
3u wadjien. Das \&idit jelbft fann aber nidit etiwa eine zielyende Sraft anwenten, jonoern múp nur ber Thätigfeit, inturbalb oer

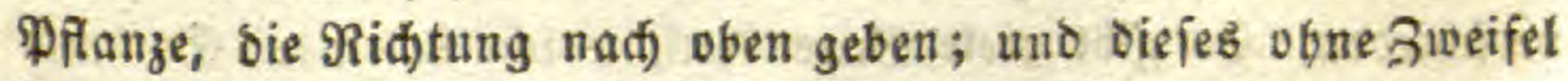

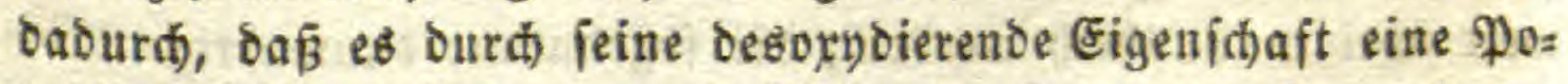

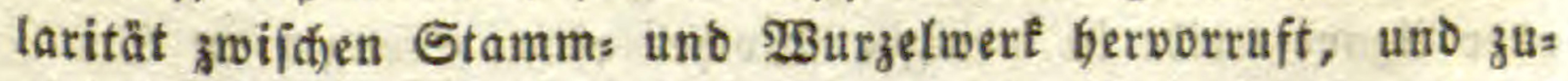
gleid) bie obern Ibeile mebr erwărmt als bie untern, moburd) fis mebre ausbünften, uno baber bie Betinnung bes Saftes zu 
Zellen beförbern. Aus bemielben Grunbe betommen bie Stoffe mehr Berwandtichaft zum Sauerftoff, zieben benielben an, ver= mindern mithin bie Ruft in bett Spiratgefäßjen, woburd neue einzubringen gez̧wungen ift. Da aud biejer 2(themprocés vor: züglid) auf bie obern Theile wirtt, fo wiro nun bie \&uft in

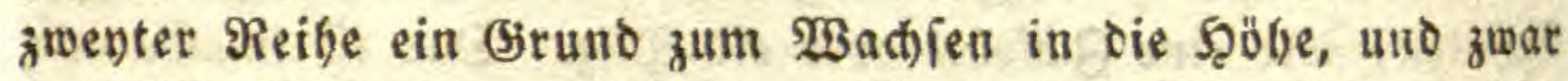

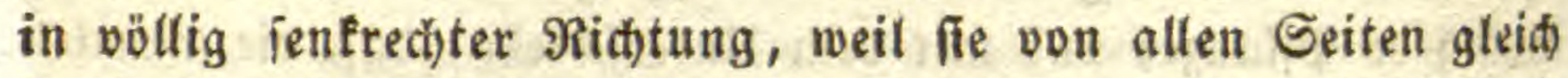
fart einnirft. Wenn fid) Daber bie Pflanzen im Sidite nach Der Gonne riditen, fo wadjien fie bey bebecttem Simmel uno wäbrend ber Radit gegen Den 3enith. Da die Pflanje am

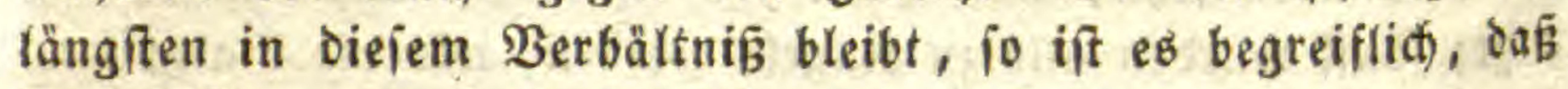
Die meiften ganz fentred)t fiteben.

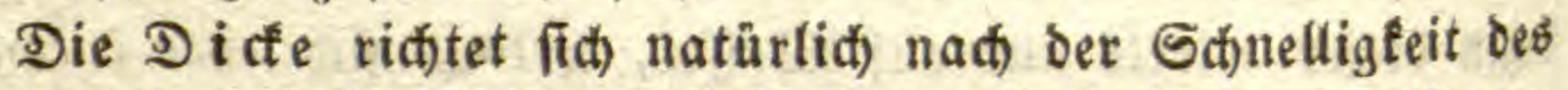

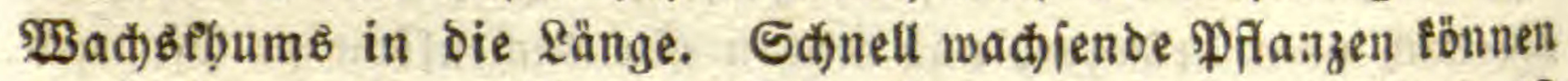
nicht biat werben. Es fino poldhe, beren Saft febr wäfferig ift uno mitbin wenig Stärfemebl abję̧t, wie bey Fräutern, Staus Den uno Sdjlingpflanzen. WYo ber Saft reid) ift an gerinnbaren

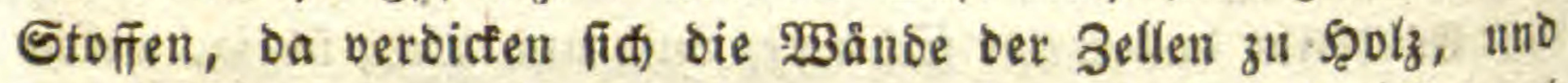

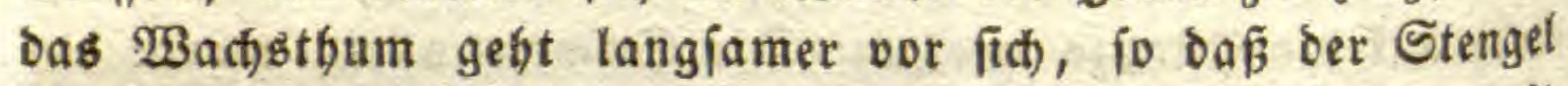
Beit bat, aud Mlafle in bie Dicte anzulegen. Pflanzen mit wäflerigem Saft pftegen baber balo zu fterben, uno bauern nut

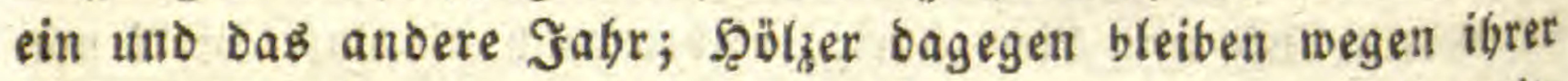
Starrbeit fteben, uno umgeben fid in ber warmen Jabrézzit,

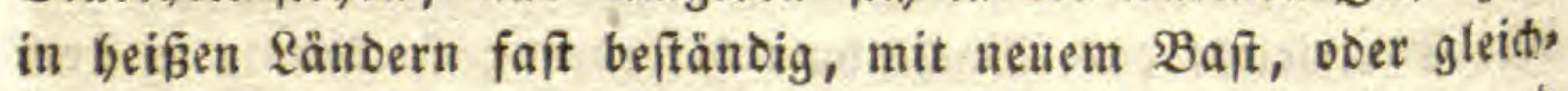
fam einem metten boglen siraut, welches wièer Blätter uno Blüthen treibt. Ein Baum, fann man fagen, if ein auts:

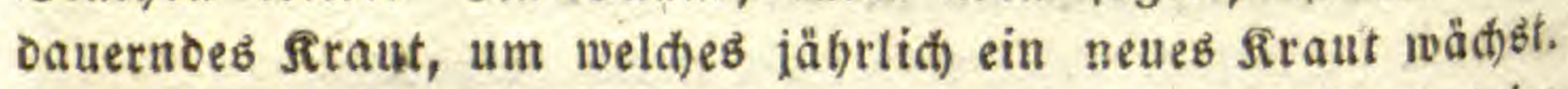
Das ift der einzige srund feines langen \&ebeng. Er bat im Grunde feine Datter, jontern fitirbt jägrlich ab uno wiro jäbrs (id) eine neue \$flanze.

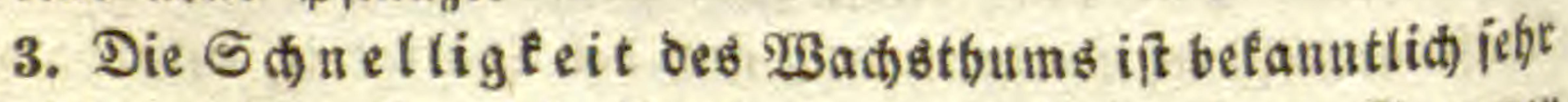
verídieben. Ë gibt viele (jrasarten, weldje in einem Sommer weit ilber mannsbod) werben; bie fogenannte baumartige 2(loe voer 2 gave treibt in wenigen 230 then einen Stengel 20 Satuth in bie Şöbe. Die Bäume watjen viet langjamer. Gienaue

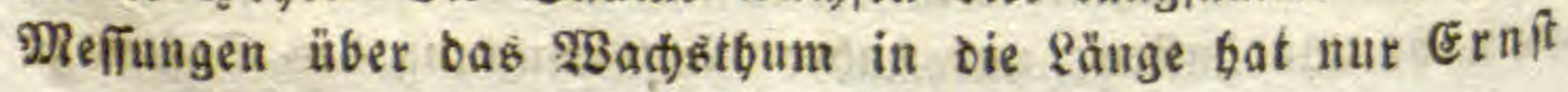


Me yer zu siönizoberg angeftellt. Die Stenge! von 21marbllik, Weitzen und (sjerfte wadtien bey Tag viel rajher als bey Nadit, uno zwar fait noch einmal fo viel; am idinellften gegen 8 unb

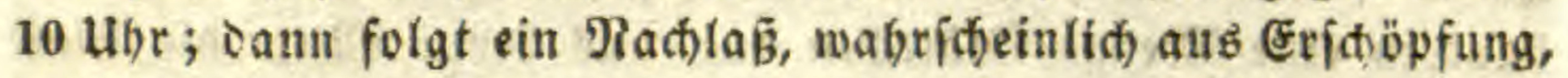
uno bann folgt eine zwente Beid)leunigung zwiichen 12 uno 4 Ubr. Mulber in Şollano bat ähnlide beobad)tungen itber Die Serlängerung eines Blatts an Der Uranie angeftellt; er bat

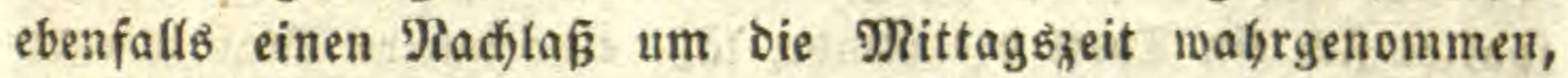

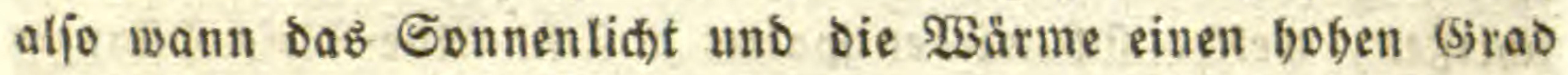
erreid)t batten. Die Blumentnoipe vom groß̉blütbigen Eactus wud) $b$ in ber Radt faít gar nicht, am meiften bagegen um Mittag im Sonnenlid)t, wabricteinlid), weil bie Fettpflanzen nur langfam erwårmt merben. Stuch bie baumartige 2tloe wuths am iđ)nellften währeno Der warmen Taggzeit.

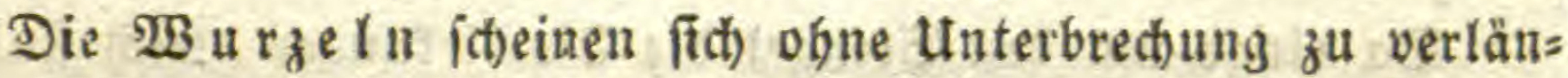
gern, auch wäbrend des WBinters, weil fte ber Stwere folgen;

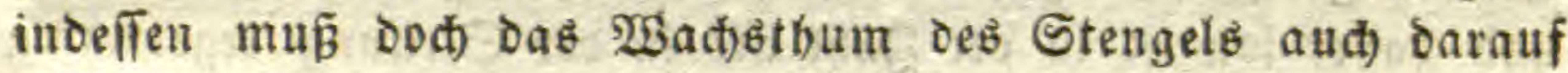
Einflus üben, was aber noch nidft unterjudt morden ift. Die Stenget verlängern fíd) in Råndern, welche einen \$inter baben,

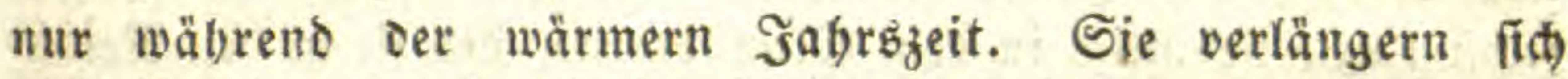
gleidfförmig, fo wie oie Zweige, uno oaber treten bie Blätter aแs einander.

Sind die $\mathfrak{B l a ̈ t t e r ~ e i n m a l ~ a u s g e b r e i t e t , ~ j o ~ w a d j i e n ~ f i e ~}$ nid)t mebr, mit 2(ubnabme bes Stiels. Die obern finoipen uno 3 weige entwicteln fith frilber, uno wactien fönnelfer als bie

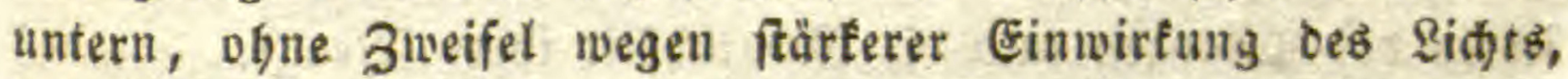
Der Euft uno Des $\mathfrak{B}$ indes.

\section{c. Theilung.}

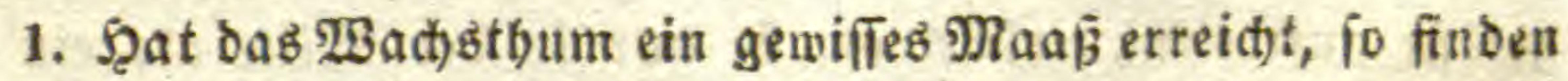
die neugebildeten Semebe feinen Plaks mebr im Snnern. Die äuBere Blaje zerreiß̄t, wiro zur Sdeide oder jum Blatt, uno

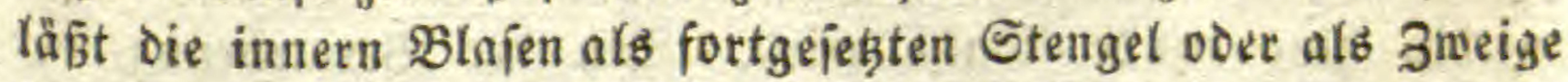

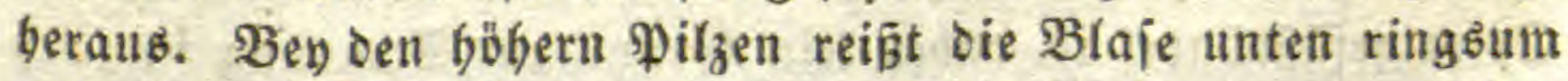
und breitet fich als Squt aus; Darauf reíft bie zwente, oritte u.f.f., uno legt fid) ebenfalls an ben Şut an. Die Samell: 


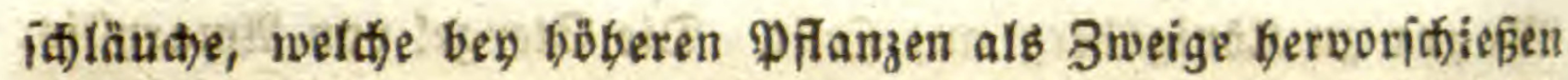
whitroen, bleiben bier an der untern oder innern fläctee des Şutes ftehen. Bey den Moojen reift, io zu jagen, bie Dbers baut in eine Menge Blättchen auf, aus beren Mitte bie Blafe

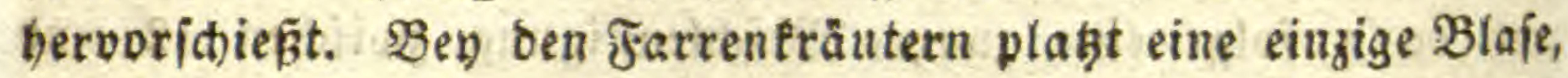
rollt fict) faft wie bar Şut eines \$ilzes auf, trägt aber bie Samen auf cer äußern Fläche. Bey den Sdjeidenpflanzen ipaltet fith ein Tbeil ber Rinde, läßst eine intrere Blaje bervors

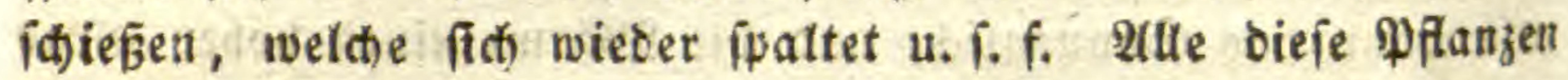
verzmeigen fidh nidft, ober nur fehr wenig, uno meiftens nur als Blittbenitiele. Bey oen Rebpflanzen treten endid innere Blafell ourd) bie Finbe bervor, rollen fich oft wie Farrenträls ter auf und laffen 3 weige beraus, welche es wieber fo maden biछ zur $\mathfrak{B}$ tütḩe.

Da rings um ben Stengel oie Einwirtungen gleid) fint, io if es begreiflich, oaß bie innern Blafen ringsum bervortreten, und bafer fowohl in ber 3 ahl als in ber Stellung regelmábig

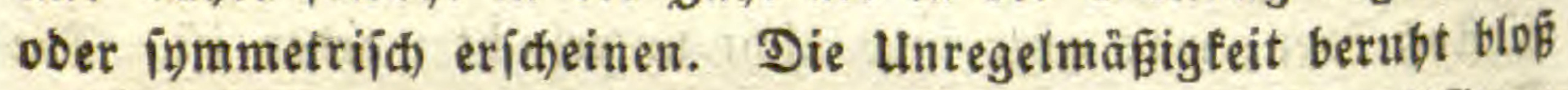
auf Bertimmerung, wovon fedoch ber (jiruno in ber Pflanje

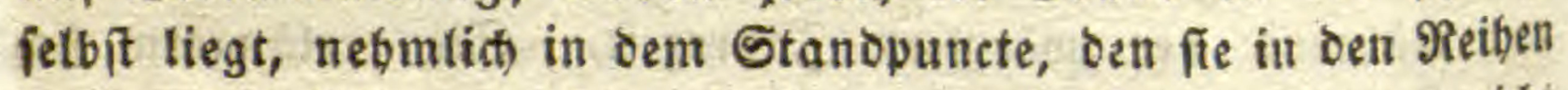
Des ganzen PFlanzenreidys einnimmt. Nlle Drgane fönnen niht in allen Pflanjen (enn, aud) nid)t in gleider 3 abl uno in gleider

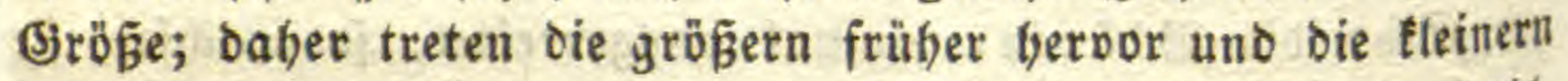
fpăter oder fraftlojer, wodurd) oie Unregelmägig Éeit in $3^{a b l l, ~}$ Gejtalt und (Sröße entiftebt. Darauf berubt eben ber Unter, fáted Der Pflanzen uno bie Möglichteit ihrer Menge.

2. Ueber baz $̧$ a hlenverbältnis wurbe foton gerebet. Die untern $\mathfrak{P}$ flanzen ipalten fit) nur einmal, uno fino oaber zwen= ober vierzäblig u. f.w., oder ibberbaupt gradjäblig. Sobald Epirals gefǟe auftreten, exicheinen fie nur in oer Mitte als eill eits ziges Büntel, wie ben den Jarren, weil bie Pflanje ibrer Itr:

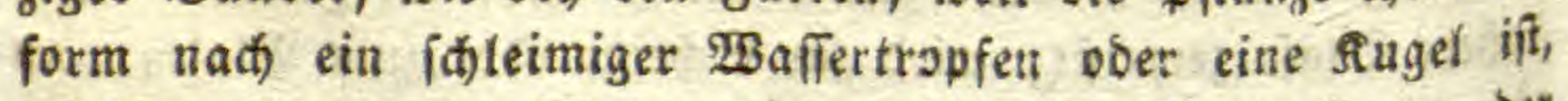
mitbill eine runde $\mathfrak{B a l z e}$ wiro. Bey ber Bermefrung ber Spiralgefäßjbindel ift oaber fein Jirunb zur Trennung in zwet Bündel vorbanben: denn jonft müste die Pflanze eine gläd) fegn, was unmöglid iff. Es entffeben baber fogleid in ber 
Walze 3 Spiralgefágbindel, uno verwandeln biefelbe in Sdeibens pflanzen, die fith tiberall in brey theilen. Die näcjite Sabl wäre 4: altein biefe ift nur $\mathfrak{B}_{i e b e r b o l u n g ~ d e r ~} 3$ abl 2, mitbin Det blumenloien Pflanzen. Sie fommt oaber felten bey ben Nebpflanzen, mit vierertigem Stengel vor, uno felbft oa fitheint fie nur Folge einer Berfümmerung zи jenn, da Die Blumen überall bie 2nlage zur fiunfabl zeigen. Die nådjte, ber runs ben $\mathfrak{B a l z e}_{\text {entiprectende } 3 a b l}$ ber Spiralgefäß乃bündel ift baber 5, und bieje tann für die allgemeine der Rek̨pflanzen angéeben werden. Die Eombinationen foweben alio zmifhen 2, 3 und 5 , und Daraus ergibt fid idon ber grofe unterífied in ber $3 a \mathfrak{b l}$ ber Formen unter ben blumenloien, Sdeiden = uno Neks pflanjen, von ber vielfaden $\mathfrak{B}$ eríbiebenbeit, welde durd bie Größ̨e, Berfümmerung uno bie Stelfung bervorgebrad)t wirb, nidft zu reden. Die Zabl oer Reşpflanzen ift Dafer notbwens

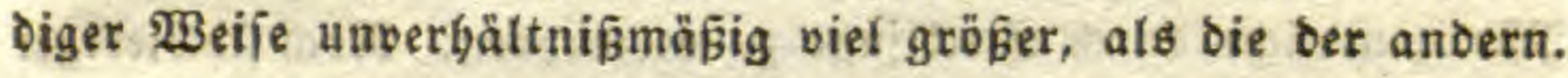

\section{d. Bermegrung.}

1. Die Theilung eines Stengels ift eigentlid) idjon eine $\mathfrak{B e r s}$ mebrung: Denn jeber Sweig ift wieder ein gauzer Stengel, ber Blätter uno Blütben treibt, uno dem nur die eigentlidge $\mathfrak{B}_{\text {Buzel }}$ feblt. Er murzelt aber, feinem Ërnäbrungşprocés nad), im Stengel ganz 10 , wie bie $\$ 3$ urzel in ber Eroe, uno fann baber aud) abgeiकnitten uno in bie Eroe geftectt fortwachjen.

Das geidiebt feood) nur, wenn er Rnoipen hat, bie fidh के Blättern entwidfeln. Dhne biejen Borgang treibt bas Stect: reis feine $\mathfrak{W}_{3}$ zeln, theils weil ber Giegenjag is beiden Sweigs

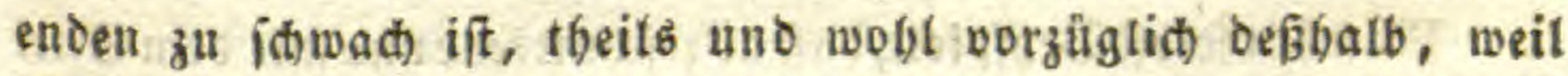
Die Blätter bie Safteinjaugung berworrufen, welder Gaft podann

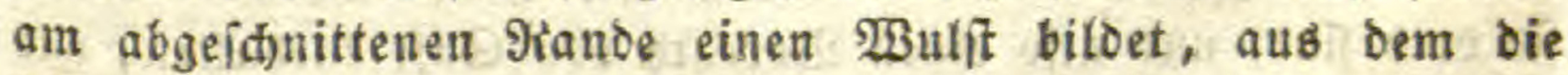
Wurzeln niederfalten. Etectlinge, weldhe idton entwictette Blảts ter, aber feine fitrofpen baben, fterben balo ab, wenn man ben beblätterten Ibeil nid)t bebectt, um bie 2tisoünítung, mitbin

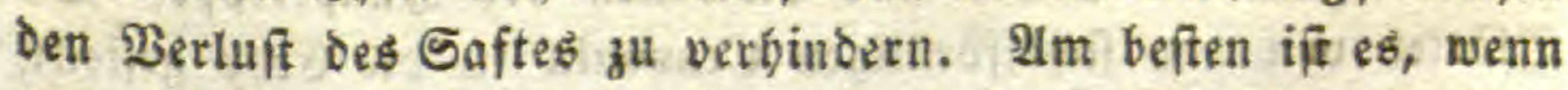
man oen 3 weig io abjinneibet, oá ein suten in bie Erbe

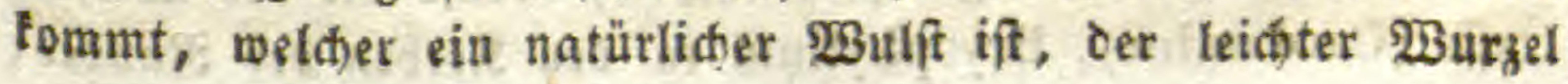




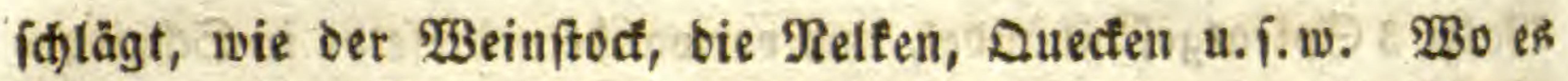
Feine snoten gibt, fotnitrt man bie 3weige ein, bamit fid ein

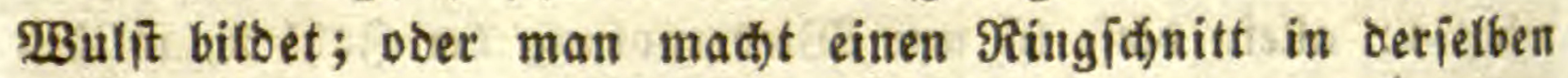

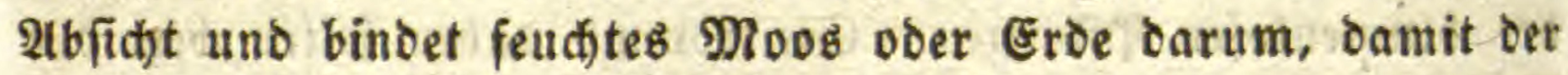
WBulft fabon am Baume $\mathfrak{B u r z e l n ~ t r e i b e n ~ f a u n . ~ S ̧ a t ~ m a n ~ j u ~}$

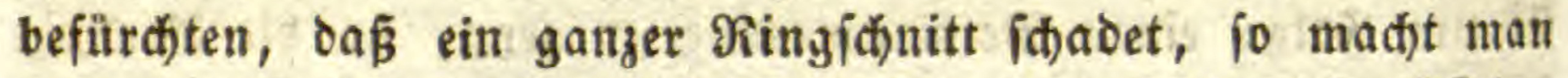
nur einen balben, woburd berfelbe 3 wect erreidft wirb. Ift ber Zweig binlänglid) angewurzelt, fo fdincibet man ibn ab.

Bey faftreichen Pflanzen braudst man ben 3 weig mur zu frïmmen und einen Theil mit Ërלe zแ bedecten, um 23 urzeln zil befommen. Soldte 3weige nent man 2(bienter.

Es fönnen alle Pflanzen burch פeifer oder 2(bjenter ver= megrt werden, fedod mit mebr ober weniger \&eidftigfeit; weidee,

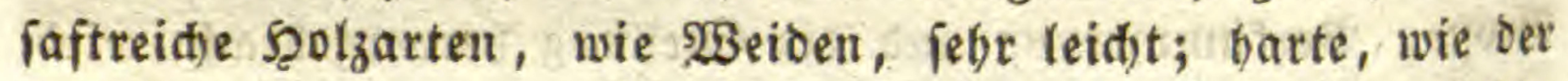
2lpfelbaum, bagegen viel iflwerer; baber pflegt man folde Pflanzen nidt ourd Stectlinge zu vermebren. Nod fitwieriger gelingt es bey faftarmen Pflanzen, wie bey den Radelfölzern.

Es gibt nidft wenig Pflanzen, welde fich felbit burd 216 : fenter vermebren, nebmliđ biejenigen, weld)e A(ustänfer treiben, wie bie Erobeeren, Brombeeren, Farrenfräuter u.f. w. Da fie

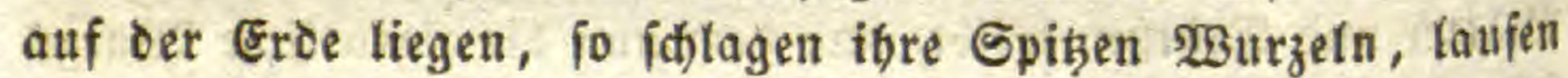
weiter, fhlagen wieder u.f.f. Selbit auf ber Erbe liegende

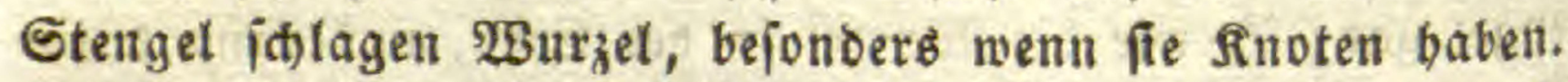

Enolid) gibt eв Pflanzen, weldje aud), an Theilen entfernt von Der Eroe, fogenannte $\& \mathfrak{n} \mathrm{ft}$ urzeln fallen laffell, wie bie Fettp fanzen, mande Feigenbäume, die Mangel = ober Wurzele bäume.

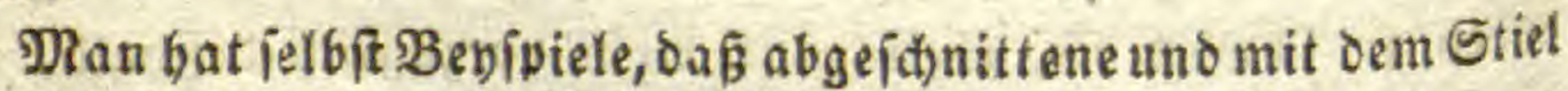
in bie Eroe geftectte Blätter $\mathfrak{B u r z e l}$ idlagen, bejonbers wern fie berb fino, uno aljo einen Botratb von Saft entbalten, wie

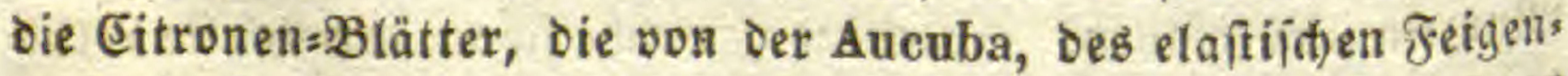
baums, Sorbeer= uno Mintenblätter. Die $\mathfrak{B}$ urzeln fommen aut Der Rilifeite bes Stiels uno bišweilen ber Şauptrippe. Die Blätter von Der fidjelförmigen Crassula in bie હrobe geftectf,

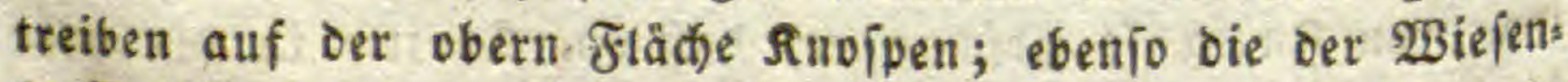

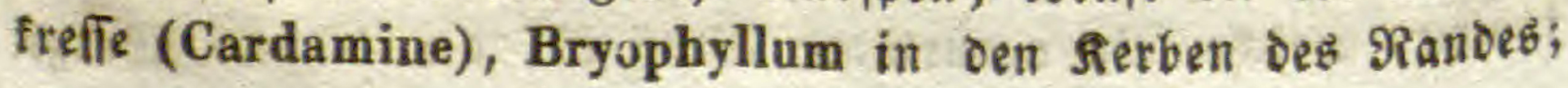


Die Sabpflitie (Eucomis) und bie Bogetmild felbft in Der \$reffe.

2. Die gewöbn liabe Bermebrunggart Der Pflanzen aber geidsieht ourd finollen uno 3 wiebeln, wovon fid tene in Der Erde bilben, bieje aber in uno aufer berielben. Die snols len finb eigentlid unterirbifde sweige, welde aus Mangel an \&idft uno Ruft mefre in oie Dicte wadjen, viel Rabrungsjaft anfammelı uno weís ober braun bleiben. Sie entwicteln fith nur, wenn fie Rnoipen haben, uno das ift der gewöbnlide Fall, wie ben den Eroäfeln, Dem förnigen Steinbred, ber Zahnwurz, dem rotben Steinbred) (Spiraea filipendula), dem Bi íamfraut, Den Georgiuen, Radttéerzen u. f.w. Da bie Erdäpfel mehrere Snsipen voer 2utgen baben, fo fann man fie in eben fo viele Theile zeridneiden, uno won jebem einen Stod befommen.

Die eigentlíchen Zwiebeln find nidists anderes als snoipen unter der Eroe, über beren Entwictelung man fid Daber nidjt wundern fann.

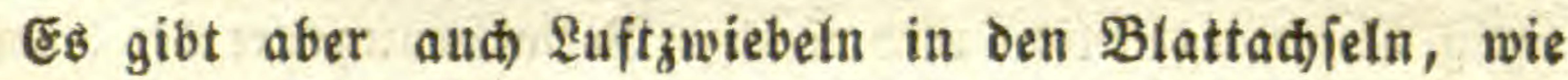

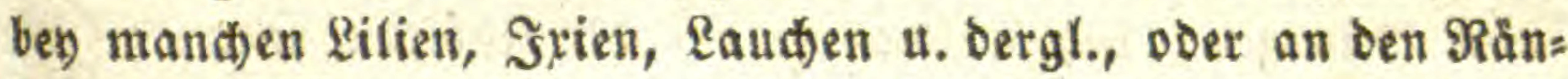
Dern ber Blätter, wie bey der Sumpfordfis (Malaxis paludosa), bey mebreren Farren und felbit Movien und Rebermoojen. Dieje 3 wiebeldien fallen ab unb wadjien fort. Sie find nidts anbes res als fnollige stnoipen.

Itle Bermebrung der Pflanzen ourd) Igeilung berubt da= ber auf ber Silloting von Snofpen uno auf ibrer frenwilligen Entblősung, wobl allgemein vermittelt burd) eine 2tnjammlung von Rabrungsiaft, walde wieber gegrïndet ift auf die Şem: mung des fenfredten Wadjetbums, und dieje wieber auf ben

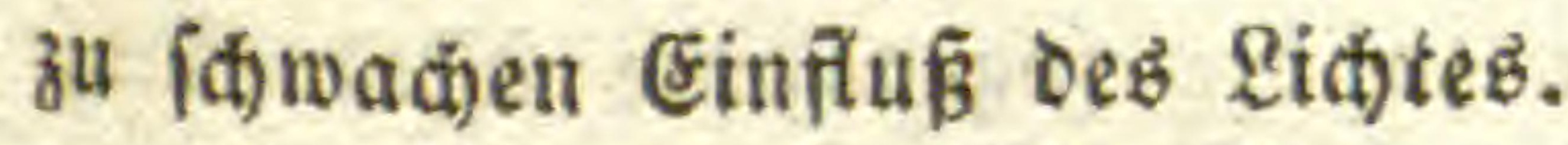

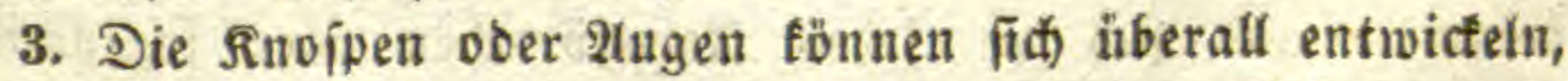
wo fie fenthtigfeit befommen. Darauf berubt ba $\mathfrak{P}$ fropfen,

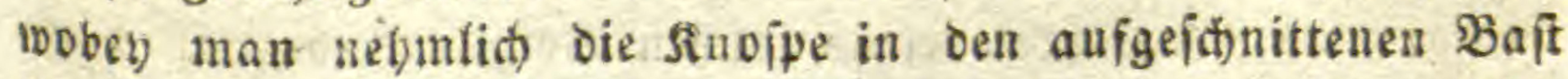
leght, wo fie hintänglich Saft befommt. Seķt man die finofipe unmittelbar binein, fo nenut man ef Aleugeln; jeģt man ben Sweig binein, fo beipt es 3 weigen; nimmt man von zwen 3weigen nabe ftebende Bäume einen \&ångsidinitt weg uno 
binbet die Fläd)en an einander, bis fie verwactfen find, fo nent man es 2lbjaugen oder Mblactieren. Diefes fann zu leber Jabrszeit geideben, und bisweilen geidiegt es von felbit, wenn शlefte veridiebener Băume did)t an einander fteben und fich orücten. In botanifitsen säarten thut man es mit feltenten Pflanzen, wie Magnolien, Paffionsblumen u. bergl., wo ku fürdten ift, Dá̧ bie andern Pfropfungsarten febliallagen.

Das Sweigen fann nur im Frïbjabr geíljeben, wann die Băume im Saft ftefien; bas Aeugeln gelingt im erifen uno zwesten Saft, nelymlid) im frühling und am Enbe bes Sommers.

Durd) bas Pfropfen fudt man vorzïglid) beffere Dbifforten auf fdled)tere Bäume oder auf wilde zu bringen. Die Pflans zen mülien fít) aber nabe berwanot fenn, wenigitens zul bens

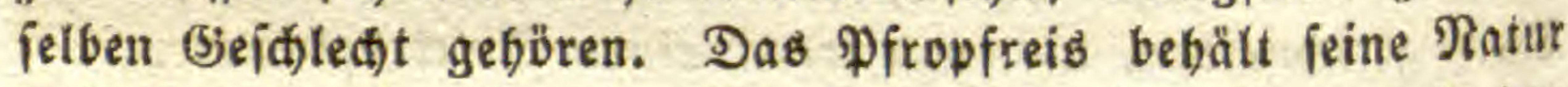
uno ift oaker im Stande, Den Saft bes alten Baums in ben feinigen zat verwandeln.

4. Dieje Entwicfelung von sinoipen uno ibre frenwillige Irens nung if bie eigentlid)e uno einzige Bermebrungsart ber blumen: loien Pilanzen, bey welden jedod) die Rnoipen entweder im Stocte eingefolofifen bleiben, wie bey Den Pilzen, uno nur burth Plaken oeffelben frey werden; oder in Seftalt von Samen und Eapieln berwortreten, wie bey den Moojen und Farren. Sebes Samenfäubdien ift eine fleine finoipe, oon ber allgemeinen Spaut voer Rinde bes Stocts umgeben bey den \$ilzen, und in Sirunde aud bey den Moojen nno farren. Reifit die Sitlle auf, io zerfatten fie zerftreut auf ben Boden, wadiel unmittelbar fort, wie eine 3wiebel. Nan bat zwar ben dell Moofen Iheile mit einem Staub entoect, weldyer Blitbent" ftaub jenn foll; wie er aber in bie jogenannte Moosbiddif fommen uno fid an jeoes Reimförndien ober fogenannten Samen vertbeilen foll, hat nod niemano gejeigt und nod

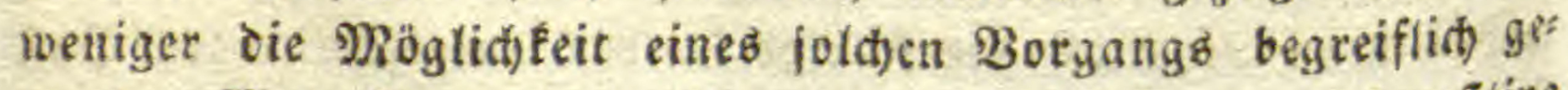
mad)t. Man fönnte Daber die blumenlofen Pflanzen auf pofitive

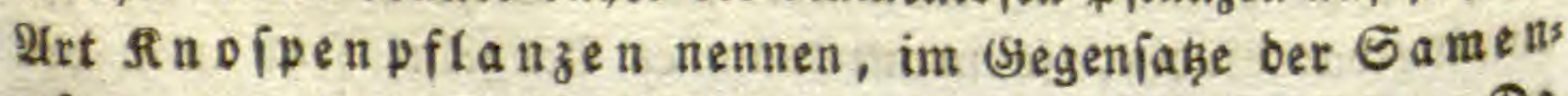
Dfanzen, weldes die Pflauzen mit Staubfäben wären. Da man jeooh) bey ber finoipe an eine Blattbitoung bentt, wäbrend 
Die Seime ber blumentojen Pflanzen eber Süullthen find, fo wirb ibnen der Rame Rnolrenpflanzen befier anifeben.

Die fieimförner Der Farren uno Mloofe find vollfommener als bey ben Flectiten, Tangen uno pilzen. Bey ten Farren

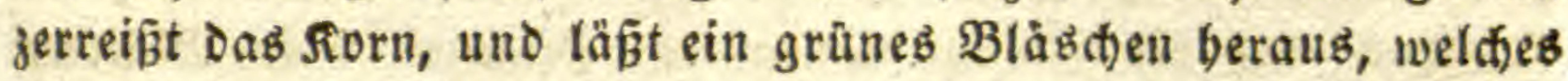
fid) in einen geglieberten, aus einer Reibe vou Zellen befteben=

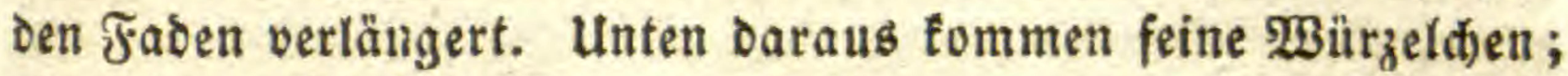
oben feģen fict) feitwärts neue Bellen an, woourch ein Blättchen entiteft aus einer einzigen Bellenlage. Nun treiben aud $\mathfrak{W u r s}$ zelfäben aus ber untern Seite bez iđmälern Endes uno brin= gen in Die Erde; am breiten Ende entifteht eine Berbictung oder

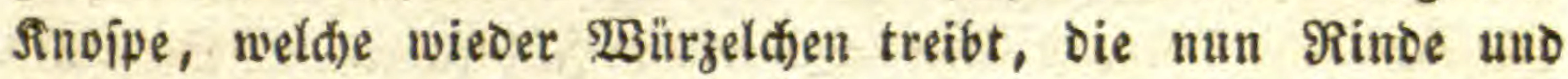
Spira!gefäfe Gaben. Man nenut das eríte Blättd)en Gamen= lappen, was es offenbar nid)t ifit, weil es fid unmittelbar in eine sinoipe verwandelt uno baher dem Stengel entipridt. Daber hat mall es Borfeim genannt. Die aufgeplaz̧te Şaut des Sorns bleibt am Sirunbe biefes $\mathfrak{B o r t e ́ m e s}$ fíhen. 2luf Diefelbe Weife entwicteln fich aud) bie fiörner bes Sdadtel= balms, und im Grunde jelbft der Mooje. Die aus bem zers riffenen Sorn tretende, formlofe Reimmalfe verlängert fich nach)

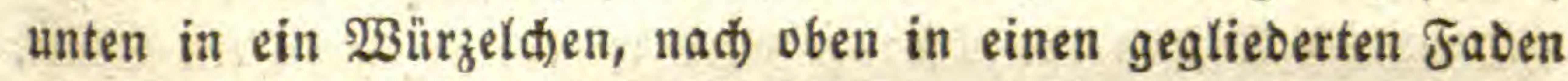
als Borfeim, welther fid allmäblid in 2lefte theilt, aus beren Mittelpunct bie finofpe fommt, welde nun erft bie bleibenden Butrzeln treibt.

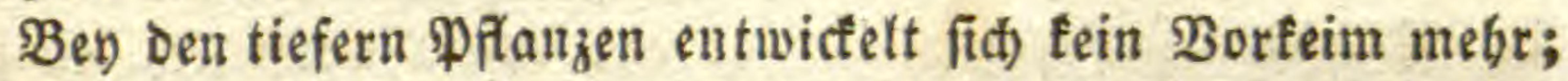
bey ben eigentliden Sangen bat jeboch bas fiorn nod) eine Şaut, aus welder die Reimmaffe tritt. Bey ben Wafferfäben uno Ulven, fo wie bey Den Flectenten uno Pilzen, ift feine Şaut megr vorhanden, weld)e zerriffe und die Mafie beraus ließ̧e; oder vielmefr bie şaut felbit verlångert fid) unmittelbar in ben Stengel, Lappen oder bie Rugel. Daв Rorn gibt verífiedene Derlängertungen $a b$, weld)e $b a$, wo fie fich berübren, zufammen= wadien uno bie veridjiebenen (jeftalten bilden. Wabridjeinlid) zieben fie von 2(uÉen í)leimiges Waffer an, woraus neue Zels len werden.

Uebrigens mag man die \$ilze, bie \$alferfäben unb Fledten Dtens allg. Raturg. II. Botanil I. 
in fo viele Theile zerreip̄en, als man will; ed wirb jeber Theil wieder eine ganze Pflanze, D. h. alfo jede Jelle fann als snot len ooer sunipe betrad)tet werden, weld)e Rabrungsftoffe ans ziebt und fid vergröBert. Im ftrengen Sinn nennt man jebod

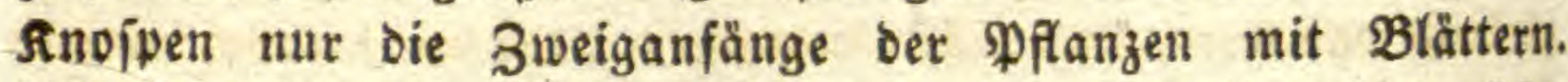
2lles Uebrige, wab fid fortpflangt ourd) unmittelbare Bergröbes rung, ift ein suollen.

\section{e. Erfä verlorener Ebeile.}

Im Ibierreid, erfeben fid febr oft verlorene Ibeile wieber. Berid)nittene polnpen befommen wieder Füblfäden, bie Sđnetten wieder einen Sopf, wenn ber Rerbenring nid)t verlę̧t iff; viele 2 Bürmer erię̧en gleidggültig bie vordere ober bintere Şălfte Des Reibes, Neeriterne abgebiffene Strablen, mande \&urdie fogar bie Zeben.

Dbiđjon man im Pflanzenreidje viel gewöbnlidber vom $13 i e$ Dereriah ber Drgane oder ber jogenannten Reproduction ipridt; fo gibt es ood), ftreng genommen, Darinn gar leine, menigftens feine von ber vorgenannten 2 (rt im Ibierreich. Rein verloren gegangenes Drgan Der Pflanze wirb wieber erfekst; tein Blatt,

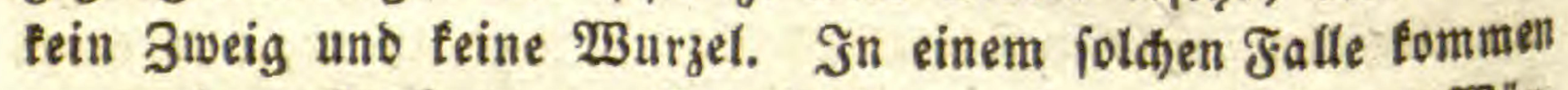
nutr anbere Rnoipen zur Entwicfelung, ober ein Hleineres Wüt: $^{2}$ zeldhen wirs zu einem grofien. Ђ̧ödiftens fönnte man etwa von Der Reprobuction ber Rinde reden: allein wenn fich ein abges

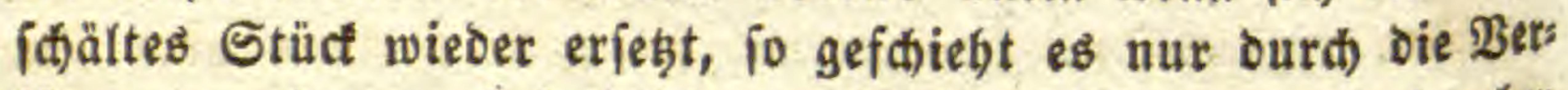

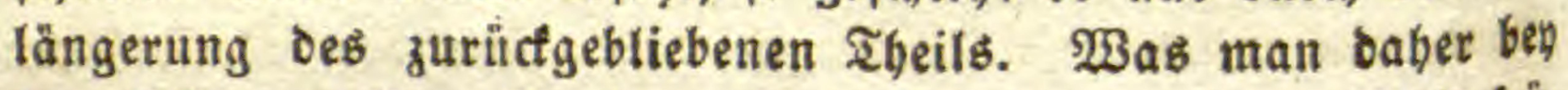
oen Pflanzen Sieproduction nennt, ift nichts weiter als bie frils bere Entwicfelung bon neuen stheilen, welde fich fpäter bod entwicfelt bätten.

Bey ben $B$ lütbentheilen vollenos wito fein einziger aud

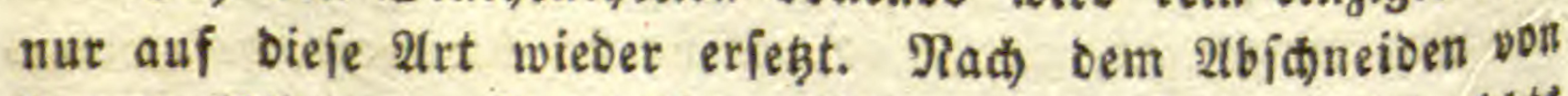
fungen Blättern, Staubfäben, Bälgen uno Gamen tritt niकt' Reues mebr an ibre Stelle. Die Pflange reproduciert fid baber nid)t; fondern wäcjst nur fort, und zwar ins Unenblide, wen! fie Gielegenbeit dazu erbält, nebmlid wenn oie jüngern uno 
weid)ern $\mathfrak{s}$ eeile, bie von oen ältern uno vertroctneten nidbt mebr ernäbrt merden fönnen, in bie Erde tommen.

Эndeffen nennt man bie Bermegrung burch Snotlen unb 3miebeln, audh bas jäbrliche Şervortreiben bes Stengets aus auscauernden $\mathfrak{B u r z e l n , ~ R e p r o d u c t i o n , ~ o b j i o n ~ e s ~ i m m e r ~ a n b e r e ~}$ Theile fino, meldee an ibre Stelle treten uno fid) bod) mit ber Beit entwictelt bätten, alio idôn vorbanden waren, ungefäbr wie bie bleibenden Zăh) unter ben Mild)zăgnen: benn bas Sajieben der Zähne fann man eben io wenig Reprobuction nennen, als bas Borídieben ber Fingerglieber. Die jåbrtic treibenden Zwiebeln und Rnollen werden immer nea gebildet, und find, wie früber gejagt, nidjts anderes als stnoipen bes abiterbenden findlens poer ber Zwiebel. Bey Şyacintben, Tuls pen, Saud) bilden fith bie neuen 3 wiebeln in ben Sdalen ber alten; bey ber Beitloje uno ber Snabwurz auswendig zur Seite; benm Safran uno Sdwwerdel am Siipfel; in allen Fällen aber in einem Blattwinfel. Die neue Snoipe treibt $\mathfrak{B u ̈ r z e l d e n ~ n a d ~}$ unten, uno wiro anfang ernäbrt burdh bie alte 3 miebel oder Den Rnollen, woburth bieje einjdrumpfen, wie die Samenlappen ber Bobnen. Daber fommt es auth, baß̧ die Seitenzwiebeln ungewỏbnlia) an einer andern Stelle aus ber Erbe bringen, uno baher zu wandern ideinen.

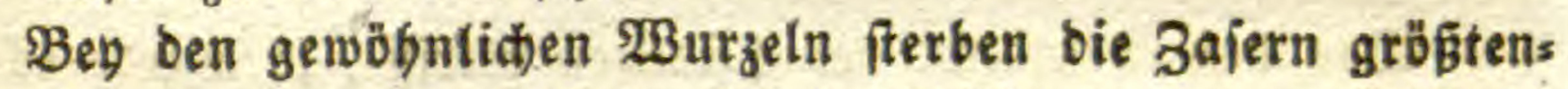
theils $a b$, uno es entwicteln fid im Frübjabr neue. Dafielbe geíhiebt mit ben Stengeln ber ausbauternben \$urzeln, wie bey

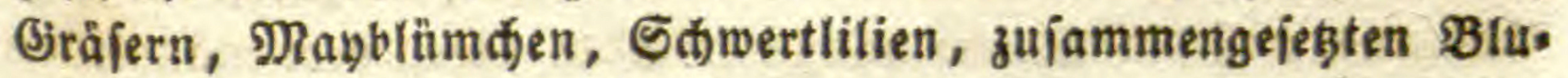
men, Doloeriblumen u. bergl.

21n ber Stelle eines abgefallenen $B$ latts tommt nie wieber ein anderes, fondern nur aus neuen sinoipen.

\section{B. Fortpflanzung.}

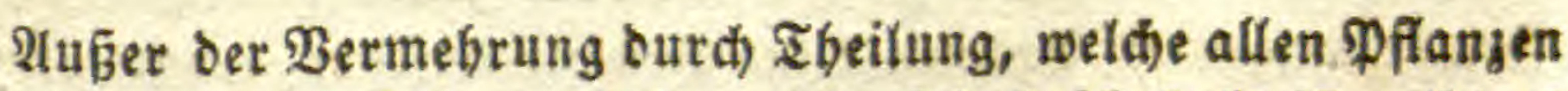

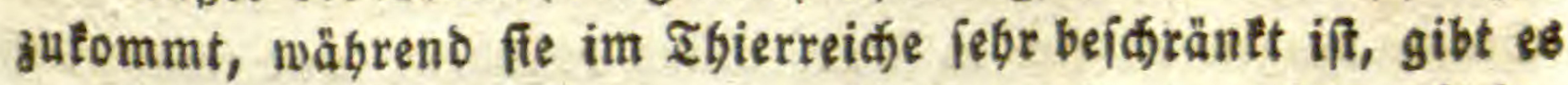
and ben den meiften Pflanzen nod) eine andere, welde mit ber (jef(h)leătsfortpflanzung ber Thiere übereinfinmt, uno bie wir zum Unterichiebe Fortpfla nzung idtedithin nennen wollen. 
Diefe geifiebt in ber Blütbe, weldhe felbit, wie wir ge= fehen baben, eine \$Bieberbolung bes Pfianzenftocts im Sileinen

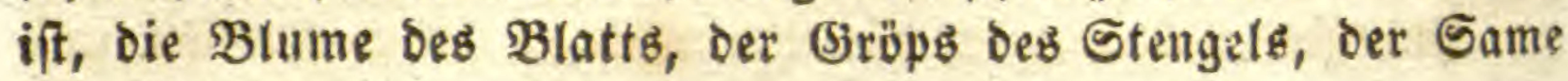
Der 23 urzel.

Es wieberbolt fid baher in ber $\mathfrak{B}$ lüthe aud bas thum Des Stodfs, uno es biloen fich in igr snofpen zur Bets mebrung, weldye bier Samen beifen. Die Samen fino daher finoipen ber Blüthe, uno die Rnofpen find Gamen bes Stocts. Wie die Blütbe icton ein abgejonderter Pflanzenftoct ift, fo ber Samen eine fid felbft ablöfende, uno nad) Der 2 (blöjung fid, ausbildende uno entwictelnde sinoppe. Diefes if ein Şaupts unteríbieo bes Samenz von ber Rnoipe; er unterideibet fid aber aud ourd feine Srgane, indem er fidon alle bren Şaupts theile befib̧t, nebmilich $\mathfrak{B u r}_{3} \mathrm{el}$, Stengel und Blatt, wåbrend oie Snoipen nur aus Blättern befteben. Der Same if baber eine snoipe mit allen aheilen bes Stocts; snoipe oagegen ift nur ein Same, ber bloß ans Blättern beftebt. Der Same ift ein ganzer, nod) nid)t entwictelter 1 flanzenftoct; bie sinoipe ift eine Blattblaie, woraus fith exit $\mathfrak{B}_{\text {urzel }}$ uno Stengel entwictelt, alio nut ein Drittels = Stoct.

\section{(3)}

Was bas (jeif)led)t ber Pflanzen betrifft, fo wurbe es erft

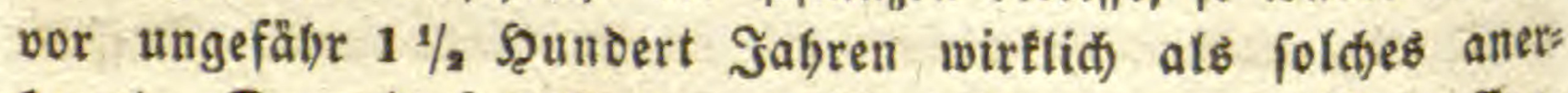
fannt. Damals fpract) man, wie es f(theint, es zuerft in Engs

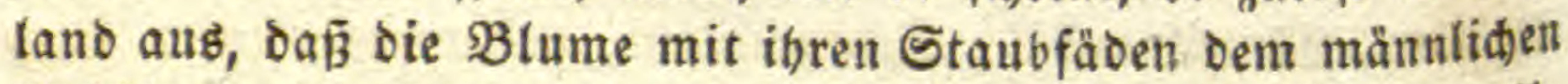
(Gefd)lect)te Der Thiere, Der (jrëpg mit feinem (striffel tem weibs lichen und die Samen bem En entiprechen. Der Tübinger Profefior Ea merariu bewies es aber zuerit auf eine wifien:

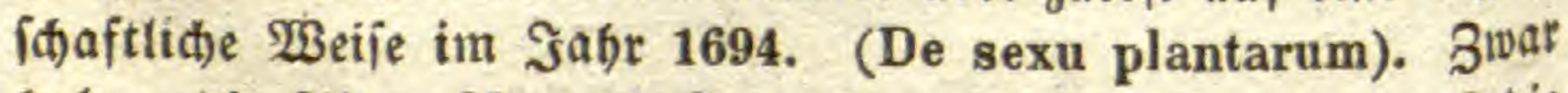

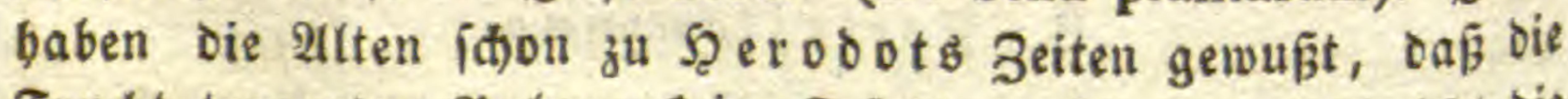
Frud)t tragenden Palmen feine Früh)te anjekzen, wenn nidt bie Staub tragenden fid) in ibrer Näbe befinden, uno man lié; baber in ben Dattelwåldern einzelne Băume von ben leģtert ftehen, bieng aud wobl, wie man eह jeb̧t nod) thut, abgeidnits tene Gtränfer berielben auf bie Fruchtpalmen, jebod ofne bas 
bey an eine Befrubtung ju benten. Man verglid) vielmebr biejes Berfabren mit ber jogenannten Eaprification cer Feigen, wobey man wilbe 3 weige auf zabme $\mathfrak{B a ̊ u m e ~ b a ̈ n g t . ~ D a d u r d ~}$ werben aber nut Gallweipen übertragen, weld)e bie Gröpie der Feigen anitecten, woburd) fie fid) weniger, die Feigen Dagegen befto mebr uno idneller entwicfern.

Íbophraft und Plinius legen wirtlid den Pflanzen ein (Befislecht bey, wenigitens $c a$, wo fie von ben Palmen

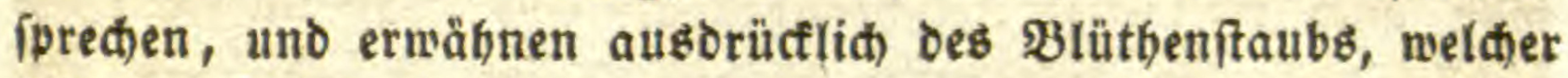
fid) mit ben Fruthtbåumen vermåble; obne oiejen- Borgang blie: ben fie unfrud)tbar. 2llein biefe 2(euferungen waren nid)t bit= länglid) beftimmt, giengen niđt auf bas ganze Pflamkenreid) äber und wurben aud) nidit weiter beactet, auser bin uno wieder von Dichtern, wobey man aber Die Gadie auth bloß

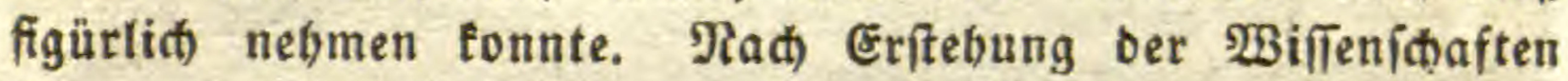
famen biejelben 2 teuferungen über bie Palmen zum Borfthein; aber erit Eesalpin fprad), 1583, von bem getrennten (5ies (d)lect)te bey nod) andern Pflanzen, wie bey unjerem \&aubbolz.

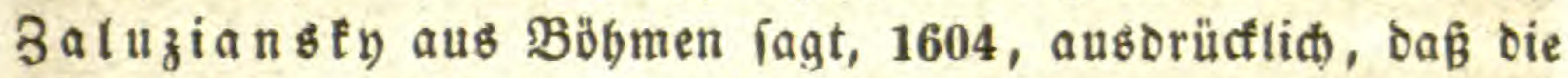

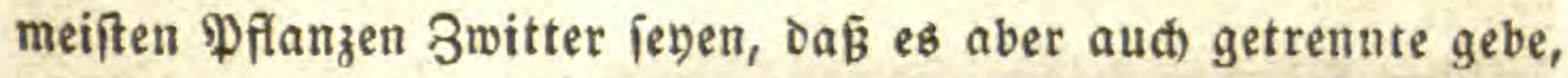
wie bey den Palmen, nennt aber weder andere Pflamien now beftimmte Iheile, uno fegt ausoritctich) bey, man nenne aud) Die färtêen Pflanzen Die männlidten, wie benm Şanf, wo aber Der ftärfere befanntlid) ber Samentragende ift.

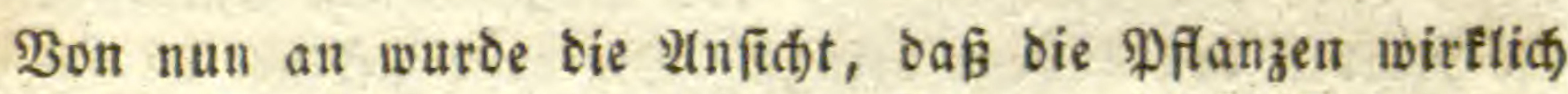
ein (jejhlect)t haben, uno daßj ben Blïtben dieje Bebeutung jufomme, fo allgemein, baßs niemano mehr daran zweifelte. Einne betradtete baber bieje Theile ber Blütbe, nebmlid bie Staubfäben und die Griffel, für die wid)tigiten Iheile Der \$flanze, und gründete barauf, $\mathbf{1 7 3 5}$, fein Pflanzenfyitem, welches er beßs= balb Sepual=Syifem nannte. Die Staubbeutel, als bie withtigiten, bienten ibm zur oberiften Eintheilung, nebmlich ber Elafien; oie (5riffet zur nädften Unterabtheilung, nebmlich ber Dro, nungen; Blume, Seld, Capiel uno Samen benukte er ju

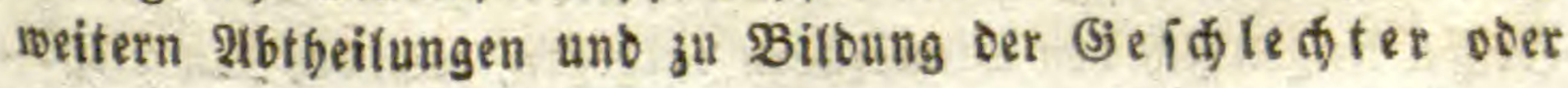


Eippen (Genera); Theile bes Stocts, bejonbers bie Blätter, ju Beftimmung Der (5) attungen (Species).

(5) rünoe.

Seit biejer Zeit hat faft niemand mebr am (jejhledte ber Prlanzen gezweifelt; man bat and fo viele Gritinde bafür, bas Einwendungen faum möglia) iđeinen. 2tbgefégen yon bem uralten (jebrauch, Die Dattelpalme fünfticic) zu beftättben, hat man aud) vielfältige (Erfabrungen gemad)t, baß andere zwey= bäuftige Pflanzen unfruchtbar bleiben, wenn fie weit von, eins anber getrennt find. Neist man ben Staubhanf aus; ebe er geftäubt hat, fo jeb̧t ber andere feinen Samen an; bie italia: nif́ce Pappel trågt in Deutíchlan feinen Samen, weil mur eine weiblidie Pflanze über bie 2 then gebracht wurbe, von ber man alle anbern burdt) Stectlinge gewonnen hat; baffeltbe gefdieht mit ber Trauerweide.

Bẹ einbăufigen Pflanzen mađte man biejelbe Errfabrung. Sdneibet man bem $23 e l i d f$ forn bie Riipen $a b$, fo tragen bie solben leine siörner; baffelbe erfolgt, wenn man bie Staubs beutel ber 3witterblumen wegnimmt, uno baber tragen auth gefüllte Blumen Eeinen Samen, wenn fid) alle Staubfäden in Blumenblätter verwanbeln. 2(ud) wenn bie (Sriffel abgeídnitten werden, bleibt bie Capjel leer. Ein Şauptbeweis enolid fïr Dieie Fortpflanzungsart ift bie Entitehung von Baftaropflanjen, wenn man ben Blitthenjtaub von verifjiebenen (Sattungen auf bie Rarben von anbern bringt. Die netre Pflanze ift ein Mits teloing zwijđen ben ältern, uno febrt bey fortgejester eigener Beftäubung balb in bie eine, balo in bie andere Gattung wies ber zurũct.

Dału tommen noch die Borgänge ben ber Beftäubung felbif. Die Staubfäben thun alles Möglidee, um ben Staub auf bie Narbe zu bringen, uno bieje, um benjelben zu betommen. Son

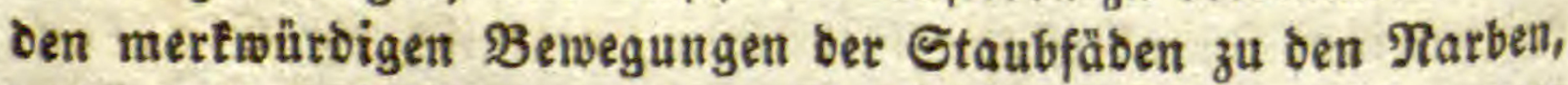

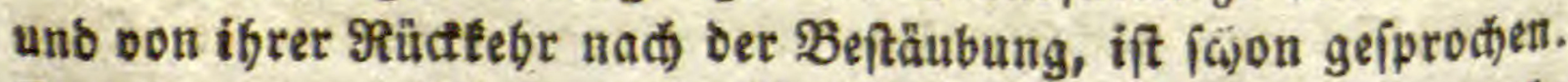
Das tann man faft bey allen Blüthen beobaditen. 2(tud) mande Orriffel neigen fíd ben Staubfäben entgegen, wie bew ben \&itien, 


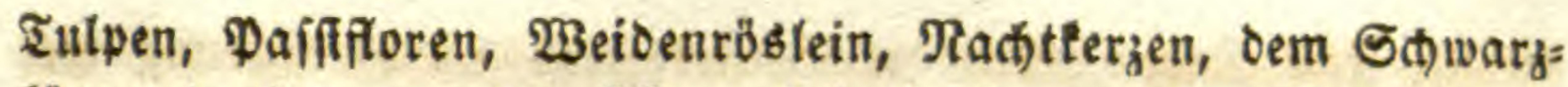

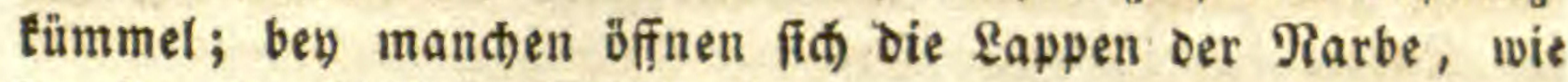
bey ber (5autlerblume (Mimulus).

In Der Regel rufen aud) Staubbeutel und Rarben zu gleider Zeit, felbft bey ein = uno zweybäufigen Pflanzen; aud fino meiftens bie Staubfäben jo geftellt, Daß́ ber Etano leiकht auf bie Narbe fallen lann. Bey aufredten Blumen fino fie gewöbnlich) länger alв ber.(jriffel, bey Gängenden fürzer; bey einbäufigen Pflanzen fteben bie Staubblumen meiftens Göber,

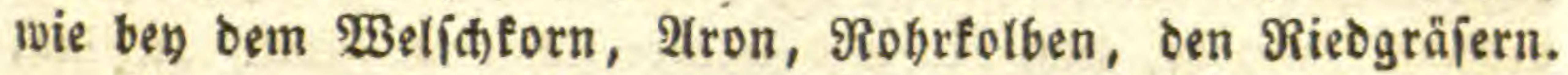

Bey ben 3witterblumen, Deren Staubfäden uno Griffel gleid) bod) find, io wie bey ben zwengåufigen, wo bie Staul= uno Samenblüthen weit von einander entfernt fteben, bilft WBino

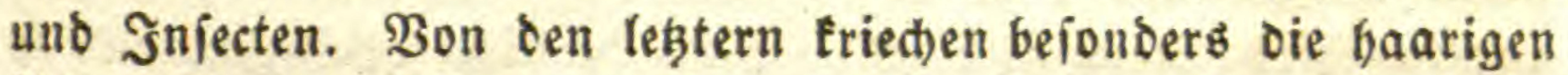
Bienen in ben Blumen umber, und ftreifen ben Staub auf ben Rarben ab.

Es gibt inbelien auth mande Sdwierigleiten für bie Ueber" tragung bes Staubs ouf bie Narbe. Seieber gebört vorż̈̈glid

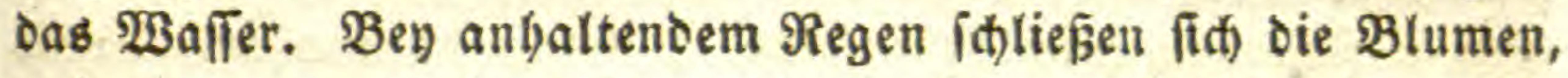
uno wenn er zul lange bauert, fo leken fte nidit an. Die Wafferpflanzen wiffen fich jedod zu belfen. Sie blüben faum unter bem $\mathfrak{B a f f e r , ~ i s m b e r n ~ b e b e n ~ d i e ~ B l u m e n ~ m e i f t e n s ~ o u r d ~}$

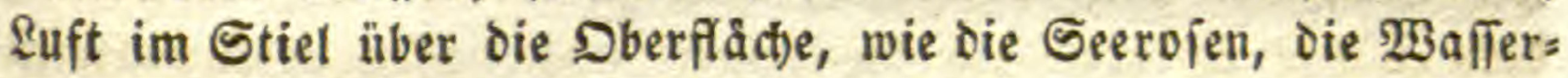

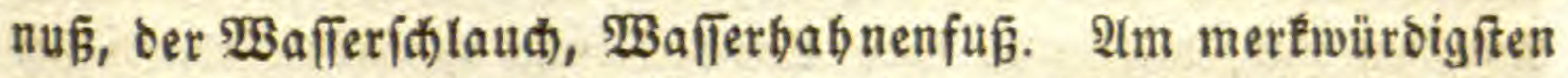

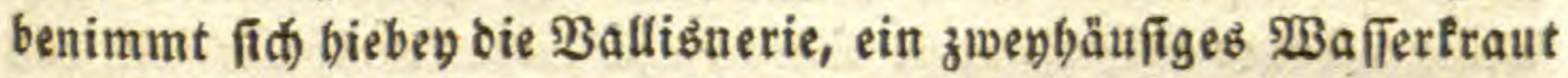
im fiibliden Europa. Die Samenblume erbebt fidh auf ibrem langen Stiel an bie Dberfläde bes $\mathfrak{W a}$ affers; bie Staubblume Dagegen reist won ibrem furzen Stiel ab uno idimimmt auf ber Dberfäd)e berum. शad) Der Bejtäubung zieht fid) Der lange Stiel wieber in Spiralen und fintt unter. Soldfe 21nftrengungen ber beioen Bläthen, um zufammen ju tommen, gleidhen fo aufs

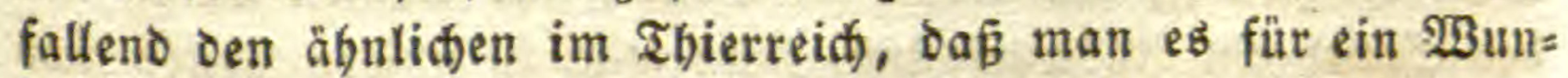
ber erf̂lären milß̨te, wenn fie nicht biefelbe Bebeutung bătten.

Sdwierigêeiten endidí) maden bie Staubbentel ben den sinab = uno Sdjwalbwurzen, wo ber Staub wadbartig an einander bängt, uno baber nidbt berumfliegen faun. İ! 
Diejem Fall fiteben aber die Beutel jelbit in Berübrung mit Der Narbe.

Dieje Umitånbe riefen bin und wieber Zuweifel über bie Rotbwenoigkeit Der Beftåubung bervor, uno mitfin äber bie Bebeutung Der Blüthentbeile unb ibrer $\mathfrak{B e r r i d g t u n g e n . ~ M a n ~}$ ftellte baber Unterfud)ungen an, ob es wirffict) feine Btïtbens pflanzen gebe, beren Samen fích aud otjne alle Beftäubung entwidfeln fönnten. Spallanzani ionderte Eamenpflanzen von Stanbpflanzen jorgfältig ab, namentlid) Şanf, Spinat, uno

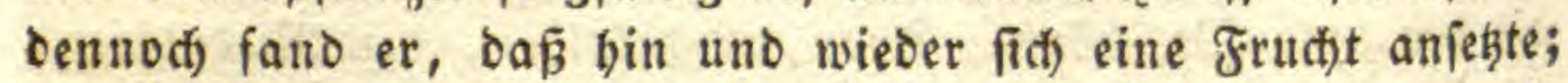
ebenio bey ber einbäuftgen $\mathfrak{B a f f e r m e l o n e , ~ n a d b e m ~ e r ~ a l l e ~ S t a u b = ~}$ blumen entfernt hatte; felbft bey Swittenblumen, Deren Staubs fäben weggenommen wurben, wie begm Baftlicum. Bielen andern Beobaditern find jol(t)e Beriuthe nidit gelungen, und es

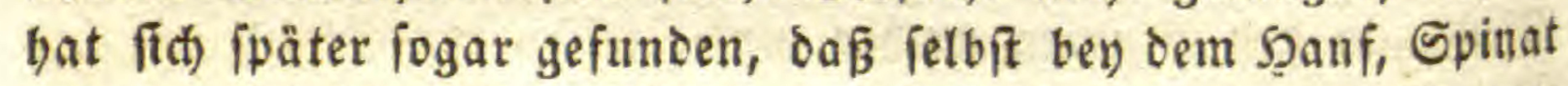
uno ben Sïtrbien Stanbblïthen auf ben Samenpflanzen bin und wieber vorfommen, welde wahrideinlid) Spalla nzani iber: ieben hat. Wenn aber aud wirflich fich einmal ein Samen obne Beftäubung entwicfeln jollte, fo folgte baraus noh nidts gegen bas (jeid)led)t der Pflanzen, als bey weldten bie Entwidelumg Der sinoipen fo alfgemein vorfommt, von ben vielen ftaublofen PFlanzen, wie \$ilze u. Dergl., nidft zu reden. Da bie Samen Dod) nidsts anderes als bie lebsten unb oaher verfümmetten snoipen fino, weldhe zu ihrer Entwictelung ber Einwirkung bes

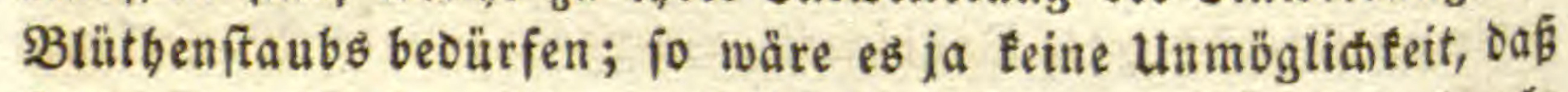
jold) eine sinoipe fidi) von felbft fortbilbete, vielleidits baburh,

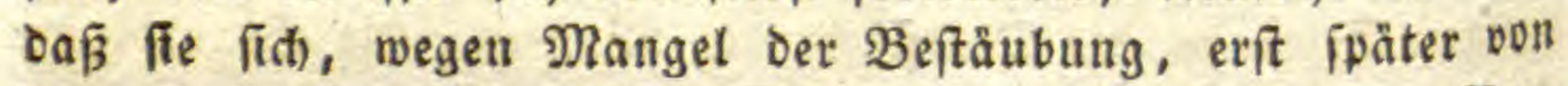
bem Samenlod) (Micropyle) ablözte. 23 enigitenz bat man $\mathfrak{B}$ en:

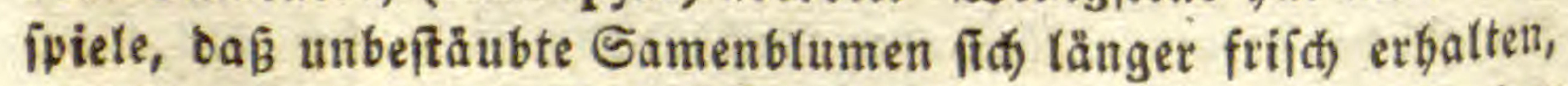
gleiafjam, alß wenn fie auf bie Beftäubung warteten. 3 แt oet alten Meynung, als wenn die Beutel nur Drüjen wären uno Der Staub ein 2tuswurfsftoff, tann man in unjern Zeiten, wo man feinen merf̌uüroigen $B$ au uno jeite nod) merfwürbigere Thätigfeit fennt, nid)t mebt zurüctebren.

Betrad)tet man nun ben Borgang bey ber Beftäubung, fo

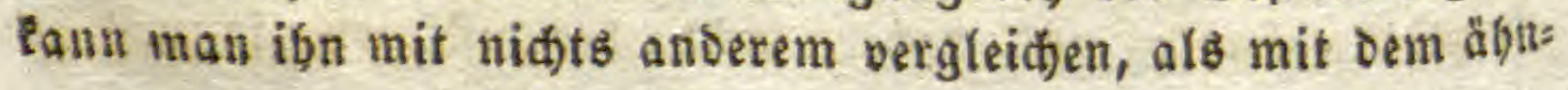


lidben Dorgang im Thierreid). Die Entwidtelung Des Rorns,

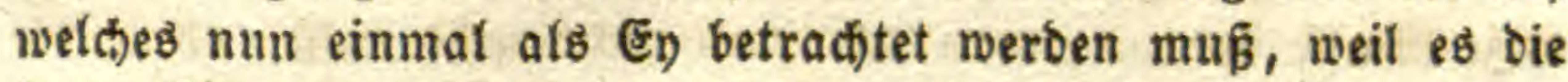
junge Pflanze entbătt, wirb beftimmt ourd) bie Einvirlung bes Blütbenitaubs. Es tragen alí bier zwey Snbivibuen zur ફ̧er= vorbringung eines britten ben; unb bas fann man bod) woht

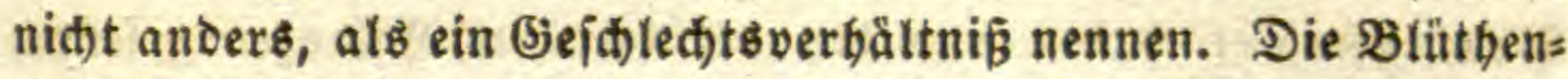
theile jelbit find aud ebenio vertheilt, wie im Thierreide, wo eł nicht minoer 3 witter gibt, einbäufige uno zwenbåufíge, nur

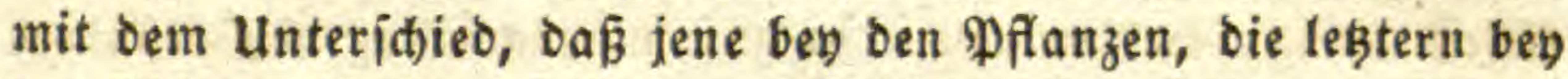

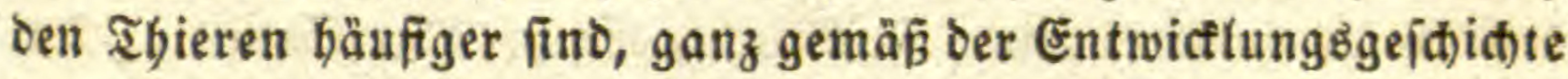
Der organifiden Reidje, nad) weld)er alles fid) zu trennen firebt, was auf eine böbere Stuffe gelangen will. Je böher bas Thier, befto böber bie Trennung; von den fliegenden Iniecten an gibt es feine 3witter mebr. Selbft im 9 flanzenreidee fteben bie zwenbäuftgen Pflanzen, nađ) meiner Heberzengung, in ben bö(fften Claffen, obicton man diefe $2(n$ fid)t nod) nidt will gelten laffen.

B ễ å ubu ng.

Die Staubfäben uno Beutel fino nidit bló bie jarteiten Drgane ber Pfanzen, jonbern zeigen aud) Erítheinungen, welde man mit ber $\Re e i_{z} b a r f e i t$ im $\mathfrak{s}$ bierteid)e vergliden bat, wenn gleid) biefelbe nid,t anf Rerventbätigfeit berubt, fondern blok auf Der bes వellgemebes, ungefähr fo wie in ten bäutigen Drganen ber Iffiere, Des Darmeanals u. Dergl.

Der Blüthenftaub beftehs, wie idon früher bemertt, aus Sügeldten, welche ganz frey in bem Beutel liegen, alio nie ein Saft abgejonbert werben, und nidjt, wie fleine snojpen, mit einem Stiel berworwadjen. Jedes Staubforn ift von zmo Şäuten umgeben, wovon ởe äusere irgenowo ein \&od) befommt uno bie innere ober beren gallertartigen Saft Gerausläß̧̈t. Der Gaft felbft entyält wieber viel Eleinere Sörperchen, welche man Duft (Fovilla) nennt. unger bat gefunden, daß̧ dieje Rörper=

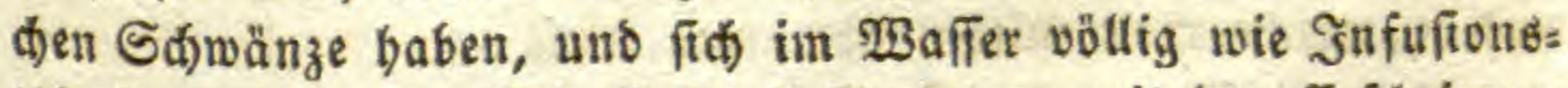
thierdien bewegen. Die Uebereinftimmung mit ben Erítheinun= gen im abierreid) fann baber nid)t gröber fegn.

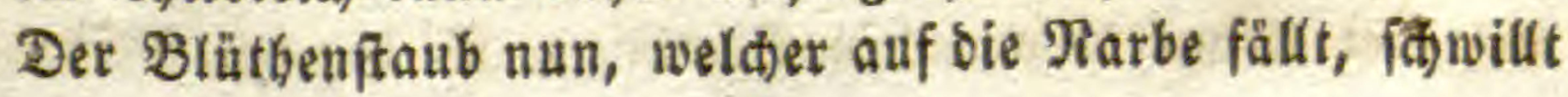


in ber bortigen fendtigleit an, plaķt uno läf̆t eine wurffför: mige Maffe beraus, won ber man nidst red)t weis, ob es bie innere Şaut felbft ift, oder nur ihr Innbalt. Dem fey nun wie ibm wolle; es bildet fich eine 23 urfit, welde zuerit $2(\mathrm{~m}$ ici, 1823, beobadtet bat. Robert $B$ rown ano 2 loolpb Brongniart haben nun bey veridiedenen Pflanzen gejeben,

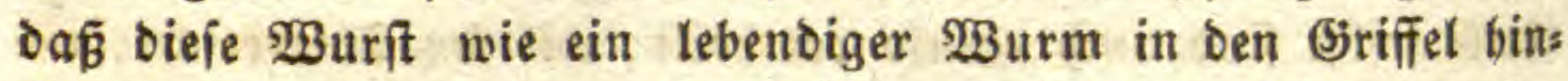
einoringt, uno zwiíd)en belien Zellgewebe, nid)t in feinem natür:

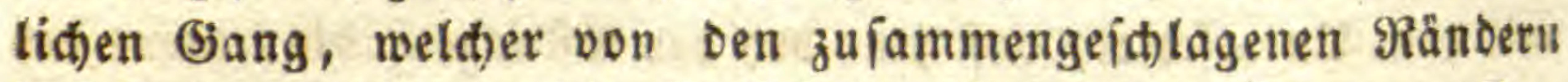
bes $\mathfrak{B a l g}$ ge gebildet wird, fortêtiect)t, biß zu dem Samen. Da: felbit glaubte man nun plaz̧e die $\mathfrak{Z}_{3}$ urft uno laffe ben Duft beralls, modurd) bas Zellgewebe des Balgs angeregt weroe, mebr Säfte dem Samen zuzufübren; oder biejer werbe felbft baourd) beftimmt, ben Saft einzulaugen uno fid) zu entwicteln. Eorba, Saleiden und 2 . Treviranu faben endid die \$urfí in bas Samenloa) (Micropyle) oringen, uno alio uns mittelbar auf ben Samen wirfen.

Endlid trug $S$ d)leiden bey Der Berjammlung ber Raturs

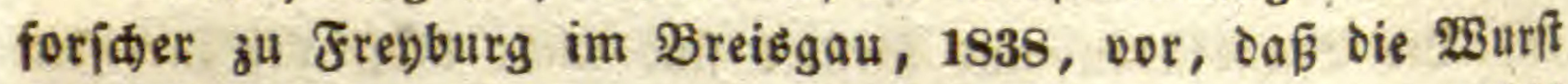
felbit fith in Den Reim verwandle, und der Same vaber nidts anderes fey als ein Iragfact, worinn fid) Die junge Pflange ent: miatle. Die steime lägen alio uriprïnglid) nidbt in ber Eapiel, fonbern in ben Staubbeuteln, uno dieje mülîe man als bie

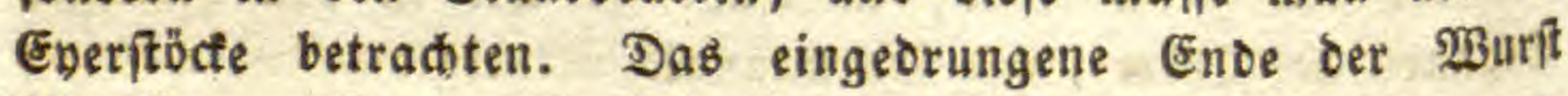
falwelle zu Samenlappen an, uno ber Sathanz werbe zum WBürzelden. Diejer Meynung traten $\mathfrak{W} y$ oler uno Enos Ii der, ebenfalls auf eigene SBeobactutungen geftïbt, bey. Der

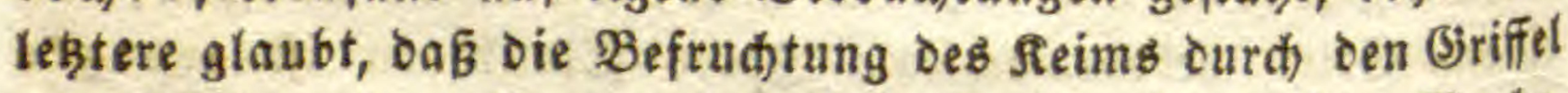
vermittelt werde, aljo etwa ourd bie Feudtigfeit auf der Rarbe. Sold) eine neue uno bödif unerwartete Sehre fonnte nidt alls Dexs als bas größte 2tuffélen erregen. Sie wiro ofne 3weifel eine groß̧e Igătigfeit in microfcopifichen Beobadtungen bervor" rufen, welde man mithin abwarten mús.

Uebereimftimmeno mit diejer 2(nfid)t fübrt man bie umges Pebrte Rage bes fieims im Samen an, uno Das Sortommen mebreter feime in mandjen Samen, 3. 25. bey ber פiftel uno 


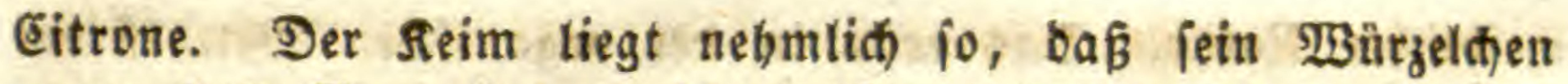
gegen bas Samenlod geridtet ift, utio jein sopf ober bie Samenlappen gegen ben Stiel bes Samens, alio verf́ebrt: benn

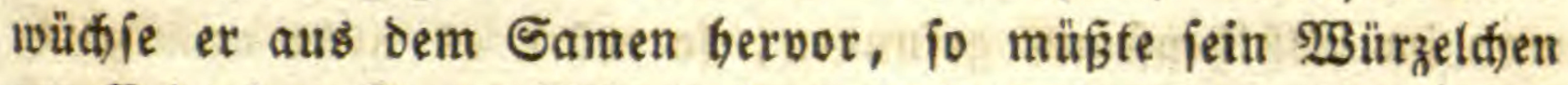
am Ende bes Samenftiels fteben und fein Sopf am Samenlod) liegen.

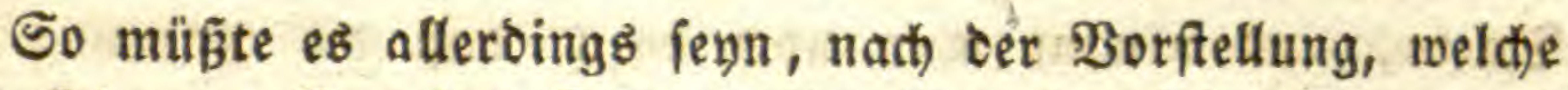
man fith vom Bau bes Samens madt; aber feineswegs nach ber meinigen, welthe id) Seite 80 entwicfelt babe. Der Same ift tein oben geöffneter Bedfer, fondern ein eingerolltes Blatt, wie ein Farrenblatt, weldes das Samenlod) an feiner Spize bat, aus weld)er ber Seim uriprünglich) bervor wächst, uno feineswegs aus bem Ënde ठes Samenftiels. Das Reimwürzel: (hen, weld)es fich ipäter, wabricheinlich burd) ben Einflus bes Blüthenftaubs, nebmlid) des bis zu ibm oringenden Duftes, abtöst, mußs baher nothwentig gegen das Samenlod) gerid)tet ienn, ober verfebrt gegen das Ende des Samenftiels, nebmlid Den Rabel leben. In Der Lage Des Reims fomrat baber nid)ts vor, was für die oben gegebene 2(nfitht fpräd)e. Was bie Pehrzahl ber Seime in mandhen Gamen betrifft, io ift es ja nidt unmögliđ, daß̧ ben manden splanzen melorere finoipen aus ber Spize bes Samenblatts wadfien. Bor ber Şand wollen wir alfo ben ber alten Mennung bleiben, weldhe über= bießs das ganze abierreid) für fich bat, wo bie feinften und ges naueften Beobadtungen die uriprïnglide Entiftebung bes feimes

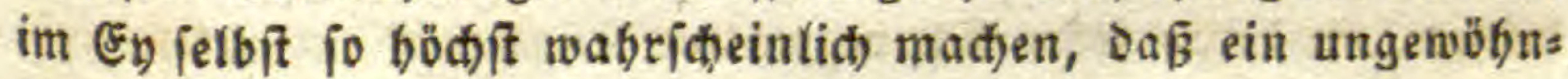

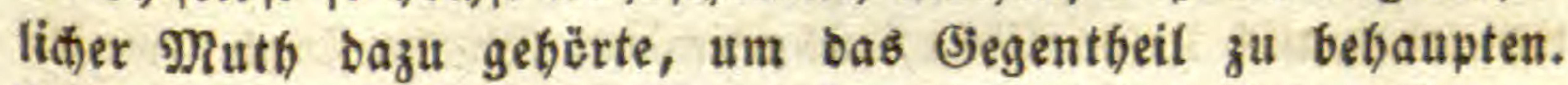
2(lleroing baben bie jogenannten Samen ber blütbenlofen Pflanzen groge 2tegnlidfét mit bem Blütgenitaub. Sie fino aber Inoipen, weldhe fid im inbifferenten Stod entwicteln, obne einen Giegen= fab; bie Staubförner aber fino suofpen in ber bifferenten Blütbe, uno baben ifren (jegenjaks in andern snoipen, nebmlid) ben Gamen. Beide fino baker nut balbe Rnoipen, welde fidi nur Durd) Bereinigung wièer ergänzen föntren. - 2(ud) biejenigen Ibiere, welde fíd bló aus Enern fortpllanzen, wie bie Po:

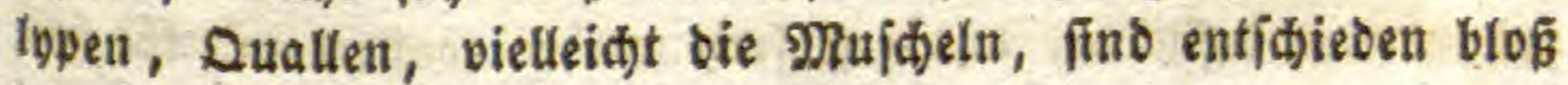


weiblidfer Ratur. Dak erfte in ber organifiten Melt ift ein

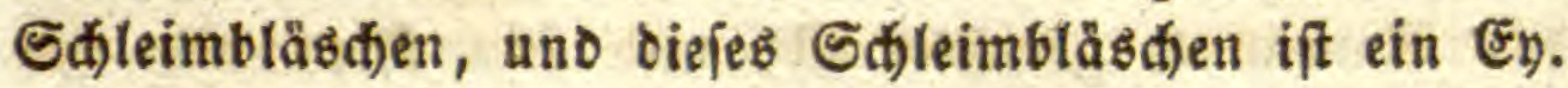

sebren wir nun zu ben Эnfuffonstbierchen jurüa, weldbe man im Slütbenftaub gefunben, fo wäre eళ nidtt unmögliक), Dó bie jogenannte $\mathfrak{B u r f i ́ t ~ f e l b i t ~ n i d b t s ~ a n d e r e s ~ w a ̈ r e . ~ D a n u ~}$ wäre der Beftåubungsact ber Pflanzen ganz gleí, bem ber Ibiere, uno nimmt man noch baz̆lt, baß̧ bie Jjäbrung nur Durd) Şefe berworgerufen wird, uno die WBirtung ber Şefe felbft nidfts anderes ift, als ibre Berfallung in unenolid) viele mictos fcopifote Pflanzen, welche in Der ganzen gäbrungsfähigen Maffe šbnliche bervorbringen; fo wiro es immer flarer, baj alle Er: zeugung von treuen (jefd)öpfen einerlen ift mit ber Urerzengung

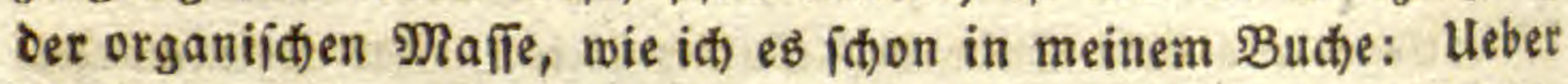

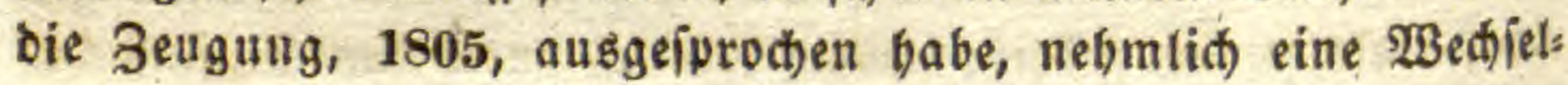
wirkung von mirtlid, lebendigen $23 e j e n$, wovon bie einen iton tbierifde Bewegungen baben, wie bier bie Staubthierden; bie andern aber, nebmlid die Eyer ber Thiere ober bie Samen ber Pflanzen, biefe felbffttändige Bewegung erft erbalten ourd) oie Einwirfung ber eriteren. Die Stanbtbierdien fino bie Şefee welthe ithon in lebentige Grunomaffe zerfallen oẹ gåbrungs: fäbigen Maffe ठев Dotters oder Des Samentorns, oder viels mehr oes bereits darinn entworfenen Seims bie gleidje \&ebents: bewegung ertbeilt, welche aber, ba fie bier bereits in materielle

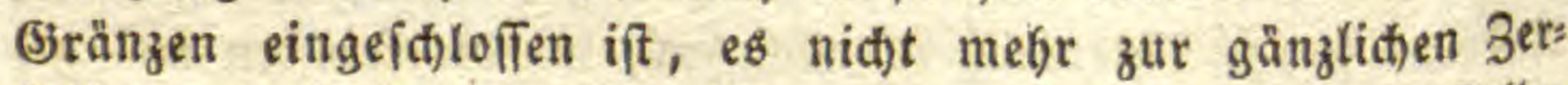
fallung in Infujorien, fondern nur zur Bildung von Zellen bringt, in beren jeoer fith) vegetative Rägeldhen entwicteln, z $^{\text {th }}$

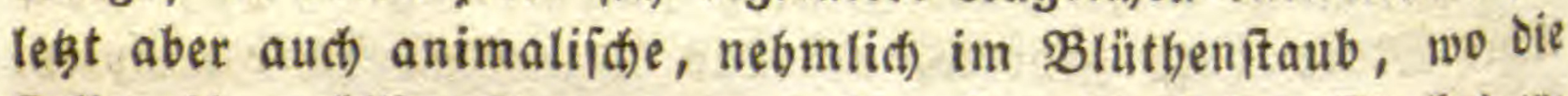
Zellen ibre völlige Trennung von ber Seerriftaft bes Stocteb ets reidit baben.

2lle Entitetung bes organifhen ift ein infujorialer proces, worian fich Thiere uno Pflanzen mit einander vermåblen; uno jeder nette Drganismus, fey er Pflanje ober Thier, ift nidfte ans Detes als eine 2unhäufung von Infujorien, nid)t von foldten,

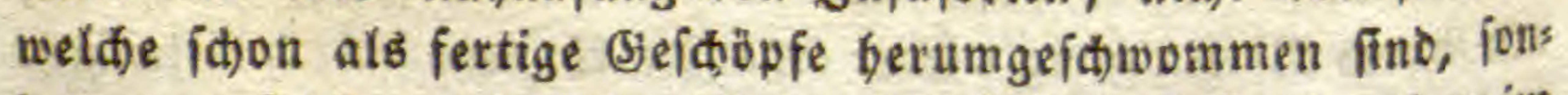
bern von folden, bie fich nod im follafenden 3 uftande oder im gebundenen befinden, uno erif frey werben wollen unb tonnell, 
nađbem fie wäbreno beß \$ađstbums eine Şülle nach ber ans bern abgeftreift haben. In Der offenen uno beleudteten Blume werben fie ganz frey im Sliatbenftaub; in ber veríblofienen finitern Eapiel bleiben fie oagegen gebunden, bis jene fid) mit ibnen vereinigen uno fie ourd) ibre raftlofen Bewegungen uno Reizungen aufwecter. Das geidiebt wobl ofne 3weifel ourd) Sherworrufung einer Polaritåt in ben Bellen oder Säften bes ริorni.

Man bat aud den Nugsen ber Blìtbenbüllen, nebmtid Des Reldbs, Der Blumenblätter uno ber Sonigorïjen benm $\mathfrak{B} e=$ ftäubungşgejđäft in Betrađtung gezogen. Daß jene das Maffer

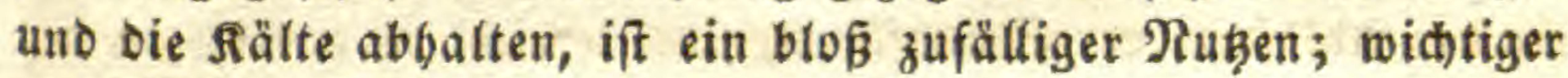
aber ifit ber ftarfe Berbraud) Des Salierítoffgajes Durd) bie ges färbten Theile, nebmliț die Blumenblätter uno bie Staubfäben. Jm Fimitern verzebren dieie meiftens nod) einmal fo viel, als die Blätter, 子. B. acht Theile, wenn jene nur vier; uno es ent= ftegt eine entiprechende Menge Rohleniäure. Şieraus folgt alio, Daß̧ Die gefärbten Theile mehr Rohlenitoff verlieren, uno Daber wäfferiger, ih)leimiger und zarter werben, mithin güntiger für bie enolide Tremunng ter Sellen oder Staubtörner in Den Beuteln, io wie des Reimpulvers in ben \$ilzen, Mtopien u.f.w. Die Blumen fund Daber nicht bló̧ eine Bierde Der Planze, jondern baben mirtlid ein (jejhäft, nebmlid bie Stoffe z" entzieben, weldie die infuioriale Maffe gefangen halten.

Mit bieîem ftarfen Berbraud Des Sauerftofigajes fheint auch größere Bårme= Entwicfelung verbunben zu feyn. Man

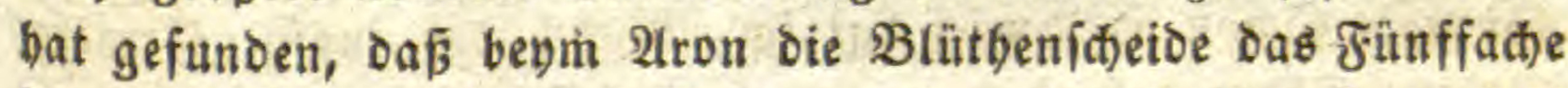
ibrer (jröge von Sauerftofigas verzebre, der Rolben jogar bas

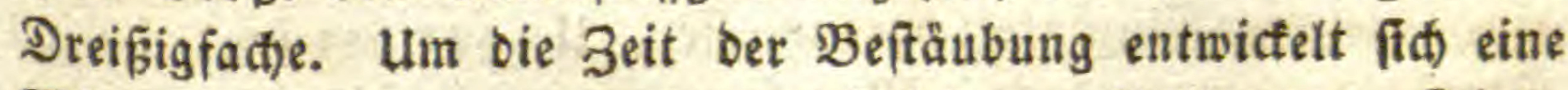
Wärme, welde, ie nad) ben veridjiedenen (jattungen, fieben,

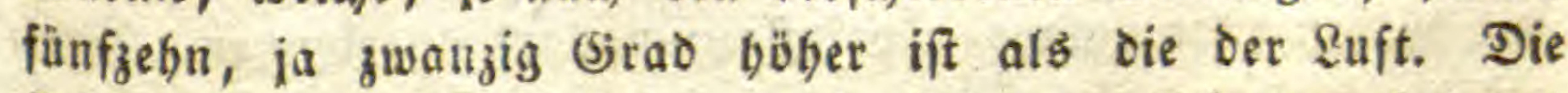
Eridjeinung ift aljo Diejelbe, welde fid) benm fieimen zeigt, mo ebenfalls bie Bärme nur bemertbar wirb, wenn viele Samen benfammen liegen.

Die Şonigbrilfen jonbern igrerieis ben 3ucfer ab, auf baß Das Mebl in ben Gamen rein eríheine, uno fino mithin ein 
An fab von frucht, morinn fith Die falzartigen Theile fammeln, wie bie Säuren uno der überfluifige Sd)leim in ben 2tepfeln und Beeren. Seber Theil hat baher feinen Ruken und fein

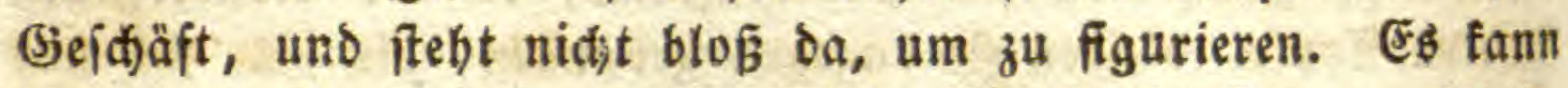
überbaupt in ber organiijben Belt eein Ibeil fidt) entwiteln, Der nichts thut. Er zeigt fid) entweder nur als Uebergangsglied zu einem anbern ऽrgan, oder als 2lbfitreifung beffielben, Damit fein Procés rein bargeftellt werben tönne. Man fann jagen, die Blumenblätter fin ber erifte 2nfang ber Staubbiloung, utto fie iegen ibren mişlungenen Staub als Farbenmebl ab; nad) uno nad) näbert fid) ber Staubbildungsprocé mebr jeinem Biefe in ber Ablöiung Der Staubfäden, uno erreicht es endidid in ben Benteln. Ebenio regt fíd) Die Samenbildoung in Der Ent:

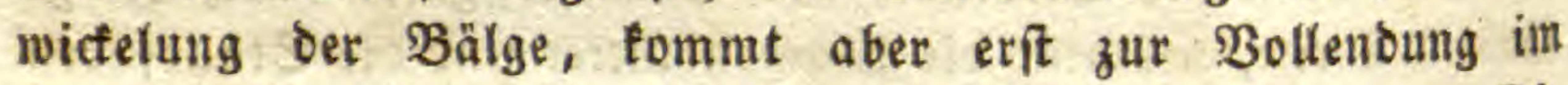
Serwortreiben igrer Ranbênofipen, nebmliab der Samen. Die Blumenblätter find Der Reib Der Staubbeutel, uno bieje feine Drííen: fo fino die Samentörner die Drüien der Bălge. Ë ift baher alles eins, uno nur bie Stuffe ber Entwidtelung if verídieden.

\section{Beftäubung Der blätbenlofen pflanzen.}

Bey ben jogenannten Eryptogamen oder blütbenlofen Pflans zen, beren Capicl, wie id gezeigt babe, ber Gamen jelbit if, alio ben ben nactiamigen Pflanzen, findet man, mit 2 usnahme Det Moofe, feine Iheile, welde man für Stauborgane ausgeben fönnte. Saton Şeowig bat im $\mathfrak{B}$ infel ber fnoipenförmigen Blätter Fäben gefunben, welche in ber Jeudtigteit plaß̧en unt

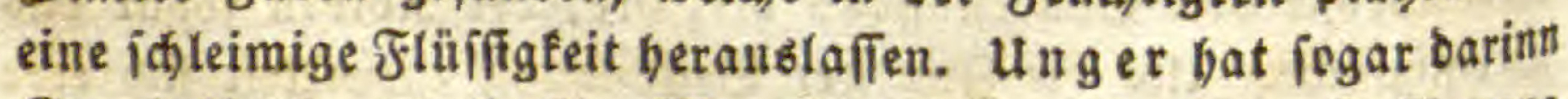
Gtaubtbierden entbect. Man fann baber bier bie erfte Regung zur böbern oder polaren Fortpflanzungsart anerfennen. IMerts witroig bleibt es aber immer, daß̧ bey ben offenbar böber ftebens Den Farren man nichts 2(ebriliches entbectt hat. Inderilen finben

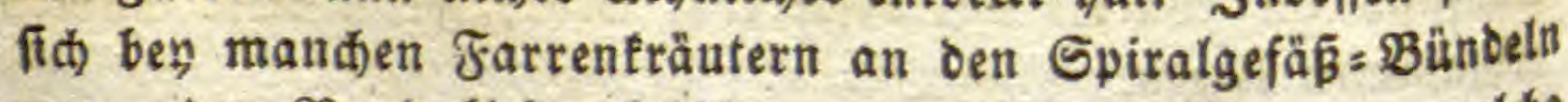
gegen ben Rand Eleine Şöblen mit gelbliđen särnern, weldte viefleidt Blïthenifaub fegn Eonnnen. 
Bey ben Fledten uno sangen finden fid nod zwenerlen Rörner, wowon bie fleinern vielleid)t bem Shlithenftaub ents jprecten. Bey ben pilzen fommt aber nur einerley 2 (rt von Sïrnern vor. Đas wäre alles ber allmäblidten Entwictelung ber Pflanze unb ibrer Trennung in polare Drgane gemäß. Die Pilze fino nod eine ganz inbifferente bellen= oder Pulvermaffe;

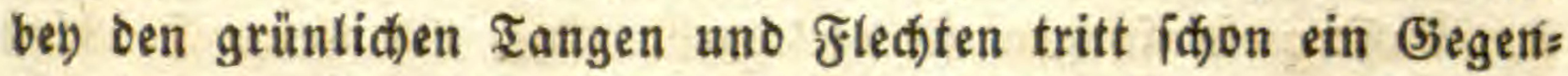
fak heroor, fowoht zwiíthen Stoct und Fortpflanzungsorganen, als zwifhen ben lestern felbift; bey Den grünen Moofen fheiden fie fich fófon befimmt in Samen oder fogenannte Eapieln unb in Fäben; bey Den Farren ebenfalls in folde Eapfeln uno sörnerbüblen, weldfe jeovd) nod) zweifelbaft find.

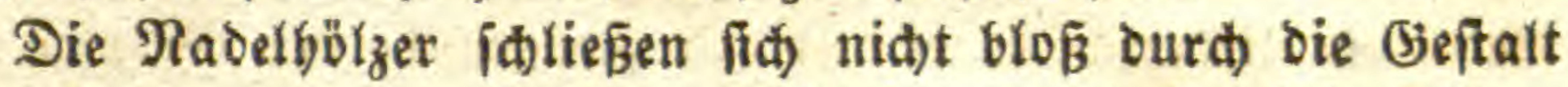
ihres Stammes, ibrer Aefte uno $\mathfrak{B}$ lätter, uno durd ben füm: merlichen 3uftand ihrer Spiralgefäße an bie Farren; fonbern auch auffalleno ourd ibre unbedectten ober capjellojen Samen. Sie baben aud) feine Blumenblätter, aber volltommene Staub: fäden uno Bettel. Da jedod) bie Stauborgane fid ídon bey Den äđten blütbentojen \$flanzen ober Ernptogamen zeigen, io

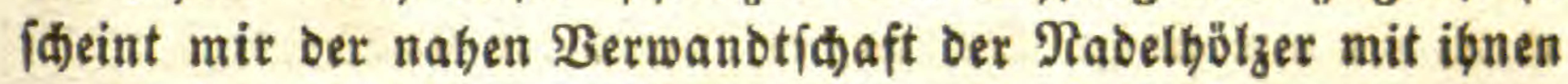
niकts entgegen zu fiteben.

\section{Reifung.}

Die SReifung bejiegt fidh auf bie ber Samen, uno des Bröpieg.

Gelten werben alle Samen befruchtet, was obne 3weifel Davon abbångt, ob ber Duft Des Blïthenitaubs zu allen gelangt,

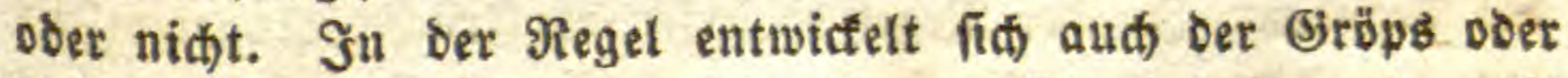
bie Frudt nidt, wenn gar tein Samen Staub befommt, wobl aber weun nur ein einziger reifen fann. Es gibt jeobd 2ubs nabmen, wie bey ben Irauben, der 2nanas uno dem $\mathfrak{B}$ rods= frudtbaum, wo bie Frudt fid) aud ftarf entwictelt, unb meis ftens fidmactbafter wiro, wenn feine Samen fid) anjegen. Ëbenjo gibt es febr viele Pflanzen, ben weldent regelmäpig mebrere Gamen zu Grunde geben, was aber größtentbeils ourd ben Druct von andern Samen veranlapt wiro. 


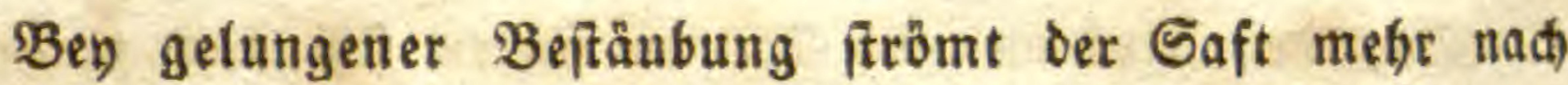
Dem (Sröps, weil burch) bie Belebung Des Samens ein (jegens

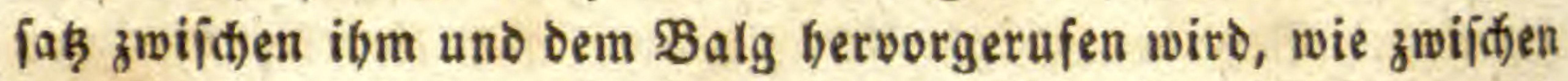
ber finofipe uno bem 3 weig, oder zwifhen oen Blättern uno

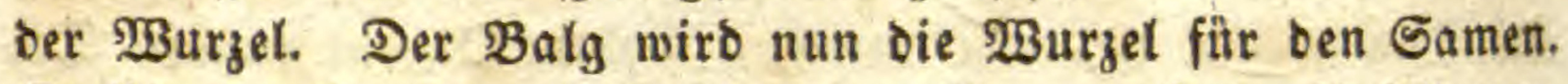
Stellt man 3weige mit Frtithten, \&. B. von einem $21 p$ felbaum,

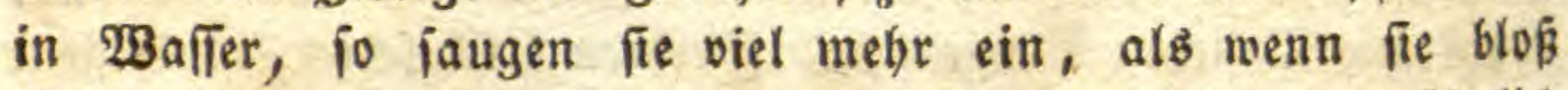
Blätter baben. Der Stoct der Rråuter vertroctnet gewwöbnlich

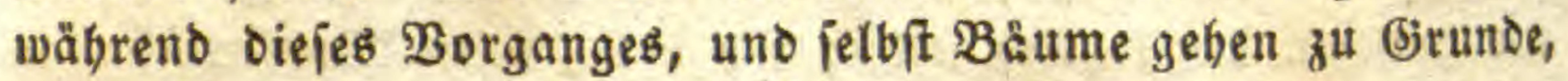
ober leiben wenigfteng, wenn fie übermäßig frildte tragett.

Der Erfolg biejes Saftzuflufies äufert fid) aber auf żwener: ley 2rrt. Es gebt entweder aller Gaft zu ben Samen, doer es

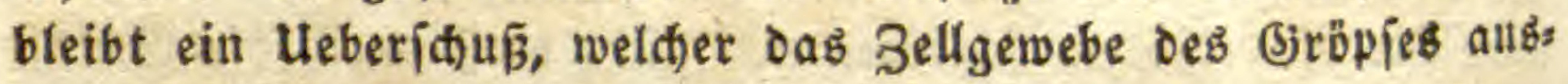
bebnt uno in Frudi)t verwandelt.

Das Reifen erfolgt in jefre verifiedener Beit, wie ben ben Shieren, uno man hat bie Gieję̧e bafür ebenfalls nod) ni(d)t

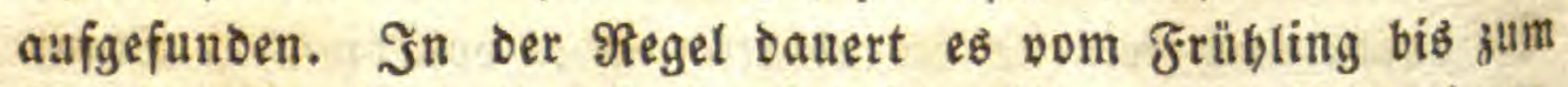

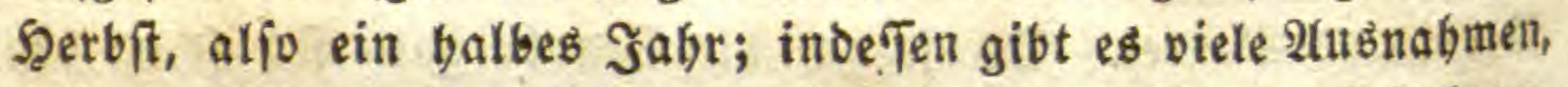
bejonders ben Den Sräutern, weld)e meiftens fürzere Beit braws:

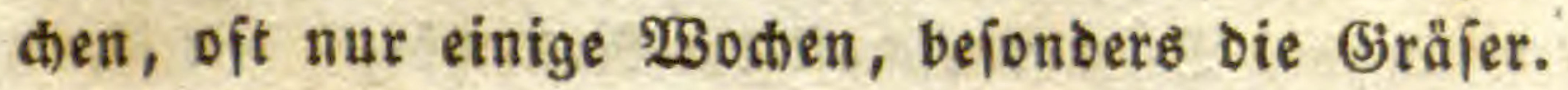

Dieje 3eit bängt nidjt von ber (jröß̨e des Gamens ab: benn wo fie flein find, eriekt gewöbnlid) die Menge die (jrö́re.

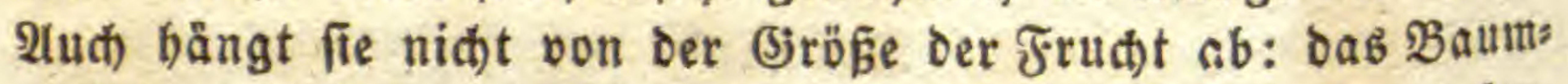
objit braudit faft ein balbes Jabr, währeno oie Sitrbjen, bejons Ders die Melonen, nur einige Monate nötbig haben. Die Riríchen werden früher reif, als bie Birnen, dieje früher alø bie 3 wetichen, biefe früber als bie 2lepfel, und bieje früber als Die Irauben. In Der Reget bebürfen bie Frtid)te längerer Beit, als Die Bălge ober Eapieln, die Tülfe ebenío mehr als bie Fleifđfrüd)te.

Es gibt indeflen aud Pflanzen, Deren Früd)te zur शeifung

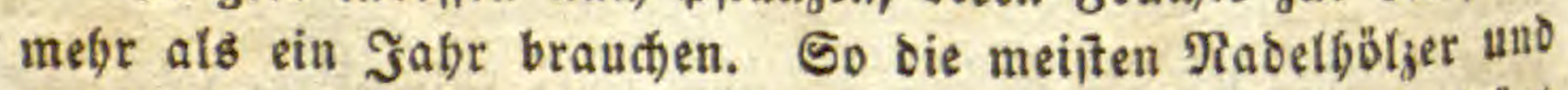
felbit die \$omeranzen. Der Unterichieo ber Temperatur trägt natürliđ aud viel baz̧u bey. In Spalierbăumen reifen bie

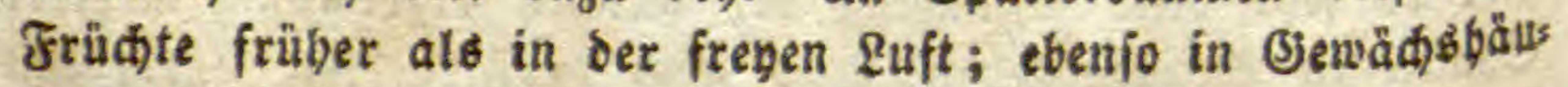
iern ober unter હાláern. 
Mran hat bemerťt, baf bie Gröpie mit Spaltmûnbungen, wie bie şülfen, biel frülyer reifen, als bie olyne biefelben, wie bey) unjern obftbäumen.

Die affgemeine Errícheinung nađ̆ einer gefungenen Bẹttä!

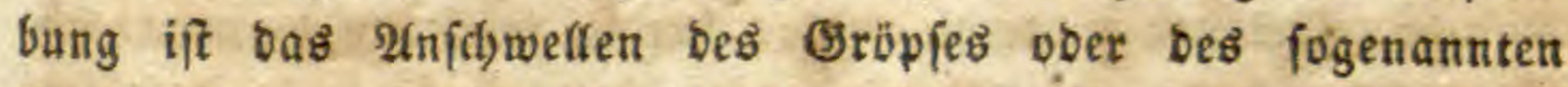

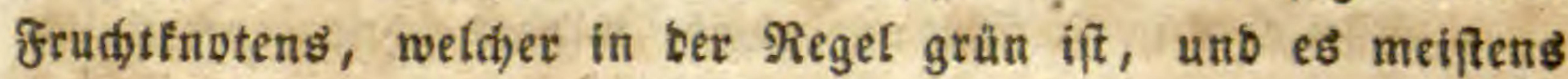
bleibt bis gegen die voflfommente Reife, wo er gewöbntid after. ten) Farben annimmt, wie bie B(ätter, bod) nod) zablreidgere, wie gelb, rotl), Glau, weíp, wie bey Der Gyerfrud)t (Solanum melongena), und felbjt fobwarz und geidäatt. Die faftigen Frtüd)te befommen meiftens eine gewifie Durdjitidigleit.

Die Farben Der Eröple ober Früd)te ftefen weder in $B$ e. ziefjung zu benen ber $\$$ Blumen nod, ber Samen; inbefien werben bie meiften lgäutigen ober troctenen Gröppie blof́ graulidggelb ober braun. Die Mandjfaltigfeit Der farben zeigt fidh nur bey

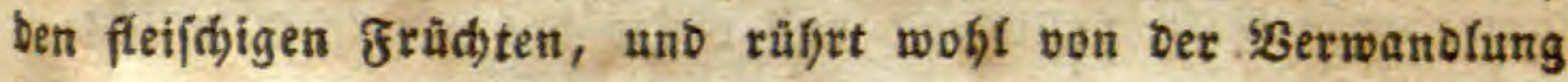
Der verídiebenen Säuren ber. Die rothen finb gern fauer, wie

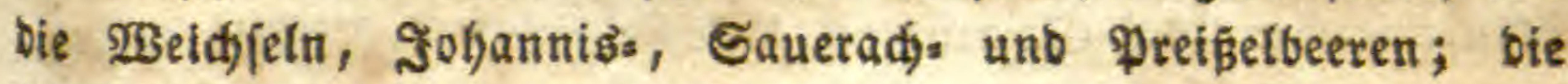
blauen ober fid)warzen gern füf, uno entbalten mithin mefor Sucter, wie bie Speibelbeeren, Pfaumen, Sd)warztiriden unb bie idgwarzen Sobannisbeeren. Snbefien Eann man nidgt aus ben

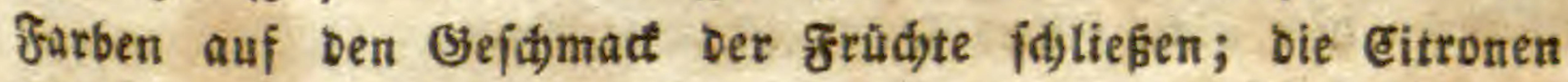
fino fauer, bie pomeranzen füs ben gleidher färbung; jebod) ift bier bie Defte nid)t unmittelbar bie bes Gröples. Heberhaupt fideint ber füse SEefdymat bey ben getben grüd)ten vormaltenb, wie bey ber 2tnanas, 2tpricofe, Stad)elbeere, ben Pfiaumen unb Iepfeln.

Bey anfjaltenbem Regenwetter werben bie frủdjte wäfferig unb fab; ebenjo auf jungen 8 äumen, wo fie zugleid weniger zahfreid) ex[dyeinen, weil bie Şauptnafyrung auf bie \$lusbiloung bes Stocts berwendet wirb. Eine gewiffe sroctentyeit if bem Reifen Der Früd)te zutrăglid, bejonoers wenn fie viel Melł! bervorbringen foflen, wie bas Cetraite; Den jaftigen Früd)ten if bin uno wiever ein Regen zuträglid, befonders bem IBeinftod unb ben Dbjtbảumen. Die Englänber baben bie Stadjelbeeren, 


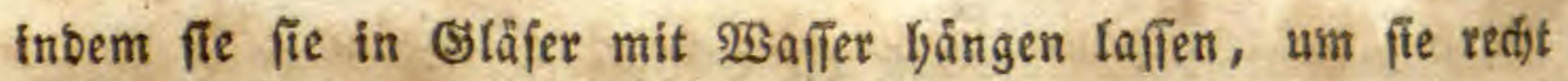
gró̋ zu madyen.

Die meiften gruid)te reifen nod nadh, nefimlid, nadbern fie vom Baum genommen worben, wie bic $2 B$ interbirneh, 2tepfel, MRifpeln, Melonen u. Dergl. Shre lgerben Gafte verwanbeln fid Dabey aflmähltdy in Bucter, unb zwar, wie eb (d)eint, vorzüglid) bef̧halb, weil fie teinen wäfierigen Saft mel)r befommen.

Jrüd)te, von Sonfecten angeftod)en, veifen früfjer uno werbent fïper als anbere, wie sirfdien, 3wetíchen unb Shepfel. Die Feige if zrwar nur ein fleijdiger grutbtboben; fie twirb aber aud) fräher reif, wenn iffe (s)aflwefpe bie Eyer in bie Eament regt, unb, wie malt befjauptet, felofi wenn man ben frudthtboben von 2 ufient anftid)t, wab aud) bey Melonen gefingen foll. (E) if Gier biejelbe (Eridjeinung, wie bey ben Galläpfeln, wo burd, bie Berwundung, bejonbers burdi bas beftänoige Ragett bet

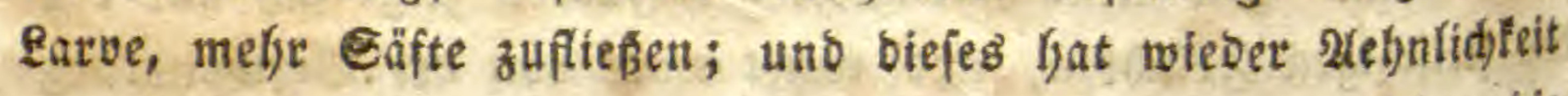
mit ber Beftaubung, wo ber Duft ber Etaubläner ober bie Staubthierdjen bas Samenforn beftảnbig zur Ifoätigleit reizen.

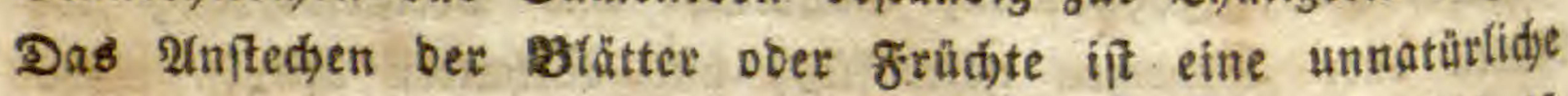

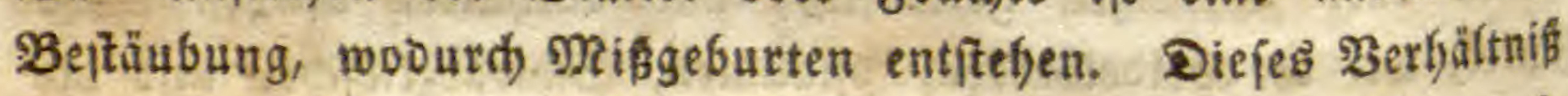

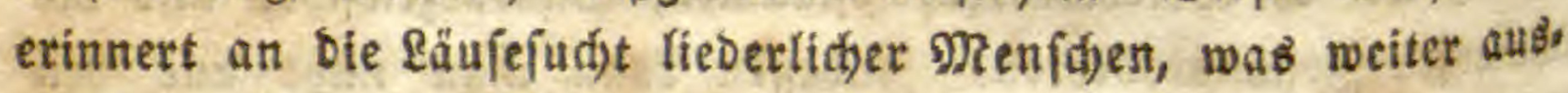
zufäbren lifer nidjt feines Ortes ift.

Ifud) reifen bie früdyte fdynefles, wenn man einen rings fidnitt unter benfelben in ben smeig madjt, wafridheinfidy weil fie fobann meniger Baffer befommen, moburty bas Reifen immet verägert wirb, inbem bie frud)t gleidjfam immer jung bleibt

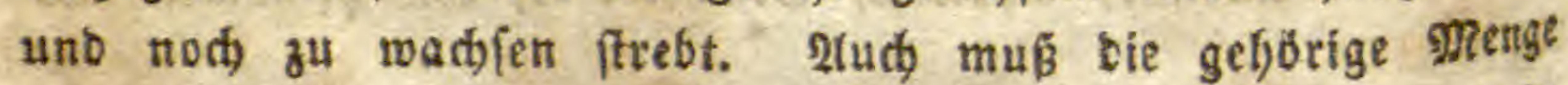

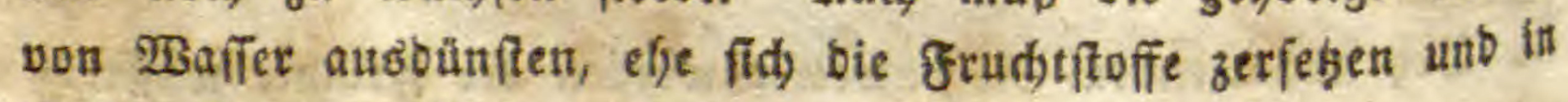
Bucter ober Delgl verwanbein.

Früd)te, weld)e viel vom winbe bin und Ger geidjauflelt werben, bleiben fleiner, ohtte sweifel weit fie melyr vertrodthen; baher merben fie an Epafieren gröger.

Es ift gewís, baß́ bie grủdyte im unreifen 3 utanb meljr গুSaffer enthalten al int reifen, und zwar ungefábr 10 \$rocent melys; umgelefyrt vermefrt fid um eben foviel ber suder, ofne sweifel auf Roften bes Ehleims, ber Eallert uno ber 


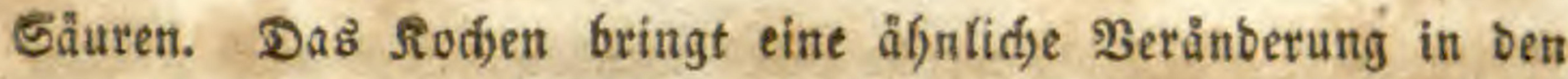

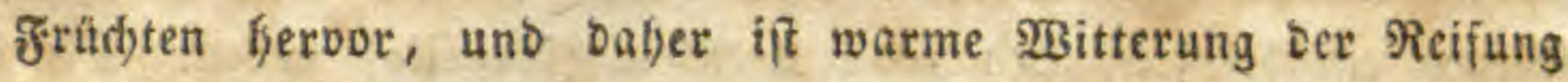
fo zuträglich. Serbe Früd)te, wie bie Mifpeln, werben ourd) langes Riegen fur uno teig wie getod)t.

\section{Reifung Der Samen.}

Iffe bieje Borgänge in ber frudt), nefmmlidy bie chemif́dyen

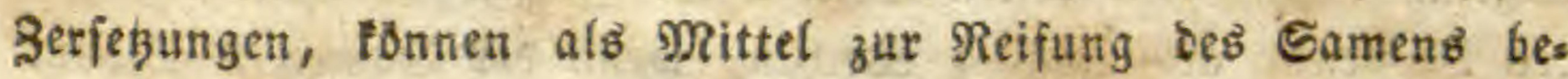
trad)tet werben, wie bas $25 a$ d)sthum bes Etocts, nefmlich Bers

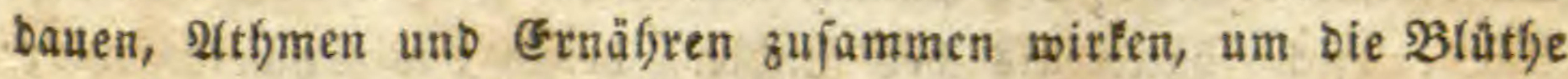
hervorzubringen. Soldje Umitänbe (d)einen jebod) nur nötfig zu feyn ben benjenigen \$flanzen, bie fleifdfrüd)te hervorbringen, b. h. gröbtentheils foldgen, beren Grïps vom seld umgeben ifi, wie bey Den $2 \mathbb{A} e p f e l n$, Rärbien, viclen פeeren und jelbit Pflaumen, wo alfo bie Spaut beb (bob̈pfee nid)t unmittelbar aug= Dünften Pann, wie bey den blof̂en Şülfen, Bälgen uno Eapfeltr.

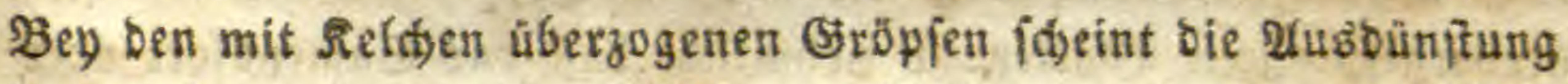
fo zu fagen im Reldje ftecten zu bleiben, und fid) zu Säften

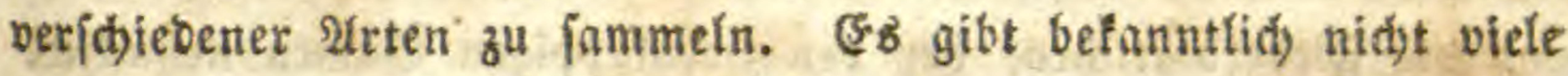
Früd)te, bey weld)en fidh bie Săfte zwifd)en Den Gröpşbäuten.

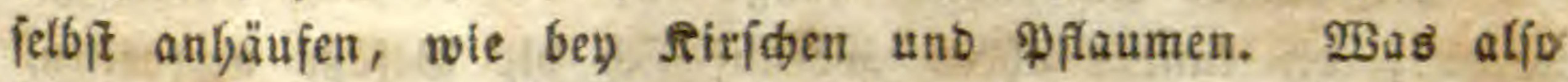
Gier als Saft auชgefajicben unb aufbewafyrt wirb, geft bey ben

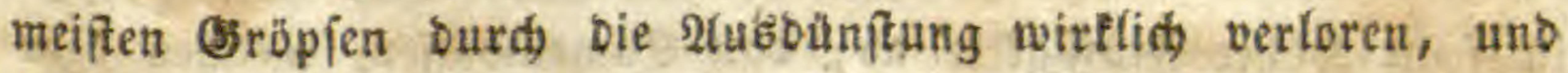

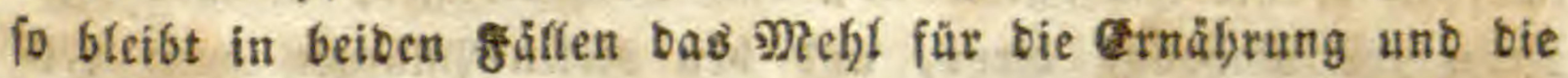
2usfülfung ber Samen zurüc. Tenes wiro in ben Sament

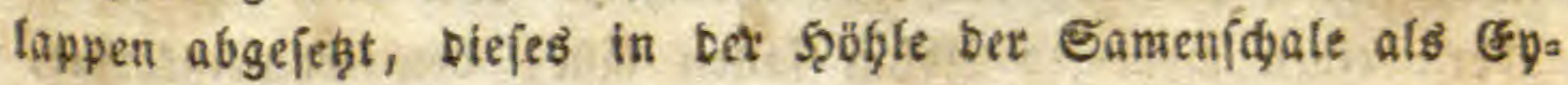
weí̧̨örper.

Die exite Erfidgeinung ber Samen zeigt fith als eine fleine 2frijd)weftung bes jogenannten Samenträgers, weldyer in ben

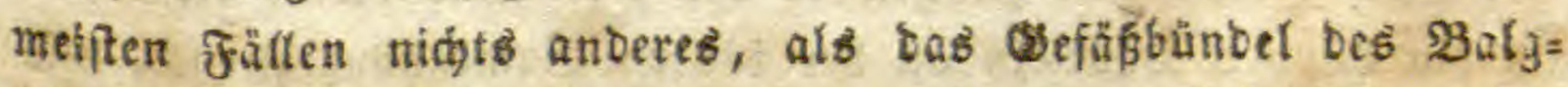
randes ift. Diefe 2tnfd)weflung ober 2 barje verdidt fidy an ber

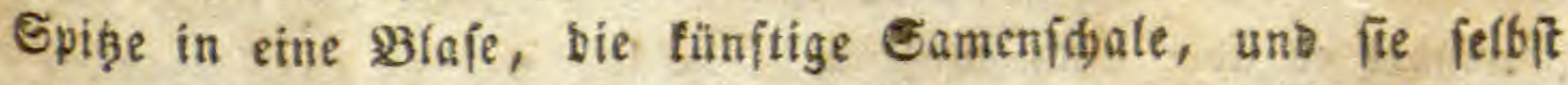
wirb zum Samenftiel. Der Eamen betommt entweber an feinem Obipfer ober audy in ber săhe ber çinfügung bes Stiels, afio an feinem Chrunbe, eine fleite Deffnung, bas Samentods (Micropyle). Dapurd fieft man, bá, ber Samen aus jwey. 


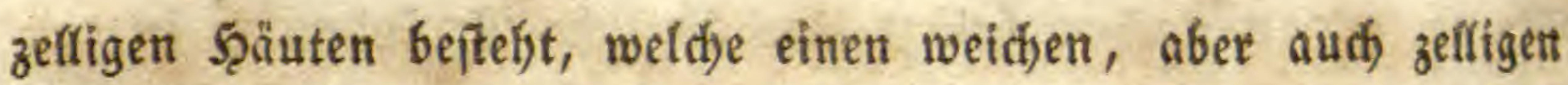
Sörper einfthließ̄en, den man Rerntein (Nucelle) nennt. Der Stiel frümmt und vertängert fid) auf mandgfaltige $\mathscr{X}$ rt, und baburdy entifergt feine veriffítene Rithtung und Eage. Das Sernleit wito aftmälylid) holfl ober factt fid) eit, wie einige mennen, und Dann zeigt fid) Darinn Die erife Spur Des Reimb, ungefälir nad) bem eriten Drittel Der ganzen Entwictelunggzeit Des Samens, afjo nad) 4 5sod)en, wenn ber Samen 3 Monat zum Reifen braudt; bey Samen mit einem grogen Enweistörper

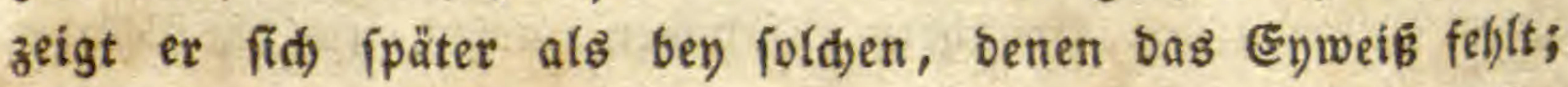
wabríd)einlid beghalb, weil er bort viel Eleiner bleibt, Gier aber bie ganze Samenhable ausfüft unb baher fdgeffer wädst, alio exît nad) vorangegangener Beftäubung. Es rourbe fidon gejagt, bas biejer Reim, nad (Einigen, nid)ts anderes fenn foll, als bie eingebrungene $\mathfrak{S B u f t}_{\mathrm{B}}$ ober bas Staubthierdjen felbft, nach meiner झlennung aber bie aus ber Spize bes Samenblatts

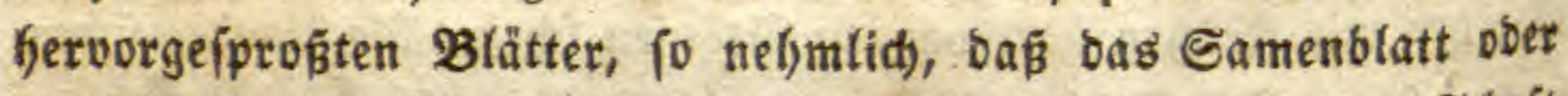
Die Sdale bie Blattidheibe vorftellt, Der Fiem aber ben Sdaft uno bie Fieberblättden, bey ben zwenlappigen Eamen nelymlid.

Die d̋usere Samenlyaut fängt an, bidjter unb härter zu werben; bie innere aber, worauf fid) bie Sefäßse vertheilen, bleibt weid), uno wiro zulę̧t fełp bünn. Das Rerntein fonoert

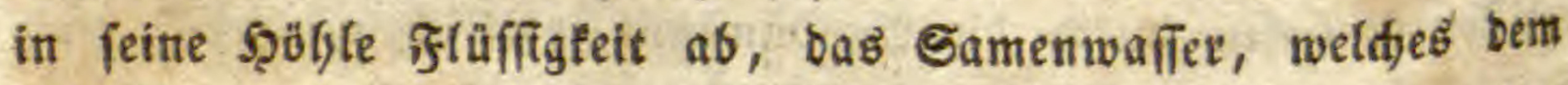
Reim zur Rabrung Dient, unb bey vielen \$flanzen ganz vers biaudit wirb, wie bey ben Şülfenfrüd)ten, aber aud) bey vielen

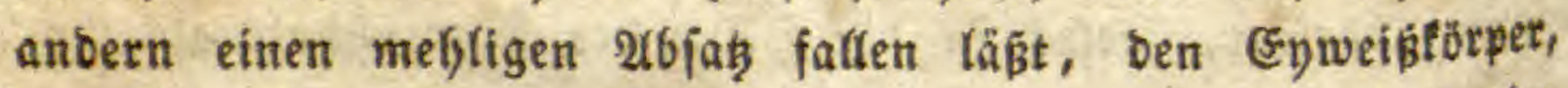
ber nad) feiner \$renge ben Reim balb ganz umgibt, Galb ifm nur zur Seite liegt.

Das vertrodtuete Beflgewebe bes Rernleins bleibt bismeilen ats ein ouñnes ร̧ăutlein an ber innern Samengaut zurüct, wie bey ben seurbfen, Swetid)en, Wुolfsmildarten u.f.w.; oft vels fdrwinbet es aber aud) gänzlidy.

Der Embryo zeigt fidh immer zuerfit in ber शähe beß Eamentods, alio am Sipfel bes Samens ober ber Blattítheibe, uno wädget nie aus bem (Srunbe befielben ober bem Samenftiel betaus. Ex exidyeint 2 Infangs als ein ganz tleines, weideb 
und farblofes Sörndien, befonbers bey ben Snjeibenpflangen,

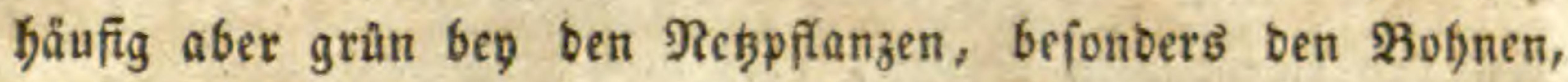

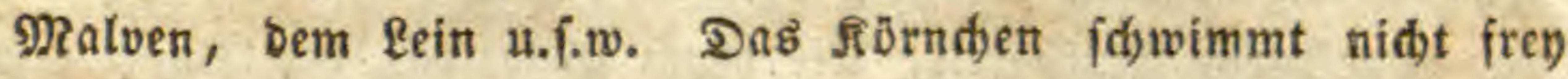
im Samenwaffer, fondern hängt, nad) $\mathfrak{E}$. Treviranu\& und Ubofph Brongniart, burd) einen zarten Jaben mit bem Sipfel bes Gamens, alfo obne Sweifel mit ber Mittelrippe befielben zufammen. Der Faben if meiftens fehr furz, bey ben Şülfenfrüd)tet jeboch) uto ber Eapucinerbtume ziemlids lang. Diefer Fraben ober Reimftiel wiberiprid)t mithin gänzlid ber

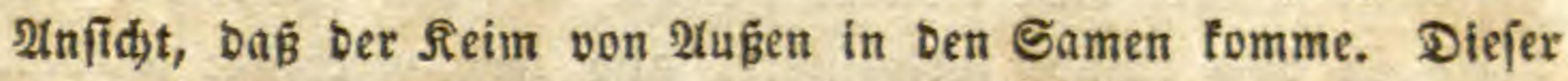
graben fidrumpft balb ein und löst fid) ab, weil ber Reim nun

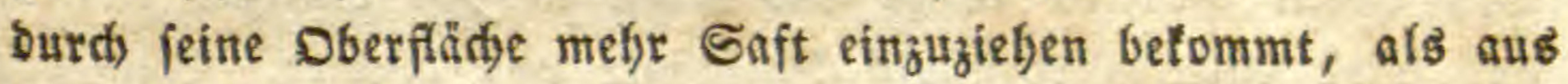
Dem Eröps. Benm seimen faugt ex auf älunlide sart bas

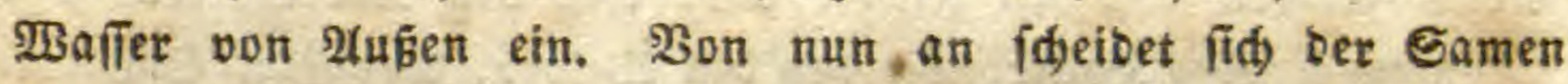
in ein unteres und oberes Ende, ober WBurzelden unb Samen: lappen, inbem fier ber bitfere Ilyeil fid) aftmälfid, fpaltet, wenn er nefymlid) zween Rappen befommen foft. (Er wäd)sit gewölnutid fo lang fort, bis er bie Şjhle bes Samens ober bes Enpeis= töpers ausfüflt. Injangs befteht er blop aus seflgewete, in weld)em fid aber aflmählid) Die Spiralgefä̧́e entwițeln. Die Subjtanz ift faft aftgemein füplidyer Sd)leim, weldyer bey ber serbärtung fich gröftentheils in Stärtemebl verwandelt uno etwas Rleber. Mandymal fobwik̨t ber überidyüfifge Sdjleim aus, mandimal feşt fid) aud) Del in beri seften Des Reimes ab. Durdb bie :ertroctinung werben afte Samen fdywerer ats und feimen baher immer auf bem Greunde befielbett.

\section{צน รีt}

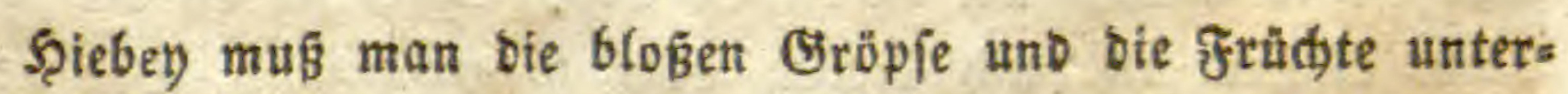
idjeiben. Sene vertroctnen mit ber Reife ber Samen, ipalten

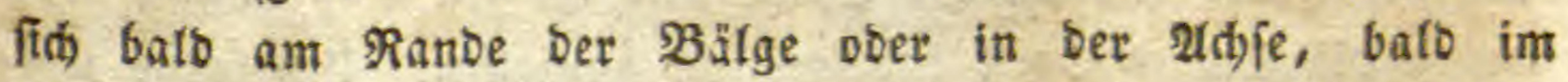
Rücten, balb an ben Seiten, balb enblid) audh nad) Der Duere, und faffen bem Samen frewent Itusgang. Bey ben Früd)ten aber bleiben bie Samen eingefdofofien, uno werben erit fren

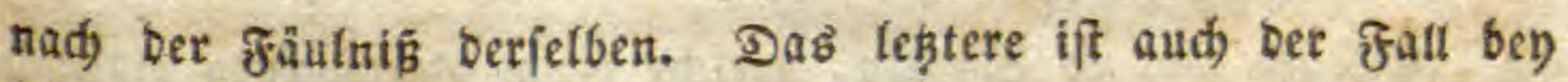

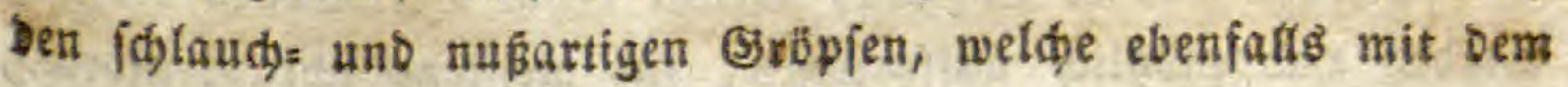


Samen abfallett utto fid exft bey ber Berwitterung offten, wie ben) ben eigentliden Rüfen, Dber aud) zerfprengt werben burdi Die eingelogene flüfifgete, wie beym Betraibe, Den Ropfa unb Dolbenpflanzen. Die Stiele Der grüd)te fraben ziemlid̆ allges mein ein Gelent, wovinn fie abfallen. Diefes Selent bitbet fith bier wabridgeinfid beşalb ftärter aus als bey ben blofent

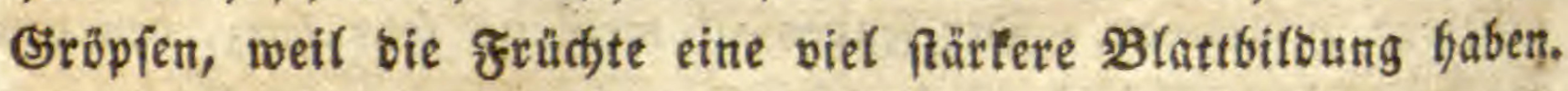

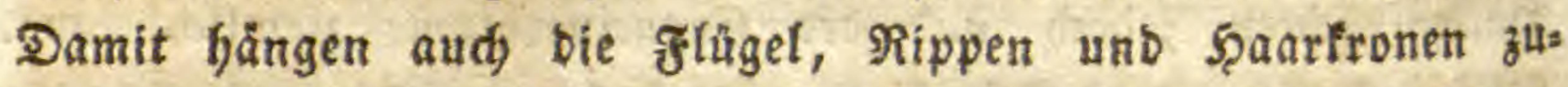
fanmen, womit viele troctene grüd)te verfeljen fino, uno wos burd, fie vom wsinbe fortgefüfrt, affo weit verbreitet werber. Bey vielen Sräfern bleibt bas sern in ben Spelzen fteden, und wirt baburd ebenfalls baujdiger und leidter. Yuth bey vielen Samen lommen flügel vor, wie bey গabelfalzern und Bignonien, ober Staare, wie ben Den গ্Sriben, \$appeln, Sdywalbs wurzen, פBeibenrőstein, Băumwotte u.f.m.

Bey Den Fleifdffundten find bie Beeren in ber Regel viels famig, affe anbern wenigs ober einjamig, wie 2tepfel uno \$flato

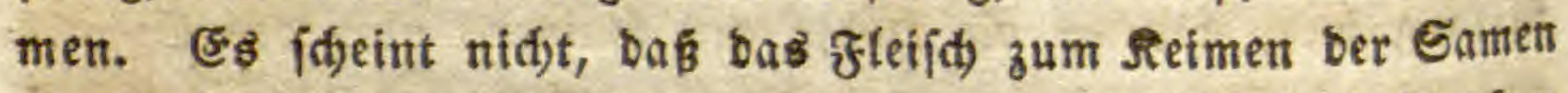
etwas bentrage, ia fie leiben fogar, wenn bas fleifid) langfam fault, nelgmlid) wenn man bas obit aufbewahrt. In ber frepen

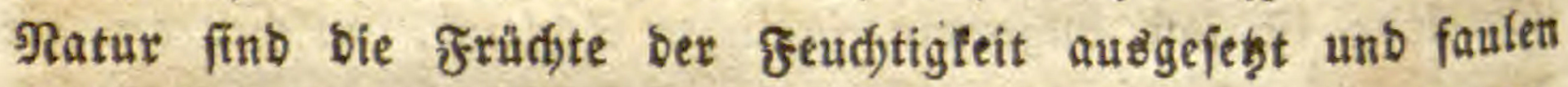

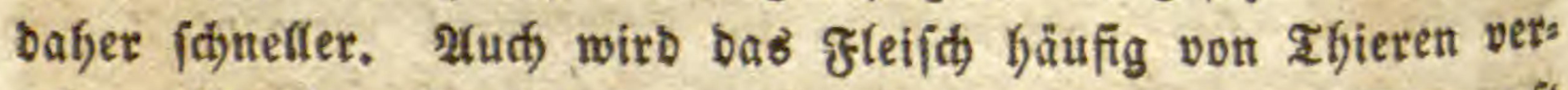
zel)rt. Ben ben seủrbjen, wo ble Einlenfung felflt, veridrumpit und verwest ber Etengel von felbft.

Früdbte ober Eamen, weld)e reidft vom झBinbe fortgefúfut merben, gebeihen meiftens auf jebem $B o b e n ;$ nidjt io bie grteids früd)te. Unter ben troctenen Đröpien frteuen bie Şălfen unb Bälge ifyre Samer am teidjteften aus, inbem fie an ber intrern Raht llaffen und fid) breben oder berabbängen. Die meiftent

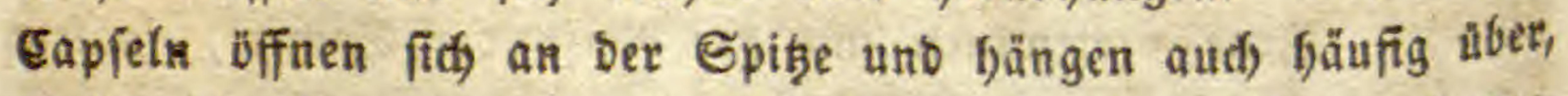
wobey bie Samen burd ifhr (Bewid)t ausfaften. Uebrigent wets

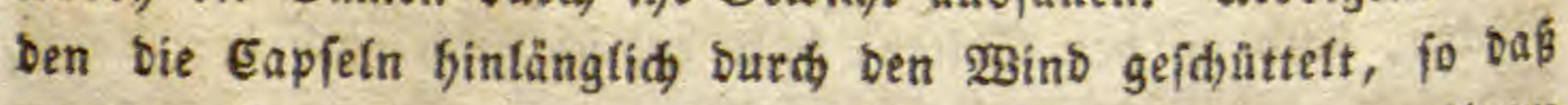
es ben Samen nidft an Eelegenheit feblen tann, von ifrem Bebăltnís frey zu werben.

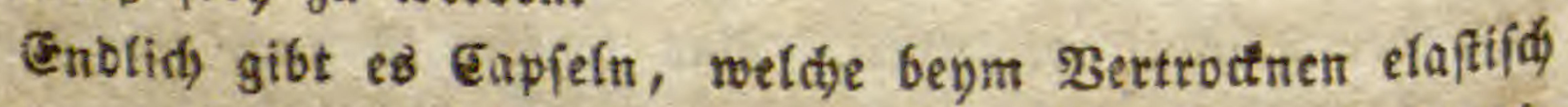

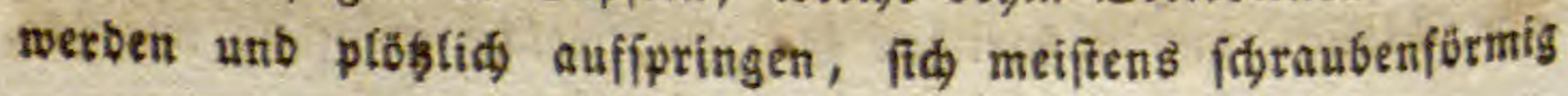


zufammenrolfen unb bie Samen fortichleubern, wie-bey bem Springtraut, ten Stordjidnäbeln und felbit ber Springgurfe.

Die Samen reiśen am Eribe bes Stiets ab und beljalten fobann bie Rabelfefte, aljo nidjt wie bie Blätter, an benen ber Stiel bängen bleibt.

\section{Sêmen.}

Sีn Der Reget leimen bie Samen nut, wenn fie volftommen reif fitto, nelgmlid) fo mit $\mathfrak{R e f l}$ angefüflt und eingetrodtnet, DaF fie in ber folge nidjt einfdrumpfen. Ben folden veridgrumpften

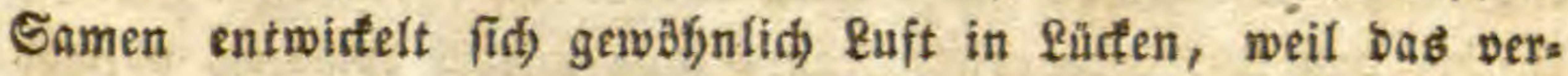
Dunftende $2 B a f f e r$ nidgt mefre erfeģt wirb, und baher plegen fie

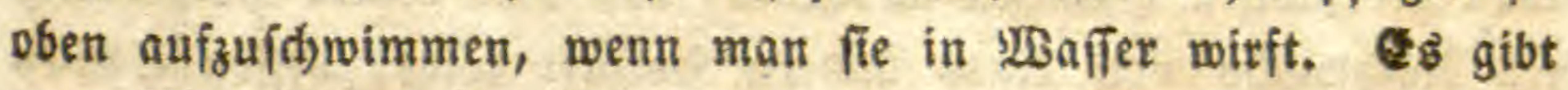
zwar Beyfpiele, bas noch nid)t ganz reife Samen gefeimt haben, befonbers Soulfenfrãd)te, jebod nur, wenn fie gleid) wieber in bie Erbe tamen. DaE find aber \&usnafimen, weldhe felten vor-

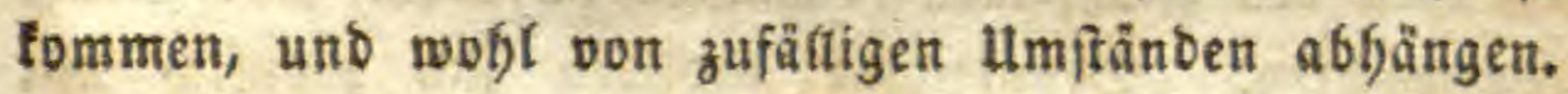

Da zum Reimen wafier, ङaueritoffgas und eit gewifier গু马ämegrab erforberlid, ift; io tönnen bie Samen lange liegen und ifyre Reimfäbigfeit behalten, wenn fie vor biejen Einflüfen geidüb̧t finb. Die meiften bleiben mefrere salgre gefuno, uno man nimmt als mittlere 3eit 6 sabre an. Das ift aber bes

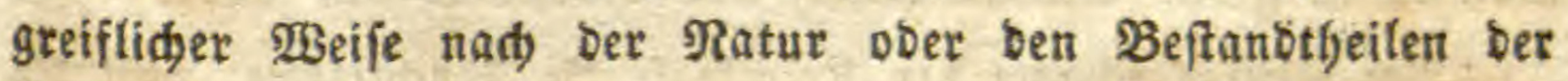
Samen jefr veridgieden. Samen von grafierpftanzen bâtien

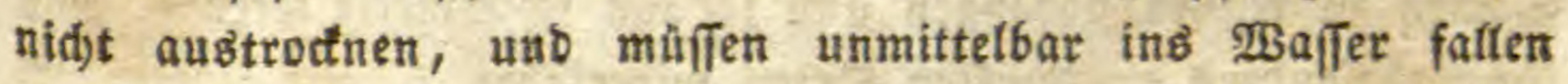
ober wenigftens feudyt gebalten werben, wenn fie teimen foffen. Sebre lleine Samen pilegen aud bato ifre Reimfähigleit zu vertieren, ofjne sweifel, weil fie zu hart werben. Die Samen Der Sternpflanzen, worunter audh bie Caffeebohnen gefören, bürfen nid)t lang liegen; ebenio bie von Dotbenplanzen, wie sitummel, Engetwurz u. Dergl.; ferner bie Der Radjenblumen, wie Safonentamm, Sufweizen, bie vom Diptam und von ben Munten.

Das Eltraibe bleibt am lăngiten teimfäbig, in ber Reget 6-10 jabre, Man hat aber Beyfpiele, Daf Rörner mefyr als 100 Jabr alt nod) zum Seimen gebradgt werben Ponten, is 
fogar nods meldye aus ägyptifjen Mumien, bie mitfin einige Iaufenb Sabr alt waren. Frenlid) waren fie aud vor aften äufiern Einfüfifen bewabrt. Iud) bie Şülfenfrüd)te, bejonbers bie Bobnen, Fönnen uีber Şunbert Sabr-alt werben; Sament von Sinnpflanzen teimten nod nad' 60 Jabren. Faît bafielbe fann man von Den Rernen der Rürbjen uno Den Samen ber Malven fagen. Farrenfamen, vbidjon felje flein, feimte nodh aนธ่ einem Herbario, obfdion er 50 Sahte alt.

Tief in ber Erbe vergrabene Samen halten fid) ungewöftts (id) lang, wenigftens fudjt man baraus bie Exjopinung z̆ ets ftären, bas unfräuter viele \$ăbre lang wieber fommen, obiđon man bie jungen Pflanzen aušrauft; baßs nad) einem Şo (zabtrieb

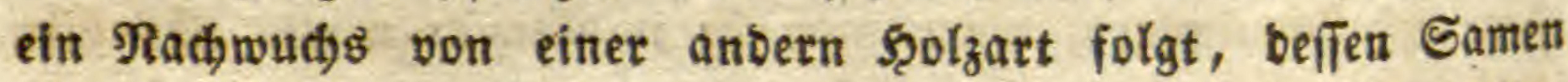
mithin viefleid)t Squnbert Sabr unter Der Erbe ausgehalten Gätten. આus Gräben, bie feit Menidhengebenten zugeworfen waren, fah man ben Flohfamen (Plantago psyllium) und Sted)= apfel hervormadbien. Branbpläbe bebecten fich plöblid) mit Raufe (Sisymbrium irio); unt mit Riteuztraut (Senecio vis. eosus). Da fibrigens biefe \$fanzen auf Sdjutt ober Mauern wadjen, fo if ein fdnelfes Ueberhanbnefymen in biefem gatte wohl begreiflid). Um (setraibe lang aufzubemabren, finuttet man es in grofe Sruben (Silo) und bebectt es mit Erbe.

$\mathfrak{A m}$ meifter fdabet ber Reimlraft bie Fendjtigleit, meil bie Samen zu leimen anfangen unb fobann fdimmelig werben, was ihnen bejonbers an bunllen Drten wiberfährt.

Die Bärme wirlt nidjt fo naditheilig ein, vorausgefebt, baß fie trodten iff. Setraibe tann man bey 90 (5rab Reaumut troctnen, obne bas es feine Sieimfraft verliert; bringt mant $e^{3}$

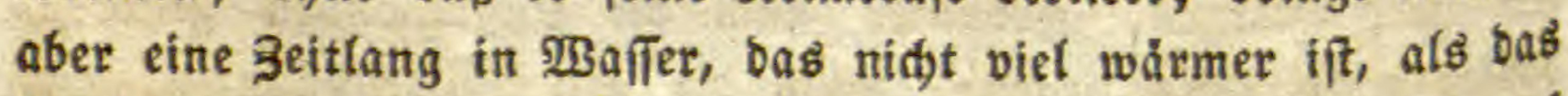
Blut, fo verbirbt eछ fおon. Die Rălte wirlt gar nidjt auf trodtene Samen.

Itm (5etraibe auf Speid)ern lang zu exbalten, muß Feud)s tigleit und \$ärme abgebalten werben, und bas geidielgt ant beften burd) freyen Buftz̧ug unb Itmwerfen. Triff man es nidst zur Saat braudgen, fonbern für bie 3eit be Mangels aufbes 
wafjen, fo troctnet man es in befonbers bazu eingeriogteten Defen. Man hat Dann bie Rornwătmer nidłt z̆l fürdyten.

Die Samen von obft madjt man aus, und bebt fie trotten auf.

Das Obft felbit, befonbers Iepfel, balten fidh an einem luftigen, füblen Ort faft ein Salyr fang; ober aud), inbem man fie in Fleinen Fäfiern unter bie Erbe vergräbt. Eebr faftreides Dbft, wie Siridien unb Swetiden, mus fitnefl getroctitet werben. Man bat Dazu eigene Defen unb Darren. 2fud fdneidet man Die 2 epfel in Sdyniķe und troctnet fie an ber Ruft.

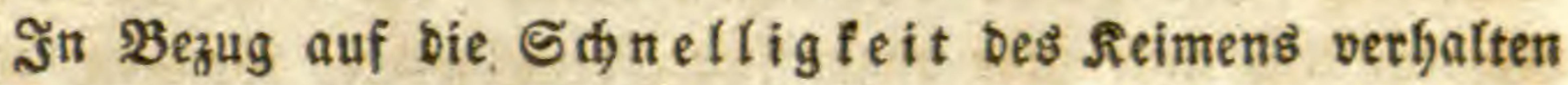
fid bie Samen febr verídieben.

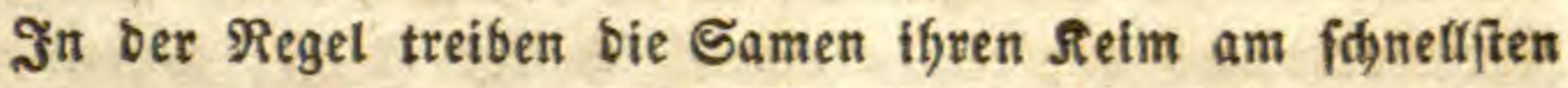
aus, wenn fie jogleid) auf bie Erbe faffen; unb bann erfolgt

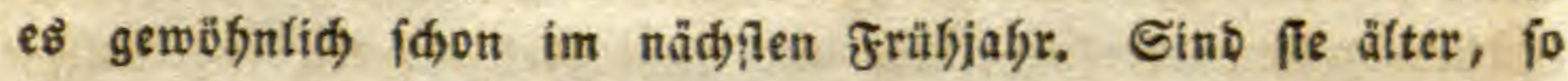
Pobnnen fre ein halbes salyt liegen.

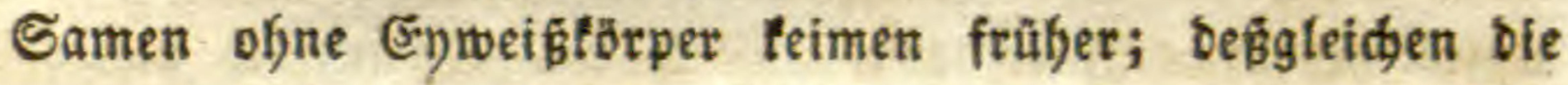

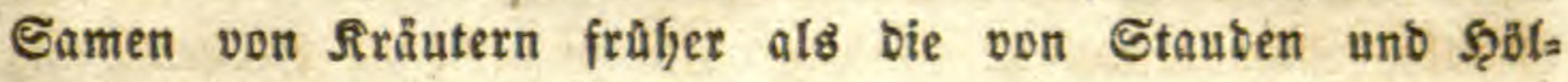
zern. Samen, weld)e früher leimen, pflegen aud fduefter zu wadhien; ben f̧ölzern gefjt beides febr langfam.

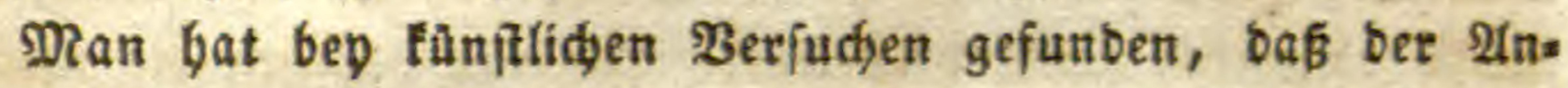
fang bes Reimens auferorbentlid) veridjieben ift, ofne baf man bis jeb̧t ein beftimmtes (3eję̧ bätte ausfinbig madjen fünnen. Mandie Feimen fibon in ben erften Tagen, anbere erft nad Monaten, ja erit nad) einem bis zwen Jaljren.

3u Denienigen, weldhe fdou in ben erften 8 Tagen teimen,

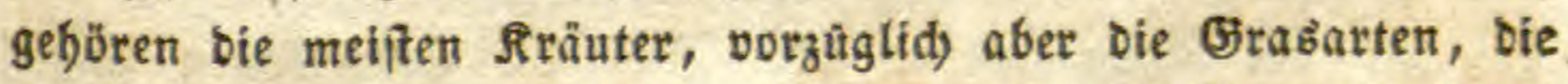
Sopfblüthen uno bie Sdjotenpflanzen; Die Spülfents, Dolben=, Sippen: und Radjenblumen fdjeinen 14 Inge und megr 3 us marten. Inbeffen ift bie Sadje fo veräriberfidy unt nod zu wenig genau beobad)tet, Daß́ man nod) nid)tร barüber fagent fann. Es bängt febr viel bavon ab, ob bie Samen frijh) ober alt unt mithin fefre trodten finb. 2lbgefelyen von ben Samen, weldge fdon bey nafiem 2 Better in ben Fruditfüflen feimen, wie bas Stetraibe, ober in felfr wäfierigen früd)teh, wie mandy. mal bie ber siurbfen, gibt es jeDod) aud) andere, meld)e biefes 
gewälnfidy thuth, ofge befonbere Einflatie, wie bie Samen bet

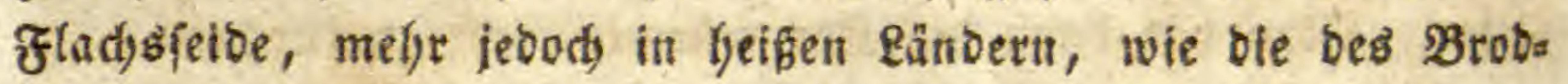
baums unઠ ber $\mathfrak{B u r z e l b a ̈ u m e ~ ( R h i z o p h o r a ) . ~}$

Die notlymenbigen $B$ ebingungen

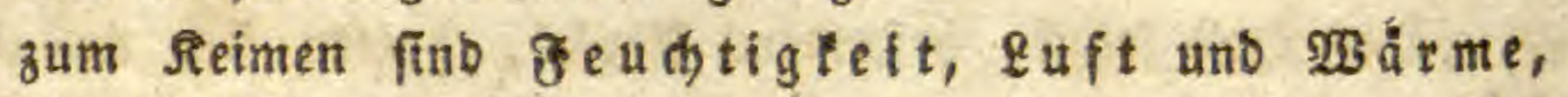
wenigitens uีber bem Befrierpunet; $\mathfrak{B}$ eguี bo bere Bärme, gegen $20^{\circ} \Re$, , Sauer it offga ober ver= bủnte Gäuren und Dunfelbeft.

a. Sm feimfäbig fenn ober nidjt; Das Einfaugen if baber blós eine phyffealifde, und teine organifidje (Erid)einung. Das ergibt fids aud aus bem grofen Ërvidbt, weldjes bie aufqueflenten Eamen Gebent ober wegidjieben, entfpredyent ber Rraft, womit nafie Seile fich verbicten uno groß̧e Raften heben. Der Samen faugt an ber ganzen Oberfädbe ein, uno nidjt bloß an ber Nabelfittle;

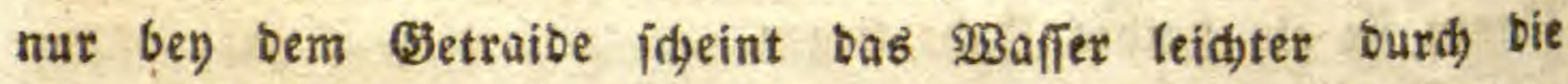
lę̧tere Etetle einzubringen. 2Bas bas Eamenloch babey thut, if nod) nidjt ermitteft. Hebrigen fann man bie Samenidale, 3. B. ciner Bofine, abziefjen, unb bie sefmung wiro body von Statten gef)en, weil Der ganze Reim, fowohl bas wsürzeldien als bie Rappen, einfaugt. Heberzillyt man bagegen bie Eament ichale mit einem Firnif, fo bört bas Reimen auf, nidst abet, menn man eine Etefle bavon frey läpt, fey es bie bes গabels voer eine andere.

Das waffer wirb burd) bie Samenhaut nidt verinbert, benn es bringen audb Farbenftoffe ein.

Sit Der Eyneiffötper ober find bie Eotylebonen anges

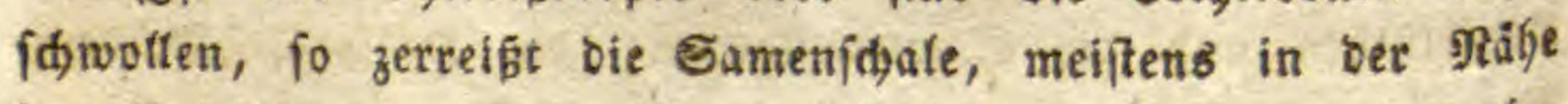
Des Rabelş, wenn ber Eamen gleidhförmig ringsum bat eine faugen fönnen, fonft aud) ah anbern Cteften, unb bahjer unregeta

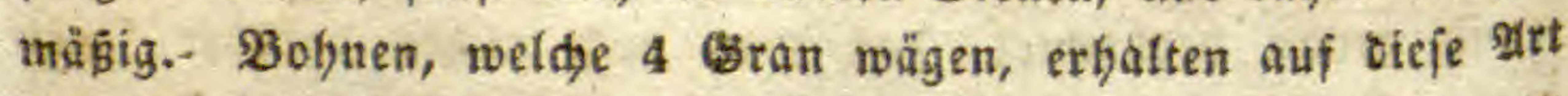
Das Doppelte Gewidht. Sat bie Bobne einmal angefangen fa feimen, fo fann man bie Samentappen abjdneiben, ofye bafi fie zи (Srunbe getht; fie bteibt jedod) fleiner. Das getingt jes bod) nidyt immer, uno nody wentger bey affen Pfanzen. Samen mit einem großsen Gyweistorper Gaben nur bünne, blattartige 
Samentappen, unb bafjer ift es jener, weldyer einfaugt, weid, wirb unt bie Rafrung liefert. Soldbe Samentappen babent mefir Spaltmündungen, und fônnen Daher leidjter einfaugen. Hlebrigen (ann man nad) erfolgter seimung aud) ben (5yweifs=

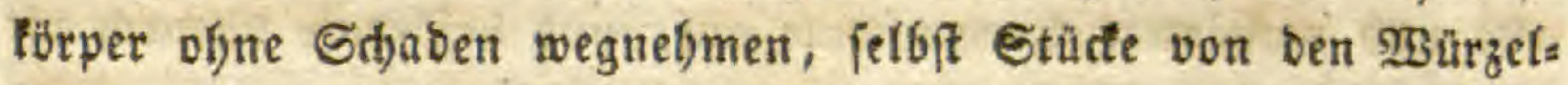
den uno ben Blattfeberdien abfdneiden. Das tann nidyt in Sermunberung feben, wenn man bebenlt, bas bas Sewebe bes

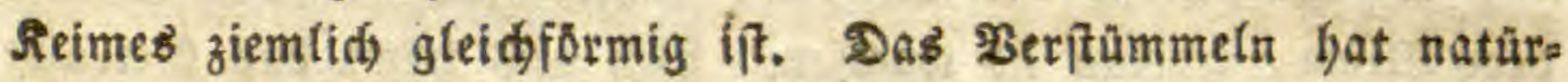
lid feine Gränze.

b. Ce if burd ఇerjudge Ginlänglid) ausgemad)t, baß tein Samen feimt obne Sauerfoffgas; nidgt in abgetodbtem ober

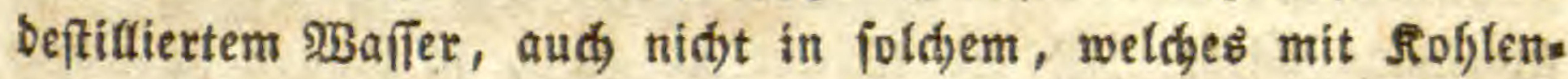
fäure voer Etidơges gefättigt ift; nidft it freyem Etictgas, T3afferfoffgas und tohlenfaurem sas; endlid nicht in lufta

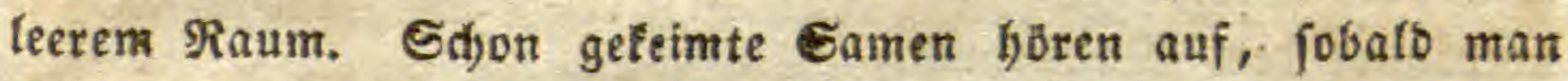
fie in unathembare Gasarten verfę̧t. Sie leimen aber fdon, wenigitens eine Zeit lang, wenn man nur etwas weniges Sauer. ftoffgas binzuläbt; am beften gefft es in Der atmoiphärijden Euft; fdneffer frenlid) in einem Heberidus von Sauerftoffgas, aber bann geht auch gewöbnlid) bas pflänzden balb zu Grunbe,

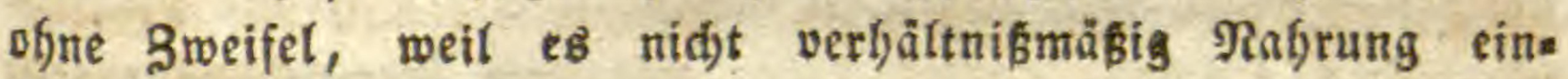
zieben fann.

Enblidf hat man, vorzugglid $\mathfrak{T h}$. Eauffure, aud burd,

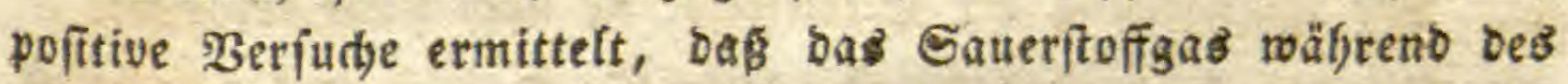
Feimens wirffid) perfdyninbet unb stohlenfäure an feine Steffe tritt. Getraibe verwanbelt auf biefe Itrt $1 /$ soo feines (3) s widgts Sauerfoffgas, Bofnen $1 / 100$. Eie verwenben es aber nidht in ifren eigenen Reib, jondern geben ben Rohlentifoff ab zur Bifloung Der Roflenfäure. Eperrt man baher Eament in atmojphärifdjer Ruft mit Sealfwaffer, fo fteigt es in bie şübe unb wirb getrübt, inbem fid loffenfaurer Ralf bilbet. Die Stoffe bes Samens geben Daher seoflenitoff ab, nelymen Waafier auf und werben baburd) cljemifid peränbert.

Afexanber v. Gambolot hat fidon früher gezeigt, bá Samen in verounntem હhlor ooer in orngenierter Saljfäure viel (d)nefler Feimen, unb oás man baburd) ganz alte unb vertrodnete 
Samen nod) zum Reimen bringen tönte. - Sanbere Găuren Doer fauerftoffreidye sörper mirfen nidbt auf biefe 2 trt, fellop? wenn fie leidht Saurexftoff abgeben, wie Salpeterfäure uno Braun.

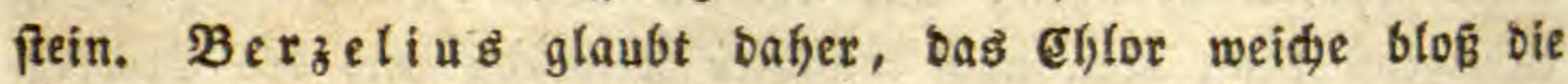
alte und verfärtete Samenidjale auf, unb beförbere baburd bie Einfaugung bez

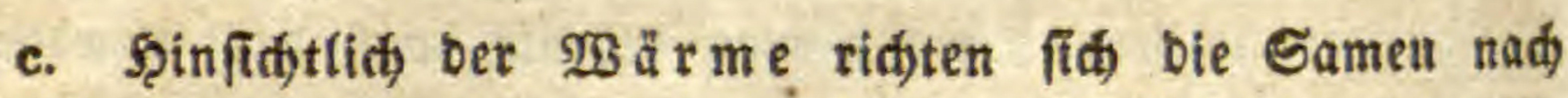
bem ฮlima, worinn fie wadjen. Bey uns leimt bas (setraibe idon bey wenigen Eraben äber bem Stefrierpunct; in ber Regel

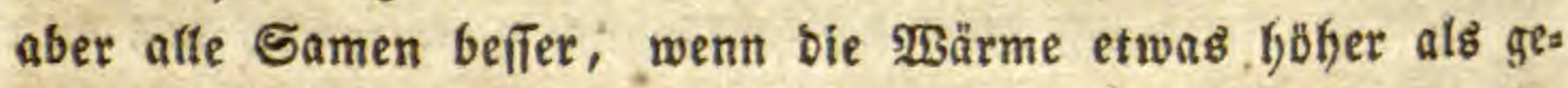
mbignlich ift, alfo über 16 Srab, wobey bas Einfaugen bea

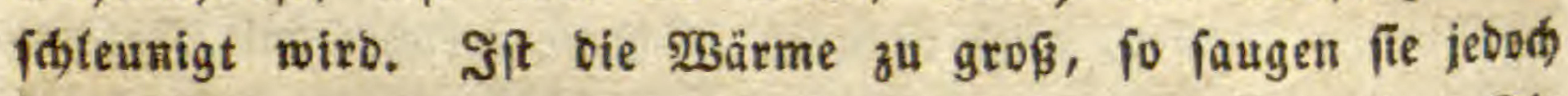
3u viel ein, un werben baburd wäiferig uno (d)wad). Die Blutwårme, aljo etwa $30^{\circ} \Re$.; ift Dem Reimen idäblid), unb âberfaupt bem 2 Badstbum.

d. Ebenfo ift bas unmittelbare Sontrenlid)t bem Reis men fdăblid), theits wegen zu ftarter 2 erbunfung, theils weil (iid) bann bas Gauerfoffgas nid)t mit bem Rohlenftoff verbinden Fant. Das Tagesfid)t wirlt weniger nadtheilig; bie Rad)t am vortheilfafteften, weil biefes bie ungeftürte Athemzeit ber Pflanzen if. Das feimen beginnt bafjer mit bem (Erweid)ungsproce unb Dem 2 themproce年, worauf bie Berję̧ungen folgen.

Die Esinwirfung Der (electricität ift nod) nid)t erforid)t.

Da ber Gauptbeftand heil ber Samen Stärtemebl itit, fo wiro biefes zuerft erweidst, fobann bictfunffitg, wie eine 21rt

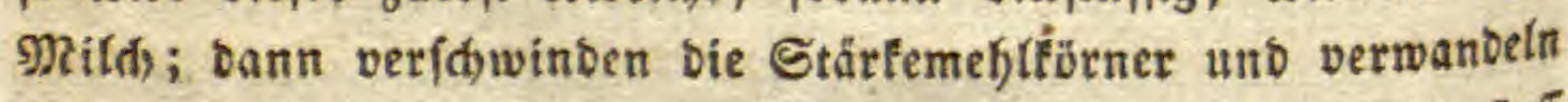
fid) in surfer und Edjleim, wafrifideinlidy, inbem fie Roflenflofi verlieren und mit

Das Reimen if alfo eine 2rt (3äfrungsprose gefebrt, indem aud) bey ber șährung fproffenbe fiorper (id)

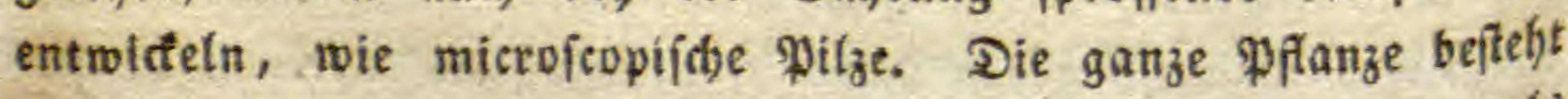
aus fotden fërperdien, weldye fidh von einanber trentren, als Saft fid) bitt und her bewegen und endfid) zu zeften erftarten. Das seimen und Wadhen ift ein lebenbiger (Säl)rungsprocé vier ein Salvanismus in unentlid) fleinen Rügeldgen, worinu 


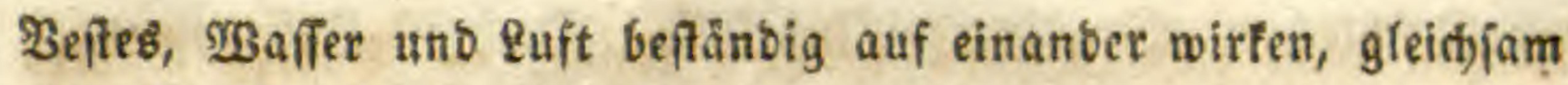
mit einander fpielen und fid) Daburit) benegett.

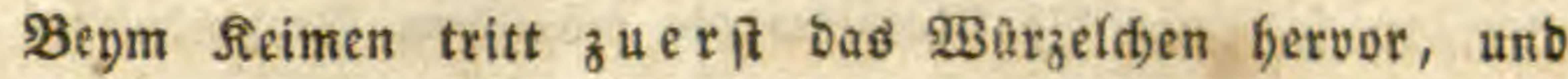
zwar beg den Sdyeidenpflanzen immer Durd) bie Rabelifelle,

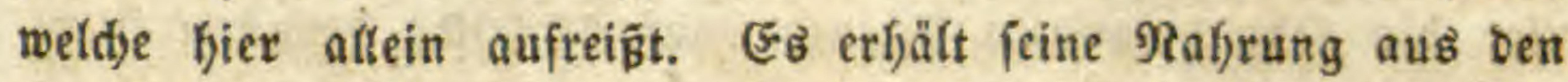
Samerilappen, uno mitfin geft bie erife sBenegung bes Saftes nach unten, weil ber Begenfagh zum lid)te nody fefilt. Darauf

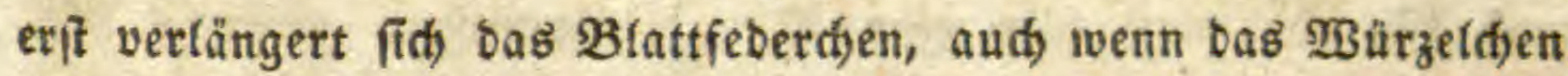
nod) nidht veft feht und aus ber Erbe einjaugen fann. Beibe verlängern fidh fo lang, afs bie Rahrung aus bem Eymeiffötper unb ben Samenlappen hinreidyt: Dann fterben beibe ab, wofern Die şurzel nidhts einzufaugen befommt.

In ber Regel werben bie Samenlappen gröfer unb bitter, Geben fid) meiftens über bie Erobe empor, werben grünfid, affo

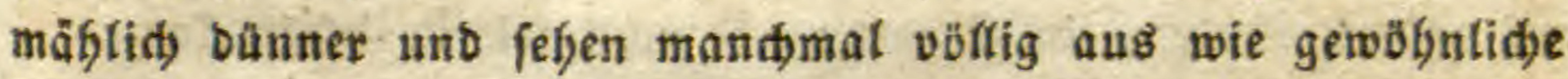
Blätter. Siemlid) fo bey den şalfen, Malven, WBinben und

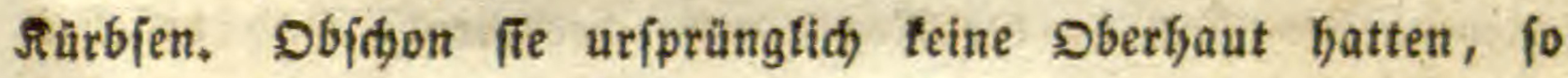
befommen fie nun eine foldse, uno zwar mit vielen Spaltmün bungen, uno zeigen audh Spiralgefä̈e. Ţăbrent ber zeit tritt aud) bas Blattfeberdien hervor und verwanbelt fid in bent

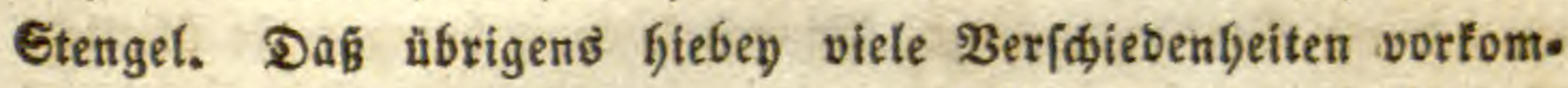
men, lä wảre zu weitläufig unb aud) nid)t an feinem Drte.

\section{(S) a t $t$ ung (Species).}

Seber Ifyeil, weldyer fidh von einer Pflanze ablöst uno fortwäd)et, fey es Rnofpe voer Samen, wirb ber \$utterpflanze gleidh, uno ifî baher mit lihr von berfelben \&attung. Die Gattungen werben mitfin von ber Natur felbft hervorgebrad)t, und fino ber unmittelbare Begenftand unferer Beobadytungen. Die Sufammenfteftungen aber von äbntiden Eattungen, unter

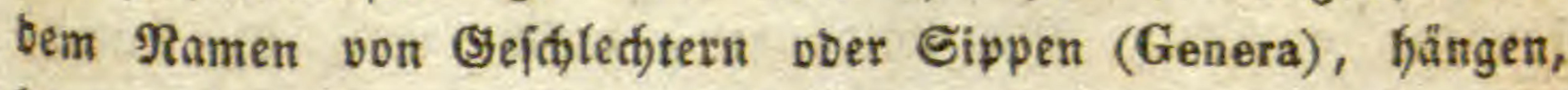

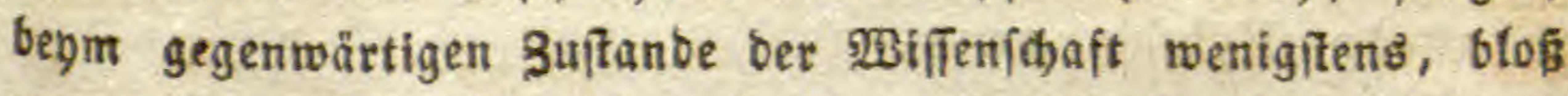
von unferm Sdyarfintun $a b$, ob wir nefymlid, bie Aefnlidgteiten tidetig erfant baben voer uicht.: Die Babt ber Sattungen ift Dafjer eine bejtimmte, wenn fie-auds nod fo grób lît; bie zabl 


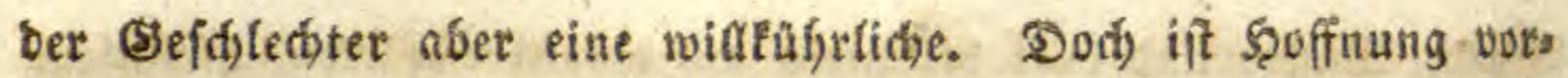
Ganten, daś man aud diefe einftens werbe beptimmen fünnen, ungefägr fo, wie bie Gjemifer bie müglidjen Berbinoungen bert Stoffe zu beredinen im Stande find. \$Man fidlägt bie 3afhl

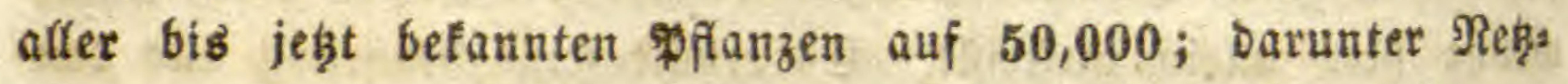
pflanzen 32,000 , Sdbeibenpfanzen 7000 , Glüthenlofe \$flanzent

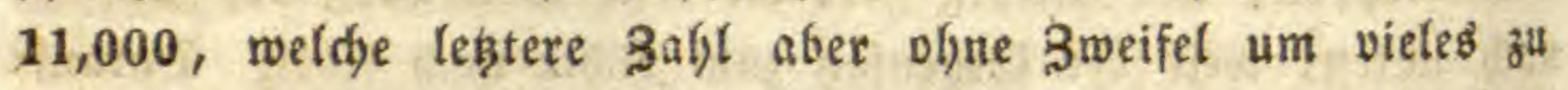
grof ift, ba man bier eime Menge Wattungen gemedth hat, weldbe fíd) fpảter als bloße xbänbexungen gezeigt baben. Man fann bödgiftens annefmen, baß́s bie zwo leb̧ten Xbtheilungen einanber gleid fino, uno etwa 14,000 betragen, was mitfin wettiger als bie Sälfte ber Regpplanzen ausmadyen würbe. Die Sdyeibenpflanzen betragen tein Biertel Der Neßzpflanzen.

Die Pflanzen arten jebod) nidgt jelten aus, je nadjoem fit auf andern Boben, in Edhatten, geuditigfeit u. bergl. pommen. Dian nent fie SArten und Abảnberungen (Varietas). Dic Bets fdiebengeiten fino in ber Regel nidft bebeutend, uno beftehen meiften blos in ber Brbbe, ber garbe, Bebaarung, bem Br:

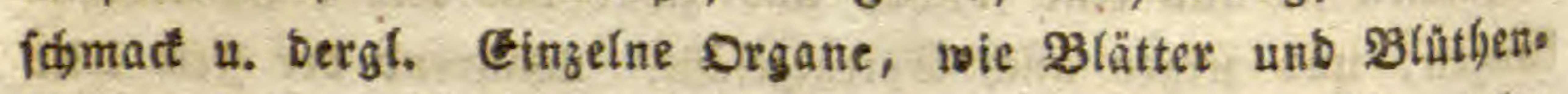
theile, anbern fidh faum in Der beftalt, Rage unb $3 a$ hl, auser etwa burdy ఇerfùmmerung. Eine zeit lang bringent fie äfonlid)e hervor, lebren aber bey ber sortpflanzung burd) Gamen nach unb nad in ben uripruinglidgen Buftand zurutc. Durd blobe 23ermeffrung fann man fie lang im gleidfen Sultanbe erbalten, unb bakn nennt man fle Epictarten.

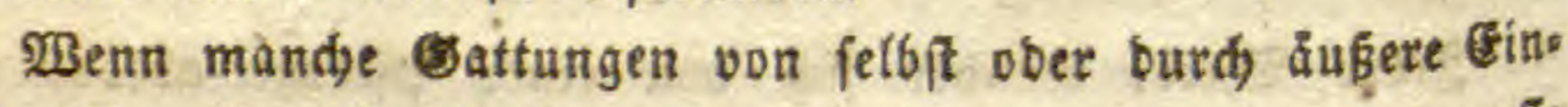
fluffe felse abweidgenbe gormen antehmen, fo nennt man fie Mißsbiloungen. Das fommt bäufig bey cultivierten \$fanzen vor, aber fefir felten bey wilben. Shieljer gegören aud ble ges füßten Blumen.

Durd) Bermifdung veridbiebener Gattungen ben ber bes ftäubung entitefyen mittelbiloungen, weldye man $2 B$ aft at bs pilanzen (Hybrida) nennt.

Eie fetzen feiten Samen an, uno Darn fefren fie ebento faltร zur urfprünglid)en Samen. Đattung zurüct, wenn fie theer eigenen Beftäubung, becen fie jebod) felten fälyb fith, 
aberlafien werben. In ber Regel gleiden fie am meifiten ber Samenpflanze; bod) gelingt $e s$, bie Sungen affmählidy in bie Staubplanze überzufüfren, wenn man $3-4$ Jalge lang bene felben feemben Staub barauf bringt, ein Beweís, Doß ber Stuub ebenfovicl zur servorbringung ber jungen bas Samenforn ober bas fogenannte Ey.

Die Combinationen find fo mandifaltig, Daßs es unmöglid

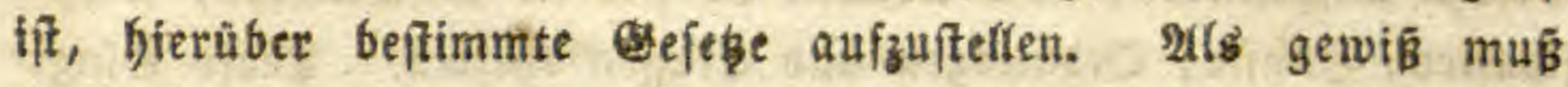
mant aber annefimett, baf feinte Gattung von felbft burd) bent Berlauf ber zeit fidi) in eine anbere umbíbet uno baś bie ganze Mandfaltigleit Det Pflanzenwelt fidh aus wenig ut=

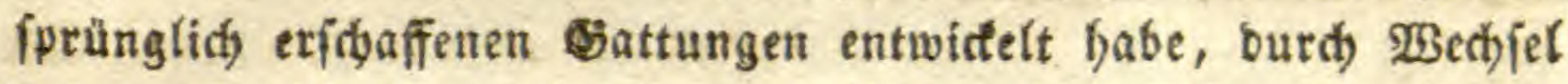
Des Drt8, ber Feuditigleit, Des Eidits, ber. æaärme u. bergl., vber audh burdh wedpjerfeitige seftäubung. Die pftanzen aus

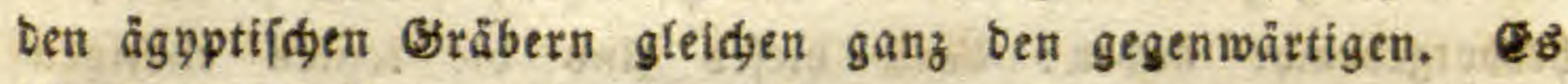
if̣ tein sweifel, baß̧ afte planzen aนs bem uriprüngliçen

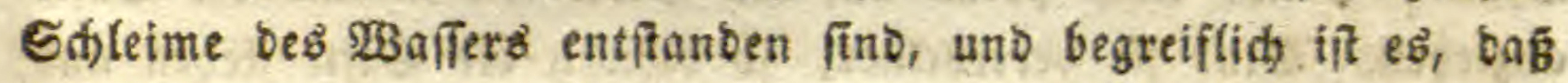
ber nod) ungeformte Sdyleim at jebem verfápiebenen orte feiner Entwidelung aud eime andere Seftalt angenommen fabe, D, b. 34 eitrev eigenthumbliden battung geworben fey. Man Pant aber nidbt annelymen, basieine Pfanze, weldge etwa 20 Spiral= gefäsbündel Gat, 5 Btumenblätter, 25 Staubfäben, 5 Eriffel 4. f.w. sine junge hervorbringen folfte mit anbern Sabien.

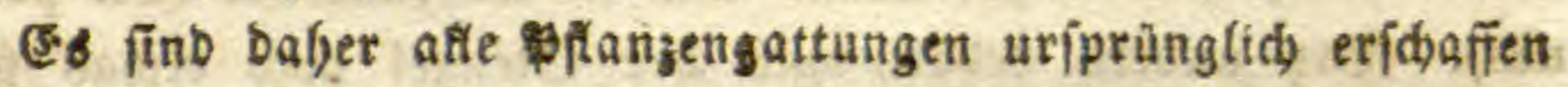
worben; aber beflyalb nidst notlfwendig zu eitter 3eit. Co wie fidh bas đlima änoerte, bie geographifdse Breite, ber Salleim: unb Salzgefjalt bes ssafiers, fo muften aud wieber andere Planzen entitehen.

Dabey Gat man fich gewunbert, warum benn gegenwåtig Feine mebre entilefen. Darauf fann man antworten, bafs bie

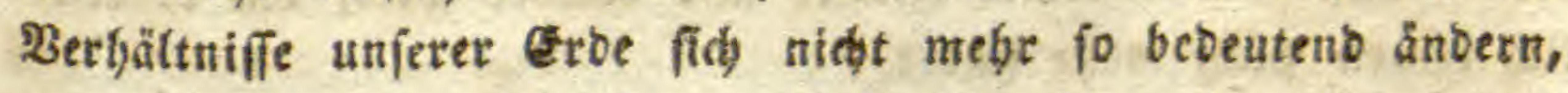
aus bem einfadgen runbe, weil fie firh figon fo viel geảnoert baben, als fie fonnten. Inbeifen entipelgen ofyne sweifel nods inamer von felbft niebere \$fanzen, wie wafferfäben und Pilze: aber bennod feine eigenen attungen, weil begreiflid)er Weife figot affe sergaltniffe in frubern 3eiten ba gewejea finb, welde. 
jest nar nod) an Iaufend Orten fid) wieberholen. Hus bemfelben. Orunbe ift egs aud) begreiflid), warum teine bjgeren pflanzen mefre entiltfen. Die Unterídiede fino nirgenos mefre jo grós wie ebemats. WSir mülfen baher annefymen, dá die Pflanzen. fíböpfung geendigt ift, und bás wir bafjer einftens werben in Stanbe fenn, bie zal)r Der Pfinzen zu beptimmen unb audi bie

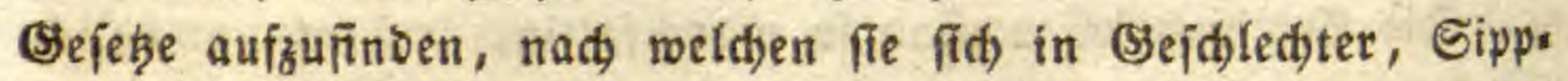
fohaften, sünfte, Dronungen uno હlafien theilen. Diefe Dinge fint fiderlidy alfe beftimmt, wenn gleid) jez̧t jeber es wagt, for genannte \$flanzenfamilien nad) eigenem selieben, unb oft aนb bloģer ceitelteit, aufzulteflen.

\section{Dauer ber Benäd).}

Streng genommen iterben afle Pfanzen, fobalb fie Sament Gervorgebradjt haben: Denn biejes find bie leghten thätigen Theile, weldye nod) polar auf ben Stct wirten und bie Eäfte anzieben. Gino fie vertroctnet, fo bleiben bie Gäfte ftehen uno bas seffgewebe vertrodtnet nach) und nad) ebenfafls. Dab wibers fäbrt in ber $\Re$ egel aflen blumentofen unb Sheibenpflanzen; auth

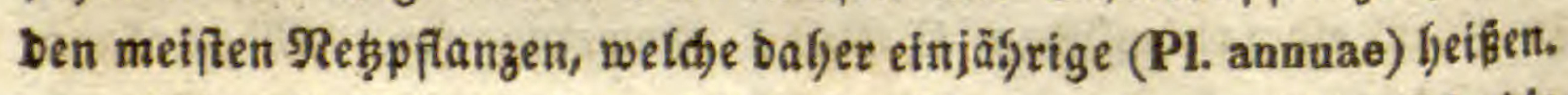

Es gibt jebod unterídiebe. Bey vielen exfallt fid bie

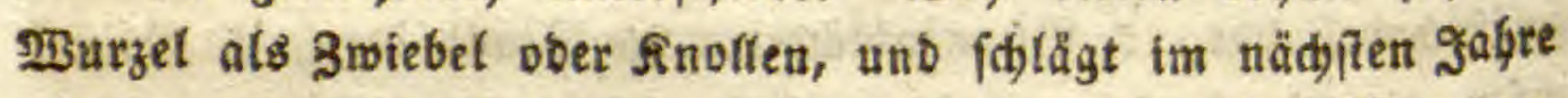
wieber aus, uno baher nennt man fie ausbauernbe (Pl. perennes). Bey anbern begält aud ber Stengel nod) ctwas Saft und bauert aus, b. b. er verbolzt. Dann bilbet fidh um ben alten halbvertroctneten $\mathfrak{B a f t}$ ein neuer, ber wieber $\mathfrak{B l a ̈ t t e r ~ u n b ~}$ 2Btuีthen treibt. Das find bie Şolzpflanzen. 2aber aud̆ biefe Gaben ein Geidbränltes Rebenszlef: benn jäfrlid, wirb bie rinbe

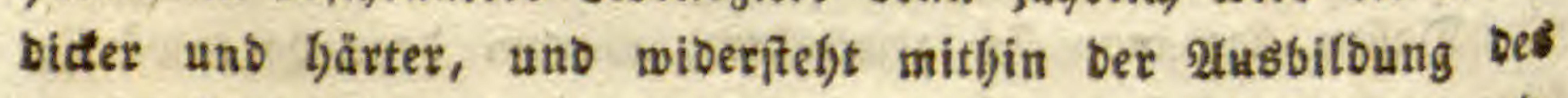
neuen Baffes, ber tmmer bânner unb bünner wirb, bis er enbo (id) teinent plą̧ melyr finbet.

Die Bäume fönten baher nur langfam an Dicte unb Eänge

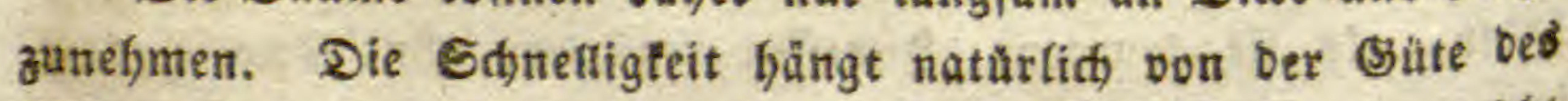
Bobens unb ber æitterung ab. Unjere Dbjibäume werben nidbt

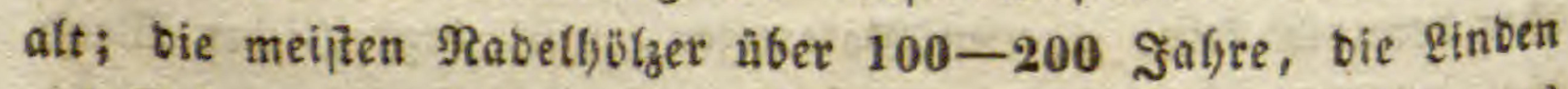
und Eidjen gegen 1000 und melgr. Son ben હebern Des Ribunuts 


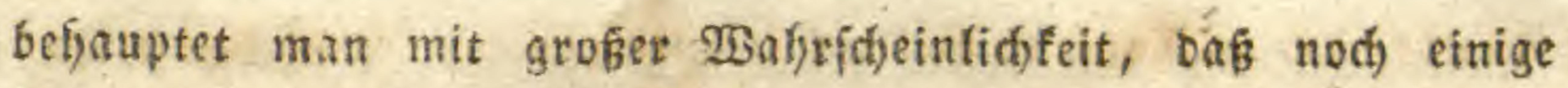

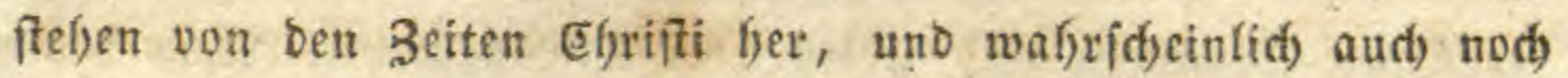

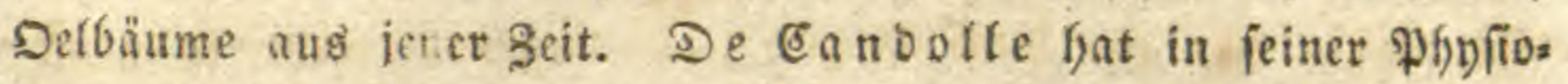
logie bie (Seldidite von aflen befannten ungefjettern 3 äumen ge:

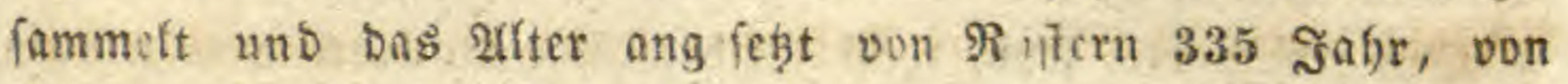
Epheu 450, Räıd)en 576, Pomeranzen 630, Delbaum 700, Pla= tane 7:0, Eeder 800, Eite 1200, Eidje 1500, 2ffenbrobbaum 5000.

Die Sdgcibenffanzen leben in Der Reget viel fürzere seit. (Es gibt jebod, शalmen, weld)e über 100 Ed)ul (jod) werben, und man glaubt, Daß̃ bie હocoşpalme 6-700 รafjr erreidje. Der berülgmte Dradjenblutbaum auf ben canarifjen Injeln war 1402 foljon ebent fo didf und holst, wie jeşt. Er hat 45 巨(f)uly im umfang.

\section{Blattall.}

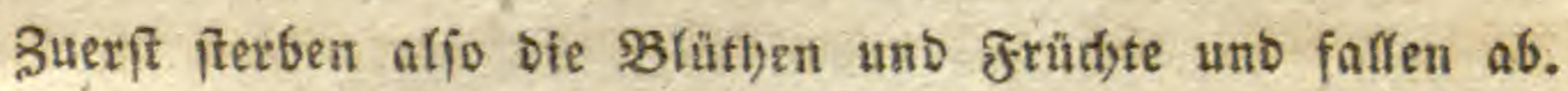

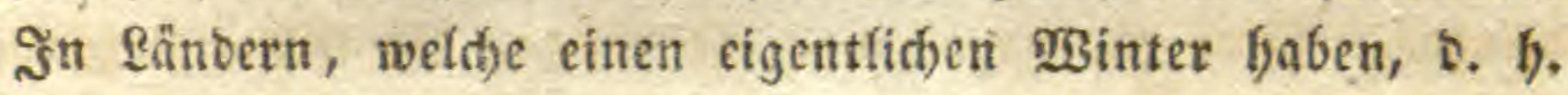
wo bie Fialte längete 3eit unter bem (Sefrierpunct bleibt unb ber Boben mit Schrree bebectt ift, faften bie Blätter am Ende Des Seerbfes ab, vorziglid) bey den Bäumen; Denn ben ben STräutern ftirbt Der Stengel mit ben Ylăttern, uno beibe bleiben

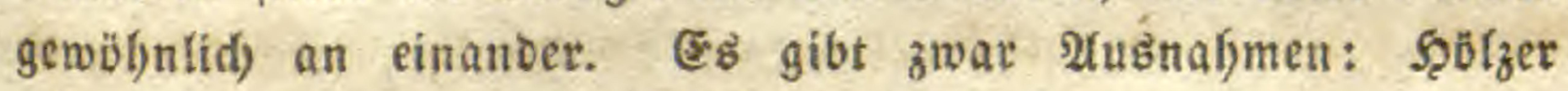
mit berben unb trocfenen $B$ lättern, befalten fie gewöfnlid) ben SSinter aber, ober verfieren fie wenigitens nidgt auf einmal, fonbern nadi uno nad), fo wie bie neuen hervorwadjen, und Dafer finben fid) gewägnlid) 3 lätter von $2-3$ gafbren bey)= fammen. So bey Dem Rabelfolz, Budjsbaum, Epheu, ber Stedspalme, ben seciben, Seeibetbeeren M.f.w.

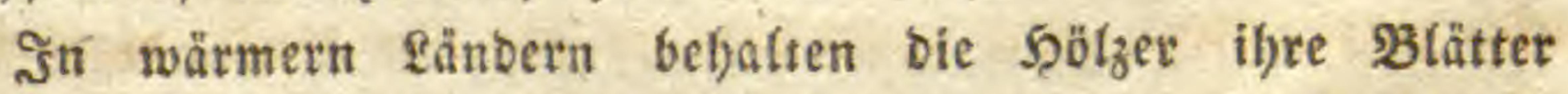
länger, unb werfen fie meiftens nur zu unbeftimmten Beiten $\mathfrak{a b}$; 2horn, Rainweibe, Jasmin, Eidhen fidon in \$tafien. "Mandse Blătter Gleiben aud) im vertrodtneten 3uftanbe hängen, wie bel) ben (Fidjen und Budden, uno faften erit im Früljafje $a b$, wann und weil fith bie Rnoipen entwicteln.

Die Urfadje Des Eaubfalts liegt offenbar im geringeren

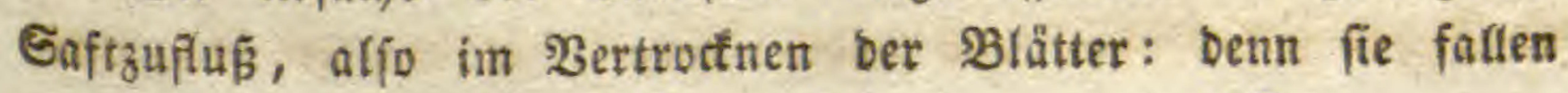
Dfen s aflg. शaturs, II. Botanik I. 


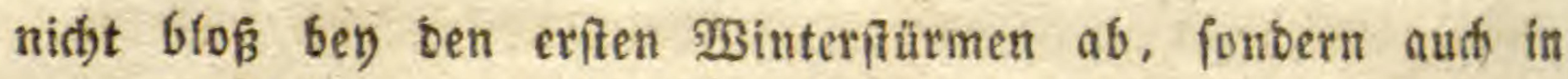
trodenen Sommern und überbeizten Ireibhäufern. 2utch fallen fie frülyer ab an geringelten 3weigen uno an faftreicben ober bleft)en Pflanzen, wenn fie getroctnet werben. Die Blätter müffen jebodh reif jegn, fomįt bleiben fie audh vertroctnet büngen, wenn etwa bie 3weige zu frül abfierben, fey es von felbft ober Durd) Xfbidneiben, ober burd) 2(nftechen von Injecten. Die Röfung bes Blatts geidielyt gewölyntid) im (Selenfe; man glaubt

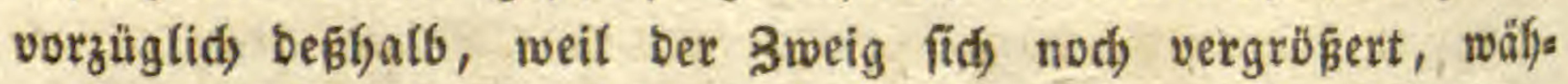
rento ber Blattitiel feine Dicfe befaält. Damit ftimmt ant beftent

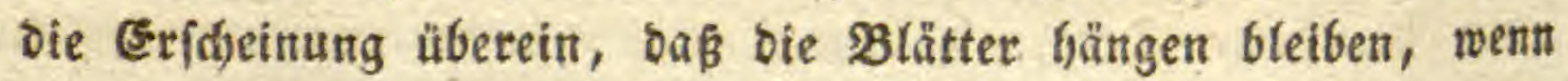
Der Bweig vorfjer vertroctuct.

3uerfit wedjelt Das Blatt feine Farbe, wirb blumenartig, meift getb ober roth, uno bann wirb es gewäbntial hold, fo bas Die Dbere Fläd)e gewülbt erfd)eint. Die Blätter ber 2lejđhen, Ieacien, bes f̧olbers faflen grün ab. Sie legen fid) an ben Stamm ober an ben gemeinfdaftlichen Blattficl, uno bant faffen bie leb̧tern bald einzeln $a b$, wie ben Dem $\Re u s b a u m, ~ G a l b$ mit Dem gemeinfdaftlidjen Etiel. Die $\mathfrak{B l a ̈ t t e r}$ an ben untern 3weigen faften früher $a b$, weil ber Saft immer melye nadh oben fitrebt.

Rad) ben $\mathfrak{B l a ̈ t t e r n ~ v e r t r o c t h e n ~ b i e ~} 3$ weige, nad biefent bet Stengel unt nach biefen endlich bie $2 B u r z c l$, ben Den Rräutett

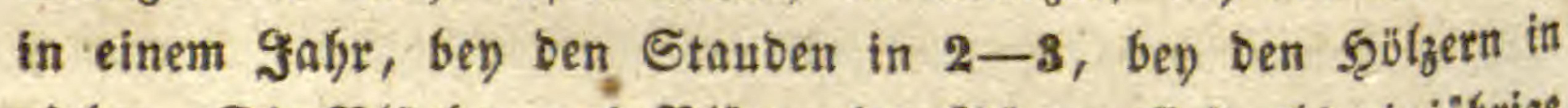
vielen. Die $\mathfrak{B}$ tütthen uno $B$ lätter ber $\mathfrak{B}$ äume fino alB einjägrige

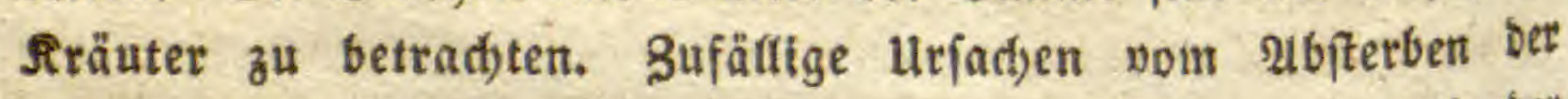
Pflanzen gibt es fefor viele. Şinderniffe im Boben, zu viel obet

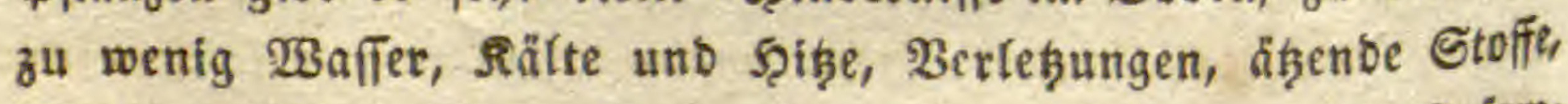
Säuten, Sifte, Sd)marob̧er u.f.w., furz afles, was ble Bufama mentwirfung ber Elemente, bes \&id)tร, ber T3ïrme unb bet Sd)were; Der Luft, bes Waffers uno ber Erbe, oder ber Rahs rungsftoffe, unterbrid)t ober Rranflyeit hervorbringt, ein (segens

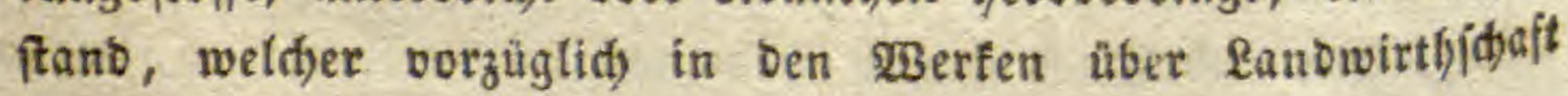
und (Gärtnerey abgefjandelt wirb. 


\section{Siter a $x$.}

1. 2ullgemeine Sthriften.

bieber gebören aud bie Werfe von $\Re$. (S) rew, Niafpigbi und geeutwenboef.

Duh a mel, Physique des Arbres. 1758. 4., beutíi 1765. 8. IV.

Mustel, Traité théorique et pratique de la Végétation, 1781.

8. II.

Tob. Sedwig, Sammlung zerftreuter 2tbbandungen. 1783.

Comparetti, Fisica regetabile. 1791. 8.

Plenk, Physiologia et Pathologia plantarum 1794. 8.

R a f $n$, Pflanzen= Pbofiologie. 1798. 8.

Re

Deffen Pflanzen=pbufiologif́te elbbandlungen. 1803, 8. III.

S ene bier, Physiologie végétale. 1800. 8. V.

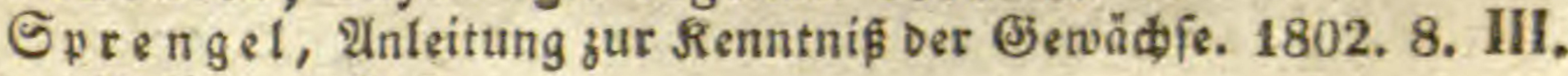
Bwepte 2ruflage. 1817.

Mirbel, Traité d'Anatomie et de Physiologie végétale. 1802.8.

Idem, Elémens de Physiologie régétale. 1815. 8. IIII. 1806. 8 .

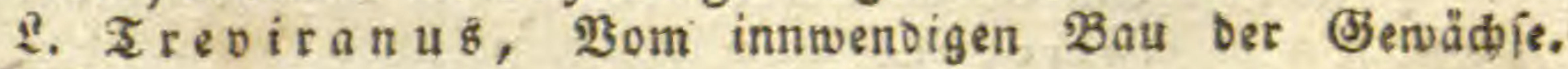

Perotti, Fisiologia delle piante. 1810. II. 12.

I inf, Brundebren Der 2 natomie und Pbufiologie ber \$fianzeit. 1807. 8. Radträge. 1812. 8.

Riefer, 2lphoriżmen auš ber Pbofiologie ber Pflanzen. 1808. 8. Sprengel, Bon bem $\mathfrak{B a u}$ uno ber Natur der Eservädjie. 1812. 8.

A. Dupetit-Thouars, Hist. d'un morceau de bois, 1815, 8.

R. Treviranus, Biologie IV. 1814.8.

Kieser, Mém. sur I'Organisation des Plantes. Haarlem. 1814. 4. 345. P1. 22. - Şauptwert, 
Keith, System of physiological Botany. 1816, 8. II.

(5. 5., S chult, Die Narur oer lebendigen Pflange. 1823. 8. II.

Dutrochet, Recherches anat. et phys, sur la structure des Végétaux 1824 .

5un dest agen, Die Inatomie, ber Ebenismus und bie phys fiologie der Planzen. F829. 8

Agardh, Lärobok i Botanik 1829. 8. II.; ald Det fo

De Candolle, Physiologie régétale. 1832. 8. III ; atch Deutid). - Sauptruerf.

2. Treoirnnus, Pbyfiologie ber (jenäh) e. 1855. 8. II. Sguntwerf. 8. II

Dutrochet, Mémoires anat. et physiol. des Végétaux. 1837. 8. 11 .

Rafpail, Nouveau Système de Physiologie végètale. 1837.

Meven, neues Stftem ber Pflanzen=\$bufiologie, 1837. 8. III;

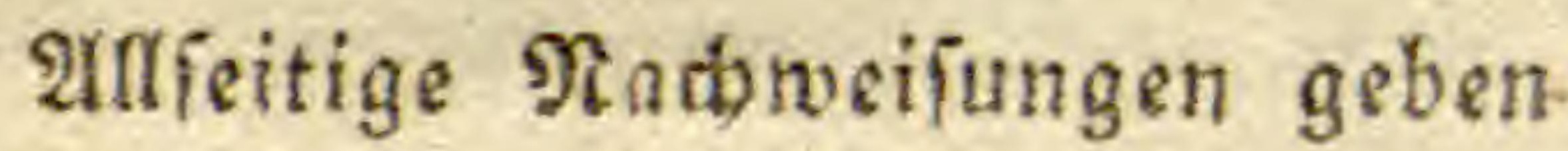

bie bot. Beridbte von wif ff $\mathrm{r} \ddot{\mathrm{B} m}$, überfegtt und vermebrt vont seilfumied. 8.

\section{Nidftung ber Pflanzen.}

Dod art, Mém. acad. 1700.

De la Hire, ibid. 1708.297.

H. Johns on in Edinburgh. new philosophical Journal. 1828.

312. (Linnaea. 1830, V. 145).

Sfen, Sfis 1832. 5. 804 .

v. Bo itb in 2unnlen Der (5etvädsftunde. 1831. IV. 404.

Knight in phil. Transact. 1806. 99. (\&. Trevirants, Benträge. 1814. 8. 191.)

Dutrochet, Recherehes sur Endosmose etc. 1828.

Idem, Mém, des Végétaux. 1837. 8. 11. 1. - Viscum p. 60. Poite a u in Ann. Soc. horticult. Paris IV. 8. 297. (2unnden ber (Semädgrfunde IV. 406.)

Pinot in Journal de Pharmacie. 1829. 490. (Botan. Beit. 1829. 6×7.) Dutrochet, ibid, 1830. p. 28.

Mulder, Bydragen tot natuurk. Wetenschappen IV. 1829. 128. (Linnaea; 4830. p. 191.) merf. 11.

Gleditsch, Mém. Ac. Berlin, 1765. - Dermifthte Bes

De Candoll e, Mém. Soc. d'Arcueil. II. 1809. 104.

Ka ight in phil. Transactions, 1812. Manfen.

Polm, lleber das $23 i n b e n$ Der $¥$ fanjen. 1827. 8.

In o bf, Defigleitien. 1827. 4.

Mustel, Traité de la Végétation. 1783, 1. 151.

B onnet, Usage des Feuilles pag. 104. Deutít 1762 unt 1803. 4. 
Mrtius in phofical. Befuit. II. 98.

B ofe, De radicum directione. 1774. 4.

\section{Richt.}

Senebier, Expériences sur $\mathrm{l}^{2} \mathbf{A}$ tion de la lumière dañ les Végétaux. 1782, 8.; Detttíth 1785.

Eaton, W3irfung oes Yid)ts auf bie Bäume in Sillimanz Sournal XIII. 1827.93. (Eiteratut-Blätter f. Bot. I 522.)

A. a b Humboldt, Aphorismi ex doctrina Physiolegiae chemicae plantarum, in ejusd, flora fribergensi, 1793. 4. 179.

(3) reng Sournat oer Doufit. V. 196.

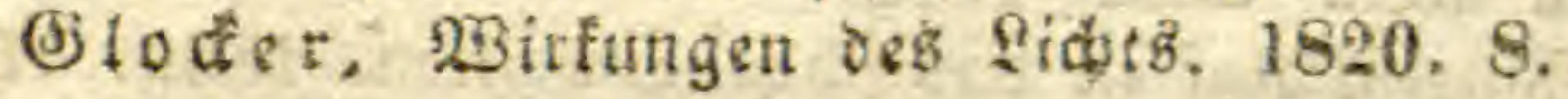

\section{S) flanzenfä) laf.}

Val. Cordus, Hist. plantarum. 1561. 11, 156. Glycyrrhiza.

Garcias ab Orte, Aromatum, 1574. 8. 120.

Linnaeus, Somnus plantarum. 1755., in Amoenitat. IV. 337. Phil, bot. \$. 535 .

S.branf, Bom Pfanzenfdlaf. 1792, 8.

Dutrochet, Du Reveil et du Sommeil in An. Sc, nat. sec. série. V1. 177.

Dillenius, Hortus elthamensis If. Mesembryanthemum.

5ुill, Der Edlaf Der Pfinzen. 1768. - 1776. 8 .

\section{Betregungen. \\ a. Der Blätter.}

Mimosa pudica, R. Camerarius, de Herba mimosa. 1688. Breynius, Centuria, 31.

Mirbel, Elémens de Physiologie I. 166.

Burnett, Edinburgh Journal of Sc. 1829. 166. (Riteratur. Blättet fü: Botanif. 18:8, 124.)

Comparetti in Mlem. acad. Turin prés. V. 209.

Debme in Bertinet Beicbiftigungen H1. 79. Ill. 138.

G a h a a n in medic. Comment. of Edinburgh, Dec. II. 4. pag. 575.

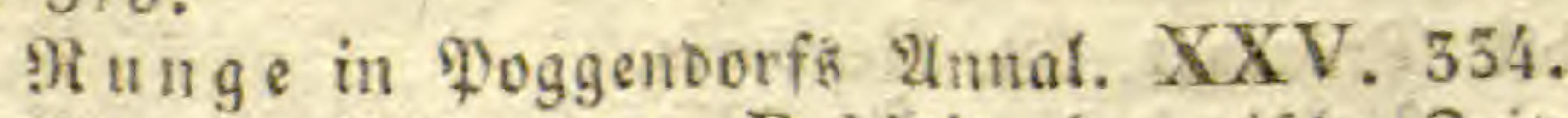

Di o bl, Blätter oer Robinia, boranifol Beitung. 1832. 503.

Pa rent, Mém. acad. $\$ 709$.

La marck, Encyclopédie méthod. Bot. I. Acacia p. 17.

Dutrochet in Journal de Pharmacie XIV. 828. p. 322. Mém. H. 1837. 534. Journal de phys, 1822, 474.

Ellis, Dionaea muscipula. 1770. 4., Deutfol 1771.

5nis ne, (Sjetreue Daffethug. III. 1813. Nir. 59. Drosera,

Mirbel, Élémens de Physiologie 1. 163. Hedysarum gyrans. 
Brouss onet, Mém. Acad. 1784. p. 616. (Journal de Plysique $30,364$.

Cels, Bulletin philomathique an. XI.

Olivi in Memorie Soc. italiana. VI. 161. (tt fteris Annas ten VI. S. 50.) Shrant ebend. IX. S. 1.

Linnaeus fil. Suppl, plant. 332. Hedysarum.

Sylvestre, Bullétin philomathique. 1793. (Utferi \& Annas

len 19.) Hedysarum.

Şufeland in $\mathfrak{B}$ oigt Mag. VI. Hedysarum.

Sinn im Samburger Dagazin 22. S. 40.

Percival in Memoirs soc, of Manchester II. 125. Hedysarum. Pobl in \{eipz. Sammlungen zut \$byfif I, 502. Hedysarum. De la Hire in Mém. acad. 1712.

Me inede, Pfanzenidlaf in ballifan Sariften. 1809. 46.

Fr. Ho ffmann in Tydfchrift natuurl. Gesch. III, 203.

Morren in Bulletin acad. Bruxelles, 1836. Nro. 10.

Rotb, Beytrảge zur Botanif I. S. 60. - Magazin für bie Botanif II. 27. Drosera.

Rumph, Herbarium amboinense V. 301.

Bruce in phil. Transact. $75,1785,356$.

Dufay in Mèm. Acad. 1736.

Spittal in Edinb. n. phil. Journ. 1830. 60.

2. Ireviranus, 3eitfinrift für Đbyfiol. I. 175.

M a jo in quarterly Journal of Science. 1827. III. 79.

Deी़ि in

\section{b. Bewegung ber Blithentbeile.}

Borelli, Hist, et obs, phys. I, obs, 100.

S. Vaillant, De structura florum, p. 9.

Lups, De irritabilitate, 1748. 4.

Covolo, Irritabilità di alcuni Fiori, 1764. 8.

Rolreuter, 3te Fortiegung 125.

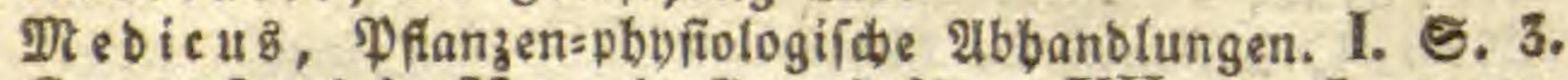

Carradori in Memorie Soc, italiana XII. 33. Lactuca.

Tupper, Sensaction in Vegetabels.

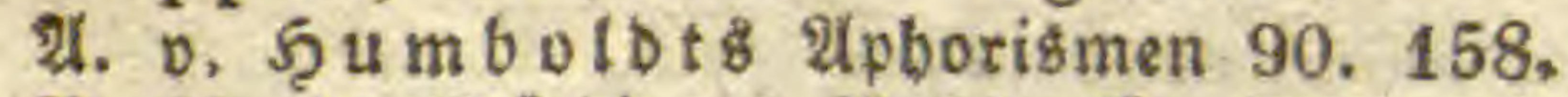

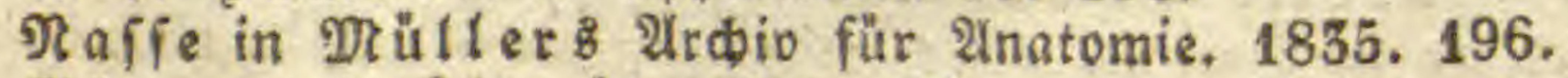

(5) öppert in Rinnåa. 1828. 237.

Linna eus, Flora suecica 311. Berberis.

$\mathrm{S} \mathrm{mith} \mathrm{in} \mathrm{phil.} \mathrm{Transact.} \mathrm{78.} \mathrm{Berberis.}$

Hooker, Exot, fl. 1. tab. 32. Stylidium.

Morren, Mém. Ac. Bruxelles XI. Stylidium. hoekia.

R. Brown, Prodromus flor, n. Hollandiae. 572. Leeuwen-

Endlicher, Monographía tab. 8. Caleya.

Lindley, Orchideae 1. 47. Megaclinium.

ร̧umbolot \& Epborismen 70. Berberis.

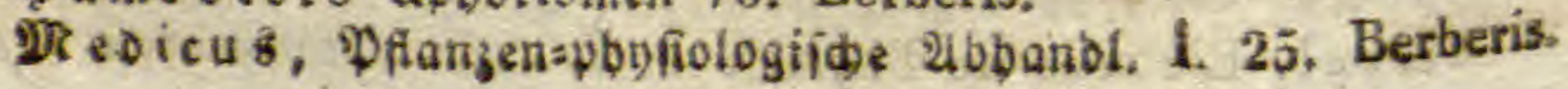


Rolreuter, 3te Fortfésung. Ciftus, Cactus. Smith, Engl. Flora III. 468. Centaurea.

\section{Färbung.}

Schle b)tenbal, gefhädte Blätter in Sinnảa V. 1830. 494. Dut ro chet, Organes aërifères in Ann. Sc. nat. 25. 1832. 242. Mustel, Traité de la Végétation I. 152.

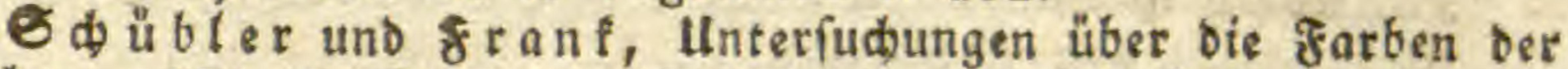
Blütben. 1826. 8. S. 31 . (S 中) weiggers Sabrbud) der Ebente XVI. 1826. 285.) 1834. 8 .

Pieper, Dab nedfelnbe Farben= Berbältniß bes Blattez.

Macaire-Prinsep, Coloration des Feuilles in Mém. Soc. Genève 1I. 115. IV. p. 1. (ङe igers Dagazin 1829. 115.) Ann. de Chimie. 1828. p. 415.

Guibourt in Journal de Pharmacie XIII, 1827.

Lemaire in Bulletin philomatique. 1824. 290. 1762. 12.

H. Saussure, Sur l'écorce des Feuilles et des Pétales.

L amarek, Flore française. 1778. 8. 124 .

Ramon de la Sagra, Annales de Sciencias, Habana II. 1828. 116. (Bibliothèque universelle 41. 1829. 84. Sinnäa VII. 1832. 54.)

S d üb fer unb $\mathfrak{E}$ a denmeyer, Unterfudungen über bie Jarben= Beränderungen ber $\mathfrak{B}$ tủthen. 1833. 8 .

(5). M eyer, Die Entwictelung ber Fled)ten. 1825. 8.

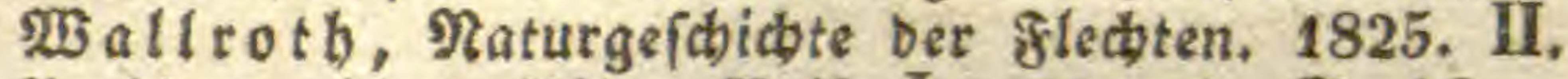

Palla s̊, blaue Pilze, Reife I. 1771. 4. 5. 46.

Bonnet, Le bel Azur des Champignons, Oeurres 8. X. Journal de Physique III. 1774. 1779.

Fabbroni in Annales de Chimie 25. 301.

IRarcet in Annalen ber Bsewädsfunbe IV. 301.

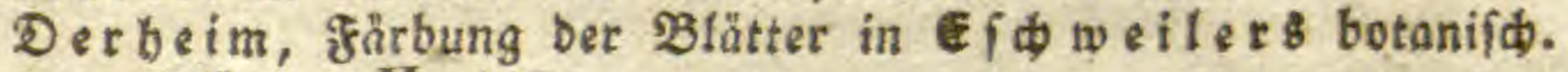
Sitteratur= 8 lättern II. 403 .

Runge, Ebemifobe Unterfudungen ber Evnareen. 1828. 4.

ऽ

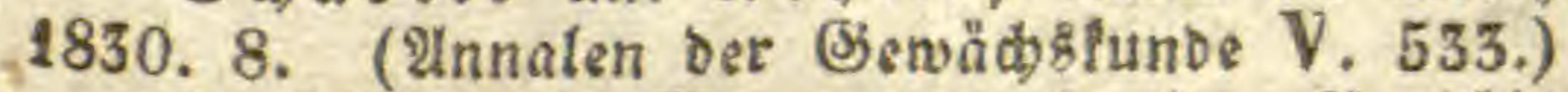

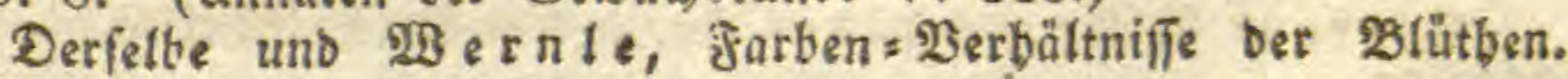
1833. 8.

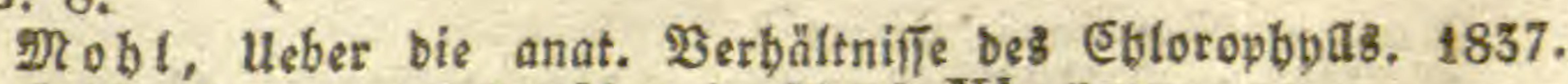

Scbleiben, aut baruber in Iinnä XI. 531.

Mr a rquart, Ueber Die Farben Der Btütben. 1855. 8.

Mobl, Ueber Die winterliфe gärbung Der Blätter. 1837.

\section{Reuditen.}

5umbofot, Heber unterisbifibe (5)asarten. 1799. 68. Rhi- 
P1. Şeinrib, Die \$bospborešen; Det Sibrper. 1S11. 4.

D e Candolle, Flore française. 1815. 8. 45. Agaricus.

Rees und (5). Bifbof in leopoldin. Berbandlungen XI. 603. Rhizomorpha.

Earode, Berliner Berbandungen I. 222.

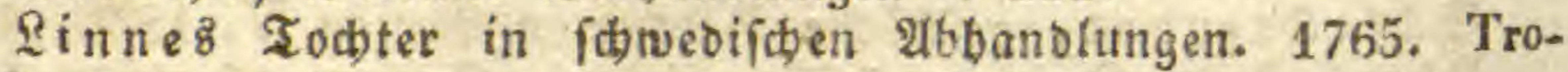
paeolum etc.

Joh $\mathrm{n}$ son in Edinburgh Journal of Sc. VI. 415.

Non a in ufteris 2mnaten V. 5.

50 pe, Neuce botonifbes Inftenbudy. 1809. 52.

2. Treviranus, Beitibrift für Pbufiologie III. 1829. 257.

5aggren in Ereft\& Annalen. 1789.

Martius, Reife in Brafilien II. 726.

Mornay, Philos, Transact. 18i6. 279. (B) i ibert 8 21ns nolen 56. 367.)

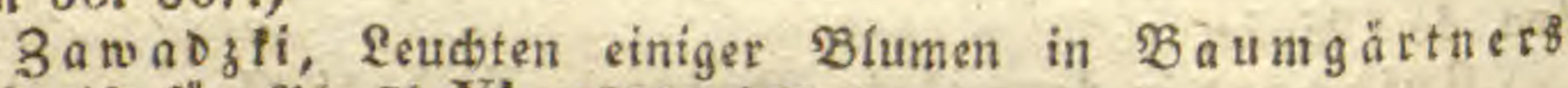
3eitichrift für pbyfî VI. 1829. 459.

Meioinger, Reudten be\& 5̧olzes in Berliner Befdäftigun gen 1II. 122 .

Rumph, Herbarium amboinense VI. 130. Fungus igneus.

Delile in Archives de Botanique II. 519, 1837.

Duhamel, Phys. Arb. 1. 150. Dictamnus.

Bertholon, De l'Electricité de Végétaux. 1783. Dict.

Sngenbouß, Berfude mit Pflanzen L. 191. Dict.

פgitloenow, Rräuterfunoe, 2uff. 6. 458. D.

Bi ot, Inflammation de la Fraxinelle in Ann. de Chimie. 1832. Août.

\section{2⿺ärme.}

Rofentbal, Beriude über die 233 rme. 1783.8 .

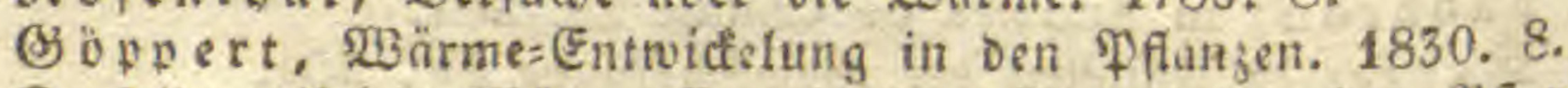

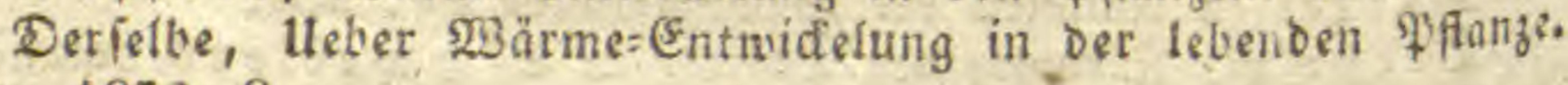
Wien. 1832. 8.

थl gardb, Biologie ber Pflanzen, 173.

Sprenge1, Rau der (benüder, 346.

Senebier in Mém. de l'Institut 1. 1796.

1807. 51 .

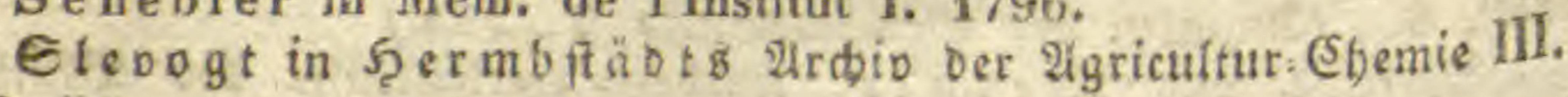

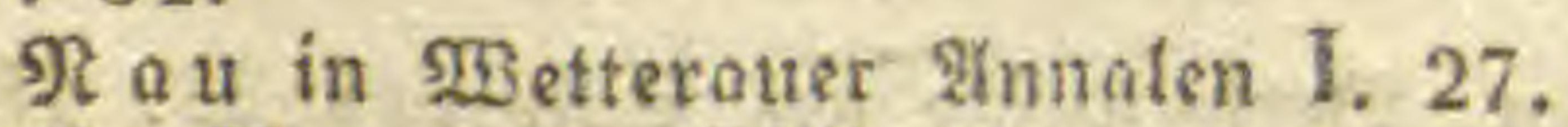

G. Hunter, Plil. Transact. 1775 et 1778 . (Journal de Physique 1X, et XVII.)

Ed b pf in शaturforfder 23. 1788. 1.

Bierfander in idswedifden 2hbanolungen 39. 1778. - Nya handligar Xlil. 1792.

Pictet, Bibliothèque britannique I.

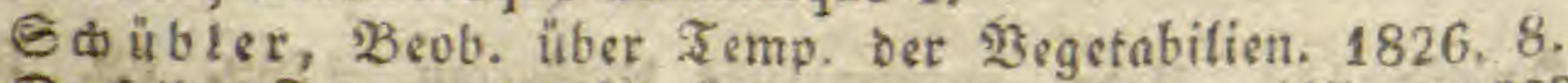
Derílbe, Iemperatur=23eränberungen oer 2 egetabilient. 1829.8 . 万ermfäot in Berliner Diagazin II. 1808. 316 . 
Rive et A, De Candolle in Mém, Soc, phys, Genève, IV. 71. (2unalen ber \$bufif XIV. 590.)

Reum, Pfanzen=\$bufiologic 167.

$\mathfrak{S}$ inf in $\mathfrak{B}$ erb. Des Gjartenbau= Bereing I. 165.

Scherer in Jacquin Collectaneis I. 172.

Pollini in Bibl. ital. VII. 1717.

Gierßoorf, lleber verfrome 3 äume.

P. Pictet in Mém. de Genèye III. 25.

\section{Electricitüt.}

4 Gardini, De influxu electricitatis in Vegetantia, 1784.

I morett $i$, lleher die Rbaboomantie I. 141.

Bertholon, Electricité des Végétaux. Deutích 1785. 8.

D) uernob, tleber Reimung ber Dionocotblebonen. S. 54.

Duh a mel, Physique des Arbres II. p. 269.

Histoire de l'Académie des Sciences. 1729.

De Candolle, Physiologie III. 1088.

Mat thew, Edinburgh new phil. Journ, 1831. Oct.

Senebier, Physiologie 1II. 345.

Van Márum, Journal de Physique 41. 1792. 218.

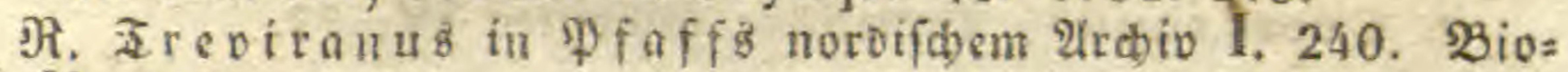
logie ll. 442.

Becquerel et Dutrochet in Ann. Sc, nat, sec. Série IX. pag. 80 .

Nollet in Mém. acad. 1748. p. 254.

\section{Bersaumitg. - Einfaugung.}

S. Gmelin, Fuci p. 38 .

Raulfuß, Frarrenfräuter 5.64.

Bonnet, Usage des Feuilles $§ .78$. Deutí() 1762 unb 1802. 4 .

Dupetit-Thouars, Reponse à Monsieur Dutrochet. Ann. Sc nat, XIX. 323 .

S马eowig, Rleine Edriften TI. 128.

Raumburg in Römers 2trotio II. 15.

Mobl, Botan. Beit. 1832 . Nr. 5.

Simon, Jacinthes p 22.

Du hame 1, Physique des Arbres II. 89. 203.

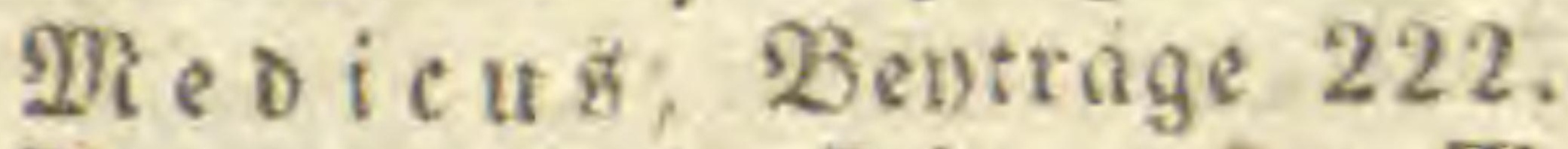

Bowman in Linneàn Transactions XVI, 599. Edpmaroger.

Va ucher in Mém. Mus. X. Orobanche.

I. Murray in Edinburgh phílos. Journal XVI.

Sisiegunan in Datturger Edriften II.

Link in Ann. Sc, nat, XXIII. 147.

Th, S a ussure, Recherches chimiques 252. 
Helmont, Ortus Medicinae. 1652. p. 53. 82. SBeibenzweig. (Stebt nidtt auf Diefen Seiten.) finben.)

R. Boyle, Chimista scepticus pag. 100. (Sif aud nitht zut

K r aft in n. Comment, petrop. 1751.

Eller, Pbuficalifbe Edbriften II. 240.

$\Re$ ülbel in 5amburger Magazin XV.

Bonnet, Mém. ac. 1750.143.

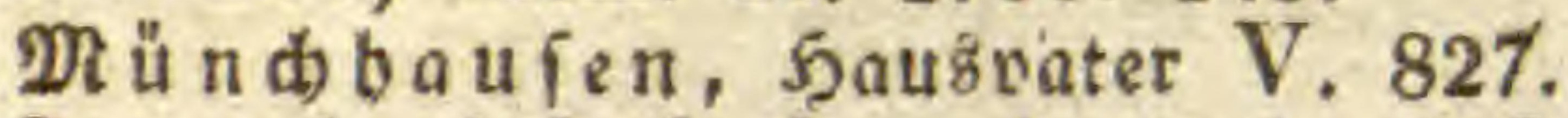

C arradori degli Organi assorbenti delle radici delle piante. 8. De Cand olle sur les Lenticelles in Ann. sc. nat. VII. 1825. 7. Pollini osserv, sulla veget. degli Alberi, 1815. 8.

\section{Wâfer: Ěinfaugung ber Slätter.}

H u m b ol d t, Flora fribergensis 159.

Deffen 2 pboriżmen 173.

Hales, Vegetable Statick p. 5. 20. 24.

Duhamel, Physique des Arbres I. 153.

Mariotte, Ess. 1. Vég. 81.

B onnet usage des Feuilles 21. 67.

\&. Ireviranus, 2ermifdte Sdriften IV. 77.

\section{Eintwitfung Der crobe.}

Dคด D, Ugrietltur=-Ebemie 209.

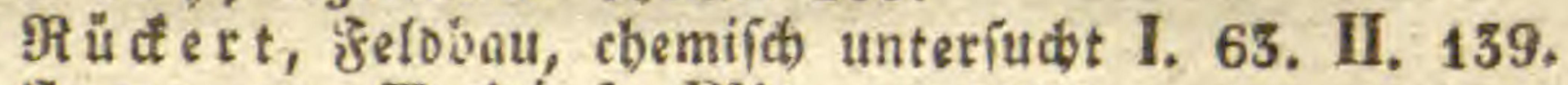

S a uquet, Traité du Plâtrage. 1820.

Peschier in Mém. Soc. phys. Genève V. 180.

S屯ủbler, Einwirlung veríbiebener Stoffe. 1826.

\section{Salze uno Säuren.}

Pallas, Reifen I. 215.

Tobn non, 2nwenbung bes Rodfalzes auf Fefobau. 1525.

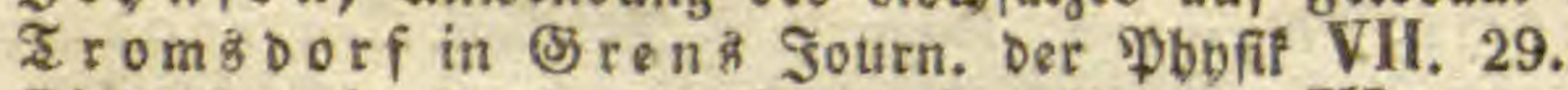

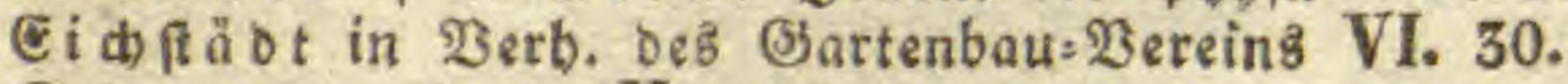

Edonoer, ebenda II. 425 .

Göppert, De Acido hydrocyanico. 1827.

Marcet in Mém, de Genève HII. 59.

\section{Netalle.}

F. J a eger, De Effectibus arsenici. 1808.

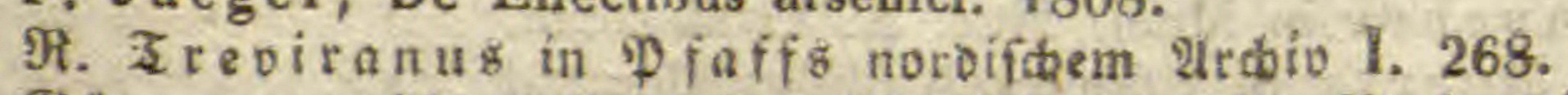

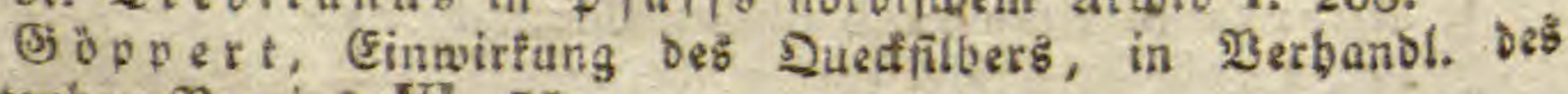
Şartenbau= Bereing VI, 75 .

VR ünd) b a u fens รุauşater V. 845. 
Эobn, Ernäbrung Der Pflanzen 259.

Zogel, Sfiz 1830. 499 .

\section{Rabrungsmittel.}

Hassenfratz in Annales de Chimie XIII.

Rirnan, Uleber Düngmittel 70 .

Ingenbouß, tleber oie, Ernäbrung ber Pfanzen. 1798. 8 .

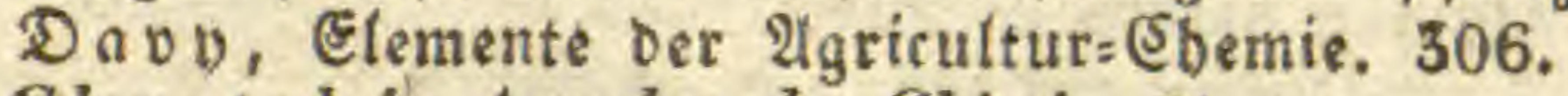

Chaptal in Annales de Chimie 74.

Rü dert, Det Felobau chemifich unterfubt) I. 319.

\$. Sdrader, Erzeugung ber eroigen Befandotbeile in ben (5)etraibearten. 1800.

Braconnot in Annales de Chimie 61.

Sobn, Ernäbrung der Pflanzen, 1819. 8.

Knight in phil, Transactions, 1820. 156.

\section{6. Şewegung Des Sellenjafts.}

Corti, Lettera sulla Circolazione del Fluido in varie piante. Modena, 1775.

Fontana, Affirmatio in Journal de Physique VIII. 1776. 232.

R. Treviranus, Bentr. zur झflanzenpbyf. 1807. 91.; verm. Sфriften II. 75 .

Goz zi in Brugnatelli Giornale di Fisica. 1818.

Amici in Memorie soc. italiana. Modena XIX. 1823. (Annales sc. nat. 1824 . 44.)

Agard in ben leopolbinifien $\mathfrak{B e r b a n d u n g e n ~ X I I I . ~} 1827$.

Me yen, ebenda. 2. S. 841.; Rinnea 11. 55.

Raulfus, lleber bas Reimen ber Sbaren 51 .

H. Slack, Ann, sc. nat. Nouv. Série 1. 371.

Dutrochet, Ann, sc, nat. 1831. 453.

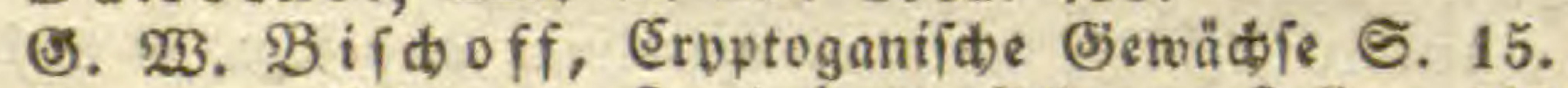

Meven, Ueber den Snubalt Der Pfanzen=Bellen. 1828, 8. 70.

R. B rown on Impregnation in orchideae 21.

\section{Berridytung ber aeffen.}

Dutrochet, Endosmose.

Me e en, Innbalt der Dflanzenzellen. 1828, 8 ,

I. Ireviranu8, Bermifte Edoriften IV.

Link, El. philos, bot. 117.

R u b o l $p$ bi, Unatomie Der Pflanzen $\oint .20$.

Dutrochet, Recherches sur la structure des Végétaux p. 16. 9. Moloenbatwer, Bentrüge E. 12. 


\section{2ltbmung.}

\section{¿uftprocéb Der $B$ lätter.}

Hales, Vegetable Statick 329.

Priestley, Experiments and Observations 1. p. 28. II. p. 1.

- Berfuche uno Beobachtungen 1. II.

Cavallo, On the nature of aire.

Sugenbous, Berfube mit Planzen. 1786. 8.

Senebier, Einfure des Sonnentidts, 1785. 8.

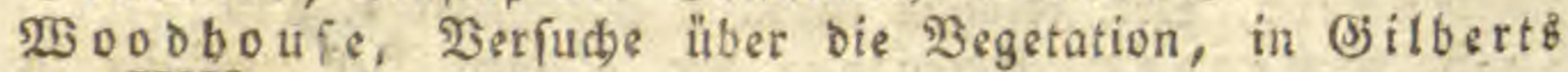
थninalen XIV. 348.

Th, de Saussure, Rech. chim. sur la Végétation, 1804.

Palmer, De Plantaruip Exhalatione. 1817. 8.

(5) rifbow, Unterf. über bie Mtbmungen Der Siewäd) 1819.

Ru mforo \& 2 erfucbe. 1787.; in feinen fleinen Sdbriften IV.

2. 1805.321 .

5. Dav1), Otftem ber Agricultur= Sbemie 253.

Sin $\mathrm{P}$, Girundebren 283.

- Burnett in Journal of the royal Institution, 1830. October.

Macaire in Mém. Soc. phys. Genève. IV. 47.

Humboldt, Flora fribergensis 174 .

Marcet in Mém. Soc. phys. Genève VII.

B. Heyne in Linn. Tromsactions VII.

Succow in Actis Theod, Palat. V. 165.

(5) irtanner in (3) rens Sournal Der pbufif HI. 317.

Il s 1 ar, Fragmente neuerer Pflanzenfunde 153.

ginf in Sabrbihdern ber (Stenäbstunoe 1. 73 .

Guettard, Mém acad. 1749.

B onnet, Recherches sur l'usage des feuilles, 1754.4., beutí, 1762 und 1803.

Knight, Philosophical Transactions, 1803. 277 1804. 183.

Th. B ischoff, De vasorum spiralium structura et indole. 1829. 8.

Ad. Brongniart, Recherches sur la structure et les fonctions des Feuilles in Ann. sc, nat, XXt. 1830. 426.

Gilby, Diss, de mutationibus quas aëri infer, etc. Edinburg. 18!5. 8 .

lluger, Leter Exantbeme Der Pfanzen.

Krocker, De plantarum Epidermide. 1800, 8.

19. Serridatung Der Epaltmünoungen.

Grew, Anat, of Plants, 1682. $\$ 27$.

Sa ussure, Observations sur l'écorce des Feuilles, 1760.

Bonnet, Recherches sur l'usage des Feuilles. (Oeurres 1779. 8. XI.)

Van Marum, De motu Fluidorum. 1773. 
229. 143 .

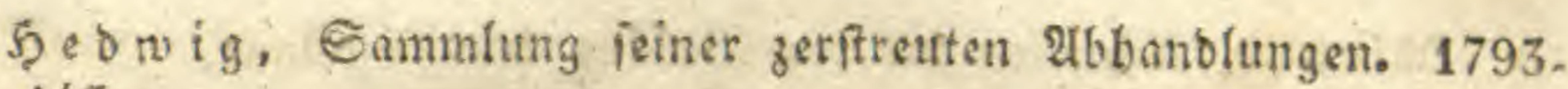

Sd)ranf, Bon Den Nebengefäfen ber Pflanzen. 1794, 92.

Sngen bouk, teber Ernäbrung oer \$flanzen. 1798.

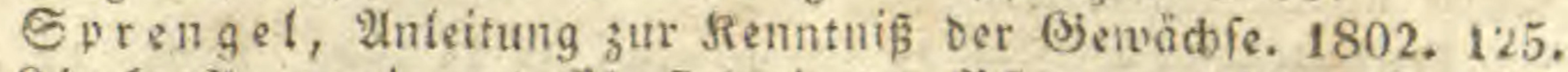
Sinf, Anaromie uno pbufiologie ber pflanzen. 1807. 5. 110. Rub olobi, Uhatomie der Pfinjer. 1807. 5. 102.

$\mathrm{D}$ e $\mathrm{C}$ and olle in Bulletin philomathique nr. 44. p. 156.

Kieser, Mém. p. 231.

\section{Serridutung ber Sfiralgefäñe.}

Malpighi, Anat. plantarum I. p. 32. Grew, Anat. of Plants p. 125.

I. Hill, Construction of Timber p. 23.

Reichel, Le vas, plant. spiral. 1758.

․ Treviranus, Bau Der (Semähfe 97. Benträge S. 35. Ruo olpbi, Anatomie oer Pfanzen. 1807, 5. 197.

Bernbaroi, lleber Pfanzen=Befäße S. 44.

Riefer, Pbutotomie S. 107.

S.-Mi olden baner, Belträge 1812, 4. ఠ. 317.

Hedwig, De fibrae veg. ortu p. 20.

Mirbel, Hist, nat etc. I. p. 85.

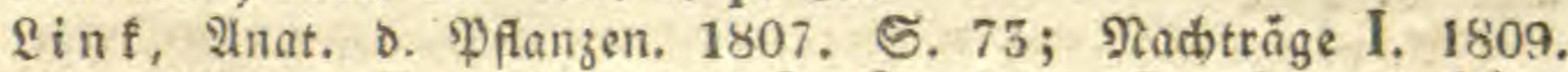
18. Sirunolebren Eap. 3. 1837. 1. S. 191. Sur les trachées, Ann. Sc, nat. 23. 1831. p. 14\%.

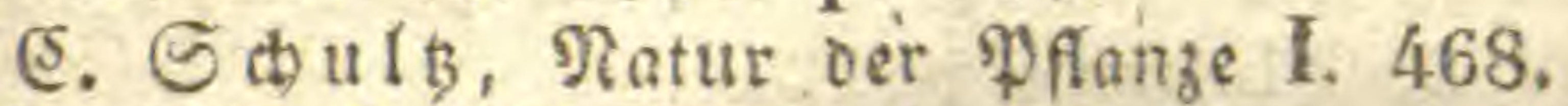

L. B is ch off, Vas, spir, structusa etc, 1829. 8.

F o cke, Respir. Veget. p. 16.

Bonnet. Puben ber Blätter 9.90 .

Hales, Statick p. 45.

Sprengel, Banu oer Bjenäbre 97. S. 153.

Ki e ser, Mém, sur l'Organisation des Plantes, Haarlem. 1814. 4. 173.223 .

Moldenhawer, Diss, de Vasis plantarum, 1779. 4.

M a y er, Sur les vaisseaux des Plantes in Mém, acad. Bérlin. 1788.

\section{Eaftlauf.}

Hales, Statick, 1727, 8,; fram. 1735. 4.; beutfí, 1747. 4. Walker, Transactions of soc. of Edinhurgh. I, IL 1790.

Vauquelin, Expériences sur la séve des Végétaux. 1799. 8. Knight, Philos. Transact. 1803. 1804. 1806. 1809.

Tu rpin, Essay sur la Végétation.

Idem, Histoire d'un morceau de bois.

Noretti et Guicciardi, De nonuullis physiologico-botanicis. 1831 . 
Mirbel, Mémoire sur les Fluides des Végétaux.

5.. Eotta, Benegung deß Gaiteś. 1806. 4.

Э. Dever, Naturgetretue Darfellung ber Bewegungen ber Gäfte u.f.w. 1808. 8.

Delabaisse, Sur la Circulation de la sève. 1733. 12., et in Recueil des Diss. à l'Acad de Bourdeaux IV. 65.

L a Hire in Hist. Acad. des sciences. 1693.

Gouan, Sur les causes du mouvement de la sève. 1802, 4. Goe ppert, Nonnulla de plantarum nutritione. 1825. 8.

Dutrochet, l'Agent du mouvement vital chez les Végétaux etc. 1826. 8.

Idem, Nouv, rech. sur l'Endosmose. 1828.

1834.8.

Meyen, theber bie Bewegung ber Säfte in ben Pfanzen.

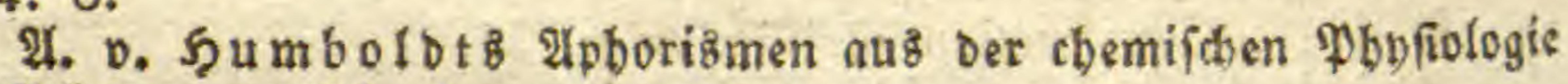
Der Pflanzen. 1794. 8.

Th, de Saussure, Recherches chimiques sur la Végétation. 1804. 8.; Deutíc 1805.

Wahlenberg, De sedibus materiarum in plantis. 1806. 4.

Rafpail, Journal des sciences d'observations II. III.; Annales des sciences naturelles. 1825 et 1826 .

Coulo mbe, Circulation de la sève in Mém, de l'Inst, nationale II. 246.

2. v. Şu mbulbt in (5) ifbert 8 Innalen der Phyfif. VII. 334 .

פ. Treviranus, Bau Der Bjenäbie 102.

Duh amel, Physique des Arbres. 1758. II. 236. IV. 295.

Mariotte, Essay de Physique p. 82.

Tylk owsky, Philos, curiosa in Actis Eruditorum, 1682. 150.

S inf, Anatomie Der $\mathfrak{P}$ flanzen. 1807. S. 79.

Hill, Construction of Timber, 1770. 8. 32.

W alker in Edinburgh, phil. Transactions V. 1, p. 3. (Eamms

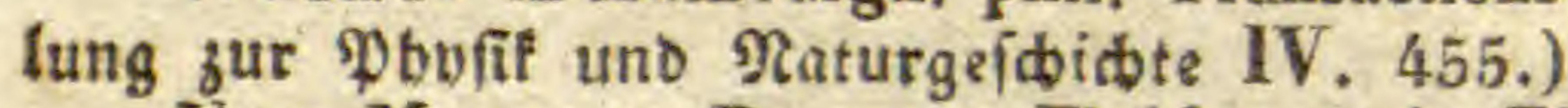

Van Marum, De motu Fluidorum in Plantis. 1773.

Frenzel, Umlauf Der Säfte in Den Pflanzen. 1804. 8.

Kieser, Mém. 237.

Raj us, Hitsoria plantarum I. p. 8.

Erelyn, Sylva p. 80.

Duroi, Wilde Baumzudt I. S. 10.

Fermin, Description de Surinam I. 195.

R u mph, Herbarium amboinense I. p. 5. V. p. 135.

Mirbel, Elémens de Physiologie végétale. 1815. I. 198.

Eprenget, Bau der S5rmäđfe 435.

Ireviranug, Bevträge 257.

Vaucher, Séve d'Août in Mém, Soc. Genève I.

Malpighi, Anat. plant, cap. 22.

Grew, Anat. of Plants 125. \$. 11.

Coulon, Diss. de mutato humoris indole pag. 14.

B urnett in phil, Magazine. 1829. April.

Pollini, Vegetaz. dei Alberi p. 146. 
Dupetit-Thouars, Essays.

Perrault, Oeuvres 1. p. 77.

Dodart in Mém, acad. 1700 . p. 78.

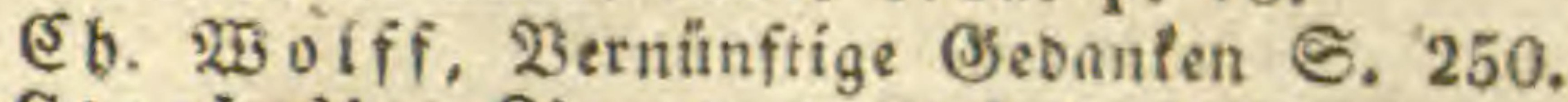

Staehelin, Obs anat, et bot. 1731. 4 .

A. Hunter, Georgical Essays I. 170.

Ingenbous, Deriude mit Pfanzen. 1780. 8. - Leber Ers näbrung Der Pflanzen. 1798, - Dermifdte Edriften.

\section{Evcloje.}

9. P. Molden bawer, Beyträge 148.

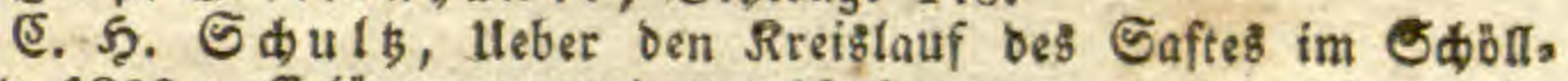
fraut. 1822.; Erläuterungen Dazu. 1824.

Rudofpbi, Pbyfiologie III. 316.

Sdu $t^{\prime}$, Die Ratur ber lebenbigen Pfanze.

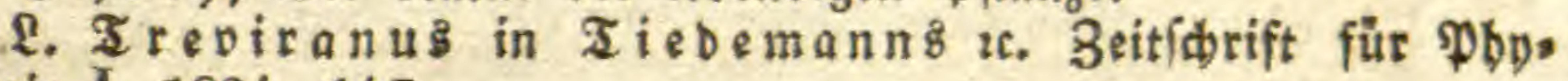
fiologie I. 1824. 147.

Surriray in Ann, soc. linn, du Calvados II. 56.

Schultz in Bibliothèque universelle, 1827. Novembre. Botanifbe Beitung. 1828. গr. 2. 3. 9.

Me ben in Sinnäa II. 1827. 661.; Reopoldinifbe ßerbanb= lungen XIII, 2.

Mirbel, Amici, Dutrochet in Ann, sc, nat. XXII. 1831. 84. 426.433.

Schultz in Ann. sc. nat, 1833.; Archires de Botanique II. 1833. 420 .

\section{2lbjonberung.}

Krocker, De plantarum epidermide. 1800.

F. Fis cher, De Filicum propagatione.

Deven, Gectetions=Drgane oer pflanzen. 1837. 4.

Guettard in Mém. Ac. 1745. p. 268, 1747. II. p. 10.

Gd ranf, Bon Den Rebengefäßen ber Pfianzen. 1794.

Mirbel in Mém. Mus. IX. 455.

(3) riefelid, Sileine botanif́che Sdoriften. 1836. I.

G. Struve, De Silicia in plantis monnullis. 1835.

Sif hoff, Eruptogamifhe Đervähre I. 14. 50.

Lehunte in Edinb. phil. Journ. 1832.

Rumph, Herbarium amboinense I. 22. IV. 9. Tabafchir.

V a uquelin in Journal de Pharmacie. 1826.

Daubeny in Edinb. phil. Journ. 1835. July.

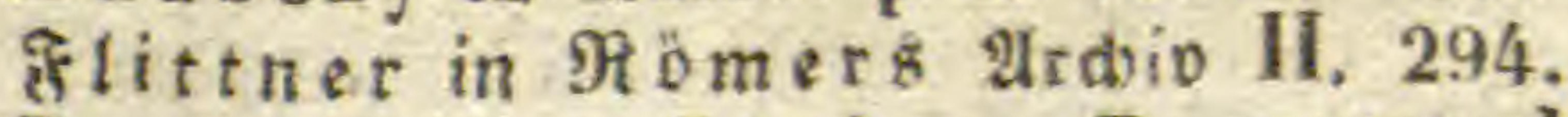

Brugmans et Coulon, De mutata humorum indole. 1789. pag. 77.

B a cker, Diss. de radieum plantarum physiologia $§ .36$.

Macaire, Assolemens in Mém, Soc. phys. Genève V. 287. 


\section{Nectarien.}

Fontedera, Anthologia. 1720. 4. p. 49.

G. R. Boelh mer, De Nectariis, 1758. 4 .

Linnaeus, De Nectario florum, 1763. (Amoen, acad, VI.)

Kotb in Magazin für die SBotanif 11. 1787. 39.

1 Weihe et Sprenge1, De Nectariis. 1802.

Me ine ofe, Ueber bie Bedeutung der Nectarien, in Den balli: fden meuen Gdtriften 1809. S. 19.

(Sb. (S. Sprenget, Das entoefte (S)beimnis in Der Befruds: tung. 1793 .

Cassius, Opusc. phytol. I. 223. II. 249.

Dunal, Fonctions des Organes floraux. 1829. 4.

Soye r-Will emet, Nectaires. 1826. 8, et in Ann. soc. linn. de Paris V.; Desvaux ibid. 123.

Fis cher, Mem, des Naturalistes de Moscou I. 248.

Rurr, Unterfudungen über bie Bedeutung ber Nectarien. 1833. 8 .

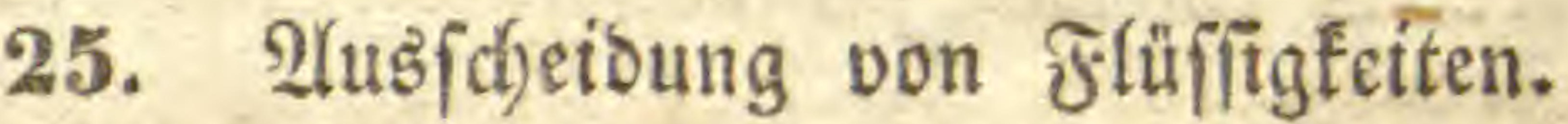

\section{Sales, Statif 23.}

Sierfanber, Sdwebirthe 2Abbandungen 35. 66 .

5abenidt in bot. 3eit. 1823. 34.

Somiot in $\operatorname{linnäa}$ VI. 65.

Graham in bot. Mag. II. 2798.

Rumph, Herbarium amboinense V. Nepenthes.

Wallich, Plantae asiaticae II. 35.

\section{6. (3)etüche.}

L innaei Philosopltia botanica. 1751, 8, 284.

Idem, Odores Medicamentorum. 1752. (Amoenit. III, 195.)

Stinfende pflanzen in Qinnä̆ II. 671. III. 194.

Clocquet, Dissertation sur les Odeurs 4.

Four croy, Annales de Chimie 26. 232.

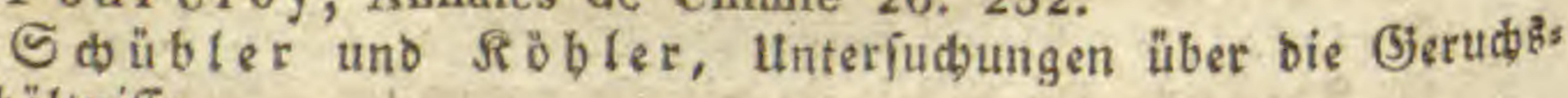
Berbältniffe.

Chevalier in Ann. Sc. nat, I. 444. Vulvaria.

\section{Bergröserung.}

Nobt, Ueber Bermebrung ber Pfianzenzellen. 1835. $\mathrm{XI}, \overline{\mathrm{B}} 5$. 
Dutrochet, Archives de Botanique II. 231.

Burggoorf, Naturg. vorzügl. Şolzatten I. §. 278.

Sier 8torf, Ueber erfrorne Bäume 20.

Dupetit-Thouars in Ann. Sc. nat. XIV. 322.

Desfontaines in Ann. Sc, nat, V. 374.

Duvau, ibid IX. 338.

Journal of r. Institution. 1830. October.

(S) öppert in $\mathfrak{B e r b}$. Dess preuß. SJartenbau= Bereins VIII. 17.

Delile, Voyage horticole p. 6.

Keith in Annals of Philos. 1819. Nro. 56.

Idem in Edinburgh, phil. Magaz. 1834. 205.

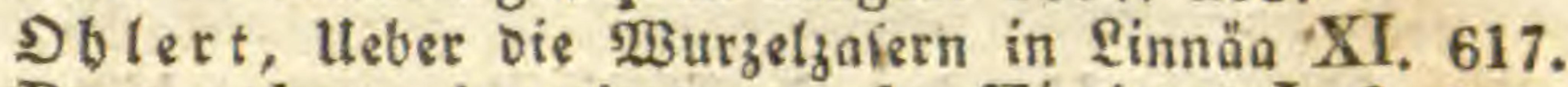

Dutrochet, Accroissement des Végétaux I. \$. 2.

Martius, Palmae tab. 45. 66. 84.

Hu mboldt, Plantes équinoctiales I. 5. tab. 1. Ceroxylon.

Mirbel, Ann. Mus. XIII, 136. Ptychosperma.

Rumph, Herbarium amboinense V. 97. Rotang.

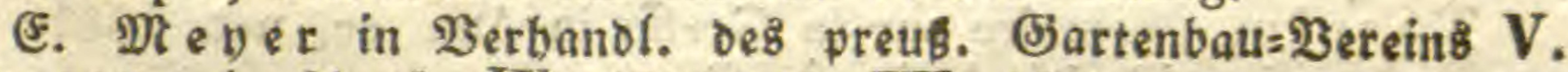
1828. 110.; in Pinnäa IV. 1829. 98. VII. 455.

Duch aisne in Ann. Mus. VII. 248.

Mulder in Bydragen tot de natuurkundige Wetenschappen IV. 1829. 251. 420.

Vriese, Tydfchrift v. nat. geschiednis III. 46.

Berthel ot in novis Actis leopoldinis XIII. t. 39. Dracaena.

Dupetit-Thouars, Histoire d'un morceau de bois.

Dobl, Palmen in Dem Werte von Martius.

Meneg hini, Struttura del Caule. 1836.

Desf ontaines, Histoire des Arbres II. 574.

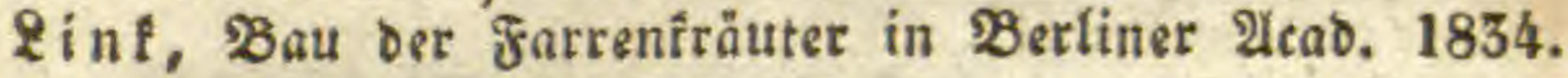

\section{Bermegrung.}

D una l, Hist. nat. des Solanum. 1813. 4.

Turpin, Organisation des Tubercules du Solanum in Mém. mus. 1829 .

Succarini, Mtonogr. ber amerieanifisen Sauerflearten, nebf Nadtrag. 1833. 4.

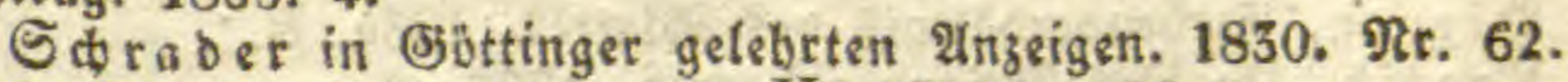

A. Riehard, Ann. sc. nat. II. 1824. p. 12.

Henslow, Ann. sc, nat. XIX. 103.

Rnofpen: Linne, Gemm, arb, in Amoen. II. 188.

Æ. Miever in Sinnäa VII. 441.

Moretti et Guicciardi, De nonn, animadr. in motum lymphae. 1831. 8 .

A. Henzi in nor, act, nat, cur. XVII, tab. 39.

Cassini, Bulletin philomatique. 1816. 71.

Rnigbt in Ireviran

DPen \& allg. शpaturg. II. Sotanif I. 
Sebwigs zerftreute elbbanblung II. 125.

Turpin, Ann, soc, horticulture de Paris IV. 1829.; Ann. sc. nat. XXIII, 1831.

Durd) Blätter: Ugricola, Univerial= Bermebrung allet Băume. 1716. I, 109. II. 43.

De Candolle, Mém, sur les Lenticelles in Ann, sc. nat. 1827. Miller, Phil. Transact. 58. p. 203.

\section{Pfropfen.}

Tho uin, Monographie des Greffes in Ann, mus, hist. nat, II. 253. XVI.

Idem, Noureau Cours d'Agriculture VI. 496.

Tschudy, Essay sur la Greffe. 1819. 8.

Knight, Horticultural Transact I. 194. II, 199. 201. V. 292.

Turpin, Mémoire sur la Greffe in Ann. sc, nat. 1831.

Cabanis, Traité de la Greffe.

Mủn đ) ด a น

Dupetit-Thouars, Easay pag. 41. - Mélanges XIII.

\section{Reprobuction.}

Tristan in Mém, Mas, X, tab, 2.

Morren, Bydragen natuurk. Wetensch, IV. 358.

Ebrbart, Bevträge III. 70 .

Mtobl, Entwidtelung beß̉ Rorfs unb bet Borle. 1836.

I. Frisch, Miscellanea berolinensia Cent. II. 1727. 26.

Duhamel, Physique des Arbres II. 42.

Rnigbt in Treviranu \& Bepträgen 223.

\section{Raubfalf.}

Böhmor, De foliis deciduis, 1797. 4.

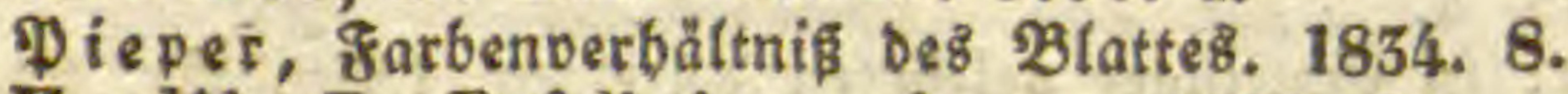

Vrolik, De Defoliatione arborum. 1796, 8.

Duroi, Baumzuकt II, 94.

V au che r, Sur la Chûte de Feuilles in Mém. de Genére I. 120. Bo itb in bot. 3eit. 1824. Ne. 33. 


\section{Entwidélung Der Blûthen.}

Engelmann, Prodromus de Antholyfi, 1832. 8. Roeper, De Organis plantaram. 1828.

Ro e per, Obs, in florum naturam, Linnaea I. 437. 1830. 353.

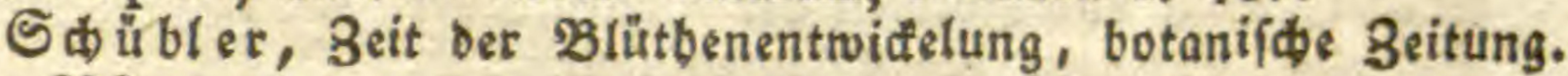

Linna eus, Calendarium florae, 1756. (Amoen, acad. IV. 387.) Philosophia botanica, 1751. p. 272.

Stillingfleet, Miscellaneous Tracts, 1759. 8.

Lamarck in Mirbel Elémens de Botanique, 1815. I. 287. Gilibert, Chloris grodnensis. 1781.

Idem et Madame Lortet, Calandrier des flores pour Grodno et Lyon 1809. 8.

Bigelow, Forwardness of the Spring etc. 1817,; in Sillimans Journal I. 1817, 76. Idem, 1828. 4.

Horologium florae, Lin naeus philosophia botanica 272.

De Candolle, Mémoires de Savans étrangers de l'Institut I.

Draparnaud, Sur le moeurs des Animaux et Végétaux 38.

Virey, Flore nocturne in Journal de Pharmacie XVII. 1831. 673.

Ramon de la Sagra in Ann. sc, de la Habana, 1828.

Venten at, Bulletin soc. phil, I, 651. Agave foetida.

Linna eus, Metamorphosis plantarum. 1755. (Amoenit. IV.)

Idem, Prolepsis plantarum. 1760. (Amoenit. IV.)

Fr, Wolff, Theoria generationis, 1759 et 1774, 8 .

(5) ötbe, Netbamorpboje Der Pflanzen. 1790. 8.

D Pen, Raturpbilofopbie. 1810. II. 8. 75. - 1831. 181.

\section{Bau bet $\mathfrak{B}$ lütben.}

Mirbel, Anatomie des Fleurs in Ann, Mus. IX، 458.

Se ow ig \$ vermifdte abbandungen 1. 65.

Mirbel, Labiées.

a untb, Ssraßblütbe in Einnäa V. 57.

L. Rich ard, Mém. Mus. I. 366.

Gleichen, Nouv, découv. 24.

\&. TreviranuB, Beitjфrift für Pbofiologie II. Bermifфte Sobriften I. II. IV.

(5) ledtendal, Einnaea I. 602.

Plob1, Umwaindelung oon 2untberen in Earpelle. 1836.; über bie ftbröfen 3ellen ber 2ntberen in ber botanifben 3eitung. 1836. 697. - Erlätterungen und פertbeibigunger 26. 
Mirbel, Ann, mas, IX.

Purkinje, De Cellulis antherarum fibrosis. 1830。 4.

Boseck, De Antheris florum.

Ludwig, De Pulvere Antherarum. 1778. 4.

Robert B rown, Linn, Transactions XIII. 1821, 211.

A. Brongniar't, Génération de l'Embryo in Ann. Sc. nat. XII, 1827. XV.

Mirbel, Sur le Marchantia in N. Ann. Mus, 1.

Pobl, Bau unb Formen ber Poflenforner, 1834.

Derielbe, Strurtur ber Pflanzenfubftanz.

nåa XI.

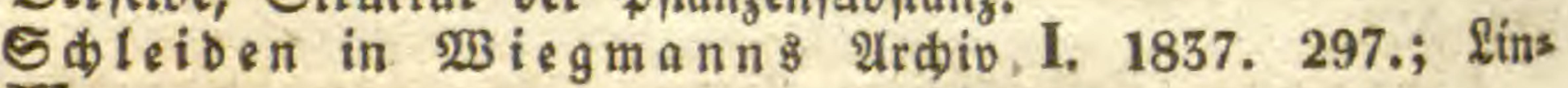

Hedwig, Fund. Hist, nat. Muscorum II. Introd. X.

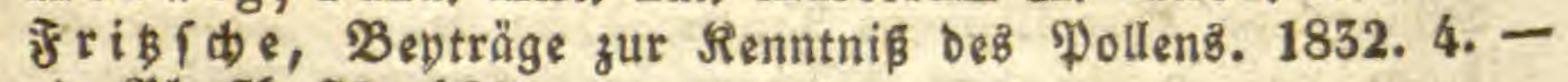
2nn. D. Phyfif. 32. 482.

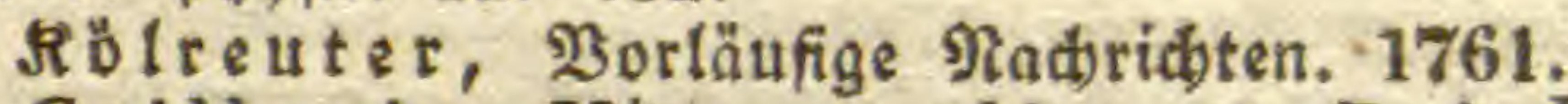

Guill emin, Mém. soc, hist. nat. Paris II. - Recherches sur le Pollen, 1826.

Frifśche, Uleber ben Pollen in Mém. étrang. acad. Petersbourg III.

Beauvois, Journal de Physique, 1811.

R ü bing in tinnäa VIII.

B if

Robert Brown, On Orchideae and Asclepiadeae, 1831. Annals of Philosophy. 1831.

A gardh, Ann, sc. nat, sec. Série VI. 193.

Єbrenberg, Ueber bas Pollen ber 2lzclepiabeen. 1831. 乏innảa 1829. ธ. 94.

A mi ci, Osservazioni sopra varie Piante in Mém. scc. italiana XIX, - Ann, sc, nat, II. 67. et 1830. 331.

Rafpail in Mém, soc. hist, nat. Paris III. 1827. 221.; et in Férussacs Bulletin XV, 89. 1828. 8.

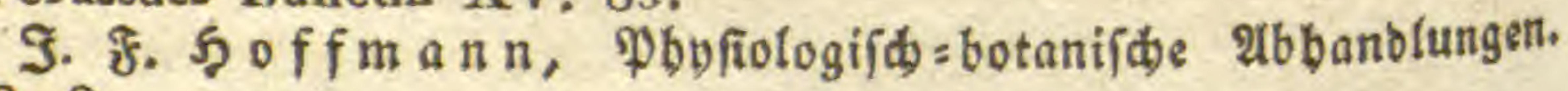

Rob, Brown, A. brief account on the Particles in the Pollen. 1827. 8. (Bermifibte Sdbriften IV. 141).

Mirbel, Sur l'Ovule. Ann, sc. nat. 1829. 302. IV. 75 .)

R. B rown, On kingia, 1826. 8. (

Der Drbiben: R. Brown, Flora N. Holl. 309.; Bauer, Illustrations; Dupetit-T houars, Orchidés 13.; Wydler, Archives de Botanique II. 310.; A. Richard in Mém. soc. hist, nat, Paris I.; Orchides pag. 17.; Poeppig nova genera I. tab, 91.

Der थ 3 clepiaben: Jacquin, Misc, austr, I. tab. 1,; R. Brown, On Asclepiadeae; in Linnean Transact. XVI. 722.; A, Brongniart, Ann, sc. nat, 24. 1831. p. 275.; (S) leident,

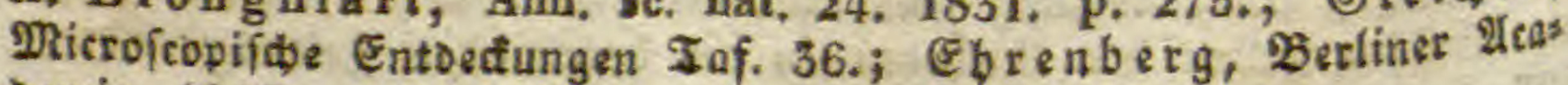
bemie. 1829. 


\section{Entwictelung ber Fruct)t.}

Sinclair, Hortus gramineus, 1825, 8.

B érard, Mém, sur la Maturation des Fruits 8., et in Annales de Chimie XVI. 152. (હ. Sprengel, शeue Entbed. III. 1822. 374.)

Th, de S a ussure in Mém, soc. Hist, nat, de Genère I. 1821. 384 .

פe edicus, Beyträge zur Pflanzens2tnatomie, 1799, 262.

Thouin in Ann. Mus. VI. p. 437.

$\mathfrak{R} u n t \mathfrak{b}, 2$ läthen= unb Frudtbilbung ber Eruciforen in Berh. शbbandlungen. 1832.

Richard du fruit, beutíd 1811. 8.

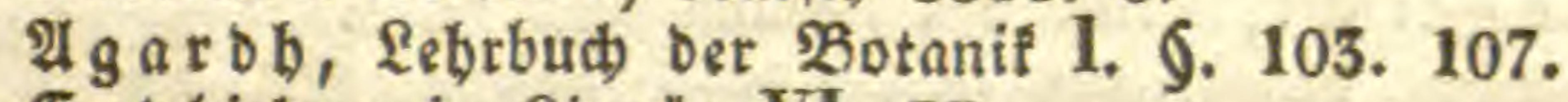

Enblider in Sinnäa VI. 37.

2. Ireviranu 8, Beitfdrift für Phyfiologie IV.

A. St. Hilaire, Placenta central libre in Mém. Mus. II.

Ga ertner, De Fructibus et Seminibus plantarum I. 62.

\section{Entwictelung Der Samen.}

Mirbel, Recherch, sar la Marchantia tab. 3.

I, Hedwig, Theoria generationis et fructificationis plantarum. cryptogamicarum, 1784. 4.

थ. $\mathfrak{B} . \mathfrak{B}$ if in leopoldinifien Berbandlungen XIV. 147. II. 781, - Botan. Beit. 1836. গr. 6.

Raulf $u \beta$, Daß $\mathfrak{B}$ efen ber Farrenfräuter, 1827, 4.

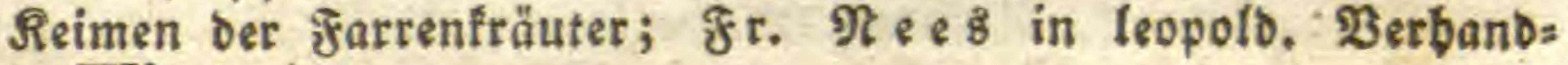
lungen XII. 1. 157.

I. G a ertner, De fructibus et seminibus plantarum, 1789. II, 4.

K. Gaertner, Carpologia. 1805. I-III. 4.

Duhamel, Des Semis et Plantations. 1760. 4.

S. Gérardin, Mém, de conserver les graines 8.

Sittmann, Embryo bes Samenforns. 1817, 8.

Tittmann, Reimung Der \$flanzen. 1821, 4.

Lefebure, Germination. 1800. 8.

Ro e p er, Enumeratio euphorbiarum. 1824. 4.

Richard, Conifères, 1826. 98.

Trap a: Mirbel, Élémens phys, I. pag. 80.; De Gandoll e, Organographie II. 91.

H o m berg, Mém, acad, 1693.

थ. รุ u m bolbt, Ipborismen. 
Sфübler, Das Reimen ber Samen in einfaden Erben, in Den Şofwuler B̉ăttern S. 94.

De Eandolles Pbyfiologie II. 287.

Ramon de la Sagra, Annales de scienc. de la Habana, $1827-1829$.

Adanson, Famille des Plantes, 1763. I. 84.

Reuter, Der Boben uno die atmofph. \&uft u.f.w. 1833. 8. Ş unbesbagen, 2lnatomie unb Pbofiologie ber Pflanzen 326. B oehmer, Commentatio de plantarum semine. 1785. 8.

R. B rown, Linn. Transact. XII. 1. 148.

De Cand olle, Legumineuses. 1825, 4. 69.

$\mathrm{V}$ a stel in Bulletin philomatique Nro, 66. 138.

Knight, Philos. Transact. 1809. p. 1.

Bernbarbi, Berfdiebenbeiten des Pflanzen:Embenos in Rin nảa VII. 1832. 561.

L. Richard, Lemna in Archines de Botanique I. 201.

A. Brongniart, Fruit des Lemna ibid II. 97.

Şartmann, Desgleiden in bot. Beit. 1824. Nr. 12.

A ch ard in Mém. acad. Berlin 1778. 31.

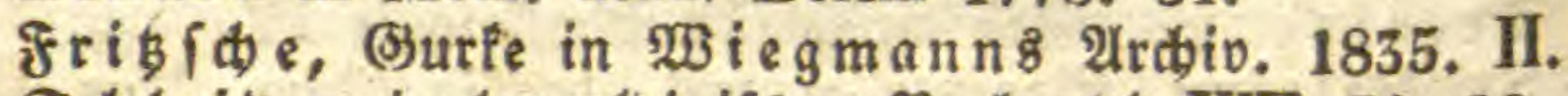

Sdleiben in leopoloinifकen Berband. XIX, 34. 86, 112. Qinnäa XI. 527.

Treviranus , Entwidtelung bes Embryo. 1815. - Symbolae phytologicae 63.

Correa de Serra in Ann. Mus, XVIII. 206.

A. Jussieu in Mém. Mus. XII. 510.

R. Brown in Edinburgh, philos, Journal. 1827. IV. Conifera.

Sdleiben in 23 iegmanns Ardiv. 1837. I. 307.

Eorba, Befrudtung in leopold. Berbanol. XVII. 599.

Duvernov, Reimung Der Mtonocotylebonen.

E d w a rds et Colin, Germination in Ann. Sc, nat, Sec. série I. 265.

Martius in bot. Beit. 1836. Nr. 1.

Seiffer, unreife Samen, Sfiz 1838. 113.

Burg \& borf, Slaturg. Der Şolzarten II. §. 130.

H umboldt, Flora fribergensis 156.

F. Fif

\section{Beftåubung}

ber \afmen: Herodotus I. §. 193.; Theophrastus II. sap. 9.; Plinius XIII. cap. 4,; Casfianus Bassus pag. 103.; Jorianus Pontanus 1505.; Prosper Alpinus, Hist. nat. Aegypti II. pag. 14. cap. 7.;, Gledits ch, Mém, acad, Berlio. 1749. 103.; Delile, Flore d'Égypte 172.

Caesalpinus, De Plantis, 1683.

Patrizio, Discussiones peripateticae II. Lib, 5 . 
et 1604. 4.

A. Zaluzanius, Methodus herbariae. 1592, 4. 1. cap. 24,

Rud. Jac. Camerarius, Epistola de Sexu plantarum, Tubingae. 1694. 12, , et in Miscell, nat. cur. Decuria III. Annus 3. 1696. Appendix p. 31. (Non Decuria III. Annus 2. Appendix p. 37 . de quercuum Gallis.)

I. H. Burckhard, Epistola de charactere plantarum naturali, 1702. 4. et 1750 .

Morland in phil. Transact. XXIII. 1703. Nro. 287.

Ge of froy in Mém, ac. 1711.

S. Vaillant, Discours sur la Structure des Fleurs. 1718. 4. et 1728 .

La Cro ise, Connubia Florum. 1728. 8.

P. Bl air, Botanical Essays. 1720. 8.

Pon ted era, Anthologia sive de Florum natura. 1720. 4.

A. Jussieu, De Analogia inter Plantas et Animalia. 1721. 4.

R. Bradley, Philosophical Account of the Works of nature. 1721. 4 .

Calandrini et I. A. Trembley, Theses de generatione plantarum. 1734. 4.

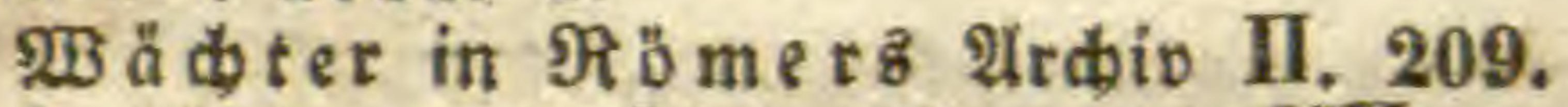

S alis bury in Linn. Transact. VII.

Linn a u s, Sponsalia plantarum, 1746.

Idem, De sexu plantarum. 1760. (Amoenitates acad, X. 100.) Đeegen biefe wieder: Rajus, Hist. plant. I.

Bory St. Vincent, Voyage II. 63.

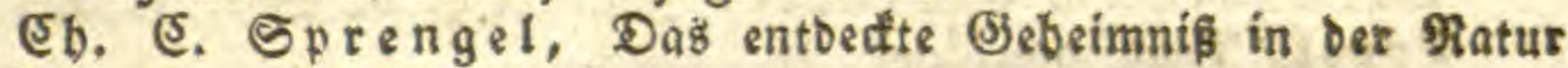
Der Befrudtung. 1793, 4. \&.

Dagegen: Spallanzani, Della Generazione di diverse Piante, nella Fisica animale et vegetabile, 1782. 8. III. - En français. 1786.

S belver, Eritif ber Eebre von ben Eefífledtern ber Pflans 3en. 1812. 8. Fort fegungen 1814 und 23.

Señfhel, Ueber bie Serualität der Pfíanzen. 1820. $S$.

\&. Treviranus: Die Rebre vom Bsef́ledte ber Planzen. 1822. S.; vermifhte Sdbriften IV. 95.

Autenrieth, De discrimine sexuali. 1821. 4.

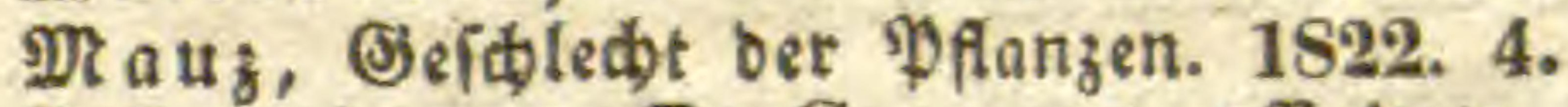

Schweigger, De Corp. nat. affinitate. 1814.

Mikan, R. J. Camerarii Opuscula 159.

Бdrant, Botanifte Beitung. 1822. Nr. 4.

Desfontaines in Mém. acad, sc, 1783.

S m ith, Phil. Transact. 1788.

פe edicus, Pflanzenspbufiologif́te 26bbanot, 1803. I. 58. 120. S difubr, Şanbbut 1791. III.

Morren in Ann. Soc. Horticulture de Paris XX.

Braconnot in Férassac Bulletin sc. nat. IX. 175.

Salisbury, Paradisus londinensis tab. 77.; asiat. Journal Nro, 154. Stylidium. 
Ebrenberg in Bertiner शenbemie. 1829.

Alph. De Candolle, Monographie des Campanulées. 1830.4. Monti, De Aldrovanda in Commentariis acad. bononiens, 1747. 4. 404.

Nuttall, De Vallisneria in Journal, Philadelphia, 1822.

Mirbel, Marchantia in Ann, mus hist, nat. 1. 93. (Ann, Sc. nat. 25. 1832. 73.) - Archives de Botanique I. 97. 143.

2. Ireviranuв, Beitidrift für Pbofiologie II. 226.

A. Brongniart in Ann. Sc. nat. XII, 152\%. 170. XXIV. 109. XV. 393 .

Rob. Brown in linnean Transactions XVI. 742. Orchideae, Bermiftote Sdyriften IV. 1830.

Eoroa, Reopoldinifas Berbandungen XVII.

Sकleioen in 23 iegmann \& 2 rbio f. Raturg. III. 312.

Wydler, Formation de l'Embryon des Scrophulaires in Bibliothèque universelle. 1838. October.

Enolider, (5rundzüge ciner neuen Tbeorie ber Pftanzens zeugung. 1838. 8. 22.

37. Beftäubung Der blütbenlofen Pflanzen.

Staehelin in Mém. Acad. 1710.

(B) leid) en, Microfcopifabe Entbetungen. 1774. 4. 55. Unter: (uh)ungen. 1762. Fol.

Bernbarbi in $\subseteq$ d) rabers sournal f. b. Bot. V. 2.

Presl, Tent, pteridogr. 16.

S chott, Gen. filicum II.

Hedwig, Theoria gen. tab. 10.

Idem, Fundamenta I, p. 74.

unger in bot. Beit. 1834. Fro. 10.

Mever 8 Rebenfitunden 130.

Sф ärer in Sdweizer naturwiffenfobatliden थnzeigen 1. 23.

Lyngb ye, Hydrophytologia p. 35.

Quce in $U_{\text {fteris }}$ Unnalen XV.

I gar b b in Iinnäa X. 449.

$\checkmark$ a uch e r, Hist, des Conferves p. 43.

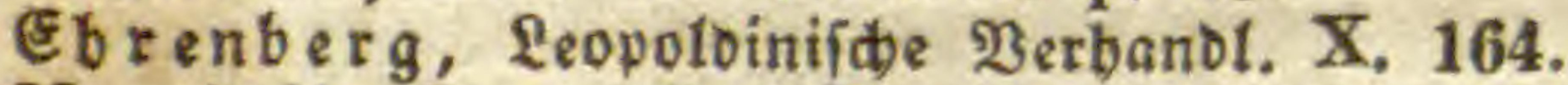

Marsigli, Generazione Fungorum p. 28.

Buxbaum in Comment, petrop. III. 264.

A udouin in Ann, Sc, uat, Sec, série, Zool, VIII, 257.

38. Megrere Sieime in einem Samen.

I. Gaertnier, De'fructibus etc., Introd.\$168. Pinus eembra, Allizm.

Dupetit-Thouars in Bulletin philomathique. 1808. 251. 
Idem, Hist. d'un morceau de bois p. 84. Zea. Sकleioen in 2 iegmann \&ै Urbiv III. 312. Mirbel, Elemens I. p. 58. Cynanchum.

R. Brown, Flora novae Hollandiae 296. Hemerocallis,

Bernb a r bi in bot. Beit. 1835. Nr. 37.

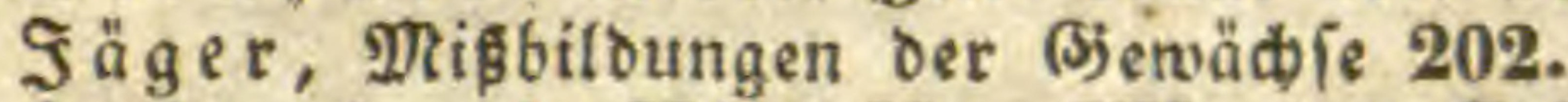

A. Jussieu in Mém. Mus. XII. 519. Polembryum.

.Wall ich, Plantae asiaticae II. p. 5. Carpinus.

\section{Reifen ber frudst.}

Kaempfer, Amoenitates IV. 701. V. 809.

Burgżoorf, Jefdidte ber Şolzarten II. 129.

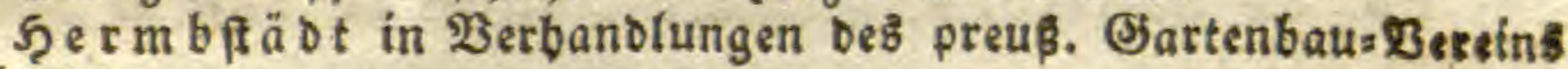
VIII. 98.

2. Trenirant\$ in finnảa IV. 71. Jeigen.

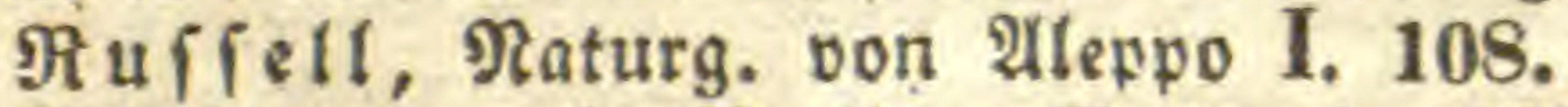

Willbe now in Berliner 2 cabemie. 1799. 79.

De Candolle, Mém. sur la Maturation des Fruits. XVI. 156.

Bérard, Sur la Maturation des Fruits in Ann, de Chimie

Couverchel, Ibidem. Bb. 46. p. 156.

Th, de Saussure, Influence des Fruits sur l'air in Mém. Soc, de Genève I. 245.

Morre $n$ in Ann. Horticulture de Paris XX.

R. Brown in linnean Transact, XII, 143.

40. Sieimung alter Samen.

Du h amel, Des Semis pag. 93.; Reneaume, Mém, acad. 170s. \erbanolungen beß preußs. ઉartenbau=ఇereins XI. 11.

(5 a y im Edweizer nat. 2Inzeiger III. 32.

Transact, Soc. linn, de Bordeaux, 1835.

Hooker, Bot. Companion II. 299.

Th, de Saussure, Dessechement des Graines in Mém. de Genéve III. 2. p. 1.

Botan. Beitung. 1S35. Nt. 1. Numient Samen.

હ. v. Sternberg, Reimung von Mumien=Samen, bev Ber* faumlung der Raturforficer zu Etuttgart. Sfis 1836. 231. 


\section{Reimung beg Reimpulvers.}

\&. Treviranu\&, פermifdte Sduriften II. 79. IV. 212.

MOb 1, Entwictelnng uno Bau ber Sporen in botan. Beit. 1833. গ⿰r. 1 .

S chott, Gen, filicum I.

A gardh, Propagation des Algues in Ann. Sc, nat, sec, Sésie, VI. 194.

$\Re$ ot b, Botanif́be Bemerfungen $ఠ .180$.

(5.) Mever, Nebenfunden $\mathbf{1 7 5}$.

Cassini, Opusc. phyt. II. 368. Phallus.

Ehren berg, De Mycetor. genesi in nov, act. nat. cur, X. 164. Fr. Nees, ebenda XVI. 91.

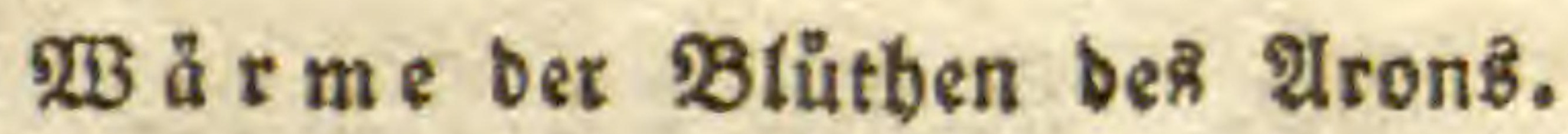

L a marck, Encyclopédie méthodique III. 1789. p. 9.

Hubert in Bory Voyages II. $6 \mathrm{~S}$.

Senebier, Physiol, végétale III. 314.

Th, de Saussure, Action des Fleurs sur l'Air in Aan, de Chimie XXI. 279.

2. Treviranuz in Zeitídrift für Pbyfiologie 111. 266. Pbyfiologie, 183s. II. 691.

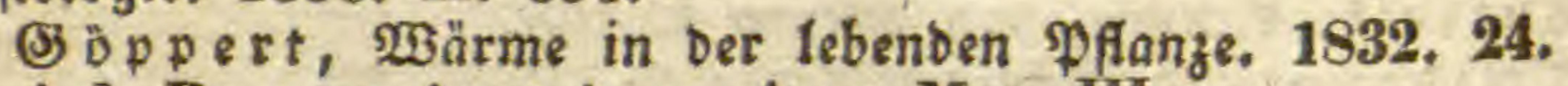

Ad. Brongniart in n, Ann, Mus, III.

Vrolik et Vriese in Tydfchr, natuurl, Geschiedenis II. Nr. 4.

\section{2Itten und I6arten.}

Galesi o, Traité du Citrus. 1811. 8.

Idem, Teoria d. Riproduzione vegetabile. 1816.; beutíf 1814.

Pollini, Sopra la Teoria di Galesio. 1818. 8.

Duhamel, Sur les Causes de la multiplication des espéces in Mém. ac, 1728.

Duch a isne, Manuel de Botanique. 1764. 8. 34.

Idem, Hist. nat. des fraisiers. 1766. 8.

R. Swe et, Geraniaceae, 1821. S. V.

Irattinnid, Neue 2rten von Pelargonien. 1825. 8.

Herbert, A. Treatise on boulbous roots. 1824. Amaryllis.

Bernbarbi, Ueber bie थrten ber Datura in Tromm n. Sourn. für \$barmacie 26. S. 118. (Qinnäa 1833. 155.)

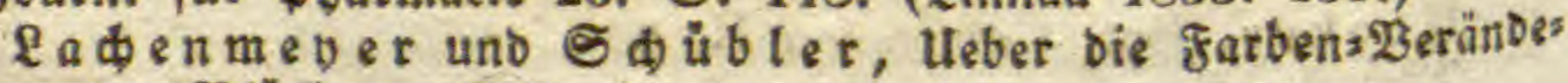
sungen Der 2 lüthen. 1833.8

Ris so, Hist. nat. der Orangers 18. Føl.

Idem, Productions de l'Europe méridionale Il. 1826. 8.

De Ea n oolle, Spietarten bez Robls uno Der Rettige. 1524. 8.

De eger, Eultivierte Roblarten. 1S33. S. 


\section{Saftaropflanzen.}

Linnaeus, Plantae hybridae. 1751. (Amoen, acad. III. 28. VI. 293. $X, 126$.

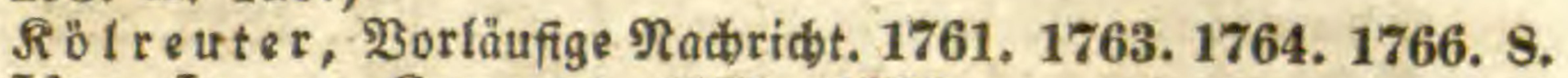

Idem, In nov. Comment. 1775-178s.

S a g e ret, Hybrides in Ann, sc. nat. VIII. 1826. 294.

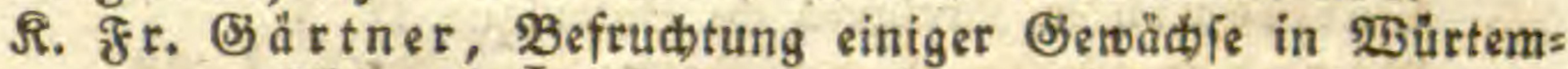
berger naturn. 26b̧anti. I. 1826. 35.; botan. Beitung. 1829, 686 . Sโiz 1832. 495.

Kn igh t in horticultural Transactions IV. 367.

Schiede, De plantis hybridis. 1825. S.

\&. Treviranus, 2ermifate Sdrifter, IV, 127.

1828. 4.

ม. W i egmann, Baftarb = Erzeugung im Pflamzenteide.

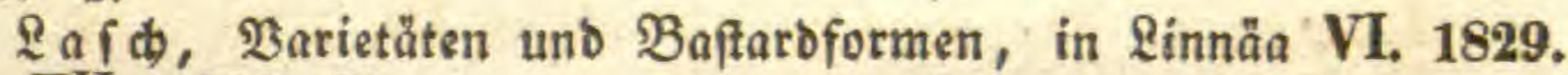
405. VII. 1832. 74 .

Le coq, Recherches sur la Reproduction des Végétaux. 1827. 4.

G. Koch, De Salicibus. 1828. 8. 9.

Reichenbach, Flora excursoria.

Vill ars, Plantes hybrides in Roemeri Collect. bot. 186.

De Candolle, Hybridae in Mém. soc. hist. nat. Paris 1.

Vass alli-E and i, Calendario georgico di Torino, 1802.

Seringe, Bulletin botanique. 1830. 117.

B e n j. C o ok, In phil. Transact. 1745.

\section{Sdymarozer.}

G a spard, Mém, sur le Gui (Viscum) in Magendie Journal de Physiologie VIl. 1827. 8. 227.

Vaucher et Desmoulins, Orobanches in Ann, Sc, aat, sec. sórie. III. p. 65 .

Unger, Parafiten in $\mathfrak{B}_{\text {iener }}$ Unnalen I., 33.

Du ha mel, Mém. Acad. 1740. 695.

J. B a nks on Blight in corn, 8.

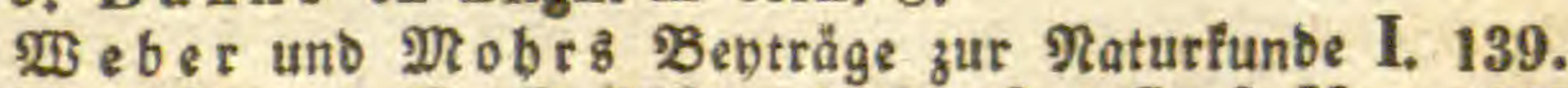

Henchman, On Orchideae in Loudon Gard. Mag. 1835. 139.

\section{Miß̄bilbungen.}

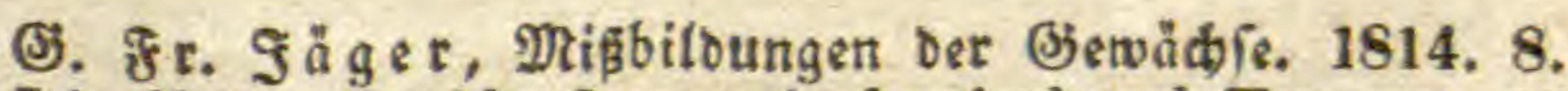

Lindley, Double flowers in horticultural Transact. 1826. 4. Knight, ibid, I. 30.

Kn ight, Linn. Transact. IX, 268. - Striemige Blätter.

B rad l ey, Treatise of Gardening. 1796. 8. Il. 129. 
Bl a ir, Botanical Essays, 1719. 8.

Linnaeus, De Peloria. 1754. 4. (Amoen, I. 70.)

R ö per, bépgleiфen in \&innäa. 1827. 85.

Lelieur, La Pomone'française. 1817. 8.

Mo quin, Irrégularités de la Corolle in Ann, sc. nat. 1832.

Duvaux in Ann. Sc, nat, VIII. 168.

હbamiffo, હbelone in \&innäa I. 57. VII. 1S32. 206.

Sd) f edten b a l in Linnäa V. 1830. 493.

Ratzeburg, De Peloriis. 1825.

Guillemin in Archives de Botanique II. 1.

$\Re 8$ per in Berbanol. ber Bazler nat. Befक. I. 30.

6. Soffmann in Uferis थnnalen XIII. 90. 


\section{Beronbere \$flatzenfunbe.}

Bisher haben wir unร blö mit Der Pflanze uีberhaupt bejdäftigt, nefgmlid) mit ifren Drganen uno beren $\mathfrak{B e r r i d j t u n g e n . ~}$ Diefe Drgane, in ocr 3abt 13, wie wit gefelfen haben (S. 10), finben fich aber nidjt gleích afte beyfammen, und nod) weniger afle an einem beftimmten \$lab, fo bá jebe entftefenbe \$flanze ber andern gleid) wäre, uno es̉ alfo überaft nur eine einzige Sătung găbe, etwa jo, wie man fí benten fönute, Daß́ zuleß̧t ber Menjid, nad) Bertilgung after Thiere, aftein bie (Erbe bes völferte; fonbern bie Organe entiftelgen aftmäblid), inbem fie fids Qus ben (s)erveben entridteln unb trennest, uno batb biejen, balo jenen Plab einnehmen, bis fie enolid), afte begfammen und an Demijenigen Plaţe fint, wo fie einanber bas Eleidggevidyt balten unb gemeinidhaftlid) wirfen fünnen. Šebe fold)e Entwictelungss. ftuffe beiteht mithin aus anbern ober anbers geftalteten Drganen, und fefft eine befonbere Pflanze für finth vor. Es wirb baher to vielerten Pfanzen geben, als es Drgane gibt, uno fie werben

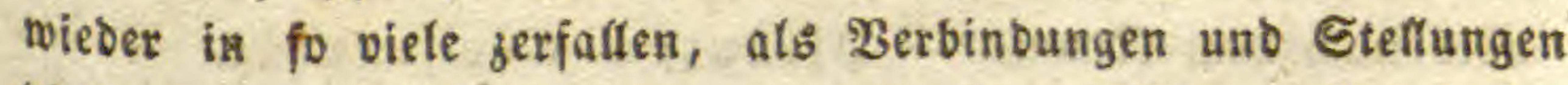
Diefer Organe möglid) fint. Die einzelnen pflanzen fint bafer nidfts anberes als bie felbifitänbige Darfteltung ber Pflanzens" organe in alten thren mögliden Serbältnifiten, unb bie Summe bicfer Pflanzen ift bas pflanzenteidg. 
Da fie, naต̆) \$em Sorbergebenben; in cinem notfwenbigen Sufammenfiang, alfo in einer beftimmten orbnung, âber uno neben einanber felgen; fo bilden fie eine wolgtgepronete Menge, in weldyer jebe ibren befitimmten \$lah hat, wie bic ausgezeidya neten Steine ober $\mathfrak{B a l f e n}$ an einem Şebänte: Darum vergleidst man bas Pflanzenreid) mit einem (Sebäube, uno gibt ifm ben Ramen $P f l a n z e n f y$ item.

Die Pflanzen ftehen aber nidht bló ifhent Entwidelungös

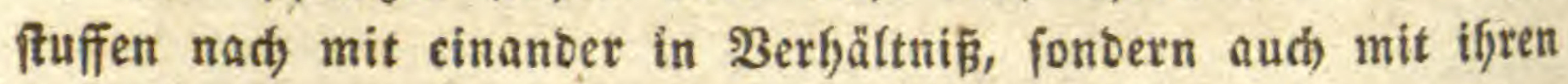
Umgebungen, alfo mit ben Elementen, Den Thieren und ben Pflanzen petbît.

Şโr fommen ober bie $\mathfrak{P f l a n z e n = E e o g r a p h i e . ~}$

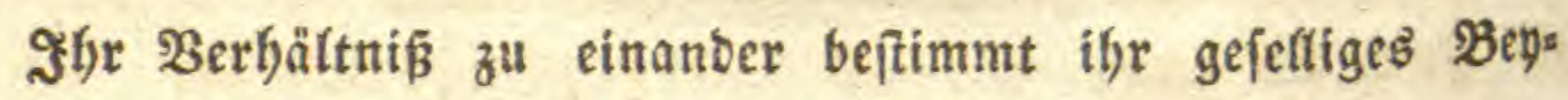

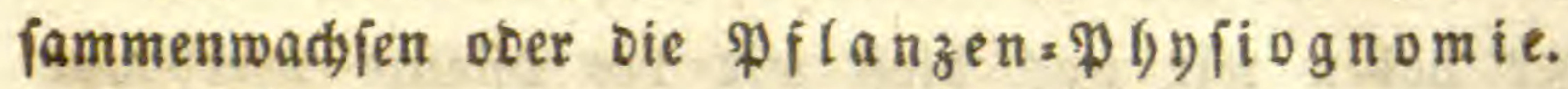

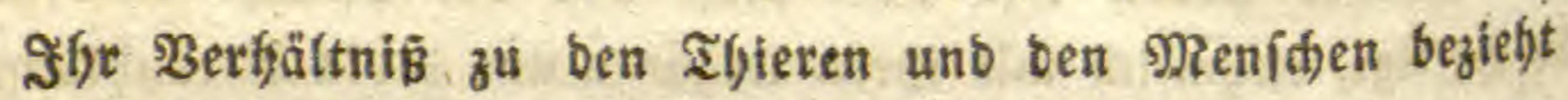
fid) auf bie Einwirfung Der leģtern, und Geftimmt bie Pflanzents Deconomie; hieber vorzŭglidi bie (e) lturpflanzen.

Die befonbere Botanil zerfäft baher in 4 grofe Ibthel= tungen.

1. In bas $P f l a n z e n=$ Sq ptem.

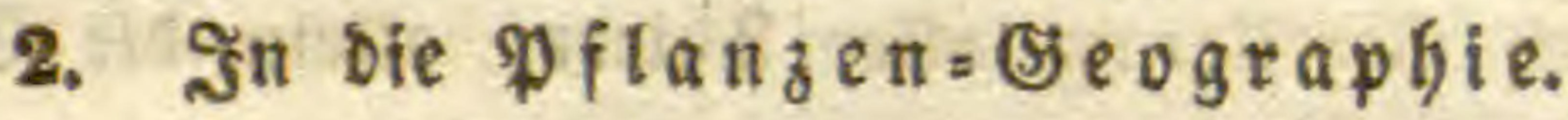

3. In bie Pffanzen= 9 hyfiognomie.

4. In bie 厄ultur=pflanzen.

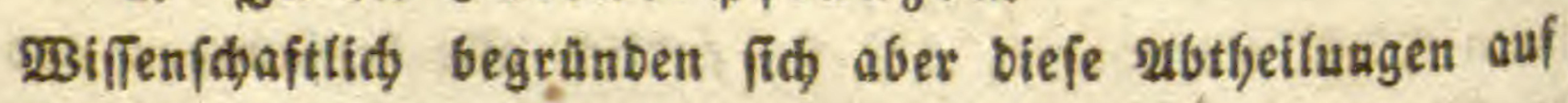
folgenbe art.

I. Dronung ber Pflanzen nady ibren intern $\mathfrak{B}$ erbälts niffen ober nad, ber Entwictelung ibrer organe in Der Beit Pflanzen= Syftem.

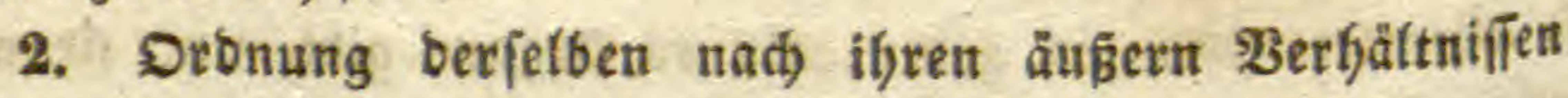
ober nad bem Raume - Pflanzen=\$e ograpfie.

3. Nad) ibren eigenen Berbåltnifien - Pftanzent Pbyitognomie.

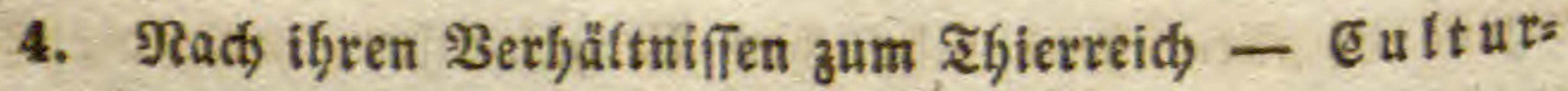
Pflanzen. 
Diefe Berhătniffe weiter jerlegt, geben folgende Blic: berung.

I. Pf $\mathfrak{l a n}_{z} e n=$ Sy fitem.

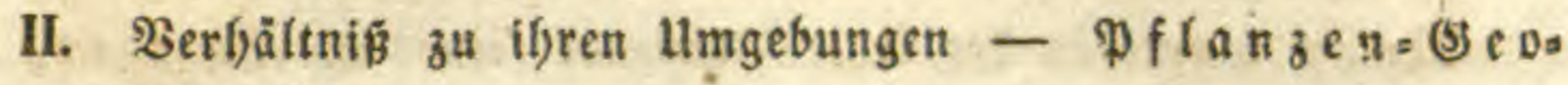
graplie.

A. Sur Sonne ober zum Aether, nelgmlid) \$Bäme, Sidit unb Sdyere - Berbreitung ber Pflanzen,

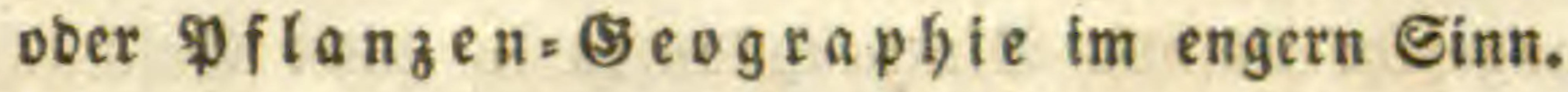

B. Sum planeten - Standort.

a. Sur $\mathfrak{E u f t}$ - Spöfe bes Stanborts.

b. Sum $\mathfrak{B} a f i e r-\mathfrak{B}$ afierpflanzen.

c. Bu ben Eে rben - TBahl bes Bobens.

III. 3u anbern $\mathfrak{P} f \mathfrak{a} n z e n-$ Sefelligfeit, $\mathfrak{P} f(a \pi z e n=\mathfrak{W})=$ fiognomie, gleidjam ber Pflanzenftaat.

IV. Sum Igierreid) - Pflanzen=Decouromie.

a. 3ิu ben Thieren, infofern fie ifnen zum

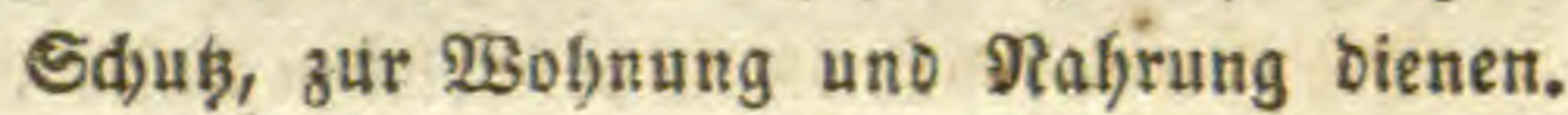

b. Sinjofern ifre $\mathfrak{B a d}$ sthum butd fie beptimmt

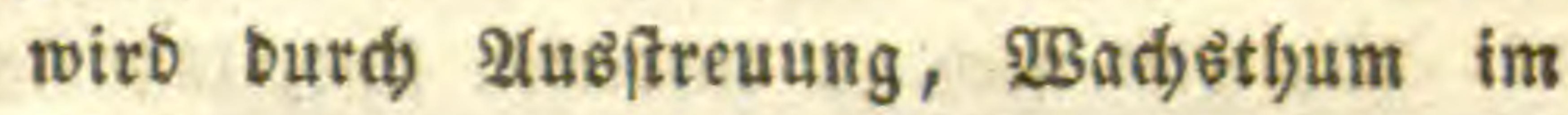
Mift.

c. 3u Dem Menidjen, infofern fie burd ifn einen bejonbern 2 boben befommen, Sdjutt, Anger, Wiejen, Walb, felber - Eutturs pflanzen.

3abl ber pflanzen.

(sigentlich follte nun bas pflanzenifitem folgen: ba es aber bequemer iff, baffelbe, in einem befonbern Banbe zu haben, fo foll es ben Sdhlus madjen. Sier bavon nur fo viel, was bie Babl ber Pfanzen betrifft.

Diefelbe läßt fid) bis jeb̧t nur annäherungşweife beptimmen, weil wir bie Sefeze nod nidjt Eentien, wornad) fid bie

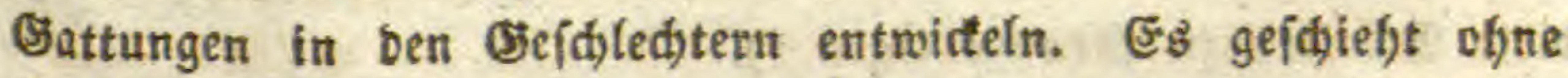
Sweifel nad ftuffenweifen Combinationen, wie bey ben chemiiften Berbinbungen. Selbft âbe: Die 3abl ber (Eefd)led)ter herrfd)t nod bie aflgemeine traurige Megnung, baj fie grånzenlos unb 
fogar gefeb̧los fey: allein id) glaube mid) nidjt zu irren, wenn id') nadyzuweifen fudje, baßs fie wieber organen=Stuffen find in ben Pfanzen=?ืünften.

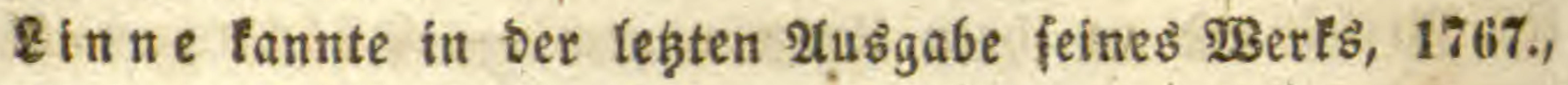
ungefäbr 80130 Pflanzengattungen in 1228 (sefd)led)tern, wors unter 670 blüthentofe in 50 (sejd)led)tern.

Perfoon befdyrieb vor 30 Jathren in feinem Pflanzeninftem ungefälyr 20,000 Btütbenpflanzen in 2304 (sefílyled)tern. Seit= bem hat man wieber fo viele neue \$flanzen fennen gelernt, bas

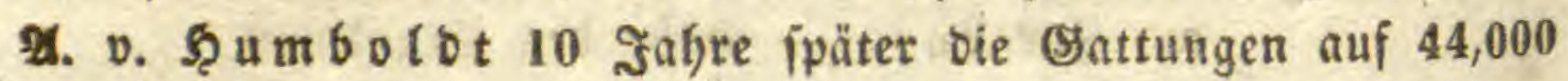
recfinete, Decandolle wieber 10 Jafye fpäter auf 56,000 , uno jej̧t glaubt man 60,000 za fennen.

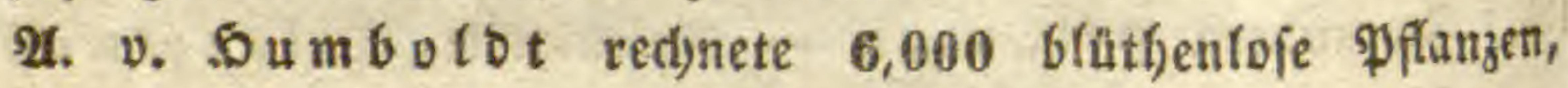
obne bie Farren, uno mitbin 35,000 B(ütf)enpflanzen nebit bert Farren. Die 3ald ber Sdjeibenpflanzent folligt man auf 10,000 an, forglid) Glieben für Die Nebpflanzen gegen 30,000 .

Sprengel-bat 1930 befdrieben 3667 (3) fdhled)ter B(üthens pflanzen uno 492 Btütlyentofe.

Wie viel nod) zu entbecten fino, läst fich) begreiftidyer SBeife nidst beftimmen; walyrid)einlidb aber nid)t mefre balb fo viel, ba bie pflanzenteidjften zonen fdjon faft nad) aften Ridjtungen burdfuntht fint.

\$3ir fangen nun mit ber Pftanzen=\$seographie an, ober mit Dem $\mathfrak{B}$ orfonmen ber Pflanzen.

\section{Pflanzen=(Şeograpbie.}

Diefes ift eine rsiffenidaft ber neucfen zeit, untb erit

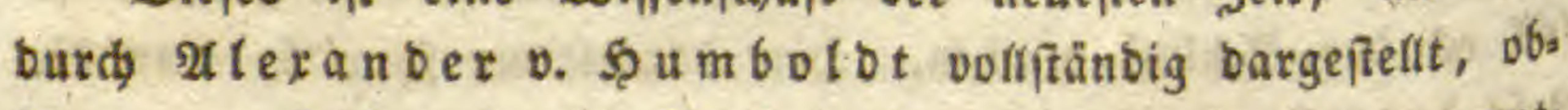

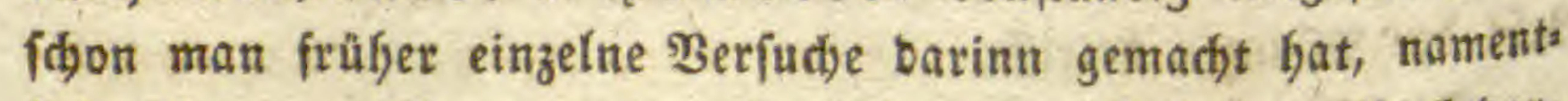

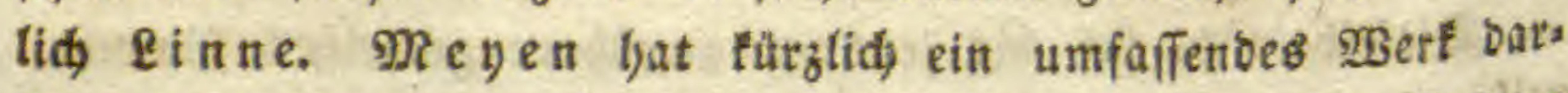
über herausgegeben. S(t) wetbe ben ber folgenben Darfitfung biefe Arbeiten zu (5runbe Tegen *).

*) Die Şauptwerke find:

A. de Humboldt, Essay sur la Géographle des Plantes. 1805. 4. Deutí(): Soeen zu einer (Seograpbie ber Đfanzen. 1807. 4. 


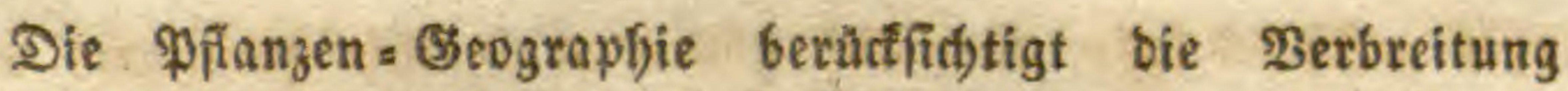
nad) Famitien, (5)efd)tedtern uno Gattungen burd afle sonen Der Erbe.

Diefe werben, wie oben bemerlt, Durch zwey Şaupt=Eins flüfie bejtimmt: Durd) Die Sonne unb ben ஒlaneten, woourd das 2aterland unb ber Etanoort beftimmt wirb.

A. Berbåltnis ber Pflanzen zur Sonnc.

$$
\text { Berbreitung oder } \mathfrak{B} a t e r l a n d .
$$

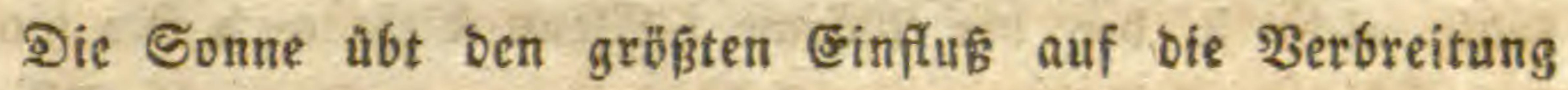

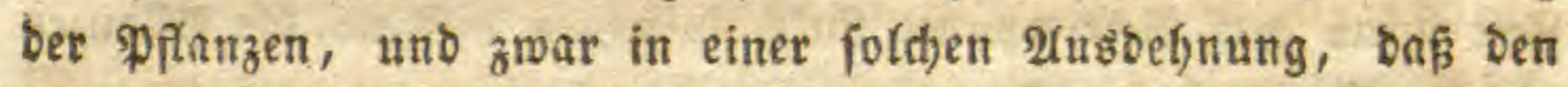
anbern (Einfluffen nur eine untergeorbnete Rotte tabrig bleibt.

a. Einflu ber Sđiwere.

Die Sthwere fareint nut bie fenfredfte Ridstung jeber Pflanze zu beftimmen. Db fie auf bie siube bez Standorteg, 3. 3. auf bem Meeresboben ober auf Den Bergen, Einfufs

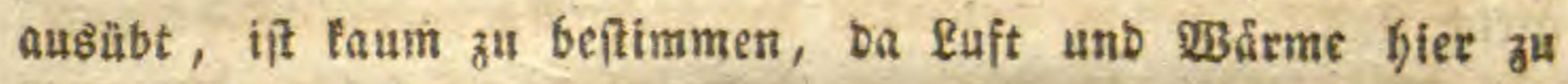
nugenfä́ltig wirfen.

2(nfithten ber Natur. 1808 und 1826.

Nova genera et species plantarum etc. I. 1815. Fol.

Prolegomena de distributione geographica plantarum. 1817, 8.

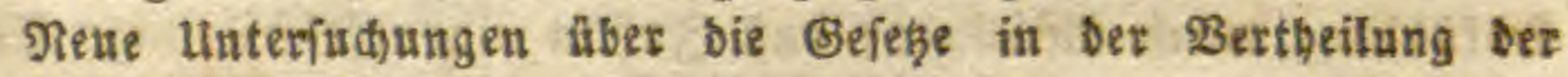
Pflangenformen. Sitß 1821. 1033.

Beilf d) mieb bat biefe 2trbeiten gefammelt, und vermehte unter Dem Iitel: \$flangen:-Geographie. 1831. 8.

F. Stromeyer, Commentatio inaug. sist. hist. vegetabil. geograph. 1800. 4.

3. Ebermeier, von ben Stanbörtern ber \$flanzen im allges meinen. 1802.8.

Wahlenberg, Flora lapponica. 1812. 8.; De vegetatione in Helvetia. 1813. 8.; Flora Carpathorum. 1814. 8 .

Rob. Brown in Flinders Voyage II. 1814., in Tuckeys Congo; alles in beffen $\mathfrak{B}$ ermifiten Sdiviften. 1825. I. 8. 1-366.

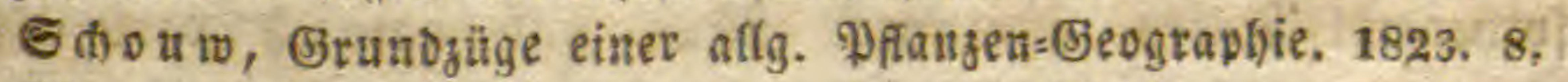

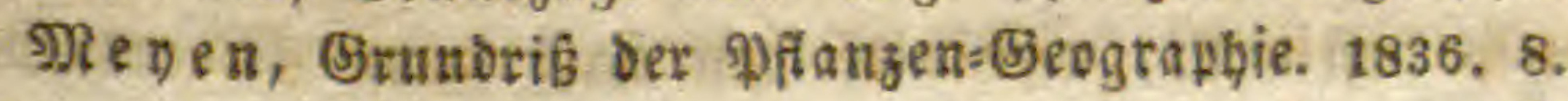

Defen a alfg. Taturn. II. Botanif I. 


\section{b. Einflú ber פ⿹勹冫}

Unter ben Sonnen=Einfüffen if offenbar bie $2 B$ ärme bey weitem ber vorherridhende, weil fidi bey iffe eit viel gröbeter unteridaied auf bem \$laneten zeigt, als bey Eidt, Euft, wafier unb Erbe: benn wo planzen madjen, fen eв unter Dem भequatot ober gegen bie pole, auf Şüben ober Iiefen, Da mus überall eine gerwiffe, uno zwar gleidfürmige Menge von शabrungsfitoff, feunjtigteit und Ruft vorhanben feyn. Sebridyt $e^{B}$ an einem biefer Theile, fo entfteljen fie gar nidjt und ber Boben bleibt

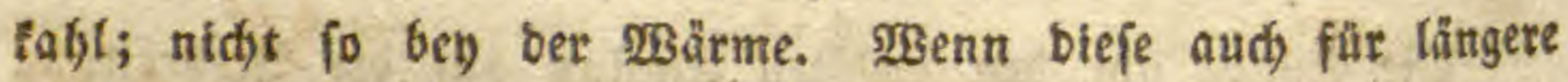
seit unter ben Gefrierpunct finft, fo gefjen befbalb bie \$flanzen niḑt notlywentig zu Grunde.

Biele fino unter einer looken, viele unter einer niebetn Temperatur entfanoen; unb ba firl biefe nady ber Entfernutg vom 2(equator tidftet, fo finben wir aud) bie veridgiebenfen

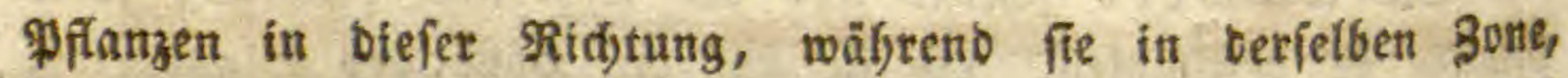
rings um bie Erbe berum, fich ziemfidh älntidh utto felbl gleid) find.

gRan theilt bie sonen mit Red)t In bie lyeise, bie zwel gemábigten und bie zwey Falten. Eל ift aber bePannt, Dak bie SBärme nidbt unter affen (5raben um bie gatnge Erbe ferum gletid) ift, Daß 3. B. Europa wärmer ift als rfiten, bort wegen ber länger tauernben Erwärmung ber Erboberfäd)e, hier wegen ber 2 bfühlung burd) Oftwinbe; baß Sonfeln eine gleidförmige Tema

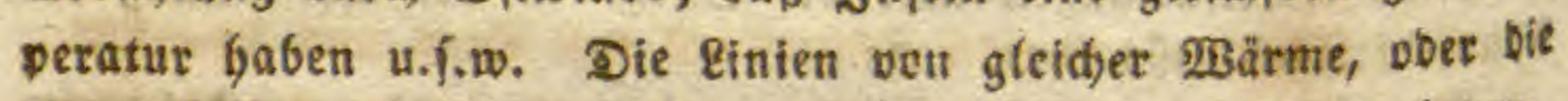
Sothermal=8fnien finb baher nidft grab um bie Erbe herum, fonbern bilden mandifaltige 3idzade, inbem fie balb fobler gegent Rorben fteigen, balo tiefer gegen Güben faflen; uns barnath

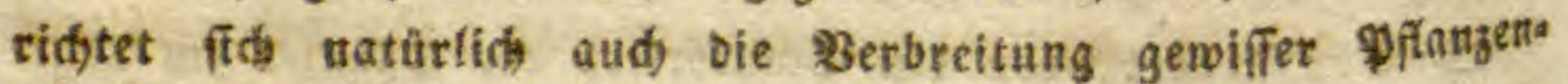
ริด

अ zaftreidger Thermometer=Beobad)tungen blefe ginfen von gleímer

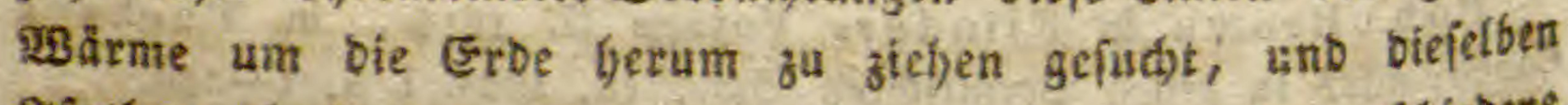

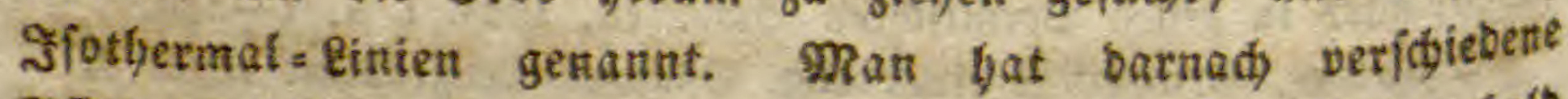
pflanzen=3oren beftimmt, unb diefelben batb butd meere, ball 


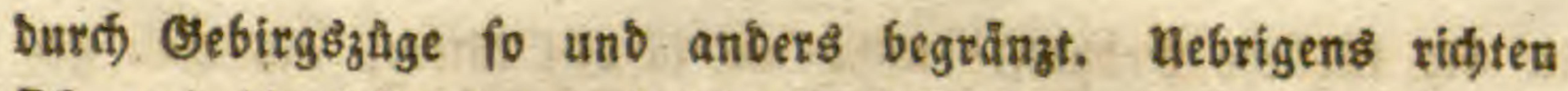
fid auds Die Pflanzen nad ben wselttheiler.

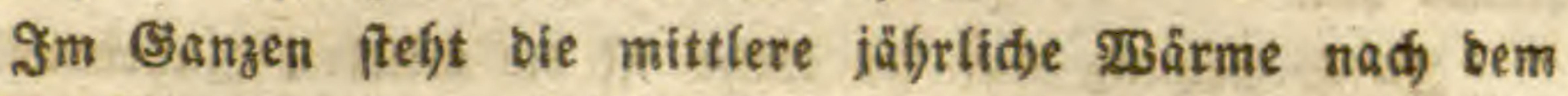
$100^{\circ}$ get If)ermometer auf forgende $2(r t$ :

Rörblidje Breite.

$\begin{array}{lr}0^{\circ} . & 27,5^{\circ} . \\ 20^{\circ} . & 25,4^{\circ} . \\ 30^{\circ} . & 21,4^{\circ} . \\ 40^{\circ} . & 17,3^{\circ} . \\ 50^{\circ} . & 10,3^{\circ} . \\ 60^{\circ} . & 4,8^{\circ} .\end{array}$

Reue Weft. $27,5^{\circ}$. $25,4^{\circ}$. $19,4^{\circ}$. $12,5^{\circ}$. $3,3^{\circ}$. $-4,6^{\circ}$.

Die Bärme ridftet fid) bemnad) nidst ganz genau nad) Der6 Breitegraben, unb nimmt, namentlidh in 2rmerica, viel fdnefler ab. 24ud bie mittlere Sommerwarme ridgtet fid) nidbt nady ber

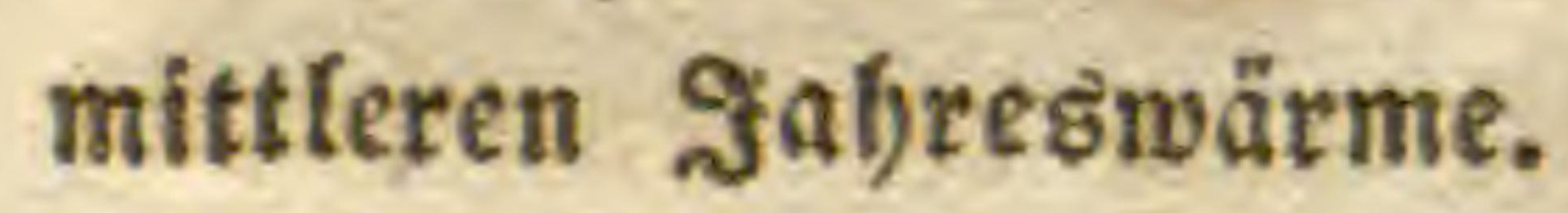

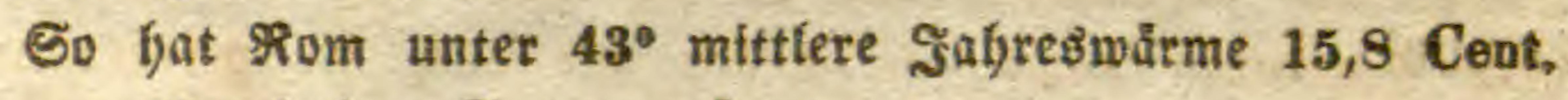
unb nur 23 mittlere Sommerwåme.

Rorb= America unter $36^{\circ}$, von iener aud $15^{\circ} \mathrm{C}$. , von biefer 26,7 .

Paris unter $48,5^{\circ}$ hat 10,9 unb 18,9 .

Stoctifolm unter $60^{\circ}$ hat 5,7 und 15,1 .

Imerica unter $48^{\circ}$ hat 5 und 19,5 .

Rapplant unter $65^{\circ}$ hat 0 und 11,5 .

Inbien, bas heíre Arica und Imerica baben mittlere Saf)reșåme $25-27^{\circ}$.

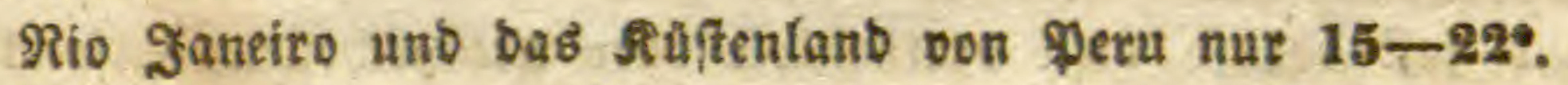
Die füblidbe gemäbigte sone hat auf beiben Eontinenten, unb in Suftratien bis gegen $34^{\circ}$, faft gleides बlima; am Dor=

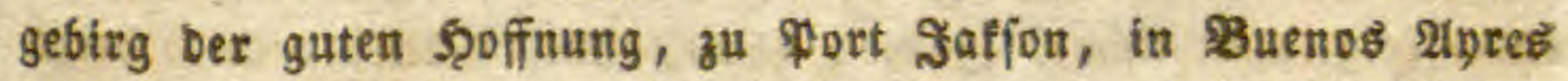
unter 33 und $34^{\circ}$ mittlere Jahres wärme $19,5 \mathrm{C}$.; babey fältere Sommer, aber milbere \$sinter als auf ber nơrblidgen Şalb. lugel: Daljer gibt eह bis $40^{\circ}$ nod baumartige farrenfräuter unb Drbiben uno Bäume mit grŭnem Baub; jenfeits aber bił 34 $54^{\circ}$ find bie Gommer Eâler wegen bes Rebels und Des Gdgnees. In Eappland gibt es unter $70^{\circ}$ nod, Gobe Riefern,

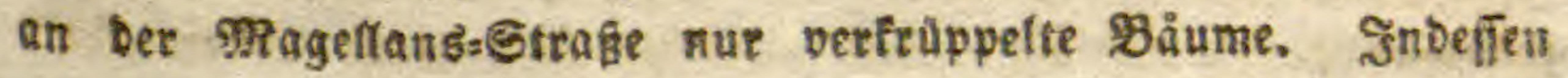


ift bie füblitbe Eroblälfte nídyt um fo viel fälter, als man ges glaubt bat.

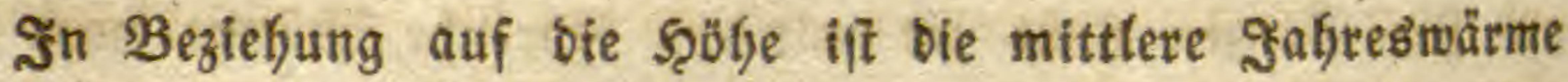
in Europa unter $46^{\circ}$ Breite auf einem Berge von $6000^{\prime}$ ber von Rappland in ber Ebene gleid); in ber heifen Sone ben gleidjer Şöhe ber von Stcilien. Ben einer foldyen sablye vets minbert fid) bey uns bie mittlere Safresmärme um $12 \mathrm{C}$.

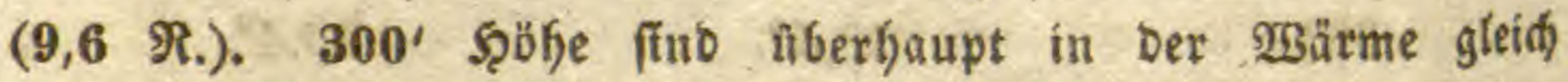
einem Srab güberer Breite.

Die mittlere $\mathfrak{B a}$ åme ift:

Unter bem Xequator 27,5 C. $\quad$ \$n ber gemäpigten Bone 12. $3000^{\prime}$ god ift fie $21,8, \ldots \ldots \ldots \ldots . .55$.

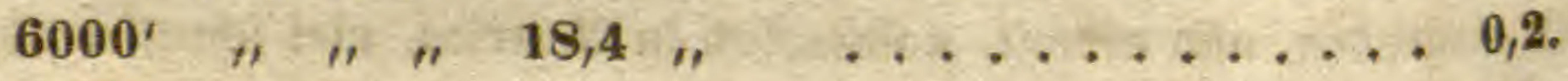

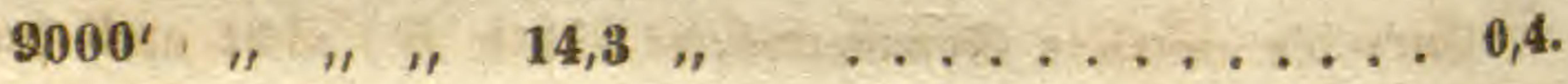
$12,000^{\prime}, " 11,7,3$, 15,000 " " " 1 "

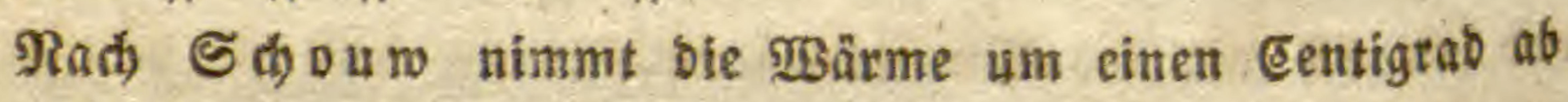
bey je 500', Dber um einen (Erad Reaumur bey ie $636^{\prime}$.

\section{Bertigetlung Der Pflanzen.}

Da bier nur eit furzer $\mathfrak{B}$ egriff von ber \$flanzent (5eographie gegeben werben fann; fo ift es nád)t nüthig, weiter in bas Einz zefne einzugelsen.

Nan fennt jeb̧t melje als 30,000 Nebpflanzen ober Dicos tylebonen, gegen 10,000 Sd)eidenpflanzen, Monocotylebonent, und faît ebenfo viele blüthentofe ober $\mathfrak{A}$ cotnlebonen, alfo $3 \mathrm{mal}$ fo viel Rebpplanzen als Stheidenpfianzen boer Glüthentufe. Ton

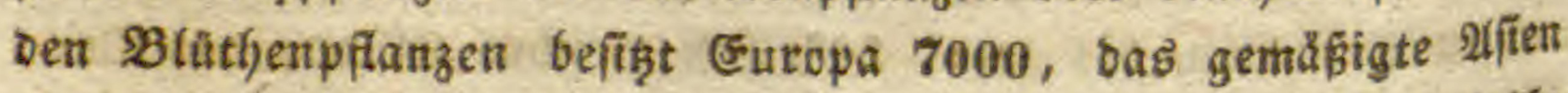

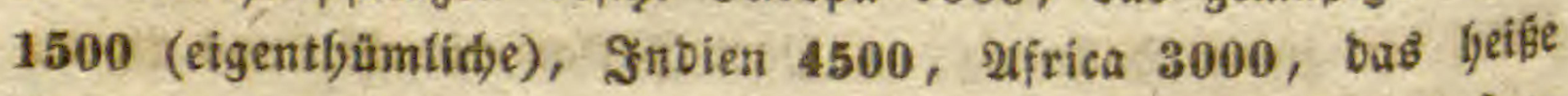
2merica 13,000, in beiben gemäßigten zonen 4000, 2uftras lien 5000.

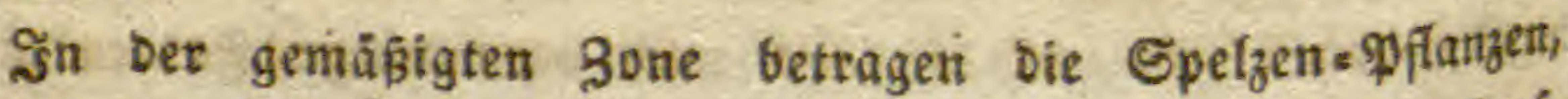
nefimlid, bie Ortäfer, Riebgräjer und Simjen, nebfr ben fopfs blûtlyigen (zufammetrgefeb̧te), melyr als $1 / 4$ afler bafelblt pots

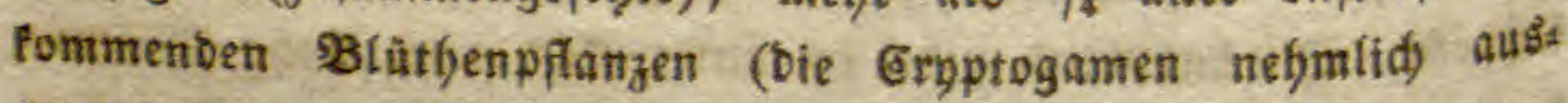
genominen). 
Unter faft 4000 Pflanzen (bie Cryptogamen immer augges nommen) bes beißsen Americas finb über 600 Sabeibenpflanzen anb uีber 3000 Rebpflanzen, überbaupt bie Sdjeibenpflanzen zts

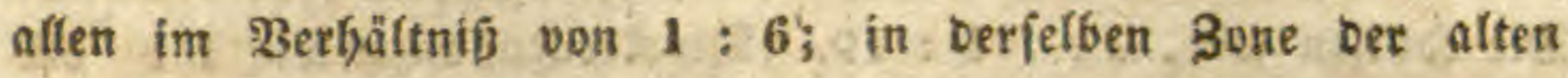
Melt wie $1: 5$.

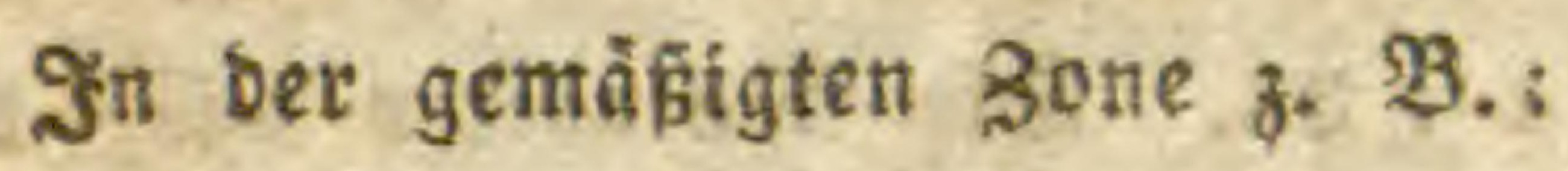

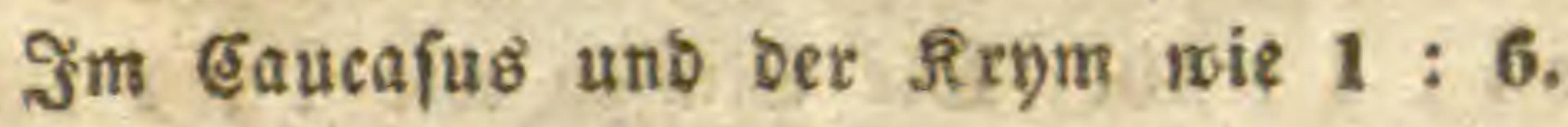

รัก 2regupten wic $1: 5$.

In ber Barbarey wie $1: 4,8$.

In Reapel unb Grantreid, wie $1: 4,7$.

Jin Rorbametica mie $1: 4,6$.

Jin Dentidland mie $1: 4$.

Sin England wie $1: 3,6$.

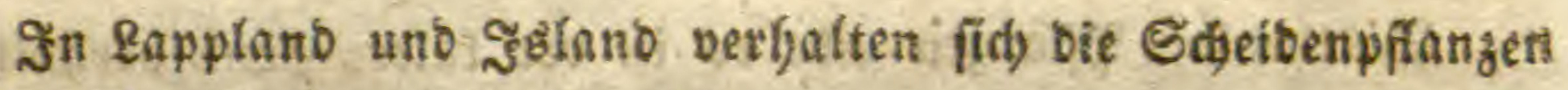
zu ben Nekpflanzen wie $1: 2,2$.

Die Sdjeibenpflanzen nefymen alio gegen Rorben zu, und Da fie zugleid, bie Feuditigfeit lieben, io fino fie badufiger in

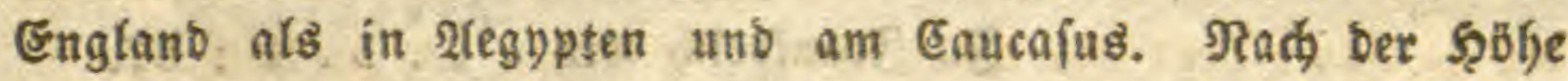
nebmen fie aber $a b$ : in ben Iabälern ber Stbweiz verbalten fie fid) zu affen Pflanzen wie $1: 4,3$; über ben 2ntpenrofen wie $1: 7$. Sn ber Mitte yon Europa, zwifhen 42 unb $45^{\circ} \Re$. B., wadjfen gegen 6000 Pfaitzen; Darunter 2200 blütbentofe utro 3500 Bithtfenpflanzen, unb unter ben Yekzten finven fids 500 Ropfpflanzen, 300 G̋räfer, 250 Şüljen, 200 Rreuzpflanzen;

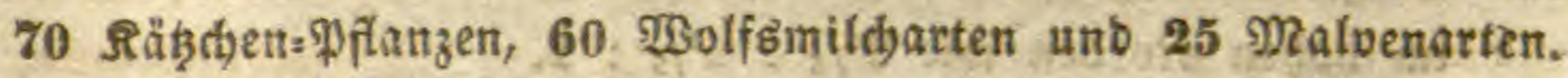

Jit Frantreid rechnet man 3645 , in Deutfdglant 1894 B่̧นีthenpflanzen.

3u affen Blutthenpflanzen verbuften fid in Deutfdglart:

Die Ropfpflanzen wie. 1: 8 . Die Drdiben mie .. $1: 43$.

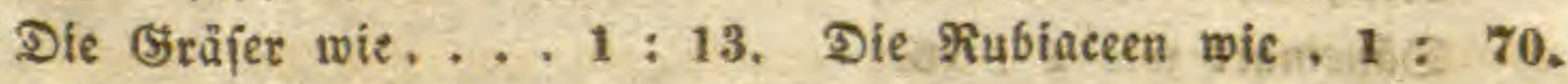
Die Sâtlen wie... 1: 16. Die Boragineen wie 1 : 72 . Die Rrenzpflamen wie $1: 18$. Die Seiben wie 1 , 1 : 90. Die Dofben wie... 1:22. Die Simien wie . 1 1 : 94. Die Rippenblumen wie $1 ; 26$. Die Eupfyorbiaceen wie 1 : 100. Die Riebgrăfer wie. 1:27. Die Malvaceen wie, $1: 230$.

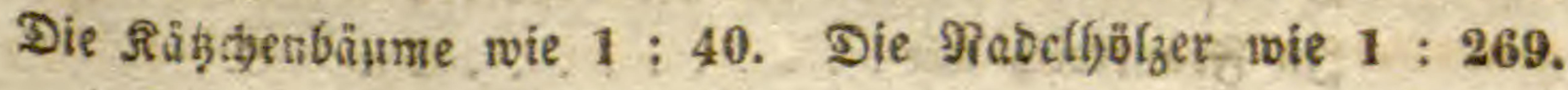




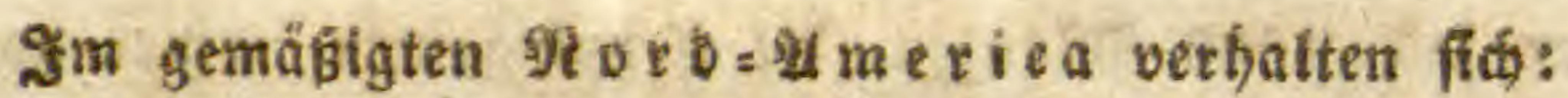

Die Ropfpflanzen wie 1: 6. Die Rippenblumen wie 1: 40. Die Gräler wie... 1 1: 10. Die Dolben wie . 1 : 47 .

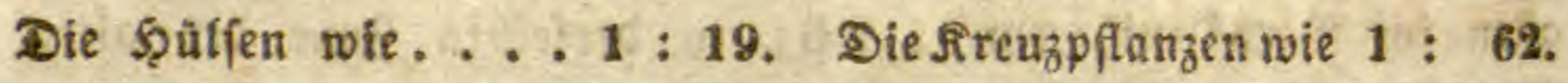

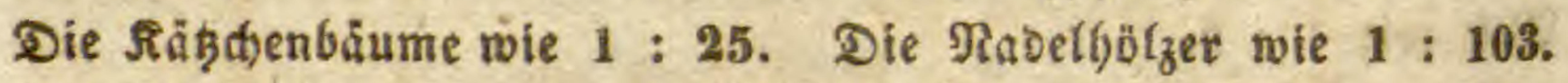
Die Şeiben wie....1:36. Die פralvaceen wie $1: 125$. Die Riedgrảjer wie . 1 1:40. Die Simfen wie .. 1: 152 . Sn Eapplano:

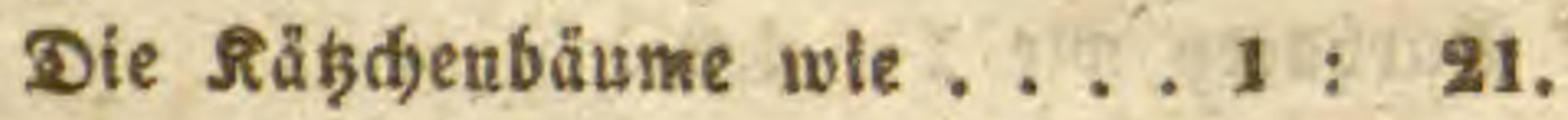

Die Șeiben wie ....... 1: 25.

Die Dolben wie....... 1: 55.

Die sippenblumen wie..... 1: 70.

Die शabelfötzer wie .... 1: 160.

B(ŭthentofe Pflanzen gibt es in ber talten zone verbältnif̧

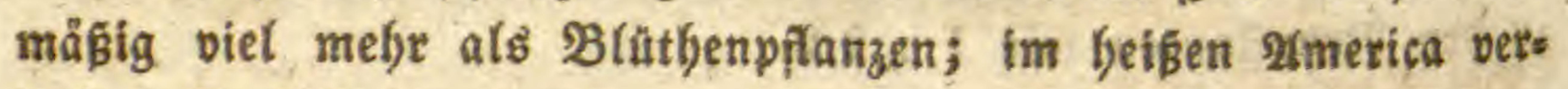
Galten fie fid wie 1 : 9.

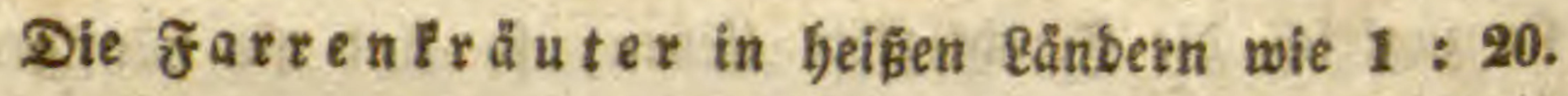
İn frantreid wie ....1: 37 . Die Spelzetpflanzen in ber fjelín Bute wie $1: 11$.

รัn ber gemäbigten wie. . 1 : 8 . In ber falten wie...... 1: 4 .

sefuntbers vermelyten fid bier bie Riebgräfer.

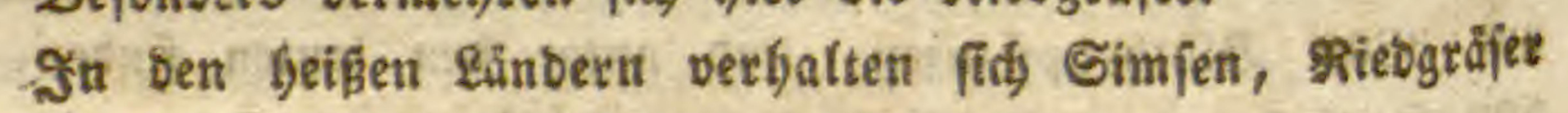
and strafer wie $25: 7: 1$;

im foljen Forben wie $2^{2} / 5: 2^{3} / s: 1$.

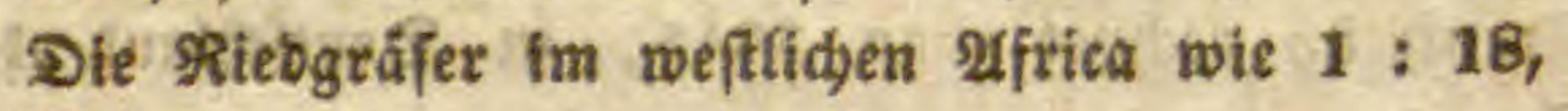

Subsumerica mie $1: 57$,

Ditinbiet wie $1: 25$,

- Stelifoffano wie 1 : 14 ,

Dånemart wie 1 : 16.

Gräfer in Diftinbien unb פBeft=21frica wie $1: 12$.

Dle sopfiftanzen.

Im Norgebirg ber guten feoffinung wie 1 :

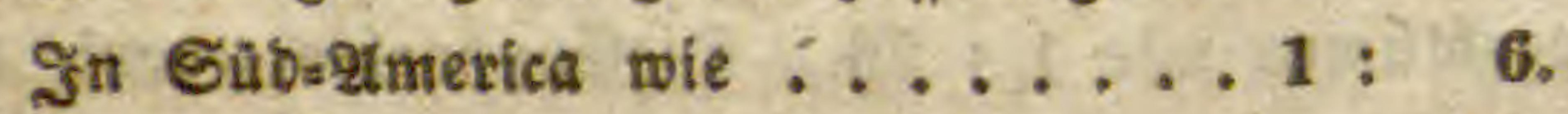

In Norb=2metica role. . . . . . 1: 6 .

In grantreid wie......... 1: $s$. 
In Rapplanb uno Ramtfojatke wie, $1: 13$.

In Dftindien unb Reulgoflanto wie. .1: 16.

IIm ฮongo wie ........... 1 : 23.

Die sqülfenpflanzen.

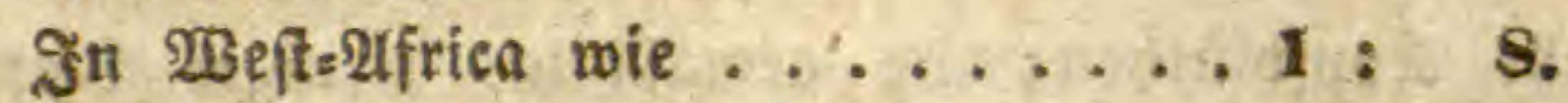

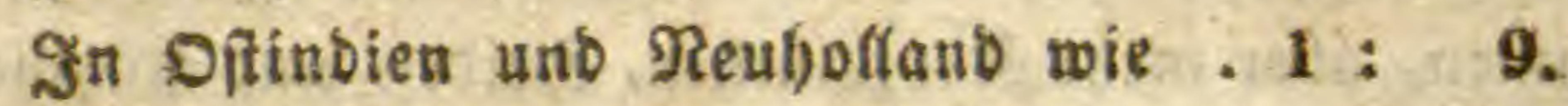

ฐัm gemäpigten Sibirien mie .... 1: 14.

In ber Sdwweiz wie......... 1 : 15 .

รี Bayern wie .......... 1 : 22.

Ben Rom wie ........... 1 : 95.

In ber provinz wie ......... 1 : 103.

In Englant wic........... $1: 206$.

Dié sippenblumen.

Jn grantreid) wie ........ 1: 24 .

In Rord $=2(m e r i c a$ wie . . . . . . 1: 40 .

Die Rreuźlumen.

In Der beínen sone fait teine.

Die $\Re$ ubiaceen.

Im Geísen Iffrica wie....... 1 : 14.

ฐัm beifent 2tmerica wie...... 1 1 : 29.

ส̇n Deutidlant mie........ 1: 70 .

In Sapplanb wie ......... 1: 80 .

Die Euphorbiaceen.

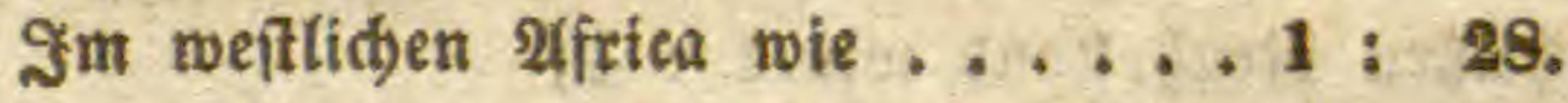

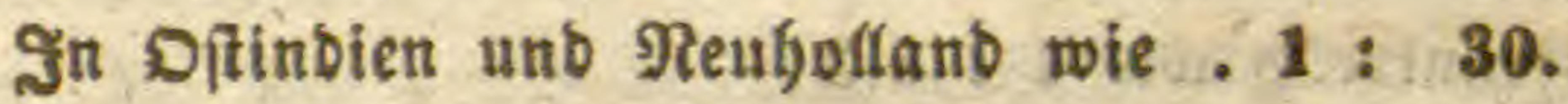

Int Eapplant wie.......... 1:500.

Die Szeiben und Alpentofen.

In Eappland wie ......... 1: 95 .

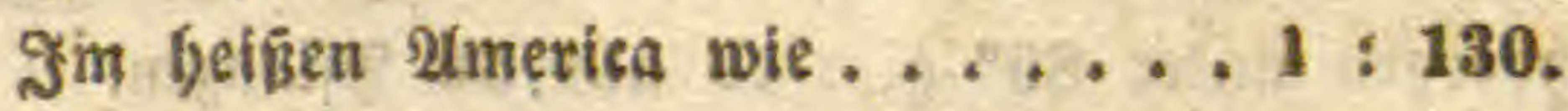

Die Rä̉bdenbäume.

In Eappland wie . . . . . . 1: 20.

S̊m Geifen Imerica wie... . . 1: $\mathbf{8 0 0 .}$

Die Dolben.

Jim beifen 2 merica wie....... 1: 100.

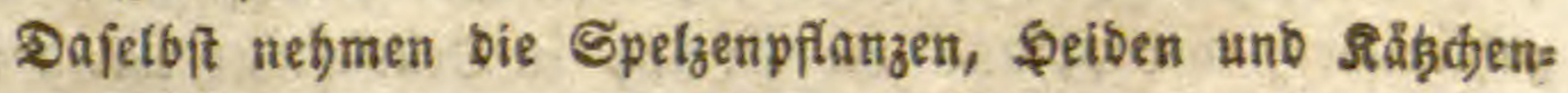
bäume gegen bie Pole zu; Die şülfen, Rubiaceen, Euphorbies 


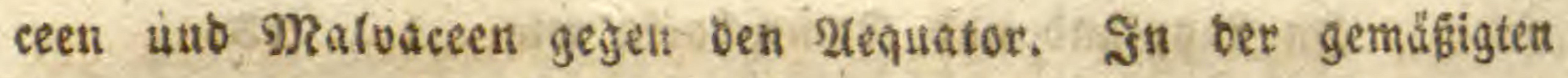
Zone erreíben bie Ropfblütljen, Rippenblumen, Dotben = uno

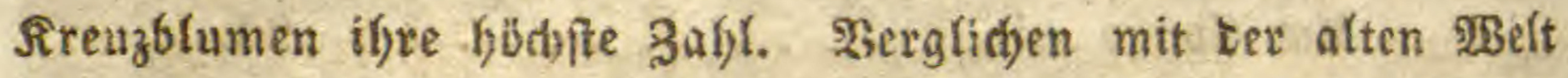
gibt es im beifen 21 mevica weniger Riebgräfer und Rubtaceen, aber mehr Ropfblüthen; in gemäsigten weniger sippens uno STeuzblumen, aber mefr Ropfbläthen, Seeiben uno säb̨henbäume, als in ber entfpredhenden Sone bey uns.

Die Sdyeibenpflanzen

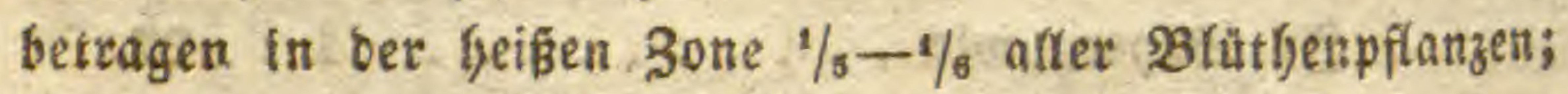
in ber gemäßigten 3one $\left(36-52^{\circ}\right) 1 / 4$, in Der falten Sone $1 / 8$.

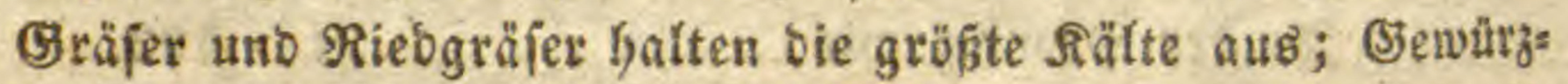
rofire (Ecitamineen) Dagegen, Pifange, Bromelien unb \$alment treten faum uีber Den SSendefreis herauz. Mit Nusnahme Der Sceiben, Relten, Dez Eaubs und Rabetfotzes, nefymen bie

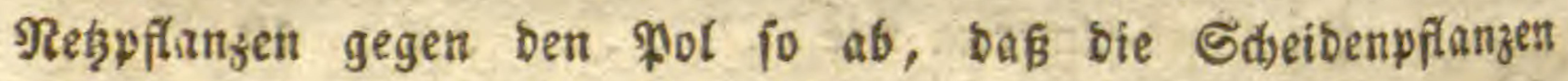

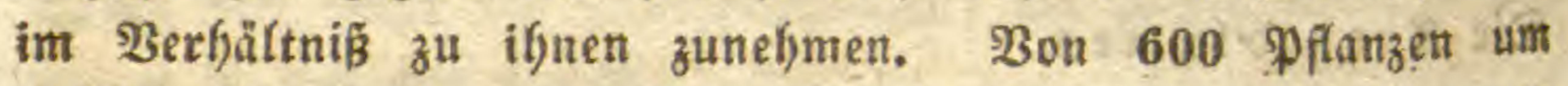
upfala Aberichreiten 342 ben Polartrels nicht, und barunter fint 76 . Nebpflanzen.

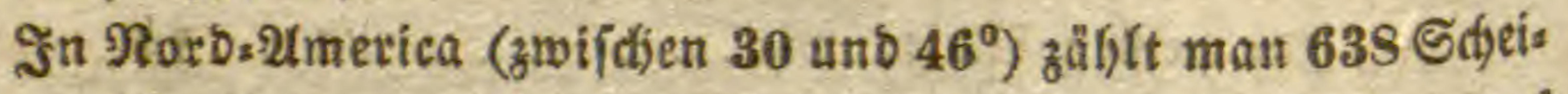
bens, 2253 Nebpflanzen; in Reufotfand 860 und 2900; auf Şรtand 135 und 239; in Rappland 157 anb 340.

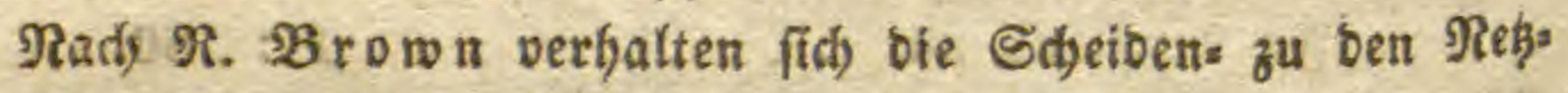
pilanzen in ber heisen sone von 30 bis $30^{\circ}$ wie 1: 5 ;

im Geifen Reulgoflano wie 1:4;

in franfreid wie $1: 3,3$;

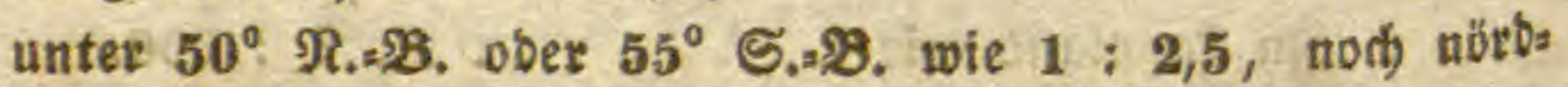
lidjer wie 1:2,2;

in Rapplanb $\left(60-71^{\circ}\right)$ wie $1: 2$; in šblanb wie $1: 1,7$; auf Epibzbergen unter $80^{\circ}$ gibt eछ nur 30 pflanzen.

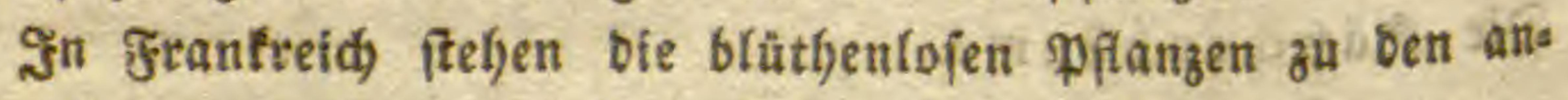
bern wie 1: 2, in ber heisen sone wie 1:5;

bie farrenträuter nehmen nady Suben zu wie $1: 2: 5$,

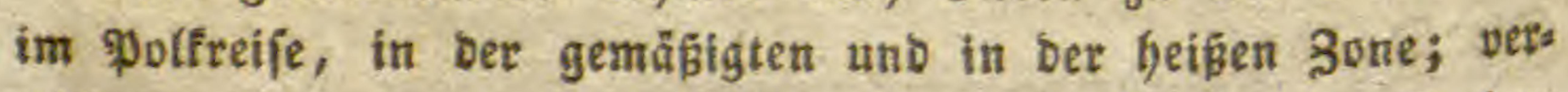

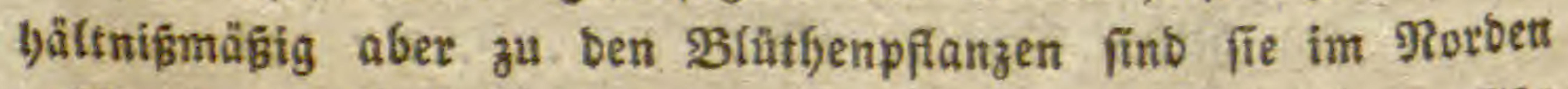
zablreidyer; in Eapplanb wie 1:26; in Deutfdland wie 1:70; in Frantieid) wie 1 : 72. 
Die einjäbrigen Pfanzen äfrrbaupt betragen in ben ges mäß̈gten Zonen ben 6 ten Theil, in ber heísen ben 20 ten, in Rapplanb ben 30iten, weil hier Die Samen erfrieren, bort ba= gegen affer fitraudbartig mirb.

Ropfotuttgen fent man gegen 3000 , Sputffen über 2000, unb man nimmt an, bas fie mit ben Spetzenpflanzen ben 3ten Sigeil affer B(üthenpflanzen ausmad)en.

Эัn Der beifen zone nelymen bie Rippen= und Spelzenpflanzen, bejonderb bie Simfen uno Rieogräfer, $a b ;$ Die Rreuz= unb Dotoenpftanzen feblen faft gănzlid); Dagegen ipt Ueberid)uE an

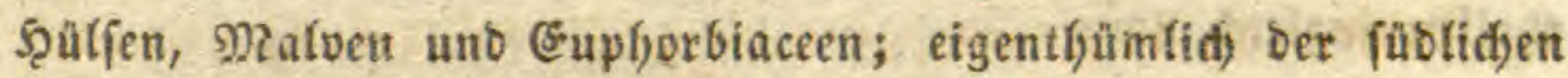
Erobälfte find bie Proteen, Diosmen, Eajuarinen und Diffenien.

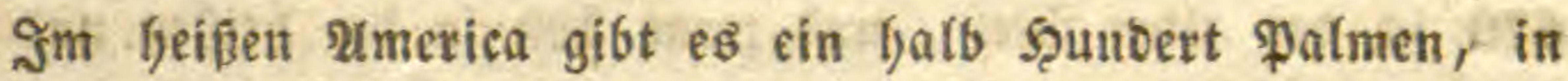
Reuffoltano bavon nur 6; in Rordamerica fommt unter $34^{\circ}$ nod) eine Srergpatme vor (Chanaerops palmetto), in (Europa nod) unter 44. (Ch. humilis); auf Neufeefand eine unter $38^{\circ}$ S.8., auf Reulfolfand unter $34^{\circ}$.

Ṡm Geisen 2 merica fitio bejonbers reidfich die \$fefferarten, Bignonien (41), Reffetarten, Terenbintlyaceen, Melaftomen, Eaps pariben, Paffifloren, Solaneen, raubbläiterige uno Rubiaceen. Die Streuz und Dotbenblumen finben fidh nut auf Şöben.

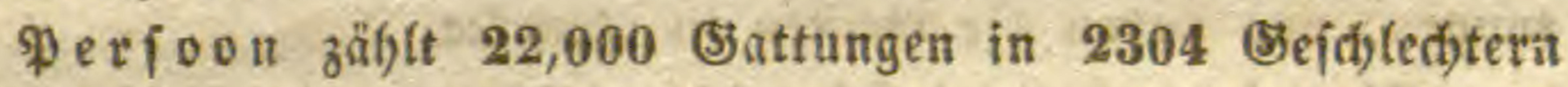

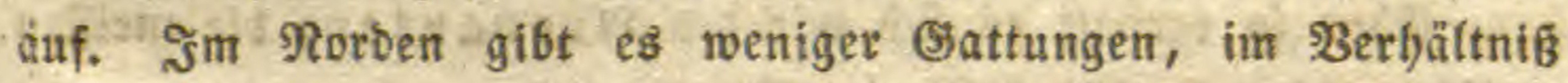
ju ben (sefdjled)tern, als im Sttben; in Rappland wie 2,3: 1;

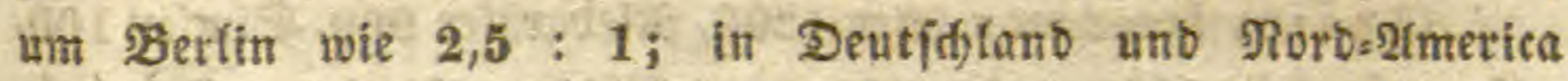

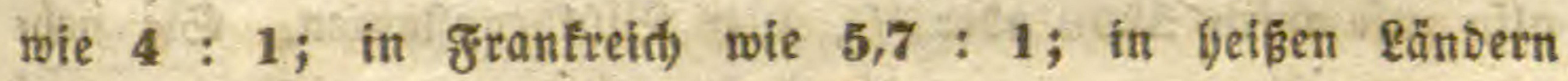
wie $10: 1$. Es fommen alfo abberfyaupt etwg 10 Gattungen auf 1 (sefdyled)t.

Uebereintimmenbes 90 orfommen.

Befanntlid) fino bie meiften Thiere in Imerica von benten

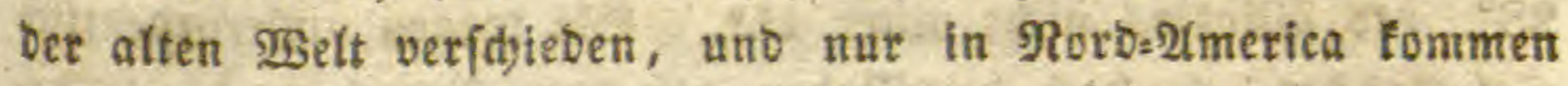

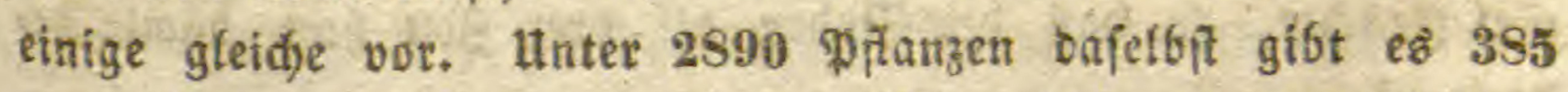
europäiffige, wovon 39 Gräjes, 25 Riebgräfer, 32 Ropfbtüthen, 21 Rreuzpflanzen, is Relfen uno meffere andere.

Auth in Reufofland gibt es 45 europaifid), rovon bie 
Şälfte Spelzenpfianzen fint. Son felnen 4160 Sattungen loms men 165 in Ëuropa und Rord=2America yor.

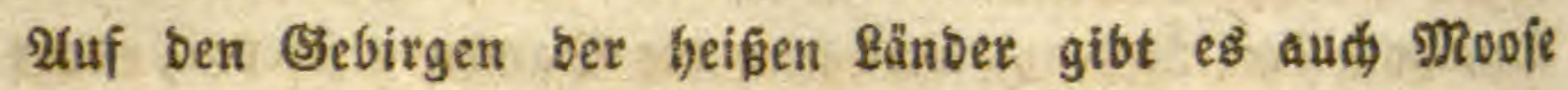
uno Flechten aus caropa; Farrentrảuter óagegen fefrr wenige. Das beise 2merica hat faft gar feine Blüthenpflanzen mit ber

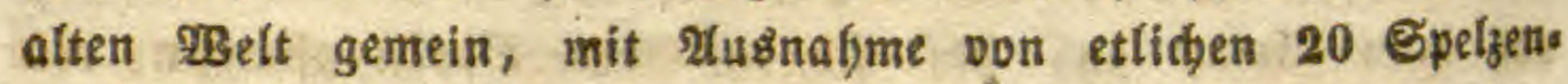
pflanzen.

T3as bie Terbreitung ber familien betrift,

fo tommen bie flediten und Moofe in meljeren Welts theilen zugleid) vor;

nid)t fo bie Farren frå ater. Unter 1000 Sattungen fino 470 in ber aften $25 e l t$, unb zrwar 300 in ber heigen und 170 in ber gemäßigten uno Palten Sone.

Fn ber neuen 2 Belt 530 ; bavon in jener sone 460 , in Diefer nur 70; im Stanzen alfo in ber beifen sone 760, in Det anbern tur 240.

C̋anz Europa bat nur 70, Deutídjland 40, England 39 , Sappland 19, Rord=21merica 45 unter 1575 Blüthenpflanzen.

Die 9 fefferarten lieben feudte uno laue Euft, unb

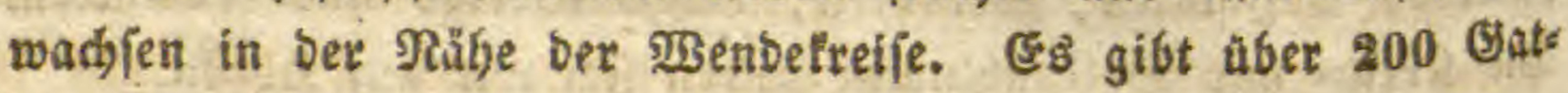
tungen, und bavon bie meiften in 2tmerica.

Eben fo verbält es fich mit ben 2 ronarien; bis meiften zwifipen 30 uno $45^{\circ} \mathrm{S} .26$. in 2 merica.

(5) r äfer tennt man über 1200, Riebgräier 900, Cimjen 100, alfo zufammen 2200 ober $1 / 10$ aller $B$ lüthenpflanzen. Sie nelyo men vom 2lequator gegen bie Pole, ober von Den ebentn auf Die Bebirge zu, uno melje von Deutídlanb aus nad Norben alร vom 2requator zur gemåsigten 3one.

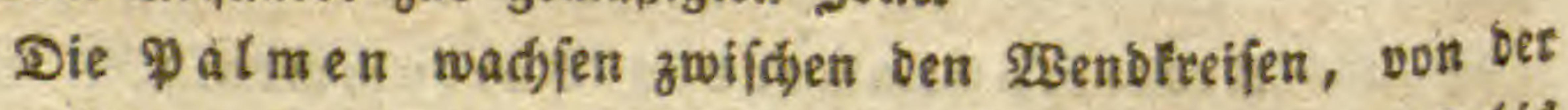

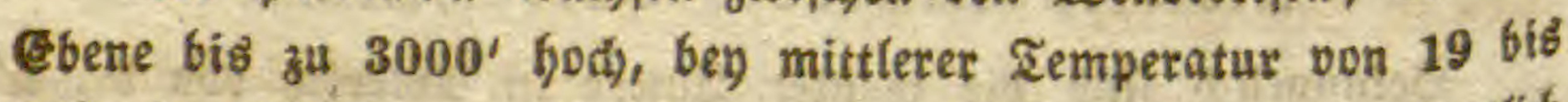

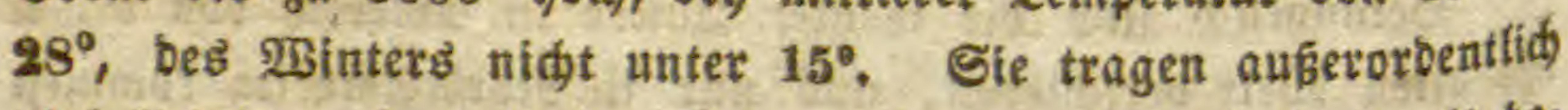
viel grundte, fo baßs ber Boben oft brey soll bod) bamit bes bectt ift.

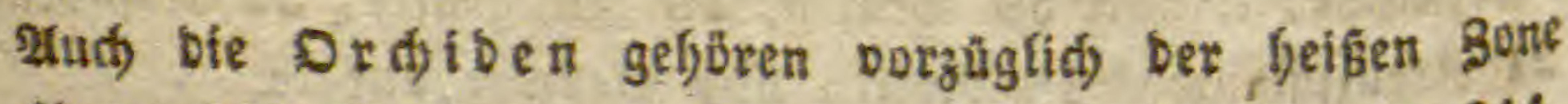
an. Inter 700 Battungen bat Europa nur S0, 2tmerica 244, 
bie meiften von $5000-7000$ sgüge, unb hiet wieber die Sd)ma= rob̧er am zahlreidjfen.

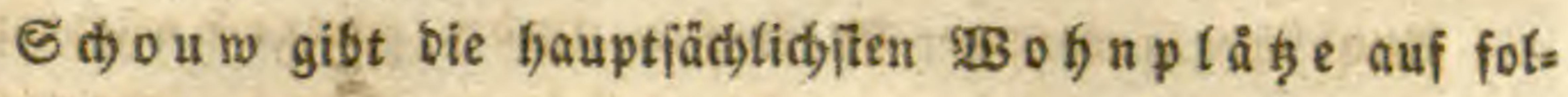
gende 2 itt an:

Fitrt bie Moofe und Steinbredge bie Ränber innerljalb bes \$olartreifes unt bie göbern Esebirge von હuropa; bie Rieogräjer in ber \$olarzone.

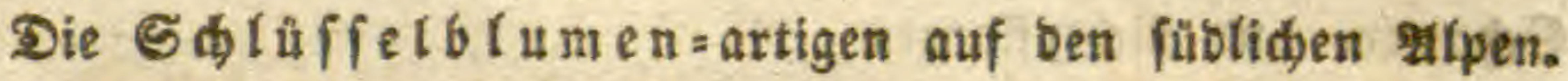
Die DoIben unb R reuzblumen im mitteren Curopa unb in Stbirien; bort vorzunglid) bie Salatblumen, hier bie Difteln.

Die Sippenblumen unb Relfen im fübtiden Europa, nörblidben Xffica, Ëriechentanb uno Rleinafiten.

Die gre teten in Standinabien.

Die Spelzenpflanzen in Deutídaland; bie Ranutis

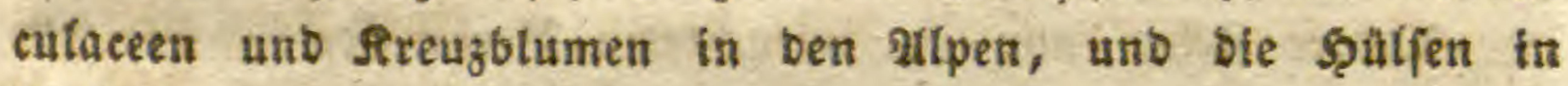
\$ttalien.

Die Aferarten in Rord-2merica.

Die Magnolien in fübliden Rorbs2merica.

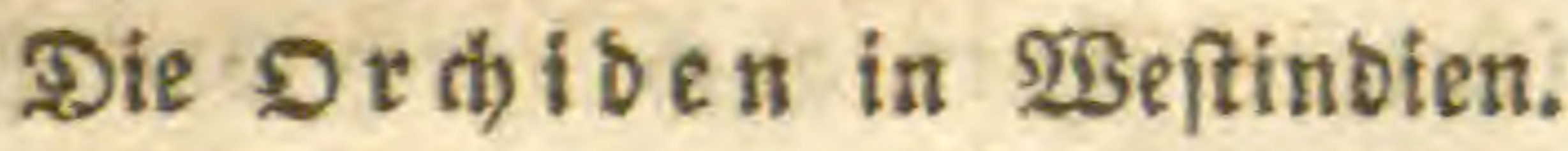

Die $\mathfrak{P}$ ifmen, Pieffer, gatteldipeln, Rubiaceen unb \$affta floren in Sübstmerica; bie Ehinastrten uno Speibelbeeren in Göbern Bregenten.

Die Gaumartigen \& opfpflanzen in Biflidjen Sùb= Mmerica.

Die Proteaceen unb Speiben in Wुeftafrica unb Reus Golland; in bem leb̧tern Mryten, Cajuarinen, Reftiaceen und blattlofe थcacien.

Die Etapelien, Mefembryanthemen, Nroteaceen, Polyg

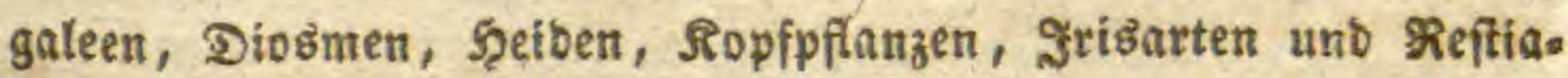
ceen in SüD=2frica.

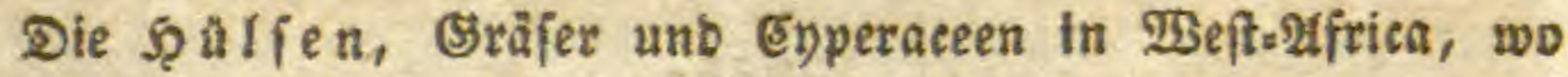
bie Palmen, Pfeffer uno gactelbifteln fait ganz feglen.

Die Sewitrzarten ober Scitamineen in Jnbien; bie Melaftomen, ordjiben unb Farren auf bem 5̧od)latib. İก Dff 2xitica ziemlidy fo.

Die פ? imofen unb હaffien ina mittleten Mfrica. 


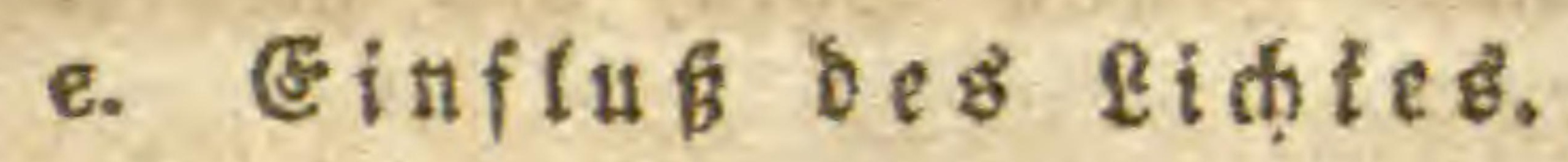

Inabfängig von Der গুGärme, weldbe bas sidjt Gervorbringt, wirft es auth Durd) feine DesDrybierende Sraft auf bie \$flanzen, unb befimmt baburd ifren 230 finort nad) ber Dunfelfeit ober Sgefligleit, weldhe theils ourd) die Entfernung vom Sonnenftand, theils burd) Die umgebung beftimmt werben. (5) gibt bafjer Sdgatten= und Ridstpflanzen.

(5) ift befantt, baß viele Pffanzen ben Sdyatten vorzielyen,

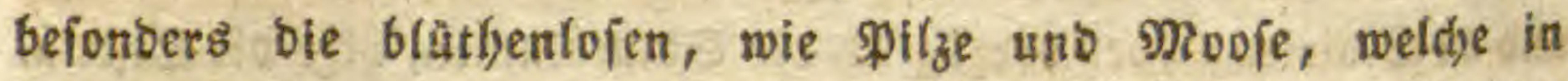
bichten $\mathfrak{y}_{3 a ̈ l}$ bern am üppigiten gebeiben. Für bfe Tange wito Das lifyt Durd) bas 5 gaffer gemilbert. Biele Rräuter lieben bet Edjatten uno finben fid) baber nur in Mäldern ober binter Jelfen.

2tnocre ftehen nur an Geleudsteten Bergwälbern, mie bie meiften ftarfichenben sräuter, bie Rippenblumen. Itnter ben blüthenlofen zieljen bie fledften affein bas \&idjt por.

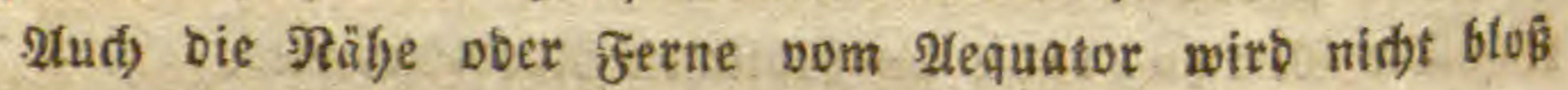
Durd) Die গ্Bärme befitimmt, fonbern fidber audy burd bas \&idt. Die meiften blüthenlofen fteben gegen bie \$ole; ebenio bie gabels bülaer, welde grofe Bermandfibaft mit ben Fartenfräuten Gaben. Die Palmen lieben bie Eonne.

B. Berbăltniē oer Pflanzen zum Planeten. Stanbort.

Der Planet theilt fih in breb Mraffen: Buft, \$Baffer unb Crbe, wie fid) Die Sonne in Drey Rräfte theilt.

a. Einflúb ber $\mathbb{R} u f t$.

Sू 6 b.

Die luft wirtt ein Durd) ibren Drud, Ljye Bewegung, ifre clectricität und Drybation. Die WSirfung ber beiben leb̨: tern if nod nirbt binlänglid) erforid)t. \$ilze und mandbe andere Pfanzen fieben ftebenbe unb bumpfe Quft. Die MBirfung ber 
Winte ift beffer befannt, befonbers ber beftänigen \$affatminbe unb Moufion, weldye fids jebod auf bie beise sone bejdbänfen, wo die Pflanzen periodifd) welfen uno fid) roieber erfrifden, je nad) Dem Binbwedjfel. (E: ift inbefien idjwer, eine Dariteftung biefer Beränberungen zu geben.

Es bleibt Daher nur ber Druct ber \&uft übrig, weldjer it

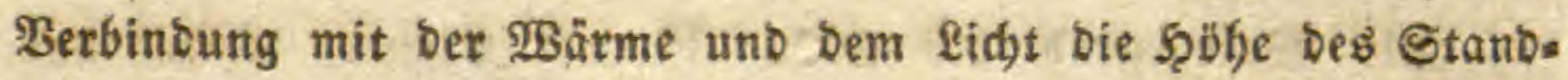
ortes beftimmt.

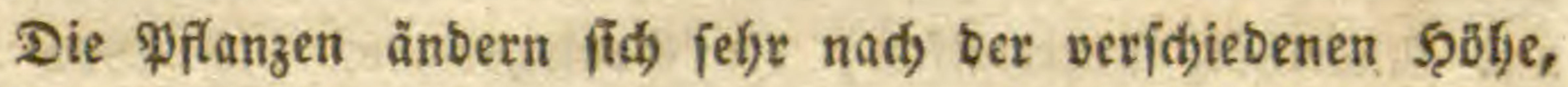
bejonders in heiß̧en Ränbern.

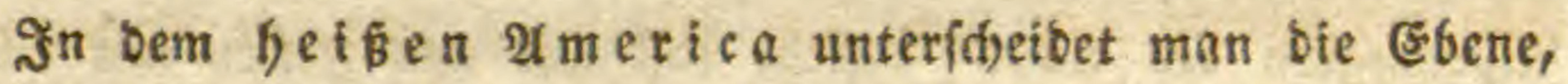
bie gemäbigten Şügel und bie falten Berge; iene geft $1800^{\prime}$ bod), Gat eine mittlere Sabreş wärme von $23-30^{\circ}$, uno ift mit

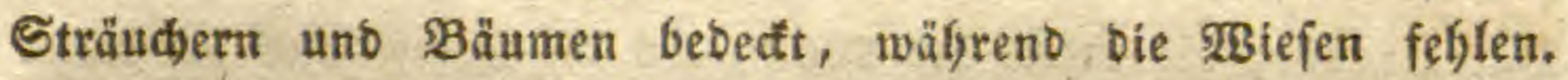
Diefe Ebenten fefjen im Sommer verbrannt aus; es wadjen

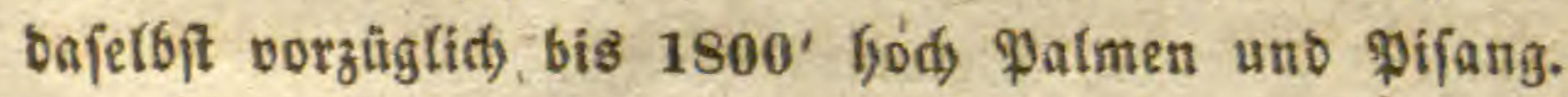

Den idünften Pfanzenwudys fyat bie gemäbigte Sregenb von 1500-7000', bey einer mittleren Wुärme von $17-25^{\circ}$; હacao, 厄hinabăume, \$almen, Gaumartige Farrenftảuter, Melaftomen, Paffifloten, Drdiben.

Die falte (Ssegend liegt zwifden 7000 und 15,000', wo bie Sđ̆neegränze anfängt, in 'Der Eđthweiz bey 8000 '.

Die Efina=2rten fommen bis $9000^{\prime}$ vor; Die Bäume hören bey $12,000^{\prime}$ auf, und es wadjien bajetbit nur fparjam (stäfcr unt ffechten.

In Merico, zwifden 17 und $21^{\circ}$, geft die heiße Begend $1800^{\prime}$ hod, mit $25^{\circ}$ wärme; die gemäfigte bis $6000^{\prime}$, bie falte bis 14,000'; Baumgränz̧e bey 12,000'.

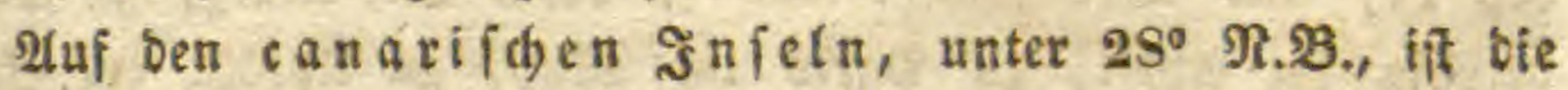
Sdyneegrảnze 12,000 unt Die Baumgränze gegen $7000^{\prime}$.

Iuf M a be Ea gefen bie Facteldiffeln $600^{\prime}$ hod), ber Bein $2000^{\prime}$, Die ฮaitanien gegen $3000^{\prime}$, Die (sinịter und Farrenfräuter gegen 4000', bie Şeiden uno Rorbeeren ûber 5000'. Reffen, Steinbred)e, Raub= und Rabelfyol felflen gänzlid).

In Reapel ift ber badjite Berg 9377, bod, unb falf immer mit Sdince bebertt, bie Berge von Ealabrien 5-7000' 
2Mm Stranbe wåd)รt Dejembryantlyemen.

§ัก Den höfern (E) Rreuzoorn; auf ben 5̧ügeln bis 700' hod ber Delbaum, bie immergrüne (ciđ)e, Der इัแbasbaum und angebaut ber Sirbels baum.

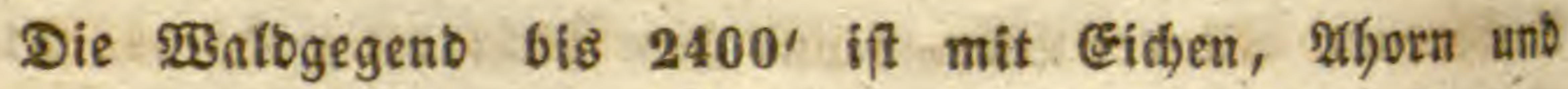

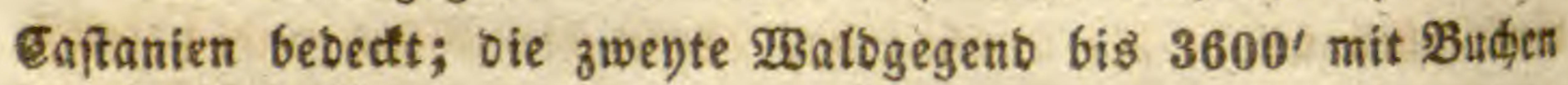
unb Nabetfotz untermifid)t; Die SSebirgstegion bis $4800^{\prime}$ mit :Bsiejenträutern, aud) STrummlyolz und Sevenbaum; bie erfe Ilpenregion bis 5400' befteht fait nur aus Felfen mit 2lpente Pflanzen, Soldanefla u.f.w.; Die zwente allpengegenb bis $6000^{\prime}$ Gat Inemonen, Steinbreche, Enziane un๖ einige Sträudjet, mie Bärentraube; bie britte bis 9000', wo bie Semfe und bet 2toter baufen, nur nob fleine 2afpenträuter, Steinbreçe, 2tnbroface; in ber Eisgegend Flechten, গBermuth, Rreffe.

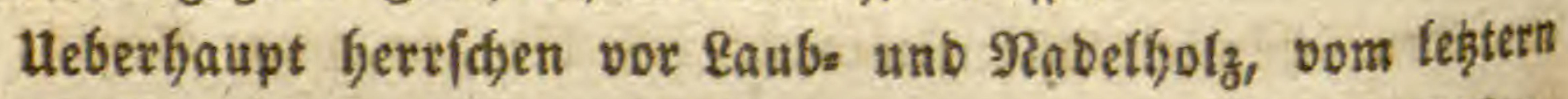
melgrere (Sattungen, bie uns feflen, vom anbern vieletten) (Eid)en.

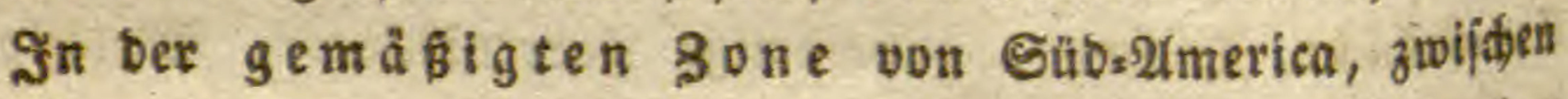
45 und $47^{\circ}$ श.R., ift Die mittlere Sabregtemperatur in ber (Ebene 12,5; bey (5enf 9,6 bey 1080'; auf bem (5ottharb 0,9 bey 6390 '.

24uf ben Berghöhen if ber unteridgieb zmifdhen ber Sommet unb 2 Binters, unb bev Iags unb Nadjtwätme geringer alo in Den Ebenen.

Iัn Europa blält ber \$firfidbaum, wann bie mittlert

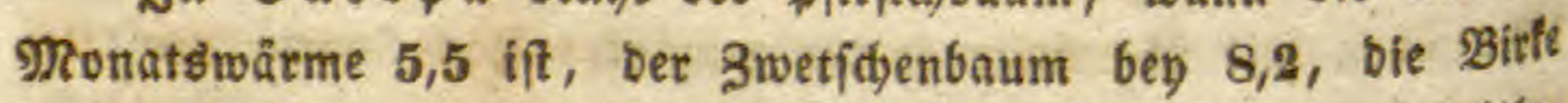

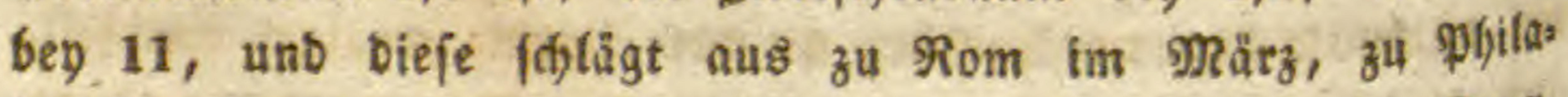
befphia im Xpril, zu Paris im May, zu upfala im Sunt), wädst baher auf bem Sottlatb, wo bie \$Bärme im wärmfen Monat nur $s^{\circ}$ ift, nicht melyr.

İm Eaucafus, znifd)en 42 unb $43^{\circ}$ iff bie Edgnecgtänge bey $10,000^{\prime}$, ber Ilpenrofen bey $8000^{\prime}$, ber Eber-2lefden bel)

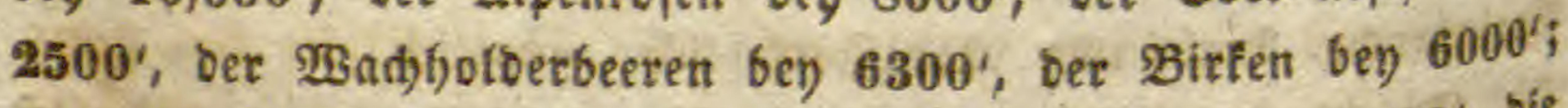
f̧aber uno Serfte wädobt bey 6000 ', Die Riefer bey 5,400 ', bir (side ber) 2700 '. 
Iuf ben Pyrenden, unter $421 / 2-43 \circ$, ift bie Edjnees grånze bey 8400', vben ftében veriftiedene siefern; bey $6000^{\prime}$ פSeiptannen, bey $\mathbf{5 4 0 0 ^ { \prime }}$ (Eid)en, bey) $7200^{\prime}$ Alpentofen.

2uf ben Sd) weizeralpen, unter $45^{8} / 4-461 / 2^{\circ}$, if bie

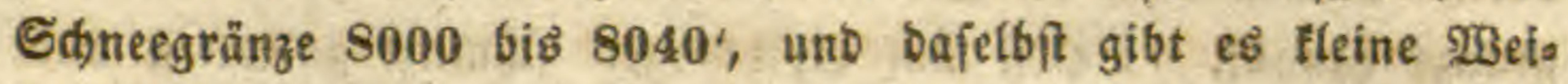
ben, tiefer unten 2 (fpenvofen; bey $5500^{\prime}$ 'Beírtannen; bey $5200^{\prime}$ Bürden und Riefern; bey $4500^{\prime}$ bie Rothtanne; bey $4300^{\prime}$ bie Birfe; bey $4000^{\prime}$ bie $\mathfrak{B u t h e ; ~ b e y ~} 3300^{\prime}$ bie Eidhe, und bafelbft wåd) st aud Setraibe; bey 3000' Der Rirífbaum; bey 2400'

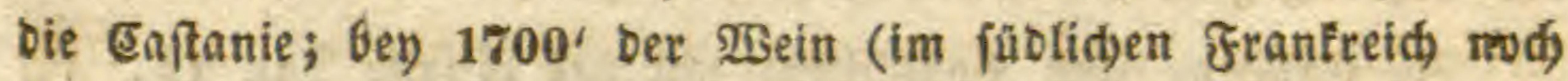
bey $2400^{\prime}$ ). Die Baumgränze ift bey $5500^{\prime}$.

Ueber ber Sdnneegränze finben fid) Steinbredje, Enziane, Silenen, Aretien, פBolverley, siteffen.

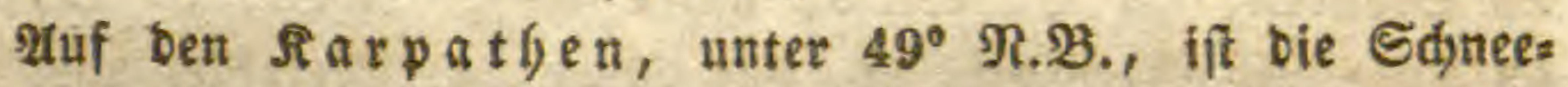

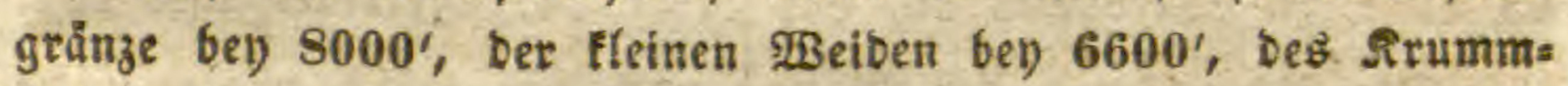
Golzes bey 5600', ber Rothtanne bey 4500', Der Rärche und હimbernuf bey 4200'; tiefer Die פseińtanne uno Riefer; Die Budbe, Erte und Bitfe unter 3600 '.

Ralte 30ne.

3 wifdben einem füblidgen unb nö:blidjen Ort if ber linter= (d) ie Der WBinterfälte viel größ̄er als oer Sommerwätme; baber änbert fidy von Deutídland bis zum Polarfreis ber Pflanzenwudbs menig. Der Unterfdieo Der Sommerwärme von

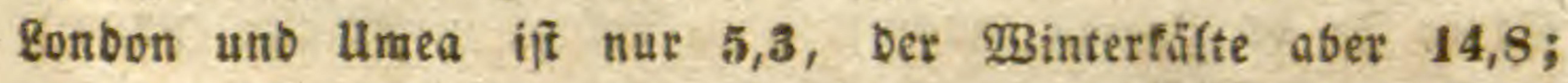
von Paris und upfala 3,3 uno 7,7: benn bie Eommermärme

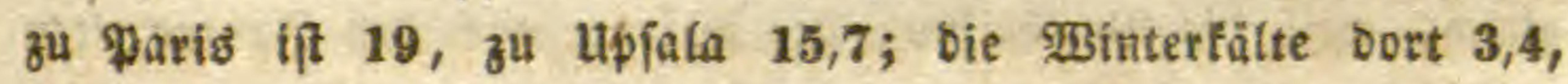

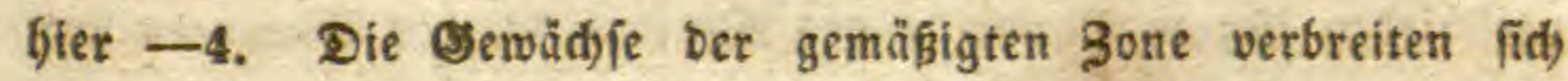
viel weiter als in ber heísen, wo bie \$̧åme weniger wedjelt, unb wo fie in ber Fbene und auf ben Bergen immer feffe ungleich ift.

In Eapplanb, von $67 \% / 2$ bis $70^{\circ}$,

if bie mittlere Iemperatur unter 0 , unt bie Søneegrånge bey 3300'; 2lpenrofen bey 2900', 3wergbitfen bey 2600', 3wergweiben bey $2000^{\prime}$, \$Beifbirfe bey $1600^{\prime}$, Rtefer bey $900^{\prime}$. Die Baumgrånze bey 2000', in finnmarfen bey 1500', in

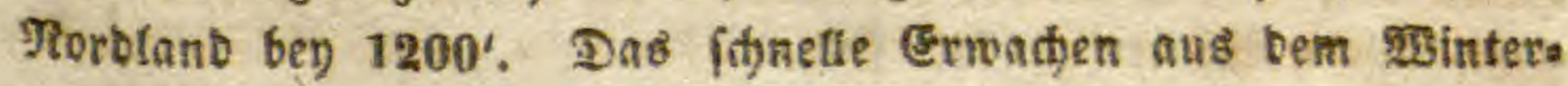




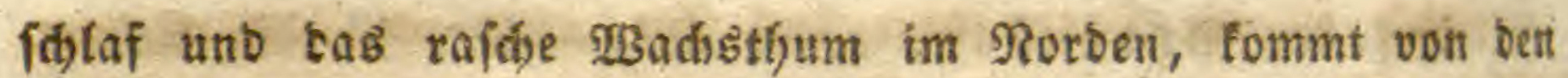
längeren Ingen ber, woburdy bie 25ärme an ber Edhneegränge

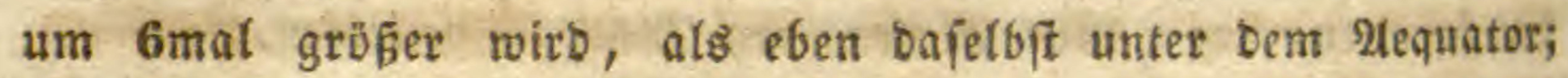
barum reidien aud) bie Bäume in शorben näber an bie Sdinee: gräıze binauf. Selbît auf Spib̧bergen fd)mitz̧ zuweifen affet Sdinee ab wegen bes anlyaltend feitern Seimmels; unter bem 2hequator aber ift $6 \mathcal{E}$ ben einer şülfe von 15,000 faft inmer trüb, unb baher Das Wetter veränberfich, was auch ziemlith von ber Sdhweiz gilt, ben einer şülye von $8000^{\prime}$.

3ิ Cayenne uno \$onbidery fat ber längfe Tag 12, auf St. Domingo 13, zu Sิfpafjan 14, zu Paris 15, Dublin 16, Ropentagen 17, Stotfiolm 18, Drontlyeim 20, Htea 21, Tornea 22 Stunben; zu Enontefis, unter $681 / 2^{\circ} \Re .23$., in Rapplanto

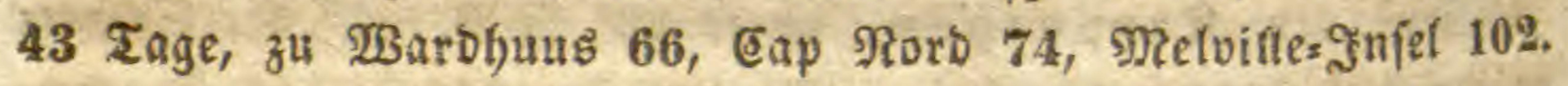

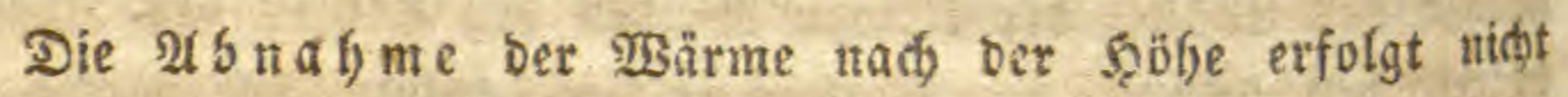

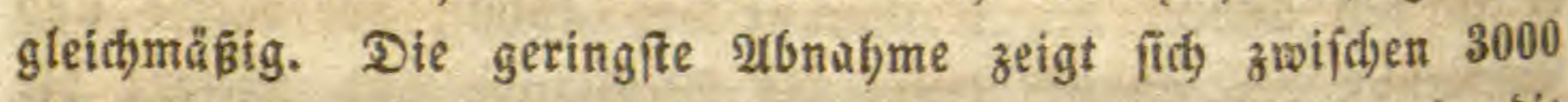
unb $6000^{\prime}$, nefimlid um $3,4^{\circ}$. Seb̧t man in Silb=2rmerica bic

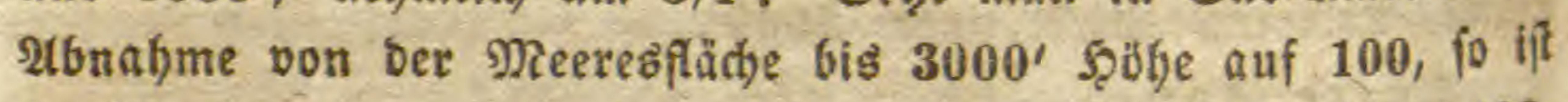
fie bis $6000^{\prime}$ mur 59, bis $9000^{\prime}$ if fie 72 , bis $12,000^{\prime} 128$, bỉ $15,000^{\prime} 96$; bey $6000^{\prime}$ ift die mittlere wärme $17^{\circ}$.

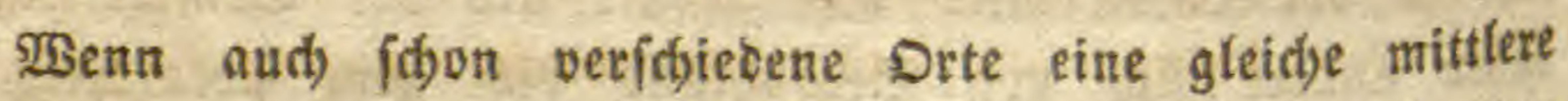
Semperatur (3. Y. von $\mathbf{1 5}^{\circ}$ ) Yjaben, wie Duito $\left(9000^{\prime}\right.$ ) ober Ganta Fe De Bogota $\left(8200^{\prime}\right)$, ober Soluca in Mrerieo $\left(\$ 300^{\prime}\right)$, Stalten und jüblid)es Franfreid); io ift Dennody bas (efima nidht gleid, weil bie \$ertheilung ber \$Bärme nadh ben Saljebzeiten

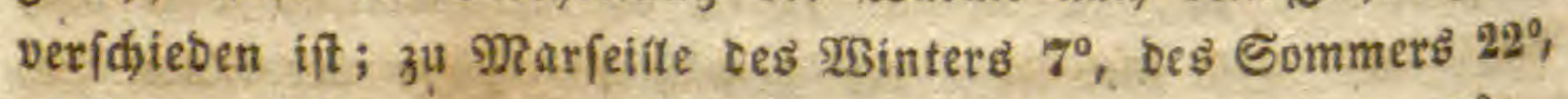
zu Duito faft bas ganze Jalir ben Tage $17^{\circ}$, ben Radht $10^{\circ}$.

รัก Europa tönnen jwen Drte von mittlerer Temperatut

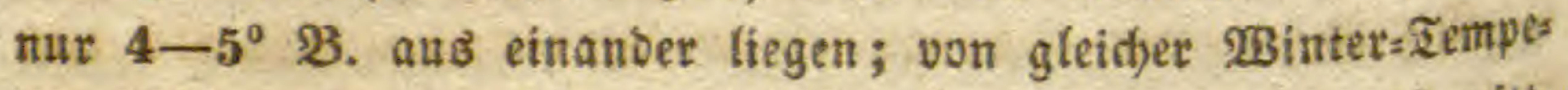
ratur aber um $9-10^{\circ}$. Sey uts hat ein ort von $10^{\circ}$ mitts

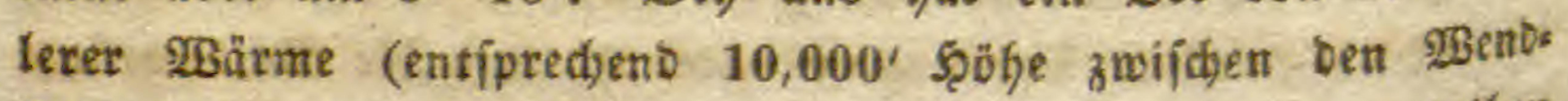
freifen) im Geikeiten Monat nid)t unter $19^{\circ}$; barum gebeiben europäifide Dofitiäunte nidbt bey Quito, weil bort bie Sommet

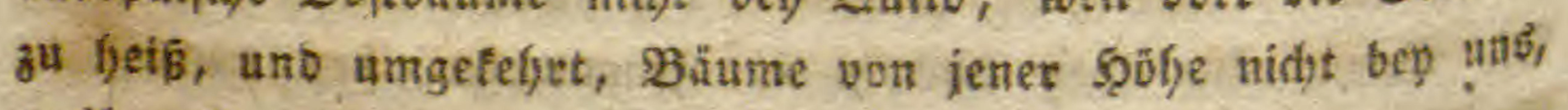
weil unfere গ̇inter $3^{4}$ falt finb. 
2u(t) ift bie Temperatur bes Boben s im Rorben ver:

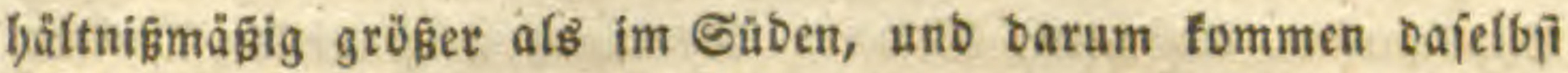
nod) viele Pflanzen vor, weldye fonit nid)t fortfämen. Swifden Den $\mathfrak{B}$ endofreifen fît ber Boben $2^{\circ}$ fälter als Die Euft; in Sd)waben $1 / 2^{\circ}$ wärmer, im Rorben nod) wärmer.

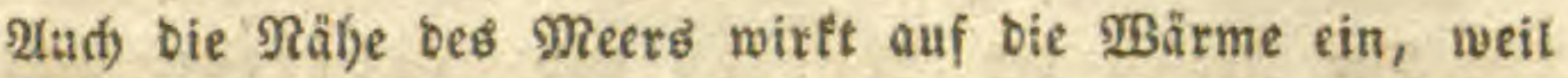

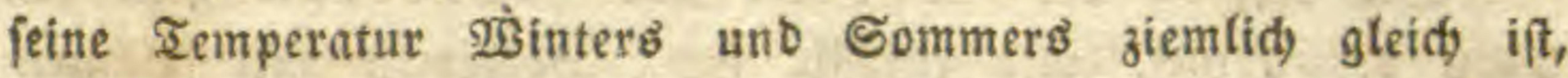

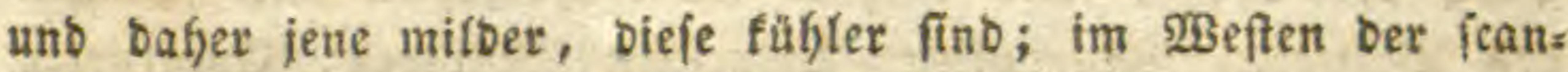

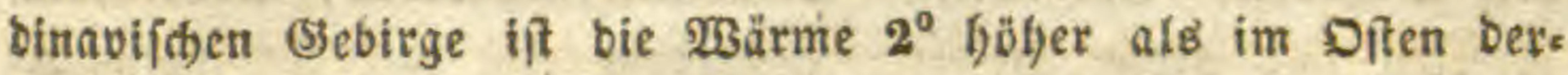
jelber.

Meyen theilt bie Berghoben, wie bie Breitenzoncr, in 8 Regionen ein, unD beftimmt für jebe Region unter Dem 2lequator ungefähr 2000', well bort bie Schneegränze gegen 16,000' hod) liegt. Die Regionen werben mit Berüdfid)tigung ber verf́chie= Denen Breiten, wo Die Sdneelinie immer tiefer berabfintt, bis auf $1900^{\prime}$ in ber Polarzone, auf folgenbe 2 trt beftimmt:

Gölye unter bem Requator bey

$$
\begin{aligned}
& 15,200^{\prime}-\mathfrak{A f f}_{\text {penfråuter, }} \\
& 13,300^{\prime} \text { - Iffpenrojen, } \\
& 11,400^{\prime} \text { - Radelfölzer, } \\
& 9,500^{\prime} \text { - Raubfjölzer, } \\
& \text { 7,600' - ฐmmergrüne Raubbölżer, } \\
& 5,700^{\prime} \text { - Miyrten und Rorbeeren, } \\
& \text { 3,500' - Farrenbäume und F̧eigen, } \\
& \text { 1,900' - Palmen und Bananen. }
\end{aligned}
$$

Diefe Regionen finfen natütlich immer meffe berunter, je weiter man nad) Norben fommt, wo ilfre Pfanzen aftmäflids

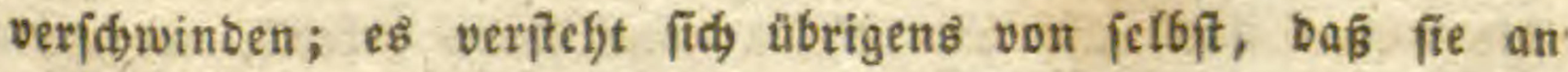
Den (Gränzen übergreifen.

Die Region ber a f men unb $B$ ananen geft von Der (5)bene bis $1900^{\prime}$ hod, und zeidinet fid auser ben genannten

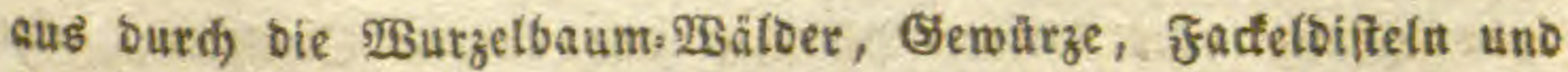

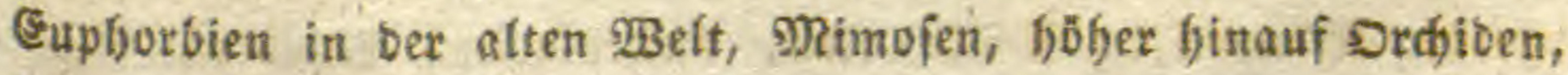
Potbos und \$feffer in ber neuen.

Die Region ber baumartigen farren und feigen reidgt

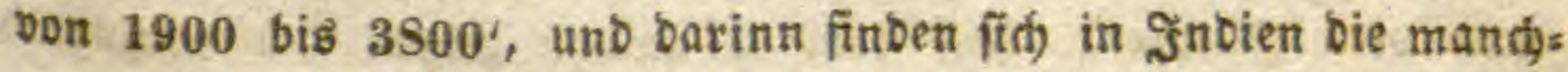
DPen s alfg. Taturg. II. Botanit I. 
faltigen Feigenwãlber, mit Ettråud)ern von S̈ufticien, Ruettien, \$hyllanthen, Brewien, Eplanen, Dracänen nebit vielen Irviber, Drdbiben unb Pfeffern; auf ben Subfees Snjeln ber Brobfrudts baum unb Broufionetien; in 2 Imerica vorzüglich Die Nelaftomen unb mefrere rolfrartige Datmen.

Die Region ber Mnten und eorbeeren geft von 3800 bis 5700', und enthält meift Şolzarten mit glänzent Den Blăttern, Magnolien, Cameflien, Proteen, Čncalypten, 2teacten uno grobe Şeiben; auberbem auf ben Sebirgen ber Benbfreife, Storaxbäume, Relfenbäume, Rottange unb viele Rubiaceen, Eidben, Mimojen, Bignonien unb Solanen.

Die Region ber immergruntuen $\mathbb{E} a$ ubgólzer erftedt (iti) von 5700 biz $\mathbf{7 6 0 0}$, und hat unter bem 2 tequator bả atte genefymfte Elima. Dafelbft gibt es befonbers 2Bälder von immets grủnen (Eid)en, unb aub̆ bie gorbeerwälber fleigen Ginauf.

Die Region ber \&aub wälber geht von $\mathbf{7 6 0 0}$ bt 9500 ',

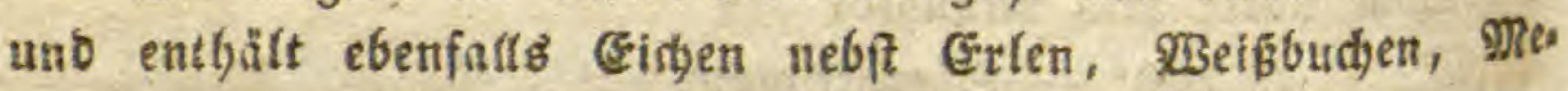
laftomen, Rhexien, Erotonen, Eerniftömien, ฐolgannisftäuteth, Fudfiten, Speibetbeeren, Sauerad, Barmabefien, Duranten, Eas ftifleyen, columeflen, cmbotfryen, Eluften.

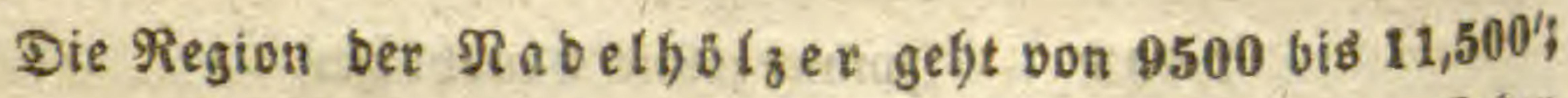
bieje Băume feblen jeboh meiftens ber 2lequatorialsogne, finten fich aber bäuftg in פRexico, unb Darunter befonbers bie હypreffent, nebft Baadbotber, baumartigen Bilien, araganthen, Ropfblumeth, Facteldidteln uno હijîrojen.

Die Region ber 2 Ipentofen gefot von 11,400 bis 13,300'; bie थnben fito ganz mit biefen Străudbern bebedt, wotuntet bejonbers bie Befarien, and Factelbifteln, Eaffiten unb Eoafen.

Die Region ber थl (penfräuter enblich erftrectt fid vort 13,300 bis $15,200^{\prime}$, unb enthått gröstentheils ausbouernbe unt gewûtzhafte ober bíttere \$flanzen mit furzen Etengeln, aber groken Blumen, wie MRimulen, Ealceolarien, Bupinen, Eiben, ben uns Enziane, 2retien, Primeln, Anemonen unb gelbe Seppis pflanzen, פolverlen) u. bergl.; ebenfo gemur'zl)afte Dolbenpfanzen

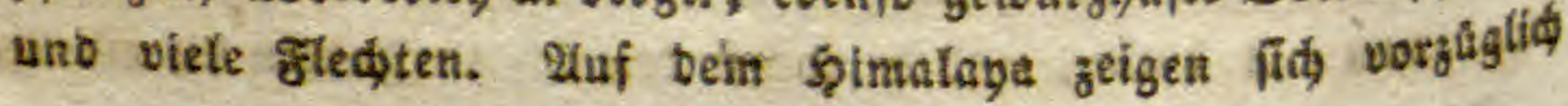


Ranutifeln, Sturmbut, Storchidgnąbel, Potentiffen, Epilobien, \$rimeln, Doften, Salbeg, Difteln, Mlant und Rnöteride.

\section{b. Einflu bes खुaffer.}

\section{Eafferpflanjers.}

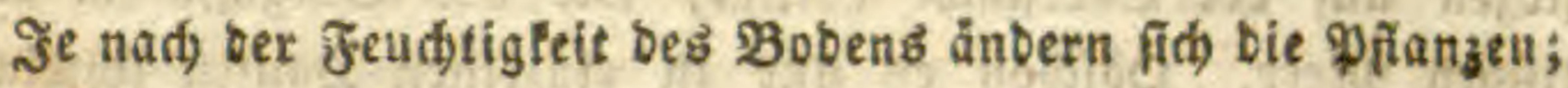
anbere fogar auf foldjem, weldyer nur ber Heberidywemmung auss geiełst ift; anbere an Ufern, in Sümpfen, Moräften, Gräben,

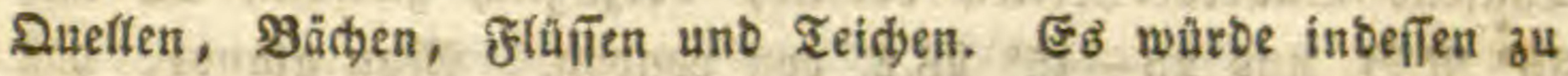
meit fúbren, wenn wir bier biefe geringen unterídiebe berüat: fidtigen woflten. Der Şauptunteridgied liegt im iûgen unb gejalzenen \$affer.

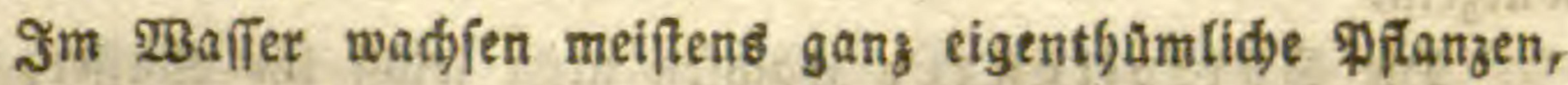
wovon auf bem Eanbe nid)t eine einzige (Sattung vorfommt, wie

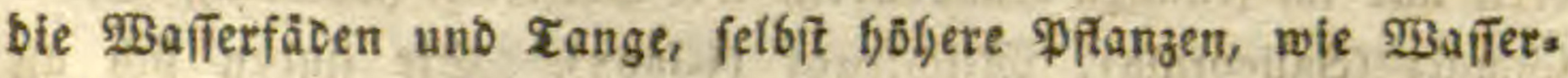
linjen, Tannenwebel, Rajaben, frebertraut, Binfen, Samfraut, Edjilf, Fofjrtolben, Gatmus, Seerofen u. Dergl. Bon anbern gibt es Battungen im $23 a$ fier und auf ben Ranbe, wie Ranuns leln, Bad)bungen, Brunuentrefíe u.f.w.

Fon ben Meerpflanzen fteben afle im Wrafier; mandie Fommen jebods aud im fúfen Waffer vor, wie bie Wafferfäben.

Dem Meer

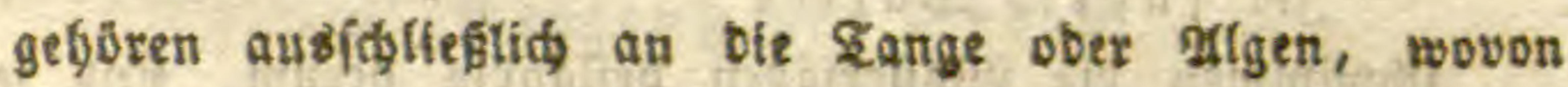
felbit im cafpifden preere vortommen. Sie wurzeln afle auf Dem Boben bes Mreers, balb an Jelien, balb auf Muídieln, balo an Pfäblen u, bergl., meiftens body oben in ber Räbe ber Ruft, wo fie bey ber ebbe zum Ifeil ins Iroctene Ponmen; eb

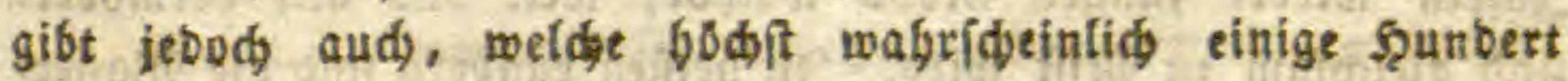

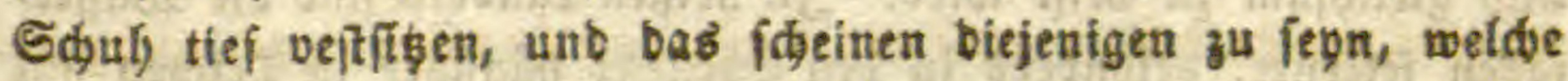
febr lang merben. sman bat Tange gefunben, bie aber 300 lang waren, felbft in Pälteren vieeren.

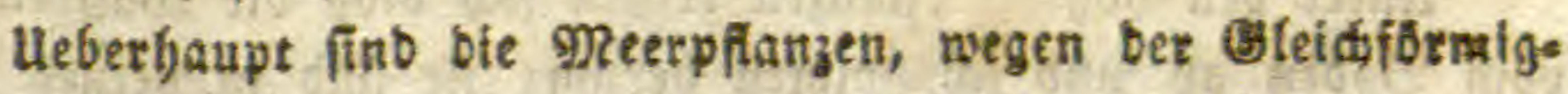
Feit ber Temperatur, nidgt fo an gewiffe Zonen gebunben, wie bie Sanbpflanzen, und mandye Eattungen fint vom Xequator

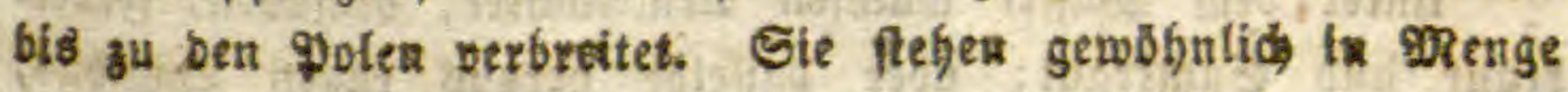


beyfammen, unb bifben ungeljeure STiefen, befonbers in ben wärmetn \$onen. Sie werben bäufig burd) Stürme abgeriffen und an ben Strant geworfen, wo fie bie fogenante flutfmart bitben, oft 刃eilen lang $2-3^{\prime}$ breit und $1 / 2^{\prime}$ bod).

Inbere werben butd) Strömungen zufammengetrieben utb flözen auf bex Oberfläd) Gerum, wie bas Sargafío im atlatt= tifden Meer. Dbfdjon es nur in einzelnen Şaufen fdwimmt,

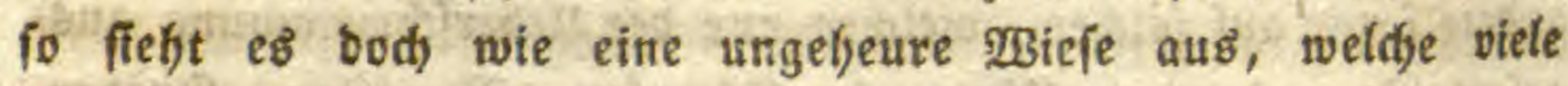
Iaujen Duabrat= Meiten bebertt, vorzüglidh zivifden 22 utb

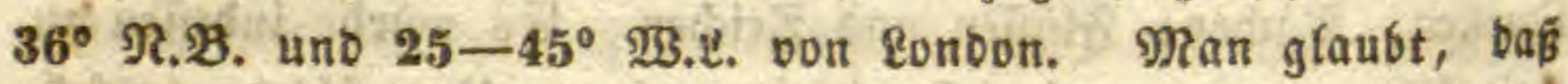

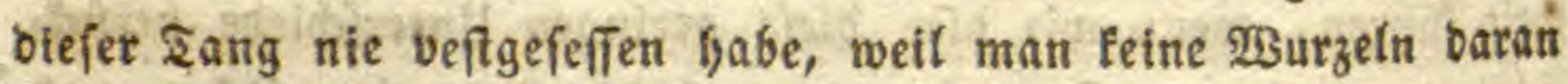
fintbet; bie jungen Pflänzdyen fdeinen wieber auf ben atten zu wurzeln.

Die Sa rzpftanzen warbjen nidbt felbit im $2 B a f f e r, ~ f o n s$ bern nut im feuthten Sanbboben, wie Salgfraut (Salsola), Gilabs

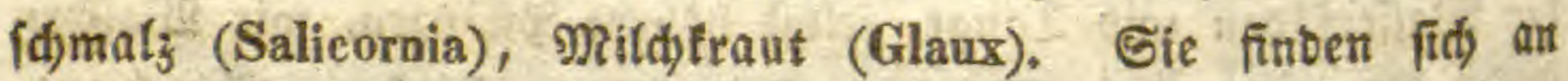
Salzquetten, Satzieen uno felbit in Steppent wie am Mreer.

Im Brunbe fann man aud hiefser redjnen Die Bäume in beisen Ränben, weldye an ben Münbungen ber Ströme fiefyen

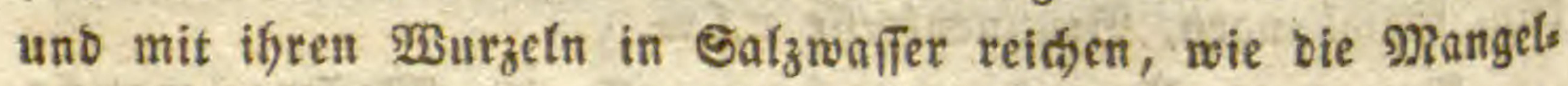
voer พSurzelbäume, 2tvicentien uno \$ruguieren. Eie bflben ganze rzătber am Strantoe.

\section{Sm $j$ it Ben $\mathscr{B}$ affer}

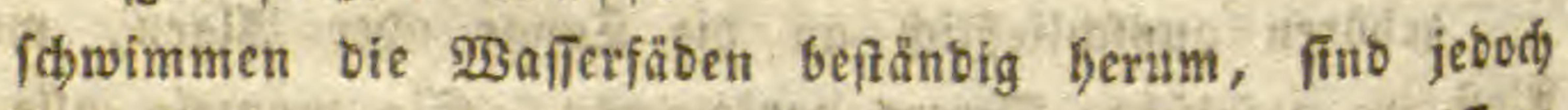
auf bem Boben entitanben unt foben fidh ipater loggeriffen; aber aud) hier fönnen junge \$ftanzen wieber auf alten wadjfent, wie benn aud) auf ben aus Roos beftefgenten, fdswimmenben Intelt wieber junges Moos wähst, weil bas alte vermobert

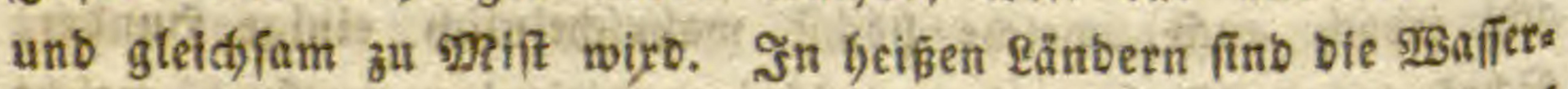
fäben feltetter, befonbers in ben (Ebenen; häufiger in হeid)en auf Bergen, wo bie Temperatur mebr gemäsigt iff.

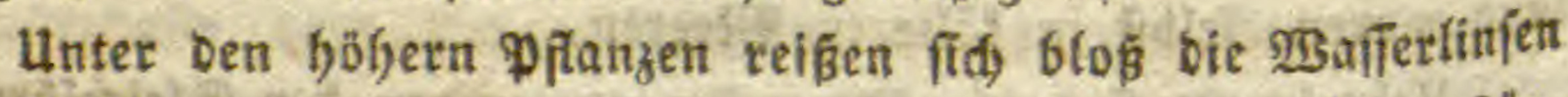
vom Boben ab und fdymimmen berum; fie fino in heipen Eärt bern felten, unb werben bajefbit burdy bie Pistia eréeb̧t.

Unter bem $\mathfrak{B a f f e r}$ wadjfen $\mathscr{A}$ (rmleud)ter, Najaben, Febets traut unb Samtraut; über bafielbe heraus ragen $B a m b u$, 


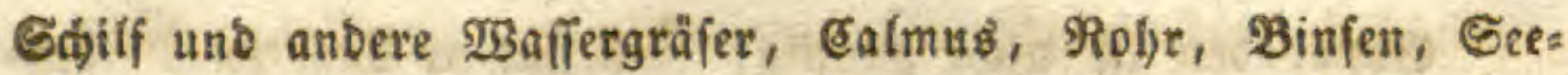

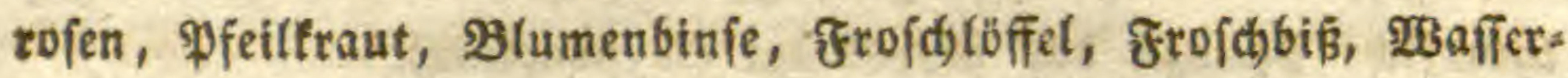

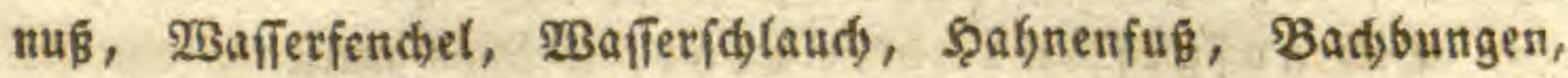
Brunnentreffe, $\mathfrak{x a f f e r a l o e , ~ B a f l i z n e r i a , ~ \$ o n t e b e r i a . ~}$

Die meiften lieben ftehenbes şaffer, ober menigitens nur

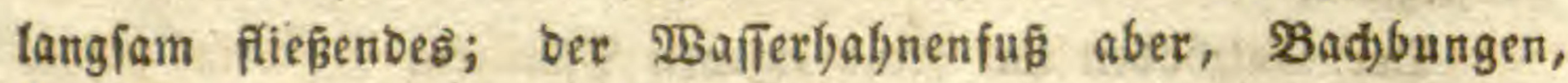
Brunnentreffe ziehen bie Bädse vor.

Esine grofe Menge von Pflanzen finben fid blö in Sümpfen,

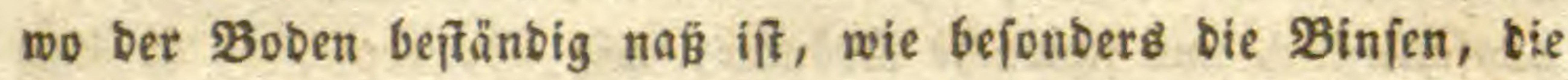
Dotterblumen, Iroffblumen, mandhe MRanzen, Impfer, WBiejen: Freffe, Jettlraut, Sd)füfielblumen, Fieberllee, פBafirrviole (Hottonia), Swevzabn, 2(jd)enffianze u.f.w.; Das 3utterrofir uno ber Reis gebeifyen nur in foldtem Boben; baffelbe gilt von ben Riebgräfern uno fạt von aften äd)ten Gräfern, Die æBiefen ver langen reidglidge $25 a ̈ f f e r u n g$, wenn fe gebeilgen folten.

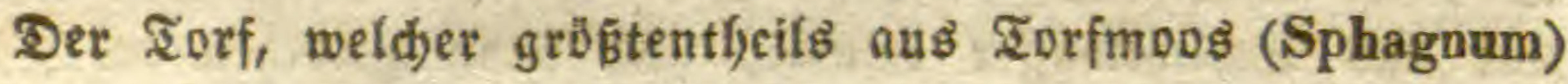
befteht, zeidutet fid) vorzüglidy Durch etgenthümlidbe Pfanzen

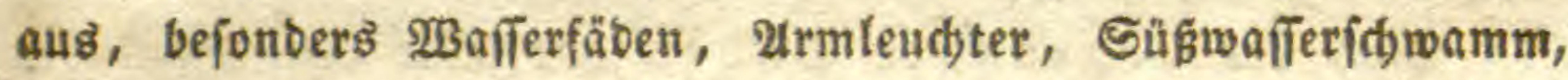
Sdjadtelfalm, Febertraut, Sonnenthau, פoosbeeren, Torfheide (Andromeda), Moffgras, Stebenfingerfraut (Comarum), mefjrere Simpen uno \$seiben.

\section{c. Einflü Der ErDen.}

Die Berfdiebenfeit ber Erben wirlt zwar nidt bebeutenb auf ben unteridied ber झflanzen, if jebod) nidjt gleidgunttig.

Das (ar anitgebirge trägt meiftens nur Nabelfolz, felo tener Baubholz, hat aber gute 2 Siefen in ben Ibälern.

Sneis, Glimmerídiefer und Ifonidhiefer verwittern leidtet, und fint baher frudtbarer als baz \$orphyr=\$ebirge. Muts Bafalt unb Raven geben einen guten Boben.

Huf Sa nofitein gebeilyen bie Raubwäloer.

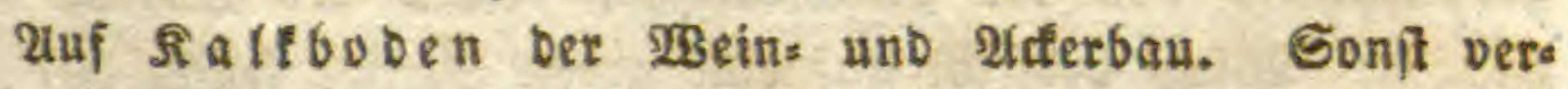

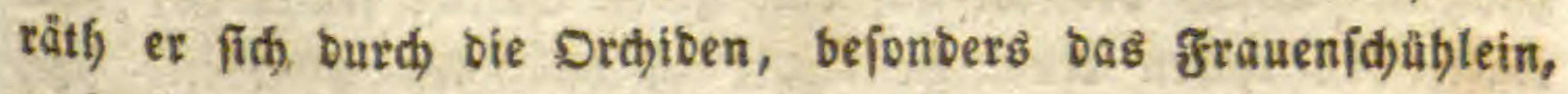
aud butál bas blaue Rammgras (Sesleria) und ben Berg: gamanier. 
Gypsboben if nitht gatnitig, ood bat ex auth feine eigells thümlitbe Pfanze, bad Cyypsfraut (Gypsophila).

Das a ufgefdowemte $\mathbb{R a n D}$, weldhes meiftens ein Ges. mifd) if mit vorwaltenber $\mathfrak{x}$ fonerbe, if Den Pflanzen am günitigiten.

Der Eatzboben bat feine efgenen pflanzen.

Der SanDGODen wirtt vorzüglid, nadbtheiltg burd feine Zroctenfyeit unt Rorterfyeit: er nåhrt, außer eintgen 2 Beiben, faft

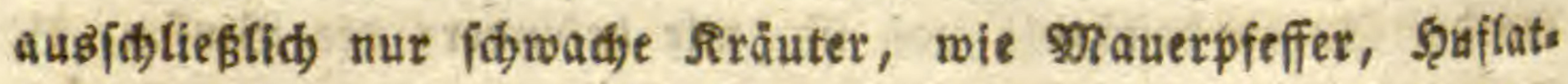
tid), F̧unfingerfraut, Brud)traut, meiftens jebod) nur (Eräfer, motuntee ber fogenannte Sanbfaber (Elymus arenarius) bas wid)s

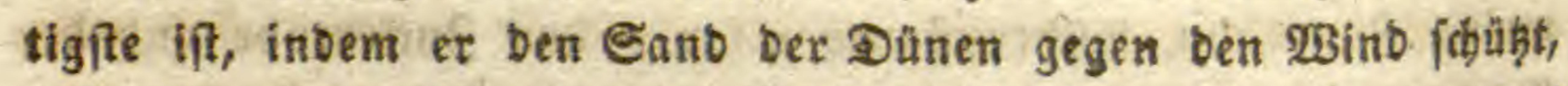
unb feine $\mathfrak{B}$ urzeln unter bem Namen $\Re$ otfwurzeln $50^{\prime}$, ja $100^{\prime}$ burd Denfelben heruntertreibt, um ben feuditen Boben zu erreidjen. In fanbreiden (3egenben gräbt man Särten fo tief aub, bis man auf bas Sdjidtwaffer Pommt, unb bann gebeiben bafelbft bie meiplen Bartengewädjé.

Iud) ber angebaute Boben bat feine eigentbümlidjen wilben Pflatzen. Iuf ben felbern z. B. Iold, Siornblumen, Winden, Spart, Senf, Sdarte, Sauerampfer, Difteln, Whet: muth, Miere, Melben, Bingelfraut, \&brenpreis, Rattertopf;

an Begen unb Säunen Reffeln unb Taubnefieln, Etdotie,

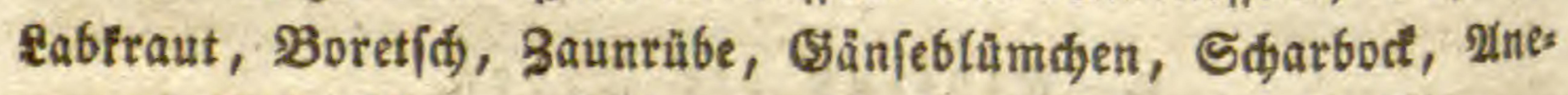
monen, Sdwalbwurz, Erbraud), Dofte, Rainfarren, Beil(hen;

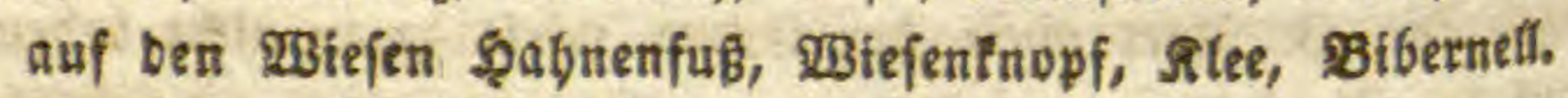

\section{Betbăltní ber Pfanzen unter etnanber.}

\section{Dflanzen=Pbofiognomie.}

Das zerftreute unb gefeflige Borlommen ber Pflanzen fiheint

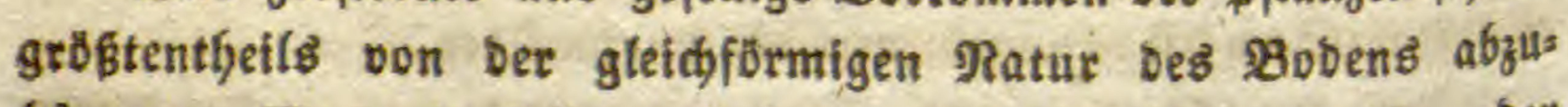
föngen. WBenn berfelbe auf eine grofe etrecte feudit tift, ober einen beflimmten chemifiden ober medjanifden (Ebaracter bat, wie Raft unt Ifon=2Boben, wie 'Sand, tocterer Grunb ober grelíen u. bergl. Jimbefien fibeint ifge Menge bod) aud) von 


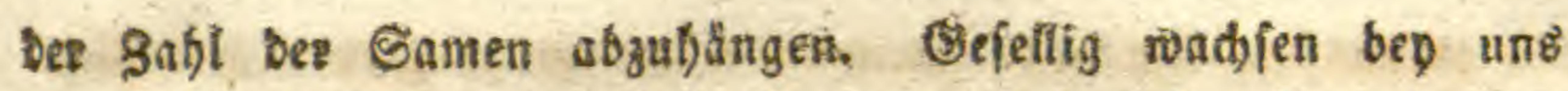
vorzüglid) Die Speiben, ફ̧eibelbeeren, Snỏterid), Sumpfmods, Siefern uno das Rabelfolz ubethaupt, fo wie vieles Raubbolz, wie Eidjen, Butben und Birfen.

Einzeln fethen viele Pfanzen, bie Enziane, Seibelbaf, Eidjtnelfe, Bifien, Drdjiden.

In ber beipen Zone felyen bie Pflanzen von einerley (state tung weniger beyfammen, ofhe 3weifer wegen ber grofen Mand): faltigleit ber $P$ fanzen.

(3) eid) loffene Wälber bifben in Mmeriea bie Mangeto

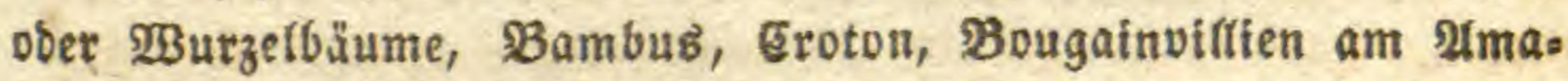
zonenftrom; bäufiger finben fie fid, fdyon in शrexico ober auf

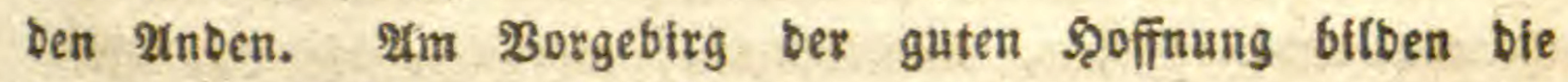
Proteen und Mimofen

(3) efellig fann man afle Pflanzen nennen, weldye ange: baut werben. Sie gebeifien in Mrenge beyfammen, weil man (ifmen einen gleidfformigen Boben bereitet. Betraibe affer Art

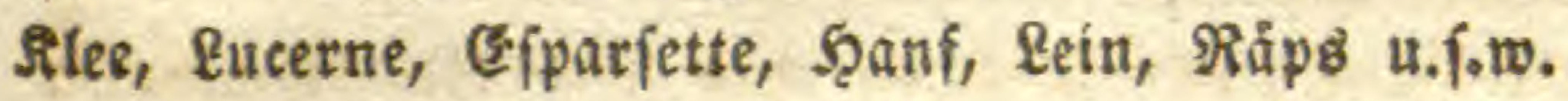

Daffelbe gilt von bent wisiefen, wo zwar meiftens ver.

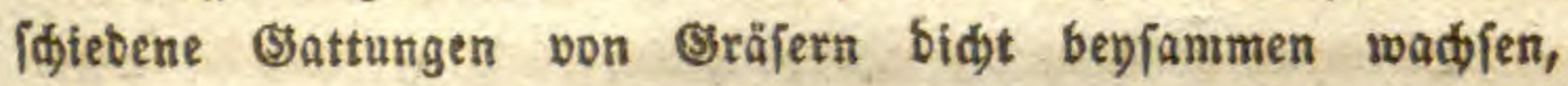
mandmal jebod) audi) von einerleb (5attung, bejonbers menn bie Eultur eingreift;

ebenio von ben Rabelo und Baubwälbern, weil fie einerley Boben auf groṕen Strecten finben, unb burdi igren Sdatten bas :3adjsthum ber anbern Pflanzen finbern.

खm gefefligiten inbefien finb in ber freyen Ratur bie nies Derften Pflanzen, bejonberz bie Mafferfäben, Iange, WBafier= linjen, fledten, $\mathfrak{R o d f e}$ und felbft bie Pilze, menn man bie eigentfiden Sdymarober babey in Betradyt zielst. Die Renn: thierfied)te bebedt im Rorben ganze Eänberftrecten, bie Moofe viele \$ăber unb Sŭmpfe. Tud) bie gartenltüuter wohnen gefetlig, obidion mefje in getrenten Şaufen.

Rady ben Moofen fam man woht bie of rdifer bie gefele ligften Pflanzen nennen, inbem fie faft aften Boben bebecten, meldjen jene und bie Bambustobe finbet fing inmer in Menge benfammen. 
Itnter Den Rräutern werben oft ganze Felber von Ifby: mian bebect', ganze Bergwände vom rotfyen Fingerfyut unb vom gelben Enzian; ganze Bergwälder von Sccibelbeeren, ganze Iants frecten unt (Sebirge pon Setbeltaut, fowof)l im Rorben, als am Dorgebing ber guten Soffmung.

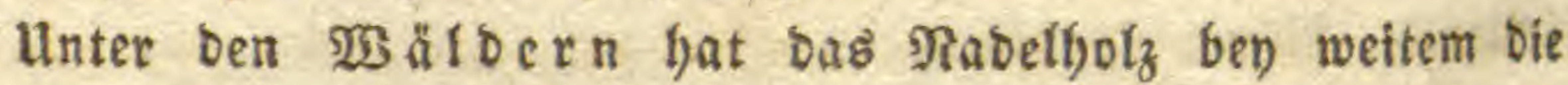
größte 2(uboebnung; füblid)er auf ben (3ebirgen, nörolidber in ben Ebenen. Die Raubwälber fteigen in ber Regel weniger hod), uno brechen viel mebr ab. $B$ en uns befteben fie meift aนs Eidjen, Buben, Şagebudben uno Errten; im Rorben aus Birlen.

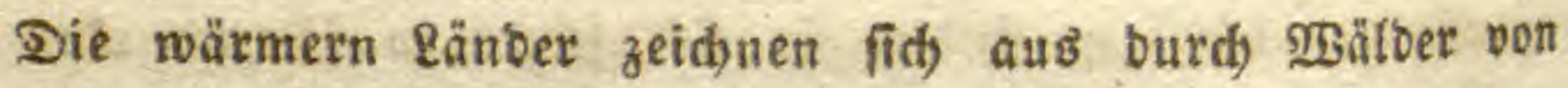
eigentbümlidben Cidben, Rabelfb̈lzern, worunter bie Eyprefien,

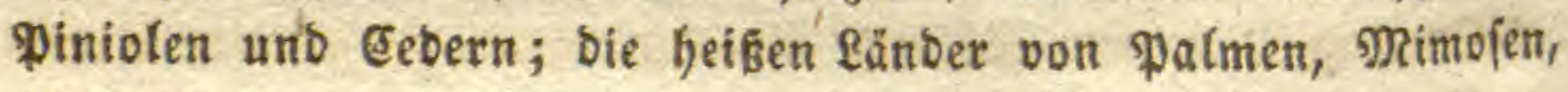
હbinabäumen, Protecu, Eucalypten, Iectbäumen unb Bambus.

આud cie (S) w uีtzpflanzen ober Scitamineen wadjen gefeflig; ebenfo die Factelbifteln.

3u Den gefeftigen Pflanzen fann man aud bie Sd)marob̧et redinen.

Darunter gefjören bie meiften fleineren Pifze, uno in biefem Sinn afle pilze, inbem fie woht nur auf faulenben Stoffen entiteben.

Die boblern Sdbmaroberpflanzen madjen auf ben $23 u z$ eln, wie Die Erven=\$Bürger, Der Fid)tenfpargef (Monotropa), Sd)uppent swrz, Die Balanoplyoren uno Raffleften; fie find faft blattlob uno miffarbig.

Inbere wadafen am Stengel ober an ben 3weigen, wie Fladisfeite, Miftel unb Epheu in unfern Segenben, fo wie ein

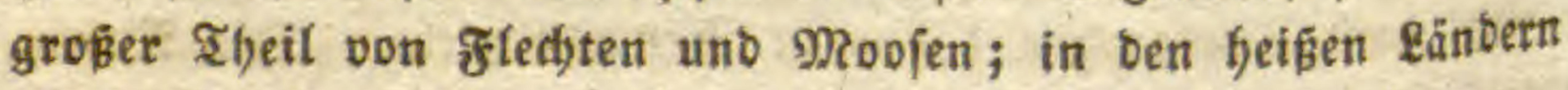
Die Tiflanbfien, viete Díbiben, 2tronarten und Farrenfräuter.

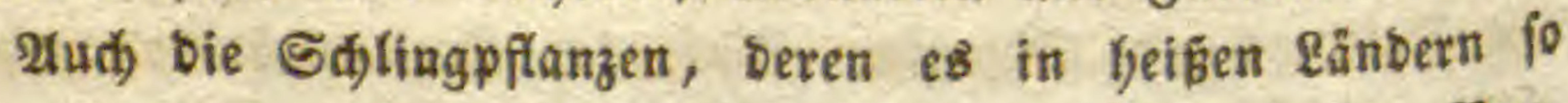
viele gibt, wie in Xmerica bie Pafffforen, Bignonien, Baus binien, Banifterien, Srriftotodjien, ftno gefeflige $\mathfrak{P}$ flanzen, unt

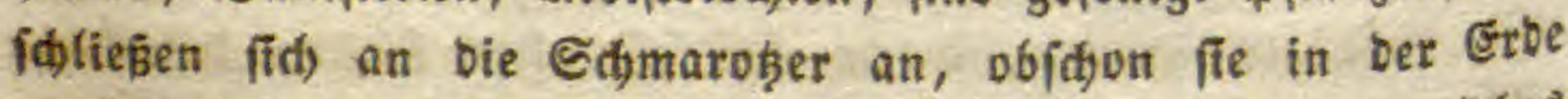
wadbien. Sie geben ben utwälcern ein ganz eigenthümlidjeb Mnfeben, inbem fie wie Euirlanben von einem Baum fum ans 
bern laufen, hoter bic (Sipfel fteigen unb wieber yon Denfelben berunterfaften. In ber alten $\mathfrak{B g e l t}_{\text {gibt }}$ es weniger, werden aber burd) bic ungeheure Ränge ber Rottange theitweife erfeģt. Bey uns fant man nur bie $\mathfrak{B a l b r e b e , ~ S a u n r u ̈ b e , ~ b e n ~ S ̧ o y ̣ f e n , ~}$ Die Eสt) vergleidyen.

Xuछ Der Sefefligfeit Der Pflanzen entipringt Die fogenannte Pfy fiognomie bes \$fanzenreithes, weldye ben elgaracter einer Esegeno voffendet. Den sauptefaracter erbält eitte Begend ima

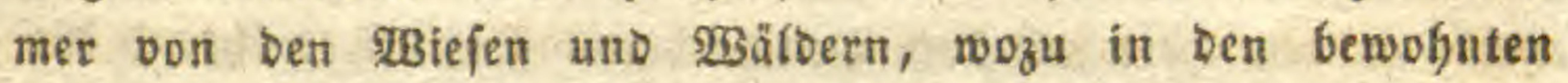
Sänbern nod) Die gelber fommen, aljo eigentlid) von ben Gräfern uno Bäumen, inbem audy bas (setraibe, weld)es bie meiften

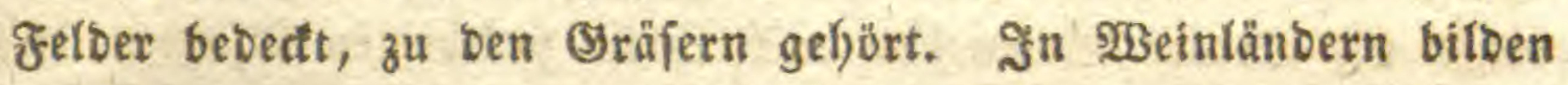

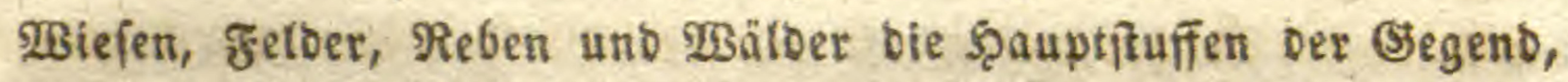
felten gefrönt mit felfenwänden, fmmer aber burdyfirümt von

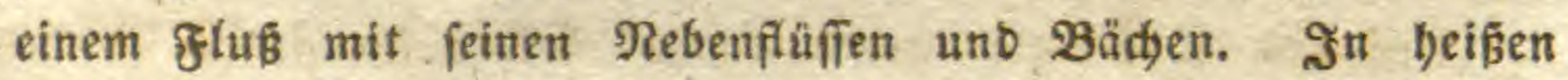

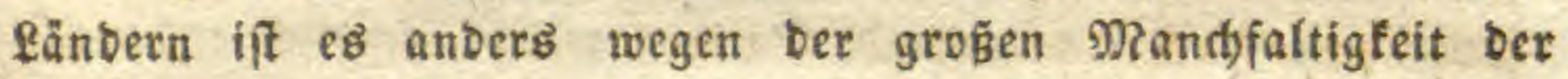

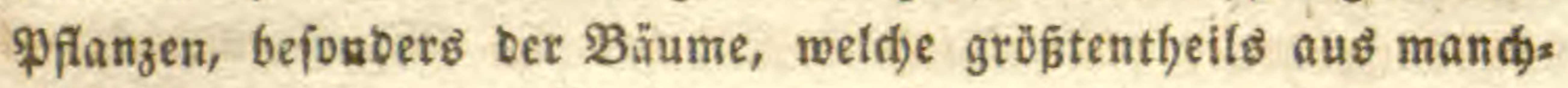

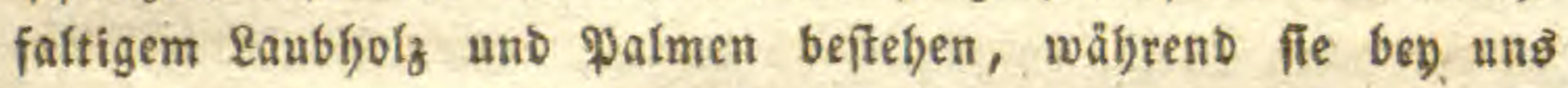

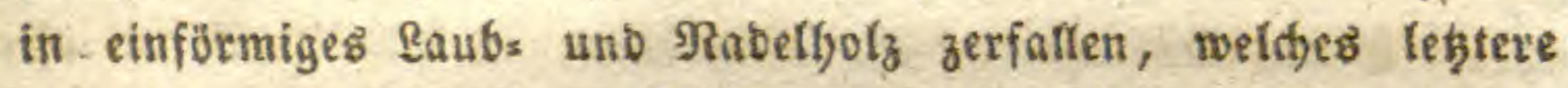

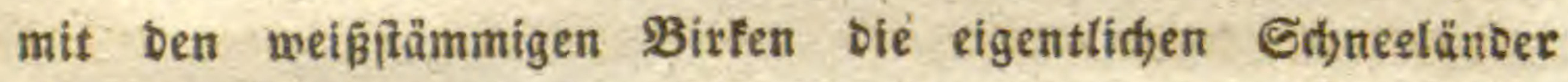
characterifiert, uno in Den heifen Länbern von anbern Gattungen, bejonbers Araucarien, Ëpreffen und Cafuarinen vertreten wirD; bie leģteren in 2 uftralien in $\mathfrak{3 a ̈ l b e r n ~ v o n ~ 2 r e a c i e n ~ u n d ~ E u c a : ~}$ Inpten, Die ungebeuern Araucarien auf Den Corbifteren ber 2 Anben.

eigentlitbe $\mathfrak{B}_{\text {iefen gibt }} \mathrm{E}$ nux in Den gemäsigten 3onen, wo bie Strasarten flein find und einen lieblid) grünen Ieppich bilben; in Den beifen fändern werben fte ftraud)= und baum

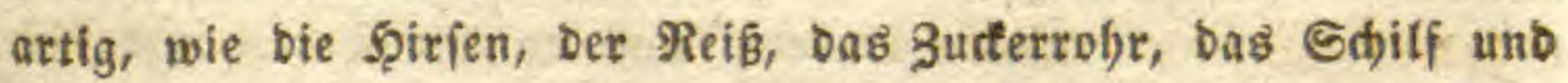

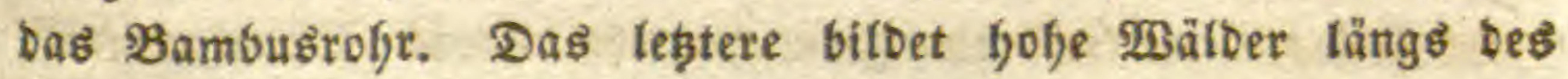
Stranbeg und ber grtüîe, ungefäbr wie unjere ફ̧seiben; bie 2rten von Bufterrofir hohes (sebüid) in Denfelben Ragen. Die anbern (šräfer fino meiftens mannslyod), uno bedecten unabfet): bare (5) werben auf furze seit von Den präl)tigften Blumen ber litiens artigen (sewäd)fe geidgmüdt, in 2(ften vorzüglid) von Tulpen, 
in Africa oon Jrien and merien.

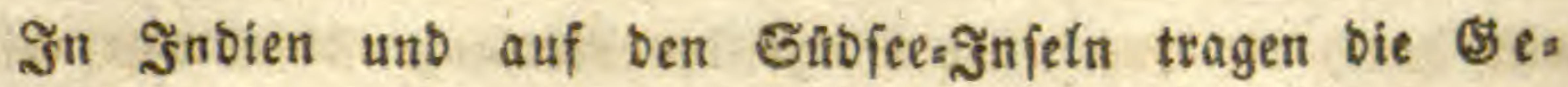
wh unzpflanzen ober Scitamineen, weldi)e truppweife beyfammen

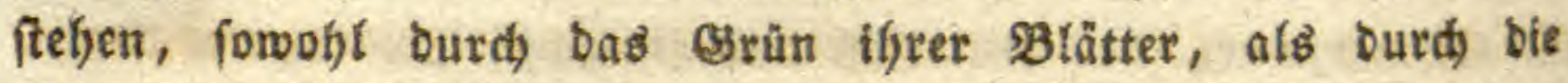

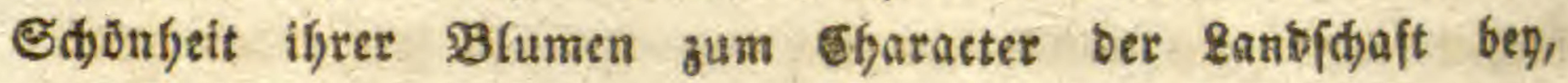
weld)e ùberbię angenelym verziert wirb burdh bie bobern (Sruppen yon Banauten, faft um jebe şâtte. Die Zäune werben ba mit gactelbifteín, bort mit ber fogenannten baumartigen $\mathscr{M}$ loe, an einem anbern Drte mit Dem Drachenbaum gebilbet, wäbrenb bie fonberbaren \$anbange truppweife in ber ferne ftelgep, vorzûg. (iid) in Den (Ebenen, unb eine Menge Euftwurzeln fatten laffen; ebenío bie niebern Bromelien mit ifren prảdtigen $B$ tumen in

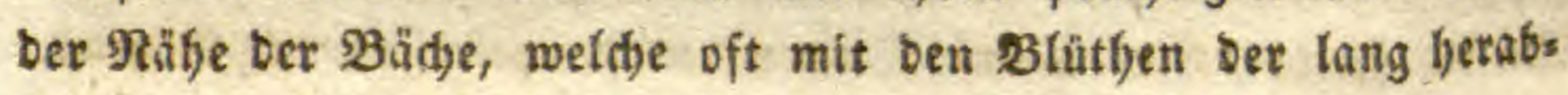
Gängenden Tiftandfien aud) bie refte ber Bäume zieren.

Iuf ben fübamericaniflden Bergen bilben bie gactelbifteln, 2lgaven unt Dudten bebeutenbe Bäume, weldhe, freyfid) exfi nad

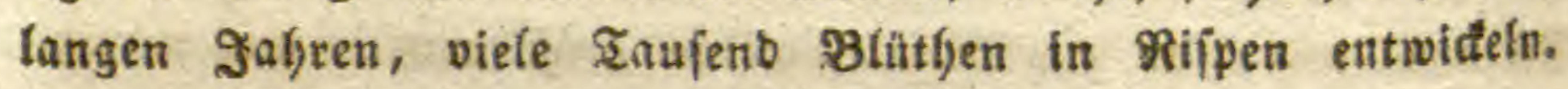

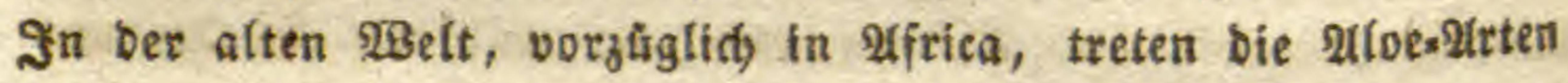

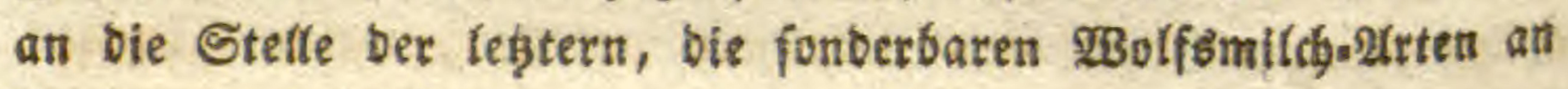
Die ber Factetbifteln.

Den ausgezeidonetiten Gharactes belommen aber bie fabo lidjen Segenben von ben \$afmen mit ifren-ungeheuern Bläto tern. Sie ragen nidbt felten $80-100^{\prime}$ in bie \&uft, ja es gibs bie $190^{\prime}$ bodh werben, alfo viel büber ats unfere meiften Ihürme. Dft fteben fie in Oruppen zerftreut, oft bilben fie aber auth neilenmeite :Bălder; oft flefjen fie einzeln, und ragen wie Săulen hod) über bie anbern 3 ăume hervor. Sie fieben, wie bie meiften Sdyeibenpflanzen, feuditen Boben, unb an ber Norbgrånze beł \$3enbfreifes bedecten bie 3wergpalmen grofe Streden von

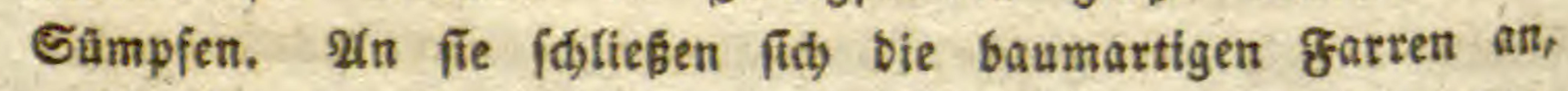
weld) bey uns nidjt viel zum Eharacter ber (S)genb beytragen.

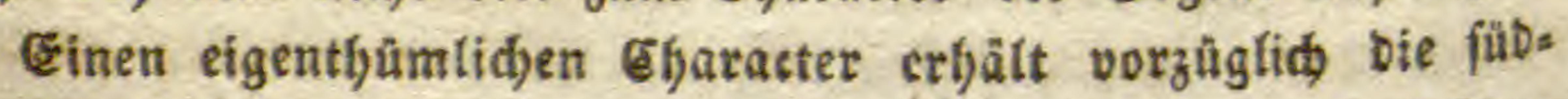

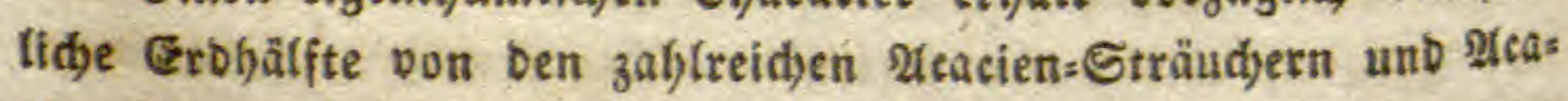

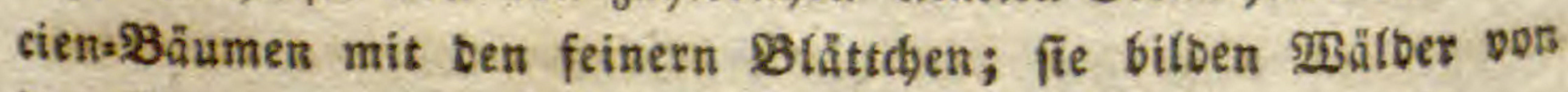
bez Ebene ail bis auf bie Berge 2000-8000' hody. 


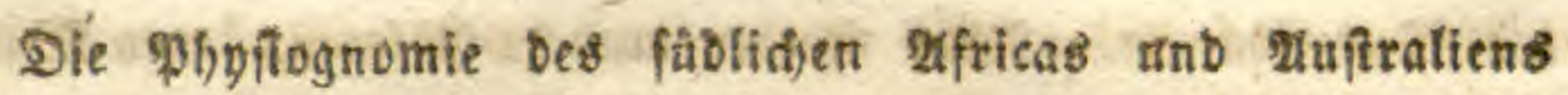
wirb vorzüglid burth bie speiben und proteen beftimmt, wetd)e ganze গ̧älder bilben. In Reulbutlano tragen bazu viele myrtenartige Bäume bey, befonber bie Melaleuten, Metros fiberen, uno Crucalypten, weldye legtere zu ben bödyften Bäumen

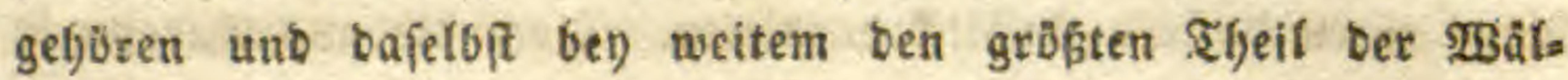
ber bilben.

Die Myrten năbern fid fdyon melye den nörbliben בonen,

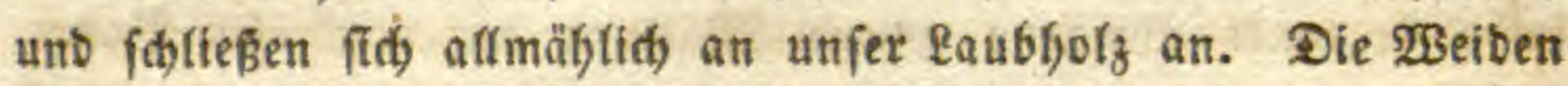
und Erten bilben ben Saum unferer Bäche und flüfîe, wie bie

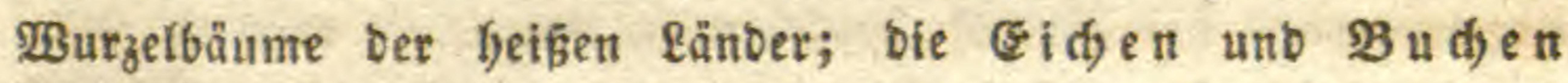

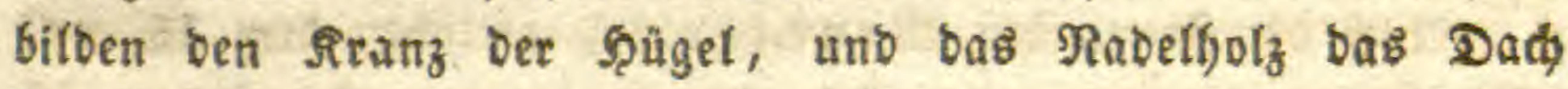
ber Berge.

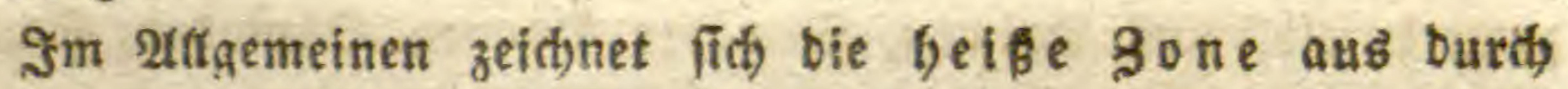
bie größ̈te Mandfaftigfeit ber Seftaften, bie grö̈te prad)t ber

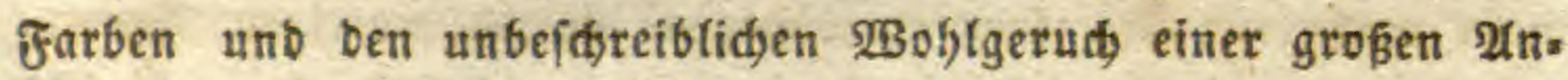
zah)! von B(ủthen, fowoh)t bey stäutert atร Bäumen; burd

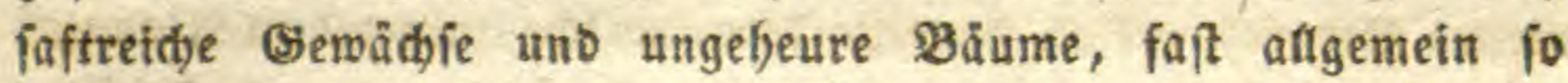
bidbt begfammen, Daßs feine Sonne burdbringt. (Eigentfümlid, uno characteriftif́, für biefe sone fino die baumartigen (sräfer, bie fdünen Ordjiben, Die Şewŭrze, Bananen, Palmen, Feigen, Mimofen, bie mandbfaltigen Edjlinggemädble unb prädtigen Sdymaroker, bejonbers Drdbiben; in ben urwäbern bie unges beuren $\mathfrak{B}$ oftbăume.

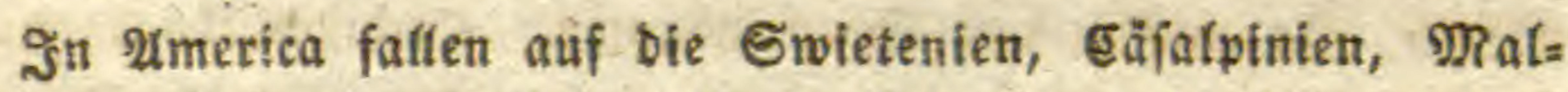
pighiett, Ynonen, 9tnacarbien, Berthofletien unb bie Sopfbäume; in Inbien bie ungeheuern Feigenbäume, Sapinben, Brobfrudta

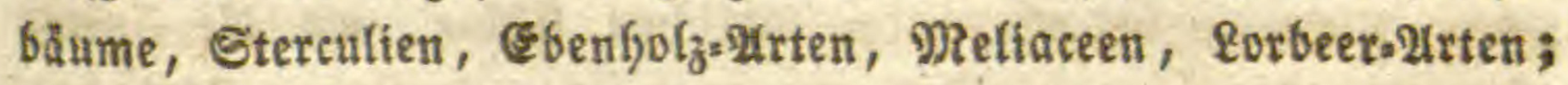
in Mfrica ber Mrfenbrodbaum.

Wenn einerjeitz bie Sdlingpflanzen bie WBă(ber unbutd)= Dringlid) madjen, aber zugleib verzieren; fo überrajd)en ebenfo bie Umidhlingungen ber $\mathfrak{A}$ efte vieler Bäume zи einem bidyten (Jefled)te, wie bey ben (Eluften, Marcgravien, Ruyfdien, Roran= teen, afpo befonbers bey bent Suttiferen; nidtst weniger bie Bäume mit \&uftwuzzeln, woraus wieber neue Stämme werben, weldye mit bem MRutterftamm einen Ileinen $13 a l b$ bilben, wie 


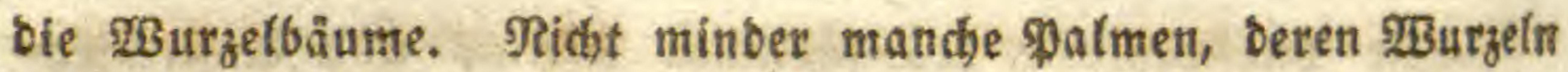
fid) gleid, loben Seltitangen äber bie Erbe erheben.

Eigenthümlidy für Brafilien finb bie jogenannten eatinga

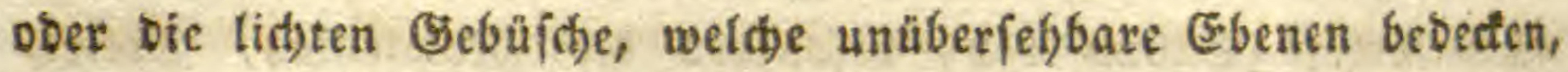
in ber beißen \$ahrszzeit bie Blätter verlieren, uno fobann bem

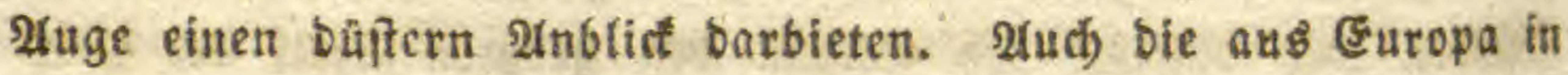

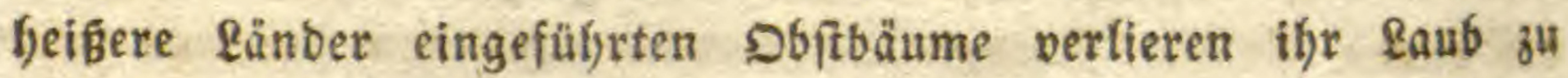
Derielben Salywṡzeit, unD felfen baher mie verborrt aนs. Da/s felbe begegnet übrigeng ganzen MBälbern auf troctenem Boben, fo baß ibre butren ungebeuren Aefte fdhauerlid) in bie \&uft emporragen.

2(ud) bie zonen Der 23 en of refife, zwifden bem 15. und 23. ${ }^{\circ}$, baben if)re eigenthutmlide Nyptiognomie. Es finben fidt) zwar bafelbft noch) Walmen, Şewürze, 2unonen, Sapinden, Sdfings pflanzen unb fdymarobende Drdjiben und 2 rroiben; aftein nidst mefre vorherrident, fondern Dagegen bie baumartigen farren, Winben, bie zahlreiden Pfefferarten unb Melaftumen mit feft piefem Straudhwerf in ben feltener ift, ober gewiffermaaken als Stgmarober = uno Sd)lings pflanzen auf Den Bäumen felber fel)t. lunter Dem 2 Benofreis Des Steinborts ober auf ben Sübjees snjeln, bilben befonbers Die Panbange bas Straudiwerf, bie Bromelten bas Edlingwetl, uno Die garrenfräuter bie Sdymaroģer in ben $13 a ̈$ lbern vot

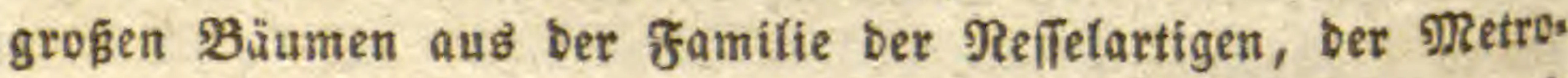
fiberen, Jambufen uno Dradjenbäume. Drdbiben bagegen unt Dolbetrpfanzen feflen. Unter bem nörblidgen \$્Benblreife zeiget

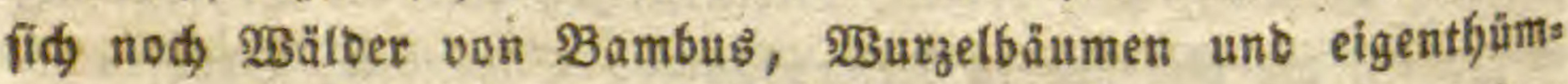
lidsen Fidhten, befonbers im fäbrithen (G)ina, wo bie Eultur

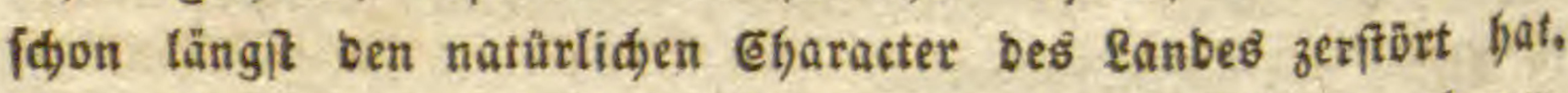
Feigenbảume mit Beltenwurzeln, હocospalmen, Pifange, baums artige Spibisten u.f.w. finden fid) angepflanzt.

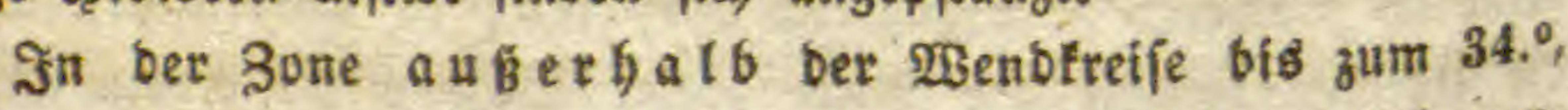

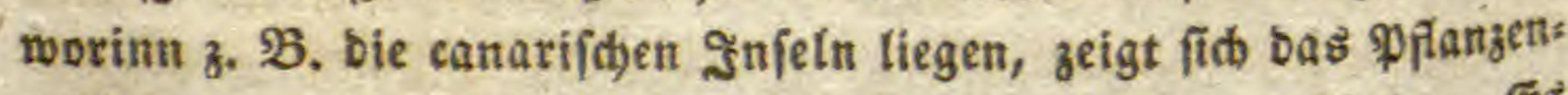
reiđ) aud) nod) Das ganze Jăahr in feinem grünen Rleide. EУ gebeiben nod) Bunanen und bie Dattelpalme, nebf: ber swerg= palme; bartunter eine Menge Æsttpflanzen, wie \$ortulaf, 厄rafs 
fulen, Mefembeyantifemen, baumartige Eupljorbien unb Eemper:

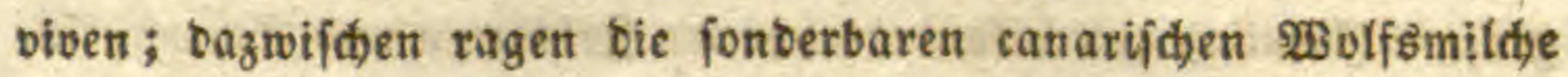
wie ungeheure 2irm(eud)ter hervor, unb bifben fleine शräl(bd)en; fûr 2 tegypten ift bie Sncomoren=?reige characterifti(d). Die Feloer im 23 eften bes Şimalayas, unter $28^{\circ}$, prangen wälyrento ber

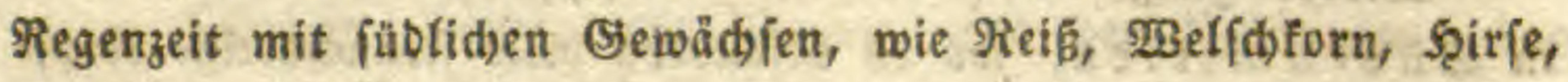
Sorghum, Sefam, S̊ngwer, Fomaten, Şibisfen, İnolgo uno

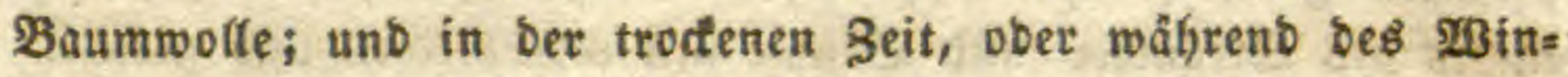
terb, ttagen fie curopäijhes Setraibe, nebit 2 sicten, Bobnen, Corianber, Möhren, Tabact, Rein, Safflor; felbft europaiifdye wirbe Seräuter fino bann nid)t felten, fowoh) auf bem trodtenen

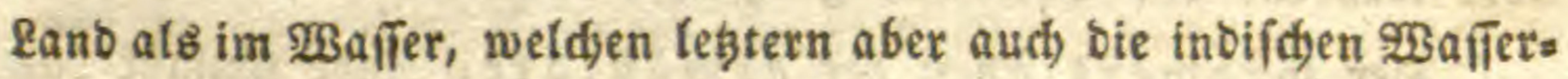
pflanzen beygemijht finb. Unter ben Bäumen finben fid) $\mathfrak{A}(a)=$ cien, Feigen, Melien, Maulbeetbäume, Baubinien, Eorbicn, Ometinen, freusborne, Sufticien, Bonouc u.f.w. Iuf ber oft feite, näher bem Mecre, finben fid) nod Das Bambusrolfr, bie

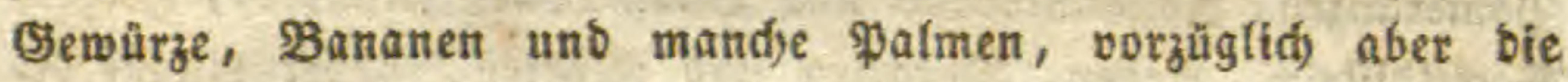
Theeftaube, Hucuba unb bie Eameftien, weld)e fid) bis efina unb Sapan exifrecten.

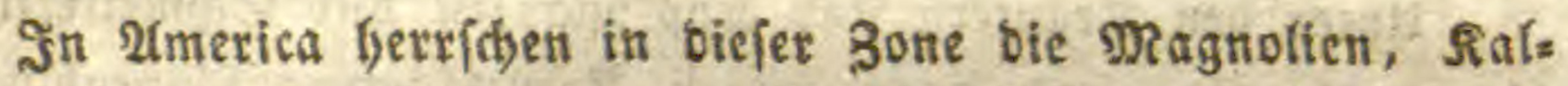
mien, Eyprefien, Ealycanthen, veridiebene gorbeersatten, Dattel= pflaumen, Eidgen unt f̧idjten, baumartige B̧rä̌rer, Brombeer=

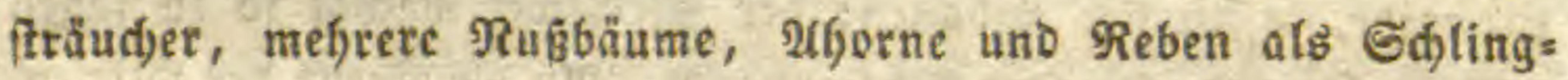
pflanzen.

Senfeits bes fübli de e th aus. Es gibt bajelbit, merfwürbiger $23 e i f e$, aud) wieber viele europäiffice Pfanzen, befonbers an ben flatifen vont Reuljofland; aber vorherrfhend fint bie Speiben, Die Myrtenarten, bie pros teen, Mimojen und Eajuarinen mit Mifteln un Riemenblumen.

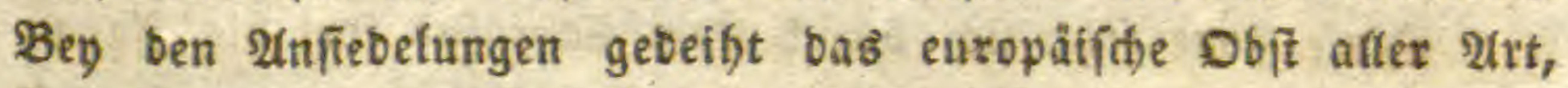

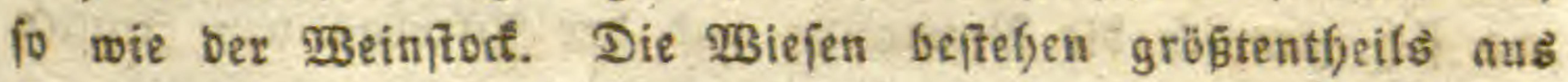

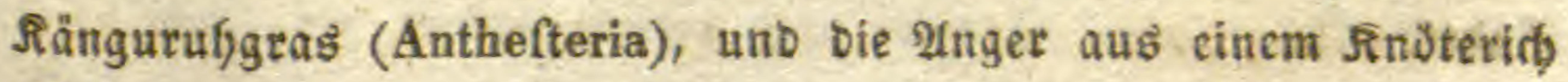
(Polygonum junceum).

Dbidon bas Neulfottanb mand)e Nefgntidfeit hat; fo herridhen bod hier vor alten anbern bie Sqeiben, Proteen unb Diosimen vor, nebfit ben 


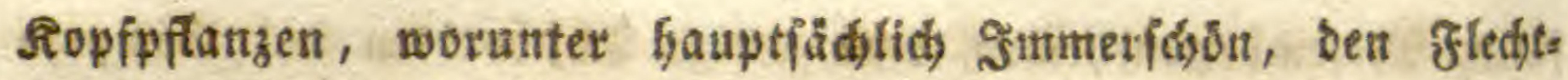

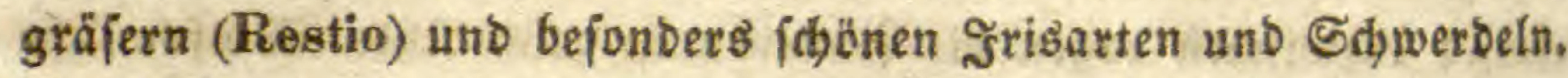
Es feblen burdgañngig bie \$almen, wie in Reutgofland; Dagegen gibt es viele 3amien.

Wieber ganz verfofieben ift bie Pryffoghomie biefer sone in Sä $b=21$ merica, wo es bejonbers viele fraudyartige Sopf: pflanzen gibt, fo wie Mryvten; ubberhaupt fieft man bier faft

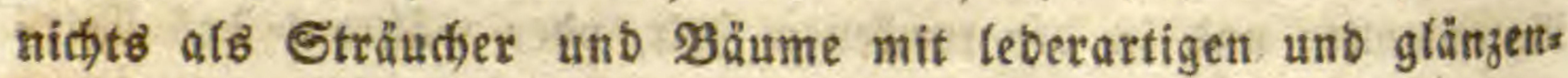
ben Blättern, fo wie Factelbifteln nebfi baumartigen Böräfern. Iudh Rippenblumen unb präd)tige sifien zieren ben Boben, welde aber wäh)ren bes Sommers gảmzlid verborren.

Der wảrmere Theil ber gemä Bigten Bone umfaß́t bas

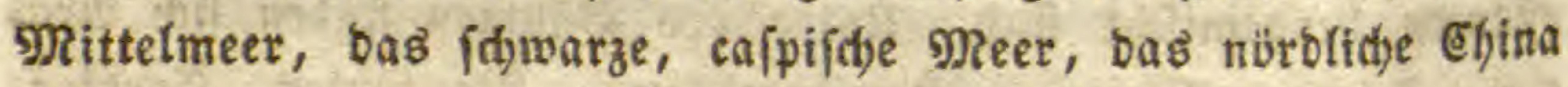
und Sapan, uno wirb befonbers mild erhalten burch bie gró́etr

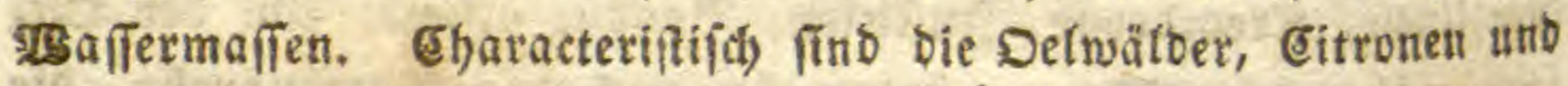
Pomeranzen, Sofannisbrob unb Baumivofte, Manbeln, zeigen,

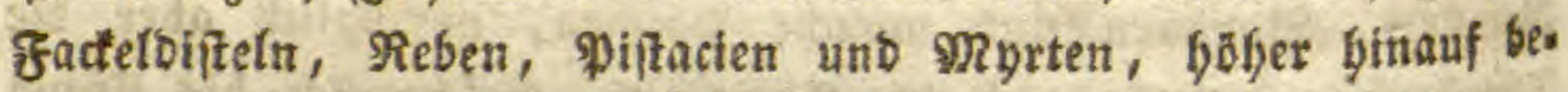
fonbere Eiden und Fidbten.

Unter ben Rräutern find STopfpflanzen unb Ed)metterlings: blumen bäufig, und bann folgen Rreuzblumen, Sippenblumen, Netfen und Dolben; Sucterrobr, હaffee und Jntigo, nebft unietm Getraibe, laffen fid, anbauen; ber $2 B$ einftoct wädbst fo zu fagen

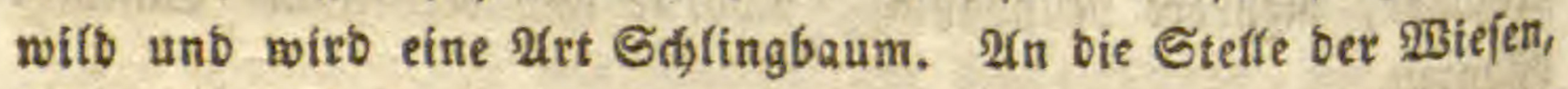
weldse im Norben bas 2luge exfreuen, treten bier bie immers grủnen $23 a ̈ l b e r$ uno fđjönblühenbe Sträudjer, wie ber Rabanubr

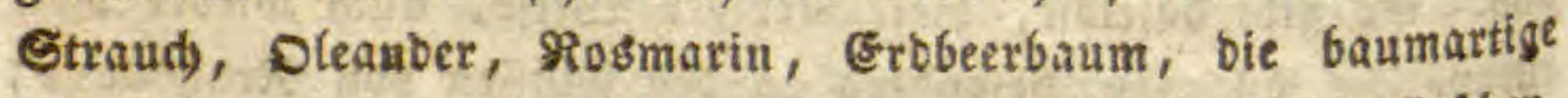
Şeibe, ber Rorbeer. uno Baftarblorbeer-Baum, bie \&orbeertirfden,

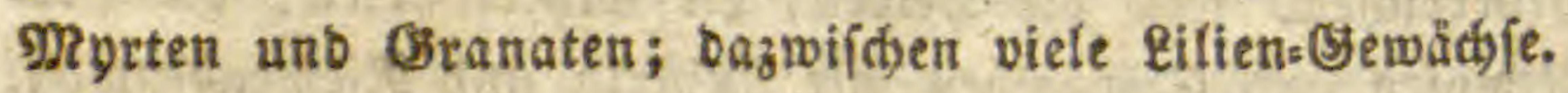

Diefe 3̧one feb̧t fidh oftlich bem caucafus fort bis Sapan, no fid) ziemlidy bie segetation unb ber Xuterbau von ștalien finbet.

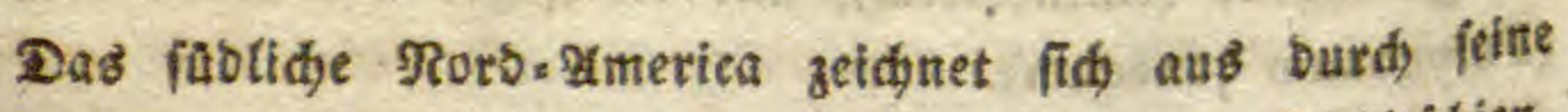

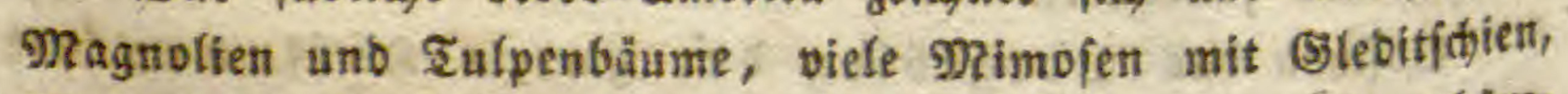

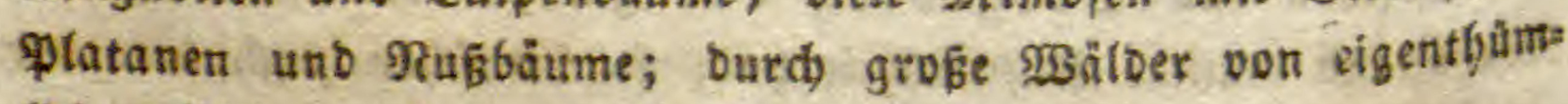
tidyen (Etdhen, Budjen unb Meidyen. 
Der entipredjende Girtel ouf ber fâb(lid) en Şălfte läuft burd) Reufetand, Diemenstand, bie Pampas von Buenos=2tyres und (Eljiti. Die wälber finb ebenfalts immergrün, befteben aber aus anbern Bänmen, worunter in suftratien fid) ber Dradjenblutbaum auszeidnet, nefft verfdiebenen Mimofen, Mro= teen, Nyrten, baumartigen farren unb Der Betelpalme; Dars unter ber neujeelänbijaje Fladjs, weldjer an bie Bromelien er: innert. In bem antericantifchen Strich veridyminben bie \$almen, und es treten anbere immergrũte Bäume auf, wie befonbers Butben, Perfea, Eaurelia, worunter fơdhfien, Erobeerbäume,

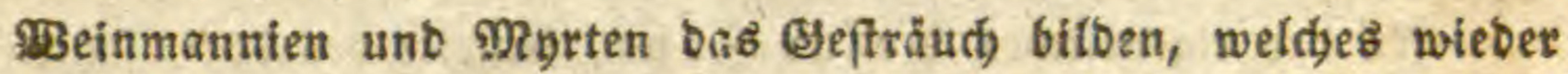

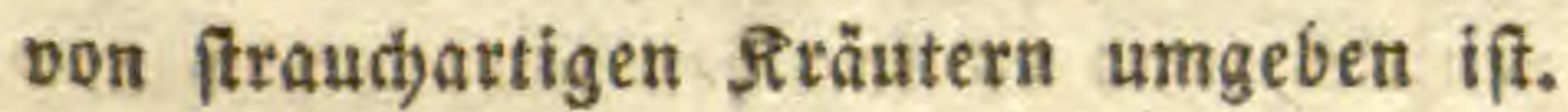

Die lältere gemäfigte Bone fält zwifhen 45 unb $58^{\circ}$, ober zmifdjen bie europäifdyen (3) birgbetten unt bas beutifhe geer, nebft ber Difiee. Sie befommt ifren Eharacter von ben

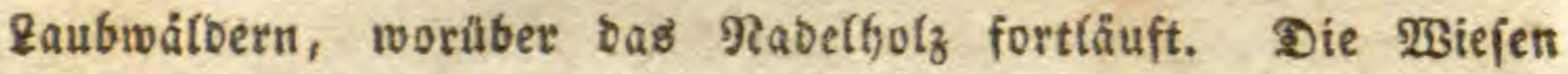
werbert ausgebefnter uno tragen wefentlid) zur Phyfiognomie ber Qänber bey; ifer Errün wirb unterbrodgen vort Rreuz= uno Dolben= pflanzen, nefft Ranunteln; Die Sanbebenen bagegen find mit Şetben bebectt; in ben Säunen unb an ben Traufen ber $23 a ̈ l b e r$ blühen Sd)warboorn, 2Beifborn, Sd)lingbaum, Rainmeibe, Saus erady, Pfaffenthuttein, Rojen uno Brombeeren. \$m \$Binter

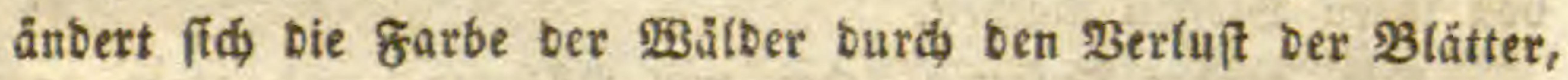
unb nur bie wsiejen zeigen fidg nod) grün, wenn fie vom Edgnce befreyt werben. Die traurigen Steppen oon elfien fint mit

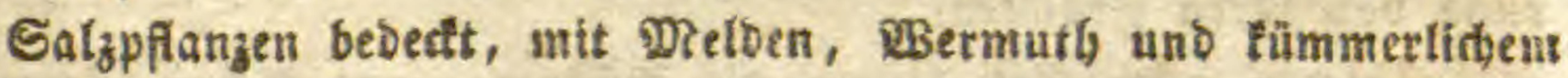
ciras.

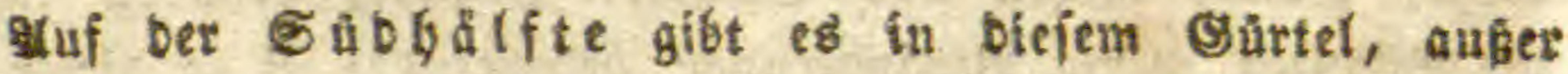
Datagonien, fein veftes Rano, uno bajelbit fino bie Budgen bie vorberridgende Solzart.

Mudb bie falte $\mathrm{B}$ one gat man in eine milbere unb ftrengere eingetheilt, jene von 58 bis $60^{\circ}$. Die Baubbötzer verminbern fid, unb nur Birfen, Reidyen, פogelbeerbäume'unb 2lipen bleiben übrig; bagegen nimmt bas গabeltyolz fait aflen Woben eia; bie Dbftbåume gebeihen nur fümnerlidy, unb fangen 


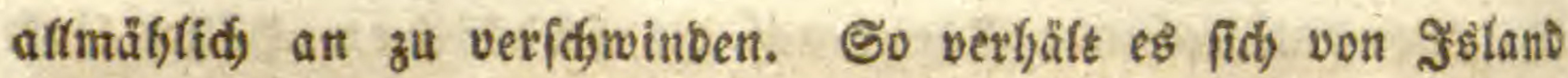
burd) Rorwegen, Sd)weben und Sibirien bis famtidatfa.

In ber ftrengern falten Sone, jenjeits Des $66.0^{\circ}$, werben

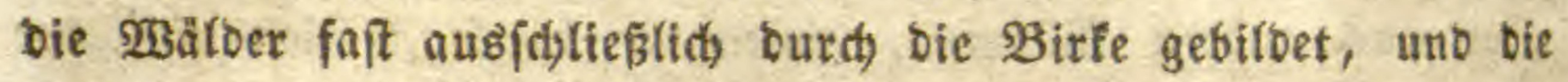
Natelwälber zeigen fid mefre zerftreut; unter ben Strätd)ern

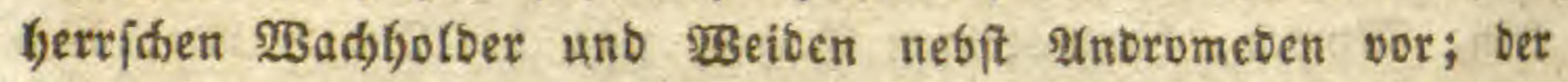
fahle Boben ift mit Flechten bebectt, befonbers mit ber Rentis

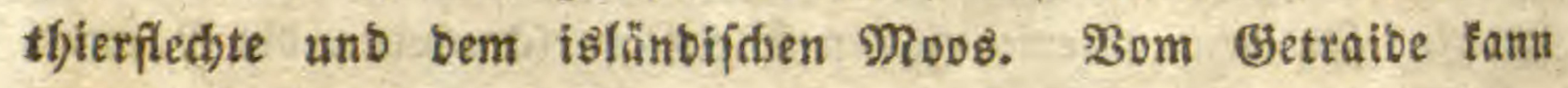
nux nod Berite und Roggen angebaut wersen. Die Alpens pflanzen reidjen bis zum Stranbe berunter.

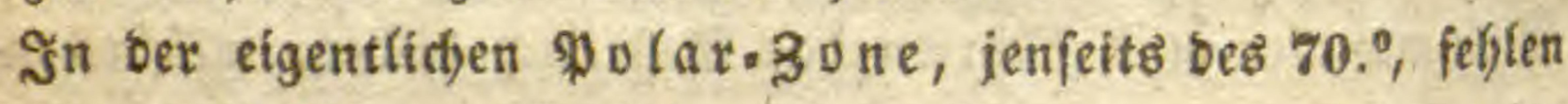

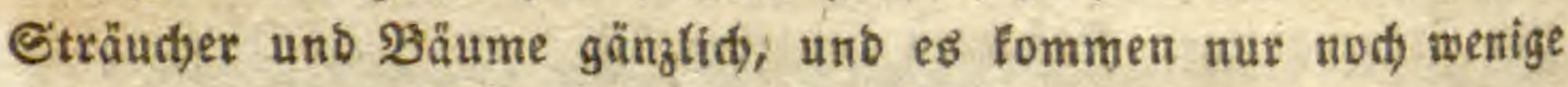
Sräuter vor, weldbe an bie alpen=firäuter erinnern, bejonbers

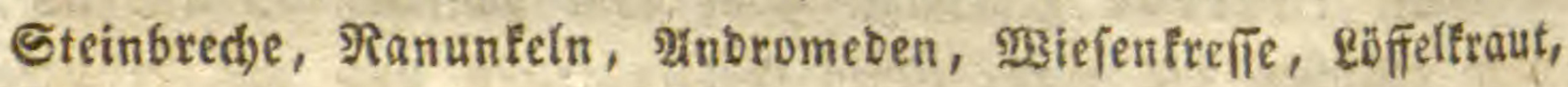

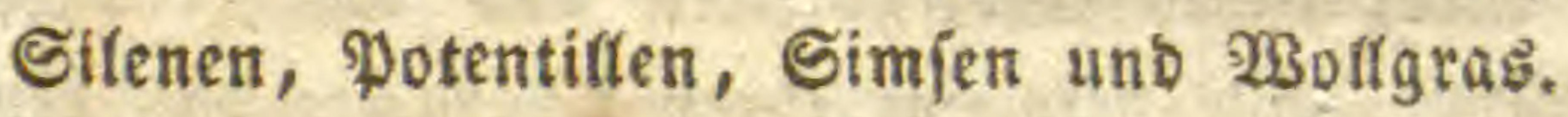

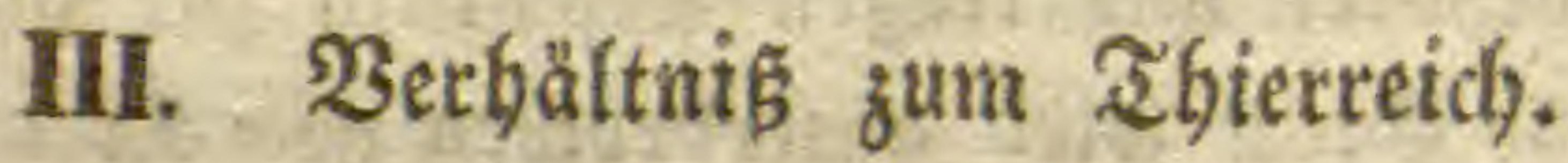

Die meiften Pfanzen fino irgeno cinem Ihtere von Pagen,

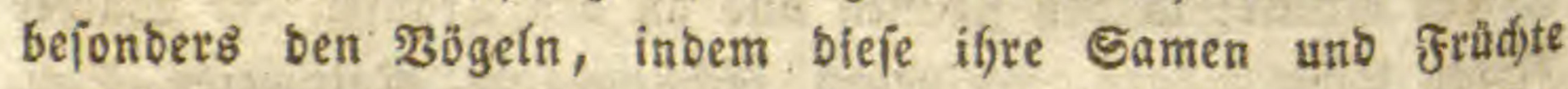

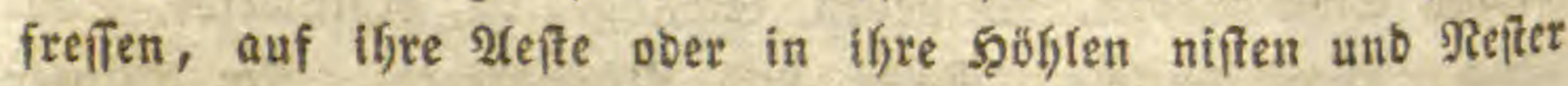
von ifren Stoffen madjen.

Die meiften sunfecten leben von Pflanzen, und zwat von

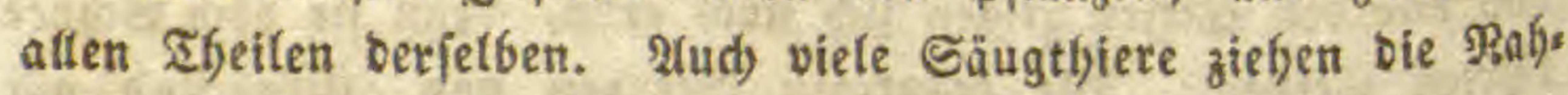
rung von ifyen Früd)ten.

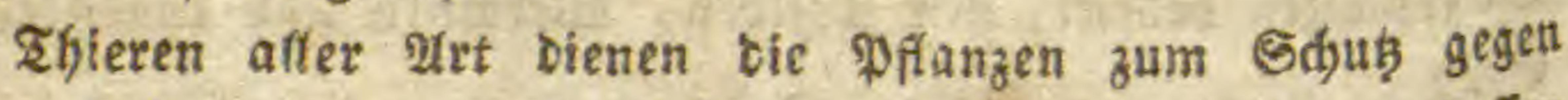
Şike, Sälte, Regen uno Sdinee. Daburth exteiben inbefient Die Pflanzen wenig Berảnberung: bebeutender if in biefer Şin fid)t ber Einflus bes Miftes, indem theil(s baburd) viele P(anzent iffe Rabrung finben, theils mander Mift feire befonbert

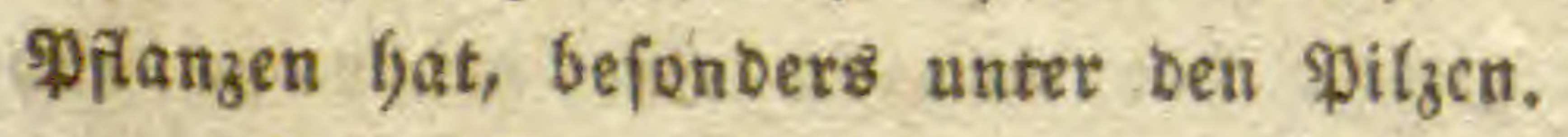

Die grubste Beränberung erlébet aber bas $\$$ flanzenteid burdh ben פenidsen, inbem er bie Unftäuter vertilgt, um fétren

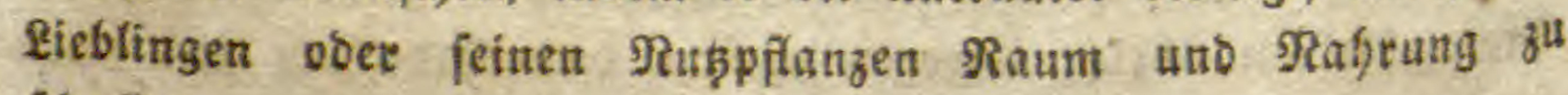
idgaffen. 
Das Eebeifen ber angebauten Pfanzen ridjtet fidg nitbe gerabezu nach ber Breite unb Şöfle. Tom $48 .^{\circ}$ an gegen bew Pof nimmt bie Sommerwärme nidbt in Demfelben Grab $a b_{r}$

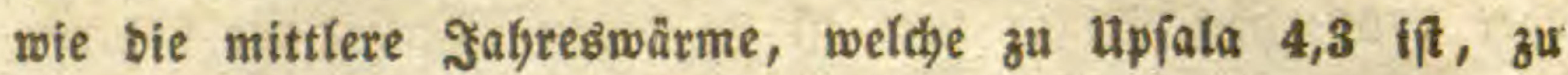
(5binburgh 8,8; unb bennod) find bort bie Gommer viel wärmer als hier, wo ber Seimmel oft bewöft ift und bie Tage türzer find. Bey Enontefis (unter $68^{\prime} / 2^{\circ}$ und $1300^{\prime}$ ) ift bey $-2,7$ mittlerer Semperatur ber Unterfdjied zwif́den Sommers unb

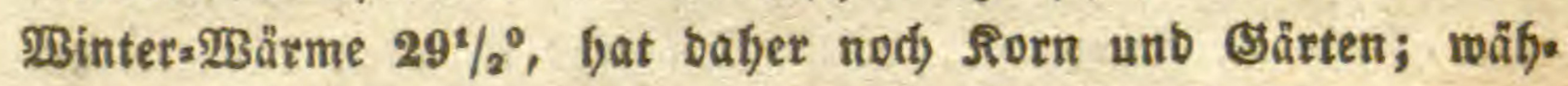
renb bas Rorbcap (unter $71^{\circ} 2600^{\prime}$ hod(b), um $3^{\circ}$ wärmer, nur

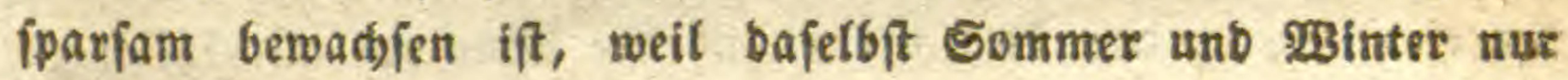
um $11^{\circ}$ verfdieben fint.

\$ifang, bey $21^{\circ}$ :Bärme, fteigt unter Dem dequator gegen

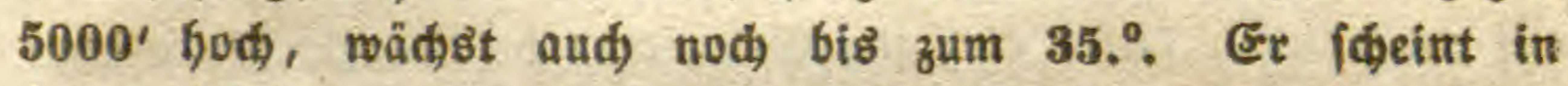

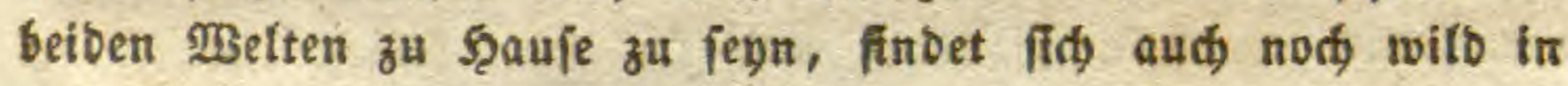
Diftinbien unb ber Säbjee, und fteht angepflanzt überafl um bie

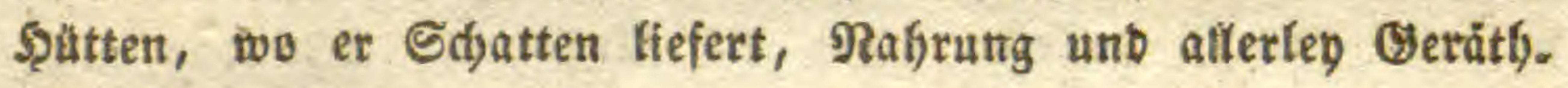
Er ift ein Baum, weldjer weiter als irgend ein anberer auf ber erbe verbreitet ift.

Die હitronen verfangen $17^{\circ}$; bie Pomeranzen tönnen $7^{\circ}$ Rălte extragen.

Der Delbaum Gat feitten eigentlidben 230 bnplaķ im füblidjen Europa und in ber Rebante, unb gebeifyt bey $17^{\circ}$ und einer Sommerwärme von 5,5 zwifíden 36 unb $44^{\circ} \Re .2$, ; nur $34^{\circ}$ in

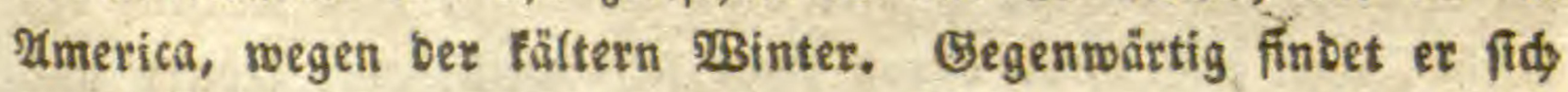
auds auf ben canarifden Iñfeln, in Mexico, gegen $3000^{\prime}$ hod); auf ber 23 eftlüfte von \$eru unb Egill. Er bilbet überafl fleine

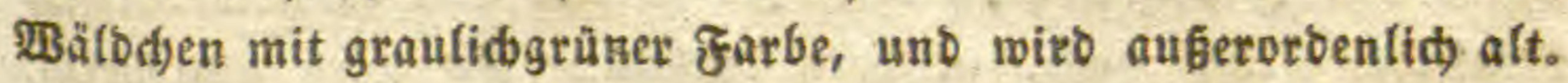

Das Setraibe gebeift noゆ ben $2^{\circ}$ mittlerer Rălte, went nur bie Sommerwärme $10^{\circ}$ ift; in Eapplano bey $70^{\circ}$, unter bem 2lequator bey $9600^{\prime}$ Segble; auf ben Geealpen bey $6600^{\prime}$.

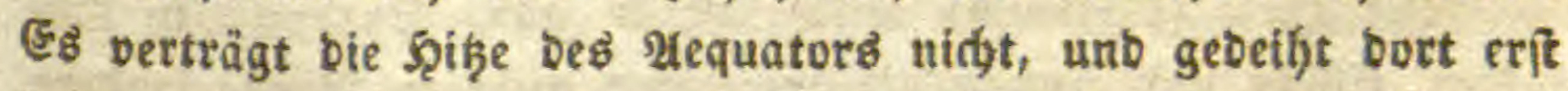
in einer Sobbe, wo es im füolisben franfreid faum nod) forts

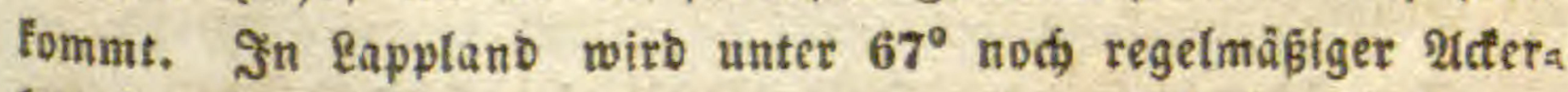
bau getrieben; bey Enontefis werben SSerfe und Rüben gepflanzt; unter $70^{\circ}$ Eroäpfel, Braunfobl uno Stadbetbeeren. In Ifien

Deens allg. Maturg. II. Botanil I. 
Gobrt ber Adterbau fdon ben Sobotsl, untet $60^{\circ}$, auf; in Canaba fidon unter 51\%. Juf bem Sdjwarzwalo, in ben Bogeien gefit Der Getraibebau nur 2200 bod, wäfrend er fit ber Sdyeig aber $4000^{\prime}$ 'jod) fteigt; bort if ex wegen Mangel ber hobferen

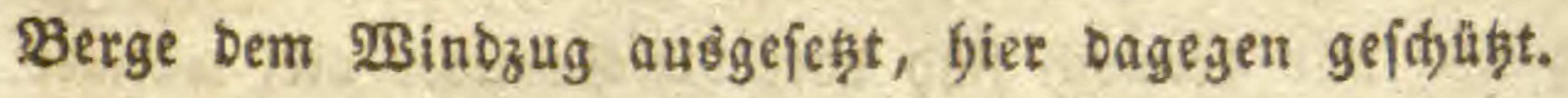

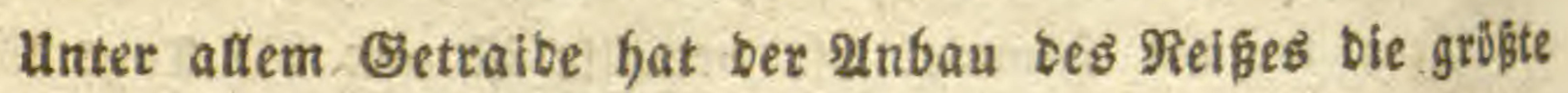

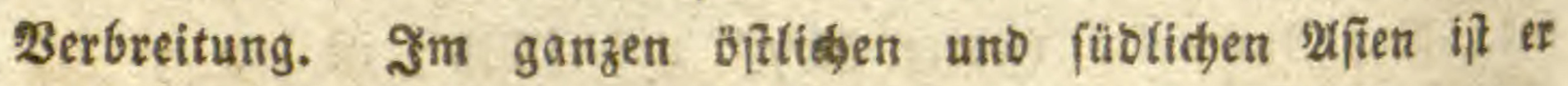
Das affgemeinfte Rahrungsmittel; faft ebenfo in Perfiet, 2uras bien, Nubien, 2egypten, Rlcinaftes unb in affen Ränbetn am Mittelmeer; gegenwärtig aud) in Dseftinbien, Rorb. unb Gubs Imerica, wo er bas $\mathfrak{3 e l j d j f o r n ~ u n b ~ b i e ~ M a n i o c a ~ a f t m a ̈ b l i d ~ z ̆ ~}$

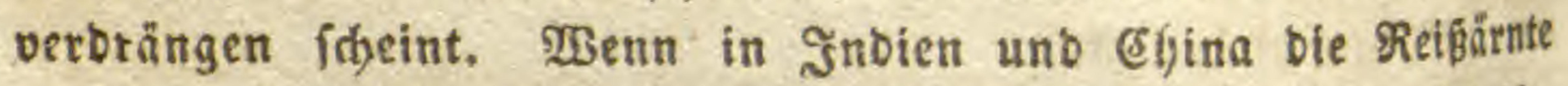
mifflingt, fo erjolgt f̧ungersnoth), weil man fith, unfluger ISeife, auf ben 2 nbau biefer einzigen Eetraibart befdjränft. Er wábgt betanntlid, auf Sumpfboden, und two man feinen natürliden Gat, gräbt man ben Boben eî, Gis man auf Wsaffer tommt; ia man pumpt baffetbe fogar auf Satnhoben. WSo bas nidt megglid) ift, oa fäct man if)u beym (Eintritt ber $\Re$ egenzeit, nötbs lich im Mpril und Day, füblich im September und october.

Das welfdforn ober ber Mais ftammt befanntlid) aud Imerics, und wurbe bort fobon vor ber Entbectung angepflangt. Er gebeift am beifen in einem beifen unto troctenen Elimt. E.r mirb bis zum $35^{\circ}$ in Californien gebaut; in Europa nod am Rhcin, alfo bis $49^{\circ}$; Giev aber meift nur zum Mäfen bes Bielys, weil bas \$rod Davon zmar fehr weif, aber troden unb

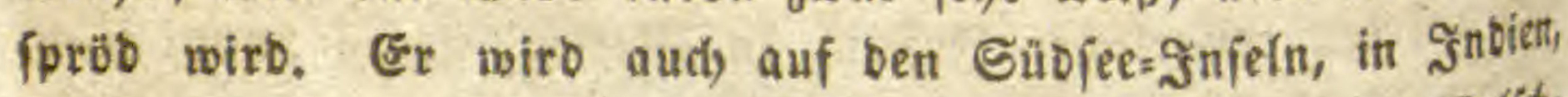

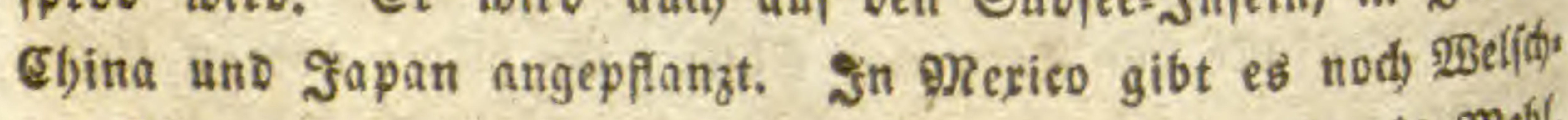

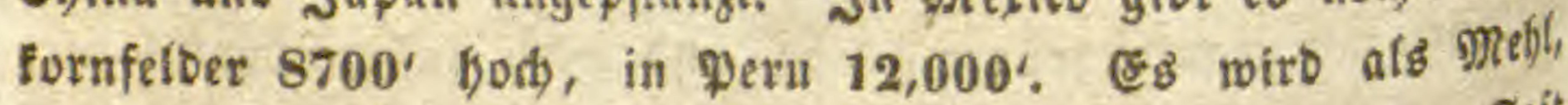
Brod uno aud) zu cinem bierartigen Eetränt benukt; ber Eaft aus bem Stenget zu Brantwein.

Die Şirfe (Panicum) wirb faft in gatr Europa, in Dife indien, बbina uno Japan gezogen, aber nidjt zu Brod, fonbers ats (Srüse.

Die Moorhirfe ober Dutrah (Sorghum) ift in ber alten BBeft bas cetraide beiser Einber, befonbers afrieas und ofte 
inbiens, wirb jebodi àub in portugal unb in ber Revante ge=

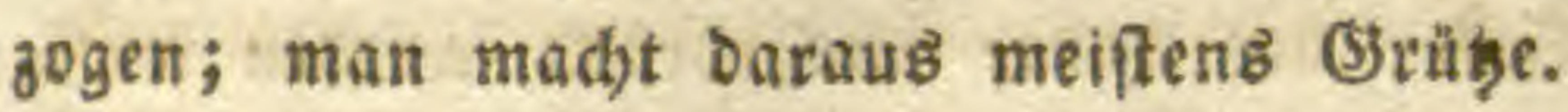

Der Budweizen ober bas feeibelorn (Polygonum fagopyrum) idfliefst fid) bem (setraib an, und wisb ebenfatts al3 Grtühe betuibt, geljört aber bem nörblid)en Europa uno 2yiten an.

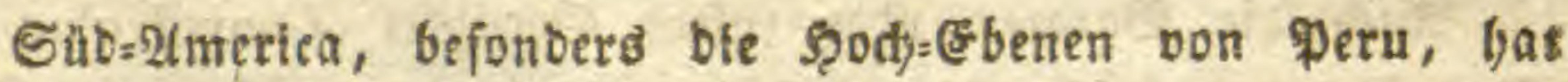
eine äfnlid)e planze, Die Дuinoa (Chenopodium quinoa), weldye

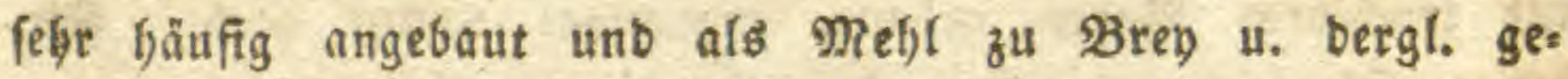
braud)t wirb. Sie ift mit ben Eroäpfeln bie Speife ber armen \&eute.

Die Erbäpfel (Solanum tuberosum) verbanten wir Atmerica, wie bas $\mathfrak{B B}^{3}$ lidforn; fie fommen faft in affent elimaten fort,

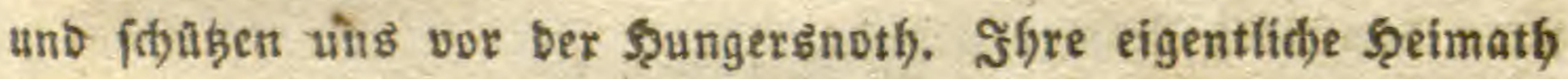

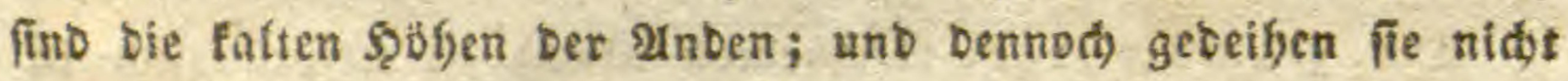
bló in Eapplano, sondern in sinbien, Ebina, Japan uno auf

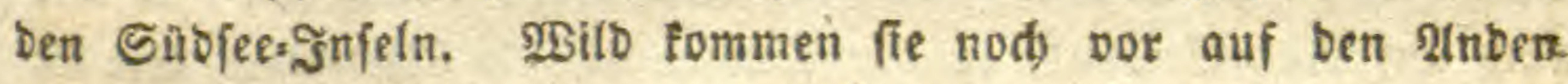
von Peru und (E)ilf, ob aud in Merico tif zwelfelfaft.

Die Afronarten, beren 23 urzeln wie Erbäpfel gegeffen wers:

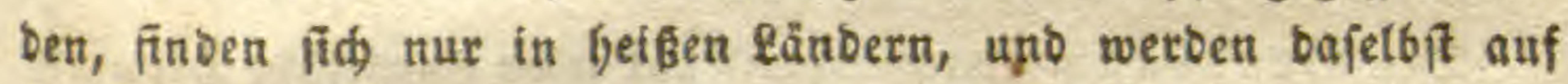

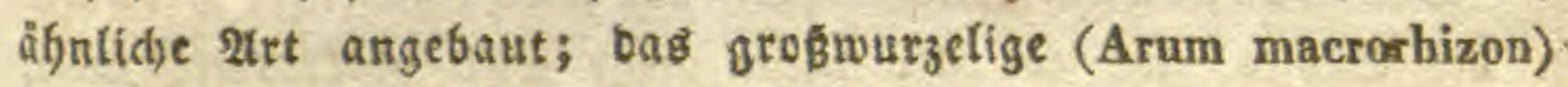
in Dithinbien und Cgina; Das gemeine (Caladiam esculentum) in

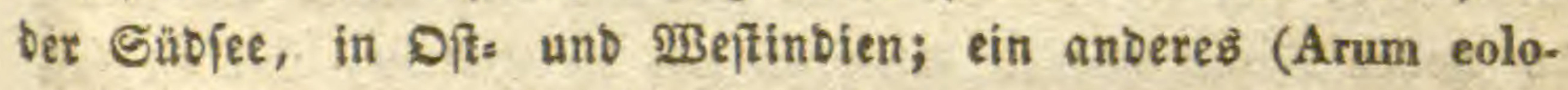
casia) in Mfrica; bas fdurfe (C. acre) in Neuboftand; bie: meiften baben fidh aber aud in andere ganber verbreitet, wo

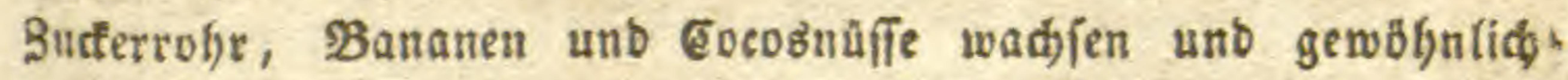
um bie bewäfferten Aronfetber fteben. Die Rnoffen werben âbet-

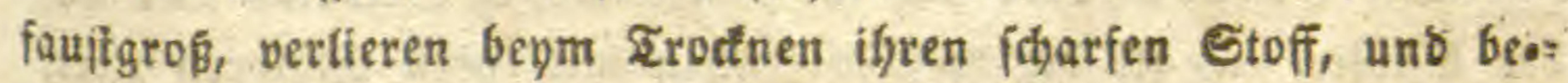
fommen burd) Röften cinen angenchmen Bseidmad. Ruf ben Sanbwid)= Jnfeln fteigen bie felber $800^{\prime}$ bod). Sie finb mit Den Parabiesffeigen, Den cocosinaffen unb ber Brobfrudgt baš genobinnlidite Rabrungsmittel ber Einwohner.

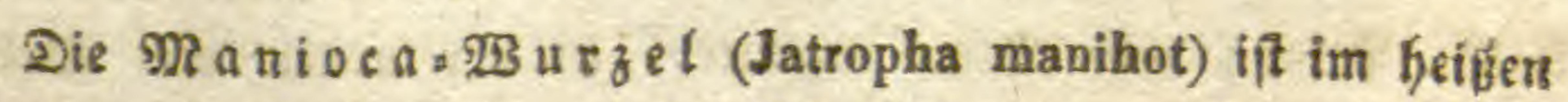
Imerica ebenfalts cine gewölnnlidbe Rahrungëpflanze in bem (iebiete ber Bananen, firigt aber nidft fo hod hinauf, nur tuts 
gefäbr 2000'. E্s giot zwo 2lrten, bie fâge unb bittere, mit einem fehr giftigen Saft, ber Daher aus̆gebrürt' wetben muf̧.

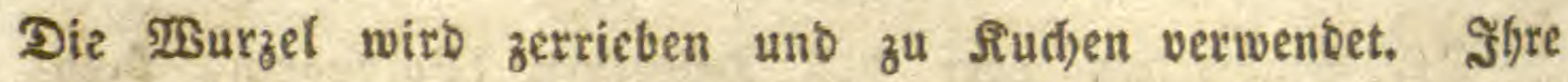
Felber liegen auf folfem unb troctenem Boben, wo fie aber faft cin Sabre lang braudbt, ef)e fie ausgewadjen ift; fie witb jebods féfr gró, armebid und lang.

2ud bie ßataten ober fü̧en Erodapfel (Convolvulus batatas) fino Dem heísen 2(merica cigenthüm(id), unD werben überall auf troctenem Boben gebaut, mandbmal $5000^{\prime}$ hod). Sie Gaben fid, von ba über bie Sübfee, nady Ditindien unb Cbina verbreitet, unb gebeifgen felbit nod) weit auberbalb ber Mendtreife.

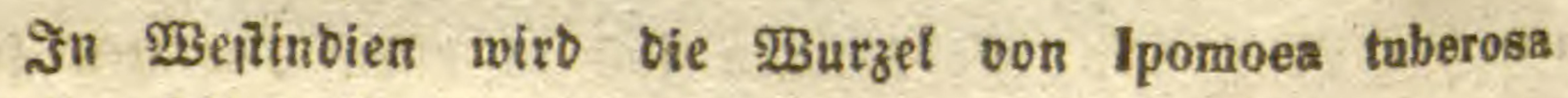
unter bemielben Ramen gebaut.

Die Damswurzel (Dioscorea alata) ift uriprünglich in Dplinbien zu Sgaufe, uno wirb bafelbft affgemein gebaut, fo wie aud) auf Reu=Ecetanb, in ber Sübfee unb in 2tmcrica. Sie if

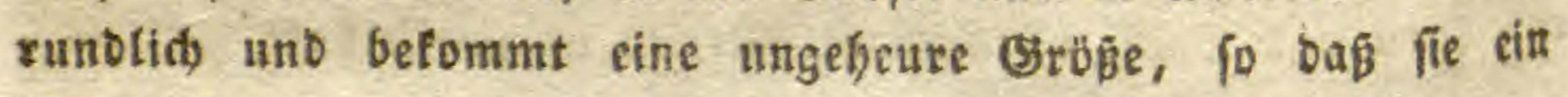
Mann faum umflaftern fann.

Der $B$ roobaum (Artocarpus) lyat feine eigentlide seimath). in ber Subjee, wo er aber nidjt mefjr wilo vorfommt; mast vermuthet, Daßs ex aนs Ditindien famme. Cr bilbet mit feiner

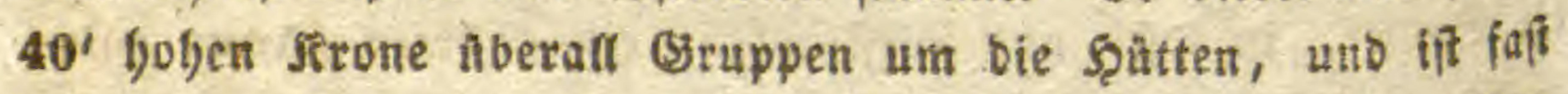

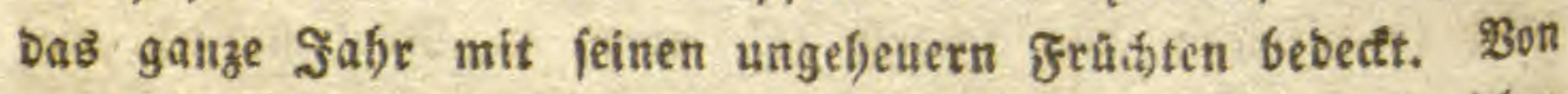
5-6 Bäumen forf ein Menfís ein iganges jabr lang teben fornnen.

Die eocospalme hat ihr Baterlano in Oftindien unb auf

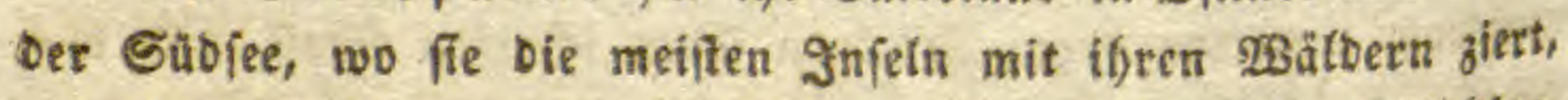
unb ben Seefahrern zuerft in bie צugen füfft. In Ditinbien,

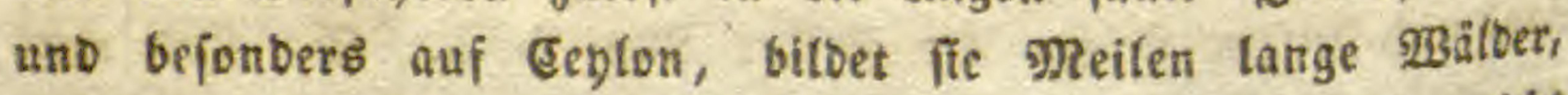
weldye ganze Dörfer und Stäbte bejdatten. Sie geht nidbt aber ben $280^{\circ}$ binaus, unb ift überatt in ber alten Welt von Reis, pifang und Rron begleitet, in ber neuen von melíf; forn und Banioca, auf ben Gubfer. Infela von Bataten uno 7 gam. 
Die Dattelpalme vertangt $22^{\circ}$, zwifhen 29 unb $35^{\circ} \mathrm{B}$. wådst nod) an Mauern in Statien unter $44^{\circ}$. Shre eigentlidje

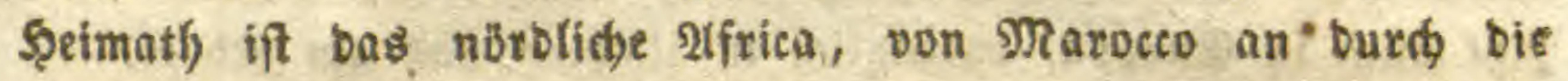

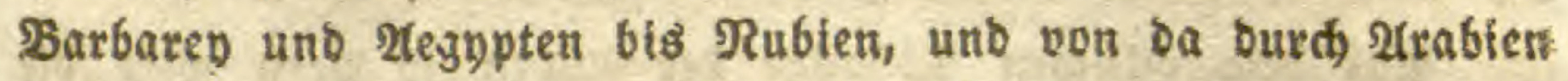
bis Syrien unb perfien, in fanbigem Boben mit פBafier. Bon

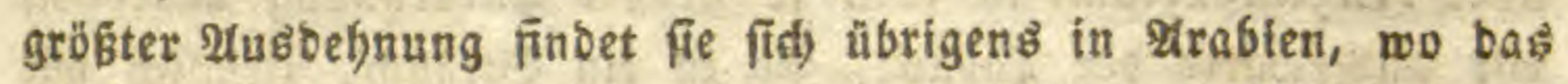

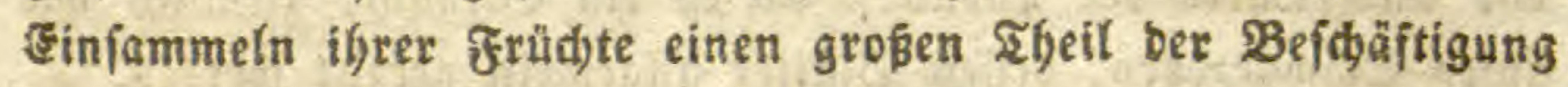
Det Einnofner ausmacht.

Dex Sngo fommt von veríditebenen palmeneyiten in Dfts indien.

Der eigentliche Sagopraud) (Cycas) bebertt bie naffen (E)es genben after bortigen Sinjcln, unb exitredt' fid, bis Siam unt ฐัapan.

Der Sagobaum (Sagus, Metroxylon) fitrbet fith eben= fatts in Oitinbien, uno wirb bafelbft in gropen Stredten angeo pflanzt.

Die DBein= ober Federpalme (Borassus) witb eben= Dajelbit in grofien mafien angepfanzt. E: gibt inbelien not)

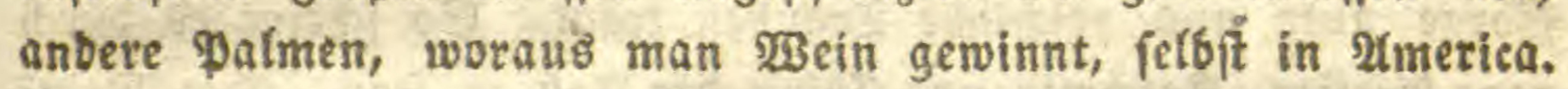

Det (e aff anienbaum gebeift bey $91 / 3^{\circ}$ mittlerer Wärme

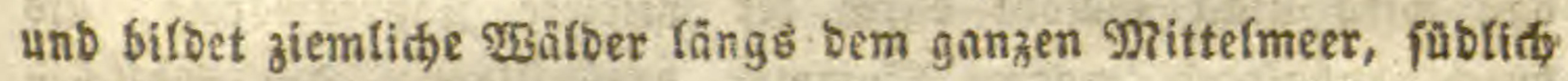
ben 2(fpen, felbit nod) an $\Re$ fein bis franffurt; fobann vons

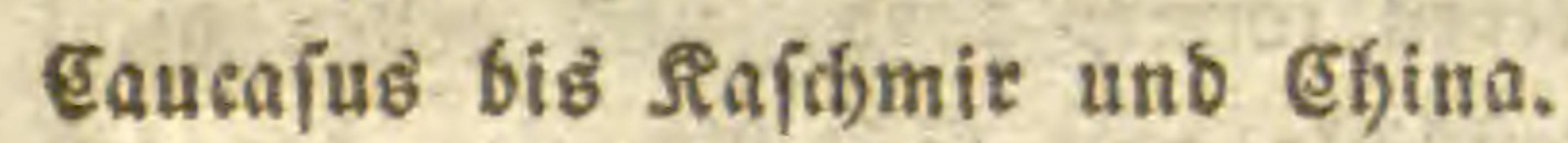

Die brafitianifdjen ober 马uvi = Rŭffe (Bertholletia) bilden an ben Etrümen, in ber Rähe bes Nequators, ausgebelynte

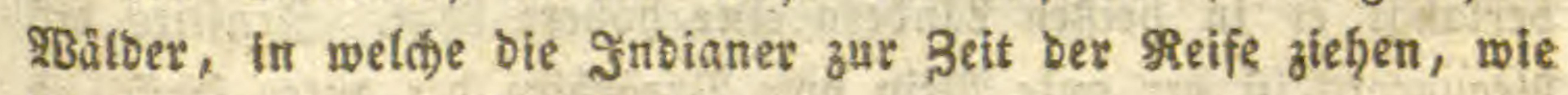
Die Straber in bie Dattelmälber.

Die Betelpatme (Areea) bitbet in Ditintien und auf ben

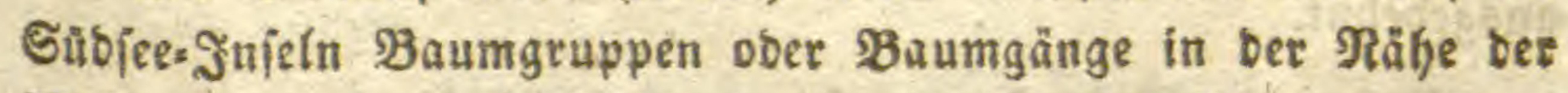

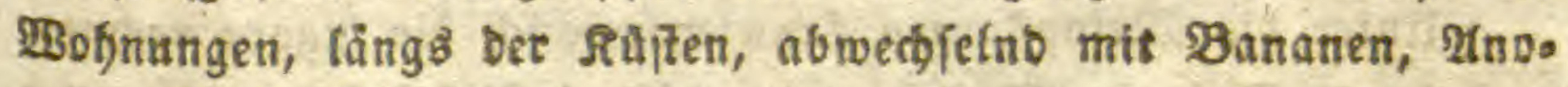
nen unb Silimbi; and) Pommt fie in ausgebebuten 2tnpfanzungen

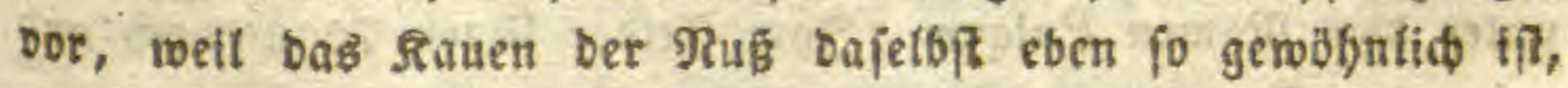
toie bey uns Das Rauthen voer Sdynupfen.

Die Nohnfelber, zน Gewinnung bes Dpiums, baben in Ditinbien Refynlidyfett mit Den Reiffetoern, uno tefimen ciness grofien. Ifycil bes soben weg. 
Tabatsfelter gibt es in grober Itusbefjnung in Ejina, in ber Sabbee und faft in ganz Imerica, befonbers SBeftinbien,

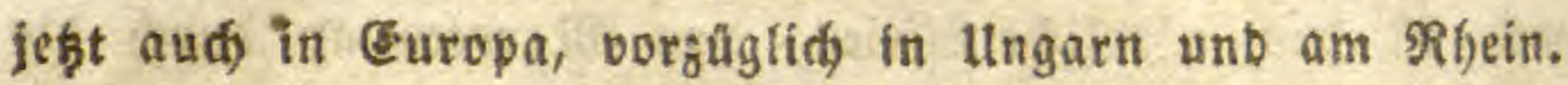

2uf bem Bftlidgen Abbange ber 2tnben in Peru witb bie Coca (Erythroxylum) in eben fo groper 2usbehnung angebaut, wie anberwärts ber Tabat. Cs if ein Straud, ziemlith wie unjer Sd)warzborn, beffen 8 lätter aflgemein gefaut werten.

Der Beinftor gebeift in Europa bey $10-17^{\circ}$, vom 36 .

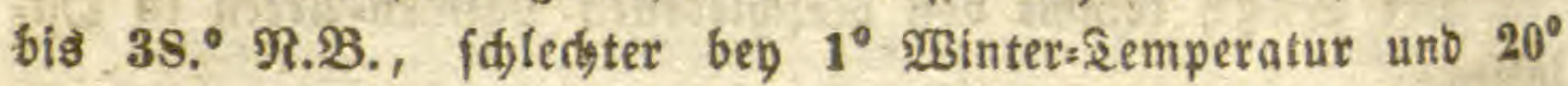

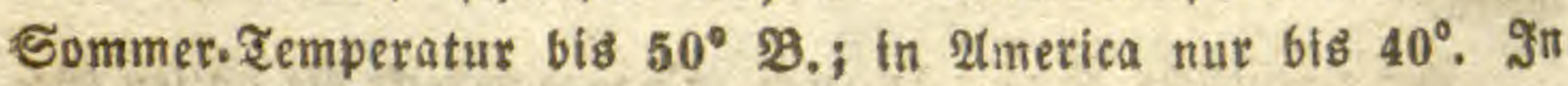
ben wärmern Eändern mä́djgt er in ben Ebenen balb willo; in ben fältern bagegen an fontrigen Sügeln, forgfältig gepflegt uno mit Steden geftủbt. Er Eommt an verfd)iebenen Drten in Europa, felbit am Rifein, in Buid)wäldern wilo oter wafts idjeinlich verwilbert vor, trägt aber ungenieß̧bare Trauben. Seinte eigentlidbe Seimath (d)eint bie \&evante zu fevn, befonbers Mins grefien, füblid) bem Caucajus, wo er nod) gegenwärtig ofyne afle Eorge gute uno reidjlidbe Irauben trägt. So folgeint ev burd̆ ganz Derfiten, Rafomir unb Elina ber Fall zu feyn. Der \$seists bau wirb nid)t fowohl burds bie mittlere Jafjeswärme, als ourch. anflaltenb warme Sommer begünftiget. §m fübliden Norb.2America werten bie Beeren immer berb, unb gehea nidst

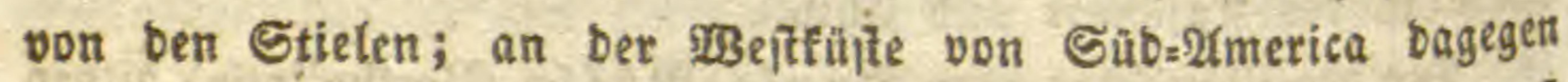

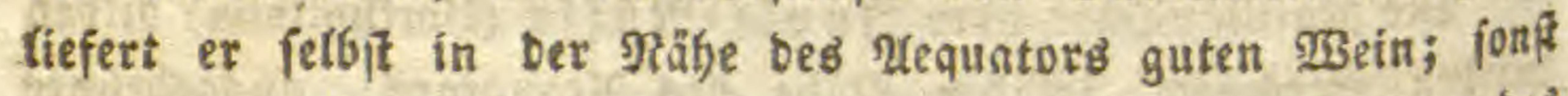

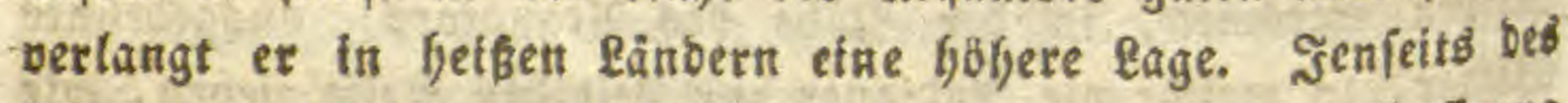

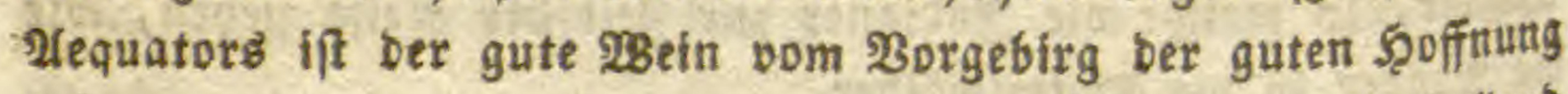
betannt; gegenwảrtig bat fid, fein 2nbau aud auf Neulfollant *ausgebefint.

Unter bie Weinpflanzen fann man aud) bie Agave redinth, saus beren Saft in MRerico ein geijtiges Befrảnt bereitet wirt unter bem Namen Pulque. Sorke felber fiegen $7000^{\prime}$ bodh und geben ter B̈egend ein eigenthünlidbes 2nifeben.

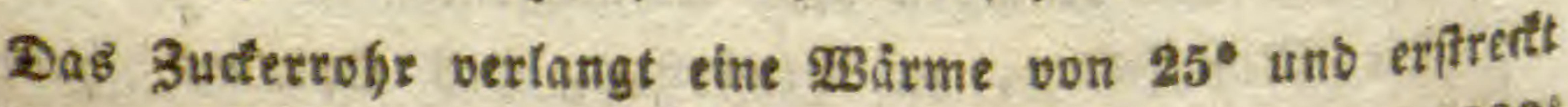
fith bis $36^{\circ} 2$. unb $20^{\circ}$.

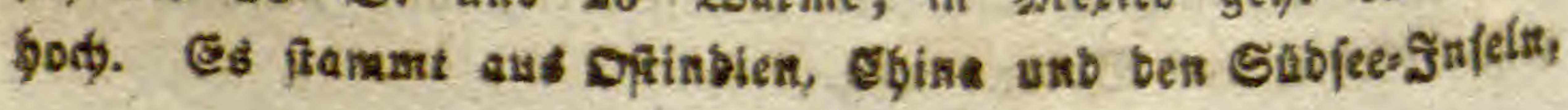


lam von ba nad Enropa bis Sicilien, auf bie canatifdjen \$infeln unb von bier nad) $2(m e r i c a$, wo eb in grofer $\mathfrak{A}$ (ubbelynung geo pflanzt wirb. (E) verlangt fumpfigen B.oben.

Der Eaffee gebört ben untern alper an, und gebeift am beften vom 2tequator bis $10^{\circ}$, und von $1200-3000^{\prime}$ seübe bey

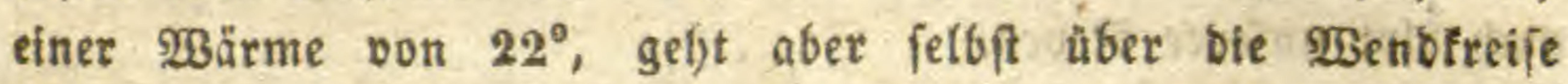

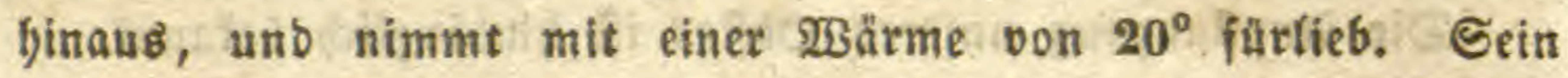
Baterland if 2trabien; er wiro aber gegenwärtig băufig in Oftinbien und 2america gebaut, und zwar in abvedjelnben Reilyen.

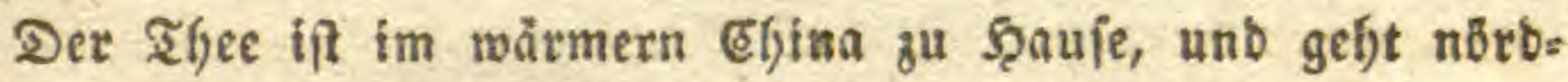
liđ) bis zum $400^{\circ}$, füb(id) biв zum Reid)e ber Birmanen, wo er itt ben Sebirgen wäd)ถt; übrigens wirb er aud) in Sapan unb Bengalen gepflanzt.

Aud) Der Pfeffer ftammt aus Diftindien, vorzugglidy von Malabar, wirb aber nun aud auf ben Snfén gepflanzt, unb zwar auf 2unfoben, wo er Stangen befonmt, wie ber \$opfen.

Der Sanf gebeifyt am beften im jüblidien Deutjhland, in Norb=2(merica unb 2rfien; ber Rein bagegen befier im nürblidjers unb yiftiden.

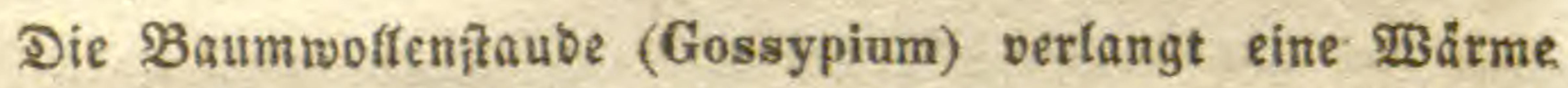
von $24^{\circ}$, gebeift vorzüglid) zwifd)en ben झsendefreifen, geht aber nod) weit barüber binaus bis zum $45 .^{\circ}$, uno wirb baher um Das̆ ganze Mittelmeer gezogen, vorzüglid in Steins 2 fiten unb Uegypten, in (Shina uno gapan, jekst aber aud) im beisen 2Imerica

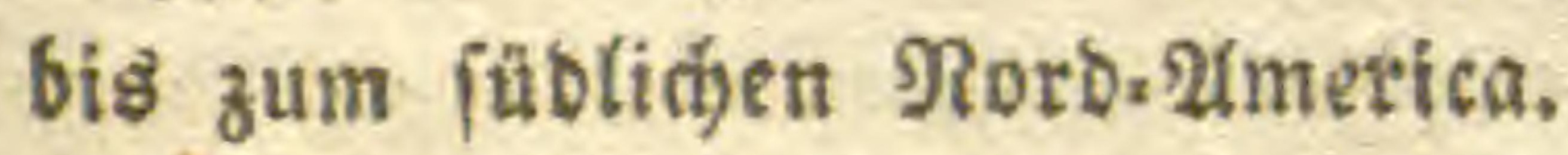

Den neufeetänbifdyen fradis (Phormium) vertritt in jenen Oegenten bie Stefle bes Şanfs, unt wiro jebt aud) in Neu. butlant gezugen.

In heísen Sänbern madjt man aud) Şanf von ben Blåttern Der Bananen und 2tgaven; aus ber Edjale um bie Cocosnufs grofe uno ftarfe Seile; aus bem solt bes \$apiers פaulbeers baums aftertey Beuge in Ghina uno ber Sabjee.

Die Inbigopflanze ftammt, wie es fijon ber शame anzeigt, Qus Dftinbien, und tam von sa nach) Xmerica, wo befonbers in Previco viel gepflangt wird. Sie verlangt feudete \&uft und etre 


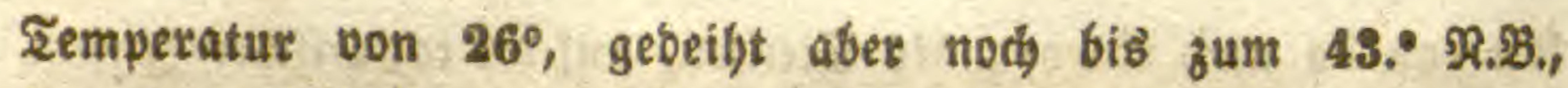

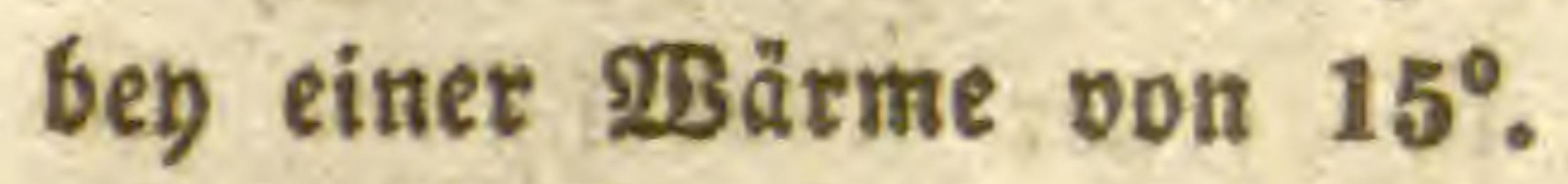

Biemlid) fo verbält es fid mit bem Eacad.

Die gactelbiftel (Cactus), worauf man bie rothe Edjiblaus

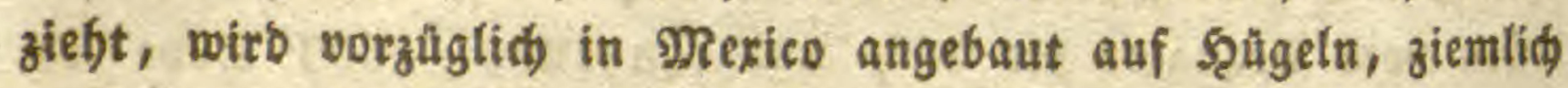
and Irt unjerer Reben.

Die Anpflanzung unferes Doftes ift binlänglid betannt. 


\section{2ligetwanste 8 otanif.}

Die angewanbte Pflanzenlunbe beidgdftigt fid) mit ber (eine mittung bes Menichen auf bas \$fanzenreid), um ев zи feinem Nuben ober \$ergnitgen, ober zu feiner geiftigen unterhaltung zu verwenben. Hebrigens wirb bie Xnwenbung ber Pflanzen betreffenben Drts angegeben, unb Der Begenftanb bier nur furz befjanbelt, vorzũglid) um zu zeigen, wie er nađ) meiner 2tnfidbt georbnet merben foltte.

(c) gehb̈ren afte planzen biebcr, weldse in irgent einer

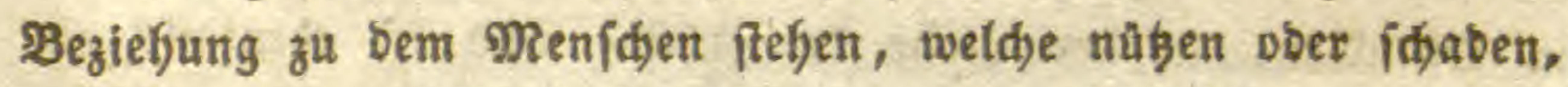

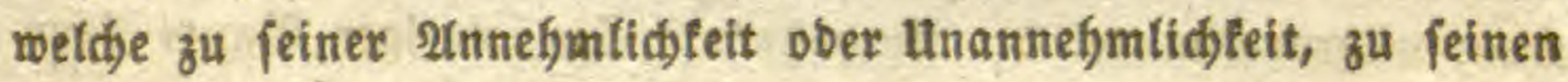
finnlidjen ober geiftigen Spieten gebören.

Die Pfanzen bienen entweber affen Stänben in ber Şause baltung - bconomifde Pflanzen, ober in ben osewerben - Eea werbspplanzen, ober zur Eefunblyeit - 2trzneypftanzen, ober zut geiftigen Unterbaltung - Sinnpflanzen und biftorif́) mertwür. Dige Pflanzen.

I. In Der Bconomifden Botanit

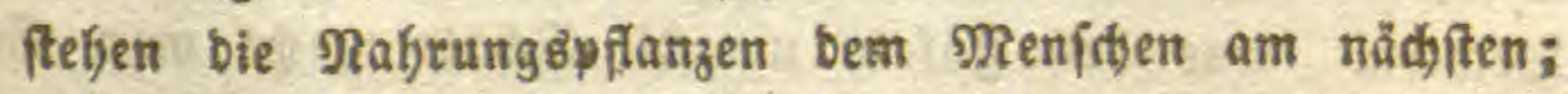
bann folgen bie f̧utterpftanzen für baร pflanzen unb enbliø bie unträuter. 
A. Tahrung 8 flanget

bienet als Speife, Sewârz unt Betränt.

Die Epeifepilanzen fint entweber roly geniefbar, wie bas Obit; ober fdwad zubereitet, wie bas (Semüle; ober völlig ver: änbert, wie bas meht.

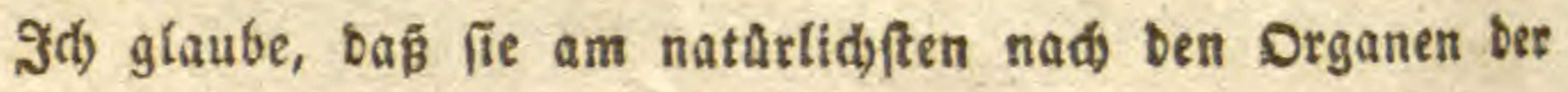
Pfinze abgetljeilt werben.

\section{Doftpflanzen.}

Darunter gehjuren affe biejenigen Pflanzentlyeile, weldse fo, wie fie gewadjien finb, ofne affe 3ubereitung genoifen werben fönnen.

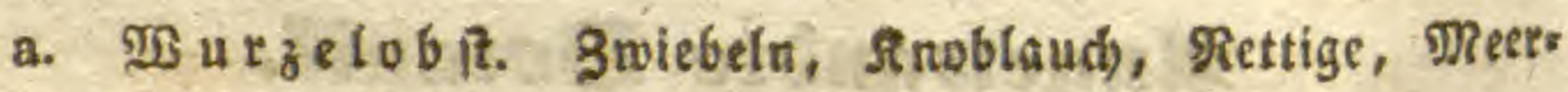
rettig, Sefterie.

b. Stengelobit als Salat: Sparget, \$opfenfeime.

c. Blattobft als Galat: Eatlid, Eidorien, Robl, getts falat, Büwenzabn, Balorian, Firefie, Bovetíd, Gauerampfer,

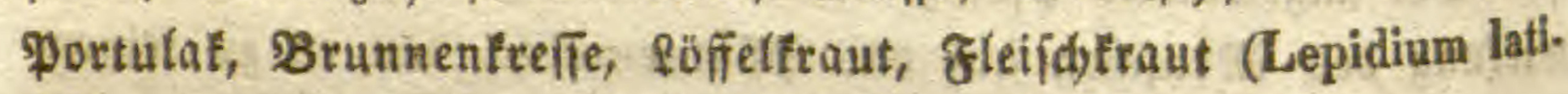
folium).

d. Samenobft: Mandeln, Şajetnüfie, פgalnüffe, Buds:

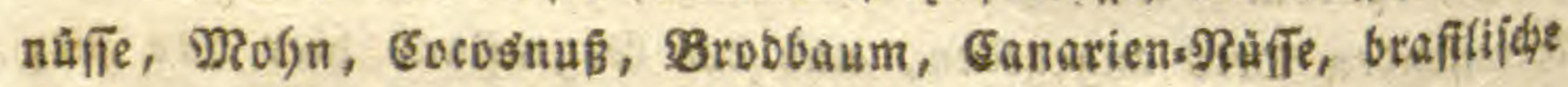
Caftanien.

Die ฮocoвnuf (Cocos nucifera) wåd)st auf ber befannten, ebenfaffs um bie ganze Erbe verbreiteten Palme, vorzüglid aber in Ditinbien, in ber Rühe ber Stüite, uno ift ebenfalts cin Sauptnafrungsmittel Der \$ewofiner. Ein einziger Baum tant 2-300 Nüfie liefern, unb babey wirb er 100 Jafre alt. Die reife grud)t enthält eitnen mildhfaft, weldyer getrunten und aud) zu einer 2trt 2trraf gebraut wirb; fpäter entwictelt fid ber pejte Sern, welther wie Manbeln idjmedt, unb befonbers mit Budes gefodjt wirb. Der sern liefert aud Das befannte Palmentl, weldjes felbit zu uns fommt. Die Garte Sdate wirb zu afferthy Dredbsterwaaren verarbeitet, au Stodfnbpfen, Büdjen unb Bedbern. 2tus den grafern um bie Edyale madjt man Seile, Bür|ten unb Decten. Die jungen Sdybffe, ober bas fogenanute

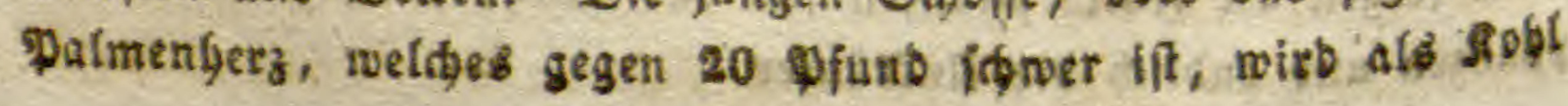




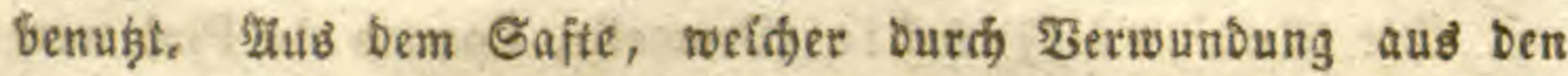
Bliúthenfolben tinnt, mad)t man Palmmein, ber aber balo fauer und baber gemöfutid) zu 2traf benust wirb. Enotid wiro aud) 3ucter baraus gewontmen.

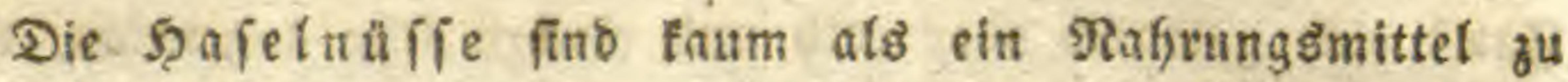
betrad)ten, fonbern mefr als untertyaltung nad) bem Elien. Man läß̈t fie wilo wadjen. Şin uno wieber zieflt man eine veredefte Stbatt in Särten unter bem Ramen Rambertos: ober Befternutife.

Sn Stalien ipt man bie Piniolen (Pinus pinea) und bie

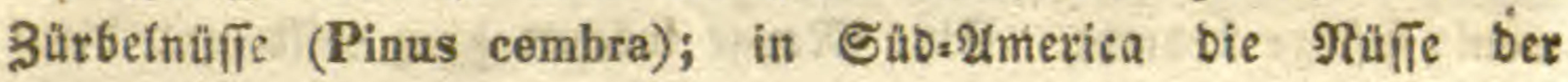
Araucaria.

In (Etried)entand werben bie (Eid)efn von zweyerley Eidjen gegefien (Quercus efculus et aegilops).

Die braftifidsen e a ftanien ober guvias (Bertholletia excelsa) fint länglidbe Steine, weldhe in Menge beyfammen in einer grofen Frud)t fteden und idmartifafte serne entyalten. Der Baum Gifbet ganze $2 B a l l b c e$ am Drinoco.

e. Sröpsobft: Jolyannizbrod (Ceratonia), Snga; als Salat grüne Bofnen= und Erbfentuatlien.

f. Blumenobft: Feigen, Erobeeren, Enjd) (Anacardium), Blumentol)l, \$rafjwafblütf̧en (Baffia), Rojenapfel (Dillenia), şoutig.

g. $\mathfrak{F} r$ d d to of t:

Uepfel, Birnen, Mifpeln, Fofenbutten, Branaten.

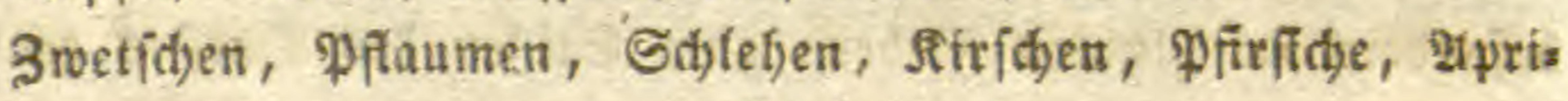
cofen, Datteln, Dattelpflaumen (Diofpyros).

Srauben, Rofinen, Fobyantisbeeren, Stadyelbeeren, Şim. beeren, Brombeeren, Şeíbelbeeren, Preifelbeeren, Mautbeeren.

Delomen, Gurfen.

Parabiesfeigen, inbianiịh) Feigen (Cactus), Rangảpfet (Passiflora).

Brebäpfet, Buaven, Mangoftane, Anonen, Blimbing (Averrhoa), Inanaß (Bromelia).

ふึก Suritam

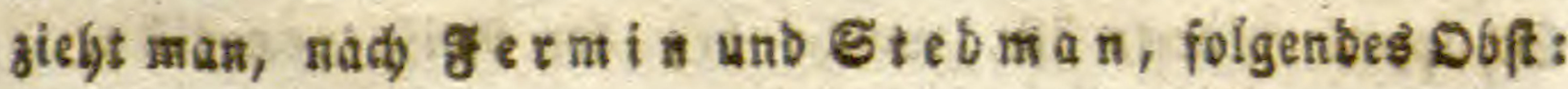




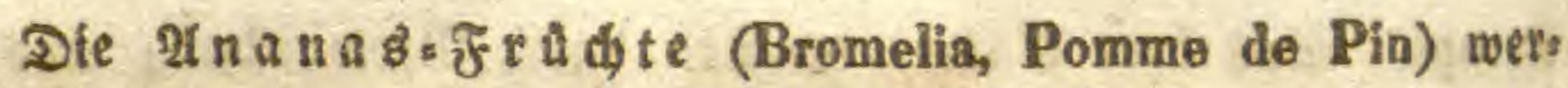
ben über afte europäifít)en grtủd)te gefę̧t. Sie madjien auf rolyrartigen Pflanzen, uno ibrer viele idmelzen in eine Irt Tannapfen zufammen oben mit einem Edjopf, ein uno zwey gauit bia, gologelb ober roth uno riechen fehr angenelgm, theils wie Erobecren, theils wie \$fixfide. Man fidneibet fie Hein und ibt fie mit rothem 2Bein unb Butter. 24us Dem Gaft

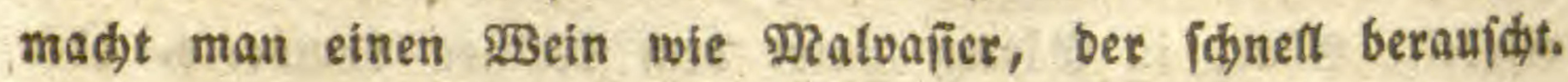
25segen ifree exfrifidenden staft wirb biefe grudt auf allen Pfanzungen gezogen und immer theuer vertauft, obfdyon fie wenig Pflege braud)t. Ceine Menge mädjat gana wilb unb bient Dem $\mathfrak{B i e h}$ zur शafrung.

Die Pumpelmus (Citrus decumana) if cine pomeranze von Der Grőß̧e eines 10jäfrigen Rinderfopfs, Dic eine fingersbide, bittere Sqaut, aber ein fäuertidjes, nadh Erobeeren uno Iraubent

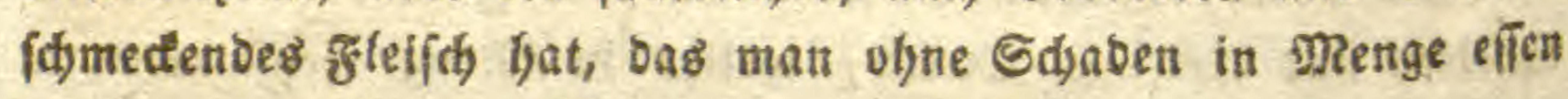
Fann. Der Baum wädjst auf aften Pflanjungen.

Es gibt bajelfie brenerfey \$omeranzen, faure, weldse

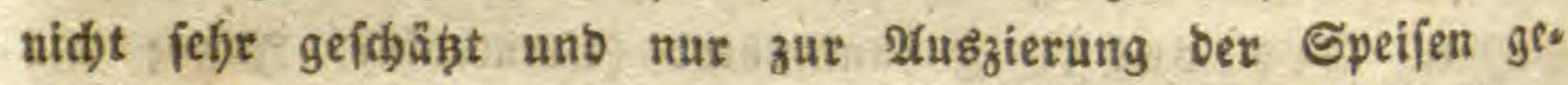
braud)t werben, ober zur Reinigung ber Şäufer, inbem fie ibnen einen angenefymen S̈erud) geben uno bie šnfecten vertreiben.

Die füsen füb felgr erfríldenb uno gefunb.

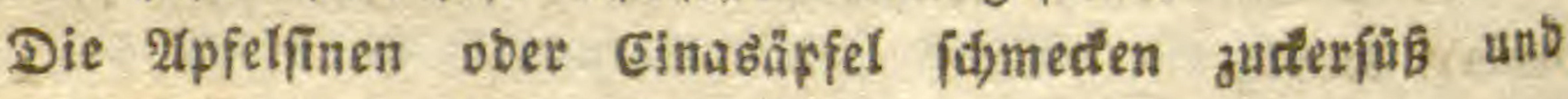
gleidgen ben portugiefijden pomeranzen.

e itron en gibt es aud ziveyerley, eine faure, welde man befonbers in bigigen fiebern zum Stiffen bes Durfice genté̈t;

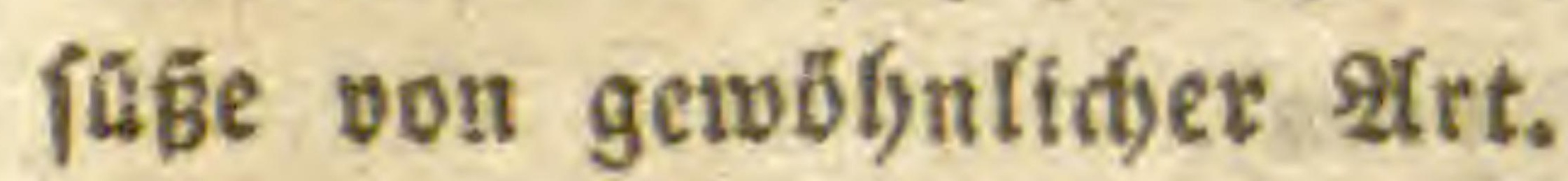

Die Eimonien, (Citrus medica limon) finb fleiner al bie Citronen, werten aber nodh bäufiger genofien, uno wegen

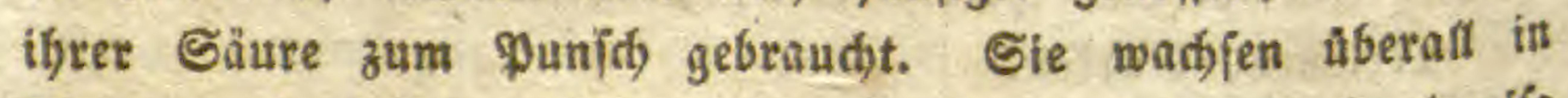
Säntren unb felbît mild, jo bas fie bie Matrofen forbooflweifé auf tie Sdbiffe tragen.

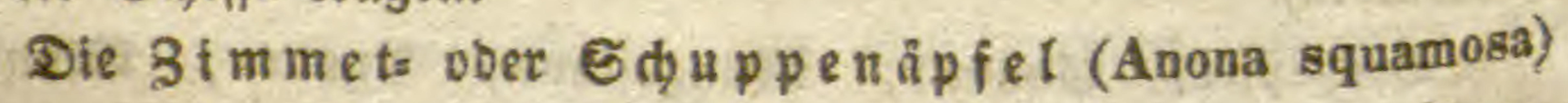

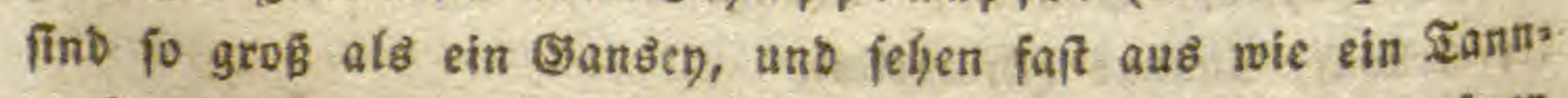

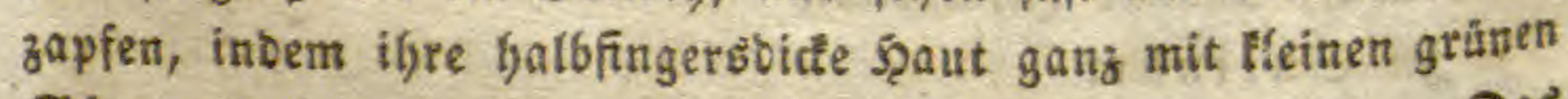
Edsuppen bevedt' ift, melde beg bet Reife verwelter. Das 
Fteifh gleid)t einem biten $\Re$ ahm, if nidyt befonbers idjmact

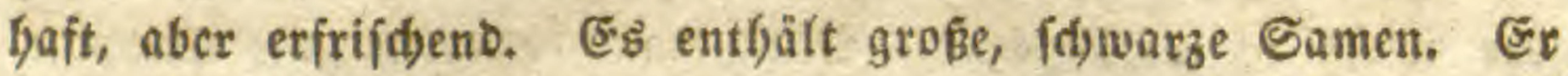
wädget auf einem großßen Straud) in ben Şärten.

Der $\mathfrak{A} \mathrm{c} a \mathrm{j} u=\mathfrak{A} \mathrm{pf} \in \mathbb{l}$ (Anacardium occidentalu) ift länglid): runb, gegen 4" Inng unb 2" Dicf, und wät)sit auf einem bofjen Baum wie Bimbaum. Nur bie Neger effen bie Frud)t. Dar. auf fibt cine nierenförmige $\Re u \beta$ mit einem Serti, ber befier fdjmett als झRandeln. (Ex wirb frífd) mit Salz gegerien, wie bie welfden গRáfie. Man fann bie Rüfie viele Jabre lang

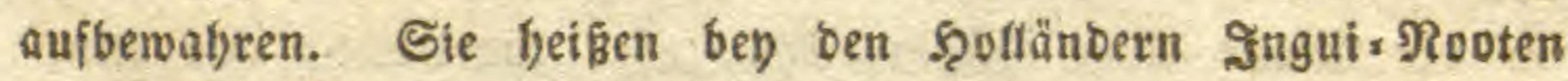

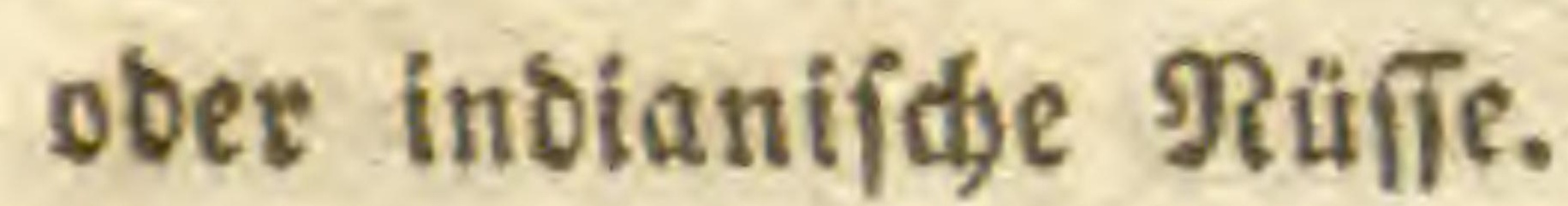

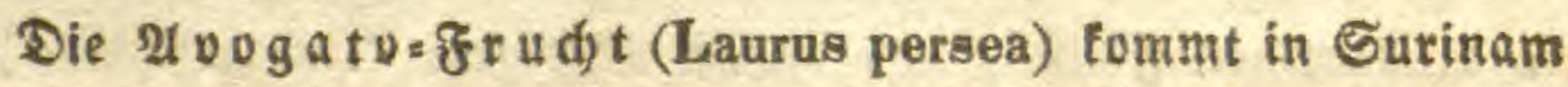

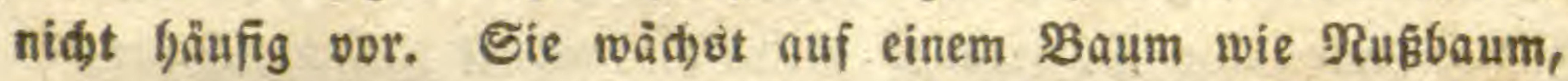
gleidt einer groben Birne und bas fleifd zergeft in Munte, wie ein Pfirfid); fie enthält einen runblidjen Stein. Mandye balten fie für bie befte frudbt ber.

Die furinamifden fifriden (Malpighia punicifolia) finb eben fo gut afs bie curopäifdsen, vicrectig, ídön roth unb fimecten, redjt reif, faft wie faure Rirfdyen. Man madjt fie

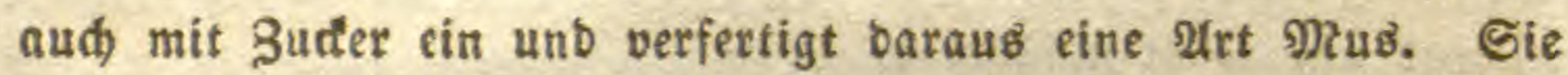
Laben inuwendig einen Sattel, wie bie welidjen शâffe, unb in jeber 2ubtheilung einen Fleinen Stein. Der Baum fieht faft aus

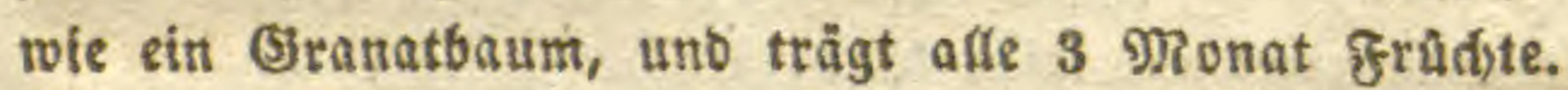

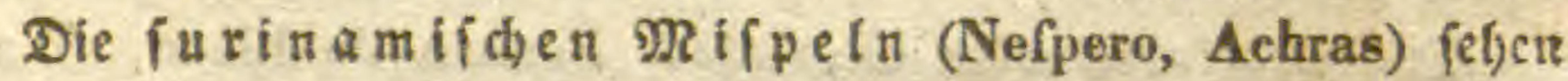
aus wie bie europäildyen, haben aber Peinen Etein, eine zarte, rothe spaut mit veftem ff(cifd), bas beym Reifen weid) wird unb einen fâsen, weinartigen Gef́lymact befontmt. Der Baum wåđ)ริt in Den Eีärten.

Der 3 u $u r=3 a d$ (Anona) ift cine birnformige grudt, faft

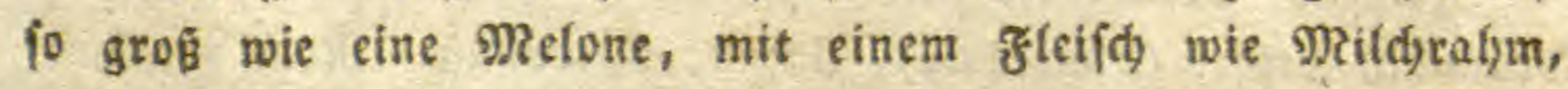

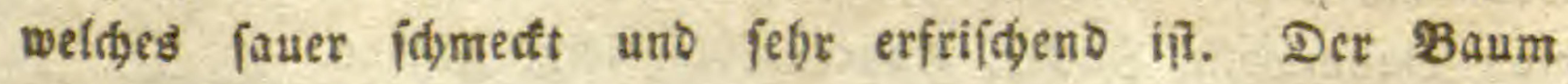
gleidyt einem Birnbaum.

Dic (S) oy a ven (Psidium) felyen aus wie Reinetten, baben aber eine firone faît wie bie Mifpeln, eine rauhe Sdjale, ans

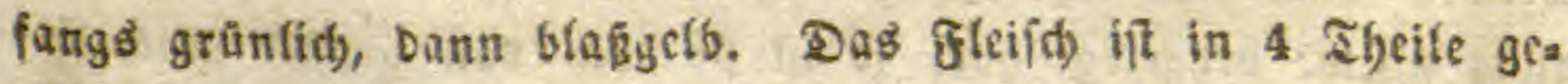
theilt und entjălt Eleine, barte Förner, ift gefund uno fann zu 
aften seiten gegerîen werben; relf tä̆lt es offenen scib, balbreif aber wirft es veritopfend. Man madit afferten gute compote

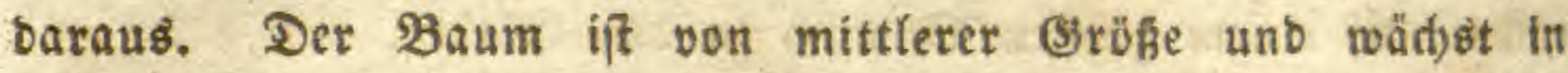

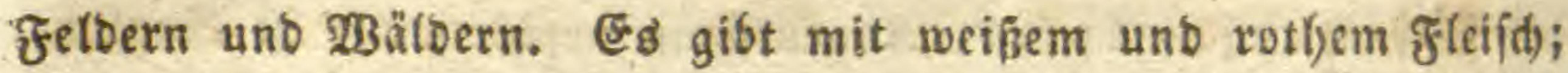

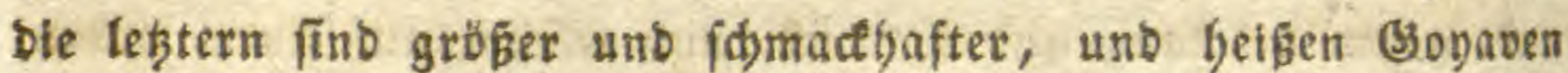
won Eayenne.

Der Sababill= ober Breyapfel (Achras mammosa) witb für eine ber beften früd)te angefefen, obfichon feine afthus grofe Sübigfeit nidyt nad) eines jeben (5efdymart ift. Ere if

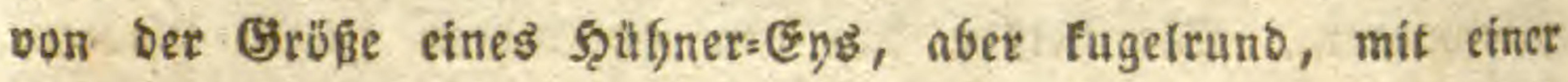
fammetartigen und zimmetfarbenen Spaut bebectt, unb entfáft

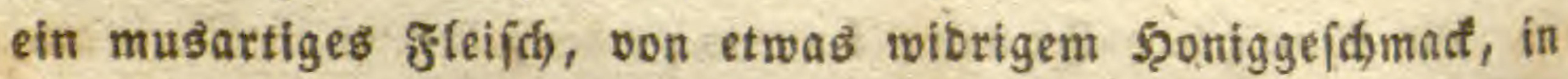
Fädber wie eine Pomeranze getheilt, mit je einem fdgwarzen sern. Der Baum ift fefre gros, unb erft nad) 5-6 jabren tragbar.

Der $\mathfrak{I} a m a r i n b e n b a u m$ (Tamarindus) ift eingefüfrt, hat

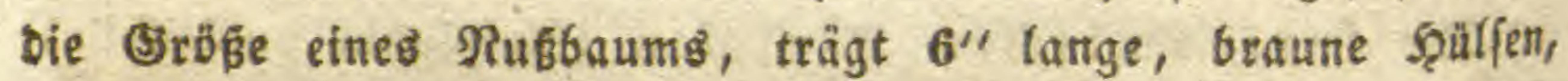
morinn graues Marl mit violetten Bofgnen, weldse vor ber Reife eingemad)t werben. Sie find, io wie bas Marf, felje ets frifdend uno leid)t abfüfyrent.

Der $2 B$ e inft oct bat faft bas ganze \$abre reife uno unteife Trauben, weldse aber idjledyt fdjmetten, und nur in fo fern nük̨en, als man zwenmal lefen faun.

Die Matfujas ober Marcafas (Pomme de Liane, Water lemon, Paffiflora laurifolia) ift eine felyr fleiffige, ovale und ge(be ßrud)t, wie ein (Sranatapfel, weld)e cine graue, fäucrlide Baffert mit eyförmigen uno wobfried)enten Samen, entliătt. Sie witb wie ein (E) geöffnet und ausgefd)fürft.

Jreigen, Parabiesfeigen, (sranaten, 厄acao, Bianens ober

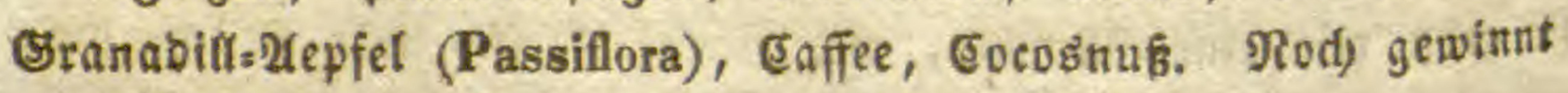

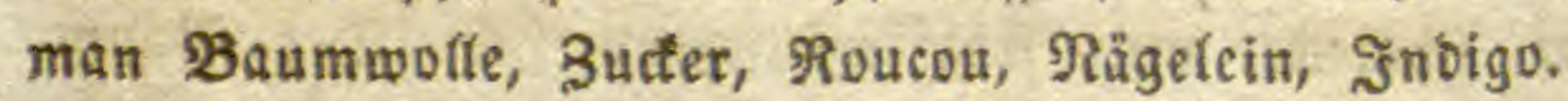

Die eocospalme wiro in Surinam $60-80^{\prime}$ yod, if aber feiten gantz grab. Dbidjon fie nidjt Das lob verbient, weldyes man ifs in Begug auf Nalyrung, Rleibung, WSofhs sung u.f.w. bengelegt hat, fo ift fie bod, vout groper sisintigs

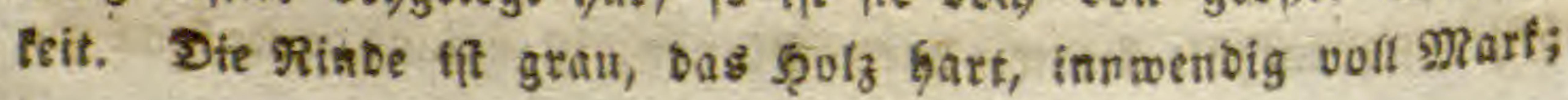




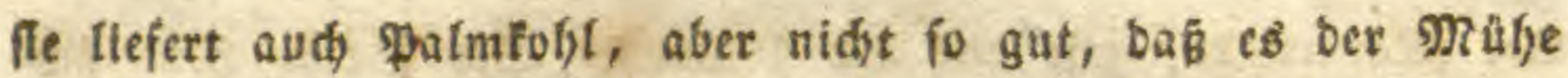

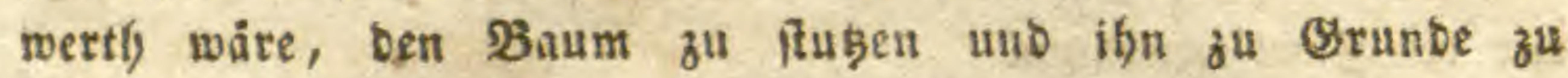

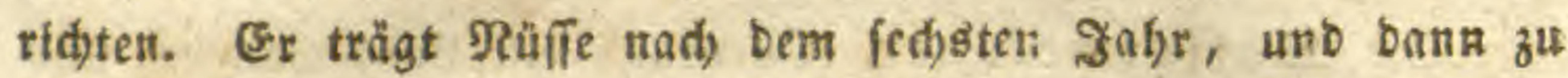
jeber Saljrzzeit 6-8 in einer Rifpe unmittelbar am Etamm, fo grof wie ein Stopf, feinlyart in einer fajerigen şüfle. Șung entigalten fie einen weifen Saft, wie Mild) mit গুaffer und Bucter, weldjer ein frifd)e unb angenefymes betränt ift; reif bitset fid barinn ein holyler, fehr figmadtlyafter Rern.

Die \$apayafrud)t (Carica, Mamoera) wảdst auf einem 25' boben fdywammigen Baum. Crs gibt tleine, nidjt gröfer alל eine Duttte, von Der Ceffaft einer (Burfe, anfangs grüntidy, bann gelblid; wirb oor Der Reife mit Sufer eingemadt, fo wie bie groß̧e woblriedjenbe 9 (ütţe. Beibe finb gut unb magen: ftärfent. Die anbere wirb fo groß, wie eitte DRefone, betommt ein golbgelbes fteif́), unb wirb nur reif gegefien, aber gelodt, weil fie zu tühtenb ift.

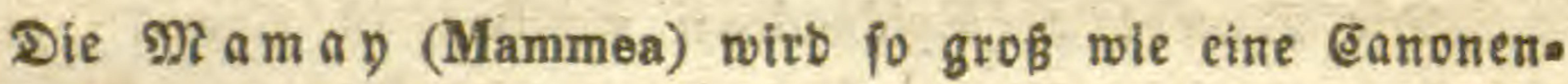
fuget, 6-8 solf-bid', mit einer bicten, rüthlichen uno leber. artigen Rinbe, Die abgezogen wirb. Das berbe, gelbe unb bal= famifid) riedjenbe fleifh enthält einen Stein, fo grob wie ein

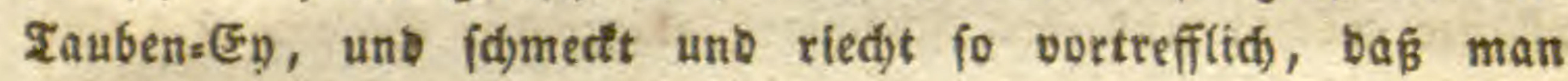
glaubt, Tage lang ben (sefdsmatt bavon im Nunbe zu haben.

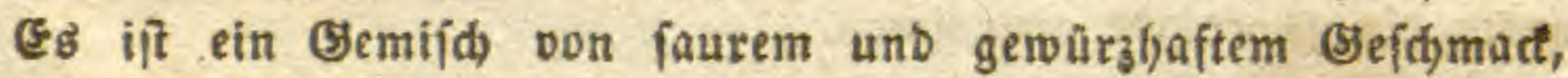
ber jeben anbern übertrifft. (E) werben bavon Marmelaben unb Iorten gebacten, weltben bie aus ben beften europäiftben Frùd)ten verfertigten weit nadjflchen. Der sern iff febe bitter;

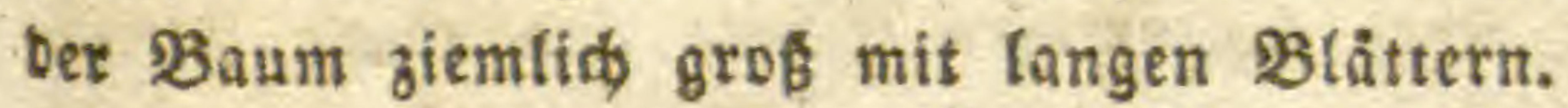

Die Marmetabe. Doos (Duroia) fino nidyt grōeret als ein Pfirfich, aber eyfbrmig, raul) unb gelblid). Das fleifd) ift eine 2(rt Mus von rőthllḑer Farbe mit linfenartigen Samen,

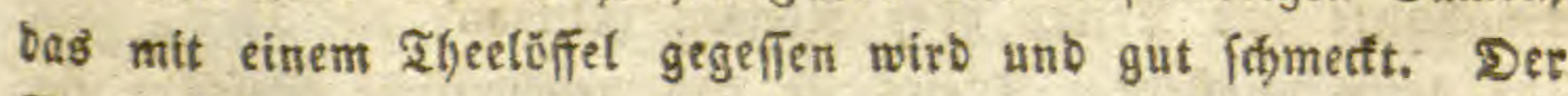
Baum fief)t wie eine fleine palme aus.

Die Mupees ooer Mo mbin (Spondias) finb gelbe lăngs lidbe frùd)te mit wenig fleif̧, bas bie 3äljne etmas prumpf madat, aber fefre augenehom riedit. Mran madjt baraus eine 
Xrt Marmelabe, wie aนร Der Mamay. Der Baum fieft aแรื wie ein Swetifjenbaum.

Die פgaffermelonen (Cucurbita citrullus) wadfent febr leidyt in aften Gärten, fdymecten gut uno Püflend, und man fann nad Eefaffen Davon effen, ofne fdlimme Folgen.

Die e antalupen finb felje grofe, farfgerippte Meloner mit rothem, zartem Fleifh von vortrefflidsem (Sefdymad.

Die gewblynlfden Pelonen (Cucumis melo) fommen äberaft vor und find fefje fdhmadtlfaft; mit Pfeffer ober Salf fann man bavon effen fo viel man will.

Die $\mathfrak{A}$ bo vai $=\mathbb{F}$ rud) $t$ (Cerbera) wädgt auf einem Baum, wie Birnbaum, if aber giftig. 2(uв Dem Stein madjen bie İnoianer Rlappern, womit fie fid bey ifjen Tänzen puḩen.

Die Pommes de Tettons (Solanum mammosum) wadjen auf einem Baum an ben æBiefen, find fo groß́ wie eine Reinttte, golbgelb unb giftig.

Die 9 aniffe (Epidendrum vanilla) ift eine $7^{\prime \prime}$ lange, Fleinfingersbreite, röthlithe frud)t, wie eine Єdjute, von gewätz" Gaftem (E) idymad unt angenelgmem (Serudh, wie ber peruvianifide Butfam, weldye auf einer 12' bohen, rantenben Edymarokets pflanze wädsot und voff fidwarzer glänzender Samen ift. Sic wirb at8 2rizney gebraud)t, um ben Magen zu färten, audd untet bie efjocolabe genommen.

Der ฮ a f e baffen $=\mathfrak{B}$ a um (Crescentia) fieht aus wie eir grofer Xrpfelbaum, unb ftebt auf affen Pflanzungen. Er trägt grobe Früdste, wie Rùrbien, runbe unb eyformige, 1-2' lang und $8^{\prime \prime}$ bid, mit einer bolzartigen Sdjale und einem freifd. nebit Samen wie ben ben sürbjen. Nan nimmt es aus

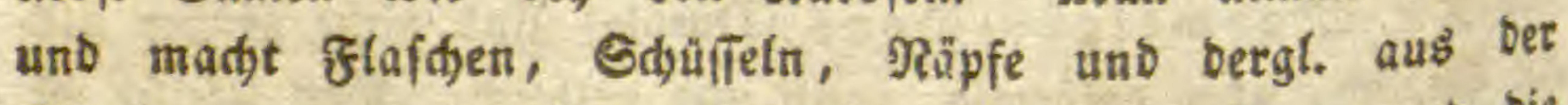
Sdjale, worauf bie Reger afterley friguren graben, uno bie Einjd)nitte mit Rreibe ober Roucou (Orlean) aนsfülten, เฉตื fehr artig ausfteht. Diefes lif bas gewölynlidbe (seidirt im ganzen Rande.

शad) I

in (3)yana vocr auf ben Mntilten

folgendeต Obit, zum agheil wilb: 
Pamea (Badamier), Ximenia (Croc), Chrysophyllum (Macoucou, Caimito, Staer-appel), Achras fapota (Nesperia, Bulleetree, Mifpel-boom), A. mammosa (Mammee, Marmelade).

Solanum pseudocapsicum, lycopersicum (Tomate), melongena (Aubergine), Ambelania, Hancornia (Mangaba).

Coccoloba (Raisinier), Guevina (Nebu), Brosimum, Pichurim (Ocotea), Elephantenlaus (Anacardium), Spondias (Ciruelo, Prunier d'Espagne, Mombin).

Arachis (Pistache de terre), Umari (Geoffroea), Angelin (Geoffroea), Inga vera, Pacai.

Melastoma, Mèles f. Cormes (Valdezia), Cupi (Acia), Parinari (Petrocarya), Hedyerea, Jicaco=\$flaumen (Chrysobalanus, Prune des Anses), Eujaven (Psidium), braffliíde Eaftanicn (Bertholletia), Iopfbaum (Lecythis), Marmite des Singes (Lecythis).

Barbabob=-Sirfiden (Malpighia), peruanifthe 厄aftanien (Caryocar), Anippen (Melicocca).

Eacro=Baum (Theobroma), Baftarb=Eeber (Bubroma), Guatteria, Lardizabala, Anona (Corossol, Courou, Water-Apple, Pomme de Canelle, Zuur-Sak, Custard-Apple, Cherimolia, Coeus de boeuf, Prickle-Apple, Steer-Apple).

Un sể doen frä utern

gibt es in Surinam verfdiebene Sioftarten, Mören, Pas ftinafen, Bibertelf, Rerbel, Peterftlic, Portulaf, Meerportutal (Sesuvium), Sauerampfer, Raudh, Şmiebeln, Edjatotten, Rreffe, Surfen, Sopffafat, Enbivien, હidjorien, Selferie, Spargel, Erb: fen, Bofjnen, Rüben, Rabtşben, Rürbfen, Pfeffer, ipanifder Pfeffer, 2luberginen (Solanum melongena), פam, Eibijó, Reíp.

Arzmeypflanzen

wadjen bafelbft: Duafía, Simaruba, Eaffien, Sarfapariff, inbianifidje: Blatt (Malabathrum), J̊ngmer, befîen erbapfels

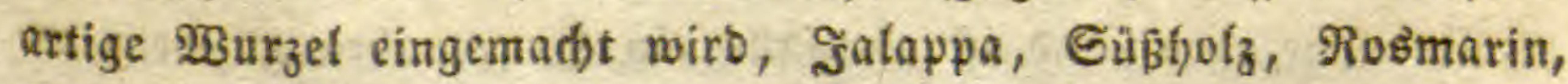

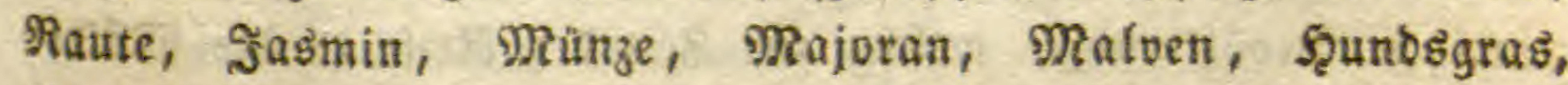
Fendyel, Frauenfjaar, Bafitien, Salbey), Taujenbgulbentraut,

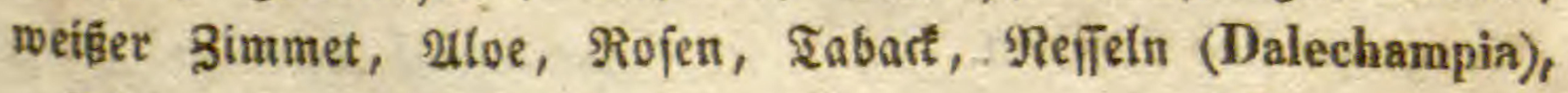

Dfens aflg. Fatnrg. II. Botanif I. 
Botbruthe, Egrenpreiz, Eifentraut, Scerofe, ミetifien, Mutter= fraut, Beinfraut, Brudstraut, Baunübe, TBafferboften, Şăllner= Darm, Rräfenaugen, Sinnlraut, Ricimus, J̊pecacuanba, Pudjiri (Bois de Crabe).

\section{In bén 2 sătoern}

wädst Der Eapivi. ober Copahu=Balfam, Das Esummi Aracocerra ober ber Racofifini=Baljam, welder einerlen ift mit Dem peruvianifaen; Der grofe Eatanier ober Mauricn, wotint Der Palmwurm lebt. Der Earoubter ober Eocuft=Tree, aud Rocus, freist ber fönig Der SBälber, weil er einen Stamm befommt $70^{\prime}$ boh) und $9^{\prime}$ bict, und bas befte grolz liefert, aud) Eopal; Sanbbüd)fenbaum (Sablière); Mapa; Pefeia; 2 a = gaffe; Ilcoma; Balata; Esuaiac; Esifentyolz; Retterholz; Ittağs folz; Ceber; Mafaut. -

Die Parabiesfeigen, Bananen ober Pifange (Musa)

find fpannelange, fleifdjige frühte, welde zwifden oent gBenolreifen faft bey iebem 5̧aufe gepflanzt werben, felbft von ben Galbwitben Sinbiantern in atmerica. Sie ptefent auf palment artigen Bäumen, etwa 20' fod, fait bas ganze $3 a f r$, unb off

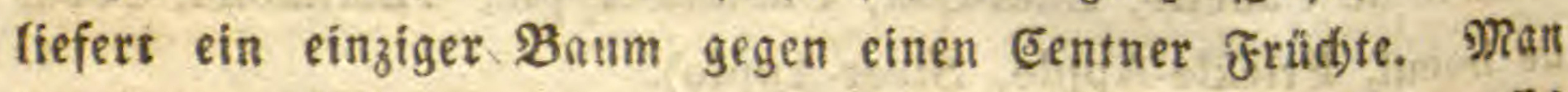

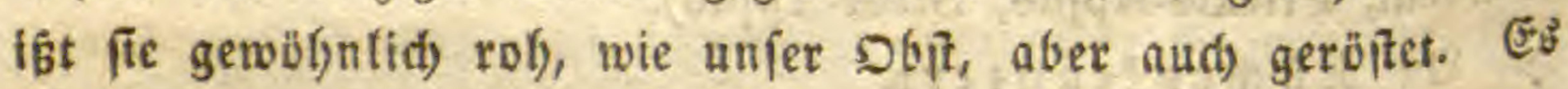

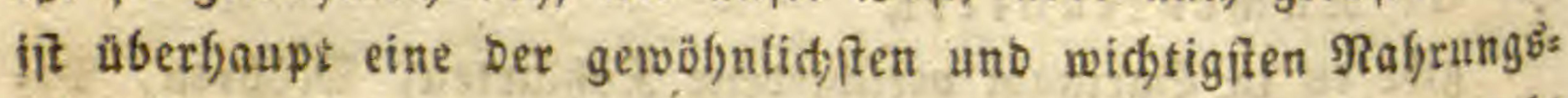
pflanzen um bie ganze Erde berum. Ifue ben gajern madst

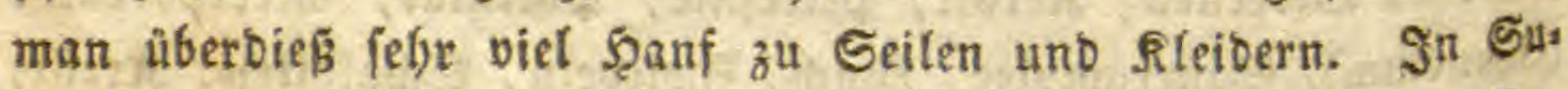
rinam pflangt man bey Der 2infegung eines (3uteg zuerjî $\mathfrak{B} a$ nanen und fpäter Caffee, jene $36^{\prime}$ aus einanber und fobann Eaffee(trüud)er bazwifdhen 9' vont cinattoer; länge ber Goänge

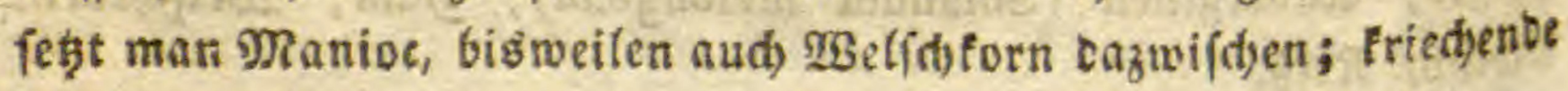
Pflanzen aber, wie Yam unb Bataten, mús man weglaffen.

\section{Die Dattelpatme}

wirb im ganzen Orient und im nbrolidjen 2 frica in grofien

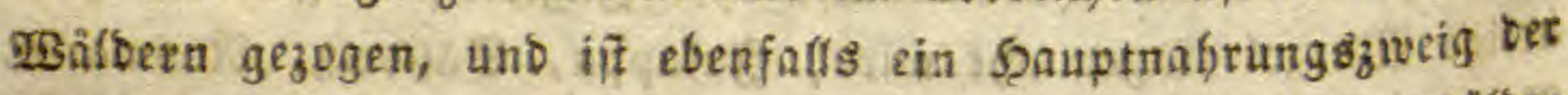

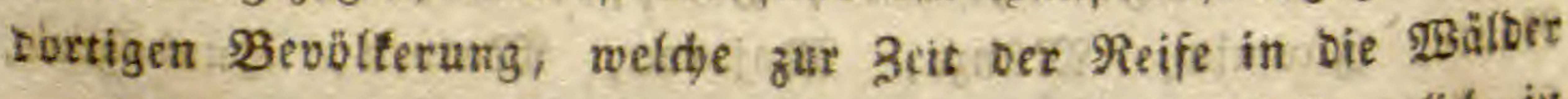
wantert, um bie Dasteln zu fammetn, weldye befanntfids it Menge ju uns fommen. 
Inoifde\& $D$ bft.

2rnands, Pandanus, Nipa, Cocos, Phoenix, Areca.

Mangi (Rhizophora), Luffa, Momordica, Trichosanthes, Cu* camis, Cucurbita, Zanonia.

Terminalia bellerica, moluccana, catappa, Diofpyros, Embryopteris, Ardisia, Bassia, Mimusops, Cordia, Carissa, Stryehnos, Willugbeia, Thoa, Morella.

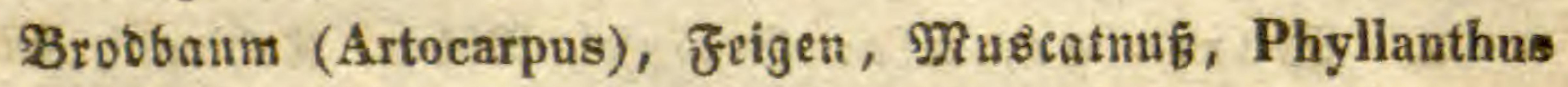
emblica, Bancouโnuв (Aleurites), Sauerfnopf (Cicea).

Maqui (Aristotelia), Granatpflaumen (Samyda), Hovenia,

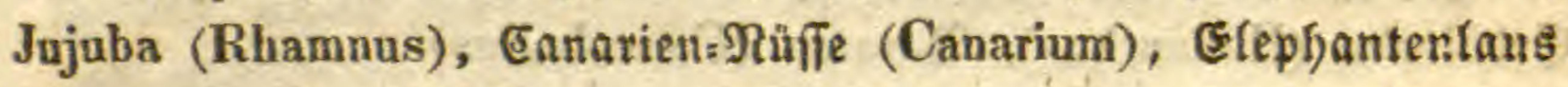
(Anacardium), Blimbing unb Catambota (Averrhoa), Mangas (Mangifera).

Geoffroea horsfieldi, Refferbaum (Hyperanthera), Cynometra, Prosopis, Inga duleis, Tamarindus.

- Staiferfrud)t (Alangium), Melastoma, Sujaven (Psidium), Rägeleir (Eugenia), న̃ambujen (Eugenia domestica).

Flaceurtia, Stigmarota, Crataeva, Litchi (Nephelium), Sandoricum.

Eimonien (Limonia), Lansium (Cookia), Elepfantenterpfet (Feroniz), Sdbleimapfel (Aegle), \$umpelmus (Citrus decumana). Mangvifane (Garcinia), feg bie befte Frudit.

פ̧itbe Sliven (Elaeocarpus), Grewia, Durio, Rofenäpfel (Dillenia), Uvaria, Anona.

2hnęerdem wirb in jonoien, nebit vielen anberen, an. sebaut :

Sdywarzer Pfeffer, Betel, Eubeben.

Das ę̧bare Aron, die Tacca.

Ðalgant, Kaempferia pandurata, 3itwer, Curcuma.

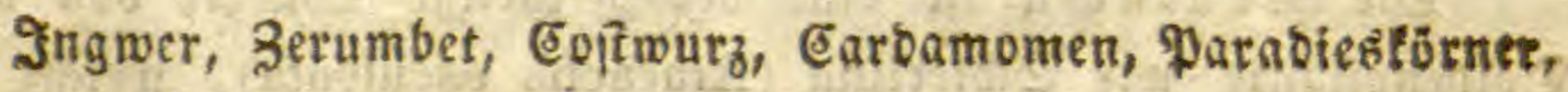
Amomen, Heliconia, Parabiesfeigen, Ananas.

Coix, Saccharum, Eleusine Oryza, Sorghum, Bambus.

Dioscorea, Smilax, Dracaena, Cycas, Pandanus, Nipa, Sagus, Elate, Cocos, Phoenix, Caryota, Areca, Gomutus, Corypha, Lodoicea, Borassus. 
2t纟 Gemuft:

Cichorium endivia, Tuffilago japonica, Baccharis balfamifera, Crotalaria, Coronilla grandiflora, Hedysarum umbellatum. Abrus, Clitoria, Arachis, Phaseolus radiatus, max, Dolichos, Mannebob)nen (Dalbergia glabra), Desmanthus u. a.

2. E) $\mathrm{em}$ if $\mathrm{p} f \mathrm{f} a \mathrm{n} z \mathrm{n}$

fint béejenigen, weld)e burd Gloß̧es Rod)en egbar werben.

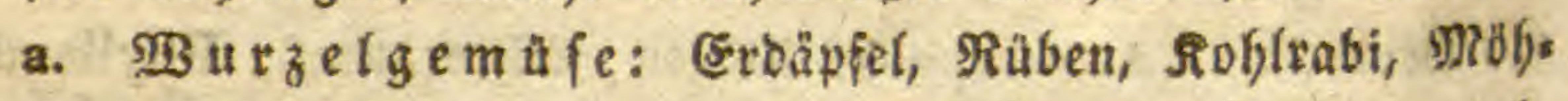
ren, Paptinafen, Sutterwurzeln (Sium fifaruni), Şaberwurzefn (Tragopogon), Sd)warzmurzeln ober Scorzoncren (Sc. hifpanica), Erobirtren (Helianthus), Bataten (Convolvulus).

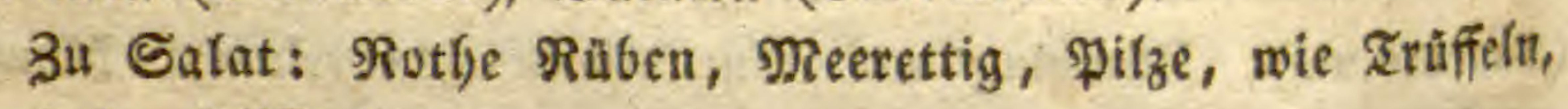
Mord)eln, \$rifferlinge.

Die Erö̈pfel

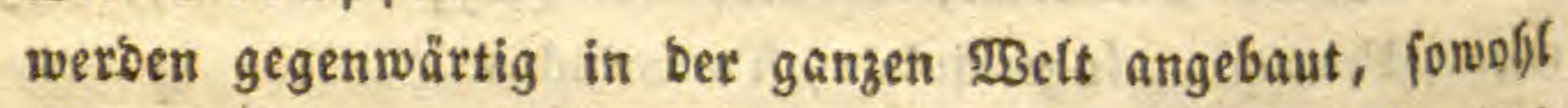
in ber beiseften wie in ber tälteften Bone, uno fino bafyer bas eigentlid)e Ed)ubzittel vor ber Şungersnotl) geworben. In Sübs America wurben fie fidon bey) ber Entbectung in ben Fältern Gegenben ber 2unden angebaut. Das Mebl ift zat naidst braudbar zu Brod, weil es zu fpectig ober floftg wirb; bagegent fönnen fie ganz gefotten ober geröftet gegeffen werben, uno in

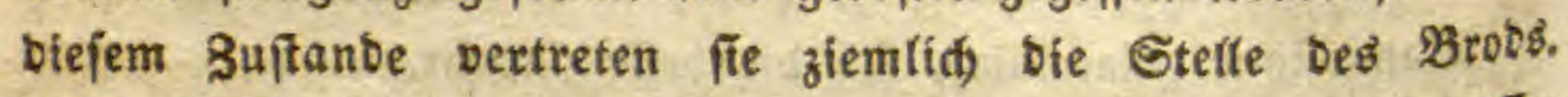

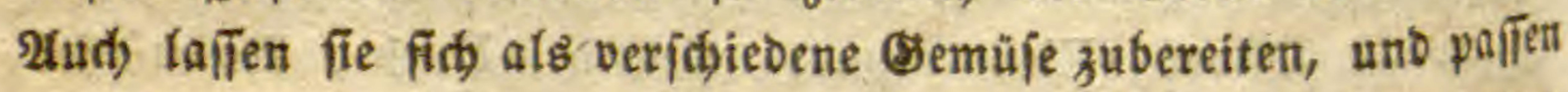
zu aften anberti Speifen. 2Ho ifrem Stärfemelyl Fann mant

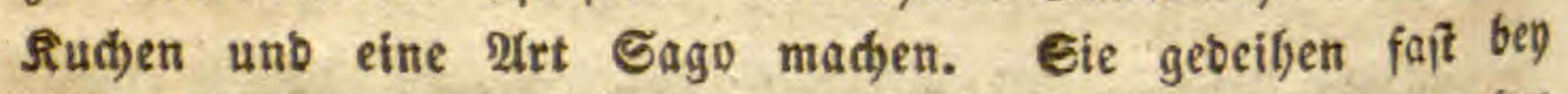
jeber פ্Sitterung, wenn es nur nidyt zu anfjaftend naß̂ obet trocten ifi. Sie wevben meijtens físittweife von einanber in Eöder geifb̧t, voer aud) in furdjen gefegt uno jobann mit bent Pffuge bebedt.

Die $\mathscr{A}$ racad) a if eine erbapfefartige Wurzel von einet DolDenpflanze wic Sdjierling (Aracacha esculenta), weldie auf

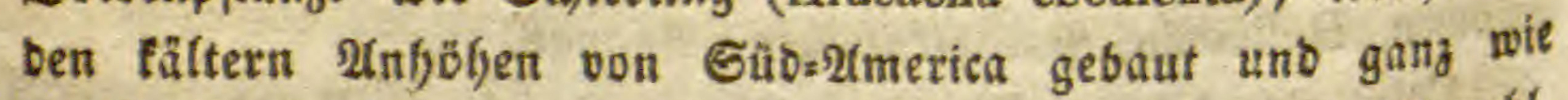
Erbappel gentifen wirb. Sie gibt überbief ein feines Stärtemelyl.

Die \$feifwurzel (Arrow-root) fommt von einer benútzs pflanze (Maranta arundinacea) in Surinam uno 20 eftinbien, unt if ein wagredter, langer, weiser stroflen, weldyer fege feine 


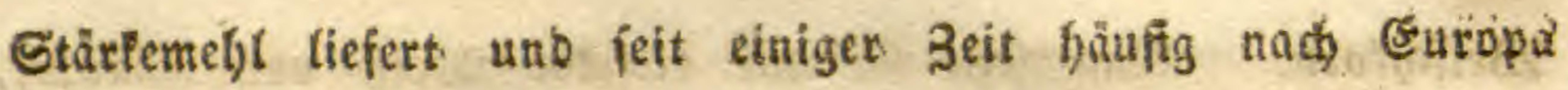
fommt.

In ben heifen Ränbern gibt eb̉ mehreze 2 ro na teten

mit fnofligen 2 Burzeln, wie Eroåpfel, weldhe ebenfalls felyr melylreid) find unb ebenjo gegefien werben. Sie entralten zwar einen idyarfen Stoff, weldyer fich aber beym Rodben verliert. Sie

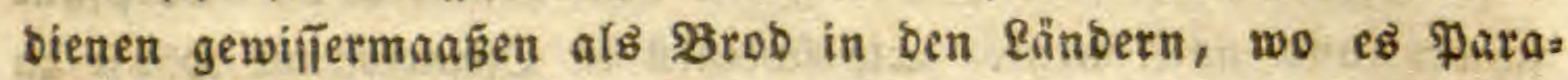

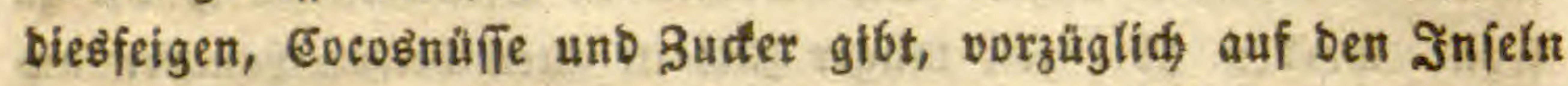
ber Cübfee, wo Das gemeine ę̧Gare Aron (Caladium esculentum) uno bas grofrwurzelige (Arum macrorhizon) unter bem Ramen Tarro gebaut wirb. Die Felber fino, wie Reiśfelber, zum Bewäîern eingerid)tet, uno bie Mflanzen werben ungefälys wie ber siofl von einanber gefegt. Die senoften werben fo gros wie ein frinberfopf, uno werben gerbiftek uno gefotten ges geffen; fie foflen wie bie Bataten fdbmerten. Die gemöfutidbe Epeife bavon ift jebod Brey, weldyer poë hei st und 24 Stun: ben gäbren muß̈, ehe er genieß̧bar ift. Die \$lätter werben als SEmūife benubst.

\section{Dic $\mathfrak{R}$ a nioca= $\mathfrak{Z B}$ urzel (Jatropha manioe)}

ift eigentlich im heisen 2tmerica zu 5̧aule, wito aber jebst aubh in 2rfrica angebaut. Sie liefert einer grofen Nenge von Menidjen Das 3rob, ober vielmelgr Rudben, weldie Eafiave ges

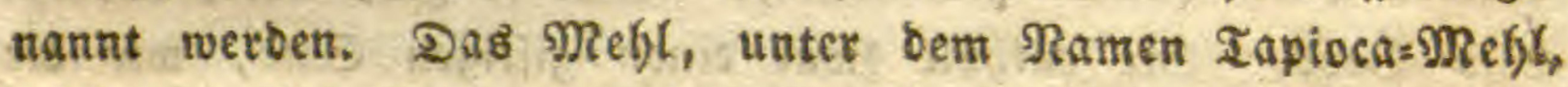
wirb zu aften Arten von (Semüfen benuģt, unb aud) zu eitusr

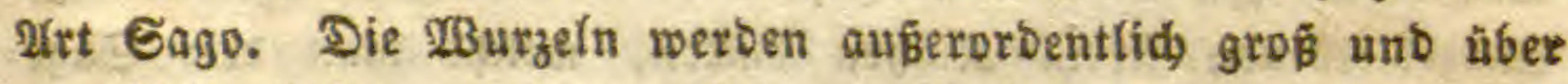
armsbict, lieben troctenen Boben und braudben meiftens ûber

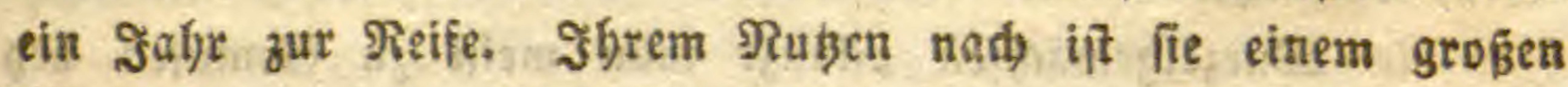
Theil ber americanifdjen Bevülferung Daร, waళ für uns beE Erbapfel ift.

Die Bat aten ober (amoten (Convolvulus bataias)

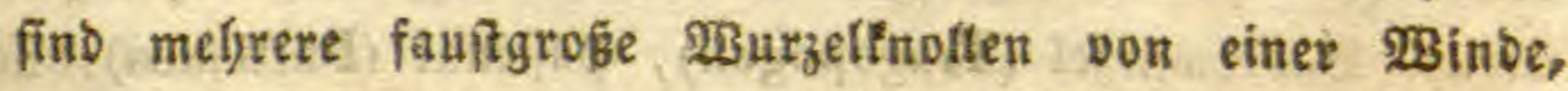

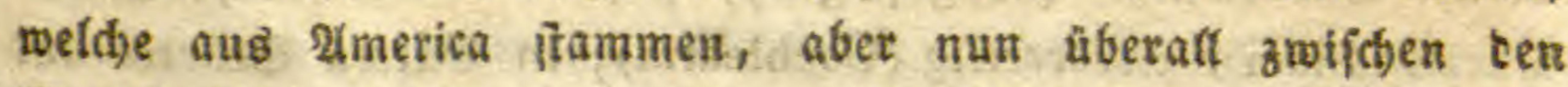
Tुbenbfreifen angebaut werben. Sie fdjmecten, bejonbers ge= röftet, viel beffer als Ëroüpfel, und laben baber aud ben Namen füpe Butaten befonmen: iie fino iebod) fein fo aftge=

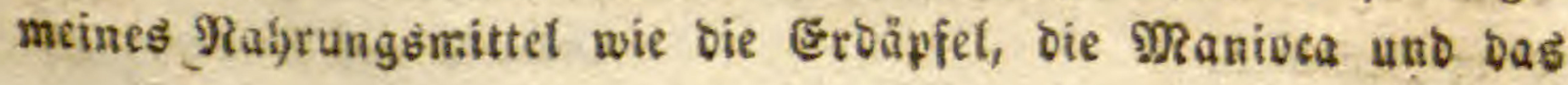




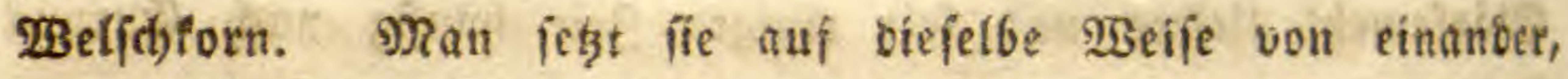
wic Die Erdäpfel.

Die Bataten, welde in $\mathfrak{B}_{\text {Beftinden }}$ gebaut werben, fommen von einer anoern, aber älgntidsen Pfanze (Ipomoea tuberosa).

Die J gnames ober Ya werben melyrere Sdfulf lang uno über armsbict, 20-30 \$funb (d)wer und nod) mely). Sie fidyeiten in Dptrinoien zu Şaufe zu

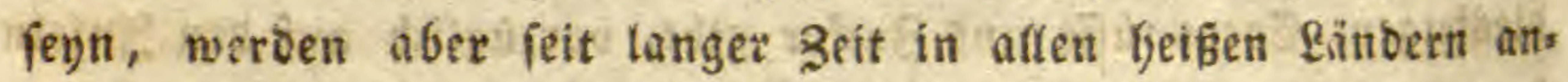
gebaut uno ebenfafts zu Meblipeifen verwenoet. In Suritam werben fie nur $3-4$ qfund folwer; ein $2\left(t e r\right.$ fann aber $10^{*}$ bis 20,000 \$funo liefern, Sie fdymeten gut gefotten uno geröflet, fino leidgt zu verbauen unb bie Sauptnalyrung ber $\Re e g e r$, bey Denen fie bie Steffe Des 9 rrods vertreten. Mant pflanzt fie tidjt weit voin einander, und narty 6 seonaten find fie fidst reif.

Die $\mathfrak{B u r z e l n}$ ber Oca (Oxalis tuberosa) merben aith) alg Nafrungamittel angebaut, aber nur auf ben höbern $B$ ergen von (6)ili, Peru uno Merico.

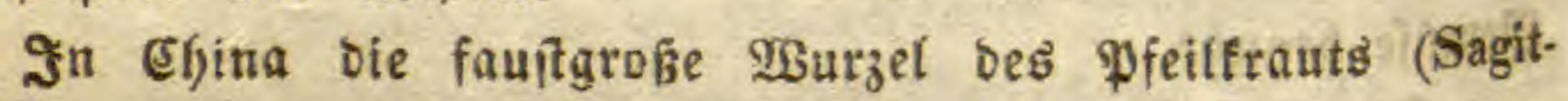

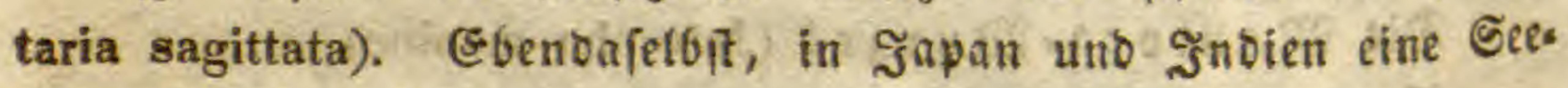
rofe (Die Nymphaea Ppeciosa).

2tuf ben Motuden baut man eine aronartige \$fanze mit Ramen Tacen (Tacea pinnatifida), welde fo grof wirb, wie ein Raib Brod. Eie entlyät zwar einen giftigen Saft, wie bie Manivea. Sf er aber ausgeprebt, fo fann man aus bem jus

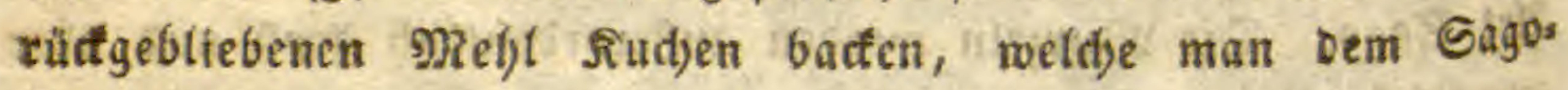
эrod vorzieft.

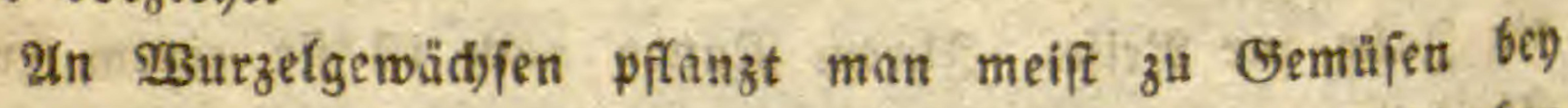
uns trod) in Feloern die Rûben (Brassica rapa), Die Rohtraben

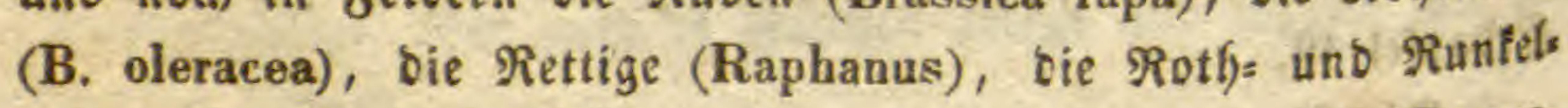
räben (Beta), bie mốren (Daueus), Sajwarzwurzel (Scorzonera), Şaberwurzel (Tragopogon), \$aftinaf (Paftinaca), zudters wurzel (Sium), 刃eerrettig (Cochlearia); in (särten Eetferie unb

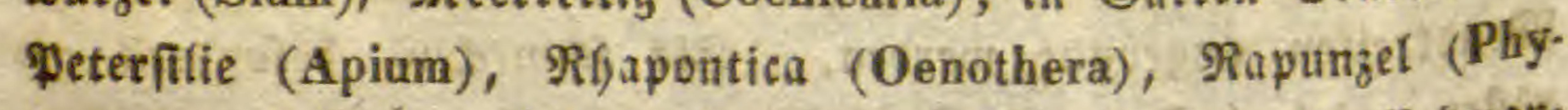
teuma), Erobirnen (Helianthus), Eronüfie (Lathyrus), Eromants betn (Cyperus), Erocaftanien (Bunium), eidjorien uno verídjiles Dere Sutebrfit. 
b. Stengelgemüfe: Spargel, Spopfenleime, Porre.

c. Blattgemüfe: Aof)l, Mangolo, MReloe, Spinat, geerfofit (Crambe).

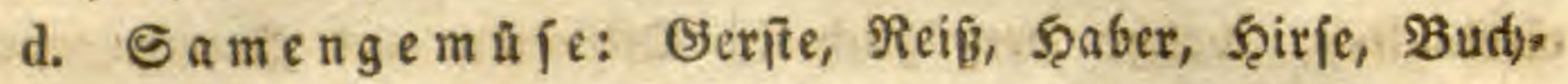
weizen, Bolgnen, Erbjen, Simfen, Supinen, Platt=Erbjen, Eall. bohnen, Duinioa, Eaptanien.

Die હa fanien find befant. Sie werben gefotten uno geröftet gegefien. (E) gibt $\mathfrak{B a ̈ l b e r ~ b a v o n ~ i m ~ g a n z e n ~ f u ̈ b l i d g e n ~}$ Curopa, und in bemfelben Strid, Durd) ganz (fifen binburd).

e. (5) röрş gem âfe: Bofnenbülfen, Erbjenfüljen.

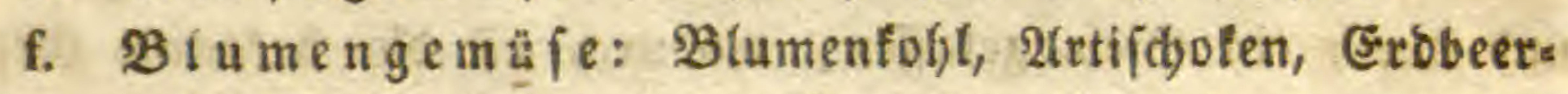
fpinat, Solberblütben, Crotalaria, Coronilla, Dillenia.

g. Frudtgemüie: Sapfel, Birnen, 3metidjen, Firidyen, Rofenbutten, Stürffen, Tomaten, Seibetbeeren, Spolderbeerent.

Der $\mathfrak{B r o d b a u m}$ (Artocarpus ineisa) fteft auf ben Subfees

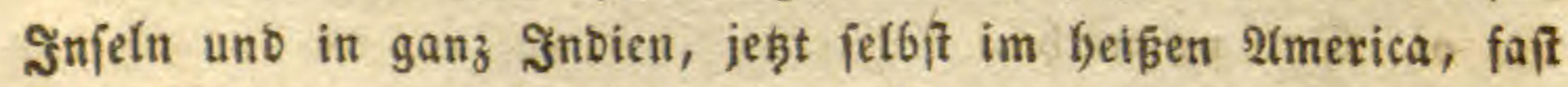
um afle Şütten, uno trägt unmittelbar an ben 2leftent ober am

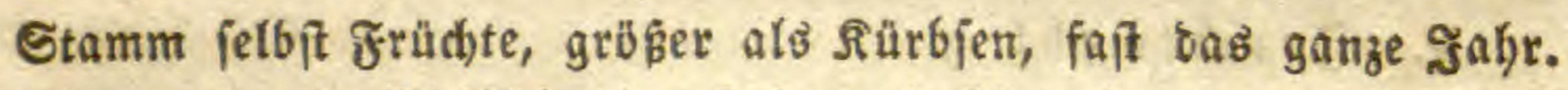
Sie werben in Fleifd)brüly gefo(t)t uno fdmecten bann wie 21rti= fdocten; ober fie werben geröftet uno bann wie Brob gegeffen. Iี Sdyciben geidhnitten unb getroctnet laffen fie fid lang auf= Keben, und fino überf)aupt ein feljr gutes গafjrungsmittel fúr bie arbettende 厄lafte. જon menigen $\mathfrak{B a ̈ u m e n ~ f a n t ~ c i t r e ~ f a m i l i e ~}$

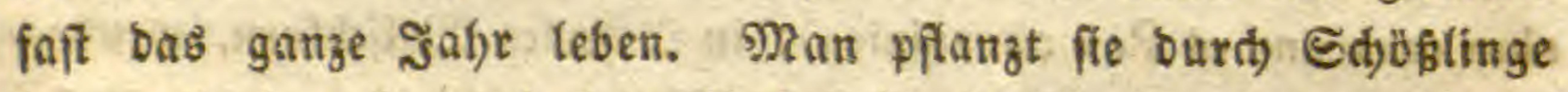
fort und bemubt aud) ben Bait alB Şanf. 2(ud bie Gamen fimecten geröftet wie હajtunien.

\section{Meblpflanzen.}

3u ben Meflipeifen fann man erit bie Stoffe gebraudjen, wann fie zu Staub gemadit uno gefodt worben find; zum 2 rob müf̣en fie gălyren.

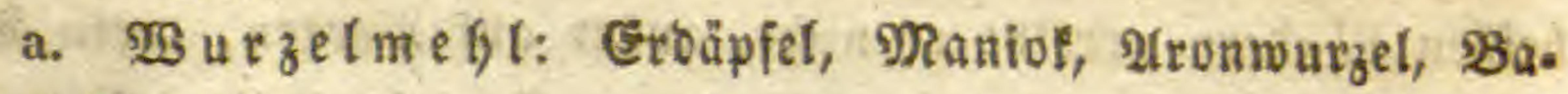
taten, Mracad)a.

Die গ্Baffernuв (Trapa) wäd)st in S̃nbien unb elyina febr bảufig, und fommt ouf bie gärtte afs ein mefliges Rafy. rungsimittel Der 21tmer. 
b. Stengermefl: Sago.

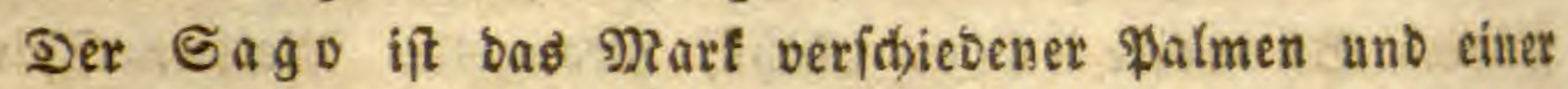
palmenartigen Pflanze, mit Ramen Sird)enpalme (Cycas

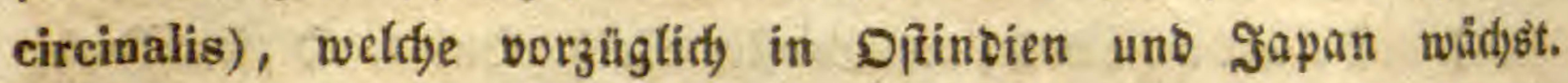
Das Miarf wiro aus bem Stumm genommen, ehe bie frudjt reif ît.

Dic eigentlide Sagopalme (Metroxylon sagus) wirb ebenfafts in Dftindien gezogen. Sie liefert melyzere Centnet 刃art, mus jecod), wie aud bie vorige, umgehauen werben,

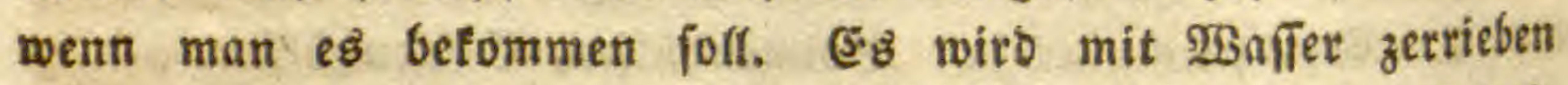
und burd) ein Sieb gelaifien, woburd' es bie befannte Seffalt von Rörnern exhält.

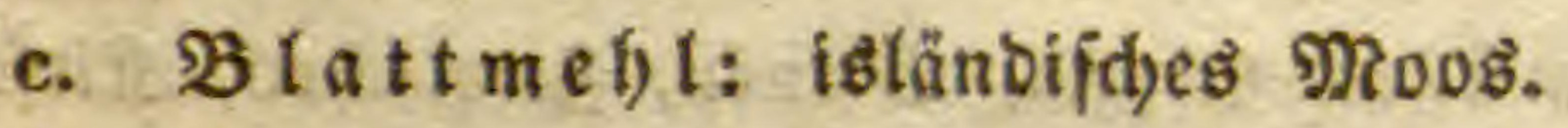

d. Samenmelfl: Roggen, 2Beizen, Dintel, Ëertle,

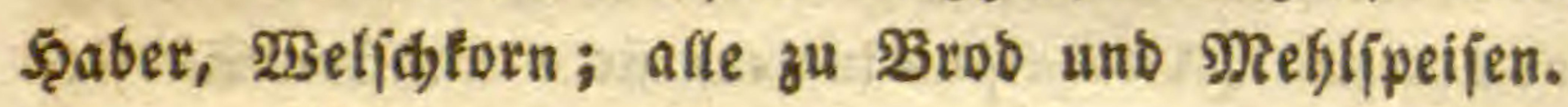

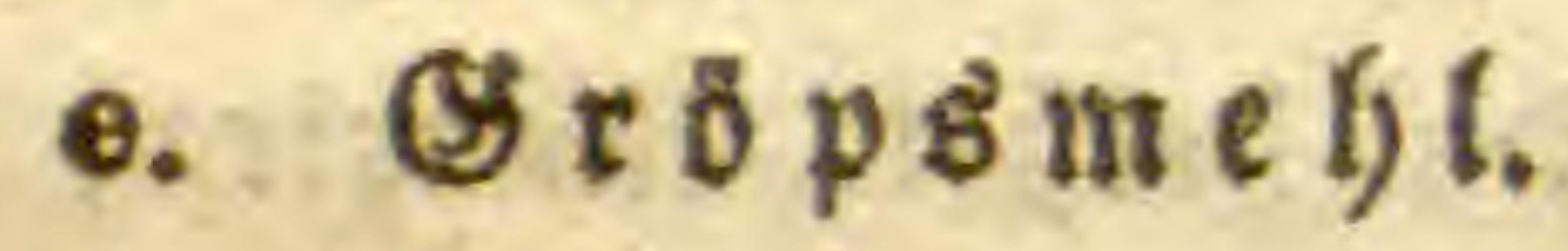

f. $B$ lumentebl.

g. Fruditmebl.

Sebe 3one bat ifre eigenthumlides of et $r$ aibe.

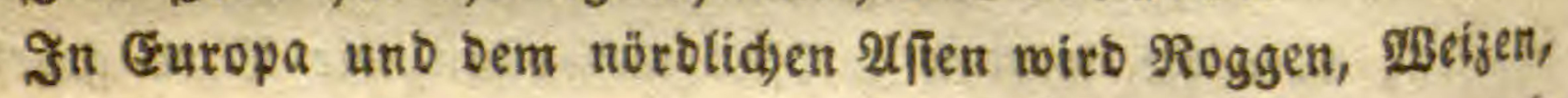
Dinfel, Serfte unb Saber gebaut, im Süben von Europa unb

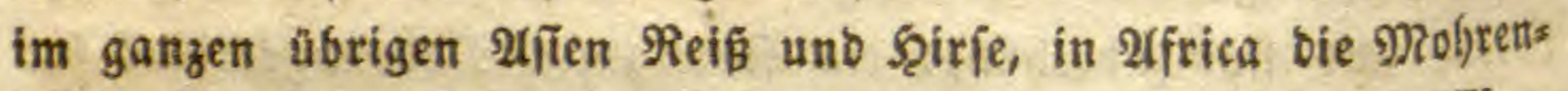
birfe (Sorghum vulgare) und einige andere Seirfenarten (Eleu-

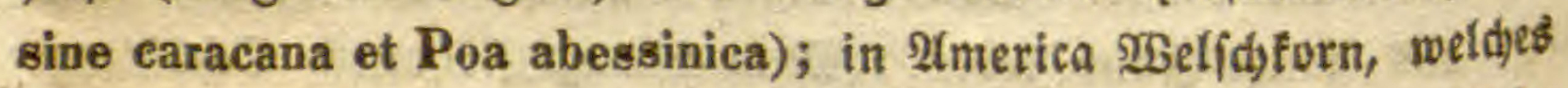
fidb von ba aus nad) ber alten WSelt verbreitet bat. Utret

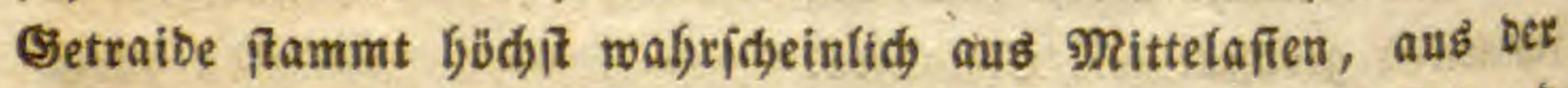

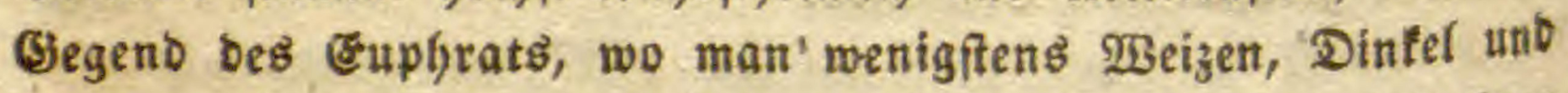

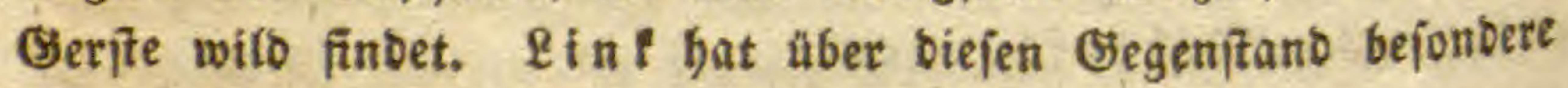
unterjudinugen angeiteftt in feiner Utwelt. 1834.

Dofidon Der Wheizen in wärmern Segenden am beften ges beift, fo fäet man ifyn bod, bis zum $600^{\circ}$ Breite; in gatls heifen eänbern gebeift er nidjt, auper auf 2 ergen, beren $\mathfrak{x} e m$,

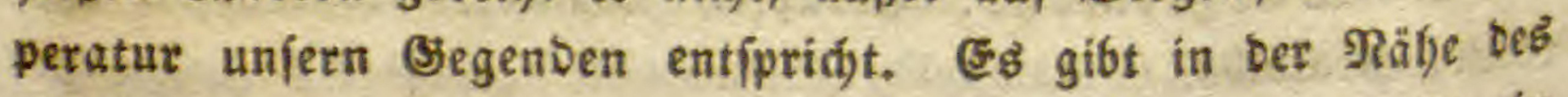

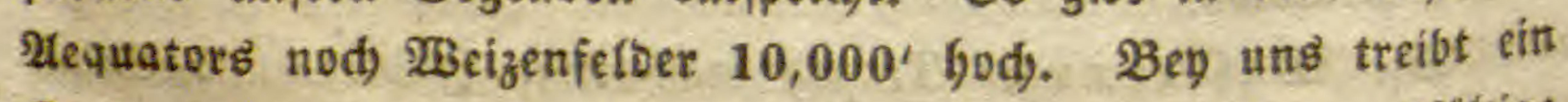
Rorn gewöfnlich nur eine Uehre, uno gibt mitbin nur 6fältig; in Mesico 24 fä́titig. 
Der Dinfel wirb melge in fûblidjen (5)egenden gebaut, stalien und Griedjenlant, uno idjon in ben altepten Beiten.

Bey uns if bas affgemeine Bjetraibe ber Roggen, woraus vorzüglid) SBrod gebarten wirb; aud bie (jerfte gebourt ben nörblidjen Gegenden an, wirb aber faft blö́ zu Bier gebraud)t; ber Saber wädyst auf bem idhled)tern und lältern Boben, balser auf Den Bergen, unb bient zum शferbefutter. Die צlten ideinen ihn nid)t gefant zu haben; fie fütterten bie Pferbe mit (Jerfite.

Die Şirfe (Panicum miliaceum etc.) fommt mefr im füba

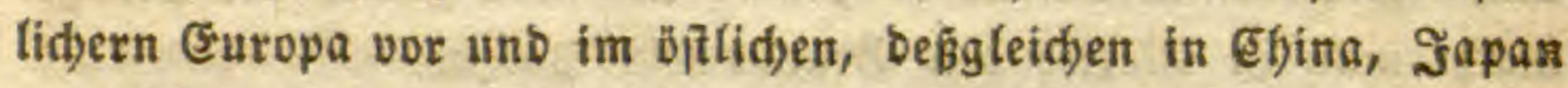
unb Oftintien; fie wirb bloß z̆ Grrüke benug̨t; Der Sd)waben (Feftuca fluitans) in Edblefien und Polen, an Ufern und auf

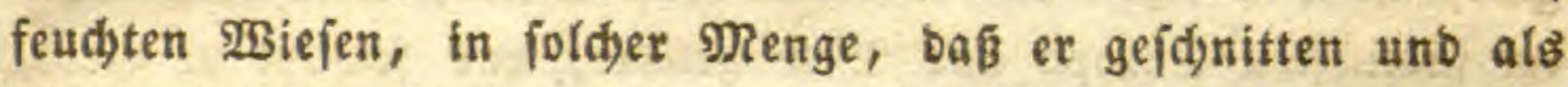
Strübe in ben Scanbel gebrad)t wirb. Wan gibt fidh nidgt bie Mäle, Denjelben anzubauen.

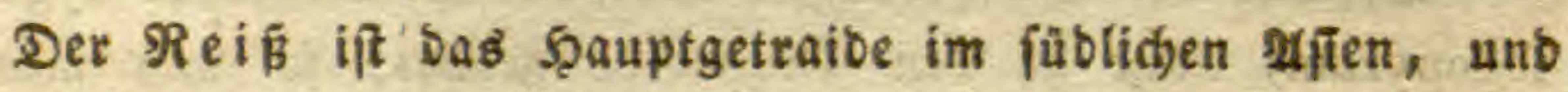
ift von ba nach bem פrittelmeer gewanbert, um bas er nun

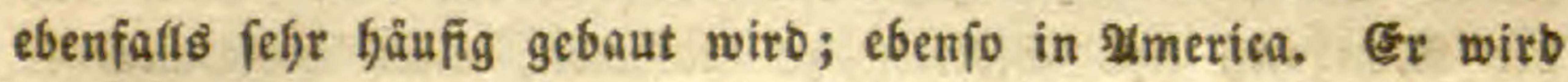

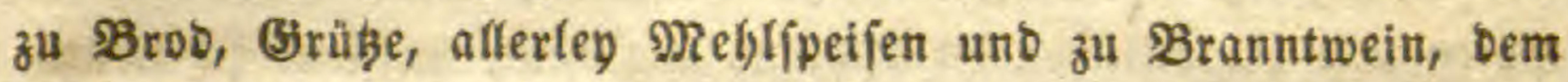

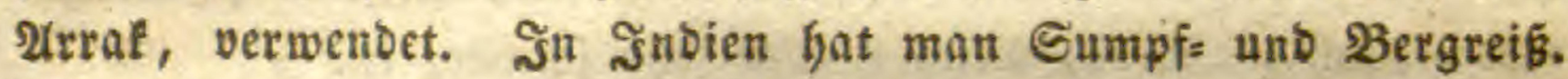
Die zelder fǚ ben exifen werben vertieft, Damit man fie unter

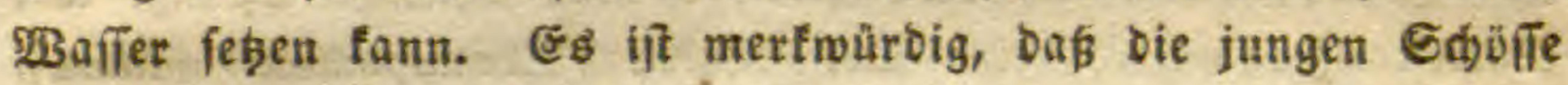
verpflanzt werben. In $3-4$ Monaten ift er reif. Der Bergs reiß wirb wirflid) auf troufenem $\mathfrak{B}$ oben und auf Bergen ges pflanzt, wo man Reute gebvannt hat. Er bringt 40 fwittig, Der Sumpfreís 100fältig.

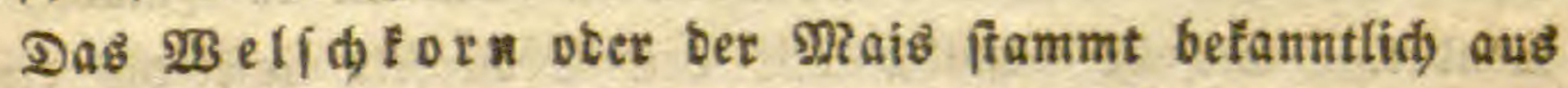
bem heisent 2 merica, wo es fison bey befien Entbectung ange: pflanzt wurbe; e⿱ bringt 200-400fältig; in Ealifornien, unter

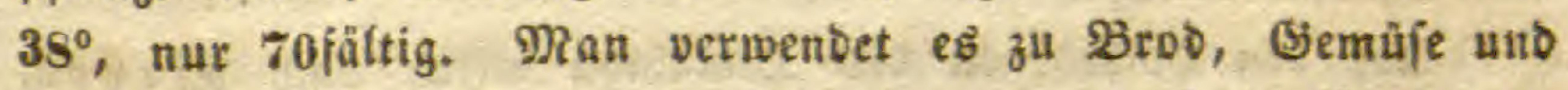
Maîffutter für Rinoviel) und Sdyweine; gegenwärtig fängt man aber an, ben æeizen zum Brobe vorzuzieben. Der 2 nbau biefes nübzlid)en STorns fam bato nad) Europa, 2Africa und शrfien; bey uns aber wirb cอ nut im (üDdid)en Deutid)land mit Erfolg ges

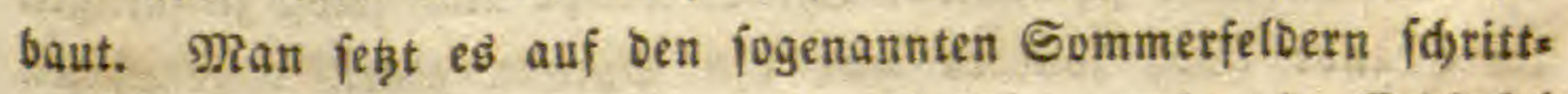
weit yon einanber in Qüber oder fruboen, wie die Erbäpfel 
und Bobnen. Sie dehren find grope fiolben, welthe abge brodgen, abgrzogen und an Gd)nüren unter Die Däd)er zum Stochen aufgerjängt werben. Die s̈b̈ener, viel größer als

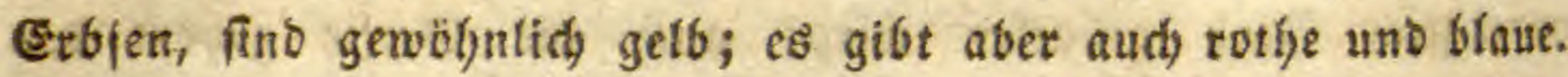

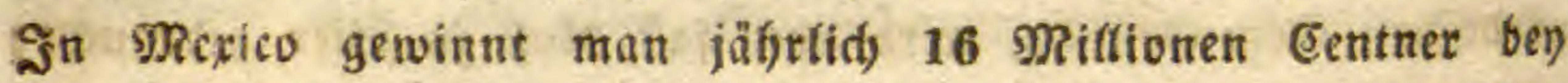
einer $\$$ evëtferung von $5,000,000$, Pommt aljo auf jeben Menfiden 3 Eentner. Es wiro Dafjer viel bem 2 iel) gefüttert, uno feltift

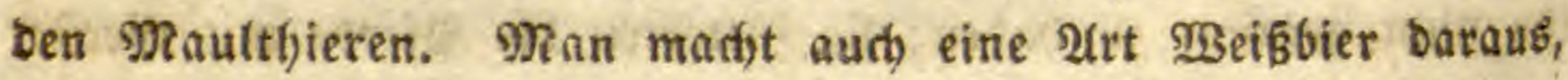

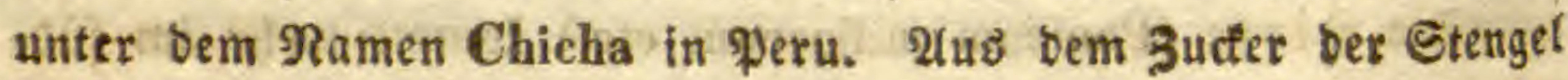
madyt man in Merico ben Branntwein Pulque.

Die Molirenhirfe ober bas Regertorn (Sorghum valgare) if bas eigentlidje (3etraibe von Xfrica, wiro aber aud) Int füblidgften Europa und 2 fien gebaut, und fowohl z̆ $\mathfrak{B}$ tod, säglid) aber zu (Eräge unter bem Ramen Cuscussu, gebraud)t.

Obfdion ber Bud) weizen ober on Şeibelorn (Polygonum fagopyrum) nid)t zu Den (Srasarten gehdrt, fo mú⿱㇒㠯 matt es feinem Sebraudbe nady zum (setraibe redynen. Fr fdeint aus Der Mrongoley und Sibitien zu frammen, witb aber aud) th

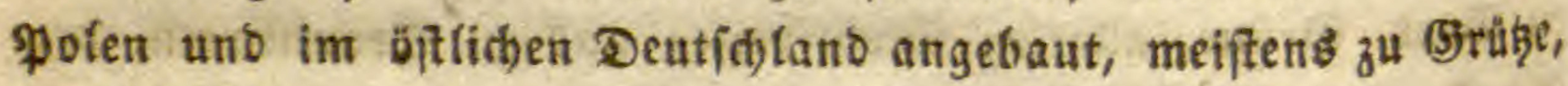
jebod aud zu Brod, weldjes aber febr idjwarz ift.

Jim füblitben America gibt $\mathrm{eb}$ cine åbnlide Pflange mit Ramen Quinoa, eine Urt Melbe (Chenopodium quinoa), weld)es auf ben Şod)ebenen von Peru angebaut wirb, wo fein anberes Setraibe mefre wädgrt. Sie wirb 3-4' god, uno thre

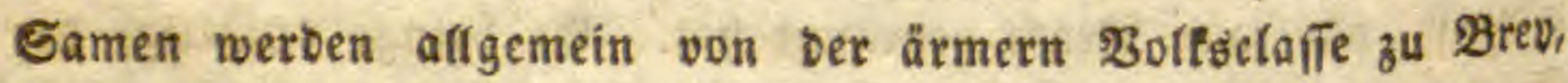
હjocolade, und einer 2 rt Brantwein (Chicha de Quinoa) vet: wentet. Sie ift bajelbit mit ben Erbäpfetn faft bie einzige

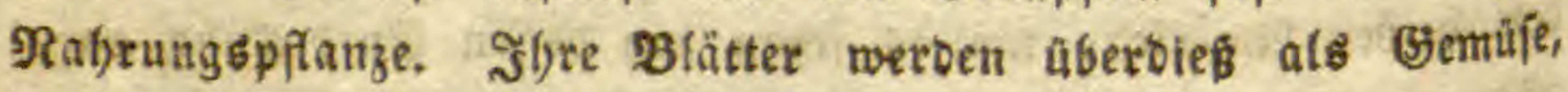
wie Spitat, benub̧t.

Iuf ben Sporbebenen bes Spinalaya wirb, nad) פe eye ber פRel)lo2dmarant (Amarantus fariniferus) zu äfnlidfen 3weffen angebaut.

\section{Se}

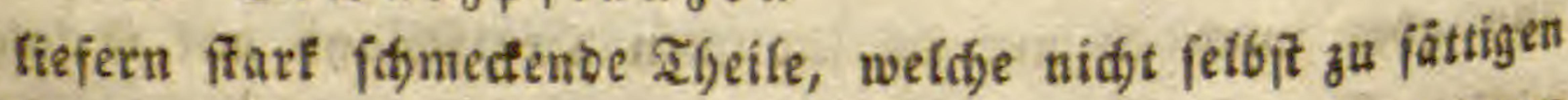
im Stande find, fondern nur ben Epeifen einen angenelumen Geidymad geben. 
a. 2 Burzelgemûtz: Swiebeln, finoblăd, Forre, Sd)as lotten, rothe Rüben (Beta), Sellerie, Rl)apontica (Oenothera),

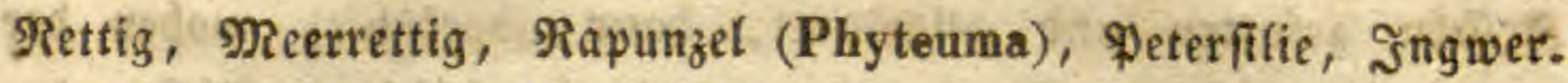

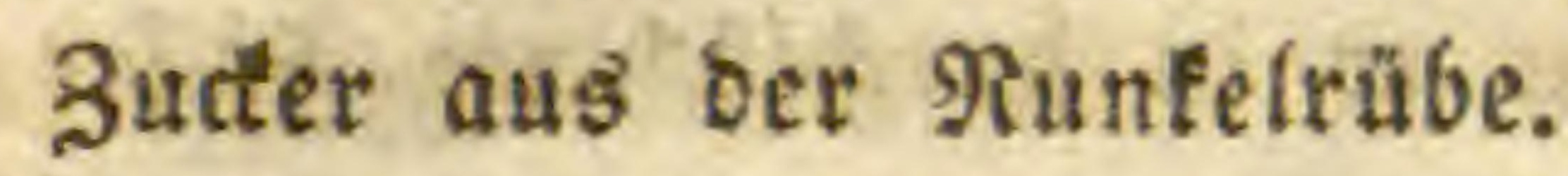

Durd) Die affgemeine Ränberfperre von Rapoleon gezwangen, That man in Europa angefangen, 3 utter aนร $\Re$ u n $f \in \mathcal{l} x$ ủben (Beta) zu mathen. Sie merben baber nun bäufig angepflanzt und an bie fabriten verfauft, weldse aber nur beftegen fönnen, weil mant bie Confumenten zwingt, eine ungeheure Einfuh) zu

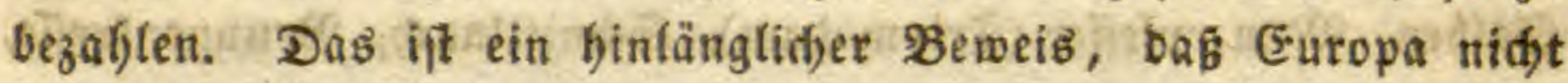
zur Secroorbringung bes 3utters geidhaffen ift.

b. Stengelgewürz: Peterfilie, Rerbel, Majoran, $\mathfrak{E a}_{\text {a }}$ venbel, Dragun (Artemisia dracunculus), Bofnenfraut (Satureia), Baftien, Ifymian, Y) Sop, Bimmet, Sucter.

Das 3 u terrofir frammt aus Ditindien uno tam von bort nad) 2 merica, wo fid) groß̈e Pfanzungen mit vielen Negern finben. Es wächst auf feudstem Boben, gebeibt aber in ber foisen sone nud $6000^{-}$yod. ORan pflanzt es als Etectlinge,

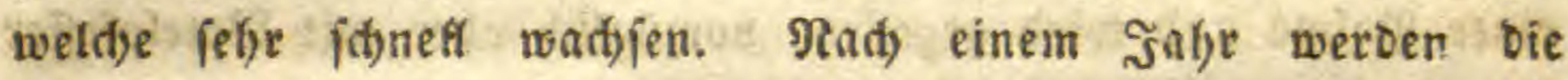
Spalme abgeidnitten uno burd) eine praidine gequetidst. Die

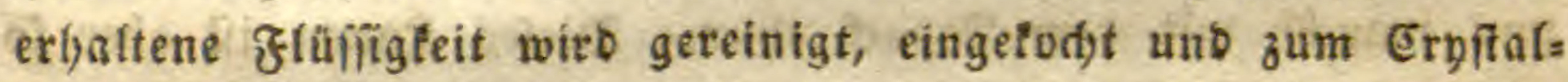
tifieren bingeifeftt. Die 3udferpflanzung bejdäftiget befanntlid, Miflionen von Menfdsen, und tit wohl einer ber widjtigiten (5egemptante bes şandets.

जิ Surinam enthätt eine 3uterpflanzung gewöfuntid) 5 bis 600 Mrorgen, in Duabrate abgetfeift, worinn man bie (djulfs tange Stectlinge in graben uno parafteten Reifen febst, und zwar zur Regenzeit. Die Sdjüfle, weldye aus ben Rnoten fonts

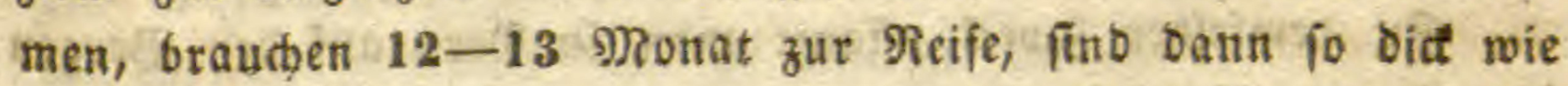
eine Flöte uno getb; ber ganze Stodt 6 -10 bods. Die Ectas ven milfen fie oft bebacten, um bas Unifraut wegzuifjaffen. פRandhnal find 400 Ectaven nüthig, und biefe fönten 20,000 bis 24,000 Rouíbor topten. Das gefdnittene Rofje fómmt auf eine Măble und wirb bafelbft Durd) 3 eiferne $\mathfrak{B a l}$ en gis trieben, wobey oft eitt Finger bes Eclaven gefaft wirb, fo bak mon augenblidtid ter צrm mit eitrem Beil abgaten múb. 
WBenn einer ben Saft loftete, nurbe ifhm früher nidyt felten bie sunge auggerifier. Der Saft wirb nad) uno nad) in 5 fupfernen Reffe'n gefotten und gefdüumt, bant abgefithlt, wobey bet Sucter fich abjeb̧t. Dann formt er in Durdblbdberte Fäffer, bat mit bie Melaffe abtropft. So wirb er nach Europa gejdidt, um raffintert unb geformt zu werben. शan madst befantlid aud) Rbum bavon, uno aus bem Sdiaum einen fdjled)ten Brantst= wein für Die Reger, weldyer Rill bevil (Teufelstod) Geíst.

c. B fat $\mathrm{g}$ e w a $\mathfrak{r} z$ : Pfeffertraut (Lepidium latifolium), Galbey, Mauerpfeffer (Tripmabam), Sdgnittlaud, Brunnenfrefie, \&öffelfraut.

Bum Rauen : Betel, zabadt, Coca.

Sum Raudben: זabact.

d. Samengemuี Fentyel, Irnis.

ฌuв่catnu.

3u Del: Rübjamen, Mofn, Şanf, WBalnuE, Dliven.

Die Betel $n$ u $B$ (Areea catechu) wäd)st in Oltinbient auf einer Patme und wiro gegeffen, vorzüglid) aber mit Betelpfeffer uno Ralf zu einer Art Teig gemad)t uno gefaut, wie eg bey) uns mandise mit bem Tabad thun. Diejes seauen ift aber fo

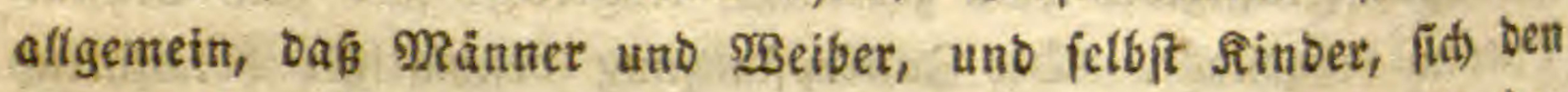
ganjen Iag bamit bef̧äftigen. Der Baum wirb bafer in ber Rähe Der Şäufer gepflanzt, und bie Näife fino ber Oegenftant eines ausgedefnten Santels.

Hebereinlimmeno Damit if ber Mnbau bes Betefpfefs fer $s$ (Piper betie), weldher, wie unfere Bohnen, faft von jeber gamilie gepflanzt wirb, befonders auf wafferreidgem Boben.

3u bemfelben 3 wert pflanzt man in Peru auf ben Bergen bie Coca (Erythroxylum coca), beren $\mathfrak{B l a ̈ t t e r ~ v o n ~ j e b e r m a n ~}$ ben gatrzen Tay gelaut werben. Es ift ein Straud wie unjer Ed)warzoorn, von Dent bie Blatter abgeftreift werben, wett et 4-5 Jafre alt ift. Sie fommen im Scandel burdy ganz peru.

Su blefen Pfanzen, weldye blof um bes Reizes miffen ober 3um Beitvertreib genolien werden, gefiört aud ber Iubad, welden oie 2(mericaner fidon bor ber Entbedung geraudit haben. 
Er wirb ungefäbr wie Bofnen angepflanzt, felbit bey uns, unb if ber Begenftand cines ausgebefnten (sewerbs.

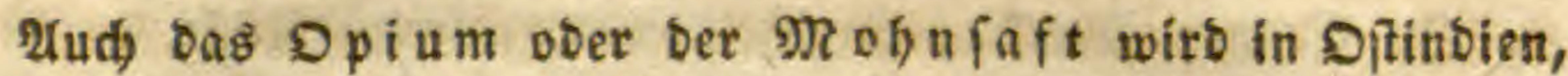
unb bejonbers in Efina, theits gegeffen, theils geraudt, und beşatb ber Drohn aftgemein angepflanzt, auf Felbern, weldie

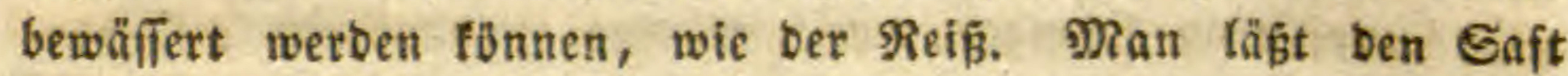
Durd) Nabelfitide aus ber Eapfel fitfern und an ber Sonne trocts nen; bann formt man ifhn itt suchen 4 " grob, witelt ihn in Mohnblätter und fdjlägt ifa in Fifiten zu 133 Pfunb, welde 1400 Reidsitfjafer foften, wenn bas opium ganz fein ift. Dex

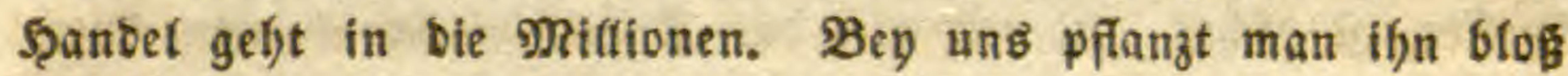
um bes guten Deles wiffen, weil ber Saft wenig Dpium liefert.

In Delgewäd)

werben bey unछ gepfianzt $\Re$ å $\$$ (Brassica rapa biennis et annua); $\mathbb{E}$ wat (Brassica napus biennis et anuua); Dotte (Myagrum sativum); Rein, MRofhn, Şanf.

Xud) Der $\Re$ u в

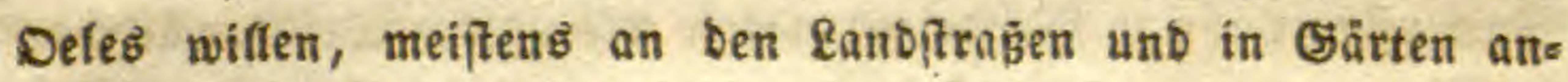
gepflanzt: Denn Das Effen bes Rerns bauert nur fo lang bie

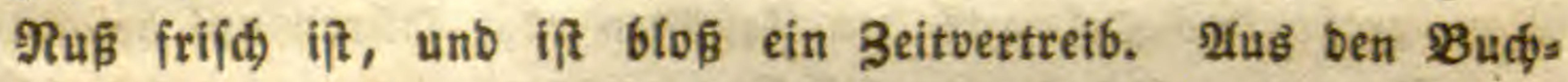
nůfien wird befanntlid, ebenfalts etwas Del gemonnen.

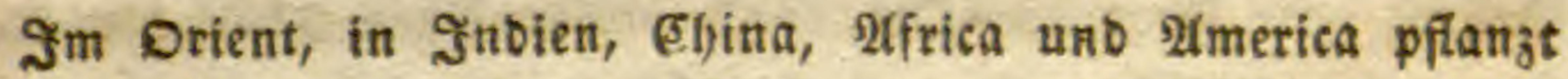
man ben $\mathfrak{B}$ u nberbaum (Ricinus) um bas Ricinus- ober Eaftor:Del aus ben Samen zu fod)en ober zu prefien. Mran braudbt bas Del an bie Epeifen und ats odrzney. Bey uns ftegt Die शfanze bló tn Eärten.

Şăfiger aber if in Diftindien, Uegypten and ber Tủrfeg

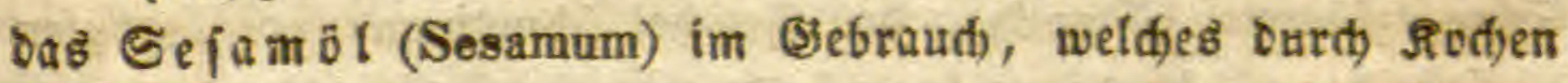
Der Samen gewonnent uno zu Speifen verwentet wirb, fo wie

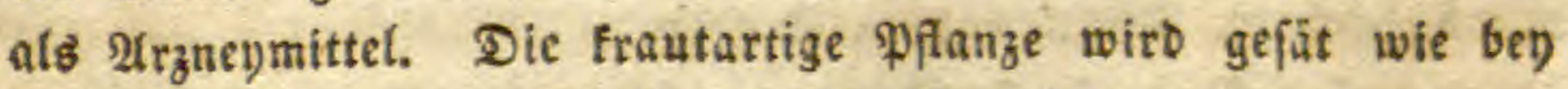

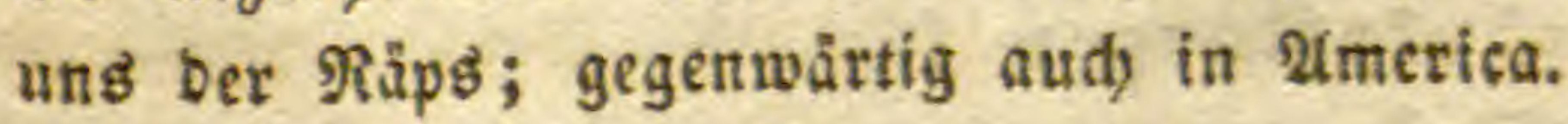

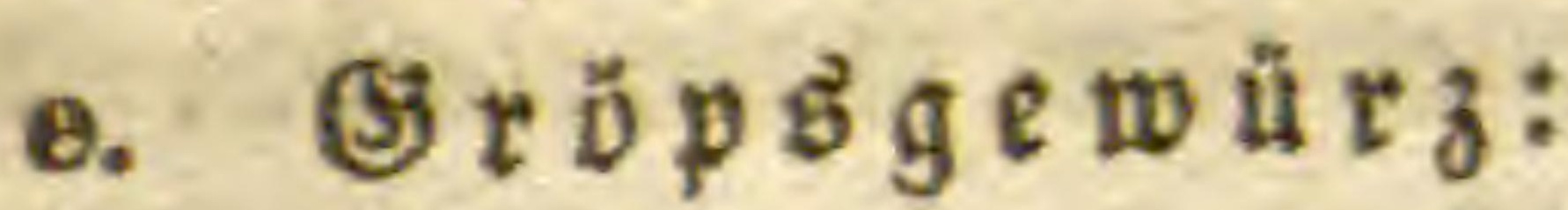

Muscatblütlye, Sanifle, ipanif́cer Pfffer (Capsieum).

f. Blumengewả rz:

Eappern, türfifde strefie (Tropaeolum), Sopfen, Safran, Sonig, Eavendel. 


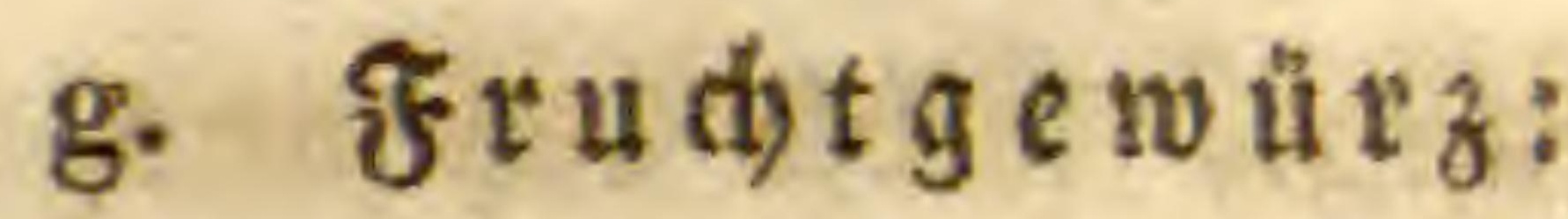

TBady)yotberbeeren, Nägelein, Pfeffer, Cubeben (Piper). 3u Enlat: Gurlen, Preifelbecten, unteife Rüfe.

Der Pfeffer (Piper nigrum) if vorzüglid) in Matabar zu Şaule, wirb aber in ganz Difintien gepflanzt, ungefälyt wie unfer Şopfen an Stangen, weil ex eine angbaucente und ralls Fenbe Pflanze ift. Die \$fefferfelber find auf 2 (nfybgen, Drey bis vier Störte tragen jährtid) 1 Pfuno Beeren, weldse in 5 Monaten reif werben. Sie find roth, werben aber benm 2tubbreiten und Trodtuen auf Dem Boben fdwwarz. Der meipe Pfeffer ift nidts anderes als bas forn, nadbem man burd) Făulniß̄ in beträgt aud) viele Miftionen $\mathfrak{P}$ fund.

3u Del:

Sัn Den märmern Segenden von Europa uno im Morgen= lanbe ift bie vorzüglidylte Delpilanze ber Delbaum (Olea). Er gebeift bis 2lix, füblid) von Byon, uno aud in ber Sirym.

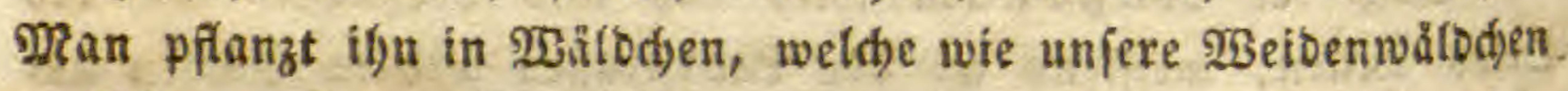
aแรfefyen. Gegenwärtig findet man if)n audh häufig in 2tmerica. Man prefit bas Del aus ben Früchten ober Dliven auf befors

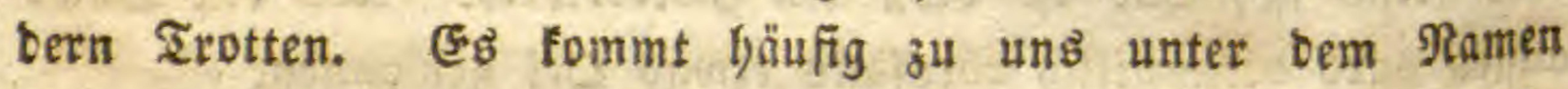
Baum, ober Provencer=Del, uno bitbet einen Theil Des Reid)= thums ber füblidgen (segenden. Hebrigens werben aud bie slie ven als eine 21rt Semür ober Salat gegefien.

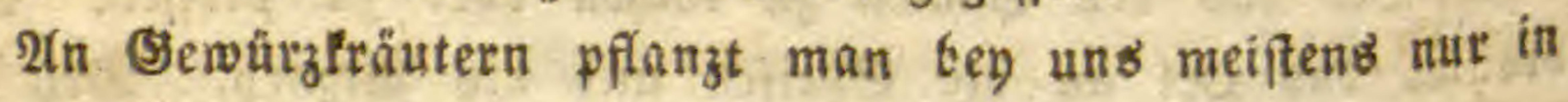
Eårten, bin uno wieber aud) in gangen felbern,

Den 2 Inis (Pimpinella), Den Corianber, Den Rümmel, ben Sdgwarztummel (Nigella), Den Fendbel (Anethum), ben Şopfen in bejonbern fetbern an fangen Stangen, vorzäglid) in $\$ B$ bु)ment ben rabat am Rgein und in Ungarn.

5. Setränfpflanzen

liefern foldye Stoffe, woraub entweber unmittelbar burb

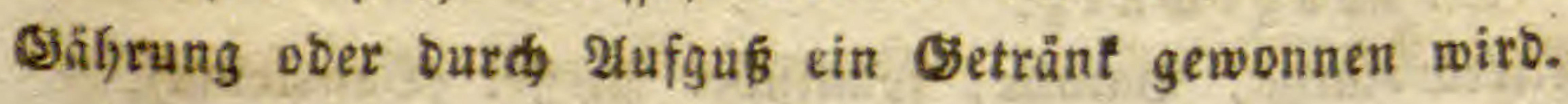

a. $2 \mathbb{B}$ u $\mathrm{z}_{z} \mathrm{l}_{\text {get }} \mathrm{r}$ inf :

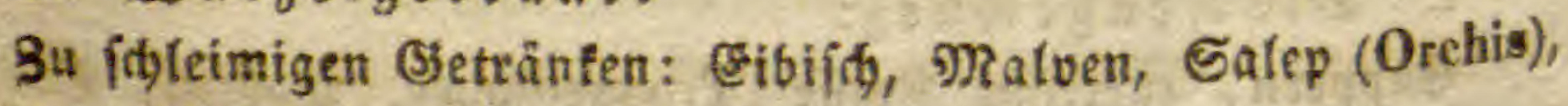
Dueden, Sübrolz. 
3u ciner थrt Eaffee: Eidyorien, Scorzonere, M?b̆hten.

3u Branntwein: Erbäpel, Manioc.

b. Stengelgetränf:

Buteribafier, Birlenjaft, Mild bes Ruhbaums.

3น Rum: 3uderrohr.

รัก Suีb-24merica gewinnt man ben pafmmein aus beg Rỏnigzpalme (Cocos butyracea), aber nid)t aแส Der ßtûthene idfeibe, ionbern aus Dem Stamm felbit, in Den man ein fpannes tiefes Iody (d)neibet, worinn fid) ber Saft fammelt nno fid fait unmittelbar in Bein verwandelt.

c. $\mathfrak{B}$ lat $\mathrm{tget}$ rản $\mathrm{P}$ :

gewöfnlidh zu Ifyee: Thee, Mate ober paraguay=:Thee (Hex), Münze, Melifie.

Der Iheeftraud) ift ein (Eigentfum von (Ehina, weldjes

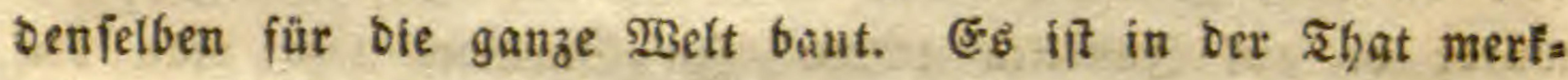
würbig, bas man nod) nie redjt ernithaft veríndt bat, biefe Pflanze in anbern 2 Belttfeifen anzufiedetn. Er wäd)Bt auf $B e r g e n$ bis zum 40. $\Re .8$. Der befannte Theenufgur ift in હbina feit ben älteiten Beiten im (\$ebraud), uno bient afs aflgemeines Sctränt. Su ung ift er erit vor einigen sabrlunberten gea fommen, und wirb aud) gegenwärtig grëśtentheils nur in Fa. milien von Stande getrunfen, weil er ood mefyr ein blofer Beitvertreib iłt, als ein wirflidyes (Betränf. Man ziel)t Die

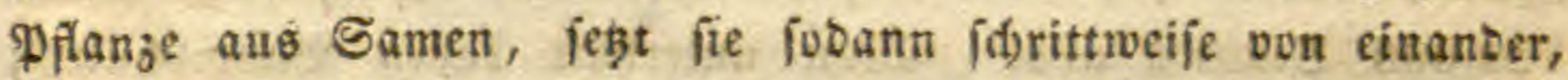
ftubst file ab, Damit fie mefre 3weige uno Blätter treibe, uno

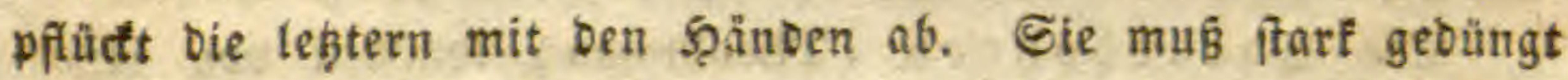
werben. Die Bfätter befommen ibren Ģerud und Eefdymact erit ourd) bas röften, fapt wie ber (affee, was auf erbibtem Bled) geidieht. Daburd) entizelft Der grüne Thee. Der idwarze wirb von berjetben शfanze gemadst, indem man Dämpfe burtí

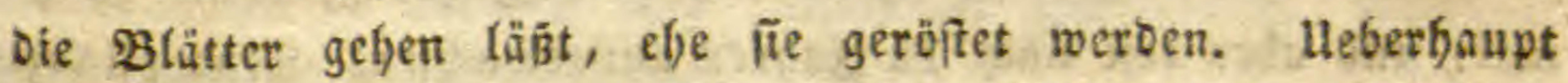
fommen affe Theearten uur pon einer Pfanzengattung (Thea chinensis). Der 5andel gefts in tie Sunderte von MRiflionen.

d. Samengetränf:

Pfanzenmild, Mandeln, (Evcosis:Mild).

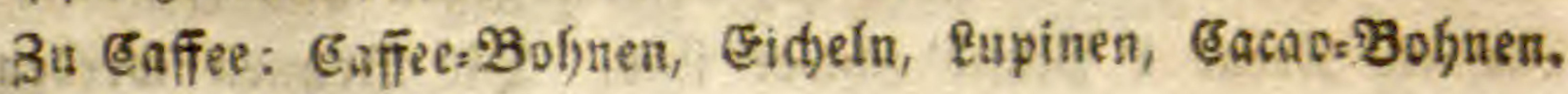


Bu Bier: Berfte, BBeizetr.

3u Branntwein: Rorn, Reis (2trrâ).

Die Eaffeebor) nen (Coffea) fommen von einem fleitten Baum in S(rabien, wo man ifrn im Sdhatten anberer Bärme

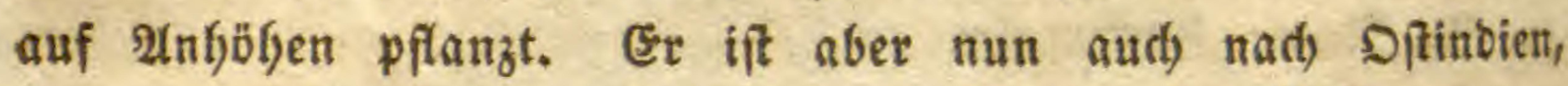
2tmerica uno auf tie Süb/ee übergegangen. Die Bofnen wers ben gefät uno bann Rlafter weit von eiranber gefę̧t. Rad

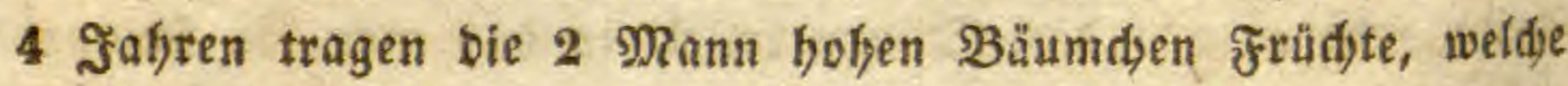
man 3 mal abnelgmen tann. Die Bofnen ftetfen zu zweyen in vothen Becren, wie Rirfden, von welden fid) bas gleifd) leidts abnehymen tăst. Der Caffee wirb nirgends fo gut wie in 2ras bien, wo er vom Meer entfernt auf Şügefn wädst. Der Đies braud) bes Eaffees fam $\mathbf{1 5 5 4}$ aus 2trabien nad) Eonftantinopel, von ba nad) Ştalien, 1643 nad) Paris. Suerit angepplanzt murbe er auf Samaica 1728. Sัn Surinam läpt man ben

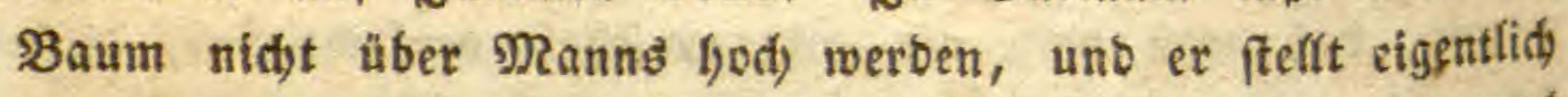
nur einen Straud) vor. (Er trägt zmenmal uno liefert jebeb̉mal

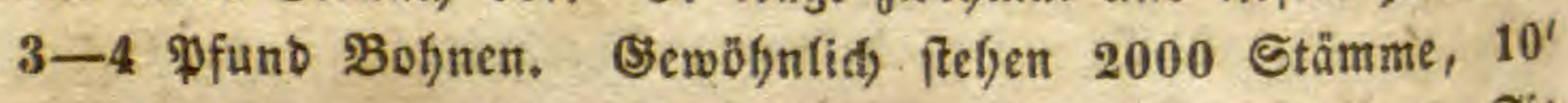
von einanber, in einem Umfang von einen 2 Waffergraben. Sic tragen nad) 3 Sabren, find ausgemadblen nad 6 und teben

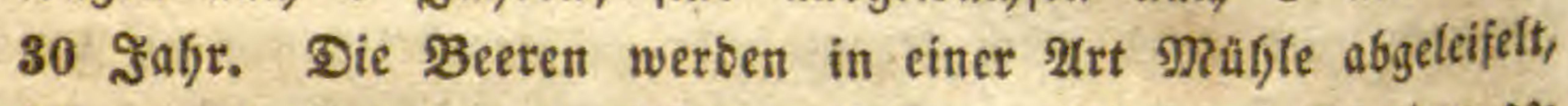
fobann bie Esibpe getroctnet, nad)her in fjolzernen Etanben ges ftósen, bamit fids bie Bofmen trenten. Man fülynt itfer 120,000 Eentner aus. Man unterfält bobey Baumidulen; aud) feģt man Bananen bazwifdhen, um Sdjatten zu haben.

Die Eacaobofnen (Theobroma) fommen von eitrem

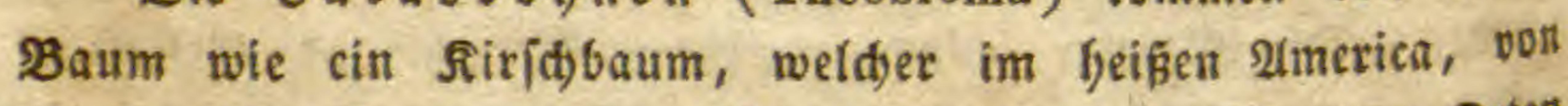
Merico bis (suyana; und auf ben Xntiflen, an fdyattigen orten angepflanzt wirb. Man feß̧t beß̧halb Manioca uno pifang bas zwifd)en. So tragen fie fdyon nach orey Sabren jäfrelid) zwens mal: fino aber erft nach $\mathbf{1 2}$ Saljren ausgewadjfen. Man pflatizt bie serne zuerit in Baumfdulen, uno feģt fie bann 12 ङ von einanber. Die Bohren jecter zu $30-40$ in einer gurfen: artigen, getben frudt, gröper alb eine Birne, 6 3oft lang unb 3 bict. Jंeber Bum gibt auf eimmal gegen 300 frithte, wos oen die fierne 1 Yfunb fofwer finb. Die Bolgnen werbent mit 
ben SQünbent aus ber frud)t gemadit, gereinigt, getrodtuct, in Tonnen gefdlagen, verfanbt und bann in ben befaunten હfor colat=\{eig verwanbelt. Man braudst babey weniger Sclaven ats bey irgend einer anbern Pflanzung, uno baber fit ber $\mathfrak{B o r}$. theil größ̈er.

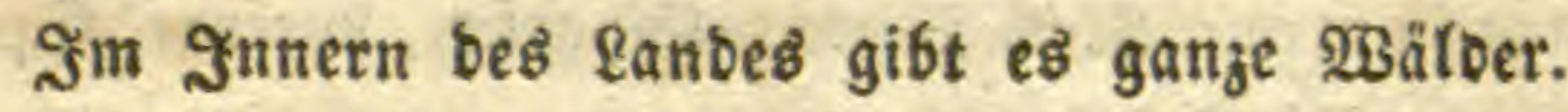

e. Eิrüpşgetränf:

Eitronen, Pomeranzen.

f. $\mathfrak{B}$ (umengetrånf:

Efamiflen, Şolber, Sdjafgarbe, Sdjwargborn.

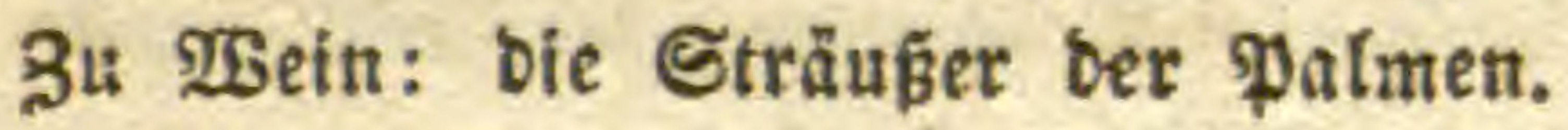

3u ఇeth: Şonig.

Palmwein wirb aus veridiebenten Palnten gemoltmen, oorzunglid) aber aแв ber eigentlid) fogenantuten 23einpalme (Borassus) in Ditinbien. Nan reibt bie B(üt)enidyeibe Der Gamen= pflanze, elye fie gebffnet ift, fdneibet 3 Tage Darauf bie Spize ab und bängt eitten Topf baran, in welden ser Saft wäbrent

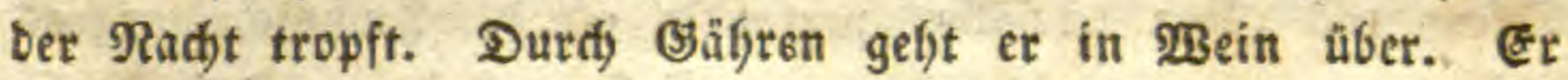
Geift Palmyra = ober Brabwein.

g. Frudgetränf:

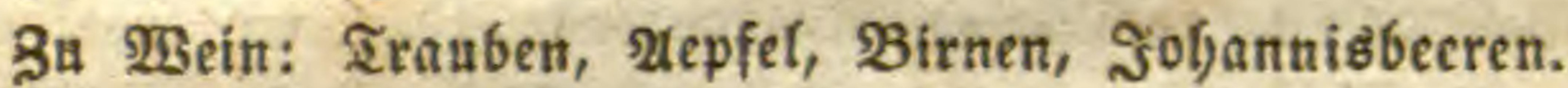

Su Branntwein: Siridjen, 3wetiden.

3u Syrup: Şimbeerea

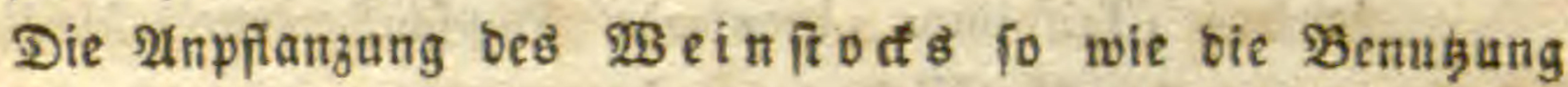
ber Irauben ift alfgemein befant. $\mathfrak{R a n}$ ist fie frifh) und ges trodket als भifinen und Corintfen; affgemein aber wirb baraus gemadft, unb aub biejem Efīig; aus ben Treftern unb ber Şefe Branntweit. Die Tatrfen madjen Traubenumb. In

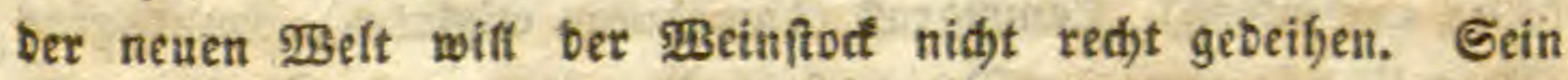

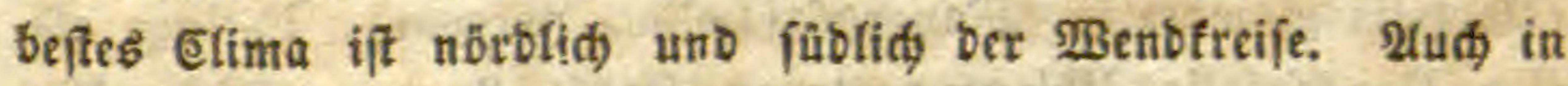
बGina gibt es wenig \$einbau.

\section{B. Futterpflanzen}

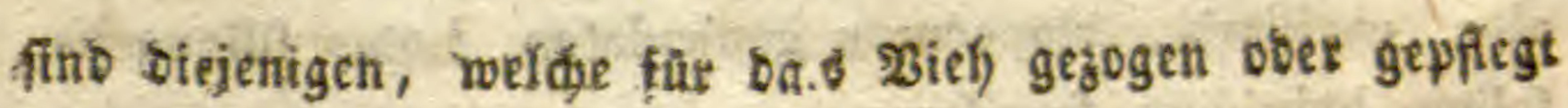
troerben.

Ofe n' है allg. Maturg. II. Botanif I. 
a. গু̧ bitrtett. इiegen.

b. Stengelfutter: Ơras, Difteln, Sproffen fût bie

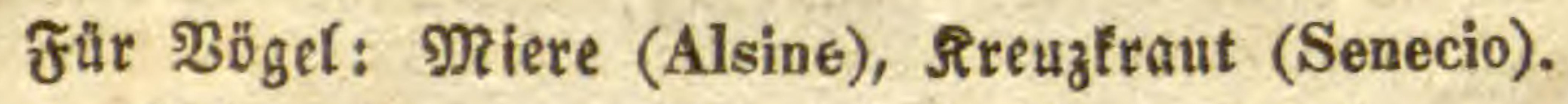

c. Blattfutter: Silee, Widten, Epparjett, \&ucerne, Spath,

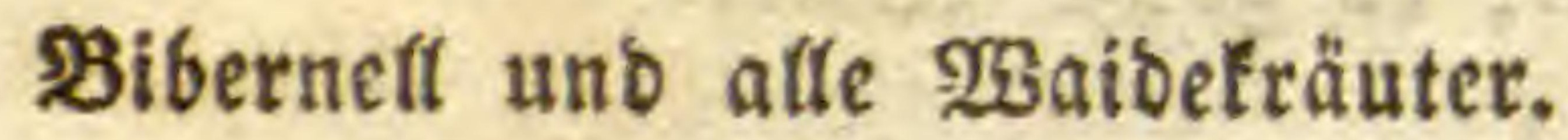

d. Samenfutter: Şaber, SBelídturn, Einjer.

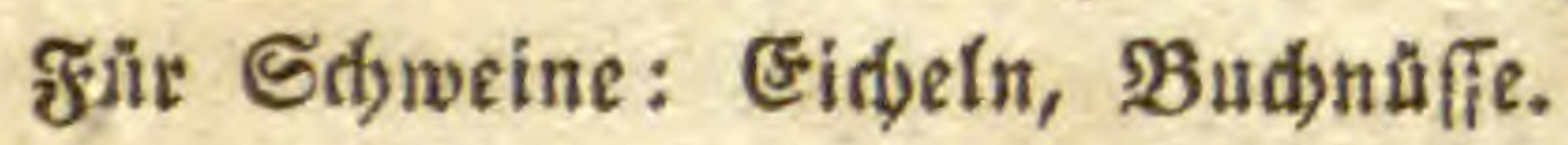

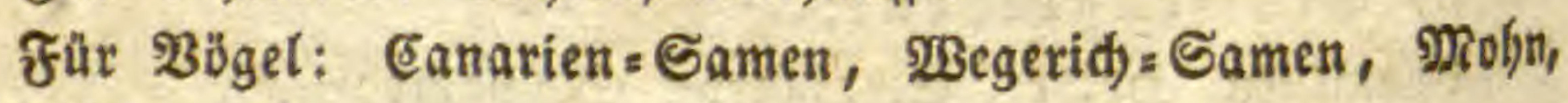
Şanf, Tannenfomen.

e. (E) $r \ddot{p}$ \&f utter:

1. $\mathfrak{B}$ tumenfutter: Rleefeu.

g. Frud)tfutter: Rürbjen, 2tepfel, Şolzäpfel, Bitnen, Szotzbitnen, 3metidjen, S(bleben.

2uf feuchtem und gutem Boben fino bie beften rsiejents pflanzen: Şabergrab (Avena elatior), Soorobaber (A. flavescens),

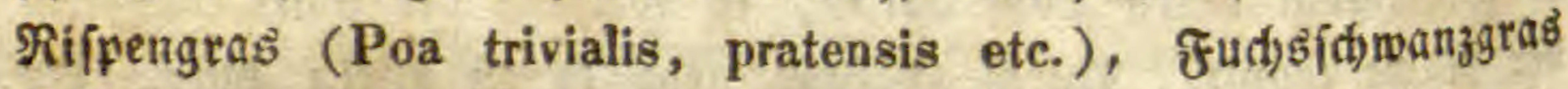
(Alopecurus pratensis), Ed)mingel (Feftuca fluitans, elatior, pratensis), Rudigras (Anthoxanthum), Fiorin=(5ras (Agroftis alba), Strauf=-Sras (A. capillaris), Roggengerfite (Hordeum fecalinum), Eiefdigras (Phleum pratense), Roģgras (Holeus odoratus), \$erls graß (Melica nutans),

Itpenflee (Trifolium alpestre), Şopfen\&ucerne (Medicago lupulina), Bogetwitfe (Vicia cracca).

2(uf feudstem, thonigem, alfo weniger frudbtbarem 30 ben finઠ bie beffern Frräuter: Juttertrefpe (Bromus giganteus), roljts artigcs Canarien=(S)as (Phalaris arundinacea), Rajenjammiéle (Aira caefpitosa), Rammgras (Cynosurus cristatus), ร̧untต̣gta (Dactylis glomerata), Rangras (Lolium perenne), Feftuca ela. tior, Poa trivialis, Phleum pratense, Şopfene\&ucerne, Erobeertlee. IUf Sumpfboden fteht meiftens Riebgras; zu ben befiern gehören: Phalaris arundinacea, Poa aquatica, Feftuca fluitans, Aira aquatica, caespitosa, Bromus giganteus, Agrostis palustris, alba, capillaris, Alopecurus geniculatus, Lotus filiquosus. Trifolium hybridum, fragiferum. 


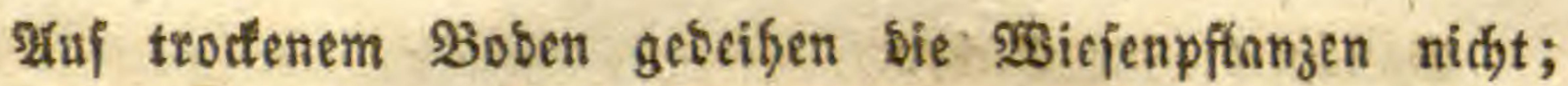
inbefien nod): Poa anna, Briza media, Avena elatior, flavescens, Alopecurus pratensis, Holeus lanatus, Poa pratensis, Feftuca elatior, Anthoxanthum odoratum, Agrostis capillaris, Trifolium alpestre, repens, Medicago lupulina, Vicia cracca, dumetorum, Lathyrus pratensis, Thymus serpyllum.

2taf trodtenem, fandigem Boben gebeilfen nod): Poa bulbosa, Bromus mollis, inermis, Festuca ovina, duriuscula, rubra, Dactylis glomerata, Anthoxanthum odoratum, Avena flavescens, Holcus lanatus, mollis, Cynosurus caeruleus, Melica ciliata, Poa annua, Trifolium repens.

\section{For îtpfla}

tiefern Brenn= unb $\mathfrak{B a u f o f z , ~ S t r e u , ~ B a n t , ~ B a n t , ~ R a i f e , ~}$

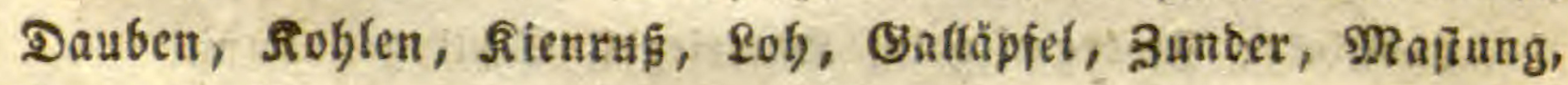
Sarz, Pech.

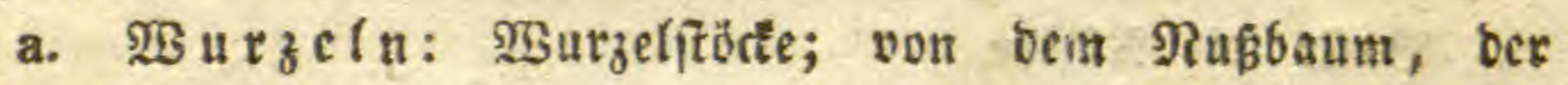
Birle, Erle, פappel, Sireuzborn betontmt man Mafern.

b. Etengel:

Die Bäume liefern $\mathfrak{B a u h o f}$ : Ianuc, fidfte, Fofre,

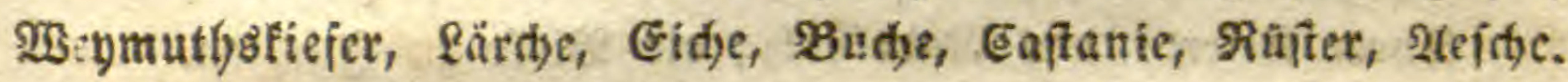

Brennfof

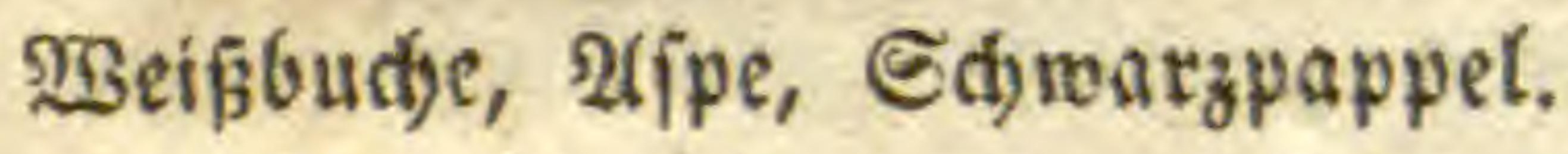

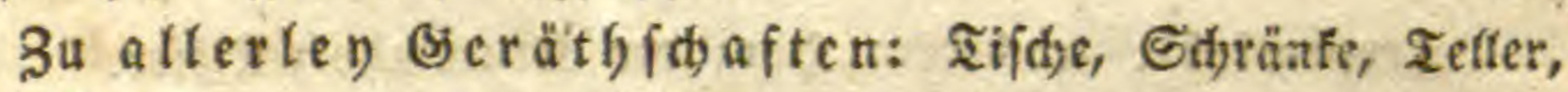
Söffel, Sdrauben, Steigen. Die meiften ver vorigen; befonbers

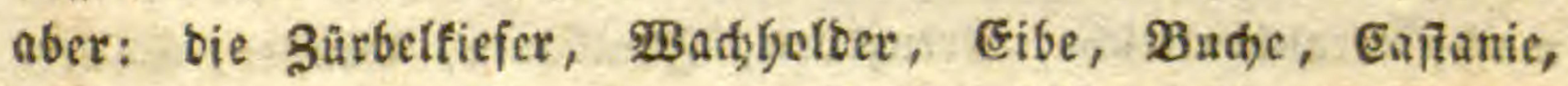

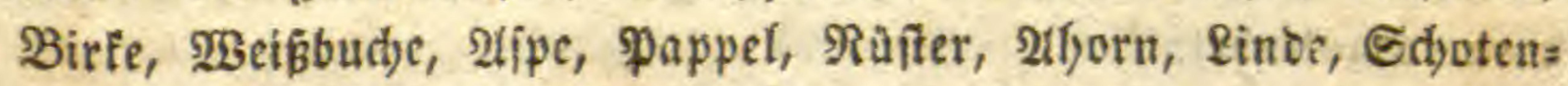
born ober unäd)te Acacie, Riß̧baum, Riridjbaum, 3wetjd)en= Gaum, 2ogelbeerbaum, Birnbaum, 2lpfelfaum, Faulbaum.

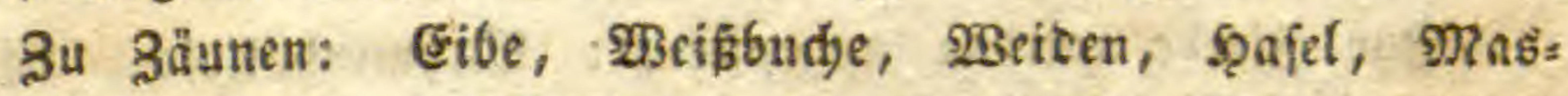

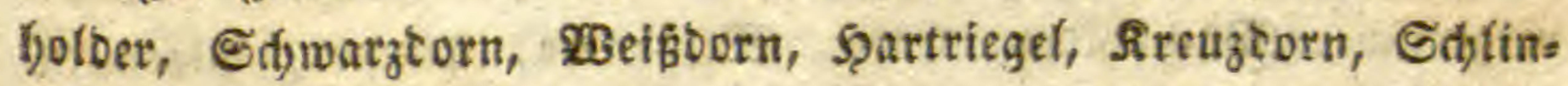

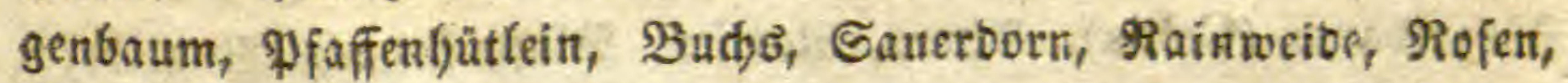
Brombeeren, SGalorebe, Bottborn (Lycium).

Rolf liefern: Die Rinben Der Eithen, Eajanien, Erten, Rü=

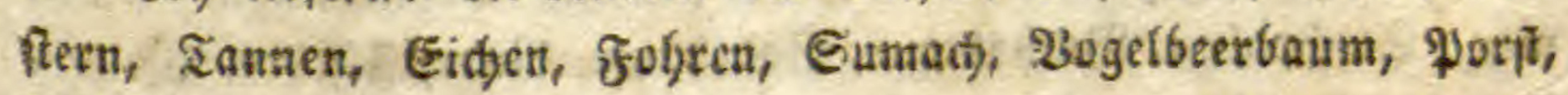
Bärentraube. 
Etaftäpfel: bie Eidjen.

Facteln, stienjpahn, S̨arz, peh), Theer und stientußs: bie Rabelfölzer; bas \$ed) vorzüglid) aus tem Şarze ber Rotlftante.

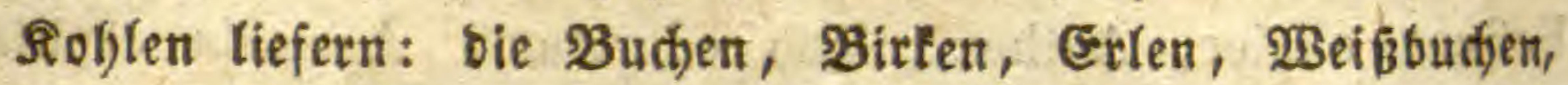

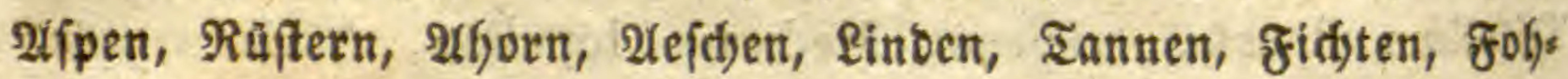
ren, Eärd)en. Gute Pulverfohle: 'Faulbaum, 2(jpe, Şajel, Einbe, Papper.

Die Stangen ober Eohben liefern $2 B$ eflentholz, $\Re$ aife: bes

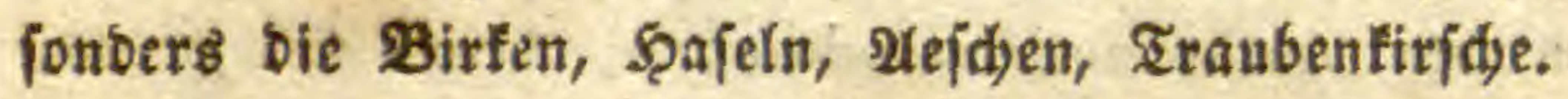

Dic Eträudber: Brennbolz, Serten, Stöde; Dergleidyen fint: Spafel, Nasholber, Sdywarzborn, Şartriegel.

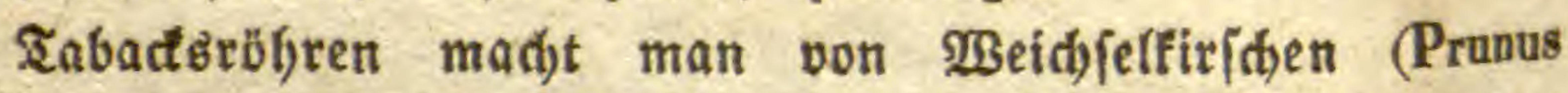
mahaleb), S(d)neebatf, Sd)lingenbaum, Şotber, Mrasholber, Tav maristen.

Rabftóte: : 3wergmifpeln, Sartriegel, Sdlingenbaum.

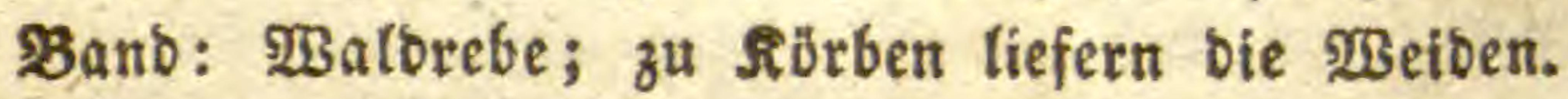

Baft: Die Ruffer.

Bejen: bie Birten, Pfriemen, Şeibe.

Sucter: ber Saft ber Birfen, bes Arfjorns.

Gummi: ber Ritifjbaum.

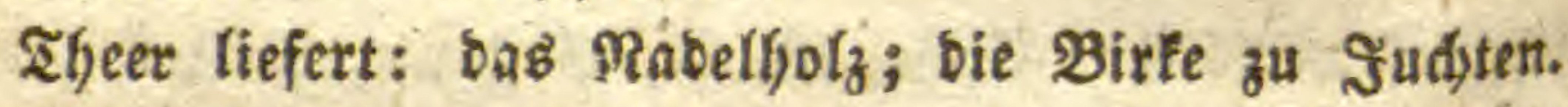

Tempentin: Das รatz ber \&ärd)e.

Terpentinbr: aus bem Şarz Der Ŝtummholz=Siefet.

Farben liefern: bie Duercitronteide, bie Erte, 2leide, Sus mad), Traubenfiridse, Rrenzborit, Faulbaum, Sinfter, Sauts born, Spaufjedjel.

(Eute \$ottajhe liefern: Die Buthe, Xrpe, Pfriemen.

(Biftig find: Sumad), Selbelbaft, porft.

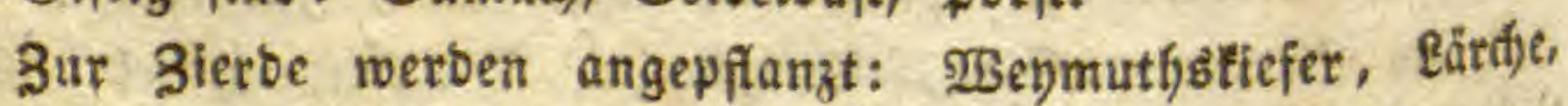

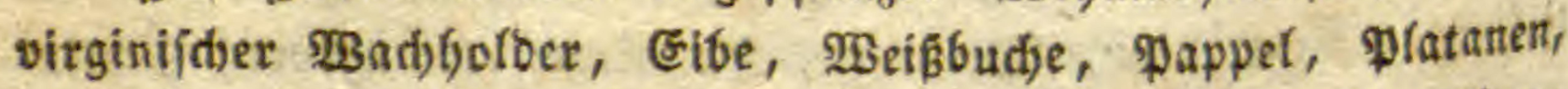
Bürgetbaum (Celtis), Afborn, 2teacien, B(afenftraut), $\mathfrak{B}$ ogelbect:

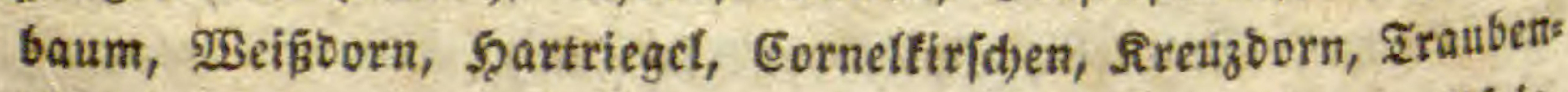

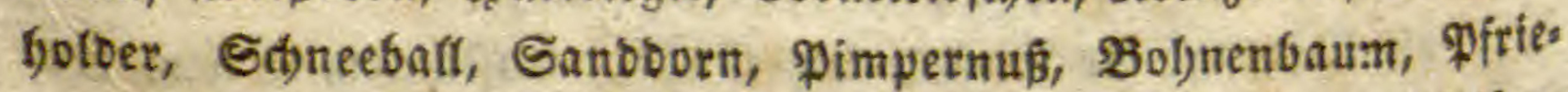
men, Stedbatme, Budjebaum, Sabebaum, Rinbe, flteber, \$feifent

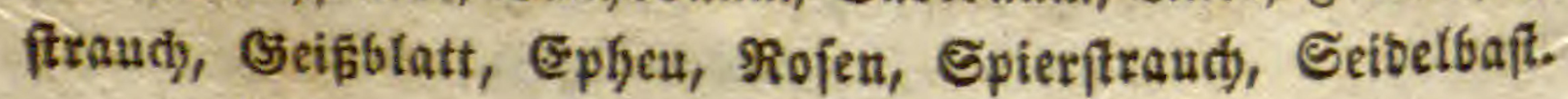




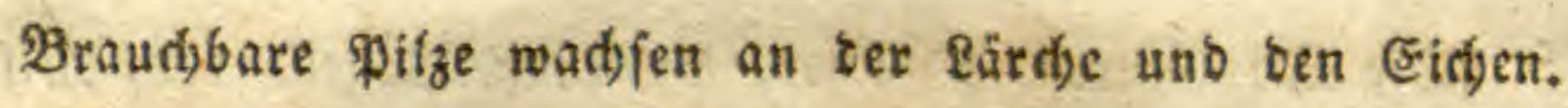

c. Dab $\mathbb{B} a \mathfrak{b}$

wirb gebraudyt affgemein als Streu.

$\mathfrak{A l}$ Jutter für siegen unb Edyafe: bas Birfenlaub, bie

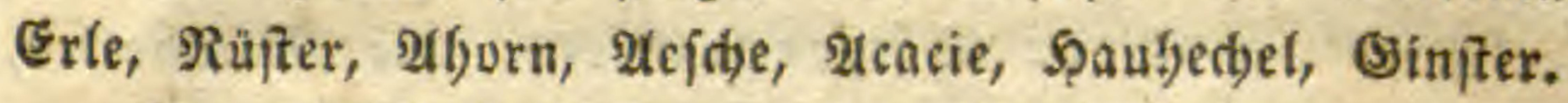

Für die Seibemwůrmer: Der Maulbeerbaum.

Jarben liefert: Das Raub ber Eaftanien, Birfen, Weiden,

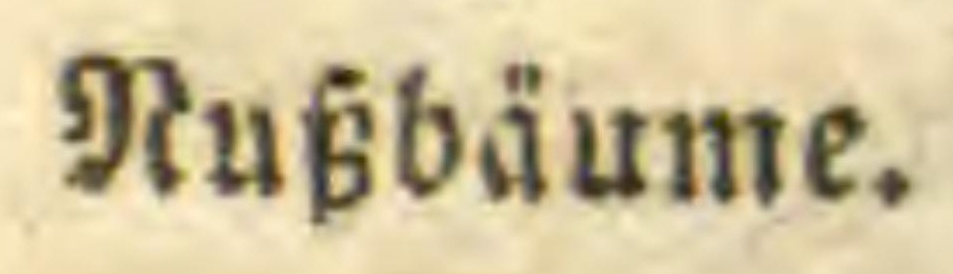

E)aftäpfel: Die Eidyblätter.

d. Samen

finb von ben meiften ein guteg $\mathfrak{B}$ ogelfutter.

Die Samenwolle ber \$appeln und Beiden glaubt man zu \$apier u. Dergl, verarbeiten zu fünnen.

Del fiefern: bie Samen ber Budgen, Şajelnülíe, 253ats

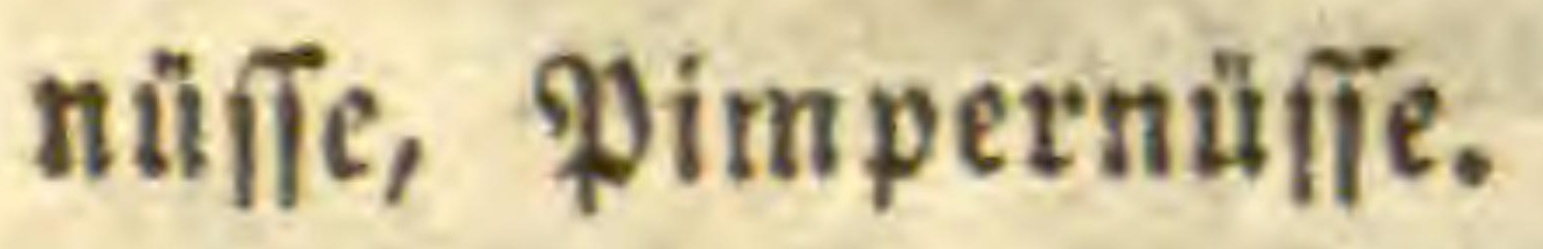

e. जิ röps.

3ur 3ierbe bie bes Blajenftraudes, ber \$impernuß, Pfaffena bùttein.

f. Brumen

bienen zur 3ierbe: yon 2teacien, Edywarzborn, WBeifs Dorn, solber, Sd)neeball, PimpernuF, Bolnnenbaum oder Evold: regen, Pfriemen, Sinfter, flteber, Pfeifenpitrauch ober wílder

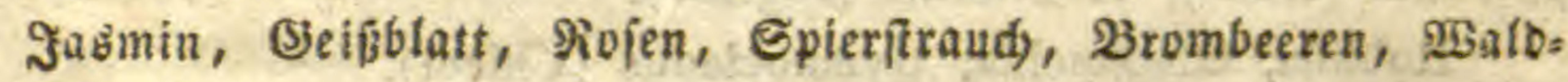
rebe, secide.

Şonig liefern: Binben, Hhorne, Rreuzborn, Bobnen=

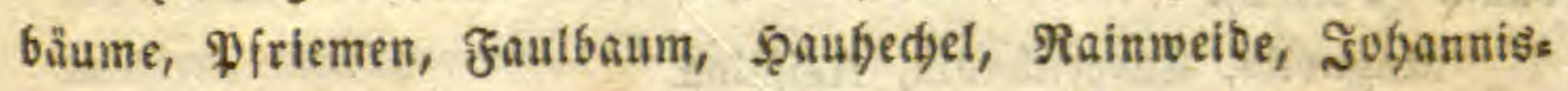
beeren, Scişblatt.

พBa d) Eärden u. f.m.

Farben: Die Blüthen ber $\$$ friemen, Des Gagets.

g. $g r u d) t$.

Me a ît ung liefern: bie Eidjefn unb Budjectern, Rof́cafta.

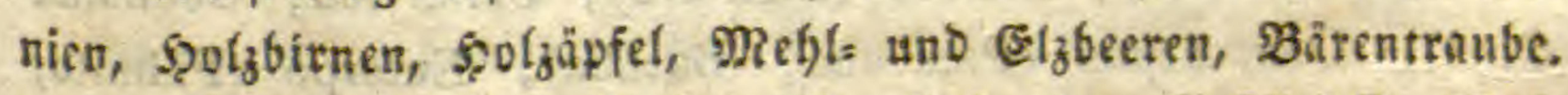

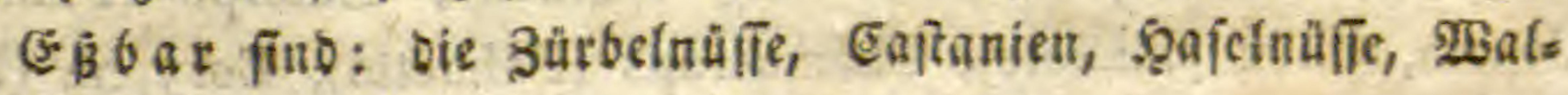
nutîe. 


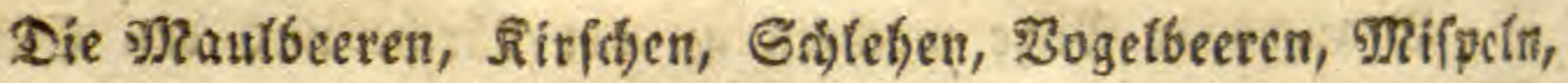
Eornelfirf(t)en, Mef)!s uno Elzbeeren, Jobannibs uno Stabets beeren, Rofenbutten, Broma, Scimberen, Seibel= unb \$reifels beeren.

Efilig ober anbere Säuren liefern: Die Maulbeeten,

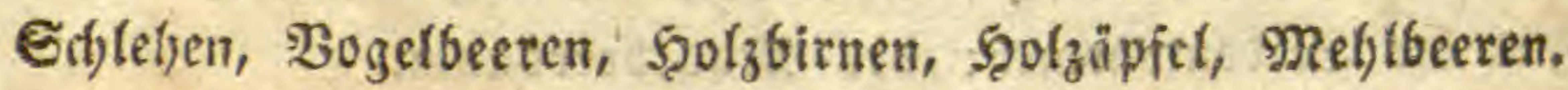

(3) e wär z: Die \$Sadjholderbeeren.

Terpentin b̈ : bie jungen 3apfen ber

Farben: bie \$Beeren bes Rreusborng, Faulbaumb, ,̧ols bers, Dintenbecren, Brombeeren, Raufdbeeren,

Bogelfutter: bie Bogelbeeren, Meflbeeren, 타마eern (Pyrus aria et torminalis), Şagebutten, Şolberbeeren, Beeren Deg Edgnecbaflg, Der Sted)pafme, Bătentraube, Raufibbeten.

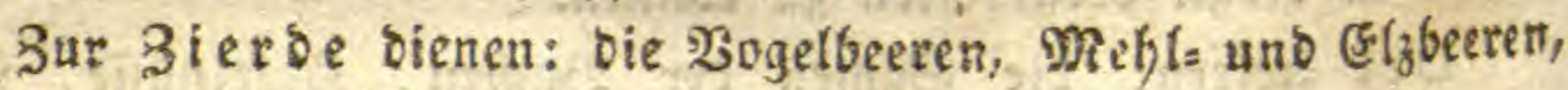

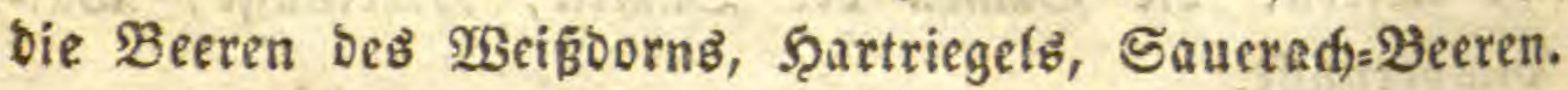

(S)iftig oocr Bred)enerregen of fins: Die frrudite ber

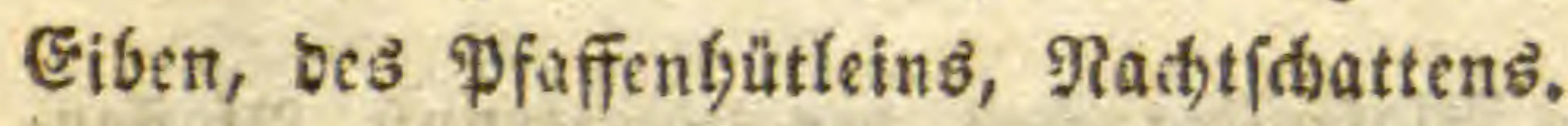

S马i $\mathrm{C}_{3}$ er in Rord $=2$ merica.

Taxodium, Thyia, Juniperus.

Symplocos, Halesia, Heisteria, Diofpyros, Bumelia, Hamiltonia, Nyssa (Sour-gum-tree), Dirca, Eaffafrab (Laurus 1.), Celastrus, Apalachine (llex), Effiggaum, Eiftbaum (Rhus), 厄0s pafbaum (Rhus), Nufbäume (Juglans).

Robinia, Gleditschia, Gymnocladus (Chicot).

Burfer=2lforn, americanifotes (Epheu (Ampelopsis), Revers baum (Ptelea).

Magnolia, Tulpenbaum, Asimina.

Şด faer in Sübamerica:

Colymbea, Zamia.

Mauritia vinifera, Desmoncus, Acrocomia (Macaya), Astro. earyum (Grigri, Murumuru, Ayri, Tucum), Guilielma (Pirijao, Paripou), Elaeis (Avoira), Manicaria faccifera, Cocos, Oreodoxa (Palma real), Iriartea (Baxi-uva), Ceroxylon, Geonoma (Ouai), Oenocarpus (Patavoua, Bacaba), Euterpe (Palmito, Jocara, Chou palniste), Chamaerops (Palmetto), Corypha (Palmillo, Soyale, Carna-uba), Sabal (Swamp-palmetto). 
Rhizophota (Paletuvier, Mangrove), Chimarrhis (Bois do tivière), Cuninghamia (Bois de Losteau), Siderodendrum (Bois de fer).

Morinda (Royoc), Cinchsna, Genipa, Randia (Gratgal); Dus roia (Marmolade-Doosies-Boom), Hamelia (Mort aux rats, Bois des Princes).

Ternftroemia, Bucida, Jacquinia, Sideroxylon, Chrysophyllum, Cordia (Bois de Chypre), Ehretia, Citharexylon (Ereigentyotz, Bois cotelet), Aegiphila (Bois tabac), Tabernao montana (Bois laiteux), Thevetia (Ahovai), Lasiostoma (Curaré), Ignatia, Allamanda, Willughbeia (Pacouri).

Triplaris, Conoearpus (Button-tree), Lagetta, Embothrium.

Cecropia (Bois trompette), Brosimum, Galactodendrum, gelbes srafilientyolz (Morus).

Hernandia (Bois blane), Virola (Voir-Ouchi), Gyrocarpus (Volador), Adenostemum, Peumus (Boldu).

Federijarz (Siphonia), ふ̦ungferntyolz (Phyllanthus virginea), Cascarilla (Croton), Alcornoque f. Chabarro (Alchoruea), Bois à Calumet f. Piriri (Mabea), Sanobúdbfenbaum (Hura), Beims baum (Sapium), Mranfininellbaum (Hippomane), Liane papaye f. graine de l'anse (Omphalea).

Bejuco (Hippocratea), paraguay)=\{lfee (llex), Maravedi (Ilex), Acomat (Homalium), Caffé diable (Samyda), Liane brulé (Gouania).

Poivrier C. Areira (Schiaus), mäbdent:\$flaumen (Comociadia), Guao (Comocladia), Balfambăume (Ieiea, Énceins, Taeamahaca, Aracouchini, Cèdre blanc, Chipa), Gommier (Bursera), Bois cochon (Tetragastris.)

Dog-wood (Piscidia), Balfambaum (Myroxylon), Swartzia (Bois ì flèche), Dradjenblut (Pterocarpus), Ébenfyof (Amerimnum), Dartrier (Vatairea), Bebe-boom (Dalhergia), Quinate (Nissolia), Tongabofne (Dipteryx), Pois fabre (Panzera), Vouapa (Macrolohium), Bois de Campèche (Haematoxylon), f̧errambut $=$ ŞO $_{z}$ (Caesalpinia), Bauhinia, Locuft-tree (Hymenaea Courbaril), Eopaiva=Balfam (Copaitera), Mimosa sensitiva.

Bois de Luce (Petaloma, Mouriri, Silverwood), Bois puant 
(Foetidia et Guftavia), Piment= ober samaica=\$feffer (Myrtus pimenta), Balata blanc (Couratari, Maou), Calebasse à Colin (Couroupita), Mabouia (Morisonia), Rocou (Bixa).

Eeifenbaum (Sapindus), Bifamljolz (Guarea), Maflagony (Swietenia), Eeberfolz (Cedrela), weíser simmet (Canella), Clu sia, 2tngoitura=Rinbe (Bonplandia), (Juajac (Lignum fanctum),-

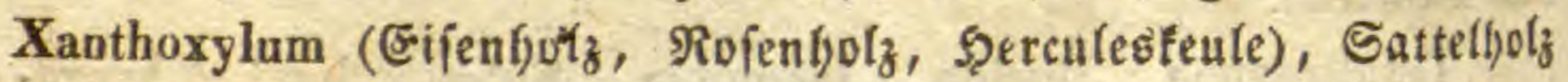
(Elaphrium), Quassia, Simaruba, Gomphia.

Smegmaria, Cacao sauvage (Carolinea), $250 f t b a u m$ (Bombax), Arbol de Manitas (Chirostemun).

Apeiba et Bois à mèche (Aubletia), Bois de foie (Muntingia), Winterşrinbe (Wintera), Bitterfyolz (Xylopia).

Die merfwürbigen Bäume unb Cträudjer ber inbifden

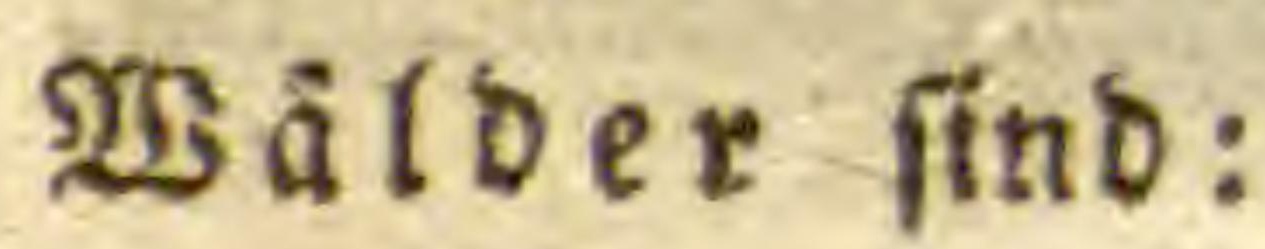

Casuarina, Ginkgo.

Bambus, Rottang.

Rhizophora, Cleyera, Avicennia, Terminalia, Olax (Stinfs

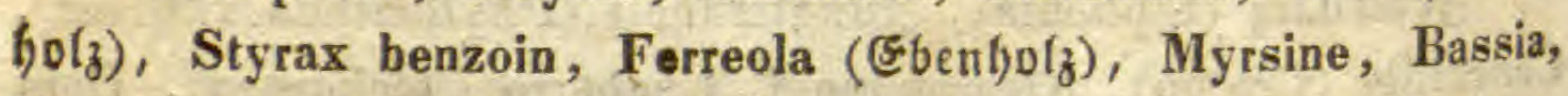
Premua, Gmelina, Tectonia, Echites, Cerbera, Strychnos, Gnetum, Santalum, Antiaris, Morus.

Ialgbaum (Tomex, Stillingia), 3immet, Eamplertbaum,

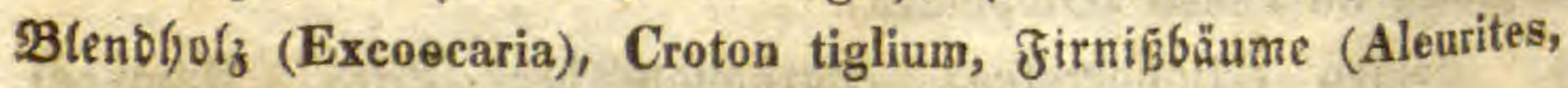
Augia, Rhus), Sapium.

$\mathfrak{A l}_{\text {berfol }}$ (Aquilaria), Balfam=Baum (Amyris), Olibanum - ber $\mathfrak{3}$ rigraudy (Boswellia), Bois de Colophane-bâtard (Bursera), Cussambi (Piftacia).

Erythrina, Butea, Sophora, Santelfolz (Pterocarpus), Eifietrs

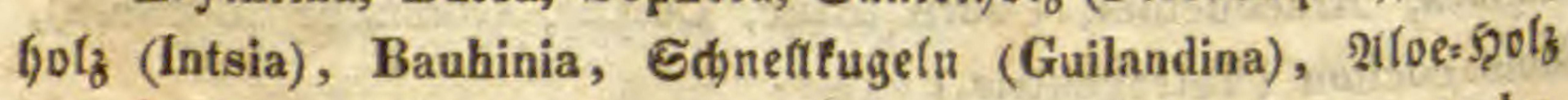
(Aloëxylon), WBagbofnen (Adenanthera), Acacia feandens, catechu. Hicann (Lawsonia), Barringtonia, Stravadium, Sapindus, Eifentolz (Stadmannia), Rafpelfyolz (Flindersia), Etrand=(S)anas teat (Xylocarpus), Azedarach (Melia), Shorea, Dipterocarpus, Dryobalanops, Vateria.

Tacamahaca (Calophyllum), Eummigut (Stalagmitis), Bois de fource (Leea), Cissus, Ailanthus, $\mathfrak{P f e f f e r f j o l}_{3}$ (Xanthosylum), Fagara, Ochna. 
Baummolle, Boftbaum (Bombax), Bois de merde (Sterculia), Kleinhovia, Büttneria, Hlaunbaum (Decadia).

Cortetsföruer (Menispermum), Etern=2tniz, Magnolia, Dams mar=8Baum (Xylopia), Arbre de Mâture (Guatteria).

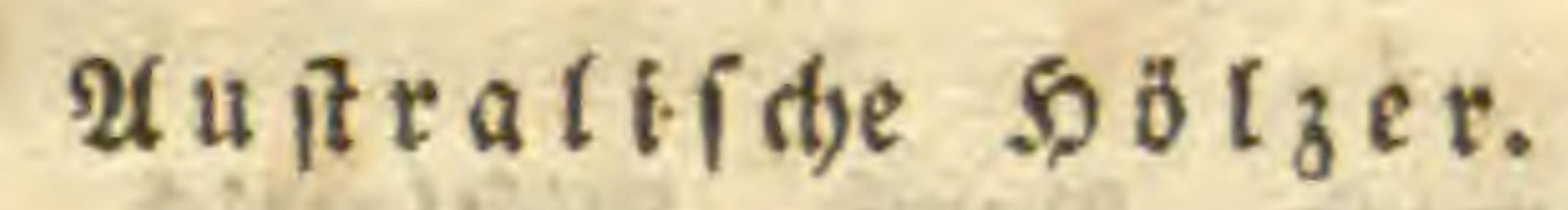

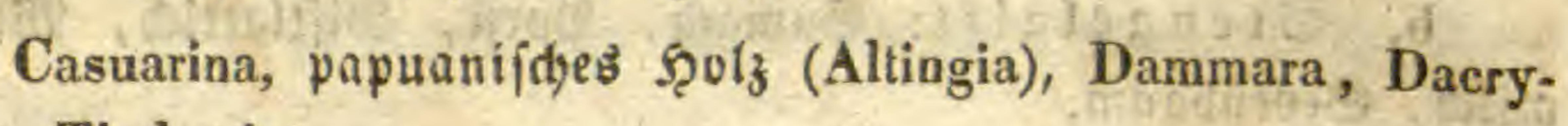
dium, Thalamia.

Epaeris, Embothrium, Lomatia, Dryandra, Banksia, Lambertia, Hakea, Knightia, Persoonia.

(5) ummi=Baum (Ceratopetalum), Fabricia, Melaleuca, Metrofideros, Eucalyptus.

Bäume am $\mathfrak{B}$ orgebirg ber guter froffnug.

Leueadendron, Aulax, Protea, Brabeium.

Irommelbaum (Mithridatea), Sottentutten=Siridien (Celastrus), Bois jacot (Celastrus), Bois d'Olives (Schrebera), Bois de Colophane (Colophonia).

Rotber Élientaum (Cunonia), Bois de Brède (Erythrospermum, Bois de Ronde (Erythroxylon), Bois d'éponge (Gastonia), Grewia.

\section{Il $\mathrm{f} f \mathrm{r}$ åter}

gibt es jowofh auf Felo unb Wiefen, als im Warbe. Man fann aud) bie Sifteflanzen bazu redanen.

a. \$urzelunfraut: :aecten, Bromberftraud, Saus bedpel.

b. Stengelunfraut: Safjweizen, Soufnesfamm, Di: fteln, after(ey) Sträudjer, WSindhaber, Rold́, Riebgras.

c. B lattunfraut: Nefieln, Squflattidy.

d. Samenunfraut: Trefpe.

e. (3) rüpsunfraut: ફ̧ederia).

f. Blumenunfruat: Slatidrofen, BBurjerblumen, Egas miften.

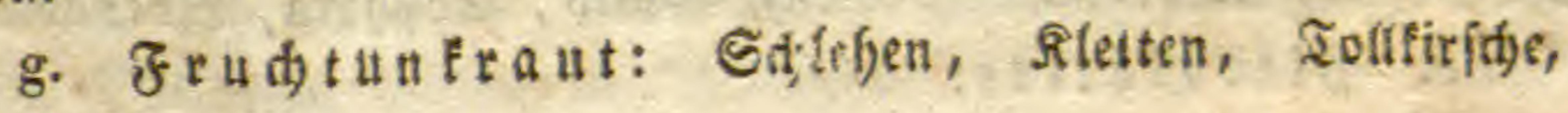
Rad)lf(d)atten. 


\section{E. Biftpflanzen.}

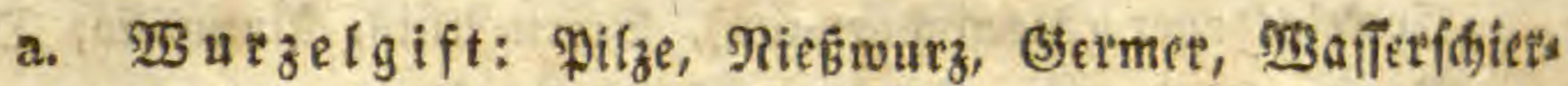
ling, Manive, Beitlofe, Raiferfrone, Seafelwurz, Djerluecy, Saunrübe.

b. Stengelgift: Sumadi), Porit, Siftattid), Wolfs" mild, Gevenbaum.

c. Blattgift: Edbierling, SoundBpeterfitie, Eifthafintm fußs, Sturmbut, Fingerbut, Nadtidhatten.

d. Samengift: Taumelfoldh, Biljenfraut, Etedbapfel.

e. C) röpsgift: Codtelstörner.

f. $B$ (umengift: Sturmbut.

g. Frudgtgift: Tofffirfód, Scibelbapt.

\section{F. Sietpflanzen.}

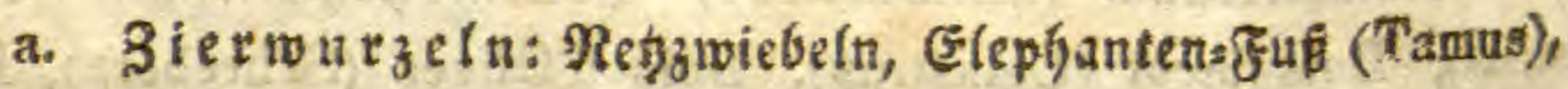
(Erofdyeibe (Cyclamen).

b. Sierfienger.

Stauben: Facteldifteln, bas 5brätrige Epheu, Wafts floren, Cobäa, Eupinen, Capuciner, Trefie, Eornbalis, Mauranbia, Wiermutl), Seidenpflan ${ }_{3}$ e, fiermesbeeren.

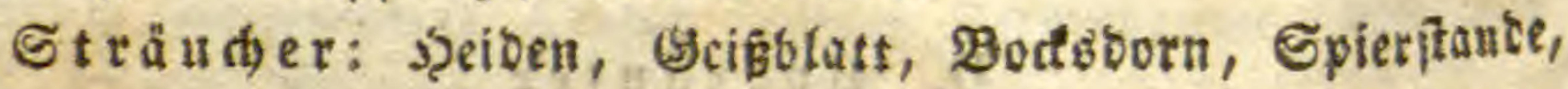
Cameftien, Dids̄men, Proteen, Myrten, Metafeufen, Mretros fiberos, Calycantfus, Şartriegef, Suths, Waltrebe, 2tmorpha, Inbromeben, Ariftolochia sipho, Trompeten 3 fume (Bignonia), Eatalpe, Blafenftraud, Şartriegel, Gimter, Epheu, Hibiseus fyriacus, Sanboorn, \$eripfoca, wilber కămin (Philadelphus), Ifpentofen, Sumah), Pfriemen, gfieber, Tamaristen, Cankebalt, รeufdlanm, รัubenburn.

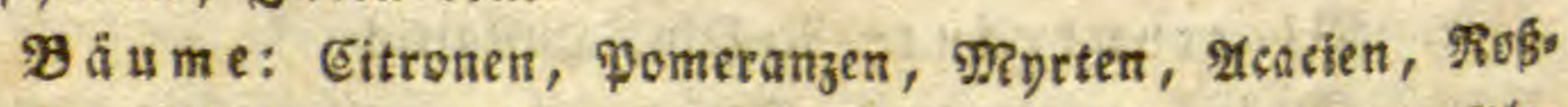
caftanien, Mimpernub, Irauermeibe, Eypreffen, Eevenbaun, \$las tanen, Rinden, 24horn, S̈แbasbaum, Bofnenbaum voer Golss regen, Geibelbaip, Dleapter, Eslebitidjia, gorbeer, sulpenbaum, Ragnofien, Eeberbaum (Ptelea), Einto, Eophora, gebensbaum. c. Sierblätter:

Fartenträuter, Etrelibia, 2ron, Rloe, Yucca, Rgave, 
Panbang, Polmen, Bafflien, Sausmurz, WBinben, Erafiula, 3oferblume, Begonien, Whyffantfus, Mimofen, fünfolättriges Epseu, Brennbofnen (Dolichos), Stunbenbfumen (Hibiseus), Bärenffau, Şorufraut (Cerastium tomentosum), Etcinbred)e, Scabiofen, Mausborn.

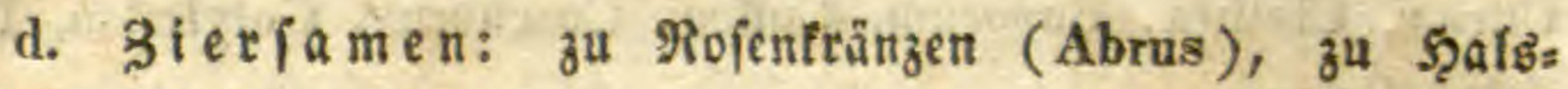
fd̆nüren u.f.w.

e. Siergröpfe: Siobsthrånen, Pfaffenthutlein, Gdnnectens

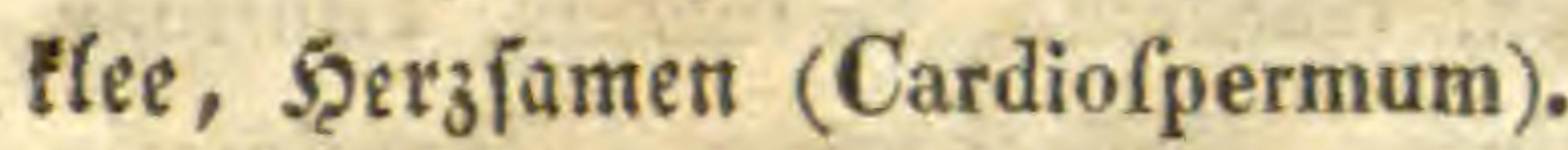

f. Sierblumen: Eflien, Eafla, Raiferfrone, थffodifl, Manblümd)en, Safran, Sdgnectropfen, Siegwurz, Tagfifien (Hemerocallis), Şyacinttyen, Sthwerdel, Inotenflume (Leucojum), Rarciffen, Pancratien, Stern=.̧yacinthe (Scilla), Sif́nr: bindjien, Tulpen.

2toonis, Simmelsroie (Agroftemma), 2tmarant, Etadjels mofyn (Argemone), 2fiter, Bafefte, Eacalia, Ringelblume, Elodena blumen, Şafnentantm (Celosia), Rornbtumen, Jgadboblume, Revfoje, Efrnfantfemen, (s)ome, Commelyne.

Eted)apfel, Ritterfforn, Stord) ftinäbel, Rugelamarant (Gomphrena), Şefiotrop, Stundenblumen (Hibiscus), Batfamine, TBins Den, Robetia, Ropezia, Malven, 3aferblumen, Şungfer in Şaaren, Radtferze, Mobn, Rciebe, Ecabiojen, Silenen, Irabescantia, Etrofblume (Xeranthemum), Sinnia.

3 weyjăfrige Bierpflanzen:

Sted)telfe, Eöwenmaul, Shtern, Blodenblumer, Eelfia, Floctenbfume, Ritteriporn, Reffen, Radtuiofe, Monbviole, Bafer= blumen, Monarbe, Rad)tferze.

2t us ba a

Sdjafgarben, Sturmlyut, 2(nemonen, 2tetey, Manblieben,

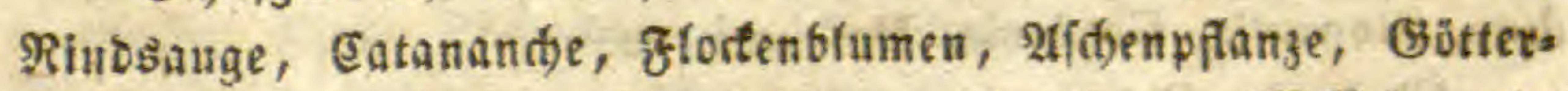
blume (Dobecatfeen), Rugetblume, Efriftwurz (Helleborus), Bid)tnelfen, Oautlerblume (Mimulus), Eidstrofe, Ftammenblumen

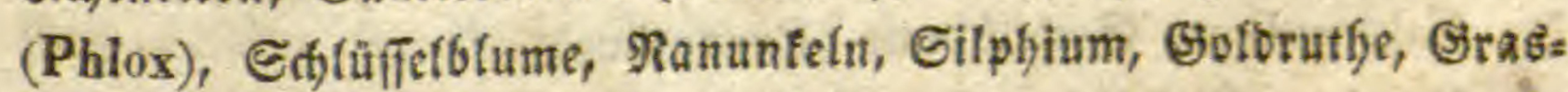
nelfe, Balorian, Sinngrùn, Seildyen.

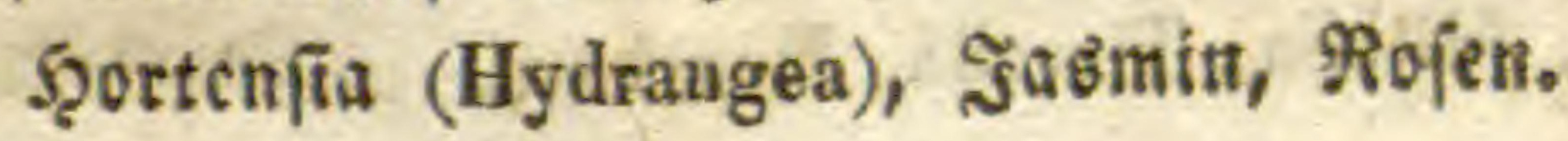




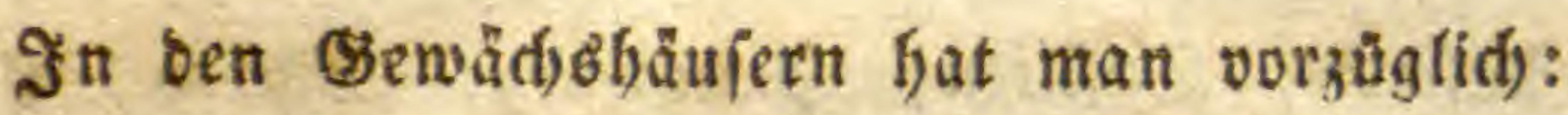

Achania, Agapanthus, Agave, Aloe, Alftroemeria, Amaryllis, Asclepias, Aucuba, Banksia, Begonia, Bignonia, Bromslia, Bryophyllum, Buddleia, Buphthalmum, Cactus, Camelia, Canna, Capparis, Casuarina, Ceratonia, Cestrum, Chironia, Cistus, Citrus, Clethra, Cneorum, Coffea, Corchorus, Cotyledon, Crassula, Crinum.

Diosma, Elichrysum, Erica, Eucomis, Euphorbia, Ferraria, Ficus, Frankenia, Fuchsia, Gardenia, Geranium, Gloriosa, Gloxinia, Gorteria, Haemanthus, Heliotropium, Hemimeris, Hermannia, Hibiscus, Hoya, Hydrangea, Hypoxis, Ipomea, Ixia, Jasminum, Jufticia, Lachenalia, Lavatera, Laurus, Lobelia.

Magnolia, Manulea, Melaleuca, Melia, Melianthus, Mesembryanthemum, Metrofideros, Mimosa, Mirabilis, Moraea, Musa, Myrtus, Nerium, Olea, Osteofpermum, Passiflora, Pelargonium, Phlomis, Phoenix, Phylica, Phyllis, Piper, Piftacia, Plumbago, Polyanthes, Polygala, Pothos, Protea Prunus laurocernsus, Punica, Rivina.

Sanseviera, Scilla, Sisyrinchium, Smilax, Sparrmannia, Spigelia, Stapelia, Strelitzì, Tarchonanthus, Tigridia, Veltheimia, Volkameria, Viburnum tinus, Wachendorfia, Weftringia, Yacea, Zygophyllum.

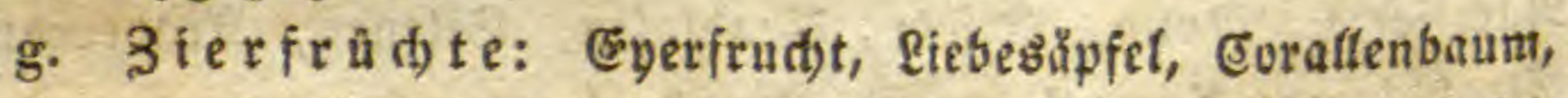

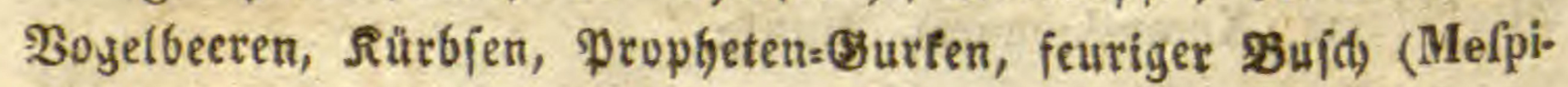
lus pyracantha), Erobeer:Spinat (Blitum).

$B$ f umen in Rord $=2$ merica.

Hypoxis, Crinum, Tradescantia, Helonias.

Solidago canadensis, Aster, Polymnia, Silphium, Coreopsis, Rudbeckia, Eupatorium purpureum, Liatris, Ambrosia.

Lobelia, Clethra, Kalmia, Aristolochia sipho, Malachodendron, Stewartia, Gordonia, Dodecatheon.

Chelone, Chionanthus (Sthreebaum), Catalpa, Martynia, Monarda, Phlox, Spigelia, Apocynum, Iresine, Phytolacea.

Calycanthus, Sctielftume (Ceanothus).

Glycine, Podaliria, Amorpha, Cassia.

Claytonia, Itea, Mitella, Tiarella, Heuehera. 
Oenethera, Gaura, Rhexia, Corydalis, Sanguinaria, Jeffersonia,

Rubus odoratus, Spiraea, Crataegus coccinea.

$\mathfrak{B}$ lumen in Sûb= $\mathfrak{A}$ merica:

Dracontium, Caladium, Cymbidium, Oncidium, Dendrobium, Gongora, Anguloa, Epidendrum, Vanilla, Costus, Alpinia, Renealmia, Thalia, Maranta, Heliconia.

Tillandfia, Pitcairnia, Bromelia, Sisyrhinchium, Ferraria pavonia, Amaryllis, Yucca, Alftroemeria, Furcraea, Agave, Commelyna.

Helianthus, Tagetes, Galinsogea, Verbesina, Zinnia, Ximenesia, Georgina, Baccharis, Genipa.

Gloxinia, Trevirania, Gesneria, Lobelia, Passiflora (Murucuja), Combretum, Schousboea, Maurandia, Capraria, Buddleya, Datura arborea, Nicandra, Cestrum, Capsicum, Solantum, Mimulus, Ruellia, Bignonia, Heliotropium, Nolana, Tournefortia, Lantana.

Ipomea, Cobaea, Asclepias curassarica, Plumeria (Jasmintree), Theophrasta, Petiveria, Rivina.

Erythrina, Genêt épineux (Parkinsonia), Rofa de Monte (Brownaea).

Lopezia, Fuchsia, Cactus, Blakea, Melastoma, Bois de Gaulette (Hirtella), Ryania, Bocconia, Argemone, Tropaeolum, Waltheria, Ayenia.

Blumen am Borgebirg ber guten f̧offung.

Calla, Satyrium, Disa, Strelitzia, Ixia, Antholyza, Aristaea, Ferraria, Moraea, Wachendorffia, Dilatris, Hypoxis, Tulbaghia, Amaryllis, Haemanthus, Massonia, Albuca, Agapanthus, Cyanella, Lachenalia, Eucomis, Aletris, Veltheimia, Apiera, Aloë, Gethyllis, Xyris, Philydrum, Commelyna.

\section{Arctotis, Elichrysum, Tarchonanthus.}

Erica, Combretum, Myrsine, Chironia, Stapelia, Achyranthes, Gnidia, Struthiola, Dais.

Cluytia, Cassine, Phylica, Crassula, Cotyledon, Mesombryanthemum 
Polygala myrtifolia, \$elargoticn, ßutceoftrautit) (Diosma), Şonigflume (Melianthus), Hermannia, Sparrmannia.

It s gezeidnete $\mathfrak{B l u m e n}$ in snbten, Egita un

Angraecum scriptum; Cymbidium praemorsum; Dendrobium moniliforme; Aërides retusa, arachnites; Epidendrum amabile.

Kaєupferia rotunda, Hedychium, Galanga, B(umenrofyr.

Pancratium, Crinum, Amaryllis, Polyanthes, Gloriosa, Sanseviera, Xyris, Philydrum, Nymphaea, Euryale, Nelumbium, Dianella, Pandanus.

After, Chrysanthemum, Siegesbeckia, Eclipta, Vernonia. Mirabilis, Aucuba,

Ixora, Pavetta, Muffaenda, Gardenia, Seriffa, Myonima, Guettarda.

Cochlofpermum, Camellia, Cleyera, Combretum, Quisqualis, Bladhia, Mimusops (Elengi), Datura.

Thunbergia, Jufticia, Nyctanthes, Jasminum, Incarvillea, Bignonia, Clerodendron, Vitex, Ocimum.

Asclepias carnosa, Periploca, Pergularia, Nerium, Ophioxylon.

Gomphrena, Achyranthes, Celosia, Amarantus, Begonia, Irauerfraut (Phyllanthus), Croton variegatum.

Crotalaria, Aeschynomene, Abrus, Clitoria, Erythrina, Butea, Saraca, Pfauen=Blumen (Poisciana), Cassia alata.

Hydrangea, Lagerftroemia, Capparis, Balfaminen, Hiptage, Mesua.

Oxalis sensitiva, Sida, Helicteris, Hibiscus, Pentapetes, Champac (Michelia), Unona.

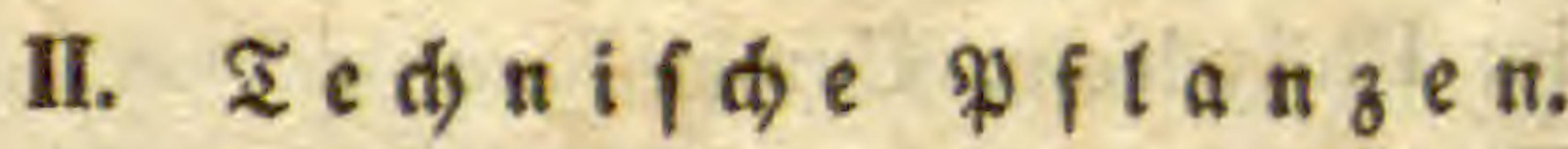

Davon braudt man entweber bie Theife ber Pfanjen felbiet, wie Şolz ober Rinbe, Fruld)te u. Dergl., zul afferley Gies räthidhaften und Färbereg. 


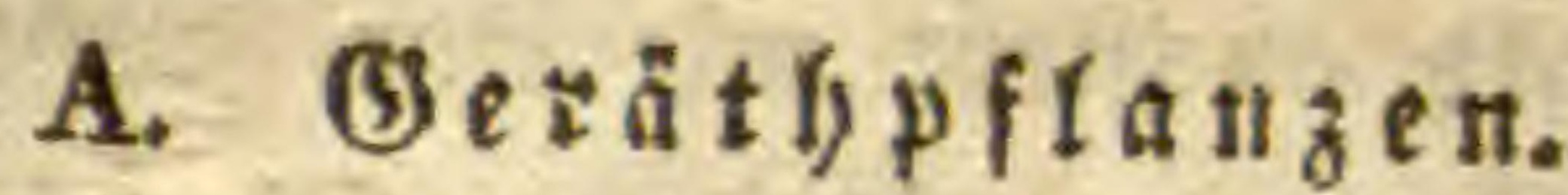

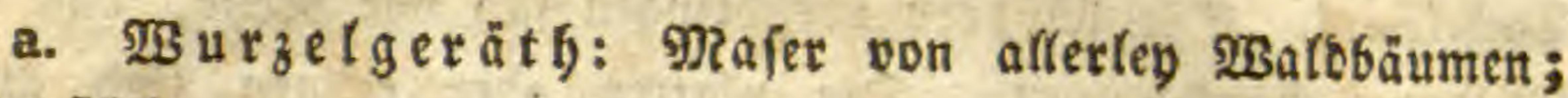
Sinoteriftörte.

b. Stengelgerảtb: Biele Soblzarten; Stürfe, Rabptöte, Pfeifentäbren, Bogen, Rörbe, Rottang.

Die Reger in Suritam madjen fehr foböne Rörbchen in

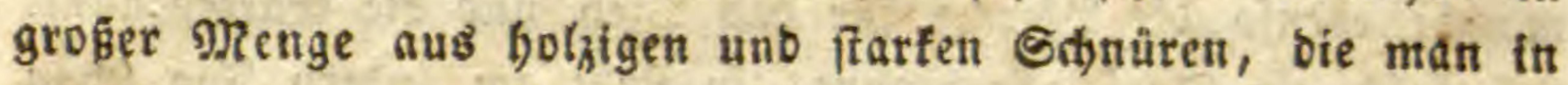
ber Rinbe ber Rofflpalme findet; man fiddt fie mit einer Irt Binfe, WBarimbo, weldye man fpaltet und vom Mark abs fonbert; man mad)t aud, anbere mit binnen Bianen.

Strol) uno Edjiff zu Şüten, Stüblen, Blenpitiften.

c. B(attgerätf): Ton Palmen zum Dadbecten, bie Stiele zu Stäben in Fedher und Sonnenidjirme.

In Surinam mant man in ben Ragern şütten, ober viels melgr Däd)er, um bie Şangmatte gegen Regen und Sonne zu idügen, wozu bie ged)erpalme (Latanier) faft aftes Material tiefert. Sin einer Stutibe fittib fie fertig, uno man braudyt weber

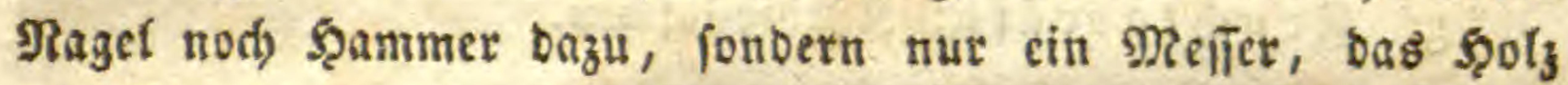
vom Latanier, ber fier Parafolla, in Cayente Pinot beíst, Lianen, bie bey ben Epaniern Bijacos, in Surinam Taitai beifen. Der Eatanier ifit eire \$atme, wetdye in fumpfigem, auds gutem Boben wåd)st, fidenfelsoita, $30-50$ ' bod), braun, auf 1 "Dide fehr hart und bann voll Marf, wie Der Solunber. Det untere Theil bes Stammes taugt nidytb, oben aber twirb

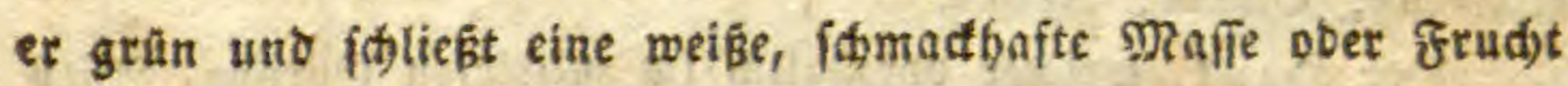
ein, bie soffl (Chou) beifst uno bey affen palmen vortummt.

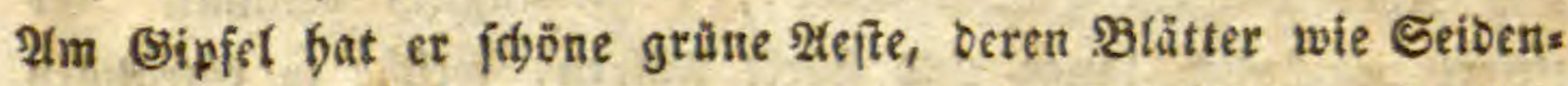
bänber berunter bängen, unb eine Irt \$arajol bilben. S3u ben Şütten fonneibet man ben Gtamm in $7^{\prime}$ lange Gtúcte, fpaltet Diefelben zu hanbbreiten Brettern und nimmt bas Marf ber= aus. Dann feflt man fie oidht neben einanber auf 2 Balfen, anb binbes bie \$foffen, fo wie bie $23 r e t t e r$, mit Bianen zufams men. Diefe Rianen laufen als büne uno bicte Sdynãe auf

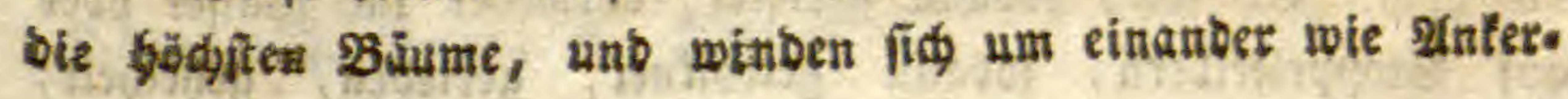


taue, farten audi beturiter auf bie Erbe und wurzeln wieber

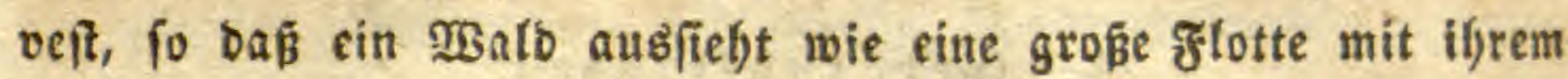

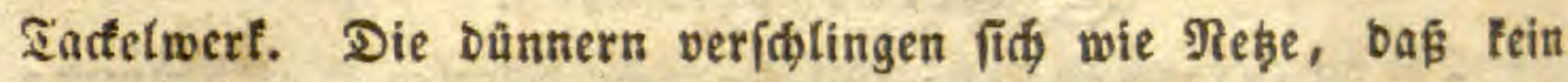
Sgilopret Durdblommt. Die platten ober ectigen finb giftig. Die Dädjer Der Şütten werben mit ben mannżbreiten Blättern Des Rataniers bebectt. Diefe werben fpäter rofenroth und fehen felfr fdjön aus. Fenfter, Tif́die und Stülile werben ebenío ges

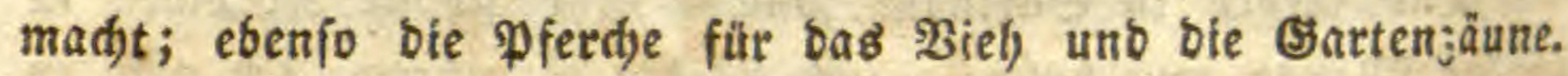
Sit fold ein Dorf abgebrantit, fo fteft am andern Tag (fiton wieber ein neues ba. Die Blütfentifpe bes \&ataniers fant man zugleid) als Bejen braudien.

d. Samengerătí: Su Sieratben, Rojenfränzen (Abrus), Samengemälben.

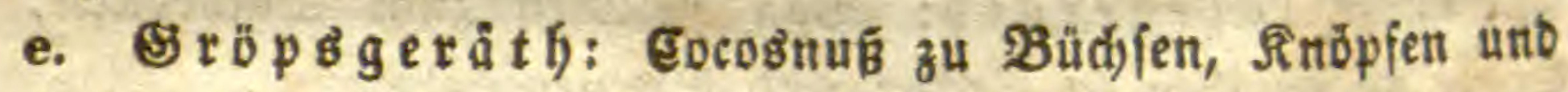
Sandr)aben an Stöcte uno Sonnenidjirme; Riridjiteine zu giguren, in ฒืärmfäcte.

3u Rlappern: ber Alfovai (Cerbera).

f. B(umengerätb): WBeberbiftel.

g. Frud)tgerätf): S(ürbisfaf́d)en.

\section{B. gaferpflanzen.}

a. 2 urzelfafert.

b. Etengelfafern: Baft von Shanf uno Seia, Crotslaria, Corchoras, Boehmeria, Pifang, Malven, Sida, Urena, Hibiscus, Unona, Anona.

Der Şanf, weldher vorzüglid, im mittleren Europa, 2tîn unb Norb=2(merica gebaut wirb, if fintänglid, befant. Er liefert vorzŭglidg lange unb ftarfe gafern, weldye zu Strängen uno gauen, als zu weldyen ber gladis zu furz uno feit tit, verwenbet werben. Ere witb in guten Boben gefät unb wädsat aber mannshod). Da er getrennten sefoledts ifi, fo lidtet man ben stäthenthanf, weldjer fimmel heißt, aus, unb lä́t ben Samentjanf ftefjen, ber mandjmal Stengel treibt 12', ja $20^{\prime}$ hod). Er witb jobant geröftet, entweber in פ্safier ober auf Stoppelfelbern, fobann getrodfnet, gerieben, gefjedjelt, 
gefponten und gewoben; ber zu Seilen wirb aber nus freyer

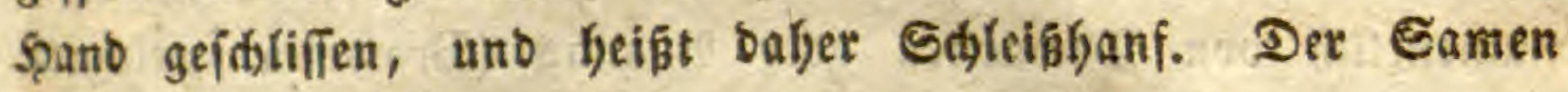
liefert bas Şanför.

Der fla d) B witb auf älntid)en felbern gebaut, iebod) melyt im Rorben von Deutjhland, in Me'en, Rievlanb u. f.w. Da ex faum $3^{\prime}$ bod' wirb, und bunne Stengel bat; fo gibt er teine Gajern zu Seilen, fondern blok zu Reinwant, weldye fefgr fein unb in bic ganze æBeft verhanbelt wirb. Das Röften geidjielyt im Irodnen auf ben Etoppeln. Bred)en, Şed)eln u.f.w. ift einer(ey, bod) wirb er aud geidjlagen ober mit cinem fdjerbs: förmigen Şolze geid)wungen. Der Samen liefert bas Reinb̈t. Die Reinmand, fowohl von fladis als Spanf, wirb bló; zu Şemben, Borfängen, \$ett= und Tafelzeug verwenbet, bödjit felten 34 Rleibern, auber etwa ber f̧anf vom Lanboolf als swild). Der Şanf gibt bie Särte fŭr bas Getraibe.

24us ber Rinbe einer Malvenart (Urena sinuata) gewinut man burch) Röftung fafern, woraus man Sdynüre zu Sang: matten maditst.

Rinbenfajetn: Brouffonetia, Brobfrudbtbaum.

c. Blattfafern: Reufeelänbifther Sanf (Phormium), baumartige 2lloe (Agave), Bromelien (Caroa), Cocos ventricofa.

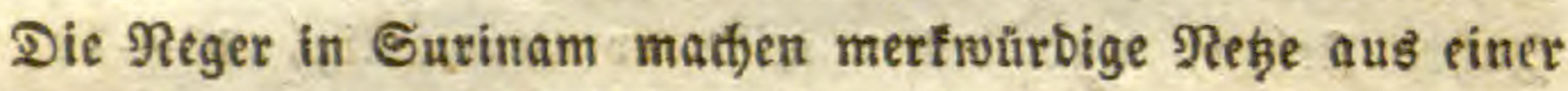
Sdeibenpflanze, einer 2 art $\mathfrak{A}$ toe (Agave), in ben $\mathfrak{B a ̈ l}$ bern, mit gezälynelten fted)enden 2 lättern, weld)e weißse fajern entfjalten,

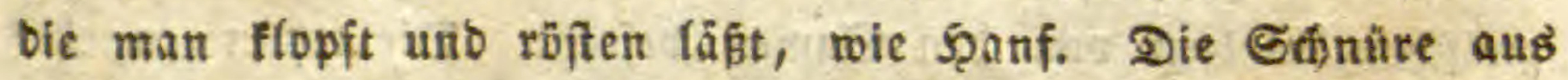
biejen gajern finto viel frärler als bie curopäifjoct, faulen aber balb, unb finb baher auf ben Sdjiffen nidht zu braudben. Diefe

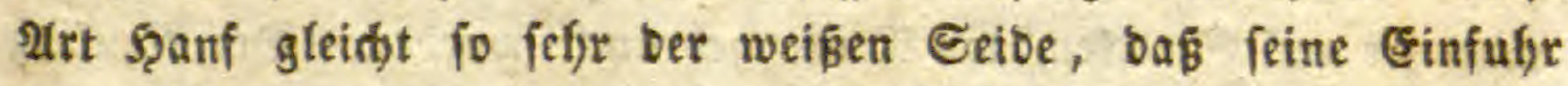
In veridjiebenen Eirtbern verboten ît, um Betrug zu verbindern. Die Jntianer nennen bieje Pflanze Curetta, in Surinam inbifide Seife, weil fie cine weidse Enbftanz hervorbringt, welde von

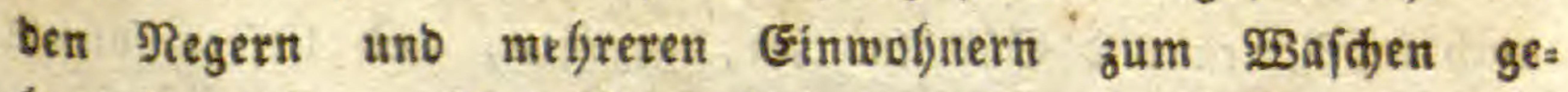
braud)t wiro. - Das 刃arf gălt lang Freuer wie Runte.

3u \$apier: Papyrus, \$almblătter.

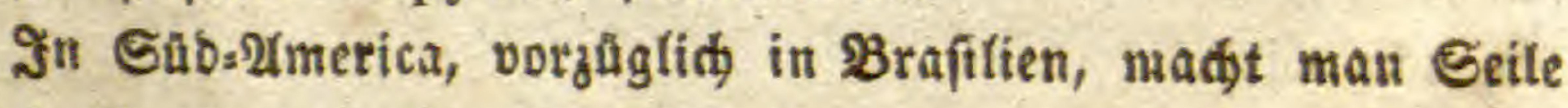
Deens allg. Naturg. II. Botsnie I. 
unb Senebe von bett 2 lattert veridjebenter Sdeibenpflangett, namentlict) von stomelien ober 2tranas: (Bromelia variegata, sagenaria). Sie wadyfen milb, und bebecten grofe Strecten an

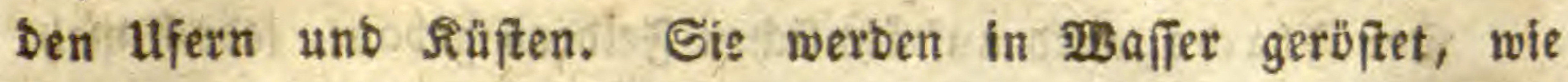
Şanf, und fodann gefdjagen. Man madjt vorzüglid, Rek̨e Davon.

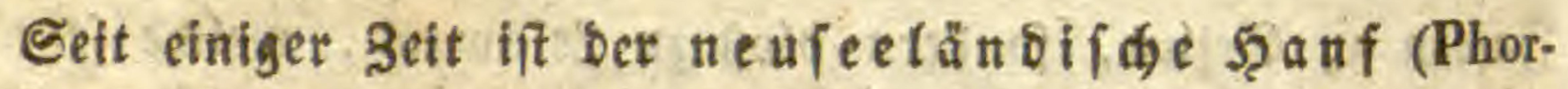
mium tenax), weld)er ebenfaftb von ben B(ăttern einer edjeiben: planze fommt, berülymt geworben. Man pflanzt ifgn jeģt in

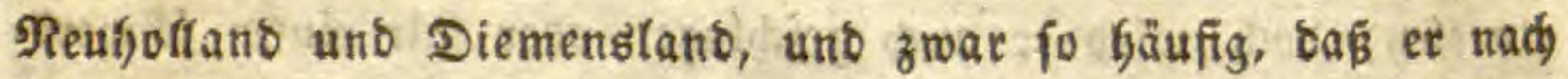
Englano verfültt wiro. Man madjt befonbers Seife Davor.

d. Samenfafern: Baumworle (Gossypium et Bom-

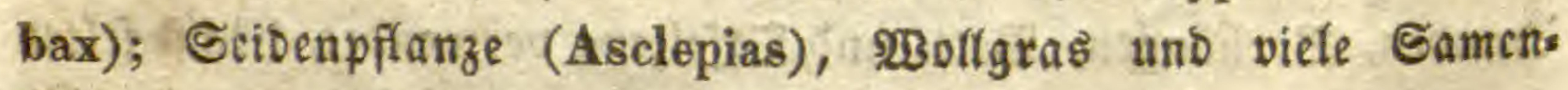
baare.

Die $\mathfrak{B} a$ u m wo lle (๔attun) wirb gegenwätig am meiften zu STleibert verwenbet, vorzăglid) für Frauenzimmer, unb zwar

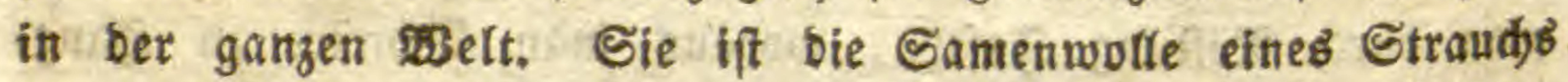
(Gossypium arboreum), weldjer aนb Oftinbien ftammt, aber gegenwärtig in aflen wäemeen Ränbern angefät wìiro. Un bas Mittelmeer läbt man if)t nur einmal bläben, und er bleibt bakei frautartig; in Doftinbien bagegen läat man ifnn mefrere Sabre ftelen, und baber wirb er baumattig, 10-12' bods.

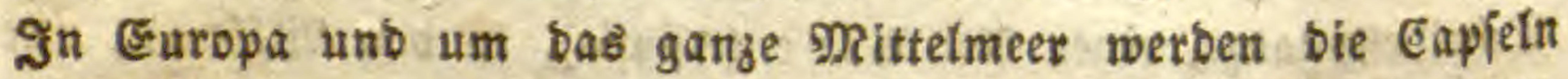
im Detober gepflütt, auf Sdjiffmatten getroctinet unb bie 930 olle

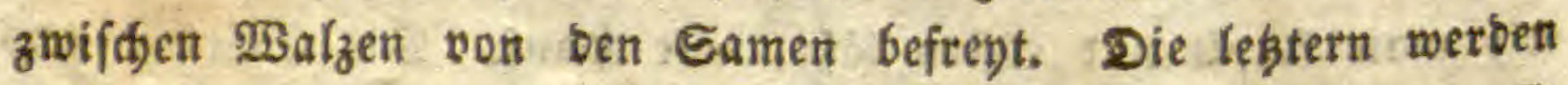
bem $\mathfrak{B i e l}$ gefüttert. Da bie 230 fle fehr turz ift, fo fann fie nid)t zu Seilen gebraud)t werben. హิn Củb=2(meriea pifanzt man fie auf Strecten, wo Reute gebrant worben. Der Nanfing fommt von einer andern Gattung, weldge fäufig in Efina ges baut wirb.

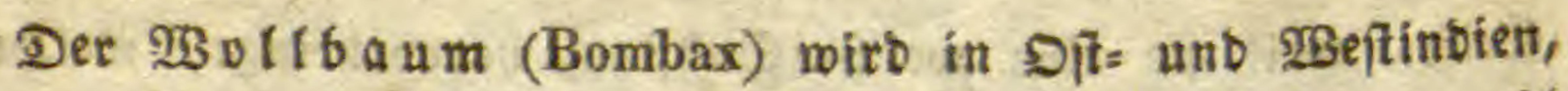

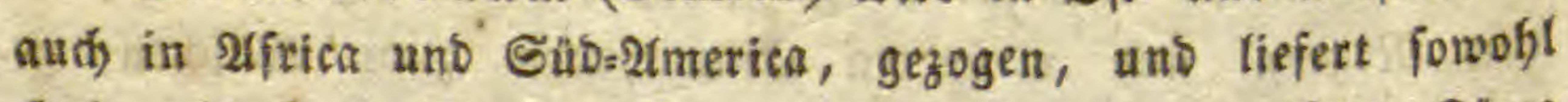

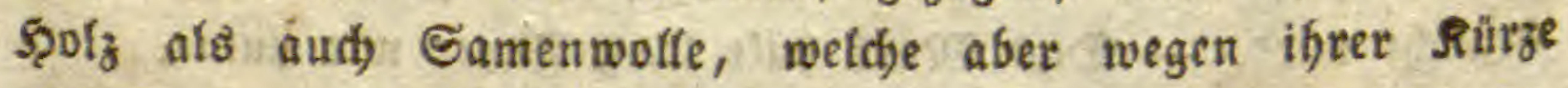
nidbt geiponnen, fonbern nut zum 2tusjtopfen ber Polfer ges braudyt wito. 
Die 5 baumwollenpflanze wurbe exft $\mathbf{1 7 3 7}$ in Cus rinam eingefübrt, fatte aber bis 1750 ober 1772 wenig Erfolg. (Es gibt bafelbit mefrere 2rten oot Baumtwoflenbäumen. Der gemeine und nüblidisere ift ein Straud, $6-8$ ' hod, ber vor Salte und Tag feinen Stoff refert, und zroar zwenmal bes Saffrs. Şeber Etot gibt 20 Unzen Baumwofte. Die Blätter

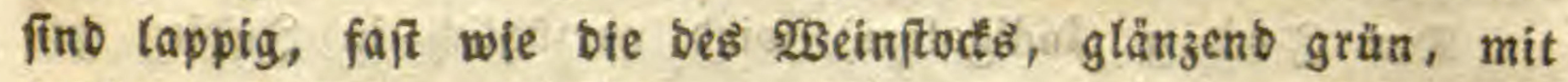

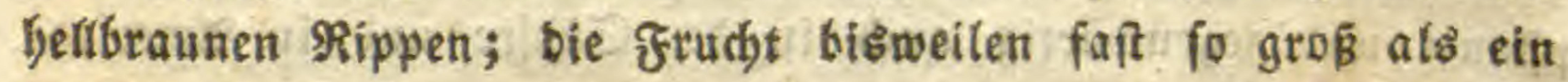

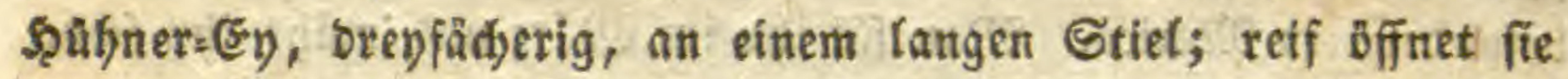
fid) von jelbit, und läst bie gloden felfen fo weís wie Edgnee; Dazrwifden fojwårzlidje sörner, faft wie bie ber Trauben; Lie Blume getbfid. Er ift leidjt unb ũberafl zu pflanzen, unb ges beift féfr gut, went nidjt zu-viel Regen bie \$aolfe zerftört. Man muв bie Rörner etwas weit ftecten. Die 2tbjonberung Der förner von ben froden bejorgt ein einziger Menfly auf cince bejonbert Mafdine Dber MRuffe: bann bringt man fie in Baften von 3-4 Centner; fie muß aber befeuditet fenn, weit fie fomft aufbunfet. Man fülyt in einem Salje blop nad) $2(m=$ ferbam und Rotterbam 3000 Baffen, Sterling, aus. Die beffern Pflanzungen Itefern jäfrlid über 25,000 Pf. Etert. Der \$reis wedffett von 8-22 Cous bas \$funb. Sie wirb gefpennen an ber Spinbel, und zwar felfi fein; bie Negerinnen pitiđ̌ten Strŭmpfe, für bie man oft 2 Buis neen befommt. Die jnbianer matien fefre fadme soungmatten Daraue, Die fle za Paramaribo verfaufen.

e. Eröpsfafern.

f. Bfumenfafern.

g. Frudffafern: Rinbe ober Reifel ber Cocosnus wirb zucrił gefd̆fagen, bann im $\mathfrak{B a f f e r}$ geröftet unb zu vortreffifiden 2ufertauen verwenbet.

C. F̆r berpflanzen.

a. 2 urzerfarben: Sirapp, Eurcuma, Barbnteifter, Eabfraut, Ddjenzunge, rothe Rüben, Eaterampler, Sormentiff. Unter ben farberpfraitzen feben Rrapp (Rubia) unb 
In $n$ ig (Indigofera) oben an. Der erjete wits fait in gant Europa, und befonbers bäufig am Rbein, angebaut, unb licfert

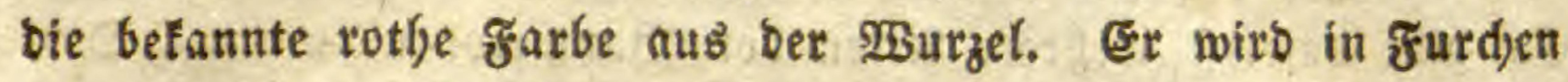
fpanneweit von einanber gelegt.

b. Stengelfarben: Snoigo, Sgau, Sauetborn, Erle, Sanbelfolz, Fernambuc, garbenfled)ten, Sauerad), Sdjölffraut.

Der Ṡnoig (Indigofera) wirb vorzŭglid) in sinbien ge. yflanzt und gegenwärtig aud in ber Sübjee uno in 21merica, bejonbers in Mexico. Man fät ifh im März uto mälyt ifn fdyon

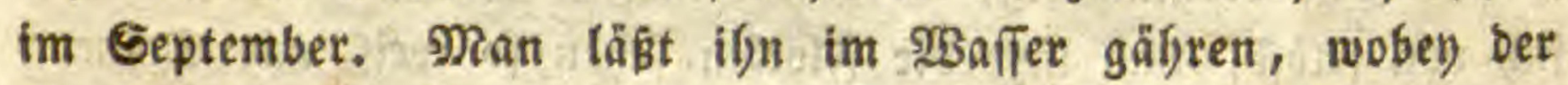
garbenftoff in : গBaffer übergeht uno zu Boben fintt, anfangs gelb, Dann blau. Die Maffe wirb in hörzerne Formen geprefst, getroctnet und jobann in ben Şandel gebradjt. Blós aus ben englifiten Coloniett fommen 60,000 Eentner, Das \$fund etwa 孔u 2 Ifalern.

Die Codyenillpflanze (Cactus) wirb nur in Rerico

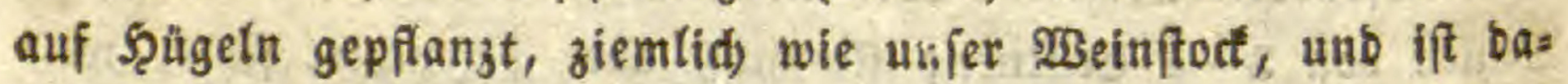

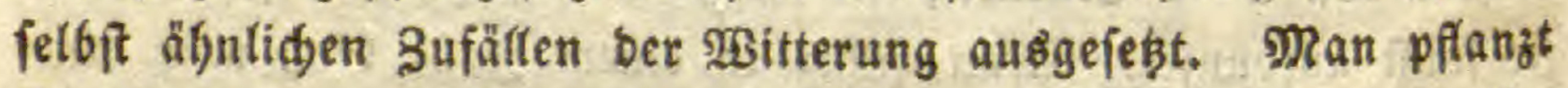
fie aber nidbt um ibrer jelbit wiffen, fonbern wegen ber Sdjilbs läuje (Coccus), meld)e die fajüne garbe liefern uno fidi) vont ifrem Gaft ertäbren. Biefe Iflerdhen forbern eitne \$flege faft wie bie Seibenwatrmer.

Der $y_{3}$ a น (Reseda) wirb hin und wieber angefät. Dab ganze Siraut liefert eine gelbe garbe.

c. Blattfarben: Birfe, Waib, J゙nbigo, Einfter, Ealls äpfel, Sdjarte.

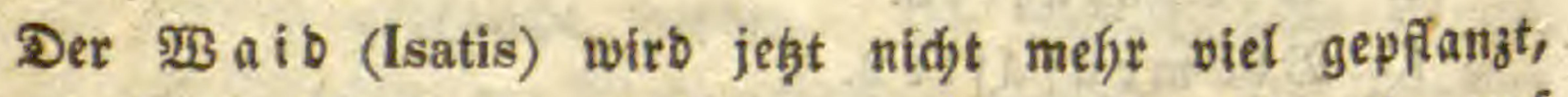
weil ex burd) ven snoig verbrängt wiro. Man fät iffn auf Netern, wie ben Flads. Die Blätter werben auf einer æüfle gequetidgt, Daun in Şaufen geidhüttet, gefnetet, in suugeln ges formt uno bann weiter ber Ģälbrung unterworfen.

d Samenfarben: Bortiborn.

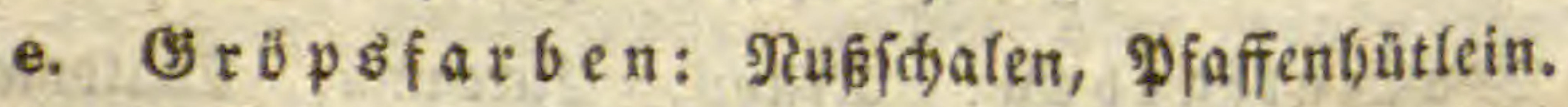

f. Blumenfarben: Safflos, Saffan, Boflbtumen, Färs ber: હhamifle, Seibelbaft, Sturmbut. 
Der Safflor (Carthamus) wiro gefät. Man ziefft bie Blüthen mit einem frumpfon Meffer aus unb trớnet fie im Sdyatten. Sie geben eine rothe Farbe. Er ftammt aus Dem Morgenlande.

Bom Saffran (Crocus) fieft man in ber sevante grofe Felder, Gin und wieber aud) bey uns. Man pflitdt bie Blumen, Fneipt bie Rarben $a b$, troctnet biefelben im Sd)atten und bebt fie bann in einer Grjadytel ober 3 faje auf.

g. Frud) $t$ farben: Freuzberen, Şartriegel, Faulbaum (E)rifoplos fraut.

D. Serberpflanzen.

a. Wurzeln: Tormentill.

b. Stengel: Rinde von Eidjen, æBeiden, Rüftern, Rof. caftanien, Tamaristen.

c. Blätter: Berberftraud) (Coriaria), Eerber:Eumad) (Rhus).

d. Samen.

e. (3) $x$ üp 8 .

f. Blumen.

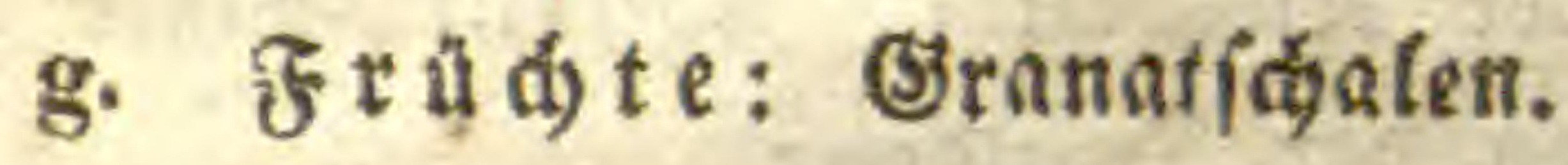

III. $2 x z n \in y p f t a n z e n$.

Ben biefen gibt $\mathrm{cB}$ fo viele, Daßs nur einige ber belatnteren angefübrt merben föntuen.

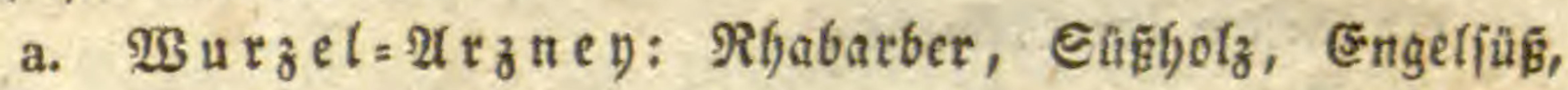
(Fibifd), Salep, EGinawurzel (Smilax), Bencbictenwurzel, 2inges lica, Diterfucen, Enzian, Sthlangenwurzel, Sletten, Mlant,

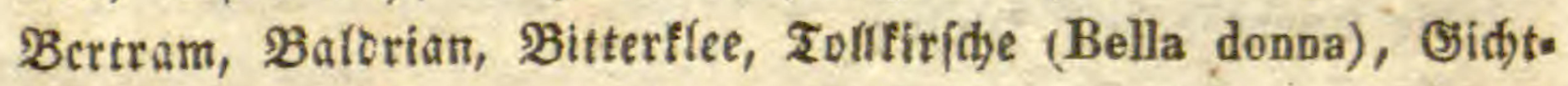

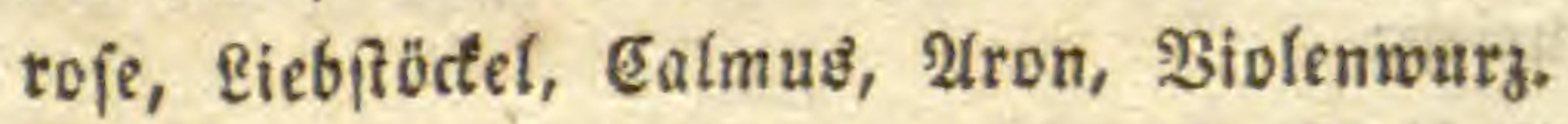

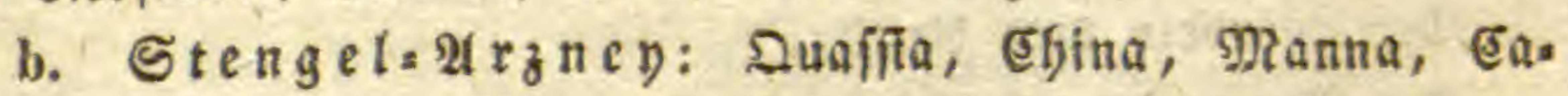
ted)u, Dradenblut, Mutterfraut, Rainfarren, Brabenfraut,

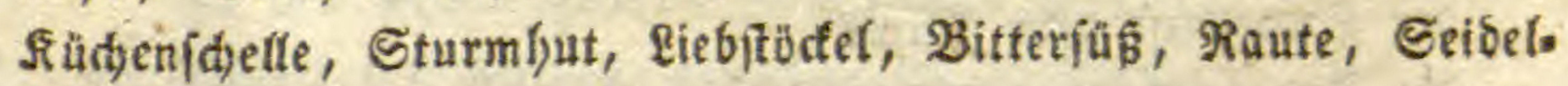
bafi, Traubenfixide, Sevenbaum.

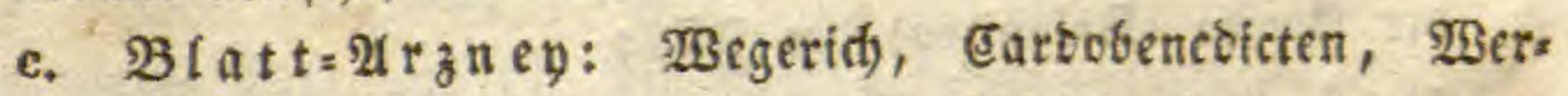

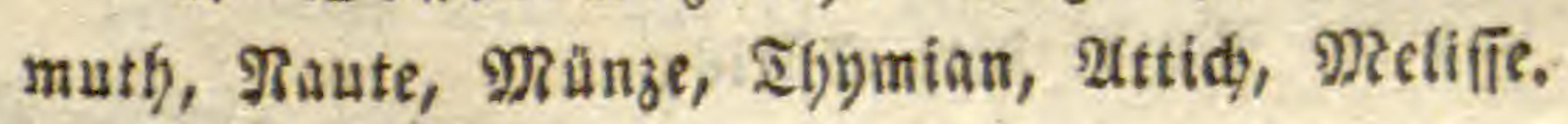




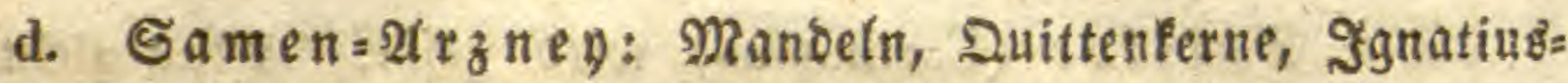

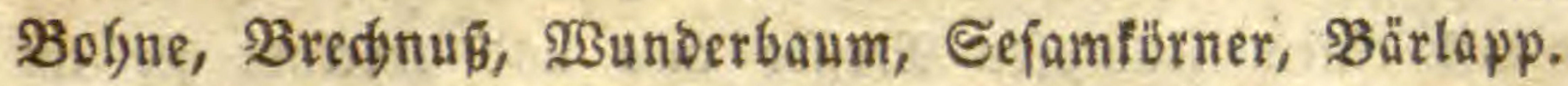

e. (5) Pfeffer.

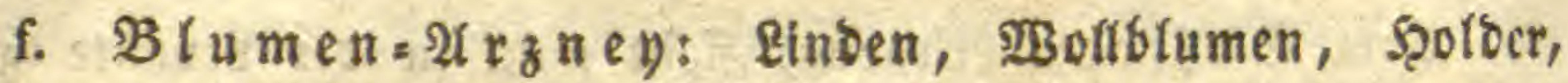

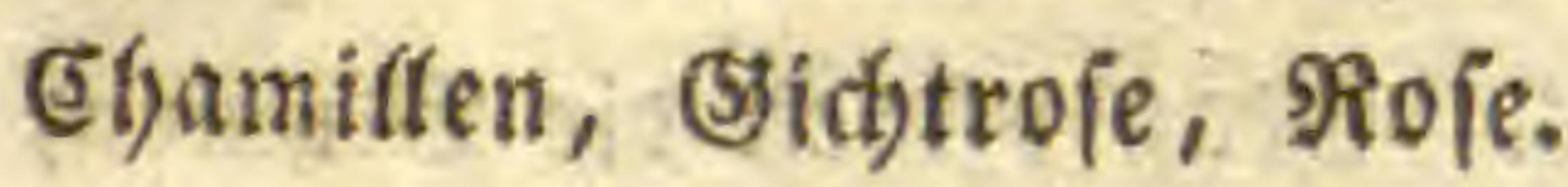

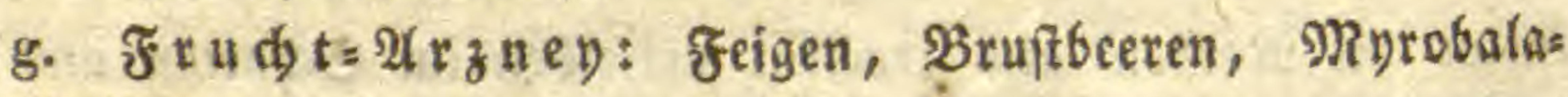
nen, Balfams2lpfel (Momordica), Rreuzoorn.

\section{Sุiftorifde Pflanzen.}

Die biftorifden Pflanzen fann man auf Diejenigen befdorät= fen, meldbe bey ben Gdyriftifllern vor unferem Beitalter vor= fommen.

R. Sprengel, Die Frau v. Ëenlis uno Dierbads Gaben fich mit ber Bufammenfterfung berfelben befdäftigt. Man fann fie wicber ttad) folgenden (S̈efid)tspuncten betrudbten:

A. Mythologif be Pflanzen.

Unter ben forifpflanzen waren gemcift:

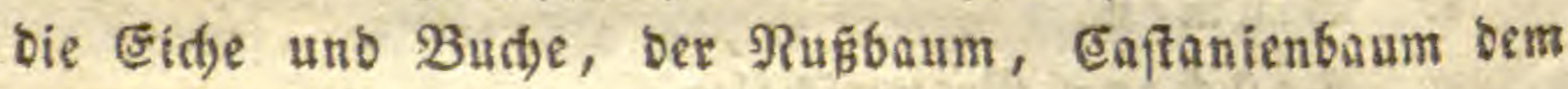
Sัupiter, Pan und Den (Söttern Der Druiben;

Die \$appel bem Sercules und bem श्रercur;

Die Traucrweibe ber Juno;

bie Rüfter Dem Morpheus;

Die Arejue Der Remefis;

Die Pfatane Den Benien;

Die Fidste ber હりbcle, Dem Pan, Reptun, Şทmenäub;

Die enprefte bem \$luto;

Die Eibe ben Furien;

ter Roorberr Dem 2ipoll;

Die Miyrte Der senus;

ber Ceibelbaft ocm Sanus;

Dic Iamarisfe bem Dfiris;

Die \$erfea (Balanites) Der Sfis;

Das Ephen uno die פrafoe Dem Dfiris; 
bas Epheu und Cinngrün bem ßacd)us;

Der Mandelbaum ber Phyttis;

Der Maulbeerbaum Dem Pyramus uno Der Iftĭbe.

Untcr ben Stauden uno firäutern:

bas Stecfenfraut (Ferula) bem Bact)us uno Prometfyeus; Die Secrofe Der รีfి uno bem Searpocrates;

bas Sdbilfrolyr Dem Palämon;

die Eräfer bem Mars.

Mytbologifde Rabrungspflanzet.

Bu ben mythologifonen Rahrungöflanzen geföten:

das Eetraibe der Eeres;

bie Dattelpalme bes Mercurs;

ber Delbaum utro Birnbaum ber Mtinerva;

Der 2 (pfel bes 2 (polts;

Die Birne uno Duitte Det Benu\&;

Der Duittenbaum des Sercules;

bie Aepfel ber Seefperiben;

die Mandeln Der Enbele;

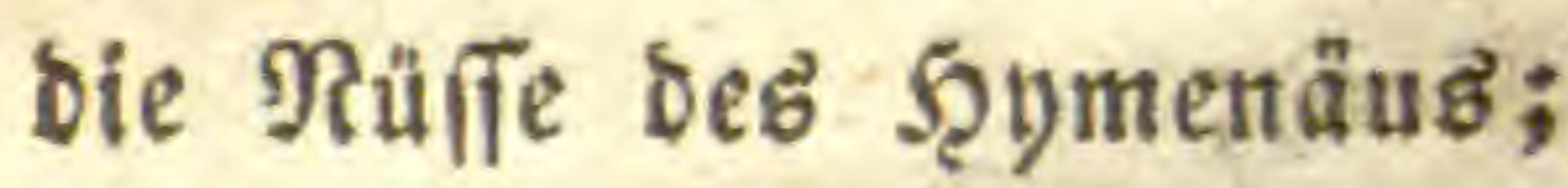

Die Pomeranzen oder Ucpfel Der Sefperiben;

Der Feigenbaum bes Bacthus, Mercurs und Saturns:

bie Saubofinen ber büfen (Steifter;

oer Molnn bes Morpheus, Der હeres unb ber :enus;

Der Sefam der હeres und Proferpina;

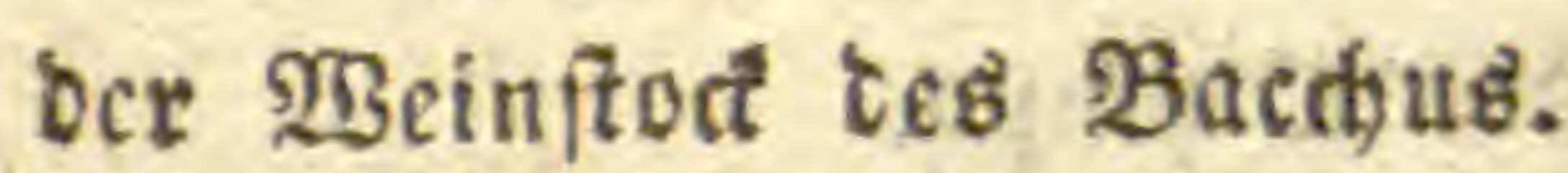

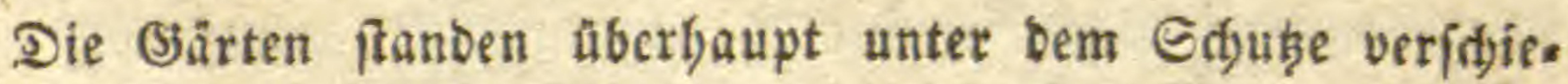
Dener Ëottheiten.

Mvthologifae sierpflanzen.

\$u ben mytholpgifden Bierpflanzen gehören:

bie Blume ber Aurora, nebmlid, bes Saffran;

Die $\mathfrak{3}$ lume Der J̃ris;

bie weife $\mathbb{R}$ ifie und bie șmmortefle (Gnaphalium ftoechas) Der సัuno; 
bie Shyacinthe ober ber Sdwwerbel bes 2tpolls;

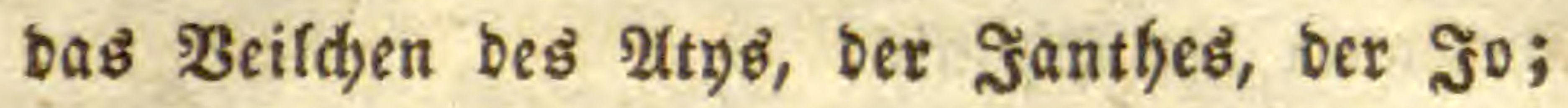
Rarciffe bev Rarciffes;

Saffran ber હeres und ber Eumeniben;

Die Sonnenblume ber Elntie;

Die Rotubblume ober Secroje ber șfts;

Epargel ber Perigone;

Der Rein und

Die Blume bes E(y)fums (Asphodelus);

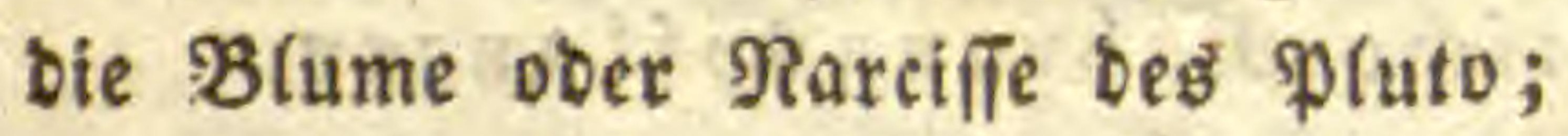

ber Tlyymian und Steinflee Der Mufen;

bie Blume ober ber Ritterfporn Des Atjar;

die Planze ober bas sefenlraut bes Tartarus;

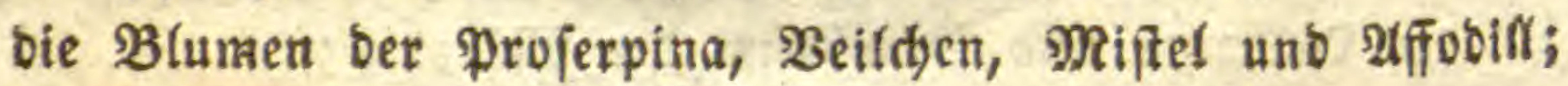

Die Revfoje ber S̃;

bie Blume bes 2 bonis (Adonis);

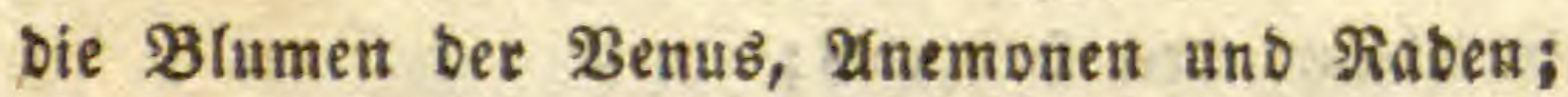

bie Blume ober Rofe des Eupiod;

bie $\mathfrak{B}$ (ume Der Diana (Rubrfraut);

bie $\mathfrak{B}$ lume ber 2 triabne (Leontice);

bie Blume ober Elftroje bes Şelios;

die Blumen Des Ş๊menäus: Majoran, Meeliffe, Mảnze,

Befenfraut, $\mathfrak{A}$ fer;

Die Blume ber ફ̧etena: Raķenfraut;

Die Blumen ber flora: Btumenbinfe, Mimofe;

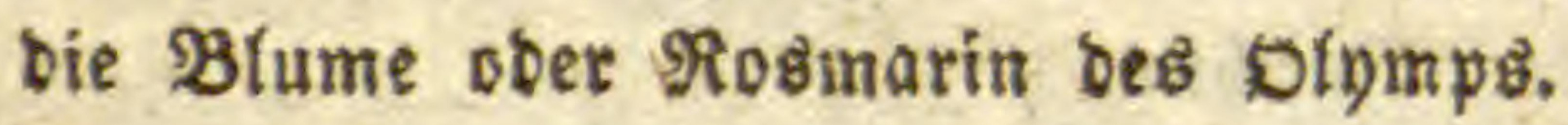

Mythologifde Speilfrater.

Des Dfiris: : Römenmaut, Meloe, Malve;

Des Şorus: ein 2fnoorn;

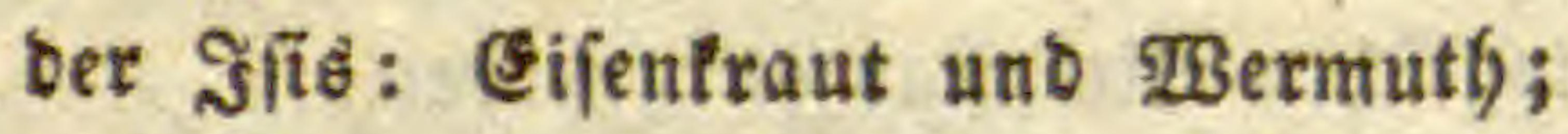

Deซ Typhon: Diterfucey, (Saudjheil, Meerzwiebel;

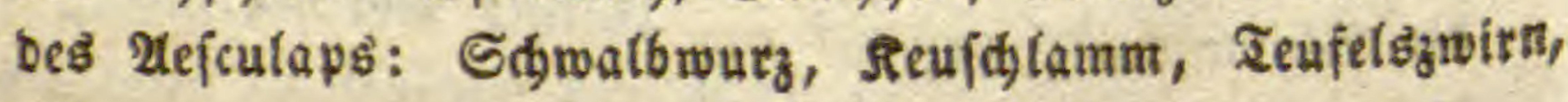
Sdierling;

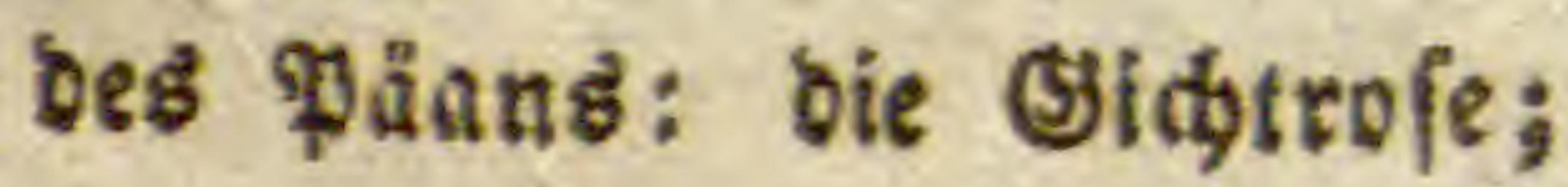


Des Spercules: :Bärenffau (Heracleum), Bnabenfraut, Sec rofe, - Bilfentraut, Sinöterid), Sieft (Stachys), Dofte;

bes Mercurs: Bingeffraut, Swiebel;

Der Sucina: Dolte unb şermutl);

Der Minerva: Doermennig, Mutterfraut;

DeB હf)irons: Tnufenogüldenfraut, Sdgmeermurz, Opopanar;

bes 2ddiffes: Sdyafgarbe;

Des Teucers: Gamander (Teucrium);

Des Méampus: (5ermer (Veratrum);

Des Slymps: Sd)tüfitelblume;

im (Sarten ber 5̧ccate: Folltraut, Rachtidjatten, Eturms Gut, Erojdeibe, Erbeidjel, Ruvendel, Mrünze, Rreffe, Malve, Eejam, Egamiffe, Frauenfaar u.f.w.

\section{3aubers, $2 B$ unber: und Gifterüter.}

Der Mebea : Beitlofe, \$adjlfolber, \$Begerid), Enfflor, Bolb. blume (Chrysanthemum) u.f.w.;

Der Circe: 2utraun (Atropa mandragora);

Dez MIaucuz: Mauerpfeffer,

Şajetrutbe, Şolber, Raute, Diptam=Dofte (Origanum die-

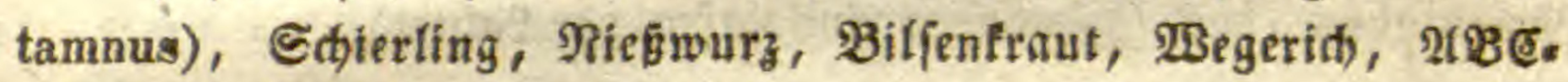
Pflange (Spilanthes) ber șnbier.

(ङ) egen $3 a$ u $b$ r.

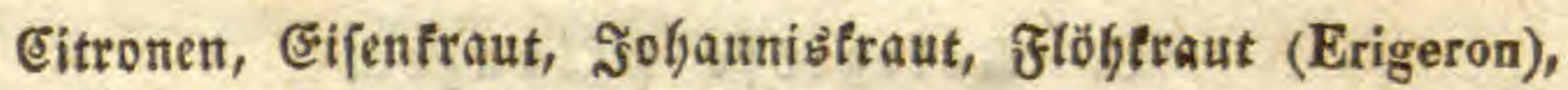
Mofyfraut (Allium nigrum), Baltrian.

\$B un berf $\mathrm{r}$ ă ter.

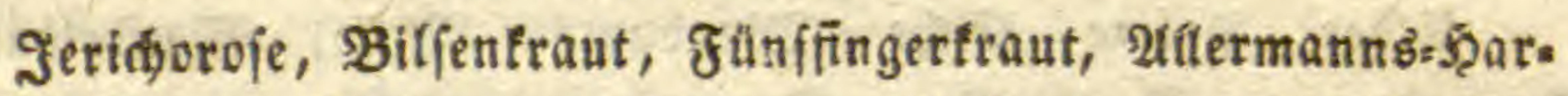
nif́), Şarmel (Peganum), Aftraun, Estujeng, Stunbenblumen, bie leudtende Baaras auf bem Ríbanon, Farrenfraut, Baromez, Frauenfiaar.

B. Snmbolifide ober finnbilotidge Pflangen. a. $g r$ ö $f(t)$ d e.

Fidte, Palme, Lorbeer, Birfe als Mayen, Manbelbaum, Mautbeerbaum, Ģranatbam, Delzneige, Tulpe. 
Siegesิzeidyet.

(Eppid) (Apium graveolens).

b. Bezůglid) auf \&iebe ober Ebe.

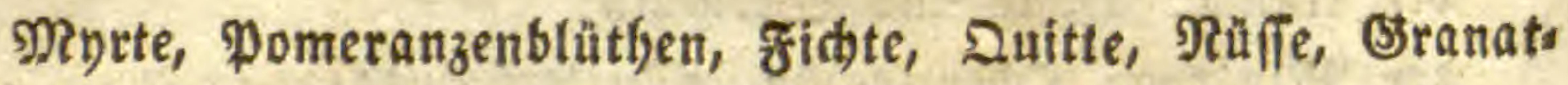

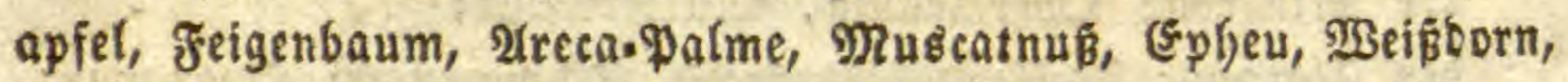
Reuidbaum, Geibelbaft, Rosmarin, Mobn, Sefam.

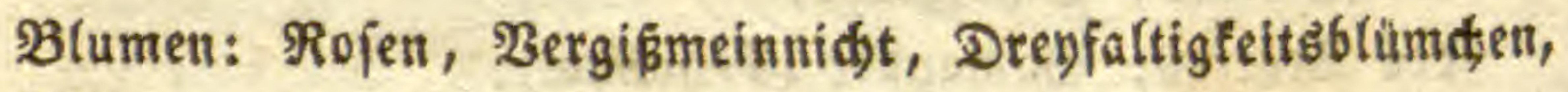
Rotusiblume.

c. Traurige.

Cทprefie, Rüfer, Trauerweibe, Rosmarin, Şyacintthe ber 2Itten (Gladiolus), 2tmarant, 21ffobift, Eppid) (Apium graveolens), Eattid, Saubofine.

d. Zur $B$ rumeniprad) ber Tülen gehören:

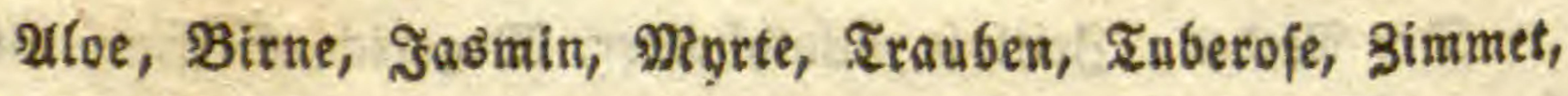
Piftacie, Gurfe.

Su unferer Btumeafpracte:

Die Maafliebe, Sergismeinnid)t, Roje, bie Sgaarltonen tes Römenjabns (bаз jogenannte 2usblajen ber \&idbter).

Die änbier faben eine Menge Btumen ber 2rt.

\section{Religiofe pflanzen.}

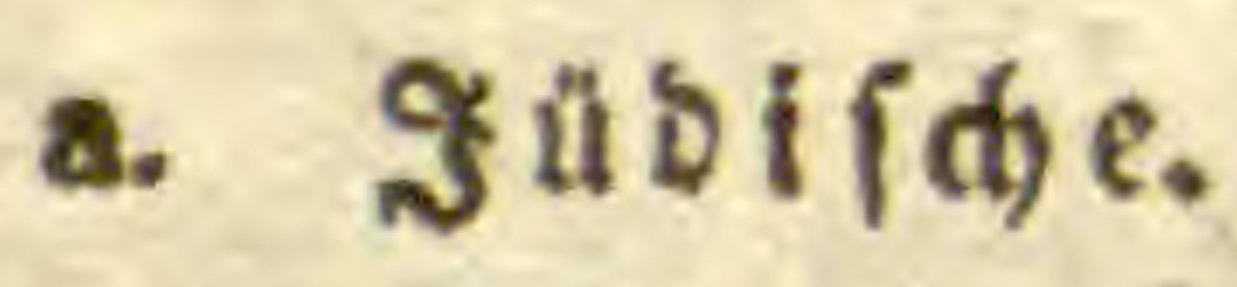

Eeter, Palme, Eidte, Bimbaum, Rüfie, Nantelbaum,

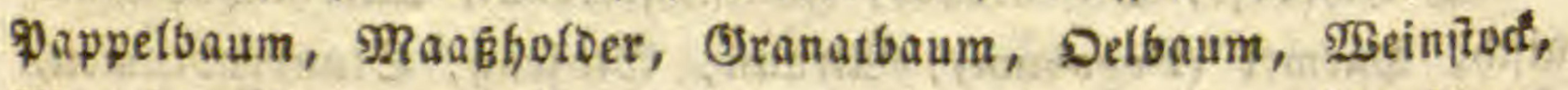

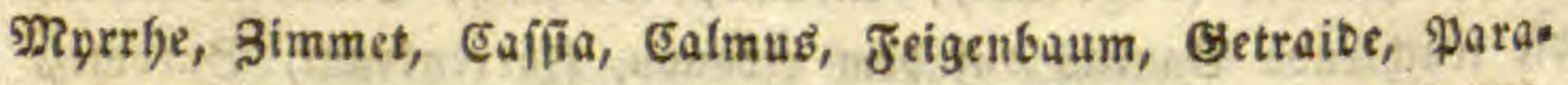

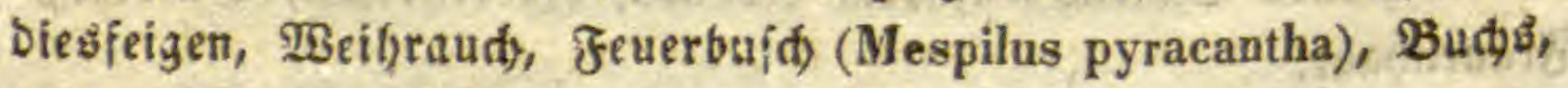
Yiop (Thymbra), 2llfagi=Straud) (Kimofeh), Ritie.

Speifen ber suben:

Granatäpfel, geigen, Manbeln, Rofitten, Rürbien, Bofinen, Mangold, Rnoblaud, Fend)cl, Rüife, Eitronen, Eattid, \$eters

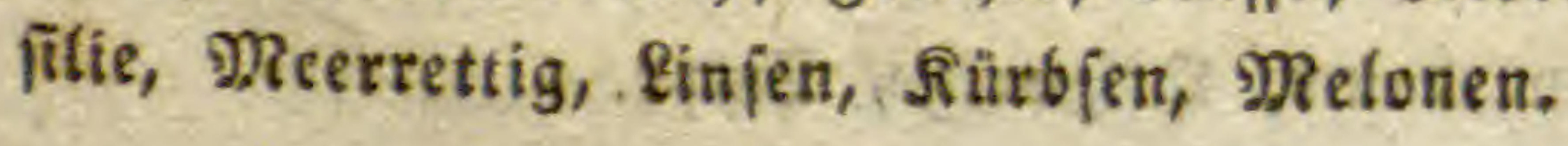


Radh Sprengel (B̈efdidite ter Bosanit) tommen folgenbe Pfanzen in ber 2 Bibel vor:

Abattichim (PI.) = Cucurbita citrullus.

Abijjona $=$ Capparis fpinosa.

Achu $=$ Arundo donax.

Adaschim (Plur) = Ervum lens.

Agmon, $\mathbf{A c h u}=$ Arundo donax.

Ahalot, Ahalim (Pl.) = Excoecaria agallocha.

Algummim ober.

Almuggim (Pl.) $=$ Pteroearpus santalinus.

Allon, Elon $=$ Pistacia terebinthus.

Allon $=$ Quercus aegilops.

Almuggim (PI.) = Pterocarpus santalinus

Argaman $=$ Quercus coccifera.

Armon = Platanus orientalis.

Atad $=$ Zizyphus Spina Christi.

Baca = Amyris gileadensis? Morus ?

Bad, Schefch, et Butz = Gossypium herbaceum.

B'dolach $=$ Borassus flabelliformis.

Befem $=$ Balfam.

Borit $=$ Salsola kali et Anabasis aphylla.

Botnim $(\mathbf{P l})=$ Pistacia vera.

B'rosch, B'rot (Gopher [Celsius]) = Cupressus sempervirens.

Butz = Gossypium herbaceum.

B'zalim = Allium cepa.

Caminon $=$ Cuminum cyminum.

Chabatzelet $=$ Narcissus orientalis.

Challamut $=$ Portulaca oleracea.

Carcom $=$ Curcuma longa.

Charulelschami (arab.) $=$ Ceratonia siliqua.

Charul $=$ Zizyphus paliurus

Chatzir $=$ Allium porrum $\mathrm{f}$. fcorodoprasum.

Chatzatz $=$ Lycium rauwolfii.

Chedek = Solanum sanctum.

Chitta = Triticum aestivum. 
Copher = Lawsonia inermis.

Cussemet $=$ Triticum spelta.

Dardar = Fagonia arabica.

Dochan $=$ Sorghum faccharatum.

Dưdaim (perí. destenbìeje) = Cucumis dudaim.

Egoz = Juglans regia.

El, Ela $($ allon, elon $)=$ Pistacia terebinthus.

Ereb (arbe nachal) tzaphtzapha $=$ Salix babylonica.

Erez $=$ Pinus cedrus.

Eschel = Tamarix articulata.

Ezob = Origanum creticum.

Gad $=$ Coriandrum sativum.

Gephen $=$ Vitis vinifera.

Gome $=$ Cyperus papyrus.

Gopher $($ Celsii $)=$ Cupressus sempervirens

Hadas (etz abot) $=$ Myrtus communis.

Hobnim = Diofpyros ebenum.

Kane hattob = Acorus calamus.

Ketzach = Nigella fativa.

Kidda, K'tziot = Laurus cassia.

Kikajon (arabijd) chirva) = Ricinus communis.

Kimosch $=$ Hedysarum alhagi.

Kinnamon $=$ Laurus cinnamomum.

Kifehfchuim (Pl.) = Cucurbita chate.

Kussemet $=$ Cicer arietinum.

Laana $=$ Artemisia judaica 1. ablinthium.

L'bona = Amyris kafal.

Libne $=$ Styrax officinale.

Lot $=$ Cistus creticus.

Luz $=$ Amygdalis communis.

Malluach $=$ Atriplex halimus.

Michelia tsiampaca ober Eugenia malaccensis fey Der 9 Bum Der Ertenntnif.

Mor $=$ Myrrbe.

M'ror $($ arab. marurieh $)=$ Cichorium intybus. 
Na-atzzutz $=$ Zizyphus vulgaris.

Nerd $=$ Valeriana jatamansi f. Andropogon nardus.

Nerium oleander foft ber Baum an פafterbäden fenn, beffen Blätter nidyt verwelten, Pfalmifi I., 3.

$(\mathbf{N}$ 'kot) $=$ Scorzonera tuberosa.

Oren $=$ Flacourtia sepiaria

Phakkuot (PI.) $=$ Momordica elaterium.

Phol $=$ Vicia faba.

Pischta $=$ Linum usitatissimum.

Retem, Rotem $=$ Juniperus oxycedrus.

Rimmon = Punica granaturn .

Schaked, luz = Amygdalus communis.

Schani, Tolaat, (argaman t'kelet) $=$ Quercus coccifera.

Sehesch = Gossypium herbaceum.

Schikmim $(\mathbf{P l}$. $)=$ Ficus sycomorus.

Schitta, Schittim = Acacia vera.

Schumim (ein PI.) = Allium sativum

Schuschan, Schoschanna $=$ Lilium candidum.

Sirpad $=$ Euphorbia antiquorum.

S'ne $=$ Rubus sanctus.

S'ora $=$ Hordeum vulgare $\mathrm{f}$. hexastichon.

Suph, $($ jam-suph $)=$ Arunde phragmites.

Tamar $=$ Phoenix dactylifera.

Tappuach $=$ Pyrus cydonia.

T'afchfchur $=$ Buxus sempervirens.

T'ena $=$ Ficus carica.

Tidhar $=$ Acer creticum.

Tirza $=$ Quercus ilex.

Tkelet $=$ Quercus coccifera.

Tolaat $=$ Quereus coccifera.

Tzori $=$ Pistacia lentiscus.

Zait = Olea europaea.

b. Egrifitide.

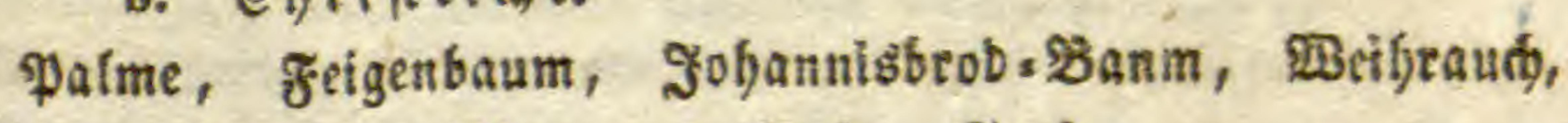
Mrgerlye, Egriftoorn (Rhamnus), Rojen, Eenf. 
392

c. Rorbifd $\mathrm{C}$.

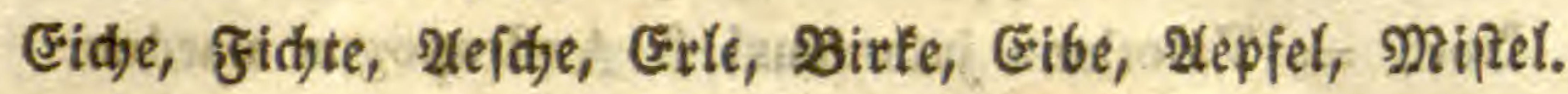

d. $\tilde{s} \mathrm{n}$ if $\mathrm{f}$ se

Banianen=Baum (Ficus), Cocosi=\$alne, Bewatrz= Rägelein, Sternanis, Sanbelfolz, Bambus, આnona=\$Baum, Ganiter=\$Baum

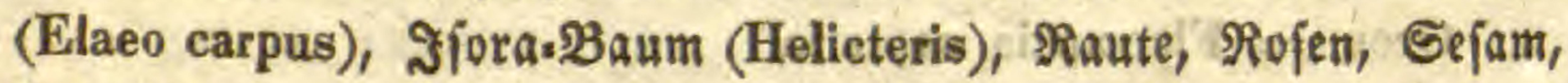
Iotusblume. 


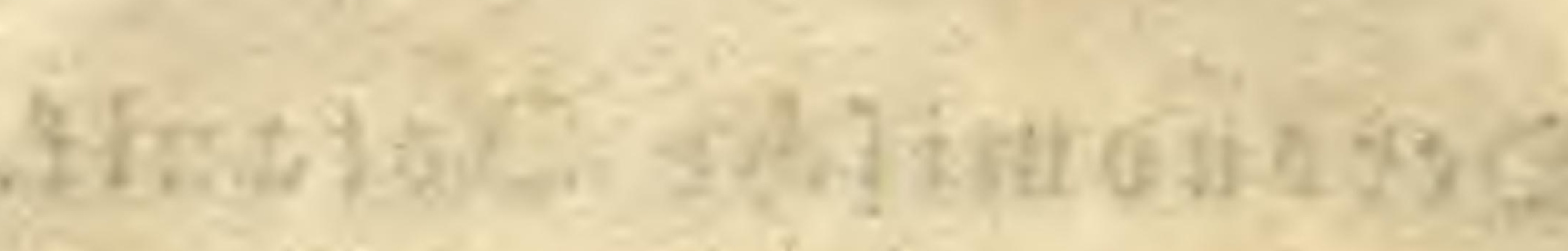

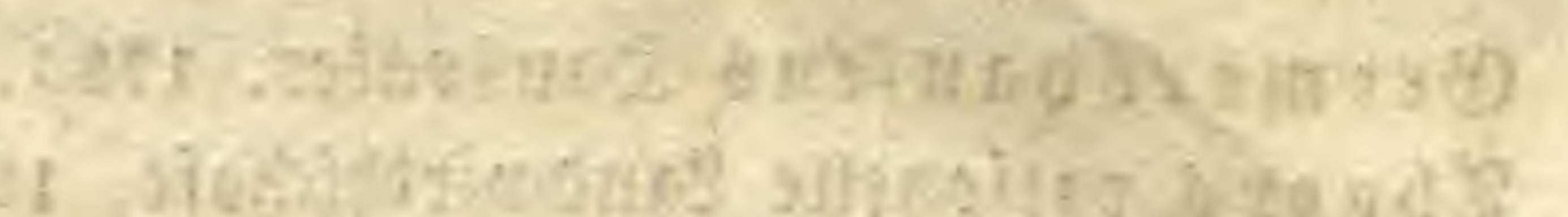

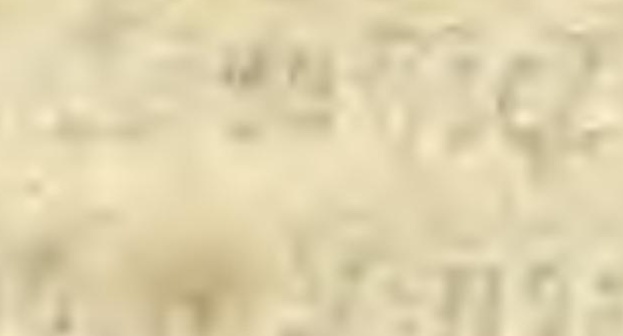

\section{Sitex a n t.}

Pflanzen=(5) eographie.

(Elef Geite 288.)

18 Linn a ei Stationes plantarum. 1754. (Amoenitates academiese, IV.)

De Candolle, Essay élémentaire de Géographie botanique, in Soc. d'Arcueil. 111. p. 295.

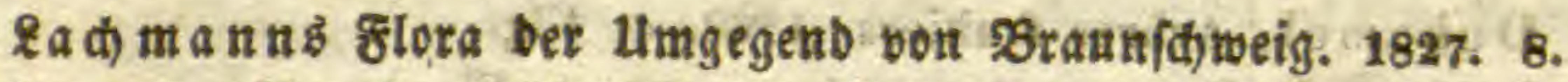

unger, über ben CEinfus bes sobens auf bie 2 Sertheilung Der Gewåd)ie. 1836. 8.

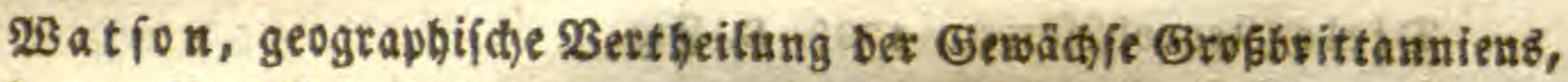
überf. von $\mathfrak{B}$ eilfd mieb. 1837. 8. 261.

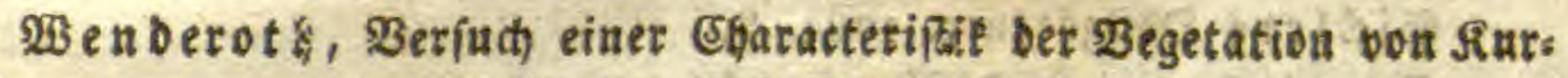
beffen. 1839. 8. 155. (פRarburger St)riften. IV.)

Linf \& lirwelt. 1834. 8.

J. Scheuch zer, Herbarium dilevianum. 1709. Fol. Fig.

Büttner, Rudera dlluvii testes. 1710. 4.

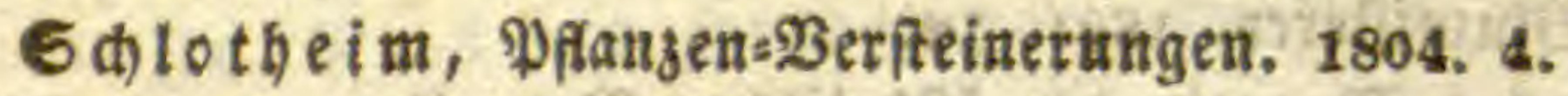

Defien Petrefacten*iunde. 1820.8 .

Sternber 8 stora Der \$orwett. 1820. 80l.

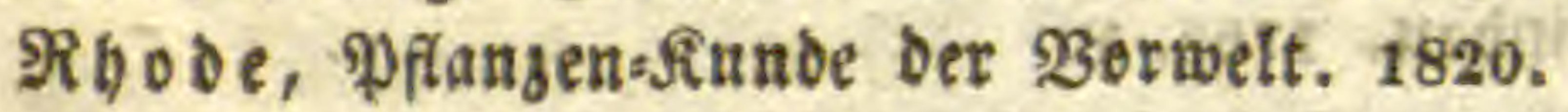

A d. Brongniart, Végétaux fossiles. 1828. 4.

Bronns Lethaea geognostica, 1834. 4.

(5) öp per t $B$ fofitile Earrenteräuter. 1836.

2Ingewanote $2 B$ otanif.

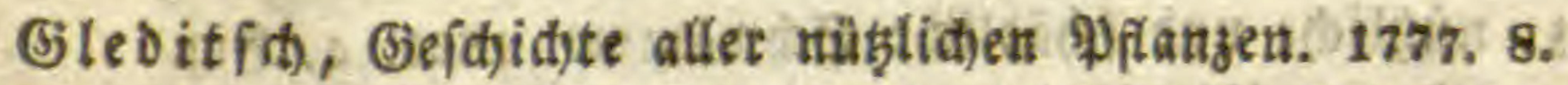

Zrattinnide \&bbilbungen öcon. uno offiein. Pflanzen. 1814. 4.

Spenuer, Sganbbuds det angewanbten \$otanic, 1834. I. 1 III. 8. 


\section{Deconomifde Botanil.}

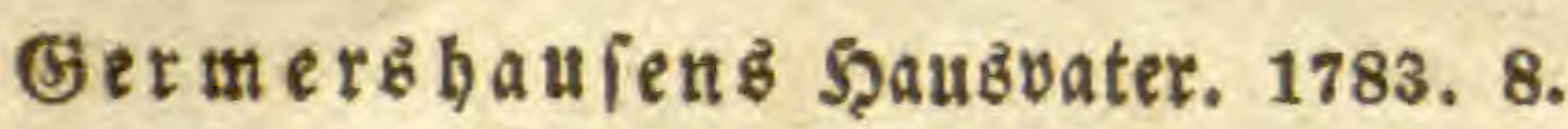

zhaer s rationelle Ranbwirthi(j)aft. 1809 und 1822. 4.

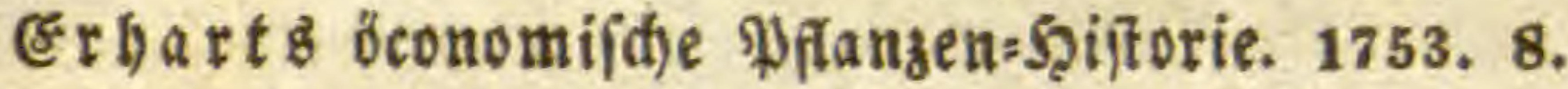

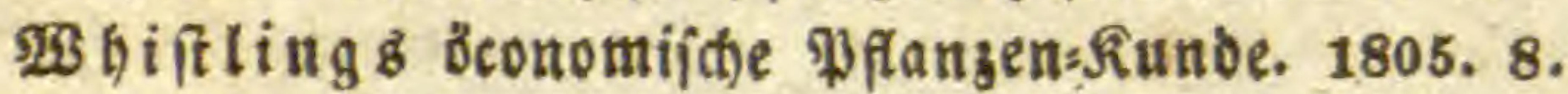

Ferners abbiloungen affer b̈conomiftien Pflamen. 1786. Folio.

Retd)art 8 Rand $=$ und (Gartenfdahy. 1753 und 1821. 8.

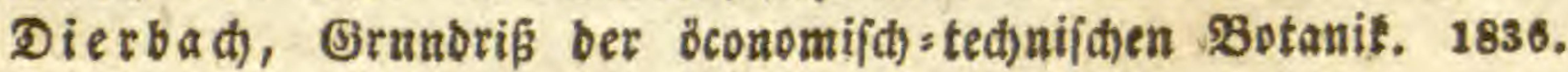

1. II. 8.

Berditolb, Seidl, Dpiz unb fieber, bconomijhs teduifide flora söbmens. 1836, 8.

Netsger s europäifbe Berealien. 1824. Fol. Fig.

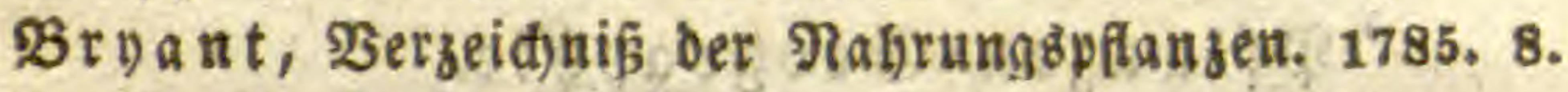

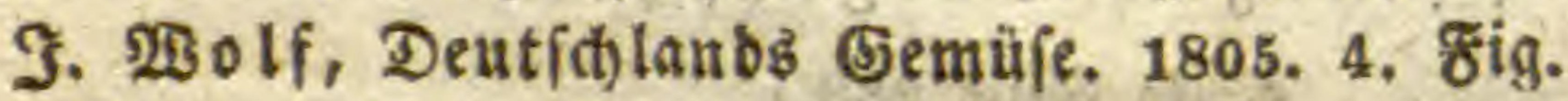

Millers sartenlexicon. 1750, 1769 unb 1802.

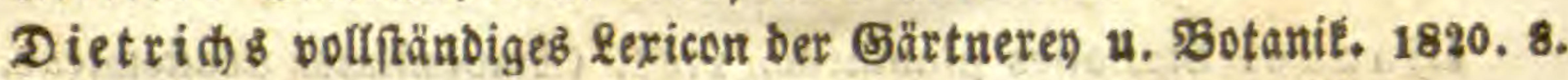

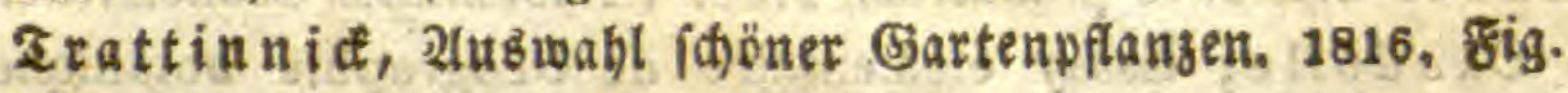

Snoops Pomologie, 1760. Fol. Fig.

Duhamel, Arbres fruitiers, 1768. 4. Fig.

J. Mayers Pomona franconica. 1776. 4. Fig.

Ehrift, \$omologie. 1809. 8.

Diel \& Rernobttiorten. 1799. 8. Fig.

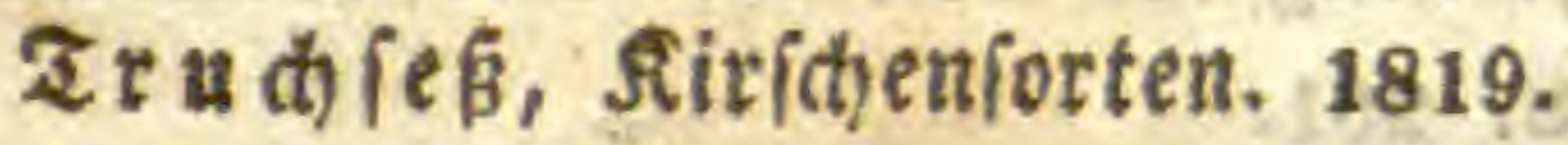

Sidelers Dbîtgärtner. 1794. 8.

Sd) mibberger \& Dbfbaumzudt. 1820, 8.

Dietrid), äfthetifae ஒflanzentunde. 1812.8.

Deffen f(t)öne Giartentumit. 1815. 8.

Co orthum 8 Şanbbut) für (Bartenfreunbe, 1814. 8.

9ieiber s slumifterey. 1821. 12.

Reid)enba () है Magazin ber äftheti(hen Sotanit. 1821. 4. Fig.

Bo ude, ber Simmer: uno genftergarten. 1822. 8.

Sprengerz ظeinbau, 1766. 8.

Ehaptals 28 einbau. 1804. 8.

3. Mayer, ębare S(t)wämme. 3801. Bol.

Perfoon \& e (ébare Sd)wämme. 1822.

Stattiunides eb̧bare Sd)wämme. 1830 .

Rrombbolz, ébbare unb fdablide Schwämme, 1831. Fol. Fig.

\&enる, nüblid)e uno finäolidje Sd)wämme, 1831. 4. Fig.

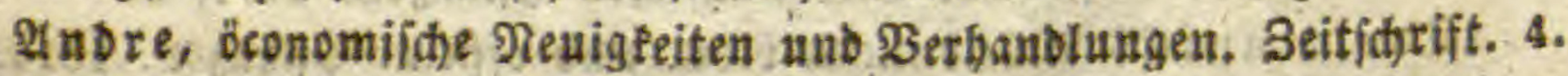

Vitta dini, Funghi mangerecci. 1836. 4 . 


\section{Forf:=20 otanit.}

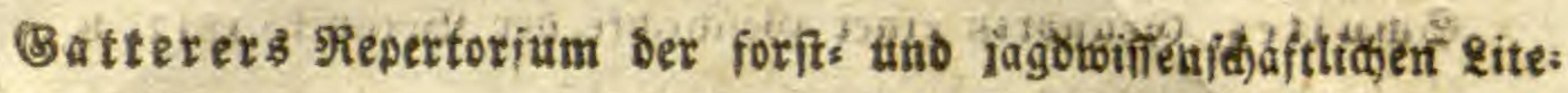
catur. 1796. 8.

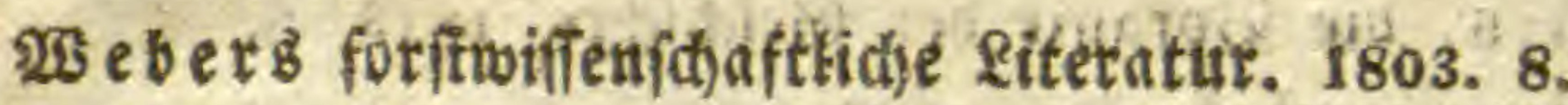

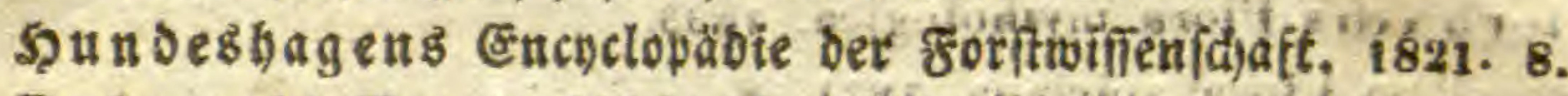

Duba mels Naturgefdidjte ber Sătume. 1764. 8. 8ig.

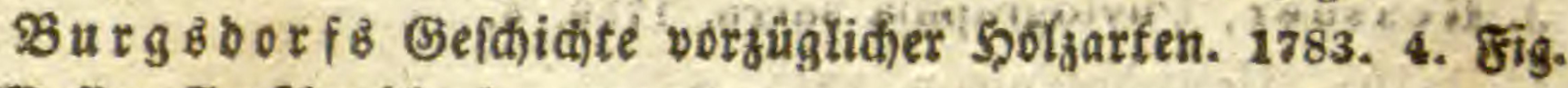

Defien Forfibanbbuth. 1805. 8.

(3) impels beutithe Solzarten. 1810. 4. Fig.

Bedpit ein s Forfts und Jagd:2Bifenf(t)aft. i818. 8.

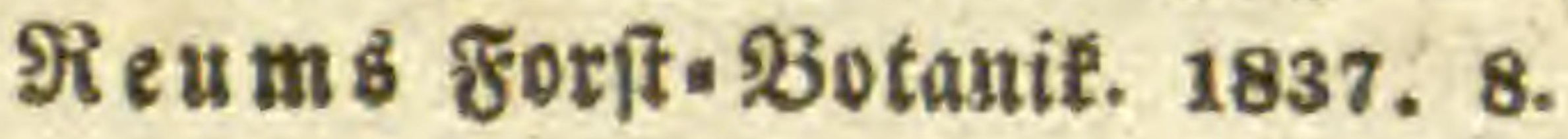

\section{Ted) nologifde 20tanit.}

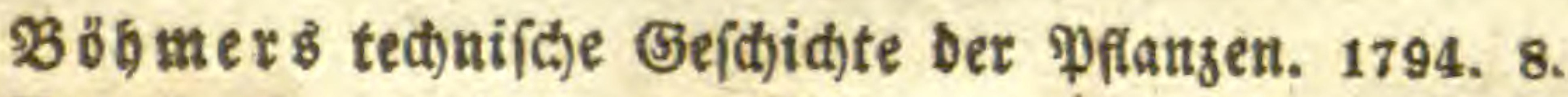

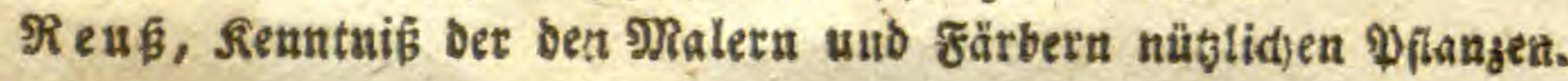
2776. 8 .

\section{Medicinifle Botanif.}

2(bbilbungen yon $\mathfrak{A r z}_{z}$ nen=(Gewäd) fer. Nürnberg, 1779. 8. Fig.

Plenck, lcones plastarum medicinalium. 1788. Fol.

รุa)

De Eandolles 2(rzneyträfte ber פplanzen. 1818, 8.

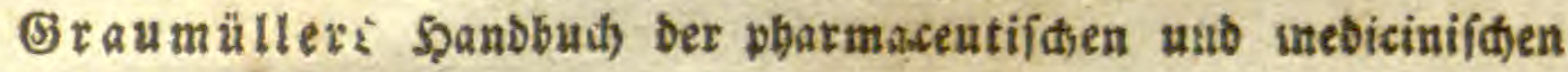
Sotanife. 1811.

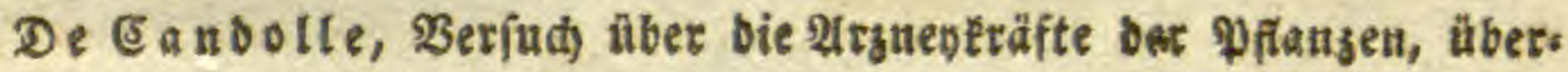
fetst von \$erleb.

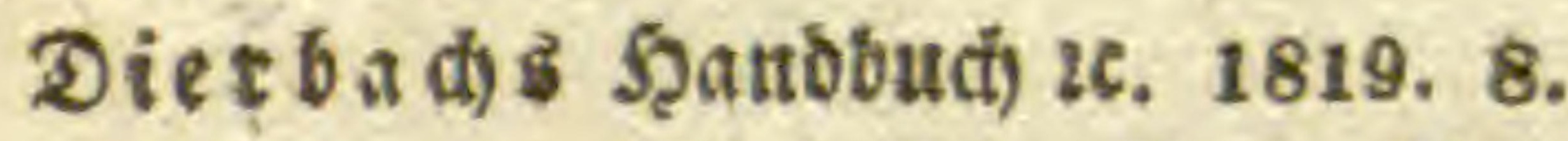

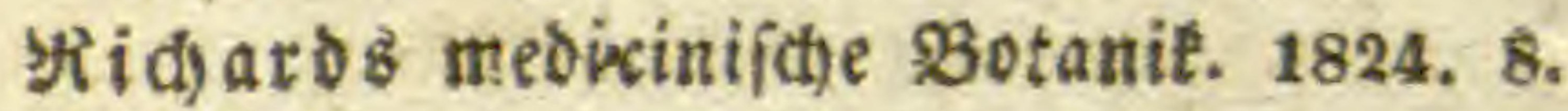

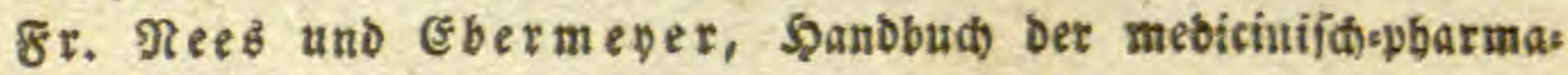
centifchen Sotanil. 1830. 8 .

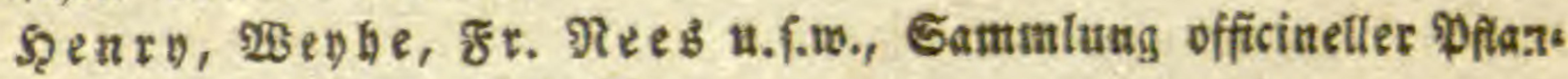
sen. Düffeldorf, 1828. Fol. Fig.

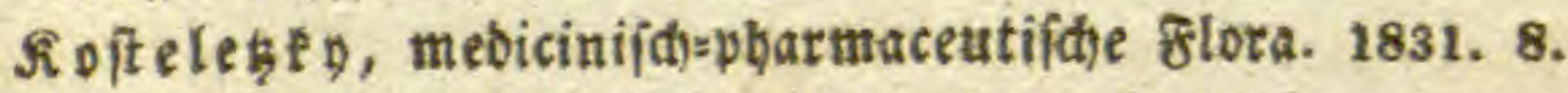

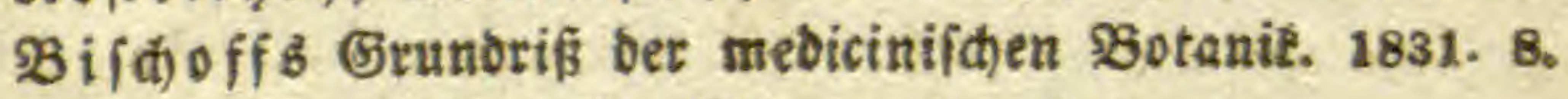

(3) eiger s Şanbbuct) für Pharmacie. 1828.

(ㄷ)

3 u d) net 3 ?abegriff ber \$barmacie. 1821.8.

56 u dinet B Foricologie. 1827. 8.

(3) melins allgemeine (Selftidite der Pfanzengifte, 1803. 8.

Dietrich, Deutímlands Giftpflanoetr. 1826. 8. Fig.

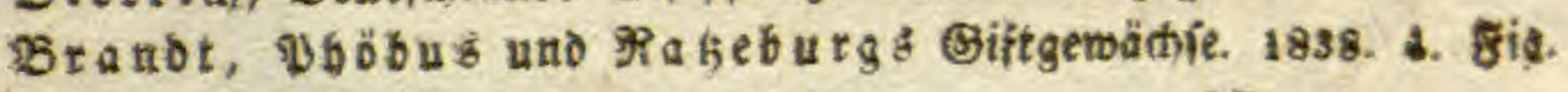

Dłen\$ allg. raturg. II. Botauif I. 


\section{Şiftorifde Botanit.}

Syrengel B (Befthidte Der Botanik. 1817. 8.

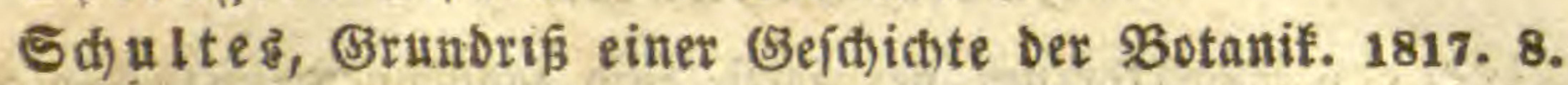
Böhmer, Plantae fabulosae. 1800. 4.

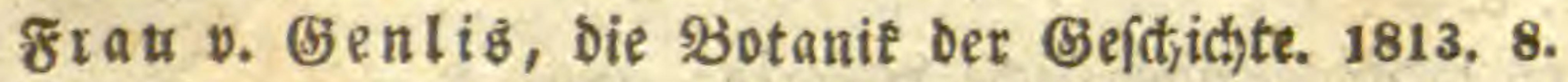
Dierb achs Flora mythologica. 1833.

Jesselben Flora apiciana. 1831. 8.

J. Gessner, Phylographia sacra, 1759. 4.

Celsiå, Herobotanicon. 1745. 8.

Retzius, Flora vi: glliana. 1809. 